Measurements and Metrics

\author{
in Small Technology \\ and Knowledge Entrepreneurship
}

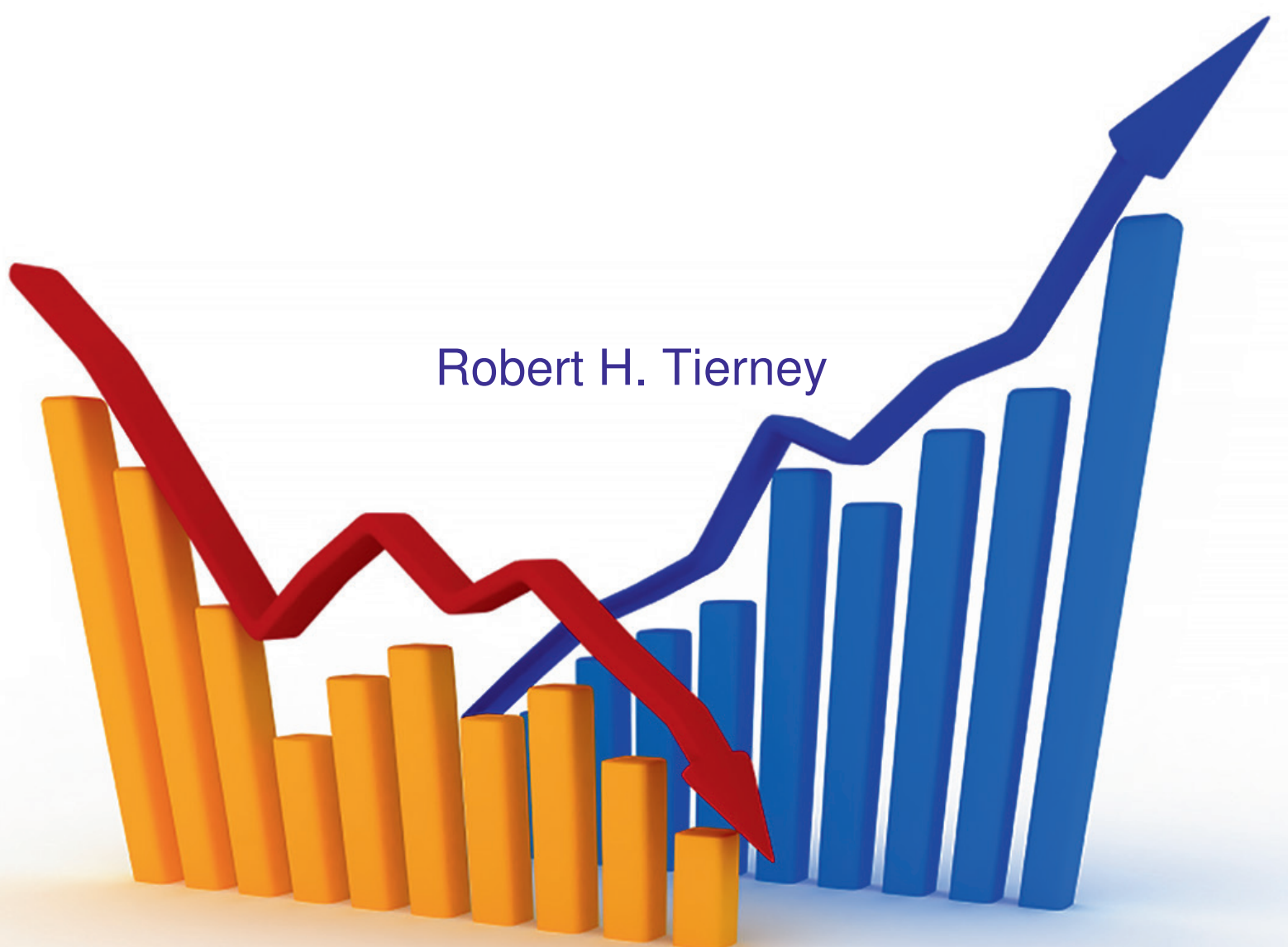




\section{MEASUREMENTS AND METRICS IN SMALL TECHNOLOGY AND KNOWLEDGE ENTREPRENEURSHIP}

Robert Henry Tierney 


\section{Promotion committee:}

Chairmen: prof. dr. R.I. van Oudenhoven -van der Zee

Secretary: prof. dr. R.I. van Oudenhoven -van der Zee

Supervisors: prof. dr. S.T. Walsh

prof. dr. J.D. Linton

University Of Twente MB/GW

University of Twente MB

University of Ottawa

Expert: Ir. M. Luizink

University of Twente MESA+

Members: prof. dr. A. J. Groen

University of Twente MB

dr. R. Harms

University of Twente MB

prof. dr. J. Kratzer

Technische University Berlin

The work described in this thesis was performed at the NIKOS group, Institute for Innovation and Governance Studies, School of Innovation and Governance Studies, University of Twente, PO Box 217, 7500 AE Enschede, The Netherlands.

Copyright (C) 2014, All rights reserved.

ISBN: 978-90-365-3601-1 


\title{
MEASUREMENTS AND METRICS IN SMALL TECHNOLOGY AND KNOWLEDGE ENTREPRENEURSHIP
}

\author{
DISSERTATION
}

\author{
to obtain \\ the degree of doctor at the University of Twente, \\ on the authority of the rector magnificus, \\ prof.dr. H. Brinksma, \\ on account of the decision of the graduation committee, \\ to be publicly defended \\ on Friday $31^{\text {st }}$ of January 2014 at 12.45 hrs.
}

\section{By}

Robert Henry Tierney

Born on the $12^{\text {th }}$ of June, 1958

in Pittsburgh, United States of America 
This dissertation has been approved by:

prof. dr. Jonathan Linton

prof. dr. Dr. Steven Walsh

prof. dr. Aard J. Groen

dr. Rainer Harms

prof. dr. Miriam Luizink

prof. dr. Jan Kratzer 


\section{Table of Contents}

\section{Section 1. Introduction}

1.1. Thesis Foundation 12

1.2. Entrepreneurial Foundation 18

1.3. Management of Technology and Innovation Foundation 20

1.3.1. Schumpeterian Waves 20

1.3.2. Small Technology 21

1.3.3. University (Knowledge Entrepreneur) Industry Interaction 24

1.4. Research Questions 24

1.4.1. Pharmaceutical Landscape 27

1.4.2. Highly Flexible Facilities 28

1.4.3. A Strategic Model for Firms Who Seek to Embrace NanoManufacturing. 28

1.4.4 Publish or Perish: How are Research and Reputation Related 29

1.4.5. What Is High Expectations: A Comparative Study of Different Disciplines? $\quad 30$

1.5. References 32

\section{Section 2. The Pharmaceutical Landscape}

2.1. Abstract and Keywords 40

2.2. Introduction 41

2.3. Literature Review 43

2.3.1. The changing nature of many new pharmaceutical innovations 43

2.3.2. Many of today's innovations are using technology differently 43

2.3.3. No Unit Cell 44

2.3.4. Differences in critical dimensions 44

2.3.5. Today's pharmaceutical innovations are more heavily constrained 44

2.3.6. Today's innovations are being shaped by different drivers 45

2.3.7. Today's pharmaceutical innovations are creating new business models 45

2.3.8. Value and gaps in traditional roadmap techniques 46

2.4. First generation roadmaps 46

2.5. Second generation roadmaps 48

2.6. Developing new roadmap processes and components 51 
2.7. Technology and Innovation 51

2.7.1. Using technology lifecycles 51

2.7.2. Using Technology Readiness Levels (TRL) theory 52

2.8. The role of drivers 54

2.8.1. The role of consortia 55

2.8.2. The role of components 56

2.9. Methods 57

2.9.1. Drivers in the changing pharmaceutical innovation arena 57

2.9.2. The role of drivers in the Technological Landscape process 59

2.9.3 The global population is aging. 59

2.9.4. Treating the disease at the molecular level 60

2.9.5. Chemical to biologically based pharmaceutical products 60

2.9.6. Central lab diagnostics to "Point of Care" diagnostics 61

2.9.7. Funding lifetime therapeutics rather than cures 61

2.9.8. Doctor to Patient Directed Care 62

2.9.9. Direct customer interaction 62

2.9.10. Personalized care 63

2.9.11. Pharmaceutical differentiation 63

2.9.12. Crisis Intervention to prevention / non invasive innovations 63

2.9.13. Detection is not enough 64

2.9.14. Movement to remote care 64

2.9.15. Increasing population 65

2.9.16. High cost of drug development 65

2.9.17. Shifts in intellectual property rights 66

2.10. Consortia and target products $\quad 67$

2.11. The role of components in the Pharmaceutical Landscape 68

2.12. The technology base $\quad 69$

2.13. The Pharmaceutical Landscape model 72

2.13.1. Technology 72

2.13.2. Drivers 72

2.13.3. Consortia 73

2.13.4. Components 73

2.13.5. The Pharmaceutical Landscape 73

2.14. Discussion and Future Research 74

2.15. References 76 


\section{Section 3. Highly Flexible Facilities}

3.1 Introduction $\quad 85$

3.2 Literature Review $\quad 87$

3.2.1. Highly Flexible Facilities 89

3.2.2. High Volume Facilities Metrics 90

3.2.3. High Volume Facilities Global Metrics 90

3.2.4. High Volume Facilities Local Metrics 92

3.2.5. Innovation, Research and Development Metrics 94

3.3. Methodology 95

3.3.1 Characteristics of a Highly Flexible Facility 96

3.3.2 Characteristics Review 97

$\begin{array}{ll}\text { 3.3.3 Questionnaire Development } & 100\end{array}$

3.4. Results 101

3.5. A Metrics Selection Model for Highly Flexible Facilities 103

$\begin{array}{ll}3.6 & \text { Discussion and Conclusions } \\ \end{array}$

$\begin{array}{lll}3.7 & \text { References } & 107\end{array}$

\section{Section 4. A Strategic Model for Firms Who Seek to Embrace Nanomanufacturing.}

4.1. Abstract 117

4.2. Introduction 118

4.3. Literature Review 121

4.4. Methods and Model Building 122

4.5. The Strategic Nanomanufacturing Model 127

4.6. Conclusions and Future Efforts 130

4.7. References 132

Section 5. Publish or Perish: How are Research and Reputation Related.

$\begin{array}{lll}\text { 5.1. Abstract } & 137\end{array}$

$\begin{array}{lll}\text { 5.2. Introduction } & 138\end{array}$ 
5.2.1. Determinants of an Institution Reputation 139

5.2.2. Research Status and Ranking 141

$\begin{array}{lll}\text { 5.3. Methods } & 145\end{array}$

$\begin{array}{llr}\text { 5.4. Results } & 148\end{array}$

5.5. Discussions 161

5.6. Implications 166

$\begin{array}{lll}\text { 5.7. Conclusions } & 167\end{array}$

$\begin{array}{lll}\text { 5.8. } & \text { References } & 168\end{array}$

\section{Section 6. What are Research Expectations? A Comparative Study of} Different Disciplines.

$\begin{array}{llr}6.1 & \text { Abstract } & 179 \\ 6.2 & \text { Introduction } & 180 \\ 6.3 & \text { Methods } & 182 \\ 6.4 & \text { Results } & 185 \\ 6.4 .1 \quad \text { Consideration of Overall Data } & 185 \\ 6.4 .2 \quad \text { Consideration of Supplementary Data } & 195 \\ 6.5 & \text { Conclusions } & 196 \\ 6.6 & \text { References } & 201\end{array}$

\section{Section 7. Conclusions}

7.1 Conclusions on each Research Question 203

7.2 Suggestions for Future Research 205

Section 8. Acknowledgements 208

\section{List of Tables and Figures}

\section{Section One}

Figure 1.1 Time Line of MEMS 23

Figure 1.2 Time Line of Nanotechnology 23

Table 1.1 Research Questions and Expectations 26

\section{Section Two}

Figure 2.1 First Generation Roadmap Tool 48

Figure 2.2 Emergent Disruptive vs. Traditional Options 50

Figure 2.3 Three Phases of Disruptive Technology Roadmap 50 
Figure 2.4 Generic TRL's Questionnaire 56

Table 2.1 Pharmaceutical Landscape Drivers 59

Table 2.2a Individual Technology Ratings $2010 \quad 70$

Table 2.2b TRL Set Average Score 2010

Table 2.2c Individual Technology Standard Deviation, Mode and Median 2010

Table 2.3a Individual Technology Ratings 2015

Table 2.3b TRL Set Average Score 2015

Table 2.3c Individual Technology Standard Deviation, Mode and Median 2015

Table 2.4a Individual Technology Ratings 2025

Table 2.4b TRL Set Average Score 2025

Table 2.4c Individual Technology Standard Deviation, Mode and Median 2025

Figure 2.5 Pharmaceutical Landscape Model $\quad 74$

\section{Section Three}

Table 3.1 High Volume Facility Global Metrics $\quad 92$

Table 3.2 High Volume Facility Local Metrics $\quad 93$

Table 3.3 Innovation, Research and Design Metrics 95

Table 3.4 Case Studies Results 98

Figure 3.1 Metrics Selection Model 103

Table 3.5 Table 3.5 Definitions and acronyms 106

\section{Section Four}

Figure 4.1 Evolutionary vs. Revolutionary Technology Pathways 126

$\begin{array}{ll}\text { Figure 4.2 Strategic Nanomanufacturing Model } & 128\end{array}$

\section{Section Five}

Table 5.1 Correlation between total quantity of research in a given field and institution

Ranking

Table 5.2 Coefficients for regression between total quantity of research in a given field and institution ranking

Table 5.3 Correlation between total quantity of research for most prolific researcher in a given field and institution ranking

Table 5.4 Correlation between total number of citations for most prolific researcher in a given field and institution ranking

Table 5.5 Correlation between total number of coauthors for most prolific researcher in a given field and institution ranking

Table 5.6 Correlation between Hirsch index for most prolific researcher in a given field 
Table 5.7 Correlation between Web references to the most prolific researcher in a given field and institution ranking

Table 5.8 Coefficients for regression between total quantity of research for most prolific researcher in a given field and institution ranking

Table 5.9 Coefficients for regression between total number of citations for most prolific researcher in a given field and institution ranking

Table 5.10 Coefficients for regression between total number of coauthors for most prolific researcher in a given field and institution ranking.

Table 5.11 Coefficients for regression between Hirsch index for most prolific researcher in a given field and institution ranking

Table 5.12 Coefficients for regression between Web references to the most prolific researcher in a given field and institution ranking

\section{Section Six}

Table 6.1 Total Publications for Each Area of Study for 348 top universities: minimum, various percentile levels and maximum value

Table 6.2 Total Publications for Most Prolific Author for 348 top universities: minimum, various percentile levels and maximum value

Table 6.3 Total Citations for Most Prolific Author for 348 top universities: minimum, various percentile levels and maximum value

Table 6.4 H-index for Most Prolific Author for 348 top universities: minimum, various percentile levels and maximum value

Table 6.5 Number of coauthors for Most Prolific Author for 348 top universities: minimum, various percentile levels and maximum value

Table 6.6 Sample of supplement data listing medical publications data for 31 universities by alphabetical order—both number and rank are provided.

Detailed of Data Utilized in What are Research Expectations? A comparative study of different academic disciplines 


\section{Introduction}

\section{Section 1.1 Thesis Foundation}

This thesis concentrates on the relationship between measurement, management and research. Measurement is "the assignment of numerals to represent properties" (Campbell 1957 p 267) and it is the heart of modern science and technology efforts to form commonly understood discourse. Many have stated the importance of being able to effectively measure something before you can usefully manage, engineer or construct for it a pathway forward. The quote "You cannot manage what you cannot measure" is often attributed to Dr. William Edwards Deming (quotations and literature 2012). However, the quote is, in reality much older than Deming's emphasis and can be found in many different fields. I seek specifically, to increase entrepreneurial knowledge (Harms and Erhmann 2003, Harms et al. 2009) by creating new models and research to assist academic and industry creation insight and thus activity through measurement and metrics. I do so by focusing on both "knowledge entrepreneurs" and more traditional entrepreneurial action. I seek to contribute to the growing literature stream on measurement to improve entrepreneurial understanding and research.

I recognize that the notion of effective measurement standards aiding the managerial process is not new nor of a singular source. Indeed, a large number of policy makers, academics, practitioners and technologists have made some version of the above quote both earlier and later than Deming's effort. Some of those that have stated the relationship between effective management being dependant on effective measurement include: Dr. William Hewlett (one of the founders of HP), Lord Kelvin (a pioneer in the field of thermodynamics), Tom Peters (empowering decision-makers) and George Odiorne, who fathered the management-byobjectives approach (Quotations and literature forum 2012). This knowledge fathered efforts like measuring and defining differences in innovations and patents (Mansfield 1968, Marquis 1969, Souder 1987), whose efforts often initiated the practice that being able to measure any activity was noble. However, this application of knowledge has caused a standardization problem in the 
process of measurement for specific management issues.

For example, 3M has often been named the most innovative company in the United States. Many metrics show that most of 3M sales come from new products over any five year period of time. Yet most of 3 M's innovations are incremental in nature and their managerial measurement methodology does not differentiate by classification of innovation type such as incremental, generational or radical (Hulshoff et al. 1998). Where this concept is inaccurate is it does not provide a standard metric that takes into account the varied nature of different innovation classifications. Similarly, entrepreneurial scholars such as (Birch 1979, Newbert, Kirchhoff and Walsh 2007) bemoan ineffective measurement and lack of comparable metrics to create standards.

I provide value concerning the entrepreneurship definitional and measurement discussion in two areas. First, I add to the literature in the field metrics and small technology entrepreneurs. The growth of micro-electrical-mechanical systems (MEMS) and nanotechnology have spurred the advance of new facilities and the need for new models. Additionally, the pharmaceutical industry is examined and a new technology roadmap is introduced. Next I add to the literature by advancing the understanding of "knowledge entrepreneurs" (Bouchikhi and Kimberly 2001) and to further the understanding those who undertake entrepreneurial action to provide the foundation of economic change. The later group is comprised not only of high tech entrepreneur but, also the policy and economic developers who embrace entrepreneurial action (Anson et al. 2008) to generate regional wealth and job creation.

The role of universities and academics in regional wealth and employment opportunism is paramount to economic development (Ducker and Goldstein 2007). At the base of university economic development are academics themselves. Now these academics are not only known as for their instruction, but also as knowledge creators or knowledge entrepreneurs (Balaz 1996). I add to the knowledge entrepreneur with research examining academic literature measurement with two separate efforts. 
These efforts provide analytical measurements of different aspects of the top 250 universities, which house university professors or the previously defined knowledge entrepreneur. I utilized the top 250 universities identified in two separate university ranking systems as the sample base. The first effort analyzed scholarly output from each school or discipline at each university. I used that data to ascertain both individual and cumulative school and discipline contribution to the overall ranking of a university. The second effort provided a finer view of the knowledge entrepreneur. This project focused on the top researchers in 27 disciplines or schools at all the top 250 universities in order to define differences in knowledge entrepreneurship of top researchers by each field of study. This effort represent's the continuation of scholarly research into the quantification of the differences in knowledge output and citation rates from exceptional scholars by discipline. These efforts viewed together provide a basis for normalizing output across disciplines and allowing for a comparison of output across disciplines. Finally, I used the knowledge gained from this research to provide a foundation for measuring entrepreneurial action. Similar to my effort in understanding measurement and management in the knowledge entrepreneur setting, I add to the measurement in field of high technology based entrepreneurial action by focusing on entrepreneurial firms and entrepreneurial actions.

Firms and support activities that are most aligned with Schumpeterian change are in terms of initiating new economic cycles, such as those in small technology (Schumpeter 1937). In particular, I focus my research efforts on a subset of entrepreneurial actions by entrepreneurial firms, policy makers and economic development activities that have traditionally provided the greatest wealth and job creation impact - entrepreneurial action based on emerging enabling technologies (Groen and Walsh 2013, Kirchhoff 2013).

I more finely defined these actions as those that Kirchhoff characterized as being high business growth rate and high business innovation rate entrepreneurial firms and the supporting activities they require (Kirchhoff 1994). Entrepreneurial action that Kirchhoff (1994) and others 
(Birch 1979) have characterized as traditionally providing exceptional and differential regional job and wealth creation (Kirchhoff, Linton, and Walsh, 2013). We focus on entrepreneurial action centered on micro and nano technologies (Drexler 1986, Feynman 1960). These two emerging technology basis are being highly funded by multiple countries and regions around the world at a rate that exceeds any emerging technology prior to them (Gouvea et al. 2012). These contemporary emerging technology efforts are creating entrepreneurial activity as regions vie to develop Schumpeterian change for their specific economies (Drexler 2004, Gouvea et al. 2012). I provide two final points that helped to determine my selection of these emerging technology based entrepreneurial organizations. First, I focus on organizations, which utilize emerging technologies as the basis of their entrepreneurial action. History has shown this category of technology and entrepreneurial action centered on them is most often the harbingers of Schumpeterian economic waves. Second, micro-technology and nanotechnology and its commercialization are considered by many to be the most ambiguous, yet most economically important of all high tech entrepreneurial action today (Drexler 1986, Linton and Walsh 2002, Fink, Lang and Harms 2013). Now I discuss how I addressed the need for measurement to improve entrepreneurial action.

I provide three efforts that investigate the relationship between management, measurement and research for entrepreneurial action in the area of microsystems and nano- systems. Microsystems and nanosystems are described as being an enabling, emerging technology base (Linton and Walsh 2008). The first of these efforts investigates manufacturing and entrepreneurial actions for firms and organizations in microsystems and nanosystems. I applied the case study method to assist in the definitional understanding of the fields and identify areas in need of further investigation. The second effort provides an in depth understanding of economic policy maker's entrepreneurial action in the micro and nanotechnology or "small technology" (Linton and Walsh 2008) arena. Many worldwide regions economic development entrepreneurial actions are providing small technology manufacturing centers (Kautt et al. 2007) for entrepreneurial firms seeking to advance small technology commercial activities and the 15 
entrepreneurial firms themselves. This effort uncovered the dearth of measure and metrics for these small agile multi technology based fabrication facilities. Facilities that are the cornerstones required for regional development.

Specifically, my effort adds to the metrics literature for these new types of multi use facilities. I identify how the use of more traditional higher volume facilities metrics has negatively affected policy makers' (Tierney et al. 2012) decision processes for the enabling facilities. I further provided a manufacturing metric review and developed more appropriate techniques that aid in the strategic and operational management of these enabling technology based manufacturing facilities. Finally, in the third effort, I review how measurement of microtechnology and nanotechnology enabled organizations aid entrepreneurial action. I provide a new roadmap technology, which I named a "landscape" that incorporates new measurement capabilities to more rapidly advance entrepreneurial action in the $21^{\text {st }}$ century pharmaceutical industry. The landscape tool is based on the new emerging technologies of micro-technology and nanotechnology and their increasing use together as multi technology roots of $21^{\text {st }}$ century innovations.

My five efforts are designed to provide improved measurement techniques for entrepreneurial research and entrepreneurial action. My efforts have prompted me to promote an addendum to "Deming's quotation" on the relationship between management and measurement. I have rethought Deming's bromide and suggest a restatement of it as others are now doing. I suggest it to be replaced by "You cannot manage what you cannot measure and you cannot measure what you cannot define" (Allarakhia and Walsh 2011, Groen and Walsh 2013, Saner and Stoklosa 2013, Cowan 2013).

I hope to join the many that focus on measurement research that have affected managerial change. Perhaps the most famous of these are the founders of total quality movement, whose metrics measurement idioms have made far reaching operational and strategic management change. Indeed, we do have Deming, Crosby and Juran to thank for these efforts (Deming 1982, Crosby 1992, Juran 1964). Researchers that I hope soon to call colleagues are trying to similarly 16 
advance measurement in entrepreneurial action.

A full set of standard metrics and measurement continue to elude the entrepreneurial field. Many including myself are seeking to rectify improve entrepreneurial metrics in entrepreneurial research and practice. Both researchers and entrepreneurs state that good operational and strategic metrics are important for the field. Yet perhaps because of its recent popularity entrepreneurship on most critical operational, project, and strategic management activities do not have fully robust metrics. Moreover, indecisive or even no metrics leads to calamitous efforts in management practices (Kirchhoff 1994).

I initiated the introduction with a measurement discussion. I now discuss the content of that measurement entrepreneurship. In light of my focus on measurement, I initiate the content discussion with a discussion on the perceptions of entrepreneurship. The terms "Entrepreneur" and "Entrepreneurship" have become exhortations both in academia and in the popular press limiting their common understanding and therefore a mutually agreed upon common definition. Researchers, especially those that have just recently embraced entrepreneurship, have greatly expanded the definition of entrepreneurial action in a variety of contexts. Often, in doing so, these researchers call into question prior research (Shane and Venkataraman 2000; Schoonhoven and Romanelli, 2001). Today interest in entrepreneurship is being driven by the need for economic revitalization (Baumol, 1968; Stevenson and Jarillo, 1990; Wennekers and Thurik, 1999, Walsh 2012).

Entrepreneurs and entrepreneurial activity continue to improve regional competitiveness, create jobs, stimulate the larger economy, and create new wealth. However, the field has not developed standard methods to measure or have metrics, which provide an avenue for criticism of its value (Kirchhoff 1994). This lack of traditional management practice provides an avenue for detractors. For example, critics of capitalism suggest that capitalism's largest down fall is the discussion of entrepreneurial reapportionment rather than creation of wealth (Marx and Engles, 1845; Schumpeter, 1934). Recently, a structural view of entrepreneurship as the nexus of individual and opportunity was presented (Sarason, Dean, and Dillard 2006). I next provide a 17 
short discussion of contemporary entrepreneurship theory focusing on measurement and metric aspects.

\subsection{Entrepreneurial Foundation}

I review the origins of scholarly thought on entrepreneurship and its connection with economic literature (Schumpeter 1937, Kondratieff 1937, Kondrat'ev and Jakovec 2004, Marshal 1890). I further review the next wave of entrepreneurial researchers like Kirchhoff and Birch (Spencer, Kirchhoff, and White 2008, Birch 1979). Finally I highlight more contemporary technology entrepreneurial author's thoughts such as those expressed by Groen (2005), Harms (2013), Linton (2002), Shane and Venkataraman (2000), Linton and Walsh (2003).

First, the advent of the industrial revolution demonstrated the importance of entrepreneurs and entrepreneurial activity in the improvement of regional competitiveness, create jobs, stimulate the larger economy, and create new wealth. This was first suggested by Schumpeter (Schumpeter 1937) and then proven through the seminal research of the second wave of economic and entrepreneurial researchers (Birch 1979, 1987, Kirchhoff and Philips 1989, Baldwin 1995, Head 2003, Head and Kirchhoff 2009, Story 1994, Picot and Dupuy 1998, and Stearns et al. 1995). Yet, some research output from the third and latest wave of entrepreneurial researchers, especially those that have sought to redefine entrepreneurial action to include large established firms seems counter the importance of Schumpeterian or the completely new venture. Schumpeter in his efforts saw entrepreneurship and new to the world enterprises I have eliminated the Greenfield startup word made popular in later years.

Their output sometimes does more to shed doubt on earlier findings than to build upon them, (Shane and Venkataraman 2000). I find that this is consistent with the muddled discussion in innovation literature concerning incremental and radical definitional change (Linton and Walsh 2008). 
Many throughout the three waves of entrepreneurial research activity have identified a variety of important subjects and attributes associated with entrepreneurship, entrepreneurial action and the entrepreneur (Kilby 1971, Hébert and Link, 1989, Gartner, 1990, Linton and Walsh 2008). They have taken the first steps in being able to operationally or strategically define, measure, and manage entrepreneurial activity. Furthermore, there is plenty of room for those like me who seek to define, measure, and advance the field of entrepreneurship.

The interest in entrepreneurship has increased with the turn of the century compelled by established large firms' lack of capacity to develop adequate job and wealth creation (Kirchhoff et al. 2013). This is mirrored by academic interest with many researchers embracing knowledge entrepreneurship and is embracing more diverse backgrounds. Not surprisingly, the literature, previously more cohesive, has not adapted to the new wave of researchers that are just now performing research that leads to entrepreneurial literature. There currently is not a universally accepted definition of the term "Entrepreneurship". This presents a problem since there is no orientation on which to base research on. Instead the entrepreneurial discussion has shifted to aspects of entrepreneurial action.

I am most interested in the entrepreneur's role in the process of "creative destruction" (Schumpeter 1934). Yet, even here traditional definitions have either been limited or shifted in the process of creative destruction. Entrepreneurial emphasis has moved towards the creation of innovations, recognizing opportunities, developing new organizations, and availability of resources (Stevenson and Jarillo, 1990; Wennekers and Thurik, 1999). This in turn suggests differing prescriptive of potential outcomes and requires a more diverse set of current measures.

The definitional process and indeed the research approach to "entrepreneurship" gave rise to related subjects like defining an entrepreneur by the way that they recognize or create opportunity. This approach defined three subsets of entrepreneurs. The first was developed by Schumpeter $(1934,1942)$ who emphasized new independent firm formation based on seizing technological change leading to creative destruction. The second was developed by Kirzner $(1973,1997)$ who emphasized the entrepreneur as one who used innate or analyzed opportunity 
recognition and thereby filling gaps in the marketplace. Finally, a third type of entrepreneur was characterized by Williamson (2001) who focused on an entrepreneur's ability to cut transaction costs.

\subsection{Management of Technology and Innovation Foundation}

I use the entrepreneurial categorizations developed in my discussion above to link entrepreneurial literature to Management of Technology Innovation (MOTI) literature. I utilize MOTI literature to review three late $20^{\text {th }}$ century Micro-technology micro and Nanotechnology enabled industries that have come about as a result of disruptive technologies (Yanez et al. 2010). Finally I review the role that entrepreneurial firms play in that process. I specifically utilized the stream of effort that links disruptive technology concepts to how new independent firm entrepreneurship plays a pivotal role in that process in my thesis. I start with high technology harbingered economic waves.

\subsubsection{Schumpeterian Waves}

Emerging technology driven economic epochs were noticed by the economist first by Kondratieff and later furthered by Schumpeter (Schumpeter 1934, Kondratieff 1937). Schumpeter is considered a founder of both entrepreneurial and MOTI research and focused his economic wave research as being driven by new emerging technologies. Schumpeter saw that when emerging technologies grew and displaced traditional technology product paradigms the technology became disruptive. Furthermore, that process becoming the foundation of waves of economic change and growth. Technological entrepreneurs like Watt with his steam engine and later Nikola Tesla and Thomas Edison were not only inventors but also innovators and visionaries (Pretzer, Rodgers and Bush, 2007) that helped to form the foundations of these series of waves. These Schumpeterian or Kondratieff waves are built on new problems that require new solutions based on differing sets of technology.

Presently, many see novel technology as approaching the slope of a new Schumpeterian wave (Korotayev, Zinkina and Bogevolnov, 2011). This wave is based on new root technologies' 
like micro-technology and nanotechnology that are pan industrial and enabling in nature (Linton and Walsh 2008). They are the foundations of convergent technology sets that provide a stable platform on which to build economies (Romig et al 2007, Wonglimpiyara 2005). These emerging disruptive technologies become disruptive and have founded past entrepreneurial cycles that are heavily reliant on entrepreneurship activities for success (Kirchhoff 1994). We next discuss Micro-technology and Nanotechnology or small technology (Linton and Walsh 2008) as the harbingers of the next Schumpeterian wave.

\subsubsection{Small Technology}

The initiation of the next Schumpeterian wave is being driven by small technology as well as other emerging technologies. Items enabled by small tech are becoming smaller, better in performance and cheaper (Roco 2003). But again, strategic action entrepreneurial or other is being hampered by the root of all measurement processes - the lack of mutually agreed upon definition. For example if one was to ask what is the definition of small technology? One answer might be that small technologies are those technologies based upon the minimization of conventional technologies or the nature of the communities that are making that definition (Saner et al 2013). Other definitions focus on physical size (Feynman 1960) or the nature of interaction with the physical world (Walsh 2004). Examples of small technologies include the subfields of micro fluidics, micro-switches and accelerometers. I depict in figure 1.1 below the historical progression of the microsystems portion of small technologies.

The most recent economically significant segment of small technology is nanotechnology. One definition of nanotechnology is the United States Department of Energy's definition. This defines technology as the creation of functional materials, devices, and systems through control of matter on the nanometer ( 1 to $100+\mathrm{nm}$ ) length scale and the exploitation of novel properties and phenomena developed at that scale (LANL 2001). Yet many other countries offer definitions that range from being extremely similar to completely dissimilar. Examples of innovations include carbon nanotubes products, cutting tool applications and medical carriers. It is these small 
technologies and innovations that are driving the next Schumpeterian wave. Figure 1.2 shows the time progression for nanotechnology. 
Figure 1.1 MEMS Timeline

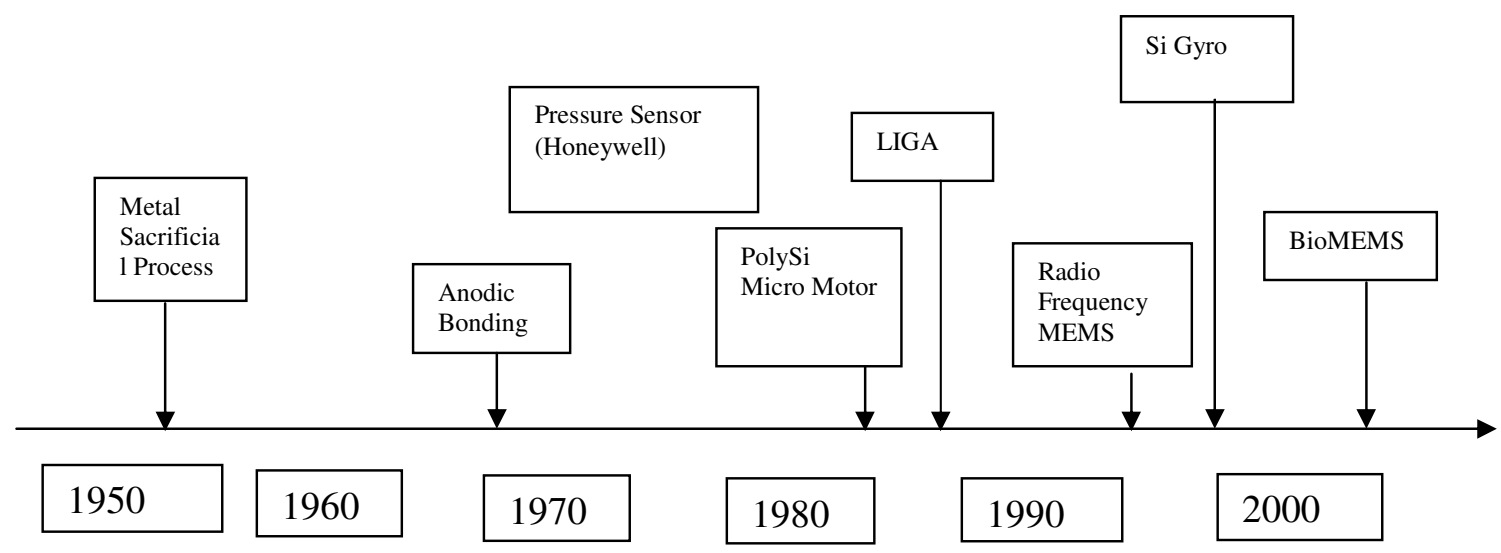

(*Developed from a Brief History of MEMS (2012))

Figure 1.2 Nanotechnology Timeline*

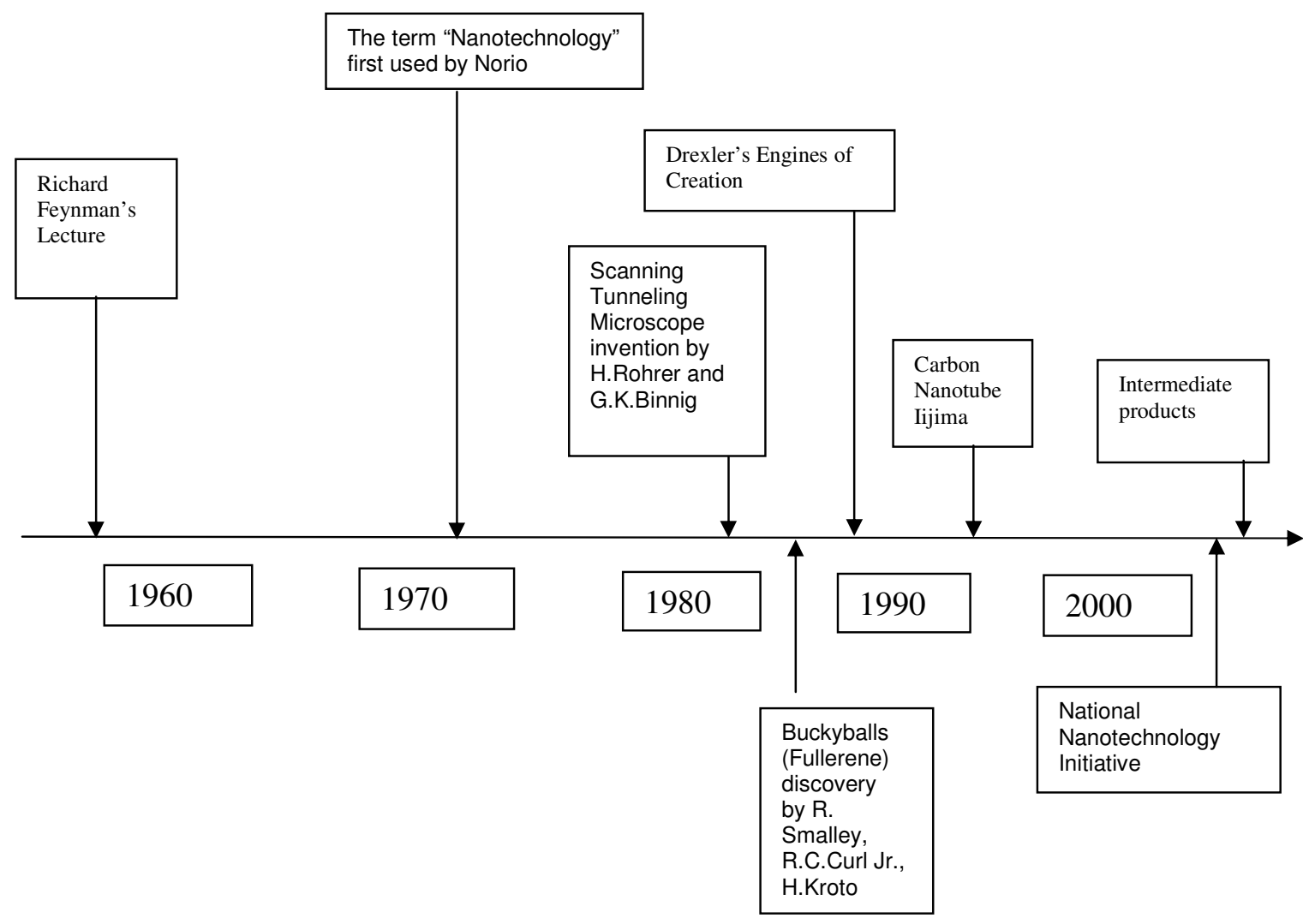

(*Developed from the American Chemical Council (2012))

Today's potential Kondratieff /Schumpeter waves are based on small tech. They are being 
driven by innovations that stem from the research and development from the collaboration between universities, government sponsored labs and private research firms. The new small tech driven Schumpeterian cycle is once again being fueled by entrepreneurial action. For example, currently the number of small business startups is down in the United States. Yet, at the same time, US small technology based startups are experiencing rapid growth (Small Business Labs Trends 2012). Entrepreneurs are forming alliances with universities and governmental labs to seek assistance and technology. However, small technology development and the inclusion of academia are not without problems. I next provide a brief discussion of this interaction.

\subsubsection{University (Knowledge Entrepreneur) Industry Interaction}

The emergence of the biotechnology as solution vector for the pharmaceutical industry provided a necessity for interaction between academia and industry (Pepeu 1999; Sanchez-Serran 2011; Breimer 2001; Dean et al. 2000, Allarakhia and Walsh 2011). Due to the Bayh-Dole act and other demand driven factors, the pharmaceutical industry that I elaborate on later, also is increasingly requiring small technology based competencies to develop next generation product platforms. This thesis resulted in the increased commercial collaboration, not only between academia and industry, but also between academic entrepreneurial spin-offs and larger pharmaceutical firms. Microsystems and nanotechnology or small technology developed by researcher in predominately academic settings with full rights to their inventions started to develop entrepreneurial firms to interact with traditional pharmaceutical firms to develop new therapeutics. Both categories of small technologies have the potential for revolutionary breakthroughs' in this industry (Roco 2003, Allarakhia and Walsh 2012) and many times the solution sets ultimately created required both as multiple root technology.

Universities are becoming increasingly entrepreneurial. A plethora of university based technology transfer offices opened in the wake of Bayh Dole legislation in the US and this trend was taken up in all developed or developing countries worldwide. Universities were forging a closer alignment between scientific research and innovation (OECD 2003; Siegel, Waldman and 
Link 2006; Rothaermel, Agung and Jiang 2007). The rise in university entrepreneurial action is epitomized by the increase in their patenting, licensing and creation of spin-off companies by academic researchers (Clarysse 2007; Siegel, Waldman and Link 2004). Evidence of different entrepreneurial performance among academics highlights the need to understand what distinguishes academic researchers in terms of their inclination to engage in knowledge transfer activities and, especially, to become academic entrepreneurs (Bercovitz and Feldman, 2008; Hoye and Pries, 2009, Kidwell 2013). Now in some universities for example patents are becoming as valuable as academic publications for professorial tenure review (Porter and Cunningham, 2005). Some negative feedback of the increase of commercial interest at universities especially by students has been voiced (Lee, 1996; Glaser and Bero, 2005). Industry involvement with academia may require specific skills and organizational capabilities than are from those required to excel in the academic arena (Bercovitz and Feldman, 2008). However, most studies suggest a positive relationship between increased professorial or knowledge entrepreneur interest in more non-traditional commercial activities with more traditional knowledge entrepreneur measures of excellence like publication rates (Geuna and Nesta, 2006; Siegel et al., 2007).

On the commercial side of the increased university / industrial interaction research shows that increasingly that firms especially in the innovation field are greatly benefiting (Jaffe, 1989; Acs and Audretsch 1991, Acs, Audretsch and Feldman 1994; Gambardella, 1992; Mansfield, 1995, Cockburn and Henderson, 1998; Cohen et al, 2002; Zucker et al, 2002; Belderbos et al, 2004; Fleming and Sorenson, 2004; Cassiman et al, 2008; Furman and Stern 2006). Further, many empirical studies have shown that academic research stimulates growth in regional industrial $R \& D$ as well as the creation of new university related research intensive ventures (Jaffe 1989; Bania et al., 1992; Anselin et al., 1997; Furman and MacGarvie, 2007; Abramovsky et al., 2007). In the next section of the introduction, I expand on my limited discussion of the focus of my research investigation. 


\section{Section 1.4 Research Questions and Expectations}

The research questions, along with their design, purpose and social implication have provided published results in five differing areas. Here I initiate with the effort on understanding and measuring radical change in entrepreneurial action in the pharmaceutical industry. Flexible facilities management and then nanomanufacturing follow this. The next two articles deal with academic publishing and reputation. I have summarized the research questions and expectations into Table 1.

Table 1.1 Research Questions

\begin{tabular}{|c|c|c|c|c|}
\hline Effort & Purpose (A) & $\begin{array}{c}\text { Design/ } \\
\text { Methodology } \\
\text { (B) }\end{array}$ & $\begin{array}{c}\text { Social } \\
\text { Implication }(\mathrm{C})\end{array}$ & Originality /value (D) \\
\hline $\begin{array}{c}\text { Pharmaceutical } \\
\text { Landscape }\end{array}$ & $\begin{array}{c}\text { Examination of new } \\
\text { drivers }\end{array}$ & Case study & $\begin{array}{c}\text { Economic } \\
\text { Development/ } \\
\text { Metrics }\end{array}$ & $\begin{array}{l}\text { Development of } 3^{\text {rd }} \\
\text { generation roadmap }\end{array}$ \\
\hline $\begin{array}{l}\text { Highly Flexible } \\
\text { Facilities }\end{array}$ & $\begin{array}{l}\text { Understanding } \\
\text { metrics for multi } \\
\text { technology facilities }\end{array}$ & Case study & $\begin{array}{c}\text { Economic } \\
\text { Development / } \\
\text { Metrics }\end{array}$ & $\begin{array}{l}\text { Inaugural exploration of } \\
\text { metrics for flexible } \\
\text { facilities }\end{array}$ \\
\hline $\begin{array}{l}\text { Embracing Nano } \\
\text { manufacturing }\end{array}$ & $\begin{array}{l}\text { Provides a strategic } \\
\text { decision model }\end{array}$ & Case Study & $\begin{array}{c}\text { Economic } \\
\text { Development/ } \\
\text { metrics }\end{array}$ & $\begin{array}{c}\text { Initial study of } \\
\text { nanomanufacturing and } \\
\text { complimentary assets }\end{array}$ \\
\hline Publish or Perish & $\begin{array}{l}\text { Examination of } \\
\text { institution and } \\
\text { research. }\end{array}$ & $\begin{array}{l}\text { Empirically } \\
\text { derived }\end{array}$ & $\begin{array}{c}\text { Research } \\
\text { development } \\
\text { metrics }\end{array}$ & $\begin{array}{l}\text { Elevation of metrics for } \\
\text { knowledge entrepreneurs } \\
\text { and institutions }\end{array}$ \\
\hline $\begin{array}{c}\text { Research } \\
\text { Expectations }\end{array}$ & $\begin{array}{l}\text { Assessment of } \\
\text { quality research }\end{array}$ & $\begin{array}{l}\text { Empirically } \\
\text { derived }\end{array}$ & $\begin{array}{l}\text { Comparison of } \\
\text { research metrics }\end{array}$ & $\begin{array}{l}\text { Advancement in metrics } \\
\text { for individual Knowledge } \\
\text { entrepreneurs }\end{array}$ \\
\hline
\end{tabular}




\section{Section 1.4.1 The Pharmaceutical Technology Landscape:}

\subsection{1.a}

Purpose

The research concentrates on the lack of understanding of current road mapping techniques addressing the evolving pharmaceutical industry. The amelioration of the pharmaceutical industry is due to environment pressures. These pressures are giving rise to new drivers and are causing concern for the development of future products. These drivers are explored and taken into account in a new road mapping technique called landscaping. This article focuses on the development of a new landscaping technique in order for firms to measure and manage their innovation process.

\subsection{1.b Design/methodology/approach -}

The article investigates a novel road mapping technique that incorporates measurement techniques and thereby expresses new theory and processes that are in alignment with the nature of these new products and innovations. The model is tested through a case study of new pharmaceutical industry innovations.

\subsection{1.c Social implications}

Health care is at the crossroads of micro, nano and semiconductor technology. The convergence of these technologies into the health care field is poised to solve many of these health problems and becomes a basis for job creation and prosperity. If a new roadmapping technique is not developed, then subsequently both health care and economic development will suffer without new roadmapping metric development.

\subsection{1.d Originality/value}

While there is an abundance of research on first and second generation roadmapping techniques, this is the first attempt at a third generation roadmap for the pharmaceutical industry. The third generation roadmapping will additionally provide insight to the dynamics of the pharmaceutical industry. 


\section{Section 1.4.2 Managing Highly Flexible Facilities}

\subsection{2.a Purpose}

Twenty first century problems are increasingly being addressed by multi technology solutions developed by regional entrepreneurial and intrapreneurial innovators. However, they require an expensive new type of fabrication facility. Multiple technology production facilities (MTPF) have become the essential incubators for these innovations. This paper aims to focus on the issue of developing metrics for those facilities.

\subsection{2.b Design/methodology/approach}

The article addresses the lack of managerial understanding of how to express the value and operationally manage MTPF centers through the use of investigative case study methods for multiple firms in the study.

\subsection{2.c}

Social implications

Innovations at the interface of micro technology, nanotechnology and semiconductor micro fabrication are poised to solve many of these problems and become a basis for job creation and prosperity. If a new metric techniques is not developed, then these harbingers of regional economic development will be closed.

\subsection{2.d Originality/value}

While there is an abundance of research on measures and metrics for High volume facilities $\mathrm{HVF}$, this is the first attempt to develop measures and metrics for Multi Technology Low volume production facilities MTPFs. 
Section 1.4.3 A Strategic Model for Firms Who Seek to Embrace Nanomanufacturing

1.4.3.a

Purpose

Nonmanufacturing is being perceived as the centric of many regional manufacturing sectors potential. Though there are high expectations, there exists little infrastructure to support such activities. This paper seeks to make a contribution by offering a categorization scheme for nonmanufacturing based on the types of hurdles that firms are likely to encounter and provide some case base examples of both evolutionary and revolutionary nanomanufactured products

\subsection{3.b Design/methodology/approach}

The article discusses the common terminology and economic ramifications of the emerging nonmanufacturing endeavors. The study then follows through with a case based strategic nonmanufacturing model on which to base strategic decision making.

\subsection{3.c Social implications}

Innovations at the nanotechnology level and are both revolutionary and evolutionary in nature. They are poised to solve many of these problems and become a basis for job creation and prosperity. If new management techniques are not developed, then these harbingers of regional economic development will be closed.

\subsection{3.d Originality/value}

While there have previous articles have investigated elements of nonmanufacturing, this is the first article to include strategic components attached to nanomanufacturing and complementary assets.

\section{Section 1.4.4 Publish or Perish: How Are Research and Reputation Related?}

\subsection{4. a Purpose}

Academic researchers (Knowledge entrepreneurs) and the topic of quality is a much discussed subject. The result has been a proliferation of measures to assess research, researchers, research outlets, and the locations in which the research occurs. By empirically assessing the relationship between institution ranking and research production, a better understanding of the 
relationship between the perceived qualities of institutions is possible.

\subsection{4.b Design/methodology/approach}

The article discusses the common terminology and metrics used in academic research and then follows through with an empirical study to better understand the relations between institution ranking and scholarly research generated by their knowledge entrepreneurs.

\subsection{4.c}

\section{Social implications}

There needs to be a better understanding of the relationship between reputation and research in different fields so that incentives and knowledge infrastructure that are the most appropriate for fostering research are offered. It is not possible to take a "one size fits all approach" so terms such as "publish or perish" or an excessive reliance on simple metrics should be avoided.

\subsection{4.d Originality/value}

While there is a plethora of research on particular metrics for scholarly research, this is the first to include empirical research linking metrics with academic excellence.

\section{Section 1.4.5 What are Research Expectations? A comparative study of different} academic disciplines

\subsection{5.a \\ Purpose}

Academic research and the topic of quality is a much discussed subject. This paper is intended to assist senior administrators and members of university level committees that must consider "what quality of research" is in fields that they lack personal domain expertise.

\subsection{5.b Design/methodology/approach}

The article discusses the common terminology used in the area of interest and then follows through with an empirical based study that measures quality and scholarly research.

\subsection{5.c Social implications}

The study allows entrepreneurs, companies, faculty and administrative professionals to seek comparisons between the differing fields of scholarly research. This allocates the best possible resource for the situation at hand. 


\subsection{5.d}

Originality/value

While there is a plethora of research on metrics for scholarly research, this article adds to the research by including empirical data on particular fields of scholarly research and universities reputations. 


\section{Section 1.5 References}

A brief history of MEMS

http://courses.engr.illinois.edu/ece485/Fall2012/485\%20Lecture\%202\%20Fall\%202012. pdf Retrieved June 2012

Abramovsky, L., Harrison, R. and Simpson, H. (2007), University Research and the Location of Business Rand. The Economic Journal, 117(519), pp. 114-141.

Acs, Z. and D. Audretsch (1988), Innovation in large and small firms; an empirical analysis. American Economic Review 78, pp. 678-690.

Acs, Z. J. and Audretsch, D. B. (Eds.). (1991). Innovation and technological change: an international comparison. University of Michigan Press.

Acs, Z. J., Audretsch, D. B., and Feldman, M. P., (1994), R and D spillovers and recipient firm size. The Review of Economics and Statistics, pp. 336-340.

Allarakhia, M. and Walsh, S.T. (2011), Managing knowledge assets under conditions of radical change: The case of the pharmaceutical industry. Technovation, 31(2-3), pp. 105-117.

American Chemical Council http://www.americanchemistry.com/Nanotechnology-Timeline Retrieved June 6, 2013

Anselin, L., Varga, A., and Acs, Z. (1997), Local geographic spillovers between university research and high technology innovations. Journal of Urban Economics, 42(3), pp. 422-448.

Anson, S., Kautt, M., Walsh, S.T., Bittner, K., (2008), Academic Infrastructure and Competence Centres for a potentially evolving Nano-manufacturing industry, International Journal of Technology Transfer and Commercialization, 7(4), pp. 436-455.

Balaz, K. (1996)

http://www.admin.susx.ac.uk/Units/spru/publications/imprint/steepdps/37/steep37 .pdf Retrieved June 52013.

Baldwin, J. R. (1995). The Dynamics of Industrial Competition: A North American Perspective. New York: Cambridge University Press.

Bania, N., Calkins, L. N., and Dalenberg, D. R., (1992), The effects of regional science and technology policy on the geographic distribution of industrial R\&D laboratories. Journal of Regional Science, 32(2), pp. 209-228.

Belderbos, R., Carree, M., and Lokshin, B., (2004), Cooperative R\&D and firm performance. Research Policy, 33(10), pp. 1477-1492.

Bercovitz, J., and Feldman, M., (2008), Academic entrepreneurs: Organizational change at the individual level. Organization Science, 19(1), pp. 69-89. 
Birch, D.L., (1979), The Job Generation Process. Unpublished report prepared by the Massachusetts Institute of Technology Program on Neighborhood and Regional Change for the Economic Development Administration. Washington, DC: U.S. Department of Commerce.

Birch, D.L., (1987). Job Creation in America: How Our Smallest Companies Put the Most People to Work. Free Press. New York, New York.

Breimer, D. D., (2001), Future training needs in the pharmaceutical sciences: academia-industry. European journal of pharmaceutical sciences: official journal of the European Federation for Pharmaceutical Sciences, 12(4), pp. 347.

Bouchikhi, H., and Kimberly, H.R., (2001), 'It's Difficult to Innovate': The death of the Tenured Professor and the Birth of the Knowledge Entrepreneur. Human Relations, 54(1), pp. 77-84.

Campbell, N.R. (1957). Foundations of Science, .Drover New York, New York. pp. 267.

Cassiman, B., Veugelers, R., and Zuniga, P. (2008), In search of performance effects of (in) direct industry science links. Industrial and Corporate Change, 17(4), pp. 611-646.

Clarysse, B., Wright, M., Lockett, A., Mustar, P., and Knockaert, M. (2007), Academic spinoffs, formal technology transfer and capital raising. Industrial and Corporate Change, 16(4), pp. 609- 640 .

Cockburn, I. M. and Henderson, R. M., (1998), Absorptive capacity, coauthoring behavior, and the organization of research in drug discovery. The Journal of Industrial Economics, 46(2), pp. 157-182.

Cohen, W. M., Nelson, R. R. and Walsh, J. P., (2002), Links and impacts: the influence of public research on industrial Rand. Management science, 48(1), pp. 1-23.

Cowan, C., (2013), A new road mapping technique for creatively managing the Emerging Smart Grid, Creative Innovation management Journal, in press

Crosby, P.B.,(1992) Quality is free: The art of making quality certain. Mentor Books Denver, CO.

Davidson, P., Kirchhoff B., Hatemi, J.A. and Gustavsson H., (2002), Empirical analysis of business growth factors using Swedish data. Journal of Small Business Management, 40(4): pp. 332-349.

Dean, P. M., Zanders, E. D. and Bailey, D. S., (2001), Industrial-scale, genomics-based drug design and discovery. Trends in Biotechnology, 19(8), pp. 288-292.

Deming, W. Edwards. Improvement of Quality and Productivity through Action by Management. In Readings in the Management of Innovation, ed. M.L. Tushman and W. Moore. pp. 454-465. Second ed., Vol. Ballinger, 1982.

Drexler, KE. (1986), Engines of Creation: The Coming Era of Nanotechnology. Anchor Books: New York, New York

Drexler, K.E., (2004), Nanotechnology: From Feynman to Funding. Bulletin of Science Technology Society 24, pp. 21-27. 
Ducker, J. and Goldstein, H., (2007) Assessing the regional economic development of universities: A review of current approaches. International Regional Science Review, 30(1) pp. 26-46.

Feynman, R. P., (1960), There's plenty of room at the bottom. Engineering and Science, 23(5), pp. 22-36.

Fink M., Lang R., Harms R. (2013): Local responses to global technological change Contrasting restructuring practices in two rural communities in Austria. Technological Forecasting and Social Change, Vol. 80, No. 2, pp. 243-252

Fleming, L. and Sorenson, O., (2004), Science as a map in technological search Strategic

Management Journal, 25(8-9) pp. 909-928.

Furman, J. L. and MacGarvie, M. J., (2007), Academic science and the birth of industrial research laboratories in the US pharmaceutical industry. Journal of Economic Behavior and Organization, 63(4), pp. 756-776.

Furman, J. L. and Stern, S. (2006), Climbing atop the shoulders of giants: The impact of institutions on cumulative research (No. w12523), National Bureau of Economic Research.

Gambardella, A. (1992), Competitive advantages from in-house scientific research: the US pharmaceutical industry in the 1980s. Research Policy, 21(5), pp. 391-407.

Gartner, W. B. (1990), What Are We Talking About When We Talk About Entrepreneurship? Journal of Business Venturing, 5, pp. 15-28.

Glaser, B. E. and Bero, L. A., (2005), Attitudes of academic and clinical researchers toward financial ties in research: A systematic review. Science and Engineering Ethics, 11(4), pp. 553- 573.

Geuna, A., and Nesta, L. J., (2006), University patenting and its effects on academic research: The emerging European evidence. Research Policy, 35(6), pp. 790-807.

Gouvea, R., Linton, J., Montoya, M. and Walsh, S. (2012), Emerging Technology and Ethics: A Race to the Top or a Race to the Bottom, Journal of Business Ethics, 109(4), pp. 553-567.

Groen, A. J., (2005), Knowledge intensive entrepreneurship in networks: towards a multilevel/multi dimensional approach. Journal of Enterprising Culture, 13(1), pp 69-88.

Harms, R. and Erhmann, T. (2003), The performance implications of Entrepreneurial management: Linking Stevenson's and Miller's conceptualization of growth', paper presented at the Babson Kauffmann Entrepreneurship Research Conference, Wellesley, MA.

Harms, R., Schulz, A., Kraus, S. and Fink, M. (2009), The conceptualization of 'opportunity' in strategic management research. International Journal of Entrepreneurial Venturing, 1(1), pp 57-71.

Headd, B., (2003), Redefining business success: Distinguishing between closure and failure. Small Business Economics, 21(1), pp. 51-61. 
Headd, B., and Kirchhoff, B.A., (2009), The growth, decline and survival of small businesses: An exploratory study of life cycles, Journal of Small Business Management, 47(4), pp. 531550.

Hébert, R. F., and Link, A. N., (1989), In Search of the Meaning of Entrepreneurship, Small Business Economics, (11), pp. 39-49.

Hoye, K. and Pries, F., (2009), Repeat Commercializers, The habitual entrepreneurs' of university-industry technology transfer. Technovation, 29(10), pp. 682-689.

Hulshoff, H. E., Kirchhoff, J. J., Kirchhoff, B. A., Walsh, S. T. and Westhof, F. M. J., (1998), EIM press, New Services. Strategic Study and Exploratory Survey of a Dynamic Phenomenon,” EIM Small Business Research, Zoetermeer, Netherlands, November, pp. 82.

Jaffe, A.B., (1989), Real effects of academic research. The American Economic Review, pp. 957- 970 .

Juran, Y.J.M., (1964), Managerial Breakthrough, McGraw Hill Publishing Company, New York, New York

Kautt, M. Walsh, S. and Bittner, K., (2007), Global distribution of micro-nano technology and fabrication centers: A portfolio analysis approach, Technology Forecasting and Social Change, 74, pp. 1697-1717.

Kidwell, D.,(2013), Principal investigators as knowledge brokers: A multiple case study of the creative actions of PIs in entrepreneurial science Technological Forecasting and Social Change, 80(2), pp. 212-220.

Kilby, P., (1971), Hunting the Heffalump. In P. Kilby (Ed.), Entrepreneurship and Economic Development: 1-40. New York: The Free Press.

Kirchhoff, B.A., (1994), Entrepreneurship and Dynamic Capitalism: the Economics of Business Firm Formation and Growth. Westport, CT: Praeger.

Kirchhoff, B.A. and Walsh, S.T., (2000), Entrepreneurship's Role in Commercialization of Disruptive Technologies, Band 13, Unternehmer und Unternehmensperspektive fur Klienund Mittelunternehmen, Berlin: Dunker and Humbolt, pp. 323-332.

Kirchhoff, Linton, J.D. and Walsh, S.T., (2013), Neo-Marshellian Equilibrium versus Schumpeterian Creative Destruction: Its impact on Business Research and Economic Policy, Journal of Small Business Management, 51(2), pp. 159-166.

Kirzner, I., (1979), Perception, Opportunity and Profit: Studies in the Theory of Entrepreneurship. Chicago: University of Chicago Press.

Knight, F. H., (1921), Risk, Uncertainty and Profit. New York: Augustus M. Kelley. Kondratieff, N.D., (1937), Long Waves in Economic Life LLOYDS BANK ANNU REV July, 1978 .

Kondrat'ev, N.D. and Jakovec, Y.V., (2004), The world economy and its Conjunctures During and After the War. International Kondratieff Foundation

Kuhn, TEST, (1962), The Structure of Scientific Revolutions. Chicago: University of 
Chicago Press.

LANL http://www.lanl.gov/mst/nano/definition.html 2001

Lee, Y.S., (1996), Technology transfer and the research university; a search for the boundaries of university-industry collaboration, Research Policy 25(6) pp. 843-863

Linton, J. D., (2002), Forecasting the market diffusion of disruptive and discontinuous innovation. Engineering Management, IEEE Transactions on, 49(4) pp. 365-374.

Linton, J. D., and Walsh, S. T., (2003), From bench to business. Nature materials 2(5), pp. 287- 289.

Linton J. and Walsh S., (2008), A Theory of innovation for process-based innovations such as nanotechnology. Technological Forecasting and Social Change 75(5) pp. 583-594.

Linton, J., and Walsh, S.T.,(2008), Acceleration and Extension of Opportunity Recognition for Nanotechnologies and Other Emerging Technologies International Small Business Journal 26 pp. 83-99.

Mangematin, V and Walsh, S., (2012), The future of nanotechnologies, Technovation, 3-4, pp. 216-226.

Mansfield, Edwin., (1968a), The Economics of Technological Change. New York: W.W.

Norton. Mansfield, E., (1995), Academic research underlying industrial innovations: sources, characteristics, and financing. The review of Economics and Statistics, pp. 55-65.

Marquis, Donald G. The Anatomy of Successful Innovations, In Readings in the Management of Innovation, ed. M.L. Tushman and W. Moore, 79-87. Second ed., Vol. Ballinger, 1969.

Marshall, A., (1890), Principles of Economics, London: Macmillan and Co.

Marx, K., and Engles, F., (1845), Capital: A Critique of Political Economy (B. Fowkes, D. Fernbach, and E. Mandel, Trans.). Harmondsworth, Eng.: Penguin Books.

Newbert, S.L., Kirchhoff, B.A. and Walsh, S.T., (2007), Defining the relation among founding resources, strategies, and performance in technology-intensive new ventures: Evidence from the semiconductor silicon industry, Journal of Small Business Management 45(4) pp. 438-466.

OCED 2003 http://www.oecd.org/els/employmentpoliciesanddata/31775229.pdf

Pepeu, G., (1999), Is there still a role for Academia? Pharmaceutical science and technology Today, 2(8) pp. 305.

Phillips, B.D. and Kirchhoff, B.A.,(1989). Formation, growth and survival: Small firm dynamics in the U.S. economy, Small Business Economics 1 pp. 65-74.

Picot, G. and Dupuy, R., (1998). Job Creation by Company Size Class: The Magnitude, Concentration and Persistence of Job Gains and Losses in Canada, Small Business Economics 10(2) pp. 117-139.

Porter, A. L. and Cunningham, S. W., (2005), Tech mining, Competitive Intelligence Magazine, 8(1) pp. 30-36. 
Quotations and Literature forum, (2012), "You cannot manage what you cannot measure," http://www.quotationspage.com/forum/viewtopic.php?t=225

Roco M.C., (2003), Broader Societal Issues of Nanotechnology Journal of Nanoparticle Research. 5. pp. 181-189.

Rothaermel, F. T., Agung, S. D. and Jiang, L., (2007), University entrepreneurship: taxonomy of the literature. Industrial and corporate change, 16(4) pp. 691-791.

Sanchez-Serrano, I,. (2011), The World's Health Care Crisis: From the Laboratory Bench to the Patient's Bedside. Elsevier. Netherlands.

Saner, M, and Stoklosa, A., (2012), Reducing ambiguity to increase emerging technology commercial potential: the case of Nanomaterials, Creative Innovation Management (in press).

Sarason, Y., Dean, T., and Dillard, J.F. (2006), Entrepreneurship as the nexus of individual and opportunity: A Structuration view, Journal of Business Venturing 21(3), pp. 286-305

Schoonhoven, C. B., and Romanelli, E. (Eds.). 2001. The Entrepreneurship Dynamic: Origins of Entrepreneurship and the Evolution of Industries. Stanford, Calif. Stanford University Press.

Schumpeter, J.A. (1934), The Theory of Economic Development: An Inquiry Into Profits, Capital, Credit, Interest, and the Business Cycle. New Brunswick, NJ, Transaction Books.

Schumpeter, J.A. (1942). Capitalism, Socialism, and Democracy. New York: Harper and Row. Shane, S., and Venkataraman, S., (2000), The Promise of Entrepreneurship as a Field of Research, Academy of Management Review, 25, pp. 217-226.

Siegel, D. S., Waldman, D., and Link, A., (2003), Assessing the impact of organizational practices on the relative productivity of university technology transfer offices: an exploratory study, Research policy, 32(1), pp. 27-48.

Siegel, D. S., Waldman, D. A., Atwater, L. E., and Link, A. N., (2004), Toward a model of the effective transfer of scientific knowledge from academicians to practitioners: qualitative evidence from the commercialization of university technologies, Journal of Engineering and Technology Management, 21(1), pp. 115-142.

Small Business Labs http://www.smallbizlabs.com/2012/01/top-ten-small-business-trendsfor- 2012.html

Souder, William E., (1987), Managing New Product Innovations, Lexington Books, Lexington, MA.

Spencer, A., Kirchhoff, B, and White, C., (2008), Entrepreneurship, Innovation, and Wealth Distribution -The Essence of Creative Destruction, International Small Business Journal, February 26(1) pp. 9-26

Stearns, T.M., Reynolds, P.D., and Williams, M.L., (1995), New firm survival: Industry, strategy and location, Journal of Business Venturing, 10(1), pp. 23-42.

Storey, D.J., (1994), Understanding the Small Business Sector, Routledge, New York, New York. 
Tierney, R., Groen, A. J., Harms R., Luizink, M., Hetherington, D., Stewart, H., Linton, J. D., Walsh, S. T., (2012), "Managing Highly Flexible Facilities: An Essential Complementary Asset at Risk," International Journal of Enterprise Behaviour and Research, Vol., 18, Issue 2, pp. 233- 255

Walsh S.T., and Groen A.J., (2012), "Introduction to the Field of Emerging Technology Management," Creativity and Innovation Management Journal, Volume 22, Issue 1, pages 15, March 2013

Williamson, O.E., and Kaiser, E.F., (2005), Transaction cost economic and business administration, Scandinavian Journal of Management, 21(1 SPEC. ISS.) pp. 19-40.

Yanez, M. Tarek M. Khalil, Walsh S. T., (2010), IAMOT and Education: Defining a Technology and Innovation Management (TIM) Body-of-Knowledge (BoK) for graduate education (TIM BoK), Technovation, 30(7-8) pp. 389-400.

Zucker, L.G. and Darby, M.R., (2002), Knowledge, capture and firm performance in biotechnology, Management Science, 48, pp. 138-153. 


\title{
Section 2
}

\section{The Pharmaceutical Technology Landscape: A new form of Technology Roadmapping}

\author{
By \\ Robert Tierney ${ }^{\mathrm{a}}$, Wahid Hermina ${ }^{\mathrm{b}}$, Steven Walsh ${ }^{\mathrm{c}}$ \\ a NIKOS, University of Twente, Enschede, The Netherlands \\ Microsystems, RD\&A/Integration, Sandia National Laboratories, United States \\ Anderson School of Management, University of New Mexico, United States
}

Reproduced with permission from Elsevier Publishing Inc. Article originally appeared in Technological

Forecasting and Social Change, February 2013 Volume 80 Issue 2 pp. 194-211

Citations presented in accordance to journal requirements 


\section{Section 2.1 Abstract and Key words}

Practitioners are finding it increasingly difficult to develop effective roadmapping efforts for many new products and innovations. We argue that this difficulty stems from the fundamental differences between many of today's innovations and earlier ones. Many current innovations are: using technology differently; more heavily constrained; forcing new business models and increasingly being shaped by drivers. Current roadmapping techniques do not translate well to this new reality. Roadmapping efforts for these innovations are increasingly failing to meet their primary goal of including technology into the strategic process of firms, regions or industries.

We seek to address this concern by creating a new roadmapping technique, one we name Technology Landscaping. We build this technique by basing it upon the relevant sections and structures found in first and second-generation roadmapping theories and practices. We then apply new theory and processes that are in alignment with the nature of these new products and innovations. We test our model through a case study of new pharmaceutical industry innovations. Finally, we present our new roadmapping technique.

Key words: constrained innovations, creative enterprise, nanotechnology, microtechnology, technology entrepreneurship, national laboratories, MEMS, Technology Roadmaps, Technology Landscape, Convergence 


\section{Section 2.2 Introduction}

Technology roadmaps were developed to insert technology into the strategic processes of firms, industries or regional development activities [120]. Technology roadmaps traditionally plot the technology requirements of one or more products or innovations along a single technology pathway over time. Technology roadmaps provide both strategic and tactical value for those that use them. At least two separate generations of roadmaps provide value to today's industries and firms. The highly successful first generation roadmap techniques advance architecturally stable technology product platforms like those found in the semiconductor industry [42,56]. Similarly, successful second generation technology roadmaps provide value for emergent disruptive technology bases like MEMS or nanotechnology [120,122]. Both first and second generation roadmapping techniques mirror the nature of the innovations and products they serve.

The nature of many new pharmaceutical innovations and products, however, vary greatly from the architecturally stable product platforms served by first generation roadmaps or even emergent disruptive technology based products served by the second. Further, these new pharmaceutical innovations are prototypical of other new innovations in a variety of industries. It is then no wonder then that roadmapping participants are finding it increasingly difficult to apply existing roadmapping techniques to these new innovations [80, 82]. Yet many firms, industries and economic development activities would benefit from a roadmapping process for these new innovations. Here we provide one path that roadmapping techniques can evolve for a third time to meet the needs of a new generation of innovations.

We argue that in order to build an effective third generation roadmapping technique we must first define the nature of these new technology innovations, particularly the differing nature of these innovations and products from previous ones. Each new generation of roadmap development has been driven by the changing nature of the innovations and products under review. We next build on the first two roadmapping techniques, identifying the value that they bring to the third 
generation process. Finally, we apply newer theory to build our new roadmapping technique.

We identify six important manners in which the nature of many new pharmaceutical innovations and products differ from earlier products and innovations. First, these innovations are created at the interface of multiple root technologies $[9,14]$. Second, these innovations often do not benefit from a unit cell such as the transistor does for the semiconductor roadmaps. Third, differing applications drive innovations that will require differing and often multiple critical dimension development for each technology being utilized. Fourth, the boundary conditions constraining today's innovations and products are much stricter than ever before [12]. Fifth, drivers are much more important to these new innovations. Sixth, new business models such as focused consortia [7] are driving technological development without benefit of predetermined architecturally stable product process platforms. Using these differences as a baseline we then review the current roadmap and innovation literature in order to develop a new third generation roadmapping technique.

We provide the new pharmaceutical innovation process as a case study [136] to further develop data and test new roadmap tactics in order to present a robust third generation roadmapping model. Many new pharmaceutical innovation processes have resisted current roadmapping techniques [8]. Newer pharmaceutical innovations often do not follow the traditional pharmaceutical industry single root technology innovation base. We found that new pharmaceutical innovations are often generated at the interface of multiple technologies. We collected interviews at conferences to identify the technologies that serve as the bases of new pharmaceutical innovations. We grouped these technologies into five root categories.

We next compiled pharmaceutical drivers from primary and secondary case based techniques. This step in our roadmapping process emphasizes the new importance of drivers in our roadmap process. We further, incorporated the pharmaceutical industry new business model of consortia into our roadmap. We used these consortia much in the same way as the first 
generation roadmaps utilize important architecturally stable process product platforms. We functionalized the time axis for technology maturity time along multiple critical dimensions by modifying Technology Readiness Level (TRL) and Technology Readiness Assessment (TRA) techniques. We incorporated our findings and present a new third generation roadmap technique.

\section{Section 2.3 Literature review}

Our literature review is designed to assist in the development of a new roadmap technique that suits the nature of many recent pharmaceutical innovations and products. We have segmented the literature review into three sections. We discuss in Section 2.1 the six ways that more recent pharmaceutical innovations differ from earlier ones. We conclude that the nature of these innovations is not well served by traditional roadmapping techniques. We next discuss in Section 2.2 the value and gaps in current roadmapping techniques as applied to these innovations. Finally in Section 2.3 we review current literature that enables new roadmapping segments required by these innovations.

\subsubsection{The changing nature of many new pharmaceutical innovations}

First, we discuss how new pharmaceutical innovations substantially differ from traditional ones. There are at least six ways that new pharmaceutical innovations differ. We postulate that these new innovations and products cannot be adequately addressed by traditional roadmapping techniques.

\subsubsection{Many of today's innovations are using technology differently}

First and second generation roadmaps are focused on a single root technology based innovation or product. A shift has occurred and many of today's pharmaceutical innovations are increasingly generated at the interface of two or more root technologies [106, 6]. Innovations developed at the interface of multiple root technologies are perhaps the single most problematic issue for current roadmapping techniques to address. Roadmapping practitioners often try to cope 
with this by designating a single technology as most important to an innovation, disregarding all others, or by trying to generate a roadmap for every single root technology and every differing critical dimension required of that technology [128]. Neither choice efficiently allows for the inclusion of technology into the strategic processes of firms, industries or regional economic activities.

\subsubsection{No unit cell}

Today's pharmaceutical innovations do not have a unit cell (component) such as a transistor [109]. The transistor is the unit cell or base element in the ITRS semiconductor first generation roadmapping effort. The lack of a unit cell does not allow for shared learning across industrial applications [109]. The lack of a dominant unit cell (component) makes it very difficult to use the strata structure $\mathrm{Y}$ axis or vertical segment of the traditional roadmapping process.

\subsubsection{Differences in critical dimensions}

Traditional roadmapping techniques follow a single technology trait trajectory. One of the most famous is "Moore's Law" [83]. Moore's law depicts the ever increasing number of transistors for a given silicon area. The ITRS roadmap uses line width as the major critical dimension. There exists no corresponding critical dimension for most new pharmaceutical innovations.

These new innovations require the technologies to improve on multiple dimensions. A traditional roadmapping effort uses technology lifecycle techniques which plot the progression of a technology along a single critical dimension (CD) pathway. Technological improvements along a number of CDs and its integration with other technologies are required to produce these new pharmaceutical innovations. 


\subsubsection{Today's pharmaceutical innovations are more heavily constrained}

Optimal innovations are more highly constrained than ever before. Now an innovation that solves a local expression of a global problem [37,100], but simultaneously adversely affects another global problem, is no longer considered optimal and therefore it may not be implemented. These constraints stem from the largest challenges or problems facing the twenty first century which are: healthcare [24]; energy [78]; the environment [24, 10]; food [44,22,24]; and water [53].

Finally, innovations are under increasingly higher scrutiny from litigation, regulation and public opinion [76]. New pharmaceutical innovations must address these challenges in order to be considered optimal [47]. Some policy makers, especially in the European Union, are using something akin to the "Hippocratic Oath" heuristic of "first do no harm" as embodied by the "Precautionary Principle" [105] for innovation, product and patent governance. Traditional roadmaps do not address this intensified concern.

\subsubsection{Today's innovations are being shaped by different drivers}

Today's pharmaceutical innovations are being initiated by new sets of drivers. One of the differences between first and second generation roadmaps is the use of technology product platforms rather than products [120] and drivers played a role [30] in that process. Yet the inclusion of very differing drivers such as changing customers expectations, fluid intellectual property procedures and resource requirements among others are catapulting drivers into a new and more important role in innovation development [8,98]. A more prominent position for drivers is required in a roadmapping technique for these innovations.

\subsubsection{Today's pharmaceutical innovations are creating new business models}

Many firms foresee the value in these new innovations yet lack the financial resources and/or competence to embrace them regardless of their size. This has caused the development of new business models such as consortia [6] to generate these new innovations. These creative 
enterprise consortia often use supply chain partners [25] to generate innovations. Differing consortia have varied rules for the sharing of intellectual property, necessary equipment and other resources. The differences between conventional products and these newer innovations are stark. These new innovations are causing radical strategic industrial and firm change $[26,65,93]$. This change is creating exceptional opportunity $[60,64]$. This reality is not addressed by traditional roadmapping techniques. A targeted road mapping technique would help firms better embrace this opportunity.

\subsubsection{Value and gaps in traditional roadmap techniques}

We review roadmapping literature in order to provide the foundation for our new effort. We selected the elements from first and second generation roadmaps that provide value to the new process. Roadmaps have a long history and have evolved to address many new needs over the years. They were first used by firms such as General Electric for internal product development in the nineteenth century [120]. First generation roadmaps then evolved to meet the needs of industries. Roadmapping practice then evolved further, incorporating new techniques that focused on emergent disruptive single root technology innovations [90]. We initiate our discussion with the evolution of first generation roadmaps.

\section{Section 2.4. First generation roadmaps}

The roadmap process was conceived as a vital strategic tool [30] and has benefitted international, national and regional long term planning [70]. First generation roadmaps have a long history and are used routinely by firms and industries today $[15,45,131]$. The roadmapping technique is also a baseline process used by firms and industries for standard product continuous improvement efforts [59]. One of the most famous applications of first generation roadmapping is the International Technology Roadmap for Semiconductors (ITRS, 2011).

One problem that practitioners encounter using this technique for new pharmaceutical 
innovations is the innovation's lack of a stable technology product platform. Previous innovations like semiconductor micro-fabrication were unable to derive value from roadmapping until a stable product process platform was developed. The ITRS roadmapping process, for example, did not begin with the invention of the solid state transistor in 1946 [110]. Rather it began in the 1970s, years after the MOS and Bipolar product platform bases provided a stable process product platform in the late 1950s $[58,89]$. The ITRS industrial roadmap today is still based on this process product platform $[11,34]$. Similarly industrial roadmaps like the aluminum industry roadmaps also followed a first generation roadmapping technique [120].

A second difficulty with first generation roadmaps is the dependence on a single root technology. The complexity of today's high tech problems have encouraged many entrepreneurs and intrapreneurs to create innovations based on complementary and/or convergent technology sets [140], rather than the traditional single technology or "silo" approach [91]. By combining technology into sets, new methods of solving problems become available [66].

The major contribution from the first generation roadmap to our model is its structure. It still provides an overall easily modifiable structure [31] for specific roadmap efforts. The structure is comprised of a time based $\mathrm{X}$ axis and functional $\mathrm{Y}$ axis strata. The initial roadmaps were developed with technology as the base layer, components in the middle stratum all feeding to products on the highest level (see Fig. 1). Traditionally these were driven by a single critical dimension (CD) of a single technology. These CDs are operationalized for roadmaps through the use of technology life cycles [27,141]. For example, decreasing the line width was the single CD that guided the roadmapping process for semiconductors [115]. 
Figure 2.1. First generation Roadmap general tool

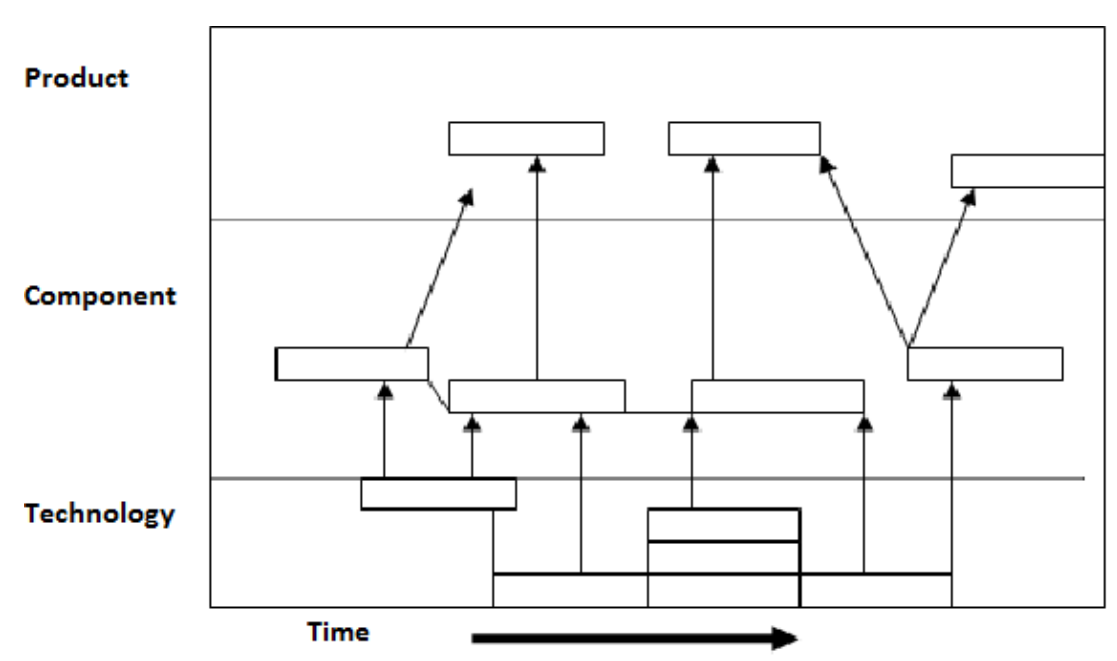

This common layered strata roadmap structure is the foundational element for the new third generation road mapping landscaping process. The multistep process is transferable; however its single root technology focus is not. We discuss the new strata as well as the techniques used to generate them in our case study and present them in our final model.

\section{Section 2.5. Second generation roadmaps}

Second generation roadmaps were developed for emerging technologies that are potentially disruptive in nature $[70,101]$. These often have no fixed market targets or stable product process paradigm [120]. These innovations are typified by having no unit cell, yet they are still are generated from a single root technology [109]. These roadmaps are designed for two types of innovations. One roadmap option is for innovations that are designed for direct product replacement [130]. This occurs when the practitioners try to predict when a traditional product process platform for a given market is transitioning to an emergent process product platform [78]. In this instance the performance measures of the previous product are known and predicted points of value that must be reached to overcome the resistance for new product marketplace change [141] can be predicted. The second and more common case of this disruptive technology roadmap 
exists when a potentially disruptive technology is being considered for use in an application space, but the exact product is unknown $[120,101]$.

The first industrial roadmap effort to embrace a non-architectural disruptive technology base was by produced by MANCEF [125,126]. This effort focused on MEMS (Micro Electro Mechanical Systems) technology and top down nanotechnology completing a series of industrial roadmaps in 2003, 2004 and 2005 [125,121,123]. MEMS and Nanotechnology do not have established base technology processes like semiconductor micro-fabrication nor did they have a unit cell like the transistor to progress. MEMS innovators sought to change the way that people were making products (disruptive), rather than sustaining the current innovation base. MEMS and nanotechnology based innovations were then characterized by the phrase "one product, one fabrication process, one testing procedure, one package" [109] creating complexities that negated the use of first generation roadmapping techniques [127].

These innovations required new roadmap processes and techniques like incorporating drivers to a far greater extent than first generation roadmapping did [70]. New operational techniques were developed such as the use of multiple technology lifecycles (Fig. 2) and the creation of a new roadmapping process (Fig. 3). MEMS innovations generated by emergent disruptive technologies were different and required a different roadmapping technique [124]. 
Figure 2.2 Emergent disruptive technologies versus many traditional options

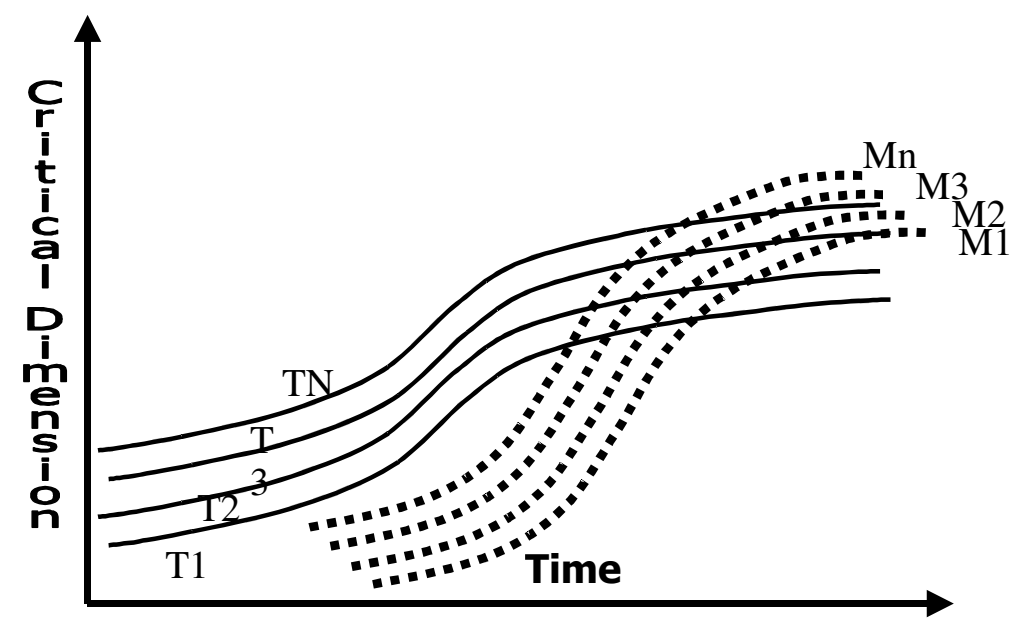

Traditional technologies Tn-T3

MEMS technologies Mn-M3

Figure 2.3: Three phases of disruptive technology roadmaps

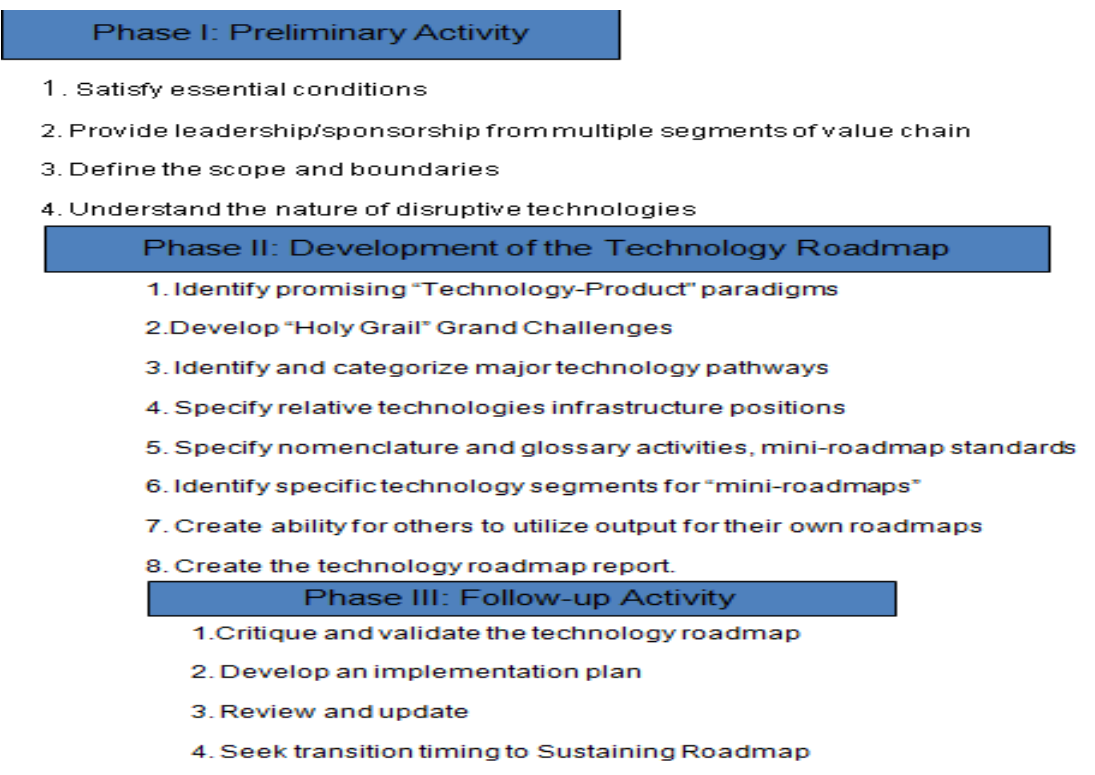

Second generation MEMS roadmaps also highlighted the importance of supportive technologies to fully enable a product or innovation [65]. Yet these innovations were not cogenerated at the interface of multiple technologies [97]. Many times the use of MEMS and a 
more mature complementary technology was required the MEMS based innovation to be systematized.

First generation roadmapping provides us with an overall structure (model) and an ability to generate roadmaps for firms, industries, and or regions seeking to improve economic development. Second generation roadmaps provide us with a method of reviewing technology pathways on more than one critical dimension. They do not, however, provide direct methods to include; multiple root technologies, constraints, drivers and new business models.

\section{Section 2.6. Developing new roadmap processes and components}

A roadmap developed for new pharmaceutical innovations must first mirror the manner in which multiple technologies are used to develop them. Here we discuss the use of both multiple technology lifecycles and Technology Readiness Levels for multiple technology sets and multiple CD progression. Our new roadmapping process must provide a larger role for pharmaceutical drivers and constraints. Moreover we must provide a role for new business models created in response to the knowledge and resource challenges of these innovations. We start by reconsidering innovation and technology development.

\section{Section 2.7. Technology and innovation}

We have argued that when innovations are created at the interface of multiple root technologies, current roadmapping techniques that focus on single technology based innovations are inadequate. To counter this difficulty we searched the technology innovation and progression literature and found two techniques that we have modified for our use. The first is multiple technology lifecycle theory. The second is Technology Readiness Levels (TRL) and Technology Readiness Assessment (TRA). We will discuss the former, but have chosen to modify and use the latter for this industrial focused pharmaceutical roadmap. 


\subsubsection{Using technology lifecycles.}

The technology lifecycle curve serves as the foundation of first and second generation roadmaps. These curves usually follow either a Fisher Pry curve which is a substitution model where a new technology based innovation overcomes an existing product platform [38] or a Gompertz curve which is a product mortality model [41]. Using either model can generate a great deal of specificity for each technology underpinning an innovation. For example, each technology can be examined for multiple critical dimension path progression. This is important for many pharmaceutical innovations since different aspects of a given technology are either important or not for any specific innovation. The use of these curves would mimic the second generation roadmap's use of technology lifecycles (Fig. 2) where the timing of technological transitions can be forecasted [39].

Yet this specificity which is good for a firm based single innovation effort is also a handicap for industrial roadmaps where a large number of innovation platforms are reviewed. For the pharmaceutical industry roadmapping effort a more general review of each technology and its integrated set is required.

\subsubsection{Using Technology Readiness Levels (TRL) theory.}

Technology Readiness Levels (TRLs) are a systematic metric structure that gauges the maturity of a particular technology as applied to an application [75]. TRL can also be used for the comparison of maturity between different types of technology. TRLs originally consisted of nine individual and distinct technology readiness levels but have been modified to include as many as 11 by other users. The authors use the TRL concept to provide a more general technology review. This allows roadmap practitioners to focus on how best a group of technologies can be used to meet the needs of a new innovation. The technique meets the needs of innovations that are born at the interface of multiple technologies.

New pharmaceutical innovations are born not only out of many technologies but also from 
improvement along many different critical dimensions of each of these technologies. The rise of technology utility is difficult to forecast since any given technology progresses non-uniformly along its many different critical dimensions. More often than not an improvement in more than one critical dimension per technology will be required to fully enable a pharmaceutical innovation.

This multiple $\mathrm{CD}$ challenge is then magnified when a new innovation requires multiple technologies to progress along multiple critical dimensions in order to meet the needs of a new innovation. Traditional roadmap efforts cannot be used since they follow a single technology progression against a single critical dimension. TRL based constructs allow practitioners to evaluate the state of readiness of a technology set and follow its progression. Lastly, TRL practitioners benefit from its general ability to embrace many technologies.

The use of TRLs for our pharmaceutical landscape requires a TRL level temporal assessment for each specific root technology as well as the complete set of technologies. Here we analyze the readiness levels of a set of five root technologies for the future development of pharmaceutical innovations. We will identify and define the five major root technologies key to many future pharmaceutical innovations. They are; chemistry, biology, MEMS, computational sciences, and nanotechnology.

We identified a given technology's TRL level through the administration of a simplified semi-structured Technology Readiness Assessment (TRA) questionnaire [114]. We provided each respondent with a brief discussion and definition of the TRL technique prior to the administration of the questionnaire. We used the traditional TRL scale of 1 through 9 for the pharmaceutical landscape. The TRL scale ranges from level 1 (the most commercially immature) through level 9 (fully commercially developed). We developed our questionnaire by reviewing many of the current TRA level questions. We then simplified this set to one yes or no question per TRL level for ease of response.

We presented the questionnaire to a pilot group of professionals involved in creating 
pharmaceutical innovations (technologists, researchers, and commercialization professionals). The respondents were asked to rate the TRL levels of each of our 5 defined technology bases as well as the set as a whole. The respondents were interviewed either in person or through a phone interview. We asked each respondent to answer the questions for each of three time periods, We asked the respondents to answer 'yes' or 'no' for each technology base initiating at level 1 and progressing in order to level 9, beginning with the current state of technology for pharmaceutical innovations. The respondents were told to stop at the level where they responded "no" to a question. We then asked the respondent to state if the level that they previously stated "no" to for the current TRL would most likely be answered affirmatively as the technology progressed over the next 5 years. Again we asked the respondent to answer 'yes' or 'no' to subsequent level questions for what they perceived to be the state of that technology in 5 years. When the respondent answered negatively we asked them to stop. We then asked the respondent to state if the level that they previously stated "no" too at the projected 5 year technology state could be answered affirmatively in 15 years. If the answer was affirmative they were then to proceed sequentially through the level questions until an answer was negative. The last level to be answered in the affirmative for each of the three time periods was then stated to be the TRL level that the specific technology had achieved at that time for the pharmaceutical industry.

We used the questionnaire to define the perceived technology readiness level of each individual technology as well as the integration of these technologies as a set. We defined what was meant by each technology. We defined the term "many applications" for the questionnaire to mean for at least 5 different technology product platforms. Moreover, we further defined some questions in the questionnaire itself. We provide the generic questions we used in Fig. 4 below. An individual firm or organization could use a much longer and more detailed questionnaire emphasizing specific technologies important to that entity. 


\section{Section 2.8 The Role of Drivers}

Many roadmapping experts recognize the potential for the use of drivers in a roadmapping process. Albright discusses roadmap drivers such as regulation, individual cultures and market drivers [4]. Shinn [103] discussed the role of lead users in the road mapping process. Coates discussed the use of multiple technologies [29]. Hernández-Ortega discussed the potential of supply chain members' ability to accept a new technology as a driver [51]. Yet most drivers operationalized in previous roadmap generations are incorporated as market drivers [30].

Some roadmapping efforts place political drivers in the market driver segment. Political driven regulation can either create instant demand for a technology based product [116] or hinder its progress (precautionary principle [105,112]). Finally, many government agencies are leveraging their economies to solve significant world problems [133,135]. Yet neither market drivers nor government policy directives encompass all the drivers in the pharmaceutical innovation development process. Here we expand the role for drivers through both secondary and primary data exploration. We place drivers in the pharmaceutical landscape as the top strata of our model.

\subsubsection{The role of consortia}

The financial, legal and knowledge resource requirements for new pharmaceutical innovations are forcing the creation of new business models particularly consortia [8]. These consortia often focus on specific subsets of the larger pharmaceutical innovation portfolio. They are often formed by firms responding to drivers and many times at their conception do not even have a full technology product pathway developed. One example is Biomarker Consortium. The Biomarker Consortium brings together the expertise and resources of various partners to rapidly identify, develop, and qualify potential high-impact biomarkers. The Biomarker Consortium is a major publicprivate biomedical research partnership. 
In the new pharmaceutical innovation landscape these consortia in many ways act as products do in the traditional road mapping process. We operationalize them in this third generation roadmapping process much as the ITRS roadmap utilizes the semiconductor based memory devices, power devices, micro processors and microcontroller products. They form the second strata in the roadmapping process. We performed secondary and primary research identifying many of these existing pharmaceutical consortia.

\section{Figure 2.4}

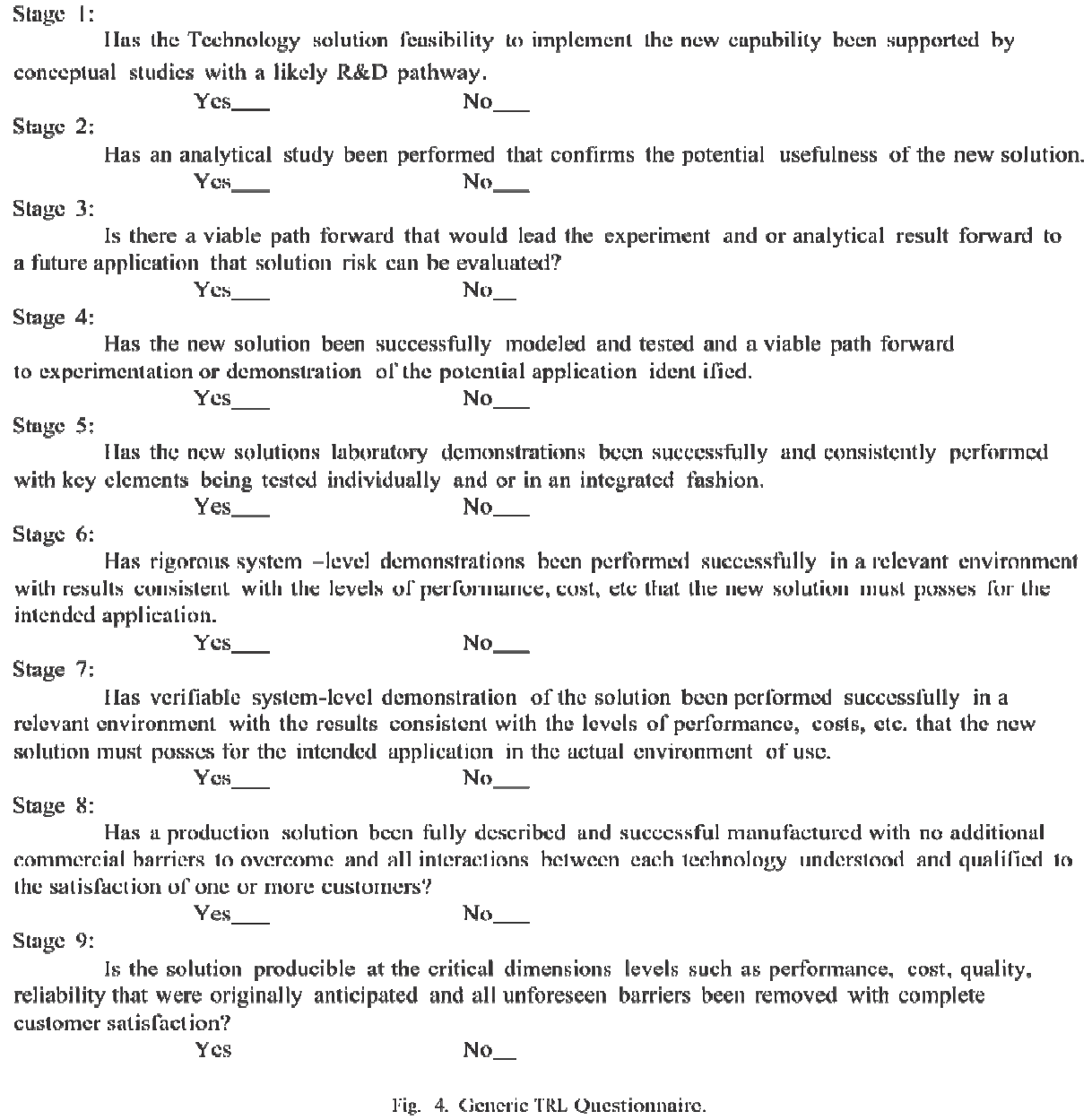

\subsubsection{The role of components}

New pharmaceutical innovations are often built upon multiple components. Components

form the third strata in our roadmap process and are used similarly to the way components are used by practitioners of earlier roadmap techniques. There exists no unit cell component for the 
pharmaceutical industry that mirrors the transistor in the ITRS roadmap. In our case one or more of our technology bases are used together presenting a number of components.

We operationalize the component strata by showing the interactions between technologies that are needed to develop them. One example is the use of nanotechnology, chemistry and biology to develop specific medical carriers. We develop the component layer through primary and secondary research. We now illustrate our process through a case study of pharmaceutical industry innovations.

\section{Section 2.9 Methods}

We employed a case study analysis methodology to generate a technology landscape process for innovations in the pharmaceuticals industry. We utilized [136], Eisenhardt's [35] and Eisenhardt and Graebner's [36] case study techniques to develop our new multistrata roadmap technique. We initiate our case study by generating a list of pharmaceutical drivers gathered from a number of pharmaceutical commercialization professionals, technologists, government policy makers, academics, lawyers and entrepreneurs using a structured survey technique [142]. We only used drivers generated from primary research that were subsequently validated through secondary research. We provide a list of the drivers in Table 1 below. We initiate the case study with a brief description of the changes in the pharmaceutical arena.

\subsubsection{Drivers in the changing pharmaceutical innovation arena}

Drug discovery and diagnostic innovations have traditionally been dominated by large, multinational pharmaceutical firms. Traditionally the therapeutic innovations these firms produced were based on a single chemical monomer technology. Similarly, diagnostics were designed around a single technology. Traditionally diagnostics were distinct from therapeutics and designed to be used by central medical laboratories either in a hospital or a facility that serviced many hospitals. The way these innovations are being currently developed in the 
therapeutic and diagnostic markets is radically changing $[67,68]$.

Now many organizations are involved in pharmaceutical drug discovery, diagnostics and innovation. Therapeutics is now more directly linked to diagnostics. The innovation process is, more often than not, based on an expanded set of converging technologies including biology, computational sciences, nanotechnology, MEMS and chemistry as we will discuss below.

Further, new intellectual property laws, especially in the United States, are severely stressing the traditional pharmaceutical Intellectual Property (IP) paradigms. These paradigms were the bases of large pharmaceutical company's competitive advantage. Until recently, large pharmaceutical firms based therapeutic innovations on their internal chemical technical competence and government sponsored research at universities which the large firms could use since universities and other government sponsored research firms did not have a legally protected right of ownership.

The single chemical monomer based pharmaceutical product has become increasingly challenged. The changing technology base for pharmaceutical innovations first incorporated biology based innovations like those found at Genentech [43]. Other technologies then became important to the pharmaceutical process. MEMS technologies, for example, became the technology underpinning for important "point of care" innovations such as those developed by iSTAT diagnostic products, now part of Abbott Lab. Next, computational sciences provided a new foundation for custom drug discovery innovations, most famously demonstrated through the Human Genome Project [52], and this again altered the way in which pharmaceutical innovations were generated. Finally, new nanotechnology innovations such as those used to clean the blood [77] and medical carriers were developed.

Non technology activities such as the Bayh-Dole Act [46] are returning more intellectual property (IP) rights to researchers and specifically, academic researchers. The less than clear distinction between discovery and invention in the patenting process [6] is further stressing the 
traditional pharmaceutical IP process. Now many public sector technology generators are patenting their research to obtain ownership rights [19]. It is not only the multiple technology platforms that are acting as pharmaceutical innovation drivers, but also legal ones as well. Next we discuss how to generate the pharmaceutical drivers. We then place them in the model.

\subsubsection{The role of drivers in the Technological Landscape process}

We initiate our pharmaceutical landscape effort through a discussion of pharmaceutical industry drivers. An overall driver for all twenty first century innovations and especially pharmaceutical ones is the precautionary principal constraint. The more specific pharmaceutical drivers are provided below. We have found a number of specific drivers through structured survey [40] of professionals in this arena. We narrowed this field to fifteen (15) by requiring support from secondary research [136]. These drivers are a force behind the advance of converging technology innovation found in the healthcare landscape [143]. We provide them below in Table 2.1 and discuss them subsequently.

Table 2.1 Pharmaceutical landscape drivers.

\begin{tabular}{|c|c|c|}
\hline $\begin{array}{c}\text { Treating the Human System is moving } \\
\text { to treatment at the Molecular Level }\end{array}$ & $\begin{array}{c}\text { Crisis Intervention to Prevention } \\
\text { /Non invasive Innovations } \\
\text { Development of Therapeutics not } \\
\text { Cures }\end{array}$ & $\begin{array}{c}\text { Chemical based Pharmaceuticals } \\
\text { to Biological Based ones }\end{array}$ \\
\hline Pharmaceutical Differentiation & Personalized Care & Patient Directed Care \\
\hline Changes in Intellectual Property & Detection not Enough & Remote Care \\
\hline Aging Population & Increasing Population & Cost of Drug Development \\
\hline
\end{tabular}

\subsubsection{The global population is aging}

Aging populations require more and cheaper medical therapies and diagnostics for improved longevity and quality of life ([92], [24]). The world's population is living longer especially in 
developed countries and medical expenses are expected to dramatically increase [62]. The more developed countries, as defined by the United Nations, have an overall median population age which rose from 29.0 years in 1950 to 37.3 years in 2000 , and is forecast to rise to 45.5 years by 2050 [133]. The aging population is a function of both increased longevity and the decreasing birth rates in developed countries. Some suggest that this large increase in longevity is driving healthcare demand $[118,144]$.

\subsubsection{Treating the human system is moving to treating the disease at the molecular level}

Traditionally the treatment of a disease is not confined to the treatment of the affected cells

but rather the pharmaceutical treatment affects the entire patient's well being. Treatment in this manner can affect healthy organs and cells as much as it affects diseased ones. Pharmaceutical innovations are shifting this treatment practice to treatment at the cellular level $[48,119]$. This treatment method is far more selective and is designed to focus on and eliminate only diseased cells. The therapeutics developed at the interface of multiple technologies creates this ability.

Today cancer is treated mainly by traditional approaches such as; chemotherapy, radiation therapy and surgery. All of these treatment modes affect the whole body. Zevalin [138] and other therapeutics are being developed to change the nature of cancer therapeutics. Specifically, Zevalin targets and eradicates CD20 antigens in B-Cell lymphomas or diseased cells preferentially to normal cells [138]. This and other projects using a subset of the pharmaceutical convergent technology set are creating "Silver Bullets" designed to seek out and eliminate only diseased cells [111]. Whether this is accomplished by scaffolding or the preferential combination of the therapies to diseased cells, the convergence of biotechnology, chemistry, nanotechnology, computational science and MEMS are making their mark. 


\subsubsection{Chemical to biologically based pharmaceutical products}

Historically, pharmaceuticals have been based on monomer chemistry. Specifically, the chemical paradigm for drug discovery and development focuses on using chemistries to equilibrate the human system [33]. One of the first commercial biology based pharmaceutical innovations was developed from whey extract by Genentech [43]. The pharmaceutical industry is now moving rapidly from chemical monomer based products to more biological and large molecule chemistry based ones [57].

Innovations based on large molecular-weight chemistries hold promise in inflammation and cancer treatments [87]. Large pharmaceutical firms are rich in chemical competencies, but are limited in many of the other technology competency bases required by today's diagnostic and therapeutic innovations. These new innovations require broad based capabilities in biology, chemistry, MEMS and nanotechnology.

\subsubsection{Central lab diagnostics to "Point of Care" diagnostics}

Traditional patient diagnostics are divorced from therapeutics and require the use of a central laboratory which is costly and time inefficient. The diagnostic process often takes days or even weeks to complete and many times either due to patient or doctor error the test results are never even communicated. One study focusing on HIV testing showed that the patient return rate is less than $35 \%$ [23], and a patient must return in order to obtain the results of their tests. Another study shows that test result delays causes doctors not to relay the information to their patients (17 to $32 \%$ of the time) when the results were abnormal [21].

The new set of convergent technologies develops innovations that produce near immediate results [18]. Now medical personnel can get the same information in an immediate manner with "Point of Care" tests. "Point of Care" devices are used by medical practitioners to take patient samples and provide the patient results during their initial visit [107]. Near real time testing 
provides immediacy and convenience for patients and the medical professionals alike. Diagnostic innovation development is moving more and more to "Point of Care" efforts either through development or purchase [79]. Examples of this trend includes: [1] and Dolomite's microfluidic systems that enhance "Point of Care" diagnostics [49].

\subsubsection{Funding lifetime therapeutics rather than cures}

Pharmaceutical firms are simply not funding research focused on medical cures. They are funding drug discovery focused on a lifetime user. Whether this is due to the difficulty and expense of finding cures [84] or the attraction of a population base of lifetime users to defray the costs of drug development [28], many of today's largest successful drug development projects are focused on a lifetime therapeutic value for their customers [81]. Rogaine and Viagra are examples of lifetime therapeutics. One was planned and the other more serendipitously discovered, however both provide value to their users. These new therapeutics are leveraging the new convergent pharmaceutical technology set.

\subsubsection{Doctor to patient directed care}

A movement within the medical community toward patient directed care is occurring [16]. Inexpensive and easy patient directed monitoring is required. Patient-centered practice improves health status and increases the efficiency of care by reducing diagnostic tests and referrals [113]. Regardless of the patient's age, constant monitoring is often required [71]. Patients requiring therapies like blood thinners are driving computational science based monitoring products for patient directed care on their own. Monitoring cost is reduced and the patients are empowered. Innovations such as these leverage the new medical convergent technology set especially biologics, computational sciences and MEMS. 


\subsubsection{Direct customer interaction}

Institutional regulations that have been in place for decades are being removed and competitive pressures on various levels are forcing pharmaceutical companies to adopt customeroriented strategies [5]. Many in the pharmaceutical industry are seeking to obtain some form of patient direct interaction with pharmaceutical firms [72]. Today, pharmaceutical firms receive the vast majority of information concerning patients using their therapeutics through filters like HMOs which minimize information flow. Some firms are already taking action. AsuteSolutions, for example, now maintains 24/7/365 sales channels for customers in the pharmaceutical field to close this open information loop [13]. Wireless and computer monitoring interaction are now allowing patient monitoring. Initial examples like Nike's Fuel band [85] (http://store.nike.com) are being developed using computational science and MEMS to create an opportunity for firms to directly interact.

\subsubsection{Personalized care}

The idea of personalized therapeutic care can be expressed as the movement from "One size fits all to one size fits one" [17]. This idea is not new and patient therapeutic dosing has been based on age, gender, bodyweight and the like for years. This concept now encompasses a much larger computational component. The Human Genome project [55] gave rise to the idea of preventative medicine customized based on genetic proclivities [50].

Designing therapeutics and understanding personalized risk for disease are logical extensions of the Human Genome project. Many [20] are utilizing individual genome mapping to develop individualized healthcare plans. The United State Department of Health sees this as the next revolution in health care, affecting everyone in the coming years [117]. The development of improved diagnosis, and treatment based on personalized care and tailored therapies are being actively investigated [74]. 


\subsubsection{Pharmaceutical differentiation}

The promise of computational benefits from efforts like the Human Genome project can assist not only patients but pharmaceutical therapeutic providers as well. The cost of new drug development has risen significantly [3]. Even therapeutics which endure the many hurdles in development and pass FDA certification often have extremely negative side effects on a small segment of the population [63]. Here if pharmaceutical firms can isolate the affected groups by genetic segmentation through computational means they can reduce the risk of a drug failure and recall while continuing to provide value to a large number of patients. Pharmaceutical risk is then limited and therapeutics useful for the vast majority of patients become efficacious [81].

\subsubsection{Crisis intervention to prevention/non invasive innovations}

The "Wellness" approach to medical treatment is becoming more accepted [139]. The increasing demand for healthy food and additives are moving the food and nutraceutical industry toward the inclusion of bio active agents and nanotechnology [54]. Nutraceuticals are becoming more accepted with up to $62 \%$ of the U.S. population now using some form of nutraceutical based product [86]. The manufacture of nutraceuticals, food additives and other supplements using large molecule chemistry, biology and nanotechnology is increasingly demanded by the public [129].

The movement from invasive to minimally invasive or to noninvasive therapies and diagnostics also is changing the pharmaceutical industry. The pharmaceutical industry is progressing toward convergent technology based non-invasive and minimally invasive diagnostic innovations [108] for patients suffering from diseases like diabetes. ALZA is perhaps the first company to modify therapeutics on the basis of minimally invasive products. They created buffered products for common aspirin and time released drugs through encapsulation technologies 
[137].

\subsubsection{Detection is not enough}

The medical industry has traditionally separated detection or test from therapeutics. Companies like Abbott labs have concentrated on detection, while others like Johnson and Johnson have focused on therapeutics. This traditional market segmentation is being challenged by the idea that detection is not enough. The pharmaceutical industry is moving to detection through therapeutics doctrine $[17,110]$. Ethical questions about the ability to diagnose without the ability to treat effectively and improve quality of life for those affected continue [104]. The MANCEF COMS (2006) medical panel turned into a heated discussion of more than 200 professionals on the subject.

\subsubsection{Movement to remote care}

Remote care is needed when trained medical personnel are not available. This often occurs: in sparsely populated areas where there is a dearth of medical personnel; when a soldier needs medical attention on a remote battlefield; or when an interdiction team is in harm's way. The promise of MEMS and nanotechnology based "Just in Time" and "Point of Care" diagnostics and MEMS based RF communication [128] gives hope to this alternative [18].

Further, remote care trends such as the increasing use of portable defibrillators with on board computer guidance have proven to be highly effective in resuscitating individuals [96]. Virtual military medicine [102] has demonstrated its military effectiveness. One such example of this change in focus is the United States Defense Advanced Research Project Agency (DARPA) funding of the Advanced BioMedical Technology Program [94]. 


\subsubsection{Increasing population}

The increasing population exacerbates all of the 5 major problems facing the twenty first century world including healthcare [24]. Today the average life expectancy is going up and the number of people living on the planet could reach 10 billion by the end of the century $[133,134]$. Increasing population is a driver for low cost medical care.

The differential in quality of life between the most economically advantaged countries and the poorest has never been larger [95]. The "Have Not" nations could simply view themselves as having less to lose. Historically, when this condition exists world unrest follows. Less costly, more effective diagnostics through therapeutics must be generated. The use innovations produced at the interface of the convergent pharmaceutical base gives potential to low cost and energy efficient products that are required [99].

\subsubsection{High cost of drug development}

The high cost of drug development when coupled with the risk of failure in any stage of the US FDA or EU approval processes can stress any firm's financial resources. A firm can lose hundreds of millions of dollars during the drug discovery and commercialization process if a drug does not progress as expected. The high cost of drug development ( $\$ 802$ million by some estimates) [3], and key trends like IP change and ever widening competencies required for leading edge innovations [32] are only increasing these risks and costs. Few firms can afford to singularly develop pharmaceutical innovations. Traditional pharmaceutical therapeutic developers are creating new business models like consortia to diffuse this risk as well as to obtain the competencies required to develop innovations (Hurley, 2008).

\subsubsection{Shifts in intellectual property rights}

The dominant form of Intellectual Property (IP) protection strategy for entities in the 
pharmaceutical industry is patents. Yet there have been huge changes in this area. The first came with the United States based Bayh Dole Act of 1988. This act provided research institutions ownership of IP as a result of federally funded research [46]. U.S. universities, small businesses and non- profits were given control of the intellectual property they generated. Further the United States has recently joined many nations in providing the rights of an invention to the researcher that is first to file rather than the traditional Unites States stance that the rights went to those that were first to invent $[73,88]$. Finally, the line between discovery and invention especially in molecular biology and nanotechnology has blurred. Patent rights provided to innovations which are provided closer to discovery have exceptional implications on "Downstream" therapeutic and diagnostic development [6].

These drivers are disrupting or radically altering the pharmaceutical industry. It has given rise to a new business model based on: competency building, patient needs, the changing intellectual property landscape, funding requirements and risk. We next discuss the utilization of consortia as a business model in the industry.

\section{Section 2.10. Consortia and target products}

New pharmaceutical innovations do not benefit from a small number of targeted final product categories that are characteristic of many first generation roadmapping efforts. Rather the new set of pharmaceutical drivers has created a plethora of new potential pharmaceutical innovations. The problem that we address here is a way to provide focus.

We utilized the consortia pharmaceutical business model to provide more focus to the industrial landscape process without moving to a single product which is the realm of firm based roadmap efforts. Different consortia, due to their growing use and specificity, focus on differing therapies, diagnostics and or knowledge on specific innovation areas. These innovation areas are used as innovation platforms in the pharmaceutical landscape. These consortia consist of firms, research entities and others that share the business risk as well as their competencies in search of 
a competitive advantage in a specific pharmaceutical innovation space. We have identified a number of these and use them as platforms for the second strata of our roadmap.

Consortia are often formed in a very early phase where a singular innovation platform has not been determined. There are usually many pathways that can be used to develop a desired therapy or diagnostic and many times these consortia embrace more than one. A specific consortium could then either choose a technology and component mix that they feel is closest to their product maturity needs or ones that they feel they can accelerate faster than experts predict.

Consortia have another trait that assists our landscaping effort — they are stable over time. Like the four semiconductor products in ITRS roadmaps, they span the time discussed in our landscape. We specifically use the following consortia: Biomarker, MalariaGEN, Zink Finger, International consortium for cardiac tissue engineering, Autism, and the European consortium for tissue engineering as the third strata in our pharmaceutical landscape.

\section{Section 2.11. The role of components in the pharmaceutical landscape}

The third stratum from the top of our technology landscape is comprised of components. Components are often the simplest segment of a roadmap to identify. However, pharmaceutical innovations are often comprised of more than one component. Further, pharmaceutical innovation technologies are stressed along more than one critical dimension. Pharmaceutical components are a critical element of a larger pharmaceutical innovation.

These components are often developed from a subset of the available pharmaceutical technology set. We performed a literature search on our example consortia to derive the pharmaceutical components list for our pharmaceutical roadmap. This resulted in many pharmaceutical components generated from differing technology subsets. Pharmaceutical components based on MEMS, chemistry and biology included: MEMS sensors; RF MEMS; microarrays, chemical monomers and others. Pharmaceutical components based more on nanotechnology and computational sciences included: cardiac tissue engineering, genomic 
mapping and synthetic vaccine development. We provide a subset of these for illustration in the pilot Pharmaceutical Landscape.

\section{Section 2.12 The technology base}

The new technologies used in pharmaceutical innovation development are disruptive in nature $[64,65]$. This has created great interest in the sector by firms and economic development professionals who are not currently involved in the pharmaceutical sector since they believe they can leapfrog existing and formerly essential infrastructure. New pharmaceutical innovations are based on new technologies $[69,132]$ which are pan-industrial in nature [145]. New regions and firms can now invest at a more even basis with established firms and regions to obtain a competitive advantage and regional economic growth $[2,61]$. Whether a firm is established or new to the industry understanding the progress of the new pharmaceutical technology set is essential.

We analyzed the pharmaceutical technology set progression through the use of a TRL based semi-structured questionnaire. We requested 20 professionals involved in the pharmaceutical commercial process to act as a pilot group. Our full questionnaire response rate was $70 \%$ or 14 respondents.

We analyzed the respondents by totaling all respondents TRL ratings for each technology category (Chemistry, Biology, MEMS, Nanotechnology, Computational Science) as well as the set as a whole for each of our three projected times. We analyzed the technology set as a whole using 2 methods. The first method we used was to take a simple average of all the raw scores. The second method we used was to take all the 14 individual respondents stated set scores averaging those. We found that the differences in set averages were negligible. We provide the descriptive statistics for our technologies in 2010, 2015 and 2025 below.

We initiate our analysis on technology progression with three tables providing TRL information on our 2010 technology set. The authors provide the average individual technology 
TRL scores as well as maximum and minimum respondent TRL scores in Table 2.2 a. We next provide the two methods for providing technology set as a whole values in Table $2.2 \mathrm{~b}$. We utilize the raw score average value in our Technology Landscape or 5.67. Finally we provide the standard deviation, median and mode in Table $2.2 \mathrm{c}$.

We continued our analysis of technology progression with three tables providing TRL information on our 2015 pharmaceutical innovation technology set. The authors provide the average individual technology TRL scores as well as maximum and minimum respondent TRL scores in Table $2.3 \mathrm{a}$. We next provide the two methods for providing technology set as whole values in Table $2.3 \mathrm{~b}$. We utilize the raw score average value in our Technology Landscape of 6.61. The standard deviation, median and mode are provided in Table $2.3 \mathrm{c}$.

We finalize our analysis of technology progression with three tables providing TRL information on our 2025 pharmaceutical innovation technology set. The authors provide the average individual technology TRL scores as well as maximum and minimum respondent TRL scores in Table 2.4 a. We next provide the two methods for providing technology set as a whole values in Table $2.4 \mathrm{~b}$. The standard deviation, median and mode are provided in Table $2.4 \mathrm{c}$.

Table 2.2.a Individual technology ratings 2010

\begin{tabular}{|c|c|c|c|}
\hline Subject & Average TRL & Minimum & Maximum \\
\hline Chemistry & $\mathbf{6 . 4 2 8 5}$ & TRL 4 & TRL 9 \\
\hline Biology & 5.2857 & TRL 4 & TRL 6 \\
\hline Comp. Science & 5.7857 & TRL 4 & TRL 9 \\
\hline MEMS & $\mathbf{6 . 1 4 2 8}$ & TRL 4 & TRL 9 \\
\hline Nanotechnology & $\mathbf{4 . 7 1 4 2}$ & TRL 3 & TRL 6 \\
\hline
\end{tabular}

Table 2.2.b TRL set average score 2010

\begin{tabular}{|c|c|}
\hline Type & Average \\
\hline Raw average method & 5.67142 \\
\hline Set average method & 5.285714 \\
\hline
\end{tabular}


Table 2.2.c Individual technology Standard Deviation, Median and Mode 2010

\begin{tabular}{|c|c|c|c|c|c|}
\hline & Chemistry & Biology & Comp Science & MEMS & Nanotechnology \\
\hline Median & 7 & 5 & 6 & 6 & 5 \\
\hline Mode (Single) & 7 & 5 & 6 & 6 & 5 \\
\hline STD Dev & $\mathbf{1 . 8 7 8 9 9}$ & $\mathbf{0 . 6 9 9 8 5}$ & $\mathbf{6} 97209$ & $\mathbf{1 . 3 5 5 2}$ & $\mathbf{0 . 7 9 5 3 9}$ \\
\hline
\end{tabular}

Table 2.3.a Individual Technology ratings 2015

\begin{tabular}{|c|c|c|c|}
\hline Group & Average TRL & Minimum & Maximum \\
\hline Chemistry & $\mathbf{7 . 6 4 2 8 5}$ & TRL5 & TRL 9 \\
\hline Biology & 6.50000 & TRL 5 & TRL 8 \\
\hline Comp. Science & 6.57149 & TRL 5 & TRL 9 \\
\hline MEMS & 6.35714 & TRL 4 & TRL 8 \\
\hline Nanotechnology & $\mathbf{0 . 5 7 1 4 2}$ & TRL 3 & TRL 8 \\
\hline
\end{tabular}

Table 2.3.b TRL Set average score 2015

\begin{tabular}{|c|c|}
\hline Type & Average \\
\hline Raw average method & 6.61428 \\
\hline Set average method & 6.57142 \\
\hline
\end{tabular}

2.3.c Standard Deviation, Median and Mode 2015 by Group

\begin{tabular}{|c|c|c|c|c|c|}
\hline & Chemistry & Biology & Comp Science & MEMS & Nanotechnology \\
\hline Median & 8 & 8 & 6.5 & 6 & 6 \\
\hline $\begin{array}{c}\text { Mode } \\
\text { (Single) }\end{array}$ & 8 & 7 & 7 & 6 & 5 \\
\hline STD Dev & $\mathbf{1 . 1 7 1 5 1}$ & $\mathbf{0 . 9 0 6 3 2}$ & 1.17803 & 1.34202 & 1.13389 \\
\hline
\end{tabular}

We utilize the raw score average value in our Technology Landscape or 7.4571. Finally in Table 4.c we provide each technology's standard deviation, median and mode.

The pilot use of TRL levels proved to be a good surrogate for the technology lifecycle curve in our case. The result is the progression in maturity of each technology set over time. We provided the standard deviation and other descriptive statistics to analyze the specificity of the technique over time. The pilot study illustrated the potential to use TRL levels to analyze the progression of sets of technologies over time. Our analysis developed set technology levels of 5.67, 6.61, and 7.46 rounded to the second decimal for 2010, 2015 and 2025 respectively.

Table 2.4.a Individual technology ratings 2025

\begin{tabular}{|c|c|c|c|}
\hline Group & Average TRL & Minimum & Maximum \\
\hline Chemistry & $\mathbf{8 . 3 5 7 1 4}$ & TRL 6 & TRL 9 \\
\hline Biology & 7.42857 & TRL 6 & TRL 9 \\
\hline Comp. Science & 7.35714 & TRL 6 & TRL 9 \\
\hline MEMS & 7.28571 & TRL 6 & TRL 9 \\
\hline Nanotechnology & $\mathbf{6 . 8 5 7 1 4}$ & TRL 4 & TRL 9 \\
\hline
\end{tabular}


Table 2.4.b TRL Set average score 2025

\begin{tabular}{|c|c|}
\hline Type & Average \\
\hline Raw average method & $\mathbf{7 . 4 5 7 1}$ \\
\hline Set average method & $\mathbf{7 . 4 2 8 5 7}$ \\
\hline
\end{tabular}

2.4.c Standard Deviation, Median and Mode 2025 by Group

\begin{tabular}{|c|c|c|c|c|c|}
\hline & Chemistry & Biology & Comp Science & MEMS & $\begin{array}{c}\text { Nanotechnolo } \\
\text { gy }\end{array}$ \\
\hline Median & 9 & 8 & 7 & 7.5 & 7 \\
\hline $\begin{array}{c}\text { Mode } \\
\text { (Single) }\end{array}$ & 9 & 8 & 7 & 9 & 7 \\
\hline STD Dev & $\mathbf{0 . 8 9 4 9 9}$ & $\mathbf{0 . 9 0 3 5 0}$ & 1.17151 & 1.29559 & 1.18666 \\
\hline
\end{tabular}

\section{Section 2.13. The Pharmaceutical Landscape model}

We provide our Pharmaceutical Landscape model based on data generated in our case study as presented in Fig. 3. The $\mathrm{X}$ axis of our landscape is a time line. We have chosen the times of 2010, 2015, and 2025 as important dates to understand the maturity of each technology as well as the technology set as a whole for the pharmaceutical industry. We then develop the model's strata from the pharmaceutical case study developed in Section 3. The roadmapping technique is the first developed around the nature of innovations made at the interface of multiple technologies. We provide the elements and the placement of the constituents in our technology landscape below in Sections 4.1 through 4.4. The model itself is found in Section 4.5.

\subsection{1.} Technology

We used modified TRL tactics to develop the technology baseline of our model. We analyzed the defined five technologies set as an innovation paradigm over time using a semi structured questionnaire. The results are the base strata for our Pharmaceutical Landscape found in Fig. 5.

\subsubsection{Drivers}

Pharmaceutical innovations are bound by the precautionary principle which is a constraint as 
well as a driver. We also provide a list of the 15 specific pharmaceutical landscape drivers we developed from primary data and supported with secondary data. A list of these drivers can be found in Table 1 above. These drivers are constant over time and form the top strata of our pharmaceutical landscape seen in Fig. 3.

\subsubsection{Consortia}

Consortia play a unique role in the Pharmaceutical Landscape model. Consortia are groupings of firms with competency and financial resources focusing on a subset of potential pharmaceutical innovations which many in the industry see as important product platforms. Consortia form the second strata from the top of the pharmaceutical landscape and are found just below the drivers' stratum. We provide many examples of consortia here from a fuller list of consortia, see [6].

\subsubsection{Components}

Many of today's pharmaceutical innovations consist of multiple components. Each component is generated from subsets of the five technologies which form the basis of pharmaceutical innovations defined in our effort. We provide an example of these industry wide components in our pharmaceutical landscape model and form the 3rd strata in Fig. 3 below.

\subsubsection{The Pharmaceutical Landscape}

We present the Pharmaceutical Landscape model in Fig.2. 5 below. The authors, through this model, provide a role for the drivers of innovation in the industry. The authors provide a new method to analyze technology progression over time for innovations generated by multiple technologies. We use consortia to provide important industry innovation focus. These innovations are born of market, technology, government policy and environmental drivers. The Pharmaceutical Landscape is a technique which accommodates the dynamic changes within the technology set of this radically 
changing industry.

Figure 2.5: The Pharmaceutical Landscape

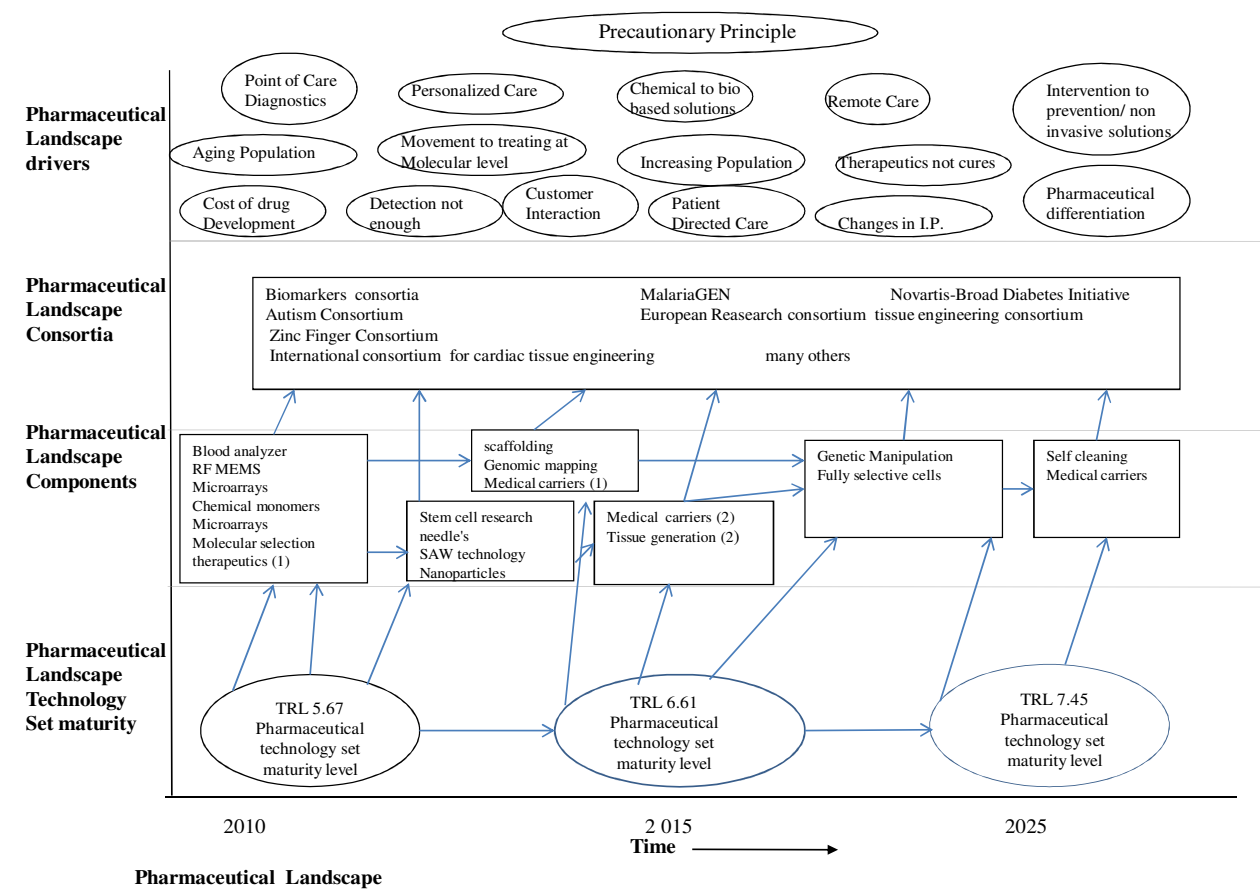

\section{Section 2.14. Discussion and future research}

The pharmaceutical landscape is a radical departure from first and second generation roadmap techniques. Our pilot study shows that this technique holds promise to provide superior value to the strategic process of firms, industries and regions seeking to profit from innovations born of more than one technology. Moreover, the knowledge of the relative maturity levels of each of the technology bases and future projections allow for project selection that meets the risk profile of the firms involved. A need to investigate how to fund embracing this field is needed. Option theory particularly the max min theory needs to be investigated.

Further effort is required on how to use TRL and TRA techniques to analyze subsets of the five technologies on which the pharmaceutical technology is based. This technique may also use roadmapping for a single technology which must meet multiple critical dimension demands for a given innovation. A more empirical evaluation is now needed. The authors are progressing on a fuller 
exploration of the pharmaceutical industry with an industry association.

Finally a number of interesting interactions were uncovered in our effort, we will present three here. The first concerns lifestyle drugs like Viagra and Rogaine which may benefit from patient predispositions; however, more study is needed in this area. Another is religious and ethical issues around tissue engineering. Again more research is required in this area to make valid conclusions. Finally we uncover a number of issues centered on the use or avoidance by some countries of the precautionary principal. Does the use of the precautionary principle in policy limit innovation or help produce an ethical innovation pathway? 


\section{Section 2.15 References}

[1]Abbott,http://www.abbott.com/global/url/content/en_US/10.20:20/general_content/General_Conte nt_00007. htm. 200612/9/2010.

[2] W.J. Abernathy, J.M. Utterback, Patterns of industrial innovation, Technol. Rev. 50 (7) (1978) 40-47.

[3] C.P. Adams, V.V. Branter, Estimating the cost of new drug development: is it really $\$ 802$ million? Health Aff. 25 (2) (2006) 420-428.

[4] R. Albright, How to use roadmapping for global platform products, http://www.technologyforge.net/enma/6020/6020Lectures/TechnologyRoadmapping/ ENMA291TRReferences/RoadmappingAlbright.pdf. 200212/8/2011.

[5] R. Alt, H. Oestele, T. Puschmann, V. Barak, T. Huber, Customer relationship management architecture in the pharma industry, Int. J. Health Technol. Manage. 5 (3) (2003) 296-314.

[6] M. Allarakhia, S. Walsh, Managing knowledge assets under conditions of radical change: the case of the pharmaceutical industry, Technovation 31 (105) (2011) 105-117.

[7] M. Allarakhia, S.T. Walsh, Analyzing and organizing nanotechnology developments: Application of the institutional analysis development framework to nanotechnology consortia, Technovation 32 (3-4) (2012) 216-226.

[8] M. Allarahia, A. Wensley, Systems biology: a disruptive biopharmaceutical research paradigm, Technol. Forecast. Soc. 74 (9) (2007) 1643-1660. [9] F. Allhoff, The coming era of nanomedicine, Am. J. Bioeth. 9 (10) (2009) 3-11.

[9] F. Allhoff, The coming era of nanomedicine, Am. J. Bioeth. 9 (10) (2009) 3-11.

[10] M. Amer, T.U. Daim, Application of energy roadmaps for renewable energy sector, Technol. Forecast. Soc. 77 (8) (2010) 1355-1370.

[11] W.M. Arden, The international technology roadmap for semiconductors-perspectives and challenges for the next 15 years, Curr. Opin. Solid State Mater. Sci. 6 (5) (2002) 371-377.

[12] N.A. Ashford, Incorporating science, technology, fairness, and accountability in environmental, health, and safety decisions, Hum. Ecol. Risk Assess. 11 (1) (2005) 85-96.

[13] AsuteSolutions, Solutions for the pharmaceutical industry, http://www.astutesolutions.com/industries-pharmaceuticals.php. 201012/09/2011.

[14] W.S. Bainbridge, M. Roco, Managing Nano-Bio-Info-Cogno Innovations, 1st ed. Springer, Netherlands, 2006.

[15] R. Baker, D.J.H. Smith, Technology foresight using roadmaps, Long Range Plann. 28 (2) (1995) 21-28.

[16] M. Beeuwkes Buntin, C. Damberg, A. Haviland, K. Kapur, N. Lurie, R. McDevitt, M.S. Marquis, Consumer directed health care: early evidence about effects on cost and quality, Health Aff. 25 (6) (2006) 516-530.

[17] T. Beugelsdijk, S. Varma, S. Walsh, Ch. 4 BioMEMS, international roadmap on MEMS, Microsystems, Micromachining and Top Down Nanotechnology, MANCEF, Naples, Florida, 2003, pp. 109-157. 
[18] M. Bissell, F. Sanfilippo, Empowering patients with point-of-care testing, Trends Biotechnol. 20 (6) (2002) 269-270.

[19] P. Boardman, Beyond the stars: the impact of affiliation with university biotechnology centers on the industrial involvement of university scientists, Technovation 28 (2008) 291297.

[20] B. Bonett, Getting up close and personal with your genome, Cell 133 (5) (2008) 753-756.

[21] E.A. Boohaker, R.E. Ward, J.E. Uman, B.D. McCarthy, Patient notification and follow-up of abnormal test results: a physician survey, Arch. Intern. Med. 156 (3) (1996) 327-331.

[22] K. Borch, Refining the debate on GM crops using technological foresight - the Danish experience, Technol. Forecast. Soc. 72 (5) (2005) 549-566.

[23] R.E. Chaisson, J.C. Keruly, S. McAvinue, J.E. Gallant, R.D. Moore, Effects of an incentive and education program on return rates for PPD test reading in patients with HIV infection, J. Acquir. Immune Defic. Syndr. 1511 (5) (1996) 455-459.

[24] M. Chan, Global health diplomacy: negotiating health in the 21st century Director-General of the World Health Organization, Address at the Second High-level Symposium on Global Health Diplomacy, 12/6/2011 http://www.who.int/dg/speeches/2008/20081021/en/index.html.

[25] H. Chesbough, A. Kardo, Beyond high tech: early adopter of open innovation in other industries, R\&D Manage. 36 (3) (2006) 229-236.

[26] C. Christensen, R.A. Burgelman, S.C. Wheelwright, Strategic Management of Technology and Innovation, 5th ed. McGraw-Hill/Irwin, Columbus, OH, 2008. [27] C.M. Christensen, The Innovators Dilemma: The Revolutionary Book that Will Change the Way You Do Business, Harper Collins Publications, New York, New York, 2003.

[28] P. Christopher, V.V. Adams, M. Dickson, P. Gagnon, Key factors in the rising cost of new drug discovery and development, Nat. Rev. Drug Discov. 3 (2004) 417-429. [29] J.F. Coates, Technological change and future growth: issues and opportunities, Technol. Forecast. Soc. 11 (1) (1977) 49-74.

[30] R. Cooper, Perspective third-generation new product processes, J. Prod. Innov. Manage. 11 (1) (1994) 3-14.

[31] T.U. Daim, T. Oliver, Implementing technology roadmap process in the energy services sector: a case study of a government agency, Technol. Forecast. Soc. 75 (5) (2008) 678-720.

[32] M. Dickson, P. Gagnon, Key factors in the rising cost of new drug discovery and development, Nat. Rev. Drug Discovery 3 (2004) 417-429.

[33] G. Dutifield, Intellectual Property Rights and the Life Sciences Industries: A Twentieth Century History, Ashgate Publishing Limited, Burlington VT, 2003. [34] K. Eijkel, E. Knol, S. Walsh, Converging technologies, http://www.itrs.net. 12/05/2010.

[35] K.M. Eisenhardt, Building theories from case study research ACD, Manage Rev. 14 (4) (1989) 532-550.

[36] K.M. Eisenhardt, M.E. Graebner, Theory building form cases: opportunities and challenges, Acad. Manage. J. 50 (1) (2007) 25-32.

[37] M. Fink, R. Lang and R. Harms, Local responses to global technological change - contrasting restructuring practices in two rural communities in Austria, Technol. Forecast. Soc., in press. 
[38] J.C. Fisher, R.H. Pry, Simple substitution model of technological change, Technol. Forecast. Soc. (3) (1971-1972) 75-88.

[39] R.N. Foster, Innovation: The Attracter's Advantage, 1st ed. Summit Books, Manila Philippines, 1985.

[40] F.J. Fowler, Survey Research Methods (Applied Social Research Methods), 4th ed. Sage, Thousand Oaks, CA, 2008.

[41] P.H. Franses, A method to select between Gompertz and logistic trend curves, Technol. Forecast. Soc. 46 (1) (1994) 45-49.

[42] M.L. Garcia, O.H. Bray, Fundamentals of technology roadmapping, Sandia National Labs press release SAND97-0665, http://www.sandia.gov/PHMCOE/pdf/ Sandia'sFundamentalsofTech.pdf. 12/05/2011.

[43] Genentech, http://www.gene.com/gene/research/focusareas/. 12/07/2011.

[44] H.J. de Graaf, M.A.W. Noordervliet, C.J.M. Musters, C.J.M. G.R. de Snoo, Roadmap for interactive exploration of sustainable development opportunities: the use of simple

instrumentsin the complex setting of bottom- up processes in rural areas, Land Use Policy 26

(2) (2009) 295-307.

[45] P. Groenveia, Roadmapping intergrates business and technology, Res. Technol. Manage 40(50)(1997) 48-55.

[46] C. Gross, J. Allen, Technology Transfer for Entrepreneurs: A Guide to Commercializing Federal Laboratory Innovations, Praeger Publishing, Westport CT, 2003.

[47] K.R. Haines, D. Smith, P.R. Anderson, A.J. Epstein, I. McMichael, P. Roberts, J. Wilkinson, J. Woodcock, J. Woods, Polices for accelerating access to clean energy, improving health, advancing development and mitigating climate change, Lancet 370 (9594) (2007) 6-12 (1264 128).

[48] D. Hanahan, R.A. Weinberg, The hallmarks of cancer, Cell 100 (1) (2000) 57-70.

[49] Dolomite MicroFluidic Products, http://www.dolomite-microfluidics.com/en/products. 201012/09/2010.

[50] A. Harmon, Gene map becomes a luxury item new times, http://www.nytimes.com/2008/03/04/health/research/04geno.html. March 4, 2008.

[51] B. Hernandez-Ortega, The role of post-use trust in the acceptance of a technology: drivers and consequences, Technovation 31 (10-11) (2011) 523-538.

[52] S. Hilgartner, Access to Data and Intellectual Property: Scientific Exchange in Genome Research, Intellectual Property Rights and Research Tools n Molecular Biology, National Academy Press, Washington DC, 1996, pp. 28-33.

[53] T. Hinkebein, M.K. Price, Progress with the desalination and water purification technologies U.S, Desalination 182 (1-3) (2005) 19-28. [54] Q. Huang, H. Yu, Q. Ru, Bioavailability and 
delivery of nutraceuticals using nanotechnology, J. Food Sci. 75 (1) (2010) 50-57.

[55] Human Genome Project information on the Human Genome Project, http://www.ornl.gov/sci/techresources/Human_Genome/home.shtml. 201112/09/2011. [56] International technology roadmap for semiconductors 2008 update, www.itrs.net/links/2008ITRS/Update/2008_Update.pdf. 79.

[57] A.J.S. Jones, J.L. Cleland, Technical and regulatory hurdles in delivery aspects of macromolecular drugs, J. Control Release 41 (1-2) (1996) 147-155.

[58] J. Kilby, Turning potential into realities: the invention of the integrated circuit, Chemphyschem 2 (8/9) (2000) 482-489.

[59] S. Lee, Y. Park, Customization of technology roadmaps according to roadmapping purposes: overall process and detailed modules, Technol. Forecast. Soc. 72 (5) (2005) 567-583.

[60] J.D. Linton, S. Walsh, Acceleration and extension of opportunity recognition for nanotechnologies and other emerging technologies, Int. Small. Bus. J. 26 (2006) 83-99.

[61] J.D. Linton, S. Walsh, Integrating innovation and learning curve theory: an enabler for moving nanotechnologies and other emerging process technologies into production, $R \& D$ Manage. 34 (5) (2004) 513-522.

[62] J. Lubitz, J. Beebe, C. Baker, Longevity and medicare expenditures, N. Engl. J. Med. 332 (1995) 999-1003.

[63] P.Y. Lum, C.D. Armour, S.B. Stepaniant, G. Cavet, M.K. Wolf, J. Scott Butler, J.C. Hinshaw, Philippe Garnier, G.D. Prestwich, Amy Leonardson, Philip Garrett-Engele, C.M. Rush, M. Bard, G. Schimmack, J.W. Phillips, C.J. Roberts, D.D. Shoemaker, Discovering modes of action for therapeutic compounds using a genome-wide screen of yeast heterozygotes, Cell 116 (1) (2004) 121- 137.

[64] B.A. Kirchhoff, Entrepreneurship and Dynamic Capitalism: the Economics of Business Firm Formation and Growth, Praeger, Westport, Conn, 1994. [65] B. Kirchhoff, S. Walsh, Entrepreneurs' opportunities in technology-based markets, Research in Entrepreneurship and Management, 2002, pp. 17-30.

[66] B. Kirchhoff, S. Walsh, Entrepreneurship's role in commercialization of disruptive technologies band 13, Unternehmer und nternehmensperspektive fur Klien-und Mittelunternehmen, Dunker \& Humbolt, Berlin/St. Gallen, 2000, pp. 323-332.

[67] I.M. Kirzner, How markets work: disequilibrium, entrepreneurship and discovery, IEA Hobart Paper No. 133, London Institute for Economic Affairs, 1997. [68] I.M. Kirzner, Competition and Entrepreneurship, University of Chicago Press, Chicago, Ill, 1973.

[69] J. Korotayev, J. Zinkina, J. Bogevolnov, Kondratieff waves in global invention activity, Technol. Forecast. Soc. 78 (7) (2011) 1280-1284.

[70] R.N. Kostoff, R.R. Schaller, Science and technology roadmaps, IEEE Trans. Eng. Manage. 48 (2) (2001) 132-143.

[71] S. Kroc, V. Delic, Personal wireless sensor network for mobile health care monitoring. Telecommunications in Modern Satellite, Cable and Broadcasting Service TELSIKS 6th International Conference, 2(1-3), 2004, pp. 471-474.

[72] A. Lyles, Direct marketing of pharmaceuticals to consumers, Rev. Public Health 23 (2002) 7379 
91.

[73] MacDailyNews Obama signs first-to-file U.S. patent reform bill into law 2011, http://macdailynews.com/2011/09/16/obama-signs-first-to-file-u-s-patent- reform-bill-intolaw/. 20119/16/2011.

[74] V. Mangematin, A. Amir-Aslani, The future of drug discovery and development: shifting emphasis towards personalized medicine, Technol. Forecast. Soc. 77 (2) (2010) 203-217.

[75] J.C. Mankins, Technology readiness levels white paper office of space access and technology NASA April 6, 1995, http://ehbs.org/trl/Mankins1995.pdf2011. [76] G. Marinkas, R. Tierney and D. Walsh, Are nanotechnology researchers, developers and their managers addressing health and safety concerns through publications and or patent applications, J. Bus. Ethics. in press.

[77] A. Markus, Tiny magnets could clear diseases from the blood technology review, http://www.technologyreview.com/biomedicine/39181/?mod=chfe. 12/07/2011.

[78] W. McDowall, Technology roadmaps for transition management: The case of hydrogen energy, Technol. Forecast. Soc. 79 (3) (2012) 530-542.

[79] S.P. McGrath, E. Grigg, S. Wendelken, G. Blike, M. De Rosa, A. Fiske, R. Gray, R. Artemis, A vision for remote triage and emergency management information integration, http://www.ists.dartmouth.edu/library/15.pdf. 20032011.

[80] Micro and Nanotechnology Commercialization Education Foundation (MANCEF), Commercialization of Micro Nano Systems Conference, 2011.

[81] Micro, Nanotechnology Commercialization Education Foundation (MANCEF), Roundtable discussion by life science investors. Albuquerque, New Mexico, 2010.

[82] Micro, Nanotechnology Commercialization Education Foundation (MANCEF), International Micro/Nano Roadmap, 3rd ed., 2011.

[83] G. Moore, Lithography and the future of Moore's law, Solid State Circuits Newsl. 20 (3) (2006) $37-42$.

[84] S. Morgan, J. Hurley, Influences on the health care technology cost-driver commission on the future of health care in Canada, Discussion Paper 14, 2002, p. 22. [85] Nike Fuel Band, http://store.nike.com/us/en_us/?l=shop,pwp,c-1+100701/hf$4294899078+12003+50142 \& c p=U S N S \_K W \_0611081618$.

[85] Nike Fuel Band http://store.nike.com/us/en_us/?l=shop,pwp,c-1+100701/hf4294899078+12003+50142\&cp=USNS_KW_0611081618

[86] J.Ness, D.J. Cirilla, D.R. Weir, N.L. Nisley and R.B. Wallace, Use of Complementary Medicine in Older Americans: Results From the Health and Retirement Study GERONTOLIST 45(4) (2004) 516524.

[87] NERAC New Perspectives on the Future of Drug Discovery http://www.nerac.com/nerac_insights.php?category=reports\&id=7 2008 12/09/2011.

[88] New York Times, First to File Bill, December 10, 2011, http://topics.nytimes.com /top/news/science/topics/inventions_and_patents/index.html, New York 2011.

[89] R.N. Noyce, Carrier Generation and Recombination in P-N Junctions and N-P Junctions Characteristics PROC IRE 45(9) (1957) 1228-1243.

[90] R. Phaal, E. O’Sullivan, S. Routley and D. Probert, A Framework for Mapping Industrial 80 
Emergence TECHOL FORECAST SOC 72(2) (2011) 217230.

[91] R. Phaal, J.P.F. Clare and D. Probert, Technology Roadmapping-A Planning Framework for Evolution and Revolution TECHOL FORECAST SOC 71(1-2) (2004) 526.

[92] Population Profile of the United States http://www.census.gov/population/www/popprofile/natproj.html 12/8/2011.

[93] A. Porter, Forecasting and Management of Technology $2^{\text {nd }}$ ed., Wiley, Somerset, NJ, 2011

[94] J.A. Poupard and L.A. Miller, Biological Warfare Encyclopedia of Microbiology $3^{\text {rd }}$ ed. 2009 Philadelphia PA.

[95] M. Pradhan, D.E. Sahn and S. Younger, Decomposing world health inequalities J HEALTH ECON 22(2) (2003) 27.

[96] S.A. Rathore, Roadmap for Implementation of Quality by Design (QbD) for Biotechnology Products TRENDS BIOTECHNOL 27(9) (2009) 546553.

[97] M. Rinne, Technology Roadmaps: Infrastructure for Innovation TECHOL FORECAST SOC 71 (1-2) (2004) 6780.

[98] M.C. Roco, Broader Societal Issues of Nanotechnology J NANOPART RES 5 (2003) 181189.

[99] M.Roco, C.A. Mirkin, M.C. Hersam, Nanotechnology research directions for societal needs in 2020: Retrospective and Outlook, Springer, New York, New York 2011.

[100] M.C. Roco, Progress in Governance of Converging Technologies Integrated from the Nanoscale, ANN NY ACAD SCI. 1093, 2006, 1-23.

[101] A.D. Romig, A.B. Baker, J. Johannes, T. Zipperian, K. Eijkel, B. Kirchhoff, H.S. Mani, C.N.R. Rao and S. Walsh, An introduction to Nanotechnology Policy: Opportunities and Constraints for Emerging and Established Economies TECHOL FORECAST SOC 74(9) (2007) 16341642.

[102] N. Ronald, R. B. Kostoff and G. R. Simons, Disruptive technology roadmaps TECHNOL FORECAST SOC 71(1-2) (2004) 141159.

[103] R.M. Satava Virtual Reality and Teleprescence for Military Medicine COMPUT BIO MED 25(2) (1995) 229-236.

[104] J.A. Schumpeter, R. Swedberg, Capitalism, socialism and democracy, $5^{\text {th }}$ ed., Routledge, New York, New York, 1942.

[105] J.A. Schumpeter, The theory of economic development. Cambridge, Harvard University Press Cambridge, MA, 1937.

[106] D.H. Shin, Potential user factors driving adoption of IPTV. What are customers expecting from IPTV? TECHNOL FORECAST SOC, 74(8) (2007) 14461464.

[107 ]H. Sidney, S.H. Wanzer, S.J. Adelstein, R.E. Cranford, D.D. Federman, E.D. Hook, C.G. Moertel, P. Safar, A. Stone, H.B. Taussig and J. van Eys The Physicians Responsibility toward Hopelessly Ill Patients NEW ENGL J MED 310 (1984) 955959.

[108] C. Som, L.M. Hilty and A.R. Köhler, The Precautionary Principle as a Framework for a Sustainable Information Society. J BUS ETHICS 85 (2009) 493505.

[109 ]A. Styhre, Institutionalizing technoscience: Post-genomic technologies and the case of systems biology SCAND J. MANAG 27(4), December (2011) 375388.

[110] A.J. Tudos, G.A.J. Besselink and R.B.M. Schasfoort, Trends in miniaturized total analysis systems for point of care in clinical chemistry LAB CHIP 1 (2001) 8395.

A. Tura, A. Maran and G. Pacini, Non-Invasive glucose montering: Assessment of technologies and devices to quantitative criteria DIABETES RES CLIN PR 77(1) (2007) 1640.

[111] M. Scott and S. T. Walsh, Commercial importance of a unit cell: nanolithographic patenting trends for Microsystems, microfabrication, and Microsystems J MICROLITH MICROFAB 1(1-6) 1114.

[112] W. Shockley, The path to the Conception of the Junction Transistor IEEE ELECTRON 
DEVICE LETT 23(7) (1976) 597620.

[113] P.R.Srinivas, P. Baker and S. Srivastava, Nanotechnology in Early Detection of Cancer LAB INVEST 82 (2002) 657662.

[114] M. Stebbing, Avoiding the Trust Deficit: Public Engagement, Values, The Precautionary Principle and the Future of Nanotechnology J BIOETHIC INQ 6 (2009) 3748.

[115] M. Steward, J.B. Brown, A. Donna, I. McWhinney, J Oates, W.W. Weston, and J. Jordan, The Impact of Patient Centered Care on Outcomes FAMILY PRAC 49(9) (2000) http://www.ucdmc.ucdavis.edu/ome/mcrtp/docs/Kravitz\%20The\%20impact\%20of\%20pati ent-centered\%20care\%20on\%20outcomes.pdf 2011.

[116] Technology Readiness Levels Handbook for Space Operations, https://telecom.esa.int/telecom/media/document/TRL_Handbook.pdf Issue 1, Revision 6 September 2008, J 1/1/2012.

[117] R. Tierney, R. Harms, A. Groen, H. Stewart, D. Hetherington, M. Luzink, J. Linton, and S. Walsh, Managing Highly Flexible Facilities - An essential complementary asset at risk INTER J ENTREP BEHAV RES (2011) In Press.

[118] U.S. Clean Air Act http://www.epa.gov/lawsregs/laws/caa.html 2011 1/13/2012

[119] U.S. Department of Health Personalized Health Care http://www.hhs.gov/myhealthcare 2008 12/09/2011.

[120] R.E. Uwe Does the Aging of the Population Really Drive the Demand for Health Care Does The Aging Of The Population Really Drive The Demand For Health Care HEALTH AFFAIR, 22 (6) (2003) 2739.

[121] P. Vallance and M. Levick, Drug Discovery and Development in the Age of Molecular Medicine Perspectives CLIN PHARMACOL THER 82(4) (2007) 363366.

[122] S. Walsh, Roadmapping a Disruptive Technology: A Case Study: The Emerging Microsystems and Top Down Nanosystems Industry: TECHOL FORECAST SOC 71 (1-2) (2004) 161185.

[123] S. Walsh and R. Boylan, C. McDermott and A. Paulson, The Semiconductor Silicon Industry Roadmap: Epochs driven by the Dynamics between Disruptive Technologies and Core Competencies TECHOL FORECAST SOC 72(2) (2005a) 213236.

[124] Wylde, J. Walsh, S., etc., (2005), “The International RF MEMS Road map”, pp.122, MANCEF, Naples, Florida

[125] S. Walsh, R. Giasolli and J. Elders (Eds.), The second edition of the International Micro Nano Roadmap, 2004, p. 674, MANCEF, Naples, Florida.

[126] S. Walsh, B. Kirchhoff and S. Newbert, Differentiating Market Strategies for disruptive technologies IEEE T ENG MANAGE 49(4) (2002) 341351.

[127] S. Walsh and J. Elders (Eds.), International Roadmap on MEMS, Microsystems, Micromachining and Top Down Nanotechnology, 2003 pp. 614, 2003, MANCEF, Naples, Florida

[128] S. Walsh, J. Linton, R. Grace, S. Marshall and J. Knutti, MEMS, Microsystems, Micro machines: Commercializing An Emergent Disruptive Technology, in MEMS and MOEMS Technology and Applications, Editor P. Rai-Choudry, SPIE - The International Society for Optical Engineering Development, Billingham, Washington, p. 479 514, 2000.

[129] S, Walsh and J. Wylde, Ch. 2 RF MEMS $2^{\text {nd }}$ ed., International Micro - Nano Roadmap, p.40-152, 2004, MANCEF, Naples, Florida.

[130] S. Walsh and J. Wylde, The International RF MEMS Road map, p.122, 2005 MANCEF, Naples, Florida

[131] S. H. Wanzer, S.J. Adelstein, R. E. Cranford, D. D. Federman, E. D. Hook, C. G. Moertel, P. Safar, A. Stone, H. B. Taussig, J. van Eys, The Physician's Responsibility toward 
Hopelessly Ill Patients, N Engl J Med 310 (1984) 955-959.

[132] J. Weiss, P. Takhistov and D. McClemments, Functional Materials in Food Nanotechnology, J FOOD SCI 71(9) (2006) 107116.

[133] C.H. Willyard, C.W. McClees, Motorola's technology roadmap process RES MANAGE 30(5) (1987) 1319

[134] O.E. Williamson, The Economic Institutions of Capitalism, Free Press, New York N.Y. 1985.

[135] J. Wonglimpiyara, The nano-revolution of Schumpeter's Kondratieff cycle. TECHNOVATION 25 (2005) 13491354.

[136] World Population Ageing: 1950-2050 United Nations, http://www.un.org/esa/population/publications/WPA2007/WORLD\%20POPULATION\%2 0AGEING\%202007.pdf 12/7/2011.

[137] World Population to reach 10 billion by 2100 if Fertility in all Countries Converges to Replacement Level http://esa.un.org/wpp/Other-Information/Press_Release_WPP2010.pdf 2011.

[138] Y. Yasunaga, M. Watanabe, M. Korenaga Application of technology roadmaps to governmental innovation policy for promoting technology convergence TECHNOL FORECAST SOC 76(1) (2009) 6179.

[139] R.K. Yin, Case Study Research: Design and Methods $3^{\text {rd }}$ Ed. Sage Publishers, 2003. A. Zaffaroni, ALZA: An enterprise in biomedical innovation TECHNOVATION 1(2) (1981) 135146.

[140] Zevalin Information on Zevalin pharmacology http://zevalin.com/v3/zevalin-rit/index.htm 2011 12/09/201.

[141] R. Zoorob and V. Morelli, Disease Prevention and Wellness in the Twenty-first Century PRIMARY CARE 35(4) (2008) 663667. 


\title{
Section 3
}

\section{Managing Highly Flexible Facilities An essential complimentary asset at risk}

\author{
By \\ Robert Tierney, Aard J. Groen and Rainer Harms \\ NIKOS, University of Twente, Enschede, The Netherlands \\ Miriam Luizink \\ Mesa p, University of Twente, Enschede, The Netherlands \\ Dale Hetherington and Harold Stewart \\ Sandia National Laboratories, Albuquerque, New Mexico, USA \\ Steve T. Walsh \\ Anderson School of Management, University of New Mexico, Albuquerque, \\ New Mexico, USA, and \\ Jonathan Linton \\ Telfer School of Management, University of Ottawa, Ottawa, Canada
}

Reproduced with permission of Emerald Group Publishing. Article originally appeared in International Journal of Entrepreneurial Behavior and Research 2012, Volume 18 Issue 2 pp. pp. 233-255

Citations presented in accordance to journal requirements 


\section{Section 3.1 Introduction}

There is a gap in strategic entrepreneurial thought where entrepreneurial action requires crucial external complementary assets (Teece, 1988) which are important to regional economic development based on entrepreneurial action (Walsh and Linton, 2000). The authors add to the body of literature that addresses complementary assets (Hitt et al., 2001; Shane, 2001). We choose small technology (see appendix A) highly flexible facilities (see appendix A) as our critical complementary asset focus.

These highly flexible facilities are critically important for entrepreneurial action and economic development (Linton and Walsh, 2008). Second, these facilities are extremely costly to build and maintain (Van Heeren et al., 2003; Walsh, 2004); costs which far outpace the resource base of even high technology based entrepreneurial efforts. Third, many see small technology as the harbingers and enablers of the next Schumpeterian economic wave (Walsh et al., 2000), Finally, firms based on these technologies are already starting to solve problems in a uniquely valuable manner (Anson et al., 2008; Corbett et al., 2000; Linton and Walsh, 2008; Romig et al., 2007; Thukral et al., 2008).

Yet these small technology highly flexible facilities are at risk. Entrepreneurs, facility managers and policy makers using current management techniques are hard pressed to convey these facilities operational effectiveness and strategic value. Effective strategic and operational management is required to keep these knowledge assets effective (Li et al., 2009). Accomplishing this requires a general understanding of the nature of the small technology based modern production processes. Modern production processes (also called convergent technologies) are progressively more multiple root technology based and are often superseding more traditional solo or single root technology production processes (Eijkel et al., 2006). The modern production process causes operational and strategic complexity.

Current best practice (Bergek and Norrman, 2008) strategic management of these facilities is using traditional single root technology high volume facilities. The results of this practice have not been encouraging and the facilities managers discussions of "doing the right things are not as 
compelling due to environmental factors. Several environmental factors are leading to an increased scrutiny of small technology based highly flexible facilities:

1) Semiconductor manufacturing facilities or high volume facilities are moving from the more developed economies of North America and Europe to the emerging economies of Asia (Ernst, 2010; Globalfoundries, 2009).

2) Financing for these facilities is being more harshly scrutinized during a period of economic uncertainty.

3) Small technology facilities are often too costly for any one firm. Increasingly regions are seeking support from governmental bodies (Elders and Walsh, 1999).

4) Small technology facilities have matured from purely research facilities to multi-use facilities with little or no operational scrutiny (Myers et al., 2000; Naughton, 2005).

5) The success of high volume facility metrics management has made metrics management and particular high volume tactility metrics the methodology of choice for all facilities (Benson et al., 1995; Sattler et al., 1997).

6) Highly flexible facilities are still perceived by many founders, managers and policy makers as extensions of semiconductor based high volume facilities and they expect to see high volume facility metrics.

We initiate our investigation of these strategic assets by delving into foundational strategic literature, strategic entrepreneurship literature and strategic literature on technology entrepreneurship in particular. We review the theory that supports the current use of metrics. We choose the case study method (Eisenhardt and Graebner, 2007; Yin, 2009) to interact with one high 
volume facility and five highly flexible facilities to garner the rich information needed to advance the field. We find that metrics usage is meeting with resistance in highly flexible facilities and when used has limited operational success.

Furthermore, some highly flexible facility managers are so frustrated with their initial use of high volume facility metrics that they simply use none at all. We find that this challenge has produced an environment where managers of highly flexible facilities are not able to effectively use even a minimum common set of metrics, which is seen as International Journal of Entrepreneurial Behaviour \& Research problematic. Finally we provide a model for highly flexible facilities managers and stakeholders for metric selection based on both our finding and the literature. We fill a literature gap concerning the strategic action of essential complementary strategic assets. We provide a model that managers of highly flexible facilities can use to express both their facilities strategic value and as a selection criteria for metrics management-based operations.

\section{Section 3.2 Literature Review}

The highly flexible facility is important to a variety of stakeholders. To a small technology based entrepreneur it is an essential strategic resource that is most often financially out of reach (Walsh, 2004). To a regional or national policy maker a highly flexible factory is a complementary asset for national policy or regional development (Romig et al., 2007). Here we provide value to the academic and practitioner community by linking the development, sustainability and operations management of this asset to strategic entrepreneurship literature, strategic technology entrepreneurship literature and general strategy literature to further the fields understanding of this issue.

Entrepreneurs derive sustainable competitive advantage from exploiting market gaps (Kirzner, 1997), lower transaction costs (Williamson, 1985) or taking advantage of technological advances (Spencer et al., 2008). Strategic entrepreneurship has many and often competing strategic perspectives (Hitt et al., 2011). While researchers in these fields demonstrate different perspectives of thought on just how to create sustainable competitive advantage, most of them highlight the 
importance of innovation (Ireland and Webb, 2007). Complementary assets like highly flexible facilities find strategic value for firm renewal, sustained regeneration, domain redefinition, organizational rejuvenation and business model reconstruction (Covin and Miles, 1999). We integrate strategic entrepreneurship to general strategy by focusing on the internal and external environment of the venture from a technological point of view (Kuratko and Audretsch, 2009).

We choose the objective rather than the normative approach to strategy, since the normative approach of prescribing metrics that worked in one arena to another is fundamental source of contention of managers of highly flexible facilities (Mintzberg, 1994). We have taken an inside out" strategic perspective and chosen the competency (Prahalad and Hamel, 1990) over the Resource Based (Barney and Wright, 2001) perspectives due to its relatively larger emphasis on technology (Katzy and Crowston,2008; Nath et al., 2010; Terziovski, 2010). The competency perspective highlights technology, production skills, and their associated management practices as the core of competitive advantage. Furthermore, the resource based strategic perspective has been found lacking when considering either new competition or industry drivers that offer competitive advantage in dynamic markets (Saarenketo et al., 2009). As highly flexible facilities are essentially technology-based, the competence perspective (Walsh and Linton, 2011) with its focus on technology and its management is a superior fit for our research.

Technology and its management is of critical importance to a competence perspective of strategy. To remain competitive, most firms must continually acquire and/or develop new skills (Linton and Walsh, 2004). Highly flexible facilities are the source of these manufacturing and technology development-based complementary assets in small technology. To date the much of the strategic entrepreneurship literature on innovation has focused on an organization characteristics (Damanpour, 1996). We seek to expand this through the competency perspective. We operationalized the competency based perspective though the industry standard metrics approach.

Metrics can condition data into useful and compact information that is easily assimilated (Pich et al., 2002). Further, researchers have suggested that the selection of metrics must be tied to the strategic imperatives of a firm of facility to attain maximum utility (Drongelen-K. and Bilderbeek, 
1999). Foundational metrics management suggests that metrics must be tied to the product and process metrics mix of a facility (Corderoal., 2005; Hayes and Wheelwright, 1979). Metrics management is the standard for the highly successful management of high volume semiconductor facilities. Due to the outward similarity between these facilities and highly flexible small technology facilities they have been directly applied. The same set of metrics are unlikely to be applicable to both extremes (Hayes and Wheelwright, 1979).

Research on semiconductor based high volume facilities show that wafer starts or the amount of material initiated into a process and the associated total system yield are the most important facilities management metrics (Sattler and Schlueter, 1998). Metrics management has pushed these high volume facilities towards automation wherever possible (Goldratt and Cox, 2004). Yet as change and innovation become important the lot move" metric or the movement of one batch process quantity to the next process step becomes the more important management metric (Goodall et al., 2002). Highly flexible facilities introduce change on many more dimensions and emphasize skilled labor knowledge (Comerford, 1993). The fundamental difference between these two types of facilities provides us with a starting point for the development of an effective management model for highly flexible facilities.

\subsubsection{Highly Flexible Facilities}

The term Multi-technology High Mix Low Volume facility (MTHMLV) was introduced to define high volume semiconductor flexible facilities (Myers et al., 2000; Naughton, 26 2005). The authors have further simplified this acronym through the addition of small technology to create the term highly flexible facility. Both our effort and the earlier work show that the workflow varies greatly between highly flexible facilities and high volume facilities and further states that operational or strategic metrics must mimic the needs of the facility.

The highly flexible facility now includes the new tasks of research and development, product and process maturation, innovation, and design validation (Pich et al., 2002). It is based on not simply semiconductor processing technology but nanotechnologies and micro electro mechanical 
systems as well. High volume facilities and highly flexible facilities differ greatly in operation and strategic value.

\subsubsection{High volume facilities metrics}

Metrics management in semiconductor high volume facilities management became recognized as semiconductor surface process technologies became the dominate manufacturing semiconductor process in the late 1950 (Kilby, 2001). Today, most semiconductor products are silicon based, produced by a semiconductor surface modification process and fall into well- defined product areas (ITRS, 2008). The semiconductor industry produces well over $\$ 261.2$ billion in commercial devices annually, and its devices are found in products affecting nearly every aspect of our daily life (SIA, 2008). Despite this success, the number of semiconductor micro fabrication facilities worldwide is shrinking.

Here we limit the our metrics investigation to the high volume facilities materials to device manufacturing even though those of packaging a device (often called back end) are important. We build on semiconductor metrics classification schemes (Sattler and Schlueter, 1998). We do so by separating these metrics into two segments. Those focused on the entire process which we name global" metrics and those focused on a single process steps which we name local" metrics (Limanond et al., 1998).

\subsubsection{High volume facility global metrics}

Many global high volume facility metrics focus on productivity and yield (Goldratt and Cox, 2004). We provide a selected list of high volume facility based global metrics in table 1 below as foundations of thought. First, we will discuss the utility of high volume facilities yield and wafer start metrics for highly flexible facility management. Next, we will address the utility of Cycle Time (CT) or the time it takes to complete an entire process and Work in Process (WIP) measures (Montoya-Torres, 2006). Finally, we discuss high volume facility management practices centered on information sharing, simulation automation, clustering and facilities upgrade below.

High volume metrics such as entire process yield and the amount of material that initiate the 
process or "wafer starts" which was developed through benchmarking techniques (Benson et al., 1995) and are key performance measures. This was further linked to the facility as it approached capacity (Leachman and Hodges, 1996). These metrics become important for highly flexible facilities by adding product mix and the required number of process steps (Sattler et al., 1997). For these types of measures to be useful in highly flexibly facilities, the product mix as well as facility activity mix would have to be much more emphasized. Finally production process speed (cycle time) measures are essential to high volume facility operation management (Montoya-Torres, 53 2006) and many of these focus on traditional bottleneck processes (Bonal et al., 1996; Fallon et al., 1995; Sattler and Schlueter, 1998).

A global metric centered on process speed is found in the process step named lithography (Jacobs et al., 2001). Process step limitations to throughput is not overcome by simple process station redundancy but rather by understanding the scope of each processes or task required (Dietrich, 2004; Maynard et al., 2003) especially in highly flexible facilities. Yet most process time metrics other than lot moves have limited theoretical backing.

We next discuss metrics derived from computer-aided efforts. Many of these applications hold promise for highly flexible facilities due to the nature of parameters. For example, modeling is used to define bottlenecks for high volume facilities and modifications to this process can make it applicable to highly flexible facilities (Guidi et al., 1999). Further Mozumder and Loewenstein (1992) discussed the focus change in a re-facilitation. He described transitioning from one size of materials input material to another (Wu, 2002). This is especially important for highly flexible facilities since many centers are older semiconductor facilities, which have been refocused.

Computer aided metrics efforts focused on process step manufacturing tool clustering and reclustering metrics (Goodall et al., 2002) have great potential application in highly flexible facilities do to their need for process scope. Further, computer aided decision tool metrics for high volume facilities failure analysis (Wagner, 2001) have potential for highly flexible facilities. Finally, the exploration of limiting information flow to workers in high volume facilities (Ishii and Watanabe, 2002) is simply not useful for the knowledge worker required in highly flexible facilities. 
Table 3.1: High Volume Facility Global Metrics

\begin{tabular}{|c|c|c|}
\hline Author & Characteristics & Analytical Technique \\
\hline Maynard et al. (2003) & Yield & Project Costs \\
\hline Sattler et al. (1997) & Yield/Wafer starts vs. cap & Ranking \\
\hline Benson et al. (1995) & Wafer Starts Capacity & Factory performance \\
\hline Leachman and Hodges (1996) & Product Mix & Benchmarking \\
\hline Sattler and Schlueter (1998) & WIP/Wafer starts & Case Study \\
\hline Fallon et al. (1995) & WIP & Case Study \\
\hline Bonal et al. (1996) & WIP & Equipment efficiency \\
\hline Ishii and Wantanabe (2002) & Control Information & Case Study \\
\hline Wu (2002) & Control 300/450 comparison & Case Study \\
\hline Goodall et al. (2002) & Control Fab tool cluster setup & Manufacturing cost \\
\hline Jacobs et al. (2001) & Cycle time Management & Case Study \\
\hline Dietrich et al. (2004) & Cycle time Management & Case Study \\
\hline Montoya (2006) & Cycle time Management & Case Study \\
\hline Wagner (2001) & Failure analysis & Case analysis \\
\hline Guidi et al. (1999) & Simulation and automation & Modeling \\
\hline $\begin{array}{l}\text { Mozumber and Loewenstein } \\
\text { (1992) }\end{array}$ & Simulation and automation & Modeling \\
\hline
\end{tabular}

\subsubsection{High volume facility local metrics}

The complexity in highly flexible facilities is defined by the distinct natures of their three main technology and the scope of very different tasks. High volume facilities complexity is defined by products produced by a large number of repetitive tasks. High volume facilities performance originate at the process step level. Semiconductor based high volume processes routinely achieve overall yields of over $90 \%$ meaning the process steps must yield nearly perfectly (Appleyard and Brown, 2001). We provide a selected group of four types of local metrics that are either potentially important to high volume facilities in Table 2 below.

Even though less than $10 \%$ of the production cost of any high volume facility are labor costs, the cost is of concern (Appleyard and Brown, 2001). This has driven high volume facilities to embrace automation at some level (Croft et al., 2001). These authors discuss theoretical labor intensive versus automated facility crossover point but the nature of highly flexible facility is that is 
knowledge intensive and not a very attractive managerial tool for highly flexible facilities.

Another set of local metrics is temporal in nature and refers to the number of process steps that can be done in a given period of time (Herrmann et al., 2000). A better temporal metric for highly flexible facilities is how long it takes a specific tool to be reset for differing layer thicknesses and exposure times and from that to process step contribution to overall process flow time (Meyersdorf and Yang, 1997) and its link to facility ofitability (Foster and Nugent, 2000).

The third group of local metrics is process step yield uniformity. Incoming material at each process step in both the highly flexible small tech facilities and semiconductor high volume facilities can yield differently due to the position of the material when it is processed. The capital equipment chosen to be used in high volume facilities are those that show the least position variability (Mozumder et al., 1994; Smith et al., 1999). Similarly high volume facilities select process step facilitating capital equipment based on reinvestment (Miller, 2004), process step capital equipment lifetime measures, specificity of the process step capital equipment (Kim and Lee, 2003; Limanond et al., 1998) and process step capital equipment contribution to maintenance (Hallas et al., 1996). Highly flexible facility managers choose process step capital equipment for their process scope rather it exceptional process step throughput at one particular process setting making these measure not easily transferable to their needs.

Table 3.2: High Volume Facility Local Metrics

\begin{tabular}{|l|l|l|}
\hline Author & Characteristic & Analytical technique \\
\hline Appleyard and Brown (2001) & Labor usage & Case Study \\
Croft et al. (2001) & Labor & Case Study \\
\hline Meyersdorf and Yang (1997) & Tool usage & Temporal \\
Konopka and Trybula (1998) & Tool usage & Temporal \\
Foster and Nugent (2000) & Tool usage/ WIP & Temporal \\
\hline Mozumber et al. $(1994)$ & Wafer uniformity & Yield \\
Smith et al. (1999) & Wafer uniformity & Yield \\
Herrmann et al. $(2000)$ & Simulation and automation & Modeling \\
\hline Hallas et al. $(1996)$ & Tools & Cost \\
Miller $(2004)$ & Tool utility & Cost \\
Limanond et al. $(1998)$ & Tool utility & Cost \\
Kim and Lee (2003) & Tool utility & Cost \\
\hline
\end{tabular}


Highly flexible facilities act as engines of innovation and entrepreneurial action (Kautt et al., 2007). They provide entrepreneurs and intrapreneurs with new product and process creation capabilities, the ability to perform proof of concept evaluation and the ability to provide experimentation at the interface of converging technologies (Walsh et al., 1996). These tasks diverge greatly from the traditional high volume facility since they simply do not perform these functions. They are much more in line with the strategic and tactical roles found in R\&D and commercial development departments of a firm (Michelin and Berg, 1985). Here the authors investigate $R \& D$ and innovation based metrics to ascertain their value for inclusion in the highly flexible facility management metrics package.

We provide in table 3 a review of potentially relevant metrics from the innovation, entrepreneurship and R\&D literature. We categorize them as decision-making, product and applications, or process focused. We start by recognizing that innovation management has utilized decision making metrics for many years (Abby and Dickson, 1983; Harms et al., 2010; Matzler et al., 2008). Highly flexible facilities need to convey their value by demonstrating their innovation volume and decision making (Adams et al., 2003) and R\&D facility activities (Meyers et al., 1997). The focus of a R\&D based innovation center is to transfer knowledge, re- invent the corporation, provide new technology product platforms and make existing technology product lines better, faster, and cheaper (Walsh et al., 1996). The idea of parallel metrics centered on R\&D and marketing (Chen et al., 2007) is an essential set of metrics for managers of highly flexible facilities to convey their strategic value. Another important metric set that provides information to stakeholder concerning the strategic value of the facility are innovation metrics (Schumann et al., 1995; Szakonyi, 1994) and those used to convey firm performance (Baglieri et al., 2001) and system design (Chen and Han, 2006; Mihm et al., 2003). The link between innovation and R\&D funding and increased market dominance has been shown (Ofek and Sarvary, 2003). Yet each highly flexible facility will have differing goals. Multiple objective and subjective methods for applied metrics in innovation, product development and R\&D situations (Werner and Souder, 
1994). Metrics sets for facilities focused on research development or engineering (Hauser and Zettelmeyer, 1997) are important for highly flexible facilities.

Table 3.3: Innovation and R\&D Metrics

\begin{tabular}{|c|c|c|}
\hline Author & Characteristic & Analytical technique \\
\hline $\begin{array}{l}\text { Ptich et al. (2002) } \\
\text { Kerrsen van Drongelen and } \\
\text { Bilderbeek } \\
\text { Abby and Dickson (1983) } \\
\text { Adams (2003) }\end{array}$ & $\begin{array}{l}\text { Choosing metrics } \\
\text { Decision making } \\
\text { Metric application } \\
\text { Metric application }\end{array}$ & $\begin{array}{l}\text { Operational } \\
\text { Operational } \\
\text { Operational } \\
\text { Operational }\end{array}$ \\
\hline $\begin{array}{l}\text { Meyers et al. (1997) } \\
\text { Chen et al. (2007) }\end{array}$ & $\begin{array}{l}\text { R\&D } \\
\text { Parallel R\&D projects }\end{array}$ & $\begin{array}{l}\text { Core competence } \\
\text { Strategic }\end{array}$ \\
\hline $\begin{array}{l}\text { Szakonyi (1994) } \\
\text { Schumann et al. (1995) } \\
\text { Werner and Sounder (1994) } \\
\text { Hauser and Zettlmeyer (1997) } \\
\text { Ofek and Sarvary (2003) }\end{array}$ & $\begin{array}{l}\text { Metrics evaluation } \\
\text { Metrics evaluation } \\
\text { Combining metrics } \\
\text { R\&D/engineering } \\
\text { R\&D investment }\end{array}$ & $\begin{array}{l}\text { Process evaluation } \\
\text { Process evaluation } \\
\text { Case Study } \\
\text { Core Competence } \\
\text { Case Analysis }\end{array}$ \\
\hline Baglieri et al. (2001) & R\&D performance & Stakeholder value creation \\
\hline $\begin{array}{l}\text { Mihm et al. (2003) } \\
\text { Chen and Han (2006) }\end{array}$ & $\begin{array}{l}\text { System Design } \\
\text { Data Envelopment Anaylsis }\end{array}$ & $\begin{array}{l}\text { Manufacturing throughput } \\
\text { R\&D performance }\end{array}$ \\
\hline
\end{tabular}

\section{Section 3.3 Methodology}

We employ a case analysis methodology to generate an understanding of the differing imperatives, nature and metric utilization between small technology based highly flexible facilities and semiconductor high volume facilities. We limited facility selectivity bias by selecting highly flexible facilities identified in other studies (Kautt et al., 2007) with differing objectives. We choose a top ten semiconductor based high volume facility to partake in the study. We had 5 responses in the affirmative and we interviewed more than one manager at each facility. They list of professionals included a facility manager, director, or vice president. Finally we reviewed all secondary data sources and facilities information to triangulate the data. We utilize the case method to investigate not only differences between high volume facilities and highly flexible facilities but also the differences among highly flexible facilities. We have utilized Yin (2009) and Eisenhardt (2007) case study techniques to interview firms, obtain secondary information and analyze these facilities through in depth interview observations and secondary data. We provide a summary of the findings in Table 4. We further our case study by administering a structured survey to all five firms 
(Fowler, 2002). The survey probes each firm's metric utilization, and we provide the results in Table 3.5 .

\subsubsection{Characteristics of highly flexible facilities}

Our case study analysis focused on 21 characteristics of highly flexible facilities. These characteristics range from basic technologies to more specific subjects such as the degree of automation in the facility. We derived these characteristics by attending conferences focusing on small tech, reviewing a series of small technology industry roadmaps and reviewing a number of articles (Eijkel et al., 2006; Walsh, 2004). All highly flexible facilities in this study are small technology based and two were in the United States and two were from different countries in Europe. The semiconductor high volume based facility was in the United States. We segmented these characteristics into four groups. The first group is the number and nature of technologies in use in a particular facility. The second group deals with the number and difference in products offered. This measure includes the number of products, processes developed, innovation efforts embraced and research efforts undertaken at a specific facility. The third group of characteristics was designed to understand facility utilization and includes measures such as number of incoming material or wafer starts and determines both facility and capital tool process step capacity and utilization. Finally, the fourth group includes measures such as metric usage, capital tool process specific availability, number of operations decisions which require lot movement holds, number changes in process steps which require capital equipment setup changes, process step capital equipment scope and amount of automation in a particular facility.

We initiate the discussion with group I characteristics. Here we focus on three small technology at forms of semiconductor microfabrication, MEMS and nanotechnology. A facility is said to have a semiconductor micro fabrication capability if it has a bipolar or CMOS front-end process. A facility having MEMS capability has a full front-end process for one of the three types of MEMS process basis (sacrificial surface, bulk silicon micro-machining or high aspect ratio MEMS, Walsh, 2004). A facility is said to have a nanotechnology process if they have a bottom up 
or top down nanotechnology capability. This allows us to illustrate the differences between highly flexible facilities.

The results of our investigation are found in the first three rows of Table 4 below. We follow with a review of our group II characteristics. We investigated facility operations as manifested by a number of different characteristics: They are: products produced at a single facility; the amount of research versus product production lot starts; the number of processes run; the number projects completed; the inclusion of an innovation mission; and the inclusion of a research mission at a given facility. We also depict each firm's group three characteristics and place them in rows ten and eleven. These rows categorize each facility's wafer starts and tool capacity. The final nine rows of table 4 refer to our group 4 firm characteristics and are much more facility specific.

\subsubsection{The results of characteristics review}

These results are found in rows four through nine in Table 4 below. There are major differences between the five facilities we reviewed. When looking at group one characteristics, for example, all of the highly flexible facilities have three major technology platforms whereas the high facility has one technology platform. When examining group 2 characteristics the difference between highly flexible and high volume facilities are stark. The number of products these facilities produce range from fifty to hundreds. Further, there exists a slight but noted difference in relative use of the facility for production versus research. 
Table 3.4: Case Study Results

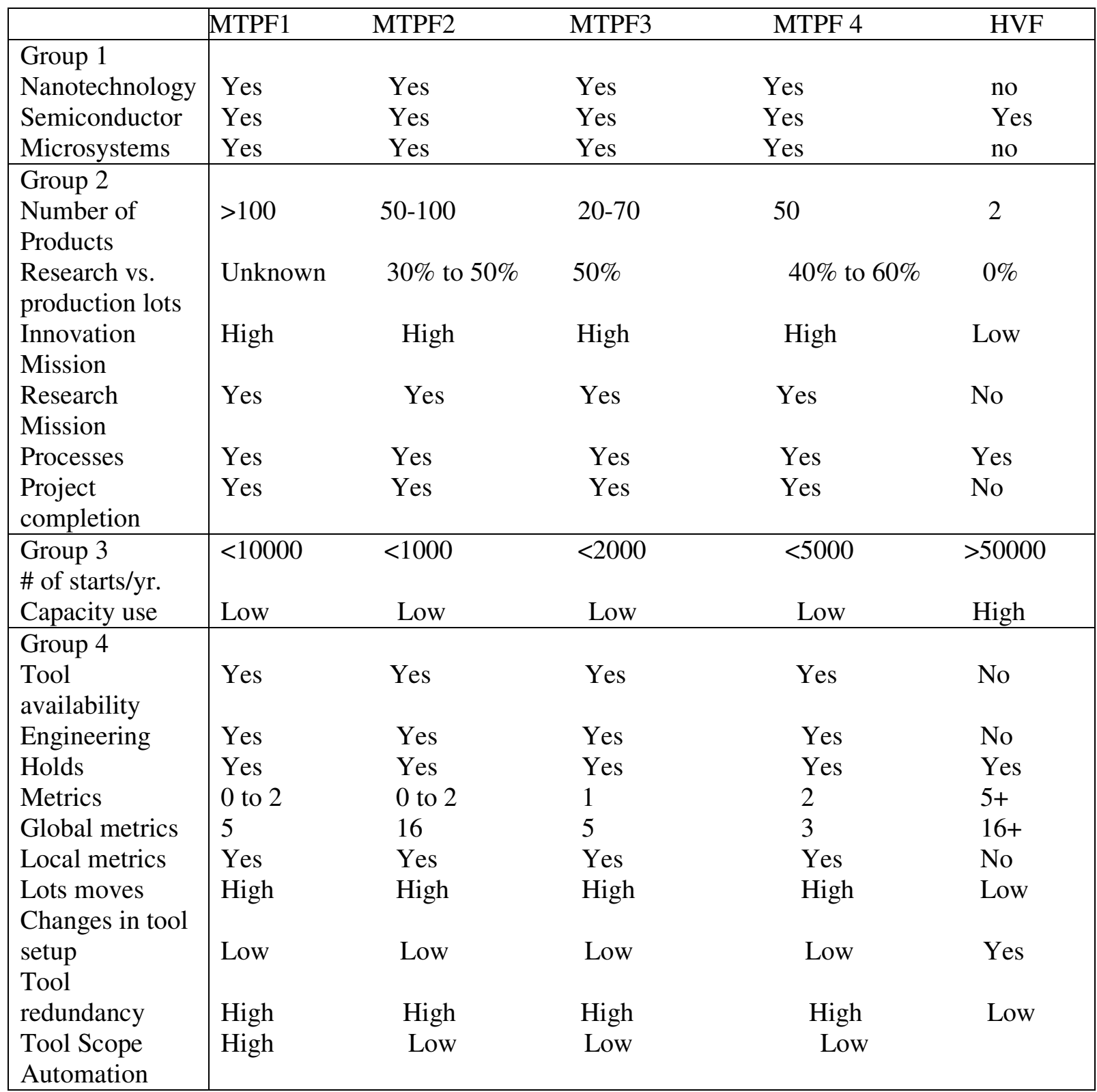

We found differences between high volume facilities and highly flexible facilities when we viewed group III characteristics responses from the five facilities. Further, there are significant differences among the highly flexible facilities as well. The nature of highly flexible facilities demands flexibility in selecting and designing metrics. Highly flexible facilities have from 10,000 to considerably less than 1,000 wafer starts per year. Finally when analyzing group 4 facilities characteristics we see an extreme difference between high volume and highly flexible facilities. There are also significant differences between the highly flexible facilities. Highly 
flexible small technology based facilities are characterized by three separate root technologies and their convergence increase production line complexity and generates significant tool compatibility and flexibility issues.

This creates a work environment where process step capital tool scope rather than its efficiency becomes the dominant concern. Further, all high volume facilities use some form of metrics, including many that are tool based or local metrics. A recurring theme in all the highly flexible facilities was the view that a global wafer starts metrics, so important for high volume facilities, provided them no or little value. Finally, lot moves, usually not seen as exceptionally important for high volume facilities, were seen as providing exceptional value to the operation of highly flexible facilities. The highly flexible facilities are focused on just that - flexibility -, rather than standard product manufacturing efficiency found in their high volume facilities. Highly flexible individual processing steps are just as critical as those in high volume facilities but integration measures take on new dimensions. For example, MEMS process times are often longer due to their use of silicon and other materials in both a structural and electrical manner rather than just electrical as in high volume facilities. Finally, the very nature of structural material changes in a bottom up nanotechnology provide process complexity issues never encountered in a high volume facility.

Our case study analysis demonstrates that the very nature of high volume facilities is exceptionally different from high volume facilities. Competency based strategic management and metrics theory tells us that the strategic management practice of technological varied firms should be different and that the simple transference of metrics would prove ineffective. More interestingly we found a great diversity of mission, scope and process activities within highly flexible facilities, a characteristic we did not expect to find. We decided to further our understanding of highly flexible facilities through a directed questionnaire. We developed the questionnaire using a rigorous questionnaire protocol to more deeply understand their utilization of metrics (Fowler, 2002). 


\section{Questionnaire development}

We developed a metrics based questionnaire with 16 queries based on our research on metrics, the definition of a high volume semiconductor facility and the definition of a small technology based highly flexible facility and the nature of the highly flexible facility which we developed in our literature review. All five facilities in our study responded. All of the respondents and their firms remain anonymous due to the International Journal of Entrepreneurial Behaviour \& Research sensitivity of their work assignments. We provide our survey results in our results section below. The first question served as a general introductory inquiry into the subject of metrics in highly flexible facilities as well as the high volume facility. The second question was developed to investigate the origin of highly flexible facility metrics. Specifically the degree to which these managers see them as highly borrowed from the high volume facilities. The third question inquired into the percentage of high volume facility metrics that had relevance to their particular situation. Question four focuses on actual metric use and their effectiveness for the efficient operation of their facilities.

The next set of questions was designed to introduce the concepts of global and local metrics. We asked the respondents through question five if the facilities used both global and local metrics as we defined them and question number six asked if high volume facility metrics emphasized wafer moves. Question seven queried the facility use of lot moves or how many times a unique start material set or lot is moved in a given facility. Question eight asked if high volume facilities metrics focused on a single process and question nine dealt with high volume metric use and technology experimentation. Questions ten and eleven were used to ascertain information about highly flexibility facilities strategic intent and the need for new metrics around these concepts for them. The next question (question 12) was a departure from the previous style of inquiry. Each individual was asked to pick from a list or provide examples of metrics they used that are non-traditional and used in their facility. Question 13 asked the respondents if their global metrics were of use and question 14 asked them to express the number of global metrics 
they used. Similarly question simply asked the respondents if they used local metrics were of use and questions asked them to express the number of local metrics they used. We provided our respondents with our definitions of global and local metrics.

\section{Section 3.4 Results}

The results are found in Table four. Four out of the five entities responded to the first question strongly agreed that the use of metrics is an enormous benefit to the management of the facility. The lone stand out was neutral in the subject area and came from a highly flexible facility. All respondents to the second question stated that they agreed that the metrics for highly flexible small technology based facilities were derived from semiconductor high volume facilities. The response to question three of if these high volume facilities metrics applicability varied. Two highly flexible facility respondents stated that the percentage of high volume facility metrics that were useful ranged from 0 to $25 \%$. The other two highly flexible facility respondents answered with $26 \%$ to $50 \%$ and $51 \%$ to $75 \%$ respectively.

The fourth question focused on metric value. Three of the highly flexible facility respondents stated that they strongly believed little value was gained from their use, one highly flexibility manager responded with a statement that any metrics were better than no metrics at all and the high volume facility manager was quite pleased with their use. The facilities managers responded to question five and six concerning the use of both global and local metrics and high volume use of wafer moves in exactly the same manner. Four individuals strongly agreed with the statement, with one individual disagreeing. All respondents to question seven, the utility of lot moves agreed or strongly agreed that lot moves were viewed as a better performing metric than wafer moves in highly flexible facilities. All five respondents either agreed or strongly agreed that high volume metrics being focused on a single process (question 8) and further that they stifled innovation (question 9).

All respondents to question 10 agreed strongly that the strategic intent of highly flexible facilities is vastly different from that of a high volume facility. Similarly the mangers response to 
question 11 or the need for new operational and strategic metrics was strong with three out of the four agreed strongly and the fourth individual agreeing. The nontraditional metrics usage question provided a variety of responses. The first highly flexible facility manager reported that lot moves and the number of multi-technology based products were how their center measured performance. This was echoed by another respondent who also mentioned lot moves, but added that process steps metrics were also important. The third respondent sought percent of facility capacity usage as a metric. The fourth respondent answered that patents and the number of research papers produced was a principal metric for the organization. The high volume facilities manager response was that wafer starts and yield are the most important metrics.

The respondent's answers to question 13 and 15 were that they all indicated that global and local metrics were important if not as a management tool then as a reporting 7 tool. Similarly the answers to questions 14 and 16 were identical. The high volume facility manager responded that they used metrics in almost all of their management practice but less than 10 key ones for both global and local metrics. Three of the four highly flexible facilities managers responded that 0 to 2 global metrics were used and 0 to 2 local metrics were used. Only one highly flexible facility used 3 to 5 global and local metrics.

Very few global or integrated process metrics are being used by those interviewed with the exception of the high volume facility, yet they all state a necessity for one that is accurate. Most suggested that highly flexible facility metrics should focus on lot moves. All five stated once more that they employ local or tool based metrics. Two of the fabrication facilities stated they utilized local metrics. One of the individuals interviewed listed the number of papers that are published and the patents that are applied for as their global metric. This is in direct contrast to the last question of whether or not global metrics would benefit the highly flexible facilities and their stakeholders. We have shown that these types of facilities are different by nature and require different metrics to operate efficiently. Further, we have shown that a great variety of metrics exists that can be applied to highly flexible facilities. Next we have synthesized a metrics model for highly flexible facilities. 


\section{Section 3.5 A metrics selection model for highly flexible facilities}

Our literature review and case study finding suggests a metrics model that allow for selectivity from a general set of metrics that could meet the diverse needs of a small technology based highly flexible facility. We provide groupings of specific metrics designed to directly support the managerial requirements generated by the missions and capabilities of small tech highly flexible facilities in our selection model. The model is designed to assist these facilities to accurately assess, operationally utilize and present their strategic effectiveness. Our model is founded on the separation of manufacturing facilities into distinct categories. The model is selective in nature to mimic the differing missions and technologies employed by each highly flexible facility (Hayes and Wheelwright, 1979). We have provided a three factor approach based on mission focus, capability (competence) scope, and capacity (figure 1).

\section{Figure 3.1 Metric Selection Model}

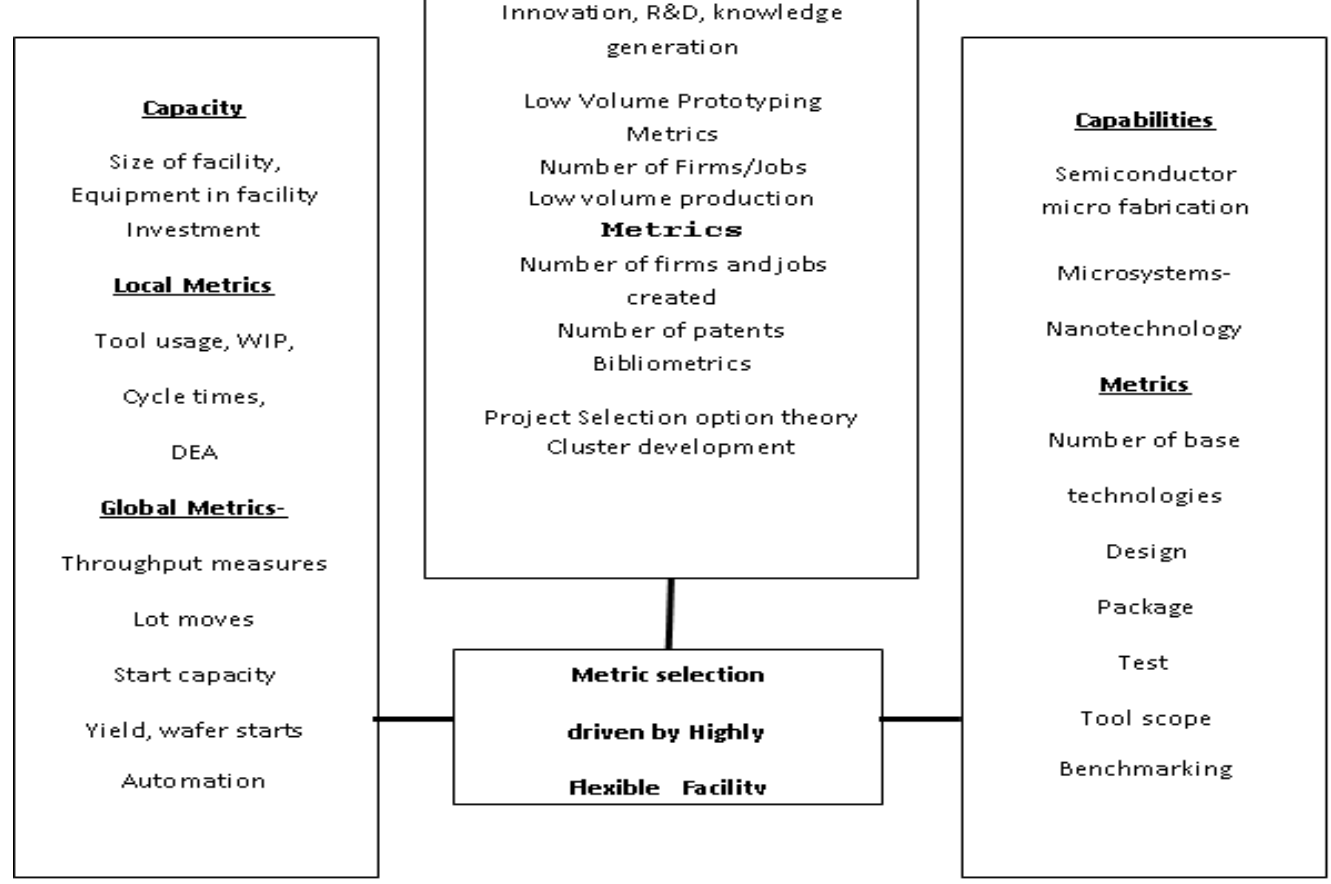


We operationalized mission by the facilities inherent nature (Hayes and Wheelwright, 1979).

The mission metric selection is at the top of the model. We develop a set of metrics that can assist managers to demonstrate strategic value of the facility through a variety of innovation and $R \& D$ metrics that speak to both facility mission and stakeholder value.

The tasks of the highly flexible facility often include: increased innovation, knowledge generation, $\mathrm{R} \& \mathrm{D}$, prototyping, and low volume production. We individually operationalize these factors. We use bibliometric measures as the metric for $\mathrm{R} \& \mathrm{D}$, knowledge generation and innovation. The bibliometric metrics are innovation awards, journal articles, citation rates and licenses. Further some highly flexible facilities are tasked with low volume product production which is usually tied to a specific stakeholder group. Here we utilize capacity measures. Finally, most ownership is focused on regional development, job and wealth creation. Here metrics are for example number of employees, firm attraction and spinouts. We next turn our attention to capacity. We operationalize capacity through a portfolio capacity and complexity approach.

Wafer starts are important for these facilities and bounded by complexity. The portfolio would be different for each highly flexible facility and include activities such as parts produced, processes developed, inventions and papers developed. Local capacity metrics are based on modified high volume facility metrics. These metrics must include tool change set up time included in tool usage, as well as process flow metrics such as work in process. For the global metric capacity segment some facilities might use wafer starts but lot movers is the most important element.

The final aspect to model is capabilities and highly flexible facilities operate the three small technologies root technologies such as semiconductor fabrication, MEMS and nanotechnology. Each of these base technologies is similar, but unique in their approach to metrics. Here we considered the metrics for design, packaging and testing as can be seen from figure 1.

\section{Section 3.6 Discussion and conclusions}

Building upon the current literature, we examined the differences in metrics for these 104 
outwardly similarly but vastly different complementary asset based facilities. Most of the metrics in place now at highly flexible facilities are based upon those historically used by high volume facilities. While these metrics work well under the automated processes that are universally used in semiconductor based high volume facilities, they do not fit the essential needs for small tech based highly flexible facilities. Given the information that was gained from the questionnaire, highly flexible facility managers prefer to use lot moves as the primary metric in their facilities. Further, there is no misuse of high volume facility metrics in highly flexible facilities they simply do not fit the needs of highly flexible facilities.

We have shown the metrics derived from high volume semiconductor based facilities retard the effectiveness of these facilities. The uses of these metrics are actually putting these facilities at greater risk of being eliminated in today's climate. We have shown how metrics literature can be used to operationalize strategic entrepreneurial action. We have also provided a basis for a metrics selection model for small technologies based highly flexible facilities.

This work provides the basis for the development of new metrics based on innovation and R\&D metrics to depict highly flexible facilities strategic value to stakeholders. Moreover this work suggests the modification of some global and local high facility metrics for capacity, mission and capability measures, and sets a direction for new metric development.

All respondents mentioned that the current set of metrics in use today actual hampers the innovation portion of many highly flexible facilities mandate. Their use inhibits the core mission of highly flexible facilities. Finally, that direct implementation of high volume facility metrics do little to assist highly flexible facility management in reaching either their strategic or operational goals or foster poor operations management.

The authors seek to assist in the effective management of highly flexible small technology based facilities. They are an essential complimentary asset for both regional economic development and entrepreneurial action. They are the potential harbingers and underpinnings of the next generation Kondratieff wave and due to current management measures and the economic climate they are at risk. This article is the harbinger for future investigation into the area of 
metrics for critical complementary assets necessary for entrepreneurship and regional

development. Our limitations are associated with the limitations of a case study approach. The

next step would be an empirical test of our model.

Table 3.5 Definitions and acronyms

\begin{tabular}{|c|c|c|}
\hline Readability term used & $\begin{array}{l}\text { Industry term and } \\
\text { definition for this paper }\end{array}$ & $\begin{array}{l}\text { Common acronym in use or } \\
\text { in literature }\end{array}$ \\
\hline Facility & Refers to a production facility & Foundry \\
\hline Small technology & $\begin{array}{l}\text { A grouping term Referring to } \\
\text { nanotechnology, } \\
\text { semiconductor } \\
\text { microfabrication, } \\
\text { microsystems or micro } \\
\text { electro mechanical systems }\end{array}$ & $\begin{array}{l}\text { Microfabrication, Nano, } \\
\text { MEMS }\end{array}$ \\
\hline Highly flexible facilities & $\begin{array}{l}\text { A grouping term that refers in this } \\
\text { paper to facilities that } \\
\text { perform semiconductor } \\
\text { fabrication, nanotechnology, } \\
\text { and micro electro mechanical } \\
\text { systems. These facilities are } \\
\text { characterized by low volume } \\
\text { production as well as } \\
\text { research, product and process } \\
\text { development. }\end{array}$ & $\begin{array}{l}\text { The two acronyms in use for these } \\
\text { foundries are: } \\
\text { MTPF (Multi-technology } \\
\text { Production facilities) } \\
\text { MTLVHM (Multitechnology, } \\
\text { Low Volume, } \\
\text { High Mix facilities or } \\
\text { foundries) }\end{array}$ \\
\hline High Volume facilities & $\begin{array}{l}\text { This designation is for high } \\
\text { volume foundries with single } \\
\text { technology single Product } \\
\text { focus }\end{array}$ & $\begin{array}{l}\text { The two acronyms that are in } \\
\text { common use are: } \\
\text { HVF (High volume facility) } \\
\text { HVSF (High Volume } \\
\text { Semiconductor foundry or } \\
\text { facility) }\end{array}$ \\
\hline Cycle time & $\begin{array}{l}\text { The time it takes a product to go } \\
\text { through a complete process }\end{array}$ & $\mathrm{CT}$ \\
\hline Work in process & $\begin{array}{l}\text { Work in process is the status of any } \\
\text { product as it progresses through a } \\
\text { process }\end{array}$ & WIP \\
\hline $\begin{array}{l}\text { Complementary metal- } \\
\text { oxide-semiconductor } \\
\text { (CMOS) }\end{array}$ & $\begin{array}{l}\text { The dominant classification of } \\
\text { surface semiconductor processing. In } \\
\text { this group of } \\
\text { processes are HMOS, DMOS } \\
\text { and others }\end{array}$ & CMOS \\
\hline Bipolar & $\begin{array}{l}\text { One of two dominate } \\
\text { classifications of surface } \\
\text { semiconductor process. It has been } \\
\text { increasingly supplanted } \\
\text { by CMOS }\end{array}$ & Bipolar \\
\hline
\end{tabular}

This paper has both academic and practitioner utility. We have utilized terms design for reader retention and flow. However some policy makers, industry strategist and some academics will be more familiar with these more precise terms 


\section{Section 3.7 References}

Abby, A., and Dickson, J. (1983), "R\&D work climate and innovation in semiconductors", Academy of Management Journal, Vol. 26 No. 2, pp. 362-368.

Adams, J. D., Chiang, E. P., and Jensen, J. L. (2003), "The influence of federal laboratory R\&D on industrial research”, Review of Economics and Statistics, Vol. 85 No., pp. 1003- 1020.

Anson, S., Kautt, M., Walsh, S. T., and Bittner, K. (2008), "Academic infrastructure and competence centers for a potentially evolving nano-manufacturing industry”, International Journal of Technology Transfer and Commercialization, Vol. 7 No. 4, pp. 436-455.

Appleyard, M. M., and Brown, C. (2001), "The influence of employment practices on manufacturing performance in the semiconductor industry”, Industrial Relations, Vol. 40 No. 3, pp. 436-471.

Baglieri, E., Chiesa, V., Grando, A., and Manzini, R. (2001), Evaluating intangible assets: The measurement of R\&D performance. Research Division Working Paper No. 01-49, Milano.

Barney, J., and Wright, K., Jr. (2001), “The Resource-Based View of the Firm: Ten Years After 1991”, Journal of Management, Vol. 27 No. 6, pp. 625-641.

Benson, R. F., Cunningham, S. P., and Leachman, R. C. (1995), "Benchmarking manufacturing performance in the semiconductor industry", Production and Operations Management, Vol. 4 No. 3, pp. 201-216.

Bergek, A., and Norrman, C. (2008), "Incubator best practice: A framework",Technovation, Vol. 28 No. $1-2$, pp. 20-28.

Bonal, J., Ortega, C., Rios, L., Aparico, S., Fernandez, M., Sanchez, A., and Malvar, S. (1996), "Overall Fab Efficiency," paper presented at the Advanced Semiconductor Manufacturing Conference IEEE, 1996.

Chen, C., and Han, L. M. (2006), "Using DEA to evaluate R\&D performance in the integrated semiconductor firm", International Journal of the Computer, Internet and Management, Vol. 14 No. 3, pp. 50-59.

Chen, H., Chen, J., Li, S., and Wei, Z. (2007), "Double dimension control method for performance measure on R\&D process", Wireless Communications, Network and Mobile Computing, pp. 62096214. 
Comerford, R. (1993), “Flexible factory: case studies”, IEEE Spectrum, Vol. 30 No. 9, pp. 28-29.

Corbett, J., McKeown, P. A., Peggs, G. N., and Whatmore, P. (2000), “Nanotechnology:

International Developments and Emerging Products", Manufacturing Technology, Vol. 49 No. 2, pp. 523-545.

Cordero, R., Walsh, S., and Kirchhoff, B. (2005), "Motivating performance in innovative manufacturing plants", Journal of High Technology Management Research, Vol. 16 No. 1, pp. 88-99.

Covin, J. G., and Miles, M. P. (1999), "Corporate entrepreneurship and the pursuit of competitive advantage”, Entrepreneurship Theory and Practice, Vol. 23 No. 3, pp. 47-65.

Croft, T., Toeante, H., and Baker, T. (2001), "Labor Modeling in a dynamic environment," paper presented at the Semiconductor Manufacturing Symposium, 2001 IEEE International, 2001.

Damanpour, F. (1996), “Organizational Complexity and Innovation: Developing and Testing Multiple Contingency Models”, Management Science, Vol. 42 No. 5, pp. 693- 716.

Dietrich, J. M. (2004), "Life cycle process management for environmentally sound and cost effective semiconductor manufacturing," paper presented at the International Symposium on Electronics and the Environment (ISEEÆ04), Scottsdale, AZ, 2004.

Drongelen-K., I. C., and Bilderbeek, J. (1999), "R\&D performance measurement - More than choosing a set of metrics", R\&D Management, Vol. 29 No. 1, pp. 35-46.

Eijkel, K., Knol, E., and Walsh, S. (2006), Converging Technologies: Architectural Innovation in Perspective, STT, Den Haag.

Eisenhardt, K. M., and Graebner, M. E. (2007), “Theory building from cases: Opportunities and challenges", Academy of Management Journal, Vol. 50 No. 1, pp. 25-32.

Elders, J., and Walsh, S. (1999), “ “TMP” Total Micro Products B.V.”, Groen, A. (Ed.) MicroElectro-Mechanical-Systems Company in Commercializing Knowledge: Examples of Entrepreneurship at the University of Twente, University of Twente, Enschede, pp. 51-54.

Ernst, D. (2010), "Why is Chip Design Moving to Asia? - Drivers and Policy Implications," http://www.nishogakusha-u.ac.jp/pdf/session2/01.pdf. (Accessed 19.12.2010). 
Fallon, M., Walton, A. J., Newsam, M. I., Axelrad, V., and Granik, Y. (1995), "Integration of costing, yield and performance metrics into the TCAD environment through the combination OF DOE and RS,” paper presented at the International Symposium On Semiconductor Manufacturing, 1995.

Foster, J., and Nugent, T. (2000), "Implantation of best known methods," paper presented at the Advanced semiconductor manufacturing conference IEEE/SEMI, 2000. Fowler, F. J. (2002), Survey Research Methods, Sage, Newbury Park, CA.

Globalfoundries (2009), "Global Foundries Breaks Ground on Worlds Most advanced Semiconductor Foundry," http://www.techpowerup.com/forums/archive/index.php/t100054.html. (Accessed 10.12.2010).

Goldratt, E. M., and Cox, J. (2004), The goal, North River Press, Great Barrington.

Goodall, R., Fandel, D., Allan, A., Lander, P., and Huff, H. (2002), "Long term productivity mechanisms of the semiconductor industry," paper presented at the American Electrochemical Society Semiconductor Silicon, 2002.

Guidi, R. L., Paradis, D. E., Whitfiel, M. T., Poag, F. D., and Jenson, D. P. (1999), "Strategy and metrics for wafer handling automation in legacy semiconductor fab", IEEE Transactions on Semiconductor Manufacturing, Vol. 12 No. 1, pp. 102-108.

Hallas, J. F., Kim, J. D., and Mosier, C. T. (1996), "An investigation of operating methods of 0.25 micron semiconductor manufacturing," paper presented at the Winter Stimulation Conference, 1996.

Harms, R., Reschke, H., Kraus, S., and Fink, M. (2010), “Antecedents of innovation and growth: Analyzing the impact of Entrepreneurial Orientation and goal-oriented management", International Journal of Technology Management, Vol. 52 No. 1-2, pp. 135-152.

Hauser, J. R., and Zettelmeyer, F. (1997), "Metrics to evaluate R, D\&E”, Research Technology Management, Vol. 40 No. 4, pp. 32-38.

Hayes, R. H., and Wheelwright, S. C. (1979), "Link Manufacturing Process and Product Life Cycles”, Harvard Business Review, Vol. 57 No. 1-2, pp. 133-140.

Herrmann, J. W., Conaghan, B. F., Lecordier, L. H., Mellacheruvu, P., Nguyen, M. Q., Rubloff, G. W., and Shi, R. Z. (2000), "Understanding the impact and process changes with a heterogeneous semiconductor manufacturing simulation environment," paper presented at the Winter Simulation Conference, 2000. 
Hitt, M. A., Ireland, R. D., Camp, S. M., and Sexton, D. L. (2001), “Guest EditorsÆ Introduction to the Special Issue Strategic Entrepreneurship: Entrepreneurial Strategies for Wealth Creation", Strategic Management Journal, Vol. 22 No. 6/7, pp. 479-491.

Hitt, M. R., Ireland, D., Sirmon, D. G., and Trahms, C. (2011), "Strategic Entrepreneurship: Creating Value for Individuals, Organizations and Society", Academy of Management Perspectives, Vol. 25 No. 2, pp. 57-75.

Ireland, R. D., and Webb, J. (2007), "Strategic Entrepreneurship: Creating Competitive Advantage Through Streams of Innovation”, Business Horizons,, Vol. 50 No. 1, pp. $49-59$.

Ishii, Y., and Watanabe, S. (2002), "Research and development of production control information system tool," paper presented at the Ninth International Symposium on Semiconductor Manufacturing, 2002.

ITRS (2008), "International Technology Roadmap for Semiconductors ITRS 2008 update," http://www.itrs.net/links/2008ITRS/Home2008.htm. (Accessed 12.12.2010).

Jacobs, J. H., Etman, L. F. P., Rooda, J. E., and Van Campen, E. J. (2001), “Quantifying Operational Time Variability: the Missing Parameter for Cycle Time Reduction," paper presented at the Advanced Manufacturing Conference. IEEE/SEMI, 2001.

Katzy, B. R., and Crowston, K. (2008), "Competency rallying for technical innovation - The case of the Virtuelle Fabrik", Technovation, Vol. 28 No. 10, pp. 679-692.

Kautt, M., Walsh, S., and Bittner, K. (2007), "Global distribution of micro-nano technology and fabrication centers: A portfolio analysis approach", Technology Forecasting and Social Change, Vol. 74 No., pp. 1697-1717.

Kilby, J. (2001), "Turning potential into realities: The invention of the integrated circuit", ChemPysChem, Vol. 2 No. 8-9, pp. 482-489.

Kim, J. H., and Lee, T. E. (2003), "Schedule stabilization and robust timing control for timeconstrained cluster tools," paper presented at the IEEE International Conference on Robotics and Automation, 2003.

Kirzner, I. (1997), "Entrepreneurial Discovery and the Competitive Market Process: An Austrian Approach.”, Journal of Economic Literature, Vol. 35 No. 1, pp. 60-85.

Kuratko, D. F., and Audretsch, D. B. (2009), “Strategic Entrepreneurship: Exploring different 110 
perspectives of an emerging concept”, Entrepreneurship Theory \& Practice, Vol. 33 No. 1, pp. 1- 17.

Leachman, R. C., and Hodges, D. A. (1996), "Benchmarking semiconductor manufacturing", Semiconductor Manufacturing, IEEE Transactions, Vol. 9 No. 2, pp.158-169.

Li, Y. H., Huang, J. W., and Tsai, M. T. (2009), "Entrepreneurial orientation and firm performance: The role of knowledge creation process", Industrial Marketing Management, Vol. No. 38, pp. 440449.

Limanond, S., Si, J., and Tsakalis, K. (1998), "Monitoring and control of semiconductor manufacturing processes", IEEE Control Systems, Vol. 18 No. 6, pp. 46-58.

Linton, J., and Walsh, S. (2008), "A theory of innovation for process-based innovations such as nanotechnology”, Technological Forecasting and Social Change, Vol. 75 No. 5, pp. 583-594.

Linton, J. D., and Walsh, S. T. (2004), "Integrating innovation and learning curve theory: An enabler for moving nanotechnologies and other emerging process technologies into production", R\&D Management, Vol. 34 No. 5, pp. 517-526.

Matzler, K., Schwarz, E., Deutinger, N., and Harms, R. (2008), “The Relationship between Transformational Leadership, Product Innovation and Performance in SME", Journal of Small Business and Entrepreneurship, Vol. 21 No. 2, pp. 139-151.

Maynard, D. N., Kerr, D. S., and Whiteside, C. (2003), "Cost of yield," paper presented at the Advanced manufacturing Conference IEEE/SEMI, 2003.

Meyers, M. H., Tertzakian, P., and Utterback, J. M. (1997), "Metrics for managing research and development in the context of the product family", Management Science, Vol. 43 No. 1, pp. 88- 111.

Meyersdorf, D., and Yang, T. (1997), "Cycle time reduction for semiconductor wafer fabrication facilities," paper presented at the Advanced Semiconductor manufacturing Conference, IEEE/SEMI, 1997.

Michelin, G., and Berg, D. (1985), "Evaluating research - ROI is not enough", Harvard Business Review, Vol. 28 No. 3, pp. 15-22.

Mihm, J., Loch, C., and Huchzermeier, A. (2003), "Problem solving oscillations incomplex engineering projects", Management Science, Vol. 49 No. 6, pp. 733-750. 
Miller, D. (2004), “Semiconductor Capital Equipment Manufacturers”, Industry Report, Vol. Aug. 24 No. 2004, pp. 1-22.

Mintzberg, H. (1994), The Rise and Fall of Strategic Planning, Free Press, New York.

Montoya-Torres, J. R. (2006), "Manufacturing performance evaluation in wafer semiconductor factories", International Journal of Productivity and Performance Management, Vol. 55 No. 3-4, pp. 300-310.

Mozumder, P. K., and Loewenstein, L. M. (1992), "Method for semiconductor process optimization using functional representations of spatial variation and selectivity", IEEE Transactions on Components, Hybrids and Manufacturing Technology, Vol. 15 No. 3, pp. 311-316.

Mozumder, P. K., Saxena, S., and Taylor, K. (1994), “Simultaneous control for multiple nonuniformity metrics using site models and monitor wafer controls," paper presented at the Advanced Manufacturing Conference. IEEE/SEMI, 1994.

Myers, D. R., McWhorter, P. J., Converse, C., and Makal, L. A. (2000), "Implications of intelligent, integrated microsystems for product design and development," proceedings of the IEEE Engineering Management Society International Engineering Management Conference, 2000 "Leading Technology Change: Management Issues and Challenges", 2000, pp. 325-330.

Nath, P., Nachiappan, S., and Ramanathan, R. (2010), “The impact of marketing capability, operations capability and diversification strategy on performance: A resource- based view", Industrial Marketing Management, Vol. 39 No. 2, pp. 317-329.

Naughton, A. B. (2005), "Aligning tool set metrics for operation in a multi technology high mix low volume manufacturing environment," http://dspace.mit.edu/handle/1721.1/34852.

(Accessed 10.10.2010).

Ofek, E., and Sarvary, M. (2003), "R\&D, marketing and the success of the next generation products”, Marketing Science, Vol. 22 No. 3, pp. 355-370.

Pich, M. T., Loch, C. H., and Meyer,(2002), "On uncertainty, ambiguity and complexity in project management”, Management Science, Vol. 48 No. 8, pp. 1008-1027.

Prahalad, C., and Hamel, G. (1990), “The core competence of the corporation”, Harvard Business Review, Vol. 68 No. 3, pp. 79-91.

Romig, A., Baker, A., Johannes, J., Zipperian, T., Eijkel, K., Kirchhoff, B., Mani, H. S., Rao, C. R. N., and Walsh, S. (2007), “An introduction to nanotechnology policy: Opportunities and constraints 
for emerging and established economies", Technological Forecasting and Social Change, Vol. 74 No. 9, pp. 1634-1642.

Saarenketo, S., Puumalainen, K., Kuivalainen, O., and Kylइheiko, K. (2009), “A knowledge-based view of growth in new ventures", European Business Review, Vol. 21 No. 6, pp. 531-546.

Sattler, L., Glassey, R. C., and Saeed, B. I. (1997), "Benchmarking semiconductor manufacturing performance using a pairwise-comparision method", IEEE Transactions on Semiconductor Manufacturing, Vol. 10 No. 2, pp. 317-321.

Sattler, L., and Schlueter, R. (1998), "Semiconductor metrics: conflicting goals or increasing opportunities, paper presented at the Advanced Semiconductor Manufacturing Conference and Workshop, Boston, MA, 1998.

Schumann, P. A., Ransley, D. L., and Prestwood, D. C. (1995), "Measuring R\&D Performance", Research Technology Management, Vol. 38 No. 3, pp. 45-55.

Shane, S. (2001), “Technology Regimes and New Firm Formation”, Management Science, Vol. 47 No. 9, pp. 1173-1190.

SIA (2008), "Semiconductor Sales Slowing," 16

http://www10.edacafe.com/nbc/articles/view_article.php?articleid=620281. (Accessed 12.12.2010).

Smith, T., Boning, D., Fang, S., Simon, F., Shinn, G., and Stefani, J. (1999), “A Study of WithinWafer Non-Uniformity Metrics”, in International workshop on Statistical Metrology, pp. 46-49.

Spencer, A. S., Kirchhoff, B. A., and White, C. (2008), "Entrepreneurship, Innovation, and Wealth Distribution: The Essence of Creative Destruction"', International Small Business Journal, Vol. 26 No. 1, pp. 9-26.

Szakonyi, R. (1994), “Measuring R\&D Effectiveness - I”, Research TechnologyManagement, Vol. 37 No. 2, pp. 27-32.

Teece, D. J. (1988), “Capturing Value from Technological Innovation: Integration, Strategic Partnering, and Licensing Decisions”, Interfaces, Vol. 18 No. 3, pp. 46-61.

Terziovski, M. (2010), "Innovation practice and its performance implications in small and medium enterprises (SMEs) in the manufacturing sector: a resource-based view", Strategic Management Journal, Vol. 31 No. 8, pp. 892-902. 
Thukral, I., Von Her, J., Walsh, S., Groen, A., Van de Sijde, P., and Akmaliah, A. K. (2008), "Entrepreneurship, Emerging Technologies, Emerging Markets", International Small Business Journal, Vol. 26 No. 1, pp. 101-116.

Van Heeren, H., Butler, P., Walsh, S. T., Elders, J., Cho, D.-I., and Yang, Y. (2003), "Status and Future of Microsystems/MEMS Foundries", in MANCEF (Ed.) International Roadmap on

MEMS, Microsystems, Micromachining and Top Down Nanotechnology, MANCEF, Naples, FL, pp. 435-455.

Wagner, L. C. (2001), "Failure Analysis Challenges," paper presented at the International symposium on the physical and failure analysis of integrated circuits, 2001.

Walsh, S. (2004), "Roadmapping a Disruptive Technology: A Case Study The Emerging Microsystems and Top-Down Nanosystems Industry", Technological Forecasting and Social Change, Vol. 71 No. 1, pp. 161-185.

Walsh, S., Boylan, R., Carr, W., Warrington, R., and Elders, J. (1996), "The strategic development of HARM manufacturing technologies", Microsystems Technologies, Vol. 43 No. 1, pp. 11-26.

Walsh, S., and Linton, J. (2000), "Infrastructure for Emerging Markets Based on Discontinuous Innovations", Engineering Management Journal, Vol. 12 No. 2, pp. 23-31.

Walsh, S., Linton, J., Grace, R., Marshall, S., and Knutt, J. (2000), "MEMS, microsystems, micro machines: Commercializing an emergent disruptive technology”, Rai-Choudhury, P. (Ed.) MEMS and MOEMS technology and applications, SPIE Press, Bellingham, WA, pp. 479-514.

Walsh, S. T., and Linton, J. D. (2011), "The Strategy-Technology Firm Fit Audit: A Guide to Opportunity Assessment and Selection", Technological Forecasting and Social Change, Vol. 78 No. 2, pp. 199-216.

Werner, B. M., and Souder, W. E. (1994), "Measuring R\&D performance - state of the art", Research Technology Management, Vol. 40 No. 2, pp. 34-42.

Williamson, O. E. (1985), The Economic Institutions of Capitalism, Free Press, New York. Wu, B. P. F. (2002), "Innovations for economical 300/450 IC fabricators," proceedings of the Advanced Manufacturing Conference. IEEE/SEMI, 2002, pp. 150-154.

Yin, R. K. (2009), Case Study Research: Design and Methods, Sage, Thousand Oaks, Calif. 


\title{
Section 4
}

\section{A strategic model for firms: Who seek to embrace Nanomanufacturing}

\author{
By \\ Robert Tierney* \\ University of New Mexico, \\ New Mexico, USA \\ E-mail: rtierney@unm.edu \\ *Corresponding author \\ Steven Walsh \\ Albert Franklin Black Professor of Entrepreneurship, \\ Anderson Schools of Management, \\ The University of New Mexico, \\ New Mexico, USA \\ E-mail:walsh@unm.edu
}

Reproduced with permission from Inderscience Publishing. Article originally appeared in

International Journal of Technology Transfer and Commerialisation 2008 Volume 7 Number 2/3 pp.171-

181.

Citations presented in accordance to journal requirements 


\section{Section 4.1 Abstract and Keywords}

The term 'nanotechnology' has captured the technological and economic interest of technologists and business professionals alike. The commercial interest in nanotechnology is overwhelming and the term often misrepresented. This is especially evident in nanotechnology market projections, which have risen dramatically over the past 5-10 years as more and more traditional 'product families' are engulfed by the diffusion terminology and then are included in these projections. Nanomanufacturing is seen as a potential Schumpeterian or Kondratief waves (Schumpeter, 1934, 1942; Kondratief, 1937); yet manufacturing processes have been shown to be greatly different in various industrial sectors. The hurdles and problems facing the companies are as diverse as those sectors. This paper seeks to make a contribution by offering a categorization scheme for nanomanufacturing based on the types of hurdles that firms are quite likely to encounter and provide some case base examples of both evolutionary and revolutionary nanomanufactured products.

Keywords: nanomanufacturing; nanoscale science; MEMS; microsystems technology; disruptive technology; top-down nanotechnology; bottom-up nanotechnology. 


\section{Section 4.2 Introduction}

The authors initiate the discussion on nanomanufacturing through a definition of the term nanomanufacturing. This definition cannot be made without an understanding of both nanotechnology and nanoscience. Nanomanufacturing, nanotechnology and nanoscience are three words, which are often used interchangeably. The authors in the introduction will provide a definition for these terms that will provide the basis for our argument.

Nanomanufacturing has been singled out as a key enabler for the future of many regional manufacturing sectors including manufacturing in the USA, Canada, Brazil, Spain, France, the UK, Germany, Japan and many of the traditional G14, but also has been highlighted by emerging economies such as China, India, Taiwan and Singapore. Yet, little infrastructure exists for true controlled nanomanufacturing. Indeed, many of the pioneering nanomanufacturing firms such as Ferrofluidics started in 1968 with their ferrofluids bearing for hard disks do not even use the term nanomanufacturing.

Most regions or countries in the world are focused on creating availability of nanotechnology (Kautt et al., 2007) and initiation of nanomanufacturing infrastructure. Strong measurement and test infrastructure is vital for its success. For example, the USA's own NIST is responsible for providing traceability and currently is utilising SBIR programs and other measures to develop measurement capabilities and calibration standards. Some studies have stated that in the near future, a plurality of designed advanced materials and manufacturing processes will be built at the nanoscale (Walsh et al., 2005). Yet nanomanufacturing means more than nanotechnology; it requires infrastructure development in measurement science (metrology) and advanced instrumentation (Walsh and Linton, 2000). Nanomanufacturing concerns itself about measurement and test because if you cannot measure it, you cannot make it or manage it 
(Walsh, 2004). Successful metrology infrastructure is essential for manufacturers to achieve the real promise of developing and manufacturing new nanomaterials, devices, and products as many new firms like Zyvex have had to learn (Thukral et al., 2008). The US National Nanotechnology Initiative (NNI) (www.nano.gov) states the vital importance of instrumentation and metrology with excerpts from their Grand Challenge workshop final report.

If this is what nanomanufacturing is, then what is nanotechnology and nanoscience on which it is based? Thoughts on nanotechnology were initiated by Feynman (1959) and developed through Nobel winning efforts have Smalley (2005) and others. Nanotechnology truly has caught the imagination of the world. Yet in Taniguchi, a giant name in technology commercialization, defined the field as:

"The name of 'Nano-technology' originates from this nanometer. In the processing of materials, the smallest bit size of stock removal, accretion or flow of materials is probably of one atom or one molecule namely $0.1-$ $0.2 \mathrm{~nm}$ in length. Therefore, the expected limit size of fineness would be of the order of $1 \mathrm{~nm}$. Accordingly, 'Nano-technology' mainly consists of the processing of separation, consolidation and deformation of materials by one atom or one molecule." (Taniguchi, 1974)

Industries have been commercializing this technology based on bulk nanoreactions for hundreds of years (e.g., Steel) albeit passively. IBM in 1990 provided their LOGO a written effort with Xenon atoms spelling IBM. Technologists and firms were investigating nano- reactions in custom catalysts and microbiology from the 1930s and intensifying in the 1950s and 1960s. The commercial definition is attributed to Drexler (1986) as expressed in his work the 'Engines of Creation'. In any case, the definition has migrated with professional emphasis and the intensity of commercial interest.

Further pioneering firms utilizing nano-based solutions simply did not enjoy a common vocabulary to describe themselves. For example, Dr. Al Chorney, former Vice president of one of the first 'Modern Day' nanotechnology-based firms, Ferrofluidics 119 
Inc., which was founded in the 1960s and now president of SC Fluids stated:

"...We simply did not know or use the term (Nanotechnology) to describe how our firm's technology base provided unique value to our customers we just knew we built unique products based on a unique technology base ... it is gratifying to have the popular press and others give firms like ours a name."

Here, we use the US NNI definition (www.nano.gov). It is often cited as one of the most useful and explicative. Furthermore, they acknowledge that many other definitions exist. They suggest that a certain technology can be considered a nanotechnology only if it involves all of the following three attributes:

1) Research and technology development at the atomic, molecular or macromolecular levels, in the length scale of approximately 1-100 nm range.

2) Creation and use of structures, devices and systems that have novel properties and functions because of their small and/or intermediate size.

$$
\text { An ability to control or manipulate on the atomic scale. }
$$

Nanotechnology is the third small manufacturing revolution based, but distinctly related to the first two revolutions: Semiconductor Micro Fabrication and Micro Electro Mechanical Systems (MEMS). Micro fabrication leverages the skill set of electrical engineers and MEMS those of mechanical engineers whereas nanotechnology leverages the skill sets of materials and chemical-based engineering and physical sciences.

What then is 'Nanoscience'? How is it different than nanotechnology and nanomanufacturing? Here, the authors looked to the members of the Royal Academy of Science to seek a bifurcation of nanoscience and nanotechnology terminology (http://www.royalsoc.ac.uk/landing). They and other similar organizations separate nanoscience and nanotechnology for clarity of research definitions. To paraphrase, this group: 
"Nanoscience is concerned with the study of novel phenomena and properties of materials that occur at extremely small length scales - 'on the scale of atoms and molecules'. Whereas, Nanotechnology is the application of nanoscale science, engineering and technology to produce novel materials and devices, including materials for biological, medical applications and other commercial applications."

Our effort is based on adding to this literature stream by delineating manufacturing categories, which are distinctly different and offer diverse challenges to firms that seek to create competitive advantages built on this technology base. We view nanomanufacturing as a firm's or corporate effort to take advantage of nanotechnologies promise as an enabling (Linton and Walsh, 2008a), disruptive (Abernathy and Clark, 1985; Foster, 1986; Walsh et al., 2005; Christianson, 1997) technology that is the harbinger of the next Schumpeterian (1935) wave of economic change.

\section{Section 4.3 Literature Review}

Categorization can assist firms in developing tactical as well as manufacturing strategies. There is a foundation from which nanomanufacturing can occur with the best chance of success. As a basis of our effort, we build on these basis models as stated here.

Physical and service-based product manufacturing were segmented earlier through product and process innovation cycles (Linton and Walsh, 2003). Three distinct products vs. process innovation theories are linked directly to differing manufacturing regimes. Abernathy and Utterback (1978) theories are systems integration based and suggest that product innovation occurs prior to process innovation and this has been shown to be relevant for industries like automobiles and computer systems such as those developed like Dell. Barras (1986) effort dispelled the prevailing thought that product innovation always preceded process innovation and shows that, in fact, quite the contrary pattern is dominant in the service sector where indeed process or infrastructure innovation precedes that of product. This is most easily visualized by MacDonald's having the infrastructure in place and in the 1980s initiating a new service product, such as breakfast. Finally, 121 
Linton and Walsh (2008b) state that some materials manufactured products such as nanomanufacturing follow neither of these patterns, because product and process innovation occur simultaneously.

These patterns have implications on how firms introduce new manufacturing processes as well as measurement techniques such as total quality control. Further, these patterns suggest which firms are more likely to be adept at entering into nanomanufacturing efforts. Firms have rarely been shown to be adaptive in manufacturing in all three sectors and much more likely to have manufacturing, measurement and test processes that work well in only one. Yet, for those who are pioneers in nanomanufacturing, rarely do they have the luxury of a robust infrastructure and many, for example Zyvex, must develop their own testing vehicles as well as nanomaterials. They might be very good at only one practice, but how do these firms achieve results at the others to embrace nanotechnology in an era of Ferment where many will be expected not only to make the nanotechnology-based products, which they will focus on, but also to produce the manufacturing and test equipment they need to produce them.

One way to aid nano-pioneers is to provide them with a manufacturing tool that can assist them by placing themselves in a sector, which helps to understand the types of challenges that they are likely to face in the manufacturing environment. The literature above shows us the great variation in general manufacturing categories, but how can we segment the challenges of nanomanufacturing still finer to get a better understanding of the potential hurdles.

\section{Section 4.4 Methods and Model Building}

We utilize a case-based method (Eisenhardt, 1989) to help develop a theory-based model to explain the differing nanomanufacturing challenges a firm might face. Here, 
we utilize three concepts that are based on previous efforts and are built from descriptive works on nanotechnology and management of technology theory. The three bifurcated concepts are:

- $\quad$ 'Top-down vs. bottom-up' (Walsh and Elders, 2003), a descriptive discussion concerning alternative manners of approaching nanomanufacturing.

- $\quad$ 'Bulk vs. Anatomically Precise Manufacturing' (Walsh et al., 2006a, 2006b) a descriptive term concerning nanotechnology used to determine the amount of direct engineering control concerning a nanomanufactured product.

- 'Evolutionary vs. Revolutionary' (Mansfield, 1968; Kirchhoff and Walsh, 2000).

These terms are derived from a management of technology theory and are focused on the use of a current technology product manufacturing paradigm (evolutionary) or a completely new one (revolutionary).

Nanotechnology is a part of both the second and third micro (and small technology) revolutions. This is seen most directly through the 'top-down vs. bottomup' distinction. Top- down nanotechnology is a lithographic-based process that follows MEMS and semiconductor- like processes. The first small technology manufacturing revolution was semiconductor micro- fabrication, a lithographic-based technology that has used precise engineering control of nanotechnology since its beginning. This technology continues to leverage the skills of the electrical engineer and designer, as well as the materials and chemical engineering fabricators. This technology has a unit cell device and has been progressing along what is popularly called 'Moore's Law' and top-down nanotechnology is extending this original technology product paradigm (Hamilton, 2003). It is interesting to note that nanotechnology has been employed in the manufacture of semiconductors (doping, dielectrics, etc.) since its inception. Furthermore, as the industry pushes down into the narrower conducting line widths 
theorized by Moore's Law, many of the critical dimensions already are manufactured at the nanometre scale.

Further, 'top-down' nanotechnology is an extension of Microsystems technology or MEMS (Elders and Walsh, 2003). MEMS is commonly thought of as the second micromanufacturing revolution. This technology leverages the skills of both electrical and mechanical designers at interfaces with biologists, chemists, physicists, and materials scientists and engineers to make thicker 3D microstructures. This technology is similar to their semiconductor micro-fabrication cousins since it is based on lithographic processes. Top-down nano-systems often focus on materials, fluidics, optical and biological systems. Terms such as Nano-Electro-Mechanical Systems (NEMS) are sometimes used to distinguish the Nano from the MEMS-based systems. Nanopatterning is an example of an NEMS process.

'Bottom-up' (Elders et al., 2003) nanotechnology is totally distinct from the first two waves of small technology manufacturing. First, it is not a lithography-based process. Bottom-up nanomanufacturing focuses on the build-up of structures, in a broad variety of applications, using atom-by-atom or molecule-by-molecule techniques sometimes controlling naturally occurring processes. It can be inorganic or organic in nature and emphasizes leveraging the skills of materials, molecular, chemical, biological, mechanical and electrical technology professionals.

The next categorization scheme that we wish to incorporate into our model is the differentiation between bulk and atomically addressed nanotechnology. This helps to align the competencies in an organization. This addresses the manner in which a manufacturing industry develops a product based on nanotechnology. This typology of effort is based on taxonomy of proactively engineered bottom-up nanotechnology. In this scheme, bulk nanotechnologies are differentiated from individually addressed 
nanotechnologies (Rahal et al., 2005).

Different material manufacturers or active bulk nanotechnology manufacturers often separate bulk nanotechnologies into passive engineered and actively designed bulk nanotechnologies. Bulk nanotechnology is the production of inorganic or organic materials in such a manner as to obtain nanotechnology-based attributes in the materials that are being produced. This manufacturing methodology controls the development of nanometer-based materials for their inclusion in products. These nanoproducts are used to make existing materials better, faster and/or cheaper. For example, the steel industry and various chemical-based industries have been using bulk nanotechnology reactions to assist in the production and improvement of their products for centuries. This is an example of passive engineered bulk nanotechnology, which is now becoming active with the increased scientific and technical understanding.

Individually addressed nanotechnology is the atom-by-atom or molecule-bymolecule manufacture of organic or inorganic material. Individually addressed nanotechnology is often associated with self-assembly of biological materials, or chemical-based systems. They often require climate-controlled, particulatecontrolled or other environmentally controlled chemically good manufacturing practice. This is a much more difficult type of manufacturing. These manufacturing technologies are newer than most bulk applications.

Finally, our model seeks to include the disruptive nature of nanotechnology. Nanotechnology's potential for strategic impact is directly proportional to the magnitude of the impact that it can provide to a firm in revolutionizing the way a current product is made. Revolutionary manufacturing occurs when a new technology product paradigm is developed, which provides an alternative pathway utilizing none of the skill sets used in the previous method to manufacture a 
similar product. It is revolutionary and disruptive if that pathway is vastly superior to the previous pathway. Figure 4.1 shows a technology $S$-curve of a traditional power device (vacuum tubes) being eclipsed by a revolutionary and disruptive technology base (transistors) because of its ability to outperform the former on many critical dimensions including reliability cost, capacity and others; here we show the technology pathways on only one method.

Figure 4.1: Evolutionary vs. revolutionary technology pathways

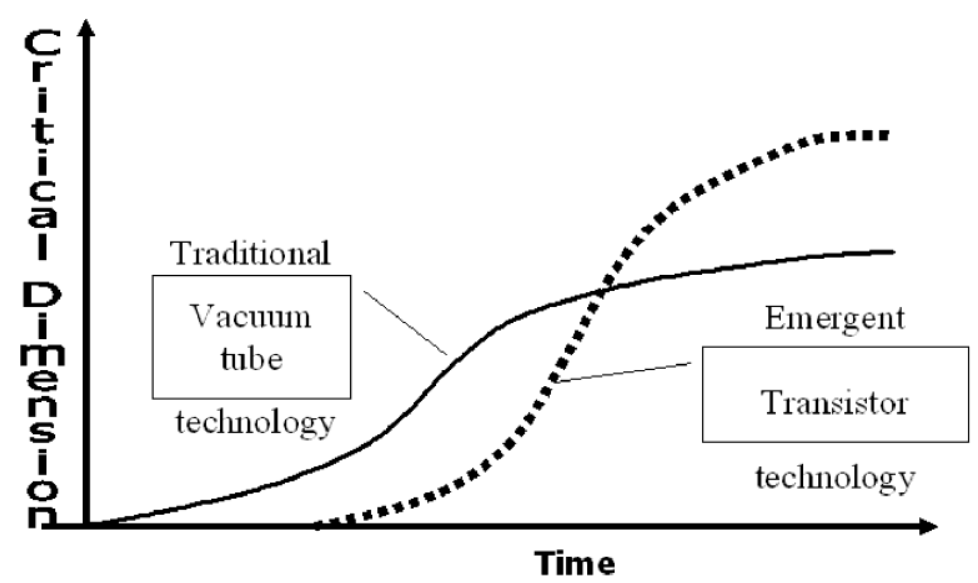

Ex: Vacuum tubes v. transistors

A technology is potentially disruptive (creates a revolutionary manufacturing method) if it can alter the way to manufacture an existing product, and in doing so create a superior technology product paradigm. Further, the technology is also said to be disruptive if it can create a new technology product paradigm. In either case, a disruptive technology renders the base skills associated with the old technology useless, and makes the previously used infrastructure obsolete. When successful, a disruptive technology becomes the sustaining technology for the new industry. Finally, a disruptive technology does not have to change the form factors of a product and may be completely transparent to an intermediate or end-user. Nano-computing or the Nano-based Ferrofluidics bearing systems are examples of nanotechnologies acting as disruptive or 
potentially disruptive technologies. This type of manufacturing technology development is often called 'creative destruction' (Abernathy and Clark, 1985) or 'catching the wave' (Bower and Christensen, 1995).

On the other hand, a technology is said to be evolutionary or sustaining when it supports the current technology/product paradigm. An example of evolutionary nanotechnology development is the creation of superior crystalline development (grainsize) in metals. The development of fine structures at the nanometer scale in sophisticated cold-rolled (of specially alloyed steels), the development of nano-crystalline aluminum and nano-crystalline powder technologies in ceramics are examples of nanotechnology acting as an evolutionary or sustaining technology. Marquis (1969) and Florida and Kinney (1990) and others have shown that this form of innovation takes advantage of existing manufacturing and marketing infrastructure and is embraced by existing customers.

\section{Section 4.5 The Strategic Nanomanufacturing Model}

Here, we specifically focus on three bifurcation schemes that when used in unison can assist firms that embrace nanotechnology (see Figure 2). Firms that utilize nanotechnology, as is basis for their search for strategic competitive advantage, can choose the type of nanomanufacturing environment they would like to pursue. In general, the risk and potential reward will increase as a firm moves away from the lower left-hand box. Further risk and reward will increase as the firm chooses more revolutionary options over evolutionary choices. 
Figure 4.2: Strategic Nanomanufacturing models

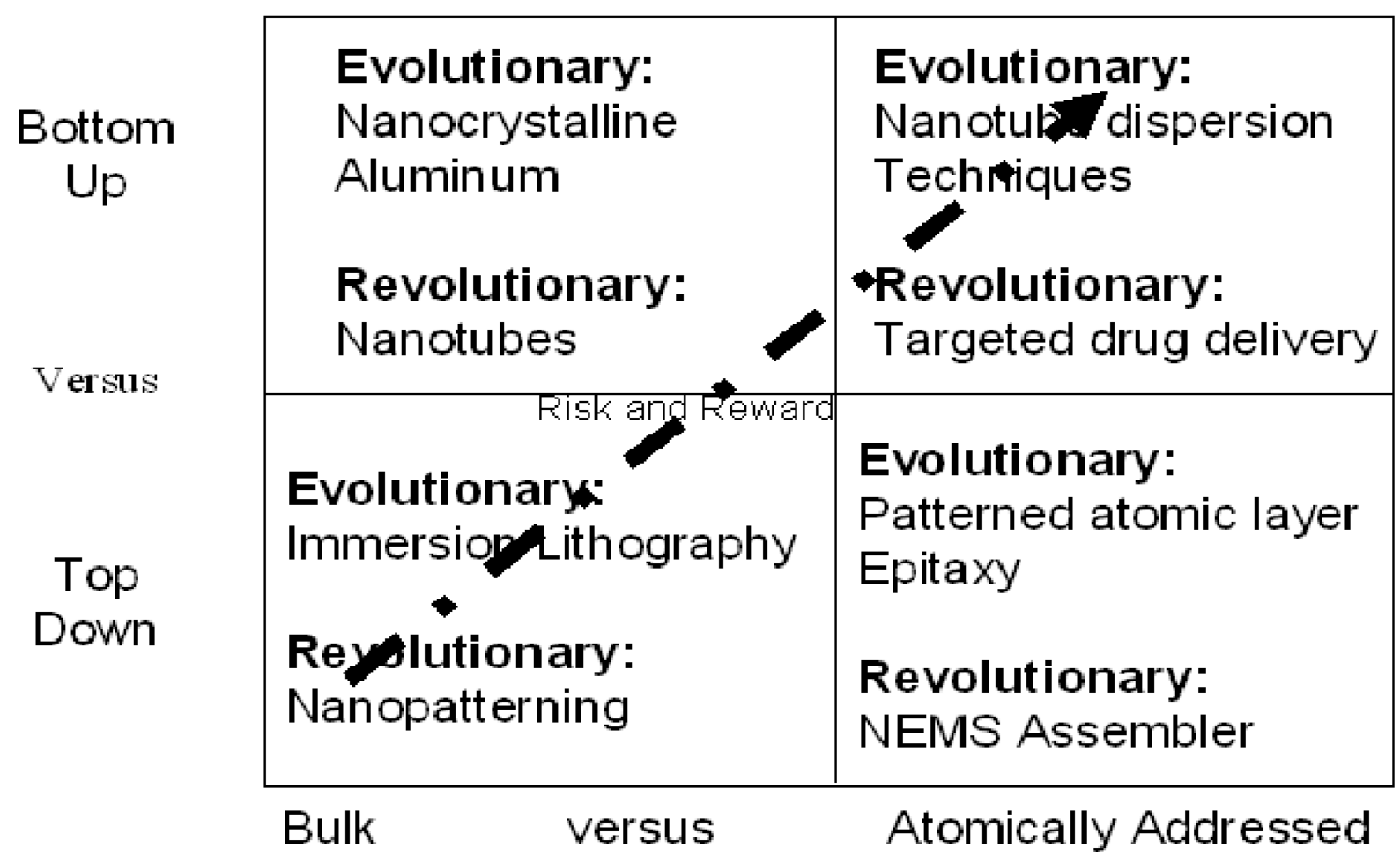

Finally, the type of complementary manufacturing assets (Frohman, 1980; Prahalad and Hamel, 1990), which are available as a firm from the industry diminishes as the firm chooses more revolutionary manufacturing options. The firms will have to themselves develop more infrastructures, greatly increasing the hurdles to overcome in order to be successful, the same time making it much more difficult for a firm to compete if they are successful with their choices. The authors now provide some examples to highlight the difficulties that many firms face when embracing nanomanufacturing-based solutions.

Nanostructured materials are a revolutionary batch produced by manufacturing technology and are represented in the upper left-hand quadrant of our model shown in Figure 4.2. Nanostructured materials have the potential to destroy the advantages of 
established firms' technical competencies. Consequently, the applications of innovations are not as apparent as those for evolutionary technologies or the risks for the nanomanufacturing firm on the market side. The technology is still at the science stage. Based on the characteristics of the technology, a laboratory such as Sandia National Laboratories might be sought as a complementary asset, to provide a funds-in research agreement with a duration of 1-5 years with partners that are either entrepreneurial and/or large firms. There is no guarantee that the manufacturing process would be a success inducing risk along the manufacturing side.

A firm might be interested in semiconductor nanolithography. Here, immersion technology might be applied to extend current semiconductor micro-lithographic techniques into the nanometer critical dimension level. This would place that firm in the lower left-hand quadrant of our strategic nanomanufacturing model, which we show in Figure 4.2. The market is shown here (semiconductor producers) limiting risk on the market side. Similarly, it is an extension of an existing technology product paradigm and would support existing infrastructure. It is an evolution rather than a revolution in product technology. One would expect existing firms in the field to embrace the developing challenge of $23 \mathrm{~nm}$ lithography on the half pitch. An example, ASML, the product leader, with well over $50 \%$ of the $\$ 6-8$ billion stepper market are on the 4 th generation immersion lithographic equipment and dominate the nanometer lithography field utilizing mostly their internal complementary assets.

Revolutionary bottom-up atomically addressed nanomanufacturing opportunities shown in the top right-hand corner of our strategic nanomanufacturing model is perhaps the most difficult for any firm to address but holds true near monopolistic or Ricardian rent opportunities. Firms that produce drugs like Zevalin, which directly targets an infected cell in this case, non-Hodgkin's lymphoma, are producing products never before 
attempted. They are fundamentally changing medical care from treating the system or the body to treating the disease at the cellular level. They encounter regulatory and market risks in a number of arenas. Further, they may create differing type one errors and type two errors that require new testing and metrology techniques for quality assurance and quality control. They will have to provide their own infrastructure in test, manufacturing, quality assurance and quality control.

Finally, we address those firms embracing top-down atomically addressed evolutionary nanomanufacturing shown in our model in the lower right-hand corner. Successful firms embracing this quadrant are probably going to be industry leaders (Mensch, 1993). An example would be IBM utilizing their analytical techniques embraced Patterned atomic layer Epitaxy. A consortium of established firms, including producers of existing equipment and manufacturers, are embracing these technologies.

Products manufactured utilizing these nanomanufacturing technologies develop into the stands upon which other technologies are based.

\section{Section 4.6 Conclusions and Future Efforts}

The authors have presented a strategic nanomanufacturing choice model based on the existing literature. The examples in this model are relative and temporal. What is revolutionary today might well become the sustaining technology manufacturing base that is evolutionary ten years from now. Nanomanufacturing, in all of its forms, is risky business. Yet, it is an enabling technology that many believe to be the base for a new Schumpeterian economy wave. It is poised to create new industries and greatly change current industries.

This effort suggests that more study should be conducted into how a firm should strategically use external parents like national laboratories; how these and other complementary assets can be used to lower the risks for a firm to embrace nanotechnology. 
Further, it suggests more study into the differing resource requirements necessary to embrace each of the four strategic nanomanufacturing quadrants. Finally, the authors are investigating an options type approach for established firms to embrace nanomanufacturing in its varied forms. Risk will increase as will the value of doing so with the knowledge of the potential model nanotechnologies have been bifurcated into 'top-down nano', which is a direct extension of microsystems lithographic systems into the nano-range and 'bottom-up nano', which is more of the atom-by-atom creation of materials-based system. Further, a finer distinction can be made between bulk version individually addressed nanotechnologies. 


\section{Section 4.7. References}

Abernathy, W.J. and Clark, K.B. (1985) 'Innovation: mapping the winds of creative destruction', Research Policy, Vol. 14, pp.3-22.

Abernathy, W.J. and Utterback, J.W. (1978) 'A dynamic model of product and process innovation', Technology Review, Vol. 80, No. 7, pp.40-47.

Barras, R. (1986) 'Towards a theory of innovation in services', Research Policy, Vol. 15, No. 4, pp.161-173.

Bower, J.L. and Christensen, C.M. (1995) 'Disruptive technologies: catching the wave',Harvard Business Review, Vol. 73, No. 1, pp.43-53.

Christensen, C.M. (1997) The Innovator's Dilemma: When New Technologies Cause Great Firms to Fail, Harvard Business School Press, Boston, Mass.

Drexler, K.E. (1986) Engines of Creation: The Coming Era of Nanotechnology, Anchor Books, New York.

Eisenhardt, K.M. (1989) 'Building theories from case study research', Academy of Management Review, Vol. 14, No. 4, pp.532-550.

Elders, J. and Walsh, S. (Eds.) (2003) International Roadmap on MEMS, Microsystems, Micromachining and Top Down Nanotechnology, MANCEF, Naples, Florida, p.614.

Feynman, R.P. (1959) 'There's plenty of room at the bottom, lecture at the American Physical Society, Caltech', The Pleasure of Finding Things Out and the Meaning of It All, Perseus Books Group, 2002.

Florida, R. and Kinney, M. (1990) The Breakthrough Illusion, Basic, NY. Foster,

R.N. (1986) Innovation: The Attacker's Advantage, McKinsey and

company, New York. Frohman, A.L. (1980) 'Managing the company's

technological assets', Research Management, Vol. 9, pp.20-24.

Hamilton, S. (2003) 'Intel reseach extends Moor's law', Computer, Vol. 36, No. 1, pp.31-40.

Kautt, M., Walsh, S. and Bittner, K. (2007) 'Global distribution of micro-nano technology and fabrication centers: a portfolio analysis approach', Technology Forecasting and Social Change, Vol. 74, pp.1697-1717.

Kirchhoff, B. and Walsh, S. (2000) 'Entrepreneurship's role in commercialization of disruptive technologies', Unternehmer und Unternehmensperspektive fur Klien-und Mittelunternehmen, Dunker \& Humbolt Berlin/St. Gallen, Band 13, pp.323-332.

Kondratief, N.D. (1937) Long Waves in Economic Life, Lloyds Bank Review, July 1978.

Linton, J. and Walsh, S. (2003) 'From bench to business', Nature of Materials, Vol. 2, May, pp.287-289. 
Linton, J. and Walsh, S. (2008b) 'A theory of innovation for process-based innovations such as nanotechnology', Technological Forecasting and Social Change, Available online, January.

Linton, J.D. and Walsh, S. (2008a) 'Acceleration and extension of opportunity recognition for nanotechnologies and other emerging technologies', International Small Business Journal, Vol. 26, No 1, pp.83-101

Mansfield, E. (1968) The Economics of Technological Change, W.W. Norton, New York.

Marquis, D.G. (1969) 'The anatomy of successful innovations', in Tushman, M.L. and Moore, W. (Eds.): Readings in the Management of Innovation, 2nd ed., Ballinger, pp.79-87.

Mensch, G.O. (1993) 'A managerial tool for diagnosing structural readiness for breakthrough innovations in large bureaucracies', in Kuhn, R.L. (Ed.): Generating Creativity and Innovation in Large Bureaucracies, Quorum Books, Westport, CT, pp.257-283.

Prahalad, C.K and Hamel, G. (1990) 'The core competence of the corporation', Harvard Business Review, pp.79-91.

Rahal, N., Walsh, S., Bryant, S., Hartley, F., Burns, D.H. and Yun, W. (2005) An Analysis of Microtechnology and Nanotechnology Patent, MANCEF, Naples, Florida, p.112.

Ricardo, D. (1817) Principals of Political Economy and Taxation, J. Murray, London.

Schumpeter, J.A. (1934) The Theory of Economic Development: An Inquiry into Profits, Capital, Credit, Interest and the Business Cycle, transl. of 2nd German edn., Oxford University Press, London.

Schumpeter, J.A. (1942) Capitalism, Socialism and Democracy, 3rd edn., Harper, 1950, New York. Smalley, R.E. (2005) 'Future global energy prosperity: the terawatt challenge', MRS Bulletin,Vol. 30, pp.412-417.

Taniguchi, N. (1974) On the Basic Concept of Nanotechnology, ICPE. Thukral, I., von Ehr, J., Walsh, S., Greon, A., van de Sijde, P. and Adham, K.A. (2008)

'Entrepreneurship, emerging technologies, emerging markets', International Small Business Journal, Vol. 26, No. 1, February, pp.101-116.

Walsh, S. (2004) 'Roadmapping a disruptive technology: a case study 'The Emerging Microsystems and Top-Down Nanosystems Industry', Technological Forecasting and Social Change, Elsevier Science, January 2004, Vol. 71, No. 1, pp.161-185.

Walsh, S. and Elders, J. (Eds.) (2003) International Roadmap on MEMS, Microsystems, Micromachining and Top Down Nanotechnology, MANCEF, Naples, Florida, p.614.

Walsh, S. and Linton, J. (2000) 'Infrastructure for emerging markets based on discontinuous innovations', Engineering Management Journal, Vol. 12, No. 2, pp.2331 .

Walsh, S., Boylan, R., McDermott, C. and Paulson, A. (2005) 'The semiconductor silicon industry roadmap: epochs driven by the dynamics between disruptive technologies and core competencies', Technological Forecasting and Social Change, Vol. 72, No. 2, February, pp.213-236. 
Walsh, S., Eijkel, K., Hruby, J., Kubiak., G., Scott, M., Brokaw, J., Saile, V., White, C. and Walsh, S. (2006a) 'The technological and commercial promise of nanopatterning', Journal of Microlithography, Microfabrication, and Microsystems (JM3), Vol. 1, Nos. 1-6, p.011001.

Walsh, S., Eijkel, K., Hruby, J., Kubiak, G., Scott, M. and Saile, V. (2006b) 'The technological and commercial promise of nanopatterning', Journal of Microlithography, Microfabrication, and Microsystems $\left(J M^{3}\right)$, Vol. 1, Nos. 1- 6, p.011001.

Walsh, S., Williams, D., Cellucci, T., Linton, J., Newberry, D., Walsh, D., Atherton, P., Eijkel, K., Tahal, N. and Giasolli, R. (2005) International Nanotechnology Atomically Precise Manufacturing Roadmap, MANCEF, Naples, Florida, p.131. 


\section{Websites}

The Royal Society Nanoscience and nanotechnology website: http://www.royalsoc.ac.uk /landing.asp? $\mathrm{id}=1210$

The US National nanotechnology Institutive, WWW.nano.gov 


\title{
Section 5
}

\section{Publish or Perish: How Are Research and Reputation Related?}

\author{
By
}

Jonathan D. Linton, Robert Tierney and Steven T. Walsh

Reproduced with permission from Elsevier Publishing Inc. Article originally appeared in Serials Review 2011 (37) pp. 244-257.

Citations presented in accordance to journal requirements 


\section{Section 5.1 Abstract and Keywords}

A study of twenty-seven fields in 350 highly ranked universities examines the relationship between reputation and rank. We find that many metrics associated with research prowess significantly correlate to university reputation. However, the next logical step, looking at the relationship that links different academic fields with the reputation of the university, did not always offer the expected results. The phrase "publish or perish" clearly has very different meanings in different fields.

Keywords: Academic reputation; Interdisciplinary studies; Publish or perish; University research reputation 


\section{Section 5.2 Introduction}

Does research status have a direct link to ranking of a university? A better understanding of the relationship between research and ranking is worthwhile as great emphasis is placed both on rankings ${ }^{1-7}$ and research activity ${ }^{1-4}$. In fact, rankings of programs, departments, faculties and universities appear to be of great interest in helping outside stakeholders assess relative quality ${ }^{1}$, 3-12. Consequently, the basis of rankings is important regardless of their accuracy. While universities have the role of creating, storing, and disseminating knowledge, there appears to be general agreement that evaluation of an institute of higher learning weighs heavily on the creation of information research. This study explores the reality of this assumption.

In an environment that places a tremendous value on research (creation of knowledge) the message to professors at universities for the last half century has been publish or perish ${ }^{13-23}$. The publish or perish message has been consistent for decades regardless of one's geographical location ${ }^{4,24-29}$ or field of study ${ }^{22,23,28-35}$. This mantra has raised a variety of concerns among academics, including self-plagiarism, ${ }^{36}$ proliferation of articles and publications ${ }^{23,37-41}$, increases in number of authors per article ${ }^{41-43}$ and the assessment of research contribution ${ }^{44-46}$ being replaced by a focus on counting the number of articles. ${ }^{47,48}$ Further questions regarding quality and quantity have been raised by the role that the Internet ${ }^{34,49-52}$ plays in the dissemination of information and the emerging movement of open access publishing. ${ }^{53-56}$ Attempts to address concerns regarding issues of quality and quantity have resulted in a number of alternatives to evaluation, including citation counts, ${ }^{4,57-59}$ journal impact scores, ${ }^{52,60-63}$ Hirsch Indices, ${ }^{52,64,65}$ journal reputation studies, ${ }^{48,63,66-69}$ and Internet citation rates. ${ }^{70,71}$

The result has been a proliferation of measures to assess research, researchers, research outlets, and the locations in which the research occurs. By empirically assessing the relationship 
between institution ranking and research production, a better understanding of the relationship between the perceived quality of institutions, the creation of knowledge and the storing of knowledge is possible. As perceived ranking is critical to a university in terms of recruiting donors, faculty, staff and students as well as engaging other stakeholders; the question of whether research is a driver of reputation is a critical question. It also offers insights into whether or not the "publish or perish" should be encouraged by university administrations. This is clearly a critical question when addressing support for library resources and acquisitions - the repositories and access point to published materials.

To better understand the role of reputation and publishing, one can determine whether a statistical relationship does in fact exist between the two. In order to address the concern raised over proliferation and lack of quality, ${ }^{56}$ it is critical to pick an archival source that acts as some reasonable measure of quality. Consequently an archival database such as Scopus is advisable, as it tracks a select group of journals and allows one to obtain a variety of publication metrics. The unit of analysis in this study is that of the university; however, similar studies could be conducted to assess the role of research on faculties, departments, research groups or programs. Having addressed the question of level of analysis, suitable metrics to compare research and reputation are now considered.

\subsubsection{Determination of an Institution's Reputation}

There is tremendous variation in the manner in which programs, departments, faculties, and

universities are assessed. Each stake-holder may use a combination of these assessments to make their personal evaluation. Ranking systems have been developed by both public and private organizations to consider the relevant ranking institutions in specific countries, such as Canada, ${ }^{72}$ Germany, ${ }^{73}$ Taiwan, ${ }^{4} \mathrm{UK},{ }^{74}$ the USA, ${ }^{11}$ and internationally ${ }^{75-78}$ or in specific fields of study. ${ }^{2,8}$, 
9 Unsurprisingly, rankings are both controversial and differ at least somewhat in their results. ${ }^{79-81}$

Arguments in support of or against any of the metrics can and have been made in a variety of sources. ${ }^{82-84}$ The most prominent international rankings are "Academic Ranking of World Universities” (AWRU), 75 “Quacquarelli Symonds Limited Ranking of World Universities” (QS), 76 "Webometrics Ranking of World Universities" (WR), ${ }^{77,85}$ and "Higher Education Evaluation and Accreditation Council of Taiwan" (HEEACT). ${ }^{78}$ All four ranking systems offer similar results. However, the greatest differences are offered by QS and WR. ${ }^{86}$ Consequently, these two ranking systems are the basis of the analysis in this paper. To rank each university, QS utilizes a composite measure of five components: academic peer review (40 percent), recruiter assessment (10 percent), faculty student ratio (20 percent), research citations (20 percent) and international orientation (10 percent). Academic peer review is based on the opinions of thousands of academics making statements regarding the quality of other universities. Recruiter review scores are based on the opinions of the relative quality of universities by thousands of recruiters regarding the quality of graduates. Faculty student ratio rewards universities that have fewer students per faculty member, as this is likely to translate into more meaningful engagement and a better learning experience. Citations per faculty member are determined by dividing the total number of citations that have occurred over the last five years in the Scopus database by the number of faculty members at the university. International orientation is based equally on the percentage of faculty and percentage of students that are classified as international

WR bases its analysis on Web-based metrics, or more specifically, size (20 percent), rich files (15 percent), visibility (50 percent), and scholarly activity (15 percent). Size is the number of Web pages recovered by the Google, Yahoo, and Bing search engines. Rich files is the volume of Adobe Acrobat (.pdf), Adobe PostScript (.ps), Microsoft Word (.doc) and Microsoft 
Powerpoint (.ppt) files associated with the university's Web site. Visibility is the number of unique external links associated with a Web site according to Yahoo Site Explorer. Scholarly activity is the number of items published according to Google Scholar and Scimago SIR over the appropriate and most recent five-year period. Having considered the widely available ranking systems of universities, the relationship between research and reputation is now considered.

\subsubsection{The Relationship between Research and Reputation}

A series of hypotheses is now developed to test questions relating research and reputation using different metrics. Following the tradition of Popperian falsification, the numbered hypothesis of interest is tested $\left(\mathrm{H}_{n}\right)$ and the alternative hypotheses $\left(\mathrm{H}_{n a}\right)$ are offered - in case the numbered hypothesis is in fact proven to be false. While the quantity of research has been flagged as a potentially dangerous metric, ${ }^{57,87,88}$ it is clearly an important metric. Consequently, consideration should be given to the relationship between research quantity and institution ranking. Hence,

H1. The quantity of research and institution ranking are unrelated.

H1a. Institutions with higher rankings will have a larger volume of research.

H2. The quantity of research in a field and institution ranking are unrelated.

H2a. Institutions with higher rankings will have a larger volume of research in a given field.

Different fields of study within a university have different traditions regarding the research produced in terms of not only volume, but also other metrics such as citation frequency, Hirsch index and number of coauthors. Consequently, the strength of relation between a university and research performance in a given academic field will depend on the relative importance of a given 
field to research, productivity and the strength of the university in a given field. For example, the field of medicine tends to generate more peer reviewed journal articles than an area such as humanities. Consequently, traditional measures of research will not relate as strongly to reputation in the humanities as compared to medicine. Alternatively, research activity in a specific field may not lend itself to a notable increase in ranking, due to the given field being considered relatively unimportant. To examine whether the relative importance of a field differs from its measured importance, it is necessary to compare the relationship between normalized data (consider relative magnitude as opposed to magnitude). Hence,

H3. The relationship between research in a given field and institution ranking is the same for normalized and un-normalized data.

H3a. Research activity in certain fields is more important to university ranking than research activity in other fields.

While fields or departments are a logical separator for research, the unit of analysis for research is an author. The presence of researchers of high quality is critical for the attraction of research funds, junior researchers, grants, post-docs, visiting scholars, and graduate students. Therefore, it is worth considering the characteristics of the top researcher within the different fields at the ranked universities. ${ }^{35,89,90}$ As with our earlier hypotheses, quantity of publications can be considered as a proxy for research. Although in this case, the career number of publications by the most prolific author is considered - instead of the total number of publications associated with the university that the researcher is currently associated to. Hence,

H4. The quantity of research by the most prolific author in a field and the institution ranking are unrelated.

H4a. Institutions with higher rankings will have their most prolific author associated to a larger volume of research. 
What about quality? The sheer volume of publication is, at best, a risky measure of quality. Consequently, it is critical to compare other measures. Hence the top researcher at an institute in a given field is also considered from the perspective of number of citations, number of different coauthors, Hirsch index, and number of Web citations. The number of journal citations or Web citations of a work refers to the number of separate documents that refer to a publication (and/or author) under consideration. The number of co-authors acts as a measure of quality as it is indicative of the number of people who are prepared to and have in the past worked with an author. Furthermore, a researcher with many partners is not only seen as desirable to work with, but also has had an opportunity to learn from working with many different people. The Hirsh index is the number of articles with at least the same number of citations. This measure is higher for researchers who frequently publish highly cited articles and is low for those who publish either infrequently and/or work that is rarely/never cited. For example, a Hirsch Indices of 15, indicates that the author's 16 th most cited paper has 15 or less cites and the author's 15 th most cited papers have a minimum of 15 cites. Having considered how each of the metrics under consideration is linked to quality, the associated hypotheses are now offered:

H5. The number of citations of the research of the most prolific author in a field and the institution ranking are unrelated.

H5a. Institutions with higher rankings will have their most prolific author having an association with a larger number of citations to their work.

H6. The quantity of coauthors for the most prolific author in a field and the institution ranking are unrelated.

H6a. Institutions with higher rankings will have their most prolific author write with a larger number of coauthors.

H7. The Hirsch index of research by the most prolific author in a field and the institution 
ranking are unrelated.

H7a. Institutions with higher rankings will have their most prolific author having a higher Hirsch index associated with their research.

H8. The number of Web citations of the research of the most prolific author in a field and the institution ranking are unrelated.

H8a. Institutions with higher rankings will have their most prolific author having an association with a larger number of Web citations to their work.

Finally, to take into consideration the possible effect of differences in the absolute magnitude of research related values in different fields, it is important to determine if there are significant differences between normalized and actual data. This leads to the hypotheses:

H9. The quantity of research by the most prolific author in a field and the institution ranking are the same for normalized and un-normalized data.

H9a. Quantity of research in some fields is more important to university ranking than research activity in other fields.

H10. The quantity of citations by the most prolific author in a field and the institution ranking are the same for normalized and un-normalized data.

H10a. Citations of the most prolific authors in some fields are more important

H11. The number of coauthors of the most prolific author in a field and the institution ranking are the same for normalized and un-normalized data.

H11a. The number of coauthors in some fields is more important to university ranking than research activity in other fields.

H12. The Hirsch index of the most prolific author in a field and the institution ranking are the same for normalized and un-normalized data.

H12a. The Hirsch index of the most prolific author in some fields is more important to 
university ranking than research activity in other fields.

H13. The quantity of Web citations of the most prolific author in a field and the institution ranking are the same for normalized and un-normalized data.

H13a. The quantity of Web citations of the most prolific author in some fields is more important to university ranking than research activity in other fields.

\section{Section 5.3 Method for Research Data Collection}

To assess the relationship between a university's reputation and its research one requires a list of highly reputable universities, the relative position of universities on the list, and the research associated with each of these institutions. The two prominent international ranking systems that were identified earlier as the most different ${ }^{86}$ in results- QS ${ }^{76}$ and WR ${ }^{77}$-were utilized. Two ranking systems were considered in order to see to what extent the results might be dependent on a given ranking system. If the results are the same regardless of the ranking system used, the validity of the findings is more robust. Also in the process, we are able to see what sort of difference may occur from one ranking system to another. As we did in fact find that sometimes substantial differences exist in ranking of universities between different rating systems, we have considered both of the systems in both data collection and analysis. The ranking data reflect WR 2010 and QS 2009 list of the top 250 universities - 350 universities in total.

For each university identified as being among the top 250 universities on QS and/or WR, detailed data on research activity were collected. For collection of research data, a database that would act as a filter for quality and at the same time is comprehensive was desired. Two databases, ISI Web of Science and Scopus, provided the best coverage. While ISI Web of 
Science has been in use for a very long period of time, scholars in social science disciplines have expressed concerns regarding the ISI journal coverage being much narrower than in the natural sciences. Consequently, Scopus (www.scopus.com) was determined as suitable source of research information, due to its broader coverage of sources.

For each of the universities identified, data were collected manually from Scopus using the following procedure: Affiliation tab was chosen.

(3) A list of all universities affiliations with the name was provided by the database. The boxes of any associated organization, institute or department were clicked to gain a complete record of university research activity. This often required further investigations using Web searches to determine whether an organization was affiliated with a university. Once the appropriate boxes were checked, the "show documents" box was clicked.

(4) The number at the top left of the "new — total documents" for the selected university was recorded. Now that the total number of publications for the institution was recorded, the process for collecting data for each field of research was followed for each university.

(5) On the left side of the screen, fields of research were identified with the associated number of publications in brackets. The values in parentheses were recorded as the total number of publications for the university under consideration in the field under consideration. Having collected the information on the field of research, one identified and collected information on the most active researcher in a given field at a given university.

(6) The list of articles for a given field was isolated. In order to do this one must eliminate the multidisciplinary category for each search. Using medicine as example, there is a selection box located on the left side of each listing. Medicine's "box" was selected and the "limit box" located at the top of the search parameters was also selected. This procedure brought a new screen with the appropriate category. This can be verified by the looking at the query entry at the top of the page, it should read (LIMIT-TO (SUBJAREA, "MEDICINE") OR LIMITTO (SUBJAREA, "MULT")). The query line is edited to remove the "MULT" category, reducing the final part of the query to (LIMIT-TO (SUBJAREA, "MEDICINE")). 
(7) Having conducted this step, the most prolific author is the first name in the author's list. By clicking the selection box associated with the first author one gains access to all of the publications associated with that one specific author.

(8) On the next screen, the author's name on the most recent publication was located and selected.

This results in the provision of a new screen with the details of the selected author. The name of the author, number of publications, number of citations, number of coauthors, Hirsh factor, and number of Web references were all recorded and associated to the appropriate university and field of research in the data-base created for statistical analysis. (The screen images associated with the process are offered in Appendix 1.) If a selected author was found to be a faculty member at a different university, the next most prolific author was selected. In a few cases, no authors were found at the university under consideration; in those cases zeroes were entered into the database describing the activity of the most prolific author. The process was conducted until the information for all 350 universities was completed.

In some cases the "more" button needed to be clicked to reveal all fields of research. Information was collected for all twenty-seven fields on the Scopus database for each university: Medicine, Physics and Astronomy, Biochemistry, Engineering, Chemistry, Materials Science, Immunology, Earth Sciences, Environmental Sciences, Pharmacology, Neurosciences, Social Sciences, Psychology, Health Professions, Economics, Decision Sciences, Business, Agriculture, Mathematics, Computer Science, Chemical Engineering, Multidisciplinary, Nursing, Veterinary, Arts and Humanities, Dentistry, and Undetermined

Upon completion of data entry and spot-checking of data to verify data entered is correct, the data were uploaded into the statistical processing package - SPSS. Correlation analysis was conducted between university rankings and the variables on research activity to see if variables 
move in the same direction, move in opposite directions, or have no relationship whatsoever in changes in value. Regression analysis was conducted to determine the relationship between different fields of research and the university ranking. In all cases the numeric ranking of each university was considered as the dependent variable, with the different academic fields of each university providing the independent variables to be regressed against the dependent. Through regression analysis, we were able to test to see if one or more of the independent variables has a linear (straight line) relationship with the dependent variable. In addition by considering the $\mathrm{R}^{2}$ value an indication is given of how much variation is explained by the linear regression — with a value between 0 and 1 representing the percentage of variation explained. Finally, test statistics were used to statistically evaluate whether the results suggest that regression coefficients are significantly different from zero and in the case of comparing different sets of data to each other, whether or not the data are from different populations - i.e., difference in results is a function in difference in underlying population and not just a function of sampling

\section{Section 5.4 Results}

H1. The quantity of research and institution ranking are unrelated.

H1a. Institutions with higher rankings will have a larger volume of research.

WR 2010 and QS 2009 correlations are -0.586 and -0.569, respectively. As these correlations are statistically significant: $\mathrm{H}_{1}$ is rejected and $\mathrm{H}_{1 \mathrm{a}}$ is supported

$\mathrm{H} 2$. The quantity of research in a field and institution ranking are unrelated.

H2a. Institutions with higher rankings will have a larger volume of research in a given field.

$\mathrm{H} 2$. This is rejected and $\mathrm{H} 2 \mathrm{a}$ is supported as all relations are statistically significant, except for the dental research category in the WR 2010 data. See Table 1. 
H3. The relationship between research in a given field and institution ranking are the same for normalized and un-normalized data.

H3a. Research activity in certain fields is more important to university ranking than research activity in other fields.

H3. This is not rejected as there is no significant difference between normalized and actual data for either WR 2010 or QS 2009 (T-Stat=0). Only five of fifty-four of the total quantity of research in the different fields are statistically significantly related to reputation of the university under consideration. See Table 2.

H4. The quantity of research by the most prolific author in a field and the institution ranking are unrelated.

H4a. Institutions with higher rankings will have their most prolific author associated to a larger volume of research.

WR 2010 and QS 2009 correlations are statistically significant, except for five of fifty-four categories: $\mathrm{H}_{4}$ is rejected and $\mathrm{H}_{4 \mathrm{a}}$ is supported. See Table 3 .

H5. The number of citations of the research of the most prolific author in a field and the institution ranking are unrelated.

H5a. Institutions with higher rankings will have their most prolific author having an association with a larger number of citations to their work. 
Table 5.1. Correlation between total quantity of research in a given field and institution ranking (bold font indicates significance at the 1 percent level or better, normal font indicates significance at the 5 percent level, smaller font indicates statistically insignificant at the 5 percent level)

\begin{tabular}{lll} 
Category & QS actual & WR actual \\
\hline Medicine & & \\
Physics & $\mathbf{- 0 . 4 2 3}$ & $\mathbf{- . 3 3 5}$ \\
Biochemistry & $\mathbf{- 0 . 4 0 4}$ & $\mathbf{- . 3 6 9}$ \\
Engineering & $\mathbf{- 0 . 5 1 3}$ & $\mathbf{- . 4 5 3}$ \\
Chemistry & $\mathbf{- 0 . 3 7 4}$ & $\mathbf{- . 4 3 0}$ \\
Materials Science & $\mathbf{- 0 . 4 6 5}$ & $\mathbf{- . 4 1 3}$ \\
Immunology & $\mathbf{- 0 . 2 6 3}$ & $\mathbf{- . 1 8 5}$ \\
Earth Sciences & $\mathbf{- 0 . 4 5 3}$ & $\mathbf{- . 2 8 1}$ \\
Environment & $\mathbf{- 0 . 3 3 6}$ & $\mathbf{- . 2 7 8}$ \\
Agriculture & $\mathbf{- 0 . 2 7 7}$ & $\mathbf{- . 3 0 5}$ \\
Mathematics & $\mathbf{- 0 . 1 7 4}$ & $\mathbf{- . 2 8 4}$ \\
Computer Science & $\mathbf{- 0 . 4 1 7}$ & $\mathbf{- . 3 1 4}$ \\
Chemical & $\mathbf{- 0 . 4 0 2}$ & $\mathbf{- . 3 6 3}$ \\
Engineering & & \\
Multidisciplinary & $\mathbf{- 0 . 2 5 0}$ & $\mathbf{- . 2 0 6}$ \\
Pharmacology & $\mathbf{- 0 . 4 6 2}$ & $\mathbf{- . 4 1 1}$ \\
Neuroscience & $\mathbf{- 0 . 2 6 9}$ & $\mathbf{- . 1 6 8}$ \\
Social Sciences & $\mathbf{- 0 . 4 3 9}$ & $\mathbf{- . 3 5 7}$ \\
Psychology & $\mathbf{- 0 . 3 9 4}$ & $\mathbf{- . 5 0 8}$ \\
Health Professions & $\mathbf{- 0 . 3 9 4}$ & $\mathbf{- . 5 5 8}$ \\
Economics & $\mathbf{- 0 . 3 2 4}$ & $\mathbf{- . 2 1 4}$ \\
Decision Sciences & $\mathbf{- 0 . 4 8 3}$ & $\mathbf{- . 5 5 0}$ \\
Business & $\mathbf{- 0 . 4 2 1}$ & $\mathbf{- . 5 3 7}$ \\
Nursing & $\mathbf{- 0 . 3 2 6}$ & $\mathbf{- . 5 2 7}$ \\
Veterinary & $\mathbf{- 0 . 3 4 8}$ & $\mathbf{- . 2 8 6}$ \\
Arts & $\mathbf{- 0 . 1 6 9}$ & $\mathbf{- . 2 0 6}$ \\
Dentistry & $\mathbf{- 0 . 3 0 3}$ & $\mathbf{- . 2 8 6}$ \\
Undetermined & $\mathbf{- 0 . 2 4 8}$ & -0.101 \\
\hline & $\mathbf{- 0 . 4 1 7}$ & $\mathbf{- . 1 7 8}$ \\
\hline & &
\end{tabular}


Table 5.2. Coefficients for regression between total quantity of research in a given field and institution ranking (bold font indicates significance at the 1 percent level or better, normal font indicates significance at the 5 percent level, smaller font indicates statistically insignificant at the 5 percent level). QS $\mathrm{R}^{2}=0.411$, adjusted 0.377 , WR $\mathrm{R}^{2}=0.555$, adjusted 0.499

\begin{tabular}{|c|c|c|c|c|}
\hline Category & $\begin{array}{l}\text { QS - } \\
\text { actual }\end{array}$ & $\begin{array}{l}\text { Normaliz } \\
\text { ed }\end{array}$ & $\begin{array}{l}\text { WR - } \\
\text { actual }\end{array}$ & $\begin{array}{l}\text { Normalize } \\
\text { d }\end{array}$ \\
\hline Medicine & -0.001 & -0.274 & -0.001 & -0.181 \\
\hline Physics & 0.000 & -0.047 & -0.001 & -0.106 \\
\hline Biochemistry & -0.001 & -0.154 & -0.002 & -0.193 \\
\hline Engineering & -0.001 & -0.100 & -0.001 & -0.096 \\
\hline Chemistry & -0.001 & -0.045 & -0.002 & -0.098 \\
\hline Materials Science & 0.000 & 0.022 & 0.002 & 0.060 \\
\hline Immunology & -0.003 & -0.093 & 0.015 & 0.352 \\
\hline Earth Sciences & -0.001 & -0.023 & -0.003 & -0.094 \\
\hline Environment & -0.002 & -0.052 & 0.001 & 0.023 \\
\hline Agriculture & 0.004 & 0.175 & -0.002 & -0.081 \\
\hline Mathematics & 0.000 & 0.004 & 0.005 & 0.104 \\
\hline Computer Science & -0.006 & -0.159 & -0.002 & -0.051 \\
\hline Chemical Engineering & 0.000 & 0.008 & 0.000 & -0.004 \\
\hline Multidisciplinary & 0.000 & -0.002 & -0.013 & -0.174 \\
\hline Pharmacology & 0.000 & -0.007 & -0.001 & -0.032 \\
\hline Neuroscience & 0.002 & 0.080 & -0.003 & -0.072 \\
\hline Social Sciences & 0.005 & 0.140 & -0.003 & -0.061 \\
\hline Psychology & 0.014 & 0.302 & -0.020 & -0.328 \\
\hline Health Professions & 0.007 & 0.077 & $\begin{array}{l}0.003 \\
-0.007\end{array}$ & $\begin{array}{l}0.032 \\
-0.055\end{array}$ \\
\hline \multirow[t]{2}{*}{ Economics } & -0.054 & -0.482 & & \\
\hline & -0.007 & -0.041 & 0.005 & 0.031 \\
\hline & 0.022 & & -0.028 & -0.150 \\
\hline Business & & 0.145 & & \\
\hline Nursing & -0.014 & -0.112 & 0.009 & 0.071 \\
\hline Veterinary & -0.004 & -0.040 & -0.005 & -0.131 \\
\hline & -0.005 & & -0.010 & -0.069 \\
\hline Arts & & -0.042 & & \\
\hline & 0.011 & & 0.017 & 0.103 \\
\hline Dentistry & & 0.074 & & \\
\hline Undetermined & -0.020 & -0.103 & 0.076 & 0.319 \\
\hline
\end{tabular}


WR 2010 and QS 2009 correlations are statistically significant, except for one of fiftyfour categories: $\mathrm{H}_{5}$ is rejected and $\mathrm{H}_{5 \mathrm{a}}$ is supported. See Table 4.

H6. The quantity of coauthors for the most prolific author in a field and the institution ranking are unrelated.

H6a. Institutions with higher rankings will have their most prolific author write with a larger number of coauthors.

Table 5.3. Correlation between total quantity of research for most prolific researcher in a given field and institution ranking (bold font indicates significance at the 1 percent level or better, normal font indicates significance at the 5 percent level, smaller font indicates statistically insignificant at the 5 percent level)

\begin{tabular}{lll} 
Category & QS actual & WR actual \\
\hline Medicine & $\mathbf{- 0 . 3 0 9}$ & -.120 \\
Physics & $\mathbf{- 0 . 2 3 4}$ & $\mathbf{- . 2 2 3}$ \\
Biochemistry & $\mathbf{- 0 . 2 5 9}$ & -.215 \\
Engineering & $\mathbf{- 0 . 1 7 9}$ & -.282 \\
Chemistry & $\mathbf{- 0 . 2 5 8}$ & $\mathbf{- . 3 0 0}$ \\
Materials Science & $\mathbf{- 0 . 2 0 7}$ & $\mathbf{. 2 2 9}-$ \\
Immunology & $\mathbf{- 0 . 2 8 6}$ & -.149 \\
Earth Sciences & $\mathbf{- 0 . 2 4 2}$ & $\mathbf{- . 2 6 3}$ \\
Environment & $\mathbf{- 0 . 1 6 7}$ & $\mathbf{- . 2 4 9}$ \\
Agriculture & $\mathbf{- 0 . 2 6 4}$ & $\mathbf{- 2 0 6}$ \\
Mathematics & $\mathbf{- 0 . 2 0 1}$ & -.086 \\
Computer Science & $\mathbf{- 0 . 3 4 0}$ & $\mathbf{- . 2 7 5}$ \\
Chemical & & \\
Engineering & $\mathbf{- 0 . 2 3 0}$ & $\mathbf{- . 2 0 6}$ \\
Multidisciplinary & $\mathbf{- 0 . 2 5 9}$ & $\mathbf{- . 1 9 6}$ \\
Pharmacology & $\mathbf{- 0 . 2 0 8}$ & $\mathbf{. 2 2 9}$ \\
Neuroscience & $\mathbf{- 0 . 3 1 9}$ & $\mathbf{. 2 0 2}$ \\
Social Sciences & $\mathbf{- 0 . 3 6 4}$ & $\mathbf{- . 3 1 0}$ \\
Psychology & $\mathbf{- 0 . 3 0 9}$ & -.256 \\
Health Professions & $\mathbf{- 0 . 1 8 4}$ & -0.05 \\
Economics & -0.099 & $\mathbf{. 2 9 6}$ \\
Decision Sciences & $\mathbf{- 0 . 2 4 8}$ & $\mathbf{- . 2 8 7}$ \\
Business & -0.148 & $\mathbf{. 2 6 0}$ \\
Nursing & $\mathbf{- 0 . 1 8 3}$ & $\mathbf{- . 1 9 5}$ \\
Veterinary & -0.155 & $\mathbf{. 1 9 2}$ \\
Arts & $\mathbf{- 0 . 1 8 4}$ & -0.091 \\
Dentistry & $\mathbf{- 0 . 1 8 0}$ & $\mathbf{- . 1 7 2}$ \\
Undetermined & $\mathbf{- 0 . 2 2 0}$ & $\mathbf{- . 2 8 5}$ \\
\hline & &
\end{tabular}


Table 5.4. Correlation between total number of citations for most prolific researcher in a given field and institution ranking (bold font indicates significance at the 1 percent level or better, normal font indicates significance at the 5 percent level, smaller font indicates statistically insignificant at the 5 percent level)

\begin{tabular}{lll} 
Category & QS actual & WR actual \\
\cline { 2 - 3 } Medicine & -0.106 & -.155 \\
Physics & $\mathbf{- 0 . 2 1 7}$ & $\mathbf{- . 2 5 6}$ \\
Biochemistry & $\mathbf{- 0 . 2 9 4}$ & $\mathbf{- . 3 1 5}$ \\
Engineering & $\mathbf{- 0 . 2 0 8}$ & $\mathbf{- . 3 1 4}$ \\
Chemistry & $\mathbf{- 0 . 2 8 9}$ & $\mathbf{- . 2 8 2}$ \\
Materials & $\mathbf{- 0 . 2 9 4}$ & $\mathbf{- . 2 9 7}$ \\
Immunology & $\mathbf{- 0 . 2 7 1}$ & $\mathbf{- . 2 5 1}$ \\
Earth Sciences & $\mathbf{- 0 . 2 3 0}$ & $\mathbf{- . 2 7 1}$ \\
Environment & $\mathbf{- 0 . 1 8 4}$ & $\mathbf{- . 1 7 1}$ \\
Agriculture & $\mathbf{- 0 . 1 8 3}$ & -.145 \\
Mathematics & $\mathbf{- 0 . 1 6 5}$ & -.135 \\
Computer & $\mathbf{- 0 . 2 4 3}$ & $\mathbf{- . 3 4 3}$ \\
Chemical & & \\
Engineering & $\mathbf{- 0 . 2 4 2}$ & $\mathbf{- . 2 2 9}$ \\
Multidisciplin & $\mathbf{- 0 . 2 9 6}$ & $\mathbf{- . 1 9 2}$ \\
Pharmacology & $\mathbf{- 0 . 2 5 3}$ & $\mathbf{- . 2 5 5}$ \\
Neuroscience & $\mathbf{- 0 . 2 9 9}$ & $\mathbf{- . 2 5 7}$ \\
Social & $\mathbf{- 0 . 2 5 6}$ & $\mathbf{- . 2 9 2}$ \\
Psychology & $\mathbf{- 0 . 2 9 5}$ & $\mathbf{- . 2 4 7}$ \\
Health & $\mathbf{- 0 . 2 2 8}$ & -.137 \\
Economics & -0.137 & $\mathbf{- . 2 8 6}$ \\
Decision & $\mathbf{- 0 . 2 5 8}$ & $\mathbf{- . 2 4 8}$ \\
Business & $\mathbf{- 0 . 2 2 3}$ & $\mathbf{- . 2 5 1}$ \\
Nursing & $\mathbf{- 0 . 2 3 7}$ & -.227 \\
Veterinary & $\mathbf{- 0 . 1 8 4}$ & -.149 \\
Arts & $\mathbf{- 0 . 1 8 0}$ & -0.084 \\
Dentistry & $\mathbf{- 0 . 2 0 6}$ & -.152 \\
Undetermined & $\mathbf{- 0 . 2 2 2}$ & $\mathbf{- . 2 1 2}$ \\
\hline & & \\
\hline
\end{tabular}

WR 2010 and QS 2009 correlations are statistically significant, except for fifteen of fiftyfour categories: $\mathrm{H}_{6}$ is rejected and $\mathrm{H}_{6 \mathrm{a}}$ is supported. See Table 5.

H7. The Hirsch index of research of the most prolific author in a field and the institution ranking are unrelated.

H7a. Institutions with higher rankings will have their most prolific author having a higher Hirsch index associated with their research. 
Table 5.5. Correlation between total number of coauthors for most prolific researcher in a given field and institution ranking (bold font indicates significance at the 1 percent level or better, normal font indicates significance at the 5 percent level, smaller font indicates statistically insignificant at the 5 percent level)

\begin{tabular}{lrc}
\multicolumn{1}{c}{ Category } & QS actual & $\begin{array}{l}\text { WR } \\
\text { actual }\end{array}$ \\
\hline Medicine & -0.133 & $\mathbf{- . 1 9 3}$ \\
Physics & $\mathbf{- 0 . 1 6 6}$ & -.086 \\
Biochemistry & -0.091 & -.071 \\
Engineering & -0.148 & $\mathbf{. 1 9 6}$ \\
Chemistry & $\mathbf{- 0 . 2 3 7}$ & $\mathbf{- . 1 8 0}$ \\
Materials Science & $\mathbf{- 0 . 1 6 5}$ & -.090 \\
Immunology & $\mathbf{- 0 . 2 2 5}$ & -.141 \\
Earth Sciences & $\mathbf{- 0 . 2 0 3}$ & -.009 \\
Environment & $\mathbf{- 0 . 2 6 5}$ & $\mathbf{. 2 6 4}$ \\
Agriculture & $\mathbf{- 0 . 1 6 8}$ & -.052 \\
Mathematics & $\mathbf{- 0 . 2 4 0}$ & -.110 \\
Computer Science & $\mathbf{- 0 . 2 6 5}$ & -.277 \\
Chemical & & \\
Engineering & $\mathbf{- 0 . 2 4 9}$ & -.136 \\
Multidisciplinary & -0.095 & -.079 \\
Pharmacology & $\mathbf{- 0 . 1 8 5}$ & -.153 \\
Neuroscience & $\mathbf{- 0 . 2 7 5}$ & -.146 \\
Social Sciences & $\mathbf{- 0 . 2 1 6}$ & $\mathbf{- . 3 3 7}$ \\
Psychology & $\mathbf{- 0 . 2 8 3}$ & -.158 \\
Health Professions & $\mathbf{- 0 . 1 5 2}$ & -0.098 \\
Economics & -0.117 & $\mathbf{- . 2 5 5}$ \\
Decision Sciences & $\mathbf{- 0 . 2 1 1}$ & -.206 \\
Business & -0.121 & $\mathbf{- . 2 4 0}$ \\
Nursing & -0.132 & $\mathbf{- . 1 8 7}$ \\
Veterinary & $\mathbf{- 0 . 1 8 0}$ & -.221 \\
Arts & -0.058 & -0.091 \\
Dentistry & $\mathbf{- 0 . 2 0 6}$ & -0.06 \\
Undetermined & $\mathbf{- 0 . 2 4 3}$ & $\mathbf{- . 2 6 9}$ \\
\hline & &
\end{tabular}


Table 5.6. Correlation between Hirsch index for most prolific researcher in a given field and institution ranking (bold font indicates significance at the 1 percent level or better, normal font indicates significance at the 5 percent level, smaller font indicates statistically insignificant at the 5 percent level

\begin{tabular}{lcc}
\multicolumn{1}{c}{ Category } & QS actual & WR actual \\
\hline Medicine & $\mathbf{- 0 . 3 6 0}$ & $\mathbf{- . 2 2 4}$ \\
Physics & $\mathbf{- 0 . 2 8 3}$ & $\mathbf{. 1 9 2}$ \\
Biochemistry & $\mathbf{- 0 . 3 2 3}$ & $\mathbf{- . 2 9 0}$ \\
Engineering & $\mathbf{- 0 . 2 6 6}$ & $\mathbf{- . 3 9 9}$ \\
Chemistry & $\mathbf{- 0 . 2 1 6}$ & -.040 \\
Materials Science & $\mathbf{- 0 . 2 6 4}$ & $\mathbf{. 2 5 9}$ \\
Immunology & $\mathbf{- 0 . 3 1 3}$ & $\mathbf{- . 2 7 9}$ \\
Earth Sciences & $\mathbf{- 0 . 3 1 8}$ & -.074 \\
Environment & $\mathbf{- 0 . 2 1 7}$ & $\mathbf{. 2 6 9}$ \\
Agriculture & $\mathbf{- 0 . 2 4 6}$ & $\mathbf{- . 1 8 8}$ \\
Mathematics & $\mathbf{- 0 . 2 0 3}$ & -.107 \\
Computer Science & $\mathbf{- 0 . 3 2 6}$ & $\mathbf{- . 3 9 6}$ \\
Chemical & & \\
Engineering & $\mathbf{- 0 . 3 5 6}$ & $\mathbf{- . 1 7 7}$ \\
Multidisciplinary & -0.080 & -.079 \\
Pharmacology & $\mathbf{- 0 . 2 4 8}$ & $\mathbf{. 1 6 7}$ \\
Neuroscience & $\mathbf{- 0 . 3 3 8}$ & $\mathbf{- . 2 8 1}$ \\
Social Sciences & $\mathbf{- 0 . 3 1 1}$ & -.367 \\
Psychology & $\mathbf{- 0 . 3 4 6}$ & $\mathbf{. 2 7 7}$ \\
Health Professions & $\mathbf{- 0 . 2 0 4}$ & -0.105 \\
Economics & $\mathbf{- 0 . 1 8 9}$ & -.297 \\
Decision Sciences & $\mathbf{- 0 . 2 6 5}$ & $\mathbf{. 2 6 0}$ \\
Business & $\mathbf{- 0 . 2 6 5}$ & $\mathbf{. 2 6 0}$ \\
Nursing & $\mathbf{- 0 . 2 4 4}$ & -.296 \\
Veterinary & $\mathbf{- 0 . 2 0 7}$ & -.208 \\
Arts & -0.149 & -0.116 \\
Dentistry & $\mathbf{- 0 . 1 7 6}$ & -.138 \\
Undetermined & -0.128 & $\mathbf{. 2 6 6}$ \\
\hline & &
\end{tabular}

WR 2010 and QS 2009 correlations are statistically significant, except for seven of fiftyfour categories: $\mathrm{H}_{7}$ is rejected and $\mathrm{H}_{7 \mathrm{a}}$ is supported. See Table 6.

H8. The number of Web citations of the research of the most prolific author in a field and the institution ranking are unrelated.

H8a. Institutions with higher rankings will have their most prolific author having an association with a larger number of web citations to their work.

$\mathrm{H}_{8}$ is not rejected. Thirteen of fifty-four categories are statistically significantly different. See Table 7.

H9. The quantity of research by the most prolific author in a field and the institution ranking are the same for normalized and un-normalized data. 
H9a. Quantity of research in some fields is more important to university ranking than research activity in other fields.

H9 is not rejected. Ten of fifty four categories are statistically significantly different. See Table 8

H10 The quantity of citations by the most prolific author in a field and the institution ranking are the same for normalized and un normalized data

H10a Citations of the most prolific authors in some fields are more important to university ranking than research activity in other fields.

$\mathrm{H} 10$ is not rejected. Six of fifty-four categories are statistically significantly different. See Table 9

H11 the number of coauthors of the most prolific author in a field and the institution ranking are the same for normalized and un-normalized data

H11a. The number of coauthors in some fields is more important to university ranking than research activity in other fields

Table 5.7. Correlation between Web references to the most prolific researcher in a given field and institution ranking (bold font indicates significance at the 1 percent level or better, normal font indicates significance at the 5 percent level, smaller font indicates statistically insignificant at the 5 percent level

\begin{tabular}{lrc}
\multicolumn{1}{c}{ Category } & QS actual & WR actual \\
\hline Medicine & 0.105 & .041 \\
Physics & 0.015 & .034 \\
Biochemistry & -0.028 & .059 \\
Engineering & -0.127 & .075 \\
Chemistry & -0.159 & -.083 \\
Materials Science & 0.010 & -.061 \\
Immunology & -0.013 & -.007 \\
Earth Sciences & -0.078 & -.056 \\
Environment & 0.069 & -.105 \\
Agriculture & $\mathbf{- 0 . 1 9 0}$ & -.102 \\
Mathematics & -0.051 & -.070 \\
Computer Science & -0.124 & -.179 \\
Chemical & & \\
Engineering & -0.151 & -.076 \\
Multidisciplinary & -0.131 & -.123 \\
Pharmacology & -0132 & -.127 \\
Neuroscience & 0.011 & -0.066 \\
Social Sciences & -0.143 & -.164 \\
Psychology & 0.042 & -0.089 \\
Health Professions & -0.085 & -0.085 \\
Economics & -0.060 & -0.041 \\
Decision Sciences & -0.046 & -0.081 \\
Business & -0.100 & -0.06 \\
Nursing & 0.021 & -.143 \\
Veterinary & 0.015 & -0.116 \\
Arts & -0.130 & -0.116 \\
Dentistry & 0.106 & -.131 \\
Undetermined & -0.062 & -0.095 \\
& &
\end{tabular}


$\mathrm{H}_{11}$ is not rejected. Five of fifty-four categories are statistically significantly different. See Table 10 .

H12. The Hirsch index of the most prolific author in a field and the institution ranking are the same for normalized and un-normalized data.

Table 5.8. Coefficients for regression between total quantity of research for most prolific researcher in a given field and institution ranking (bold font indicates significance at the 1 percent level or better, normal font indicates significance at the 5 percent level, smaller font indicates statistically insignificant at the 5 percent level). QS $\mathrm{R}^{2}=0.352$ and $\mathrm{WR} \mathrm{R}^{2}=0.368$. Columns 3 and 5 (normalized) indicate that QS and WR data are rescaled so that all variables are normal - they have the same minimum and maximum value - thereby, avoiding bias from differences in variable magnitude

\begin{tabular}{|c|c|c|c|c|}
\hline Category & $\begin{array}{l}\text { QS } \\
\text { Actual }\end{array}$ & $\begin{array}{l}\text { Normalize } \\
\mathrm{d}\end{array}$ & $\begin{array}{r}\mathrm{N} \\
\text { WR Actual d } \\
\end{array}$ & $\begin{array}{l}\text { Normalize } \\
\mathrm{d}\end{array}$ \\
\hline Medicine & -0.021 & -0.081 & 0.065 & 0.223 \\
\hline Physics & 0.004 & 0.014 & -0.001 & -0.004 \\
\hline Biochemistry & 0.002 & 0.008 & 0.004 & 0.012 \\
\hline Engineering & 0.028 & 0.087 & -0.018 & -0.056 \\
\hline Chemistry & -0.016 & -0.064 & -0.020 & -0.073 \\
\hline Materials Science & -0.016 & -0.067 & -0.030 & -0.108 \\
\hline Immunology & -0.022 & -0.076 & -0.013 & -0.044 \\
\hline Earth Sciences & 0.076 & -.121 & -0.119 & -0.170 \\
\hline Environment & 0.011 & 0.025 & -0.042 & -0.088 \\
\hline Agriculture & -0.063 & -0.123 & -0.016 & -0.032 \\
\hline Mathematics & -0.015 & -0.027 & 0.029 & 0.052 \\
\hline Computer Science & -0.059 & -0.168 & -0.039 & -0.114 \\
\hline Chemical Engineering & -0.038 & -.0100 & 0.007 & 0.016 \\
\hline & -0.034 & -0.086 & -0.011 & -0.026 \\
\hline $\begin{array}{l}\text { Multidisciplinary } \\
\text { Pharmacology }\end{array}$ & 0.009 & 0.032 & 0.006 & 0.016 \\
\hline Neuroscience & -0.006 & -0.014 & 0.001 & 0.003 \\
\hline Social Sciences & -0.084 & -0.156 & -0.089 & -0.163 \\
\hline Psychology & -0.058 & -0.120 & -0.030 & -0.058 \\
\hline Health Professions & 0.009 & 0.023 & 0.036 & 0.061 \\
\hline Economics & 0.066 & 0.112 & -0.092 & -0.121 \\
\hline Decision Sciences & -0.033 & -0.069 & -0.057 & -0.107 \\
\hline Business & 0.019 & 0.030 & -0.0097 & -0.136 \\
\hline Nursing & 0.032 & 0.078 & -0.026 & -0.052 \\
\hline Veterinary & 0.015 & 0.038 & -0.024 & -0.046 \\
\hline Arts & -0.041 & -0.073 & 0.059 & 0.098 \\
\hline Dentistry & 0.039 & -0.122 & -0.027 & -0.040 \\
\hline Undetermined & -0.052 & -0.110 & -0.094 & -0.183 \\
\hline
\end{tabular}


Table 5.9. Coefficients for regression between total number of citations for most prolific researcher in a given field and institution ranking (bold font indicates significance at the 1 percent level or better, normal font indicates significance at the 5 percent level, smaller font indicates statistically insignificant at the 5 percent level).WR $\mathrm{R}^{2}=0.348$, QS $\mathrm{R}^{2}=0.319$. Columns 3 and 5 (normalized) indicate that QS and WR data are rescaled so that all variables are normal - they have the same minimum and maximum value - thereby, avoiding bias from differences in variable magnitude

\begin{tabular}{|c|c|c|c|c|}
\hline Category & \multicolumn{2}{|c|}{ QS - actual } & $\begin{array}{l}\text { Normalized } \\
\text { WR - actual }\end{array}$ & Normalized \\
\hline Medicine & 0.000 & -0.004 & 0.000 & -0.025 \\
\hline Physics & 0.000 & 0.009 & -0.001 & -0.079 \\
\hline Biochemistry & 0.000 & -0.053 & -0.001 & -0.163 \\
\hline Engineering & 0.000 & 0.021 & -0.002 & -0.156 \\
\hline Chemistry & -0.001 & -0.134 & -0.001 & -0.063 \\
\hline Materials Science & -0.001 & -0.079 & -0.001 & -0.054 \\
\hline Immunology & -0.001 & -0.071 & -0.001 & -0.095 \\
\hline Earth Sciences & -0.003 & -0.111 & -0.005 & -0.172 \\
\hline Environment & 0.0001 & 0.122 & 0.001 & 0.084 \\
\hline Agriculture & -0.001 & -0.168 & -0.001 & -0.103 \\
\hline Mathematics & -0.002 & -0.080 & 0.002 & 0.063 \\
\hline $\begin{array}{l}\text { Computer Science } \\
\text { Chemical }\end{array}$ & -0.001 & -0.060 & -0.003 & -0.163 \\
\hline Engineering & -0.001 & -0.090 & 0.001 & 0.073 \\
\hline Multidisciplinary & -0.001 & -0.081 & 0.000 & -0.012 \\
\hline Pharmacology & 0.000 & 0.016 & 0.001 & 0.106 \\
\hline Neuroscience & -0.001 & -0.115 & 0.000 & -0.033 \\
\hline Social Sciences & -0.001 & -0.096 & -0.002 & -0.134 \\
\hline Psychology & -0.002 & -0.150 & -0.001 & -0.045 \\
\hline Health Professions & 0.000 & -0.025 & 0.001 & 0.050 \\
\hline Economics & 0.004 & 0.216 & -0.003 & -0.093 \\
\hline Decision Sciences & 0.018 & 0.004 & 0.000 & -0.008 \\
\hline Business & -0.003 & -0.141 & -0.002 & -0.082 \\
\hline Nursing & 0.001 & 0.068 & 0.000 & 0.017 \\
\hline Veterinary & 0.001 & 0.083 & 0.001 & 0.036 \\
\hline Arts & -0.001 & -0.044 & 0.001 & 0.075 \\
\hline Dentistry & -0.002 & -0.060 & 0.001 & 0.030 \\
\hline Undetermined & -0.002 & -0.124 & -0.003 & -0.154 \\
\hline
\end{tabular}


H12a. The Hirsch index of the most prolific author in some fields is more important to university ranking than research activity in other fields.

Table 5.10. Coefficients for regression between total number of coauthors for most prolific researcher in a given field and institution ranking (bold font indicates significance at the 1 percent level or better, normal font indicates significance at the 5 percent level, smaller font indicates statistically insignificant at the 5 percent level). $\mathrm{WR} \mathrm{R}^{2}=0.276$, $\mathrm{QS} \mathrm{R} \mathrm{R}^{2}=0.221$. Columns 3 and 5 (normalized) indicate that QS and WR data are rescaled so that all variables are

normal - they have the same minimum and maximum value - thereby, avoiding bias from differences in variable magnitude

\begin{tabular}{|c|c|c|c|c|}
\hline \multirow[b]{2}{*}{ Category } & \multicolumn{2}{|c|}{ QS - Normaliz } & \multirow{2}{*}{$\begin{array}{l}\text { WR - } \\
\text { actual }\end{array}$} & \multirow{2}{*}{$\begin{array}{r}\text { Normaliz } \\
\text { ed }\end{array}$} \\
\hline & actual & ed & & \\
\hline Medicine & -0.18 & -0.15 & -0.13 & -0.05 \\
\hline Physics & 0.20 & 0.09 & 0.25 & 0.09 \\
\hline Biochemistry & 0.18 & 0.16 & 0.18 & 0.07 \\
\hline Engineering & -0.01 & -0.01 & -0.11 & -0.05 \\
\hline $\begin{array}{l}\text { Chemistry } \\
\text { Materials }\end{array}$ & -0.14 & -0.04 & -0.02 & -0.01 \\
\hline Science & -0.10 & -0.05 & 0.15 & 0.05 \\
\hline Immunology & 0.08 & 0.03 & 0.17 & 0.06 \\
\hline Earth Sciences & 0.00 & -0.00 & 0.00 & -0.00 \\
\hline Environment & -0.23 & -0.11 & -0.24 & -0.12 \\
\hline Agriculture & -0.02 & -0.01 & 0.03 & 0.02 \\
\hline $\begin{array}{l}\text { Mathematics } \\
\text { Computer }\end{array}$ & -0.17 & -0.12 & -0.04 & -0.02 \\
\hline $\begin{array}{l}\text { Science } \\
\text { Chemical }\end{array}$ & -0.21 & -0.12 & -0.30 & -0.16 \\
\hline $\begin{array}{l}\text { Engineering } \\
\text { Multidisciplinar }\end{array}$ & -0.13 & -0.06 & -0.04 & -0.02 \\
\hline $\mathrm{y}$ & 0.00 & 0.10 & 0.01 & 0.01 \\
\hline Pharmacology & 0.02 & 0.01 & -0.15 & -0.07 \\
\hline Neuroscience & -0.12 & -0.06 & -0.01 & -0.01 \\
\hline Social Sciences & -0.05 & -0.04 & -0.20 & -0.15 \\
\hline $\begin{array}{l}\text { Psychology } \\
\text { Health }\end{array}$ & -0.16 & -0.10 & 0.11 & 0.07 \\
\hline Professions & 0.03 & 0.02 & 0.09 & 0.06 \\
\hline Economics & 0.04 & 0.03 & -0.13 & -0.09 \\
\hline Decision & & & & \\
\hline Sciences & -0.015 & -0.10 & -0.13 & -0.09 \\
\hline Business & 0.00 & 0.00 & -0.22 & -0.16 \\
\hline Nursing & 0.08 & 0.06 & -0.10 & -0.07 \\
\hline Veterinary & -0.03 & -0.02 & -0.12 & -0.09 \\
\hline Arts & 0.00 & 0.01 & -0.04 & -0.04 \\
\hline Dentistry & 0.00 & 0.00 & 0.08 & 0.07 \\
\hline Undetermined & -0.21 & -0.17 & -0.19 & -0.16 \\
\hline
\end{tabular}


Table 5.11. Coefficients for regression between Hirsch index for most prolific researcher in a given field and institution ranking (bold font indicates significance at the 1 percent level or better, normal font indicates significance at the 5 percent level, smaller font indicates statistically insignificant at the 5 percent level). WR $\mathrm{R}^{2}=0.356$, QS $\mathrm{R}^{2}$ $=0.317$. Columns 3 and 5 (normalized) indicate that QS and WR data are rescaled so that all variables are normal - they

have the same minimum and maximum value - thereby, avoiding bias from differences in variable magnitude.

\begin{tabular}{|c|c|c|c|c|}
\hline \multirow{2}{*}{ Category } & \multicolumn{2}{|c|}{ QS - Normaliz } & \multirow{2}{*}{$\begin{array}{l}\text { WR - } \\
\text { actual }\end{array}$} & \multirow{2}{*}{$\begin{array}{r}\text { Normaliz } \\
\text { ed }\end{array}$} \\
\hline & actual & ed & & \\
\hline Medicine & -0.40 & -0.11 & 0.09 & 0.02 \\
\hline Physics & -0.18 & -0.03 & 0.04 & 0.01 \\
\hline Biochemistry & -0.0 .6 & -0.02 & -0.59 & -0.14 \\
\hline Engineering & -0.21 & -0.04 & -1.38 & -0.25 \\
\hline Chemistry & -0.12 & -0.03 & 0.21 & 0.05 \\
\hline \multicolumn{5}{|l|}{ Materials } \\
\hline Science & -0.15 & -0.03 & -0.31 & -0.07 \\
\hline Immunology & -0.16 & -0.04 & -0.33 & -0.08 \\
\hline Earth Sciences & -0.76 & -0.15 & 0.03 & 0.01 \\
\hline Environment & 0.50 & 0.10 & -0.35 & -0.07 \\
\hline Agriculture & -0.52 & -0.09 & 0.10 & 0.02 \\
\hline Mathematics & -0.23 & -0.04 & 0.22 & 0.03 \\
\hline \multicolumn{5}{|l|}{ Computer } \\
\hline Science & -0.01 & -0.07 & -0.84 & -0.15 \\
\hline \multicolumn{5}{|l|}{ Chemical } \\
\hline Engineering & -0.69 & -0.13 & 0.47 & 0.09 \\
\hline \multicolumn{5}{|l|}{ Multidisciplinar } \\
\hline $\mathrm{y}$ & -0.00 & -0.05 & 0.00 & -0.02 \\
\hline Pharmacology & -0.35 & -0.09 & 0.24 & 0.06 \\
\hline Neuroscience & 0.07 & 0.02 & -0.07 & -0.02 \\
\hline Social Sciences & -0.31 & -0.07 & -0.52 & -0.12 \\
\hline Psychology & -0.43 & -0.10 & -0.10 & -0.02 \\
\hline \multicolumn{5}{|l|}{ Health } \\
\hline Professions & -0.05 & -0.01 & 0.43 & 0.08 \\
\hline Economics & 0.38 & 0.06 & -0.72 & -0.10 \\
\hline \multicolumn{5}{|l|}{ Decision } \\
\hline Sciences & -0.01 & -0.00 & -0.06 & -0.01 \\
\hline Business & -0.52 & -0.09 & -0.25 & -0.04 \\
\hline Nursing & 0.06 & 0.02 & -0.42 & -0.10 \\
\hline Veterinary & 0.19 & 0.04 & -0.05 & -0.01 \\
\hline Arts & -0.12 & -0.03 & -0.01 & -0.00 \\
\hline Dentistry & -0.30 & -0.08 & 0.40 & 0.08 \\
\hline Undetermined & -0.16 & -0.05 & -0.53 & -0.10 \\
\hline
\end{tabular}

H12 is not rejected. One of fifty-four categories is statistically significantly different. See Table 11.

H13. The quantity of Web citations of the most prolific author in a field and the institution ranking are the same for normalized and un-normalized data. 
H13a. The quantity of Web citations of the most prolific author in some fields is more important to university ranking than research activity in other fields.

H13 is not rejected. Six of fifty-four categories are statistically significantly different. See Table 1.

\section{Section 5.5 Discussions}

The alternative hypotheses 1, 2 and 4 through 7 are clearly supported and suggest a strong relationship between multiple measures of research productivity and the reputational ranking of universities. However, attempts to better understand the relationship between different fields of research and reputation did not provide the anticipated relations. As one considers hypotheses 3 and 9 through 12, it is apparent that while there is a statistically significant relationship between research and ranking, this relationship offers neither clear insights into the relative importance of different fields of research nor whether some fields are critical to a universities' reputation while other fields have little or no effect. While statistically significant correlations suggest that the different academic fields have a strong relation with the reputation, regression models suggest that many of these fields offer statistically insignificant relations to the exact ranking of a University. What this suggests is that although a relationship exists between research and ranking, there is much greater subtlety than a simple causal relationship. Neither a university's activity in a given academic field of research nor a focus on star faculty in a given academic field of research provides statistically generalizable insights into a university's reputational ranking. Through further consideration of the results, we can see that the slogan publish or perish is one that needs to be interpreted differently as one considers different parts of a university — central administration, faculties, and libraries 
Table 5.12. Coefficients for regression between Web references to the most prolific researcher in a given field and institution ranking (bold font indicates significance at the 1 percent level or better, normal font indicates significance at the 5 percent level, smaller font indicates statistically insignificant at the 5 percent level). WR $\mathrm{R}^{2}=0.186$, QS $\mathrm{R}^{2}=0.185$. Columns 3 and 5 (normalized) indicate that $\mathrm{QS}$ and $\mathrm{WR}$ data are rescaled so that all variables are normal - they have the same minimum and maximum value thereby, avoiding bias from differences in variable magnitude.

Category

\begin{tabular}{|c|c|c|c|c|}
\hline Medicine & 0.00 & 0.09 & 0.00 & 0.05 \\
\hline Physics & 0.00 & 0.08 & 0.00 & 0.05 \\
\hline Biochemistry & 0.00 & 0.09 & 0.00 & 0.08 \\
\hline Engineering & 0.00 & -0.08 & 0.00 & 0.12 \\
\hline Chemistry & 0.00 & -0.12 & 0.00 & -0.08 \\
\hline Materials Science & 0.00 & 0.07 & 0.00 & -0.04 \\
\hline Immunology & 0.00 & 0.03 & 0.00 & 0.03 \\
\hline Earth Sciences & 0.00 & -0.05 & 0.00 & -0.05 \\
\hline Environment & 0.00 & 0.18 & 0.00 & -0.08 \\
\hline Agriculture & 0.00 & -0.29 & 0.00 & -0.16 \\
\hline Mathematics & 0.00 & -0.10 & 0.00 & -0.04 \\
\hline Computer Science & 0.00 & -0.10 & 0.00 & -0.18 \\
\hline Chemical Engineering & 0.00 & -0.14 & 0.00 & -0.04 \\
\hline Multidisciplinary & 0.00 & 0.16 & 0.00 & 0.19 \\
\hline Pharmacology & 0.00 & 0.04 & 0.00 & -0.11 \\
\hline Neuroscience & 0.00 & -0.01 & 0.00 & -0.02 \\
\hline Social Sciences & 0.00 & -0.22 & 0.00 & -0.25 \\
\hline Psychology & 0.00 & 0.06 & 0.00 & -0.04 \\
\hline Health Professions & 0.00 & 0.05 & 0.00 & 0.12 \\
\hline Economics & 0.00 & -0.02 & 0.00 & -0.03 \\
\hline Decision Sciences & 0.00 & -0.03 & 0.00 & -0.09 \\
\hline Business & 0.00 & -0.06 & 0.00 & 0.02 \\
\hline Nursing & 0.00 & 0.06 & 0.00 & -0.14 \\
\hline Veterinary & 0.00 & 0.00 & 0.00 & -0.09 \\
\hline Arts & 0.00 & -0.03 & 0.00 & 0.09 \\
\hline Dentistry & 0.00 & 0.11 & 0.00 & -0.15 \\
\hline Undetermined & 0.00 & -0.09 & 0.00 & -0.12 \\
\hline
\end{tabular}

Clearly the norms of what is seen as important differ greatly between academic fields. For example, authors of seminal mathematical work may publish very few papers that have tremendous impact. Consider John Nash, who published quite sparingly on his Nobel Prize winning work in game theory, ${ }^{91,92}$ yet he has been very influential and offers a great deal more to the field than many mathematicians and mathematics departments of universities that are much more prolific. The nature of these norms is not readily identifiable through statistical analysis. However, a number of insights can be 
obtained that are useful on their own and offer further help in determining how to better assess differences between fields. These insights on assessing the reputation/research link will now be briefly discussed.

As indicated earlier, correlations between all the different measures of research and reputation had a statistically significant negative correlation with rank as expected (higher rank school/ greater research prominence) except in the case of Web presence. While a few fields such as Agriculture, Computer Science, Dentistry, and Social Sciences even had statistically significant relations in terms of a regression analysis, we found overall Web references are not yet important in most fields. For other metrics the correlation between institution, reputation and field performance with a given metric was almost always statistically significant.

A notable exception is Arts where it was found that correlations were frequently statistically insignificant. This could suggest that research in Arts does not have a significant effect on a university's reputation. However, it is more likely that the manner in which quality is assed in arts is just different, such as a focus on publishing books, book chapters and music compositions. Of the twenty-seven fields considered with each of the two ranking systems, fifteen categories - Agriculture, Arts, Biochemistry, Business, Chemistry, Dentistry, Earth Sciences, Economics, Health Professions, Materials Sciences, Mathematics, Medicine, Multidisciplinary, Physics, and Undetermined - have a statistically insignificant correlation with one of the five research performance metrics. The occasional absence of expected statistically significant relations calls for further consideration of the nature of research and contribution to the field. It also speaks to the lack of broad applicability to publish or perish. Having considered the correlation analysis presented in Tables 1 and 3 through 7, regression analysis and correlation coefficients are now considered. 
Consideration of regression coefficients offers insight through identifying the few fields that do have a clear explanatory relationship between the research performance criteria and a university's reputation. While a paired t-test found no difference between normalized and non- normalized data, this finding could be indicative of a general lack of statistical significance and not pertain to the few fields that have regression coefficients with a clear statistical relation to performance. When considering total publications in a field Economics, Immunology, Psychology, Veterinary, and Undetermined all have statistically significant regression coefficients. This suggests a relation between overall activity in this field and university reputation.

For the citation rate of the most prolific author, only Biochemistry, Computer Science, Earth Sciences, Economics, and Undetermined have statistically significant regression coefficients. Once again Economics appears as having a statistically significant regression coefficient. This suggest that either economics research has an impact on a university's reputation in terms of both the department and the presence of prolific and highly cited scholars or that reputable universities tend to attract and retain prolific and influential researchers.

The relation between the number of coauthors for the most prolific author and institution ranking has statistically significant regression coefficients for only the following fields: Business, Computer Science, Social Sciences and Undetermined. It is likely that the limit of 150 coauthors per researcher results in the inability to detect relationships between university reputation and coauthor numbers. Fields, such as Medicine and many of the natural sciences that are characterized by papers with a large number of authors, result in researchers reaching the 150 limit placed by Scopus quite quickly. This limit is reached quickly for a number of reasons like the involvement of large laboratories or multi-institutional teams in research, as opposed to research activities that involve a single 
researcher, two colleagues, or perhaps a student writing under supervision. In fields with sole-authorship or small group teams like Business, Computer Science, and Social Sciences the 150 co-author limit is not problematic. An interesting follow- up question is whether networks that are internal to a university, locality, region, national or international are most important. This is an important question as it indicates what are the most appropriate university efforts to facilitate and maintain research relations external to a university. It is also a complex problem as it is not only a function of field, but also the nature of the research. The presence of expensive infrastructure on fundamental research could easily bias the findings if not appropriately controlled for in areas like the natural sciences.

Only Earth Sciences has a statistically significant regression coefficient linking the Hirsh index of the most prolific author with university reputation ranking. This speaks to the critical link between Earth Sciences, star faculty, university reputation and citations as both the total number of citations and Hirsh Index for the most prolific author has coefficients with a statistically significant relationship in a regression predicting the university reputation.

Finally, Web references, the only indicator that was found to have little correlation between rank and occurrence, offer statistically significant correlation coefficients between number of Web references and university reputation in the following fields: Agriculture, Computer Science, Dentistry, and Social Sciences. It is worth returning to the question of Web references and reputation in several years to see if there is a substantial change in the influence that the Web has in relation to different fields of research. While the Web has been increasing in importance and value for over a decade, it still is in its infancy in terms of enhancing and/or replacing the traditional role of peer reviewed serials and libraries.

While overall the results suggest that the research and reputation of a university have a 
significant link to each other, it remains unclear whether the research is a significant cause of the universities reputation or that universities that have a strong reputation happen to be places where a great deal of research is conducted. However, it is clear that there are substantial differences in the relationship not only between research in different fields, but also the nature of research excellence and productivity from field-to-field. As researchers and research administrators tend to be field specific, these differences face little understanding both within and outside of the university environment. Consequently, a better understanding of these between field differences would assist not only with the link between reputation and research—but also what "publish or perish" implies in different academic fields. The term "publish or perish" as a general statement is incorrect. While there is a statistical relation between top publishing departments and the most prolific scholars, regression coefficients are statistically insignificant.

\section{Section 5.6 Implications}

For the central administration of a university this study illustrates that while a relation exists between research and reputation, simple metrics cannot be used to quantify the relationship. There are significant differences between the manner in which quality is measured across different academic fields. Consequently, one needs to better understand the differences between academic fields so as to better calibrate the inputs and outputs that can be expected from an academic field.

The lack of clear relationships between reputation and research metrics for a variety of academic fields suggests that there is no clear relation between a field and the university reputation. In other words, it is possible that the absence of a specific academic field from a university does not inherently disadvantage its standing in the global academic community and that a university can rise to prominence due to excellence in a variety of different academic fields. In summary, there is no one clear path to prominence and 
reputation. While librarians are aware of the nuances and substantial differences in norms between academic fields, few others in a university are. Consequently, articles such as this are helpful in illustrating the complexities faced when trying to appropriately balance the needs of very different academic fields simultaneously.

\section{Section 5.7 Conclusions}

Research and reputation are related to each other. The nature of this relationship is unclear. There needs to be a better understanding of the relationship between reputation and research in different fields so that incentives and knowledge infrastructure that are the most appropriate for fostering research are offered. It is not possible to take a "one size fits all approach" so terms such as "publish or perish" or an excessive reliance on simple metrics should be avoided. Further study is needed at the field level to better understand the relationship between activity and performance. Failure to understand this can lead to decisions by a central administration or the library that unwittingly undermines the goal of fostering excellence in the university's core missions and at the same time undermines the national and international reputation. While the Web has been increasing in importance and value for over a decade, it still is in its infancy in terms of enhancing and/or replacing the traditional role of peer-reviewed serials and libraries 


\section{Section 5.8 References}

1. J.F. Volkwein and K.V. Sweitzer, (2006). "Institutional prestige and reputation among research universities and liberal arts colleges." Research in Higher Education, 47

(2) (2006): 129-48.

2. S.A. Kirk, H.J. Kil, H.J. and K. Corcoran, "Picky, picky, picky: ranking graduate schools of social work by student selectivity." Journal of Social Work Education 45 (1) (2009): 65-87.

3. K. Auspurg, T. Hinz, and J. Güdler, (2008). Emergence of an academic elite? The impact of universities' size and reputation on research funding. Kolner

Zeitschrift fur Soziologie und Sozialpsychologie 60 (4) (2008): 653-85.

4. M.-H. Huang, H.-W. Chang and D.-Z. Chen, "Research evaluation of research oriented universities in Taiwan from 1993 to 2003," Scientometrics 67 (3)

(2006): 419-35.

5. M.N. Bastedo and N. Bowman, "U.S. News and World Report college rankings: modeling institutional effects on organizational reputation," American Journal of Education 116 (2) (2010): 163-83.

6. G. Boulton, "University rankings: diversity, excellence and the European initiative," Procedia — Social and Behavioral Sciences 13 (2011): 74-82.

7. N.A. Bowman and M.N. Bastedo, "Anchoring effects in world university rankings: exploring biases in reputation scores," Higher Education 61 (4) (2011): 431-44.

8. V. Safón, "Measuring the reputation of top US business schools: a MIMIC modeling approach," Corporate Reputation Review 12 (3) (2009): 204-28.

9. V. Safón, "Factors that influence recruiters' choice of b-schools and their MBA graduates: evidence and implications for b-schools," The Academy of Management Learning and Education 6 (2) (2007): 217-33.

10. N.A. Bowman and M.N. Bastedo, "Getting on the front page: organizational reputation, status signals, and the impact of U.S. news and world report on student decisions," Research in Higher Education 50 (5) (2009): 415-36.

11. J. Brennan, R. Brodnick and D. Pinckley, "De-Mystifying the U.S. news rankings: how to understand what matters, what doesn't and what you can actually do about it," Journal of Marketing for Higher Education 17 (2) (2007): 169-88.

12. P. Cyrenne and H. Grant, "University decision making and prestige: an empirical study," Economics of Education Review 28 (2) (2009): 237-48. 
13. Anon, "Publish or perish," Nature 193 (4817) (1962): 709.

14. R.J. Good, "Publish or perish — some solutions," Chemical and Engineering News 42 (36) (1964): 4-5.

15. A. Mackay, "Publish or perish," Nature 250 (5469) (1974): 698.

16. S. Lofthouse, "Thoughts on "publish or perish," Higher Education 3 (1) (1974): 59-80.

17. A.S. Relman, "Publish or perish — or both," The New England Journal of Medicine 297 (13) (1977): 724-5.

18. G.F. Nash and D.C. Walsh, "Research plans for current basic surgical trainees: still publish or perish?," Annals of the Royal College of Surgeons of England 82 (10 Suppl) (2000): 336-7.

19. S.Y. Rhee, "Carpe diem. Retooling the "publish or perish" model into the "share and survive" model," Plant Physiology 134 (2) (2004): 543-7.

20. P. Clapham, "Publish or perish," BioScience 55 (5) (2005): 390-1.

21. H.K. Schachman, "From "publish or perish" to "patent and prosper"," Journal of Biological Chemistry 281 (11) (2006): 6889-903.

22. M. De Rond and A.N. Miller, "Publish or perish: bane or boon of academic life?," Journal of Management Inquiry 14 (4) (2005): 321-9.

23. M. Angell, "Publish or perish: a proposal," Annals of Internal Medicine 104 (2) (1986): 261-2.

24. B.A. Solagberu, "Literature search in medical publications," West African Journal of Medicine 21 (4) (2002): 329-31.

25. D. Yimin, "Chinese academy of sciences: in China, publish or perish is becoming the new reality," Science 291 (5508) (2001): 1477-9.

26. J. Qiu, "Publish or perish in China," Nature 463 (7278) (2010): 142-3.

27. L. de Meis, A. Velloso, D. Lannes, M.S. Carmo and C. de Meis, "The growing competition in Brazilian science: rites of passage, stress and burnout,"Brazilian Journal of Medical and Biological Research 36 (9) (2003): 1135-41.

28. T. Plümper and C.M. Radaelli, "Publish or perish? Publications and citations of Italian political scientists in international political science journals, 1990-2002," Journal of European Public Policy 11 (6) (2004): 1112-27.

29. M.M. De Villiers and S.F. Malan, "Publish or perish: how is pharmacy research coping in a changing South Africa?," South African Journal of Science 93 (8) (1997): $355-8$. 
30. A.P. Smith, "Publish or perish: the write thing for nursing," Nursing Economics 22 (6) (2004): 342-3.

31. G. Parchomovsky, "Publish or perish," Michigan Law Review 98 (4) (2000): 926-51.

32. W.B. Mitchell and M. Reichel, "Publish or perish: a dilemma for academic librarians?" College and Research Libraries 60 (3) (1999): 232-43.

33. N.A. Frost, N.D. Phillips and T.R. Clear, "Productivity of criminal justice scholars across the career," Journal of Criminal Justice Education 18 (3) (2007): 428-43.

34. B. McKercher, "A citation analysis of tourism scholars," Tourism Management 29 (6) (2008): 1226-32.

35. U. Bunz, "Publish or perish: a limited author analysis of ICA and NCA journals," Journal of Communication 55 (4) (2005): 703-20.

36. L.F. Noè and D.J. Batten, "'Publish or perish': the pitfalls of duplicate publication," Palaeontology 49 (6) (2006): 1365-7.

37. M.-Y.Wang, Z.-X. Zhou, H.-L. Fang and X.-L. Liu, "The bibliometric characteristics of Chinese Medical Core Journals," Serials Review 37 (1) (2011): 9-13. doi:10.1016/j.serrev.2010.11.002.

38. W. Sadée, "Publish or perish, and the journal glut," Pharmaceutical Research 7 (4) (1990): 433-4.

39. E.C. Halperin, "Publish or perish - and bankrupt the medical library while we're at it," Academic Medicine 74 (5) (1999): 470-2.

40. M. Gad-El-Hak, "Publish or perish — an ailing enterprise?," Physics Today 57 (3) (2004): 61-2.

41. D.M. Chiu and T.Z.J. Fu, “"Publish or perish” in the internet age - a study of publication statistics in computer networking research," Computer Communication Review 40 (1) (2010): 34-43.

42. S. Shaban, "Multiple authorship trends in prestigious journals from 1950 to 2005," Saudi Medical Journal 28 (6) (2007): 927-32.

43. T.D. Englebrecht, S.A. Hanke and Y. Kuang, "An assessment of patterns of coauthorship for academic accountants within premier journals: evidence from 1979-2004," Advances in Accounting 24 (2) (2008): 172-81.

44. $\quad$ F.P. de Villiers, "Publish or perish—the growing trend towards multiple authorship," South African Medical Journal 66 (23) 
45. G. Holden, G. Rosenberg, K. Barker and P. Onghena, "An assessment of the predictive validity of impact factor scores: implications for academic employment decisions in social work," Research on Social Work Practice 16 (6) (2006): 613-24.

46. Xue-L. li, Hong-ling Fang, Mei-ying. and Wang, Serials Review, 37 (3) (2011): $157-161$.

47. Anon., "E-publish or perish,” Economist 395 (8676) (2010).

48. P. Śleszyński, “The position of Polish geographical journals and series as seen in the Google Scholar databases," Przeglad Geograficzny 81 (4) (2009):

551-78.

49. P. Jacsó, "Calculating the h-index and other bibliometric and scientometric indicators from Google Scholar with the Publish or Perish software," Online Information Review 33 (6) (2009): 1189-200.

50. M. Dazey and B. Parks, "Thoughts on Open Access: an interview with Diane Graves," Serials Review 36 (2) (2010): 112-5.

51. B.N. Lizotte, "Publish or perish: the electronic availability of summary judgments by eight district courts,” Wisconsin Law Review (1) (2007): 107-49.

52. J. Cohen, "Publish or perish—is open access the only way forward?," International Journal of Infectious Diseases 10 (6) (2006): 417-8.

53. H. Chanson, "Research quality, publications, and impact in civil engineering into the 21 st century. Publish or perish, commercial versus open access, internet versus libraries?," Canadian Journal of Civil Engineering 34 (8) (2007): 94651 .

54. P. Vinkler, "The $\pi$-index: a new indicator for assessing scientific impact," Journal of Information Science 35 (5) (2009): 602-12.

55. T. Eisenberg and M.T. Wells, "Ranking and explaining the scholarly impact of law schools," The Journal of Legal Studies 27 (1998): 3732 PART I.

56. G. Franco, "Publish or perish: the scientific productivity of academics in the field of Occupational Medicine,” Medicina del Lavoro 100 (3) (2009): 163-70.

57. H.M. Ortner, "The impact factor and other performance measures - much used with little knowledge about," International Journal of Refractory Metals and Hard Materials 28 (5) (2010): 559-66.

58. M. Pautasso and H. Schäfer, "Peer review delay and selectivity in ecology journals," Scientometrics 84 (2) (2010): 307-15. 
59. V.A. Cartwright and C.N.J. McGhee, "Ophthalmology and vision science research. Part 1: understanding and using journal impact factors and citation indices," Journal of Cataract and Refractive Surgery 31 (10) (2005): 1999-2007.

60. N. Bontis and A. Serenko, "A follow-up ranking of academic journals," Journal of Knowledge Management 13 (1) (2009): 16-26.

61. M. Ouimet, P.-O. Bédard, and F. Gélineau, "Are the h-index and some of its alternatives discriminatory of epistemological beliefs and methodological preferences of faculty members? The case of social scientists in Quebec," Scientometrics, 88 (1) (2011): 91-106.

62. D. Truex, M. Cuellar and H. Takeda, “Assessing scholarly influence: using the Hirsch indices to reframe the discourse," Journal of the Association for Information Systems 10 (7) (2009): 560-94.

63. S.L. Sellers, S.G. Mathiesen, R. Perry and T. Smith, "Evaluation of social work journal quality: citation versus reputation approaches," Journal of Social Work Education 40 (1) (2004): 143-60.

64. F. Schläpfer, "How much does journal reputation tell us about the academic interest and relevance of economic research?," Gaia 19 (2) (2010): 140-5.

65. A. Parameswaran and R. Sebastian, "The value of South and Southeast Asian Studies Journal Rankings," Serials Review 32 (3) (2006): 154-63.

66. L.V. Ellis and G.C. Durden, "Why economists rank their journals the way they do," Journal of Economics and Business 43 (3) (1991): 265-70.

67. A.-W.K. Harzing and R. van der Wal, "Google Scholar as a newsource for citation analysis," Ethics in Science and Environmental Politics 8 (1) (2008): 61-73.

68. H. Long, L.N. Boggess and W.G. Jennings, "Re-assessing publication productivity among academic "stars" in criminology and criminal justice," Journal of Criminal Justice Education 22 (1) (2011): 102-17.

69. D.R. Euben, "Publish or perish: the ever-higher publications hurdle for tenure," Academe 88 (4) (2002): 78.

70. M. Heesacker and T.R. Elliott, "My dog's better than your dog: publication counts and quality of clinical psychology PhD training," Clinical Psychology: Science and Practice 14 (2) (2007): 175-8.

71. R. Plomp, "The highly cited papers of professors as an indicator of a research group's scientific performance," Scientometrics 29 (3) (1974): 377-93.

72. Macleans, "Canadian University Rankings," http://oncampus.macleans.ca/ education/rankings/ accessed August 23, 2011.

73. DAAD, “German University Rankings," http://www.daad.de/deutschland/ hochschulen/hochschulranking/06543.en.html accessed August 23, 2011. 
74. Guardian, “UK University Rankings,” http://www.guardian.co.uk/education/ table/2011/may/17/university-league-table-2012 accessed August 23, 2011.

75. ARWU, “Academic Ranking of World Universities,” http://www.arwu.org/ index.jspaccessed August 23, 2011.

76. QS, “Quacquarelli Symonds Limited Ranking of World Universities,” http:// www.topuniversities.com/university-rankings/world-university-rankings accessed August 23, 2011.

77. WR, "Webometrics Ranking of World Universities," http://www. webometrics.info/ accessed August 23, 2011.

78. HEEACT, "Higher Education Evaluation and Accreditation Council of Taiwan," http://www.heeact.edu.tw/mp.asp?mp=4 accessed August 23, 2011.

79. J. Billaut, D. Bouyssou and P. Vinke, "Should we believe the Shanghai ranking? An MCDM view," Scientometrics 84 (1) (2010): 237-63.

80. S. Marginson and M. van der Wende, "To rank or to be ranked: the impact of global rankings on higher education," Journal of Studies in International Education 11 (3/4) (2007): 306-29.

81. Răzvan V. Florian, "Irreproducibility of the results of the Shanghai academic ranking of world universities," Scientometrics 72 (1) (2007): 25-32.

doi:10.1007/s11192-007-1712

82. N.C. Liu and Y. Cheng, "The Academic Ranking of World Universities methodologies and problems," Higher Education in Europe 30 (2) (2005): 12736.

83. N.C. Liu and Y. Cheng, "Examining major rankings according to the Berlin principles," Higher Education in Europe 33 (2/3) (2008): 201-8.

84. A.F.J. van Raan, "Fatal attraction — conceptual and methodological problems in the ranking of universities by bibliometric methods," Scientometrics 62 (1) (2005): 133-43.

85. Isidro F. Aguillo, Judit Bar-Ilan, Mark Levene and Jose Luis Ortega, "Comparing university rankings," Scientometrics 85 (2010): 243-56.

86. I.F. Aguillo, B. Granadino, J.L. Ortega and M. Fernandez, "Webometric ranking of world universities: introduction, methodology, and future developments," Higher Education in Europe 33 (2/3) (2008): 234-44.

87. Andrejs Rauhvargers, Global University Rankings and Their Impact, European University Association, Brussels, 2011.

88. H. Andersen, "Influence and reputation in the social sciences - how 173 
much do researchers agree?," Journal of Documentation 56 (6) (2000):

674-92.

89. B.L. Andersen, S.J. Beck, R.A. Bornstein, C.F. Emery, M.A. Fristad, J.K.

Kiecolt-Glaser, D.R. Strunk, J.F. Thayer, M.W. Vasey and K.O. Yeates,

"Problematic methods in the assessment of scholarly productivity in clinical PhD programs," Clinical Psychology: Science and Practice 15 (1) (2008): 102-4.

90. T.J. Gaeta, “Authorship: 'law' and order,” Academic Emergency Medicine 6 (4) (1999): 297-301.

91. J.F. Nash, "Equilibrium points in N-person games," Proceedings of

the National Academy of Science on the United States of America 36 (1) (1950): 48-9.

92. J.F. Nash, “The bargaining problem,” Econometrica 18 (1950): 155-61. 


\section{Appendix I. Screen Images of Steps Used to Collect Data}

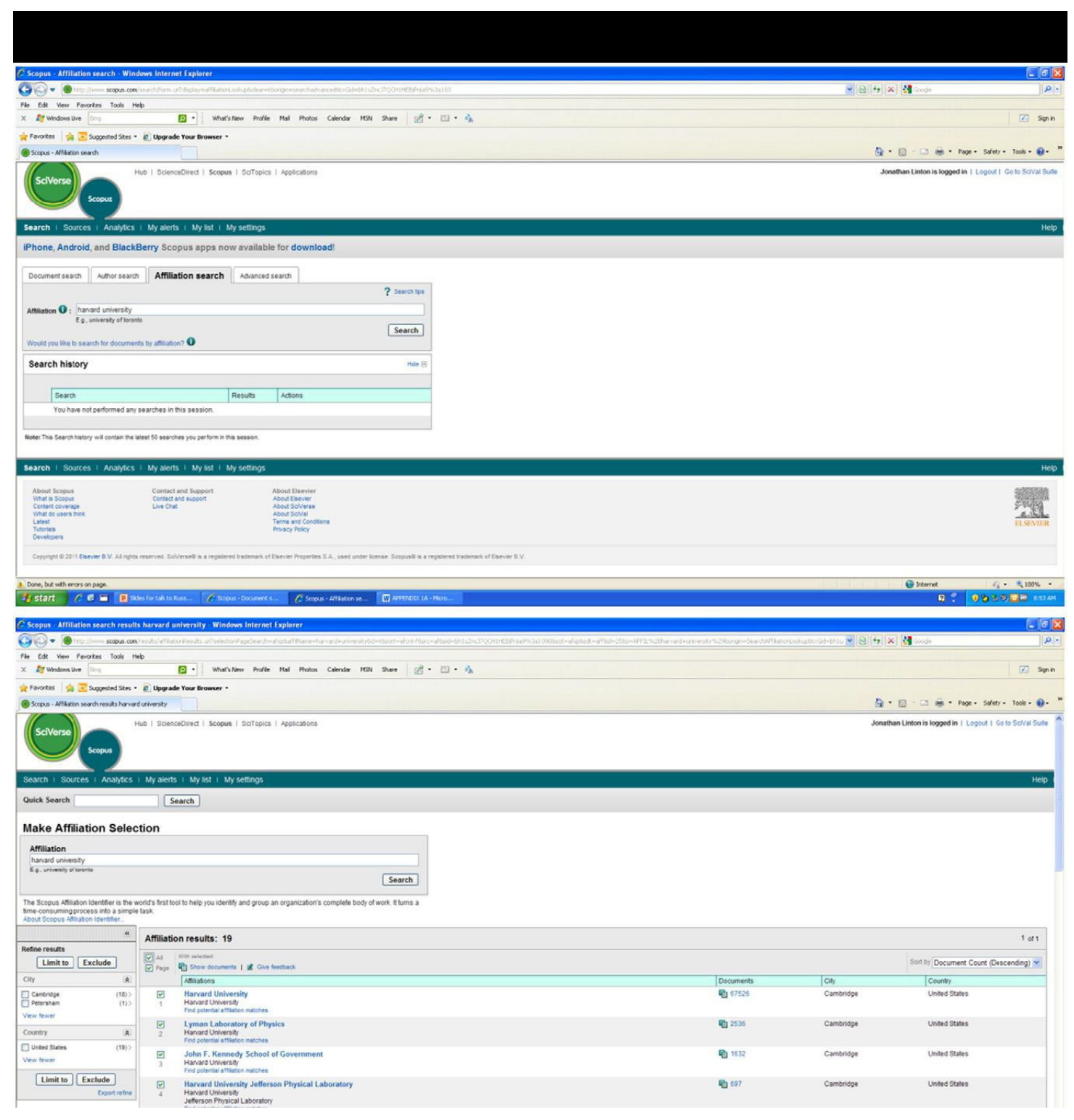




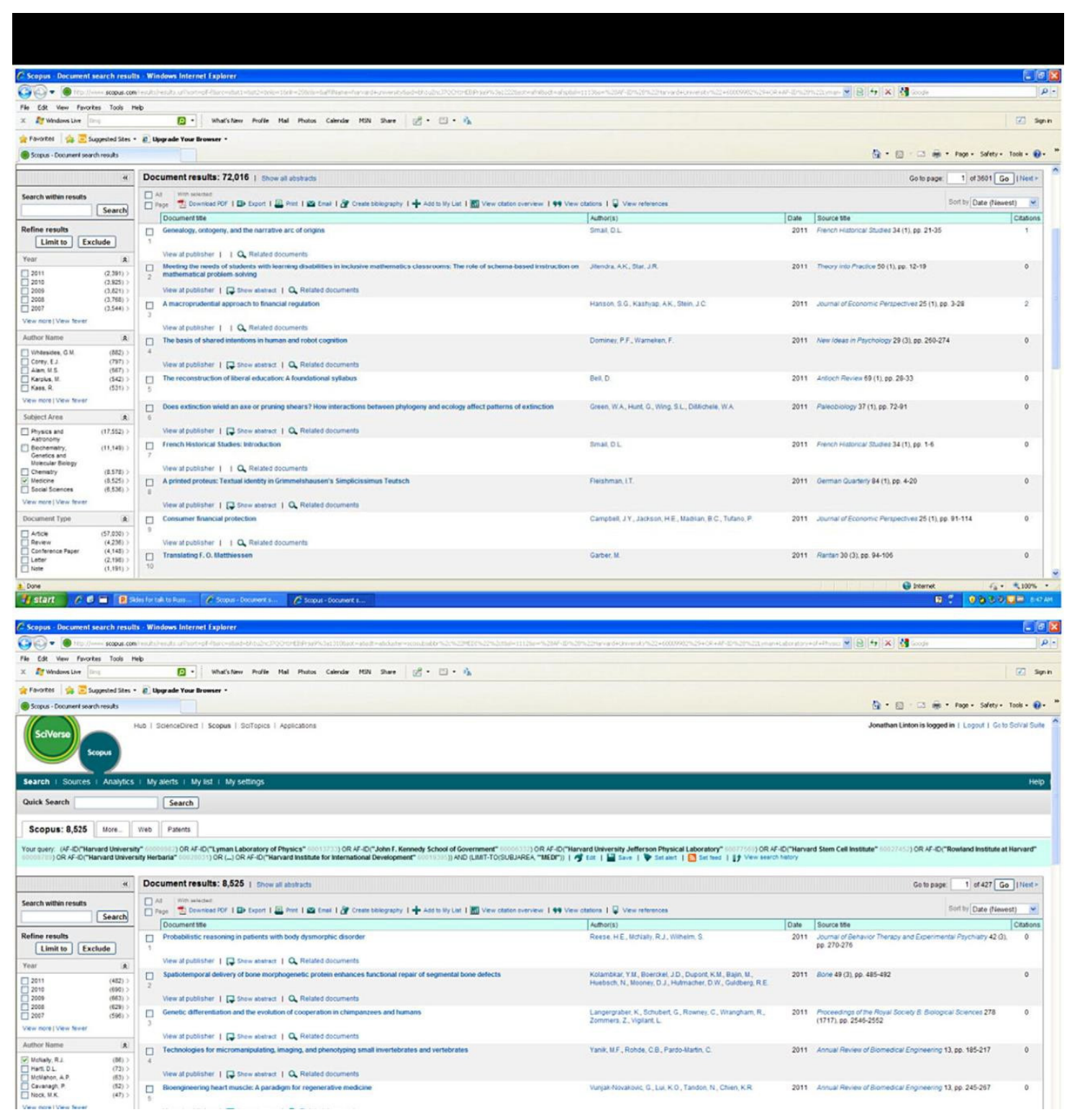




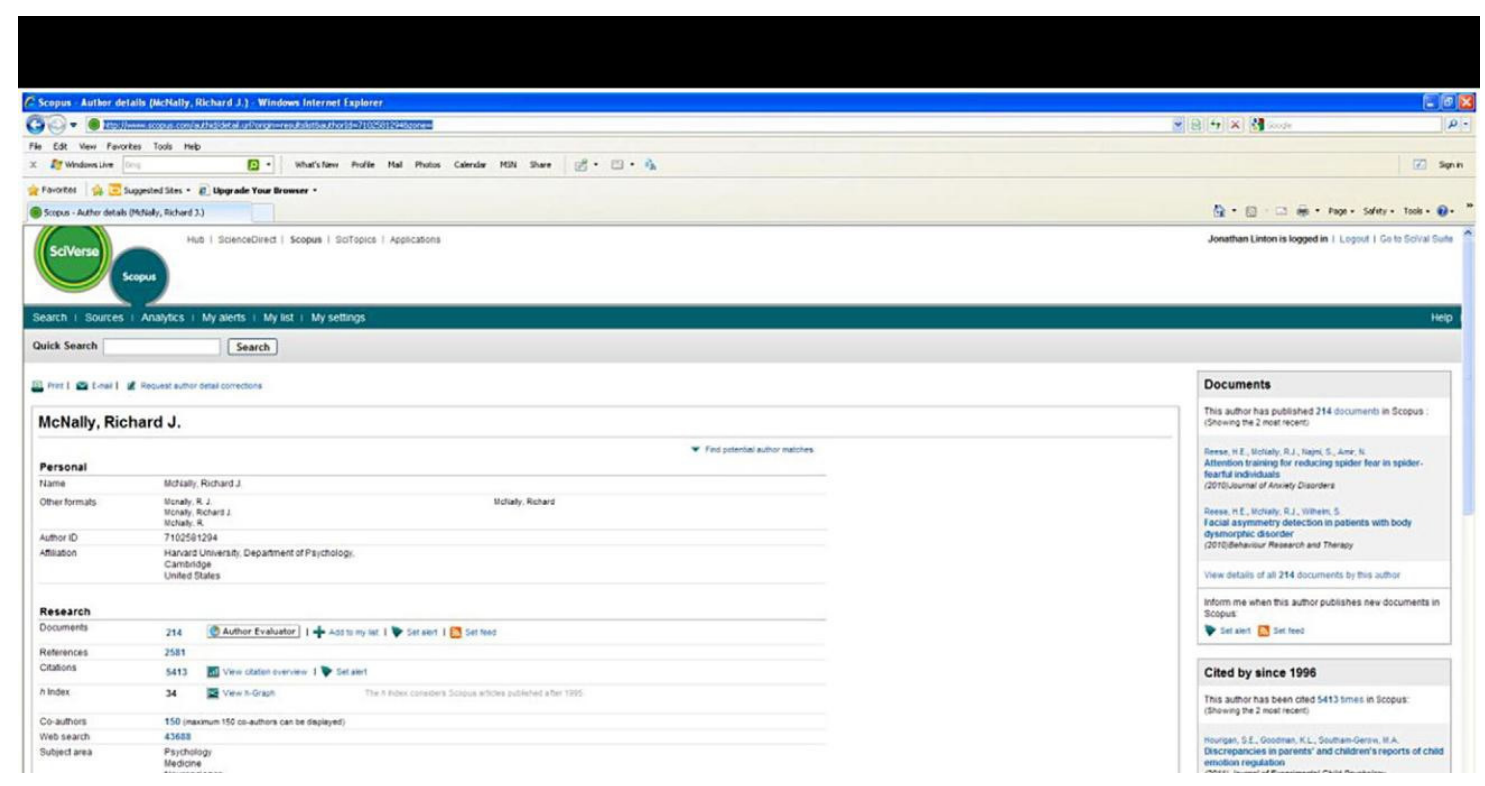




\title{
Section 6
}

\section{What are Research Expectations? A \\ Comparative Study of Different Disciplines}

By

\author{
Jonathan D. Linton a, $\square$, Robert Tierney b, Steven T. Walsh c \\ a University of Ottawa, Ottawa, Canada \\ b NIKOS, University of Twente, Enschede, The Netherlands \\ c University of New Mexico, Albuquerque, NM, USA
}

Reproduced with permission from Elsevier Publishing Inc. Article originally appeared in Serials Review December 2012 Volume 38 Number 4 pp. 229-234 


\section{Section 6.1 Abstract and Keywords}

This paper is intended to assist professors, administrators, librarians and other members of university level committees that must consider research expectations and research quality in academic fields that they lack. While this is not a problem for field experts, it is a difficulty when people are asked to make decisions in areas of study other than their own. This is commonly the case for senior university professors, librarians and administrators in regards to university wide decisions. The paper investigates this gap, through a study of 27 academic fields in 348 highly regarded universities. We find that there are almost always statistically significant differences in activity between academic fields, regardless of the metric one considers. However, it is possible to understand these differences by comparing the distribution of a known academic field to that of a field that one is not familiar with. Tables and information are provided to assist in the comparison of different fields of study on metrics such as: departmental publications and researcher level metrics of publications, citations, $\mathrm{H}$-index, and total number of co-authors. The information can also be used to support decisions associated with promotion to senior posts such as endowed chairs and professorships. Information regarding specific universities and researchers are included in the data supplement

Keywords: Research, Metrics, Interdisciplinary, H index, Citations, evaluation 


\section{Section 6.2 Introduction}

Assessing a field of study is considered difficult. However, understanding the boundaries of a field and the relative quality of different outlets in the field is critical to decisions regarding tenure and promotion. Consequently, many articles have been written in a wide range of fields to help researchers better understand and evaluate their own field (Bontis \& Serenko, 2009; Dubois \& Reeb, 2000; Fisher, Shanks, \& Lamp, 2007; Guidry et al., 2004; Linton \& Thongpapanl, 2004; Thongpapanl, 2012). It is even more difficult to evaluate the work of scholars in a different field (Henderson, Ganesh, \& Chandy, 1990; D. A. Johnston, personal communication, August 15, 2012; K. Malloy, personal communication, August 14, 2012; G. T. Solomon, personal communication, August 14, 2012; D. W. Walsh, personal communication, August 14, 2012; F.S. Wu, personal communication, August 14, 2012). While citation and publication rate are frequently put forward as proxies of research quality and relevance (Anon, 1962; Clapham, 2005; de Meis, Velloso, Lannes, Carmo, \& de Meis, 2003; De Rond \& Miller, 2005; De Villiers \& Malan, 1997; Good, 1964; Lofthouse, 1974; Mackay, 1974; Mitchell \& Reichel, 1999; Nash \&

Walsh, 2000; Parchomovsky, 2000; Plümper \& Radaelli, 2004; Qiu, 2010; Relman, 1977; Rhee, 2004; Smith, 2004; Yimin, 2001), differences between fields are not taken into account (Shin \& Cummings, 2010). As this gap still exists, this paper takes a step towards forming a better understanding of the differences that exist in research expectations between fields within a university. This is critical as librarians are often asked to offer insights into the nature and quality of a professor's research portfolio. Although the library science community is aware of the inherent differences in publication, authorship, and citation patterns that exist from faculty tofaculty and even between departments within the same faculty, this academic field knowledge may not be readily accepted by the researchers and administrators that populate the faculties of an academic or research institution. Consequently, a paper that moves us towards a better understanding of the inherent differences between fields by providing information on how 
research activity varies between fields is a valuable contribution and useful reference document. Such a contribution assists librarians when they are tasked with either offering insights into the relative quality of a candidate that is being considered by a university or providing guidance on advising what level of research activity is roughly equivalent to the activity in another field. It also offers librarians with some supporting information about the relevant importance of journals to different fields, and this information can help with decision-making regarding acquiring or discontinuing publications. Hence, this paper examines research and researcher activity in different fields for highly regarded universities (Linton, Tierney, \& Walsh, 2011).

There are a variety of reasons for members of a university community to understand differences in research expectations in different fields. Senior administrators, librarians, and professors need to understand the norms of the different academic fields within the universities' portfolio. Previous experience in a single academic department does not prepare academics for this role as they move to tasks that are more interdisciplinary in nature. While this knowledge will develop over time, the learning process can be accelerated through reading about differences in between-field norms, as is offered here and in the supplement.

Comparing between field norms is critical for hiring and promotion committees that involve university community members from a number of different fields. As this is commonplace in universities, it is an activity that needs to be understood as it is not possible to just assume that everyone will be able to identify good research and contributions in a field without understanding the difference in norms that separate an individual's field from that under consideration. Without appropriate baseline quantitative information for between-field calibration, the richness and value of qualitative assessment cannot be fully utilized. Particular attention to what constitutes substantive research activity is of particular value for decisions on promotion to full or chaired professor. Finally, an assessment of the differences in relative levels of activity of different parts of a university community can 
provide useful information to assist with decisions relating to acquisition of books, journals, and databases for the library science community.

In summary, this paper offers:

1.) A quantitative basis for better understanding differences in research expectations between different fields within and across institutions;

2.) Consideration of the common metrics to describe research activity-number of publications, total number of citations, number of co-authors, and Hirsch index (the number that represents both frequency of publication and citation simultaneously-i.e., an index of 10 states that at least 10 papers are cited 10 or more times (Truex, Cuellar, \& Takeda, 2009),

3.) Assistance to members of university committees in better understanding differences in norms — critical for providing baseline information across discipline decisions on tenure, promotion, and selection for honors such as chairs and special status such as distinguished professor;

4.) Provides equivalency in research metrics for consideration of personnel within a field or across fields;

5.) Offers a benchmark of what very prolific researchers' activity is in different fields of highly respected universities and how this varies;

6.) Provides useful insights for assessments on what constitutes a prolific researcher in different fields, which is important for recruiting and retention.

\section{Section 6.3 Methods}

In order to compare research output between fields, it is important to have a large group of universities that are active in most or all fields considered. The universities should be from a variety of different geographic locations to reflect possible differences in 
expectations and the nature of output in different countries. It was determined that these goals could be accomplished by selecting the top universities from an international ranking of universities. There are a number of different ranking systems of both a regional and international nature (Aguillo, Bar-Ilan, Levene, \& Ortega, 2010; Aguillo, Granadino, Ortega, \& Fernandez, 2008). To avoid over reliance on a single ranking system and the inherent biases of that particular system, we selected the top 250 universities from the tw o most divergent international ranking systems (Aguillo et al., 2008, 2010). More specifically, this study is based on the QS (QS, 2011) (Quacquarelli Symonds Limited) and WR (WR, 2011) (Webometrics) lists of top universities globally. Through the consideration of the top 250 universities for each of these rankings a list of 348 institutions were obtained. Repetition of data collection may result in slightly different numbers reflecting the separate counting of different parts of the same organization. For example, the University of London is made up of a number of semi- autonomous institutions. At the time of writing of this article, the University of Manchester and University of Manchester Institute of Science and Technology (UMIST) had merged into a single institution, and there are discussions of making a similar merger between the University of Leiden, Delft University and Erasmus University in the Netherlands. The data collection follows the same procedure as in Linton et al. (2011), and hence it is only reviewed briefly here.

For each university, data were collected manually from Scopus (www.scopus.com) in the following manner: (1) affiliation tab was chosen. (2) A search of the desired university is initiated. (3) Once the search is complete, all associated organizations, institutes or departments are checked to gain a complete record of university research activity. The show documents box was selected. (4) One now identifies and collects information on the most active researcher in a given field at a given university. (5) The list of articles for a given field is isolated - to do this one must eliminate the multidisciplinary category for each 
search. Having conducted this step, the most prolific author is the first name in the author list. The box associated with the first author is selected to gain access to all of the publications associated with that author. (6) On the next screen, the author's name on the most recent publication is located and selected. The name of the author, number of publications, number of citations, number of coauthors, and Hirsch index are all recorded and associated to the appropriate university and field of research in our database. If the selected author is found to be a faculty member at a different university, the next most prolific author is selected. In a few cases, no authors were found at the university under consideration. In these cases, zeroes were entered into the database describing the activity of the most prolific author. The process was conducted until information for all the universities was c o m p le te d.

Information regarding the most prolific authors in each field at each university was placed into an Excel spreadsheet. This supplement — a set of 27 tables_-provides the detailed data used in this study and can be found at (http://www.research.uottawa.ca/docs/researchexpectations.pdf). The data supplement includes numerical ranks for all institutions corresponding to each of the fields specified on Tables 1 to 5 of this paper. The statistical routines provided within Microsoft Excel were used to determine the percentile values associated with the different variables. Percentiles are a useful way to summarize the data as they give a quick simple way of depicting the underlying data. They represent the ordering of universities in a line from lowest to highest value and allow us to list the magnitude of each research related metric for the 1 st (lowest value-min), 35th (10th percentile), 87th (25th percentile), (50th percentile-median), 251st (75th percentile), 313th (90th percentile), and 348th (highest value-max). In addition, T-tests were used to compare the values of the same variable to determine if the values from the different fields are samples that come from the same population or if the samples are clearly from different underlying populations - that is the 
difference is statistically significant. The simplifying assumptions of paired T-tests and a single standard deviation describing both variables are avoided as this might bias the results. Summary statistics and results of the analysis are provided below in the next section.

\section{Section 6.4. Results}

\subsubsection{Consideration of Overall Data}

The distribution of the total number of publications in each field is summarized in Table 1. From this information, it is possible to see that there is a tremendous variation between fields of study. Furthermore, by examining the supplement (see Section 3.2), one can see there are substantial variations in research performance within a university. In some cases this is a result of a university having no activity in an area, as we see from zero or near zero minimum values for the 27 fields listed in Table 6.1. Maximum values are often non-representative due to an unusual situation such as interdisciplinary researchers having all their publications from a number of different fields counted. 


\section{Table 6.1}

Total publications for each area of study for $\mathbf{3 4 8}$ top universities: minimum, various percentile levels, and maximum value.

\begin{tabular}{|c|c|c|c|c|c|c|c|}
\hline Category & Min & 10th & 25 th & 50 th & 75 th & 90th & Max \\
\hline Medicine & 2 & 578 & 1,762 & 8,438 & 16,824 & 26,447 & 127,212 \\
\hline Astronomy and Physics & 0 & 1,008 & 2,495 & 4,961 & 8,194 & 1,348 & 42,552 \\
\hline Biochemistry, Genetics and Molecular Biology & 0 & 854 & 2,185 & 5,729 & 9,881 & 15,039 & 53,935 \\
\hline Engineering & 0 & 587 & 1,490 & 3,708 & 6,996 & 12,218 & 34,750 \\
\hline Chemistry & 0 & 876 & 1,845 & 3,069 & 4,853 & 8,117 & 21,812 \\
\hline Materials & 0 & 370 & 737 & 1,735 & 2,995 & 5,526 & 17,515 \\
\hline Immunology and Microbiology & 0 & 93 & 287 & 949 & 2,141 & 3,510 & 19,363 \\
\hline Earth and Planetary Science & 0 & 85 & 283 & 919 & 2,300 & 3,564 & 18,103 \\
\hline Environmental Science & 0 & 319 & 566 & 1,048 & 1,991 & 3,125 & 8,127 \\
\hline Agriculture/Biological Science & 0 & 97 & 261 & 1,239 & 2,783 & 5,329 & 18,452 \\
\hline Mathematics & 0 & 413 & 735 & 1,315 & 2,273 & 3,667 & 8,610 \\
\hline Computer Science & 0 & 438 & 724 & 1,313 & 2,350 & 4,089 & 11,261 \\
\hline Chemical Engineering & 0 & 168 & 388 & 747 & 1,427 & 2,525 & 7,860 \\
\hline Multidisciplinary & 0 & 59 & 105 & 256 & 504 & 1,116 & 8,485 \\
\hline Pharmacology, Toxicology and Pharmaceuticals & 0 & 115 & 325 & 989 & 1,920 & 3,070 & 15,915 \\
\hline Neuroscience & 0 & 104 & 298 & 909 & 2,152 & 3,396 & 25,837 \\
\hline Social Science & 0 & 259 & 495 & 1,061 & 2,014 & 3,343 & 19,732 \\
\hline Psychology & 0 & 78 & 321 & 776 & 1,579 & 2,675 & 6,940 \\
\hline Health Professions & 0 & 13 & 49 & 202 & 623 & 1,226 & 4,932 \\
\hline Economics, Econometrics and Finance & 0 & 71 & 171 & 339 & 621 & 1,225 & 5,889 \\
\hline Decision Science & 0 & 95 & 167 & 294 & 505 & 807 & 1,926 \\
\hline Business Management & 0 & 90 & 146 & 341 & 571 & 981 & 3,330 \\
\hline Nursing & 0 & 12 & 65 & 177 & 426 & 944 & 3,364 \\
\hline Veterinary & 0 & 5 & 23 & 73 & 224 & 1,240 & 5,106 \\
\hline Arts and Humanities & 0 & 2 & 9 & 130 & 388 & 800 & 5,108 \\
\hline Dentistry & 0 & 3 & 8 & 44 & 346 & 889 & 3,508 \\
\hline Undefined & 0 & 7 & 24 & 104 & 333 & 658 & 2,768 \\
\hline
\end{tabular}


Table 6.2

Total publications for most prolific author for 348 top universities: minimum, various percentile levels, and maximum value.

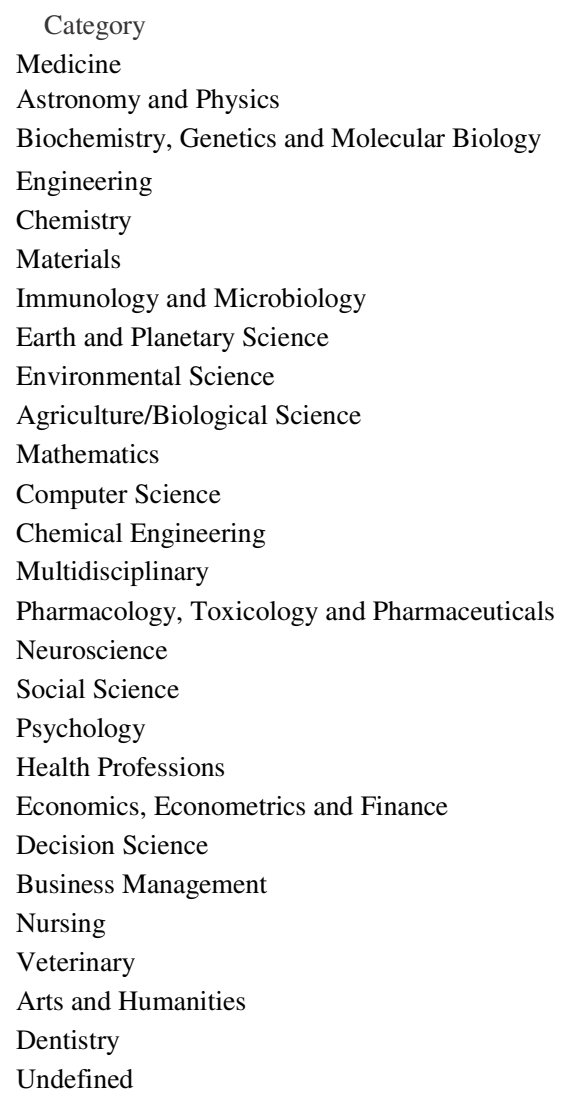

$\begin{array}{ccccccc}\text { Min } & 10 \text { th } & 25 \text { th } & 50 \text { th } & 75 \text { th } & 90 \text { th } & \text { Max } \\ 10 & 99 & 183 & 321 & 506 & 1,693 & 127,212 \\ 0 & 138 & 240 & 355 & 476 & 614 & 1,930 \\ 0 & 134 & 197 & 284 & 404 & 644 & 1,693 \\ 0 & 116 & 170 & 254 & 365 & 495 & 1,930 \\ 0 & 156 & 224 & 349 & 517 & 727 & 1,641 \\ 0 & 121 & 189 & 280 & 411 & 597 & 1,930 \\ 0 & 74 & 129 & 205 & 317 & 468 & 1,641 \\ 0 & 47 & 77 & 122 & 191 & 286 & 741 \\ 0 & 64 & 110 & 166 & 253 & 357 & 1,175 \\ 0 & 56 & 91 & 143 & 233 & 353 & 841 \\ 0 & 53 & 83 & 139 & 228 & 378 & 681 \\ 0 & 69 & 116 & 196 & 308 & 420 & 1,201 \\ 0 & 87 & 114 & 208 & 324 & 455 & 1,245 \\ 0 & 33 & 63 & 136 & 249 & 372 & 1,019 \\ 0 & 80 & 138 & 238 & 354 & 525 & 1,641 \\ 0 & 72 & 121 & 196 & 309 & 471 & 1,019 \\ 0 & 35 & 65 & 131 & 223 & 348 & 701 \\ 0 & 44 & 84 & 149 & 241 & 358 & 792 \\ 0 & 23 & 57 & 113 & 219 & 331 & 1,100 \\ 0 & 19 & 33 & 58 & 105 & 170 & 681 \\ 0 & 25 & 45 & 76 & 148 & 265 & 1,020 \\ 0 & 14 & 32 & 57 & 113 & 200 & 574 \\ 0 & 0 & 45 & 96 & 193 & 339 & 1,206 \\ 0 & 0 & 52 & 124 & 198 & 318 & 1,995 \\ 0 & 1 & 9 & 26 & 74 & 206 & 488 \\ 0 & 0 & 13 & 82 & 157 & 265 & 67 \\ 0 & 0 & 25 & 73 & 162 & 280 & 63 \\ & & & & & & \end{array}$




\section{Table 6.3}

Total citations for most prolific author for 348 top universities: minimum, various percentile levels, and maximum value.

\begin{tabular}{lccccccc}
\multicolumn{1}{c}{ Category } & Min & 10 th & 25 th & 50 th & 75 th & 90 th & Max \\
Medicine & 2 & 569 & 1762 & 4114 & 9282 & 18285 & 57461 \\
Astronomy and Physics & 0 & 743 & 1625 & 2837 & 4875 & 10127 & 39219 \\
Biochemistry, Genetics and Molecular Biology & 0 & 858 & 1894 & 3590 & 7734 & 13185 & 48832 \\
Engineering & 0 & 347 & 685 & 1376 & 2810 & 5900 & 75622 \\
Chemistry & 0 & 740 & 1639 & 3247 & 7619 & 14380 & 49335 \\
Materials & 0 & 588 & 1157 & 2454 & 4634 & 9593 & 75622 \\
Immunology and Microbiology & 0 & 591 & 1261 & 2668 & 5919 & 11069 & 68805 \\
Earth and Planetary Science & 0 & 246 & 595 & 1224 & 2125 & 3978 & 23768 \\
Environmental Science & 0 & 387 & 909 & 2052 & 3576 & 5654 & 43621 \\
Agriculture/Biological Science & 0 & 278 & 722 & 1332 & 2577 & 4572 & 43621 \\
Mathematics & 0 & 123 & 299 & 714 & 1707 & 3403 & 14794 \\
Computer Science & 0 & 165 & 378 & 1131 & 2513 & 4693 & 28740 \\
Chemical Engineering & 0 & 388 & 847 & 1663 & 3192 & 5702 & 75622 \\
Multidisciplinary & 0 & 97 & 359 & 1571 & 4284 & 11805 & 47418 \\
Pharmacology, Toxicology and Pharmaceuticals & 0 & 322 & 979 & 2139 & 4212 & 7552 & 49335 \\
Neuroscience & 0 & 501 & 1237 & 2623 & 5772 & 8775 & 43932 \\
Social Science & 0 & 85 & 302 & 1005 & 2927 & 7460 & 47418 \\
Psychology & 0 & 233 & 662 & 1781 & 3575 & 6873 & 39863 \\
Health Professions & 0 & 52 & 288 & 968 & 2591 & 5037 & 32401 \\
Economics, Econometrics and Finance & 0 & 48 & 135 & 322 & 792 & 2093 & 14794 \\
Decision Science & 0 & 74 & 183 & 491 & 1130 & 2075 & 75622 \\
Business Management & 0 & 27 & 140 & 406 & 997 & 2026 & 10348 \\
Nursing & 0 & 0 & 142 & 761 & 2806 & 6440 & 47418 \\
Veterinary & 0 & 0 & 281 & 1089 & 2459 & 5051 & 23842 \\
Arts and Humanities & 0 & 0 & 4 & 66 & 483 & 3043 & 24291 \\
Dentistry & 0 & 0 & 43 & 533 & 1352 & 2635 & 13096 \\
Undefined & 0 & 0 & 74 & 464 & 1511 & 4451 & 37338
\end{tabular}


Table 6.4

\section{H- index for most prolific author for 348 top universities: minimum, various percentile levels, and maximum value.}

Category
Medicine
Astronomy and Physics
Biochemistry, Genetics and Molecular Biology
Engineering
Chemistry
Materials
Immunology and Microbiology
Earth and Planetary Science
Environmental Science
Agriculture/Biological Science
Mathematics
Computer Science
Chemical Engineering
Multidisciplinary
Pharmacology, Toxicology and Pharmaceuticals
Neuroscience
Social Science
Psychology
Health Professions
Economics, Econometrics and Finance
Decision Science
Business Management
Detinging
Andry

$\begin{array}{ccccccc}\text { Min } & 10 \text { th } & 25 \text { th } & 50 \text { th } & 75 \text { th } & 90 \text { th } & \text { Max } \\ 0 & 10 & 21 & 35 & 47 & 62 & 113 \\ 0 & 14 & 20 & 28 & 36 & 43 & 82 \\ 0 & 16 & 22 & 33 & 43 & 56 & 110 \\ 0 & 9 & 13 & 19 & 27 & 37 & 105 \\ 0 & 12 & 20 & 29 & 39 & 52 & 150 \\ 0 & 11 & 17 & 26 & 34 & 43 & 105 \\ 0 & 12 & 18 & 27 & 41 & 54 & 124 \\ 0 & 8 & 13 & 20 & 27 & 37 & 86 \\ 0 & 11 & 17 & 24 & 33 & 41 & 93 \\ 0 & 8 & 15 & 20 & 28 & 36 & 93 \\ 0 & 6 & 9 & 14 & 22 & 29 & 61 \\ 0 & 7 & 10 & 16 & 27 & 36 & 75 \\ 0 & 9 & 15 & 22 & 30 & 41 & 105 \\ 0 & 3 & 11 & 19 & 35 & 53 & 99 \\ 0 & 7 & 14 & 22 & 34 & 43 & 112 \\ 0 & 11 & 19 & 28 & 40 & 51 & 100 \\ 0 & 4 & 9 & 17 & 27 & 43 & 99 \\ 0 & 7 & 14 & 23 & 32 & 44 & 91 \\ 0 & 3 & 9 & 15 & 26 & 39 & 77 \\ 0 & 3 & 6 & 9 & 14 & 23 & 75 \\ 0 & 2 & 7 & 11 & 17 & 23 & 115 \\ 0 & 3 & 6 & 11 & 17 & 22 & 64 \\ 0 & 0 & 6 & 13 & 25 & 39 & 107 \\ 0 & 0 & 9 & 17 & 28 & 39 & 87 \\ 0 & 0 & 1 & 4 & 12 & 28 & 78 \\ 0 & 0 & 3 & 11 & 19 & 31 & 67 \\ 0 & 0 & 8 & 18 & 32 & 63\end{array}$




\section{Table 6.5}

Number of coauthors for most prolific author for 348 top universities: minimum, various percentile levels, and maximum value.

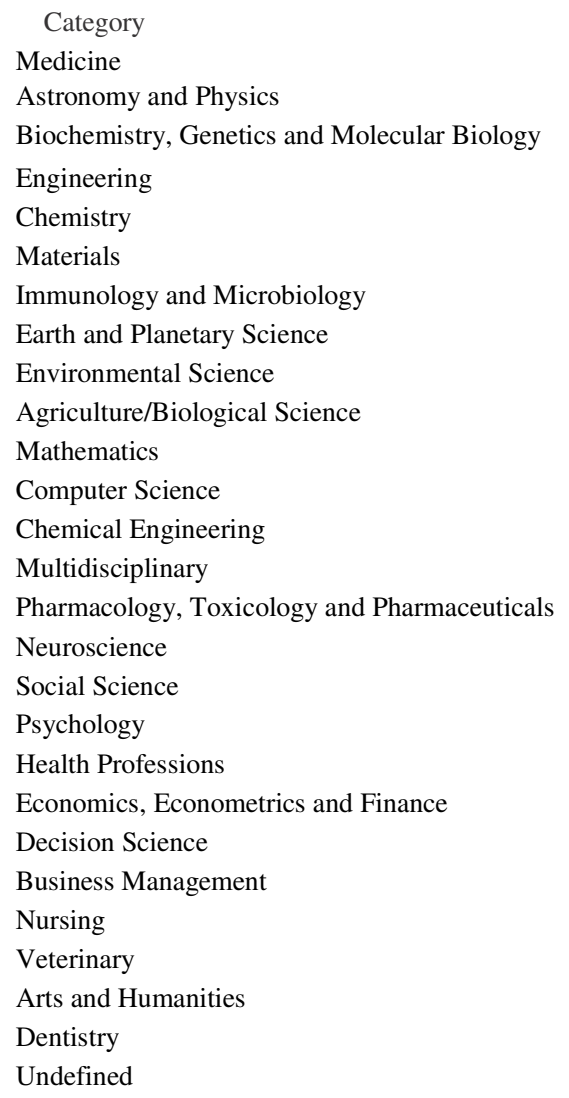

$\begin{array}{ccccccc}\text { Min } & 10 \text { th } & 25 \text { th } & 50 \text { th } & 75 \text { th } & 90 \text { th } & \text { Max } \\ 2 & 108 & 150 & 150 & 150 & 150 & 150 \\ 0 & 125 & 150 & 150 & 150 & 150 & 150 \\ 0 & 150 & 150 & 150 & 150 & 150 & 150 \\ 0 & 73 & 127 & 150 & 150 & 150 & 150 \\ 0 & 12 & 20 & 29 & 39 & 52 & 150 \\ 0 & 111 & 150 & 150 & 150 & 150 & 150 \\ 0 & 110 & 150 & 150 & 150 & 150 & 150 \\ 0 & 57 & 104 & 150 & 150 & 150 & 150 \\ 0 & 69 & 128 & 150 & 150 & 150 & 150 \\ 0 & 53 & 112 & 150 & 150 & 150 & 150 \\ 0 & 25 & 46 & 89 & 150 & 150 & 150 \\ 0 & 54 & 98 & 150 & 150 & 150 & 150 \\ 0 & 79 & 125 & 150 & 150 & 150 & 150 \\ 0 & 31 & 73 & 150 & 150 & 150 & 150 \\ 0 & 80 & 150 & 150 & 150 & 150 & 150 \\ 0 & 80 & 137 & 150 & 150 & 150 & 150 \\ 0 & 16 & 48 & 129 & 150 & 150 & 150 \\ 0 & 36 & 85 & 150 & 150 & 150 & 150 \\ 0 & 22 & 70 & 150 & 150 & 150 & 150 \\ 0 & 7 & 17 & 36 & 81 & 150 & 150 \\ 0 & 15 & 32 & 59 & 127 & 150 & 150 \\ 0 & 8 & 21 & 49 & 109 & 150 & 150 \\ 0 & 0 & 6 & 13 & 25 & 39 & 150 \\ 0 & 0 & 86 & 150 & 150 & 150 & 150 \\ 0 & 0 & 1 & 13 & 96 & 150 & 150 \\ 0 & 0 & 17 & 98 & 150 & 150 & 150 \\ 0 & 23 & 92 & 150 & 150 & 150 & 150\end{array}$

Consequently, it is suggested for the purpose of comparison that minimal and maxima are ignored. To illustrate the extent of the difference, Medicine is compared to Arts and Humanities. With a 90th percentile value of 800 a high publishing Arts and Humanities faculty compares well against a 10th percentile Medicine university (578), but poorly against a university at above the 25 th percentile $(1,762)$. The 25 th, 50 th, and 75 th percentiles are 1,$762 ; 8,438$; and 16,824 for Medicine and 9, 130, and 388 for Arts and Humanities. This constitutes a difference of a factor of 42 and 196, for the 75th and 25th percentile respectively. Clearly corrections are needed not only in terms of differences between areas of study, but consideration must be given in relation to actual placement on a distribution as a percentile, since multipliers to correct for research activity vary 
with movement along the respective distributions. Having considered total publications for an area of study, the performance of the top performer in terms of publications is now considered.

Much of what can be said about patterns and interpretation of the most prolific author in an area of study (Table 6.2) is similar to what can be said about the area of study (Table 6.1). There is, however, one additional insight worth mentioning. Universities with a higher activity level (and $\mathrm{r}$ a n k ) tend to be the beneficiaries of multiple strong researchers-not a single star research performer. The lower performing universities are often to a large extent reliant on the productivity of a single researcher (or research group). The number of citations associated with the most prolific author (Table 6.3) is exceedingly low (in some fields at the level of zero up till and possibly beyond the 10th percentile). As the percentile level increases the relative difference between the least cited area of study and most cited area of study declines significantly. For example, at 25 percent the minimum value is 4 (Arts and Humanities) and the maximum value is 1,762 (Medicine) — a difference of almost 450 times. While at the 90th percentile the minima (2,026 - Business) and maxima (18,285-Medicine) are separated by a factor of about 9 times. The H-index (Table 6.4), unsurprisingly, offers much greater consistency between different fields of study. If one discounts Arts and Humanities and Undefined, the range between minima (9) and maxima (35) at the 50 percent level is four. This declines to a factor of two as

(1) Publication volume (Table 1): Immunology and Social Sciences, Chemical Engineering and Psychology.

(2) Publications of most prolific author (Table 2): Decision Science and Undefined.

(3) Citations of most prolific author (Table 3): Engineering and Social Sciences, 
Computer Science and Health Professions, Chemical Engineering and Psychology.

(4) H-index of most prolific author (Table 4): Computer Science and Veterinary.

(5) Number of coauthors for most prolific author (Table 5): Engineering and Neurosciences, Multidisciplinary and Veterinary, Management and Undefined, Management and Dentistry.

This lack of direct comparability is a critical finding as it suggests that it is inappropriate and incorrect to base one's knowledge on the norms of one area of research on the quality of a candidate or department in another area of research. However, Tables 6.1-6.5 are very helpful in that they allow for determination of equivalencies between percentiles in one field with an equivalent level in another field. In other words, if a researcher's performance is at the 50th percentile level in their field of study one can equate this to a different field of study and in this way obtain a better understanding of whether the researcher's performance is superior or inferior to what it may seem otherwise. For example, in Arts and Humanities an H-index score of 4 (50th percentile) is equivalent to an H-index of 35 (50th percentile) in the field of Medicine.

While such information is not a replacement for expertise in a specific academic field, people making decisions at a university level can use this information to better relate between a field where they have academic field expertise and the field under consideration for which they lack academic field knowledge. The information in Tables 6.1-6.5 alerts one to the tremendous differences between academic fields and offers some insights into these differences. Such information does of course have its limitations. For example, in specialty areas such as Dentistry and Veterinary Science, there are zero values and very low values at the lower percentile rankings. This absence of activity typically indicates an absence of the specialty from the university under consideration. In fact, absence of an activity accounts for values of zero not only for the minimum in many tables, but also at the 10th percentile level in some cases. As there are tremendous differences in the specialization of universities around the world, it is unsurprising that the minimum value of most fields of study is 192 
zero-an absence of any specialist activity in these areas. Having considered the reason for extreme values (an absence) at the low end of the rankings, surprisingly high values at the high end of the spectrum are considered. Authors who are very prolific often have interdisciplinary activity. This activity opens up the possibility of greater access to funding, increased research quality through practice, and a superior network of co-authors. As there are significant differences in publishing norms from one field to another, multidisciplinary activity increases the likelihood of domination of two or more fields. If one is very prolific in a field that has higher publication or citation rates, it is likely that one's activity will be the most prolific in other fields that one's work also touches on.

For example, if one considers total publications (Table 6.2) for the most prolific author, the maximum value is held by the same multidisciplinary researcher/author in the following cases: Medicine and Biochemistry, Astronomy and Engineering and Materials, and Chemistry and Immunology and Pharmaceuticals. While in the example of total citations for the most prolific author (Table 6.3), the maximum value of total citations is received by the same multidisciplinary researcher in the following cases: Engineering and Materials, Chemistry and Pharmacology, Environmental Science and Agriculture, Nursing and Social Science and Multidisciplinary. Hence, we can see that the presence of interdisciplinary researchers at the top of the rankings and the absence of a field of study from a number of universities has a significant influence at the bottom of the rankings. Consequently, to really understand the difference from one field to another, it is best to avoid the tails of the ranking (maximum, minimum and perhaps even 10th and 90th percentiles) and focus more on the values between the inter-quartiles ( 25 th to 75 th percentile). This also contributes to the very low direct comparability between differences in fields of study.

It is important to note that there are many important aspects of research that are not captured in this study. In fields such as Arts and Humanities, the roles of books are critical but overlooked here. 
In an effort to capture a wide range of journals, data from Scopus were utilized. While Scopus is more inclusive than the ISI Web of Science, it has limitations. This study in part reflects and reports the limitations associated not only with the sources selected by Scopus but also with the quality of the database. The most notable example of this is that Scopus will not show more than 150 coauthors. Hence, in Table 6.5, there is an abnormally large number of 150s reported, as 150 refers to all numbers with a magnitude of 150 or greater. Other items that are considered important in some fields and are subject to great variation between fields, but not considered here include the following: total number of pages published, citation intensity (citations/year), number of pages, and impact factor of journals and similar metrics being adjusted to reflect the number of authors or order of authors on each paper. Furthermore, presence of work in open access outlets, repositories, reports, and working papers are also overlooked by this approach. The implications of absence of additional sources of information from this study differ depending on the field under consideration. While it is not clear whether or not this in itself warrants further study in the future, it is clear that the insights from the use of this paper should be supplemented through consultation with academic field experts in the case of many decisions.

Having noted general limitations associated with the method of data collection, issues that are specific to Scopus are now briefly described. In addition to concerns regarding the possibility of transcription errors with such a large volume of data to be processed, information changes over time. While steps were taken during data collection and auditing to limit the effect of these concerns, the data are also included as a supplement, so it can be checked and appropriate corrections can be noted by interested parties. Throughout the data collection process a number of other factors were noted as possibly giving incomplete or misleading information: change in database formatting during the data collection process, incorrect spelling of author name in the database resulting in one person having two or more identities, or error in affiliation resulting in a university being credited/not credited for a researcher. 
It has already been noted that inclusivity is a characteristic that made Scopus more attractive than ISI Web of Science for this study. While Scopus includes more journals than the ISI Web of Science, Scopus limits itself to 27 research categories. For finer grained consideration of differences between fields, the ability to consider a larger range of categories is attractive. However, the 27 categories offered in this study provide a substantial and suitable base. An alternative choice of database for this type of study is to utilize Google Scholar with or without Harzing's Publish or Perish engine (Dazey \& Parks,2010; Harzing \& van derWal, 2008; Jacsó, 2009). While this engine is popular due to its inclusivity of sources, the authors have found that the engine has issues of consistency. While it should consistently provide higher citation results than either Web of Science or Scopus, the authors have found this is not always the case. In future studies, however, the use of this database may assist in overcoming the gaps that Web of Science and Scopus have in relation to books, book chapters, or influential non-academic publications. Having considered the results, their interpretation, and the strengths and weaknesses of the method utilized, the data supplement is now considered.

\subsubsection{Consideration of Supplementary Data}

The data utilized to produce the five summary tables is available at http://www.research.uottawa.ca/docs/researchexpectations.pdf. While full disclosure is a sufficient reason to provide this information, there are more practical uses for it. Prior to consideration of the uses of such data, it is worth offering some background information. The data for all 348 universities is provided in alphabetical order for all 27 academic fields. A sample of the data supplement is offered in Table 6.6. In addition to the metrics offered regarding publication number (department and most prolific researcher), citations, H-index, and number of coauthors; the name of the most prolific author is included. Such information is of great assistance when trying to make decisions regarding highly senior university-wide research positions such as institute or distinguished professors as one is able to compare the output metrics of a professor with the most prolific research 
professors at the top universities around the world in the same field.

This can also offer guidance for awards that hold honor at a national level such a Tier I CRC chair or a Humboldt Fellowship. These values offer critical guidance and prevent hurdles from being set ridiculously high or undeservedly low through arguments that a certain field typically has very low publication and citation thresholds. If there is interest for a university to broaden its capabilities, such information is helpful in assisting in identifying what high performing faculty may look like in a field where the institution lacks local expertise. Of course there is more to excellence than the magnitude of numbers such as volume, citation and $\mathrm{H}$-index, but access to such values from a neutral source such as the supplement is helpful. Having discussed and considered the implications of the publishing data in a summarized form (Tables 6.1-6.5) and its raw format (Table 6.6 and supplement), conclusions are now considered.

\section{Section 6.5 Conclusions}

This study of 348 universities found that in almost all cases there are statistically significant differences in what constitutes research activity when comparing 27 separate fields of study. Consequently, one must be very careful when utilizing knowledge from one academic field to make decisions regarding research activity and quality in another academic field. Librarians can offer guidance to administrators and university committees on the estimated equivalent levels of publications, citations, and $\mathrm{H}$-indices using information provided by this study. While consulting with academic field experts is still advised, information comparing two separate areas provides a more complete picture to personnel at their university. This information can be used either in the absence of an academic field expert or to ensure that an academic field expert is not overly generous or stingy in how they assess high performance in their stated field of academic field expertise. By comparing quartiles or median on dimensions such as departmental publications, author papers, author citations, author H-index, or co-authors; one can at least partially calibrate the quality of researchers and departments in different areas of study. Such information assists in consideration of the most 
appropriate acquisitions, cancelations, and formats. The relative dependence on journals helps

determine and justify the balance of journals between different fields and also between journals and books. In other words fields that place a strong emphasis on journal articles warrant extensive access to serials, if the university wishes to maintain or grow research activities in this field. In fields that consider journal articles to be of a lower importance, the focus should be more on book acquisition and less on journals.

It is important to note that universities' reputations are developed in different ways. Consequently, highly ranked universities may lack certain specialties and have differing levels of research performance in the specialties that they do have. There is substantial room for further consideration of this topic; this paper is intended as a starting point for a dialog about how research activity differs across different areas of study.

\section{Table 6.6}

Sample of supplement data listing medical publications data for 31 universities by alphabetical order_both number and rank are provided.

\begin{tabular}{|c|c|c|c|c|c|c|c|c|c|c|}
\hline $\begin{array}{l}\text { Medical } \\
\text { Publications } \\
\quad \text { Data } \\
\text { Aalto }\end{array}$ & $\begin{array}{l}\text { Department } \\
\text { Publications }\end{array}$ & Range & $\begin{array}{l}\text { Most Prolific } \\
\text { Author }\end{array}$ & Published & Rank & Cited & Rank & $\begin{array}{c}\mathrm{H}- \\
\text { Index }\end{array}$ & Rank & $\begin{array}{c}\text { \# of } \\
\text { Co- } \\
\text { authors }\end{array}$ \\
\hline $\begin{array}{l}\text { Aalto } \\
\text { University } \\
\text { Aarhus }\end{array}$ & 761 & 305 & R. Hari & 301 & 193 & 7,650 & 108 & 48 & 73 & 150 \\
\hline $\begin{array}{l}\text { University } \\
\text { Arizona }\end{array}$ & 19494 & 70 & H.T. Sorensen & 537 & 76 & 8,413 & 96 & 40 & 128 & 150 \\
\hline $\begin{array}{l}\text { University } \\
\text { Ateneo de } \\
\text { Manila }\end{array}$ & 3774 & 223 & J. He & 537 & 76 & 8,416 & 96 & 40 & 128 & 150 \\
\hline $\begin{array}{l}\text { University } \\
\text { Auburn }\end{array}$ & 13 & 347 & U.M. Carajal & 29 & 345 & 20 & 345 & 0 & 347 & 5 \\
\hline $\begin{array}{l}\text { University } \\
\text { Australian } \\
\text { National }\end{array}$ & 1917 & 257 & C.J. Diskin & 1,578 & 2 & 304 & 327 & 8 & 324 & 64 \\
\hline $\begin{array}{l}\text { University } \\
\text { Boston }\end{array}$ & 5952 & 199 & A.F. Jorm & 377 & 143 & 9,729 & 84 & 47 & 80 & 150 \\
\hline $\begin{array}{l}\text { College } \\
\text { Boston }\end{array}$ & 1026 & 290 & $\begin{array}{l}\text { J.J. Paris } \\
\text { R.B. }\end{array}$ & 78 & 323 & 227 & 330 & 6 & 330 & 60 \\
\hline $\begin{array}{l}\text { University } \\
\text { Brandeis }\end{array}$ & 26336 & 36 & D'Gostino & 645 & 50 & 47,024 & 3 & 91 & 3 & 150 \\
\hline $\begin{array}{l}\text { University } \\
\text { Brigham } \\
\text { Young }\end{array}$ & 1509 & 272 & J.C. Hall & 195 & 253 & 3,134 & 202 & 44 & 101 & 150 \\
\hline $\begin{array}{l}\text { University } \\
\text { Brown }\end{array}$ & 1739 & 262 & E.D. Bigler & 224 & 237 & 2,421 & 233 & 26 & 225 & 150 \\
\hline $\begin{array}{l}\text { University } \\
\text { California } \\
\text { Institute of } \\
\text { Technology } \\
\text { (Caltech) }\end{array}$ & 12873 & 124 & E.H. Davidson & 314 & 180 & 7,278 & 113 & 46 & 89 & 150 \\
\hline
\end{tabular}




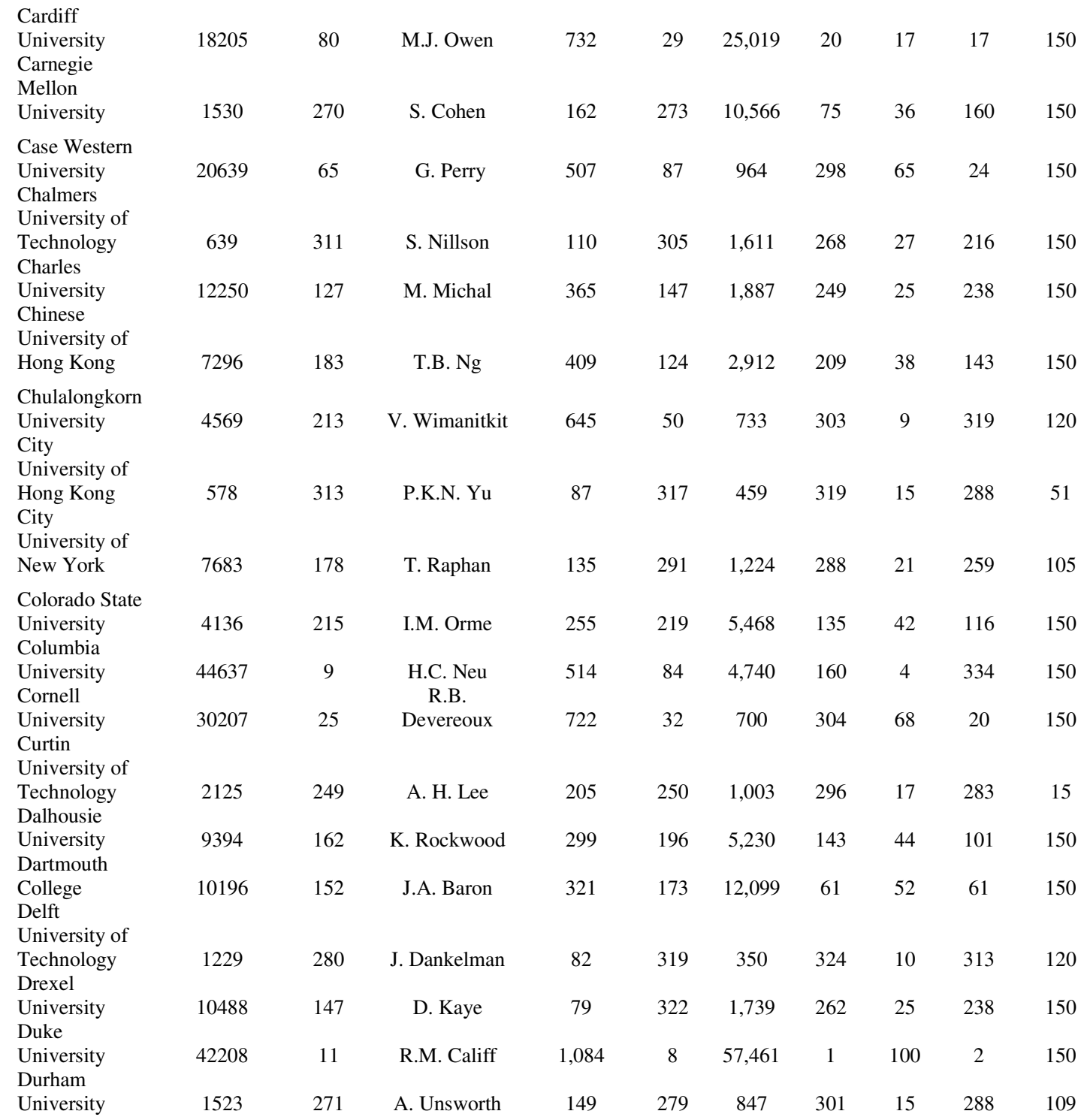




\section{Section 6.6 References}

Aguillo, I. F., Bar-Ilan, J., Levene, M., \& Ortega, J. L. (2010). Comparing university rankings. Scientometrics, 85, 243-256.

Aguillo, I. F., Granadino, B., Ortega, J. L., \& Fernandez, M. (2008). Webometric ranking of world universities: Introduction, methodology, and future developments. Higher Education in Europe, 33(2/3), 234-244.

Anon (1962). Publish or perish. Nature, 193(4817), 709.

Bontis, N., \& Serenko, A. (2009). A follow-up ranking of academic journals. Journal of Knowledge Management, 13(1), 16-26.

Clapham, P. (2005). Publish or perish. BioScience, 55(5), 390-391.

Dazey, M., \& Parks, B. (2010). Thoughts on Open Access: An interview with Diane Graves. Serials Review, 36(2), 112-115.

de Meis, L., Velloso, A., Lannes, D., Carmo, M. S., \& de Meis, C. (2003). The growing competition in Brazilian science: Rites of passage, stress and burnout. Brazilian Journal of Medical and Biological Research, 36(9), 1135-1141.

De Rond, M., \& Miller, A. N. (2005). Publish or perish: Bane or boon of academic life? Journal of Management Inquiry, 14(4), 321-329.

De Villiers, M. M., \& Malan, S. F. (1997). Publish or perish: How is pharmacy research coping in a changing South Africa? South African Journal of Science, 93(8), 355-358.

Dubois, F. L., \& Reeb, D. (2000). Ranking the international business journals. Journal of International Business Studies, 31, 689-704.

Fisher, J., Shanks, G., \& Lamp, J. (2007). A ranking list for information systems journals. 
Australasian Journal of Information Systems, 14(2), 5-18.

Good, R. J. (1964). Publish or perish-Some solutions. Chemical and Engineering News, 42(36), 4-5.

Guidry, J. A., Guidry, B. N., Hollier, L., Johnson, L., Tanner, J. R., \& Veltsos, C. (2004). Surveying the cites: A ranking of marketing journals using citation analysis. Marketing Education Review, 14(1), 45-59.

Harzing, A. -W. K., \& van derWal, R. (2008). Google Scholar as a new source for citation analysis. Ethics in Science and Environmental Politics, 8(1), 61-73.

Henderson, G. V., Jr., Ganesh, G. K., \& Chandy, P. R. (1990). Across-discipline journal awareness and evaluation: Implications for the promotion and tenure process. Journal of Economics and Business, 42(4), 325-351.

Jacsó, P. (2009). Calculating the H-index and other bibliometric and scientometric indicators from Google Scholar with the Publish or Perish software. Online Information Review, 33(6), 1189-1200.

Linton, J. D., \& Thongpapanl, N. (2004). Ranking of technology and innovation management journals. Journal of Product Innovation Management, 21(2), 123-139.

Linton, J. D., Tierney, R., \& Walsh, S. T. (2011). Publish or perish: How are research and reputation related? Serials Review, 37, 244-257.

Lofthouse, S. (1974). Thoughts on "publish or perish". Higher Education, 3(1), 59-80. Mackay, A. (1974). Publish or perish. Nature, 250(5469), 698. 
Mitchell, W. B., \& Reichel, M. (1999). Publish or perish: A dilemma for academic librarians? College and Research Libraries, 60(3), 232-243.

Nash, G. F., \& Walsh, D. C. (2000). Research plans for current basic surgical trainees: Still publish or perish? Annals of the Royal College of Surgeons of England, 82(10 Suppl.), 336337.

Parchomovsky, G. (2000). Publish or perish. Michigan Law Review, 98(4), 926-951.

Plümper, T., \& Radaelli, C. M. (2004). Publish or perish? Publications and citations of Italian political scientists in international political science journals, 1990-2002. Journal of European Public Policy, 11(6), 1112-1127.

Qiu, J. (2010). Publish or perish in China. Nature, 463(7278), 142-143. QS (2011). Quacquarelli Symonds Limited ranking of world universities. Retrieved August 23, 2011 from http://www.topuniversities.com/university-rankings/world-university- rankings

Relman, A. S. (1977). Publish or perish-Or both. The New England Journal of Medicine, 297(13), 724-725.

Rhee, S. Y. (2004). Carpe diem. Retooling the "publish or perish" model into the "share and survive" model. Plant Physiology, 134(2), 543-547.

Shin, J. C., \& Cummings, W. K. (2010). Multilevel analysis of academic publishing across disciplines: Research preference, collaboration, and time on research. Scientometrics, 85(2), 581-594.

Smith, A. P. (2004). Publish or perish: The write thing for nursing. Nursing Economics,22(6), 342-343.

Thongpapanl, N. (2012). The changing landscape of technology innovation 
management: An update ranking of journals in the field. Technovation, 32(5), 257271.

Truex, D., Cuellar, M., \& Takeda, H. (2009). Assessing scholarly influence: Using the Hirsch indices to reframe the discourse. Journal of the Association for Information Systems, 10(7), 560-594.

WR (2011). Webometrics ranking of world universities. Retrieved August 23, 2011 from http://www.webometrics.info/

Yimin, D. (2001). Chinese academy of sciences: In China, publish or perish is becoming the new reality. Science, 291(5508), 1477-1479. 


\section{Section Seven: Conclusions and}

\section{Discussions}

\section{Section 7.1}

The findings are diverse and highlight the tribulations that measurements and metrics play in both knowledge and the small technology entrepreneurship. Each investigation represented a novel method of examining measurements and metrics. In Section Two the pharmaceutical industry was examined. This is critical from a research implications/limitations scope. The pharmaceutical industry's current roadmaps dilemmas stem from the fundamental differences between many of today's innovations and earlier ones. Many current innovations are using technology differently; they are more heavily constrained and are thus accepting new business models. The innovations are increasingly being shaped by drivers. Current roadmapping techniques do not translate well to this new reality. If this is so, then these innovative health care resources may be at peril, along with firm, regional and country economic development. A new roadmapping technique is needed. From a practical point of view, the article develops an operational and strategic landscaping technique metrics management approach for the pharmaceutical industry distinctive characteristics and leverages the first and second generation roadmapping techniques.

In Section Three the metrics were examined of highly flexible facilities. Here Owing to the MTPF centers' novelty and outward similarity to high volume semiconductor fabrication (HVF) facilities, they are laden with ineffective operation and strategic management practices. Metrics are the standard for both operational and strategic management of HVF facilities, yet their 
application to this new type of center is proving ineffectual. The research implications are immense for regional economic growth. These new types of regional economic resources may be at risk. A new approach is needed to reduce the jeopardy of managing these flexible facilities and insure the success for the facility and the encompassing economic region.

Section four examines the state of nanomanufacturing. This innovative blend of multidisciplinary sciences has problems crossing into the business world. Nanomanufacturing, in all of its forms is risky business. Yet many contend that nanotechnology is an enabling technology that many believe to be the base for a new Schumpeterian economy wave. The study presents a strategic model to better enable the users of nanotechnology to set strategic policy. The study shows that there is little comprehension when it comes to nanomanufacturing and complementary assets. The investigation discusses the use of complementary assets that can be used to lower the risks for a firm to embrace nanotechnology. Practical implications are both new and established firms that embrace the nanotechnology discipline need direction in the use of complementary assets.

Section Six launches an investigation into academia with measurement at the fore front. The paper shows that there needs to be a better understanding of the relationship between reputation and research in different fields so that incentives and knowledge infrastructure that are the most appropriate for fostering research are utilized. There is a lack of understanding of metrics and university ranking. If this is true, then there is cause for concern about the employment of faculty members and their research activities as compared to others. This investigation is also is useful entrepreneurs whom seek guidance from academia. The authors developed a foundation for administrators, university personal and entrepreneurs whom seek to find the best qualified individuals for their specific requirements. 
In Section Seven the study found that there is statistically significance difference when comparing 27 separate individual fields. Accordingly, one must be very careful when utilizing knowledge from one domain to make decisions regarding the level of research performance or quality in another domain and especially research that can transfer to the world beyond academia. The lack of clear associations between reputation and research metrics for a variety of academic fields suggests that there is no clear relation between a field and the university reputation. The authors developed an insight into metrics and university rankings. This allows comparisons to be made by administrators, faculty and entrepreneurs in seeking out those individuals that best represent their interests.

\section{Section 7.2 Future Research}

The tribulations of measurement and metrics for both small technology and knowledge entrepreneurship are significant. Not with standing, normal factors as increased governmental regulations, competition and financial limitations are hindering the process. If academia and entrepreneurs can find mutual interests in metrics, then both are placed in a "Win/Win "situation.

Future research into the area of small technology and the role of universities can be take several paths. An investigation launched into the prolific publishers of academic research with the keywords of MEMS and Nanotechnology for each of the 27 different fields is needed to narrow the information available. Then this information could be placed in a plot which locates locally and regionally, the scholars that are researching a particular subject. Such information would be valuable to entrepreneurs, economic developers and strategists for governments.

A second information path that could be taken is that clusters. The subject of clusters and small technology has not been explored for years. With the worldwide growth of 
nanotechnology companies the subject has out raced the research. Areas of concern are intellectual property, academic publications and funding. Others areas that need to be investigated are the differences between established nanotechnology clusters and emerging economic centers and are there any advantage to being first establish. 


\section{Section 8 Acknowledgements}

The journey of this adventure had been at times long and difficult. However, it was worth the price of admission. To any body that walked this path before me realizes that one does not walk alone. There are many individuals, both in a mentor and support roles that provide the buttresses that are needed. First, I would like to thank the members of my committee. Dr. K.I. van Oudenhoven-van der Zee for her time and effort. Dr. Steven Walsh, who saw a spark and then nurtured it. Steve also turn into a genuine friend, which we have several interest, one of which is restoration of older automobiles. Dr. Jonathan Linton, who introduced me into the world of statistics. Having never taken a formal statistics class before and I soon realized how powerful statistics are and how much there is to know and how little I know. I thank you Dr. Linton for your patience and having influenced myself to continue more work into the world of statistics. Dr. Aard Groen, whom gave myself a chance at the program and offered valuable insights to the world of entrepreneurship research Thank you very much Dr. Groen and I hope to collaborate with you someday. Dr. Rainer Harms and his truly wonderful tips and hints on writing the thesis and suggestions during the process. Thank you very much Dr. Harms. Dr. Miriam Luizink, whom I collaborated with and offered insight and valuable feedback,. Thank you Dr. Luizink. I would like to thank Dr. Jan Kratzer for taking time and effort to be on my committee. I can only hope to continue an academic career with the same distinction as my committee members.

Of course there is support staff that without them, nothing would happen. Two individuals that need to be recognized are Ms. Monique Zuithof-Otten and Ms. Hela Klaczynski. Both of these individuals went out of their way to help me along the process. Thank you both so much. Also, I would like to thank Martin Stienstra for allowing me to stay at his house for a week last year. Thank you Martin

To those who know me realize that I am passionate about the game of ice hockey. I played as a youth and through out my career as a "goon" I loved every minute. Later in life I turn into a referee and again found the love of a sport. Not only did officiating games help pay the bills, but also provide the comic relief that was needed at many times. I only wished I carried a voice recorder to remember all the 
items that transpire between players and officials. I can not thank the members of the NMHRC enough whom I worked with especially Mike Smith, Rick Wenner, Dann Allison, Mike McCullough and Marc Hempel.

There are three individuals that are specifically responsible for my career development in USA Hockey. Those individuals are Kelly Colyer, Butch Mousseau and Paul Wilkinson. As I ascended the USA Hockey official's ladder, I realized there was much more to learn than just the typical calls. Interesting that that calling a good game parallels life. Kelly, thank you for life lessons ( yes I'll try to keep my mouth shut) and the opportunity to reach the level of calling a ACHA game and working at the Jr. level. Kelly showed how to set goals and then reach them through hard work and perseverance. Butch Mousseau, for you ability to communicate with players and officials. You kicked me in the butt when needed, but also gave valuable feedback and praise. For that I am internally grateful. Paul Wilkinson for your ability to teach a group of individuals. The energy and enthusiasm was great and I only hope to achieve those levels.

To the last person on the list, but first in my heart. I could go on for several pages and still not express the gratitude enough for Liz Davenport. I can not thank Liz enough for the support she has given me over the years and I can not think of a better person to go through life with. Thanks so much for your support and understanding. Love you. Also, I would like to mention Xena, Einstein, Smelly and Walter ( our dogs), who always knew when it was time to take a break and go for a walk. 


\section{Appendix A}

\section{Detailed of Data Utilized in What are Research Expectations? A comparative study of different academic disciplines}

$\begin{array}{ll}\text { Discipline } & \text { Page } \\ \text { Sample comparison with more recent data } & 212-214 \\ \text { Medicine } & 215-225 \\ \text { Astronomy and Physics } & 226-236 \\ \text { Biochemistry, Genetics and Molecular Biology } & 237-246 \\ \text { Engineering } & 247-256 \\ \text { Chemistry } & 257-266 \\ \text { Materials } & 267-276 \\ \text { Immunology and Microbiology } & 277-286 \\ \text { Earth and Planetary Science } & 287-296 \\ \text { Environmental Science } & 297-306 \\ \text { Agricultural/Biological Sciences } & 307-316 \\ \text { Mathematics } & 317-326 \\ \text { Computer Science } & 327-336 \\ \text { Chemical Engineering } & 337-346 \\ \text { Computer Science } & 347-356 \\ \text { Multidisciplinary } & 357-366 \\ \text { Pharmacology, Toxicology, Pharmaceuticals } & 367-376 \\ \text { Social Sciences } & 377-386 \\ \text { Psychology } & 387-396 \\ \text { Health Professions } & 397-406 \\ \text { Economics, Econometrics, Finance } & 407-416 \\ \text { Decision Sciences } & 417-426 \\ \text { Business Management } & 427-436 \\ \text { Nursing } & 437-446 \\ \text { Veterinary } & 447-456 \\ \text { Arts and Humanities } & 457-466 \\ \text { Dentistry } & 467-476 \\ \text { Undefined } & 477-486\end{array}$

Supplement for Linton, Tierney and Walsh, Serials Review (2012), 
A drawback of the formation of a database such as this is with time the data changes, people become inactive and the entry of new people does not become apparent. All other things being equal, the values should be fairly consistent as new researchers will replace older researchers that have become inactive. However, the databases that track publications are not only dynamic due to the addition of newer issues and volumes of journals. There is a tendency to add additional journals over time, some of the journals are increasing the number of articles they publish in a given period and the number of authors is gradually increasing. In addition, an author may accidently be represented numerous times as being different people due to different affiliations or different representation of their name, in some cases this splitting of a single person into two or more records can result in a reduction in the apparent magnitude of publications, citations, h-index and coauthors.

Consequently, it is useful to consider newer data to get an indication of how the metrics are changing over time. To reproduce the entire database on an annual basis is a tremendous amount of time and effort. However, to update the metrics for the authors in a few different schools and make a note of the percentage change is manageable. Consequently, we have chosen the three universities that the authors are associated with to act as exemplars. If data updating the tables for other universities is submitted to us (drjdlinton@gmail.com) by others, we will integrate the data into this section and credit the sender. If you decide to do this, please follow the format we have provided to ensure visual consistency without the need for reformatting. 


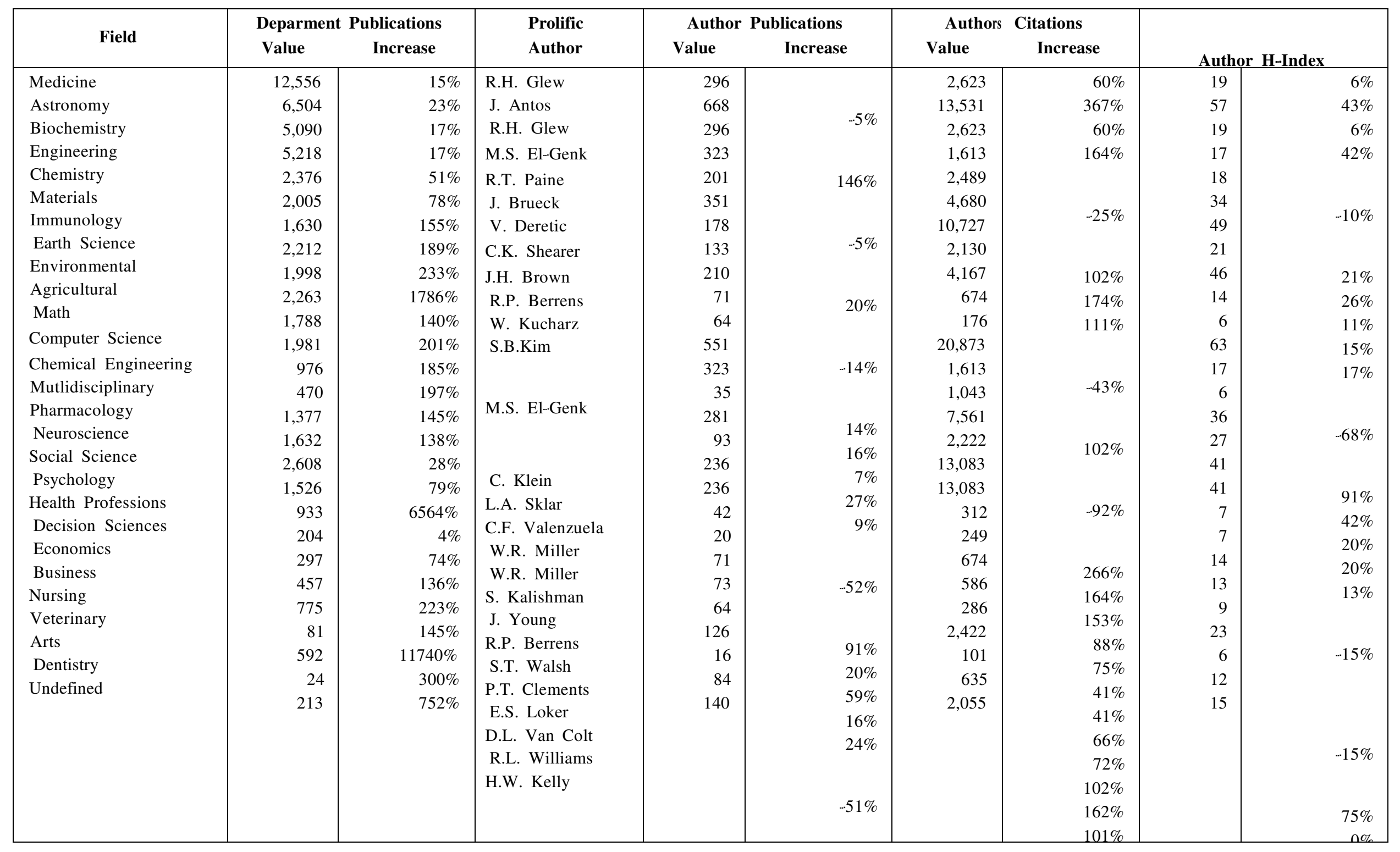

University of New Mexico - Summary of Changes between August 12, 2012 and Original Data Collection 


\begin{tabular}{|c|c|c|c|c|c|c|c|c|c|}
\hline \multirow{2}{*}{ Field } & \multicolumn{2}{|c|}{ Deparment Publications } & \multirow{2}{*}{$\begin{array}{l}\text { Prolific } \\
\text { Author }\end{array}$} & \multicolumn{2}{|c|}{ Author Publications } & \multicolumn{2}{|c|}{ Authors Citations } & \multirow{2}{*}{\multicolumn{2}{|c|}{ Author H.-Index }} \\
\hline & Value & Increase & & Value & Increase & Value & Increase & & \\
\hline \multirow{16}{*}{$\begin{array}{l}\text { Medicine } \\
\text { Astronomy } \\
\text { Biochemistry } \\
\text { Engineering } \\
\text { Chemistry } \\
\text { Materials } \\
\text { Immunology } \\
\text { Earth Science } \\
\text { Environmental } \\
\text { Agricultural } \\
\text { Math } \\
\text { Computer Science } \\
\text { Chemical Engineering } \\
\text { Mutlidisciplinary } \\
\text { Pharmacology } \\
\text { Neuroscience }\end{array}$} & 14,453 & $29 \%$ & D. Kreswski & 428 & $39 \%$ & 10,729 & $114 \%$ & 41 & $32 \%$ \\
\hline & 3,674 & $21 \%$ & X. Bao & 286 & $33 \%$ & 2,224 & $193 \%$ & 22 & $29 \%$ \\
\hline & 7,485 & $19 \%$ & S.F. Perry & 308 & $38 \%$ & 6,055 & $220 \%$ & 31 & $24 \%$ \\
\hline & 6,534 & $82 \%$ & H. Alper & 476 & $15 \%$ & 8,426 & $128 \%$ & 35 & $25 \%$ \\
\hline & 3,768 & $10 \%$ & H. Alper & 476 & $15 \%$ & 8,426 & $128 \%$ & 35 & $25 \%$ \\
\hline & 1,902 & $156 \%$ & J.C. Scaiano & 579 & $99 \%$ & 4,686 & $1224 \%$ & 34 & $55 \%$ \\
\hline & 1,297 & $175 \%$ & S.A. Sattar & 138 & $10 \%$ & 2,366 & $118 \%$ & 21 & $31 \%$ \\
\hline & 1,576 & $467 \%$ & J. Veizer & 149 & $4 \%$ & 6,751 & $124 \%$ & 35 & $17 \%$ \\
\hline & 1,916 & $191 \%$ & D. Krewski & 428 & $39 \%$ & 10,729 & $114 \%$ & 41 & $32 \%$ \\
\hline & 1,949 & $879 \%$ & J.I Arnason & 304 & $35 \%$ & 4,796 & $115 \%$ & 31 & $41 \%$ \\
\hline & 2,166 & $213 \%$ & D. Sankoff & 171 & $205 \%$ & 4,047 & $6324 \%$ & 23 & $360 \%$ \\
\hline & 4,214 & $253 \%$ & I. Stojmenovic & 266 & $36 \%$ & 3,382 & $111 \%$ & 23 & $21 \%$ \\
\hline & 1,679 & $156 \%$ & T. Matsuura & 373 & \multirow{4}{*}{$-16 \%$} & 4,941 & $133 \%$ & 32 & $28 \%$ \\
\hline & 282 & $10 \%$ & G.A. Wells & 560 & & 22,645 & $3 \%$ & 81 & $16 \%$ \\
\hline & 1,797 & $114 \%$ & R.L. Singhal & 243 & & 848 & $44 \%$ & 2 & $0 \%$ \\
\hline & 2,126 & $121 \%$ & Z. Merali & 153 & & 5,631 & $95 \%$ & 44 & $22 \%$ \\
\hline Social Science & 2,666 & $224 \%$ & P. Firestone & 65 & $3 \%$ & 1,409 & $58 \%$ & 16 & $33 \%$ \\
\hline Psychology & 1,606 & $67 \%$ & Z. Merali & 153 & \multirow[t]{2}{*}{$14 \%$} & 5,631 & \multirow[t]{2}{*}{$95 \%$} & 44 & \multirow[t]{2}{*}{$22 \%$} \\
\hline Health Professions & 763 & $5769 \%$ & I.D. Graham & 225 & & 4,647 & & 34 & \\
\hline Decision Sciences & 428 & $14 \%$ & M.G. Tyshenko & 51 & \multirow{3}{*}{$-10 \%$} & 73 & \multirow[b]{2}{*}{$-37 \%$} & 5 & \multirow[b]{2}{*}{$-19 \%$} \\
\hline Economics & 387 & $93 \%$ & M. Lavoie & 34 & & 244 & & 9 & \\
\hline Business & 574 & $171 \%$ & J.D. Linton & 139 & & 914 & \multirow{3}{*}{$3550 \%$} & 16 & \multirow{3}{*}{$400 \%$} \\
\hline $\begin{array}{l}\text { Nursing } \\
\text { Veterinary }\end{array}$ & 912 & $171 \%$ & I.D. Graham & 225 & \multirow{2}{*}{$5 \%$} & 4,647 & & 34 & \\
\hline $\begin{array}{l}\text { Veterinary } \\
\text { Arts }\end{array}$ & 70 & $27 \%$ & H.L. Davies & 117 & & 2,377 & & 26 & \\
\hline $\begin{array}{l}\text { Arts } \\
\text { Dentistry }\end{array}$ & 717 & $23800 \%$ & P. Kanaroglou & 99 & \multirow{3}{*}{$-10 \%$} & 1,428 & \multirow[b]{2}{*}{$-67 \%$} & 19 & \multirow[b]{2}{*}{$-25 \%$} \\
\hline $\begin{array}{l}\text { Dentistry } \\
\text { Undefined }\end{array}$ & 18 & $0 \%$ & D.S.K. Park & 132 & & 8,727 & & 55 & \\
\hline & 281 & $1305 \%$ & L.P. Renaud & 171 & & 2,986 & & 15 & \\
\hline & & & & & \multirow{2}{*}{$-12 \%$} & & $148 \%$ & & $33 \%$ \\
\hline & & & & & & &. $.49 \%$ & & $-6 \%$ \\
\hline
\end{tabular}

University of Ottawa - Summary of Changes between August 12, 2012 and Original Data Collection 


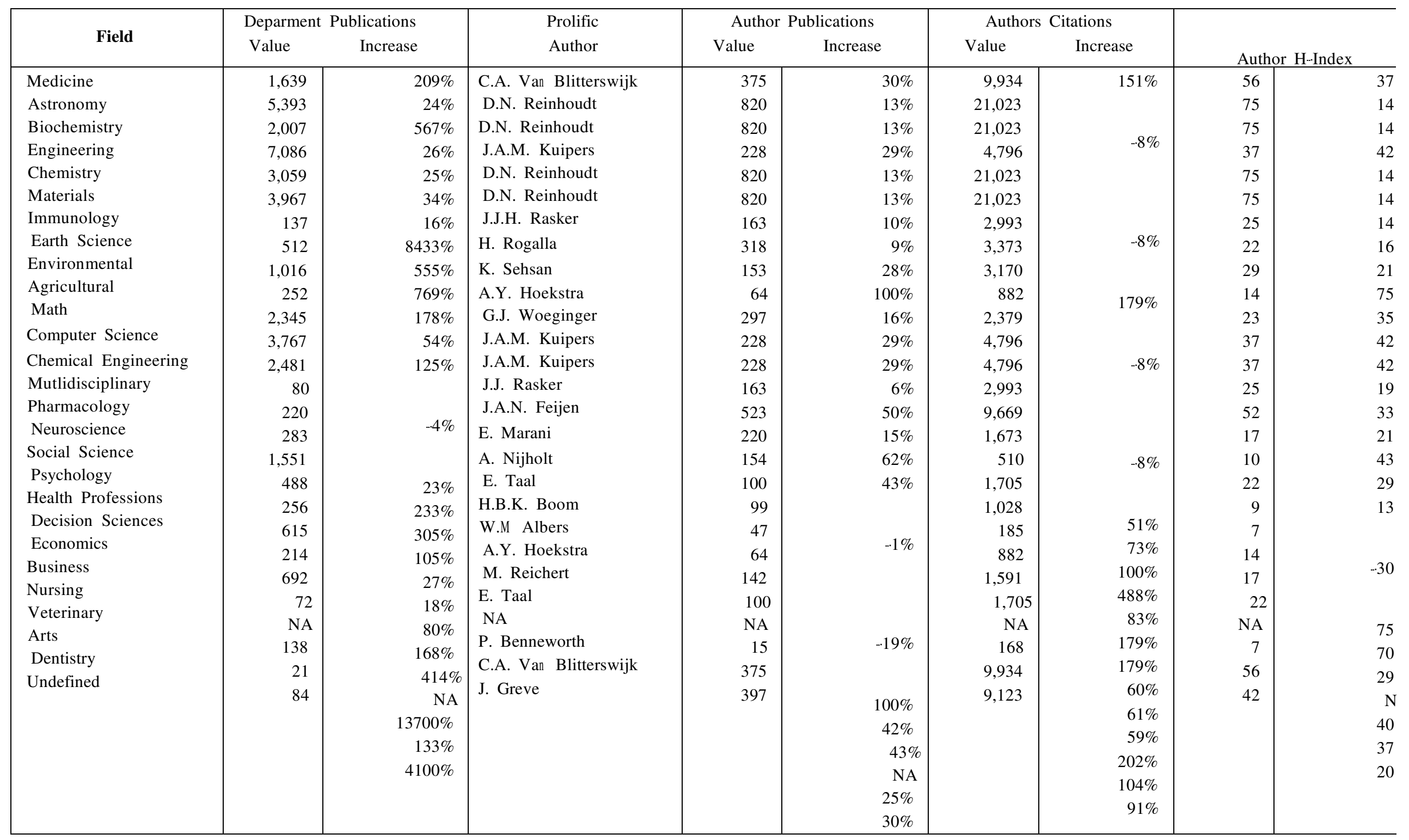

University of Twente - Summary of Changes between August 12, 2012 and Original Data Collection 


\begin{tabular}{|c|c|c|c|c|c|c|c|c|c|c|}
\hline Medical Publications Data & $\begin{array}{l}\text { Department } \\
\text { Publications }\end{array}$ & Rank & $\begin{array}{l}\text { Most Prolific } \\
\text { Author }\end{array}$ & Published & Rank & Cited & Rank & $\begin{array}{r}\mathrm{H}- \\
\text { Index }\end{array}$ & Rank & $\begin{array}{r}\text { \# of } \\
\text { Coauthors }\end{array}$ \\
\hline Aalto University & 761 & 305 & R. Hari & 301 & 193 & 7,650 & 108 & 48 & 73 & 150 \\
\hline Aarhus University & 19,494 & 70 & H.T. Sorensen & 537 & 76 & 8,413 & 96 & 40 & 128 & 150 \\
\hline Arizonia State University & 3,774 & 223 & J. He & 132 & 293 & 501 & 316 & 12 & 304 & 150 \\
\hline Ateneo de Manila University & 13 & 347 & U.M. Carajal & 29 & 345 & 20 & 345 & 0 & 347 & 5 \\
\hline Auburn University & 1,917 & 257 & C.J. Diskin & 1,578 & 2 & 304 & 327 & 8 & 324 & 64 \\
\hline Australian National University & 5,952 & 199 & A.F. Jorm & 377 & 143 & 9,729 & 84 & 47 & 80 & 150 \\
\hline Boston College & 1,026 & 290 & J.J. Paris & 78 & 323 & 227 & 330 & 6 & 330 & 60 \\
\hline Boston University & 26,336 & 36 & R.B. D' Gostino & 645 & 50 & 47,024 & 3 & 91 & 3 & 150 \\
\hline Brandeis University & 1,509 & 272 & J.C. Hall & 195 & 253 & 3,134 & 202 & 44 & 101 & 150 \\
\hline Brigham Young University & 1,739 & 262 & E.D. Bigler & 224 & 237 & 2,421 & 233 & 26 & 225 & 150 \\
\hline Brown University & 12,873 & 124 & V.Mor & 314 & 180 & 7,278 & 113 & 46 & 89 & 150 \\
\hline California Institute of Technology (Calt... & 2,196 & 248 & E.H. Davidson & 314 & 180 & 5,324 & 141 & 47 & 80 & 150 \\
\hline Cardiff University & 18,205 & 80 & M.J Owen & 732 & 29 & 25,019 & 20 & 71 & 17 & 150 \\
\hline Carnegie Mellon University & 1,530 & 270 & S. Cohen & 162 & 273 & 10,566 & 75 & 36 & 160 & 150 \\
\hline Case Western Reserve University & 20,639 & 65 & G. Perry & 507 & 87 & 964 & 298 & 65 & 24 & 150 \\
\hline Chalmers University of Technology & 639 & 311 & S. Nillsson & 110 & 305 & 1,611 & 268 & 27 & 216 & 150 \\
\hline Charles University & 12,250 & 127 & M. Michal & 365 & 147 & 1,887 & 249 & 25 & 238 & 150 \\
\hline Chinese University of Hong Kong & 7,296 & 183 & T.B. $\mathrm{Ng}$ & 409 & 124 & 2,912 & 209 & 38 & 143 & 150 \\
\hline Chulalongkorn University & 4,569 & 213 & V. Wiwanitkit & 645 & 50 & 733 & 303 & 9 & 319 & 120 \\
\hline City University of Hong Kong & 578 & 313 & P.K.N. Yu & 87 & 317 & 459 & 319 & 15 & 288 & 51 \\
\hline City University of New York & 7,683 & 178 & T. Raphan & 135 & 291 & 1,224 & 288 & 21 & 259 & 105 \\
\hline Colorado State University & 4,136 & 215 & I.M. Orme & 255 & 219 & 5,468 & 135 & 42 & 116 & 150 \\
\hline Columbia University & 44,637 & 9 & H.C. Neu & 514 & 84 & 4,740 & 160 & 4 & 334 & 150 \\
\hline Cornell University & 30,207 & 25 & R.B. Devereoux & 722 & 32 & 700 & 304 & 68 & 20 & 150 \\
\hline Curtin University of Technology & 2,125 & 249 & A. H. Lee & 205 & 250 & 1,003 & 296 & 17 & 283 & 15 \\
\hline Dalhousie University & 9,394 & 162 & K. Rockwood & 299 & 196 & 5,230 & 143 & 44 & 101 & 150 \\
\hline Dartmouth College & 10,196 & 152 & J.A. Baron & 321 & 173 & 12,099 & 61 & 52 & 61 & 150 \\
\hline Delft University of Technology & 1,229 & 280 & J. Dankelman & 82 & 319 & 350 & 324 & 10 & 313 & 120 \\
\hline Drexel University & 10,488 & 147 & D.Kaye & 79 & 322 & 1,739 & 262 & 25 & 238 & 150 \\
\hline Duke University & 42,208 & 11 & R.M. Califf & 1,084 & 8 & 57,461 & 1 & 100 & 2 & 150 \\
\hline Durham University & 1,523 & 271 & A. Unsworth & 149 & 279 & 847 & 301 & 15 & 288 & 109 \\
\hline
\end{tabular}




\begin{tabular}{|c|c|c|c|c|c|c|c|c|c|c|}
\hline Ecole Normale Supérieure de Lyon & 275 & 334 & F.L. Cosset & 180 & 264 & 3,172 & 200 & 46 & 89 & 150 \\
\hline École Normale Supérieure, Paris & 464 & 323 & N.Josso & 140 & 286 & 1,248 & 286 & 22 & 252 & 150 \\
\hline École Polytechnique & 184 & 339 & Y. Lecarpentier & 189 & 258 & 1,956 & 244 & 18 & 276 & 150 \\
\hline Ecole Polytechnique Fédérale de Lausanne & 952 & 295 & G. Wagniers & 123 & 298 & 1,823 & 257 & 27 & 216 & 150 \\
\hline Eindhoven University of Technology & 698 & 309 & K. Nicolay & 241 & 227 & 4,278 & 168 & 35 & 167 & 150 \\
\hline Emory University & 27,730 & 32 & H.E. Grossniklaus & 328 & 170 & 3,369 & 190 & 26 & 225 & 150 \\
\hline Erasmus University Rotterdam & 32,877 & 19 & P.W. Serruys & 1,206 & 5 & 39,197 & 6 & 85 & 4 & 150 \\
\hline ETH Zurich (Swiss Federal Institute of Technology) & 3,879 & 218 & P. Boesiger & 284 & 203 & 5,124 & 147 & 42 & 116 & 150 \\
\hline Florida International University & 1,452 & 274 & R.J.Herrera & 103 & 308 & 1,410 & 278 & 20 & 268 & 150 \\
\hline Florida State University & 3,181 & 228 & A.G. Marshall & 553 & 72 & 11,525 & 70 & 47 & 80 & 150 \\
\hline Freie Universität Berlin & 14,041 & 113 & R. Felix & 1,036 & 11 & 10,489 & 76 & 41 & 124 & 150 \\
\hline Friedrich Alexander Universität Erlangen Nürnberg & 15,426 & 97 & E.G. Hahn & 699 & 39 & 12,039 & 64 & 51 & 65 & 150 \\
\hline Fudan University & 9,022 & 168 & Z.Y. Tang & 381 & 140 & 3,109 & 203 & 34 & 175 & 150 \\
\hline Georg August Universität Göttingen & 14,153 & 112 & H.W. Roesky & 530 & 77 & 7,608 & 109 & 34 & 175 & 150 \\
\hline George Mason University & 431 & 325 & L.A. Liotta & 288 & 200 & 14,970 & 47 & 65 & 24 & 150 \\
\hline George Washington University & 11,632 & 131 & T.O. Cheng & 778 & 24 & 2,630 & 219 & 19 & 270 & 150 \\
\hline Georgetown University & 14,549 & 106 & I. Brook & 316 & 177 & 2,540 & 225 & 27 & 216 & 150 \\
\hline Georgia Institute of Technology & 1,647 & 265 & A.P. Yoganathan & 402 & 128 & 2,363 & 235 & 26 & 225 & 150 \\
\hline Georgia State University & 2,097 & 250 & J.M. De Castro & 109 & 306 & 1,346 & 280 & 20 & 268 & 46 \\
\hline Goteborg University & 16,368 & 89 & K. Blennow & 395 & 134 & 6,896 & 118 & 55 & 53 & 150 \\
\hline Harvard University & 7,353 & 180 & D.L. Hartl & 310 & 184 & 7,031 & 117 & 44 & 101 & 150 \\
\hline Hebrew University of Jerusalem & 11,549 & 132 & A. Ornoy & 220 & 238 & 1,801 & 260 & 22 & 252 & 150 \\
\hline Heidelberg Universität & 24,323 & 41 & E. Ritz & 1,227 & 4 & 22,594 & 24 & 58 & 45 & 150 \\
\hline Hokkaido University & 16,368 & 89 & M. Asaka & 510 & 86 & 5,089 & 150 & 35 & 167 & 150 \\
\hline Hong Kong Polytechnic University & 2,070 & 252 & P. Cho & 101 & 312 & 572 & 313 & 15 & 288 & 101 \\
\hline Hong Kong University of Science \& Techno... & 485 & 321 & M.Lung & 76 & 325 & 578 & 312 & 15 & 288 & 150 \\
\hline Humboldt-Universität zu Berlin & 15,231 & 98 & F.C. Luft & 101 & 312 & 18,233 & 36 & 62 & 36 & 150 \\
\hline Imperial College London & 20,959 & 63 & S.R. Bloom & 1,165 & 6 & 29,192 & 15 & 64 & 28 & 150 \\
\hline Indian Institute of Technology Bombay (I... & 175 & 340 & R.R. Puniyani & 51 & 338 & 163 & 338 & 6 & 330 & 48 \\
\hline Indian Institute of Technology Delhi (II... & 277 & 332 & D. Mohan & 111 & 303 & 385 & 322 & 7 & 326 & 150 \\
\hline Indian Institute of Technology Kanpur (I... & 148 & 343 & R.K. Gupta & 243 & 224 & 1,599 & 269 & 23 & 246 & 150 \\
\hline Indiana University Bloomington & 9,264 & 165 & J.S. Skinner & 214 & 243 & 4,074 & 177 & 39 & 136 & 150 \\
\hline Indiana University Indianapolis & 18,510 & 77 & L.H. Einhorn & 439 & 108 & 9,301 & 87 & 42 & 116 & 150 \\
\hline
\end{tabular}




\begin{tabular}{|c|c|c|c|c|c|c|c|c|c|c|}
\hline Iowa State University & 1,174 & 283 & P.G. Halbur & 133 & 292 & 1,875 & 251 & 28 & 209 & 150 \\
\hline Johns Hopkins University & 75,020 & 2 & J.I. Epstein & 444 & 104 & 9,823 & 82 & 62 & 36 & 150 \\
\hline Kansas State University & 821 & 302 & D.C Poole & 211 & 244 & 2,845 & 212 & 26 & 225 & 150 \\
\hline Katholieke Universiteit Leuven & 11,902 & 130 & D. Collen & 729 & 30 & 29,711 & 14 & 68 & 20 & 150 \\
\hline Keio University & 13,331 & 121 & M. Kitajima & 700 & 38 & 1,016 & 295 & 34 & 175 & 150 \\
\hline King Fahd University of Petroleum \& Minerals & 83 & 344 & F. Abu-Jarad & 56 & 336 & 167 & 337 & 7 & 326 & 53 \\
\hline King Saud University & 4,056 & 217 & M.M. Al-Qattan & 247 & 222 & 1,336 & 281 & 18 & 276 & 128 \\
\hline Kobe University & 10,292 & 151 & Y. Kuroda & 348 & 158 & 2,200 & 239 & 27 & 216 & 150 \\
\hline Korea Advanced Institute of Science \& Technology & 503 & 320 & Z.H. Cho & 207 & 246 & 1,334 & 282 & 9 & 319 & 150 \\
\hline Korea University & 2,558 & 238 & K.H. In & 81 & 320 & 531 & 315 & 10 & 313 & 150 \\
\hline Kyoto University & 35,181 & 16 & O. Yoshida & 803 & 20 & 12,900 & 58 & 32 & 185 & 150 \\
\hline Kyushu University & 22,402 & 54 & K. Sugimachi & 1,693 & 1 & 30,331 & 12 & 64 & 28 & 150 \\
\hline La Trobe University & 3,452 & 226 & R.J. Mitchell & 75 & 326 & 885 & 300 & 10 & 313 & 150 \\
\hline Lancaster University & 740 & 307 & N.J. Fullwood & 77 & 324 & 1,095 & 294 & 21 & 259 & 150 \\
\hline Leiden University & 25,108 & 39 & J.J. Bax & 798 & 21 & 16,724 & 41 & 57 & 48 & 150 \\
\hline Linkoping University & 9,959 & 154 & R. Sjodahl & 225 & 235 & 2,892 & 210 & 25 & 238 & 150 \\
\hline London School of Economics and Political Science & 1,216 & 282 & M.R.J. Knapp & 240 & 229 & 3,887 & 181 & 38 & 143 & 150 \\
\hline Loughborough University & 1,572 & 266 & C. Williams & 125 & 295 & 1,991 & 243 & 18 & 276 & 150 \\
\hline Louisiana State University & 18,465 & 78 & C. Bouchard & 621 & 56 & 23,796 & 21 & 47 & 80 & 150 \\
\hline Ludwig-Maximilians-Universität München & 32,406 & 20 & H.J. Moller & 792 & 22 & 14,781 & 48 & 53 & 59 & 150 \\
\hline Lund University & 26,893 & 35 & B. Ahren & 676 & 45 & 11,205 & 71 & 47 & 80 & 150 \\
\hline Maastricht University & 18,574 & 76 & H.J.J. Wellens & 564 & 69 & 10,805 & 74 & 43 & 108 & 150 \\
\hline Macquarie University & 1,648 & 264 & R.M. Rapee & 148 & 280 & 3,290 & 195 & 28 & 209 & 150 \\
\hline Mahidol University & 10,544 & 145 & N.J. White & 780 & 23 & 28,420 & 17 & 67 & 22 & 150 \\
\hline Masaryk University & 2,373 & 242 & I. Rektor & 181 & 262 & 1,125 & 293 & 21 & 259 & 150 \\
\hline Massachusetts Institute of Technology & 7,175 & 186 & R.J. Wurtman & 715 & 33 & 11,570 & 69 & 26 & 225 & 150 \\
\hline McGill University & 31,098 & 24 & T. Tulandi & 276 & 205 & 2,842 & 213 & 29 & 205 & 150 \\
\hline McMaster University & 20,271 & 66 & G.H. Guyatt & 819 & 19 & 45,932 & 4 & 79 & 10 & 150 \\
\hline Michigan State University & 11,265 & 134 & I.H. Chaudry & 693 & 42 & 15,076 & 46 & 46 & 89 & 150 \\
\hline Michigan Technological University & 280 & 331 & S.Zhang & 30 & 344 & 224 & 332 & 9 & 319 & 36 \\
\hline Monash University & 13,911 & 115 & D.M. DeKrester & 458 & 98 & 5,421 & 138 & 37 & 154 & 150 \\
\hline Montana State University & 986 & 292 & M.T. Quinn & 141 & 284 & 5,692 & 134 & 37 & 154 & 150 \\
\hline Moscow State University & 2,373 & 242 & N.S. Egorov & 365 & 147 & 146 & 339 & 4 & 334 & 150 \\
\hline
\end{tabular}




\begin{tabular}{|c|c|c|c|c|c|c|c|c|c|c|}
\hline Nagoya University & 16,824 & 87 & Y. Nimura & 549 & 74 & 9,202 & 89 & 38 & 143 & 150 \\
\hline Nanjing University & 933 & 297 & J.S. Li & 316 & 177 & 1,575 & 274 & 23 & 246 & 150 \\
\hline Nanyang Technological University & 868 & 298 & E.C.Teo & 56 & 336 & 220 & 333 & 10 & 313 & 42 \\
\hline National Taiwan University & 13,650 & 120 & P.R. Hsueh & 417 & 118 & 4,252 & 169 & 36 & 160 & 150 \\
\hline National Tsing Hua University & 721 & 308 & P.S. Weng & 121 & 300 & 225 & 331 & 4 & 334 & 150 \\
\hline National University of Ireland, Galway & 1,535 & 269 & B.E. Leonard & 381 & 140 & 3,487 & 188 & 33 & 183 & 150 \\
\hline National University of Singapore & 8,958 & 169 & S.S. Ratnam & 372 & 145 & 1,487 & 275 & 7 & 326 & 150 \\
\hline New Mexico State University & 617 & 312 & B.A. Smith & 102 & 310 & 1,689 & 263 & 13 & 299 & 150 \\
\hline New York University & 28,518 & 28 & I. Krozon & 413 & 120 & 4,101 & 175 & 31 & 190 & 150 \\
\hline Newcastle University & 10,682 & 142 & K.G.M.M. Alberti & 703 & 35 & 20,548 & 32 & 44 & 101 & 150 \\
\hline North Carolina State University & 3,678 & 224 & T.F.C. MacKay & 141 & 284 & 2,366 & 234 & 38 & 143 & 150 \\
\hline Northeastern University & 1,990 & 255 & J.J. Gozzo & 95 & 314 & 211 & 335 & 3 & 340 & 44 \\
\hline Northwestern University & 27,540 & 34 & R. Patterson & 439 & 108 & 2,778 & 215 & 13 & 299 & 150 \\
\hline Norwegian University of Science \& Technology & 4,083 & 216 & S. Kaasa & 258 & 218 & 8,770 & 92 & 47 & 80 & 150 \\
\hline Ohio State University & 23,407 & 47 & M.C. Nahara & 456 & 99 & 2,571 & 222 & 21 & 259 & 150 \\
\hline Oklahoma State University & 1,762 & 261 & T.W. Allen & 51 & 338 & 12 & 346 & 2 & 343 & 2 \\
\hline Open University UK & 817 & 303 & C.M. Pound & 59 & 334 & 585 & 311 & 16 & 285 & 45 \\
\hline Oregon State University & 3,018 & 232 & P.D. Whanger & 206 & 249 & 1,824 & 256 & 19 & 270 & 150 \\
\hline Osaka University & 23,348 & 48 & H. Matsuda & 982 & 14 & 11,749 & 67 & 43 & 108 & 150 \\
\hline Peking University & 9,809 & 157 & L. Wei & 111 & 303 & 240 & 329 & 8 & 324 & 150 \\
\hline Pennsylvania State University & 15,523 & 95 & L.M. Demers & 375 & 144 & 5,998 & 129 & 31 & 190 & 150 \\
\hline Pohang University of Science And Technology & 264 & 335 & V.C. Sung & 85 & 318 & 1,821 & 258 & 26 & 225 & 150 \\
\hline Portland State University & 840 & 301 & H. Livneh & 57 & 335 & 484 & 317 & 12 & 304 & 35 \\
\hline Princeton University & 2,243 & 247 & J. Trussell & 193 & 255 & 2,488 & 231 & 27 & 216 & 150 \\
\hline Purdue University & 6,273 & 197 & L.A. Geddes & 425 & 114 & 2,233 & 238 & 10 & 313 & 150 \\
\hline Queen's University & 8,255 & 176 & J.C. Nickel & 289 & 199 & 4,632 & 161 & 35 & 167 & 150 \\
\hline Queen's University of Belfast & 6,853 & 194 & J.W. Dundee & 489 & 93 & 1,587 & 273 & 0 & 347 & 150 \\
\hline Queensland University of Technology & 2,640 & 237 & D.A. Atchison & 144 & 283 & 964 & 298 & 17 & 283 & 103 \\
\hline Radboud University, Nijmegen & 25,078 & 40 & P.C.M. Van De Kerkhof & 520 & 82 & 6,270 & 125 & 31 & 190 & 150 \\
\hline Rensselaer Polytechnic Institute & 757 & 306 & G. Moss & 69 & 331 & 220 & 333 & 3 & 340 & 31 \\
\hline Rheinisch Westfalische Technische Hochschule Aach & 7,219 & 185 & V. Schumpelick & 571 & 65 & 4,754 & 159 & 32 & 185 & 150 \\
\hline Rheinische Friedrich Wilhelms Universitat Bonn & 13,738 & 119 & B. Luderitz & 565 & 68 & 4,989 & 153 & 31 & 190 & 150 \\
\hline Rice University & 1,224 & 281 & L.V. McTire & 265 & 211 & 5,208 & 144 & 30 & 199 & 150 \\
\hline
\end{tabular}




\begin{tabular}{|c|c|c|c|c|c|c|c|c|c|c|}
\hline Rochester Institute of Technology & 314 & 330 & J.P. Hornak & 34 & 341 & 205 & 336 & 4 & 334 & 47 \\
\hline Royal Institute of Technology, KTH & 781 & 304 & J. Sundberg & 138 & 288 & 769 & 302 & 12 & 304 & 138 \\
\hline Royal Melbourne Institute of Technology & 951 & 296 & J. A. Hawley & 174 & 267 & 2,644 & 218 & 34 & 175 & 150 \\
\hline Rutgers & 7,139 & 188 & D. Mechanic & 200 & 251 & 4,399 & 166 & 29 & 205 & 150 \\
\hline Saint-Petersburg State University & 578 & 313 & A.P. Kozlov & 49 & 340 & 296 & 328 & 12 & 304 & 150 \\
\hline San Diego State University & 3,416 & 227 & J.F. Sallis & 319 & 176 & 14,082 & 50 & 64 & 28 & 150 \\
\hline Sapienza University of Rome & 2 & 348 & F. Botti & 10 & 348 & 58 & 343 & 4 & 334 & 39 \\
\hline Sciences Po Paris & 26 & 346 & D. Tabuteau & 15 & 347 & 2 & 348 & 1 & 345 & 8 \\
\hline Seoul National University & 6,211 & 198 & J.G. Chi & 306 & 189 & 3,084 & 204 & 21 & 259 & 150 \\
\hline Shanghai Jiao Tong University & 4,734 & 211 & L. He & 650 & 49 & 8,548 & 95 & 39 & 136 & 150 \\
\hline Simon Fraser University & 2,073 & 251 & T.D. Sterling & 124 & 297 & 590 & 310 & 3 & 340 & 69 \\
\hline Stanford University & 41,245 & 12 & C. Guilleminault & 591 & 59 & 13,385 & 53 & 52 & 61 & 150 \\
\hline State University of New York Buffalo & 167 & 341 & J. Zhang & 193 & 255 & 471 & 318 & 12 & 304 & 150 \\
\hline Stockholm University & 2,999 & 233 & R.Room & 174 & 267 & 1,942 & 246 & 24 & 244 & 150 \\
\hline Stony Brook University & 10,557 & 144 & P.F. Cohn & 357 & 155 & 1,628 & 266 & 10 & 313 & 150 \\
\hline Syracuse University & 9,650 & 158 & S.V. Faraone & 701 & 36 & 31,524 & 11 & 80 & 9 & 150 \\
\hline Tartu University (University of Tartu) & 1,828 & 259 & T. Jurimae & 102 & 310 & 428 & 320 & 14 & 296 & 81 \\
\hline Technical University of Denmark & 1,295 & 278 & F.M. Aarestrup & 169 & 270 & 3,068 & 206 & 37 & 154 & 150 \\
\hline Technion & 7,024 & 190 & P. Lavie & 298 & 197 & 4,916 & 156 & 34 & 175 & 150 \\
\hline Technische Universität Berlin & 1,097 & 284 & U.Boenick & 94 & 315 & 119 & 340 & 5 & 332 & 134 \\
\hline Technische Universitat Chemnitz & 78 & 345 & S. Gauggel & 32 & 342 & 362 & 323 & 12 & 304 & 65 \\
\hline Technische Universität Dresden & 5,136 & 208 & H.U. Wittchen & 381 & 140 & 19,949 & 33 & 72 & 14 & 150 \\
\hline Technische Universität München & 16,058 & 91 & J. Ring & 1,012 & 13 & 13,550 & 52 & 49 & 71 & 150 \\
\hline Tel Aviv University & 19,517 & 69 & Y. Shoenfeld & 1,234 & 3 & 21,469 & 30 & 55 & 53 & 150 \\
\hline Texas A\&M University & 6,680 & 196 & F.W. Bazer & 423 & 115 & 3,366 & 191 & 39 & 136 & 150 \\
\hline Texas Tech & 5,422 & 205 & J.I. Martinez-Lopez & 262 & 216 & 12 & 346 & 1 & 345 & 5 \\
\hline Tohoku University & 18,687 & 74 & H. Sasano & 617 & 57 & 12,136 & 60 & 48 & 73 & 150 \\
\hline Tokyo Institute of Technology & 1,077 & 288 & N. Okada & 177 & 265 & 2,783 & 214 & 36 & 160 & 150 \\
\hline Trinity College Dublin & 7,299 & 181 & J. Freely & 315 & 179 & 2,491 & 230 & 25 & 238 & 150 \\
\hline Tsinghua University & 1,083 & 286 & J. Bai & 412 & 122 & 1,151 & 292 & 16 & 285 & 150 \\
\hline Tufts University & 14,196 & 111 & M.E. Falagas & 420 & 116 & 3,076 & 205 & 31 & 190 & 150 \\
\hline Universidad Autonoma de Madrid & 8,438 & 173 & M. Nistal & 263 & 213 & 1,598 & 270 & 15 & 288 & 150 \\
\hline Universidad de Chile & 7,173 & 187 & A. Csendes & 338 & 164 & 2,169 & 240 & 22 & 252 & 150 \\
\hline
\end{tabular}




\begin{tabular}{|c|c|c|c|c|c|c|c|c|c|c|}
\hline Universidad de Granada & 8,438 & 173 & M. Nistal & 263 & 213 & 1,598 & 270 & 15 & 288 & 150 \\
\hline Universidad del País Vasco & 2,650 & 236 & G. Quindos & 176 & 266 & 2,553 & 223 & 21 & 259 & 150 \\
\hline Universidad Nacional Autónoma de México ... & 5,397 & 206 & M. Selman & 192 & 257 & 4,010 & 178 & 38 & 143 & 150 \\
\hline Universidad Politecnica de Madrid & 513 & 318 & G. Salcedo & 122 & 299 & 1,311 & 283 & 27 & 216 & 150 \\
\hline Universidade de São Paulo & 25,923 & 38 & F.Q. Cunha & 261 & 217 & 4,126 & 174 & 34 & 175 & 150 \\
\hline Universidade Estadual de Campinas & 6,886 & 192 & L.A. Velloso & 151 & 277 & 1,831 & 255 & 25 & 238 & 150 \\
\hline Università degli Studi di Firenze & 14,500 & 108 & G.F. Gensini & 390 & 137 & 3,916 & 180 & 34 & 175 & 150 \\
\hline Università degli Studi di Padova & 21,069 & 62 & A. Girolami & 70 & 329 & 1,919 & 247 & 21 & 259 & 112 \\
\hline Universita Di Bologna & 14,910 & 101 & A. Tosti & 441 & 106 & 4,248 & 171 & 26 & 225 & 150 \\
\hline Universita di Pisa & 10,342 & 149 & A.R. Genazzani & 699 & 39 & 10,364 & 77 & 40 & 128 & 150 \\
\hline Universitat Autonoma de Barcelona & 9,847 & 156 & J. Egozcue & 321 & 173 & 2,616 & 220 & 30 & 199 & 150 \\
\hline Universitat Bielefeld & 1,407 & 275 & H.J. Markowitsch & 243 & 224 & 3,728 & 184 & 31 & 190 & 150 \\
\hline Universität Bremen & 1,839 & 258 & F. Petermann & 358 & 152 & 1,595 & 272 & 27 & 216 & 150 \\
\hline Universitat d'Alacant & 1,049 & 289 & C. Alvarez & 165 & 271 & 617 & 308 & 9 & 319 & 150 \\
\hline Universitat de València & 5,762 & 203 & A. Pellicer & 345 & 159 & 4,814 & 158 & 45 & 96 & 150 \\
\hline Universität Frankfurt am Main & 18,889 & 73 & D. Hoelzer & 561 & 70 & 11,683 & 68 & 45 & 96 & 150 \\
\hline Universität Freiburg & 11,278 & 133 & M. Schumacher & 527 & 79 & 8,235 & 100 & 40 & 128 & 150 \\
\hline Universitat Hamburg & 6,873 & 193 & K. Puschel & 442 & 105 & 1,452 & 277 & 15 & 288 & 150 \\
\hline Universität Karlsruhe & 843 & 300 & M.Zoller & 226 & 234 & 3,016 & 208 & 25 & 238 & 150 \\
\hline Universitat Leipzig & 11,957 & 129 & M.C. Angermeyer & 402 & 128 & 4,426 & 165 & 37 & 154 & 150 \\
\hline Universitat Munster (Westfälische Wilhelms-Univers & 13,904 & 116 & E. Nieschlag & 163 & 272 & 3,742 & 183 & 42 & 116 & 150 \\
\hline Universitat Politecnica de Catalunya & 248 & 336 & J.A. Planell & 207 & 246 & 1,873 & 252 & 28 & 209 & 150 \\
\hline Universität Regensburg & 9,071 & 167 & J. Scholmerich & 452 & 101 & 6,304 & 124 & 40 & 128 & 150 \\
\hline Universität Stuttgart & 665 & 310 & K. Pfizenmaier & 181 & 262 & 4,252 & 169 & 28 & 209 & 150 \\
\hline Universitat Trier & 443 & 324 & D.H. Hellhammer & 160 & 274 & 4,945 & 155 & 42 & 116 & 150 \\
\hline Universität Tübingen & 14,270 & 110 & C.D. Clausson & 566 & 67 & 8,341 & 98 & 40 & 128 & 150 \\
\hline Universitat Wien (University of Vienna) & 19,772 & 68 & M. Marberger & 413 & 120 & 6,414 & 121 & 45 & 96 & 150 \\
\hline Universitat Zu Koln & 14,826 & 103 & V. Diehl & 735 & 27 & 13,333 & 54 & 53 & 59 & 150 \\
\hline Université Catholique de Louvain & 7,383 & 179 & J.M. Lachapelle & 269 & 210 & 2,452 & 232 & 14 & 296 & 150 \\
\hline Universite de Liege & 6,985 & 191 & G.E. Pierard & 1,023 & 12 & 8,003 & 104 & 31 & 190 & 150 \\
\hline Université de Montréal & 14,523 & 107 & S. Nattel & 429 & 113 & 7,588 & 110 & 57 & 48 & 150 \\
\hline Université de Nice Sophia Antipolis & 2,021 & 254 & J. Gugenhelm & 243 & 224 & 2,357 & 236 & 24 & 244 & 150 \\
\hline Universite Laval & 9,211 & 166 & C. Bouchard & 701 & 36 & 29,931 & 13 & 63 & 33 & 150 \\
\hline
\end{tabular}




\begin{tabular}{|c|c|c|c|c|c|c|c|c|c|c|}
\hline Universite Libre de Bruxelles & 10,432 & 148 & R.Kiss & 469 & 96 & 3,559 & 186 & 32 & 185 & 150 \\
\hline Université Paris Sorbonne & 514 & 317 & B. Portha & 160 & 274 & 1,893 & 248 & 22 & 252 & 150 \\
\hline Universite Paris-Sud 11 & 4,770 & 210 & G. Simonneau & 329 & 168 & 9,845 & 81 & 62 & 36 & 150 \\
\hline Université Pierre et Marie Curie & 6,759 & 195 & D. Costagliola & 294 & 198 & 5,442 & 136 & 39 & 136 & 150 \\
\hline Universiti Malaya (University of Malaya) & 3,857 & 219 & K.L. Goh & 118 & 301 & 984 & 297 & 18 & 276 & 150 \\
\hline University College Cork & 1,721 & 263 & F. Shanahan & 303 & 192 & 7,040 & 116 & 42 & 116 & 150 \\
\hline University College Dublin & 3,777 & 222 & J.M. Fitzpatrick & 440 & 107 & 3,468 & 189 & 26 & 225 & 150 \\
\hline University College London & 43,488 & 10 & D.P. Milailaidus & 739 & 26 & 8,348 & 97 & 41 & 124 & 150 \\
\hline University do Porto & 3,101 & 229 & H. Barros & 273 & 209 & 1,770 & 261 & 22 & 252 & 150 \\
\hline University of Aberdeen & 9,308 & 163 & S.H. Ralston & 275 & 208 & 5,891 & 131 & 52 & 61 & 150 \\
\hline University of Adelaide & 8,686 & 171 & M.Horowitz & 589 & 60 & 13,034 & 57 & 45 & 96 & 150 \\
\hline University of Alabama & 29,771 & 26 & G.R. McGwin & 308 & 186 & 4,227 & 172 & 40 & 128 & 150 \\
\hline University of Alberta & 18,129 & 81 & P. Armstrong & 324 & 172 & 9,275 & 88 & 51 & 65 & 150 \\
\hline University of Amsterdam & 28,694 & 27 & H.R. Buller & 237 & 232 & 8,761 & 93 & 56 & 52 & 150 \\
\hline University of Antwerp & 8,553 & 172 & P.P. DeDeyn & 410 & 123 & 6,824 & 119 & 41 & 124 & 150 \\
\hline University of Arizona & 18,577 & 75 & D.S. Alberts & 239 & 231 & 5,424 & 137 & 35 & 167 & 150 \\
\hline University of Athens & 16,875 & 86 & C. Stefanadis & 643 & 52 & 8,307 & 99 & 40 & 128 & 150 \\
\hline University of Auckland & 9,612 & 159 & P.D. Gluckman & 465 & 97 & 8,995 & 90 & 48 & 73 & 150 \\
\hline University of Barcelona & 10,901 & 140 & E. Montserrat & 358 & 152 & 5,901 & 130 & 37 & 154 & 150 \\
\hline University of Basel & 17,197 & 84 & A. Gratwohl & 567 & 66 & 15,675 & 42 & 58 & 45 & 150 \\
\hline University of Bath & 996 & 291 & B.V.L.Potter & 355 & 156 & 3,191 & 199 & 36 & 160 & 150 \\
\hline University of Bergen & 10,565 & 143 & P.M. Ueland & 333 & 167 & 9,797 & 83 & 50 & 68 & 150 \\
\hline University of Bern & 19,422 & 71 & N.P. Lang & 363 & 150 & 4,837 & 157 & 38 & 143 & 150 \\
\hline University of Birmingham & 15,600 & 94 & G.Y.H. Lip & 1,046 & 10 & 15,513 & 43 & 57 & 48 & 150 \\
\hline University of Bristol & 12,546 & 125 & G.D. Smith & 498 & 90 & 13,875 & 51 & 63 & 33 & 150 \\
\hline University of British Columbia & 25,994 & 37 & M.R. Hayden & 516 & 83 & 21,990 & 28 & 70 & 18 & 150 \\
\hline University of Calgary & 13,817 & 118 & M.D. Hollenberg & 401 & 131 & 5,205 & 145 & 43 & 108 & 150 \\
\hline University of California, Berkley & 13,957 & 114 & L. Packer & 553 & 72 & 9,432 & 86 & 52 & 61 & 150 \\
\hline University of California, Davis & 23,547 & 45 & M.E. Gershwin & 835 & 18 & 15,366 & 45 & 50 & 68 & 150 \\
\hline University of California, Irvine & 15,900 & 92 & N.D. Vaziri & 472 & 95 & 5,119 & 148 & 44 & 101 & 150 \\
\hline University of California, Los Angeles & 61,436 & 4 & R.W. Busuttil & 589 & 60 & 16,783 & 40 & 60 & 41 & 150 \\
\hline University of California, Riverside & 2,465 & 240 & A.W. Norman & 313 & 182 & 3,026 & 207 & 9 & 319 & 150 \\
\hline University of California, San Diego & 33,691 & 18 & E. Barrett-Conner & 349 & 157 & 17,273 & 39 & 65 & 24 & 150 \\
\hline
\end{tabular}




\begin{tabular}{|c|c|c|c|c|c|c|c|c|c|c|}
\hline University of California, San Francisco & 59,718 & 5 & H.I. Maibach & 1,156 & 7 & 15,464 & 44 & 35 & 167 & 150 \\
\hline University of California, Santa Barbara & 429 & 326 & S. Mitragotri & 103 & 308 & 1,851 & 253 & 29 & 205 & 94 \\
\hline University of California, Santa Cruz & 210 & 338 & A.L. Fink & 207 & 246 & 6,307 & 123 & 51 & 65 & 150 \\
\hline University of Cambridge & 17,892 & 82 & L.D. Hall & 276 & 205 & 1,886 & 250 & 19 & 270 & 150 \\
\hline University of Canterbury & 421 & 327 & J.G. Chase & 131 & 294 & 321 & 325 & 13 & 299 & 150 \\
\hline University of Cape Town & 10,531 & 146 & T.D. Noakes & 398 & 133 & 4,475 & 164 & 38 & 143 & 150 \\
\hline University of Central Florida & 1,345 & 277 & A. Liberman & 68 & 332 & 93 & 342 & 5 & 332 & 64 \\
\hline University of Chicago & 36,237 & 15 & R.M. Lang & 362 & 151 & 306 & 326 & 38 & 143 & 150 \\
\hline University of Cincinnati & 21,364 & 59 & M.R. First & 305 & 190 & 3,313 & 192 & 26 & 225 & 150 \\
\hline University of Colorado at Boulder & 1,545 & 268 & D.R. Seals & 250 & 220 & 5,081 & 151 & 38 & 143 & 150 \\
\hline University of Connecticut & 14,666 & 105 & D.K. Das & 395 & 134 & 6,747 & 120 & 47 & 80 & 150 \\
\hline University of Copenhagen & 22,603 & 53 & C.F. Deacon & 105 & 307 & 2,003 & 242 & 30 & 199 & 150 \\
\hline University of Delaware & 868 & 298 & L. Snyder-Mackler & 138 & 288 & 1,802 & 259 & 26 & 225 & 150 \\
\hline University of Dundee & 8,343 & 175 & B. J. Lipworth & 433 & 112 & 5,365 & 139 & 46 & 89 & 150 \\
\hline University of Edinburgh & 15,168 & 99 & I.J. Deary & 506 & 88 & 11,172 & 72 & 47 & 80 & 150 \\
\hline University of Florida & 27,864 & 31 & W.M. Mendenhal & 403 & 127 & 5,869 & 132 & 39 & 136 & 150 \\
\hline University of Geneva & 21,267 & 60 & R. Rizzolli & 358 & 152 & 6,321 & 122 & 39 & 136 & 150 \\
\hline University of Georgia & 5,781 & 202 & J.N. Moore & 185 & 260 & 1,191 & 290 & 14 & 296 & 150 \\
\hline University of Ghent & 14,874 & 102 & F. Haesebrouck & 434 & 111 & 2,863 & 211 & 28 & 209 & 150 \\
\hline University of Glasgow & 15,746 & 93 & G.D.O. Lowe & 697 & 41 & 17,657 & 38 & 59 & 43 & 150 \\
\hline University of Gothenburg & 2,257 & 246 & C. Ohlsson & 264 & 212 & 7,414 & 112 & 42 & 116 & 150 \\
\hline University of Groningen & 20,850 & 64 & E.G.E. De Vries & 641 & 53 & 13,315 & 55 & 46 & 89 & 150 \\
\hline University of Helsinki & 19,239 & 72 & J. Kaprio & 335 & 165 & 7,859 & 107 & 47 & 80 & 150 \\
\hline University of Hong Kong & 12,217 & 128 & S.T. Fan & 640 & 54 & 18,042 & 37 & 62 & 36 & 150 \\
\hline University of Houston & 3,658 & 225 & R.E. Lewsi & 147 & 281 & 1,945 & 245 & 28 & 209 & 150 \\
\hline University of Illinois & 11,261 & 135 & B.S. Katzenellenbogen & 286 & 202 & 8,860 & 91 & 55 & 53 & 150 \\
\hline University of Illinois, Chicago & 24,037 & 42 & G.A. Fishman & 304 & 191 & 3,237 & 198 & 23 & 246 & 150 \\
\hline University of Indonesia & 979 & 294 & F. Partono & 74 & 327 & 605 & 309 & 2 & 343 & 95 \\
\hline University of Iowa & 31,840 & 22 & M.A. Pfaller & 680 & 44 & 31,582 & 10 & 79 & 10 & 150 \\
\hline University of Kansas & 13,069 & 123 & F. Wolfe & 321 & 173 & 13,042 & 56 & 54 & 56 & 150 \\
\hline University of Kentucky & 14,935 & 100 & D.A. Butterfield & 385 & 138 & 8,095 & 103 & 61 & 40 & 150 \\
\hline University of Lausanne & 5,515 & 204 & J. Tscopp & 334 & 166 & 18,405 & 35 & 85 & 4 & 150 \\
\hline University of Leeds & 17,283 & 83 & P. Emery & 575 & 63 & 2,312 & 237 & 66 & 23 & 150 \\
\hline
\end{tabular}




\begin{tabular}{|c|c|c|c|c|c|c|c|c|c|c|}
\hline University of Leicester & 7,099 & 189 & N.J. Samani & 240 & 229 & 6,110 & 127 & 38 & 143 & 150 \\
\hline University of Liverpool & 15,508 & 96 & C.A. Hart & 248 & 221 & 4,095 & 176 & 36 & 160 & 150 \\
\hline University of Ljubljana & 4,705 & 212 & F. Strle & 151 & 277 & 1,399 & 279 & 26 & 225 & 150 \\
\hline University of London (Kings College of London) & 127,212 & 1 & K.H. Nicolaides & 892 & 16 & 25,807 & 19 & 64 & 28 & 150 \\
\hline University of Manchester & 18,327 & 79 & A.J. Silman & 556 & 71 & 22,895 & 23 & 72 & 14 & 150 \\
\hline University of Manitoba & 12,443 & 126 & C.N. Bernstein & 230 & 233 & 6,070 & 128 & 38 & 143 & 150 \\
\hline University of Maryland & 4,960 & 209 & C.E.Hill & 117 & 302 & 1,628 & 266 & 18 & 276 & 150 \\
\hline University of Maryland Baltimore County & 22,902 & 50 & M/M. Levine & 399 & 132 & 8,222 & 101 & 43 & 108 & 150 \\
\hline University of Massachusetts & 1,467 & 273 & P.M. Clarkson & 174 & 267 & 3,246 & 197 & 27 & 216 & 150 \\
\hline University of Melbourne & 22,112 & 56 & R. Bellomo & 542 & 75 & 10,310 & 78 & 45 & 96 & 150 \\
\hline University of Miami & 22,676 & 52 & C. Ricordi & 525 & 80 & 12,606 & 59 & 44 & 101 & 150 \\
\hline University of Michigan & 51,188 & 7 & F. Morady & 495 & 91 & 7,862 & 106 & 43 & 108 & 150 \\
\hline University of Minnesota & 38,475 & 14 & A.R. Folsom & 635 & 55 & 35,756 & 8 & 79 & 10 & 150 \\
\hline University of Missouri & 16,775 & 88 & J.D. Tobias & 402 & 128 & 2,515 & 229 & 23 & 246 & 150 \\
\hline University of Nebraska & 2,437 & 241 & T.J. Housch & 189 & 258 & 1,204 & 289 & 21 & 259 & 131 \\
\hline University of New Hampshire & 1,078 & 287 & D. Finkelhor & 140 & 286 & 5,112 & 149 & 26 & 225 & 50 \\
\hline University of New Mexico & 10,920 & 139 & R.H. Glew & 312 & 183 & 1,636 & 265 & 18 & 276 & 150 \\
\hline University of New South Wales & 13,091 & 122 & D.A. Cooper & 523 & 81 & 23,176 & 22 & 57 & 48 & 150 \\
\hline University of North Carolina, Chapel Hill & 35,003 & 17 & D.A. Savitz & 372 & 145 & 7,093 & 114 & 40 & 128 & 150 \\
\hline University of North Texas & 1,984 & 256 & J.W. Simpkins & 283 & 204 & 3,838 & 182 & 37 & 154 & 150 \\
\hline University of Notre Dame & 476 & 322 & F.J. Castellino & 382 & 139 & 3,296 & 194 & 29 & 205 & 150 \\
\hline University of Nottingham & 9,414 & 161 & I.A. MacDonald & 445 & 103 & 4,984 & 154 & 36 & 160 & 150 \\
\hline University of Oklahoma & 11,159 & 138 & J.N. George & 220 & 238 & 4,147 & 173 & 34 & 175 & 150 \\
\hline University of Oregon & 2,761 & 235 & J.T. Rosenbaum & 300 & 195 & 3,518 & 187 & 27 & 216 & 150 \\
\hline University of Oslo & 23,753 & 43 & S.E. Kjeldsen & 416 & 119 & 10,292 & 79 & 43 & 108 & 150 \\
\hline University of Otago & 11,197 & 136 & J. Crane & 247 & 222 & 4,376 & 167 & 30 & 199 & 150 \\
\hline University of Ottawa & 11,177 & 137 & D. Krewski & 309 & 185 & 5,015 & 152 & 31 & 190 & 150 \\
\hline University of Oxford & 23,630 & 44 & A.L. Harris & 339 & 162 & 12,091 & 62 & 83 & 6 & 150 \\
\hline University of Pennsylvania & 5,870 & 200 & A. Alavi & 674 & 46 & 5,129 & 146 & 46 & 89 & 150 \\
\hline University of Pittsburgh & 51,833 & 6 & L.H. Kuller & 879 & 17 & 37,595 & 7 & 81 & 8 & 150 \\
\hline University of Quebec & 7,706 & 177 & C. Bouchard & 705 & 34 & 28,823 & 16 & 63 & 33 & 150 \\
\hline University of Queensland & 14,788 & 104 & T.H. Marwick & 409 & 124 & 7,486 & 111 & 49 & 71 & 150 \\
\hline University of Reading & 2,065 & 253 & C.M. Williams & 91 & 316 & 1,842 & 254 & 32 & 185 & 150 \\
\hline
\end{tabular}




\begin{tabular}{|c|c|c|c|c|c|c|c|c|c|c|}
\hline University of Rochester & 21,507 & 58 & A.J. Moss & 583 & 62 & 22,141 & 25 & 46 & 89 & 150 \\
\hline University of Saskatchewan & 5,227 & 207 & K. Prasad & 125 & 295 & 1,472 & 276 & 19 & 270 & 150 \\
\hline University of Science and Technology of China & 392 & 329 & Z. Tain & 184 & 261 & 1,260 & 285 & 18 & 276 & 150 \\
\hline University of Sheffield & 9,910 & 155 & R. Eastell & 307 & 188 & 9,567 & 85 & 54 & 56 & 150 \\
\hline University of South Carolina & 5,798 & 201 & R.R. Pate & 210 & 245 & 7,907 & 105 & 43 & 108 & 150 \\
\hline University of South Florida & 13,862 & 117 & H. Friedman & 435 & 110 & 2,527 & 227 & 22 & 252 & 150 \\
\hline University of Southampton & 9,524 & 160 & S.T. Holgate & 1,060 & 9 & 39,705 & 5 & 72 & 14 & 150 \\
\hline University of Southern California & 28,284 & 29 & L. Bernstein & 365 & 147 & 9,906 & 80 & 43 & 108 & 150 \\
\hline University of St Andrews & 509 & 319 & H.T.O. Davies & 328 & 170 & 5,329 & 140 & 44 & 101 & 150 \\
\hline University of Surrey & 3,082 & 231 & J. Arendt & 215 & 242 & 3,309 & 193 & 32 & 185 & 150 \\
\hline University of Sussex & 2,365 & 244 & C. Abraham & 70 & 329 & 1,288 & 284 & 19 & 270 & 88 \\
\hline University of Sydney & 22,019 & 57 & P. Mitchell & 419 & 117 & 6,219 & 126 & 48 & 73 & 150 \\
\hline University of Technology, Sydney & 984 & 293 & H.T. Nguyen & 225 & 235 & 674 & 306 & 11 & 310 & 150 \\
\hline University of Tennessee Knoxville & 4,526 & 214 & B.T. Rouse & 341 & 161 & 5,283 & 142 & 36 & 160 & 150 \\
\hline University of Texas at Austin & 2,280 & 245 & A.J. Welch & 301 & 193 & 3,252 & 196 & 26 & 225 & 150 \\
\hline University of Tokyo & 27,586 & 33 & M. Omata & 967 & 15 & 22,053 & 27 & 64 & 28 & 150 \\
\hline University of Toronto & 62,513 & 3 & G. Koren & 754 & 25 & 12,085 & 63 & 48 & 73 & 150 \\
\hline University of Tsukuba & 8,792 & 170 & H. Akaza & 491 & 92 & 2,530 & 226 & 23 & 246 & 150 \\
\hline University of Twente & 530 & 316 & C.A. Van Blitterswijk & 288 & 200 & 3,950 & 179 & 41 & 124 & 150 \\
\hline University of Utah & 22,314 & 55 & M.L. Slattery & 276 & 205 & 8,158 & 102 & 48 & 73 & 150 \\
\hline University of Vermont & 10,019 & 153 & R.P. Tracy & 339 & 162 & 22,112 & 26 & 82 & 7 & 150 \\
\hline University of Victoria & 1,808 & 260 & R.E. Rhodes & 80 & 321 & 687 & 305 & 19 & 270 & 79 \\
\hline University of Virginia & 22,910 & 49 & R.F. Edlich & 572 & 64 & 2,545 & 224 & 13 & 299 & 150 \\
\hline University of Warwick & 2,783 & 234 & G.F. Medley & 137 & 290 & 2,017 & 241 & 21 & 259 & 150 \\
\hline University of Washington & 50,019 & 8 & L. Corey & 511 & 85 & 27,474 & 18 & 78 & 13 & 150 \\
\hline University of Waterloo & 1,556 & 267 & R.L. Hughson & 263 & 213 & 3,170 & 201 & 31 & 190 & 150 \\
\hline University of Western Australia & 10,298 & 150 & L.J. Beilin & 503 & 89 & 14,725 & 49 & 48 & 73 & 150 \\
\hline University of Western Ontario & 14,388 & 109 & R.A.Hegele & 447 & 102 & 5,749 & 133 & 39 & 136 & 150 \\
\hline University of Wisconsin & 32,376 & 21 & R. Klein & 487 & 94 & 8,555 & 94 & 65 & 24 & 150 \\
\hline University of Wollongong & 1,402 & 276 & J.R. Steele & 65 & 333 & 638 & 307 & 15 & 288 & 90 \\
\hline University of York & 3,803 & 221 & M. Drummond & 308 & 186 & 4,566 & 162 & 30 & 199 & 150 \\
\hline University of Zurich & 10,857 & 141 & A. Aguzzi & 394 & 136 & 11,126 & 73 & 60 & 41 & 150 \\
\hline Univesitas Gadjah Mada & 277 & 332 & Y. Mahendrahata & 18 & 346 & 23 & 344 & 4 & 334 & 36 \\
\hline
\end{tabular}




\begin{tabular}{|c|c|c|c|c|c|c|c|c|c|c|}
\hline Uppsala University & 22,848 & 51 & L.Lind & 329 & 168 & 4,511 & 163 & 35 & 167 & 150 \\
\hline Utah State & 421 & 327 & R.W. Sidwell & 241 & 227 & 2,576 & 221 & 28 & 209 & 150 \\
\hline Utrecht University & 28,107 & 30 & D.E. Grobbee & 530 & 77 & 21,406 & 31 & 70 & 18 & 150 \\
\hline Vanderbilt University & 20,200 & 67 & F.P. Guengerich & 663 & 47 & 32,945 & 9 & 58 & 45 & 150 \\
\hline Victoria University of Wellington & 227 & 337 & J. Cumming & 31 & 343 & 100 & 341 & 7 & 326 & 65 \\
\hline Vienna University of Technology & 158 & 342 & S. Miksch & 72 & 328 & 399 & 321 & 11 & 310 & 106 \\
\hline Virginia Polytechnic Institute & 1,088 & 285 & D.S. Lindsay & 344 & 160 & 2,712 & 217 & 30 & 199 & 150 \\
\hline Vrije Universiteit, Brussels & 7,290 & 184 & M.Noppen & 147 & 281 & 1,166 & 291 & 22 & 252 & 150 \\
\hline VU University Amsterdam & 23,530 & 46 & H.M. Pinedo & 691 & 43 & 19,029 & 34 & 54 & 56 & 150 \\
\hline Wageningen University & 1,292 & 279 & M.B. Katan & 406 & 126 & 12,024 & 65 & 50 & 68 & 150 \\
\hline Wake Forest University & 17,042 & 85 & S.R. Feldman & 454 & 100 & 3,619 & 185 & 35 & 167 & 150 \\
\hline Waseda University & 532 & 315 & E. Tsuchida & 661 & 48 & 7,048 & 115 & 35 & 167 & 150 \\
\hline Washington State University & 3,841 & 220 & T.E. Besser & 160 & 274 & 2,753 & 216 & 33 & 183 & 150 \\
\hline Washington University in St. Louis & 31,216 & 23 & M.J. Welch & 724 & 31 & 11,837 & 66 & 42 & 116 & 150 \\
\hline Wayne State University & 21,083 & 61 & R.J. Romero & 594 & 58 & 21,849 & 29 & 59 & 43 & 150 \\
\hline West Virginia University & 7,297 & 182 & J.E. Riggs & 217 & 240 & 1,673 & 264 & 11 & 310 & 150 \\
\hline Yale University & 40,756 & 13 & R.A. Flavell & 734 & 28 & 56,589 & 2 & 113 & 1 & 150 \\
\hline Yonsei University & 9,280 & 164 & Y. Jang & 199 & 252 & 2,517 & 228 & 23 & 246 & 150 \\
\hline York University & 2,468 & 239 & R.J. Burke & 216 & 241 & 1,225 & 287 & 16 & 285 & 150 \\
\hline Zhejiang University & 3,094 & 230 & Q. Xia & 194 & 254 & 563 & 314 & 13 & 299 & 150 \\
\hline
\end{tabular}




\begin{tabular}{|c|c|c|c|c|c|c|c|c|c|c|}
\hline Astronomy and Physics Data & $\begin{array}{l}\text { Department } \\
\text { Publications }\end{array}$ & Rank & Most Prolific Author & Published & Rank & Cited & Rank & $\begin{array}{c}\text { H- } \\
\text { Index }\end{array}$ & Rank & $\begin{array}{c}\text { \# of } \\
\text { Coauthors }\end{array}$ \\
\hline Aalto University & 6,279 & 137 & R.M. Nieminen & 394 & 148 & 6,455 & 71 & 40 & 49 & 150 \\
\hline Aarhus University & 5,398 & 164 & F. Besenbacher & 358 & 170 & 6,475 & 70 & 47 & 19 & 150 \\
\hline Arizonia State University & 7,887 & 98 & D.J. Smith & 558 & 50 & 7,513 & 54 & 33 & 116 & 150 \\
\hline Ateneo de Manila University & 26 & 346 & R.A. Guerrero & 23 & 343 & 117 & 340 & 4 & 341 & 85 \\
\hline Auburn University & 2,188 & 274 & M.S. Pindzola & 321 & 200 & 1,750 & 251 & 27 & 182 & 150 \\
\hline Australian National University & 10,036 & 57 & Y.S. Kivshar & 687 & 25 & 1,578 & 263 & 49 & 14 & 150 \\
\hline Boston College & 1,194 & 304 & Z.F. Ren & 220 & 274 & 8,085 & 48 & 43 & 35 & 150 \\
\hline Boston University & 7,149 & 114 & H.E. Stanley & 480 & 83 & 10,348 & 33 & 57 & 6 & 150 \\
\hline Brandeis University & 2,282 & 269 & G.Apollinari & 405 & 138 & 4,553 & 97 & 43 & 35 & 150 \\
\hline Brigham Young University & 1,498 & 292 & D. Henderson & 368 & 162 & 3,013 & 162 & 29 & 150 & 150 \\
\hline Brown University & 7,454 & 108 & G.A. Alves & 292 & 223 & 2,690 & 190 & 33 & 116 & 150 \\
\hline California Institute of Technology (Calt... & 28,914 & 6 & R. Kass & 552 & 55 & 6,497 & 69 & 32 & 122 & 150 \\
\hline Cardiff University & 2,683 & 255 & P.M. Snowton & 176 & 296 & 682 & 319 & 17 & 288 & 150 \\
\hline Carnegie Mellon University & 8,550 & 84 & D. Bortoletto & 459 & 103 & 4,662 & 93 & 42 & 46 & 150 \\
\hline Case Western Reserve University & 4,504 & 188 & P.L. Taylor & 149 & 306 & 699 & 317 & 11 & 325 & 106 \\
\hline Chalmers University of Technology & 8,610 & 83 & T. Claeson & 319 & 201 & 2,245 & 223 & 19 & 268 & 150 \\
\hline Charles University & 5,593 & 158 & V. Sechovsky & 437 & 117 & 1,123 & 289 & 17 & 288 & 150 \\
\hline Chinese University of Hong Kong & 3,236 & 232 & S.P. Wong & 264 & 246 & 1,146 & 286 & 18 & 276 & 150 \\
\hline Chulalongkorn University & 673 & 324 & V. Sa-Yakanit & 46 & 340 & 119 & 339 & 3 & 342 & 41 \\
\hline City University of Hong Kong & 4,696 & 179 & P.K. Chu & 887 & 13 & 6,609 & 68 & 29 & 150 & 150 \\
\hline City University of New York & 4,142 & 207 & F.H. Pollak & 345 & 182 & 3,444 & 140 & 20 & 256 & 150 \\
\hline Colorado State University & 2,784 & 249 & H.R. Band & 286 & 227 & 2,449 & 200 & 25 & 207 & 150 \\
\hline Columbia University & 12,771 & 40 & M. Abolins & 263 & 248 & 2,224 & 225 & 31 & 135 & 150 \\
\hline Cornell University & 18,566 & 17 & D.L. Hartill & 468 & 97 & 4,111 & 108 & 30 & 143 & 150 \\
\hline Curtin University of Technology & 537 & 331 & J. D. Gale & 195 & 283 & 5,005 & 86 & 32 & 122 & 150 \\
\hline Dalhousie University & 2,304 & 268 & J.R. Datin & 406 & 137 & 7,651 & 52 & 50 & 12 & 150 \\
\hline Dartmouth College & 2,774 & 250 & K.D. Paulson & 371 & 160 & 2,809 & 178 & 40 & 49 & 150 \\
\hline Delft University of Technology & 7,926 & 97 & C.W.E. Van Eijk & 402 & 144 & 2,316 & 214 & 28 & 163 & 150 \\
\hline Drexel University & 2,690 & 254 & D.H. Feng & 100 & 330 & 934 & 301 & 6 & 337 & 123 \\
\hline Duke University & 7,027 & 119 & G. Apollinari & 405 & 138 & 4,567 & 96 & 43 & 35 & 150 \\
\hline Durham University & 6,499 & 130 & A. Martin & 290 & 225 & 8,566 & 43 & 35 & 90 & 150 \\
\hline
\end{tabular}




\begin{tabular}{|c|c|c|c|c|c|c|c|c|c|c|}
\hline Ecole Normale Supérieure de Lyon & 1,382 & 298 & S. Cillberto & 90 & 332 & 1,549 & 266 & 26 & 191 & 101 \\
\hline École Normale Supérieure, Paris & 4,616 & 183 & G. Bastard & 160 & 302 & 2,638 & 194 & 17 & 288 & 150 \\
\hline École Polytechnique & 8,138 & 90 & E. Gabathuler & 434 & 119 & 4,572 & 95 & 34 & 98 & 150 \\
\hline Ecole Polytechnique Fédérale de Lausanne & 7,468 & 107 & G. Margaritondo & 513 & 64 & 4,204 & 105 & 25 & 207 & 150 \\
\hline Eindhoven University of Technology & 5,440 & 161 & W.J.W. DeJonge & 372 & 158 & 3,461 & 139 & 30 & 143 & 150 \\
\hline Emory University & 1,551 & 289 & J.M. Bowman & 304 & 214 & 2,441 & 202 & 29 & 150 & 150 \\
\hline Erasmus University Rotterdam & 645 & 327 & J.W. Wiladimiroff & 417 & 128 & 3,192 & 152 & 20 & 256 & 150 \\
\hline ETH Zurich (Swiss Federal Institute of Technology) & 14,559 & 30 & H.R. Ott & 473 & 92 & 3,936 & 111 & 29 & 150 & 150 \\
\hline Florida International University & 1,408 & 296 & M.U. Khandaker & 126 & 318 & 2,039 & 232 & 28 & 163 & 150 \\
\hline Florida State University & 8,192 & 88 & K.W. Kemper & 313 & 205 & 1,249 & 281 & 23 & 232 & 150 \\
\hline Freie Universität Berlin & 7,183 & 113 & G. Kaindl & 339 & 185 & 3,183 & 153 & 22 & 237 & 150 \\
\hline Friedrich Alexander Universität Erlangen Nürnberg & 8,789 & 78 & P.G. Reinhar & 340 & 184 & 3,250 & 149 & 29 & 150 & 150 \\
\hline Fudan University & 6,122 & 142 & X.Wang & 222 & 273 & 2,855 & 171 & 22 & 237 & 150 \\
\hline Georg August Universität Göttingen & 5,710 & 152 & K.P.Lieb & 556 & 52 & 6,702 & 65 & 35 & 90 & 150 \\
\hline George Mason University & 1,458 & 294 & D.L. Hartill & 247 & 257 & 2,375 & 210 & 30 & 143 & 150 \\
\hline George Washington University & 1,872 & 282 & E. Della Torre & 178 & 295 & 522 & 326 & 10 & 330 & 118 \\
\hline Georgetown University & 1,018 & 312 & J.K.Freericks & 128 & 316 & 1,180 & 282 & 17 & 288 & 73 \\
\hline Georgia Institute of Technology & 9,402 & 67 & V. Landman & 281 & 233 & 8,015 & 49 & 46 & 24 & 150 \\
\hline Georgia State University & 1,094 & 307 & S.T. Manson & 238 & 262 & 1,483 & 270 & 22 & 237 & 150 \\
\hline Goteborg University & 9,737 & 65 & B. Kasemo & 374 & 156 & 6,704 & 64 & 47 & 19 & 150 \\
\hline Harvard University & 16,197 & 25 & D. Amidei & 501 & 69 & 9,346 & 39 & 43 & 35 & 150 \\
\hline Hebrew University of Jerusalem & 7,534 & 104 & I. Felner & 371 & 160 & 2,838 & 173 & 26 & 191 & 150 \\
\hline Heidelberg Universität & 8,767 & 79 & J.W. Gary & 592 & 40 & 8,695 & 41 & 39 & 65 & 150 \\
\hline Hokkaido University & 10,037 & 56 & H. Hasegawa & 557 & 51 & 18,907 & 9 & 27 & 182 & 150 \\
\hline Hong Kong Polytechnic University & 3,482 & 227 & H.L.W. Chang & 617 & 35 & 1,978 & 237 & 26 & 191 & 150 \\
\hline Hong Kong University of Science \& Techno... & 3,755 & 218 & H.S. Kwok & 494 & 72 & 3,379 & 145 & 32 & 122 & 150 \\
\hline Humboldt-Universität zu Berlin & 132 & 340 & R. Chaoui & 161 & 300 & 1,170 & 283 & 20 & 256 & 150 \\
\hline Imperial College London & 17,472 & 22 & P.L. Knight & 319 & 201 & 7,429 & 56 & 45 & 31 & 150 \\
\hline Indian Institute of Technology Bombay (I... & 2,273 & 271 & B.D. Padalia & 146 & 308 & 866 & 303 & 8 & 333 & 146 \\
\hline Indian Institute of Technology Delhi (II... & 3,111 & 237 & K.L. Chopra & 332 & 190 & 2,746 & 180 & 7 & 334 & 150 \\
\hline Indian Institute of Technology Kanpur (I... & 3,246 & 231 & R.K. Thareja & 110 & 326 & 613 & 323 & 15 & 307 & 86 \\
\hline Indiana University Bloomington & 7,141 & 115 & G. Giacomelli & 611 & 37 & 10,265 & 34 & 37 & 75 & 150 \\
\hline Indiana University Indianapolis & 229 & 337 & M. Wang & 51 & 339 & 80 & 342 & 6 & 337 & 45 \\
\hline
\end{tabular}




\begin{tabular}{|c|c|c|c|c|c|c|c|c|c|c|}
\hline Iowa State University & 10,563 & 54 & P.C. Canfield & 404 & 141 & 4,979 & 87 & 43 & 35 & 150 \\
\hline Johns Hopkins University & 11,893 & 48 & A. Barbaro-Galtieri & 563 & 46 & 10,870 & 25 & 47 & 19 & 150 \\
\hline Kansas State University & 3,583 & 223 & C.D. Lin & 297 & 220 & 2,251 & 222 & 25 & 207 & 150 \\
\hline Katholieke Universiteit Leuven & 7,979 & 95 & V.V. Moshchalkow & 583 & 42 & 6,816 & 63 & 34 & 98 & 150 \\
\hline Keio University & 4,226 & 201 & M. Obara & 502 & 68 & 2,701 & 187 & 20 & 256 & 150 \\
\hline King Fahd University of Petroleum \& Minerals & 1,376 & 299 & B.S. Yilbas & 391 & 150 & 1,093 & 292 & 19 & 268 & 150 \\
\hline King Saud University & 727 & 321 & M.S. Abdalla & 74 & 334 & 254 & 334 & 10 & 330 & 42 \\
\hline Kobe University & 4,453 & 192 & E. Duchovni & 456 & 107 & 3,752 & 120 & 34 & 98 & 150 \\
\hline Korea Advanced Institute of Science \& Technology & 7,680 & 100 & K.J. Chang & 504 & 67 & 15 & 343 & 34 & 98 & 150 \\
\hline Korea University & 474 & 333 & B.G. Cheon & 302 & 217 & 3,210 & 151 & 39 & 65 & 150 \\
\hline Kyoto University & 27,754 & 7 & Y. Maeno & 367 & 164 & 2,811 & 177 & 45 & 31 & 150 \\
\hline Kyushu University & 9,752 & 64 & T. Okada & 237 & 263 & 1,726 & 253 & 21 & 249 & 150 \\
\hline La Trobe University & 942 & 317 & J. Liesegang & 3 & 346 & 5 & 346 & 2 & 344 & 4 \\
\hline Lancaster University & 3,056 & 239 & P.V.E. McClintock & 324 & 198 & 1,053 & 293 & 22 & 237 & 150 \\
\hline Leiden University & 6,222 & 138 & J.A. Mydosh & 389 & 151 & 2,923 & 166 & 22 & 237 & 150 \\
\hline Linkoping University & 4,340 & 197 & B. Monemar & 486 & 78 & 2,697 & 188 & 25 & 207 & 150 \\
\hline London School of Economics and Political Science & 166 & 339 & C.Howson & 35 & 342 & 115 & 341 & 3 & 342 & 5 \\
\hline Loughborough University & 2,816 & 247 & A.S.Aexandrov & 165 & 299 & 1,473 & 272 & 21 & 249 & 53 \\
\hline Louisiana State University & 5,148 & 171 & J.P. Draayer & 256 & 251 & 861 & 305 & 17 & 288 & 150 \\
\hline Ludwig-Maximilians-Universität München & 8,663 & 80 & M. Boutenur & 324 & 198 & 3,509 & 136 & 33 & 116 & 150 \\
\hline Lund University & 9,397 & 68 & B. Asmen & 409 & 133 & 3,568 & 134 & 29 & 150 & 150 \\
\hline Maastricht University & 212 & 338 & P. Lambin & 395 & 147 & 5,360 & 79 & 39 & 65 & 150 \\
\hline Macquarie University & 1,321 & 300 & B.C. Sanders & 188 & 288 & 2,021 & 234 & 25 & 207 & 150 \\
\hline Mahidol University & 438 & 334 & I.M. Tang & 154 & 305 & 252 & 335 & 7 & 334 & 107 \\
\hline Masaryk University & 1,134 & 306 & V. Holy & 186 & 292 & 1,845 & 248 & 17 & 288 & 150 \\
\hline Massachusetts Institute of Technology & 34,017 & 3 & M. Brinkley & 527 & 59 & 25,309 & 4 & 46 & 24 & 150 \\
\hline McGill University & 3,140 & 235 & D.B. MacFarlane & 338 & 187 & 3,140 & 154 & 18 & 276 & 150 \\
\hline McMaster University & 6,628 & 125 & J.P. Carbotte & 424 & 124 & 1,677 & 256 & 18 & 276 & 150 \\
\hline Michigan State University & 8,892 & 74 & B.A. Brown & 482 & 81 & 5,102 & 83 & 43 & 35 & 150 \\
\hline Michigan Technological University & 1,468 & 293 & D.R. Beck & 120 & 320 & 422 & 331 & 11 & 325 & 47 \\
\hline Monash University & 3,107 & 238 & T.J.Hicks & 106 & 327 & 221 & 337 & 5 & 340 & 79 \\
\hline Montana State University & 1,711 & 286 & V.H. Schimdt & 143 & 309 & 760 & 311 & 15 & 307 & 150 \\
\hline Moscow State University & 20,569 & 15 & A.M. Zheltikov & 549 & 56 & 3,894 & 113 & 30 & 143 & 150 \\
\hline
\end{tabular}




\begin{tabular}{|c|c|c|c|c|c|c|c|c|c|c|}
\hline Nagoya University & 16,692 & 23 & M. Uneno & 469 & 96 & 2,284 & 217 & 28 & 163 & 150 \\
\hline Nanjing University & 9,931 & 59 & Y.W. Du & 478 & 84 & 3,047 & 160 & 29 & 150 & 150 \\
\hline Nanyang Technological University & 7,489 & 105 & S.F.Yoon & 461 & 102 & 1,853 & 244 & 22 & 237 & 150 \\
\hline National Taiwan University & 8,952 & 73 & Y.F. Chen & 686 & 26 & 6,676 & 66 & 36 & 80 & 150 \\
\hline National Tsing Hua University & 7,951 & 96 & I.N. Lin & 393 & 149 & 2,268 & 219 & 24 & 221 & 150 \\
\hline National University of Ireland, Galway & 582 & 328 & C. Dainty & 73 & 335 & 372 & 333 & 13 & 316 & 112 \\
\hline National University of Singapore & 9,333 & 69 & C. K. Ong & 414 & 129 & 2,823 & 176 & 27 & 182 & 150 \\
\hline New Mexico State University & 2,143 & 276 & J.G. Boissevain & 161 & 300 & 3,606 & 128 & 34 & 98 & 150 \\
\hline New York University & 6,468 & 133 & J.K. Percus & 195 & 283 & 1,809 & 249 & 10 & 330 & 130 \\
\hline Newcastle University & 2,716 & 252 & P.R. Bridden & 354 & 176 & 2,973 & 163 & 33 & 116 & 150 \\
\hline North Carolina State University & 7,125 & 116 & R.J. Nemanich & 421 & 126 & 5,792 & 76 & 31 & 135 & 150 \\
\hline Northeastern University & 4,824 & 176 & S.S. Banerjee & 898 & 10 & 14,731 & 14 & 46 & 24 & 150 \\
\hline Northwestern University & 12,013 & 45 & C.A. Mirkin & 352 & 179 & 15,071 & 13 & 73 & 2 & 150 \\
\hline Norwegian University of Science \& Technology & 3,217 & 233 & I. Brevik & 167 & 298 & 873 & 302 & 17 & 288 & 96 \\
\hline Ohio State University & 11,654 & 49 & H. Kagan & 409 & 133 & 3,582 & 133 & 22 & 237 & 150 \\
\hline Oklahoma State University & 2,609 & 258 & V.V. Tokmenin & 156 & 304 & 617 & 321 & 13 & 316 & 150 \\
\hline Open University UK & 1,084 & 309 & N.J. Mason & 196 & 282 & 1,308 & 278 & 22 & 237 & 150 \\
\hline Oregon State University & 2,701 & 253 & G.T. Evans & 99 & 331 & 376 & 332 & 6 & 337 & 56 \\
\hline Osaka University & 25,984 & 9 & Y. Onuki & 785 & 14 & 9,418 & 38 & 45 & 31 & 150 \\
\hline Peking University & 9,905 & 60 & Q. Gong & 379 & 154 & 1,530 & 267 & 20 & 256 & 150 \\
\hline Pennsylvania State University & 15,245 & 29 & A. Lakhtakia & 547 & 57 & 5,267 & 82 & 29 & 150 & 134 \\
\hline Pohang University of Science And Technology & 4,666 & 180 & S.I. Lee & 374 & 156 & 2,707 & 185 & 28 & 163 & 150 \\
\hline Portland State University & 649 & 326 & J.Jiao & 120 & 320 & 1,361 & 276 & 18 & 276 & 150 \\
\hline Princeton University & 29,891 & 5 & H. Rabitz & 645 & 33 & 10,986 & 23 & 35 & 90 & 150 \\
\hline Purdue University & 12,018 & 44 & G. Apollinari & 408 & 135 & 4,719 & 92 & 44 & 34 & 150 \\
\hline Queen's University & 3,809 & 217 & V.H. Smith & 244 & 260 & 1,376 & 275 & 20 & 256 & 150 \\
\hline Queen's University of Belfast & 4,515 & 186 & F.P. Keenan & 424 & 124 & 1,737 & 252 & 24 & 221 & 150 \\
\hline Queensland University of Technology & 780 & 320 & R.L. Frost & 602 & 38 & 8,154 & 46 & 40 & 49 & 150 \\
\hline Radboud University, Nijmegen & 4,961 & 174 & R. Clare & 223 & 272 & 2,295 & 216 & 28 & 163 & 150 \\
\hline Rensselaer Polytechnic Institute & 5,629 & 156 & T.M. Lu & 329 & 192 & 2,578 & 196 & 25 & 207 & 150 \\
\hline Rheinisch Westfalische Technische Hochschule Aach & 8,530 & 85 & K.W. Bell & 464 & 99 & 3,797 & 119 & 35 & 90 & 150 \\
\hline Rheinische Friedrich Wilhelms Universitat Bonn & 8,647 & 82 & E. Dochovni & 464 & 99 & 3,862 & 115 & 34 & 98 & 150 \\
\hline Rice University & 5,766 & 148 & F. B. Dunning & 256 & 251 & 1,045 & 295 & 18 & 276 & 150 \\
\hline
\end{tabular}




\begin{tabular}{|c|c|c|c|c|c|c|c|c|c|c|}
\hline Rochester Institute of Technology & 1,224 & 302 & B.W. Smith & 122 & 319 & 1,110 & 290 & 18 & 276 & 150 \\
\hline Royal Institute of Technology, KTH & 8,815 & 76 & K.V. Rao & 308 & 209 & 2,655 & 193 & 19 & 268 & 150 \\
\hline Royal Melbourne Institute of Technology & 1,069 & 310 & W. Van Megan & 103 & 329 & 1,896 & 240 & 13 & 316 & 150 \\
\hline Rutgers & 10,101 & 55 & A. Beretvas & 511 & 65 & 10,234 & 35 & 46 & 24 & 150 \\
\hline Saint-Petersburg State University & 7,479 & 106 & V.M. Shabaev & 140 & 313 & 576 & 324 & 24 & 221 & 125 \\
\hline San Diego State University & 1,227 & 301 & S.B. Oseroff & 149 & 306 & 2,258 & 221 & 19 & 268 & 150 \\
\hline Sapienza University of Rome & 0 & 347 & & 0 & 347 & 0 & 347 & 0 & 347 & 0 \\
\hline Sciences Po Paris & 0 & 347 & & 0 & 347 & 0 & 347 & 0 & 347 & 0 \\
\hline Seoul National University & 8,994 & 71 & B. Lee & 414 & 129 & 1,847 & 247 & 31 & 135 & 150 \\
\hline Shanghai Jiao Tong University & 6,613 & 126 & H.Y. Fan & 364 & 166 & 782 & 309 & 22 & 237 & 137 \\
\hline Simon Fraser University & 3,205 & 234 & M.L.W. Thewalt & 225 & 270 & 1,634 & 261 & 13 & 316 & 150 \\
\hline Stanford University & 18,076 & 19 & J.S. Harris & 911 & 8 & 11,966 & 20 & 48 & 18 & 150 \\
\hline State University of New York Buffalo & 33 & 344 & M. Haka & 36 & 341 & 663 & 320 & 7 & 334 & 110 \\
\hline Stockholm University & 4,024 & 209 & B.Asman & 410 & 131 & 3,587 & 130 & 29 & 150 & 150 \\
\hline Stony Brook University & 10,992 & 53 & D.B. Fossan & 270 & 241 & 1,253 & 280 & 18 & 276 & 150 \\
\hline Syracuse University & 4,020 & 211 & S. Stone & 237 & 263 & 1,998 & 236 & 28 & 163 & 150 \\
\hline Tartu University (University of Tartu) & 1,458 & 294 & M. Kirm & 183 & 294 & 851 & 306 & 18 & 276 & 150 \\
\hline Technical University of Denmark & 5,788 & 147 & J.M. Hvam & 269 & 245 & 2,173 & 228 & 27 & 182 & 150 \\
\hline Technion & 9,811 & 62 & J. Goldberg & 430 & 120 & 3,707 & 124 & 34 & 98 & 150 \\
\hline Technische Universität Berlin & 6,492 & 131 & B. Bimberg & 967 & 7 & 18,234 & 10 & 57 & 6 & 150 \\
\hline Technische Universitat Chemnitz & 2,194 & 273 & D.R.T. Zahn & 364 & 166 & 1,762 & 250 & 21 & 249 & 150 \\
\hline Technische Universität Dresden & 5,721 & 150 & D.B. MacFarlane & 527 & 59 & 7,291 & 57 & 32 & 122 & 150 \\
\hline Technische Universität München & 13,444 & 38 & M. Stutzman & 465 & 98 & 6,621 & 67 & 41 & 47 & 150 \\
\hline Tel Aviv University & 11,190 & 51 & G. Alexander & 553 & 54 & 8,485 & 44 & 34 & 98 & 150 \\
\hline Texas A\&M University & 8,812 & 77 & M.O. Scully & 474 & 89 & 5,040 & 85 & 36 & 80 & 150 \\
\hline Texas Tech & 2,255 & 272 & C. Bromberg & 470 & 95 & 4,216 & 104 & 46 & 24 & 150 \\
\hline Tohoku University & 23,118 & 12 & A. Inoue & 1,930 & 1 & 38,085 & 2 & 71 & 3 & 150 \\
\hline Tokyo Institute of Technology & 17,906 & 21 & H. Takezoe & 492 & 75 & 4,010 & 110 & 32 & 122 & 150 \\
\hline Trinity College Dublin & 3,019 & 242 & J.M.D. Coey & 533 & 58 & 12,766 & 18 & 37 & 75 & 150 \\
\hline Tsinghua University & 13,582 & 36 & G. Sin & 456 & 107 & 808 & 308 & 14 & 311 & 150 \\
\hline Tufts University & 2,433 & 263 & A. Vilenkin & 188 & 288 & 3,641 & 126 & 25 & 207 & 67 \\
\hline Universidad Autonoma de Madrid & 7,574 & 102 & F. Flores & 333 & 188 & 2,392 & 208 & 25 & 207 & 150 \\
\hline Universidad de Chile & 1,895 & 280 & M.T. Garland & 210 & 279 & 1,136 & 287 & 17 & 288 & 150 \\
\hline
\end{tabular}




\begin{tabular}{|c|c|c|c|c|c|c|c|c|c|c|}
\hline Universidad de Granada & 7,574 & 102 & F. Flores & 333 & 188 & 2,392 & 208 & 25 & 207 & 150 \\
\hline Universidad del País Vasco & 3,739 & 219 & P.M. Echenique & 326 & 196 & 3,122 & 156 & 36 & 80 & 150 \\
\hline Universidad Nacional Autónoma de México ... & 9,835 & 61 & O. Pizio & 141 & 312 & 429 & 330 & 14 & 311 & 78 \\
\hline Universidad Politecnica de Madrid & 3,028 & 241 & E. Munoz & 234 & 266 & 1,869 & 242 & 26 & 191 & 150 \\
\hline Universidade de São Paulo & 12,230 & 41 & V.S. Bagnato & 298 & 219 & 1,879 & 241 & 19 & 268 & 150 \\
\hline Universidade Estadual de Campinas & 6,219 & 139 & M. Knobel & 193 & 285 & 2,211 & 226 & 23 & 232 & 150 \\
\hline Università degli Studi di Firenze & 6,138 & 141 & A. Bay & 493 & 73 & 4,735 & 91 & 40 & 49 & 150 \\
\hline Università degli Studi di Padova & 10,006 & 58 & R. Contri & 584 & 41 & 6,324 & 72 & 32 & 122 & 150 \\
\hline Universita Di Bologna & 8,156 & 89 & G. Giacomelli & 577 & 44 & 10,349 & 32 & 34 & 98 & 150 \\
\hline Universita di Pisa & 6,460 & 134 & A. Hocker & 355 & 172 & 2,896 & 167 & 28 & 163 & 150 \\
\hline Universitat Autonoma de Barcelona & 4,542 & 184 & J.P. Lees & 766 & 15 & 15,909 & 12 & 49 & 14 & 150 \\
\hline Universitat Bielefeld & 3,687 & 220 & F. Karsch & 246 & 258 & 3,249 & 150 & 35 & 90 & 150 \\
\hline Universität Bremen & 2,620 & 257 & D. Hommel & 443 & 111 & 3,416 & 141 & 28 & 163 & 150 \\
\hline Universitat d'Alacant & 1,199 & 303 & A. Belendez & 216 & 276 & 698 & 318 & 20 & 256 & 94 \\
\hline Universitat de València & 6,016 & 143 & T.J. Adye & 556 & 52 & 8,264 & 45 & 36 & 80 & 150 \\
\hline Universität Frankfurt am Main & 7,221 & 112 & W. Greiner & 889 & 11 & 12,843 & 17 & 35 & 90 & 150 \\
\hline Universität Freiburg & 5,482 & 159 & J.W. Gary & 723 & 20 & 10,564 & 29 & 40 & 49 & 150 \\
\hline Universitat Hamburg & 8,194 & 87 & I.P. Duerdoth & 488 & 76 & 3,751 & 121 & 34 & 98 & 150 \\
\hline Universität Karlsruhe & 8,966 & 72 & W.D. Apel & 458 & 105 & 3,464 & 138 & 31 & 135 & 150 \\
\hline Universitat Leipzig & 4,264 & 200 & J. Karger & 350 & 180 & 2,311 & 215 & 29 & 150 & 150 \\
\hline Universitat Munster (Westfälische Wilhelms-Univers & 4,351 & 194 & R. Pottgen & 438 & 116 & 1,485 & 269 & 29 & 150 & 150 \\
\hline Universitat Politecnica de Catalunya & 3,525 & 226 & L. Torner & 303 & 215 & 2,336 & 212 & 34 & 98 & 150 \\
\hline Universität Regensburg & 4,758 & 177 & W.Wegscheider & 408 & 135 & 4,421 & 100 & 36 & 80 & 150 \\
\hline Universität Stuttgart & 7,597 & 101 & F. Scholz & 339 & 185 & 2,722 & 183 & 23 & 232 & 150 \\
\hline Universitat Trier & 73 & 342 & A. Jabs & 16 & 344 & 8 & 345 & 1 & 346 & 4 \\
\hline Universität Tübingen & 5,454 & 160 & A. Faessler & 717 & 22 & 7,480 & 55 & 33 & 116 & 150 \\
\hline Universitat Wien (University of Vienna) & 5,651 & 153 & H. Kuzmany & 270 & 241 & 3,359 & 146 & 30 & 143 & 150 \\
\hline Universitat Zu Koln & 6,674 & 124 & P. Von Brentano & 484 & 79 & 2,163 & 230 & 33 & 116 & 150 \\
\hline Université Catholique de Louvain & 3,428 & 228 & X. Gonze & 131 & 315 & 3,631 & 127 & 27 & 182 & 143 \\
\hline Universite de Liege & 4,310 & 198 & M. Ausloos & 405 & 138 & 1,947 & 238 & 24 & 221 & 150 \\
\hline Université de Montréal & 4,515 & 186 & J.W. Gary & 723 & 20 & 10,564 & 29 & 40 & 49 & 150 \\
\hline Université de Nice Sophia Antipolis & 2,495 & 261 & D. Sornette & 290 & 225 & 3,397 & 144 & 37 & 75 & 150 \\
\hline Universite Laval & 2,930 & 244 & S.L. Chin & 270 & 241 & 2,411 & 205 & 41 & 47 & 150 \\
\hline
\end{tabular}




\begin{tabular}{|c|c|c|c|c|c|c|c|c|c|c|}
\hline Universite Libre de Bruxelles & 5812 & 146 & D. Baye & 186 & 292 & 1635 & 260 & 19 & 268 & 150 \\
\hline Université Paris Sorbonne & 231 & 336 & J. Bouchez & 67 & 338 & 703 & 316 & 12 & 323 & 150 \\
\hline Universite Paris-Sud 11 & 21065 & 14 & A. Revcolevsich & 427 & 123 & 3896 & 112 & 37 & 75 & 150 \\
\hline Université Pierre et Marie Curie & 15441 & 27 & M. Begalli & 143 & 309 & 996 & 297 & 19 & 268 & 150 \\
\hline Universiti Malaya (University of Malaya) & 2278 & 270 & S.W. Ng & 1108 & 4 & 3409 & 143 & 16 & 302 & 150 \\
\hline University College Cork & 1541 & 290 & G. Huyet & 133 & 314 & 516 & 327 & 16 & 302 & 150 \\
\hline University College Dublin & 1801 & 283 & S. Malik & 226 & 269 & 730 & 314 & 18 & 276 & 150 \\
\hline University College London & 12022 & 43 & A.A. Carter & 472 & 94 & 4015 & 109 & 35 & 90 & 150 \\
\hline University do Porto & 719 & 322 & J.B. Sousa & 208 & 280 & 774 & 310 & 14 & 311 & 150 \\
\hline University of Aberdeen & 2122 & 277 & J.N. Low & 429 & 121 & 977 & 299 & 17 & 288 & 150 \\
\hline University of Adelaide & 2830 & 246 & A.W. Thomas & 354 & 176 & 2743 & 181 & 36 & 80 & 150 \\
\hline University of Alabama & 3901 & 213 & A. Bay & 493 & 73 & 4775 & 90 & 40 & 49 & 150 \\
\hline University of Alberta & 7353 & 109 & D. Axen & 403 & 142 & 5480 & 78 & 34 & 98 & 150 \\
\hline University of Amsterdam & 6873 & 121 & K.H.J. Buschow & 1148 & 3 & 13899 & 16 & 20 & 256 & 150 \\
\hline University of Antwerp & 4345 & 195 & F.M. Peeters & 674 & 28 & 9761 & 37 & 39 & 65 & 150 \\
\hline University of Arizona & 14000 & 32 & J.V. Moloney & 440 & 113 & 3598 & 129 & 34 & 98 & 150 \\
\hline University of Athens & 3838 & 215 & W.D. Apel & 482 & 81 & 3662 & 125 & 32 & 122 & 150 \\
\hline University of Auckland & 1779 & 284 & D.F. Walls & 260 & 250 & 4284 & 102 & 24 & 221 & 150 \\
\hline University of Barcelona & 6607 & 127 & M. Davier & 514 & 63 & 5311 & 81 & 31 & 135 & 150 \\
\hline University of Basel & 3636 & 222 & H.J. Guntherodt & 458 & 105 & 7158 & 59 & 40 & 49 & 150 \\
\hline University of Bath & 2400 & 265 & P.S.J. Russell & 353 & 178 & 7077 & 61 & 53 & 10 & 150 \\
\hline University of Bergen & 2175 & 275 & B. Stugu & 326 & 196 & 3503 & 137 & 34 & 98 & 150 \\
\hline University of Bern & 4378 & 193 & H.U. Gudel & 449 & 109 & 4840 & 88 & 39 & 65 & 150 \\
\hline University of Birmingham & 8829 & 75 & J.W. Gary & 476 & 86 & 4165 & 106 & 36 & 80 & 150 \\
\hline University of Bristol & 7323 & 110 & G.S. Abrams & 578 & 43 & 8689 & 42 & 40 & 49 & 150 \\
\hline University of British Columbia & 9032 & 70 & J.W. Gary & 476 & 86 & 4131 & 107 & 36 & 80 & 150 \\
\hline University of Calgary & 1394 & 297 & T. Ziegler & 368 & 162 & 7997 & 50 & 49 & 14 & 150 \\
\hline University of California, Berkley & 31444 & 4 & M.L. Cohen & 648 & 32 & 24662 & 5 & 43 & 35 & 150 \\
\hline University of California, Davis & 8099 & 91 & C. Bromberg & 474 & 89 & 4818 & 89 & 46 & 24 & 150 \\
\hline University of California, Irvine & 7242 & 111 & A.A. Maradudin & 484 & 79 & 3881 & 114 & 18 & 276 & 150 \\
\hline University of California, Los Angeles & 18314 & 18 & A. Barbaro-Galtieri & 563 & 46 & 10870 & 25 & 47 & 19 & 150 \\
\hline
\end{tabular}




\begin{tabular}{|c|c|c|c|c|c|c|c|c|c|c|}
\hline University of California, San Francisco & 979 & 315 & M. Roach & 236 & 265 & 4,310 & 101 & 43 & 35 & 150 \\
\hline University of California, Santa Barbara & 14,493 & 31 & J.S. Speck & 517 & 62 & 12,657 & 19 & 57 & 6 & 150 \\
\hline University of California, Santa Cruz & 4,160 & 205 & H.R. Band & 187 & 290 & 2,168 & 229 & 22 & 237 & 150 \\
\hline University of Cambridge & 26,740 & 8 & D. Ritchie & 746 & 16 & 11,571 & 21 & 43 & 35 & 150 \\
\hline University of Canterbury & 1,535 & 291 & G.E. Sredman & 119 & 322 & 482 & 328 & 13 & 316 & 87 \\
\hline University of Cape Town & 1,088 & 308 & J. Cleymans & 112 & 325 & 996 & 297 & 16 & 302 & 150 \\
\hline University of Central Florida & 4,875 & 175 & S.T. Wu & 448 & 110 & 2,487 & 199 & 31 & 135 & 150 \\
\hline University of Chicago & 15,519 & 26 & S.A. Rice & 575 & 45 & 7,665 & 51 & 26 & 191 & 150 \\
\hline University of Cincinnati & 4,146 & 206 & R. Kass & 613 & 36 & 7,126 & 60 & 32 & 122 & 150 \\
\hline University of Colorado at Boulder & 13,098 & 39 & N.A. Clark & 294 & 222 & 5,357 & 80 & 28 & 163 & 150 \\
\hline University of Connecticut & 4,468 & 190 & Y. Hahn & 214 & 278 & 615 & 322 & 11 & 325 & 68 \\
\hline University of Copenhagen & 8,657 & 81 & R.A. Broglia & 376 & 155 & 2,017 & 235 & 21 & 249 & 150 \\
\hline University of Delaware & 5,614 & 157 & G.C. Hadjipanayis & 459 & 103 & 4,483 & 98 & 28 & 163 & 150 \\
\hline University of Dundee & 1,021 & 311 & J.N. Low & 429 & 121 & 1,048 & 294 & 17 & 288 & 150 \\
\hline University of Edinburgh & 5,715 & 151 & A. Hocker & 264 & 246 & 2,632 & 195 & 27 & 182 & 150 \\
\hline University of Florida & 11,954 & 47 & S.J. Pearton & 1,420 & 2 & 20,761 & 8 & 54 & 9 & 150 \\
\hline University of Geneva & 6,156 & 140 & N. Gisin & 362 & 168 & 6,892 & 62 & 51 & 11 & 150 \\
\hline University of Georgia & 2,316 & 267 & H.F Schaefer & 1,098 & 5 & 21,762 & 7 & 47 & 19 & 46 \\
\hline University of Ghent & 4,539 & 185 & R. Baets & 250 & 256 & 2,029 & 233 & 24 & 221 & 150 \\
\hline University of Glasgow & 6,489 & 132 & G. Apollinari & 510 & 66 & 10,081 & 36 & 46 & 24 & 150 \\
\hline University of Gothenburg & 28 & 345 & M. Bath & 70 & 337 & 204 & 338 & 16 & 302 & 108 \\
\hline University of Groningen & 6,538 & 128 & J.T.M. De Hosson & 501 & 69 & 3,826 & 118 & 30 & 143 & 150 \\
\hline University of Helsinki & 5,739 & 149 & J. Keinonen & 307 & 211 & 2,396 & 206 & 26 & 191 & 150 \\
\hline University of Hong Kong & 3,256 & 230 & A.B. Djursic & 254 & 255 & 2,276 & 218 & 24 & 221 & 150 \\
\hline University of Houston & 5,249 & 168 & D.J. Kouri & 345 & 182 & 1,339 & 277 & 16 & 302 & 150 \\
\hline University of Illinois & 24,008 & 11 & H. Morkoc & 1,052 & 6 & 14,330 & 15 & 43 & 35 & 150 \\
\hline University of Illinois, Chicago & 4,100 & 208 & V. Bhatngar & 302 & 217 & 3,338 & 147 & 36 & 80 & 150 \\
\hline University of Indonesia & 89 & 341 & K. Kagawa & 87 & 333 & 233 & 336 & 12 & 323 & 107 \\
\hline University of Iowa & 4,497 & 189 & V.B Golubev & 309 & 207 & 1,647 & 257 & 26 & 191 & 150 \\
\hline University of Kansas & 2,910 & 245 & H. Severini & 256 & 251 & 1,848 & 245 & 26 & 191 & 150 \\
\hline University of Kentucky & 3,549 & 225 & P.C. Eklund & 292 & 223 & 9,082 & 40 & 43 & 35 & 150 \\
\hline University of Lausanne & 1,011 & 313 & A. Bay & 348 & 181 & 3,833 & 117 & 35 & 90 & 150 \\
\hline University of Leeds & 5,440 & 161 & I.M. Ward & 671 & 29 & 7,570 & 53 & 24 & 221 & 150 \\
\hline
\end{tabular}




\begin{tabular}{|c|c|c|c|c|c|c|c|c|c|c|}
\hline University of Leicester & 2,751 & 251 & M.Lester & 200 & 281 & 864 & 304 & 21 & 249 & 150 \\
\hline University of Liverpool & 8,092 & 92 & A. Hocker & 355 & 172 & 2,837 & 174 & 28 & 163 & 150 \\
\hline University of Ljubljana & 3,898 & 214 & M. Danilov & 400 & 145 & 4,482 & 99 & 39 & 65 & 150 \\
\hline University of London (Kings College of London) & 25,235 & 10 & J.W. Gary & 732 & 17 & 10,600 & 27 & 40 & 49 & 150 \\
\hline University of Manchester & 13,609 & 35 & I.P. Duerdoth & 488 & 76 & 3,745 & 122 & 34 & 98 & 150 \\
\hline University of Manitoba & 2,572 & 259 & G. Williams & 115 & 324 & 525 & 325 & 14 & 311 & 85 \\
\hline University of Maryland & 20,301 & 16 & S. Das Sarma & 478 & 84 & 6,119 & 73 & 40 & 49 & 150 \\
\hline University of Maryland Baltimore County & 2,796 & 248 & C.R. Menyuk & 318 & 203 & 2,697 & 188 & 24 & 221 & 150 \\
\hline University of Massachusetts & 5,139 & 172 & H.R. Band & 286 & 227 & 2,393 & 207 & 25 & 207 & 150 \\
\hline University of Melbourne & 5,647 & 154 & M.Hazumi & 306 & 212 & 3,858 & 116 & 39 & 65 & 150 \\
\hline University of Miami & 1,158 & 305 & R.M. Leblanc & 306 & 212 & 2,512 & 198 & 26 & 191 & 150 \\
\hline University of Michigan & 574 & 329 & H.P. Chan & 245 & 259 & 2,233 & 224 & 29 & 150 & 150 \\
\hline University of Minnesota & 13,668 & 34 & D.G. Truhlar & 888 & 12 & 27,089 & 3 & 64 & 5 & 150 \\
\hline University of Missouri & 7,069 & 117 & W.Y. Ching & 297 & 220 & 3,320 & 148 & 27 & 182 & 150 \\
\hline University of Nebraska & 4,023 & 210 & D.J. Sellmyer & 366 & 165 & 2,685 & 191 & 28 & 163 & 150 \\
\hline University of New Hampshire & 1,890 & 281 & D. Doughty & 116 & 323 & 1,679 & 255 & 27 & 182 & 150 \\
\hline University of New Mexico & 5,283 & 166 & J. Antos & 271 & 240 & 2,896 & 167 & 40 & 49 & 150 \\
\hline University of New South Wales & 5,951 & 145 & M.A. Green & 403 & 142 & 3,051 & 159 & 28 & 163 & 150 \\
\hline University of North Carolina, Chapel Hill & 4,296 & 199 & P.H. Frampton & 233 & 267 & 1,464 & 273 & 17 & 288 & 130 \\
\hline University of North Texas & 1,559 & 288 & W.E. Acree & 439 & 115 & 1,475 & 271 & 26 & 191 & 150 \\
\hline University of Notre Dame & 6,533 & 129 & J.K. Furdyna & 559 & 49 & 8,144 & 47 & 29 & 150 & 150 \\
\hline University of Nottingham & 5,984 & 144 & M. Henini & 631 & 34 & 5,964 & 75 & 31 & 135 & 150 \\
\hline University of Oklahoma & 2,319 & 266 & H. Severini & 256 & 251 & 1,848 & 245 & 26 & 191 & 150 \\
\hline University of Oregon & 3,962 & 212 & H.R. Band & 286 & 227 & 2,415 & 204 & 25 & 207 & 150 \\
\hline University of Oslo & 5,275 & 167 & T. Camporesi & 329 & 192 & 2,763 & 179 & 27 & 182 & 150 \\
\hline University of Otago & 569 & 330 & K.C. Gordon & 191 & 287 & 1,638 & 259 & 22 & 237 & 150 \\
\hline University of Ottawa & 3,048 & 240 & X. Bao & 215 & 277 & 758 & 312 & 17 & 288 & 130 \\
\hline University of Oxford & 22,783 & 13 & N.H. March & 682 & 27 & 2,661 & 192 & 15 & 307 & 150 \\
\hline University of Pennsylvania & 117,283 & 1 & A. Hocker & 355 & 172 & 2,837 & 174 & 28 & 163 & 150 \\
\hline University of Pittsburgh & 7,693 & 99 & J.T. Yates & 602 & 38 & 16,262 & 11 & 37 & 75 & 150 \\
\hline University of Quebec & 3,332 & 229 & S.L. Chin & 273 & 237 & 2,323 & 213 & 40 & 49 & 150 \\
\hline University of Queensland & 3,553 & 224 & G.J. Milburn & 270 & 241 & 5,538 & 77 & 34 & 98 & 150 \\
\hline University of Reading & 2,420 & 264 & R.C. Newman & 228 & 268 & 1,381 & 274 & 13 & 316 & 150 \\
\hline
\end{tabular}




\begin{tabular}{|c|c|c|c|c|c|c|c|c|c|c|}
\hline University of Rochester & 12,010 & 46 & A. Beretvas & 272 & 238 & 2,891 & 170 & 40 & 49 & 150 \\
\hline University of Saskatchewan & 2,442 & 262 & A. Hirose & 127 & 317 & 456 & 329 & 11 & 325 & 124 \\
\hline University of Science and Technology of China & 11,383 & 50 & G.C. Guo & 421 & 126 & 3,092 & 157 & 31 & 135 & 150 \\
\hline University of Sheffield & 6,841 & 123 & M. Hopkinson & 522 & 61 & 4,278 & 103 & 32 & 122 & 150 \\
\hline University of South Carolina & 3,684 & 221 & J.R Wilson & 495 & 71 & 2,952 & 164 & 28 & 163 & 150 \\
\hline University of South Florida & 951 & 316 & G.S. Nolas & 143 & 309 & 1,166 & 284 & 22 & 237 & 150 \\
\hline University of Southampton & 8,359 & 86 & D.J. Richardson & 655 & 31 & 11,416 & 22 & 50 & 12 & 150 \\
\hline University of Southern California & 8,082 & 94 & K. Maki & 476 & 86 & 3,016 & 161 & 26 & 191 & 150 \\
\hline University of St Andrews & 3,829 & 216 & W. Sibbett & 440 & 113 & 2,538 & 197 & 28 & 163 & 150 \\
\hline University of Surrey & 5,165 & 170 & S.R.P. Silva & 327 & 194 & 3,416 & 141 & 32 & 122 & 150 \\
\hline University of Sussex & 4,214 & 202 & P.D. Townsend & 360 & 169 & 2,733 & 182 & 23 & 232 & 150 \\
\hline University of Sydney & 6,378 & 136 & D.R. McKenzie & 372 & 158 & 4,616 & 94 & 28 & 163 & 150 \\
\hline University of Technology, Sydney & 697 & 323 & M.R. Phillips & 157 & 303 & 824 & 307 & 17 & 288 & 150 \\
\hline University of Tennessee Knoxville & 6,844 & 122 & H.R Band & 286 & 227 & 2,418 & 203 & 25 & 207 & 150 \\
\hline University of Texas at Austin & 16,434 & 24 & D.L. Kwong & 689 & 24 & 7,254 & 58 & 38 & 73 & 150 \\
\hline University of Tokyo & 42,552 & 2 & Y. Tokura & 901 & 9 & 39,219 & 1 & 82 & 1 & 150 \\
\hline University of Toronto & 13,715 & 33 & A. Mandelis & 308 & 209 & 1,127 & 288 & 19 & 268 & 150 \\
\hline University of Tsukuba & 9,756 & 63 & Y. Masumoto & 358 & 170 & 3,124 & 155 & 24 & 221 & 150 \\
\hline University of Twente & 4,342 & 196 & D.N. Reinhoudt & 724 & 19 & 22,809 & 6 & 66 & 4 & 150 \\
\hline University of Utah & 6,453 & 135 & G.B. Stringfellow & 310 & 206 & 2,360 & 211 & 18 & 276 & 150 \\
\hline University of Vermont & 868 & 319 & J.Yang & 72 & 336 & 724 & 315 & 20 & 256 & 33 \\
\hline University of Victoria & 2,673 & 256 & G. Vasseur & 410 & 131 & 2,721 & 184 & 26 & 191 & 150 \\
\hline University of Virginia & 8,090 & 93. & L. Andrews & 698 & 23 & 10,877 & 24 & 39 & 65 & 150 \\
\hline University of Warwick & 4,701 & 178 & V.B. Golubev & 309 & 207 & 1,647 & 257 & 26 & 191 & 150 \\
\hline University of Washington & 13,465 & 37 & T.H. Burnett & 218 & 275 & 1,153 & 285 & 21 & 249 & 150 \\
\hline University of Waterloo & 5,634 & 155 & P.F. Bernath & 462 & 101 & 3,076 & 158 & 28 & 163 & 150 \\
\hline University of Western Australia & 2,520 & 260 & L.Faraone & 275 & 235 & 749 & 313 & 17 & 288 & 150 \\
\hline University of Western Ontario & 4,459 & 191 & T.K. Sham & 303 & 215 & 2,263 & 220 & 20 & 256 & 150 \\
\hline University of Wisconsin & 18,061 & 20 & V. Barger & 473 & 92 & 5,065 & 84 & 38 & 73 & 150 \\
\hline University of Wollongong & 1,633 & 287 & S.X. Dou & 561 & 48 & 6,118 & 74 & 34 & 98 & 150 \\
\hline University of York & 2,941 & 243 & R. Wadsworth & 284 & 231 & 1,550 & 265 & 25 & 207 & 150 \\
\hline University of Zurich & 4,194 & 203 & A. Linden & 396 & 146 & 2,706 & 186 & 25 & 207 & 150 \\
\hline Univesitas Gadjah Mada & 49 & 343 & M. Yasin & 11 & 345 & 11 & 344 & 2 & 344 & 30 \\
\hline
\end{tabular}




\begin{tabular}{|c|c|c|c|c|c|c|c|c|c|c|}
\hline Uppsala University & 9,506 & 66 & D. Bertrand & 386 & 152 & 3,586 & 131 & 32 & 122 & 150 \\
\hline Utah State & 665 & 325 & R.W. Schunk & 187 & 290 & 958 & 300 & 11 & 325 & 150 \\
\hline Utrecht University & 6,968 & 120 & G. Blasse & 474 & 89 & 3,510 & 135 & 14 & 311 & 150 \\
\hline Vanderbilt University & 4,639 & 181 & J.H. Hamilton & 435 & 118 & 1,271 & 279 & 20 & 256 & 150 \\
\hline Victoria University of Wellington & 996 & 314 & H.J. Trodahl & 176 & 296 & 1,033 & 296 & 15 & 307 & 150 \\
\hline Vienna University of Technology & 7,041 & 118 & G. Strasser & 332 & 190 & 1,511 & 268 & 26 & 191 & 150 \\
\hline Virginia Polytechnic Institute & 5,096 & 173 & H. Aihara & 241 & 261 & 2,123 & 231 & 34 & 98 & 150 \\
\hline Vrije Universiteit, Brussels & 898 & 318 & D. Bertrand & 386 & 152 & 3,586 & 131 & 32 & 122 & 150 \\
\hline VU University Amsterdam & 3,127 & 236 & R. Griessen & 275 & 235 & 2,446 & 201 & 30 & 143 & 150 \\
\hline Wageningen University & 414 & 335 & F.A.M. Leermakers & 192 & 286 & 1,596 & 262 & 18 & 276 & 150 \\
\hline Wake Forest University & 493 & 332 & R.T. Williams & 106 & 327 & 1,097 & 291 & 13 & 316 & 150 \\
\hline Waseda University & 5,243 & 169 & A. Beretvas & 272 & 238 & 2,892 & 169 & 40 & 49 & 150 \\
\hline Washington State University & 2,032 & 279 & L.S. Wang & 283 & 232 & 3,724 & 123 & 49 & 14 & 150 \\
\hline Washington University in St. Louis & 5,392 & 165 & D.G. Sarantites & 327 & 194 & 1,869 & 242 & 23 & 232 & 150 \\
\hline Wayne State University & 4,183 & 204 & C.L. Plager & 279 & 234 & 1,688 & 254 & 24 & 221 & 150 \\
\hline West Virginia University & 1,751 & 285 & M.S. Seehra & 225 & 270 & 1,573 & 264 & 20 & 256 & 150 \\
\hline Yale University & 11,040 & 52 & A. Hocker & 355 & 172 & 2,847 & 172 & 28 & 163 & 150 \\
\hline Yonsei University & 5,418 & 163 & J.H. Kang & 314 & 204 & 2,924 & 165 & 36 & 80 & 150 \\
\hline York University & 2,082 & 278 & D.K. Bohme & 263 & 248 & 1,920 & 239 & 21 & 249 & 150 \\
\hline Zhejiang University & 12,106 & 42 & D. Yang & 441 & 112 & 2,181 & 227 & 26 & 191 & 150 \\
\hline
\end{tabular}




\begin{tabular}{|c|c|c|c|c|c|c|c|c|c|c|}
\hline Biochemistry, Genetics and Molecular Biology & $\begin{array}{l}\text { Department } \\
\text { Publications }\end{array}$ & Rank & Most Prolific Author & Published & Rank & Cited & Rank & $\begin{array}{c}\text { H- } \\
\text { Index }\end{array}$ & Rank & $\begin{array}{c}\text { \# of } \\
\text { Coauthors }\end{array}$ \\
\hline Aalto University & 1,091 & 304 & M. Leisole & 121 & 319 & 1,183 & 296 & 18 & 294 & 144 \\
\hline Aarhus University & 9,721 & 89 & T.F. Orntoft & 232 & 227 & 5,538 & 116 & 44 & 79 & 150 \\
\hline Arizonia State University & 1,241 & 298 & D. Gust & 233 & 225 & 5,180 & 132 & 38 & 125 & 150 \\
\hline Ateneo de Manila University & 14 & 346 & F.M. Dayrit & 17 & 343 & 193 & 341 & 5 & 341 & 30 \\
\hline Auburn University & 2,099 & 264 & C.R. Clark & 108 & 326 & 471 & 329 & 11 & 325 & 75 \\
\hline Australian National University & 7,333 & 137 & P.G. Board & 265 & 190 & 3,299 & 195 & 30 & 197 & 150 \\
\hline Boston College & 1,098 & 303 & E.R. Kantrowitz & 152 & 296 & 853 & 314 & 16 & 307 & 150 \\
\hline Boston University & 11,672 & 62 & L.A. Cupples & 372 & 106 & 13,386 & 34 & 57 & 31 & 150 \\
\hline Brandeis University & 3,601 & 218 & G.A. Petsko & 333 & 133 & 8,811 & 68 & 31 & 185 & 150 \\
\hline Brigham Young University & 663 & 322 & M.L. Lee & 377 & 104 & 5,085 & 136 & 32 & 179 & 150 \\
\hline Brown University & 5,187 & 184 & D.E. Cane & 251 & 198 & 2,498 & 230 & 36 & 145 & 150 \\
\hline California Institute of Technology (Calt... & 6,770 & 145 & E.H. Davidson & 314 & 150 & 5,324 & 125 & 47 & 68 & 150 \\
\hline Cardiff University & 7,986 & 121 & W.G. Jiang & 319 & 144 & 3,447 & 188 & 34 & 164 & 150 \\
\hline Carnegie Mellon University & 2,707 & 246 & C. Нo & 260 & 195 & 231 & 340 & 26 & 236 & 150 \\
\hline Case Western Reserve University & 12,239 & 58 & M.A. Smith & 1,133 & 7 & 23,902 & 15 & 75 & 9 & 150 \\
\hline Chalmers University of Technology & 1,530 & 287 & B. Norden & 319 & 144 & 5,480 & 120 & 36 & 145 & 150 \\
\hline Charles University & 6,518 & 150 & M. Stiborva & 164 & 290 & 982 & 310 & 23 & 251 & 150 \\
\hline Chinese University of Hong Kong & 4,199 & 209 & T.B. $\mathrm{Ng}$ & 409 & 85 & 2,912 & 212 & 38 & 125 & 150 \\
\hline Chulalongkorn University & 1,550 & 286 & V. Wiwanitkit & 645 & 34 & 733 & 320 & 9 & 332 & 120 \\
\hline City University of Hong Kong & 840 & 316 & M. Yang & 167 & 285 & 2,083 & 249 & 23 & 251 & 150 \\
\hline City University of New York & 4,627 & 198 & R. Bittman & 249 & 203 & 3,526 & 181 & 27 & 229 & 150 \\
\hline Colorado State University & 5,025 & 188 & A.T. $\mathrm{Tu}$ & 201 & 257 & 832 & 315 & 9 & 332 & 150 \\
\hline Columbia University & 7,568 & 132 & I.B. Weinsten & 485 & 67 & 8,608 & 73 & 46 & 73 & 46 \\
\hline Cornell University & 23,447 & 14 & H.A. Scheraga & \begin{tabular}{l|l}
1,035 \\
\end{tabular} & 9 & 20,644 & 21 & 44 & 79 & 150 \\
\hline Curtin University of Technology & 589 & 325 & E. Chang & 315 & 149 & 295 & 338 & 8 & 338 & 132 \\
\hline Dalhousie University & 4,595 & 199 & M.W. Gray & 189 & 264 & 3,731 & 169 & 29 & 208 & 150 \\
\hline Dartmouth College & 5,879 & 169 & B.L. Trumpower & 144 & 305 & 2,659 & 222 & 20 & 278 & 150 \\
\hline Delft University of Technology & 2,329 & 257 & J.J. Heijnen & 307 & 158 & 4,837 & 147 & 45 & 77 & 150 \\
\hline Drexel University & 4,372 & 203 & M.C. Phillips & 184 & 268 & 4,527 & 151 & 42 & 89 & 150 \\
\hline Duke University & 20,440 & 19 & R.J. Lefkowitz & 752 & 21 & 43,621 & 3 & 93 & 3 & 150 \\
\hline Durham University & 2,257 & 260 & J.A.K. Howard & 792 & 16 & 10,618 & 54 & 46 & 73 & 150 \\
\hline Ecole Normale Supérieure de Lyon & 984 & 310 & V. Laudet & 181 & 273 & 4,926 & 145 & 40 & 107 & 150 \\
\hline École Normale Supérieure, Paris & 2,129 & 262 & P. Sinay & 242 & 213 & 2,581 & 226 & 27 & 229 & 150 \\
\hline École Polytechnique & 1,128 & 301 & S.Z. Zard & 236 & 222 & 2,176 & 244 & 28 & 220 & 150 \\
\hline
\end{tabular}




\begin{tabular}{|c|c|c|c|c|c|c|c|c|c|c|}
\hline Ecole Polytechnique Fédérale de Lausanne & 2,100 & 263 & U. Van Stockar & 150 & 298 & 1,182 & 297 & 20 & 278 & 150 \\
\hline Eindhoven University of Technology & 1,424 & 293 & E.W. Meijen & 493 & 60 & 11,926 & 45 & 67 & 15 & 150 \\
\hline Emory University & 1,151 & 300 & A. Padwa & 612 & 43 & 9,843 & 59 & 35 & 155 & 15 \\
\hline Erasmus University Rotterdam & 10,888 & 73 & S.W.J. Lamberts & 672 & 27 & 19,529 & 22 & 50 & 54 & 150 \\
\hline ETH Zurich (Swiss Federal Institute of Technolo & 9,885 & 86 & K. Wuthrich & 591 & 45 & 39,101 & 5 & 57 & 31 & 150 \\
\hline Florida International University & 887 & 312 & R.J. Herrera & 103 & 327 & 1,410 & 287 & 20 & 278 & 150 \\
\hline Florida State University & 3,394 & 224 & A.G. Marshall & 553 & 51 & 11,525 & 49 & 47 & 68 & 150 \\
\hline Freie Universität Berlin & 8,220 & 116 & W. Saenger & 403 & 88 & 7,926 & 84 & 35 & 155 & 150 \\
\hline Friedrich Alexander Universität Erlangen Nürnb & 6,705 & 146 & W. Hillen & 238 & 219 & 4,830 & 148 & 32 & 179 & 150 \\
\hline Fudan University & 5,771 & 173 & Y. Xie & 270 & 186 & 997 & 309 & 16 & 307 & 150 \\
\hline Georg August Universität Göttingen & 9,566 & 91 & G.H. Braus & 138 & 310 & 1,635 & 274 & 23 & 251 & 150 \\
\hline George Mason University & 169 & 340 & L.A. Liotta & 288 & 170 & 14,970 & 32 & 65 & 17 & 150 \\
\hline George Washington University & 3,138 & 235 & W.B. Weglicki & 219 & 235 & 1,695 & 270 & 14 & 317 & 150 \\
\hline Georgetown University & 6,466 & 155 & R.B. Dickson & 301 & 161 & 7,393 & 95 & 47 & 68 & 150 \\
\hline Georgia Institute of Technology & 3,039 & 237 & A.S. Teja & 211 & 245 & 1,662 & 271 & 15 & 314 & 142 \\
\hline Georgia State University & 1,591 & 285 & W.D. Wilson & 197 & 261 & 2,835 & 218 & 29 & 208 & 150 \\
\hline Goteborg University & 10,109 & 83 & B. Norden & 320 & 143 & 5,308 & 127 & 36 & 145 & 150 \\
\hline Harvard University & 9,881 & 87 & E.J. Corey & 935 & 12 & 31,203 & 8 & 48 & 64 & 150 \\
\hline Hebrew University of Jerusalem & 11,667 & 63 & A. Levitzki & 302 & 160 & 7,958 & 82 & 37 & 138 & 150 \\
\hline Heidelberg Universität & 12,556 & 54 & K.Beyreuther & 426 & 78 & 11,343 & 51 & 54 & 39 & 150 \\
\hline Hokkaido University & 15,181 & 34 & A. Matsuda & 652 & 32 & 8,380 & 78 & 34 & 164 & 150 \\
\hline Hong Kong Polytechnic University & 1,364 & 295 & A.S.C. Chan & 252 & 197 & 4,268 & 157 & 39 & 115 & 150 \\
\hline Hong Kong University of Science \& Techno... & 1,691 & 280 & Y.H. Wong & 160 & 291 & 1,902 & 260 & 22 & 259 & 150 \\
\hline Humboldt-Universität zu Berlin & 2,015 & 268 & B. Dorken & 331 & 135 & 7,575 & 91 & 48 & 64 & 150 \\
\hline Imperial College London & 15,113 & 35 & A. Dell & 332 & 134 & 5,483 & 118 & 40 & 107 & 150 \\
\hline Indian Institute of Technology Bombay (I... & 1,069 & 305 & P. Mathur & 141 & 308 & 428 & 332 & 14 & 317 & 138 \\
\hline Indian Institute of Technology Delhi (II... & 1,040 & 306 & M.N. Gupta & 174 & 278 & 1,338 & 290 & 22 & 259 & 101 \\
\hline Indian Institute of Technology Kanpur (I... & 993 & 309 & V. K. Singh & 378 & 101 & 3,706 & 171 & 28 & 220 & 150 \\
\hline Indiana University Bloomington & 6,828 & 143 & J.C. Huffman & 780 & 18 & 12,354 & 42 & 33 & 172 & 150 \\
\hline Indiana University Indianapolis & 7,672 & 129 & G. Weber & 270 & 186 & 1,988 & 252 & 14 & 317 & 150 \\
\hline Iowa State University & 6,461 & 156 & J.A. Olson & 206 & 250 & 1,988 & 252 & 16 & 307 & 150 \\
\hline Johns Hopkins University & 31,570 & 4 & D. Sidransky & 395 & 92 & 21,296 & 20 & 77 & 6 & 150 \\
\hline Kansas State University & 3,540 & 220 & K.J. Kramer & 201 & 257 & 1,923 & 258 & 22 & 259 & 150 \\
\hline Katholieke Universiteit Leuven & 9,324 & 98 & E. DeClercq & 1,641 & 2 & 335 & 337 & 72 & 11 & 150 \\
\hline Keio University & 6,668 & 147 & N. Shimizu & 815 & 15 & 28,088 & 11 & 57 & 31 & 150 \\
\hline King Fahd University of Petroleum \& Minerals & 249 & 335 & A.A. Isab & 138 & 310 & 497 & 326 & 14 & 317 & 98 \\
\hline
\end{tabular}




\begin{tabular}{|c|c|c|c|c|c|c|c|c|c|c|}
\hline King Saud University & 1,442 & 291 & J.S. Mossa & 113 & 324 & 721 & 321 & 10 & 330 & 147 \\
\hline Kobe University & 7,232 & 139 & K. Chihara & 441 & 74 & 4,487 & 153 & 31 & 185 & 150 \\
\hline Korea Advanced Institute of Science \& Technol & 2,771 & 244 & S.Y. Lee & 186 & 266 & 2,357 & 239 & 30 & 197 & 150 \\
\hline Korea University & 3,882 & 213 & C.W. Kim & 102 & 328 & 802 & 317 & 15 & 314 & 150 \\
\hline Kyoto University & 34,660 & 2 & S. Shimizu & 349 & 119 & 2,846 & 216 & 32 & 179 & 150 \\
\hline Kyushu University & 16,428 & 28 & K. Sugimachi & 1,693 & 1 & 30,331 & 9 & 64 & 18 & 150 \\
\hline La Trobe University & 2,548 & 249 & D.G. Stephenson & 136 & 312 & 1,561 & 279 & 21 & 271 & 87 \\
\hline Lancaster University & 311 & 329 & R.D. Bardgett & 121 & 319 & 3,032 & 206 & 39 & 115 & 150 \\
\hline Leiden University & 13,522 & 42 & J. Reedijk & 1,013 & 11 & 17,105 & 26 & 41 & 97 & 57 \\
\hline Linkoping University & 3,439 & 222 & K.E. Magnusson & 237 & 221 & 2,894 & 213 & 18 & 294 & 150 \\
\hline London School of Economics and Political Science & 176 & 338 & P.F. Urbach & 23 & 342 & 139 & 342 & 4 & 343 & 15 \\
\hline Loughborough University & 1,162 & 299 & M.R. J. Elsegood & 322 & 140 & 2,938 & 210 & 28 & 220 & 150 \\
\hline Louisiana State University & 10,447 & 78 & N.G. Bazan & 398 & 90 & 4,960 & 141 & 40 & 107 & 150 \\
\hline Ludwig-Maximilians-Universität München & 14,821 & 39 & W. Neupert & 355 & 115 & 5,422 & 122 & 55 & 37 & 150 \\
\hline Lund University & 16,663 & 27 & B. Mattiasson & 593 & 44 & 8,060 & 81 & 31 & 185 & 150 \\
\hline Maastricht University & 4,989 & 190 & J.F.C. Glatz & 270 & 186 & 3,459 & 187 & 40 & 107 & 150 \\
\hline Macquarie University & 1,666 & 281 & R.S. Vagg & 87 & 334 & 385 & 336 & 5 & 341 & 53 \\
\hline Mahidol University & 2,789 & 243 & S. Fucharoen & 286 & 172 & 1,888 & 263 & 21 & 271 & 150 \\
\hline Masaryk University & 1,649 & 282 & J. Marek & 144 & 305 & 860 & 313 & 18 & 294 & 150 \\
\hline Massachusetts Institute of Technology & 14,332 & 40 & R. Langer & 920 & 13 & 48,832 & 1 & 93 & 3 & 150 \\
\hline McGill University & 17,985 & 24 & N. Soneberg & 390 & 93 & 12,554 & 41 & 77 & 6 & 150 \\
\hline McMaster University & 7,569 & 131 & R.M. Epand & 416 & 82 & 5,120 & 133 & 35 & 155 & 150 \\
\hline Michigan State University & 10,013 & 84 & J.M. Tiedje & 369 & 108 & 12,332 & 43 & 54 & 39 & 150 \\
\hline Michigan Technological University & 619 & 323 & R.L. Luck & 93 & 330 & 502 & 325 & 12 & 323 & 112 \\
\hline Monash University & 8,449 & 111 & D.M. DeKrester & 458 & 72 & 5,421 & 123 & 37 & 138 & 150 \\
\hline Montana State University & 1,712 & 278 & M.T. Quinn & 141 & 308 & 5,692 & 112 & 37 & 138 & 150 \\
\hline Moscow State University & 12,433 & 57 & A.B. Rubin & 335 & 128 & 549 & 324 & 11 & 325 & 150 \\
\hline Nagoya University & 14,922 & 37 & T. Mizuno & 469 & 70 & 2,284 & 243 & 28 & 220 & 150 \\
\hline Nanjing University & 2,431 & 255 & H.Y. Chen & 432 & 75 & 5,237 & 128 & 42 & 89 & 150 \\
\hline Nanyang Technological University & 1,816 & 275 & J.H. Tay & 246 & 207 & 2,050 & 250 & 31 & 185 & 150 \\
\hline National Taiwan University & 6,057 & 165 & S.M. Peng & 629 & 38 & 9,555 & 62 & 41 & 97 & 150 \\
\hline National Tsing Hua University & 2,306 & 258 & T.H. Lu & 150 & 298 & 1,086 & 302 & 22 & 259 & 150 \\
\hline National University of Ireland, Galway & 1,482 & 289 & B.E. Leonard & 381 & 100 & 3,487 & 186 & 33 & 172 & 150 \\
\hline National University of Singapore & 7,718 & 126 & S.F.Y. Li & 208 & 248 & 3,550 & 177 & 28 & 220 & 150 \\
\hline New Mexico State University & 1,113 & 302 & J. Y. Wang & 613 & 42 & 8,542 & 76 & 76 & 8 & 150 \\
\hline New York University & 13,093 & 47 & N.E. Geacintor & 330 & 136 & 2,503 & 228 & 33 & 172 & 150 \\
\hline
\end{tabular}




\begin{tabular}{|c|c|c|c|c|c|c|c|c|c|c|}
\hline Newcastle University & 7,331 & 138 & W. Clegg & 615 & 41 & 7,787 & 86 & 37 & 138 & 150 \\
\hline North Carolina State University & 6,217 & 161 & T.R. Klaenhammer & 194 & 263 & 3,933 & 164 & 28 & 220 & 150 \\
\hline Northeastern University & 1,843 & 274 & B.L. Karger & 247 & 204 & 5,378 & 124 & 36 & 145 & 150 \\
\hline Northwestern University & 13,111 & 46 & V.C. Jordan & 505 & 58 & 16,046 & 28 & 42 & 89 & 150 \\
\hline Norwegian University of Science \& Technology & 2,710 & 245 & H.E. Krokan & 142 & 307 & 3,288 & 198 & 33 & 172 & 150 \\
\hline Ohio State University & 15,432 & 33 & L.A. Paquette & 1,166 & 6 & 9,902 & 58 & 31 & 185 & 150 \\
\hline Oklahoma State University & 2,501 & 252 & C.A. $\mathrm{Yu}$ & 171 & 282 & 1,573 & 276 & 23 & 251 & 150 \\
\hline Open University UK & 852 & 314 & S.P.R. Rose & 292 & 167 & 132 & 343 & 4 & 343 & 12 \\
\hline Oregon State University & 5,264 & 183 & P.D. Whanger & 206 & 250 & 1,824 & 266 & 19 & 287 & 150 \\
\hline Osaka University & 25,702 & 10 & N. Taniguchi & 554 & 50 & 12,937 & 40 & 47 & 68 & 150 \\
\hline Peking University & 6,494 & 151 & C.S. Tang & 299 & 164 & 1,258 & 293 & 19 & 287 & 150 \\
\hline Pennsylvania State University & 13,164 & 45 & S.J. Benkovic & 492 & 61 & 1,588 & 275 & 40 & 107 & 150 \\
\hline Pohang University of Science And Technology & 1,770 & 277 & P.G. Suh & 222 & 234 & 3,205 & 201 & 34 & 164 & 150 \\
\hline Portland State University & 598 & 324 & L.I. Crawshaw & 43 & 341 & 283 & 339 & 8 & 338 & 83 \\
\hline Princeton University & 5,099 & 186 & A.J. Levine & 350 & 118 & 27,728 & 12 & 62 & 20 & 150 \\
\hline Purdue University & 11,112 & 68 & D.J. Morre & 460 & 71 & 2,450 & 234 & 24 & 246 & 150 \\
\hline Queen's University & 5,504 & 179 & R.Ross & 153 & 295 & 3,992 & 161 & 14 & 317 & 150 \\
\hline Queen's University of Belfast & 3,803 & 214 & P.G. Johnston & 182 & 271 & 3,724 & 170 & 34 & 164 & 150 \\
\hline Queensland University of Technology & 1,309 & 296 & G. Smith & 203 & 255 & 982 & 310 & 17 & 302 & 118 \\
\hline Radboud University, Nijmegen & 11,028 & 70 & J.H. Veerkamp & 319 & 144 & 3,914 & 165 & 31 & 185 & 150 \\
\hline Rensselaer Polytechnic Institute & 1,497 & 288 & R.J. Linhardt & 449 & 73 & 6,664 & 102 & 42 & 89 & 150 \\
\hline Rheinisch Westfalische Technische Hochschule & 3,582 & 219 & P.C. Heinrich & 310 & 155 & 7,101 & 96 & 38 & 125 & 150 \\
\hline Rheinische Friedrich Wilhelms Universitat Bonn & 8,419 & 112 & K. Sandhoff & 341 & 123 & 5,114 & 134 & 41 & 97 & 150 \\
\hline Rice University & 2,869 & 242 & G.J. Schroepter & 212 & 242 & 1,076 & 305 & 14 & 317 & 150 \\
\hline Rochester Institute of Technology & 128 & 342 & R.D. Frisina & 67 & 338 & 919 & 312 & 18 & 294 & 96 \\
\hline Royal Institute of Technology, KTH & 1,980 & 270 & M. Uhlem & 334 & 130 & 7,414 & 93 & 43 & 84 & 150 \\
\hline Royal Melbourne Institute of Technology & 855 & 313 & J. A. Hawley & 174 & 278 & 2,644 & 224 & 34 & 164 & 150 \\
\hline Rutgers & 9,369 & 96 & C.S. Yang & 387 & 94 & 10,707 & 53 & 59 & 25 & 150 \\
\hline Saint-Petersburg State University & 2,067 & 266 & S.G. Inge-Vechtomon & 122 & 318 & 823 & 316 & 9 & 332 & 150 \\
\hline San Diego State University & 1,449 & 290 & C.C. Glembotski & 97 & 329 & 3,524 & 182 & 29 & 208 & 150 \\
\hline Sapienza University of Rome & 0 & 347 & & 0 & 347 & 0 & 347 & 0 & 346 & 0 \\
\hline Sciences Po Paris & 0 & 347 & & 0 & 347 & 0 & 347 & 0 & 346 & 0 \\
\hline Seoul National University & 8,132 & 118 & Y.J. Surh & 199 & 259 & 4,196 & 160 & 39 & 115 & 150 \\
\hline Shanghai Jiao Tong University & 3,751 & 215 & L. He & 650 & 33 & 8,548 & 74 & 39 & 115 & 150 \\
\hline Simon Fraser University & 2,472 & 253 & R. Gries & 119 & 322 & 679 & 322 & 16 & 307 & 150 \\
\hline Stanford University & 25,017 & 12 & I.L. Weissman & 590 & 46 & 40,038 & 4 & 31 & 185 & 150 \\
\hline
\end{tabular}




\begin{tabular}{|c|c|c|c|c|c|c|c|c|c|c|}
\hline State University of New York Buffalo & 33 & 345 & W.S. Durfee & 15 & 344 & 122 & 344 & 7 & 340 & 34 \\
\hline Stockholm University & 5,010 & 189 & G. Widmalm & 212 & 242 & 1,382 & 288 & 21 & 271 & 150 \\
\hline Stony Brook University & 7,960 & 122 & G.D. Prestwich & 489 & 64 & 8,679 & 71 & 51 & 51 & 150 \\
\hline Syracuse University & 4,910 & 191 & M.M Meguid & 354 & 117 & 3,184 & 203 & 30 & 197 & 150 \\
\hline Tartu University (University of Tartu) & 1,407 & 294 & J. Jarv & 92 & 332 & 387 & 335 & 9 & 332 & 123 \\
\hline Technical University of Denmark & 3,278 & 230 & J. Nielsen & 428 & 77 & 5,208 & 130 & 41 & 97 & 150 \\
\hline Technion & 4,764 & 193 & A. Ciechamover & 178 & 274 & 11,394 & 50 & 41 & 97 & 150 \\
\hline Technische Universität Berlin & 3,731 & 216 & F. Bohlmann & 780 & 18 & 4,938 & 144 & 0 & 346 & 150 \\
\hline Technische Universitat Chemnitz & 307 & 331 & H. Lang & 295 & 165 & 1,858 & 265 & 24 & 246 & 150 \\
\hline Technische Universität Dresden & 3,047 & 236 & R.B. Salzer & 123 & 317 & 785 & 318 & 19 & 287 & 150 \\
\hline Technische Universität München & 9,358 & 97 & A. Bacher & 382 & 98 & 3,509 & 184 & 38 & 125 & 150 \\
\hline Tel Aviv University & 9,787 & 88 & R. Nussinov & 349 & 119 & 5,211 & 129 & 46 & 73 & 150 \\
\hline Texas A\&M University & 10,270 & 81 & J.E. Womack & 364 & 111 & 3,609 & 174 & 27 & 229 & 150 \\
\hline Texas Tech & 3,476 & 221 & R.A. Bartsch & 345 & 121 & 2,817 & 219 & 25 & 240 & 150 \\
\hline Tohoku University & 15,485 & 31 & H. Sasano & 617 & 40 & 12,136 & 44 & 48 & 64 & 150 \\
\hline Tokyo Institute of Technology & 6,815 & 144 & M. Yoshida & 283 & 175 & 3,544 & 178 & 38 & 125 & 150 \\
\hline Trinity College Dublin & 306 & 332 & K.F. Tipton & 341 & 123 & 3,063 & 205 & 22 & 259 & 150 \\
\hline Tsinghua University & 3,993 & 212 & H.M. Zhou & 235 & 223 & 1,062 & 307 & 20 & 278 & 150 \\
\hline Tufts University & 6,896 & 141 & J. M. Ordovas & 492 & 61 & 10,540 & 55 & 50 & 54 & 150 \\
\hline Universidad Autonoma de Madrid & 6,483 & 153 & M. Salas & 251 & 198 & 1,412 & 285 & 22 & 259 & 150 \\
\hline Universidad de Chile & 4,356 & 204 & M.T. Garland & 210 & 247 & 1,136 & 299 & 17 & 302 & 150 \\
\hline Universidad de Granada & 6,483 & 153 & M. Salas & 251 & 198 & 1,412 & 285 & 22 & 259 & 150 \\
\hline Universidad del País Vasco & 2,508 & 251 & F.M. Goni & 235 & 223 & 3,400 & 190 & 35 & 155 & 150 \\
\hline Universidad Nacional Autónoma de México ... & 6,341 & 158 & R.A. Toscano & 288 & 170 & 1,489 & 280 & 16 & 307 & 150 \\
\hline Universidad Politecnica de Madrid & 1,019 & 307 & F. Garica-Olmedo & 83 & 335 & 1,332 & 291 & 16 & 307 & 99 \\
\hline Universidade de São Paulo & 12,900 & 49 & R. Curi & 378 & 101 & 2,812 & 220 & 29 & 208 & 150 \\
\hline Universidade Estadual de Campinas & 4,260 & 207 & S. Marangoni & 189 & 264 & 1,012 & 308 & 21 & 271 & 150 \\
\hline Università degli Studi di Firenze & 7,712 & 127 & C.T. Supuran & 644 & 36 & 15,592 & 29 & 59 & 25 & 150 \\
\hline Università degli Studi di Padova & 11,251 & 67 & C. Toniolo & 557 & 49 & 8,730 & 70 & 32 & 179 & 150 \\
\hline Universita Di Bologna & 8,364 & 113 & C. Franceschi & 510 & 57 & 15,123 & 31 & 53 & 43 & 150 \\
\hline Universita di Pisa & 6,489 & 152 & A. Lucacchini & 310 & 155 & 1,353 & 289 & 19 & 287 & 150 \\
\hline Universitat Autonoma de Barcelona & 5,529 & 178 & J. Egozcue & 321 & 142 & 2,616 & 225 & 30 & 197 & 150 \\
\hline Universitat Bielefeld & 2,294 & 259 & A. Puhler & 309 & 157 & 7,674 & 89 & 40 & 107 & 150 \\
\hline Universität Bremen & 1,632 & 283 & J. Bullerdiek & 241 & 216 & 1,650 & 272 & 26 & 236 & 150 \\
\hline Universitat d'Alacant & 971 & 311 & M.Yus & 432 & 75 & 5,013 & 139 & 44 & 79 & 150 \\
\hline Universitat de València & 4,541 & 201 & A. Moya & 184 & 268 & 3,615 & 173 & 31 & 185 & 150 \\
\hline
\end{tabular}




\begin{tabular}{|c|c|c|c|c|c|c|c|c|c|c|}
\hline Universität Frankfurt am Main & 8,987 & 104 & H. Ruterjans & 165 & 288 & 1,572 & 277 & 21 & 271 & 150 \\
\hline Universität Freiburg & 8,987 & 104 & N. Pfanner & 233 & 225 & 3,747 & 168 & 53 & 43 & 150 \\
\hline Universitat Hamburg & 6,065 & 164 & H. Steinhart & 271 & 185 & 2,353 & 240 & 26 & 236 & 150 \\
\hline Universität Karlsruhe & 1,966 & 271 & M.Zoller & 226 & 231 & 3,016 & 208 & 25 & 240 & 150 \\
\hline Universitat Leipzig & 6,373 & 157 & A.G. Beck-Sickinger & 216 & 238 & 3,266 & 199 & 31 & 185 & 150 \\
\hline Universitat Munster (Westfälische Wilhelms-Un & 8,261 & 114 & A. Steinbuchel & 301 & 161 & 2,998 & 209 & 39 & 115 & 150 \\
\hline Universitat Politecnica de Catalunya & 201 & 337 & C. Aleman & 268 & 189 & 1,431 & 284 & 22 & 259 & 150 \\
\hline Universität Regensburg & 6,051 & 166 & R. Jaenicke & 285 & 174 & 5,906 & 110 & 32 & 179 & 150 \\
\hline Universität Stuttgart & 2,185 & 261 & R.D. Schmid & 165 & 288 & 2,698 & 221 & 34 & 164 & 150 \\
\hline Universitat Trier & 258 & 334 & D.H. Hellhammer & 160 & 291 & 4,945 & 143 & 42 & 89 & 150 \\
\hline Universität Tübingen & 9,488 & 94 & F. Lang & 643 & 37 & 17,517 & 25 & 60 & 24 & 150 \\
\hline Universitat Wien (University of Vienna) & 9,312 & 99 & E. Kenndler & 211 & 245 & 2,511 & 227 & 31 & 185 & 150 \\
\hline Universitat $\mathrm{Zu}$ Koln & 7,484 & 134 & V. Diehl & 735 & 22 & 13,333 & 35 & 53 & 43 & 150 \\
\hline Université Catholique de Louvain & 5,627 & 175 & A. Goffeau & 232 & 227 & 8,644 & 72 & 38 & 125 & 150 \\
\hline Universite de Liege & 4,886 & 192 & J. Balthazart & 319 & 144 & 2,412 & 236 & 38 & 125 & 150 \\
\hline Université de Montréal & 8,994 & 103 & M. Bouvier & 215 & 239 & 5,481 & 119 & 49 & 62 & 150 \\
\hline Université de Nice Sophia Antipolis & 2,579 & 248 & G. Alihaud & 219 & 235 & 4,700 & 150 & 30 & 197 & 150 \\
\hline Universite Laval & 7,432 & 135 & C. Bouchard & 701 & 25 & 29,931 & 10 & 63 & 19 & 150 \\
\hline Universite Libre de Bruxelles & 6,211 & 162 & P. Robberecht & 318 & 148 & 2,862 & 215 & 28 & 220 & 150 \\
\hline Université Paris Sorbonne & 332 & 328 & C. Rolland & 79 & 336 & 415 & 334 & 10 & 330 & 80 \\
\hline Universite Paris-Sud 11 & 8,600 & 110 & G. Kroemer & 378 & 101 & 22,582 & 17 & 105 & 2 & 150 \\
\hline Université Pierre et Marie Curie & 8,686 & 109 & J.C. Tabet & 240 & 218 & 1,889 & 262 & 21 & 271 & 150 \\
\hline Universiti Malaya (University of Malaya) & 2,074 & 265 & S.W. Ng & 1,108 & 8 & 3,409 & 189 & 16 & 307 & 150 \\
\hline University College Cork & 2,020 & 267 & D. Van Sinderen & 121 & 319 & 1,730 & 269 & 29 & 208 & 150 \\
\hline University College Dublin & 3,387 & 225 & A.R. Manning & 176 & 276 & 439 & 330 & 11 & 325 & 150 \\
\hline University College London & 19,227 & 21 & G. Burnstock & 1,019 & 10 & 32,401 & 7 & 62 & 20 & 150 \\
\hline University do Porto & 781 & 320 & I. Azevedo & 156 & 293 & 622 & 323 & 12 & 323 & 150 \\
\hline University of Aberdeen & 5,471 & 180 & C.J. Secombes & 261 & 194 & 2,469 & 233 & 36 & 145 & 150 \\
\hline University of Adelaide & 6,073 & 163 & M.I. Bruce & 407 & 86 & 2,501 & 229 & 26 & 236 & 150 \\
\hline University of Alabama & 13,283 & 43 & C.T. Curiel & 547 & 53 & 6,871 & 98 & 70 & 13 & 150 \\
\hline University of Alberta & 13,200 & 44 & B.D. Sykes & 402 & 89 & 9,534 & 63 & 39 & 115 & 150 \\
\hline University of Amsterdam & 11,601 & 65 & R.J.A. Wanders & 765 & 20 & 14,694 & 33 & 53 & 43 & 150 \\
\hline University of Antwerp & 4,180 & 210 & L. Moens & 396 & 91 & 4,373 & 155 & 40 & 107 & 150 \\
\hline University of Arizona & 12,170 & 59 & V.J. Hruby & 788 & 17 & 16,959 & 27 & 42 & 89 & 150 \\
\hline University of Athens & 5,896 & 168 & E. Patsouris & 247 & 204 & 1,256 & 294 & 20 & 278 & 150 \\
\hline University of Auckland & 5,135 & 185 & B.C. Baguley & 363 & 112 & 3,317 & 193 & 30 & 197 & 150 \\
\hline
\end{tabular}




\begin{tabular}{|c|c|c|c|c|c|c|c|c|c|c|}
\hline University of Barcelona & 8,023 & 119 & X. Solans & 495 & 59 & 4,210 & 159 & 30 & 197 & 150 \\
\hline University of Basel & 8,257 & 115 & U. Aebi & 275 & 182 & 6,504 & 104 & 52 & 49 & 150 \\
\hline University of Bath & 3,009 & 239 & B.V.L. Potter & 355 & 115 & 3,191 & 202 & 36 & 145 & 150 \\
\hline University of Bergen & 4,711 & 194 & R.K. Berge & 246 & 207 & 2,485 & 231 & 27 & 229 & 150 \\
\hline University of Bern & 7,425 & 136 & A. Azzi & 272 & 184 & 3,571 & 175 & 31 & 185 & 150 \\
\hline University of Birmingham & 10,407 & 79 & P.M. Stewart & 344 & 122 & 6,694 & 101 & 51 & 51 & 150 \\
\hline University of Bristol & 9,519 & 93 & F.G.A. Stone & 662 & 29 & 2,049 & 251 & 17 & 302 & 150 \\
\hline University of British Columbia & 15,438 & 32 & S.G. Withers & 365 & 110 & 4,451 & 154 & 44 & 79 & 150 \\
\hline University of Calgary & 3,302 & 228 & H.J. Vogel & 243 & 212 & 3,518 & 183 & 30 & 197 & 150 \\
\hline University of California, Berkley & 19,747 & 20 & L. Packer & 553 & 51 & 9,432 & 64 & 52 & 49 & 150 \\
\hline University of California, Davis & 18,734 & 22 & B.D. Hammock & 623 & 39 & 11,246 & 52 & 41 & 97 & 150 \\
\hline University of California, Irvine & 11,027 & 71 & J.K. Lanyi & 262 & 193 & 2,867 & 214 & 40 & 107 & 150 \\
\hline University of California, Los Angeles & 27,957 & 7 & H.P. Koeffler & 656 & 31 & 22,457 & 18 & 58 & 29 & 150 \\
\hline University of California, Riverside & 5,560 & 177 & A.W. Norman & 313 & 151 & 3,026 & 207 & 9 & 332 & 150 \\
\hline University of California, San Diego & 24,188 & 13 & M. Karin & 407 & 86 & 45,776 & 2 & 110 & 1 & 150 \\
\hline University of California, San Francisco & 28,200 & 6 & S.B. Prusiner & 213 & 241 & 7,579 & 90 & 71 & 12 & 150 \\
\hline University of California, Santa Barbara & 1,438 & 292 & T.C. Bruice & 547 & 53 & 7,848 & 85 & 30 & 197 & 150 \\
\hline University of California, Santa Cruz & 2,388 & 256 & A.L. Fink & 207 & 249 & 6,307 & 106 & 51 & 51 & 150 \\
\hline University of Cambridge & 21,305 & 17 & S. O'Rahilly & 336 & 127 & 11,652 & 46 & 61 & 22 & 150 \\
\hline University of Canterbury & 348 & 326 & J.A. Gerrard & 75 & 337 & 493 & 327 & 18 & 294 & 114 \\
\hline University of Cape Town & 3,180 & 232 & G. Gade & 176 & 276 & 1,085 & 303 & 21 & 271 & 150 \\
\hline University of Central Florida & 847 & 315 & H.W. Daniell & 135 & 313 & 2,923 & 211 & 36 & 145 & 150 \\
\hline University of Chicago & 17,758 & 25 & D.F Steiner & 329 & 137 & 5,015 & 138 & 33 & 172 & 150 \\
\hline University of Cincinnati & 9,631 & 90 & E.G. Kranias & 251 & 198 & 3,964 & 163 & 41 & 97 & 150 \\
\hline University of Colorado at Boulder & 5,948 & 167 & T.R. Cech & 312 & 152 & 8,896 & 66 & 49 & 62 & 150 \\
\hline University of Connecticut & 8,921 & 106 & P. Setlow & 322 & 140 & 2,482 & 232 & 34 & 164 & 150 \\
\hline University of Copenhagen & 15,818 & 30 & P.E. Nielsen & 312 & 152 & 736 & 319 & 43 & 84 & 150 \\
\hline University of Delaware & 3,264 & 231 & A.L. Rheingold & 1,575 & 3 & 25,528 & 13 & 54 & 39 & 150 \\
\hline University of Dundee & 6,640 & 148 & P. Cohen & 413 & 84 & 24,957 & 14 & 75 & 9 & 150 \\
\hline University of Edinburgh & 12,000 & 61 & P.J. Sadler & 386 & 95 & 4,775 & 149 & 38 & 125 & 150 \\
\hline University of Florida & 14,891 & 38 & S.P. Kalra & 292 & 167 & 5,113 & 135 & 38 & 125 & 150 \\
\hline University of Geneva & 9,917 & 85 & J.C. Sanchez & 173 & 281 & 5,424 & 121 & 41 & 97 & 150 \\
\hline University of Georgia & 9,547 & 92 & J. Travis & 238 & 219 & 4,984 & 140 & 32 & 179 & 150 \\
\hline University of Ghent & 9,059 & 101 & J. Vandekerckhove & 373 & 105 & 9,351 & 65 & 50 & 54 & 150 \\
\hline University of Glasgow & 9,431 & 95 & G. Milligan & 369 & 108 & 5,599 & 114 & 43 & 84 & 150 \\
\hline University of Gothenburg & 790 & 319 & C. Ohlsson & 264 & 191 & 7,414 & 93 & 42 & 89 & 150 \\
\hline
\end{tabular}




\begin{tabular}{|c|c|c|c|c|c|c|c|c|c|c|}
\hline University of Groningen & 10,290 & 80 & A.J.M. Driessen & 278 & 180 & 4,369 & 156 & 43 & 84 & 150 \\
\hline University of Helsinki & 12,010 & 60 & S. Knuutila & 370 & 107 & 5,682 & 113 & 44 & 79 & 150 \\
\hline University of Hong Kong & 5,561 & 176 & F.Chen & 184 & 268 & 1,473 & 281 & 25 & 240 & 150 \\
\hline University of Houston & 2,672 & 247 & G.E. Fox & 126 & 316 & 3,495 & 185 & 15 & 314 & 150 \\
\hline University of Illinois & 14,282 & 41 & B.S. Katzenellenboge & 286 & 172 & 8,860 & 67 & 55 & 37 & 150 \\
\hline University of Illinois, Chicago & 10,838 & 74 & R.J. Solaro & 242 & 213 & 3,263 & 200 & 38 & 125 & 150 \\
\hline University of Indonesia & 174 & 339 & P.A.W. Rogers & 177 & 275 & 2,345 & 242 & 29 & 208 & 150 \\
\hline University of Iowa & 12,757 & 50 & R.J. Linhardt & 477 & 68 & 6,712 & 100 & 42 & 89 & 150 \\
\hline University of Kansas & 7,871 & 124 & R.T. Borchardt & 473 & 69 & 5,183 & 131 & 30 & 197 & 150 \\
\hline University of Kentucky & 8,864 & 107 & D.A. Butterfield & 385 & 96 & 8,095 & 80 & 61 & 22 & 150 \\
\hline University of Lausanne & 4,670 & 197 & J. Tscopp & 334 & 130 & 18,405 & 24 & 85 & 5 & 150 \\
\hline University of Leeds & 8,854 & 108 & A.J. Turner & 275 & 182 & 4,491 & 152 & 35 & 155 & 150 \\
\hline University of Leicester & 5,729 & 174 & N.S. Scrutton & 205 & 253 & 1,748 & 268 & 27 & 229 & 150 \\
\hline University of Liverpool & 7,538 & 133 & H.H. Rees & 217 & 237 & 1,252 & 295 & 18 & 294 & 150 \\
\hline University of Ljubljana & 3,282 & 229 & D. Mikavcic & 174 & 278 & 1,130 & 300 & 29 & 208 & 150 \\
\hline University of London (Kings College of London & 53,935 & 1 & M.B. Hursthouse & 1,280 & 4 & 12,992 & 39 & 38 & 125 & 150 \\
\hline University of Manchester & 12,741 & 51 & S.G. Oliver & 247 & 204 & 6,339 & 105 & 38 & 125 & 150 \\
\hline University of Manitoba & 6,878 & 142 & J.A. Wright & 203 & 255 & 2,443 & 235 & 20 & 278 & 150 \\
\hline University of Maryland & 16,903 & 26 & R.R. Colwell & 488 & 65 & 8,320 & 79 & 35 & 155 & 150 \\
\hline University of Maryland Baltimore County & 12,653 & 52 & J.R. Lakowicx & 533 & 55 & 13,119 & 37 & 53 & 43 & 150 \\
\hline University of Massachusetts & 4,278 & 206 & K. Shetty & 156 & 293 & 1,067 & 306 & 23 & 251 & 120 \\
\hline University of Melbourne & 11,613 & 64 & C.L. Masters & 488 & 65 & 11,609 & 47 & 59 & 25 & 150 \\
\hline University of Miami & 7,662 & 130 & P.J. Walsh & 283 & 175 & 3,989 & 162 & 39 & 115 & 150 \\
\hline University of Michigan & 10,563 & 76 & R.J. Kaufman & 335 & 128 & 9,792 & 60 & 59 & 25 & 150 \\
\hline University of Minnesota & 20,671 & 18 & L. Que & 384 & 97 & 5,819 & 111 & 53 & 43 & 150 \\
\hline University of Missouri & 10,468 & 77 & G.Y. Sun & 244 & 210 & 2,161 & 246 & 27 & 229 & 150 \\
\hline University of Nebraska & 3,386 & 226 & V.N. Gladyshev & 150 & 298 & 2,352 & 241 & 39 & 115 & 150 \\
\hline University of New Hampshire & 1,249 & 297 & S.A. Sower & 128 & 315 & 1,078 & 304 & 20 & 278 & 150 \\
\hline University of New Mexico & 4,342 & 205 & R.H. Glew & 312 & 152 & 1,636 & 273 & 18 & 294 & 150 \\
\hline University of New South Wales & 6,248 & 160 & I.W. Dawes & 149 & 301 & 2,167 & 245 & 29 & 208 & 150 \\
\hline University of North Carolina, Chapel Hill & 15,021 & 36 & K. H. Lee & 417 & 81 & 4,846 & 146 & 39 & 115 & 150 \\
\hline University of North Texas & 1,798 & 276 & J.W. Simpkins & 283 & 175 & 3,838 & 166 & 37 & 138 & 150 \\
\hline University of Notre Dame & 2,545 & 250 & F.J. Castellino & 382 & 98 & 3,296 & 196 & 29 & 208 & 150 \\
\hline University of Nottingham & 7,094 & 140 & S.E. Harding & 242 & 213 & 1,933 & 255 & 22 & 259 & 150 \\
\hline University of Oklahoma & 5,335 & 182 & B.A. Roe & 245 & 209 & 15,315 & 30 & 45 & 77 & 150 \\
\hline University of Oregon & 3,318 & 227 & B.W Matthews & 303 & 159 & 8,777 & 69 & 36 & 145 & 150 \\
\hline
\end{tabular}




\begin{tabular}{|c|c|c|c|c|c|c|c|c|c|c|}
\hline University of Oslo & 11,363 & 66 & H. Stenmark & 148 & 303 & 5,514 & 117 & 50 & 54 & 150 \\
\hline University of Otago & 4,253 & 208 & W.P. Tate & 152 & 296 & 1,954 & 254 & 20 & 278 & 150 \\
\hline University of Ottawa & 6,282 & 159 & S.F. Perry & 224 & 233 & 1,895 & 261 & 25 & 240 & 150 \\
\hline University of Oxford & 22,141 & 16 & R.A. Dwek & 327 & 139 & 8,546 & 75 & 57 & 31 & 150 \\
\hline University of Pennsylvania & 27,321 & 8 & S.J. Benkovic & 491 & 63 & 7,722 & 88 & 41 & 97 & 150 \\
\hline University of Pittsburgh & 18,398 & 23 & V.E. Kagan & 415 & 83 & 5,312 & 126 & 35 & 155 & 150 \\
\hline University of Quebec & 6,592 & 149 & V. Luu-The & 215 & 239 & 3,528 & 179 & 22 & 259 & 150 \\
\hline University of Queensland & 9,270 & 100 & D.J. Craik & 334 & 130 & 3,527 & 180 & 41 & 97 & 150 \\
\hline University of Reading & 3,167 & 234 & M.G.B. Drew & 733 & 23 & 7,560 & 92 & 37 & 138 & 150 \\
\hline University of Rochester & 11,032 & 69 & R.A. Bambara & 205 & 253 & 2,400 & 238 & 34 & 164 & 150 \\
\hline University of Saskatchewan & 4,696 & 195 & J.R. Dimmock & 168 & 284 & 1,090 & 301 & 19 & 287 & 150 \\
\hline University of Science and Technology of China & 1,594 & 284 & X. Yao & 111 & 325 & 1,446 & 282 & 23 & 251 & 150 \\
\hline University of Sheffield & 7,917 & 123 & D.W. Rice & 206 & 250 & 3,386 & 192 & 28 & 220 & 150 \\
\hline University of South Carolina & 3,713 & 217 & A. L. Huges & 280 & 179 & 6,211 & 107 & 37 & 138 & 150 \\
\hline University of South Florida & 5,362 & 181 & S.M. Sebti & 229 & 229 & 4,955 & 142 & 50 & 54 & 150 \\
\hline University of Southampton & 5,823 & 171 & A.G. Lee & 241 & 216 & 2,840 & 217 & 24 & 246 & 150 \\
\hline University of Southern California & 12,637 & 53 & A. Warshel & 264 & 191 & 7,768 & 87 & 50 & 54 & 150 \\
\hline University of St Andrews & 3,168 & 233 & C. Glidewell & 645 & 34 & 3,399 & 191 & 22 & 259 & 150 \\
\hline University of Surrey & 719 & 321 & C. Loannides & 244 & 210 & 1,928 & 256 & 18 & 294 & 150 \\
\hline University of Sussex & 4,696 & 195 & M.Wallis & 117 & 323 & 418 & 333 & 11 & 325 & 70 \\
\hline University of Sydney & 10,137 & 82 & P.W. Kuchel & 277 & 181 & 1,908 & 259 & 23 & 251 & 150 \\
\hline University of Technology, Sydney & 146 & 341 & G.M. Nicholson & 47 & 340 & 439 & 330 & 19 & 287 & 102 \\
\hline University of Tennessee Knoxville & 4,125 & 211 & J.M. Becker & 197 & 261 & 1,871 & 264 & 24 & 246 & 150 \\
\hline University of Texas at Austin & 8,217 & 117 & J.L. Sessller & 421 & 80 & 6,004 & 109 & 50 & 54 & 150 \\
\hline University of Tokyo & 34,283 & 3 & S. Yokoyama & 580 & 47 & 11,579 & 48 & 50 & 54 & 150 \\
\hline University of Toronto & 28,406 & 5 & S. Grinstein & 425 & 79 & 10,284 & 56 & 57 & 31 & 150 \\
\hline University of Tsukuba & 7,700 & 128 & M. Yamamoto & 575 & 48 & 21,360 & 19 & 70 & 13 & 150 \\
\hline University of Twente & 301 & 333 & D.N. Reinhoudt & 724 & 24 & 22,809 & 16 & 66 & 16 & 150 \\
\hline University of Utah & 12,478 & 55 & R. White & 340 & 126 & 9,666 & 61 & 23 & 251 & 150 \\
\hline University of Vermont & 5,037 & 187 & M.T. Nelson & 171 & 282 & 6,074 & 108 & 47 & 68 & 150 \\
\hline University of Victoria & 794 & 318 & J. Ausio & 166 & 286 & 2,095 & 248 & 24 & 246 & 150 \\
\hline University of Virginia & 12,460 & 56 & S. M. Hecht & 329 & 137 & 3,820 & 167 & 27 & 229 & 150 \\
\hline University of Warwick & 2,980 & 240 & C. Robinson & 341 & 123 & 3,180 & 204 & 35 & 155 & 150 \\
\hline University of Washington & 25,667 & 11 & M.H. Gelb & 300 & 163 & 8,407 & 77 & 48 & 64 & 150 \\
\hline University of Waterloo & 1,010 & 308 & B.R. Glick & 182 & 271 & 1,925 & 257 & 31 & 185 & 150 \\
\hline University of Western Australia & 5,790 & 172 & A. H. White & 1,245 & 5 & 13,086 & 38 & 38 & 125 & 150 \\
\hline
\end{tabular}




\begin{tabular}{|c|c|c|c|c|c|c|c|c|c|c|}
\hline University of Western Ontario & 7,737 & 125 & D.T. Armstrong & 212 & 242 & 2,129 & 247 & 19 & 287 & 150 \\
\hline University of Wisconsin & 26,496 & 9 & H.F. Deluca & 841 & 14 & 13,121 & 36 & 36 & 145 & 150 \\
\hline University of Wollongong & 344 & 327 & R.J. W. Truscott & 149 & 301 & 1,438 & 283 & 25 & 240 & 150 \\
\hline University of York & 3,437 & 223 & G.J. Davies & 199 & 259 & 5,060 & 137 & 39 & 115 & 150 \\
\hline University of Zurich & 9,027 & 102 & A. Pluckthun & 256 & 196 & 6,539 & 103 & 56 & 36 & 150 \\
\hline Univesitas Gadjah Mada & 115 & 343 & A. Junaidi & 8 & 346 & 64 & 345 & 4 & 343 & 23 \\
\hline Uppsala University & 4,564 & 200 & B. Mannervik & 9 & 345 & 6,721 & 99 & 29 & 208 & 150 \\
\hline Utah State & 1,697 & 279 & S.D. Aust & 291 & 169 & 7,933 & 83 & 20 & 278 & 150 \\
\hline Utrecht University & 15,909 & 29 & J.F.G. Vliegenthart & 518 & 56 & 10,147 & 57 & 36 & 145 & 150 \\
\hline Vanderbilt University & 12,967 & 48 & F.P. Guengerich & 663 & 28 & 32,945 & 6 & 58 & 29 & 150 \\
\hline Victoria University of Wellington & 80 & 344 & A.G. Clark & 59 & 339 & 486 & 328 & 9 & 332 & 90 \\
\hline Vienna University of Technology & 240 & 336 & C.P. Kubicek & 250 & 202 & 2,402 & 237 & 29 & 208 & 150 \\
\hline Virginia Polytechnic Institute & 3,039 & 237 & R.H. White & 131 & 314 & 1,562 & 278 & 17 & 302 & 150 \\
\hline Vrije Universiteit, Brussels & 309 & 330 & J. Smitz & 226 & 231 & 3,557 & 176 & 29 & 208 & 150 \\
\hline VU University Amsterdam & 11,024 & 72 & H.M. Pinedo & 691 & 26 & 19,029 & 23 & 54 & 39 & 150 \\
\hline Wageningen University & 2,446 & 254 & A.G.J. Voragen & 361 & 114 & 4,240 & 158 & 33 & 172 & 150 \\
\hline Wake Forest University & 2,014 & 269 & D.W. Bowden & 186 & 266 & 2,659 & 222 & 30 & 197 & 150 \\
\hline Waseda University & 802 & 317 & E. Tsuchida & 661 & 30 & 7,048 & 97 & 35 & 155 & 150 \\
\hline Washington State University & 5,862 & 170 & R. Croteau & 283 & 175 & 3,313 & 194 & 46 & 73 & 150 \\
\hline Washington University in St. Louis & 22,459 & 15 & E. Di Cera & 166 & 286 & 1,776 & 267 & 28 & 220 & 150 \\
\hline Wayne State University & 10,764 & 75 & K.V. Horn & 229 & 229 & 3,624 & 172 & 25 & 240 & 150 \\
\hline West Virginia University & 2,945 & 241 & X. Shi & 295 & 165 & 5,595 & 115 & 43 & 84 & 150 \\
\hline Yale University & 8,021 & 120 & D. Soll & 362 & 113 & 3,296 & 196 & 33 & 172 & 150 \\
\hline Yonsei University & 4,447 & 202 & W. Lee & 90 & 333 & 1,164 & 298 & 17 & 302 & 150 \\
\hline York University & 1,878 & 273 & D.A. Hood & 93 & 330 & 1,293 & 292 & 22 & 259 & 99 \\
\hline Zhejiang University & 1,906 & 272 & P. Cen & 146 & 304 & 40 & 346 & 11 & 325 & 150 \\
\hline
\end{tabular}




\begin{tabular}{|c|c|c|c|c|c|c|c|c|c|c|}
\hline Engineering Publications Data & $\begin{array}{l}\text { Department } \\
\text { Publications }\end{array}$ & Rank & Most Prolific Author & Published & Rank & Cited & Rank & $\begin{array}{c}\text { H- } \\
\text { Index }\end{array}$ & Rank & $\begin{array}{c}\text { \# of } \\
\text { Coauthors }\end{array}$ \\
\hline Aalto University & 6,996 & 88 & K. Halonen & 349 & 100 & 1,487 & 164 & 20 & 159 & 146 \\
\hline Aarhus University & 1,043 & 290 & F.Besenbacher & 358 & 91 & 6,475 & 33 & 47 & 14 & 150 \\
\hline Arizonia State University & 9,655 & 48 & D.K. Ferry & 541 & 25 & 4,853 & 47 & 29 & 68 & 150 \\
\hline Ateneo de Manila University & 19 & 345 & G. Tangonan & 69 & 333 & 600 & 269 & 6 & 332 & 147 \\
\hline Auburn University & 5,179 & 124 & J.K. Tugnait & 244 & 185 & 1,142 & 197 & 16 & 213 & 38 \\
\hline Australian National University & \begin{tabular}{l|l}
4,033 \\
\end{tabular} & 159 & B. Luther-Davies & 423 & 58 & 3,861 & 64 & 37 & 35 & 150 \\
\hline Boston College & 380 & 323 & Z.F. Ren & 220 & 211 & 8,085 & 20 & 43 & 16 & 150 \\
\hline Boston University & 3,917 & 166 & C.G. Cassandras & 204 & 226 & 711 & 255 & 17 & 199 & 82 \\
\hline Brandeis University & 239 & 334 & J.A. Storer & 62 & 338 & 390 & 306 & 8 & 319 & 28 \\
\hline Brigham Young University & 3,001 & 196 & R.M. Izatt & 422 & 59 & 5,873 & 36 & 22 & 137 & 150 \\
\hline Brown University & 3,742 & 174 & A. Needleman & 248 & 179 & 6,338 & 34 & 28 & 75 & 150 \\
\hline California Institute of Technology (Calt... & 19,095 & 10 & P.P. Vaidyanathan & 335 & 108 & 2,299 & 117 & 20 & 159 & 74 \\
\hline Cardiff University & 3,823 & 173 & F.W. Williams & 229 & 200 & 993 & 216 & 12 & 269 & 150 \\
\hline Carnegie Mellon University & 13,427 & 28 & T. Kanade & 370 & 84 & 9,377 & 16 & 37 & 35 & 150 \\
\hline Case Western Reserve University & 5,036 & 130 & A. Hiltner & 459 & 46 & 3,321 & 72 & 29 & 68 & 150 \\
\hline Chalmers University of Technology & 9,494 & 51 & P.S. Kildal & 311 & 122 & 936 & 225 & 20 & 159 & 150 \\
\hline Charles University & 460 & 321 & P. Lukac & 193 & 234 & 689 & 260 & 15 & 226 & 150 \\
\hline Chinese University of Hong Kong & 5,522 & 115 & M.R. Lyu & 236 & 193 & 858 & 230 & 15 & 226 & 150 \\
\hline Chulalongkorn University & 1,477 & 263 & S. Jitapunkul & 89 & 321 & 70 & 342 & 4 & 342 & 66 \\
\hline City University of Hong Kong & 8,866 & 59 & K.M. Luk & 385 & 77 & 1,627 & 155 & 21 & 147 & 150 \\
\hline City University of New York & 1,322 & 276 & F.H. Pollak & 345 & 103 & 3,444 & 68 & 20 & 159 & 150 \\
\hline Colorado State University & 4,458 & 146 & J.J. Rocca & 356 & 94 & 1,580 & 158 & 27 & 81 & 150 \\
\hline Columbia University & 7,118 & 84 & X. Wang & 800 & 11 & 29,940 & 4 & 57 & 6 & 150 \\
\hline Cornell University & 10,814 & 44 & L.F. Eastman & 547 & 24 & 6,999 & 26 & 36 & 38 & 150 \\
\hline Curtin University of Technology & 1,941 & 244 & E. Chang & 315 & 119 & 295 & 320 & 8 & 319 & 132 \\
\hline Dalhousie University & 1,980 & 240 & Z. Chen & 130 & 299 & 649 & 266 & 8 & 319 & 104 \\
\hline Dartmouth College & 2,835 & 201 & K.D. Paulsen & 371 & 82 & 2,809 & 88 & 40 & 22 & 150 \\
\hline Delft University of Technology & 15,323 & 23 & L.P. Lighthart & 308 & 124 & 493 & 291 & 12 & 269 & 150 \\
\hline Drexel University & 4,759 & 138 & P.R. Herczfeld & 206 & 224 & 401 & 302 & 7 & 330 & 150 \\
\hline Duke University & 6,089 & 100 & A. Bejan & 411 & 65 & 3,021 & 80 & 27 & 81 & 150 \\
\hline Durham University & 2,041 & 237 & A. Unsworth & 149 & 284 & 847 & 231 & 15 & 226 & 109 \\
\hline Ecole Normale Supérieure de Lyon & 529 & 316 & Y. Robert & 140 & 290 & 524 & 284 & 11 & 285 & 110 \\
\hline École Normale Supérieure, Paris & 973 & 296 & Y. Chen & 149 & 284 & 1,027 & 209 & 16 & 213 & 150 \\
\hline École Polytechnique & 2,373 & 217 & J.M. Chomaz & 87 & 322 & 821 & 238 & 21 & 147 & 74 \\
\hline
\end{tabular}




\begin{tabular}{|c|c|c|c|c|c|c|c|c|c|c|}
\hline Ecole Polytechnique Fédérale de Lausanne & 7,128 & 83 & M. Unser & 347 & 102 & 4,859 & 46 & 31 & 57 & 150 \\
\hline Eindhoven University of Technology & 7,043 & 87 & G.D. Khoe & 221 & 207 & 1,238 & 187 & 22 & 137 & 150 \\
\hline Emory University & 873 & 300 & G. Bao & 307 & 126 & 2,318 & 114 & 27 & 81 & 150 \\
\hline Erasmus University Rotterdam & 988 & 294 & N.DeJong & 184 & 241 & 1,696 & 150 & 25 & 108 & 150 \\
\hline ETH Zurich (Swiss Federal Institute of Technology) & 9,522 & 50 & W. Fichtner & 358 & 91 & 1,572 & 159 & 20 & 159 & 150 \\
\hline Florida International University & 2,595 & 209 & M.A. Ebadian & 200 & 229 & 426 & 299 & 13 & 258 & 107 \\
\hline Florida State University & 1,552 & 259 & J. Schwartz & 162 & 267 & 586 & 270 & 14 & 247 & 150 \\
\hline Freie Universität Berlin & 1,364 & 272 & J. Schiller & 48 & 340 & 119 & 339 & 6 & 332 & 54 \\
\hline Friedrich Alexander Universität Erlangen Nürnberg & 6,085 & 101 & R. Unbehauen & 245 & 184 & 1,069 & 205 & 14 & 247 & 93 \\
\hline Fudan University & 4,523 & 145 & H.Min & 97 & 318 & 132 & 335 & 5 & 336 & 137 \\
\hline Georg August Universität Göttingen & 1,126 & 284 & K.P.Lieb & 556 & 23 & 6,702 & 29 & 35 & 41 & 150 \\
\hline George Mason University & 2,534 & 211 & S. Jajodia & 266 & 164 & 2,252 & 119 & 26 & 94 & 150 \\
\hline George Washington University & 2,874 & 200 & M.E. Zaghloul & 126 & 304 & 576 & 272 & 14 & 247 & 122 \\
\hline Georgetown University & 654 & 310 & S.K. Mun & 193 & 234 & 800 & 241 & 11 & 285 & 150 \\
\hline Georgia Institute of Technology & 23,445 & 3 & J.Laskar & 449 & 48 & 1,836 & 142 & 23 & 120 & 15 \\
\hline Georgia State University & 973 & 296 & Y. Pan & 259 & 171 & 1,192 & 192 & 22 & 137 & 150 \\
\hline Goteborg University & 9,919 & 46 & B. Kasemo & 374 & 80 & 6,704 & 28 & 47 & 14 & 150 \\
\hline Harvard University & 4,041 & 158 & G.M. Whitesides & 918 & 7 & 75,622 & 1 & 105 & 1 & 150 \\
\hline Hebrew University of Jerusalem & 1,939 & 245 & S. Peleg & 86 & 323 & 2,017 & 134 & 13 & 258 & 57 \\
\hline Heidelberg Universität & 1,446 & 264 & J. Wolfrum & 217 & 213 & 1,592 & 156 & 24 & 112 & 150 \\
\hline Hokkaido University & 6,861 & 91 & M. Koshiba & 441 & 51 & 2,331 & 111 & 28 & 75 & 150 \\
\hline Hong Kong Polytechnic University & 10,978 & 43 & C.K. Tse & 300 & 129 & 1,445 & 169 & 23 & 120 & 150 \\
\hline Hong Kong University of Science \& Techno... & 7,502 & 75 & M. Chan & 304 & 127 & 1,019 & 211 & 14 & 247 & 150 \\
\hline Humboldt-Universität zu Berlin & 81 & 343 & W. Ebeling & 221 & 207 & 1,095 & 202 & 18 & 187 & 150 \\
\hline Imperial College London & 2,992 & 197 & C.Toumazou & 308 & 124 & 984 & 218 & 15 & 226 & 150 \\
\hline Indian Institute of Technology Bombay (I... & 3,980 & 161 & T. Kant & 115 & 314 & 679 & 263 & 12 & 269 & 72 \\
\hline Indian Institute of Technology Delhi (II... & 5,834 & 106 & B. Singh & 341 & 105 & 1,336 & 178 & 18 & 187 & 150 \\
\hline Indian Institute of Technology Kanpur (I... & 3,887 & 169 & A. Ghosh & 180 & 247 & 721 & 254 & 16 & 213 & 150 \\
\hline Indiana University Bloomington & 2,006 & 239 & F.W. Putnam & 280 & 147 & 3,936 & 60 & 18 & 187 & 150 \\
\hline Indiana University Indianapolis & 208 & 336 & Y. Laing & 52 & 339 & 365 & 311 & 8 & 319 & 150 \\
\hline Iowa State University & 7,602 & 73 & K.A. Gschneidner & 633 & 18 & 7,358 & 23 & 33 & 48 & 150 \\
\hline Johns Hopkins University & 8,491 & 64 & A. G. Andreou & 192 & 236 & 981 & 219 & 15 & 226 & 140 \\
\hline Kansas State University & 1,738 & 251 & L.T. Fan & 411 & 65 & 1,650 & 154 & 12 & 269 & 150 \\
\hline Katholieke Universiteit Leuven & 7,926 & 72 & W. Sansen & 388 & 76 & 2,888 & 86 & 26 & 94 & 150 \\
\hline Keio University & 6,123 & 98 & K. Ohnishi & 442 & 50 & 1,432 & 170 & 20 & 159 & 150 \\
\hline King Fahd University of Petroleum \& Minerals & 3,907 & 168 & B.S. Yilbas & 391 & 74 & 1,093 & 203 & 19 & 171 & 150 \\
\hline
\end{tabular}




\begin{tabular}{|c|c|c|c|c|c|c|c|c|c|c|}
\hline King Saud University & 1,958 & 241 & H.A. Attia & 167 & 264 & 252 & 325 & 11 & 285 & 20 \\
\hline Kobe University & 3,588 & 178 & Y. Tomita & 222 & 205 & 1,368 & 176 & 16 & 213 & 150 \\
\hline Korea Advanced Institute of Science \& Technology & 12,982 & 32 & D.K. Sung & 209 & 221 & 562 & 277 & 13 & 258 & 150 \\
\hline Korea University & 4,575 & 142 & S.J. Ko & 182 & 245 & 828 & 236 & 11 & 285 & 150 \\
\hline Kyoto University & 17,586 & 12 & H. Hamada & 477 & 43 & 1,186 & 193 & 15 & 226 & 150 \\
\hline Kyushu University & 8,900 & 58 & T. Ninomiya & 238 & 191 & 569 & 275 & 11 & 285 & 150 \\
\hline La Trobe University & 863 & 302 & B.Soh & 83 & 325 & 62 & 344 & 3 & 345 & 34 \\
\hline Lancaster University & 834 & 304 & K.C. Jones & 448 & 49 & 6,609 & 31 & 54 & 10 & 150 \\
\hline Leiden University & 1,578 & 256 & A.T. Natarajan & 348 & 101 & 4,704 & 50 & 33 & 48 & 150 \\
\hline Linkoping University & 3,559 & 180 & L. Ljung & 223 & 204 & 2,802 & 89 & 18 & 187 & 116 \\
\hline London School of Economics and Political Scie & 274 & 331 & K.P. Papadaki & 26 & 345 & 49 & 345 & 4 & 342 & 16 \\
\hline Loughborough University & 5,985 & 103 & D.J. Evans & 882 & 8 & 9,579 & 15 & 39 & 26 & 150 \\
\hline Louisiana State University & 5,408 & 118 & F.R. Fronczek & 589 & 21 & 5,164 & 42 & 27 & 81 & 150 \\
\hline Ludwig-Maximilians-Universität München & 1,948 & 243 & H.P. Kriegel & 171 & 258 & 2,404 & 109 & 20 & 159 & 111 \\
\hline Lund University & 5,136 & 125 & B. Sunden & 236 & 193 & 701 & 257 & 15 & 226 & 133 \\
\hline Maastricht University & 442 & 322 & L.H.Koole & 131 & 297 & 737 & 252 & 17 & 199 & 150 \\
\hline Macquarie University & 1,217 & 281 & K.P. Esselle & 123 & 309 & 358 & 312 & 10 & 299 & 47 \\
\hline Mahidol University & 369 & 325 & P.P. Yupapin & 126 & 304 & 72 & 341 & 7 & 330 & 105 \\
\hline Masaryk University & 296 & 330 & I. Ohidal & 33 & 343 & 63 & 343 & 5 & 336 & 42 \\
\hline Massachusetts Institute of Technology & \begin{tabular}{|l|l|}
26,874 \\
\end{tabular} & 2 & R. Langer & 920 & 6 & 48,832 & 2 & 93 & 2 & 150 \\
\hline McGill University & 8,220 & 69 & M.P. Paidoussi & 341 & 105 & 1,290 & 182 & 19 & 171 & 132 \\
\hline McMaster University & 6,149 & 97 & S. Haykin & 270 & 159 & 3,077 & 76 & 20 & 159 & 150 \\
\hline Michigan State University & 7,118 & 84 & N. Xi & 371 & 82 & 1,453 & 167 & 22 & 137 & 150 \\
\hline Michigan Technological University & 3,407 & 182 & E.C. Aifantis & 233 & 197 & 2,194 & 122 & 19 & 171 & 150 \\
\hline Monash University & 5,340 & 120 & B. Shirinzadeh & 138 & 292 & 292 & 321 & 12 & 269 & 77 \\
\hline Montana State University & 1,160 & 282 & M.H. Nehrir & 71 & 331 & 544 & 282 & 11 & 285 & 52 \\
\hline Moscow State University & 7,970 & 71 & A.V. Priezzhev & 178 & 250 & 259 & 324 & 9 & 309 & 150 \\
\hline Nagoya University & 12,597 & 33 & T. Fukuda & 1,122 & 4 & 5,847 & 37 & 28 & 75 & 150 \\
\hline Nanjing University & 4,686 & 140 & Y. Zheng & 427 & 57 & 1,321 & 180 & 18 & 187 & 150 \\
\hline Nanyang Technological University & 18,108 & 11 & K.M. Liew & 419 & 61 & 2,553 & 102 & 32 & 52 & 150 \\
\hline National Taiwan University & 14,528 & 25 & L.G. Chen & 365 & 88 & 2,134 & 126 & 27 & 81 & 150 \\
\hline National Tsing Hua University & 8,779 & 60 & B.S. Chen & 257 & 173 & 2,512 & 106 & 23 & 120 & 150 \\
\hline National University of Ireland, Galway & 1,057 & 289 & W.G. Hurley & 86 & 323 & 424 & 300 & 10 & 299 & 59 \\
\hline National University of Singapore & 16,475 & 18 & L.W. Li & 410 & 67 & 979 & 220 & 15 & 226 & 150 \\
\hline New Mexico State University & 2,336 & 220 & J. Ramirez & 289 & 137 & 1,056 & 206 & 17 & 199 & 150 \\
\hline New York University & 2,463 & 213 & M. Sharir & 345 & 103 & 2,106 & 129 & 19 & 171 & 150 \\
\hline
\end{tabular}




\begin{tabular}{|c|c|c|c|c|c|c|c|c|c|c|}
\hline Newcastle University & 3,669 & 176 & A.J. Morris & 154 & 276 & 1,341 & 177 & 22 & 137 & 123 \\
\hline North Carolina State University & 9,916 & 47 & M.B. Steer & 233 & 197 & 768 & 247 & 12 & 269 & 150 \\
\hline Northeastern University & 4,725 & 139 & F. Lombardi & 244 & 185 & 494 & 290 & 12 & 269 & 143 \\
\hline Northwestern University & 9,603 & 49 & A. Routtenburg & 179 & 248 & 2,579 & 99 & 17 & 199 & 150 \\
\hline Norwegian University of Science \& Technology & 5,791 & 107 & T. Moan & 198 & 231 & 493 & 291 & 11 & 285 & 150 \\
\hline Ohio State University & 12,267 & 35 & B. Bhushan & 702 & 14 & 10,616 & 12 & 39 & 26 & 150 \\
\hline Oklahoma State University & 2,764 & 202 & R. Komanduri & 177 & 251 & 1,699 & 149 & 23 & 120 & 150 \\
\hline Open University UK & 1,364 & 272 & L.E. Edwards & 122 & 311 & 769 & 246 & 15 & 226 & 112 \\
\hline Oregon State University & 3,933 & 165 & U.K. Moon & 157 & 273 & 895 & 228 & 15 & 226 & 150 \\
\hline Osaka University & 16,636 & 17 & M. Murata & 471 & 45 & 2,518 & 104 & 21 & 147 & 150 \\
\hline Peking University & 9,295 & 55 & Y. Wang & 341 & 105 & 737 & 252 & 12 & 269 & 150 \\
\hline Pennsylvania State University & 17,562 & 13 & R. Mittra & 804 & 10 & 5,258 & 41 & 24 & 112 & 150 \\
\hline Pohang University of Science And Technology & 4,228 & 153 & B. Kim & 191 & 237 & 764 & 248 & 18 & 187 & 150 \\
\hline Portland State University & 1,490 & 262 & M.A. Perkowski & 151 & 281 & 500 & 289 & 13 & 258 & 144 \\
\hline Princeton University & 9,320 & 54 & N.K.Ha & 282 & 143 & 1,538 & 161 & 22 & 137 & 136 \\
\hline Purdue University & 20,105 & 8 & K. Roy & 522 & 28 & 4,317 & 54 & 31 & 57 & 150 \\
\hline Queen's University & 5,242 & 123 & H.T. Mouftah & 409 & 68 & 1,122 & 200 & 14 & 247 & 150 \\
\hline Queen's University of Belfast & 3,284 & 188 & V.F. Fuses & 317 & 117 & 669 & 264 & 13 & 258 & 150 \\
\hline Queensland University of Technology & 2,221 & 228 & S. Sridharan & 152 & 280 & 378 & 307 & 10 & 299 & 122 \\
\hline Radboud University, Nijmegen & 1,386 & 270 & J.A. Jansen & 390 & 75 & 4,052 & 59 & 42 & 18 & 150 \\
\hline Rensselaer Polytechnic Institute & 9,295 & 55 & M.S. Shur & 780 & 12 & 12,043 & 11 & 51 & 13 & 150 \\
\hline Rheinisch Westfalische Technische Hochschule Aach & 9,250 & 57 & T. Gries & 227 & 202 & 130 & 337 & 5 & 336 & 150 \\
\hline Rheinische Friedrich Wilhelms Universitat Bonn & 1,350 & 275 & P. Martini & 72 & 330 & 103 & 340 & 5 & 336 & 72 \\
\hline Rice University & 4,398 & 148 & A.G. Mikos & 352 & 96 & 8,229 & 19 & 60 & 4 & 150 \\
\hline Rochester Institute of Technology & 2,413 & 216 & S.G. Kandlikar & 186 & 240 & 1,336 & 178 & 23 & 120 & 101 \\
\hline Royal Institute of Technology, KTH & 8,235 & 68 & H. Tenhuner & 267 & 163 & 523 & 285 & 11 & 285 & 150 \\
\hline Royal Melbourne Institute of Technology & 2,335 & 221 & W. Wlodarski & 154 & 276 & 959 & 223 & 20 & 159 & 150 \\
\hline Rutgers & 7,372 & 77 & M.V. Karwe & 66 & 334 & 322 & 316 & 11 & 285 & 68 \\
\hline Saint-Petersburg State University & 2,485 & 212 & Y.G. Vlasov & 133 & 296 & 807 & 240 & 22 & 137 & 150 \\
\hline San Diego State University & 1,398 & 269 & F.J Harris & 65 & 335 & 206 & 330 & 8 & 319 & 30 \\
\hline Sapienza University of Rome & 0 & 348 & & 0 & 348 & 0 & 348 & 0 & 348 & 0 \\
\hline Sciences Po Paris & 7 & 347 & C. Wilkinson & 24 & 346 & 462 & 296 & 6 & 332 & 34 \\
\hline Seoul National University & 12,206 & 36 & S.K. Sul & 282 & 143 & 2,516 & 105 & 27 & 81 & 150 \\
\hline Shanghai Jiao Tong University & 16,947 & 14 & Q. Zeng & 252 & 175 & 395 & 304 & 9 & 309 & 150 \\
\hline Simon Fraser University & 2,694 & 203 & M. Saif & 113 & 315 & 521 & 287 & 12 & 269 & 41 \\
\hline Stanford University & 22,980 & & J.M. Cioff & 394 & 72 & 5,156 & 43 & 31 & 57 & 150 \\
\hline
\end{tabular}




\begin{tabular}{|c|c|c|c|c|c|c|c|c|c|c|}
\hline State University of New York Buffalo & 129 & 340 & N.M. Nasrabadi & 210 & 220 & 996 & 215 & 10 & 299 & 96 \\
\hline Stockholm University & 828 & 305 & C. Bohm & 134 & 295 & 1,245 & 186 & 13 & 258 & 150 \\
\hline Stony Brook University & 3,911 & 167 & P.M. Djuric & 171 & 258 & 1,130 & 199 & 17 & 199 & 101 \\
\hline Syracuse University & 3,375 & 184 & T.K. Sarkar & 501 & 35 & 3,935 & 61 & 20 & 159 & 150 \\
\hline Tartu University (University of Tartu) & 531 & 315 & A. Aabloo & 64 & 336 & 184 & 332 & 9 & 309 & 56 \\
\hline Technical University of Denmark & 7,227 & 80 & V. Tveraard & 217 & 213 & 3,417 & 69 & 18 & 187 & 54 \\
\hline Technion & 11,035 & 42 & S. Shami & 282 & 143 & 3,260 & 73 & 26 & 94 & 122 \\
\hline Technische Universität Berlin & 6,514 & 96 & D. Bimberg & 967 & 5 & 18,234 & 6 & 57 & 6 & 150 \\
\hline Technische Universitat Chemnitz & 1,523 & 260 & T. Gressner & 288 & 138 & 693 & 259 & 13 & 258 & 150 \\
\hline Technische Universität Dresden & 5,354 & 119 & K.J. Wolther & 168 & 262 & 195 & 331 & 8 & 319 & 150 \\
\hline Technische Universität München & 8,458 & 66 & P. Russer & 374 & 80 & 629 & 267 & 12 & 269 & 150 \\
\hline Tel Aviv University & 5,705 & 111 & V. Shaked & 228 & 201 & 2,162 & 124 & 23 & 120 & 71 \\
\hline Texas A\&M University & 16,712 & 16 & K.Chang & 368 & 85 & 2,564 & 101 & 26 & 94 & 150 \\
\hline Texas Tech & 2,965 & 198 & H. Temkin & 295 & 132 & 2,942 & 85 & 30 & 63 & 150 \\
\hline Tohoku University & 16,719 & 15 & A. Inoue & 1,930 & 1 & 38,085 & 3 & 71 & 3 & 150 \\
\hline Tokyo Institute of Technology & 15,559 & 22 & K. Iga & 484 & 39 & 2,488 & 107 & 28 & 75 & 150 \\
\hline Trinity College Dublin & 1,956 & 242 & J.F. Donegan & 187 & 239 & 827 & 237 & 17 & 199 & 150 \\
\hline Tsinghua University & 34,750 & 1 & X. Hong & 384 & 79 & 572 & 274 & 11 & 285 & 150 \\
\hline Tufts University & 1,691 & 252 & M.N. Afsar & 197 & 232 & 395 & 304 & 8 & 319 & 148 \\
\hline Universidad Autonoma de Madrid & 1,416 & 267 & J. Aracil & 126 & 304 & 376 & 308 & 9 & 309 & 150 \\
\hline Universidad de Chile & 1,068 & 288 & A. Valencia & 46 & 341 & 299 & 318 & 10 & 299 & 56 \\
\hline Universidad de Granada & 1,416 & 267 & J. Aracil & 126 & 304 & 376 & 308 & 9 & 309 & 150 \\
\hline Universidad del País Vasco & 2,154 & 231 & M. De la Sen & 405 & 70 & 561 & 278 & 16 & 213 & 71 \\
\hline Universidad Nacional Autónoma de México ... & 1,571 & 258 & L. Fridman & 151 & 281 & 469 & 294 & 15 & 226 & 83 \\
\hline Universidad Politecnica de Madrid & 5,488 & 117 & J.A. Cobos & 184 & 241 & 835 & 234 & 16 & 213 & 120 \\
\hline Universidade de São Paulo & 3,293 & 186 & A. Pessoa & 94 & 320 & 427 & 298 & 13 & 258 & 135 \\
\hline Universidade Estadual de Campinas & 4,105 & 156 & A. Garcia & 116 & 313 & 447 & 297 & 18 & 187 & 74 \\
\hline Università degli Studi di Firenze & 4,117 & 155 & R. Fantiacci & 275 & 149 & 1,014 & 212 & 15 & 226 & 150 \\
\hline Università degli Studi di Padova & 6,123 & 98 & G. Meneghesso & 221 & 207 & 884 & 229 & 19 & 171 & 150 \\
\hline Universita Di Bologna & 6,525 & 95 & L. Benini & 292 & 133 & 2,965 & 83 & 29 & 68 & 150 \\
\hline Universita di Pisa & 2,230 & 227 & D. De Rossi & 215 & 216 & 2,272 & 118 & 23 & 120 & 150 \\
\hline Universitat Autonoma de Barcelona & 1,803 & 247 & X. Aymerich & 161 & 268 & 786 & 243 & 15 & 226 & 101 \\
\hline Universitat Bielefeld & 766 & 306 & R. Ahlswede & 172 & 257 & 2,042 & 133 & 9 & 309 & 69 \\
\hline Universität Bremen & 2,686 & 204 & F. Arndt & 156 & 274 & 778 & 245 & 9 & 309 & 105 \\
\hline Universitat d'Alacant & 983 & 295 & J.M. Martinez & 164 & 266 & 1,003 & 214 & 17 & 199 & 141 \\
\hline Universitat de València & 1,750 & 250 & M.V. Andres & 189 & 238 & 1,658 & 153 & 26 & 94 & 127 \\
\hline
\end{tabular}




\begin{tabular}{|c|c|c|c|c|c|c|c|c|c|c|}
\hline Universität Frankfurt am Main & 1,006 & 292 & R. Tetzlaff & 74 & 329 & 132 & 335 & 4 & 342 & 110 \\
\hline Universität Freiburg & 2,106 & 233 & W. Burgard & 161 & 268 & 3,004 & 82 & 28 & 75 & 150 \\
\hline Universitat Hamburg & 503 & 317 & H. Hartmann & 272 & 155 & 2,954 & 84 & 35 & 41 & 150 \\
\hline Universität Karlsruhe & 7,483 & 76 & O. Dossel & 161 & 268 & 368 & 310 & 10 & 299 & 150 \\
\hline Universitat Leipzig & 351 & 329 & J. Karger & 350 & 98 & 2,311 & 115 & 29 & 68 & 150 \\
\hline Universitat Munster (Westfälische Wilhelms-Un & 1,070 & 287 & E. Nembach & 137 & 293 & 483 & 293 & 11 & 285 & 98 \\
\hline Universitat Politecnica de Catalunya & 7,514 & 74 & L. Puigjaner & 200 & 229 & 1,153 & 196 & 18 & 187 & 150 \\
\hline Universität Regensburg & 925 & 298 & A. Penzkofer & 248 & 179 & 1,681 & 151 & 26 & 94 & 150 \\
\hline Universität Stuttgart & 7,215 & 81 & H.J. Tiziani & 215 & 216 & 1,592 & 156 & 21 & 147 & 150 \\
\hline Universitat Trier & 145 & 339 & C. Meinel & 125 & 308 & 289 & 322 & 8 & 319 & 93 \\
\hline Universität Tübingen & 1,380 & 271 & U. Weiner & 161 & 268 & 2,575 & 100 & 31 & 57 & 150 \\
\hline Universitat Wien (University of Vienna) & 1,680 & 253 & A.F. Fercher & 181 & 246 & 3,213 & 75 & 35 & 41 & 150 \\
\hline Universitat $\mathrm{Zu}$ Koln & 843 & 303 & J. Stutzki & 127 & 301 & 1,009 & 213 & 19 & 171 & 150 \\
\hline Université Catholique de Louvain & 3,248 & 190 & D. Flandre & 265 & 165 & 1,165 & 195 & 22 & 137 & 150 \\
\hline Universite de Liege & 2,368 & 218 & P. Dular & 117 & 312 & 331 & 315 & 11 & 285 & 82 \\
\hline Université de Montréal & 2,353 & 219 & G. Cloutier & 183 & 243 & 681 & 262 & 17 & 199 & 150 \\
\hline Université de Nice Sophia Antipolis & 1,497 & 261 & R. Staraj & 97 & 318 & 298 & 319 & 9 & 309 & 92 \\
\hline Universite Laval & 3,708 & 175 & C.M. Gosselin & 268 & 162 & 2,321 & 113 & 27 & 81 & 150 \\
\hline Universite Libre de Bruxelles & 1,675 & 254 & P. Mandel & 812 & 9 & 4,291 & 55 & 19 & 171 & 150 \\
\hline Université Paris Sorbonne & 366 & 327 & C. Rolland & 79 & 326 & 415 & 301 & 10 & 299 & 80 \\
\hline Universite Paris-Sud 11 & 3,883 & 170 & J.M. Lourtioz & 174 & 255 & 1,374 & 175 & 21 & 147 & 150 \\
\hline Université Pierre et Marie Curie & 5,038 & 129 & G.A. Maugin & 274 & 152 & 1,246 & 185 & 15 & 226 & 126 \\
\hline Universiti Malaya (University of Malaya) & 1,312 & 277 & H. Ahmad & 63 & 337 & 42 & 347 & 3 & 345 & 82 \\
\hline University College Cork & 1,795 & 248 & A. Matewson & 179 & 248 & 548 & 281 & 10 & 299 & 150 \\
\hline University College Dublin & 1,880 & 246 & J.T. Sheridan & 207 & 222 & 789 & 242 & 21 & 147 & 139 \\
\hline University College London & 7,317 & 78 & I.W. Boyd & 315 & 119 & 2,250 & 121 & 23 & 120 & 150 \\
\hline University do Porto & 2,320 & 222 & A.E. Rodrigues & 327 & 113 & 2,143 & 125 & 27 & 81 & 150 \\
\hline University of Aberdeen & 2,171 & 229 & J.C. Jones & 175 & 254 & 251 & 326 & 8 & 319 & 106 \\
\hline University of Adelaide & 2,650 & 205 & D. Abbott & 368 & 85 & 1,862 & 141 & 27 & 81 & 150 \\
\hline University of Alabama & 4,771 & 136 & Y. Xiao & 486 & 38 & 2,415 & 108 & 29 & 68 & 150 \\
\hline University of Alberta & 8,775 & 61 & W. Pedrycz & 509 & 30 & 4,118 & 58 & 27 & 81 & 150 \\
\hline University of Amsterdam & 2,296 & 225 & T. Gevers & 98 & 317 & 845 & 232 & 15 & 226 & 72 \\
\hline University of Antwerp & 1,007 & 291 & E.F. Vansant & 284 & 141 & 2,674 & 96 & 27 & 81 & 150 \\
\hline University of Arizona & 9,486 & 53 & J.V. Moloney & 440 & 52 & 3,598 & 67 & 34 & 45 & 150 \\
\hline University of Athens & 2,067 & 235 & D. Syvrides & 137 & 293 & 540 & 283 & 12 & 269 & 124 \\
\hline University of Auckland & 3,016 & 194 & S.K. Nguang & 127 & 301 & 755 & 249 & 19 & 171 & 66 \\
\hline
\end{tabular}




\begin{tabular}{|c|c|c|c|c|c|c|c|c|c|c|}
\hline University of Barcelona & 1,578 & 256 & J. Samitier & 226 & 203 & 959 & 223 & 16 & 213 & 150 \\
\hline University of Basel & 577 & 314 & H.J. Guntherodt & 458 & 47 & 7,158 & 25 & 40 & 22 & 150 \\
\hline University of Bath & 3,942 & 164 & D.A.S. Rees & 112 & 316 & 561 & 278 & 14 & 247 & 59 \\
\hline University of Bergen & 371 & 324 & J. Sjoblom & 251 & 177 & 1,475 & 165 & 19 & 171 & 150 \\
\hline University of Bern & 479 & 319 & H.P. Weber & 292 & 133 & 2,397 & 110 & 24 & 112 & 150 \\
\hline University of Birmingham & 5,668 & 112 & P.S. Hall & 212 & 219 & 1,170 & 194 & 17 & 199 & 150 \\
\hline University of Bristol & 5,640 & 113 & D.R. Bull & 258 & 172 & 1,222 & 188 & 16 & 213 & 150 \\
\hline University of British Columbia & 8,537 & 63 & J.R. Grace & 366 & 87 & 2,619 & 97 & 26 & 94 & 150 \\
\hline University of Calgary & 4,686 & 140 & O.P. Malik & 401 & 71 & 1,743 & 145 & 19 & 171 & 150 \\
\hline University of California, Berkley & 21,432 & 7 & J.M. Prausnitz & 532 & 26 & 12,154 & 10 & 30 & 63 & 150 \\
\hline University of California, Davis & 5,036 & 130 & Z.A. Munir & 353 & 95 & 2,783 & 91 & 27 & 81 & 150 \\
\hline University of California, Irvine & 6,739 & 92 & E.J. Lavernia & 493 & 36 & 3,891 & 62 & 32 & 52 & 150 \\
\hline University of California, Los Angeles & 14,526 & 26 & T. Itoh & 567 & 22 & 7,658 & 21 & 37 & 35 & 150 \\
\hline University of California, Riverside & 2,449 & 214 & B. Bhanu & 204 & 226 & 1,298 & 181 & 18 & 187 & 127 \\
\hline University of California, San Diego & 11,296 & 40 & C.W. Tu & 422 & 59 & 3,358 & 71 & 29 & 68 & 150 \\
\hline University of California, San Francisco & 878 & 299 & D. Fried & 144 & 289 & 782 & 244 & 23 & 120 & 129 \\
\hline University of California, Santa Barbara & 8,478 & 65 & U.K. Mishra & 671 & 15 & 12,606 & 9 & 57 & 6 & 150 \\
\hline University of California, Santa Cruz & 1,137 & 283 & J.J. Garcia-Aceves & 264 & 167 & 2,046 & 132 & 25 & 108 & 104 \\
\hline University of Cambridge & 13,133 & 30 & W.I. Milne & 475 & 44 & 5,498 & 40 & 38 & 30 & 150 \\
\hline University of Canterbury & 2,133 & 232 & J.G. Chase & 131 & 297 & 321 & 317 & 13 & 258 & 150 \\
\hline University of Cape Town & 1,073 & 286 & G.A. Ekama & 127 & 301 & 1,220 & 189 & 15 & 226 & 83 \\
\hline University of Central Florida & 7,152 & 82 & \begin{tabular}{|l} 
J.J. Liou \\
\end{tabular} & 271 & 157 & 746 & 251 & 12 & 269 & 150 \\
\hline University of Chicago & 2,102 & 234 & K. Doi & 771 & 13 & 10,393 & 13 & 38 & 30 & 150 \\
\hline University of Cincinnati & 5,952 & 105 & D.P. Agrawal & 330 & 110 & 1,788 & 143 & 19 & 171 & 150 \\
\hline University of Colorado at Boulder & 8,562 & 62 & C.N. Bowman & 252 & 175 & 2,740 & 92 & 38 & 30 & 150 \\
\hline University of Connecticut & 5,282 & 122 & B. Javidi & 429 & 54 & 2,124 & 127 & 43 & 16 & 150 \\
\hline University of Copenhagen & 1,243 & 280 & P. Klaboe & 75 & 328 & 231 & 329 & 1 & 347 & 66 \\
\hline University of Delaware & 5,740 & 109 & S.I. Sandler & 261 & 169 & 2,692 & 95 & 23 & 120 & 150 \\
\hline University of Dundee & 1,442 & 265 & R.K. Dhir & 155 & 275 & 557 & 280 & 12 & 269 & 109 \\
\hline University of Edinburgh & 2,559 & 210 & T. Arslan & 272 & 155 & 354 & 313 & 8 & 319 & 150 \\
\hline University of Florida & 11,412 & 39 & S.J. Pearton & 1,420 & 2 & 20,761 & 5 & 54 & 10 & 150 \\
\hline University of Geneva & 476 & 320 & T. Pun & 140 & 290 & 1,527 & 162 & 17 & 199 & 117 \\
\hline University of Georgia & 639 & 312 & G. Hoogenboom & 161 & 268 & 1,043 & 207 & 17 & 199 & 150 \\
\hline University of Ghent & 5,514 & 116 & D. De Zutter & 249 & 178 & 1,199 & 191 & 18 & 187 & 122 \\
\hline University of Glasgow & 5,046 & 128 & A.Asenov & 246 & 182 & 1,140 & 198 & 23 & 120 & 150 \\
\hline University of Gothenburg & 76 & 344 & P. Thomsen & 130 & 299 & 2,324 & 112 & 19 & 171 & 150 \\
\hline
\end{tabular}




\begin{tabular}{|c|c|c|c|c|c|c|c|c|c|c|}
\hline University of Groningen & 867 & 301 & H.J. Busscher & 429 & 54 & 4,743 & 48 & 34 & 45 & 150 \\
\hline University of Helsinki & 1,363 & 274 & M. Ritala & 280 & 147 & 3,015 & 81 & 38 & 30 & 150 \\
\hline University of Hong Kong & 6,672 & 94 & J. Lam & 328 & 111 & 3,766 & 65 & 42 & 18 & 150 \\
\hline University of Houston & 5,065 & 127 & D. Luss & 150 & 283 & 968 & 221 & 10 & 299 & 81 \\
\hline University of Illinois & 23,442 & 4 & T.S. Huang & 660 & 16 & 9,148 & 17 & 39 & 26 & 150 \\
\hline University of Illinois, Chicago & 6,048 & 102 & A.A. Shabana & 216 & 215 & 919 & 227 & 21 & 147 & 138 \\
\hline University of Indonesia & 166 & 337 & B. Kusumoputro & 23 & 347 & 44 & 346 & 5 & 336 & 28 \\
\hline University of Iowa & 4,912 & 132 & S.M. Reddy & 482 & 41 & 1,719 & 148 & 19 & 171 & 150 \\
\hline University of Kansas & 1,425 & 266 & K.S. Surana & 154 & 276 & 243 & 328 & 5 & 336 & 66 \\
\hline University of Kentucky & 4,529 & 144 & H.S. Tzou & 218 & 212 & 1,206 & 190 & 17 & 199 & 86 \\
\hline University of Lausanne & 103 & 341 & D. Haas & 145 & 288 & 2,546 & 103 & 33 & 48 & 150 \\
\hline University of Leeds & 6,710 & 93 & J. Fisher & 358 & 91 & 3,077 & 76 & 36 & 38 & 150 \\
\hline University of Leicester & 2,012 & 238 & I. Postlethwaite & 244 & 185 & 936 & 225 & 16 & 213 & 150 \\
\hline University of Liverpool & 4,567 & 143 & D.J. Bacon & 236 & 193 & 5,841 & 38 & 30 & 63 & 150 \\
\hline University of Ljubljana & 4,221 & 154 & F. Gubina & 79 & 326 & 332 & 314 & 10 & 299 & 39 \\
\hline University of London (Kings College of London) & 16,113 & 19 & A.H. Aghvami & 271 & 157 & 834 & 235 & 14 & 247 & 150 \\
\hline University of Manchester & 12,114 & 37 & L. Li & 205 & 225 & 819 & 239 & 20 & 159 & 118 \\
\hline University of Manitoba & 4,766 & 137 & L. Shafai & 222 & 205 & 514 & 288 & 9 & 309 & 126 \\
\hline University of Maryland & 15,936 & 20 & K.J. Liu & 359 & 90 & 3,043 & 79 & 30 & 63 & 150 \\
\hline University of Maryland Baltimore County & 3,183 & 191 & C.R. Menyuk & 318 & 116 & 2,697 & 94 & 24 & 112 & 150 \\
\hline University of Massachusetts & 5,738 & 110 & F.E. Karasz & 484 & 39 & 4,988 & 45 & 26 & 94 & 150 \\
\hline University of Melbourne & 5,071 & 126 & R.S. Tucker & 273 & 154 & 1,764 & 144 & 21 & 147 & 150 \\
\hline University of Miami & 2,415 & 215 & J.M. Parel & 290 & 135 & 1,417 & 172 & 15 & 226 & 150 \\
\hline University of Michigan & 1,000 & 293 & D.J. Mooney & 284 & 141 & 7,521 & 22 & 54 & 10 & 150 \\
\hline University of Minnesota & 13,220 & 29 & L.E. Sciven & 414 & 64 & 5,603 & 39 & 19 & 171 & 150 \\
\hline University of Missouri & 9,487 & 52 & G.K. Venayagamoorthy & 239 & 190 & 522 & 286 & 14 & 247 & 130 \\
\hline University of Nebraska & 3,947 & 162 & J. Yang & 147 & 287 & 398 & 303 & 14 & 247 & 80 \\
\hline University of New Hampshire & 1,106 & 285 & M.L. McConnell & 154 & 276 & 1,024 & 210 & 14 & 247 & 150 \\
\hline University of New Mexico & 4,447 & 147 & M.S. El-Genk & 269 & 160 & 610 & 268 & 12 & 269 & 120 \\
\hline University of New South Wales & 8,330 & 67 & M.A. Bradford & 233 & 197 & 699 & 258 & 14 & 247 & 72 \\
\hline University of North Carolina, Chapel Hill & 2,611 & 208 & B.M.W. Tsui & 290 & 135 & 2,090 & 131 & 25 & 108 & 150 \\
\hline University of North Texas & 589 & 313 & W.E. Acree & 439 & 53 & 1,475 & 165 & 26 & 94 & 150 \\
\hline University of Notre Dame & 3,014 & 195 & A. Varma & 27 & 344 & 1,430 & 171 & 17 & 199 & 134 \\
\hline University of Nottingham & 5,960 & 104 & M. Henini & 631 & 19 & 5,964 & 35 & 31 & 57 & 150 \\
\hline University of Oklahoma & 3,880 & 171 & C.W. Bert & 265 & 165 & 1,877 & 140 & 15 & 226 & 113 \\
\hline University of Oregon & 262 & 333 & B.W Matthews & 303 & 128 & 8,777 & 18 & 36 & 38 & 150 \\
\hline
\end{tabular}




\begin{tabular}{|c|c|c|c|c|c|c|c|c|c|c|}
\hline University of Oslo & 643 & 311 & B.G. Svernsson & 300 & 129 & 2,191 & 123 & 24 & 112 & 150 \\
\hline University of Otago & 233 & 335 & T. Rades & 174 & 255 & 1,091 & 204 & 23 & 120 & 150 \\
\hline University of Ottawa & 3,582 & 179 & H. Alper & 415 & 63 & 3,689 & 66 & 28 & 75 & 150 \\
\hline University of Oxford & 4,088 & 157 & D.A. Hills & 264 & 167 & 990 & 217 & 13 & 258 & 112 \\
\hline University of Pennsylvania & 3,872 & 172 & R.J. Gorte & 274 & 152 & 4,479 & 53 & 42 & 18 & 150 \\
\hline University of Pittsburgh & 3,947 & 162 & A.C. Balazs & 241 & 189 & 2,814 & 87 & 33 & 48 & 150 \\
\hline University of Quebec & 4,302 & 152 & S. Kaliaguine & 323 & 115 & 4,280 & 56 & 35 & 41 & 150 \\
\hline University of Queensland & 4,849 & 135 & D.D. Do & 310 & 123 & 2,101 & 130 & 23 & 120 & 109 \\
\hline University of Reading & 2,163 & 230 & K. Warwick & 170 & 261 & 465 & 295 & 11 & 285 & 146 \\
\hline University of Rochester & 3,993 & 160 & P.M. Fauchet & 351 & 97 & 5,053 & 44 & 32 & 52 & 150 \\
\hline University of Saskatchewan & 3,293 & 186 & R. Billinton & 491 & 37 & 1,980 & 136 & 23 & 120 & 150 \\
\hline University of Science and Technology of China & 7,075 & 86 & S. Xu & 221 & 207 & 250 & 327 & 8 & 319 & 139 \\
\hline University of Sheffield & 7,997 & 70 & M. Hopkinson & 522 & 28 & 7,278 & 24 & 32 & 52 & 150 \\
\hline University of South Carolina & 3,265 & 189 & M.A. Sutton & 196 & 233 & 2,591 & 98 & 29 & 68 & 150 \\
\hline University of South Florida & 2,316 & 223 & A. Kandel & 246 & 182 & 1,248 & 184 & 16 & 213 & 150 \\
\hline University of Southampton & 10,044 & 45 & E. Rodgers & 248 & 179 & 686 & 261 & 16 & 213 & 111 \\
\hline University of Southern California & 12,312 & 34 & T.G. Langdon & 613 & 20 & 16,813 & 7 & 58 & 5 & 150 \\
\hline University of St Andrews & 367 & 326 & C. Glidewell & 645 & 17 & 3,399 & 70 & 22 & 137 & 150 \\
\hline University of Surrey & 4,909 & 133 & J.F. Watts & 234 & 196 & 1,995 & 135 & 21 & 147 & 150 \\
\hline University of Sussex & 662 & 309 & P.D. Townsend & 360 & 89 & 2,733 & 93 & 23 & 120 & 150 \\
\hline University of Sydney & 7,271 & 79 & Y.W. Mai & 419 & 61 & 4,659 & 51 & 30 & 63 & 150 \\
\hline University of Technology, Sydney & 1,262 & 279 & S. Vigneswaran & 168 & 262 & 842 & 233 & 15 & 226 & 150 \\
\hline University of Tennessee Knoxville & 4,865 & 134 & P.K. Liaw & 507 & 34 & 2,308 & 116 & 26 & 94 & 150 \\
\hline University of Texas at Austin & 15,702 & 21 & D.R. Paul & 508 & 32 & 16,217 & 8 & 41 & 21 & 150 \\
\hline University of Tokyo & 21,974 & 6 & H. Fujita & 527 & 27 & 4,236 & 57 & 26 & 94 & 150 \\
\hline University of Toronto & 14,025 & 27 & A.N. Venetsanopoulos & 332 & 109 & 1,970 & 137 & 24 & 112 & 140 \\
\hline University of Tsukuba & 4,365 & 149 & T. Yatagai & 275 & 149 & 1,255 & 183 & 19 & 171 & 150 \\
\hline University of Twente & 5,625 & 114 & J.A.M. Kuipers & 177 & 251 & 1,722 & 147 & 26 & 94 & 133 \\
\hline University of Utah & 5,777 & 108 & G.T Gullberg & 260 & 170 & 1,557 & 160 & 18 & 187 & 150 \\
\hline University of Vermont & 1,293 & 278 & A.Campo & 202 & 228 & 658 & 265 & 13 & 258 & 123 \\
\hline University of Victoria & 3,533 & 181 & T.A Gulliver & 269 & 160 & 566 & 276 & 12 & 269 & 131 \\
\hline University of Virginia & 6,912 & 90 & H.N.G. Wadley & 281 & 146 & 1,728 & 146 & 26 & 94 & 150 \\
\hline University of Warwick & 2,888 & 199 & J.W. Gardner & 148 & 286 & 1,943 & 138 & 21 & 147 & 150 \\
\hline University of Washington & 11,053 & 41 & Y. Kim & 317 & 117 & 2,120 & 128 & 23 & 120 & 150 \\
\hline University of Waterloo & 11,540 & 38 & X. Shen & 326 & 114 & 1,394 & 173 & 21 & 147 & 150 \\
\hline University of Western Australia & 3,337 & 185 & L.Faraone & 275 & 149 & 749 & 250 & 17 & 199 & 150 \\
\hline
\end{tabular}




\begin{tabular}{|c|c|c|c|c|c|c|c|c|c|c|}
\hline University of Western Ontario & 4,330 & 151 & W.D. Greason & 123 & 309 & 144 & 334 & 6 & 332 & 19 \\
\hline University of Wisconsin & 13,059 & 31 & Y.A. Chang & 409 & 68 & 2,784 & 90 & 24 & 112 & 150 \\
\hline University of Wollongong & 2,639 & 206 & G.G. Wallace & 508 & 32 & 9,671 & 14 & 40 & 22 & 150 \\
\hline University of York & 682 & 308 & E.R. Hancock & 385 & 77 & 1,111 & 201 & 20 & 159 & 150 \\
\hline University of Zurich & 352 & 328 & A. Pluckthun & 256 & 174 & 6,539 & 32 & 56 & 9 & 150 \\
\hline Univesitas Gadjah Mada & 96 & 342 & S. Kobayashi & 244 & 185 & 1,500 & 163 & 21 & 147 & 150 \\
\hline Uppsala University & 3,396 & 183 & P.Stoica & 509 & 30 & 6,961 & 27 & 34 & 45 & 150 \\
\hline Utah State & 2,044 & 236 & Y. Chen & 183 & 243 & 574 & 273 & 15 & 226 & 146 \\
\hline Utrecht University & 2,299 & 224 & M.A. Viergever & 313 & 121 & 6,626 & 30 & 38 & 30 & 150 \\
\hline Vanderbilt University & 2,612 & 207 & R.D. Schrimpf & 350 & 98 & 1,377 & 174 & 26 & 94 & 150 \\
\hline Victoria University of Wellington & 157 & 338 & H.J. Trodahl & 176 & 253 & 1,033 & 208 & 15 & 226 & 150 \\
\hline Vienna University of Technology & 6,926 & 89 & S. Selberherr & 393 & 73 & 130 & 337 & 16 & 213 & 150 \\
\hline Virginia Polytechnic Institute & 14,718 & 24 & D.J. Inman & 428 & 56 & 2,252 & 119 & 24 & 112 & 150 \\
\hline Vrije Universiteit, Brussels & 18 & 346 & A. Kropivnitskaya & 38 & 342 & 177 & 333 & 9 & 309 & 150 \\
\hline VU University Amsterdam & 1,583 & 255 & D. Lenstra & 207 & 222 & 1,672 & 152 & 22 & 137 & 150 \\
\hline Wageningen University & 765 & 307 & D. Hoekman & 71 & 331 & 281 & 323 & 12 & 269 & 77 \\
\hline Wake Forest University & 267 & 332 & A. Atala & 299 & 131 & 4,520 & 52 & 40 & 22 & 150 \\
\hline Waseda University & 5,297 & 121 & T. Osaka & 479 & 42 & 3,258 & 74 & 31 & 57 & 150 \\
\hline Washington State University & 3,636 & 177 & J. Tang & 171 & 258 & 962 & 222 & 25 & 108 & 150 \\
\hline Washington University in St. Louis & 2,279 & 226 & M.P. Dudukovic & 287 & 139 & 1,895 & 139 & 27 & 81 & 150 \\
\hline Wayne State University & 3,096 & 193 & S.H. Lui & 238 & 191 & 710 & 256 & 16 & 213 & 150 \\
\hline West Virginia University & 3,174 & 192 & N.N. Clark & 166 & 265 & 578 & 271 & 11 & 285 & 150 \\
\hline Yale University & 1,759 & 249 & C. Horvath & 285 & 140 & 4,708 & 49 & 32 & 52 & 150 \\
\hline Yonsei University & 4,337 & 150 & H.K. Baik & 214 & 218 & 1,447 & 168 & 23 & 120 & 150 \\
\hline York University & 503 & 317 & A. Contin & 328 & 111 & 3,866 & 63 & 39 & 26 & 150 \\
\hline Zhejiang University & 19,962 & 9 & K.F. Cen & 1,175 & 3 & 3,060 & 78 & 19 & 171 & 150 \\
\hline
\end{tabular}




\begin{tabular}{|c|c|c|c|c|c|c|c|c|c|c|}
\hline Chemistry Data & $\begin{array}{l}\text { Department } \\
\text { Publications }\end{array}$ & Rank & Most Prolific Author & Published & Rank & Cited & Rank & $\begin{array}{c}\text { H- } \\
\text { Index }\end{array}$ & Rank & $\begin{array}{c}\text { \# of } \\
\text { Coauthors }\end{array}$ \\
\hline Aalto University & 1,816 & 262 & K. Konttoni & 178 & 297 & 1,850 & 248 & 25 & 212 & 150 \\
\hline Aarhus University & 2,536 & 212 & K.A. Jorgensen & 271 & 224 & 5,843 & 105 & 58 & 18 & 150 \\
\hline Arizonia State University & 2,638 & 204 & G.R. Pettit & 570 & 73 & 13,412 & 37 & 35 & 110 & 150 \\
\hline Ateneo de Manila University & 19 & 344 & F.M. Dayrit & 17 & 345 & 193 & 342 & 5 & 332 & 30 \\
\hline Auburn University & 1,959 & 252 & M.L. McKee & 273 & 221 & 2,302 & 222 & 20 & 252 & 150 \\
\hline Australian National University & 5,325 & 74 & L. Radom & 377 & 149 & 10,010 & 60 & 41 & 74 & 150 \\
\hline Boston College & 1,133 & 296 & A.H. Hoveyda & 177 & 299 & 5,874 & 103 & 55 & 24 & 150 \\
\hline Boston University & 1,879 & 258 & H.E. Stanley & 480 & 101 & 10,348 & 58 & 57 & 20 & 150 \\
\hline Brandeis University & 1,813 & 263 & I.R.Epstein & 322 & 197 & 2,551 & 209 & 25 & 212 & 150 \\
\hline Brigham Young University & 2,066 & 245 & R.M. Izatt & 422 & 122 & 5,873 & 104 & 22 & 238 & 150 \\
\hline Brown University & 2,402 & 226 & D.E. Cane & 251 & 240 & 2,498 & 212 & 36 & 101 & 150 \\
\hline California Institute of Technology (Calt... & 8,297 & 34 & H.B. Gray & 606 & 60 & 14,432 & 35 & 46 & 55 & 150 \\
\hline Cardiff University & 3,028 & 177 & M.B. Hursthouse & 1,322 & 5 & 14,637 & 33 & 39 & 85 & 150 \\
\hline Carnegie Mellon University & 3,342 & 155 & J.A. Pople & 418 & 124 & 32,291 & 4 & 29 & 161 & 150 \\
\hline Case Western Reserve University & 4,324 & 111 & G.A. Olah & 961 & 18 & 11,480 & 47 & 29 & 161 & 150 \\
\hline Chalmers University of Technology & 3,267 & 161 & B. Kasemo & 374 & 151 & 7,056 & 92 & 48 & 50 & $\overline{150}$ \\
\hline Charles University & 3,613 & 141 & I. Cisarova & 369 & 153 & 1,928 & 240 & 23 & 228 & 150 \\
\hline Chinese University of Hong Kong & 2,200 & 239 & T.C.W. Mak & 803 & 28 & 10,230 & 59 & 40 & 80 & 150 \\
\hline Chulalongkorn University & 1,535 & 275 & P. Praserthdam & 211 & 273 & 852 & 306 & 16 & 287 & 150 \\
\hline City University of Hong Kong & 1,242 & 288 & N.B. Wong & 155 & 314 & 1,859 & 245 & 23 & 228 & 150 \\
\hline City University of New York & 2,452 & 220 & R. Bittman & 249 & 242 & 3,526 & 161 & 27 & 191 & 150 \\
\hline Colorado State University & 2,945 & 183 & A.I. Meyers & 347 & 176 & 5,124 & 121 & 26 & 202 & 150 \\
\hline Columbia University & 6,983 & 43 & \begin{tabular}{|l|} 
N.J. Turro \\
\end{tabular} & 747 & 34 & 16,037 & 29 & 41 & 74 & 150 \\
\hline Cornell University & 9,152 & 25 & R.Hoffmann & 484 & 100 & 11,595 & 46 & 25 & 212 & 150 \\
\hline Curtin University of Technology & 702 & 320 & R. DeMarco & 71 & 340 & 384 & 335 & 14 & 299 & 92 \\
\hline Dalhousie University & 2,252 & 235 & \begin{tabular}{|l|} 
J.R. Datin \\
\end{tabular} & 406 & 135 & 7,651 & 87 & 50 & 44 & 150 \\
\hline Dartmouth College & 1,354 & 283 & G.W. Gribble & 253 & 237 & 3,021 & 182 & 33 & 125 & 150 \\
\hline Delft University of Technology & 3,603 & 142 & J.A. Moulijn & 632 & 52 & 1,068 & 295 & 51 & 38 & 150 \\
\hline Drexel University & 1,496 & 279 & F.A. Davis & 221 & 263 & 3,528 & 160 & 36 & 101 & 150 \\
\hline Duke University & 3,772 & 135 & C.R. Hauser & 393 & 142 & 1,662 & 258 & 6 & 328 & 150 \\
\hline Durham University & 4,057 & 117 & J.A.K. Howard & 792 & 29 & 10,618 & 54 & 46 & 55 & 150 \\
\hline Ecole Normale Supérieure de Lyon & 577 & 326 & L. Emsley & 145 & 317 & 1,677 & 256 & 31 & 137 & 150 \\
\hline École Normale Supérieure, Paris & 1,522 & 277 & C. Amatore & 325 & 193 & 4,326 & 141 & 30 & 149 & 150 \\
\hline École Polytechnique & 2,463 & 218 & L. Ricard & 342 & 180 & 2,669 & 202 & 26 & 202 & 150 \\
\hline
\end{tabular}




\begin{tabular}{|c|c|c|c|c|c|c|c|c|c|c|}
\hline Ecole Polytechnique Fédérale de Lausanne & 2,961 & 182 & M. Gratzel & 663 & 42 & 41,017 & 2 & 79 & 4 & 150 \\
\hline Eindhoven University of Technology & 3,451 & 149 & E.W. Meijn & 493 & 95 & 11,926 & 44 & 67 & 9 & 150 \\
\hline Emory University & 3,207 & 163 & A. Padwa & 612 & 59 & 9,843 & 62 & 35 & 110 & 150 \\
\hline Erasmus University Rotterdam & 221 & 335 & G.J. Puppels & 106 & 330 & 1,819 & 251 & 27 & 191 & 150 \\
\hline ETH Zurich (Swiss Federal Institute of Technology) & 8,726 & 31 & F. Diederich & 428 & 121 & 10,475 & 57 & 51 & 38 & 150 \\
\hline Florida International University & 712 & 319 & A.M. Mebel & 269 & 226 & 3,050 & 180 & 31 & 137 & 150 \\
\hline Florida State University & 3,327 & 157 & W. Herz & 443 & 113 & 1,573 & 268 & 13 & 307 & 150 \\
\hline Freie Universität Berlin & 5,389 & 71 & P. Luger & 219 & 266 & 2,890 & 187 & 20 & 252 & 150 \\
\hline Friedrich Alexander Universität Erlangen Nürnberg & 5,557 & 66 & R. Van Eldik & 541 & 79 & 2,654 & 203 & 34 & 119 & 150 \\
\hline Fudan University & 5,111 & 79 & M. Zhou & 193 & 288 & 1,219 & 288 & 29 & 161 & 131 \\
\hline Georg August Universität Göttingen & 4,322 & 112 & H.W. Roesky & 530 & 83 & 7,608 & 88 & 34 & 119 & 150 \\
\hline George Mason University & 221 & 335 & G.W. Mushrush & 166 & 303 & 304 & 337 & 6 & 328 & 103 \\
\hline George Washington University & 699 & 321 & A. Montaser & 102 & 332 & 712 & 315 & 19 & 265 & 125 \\
\hline Georgetown University & 1,518 & 278 & M.T. Pope & 157 & 309 & 3,339 & 169 & 23 & 228 & 150 \\
\hline Georgia Institute of Technology & 4,701 & 94 & E.C. Ashby & 248 & 244 & 1,088 & 294 & 2 & 337 & 128 \\
\hline Georgia State University & 880 & 313 & D.W. Boykin & 250 & 241 & 1,851 & 247 & 35 & 110 & 150 \\
\hline Goteborg University & 4,781 & 91 & B. Norden & 320 & 199 & 5,308 & 116 & 36 & 101 & 150 \\
\hline Harvard University & 8,111 & 36 & E.J. Corey & 935 & 20 & 31,203 & 5 & 48 & 50 & 150 \\
\hline Hebrew University of Jerusalem & 7,032 & 42 & I. Willner & 486 & 99 & 102 & 343 & 67 & 9 & 150 \\
\hline Heidelberg Universität & 4,581 & 100 & R. Gleiter & 431 & 118 & 2,528 & 210 & 20 & 252 & 150 \\
\hline Hokkaido University & 9,660 & 22 & J. Kobayashi & 713 & 37 & 2,088 & 231 & 34 & 119 & 150 \\
\hline Hong Kong Polytechnic University & 1,660 & 267 & A.S.C. Chan & 252 & 239 & 4,268 & 145 & 39 & 85 & 150 \\
\hline Hong Kong University of Science \& Techno... & 2,189 & 240 & Z. Lin & 210 & 274 & 2,818 & 191 & 29 & 161 & 150 \\
\hline Humboldt-Universität zu Berlin & 48 & 341 & F. Pragst & 93 & 334 & 743 & 313 & 19 & 265 & 150 \\
\hline Imperial College London & 10,882 & 14 & D.J. Wiliams & 1,198 & 9 & 30,718 & 6 & 57 & 20 & 150 \\
\hline Indian Institute of Technology Bombay (I... & 2,230 & 236 & P. Mathur & 141 & 318 & 428 & 330 & 14 & 299 & 138 \\
\hline Indian Institute of Technology Delhi (II... & 1,648 & 269 & A.S. Brar & 165 & 305 & 428 & 330 & 14 & 299 & 119 \\
\hline Indian Institute of Technology Kanpur (I... & 2,569 & 209 & V. Chandrasekhar & 197 & 285 & 1,825 & 250 & 29 & 161 & 150 \\
\hline Indiana University Bloomington & 5,463 & 69 & J.C. Huffman & 780 & 32 & 12,354 & 43 & 33 & 125 & 150 \\
\hline Indiana University Indianapolis & 270 & 334 & Q.H. Zheng & 127 & 326 & 795 & 309 & 19 & 265 & 150 \\
\hline Iowa State University & 8,853 & 29 & J.H. Espenson & 394 & 141 & 2,559 & 207 & 25 & 212 & 150 \\
\hline Johns Hopkins University & 4,594 & 98 & G.H. Posner & 263 & 232 & 4,513 & 136 & 33 & 125 & 150 \\
\hline Kansas State University & 2,557 & 210 & D.W. Setser & 309 & 203 & 1,359 & 279 & 14 & 299 & 150 \\
\hline Katholieke Universiteit Leuven & 5,512 & 67 & E. DeClercq & 1,641 & 1 & 49,335 & 1 & 72 & 7 & 150 \\
\hline Keio University & 3,095 & 171 & S. Yamamura & 375 & 150 & 1,628 & 263 & 20 & 252 & 150 \\
\hline
\end{tabular}




\begin{tabular}{|c|c|c|c|c|c|c|c|c|c|c|}
\hline King Fahd University of Petroleum \& Minerals & 1,156 & 293 & H.M. Badawi & 133 & 323 & 233 & 340 & 10 & 321 & 66 \\
\hline King Saud University & 1,184 & 291 & F.S. El-Ferly & 129 & 325 & 923 & 303 & 13 & 307 & 150 \\
\hline Kobe University & 3,083 & 172 & M. Okubo & 279 & 219 & 1,669 & 257 & 23 & 228 & 150 \\
\hline Korea Advanced Institute of Science \& Technology & 3,518 & 146 & S.I. Pyun & 240 & 252 & 1,421 & 275 & 21 & 246 & 134 \\
\hline Korea University & 2,363 & 229 & J. Ko & 198 & 283 & 1,355 & 280 & 23 & 228 & 150 \\
\hline Kyoto University & 21,812 & 1 & K. Oshima & 410 & 131 & 3,975 & 151 & 31 & 137 & 150 \\
\hline Kyushu University & 9,755 & 20 & S. Shinkai & 823 & 27 & 22,798 & 13 & 60 & 14 & 150 \\
\hline La Trobe University & 1,325 & 285 & A.M. Bond & 557 & 75 & 7,332 & 90 & 27 & 191 & 150 \\
\hline Lancaster University & 529 & 329 & K.C. Jones & 448 & 111 & 6,609 & 95 & 54 & 26 & 150 \\
\hline Leiden University & 4,471 & 106 & J. Reedijk & 1,013 & 16 & 17,105 & 25 & 41 & 74 & 150 \\
\hline Linkoping University & 1,483 & 281 & I. Lundstrom & 479 & 102 & 6,230 & 99 & 34 & 119 & 150 \\
\hline London School of Economics and Political Science & 13 & 346 & A.C. Atkinson & 60 & 342 & 523 & 325 & 12 & 312 & 98 \\
\hline Loughborough University & 2,910 & 185 & A.G. Fogg & 213 & 271 & 846 & 307 & 12 & 312 & 150 \\
\hline Louisiana State University & 3,011 & 179 & F.R. Fronczek & 589 & 64 & 5,164 & 120 & 27 & 191 & 150 \\
\hline Ludwig-Maximilians-Universität München & 6,177 & 57 & H. Noth & 390 & 144 & 2,943 & 186 & 28 & 181 & 150 \\
\hline Lund University & 6,670 & 48 & B. Lindman & 415 & 125 & 5,550 & 110 & 34 & 119 & 150 \\
\hline Maastricht University & 220 & 337 & P.M. Fredrik & 121 & 329 & 3,093 & 178 & 26 & 202 & 150 \\
\hline Macquarie University & 559 & 327 & R.S. Vagg & 87 & 337 & 385 & 333 & 5 & 332 & 53 \\
\hline Mahidol University & 996 & 307 & V. Reutrakul & 122 & 327 & 1,197 & 290 & 16 & 287 & 150 \\
\hline Masaryk University & 1,290 & 286 & J. Havel & 177 & 299 & 1,121 & 292 & 21 & 246 & 150 \\
\hline Massachusetts Institute of Technology & 12,006 & 11 & D. Seyferth & 577 & 66 & 4,515 & 135 & 9 & 325 & 150 \\
\hline McGill University & 4,404 & 108 & I.S.Bulter & 285 & 213 & 1,460 & 273 & 15 & 293 & 150 \\
\hline McMaster University & 3,479 & 148 & R.J. Gillespie & 214 & 269 & 1,270 & 285 & 17 & 278 & 150 \\
\hline Michigan State University & 5,050 & 82 & H. Hart & 281 & 218 & 23 & 345 & 2 & 337 & 150 \\
\hline Michigan Technological University & 860 & 314 & R.L. Luck & 93 & 334 & 502 & 327 & 12 & 312 & 112 \\
\hline Monash University & 3,961 & 125 & G.B. Deacon & 356 & 165 & 2,968 & 184 & 28 & 181 & 150 \\
\hline Montana State University & 1,270 & 287 & T. Livinghouse & 86 & 338 & 1,590 & 265 & 20 & 252 & 78 \\
\hline Moscow State University & 14,415 & 5 & I.P. Belletskaya & 321 & 198 & 943 & 300 & 10 & 321 & 150 \\
\hline Nagoya University & 10,223 & 15 & R. Noyori & 408 & 132 & 11,261 & 50 & 50 & 44 & 150 \\
\hline Nanjing University & 5,612 & 64 & H.Y. Chen & 432 & 116 & 5,237 & 117 & 42 & 68 & 150 \\
\hline Nanyang Technological University & 2,052 & 246 & K.C.Tam & 205 & 278 & 2,143 & 227 & 30 & 149 & 150 \\
\hline National Taiwan University & 5,300 & 75 & G.H. Lee & 621 & 55 & 7,846 & 84 & 36 & 101 & 150 \\
\hline National Tsing Hua University & 3,841 & 132 & S.L. Wang & 183 & 294 & 1,576 & 267 & 24 & 222 & 150 \\
\hline National University of Ireland, Galway & 720 & 318 & P. McAdle & 156 & 310 & 600 & 322 & 10 & 321 & 150 \\
\hline National University of Singapore & 600 & 325 & J.J. Vittal & 357 & 164 & 3,898 & 154 & 32 & 131 & 150 \\
\hline New Mexico State University & 1,350 & 284 & J. Y. Wang & 613 & 58 & 8,542 & 75 & 76 & 6 & 150 \\
\hline
\end{tabular}




\begin{tabular}{|c|c|c|c|c|c|c|c|c|c|c|}
\hline New York University & 2,837 & 191 & D.I. Schuster & 195 & 287 & 2,359 & 218 & 25 & 212 & 150 \\
\hline Newcastle University & 3,671 & 137 & W. Clegg & 615 & 57 & 7,787 & 85 & 37 & 95 & 150 \\
\hline North Carolina State University & 4,496 & 104 & M.H. Whangbo & 468 & 105 & 5,447 & 112 & 29 & 161 & 150 \\
\hline Northeastern University & 2,112 & 244 & B.L. Karger & 247 & 245 & 5,378 & 113 & 36 & 101 & 150 \\
\hline Northwestern University & 9,768 & 19 & J.A. Ibers & 655 & 47 & 9,166 & 69 & 20 & 252 & 150 \\
\hline Norwegian University of Science \& Technology & 2,413 & 223 & S.J. Cyvin & 150 & 315 & 518 & 326 & 5 & 332 & 126 \\
\hline Ohio State University & 9,781 & 18 & L.A. Paquette & 1,166 & 11 & 9,902 & 61 & 31 & 137 & 150 \\
\hline Oklahoma State University & 1,886 & 257 & E.M. Holt & 197 & 285 & 1,353 & 281 & 11 & 319 & 150 \\
\hline Open University UK & 771 & 316 & A.R. Bassindale & 88 & 336 & 561 & 324 & 12 & 312 & 96 \\
\hline Oregon State University & 3,069 & 174 & J.D. White & 193 & 288 & 2,244 & 224 & 22 & 238 & 150 \\
\hline Osaka University & 15,905 & 4 & S. Fukuzumi & 525 & 84 & 9,763 & 64 & 47 & 53 & 150 \\
\hline Peking University & 7,348 & 40 & S. Gao & 367 & 154 & 4,599 & 132 & 45 & 60 & 150 \\
\hline Pennsylvania State University & 8,986 & 26 & A.W. Castleman & 435 & 115 & 4,280 & 143 & 30 & 149 & 150 \\
\hline Pohang University of Science And Technology & 2,377 & 228 & K.Kim & 178 & 297 & 4,800 & 130 & 45 & 60 & 150 \\
\hline Portland State University & 458 & 330 & G.L. Gard & 188 & 291 & 665 & 318 & 17 & 278 & 150 \\
\hline Princeton University & 6,179 & 56 & E.C. Taylor & 391 & 143 & 2,401 & 217 & 10 & 321 & 150 \\
\hline Purdue University & 12,019 & 10 & H.C. Brown & 1,100 & 13 & 12,460 & 42 & 18 & 274 & 150 \\
\hline Queen's University & 2,756 & 199 & E. Buncel & 244 & 248 & 1,376 & 277 & 20 & 252 & 150 \\
\hline Queen's University of Belfast & 2,987 & 180 & D.R. Boyd & 222 & 262 & 964 & 297 & 16 & 287 & 150 \\
\hline Queensland University of Technology & 1,072 & 302 & R.L. Frost & 602 & 62 & 8,154 & 79 & 40 & 80 & 150 \\
\hline Radboud University, Nijmegen & 2,860 & 188 & B. Zwaneburg & 289 & 212 & 2,003 & 235 & 20 & 252 & 150 \\
\hline Rensselaer Polytechnic Institute & 2,411 & 224 & K.T. Potts & 162 & 306 & 1,237 & 286 & 2 & 337 & 150 \\
\hline Rheinisch Westfalische Technische Hochschule Aach & 4,013 & 123 & D. Enders & 367 & 154 & 5,675 & 108 & 41 & 74 & 150 \\
\hline Rheinische Friedrich Wilhelms Universitat Bonn & 4,800 & 90 & M. Nieger & 413 & 128 & 28 & 344 & 28 & 181 & 150 \\
\hline Rice University & 2,768 & 198 & J.L. Margrave & 421 & 123 & 4,735 & 131 & 23 & 228 & 150 \\
\hline Rochester Institute of Technology & 295 & 333 & S.G. Kandlikar & 186 & 292 & 1,336 & 282 & 23 & 228 & 101 \\
\hline Royal Institute of Technology, KTH & 3,940 & 127 & P.M. Claessen & 212 & 272 & 2,810 & 193 & 27 & 191 & 150 \\
\hline Royal Melbourne Institute of Technology & 669 & 323 & P.J. Marriott & 208 & 276 & 1,465 & 272 & 28 & 181 & 150 \\
\hline Rutgers & 5,233 & 77 & R.A. Moss & 348 & 175 & 1,487 & 270 & 19 & 265 & 150 \\
\hline Saint-Petersburg State University & 4,972 & 85 & V.Y. Kubushkin & 146 & 316 & 948 & 299 & 28 & 181 & 150 \\
\hline San Diego State University & 605 & 324 & M.A. Ring & 67 & 341 & 292 & 338 & 2 & 337 & 69 \\
\hline Sapienza University of Rome & 0 & 348 & & 0 & 348 & 0 & 347 & 0 & 343 & 0 \\
\hline Sciences Po Paris & 1 & 347 & A. Sontot & 1 & 347 & 1 & 346 & 1 & 342 & 0 \\
\hline Seoul National University & 6,252 & 54 & K. Kim & 220 & 264 & 2,771 & 194 & 29 & 161 & 150 \\
\hline Shanghai Jiao Tong University & 2,504 & 216 & D. Dan & 367 & 154 & 2,982 & 183 & 81 & 3 & 150 \\
\hline Simon Fraser University & 1,600 & 271 & F.W.B. Einstein & 238 & 253 & 1,661 & 259 & 13 & 307 & 150 \\
\hline
\end{tabular}




\begin{tabular}{|c|c|c|c|c|c|c|c|c|c|c|}
\hline Stanford University & 9,898 & 16 & C. Djerassi & 880 & 25 & 4,364 & 140 & 2 & 337 & 150 \\
\hline State University of New York Buffalo & 57 & 340 & S. Kumar & 365 & 157 & 1,806 & 252 & 19 & 265 & 150 \\
\hline Stockholm University & 3,350 & 154 & P.E.M. Siegbahn & 331 & 190 & 6,057 & 101 & 43 & 65 & 150 \\
\hline Stony Brook University & 2,941 & 184 & I. Ojima & 261 & 234 & 4,009 & 150 & 29 & 161 & 150 \\
\hline Syracuse University & 2,660 & 202 & J. Zubieta & 518 & 86 & 17,598 & 22 & 56 & 22 & 150 \\
\hline Tartu University (University of Tartu) & 1,045 & 306 & E. Lust & 137 & 320 & 385 & 333 & 17 & 278 & 80 \\
\hline Technical University of Denmark & 3,335 & 156 & J. Ulstrup & 227 & 260 & 1,969 & 238 & 27 & 191 & 150 \\
\hline Technion & 3,065 & 175 & Y. Apeloig & 161 & 307 & 1,980 & 237 & 20 & 252 & 150 \\
\hline Technische Universität Berlin & 5,044 & 83 & F. Bohlmann & 780 & 32 & 4,938 & 126 & 0 & 343 & 150 \\
\hline Technische Universitat Chemnitz & 1,061 & 304 & H. Lang & 295 & 209 & 1,858 & 246 & 24 & 222 & 150 \\
\hline Technische Universität Dresden & 3,097 & 170 & W.D. Habicher & 159 & 308 & 699 & 317 & 14 & 299 & 150 \\
\hline Technische Universität München & 7,499 & 38 & W.A. Herrmann & 513 & 89 & 20,112 & 17 & 53 & 28 & 150 \\
\hline Tel Aviv University & 2,784 & 197 & J. Jortner & 577 & 66 & 10,562 & 55 & 32 & 131 & 150 \\
\hline Texas A\&M University & 8,919 & 27 & F.A. Cotton & 882 & 24 & 18,645 & 20 & 40 & 80 & 150 \\
\hline Texas Tech & 1,864 & 260 & R.A. Bartsch & 345 & 178 & 2,817 & 192 & 25 & 212 & 150 \\
\hline Tohoku University & 12,908 & 9 & Y. Yamamoto & 653 & 48 & 15,193 & 31 & 52 & 32 & 150 \\
\hline Tokyo Institute of Technology & 11,982 & 12 & T. Yamamoto & 532 & 82 & 8,140 & 80 & 33 & 125 & 150 \\
\hline Trinity College Dublin & 1,690 & 265 & W.J. Blau & 405 & 136 & 4,875 & 127 & 39 & 85 & 150 \\
\hline Tsinghua University & 5,890 & 59 & Y.F. Zhao & 496 & 93 & 1,421 & 275 & 19 & 265 & 150 \\
\hline Tufts University & 1,156 & 293 & D.R. Walt & 202 & 281 & 3,524 & 162 & 35 & 110 & 150 \\
\hline Universidad Autonoma de Madrid & 4,022 & 120 & M. Yanez & 291 & 210 & 2,337 & 219 & 29 & 161 & 150 \\
\hline Universidad de Chile & 2,166 & 242 & J.A. Squella & 176 & 301 & 790 & 310 & 18 & 274 & 150 \\
\hline Universidad de Granada & 4,022 & 120 & M. Yanez & 291 & 210 & 2,337 & 219 & 29 & 161 & 150 \\
\hline Universidad del País Vasco & 3,081 & 173 & T. Rojo & 270 & 225 & 2,865 & 188 & 29 & 161 & 150 \\
\hline Universidad Nacional Autónoma de México ... & 3,315 & 158 & A.F. Jallout & 273 & 221 & 601 & 321 & 14 & 299 & 150 \\
\hline Universidad Politecnica de Madrid & 555 & 328 & J. Losada & 73 & 339 & 951 & 298 & 18 & 274 & 79 \\
\hline Universidade de São Paulo & 6,632 & 50 & E.E. Castellano & 337 & 185 & 2,026 & 234 & 20 & 252 & 150 \\
\hline Universidade Estadual de Campinas & 4,713 & 93 & C. Airoldi & 340 & 182 & 1,678 & 255 & 29 & 161 & 150 \\
\hline Università degli Studi di Firenze & 5,421 & 70 & C.T. Supuran & 644 & 50 & 15,592 & 30 & 59 & 16 & 150 \\
\hline Università degli Studi di Padova & 5,100 & 81 & C. Toniolo & 557 & 75 & 8,730 & 73 & 32 & 131 & 150 \\
\hline Universita Di Bologna & 7,459 & 39 & V. Balzani & 354 & 167 & 9,539 & 67 & 59 & 16 & 150 \\
\hline Universita di Pisa & 3,814 & 133 & F. Calderazzo & 210 & 274 & 930 & 302 & 14 & 299 & 150 \\
\hline Universitat Autonoma de Barcelona & 3,406 & 152 & A. Liedos & 199 & 282 & 2,223 & 225 & 30 & 149 & 150 \\
\hline Universitat Bielefeld & 1,889 & 256 & H.G. Stammeler & 249 & 242 & 1,886 & 242 & 25 & 212 & 150 \\
\hline Universität Bremen & 1,606 & 270 & E. Lork & 205 & 278 & 916 & 304 & 17 & 278 & 150 \\
\hline Universitat d'Alacant & 2,015 & 249 & M.Yus & 432 & 116 & 5,013 & 122 & 44 & 62 & 150 \\
\hline
\end{tabular}




\begin{tabular}{|c|c|c|c|c|c|c|c|c|c|c|}
\hline Universitat de València & 5,890 & 59 & F. Lloret & 324 & 194 & 4,941 & 125 & 47 & 53 & 150 \\
\hline Universität Frankfurt am Main & 4,020 & 122 & M. Bolte & 617 & 56 & 4,536 & 133 & 29 & 161 & 150 \\
\hline Universität Freiburg & 3,653 & 139 & H. Vahrenkamp & 217 & 267 & 1,934 & 239 & 28 & 181 & 150 \\
\hline Universitat Hamburg & 3,677 & 136 & H.R. Kricheldorf & 467 & 106 & 3,351 & 168 & 31 & 137 & 150 \\
\hline Universität Karlsruhe & 3,847 & 130 & D. Fenske & 302 & 205 & 4,044 & 149 & 39 & 85 & 150 \\
\hline Universitat Leipzig & 4,577 & 101 & J. Karger & 350 & 171 & 2,311 & 221 & 29 & 161 & 150 \\
\hline Universitat Munster (Westfälische Wilhelms-Un & 3,806 & 134 & R. Frohlich & 641 & 51 & 8,753 & 72 & 37 & 95 & 150 \\
\hline Universitat Politecnica de Catalunya & 810 & 315 & C. Aleman & 268 & 228 & 1,431 & 274 & 22 & 238 & 150 \\
\hline Universität Regensburg & 3,864 & 129 & H. Brunner & 342 & 180 & 2,698 & 199 & 22 & 238 & 150 \\
\hline Universität Stuttgart & 3,619 & 140 & W. Kaim & 449 & 109 & 3,520 & 163 & 31 & 137 & 150 \\
\hline Universitat Trier & 39 & 342 & A. Meyer & 261 & 234 & 8,788 & 71 & 52 & 32 & 150 \\
\hline Universität Tübingen & 4,075 & 116 & H. Oberhammer & 265 & 230 & 1,223 & 287 & 15 & 293 & 150 \\
\hline Universitat Wien (University of Vienna) & 6,306 & 53 & H. Novotny & 299 & 206 & 1,693 & 254 & 0 & 343 & 136 \\
\hline Universitat Zu Koln & 2,690 & 201 & G. Meyer & 336 & 187 & 2,852 & 189 & 19 & 265 & 150 \\
\hline Université Catholique de Louvain & 2,593 & 207 & J.P. Declercq & 215 & 268 & 1,640 & 261 & 19 & 265 & 150 \\
\hline Universite de Liege & 2,506 & 215 & R. Jerome & 340 & 182 & 5,320 & 115 & 41 & 74 & 150 \\
\hline Université de Montréal & 2,867 & 187 & S. Hannessian & 389 & 146 & 5,842 & 106 & 34 & 119 & 150 \\
\hline Université de Nice Sophia Antipolis & 1,058 & 305 & A. Cambon & 122 & 327 & 567 & 323 & 13 & 307 & 125 \\
\hline Universite Laval & 1,572 & 272 & S. Kaliaguine & 323 & 195 & 4,526 & 134 & 35 & 110 & 150 \\
\hline Universite Libre de Bruxelles & 2,210 & 238 & J.M. Ruysschaert & 352 & 169 & 4,292 & 142 & 33 & 125 & 150 \\
\hline Université Paris Sorbonne & 306 & 331 & C. Duval & 7 & 346 & 0 & 347 & 0 & 343 & 2 \\
\hline Universite Paris-Sud 11 & 7,932 & 37 & R. Hocquemiller & 203 & 280 & 1,369 & 278 & 20 & 252 & 150 \\
\hline Université Pierre et Marie Curie & 8,673 & 33 & B. Asman & 408 & 132 & 3,558 & 158 & 29 & 161 & 150 \\
\hline Universiti Malaya (University of Malaya) & 1,845 & 261 & S.W. Ng & 1,108 & 12 & 3,409 & 165 & 16 & 287 & 150 \\
\hline University College Cork & 1,496 & 279 & P.F. Fox & 242 & 249 & 2,697 & 200 & 32 & 131 & 150 \\
\hline University College Dublin & 1,793 & 264 & A.R. Manning & 176 & 301 & 439 & 329 & 11 & 319 & 150 \\
\hline University College London & 8,704 & 32 & R.J.H. Clark & 349 & 173 & 2,278 & 223 & 27 & 191 & 150 \\
\hline University do Porto & 1,545 & 274 & A.E. Rodrigues & 327 & 191 & 2,143 & 227 & 27 & 191 & 150 \\
\hline University of Aberdeen & 2,347 & 230 & J.N.Low & 429 & 120 & 977 & 296 & 17 & 278 & 150 \\
\hline University of Adelaide & 2,629 & 205 & M.I. Bruce & 407 & 134 & 2,501 & 211 & 26 & 202 & 150 \\
\hline University of Alabama & 2,799 & 193 & J.L. Atwood & 571 & 72 & 14,695 & 32 & 43 & 65 & 150 \\
\hline University of Alberta & 6,652 & 49 & J.W. Lown & 362 & 161 & 2,958 & 185 & 22 & 238 & 150 \\
\hline University of Amsterdam & 4,529 & 103 & D.J. Stufkens & 253 & 237 & 1,867 & 244 & 23 & 228 & 150 \\
\hline University of Antwerp & 2,787 & 196 & E.F. Vansant & 284 & 214 & 2,674 & 201 & 27 & 191 & 150 \\
\hline University of Arizona & 4,935 & 86 & V.J. Hruby & 788 & 31 & 16,959 & 26 & 42 & 68 & 150 \\
\hline University of Athens & 1,899 & 255 & M. Koupparis & 156 & 310 & 1,100 & 293 & 16 & 287 & 150 \\
\hline
\end{tabular}




\begin{tabular}{|c|c|c|c|c|c|c|c|c|c|c|}
\hline University of Auckland & 2,534 & 213 & W.A. Denny & 490 & 96 & 4,960 & 123 & 38 & 92 & 150 \\
\hline University of Barcelona & 6,694 & 47 & X. Solans & 495 & 94 & 4,210 & 147 & 30 & 149 & 150 \\
\hline University of Basel & 3,133 & 168 & J.P. Maier & 340 & 182 & 1,628 & 263 & 26 & 202 & 150 \\
\hline University of Bath & 2,525 & 214 & M.F. Mahon & 372 & 152 & 3,154 & 176 & 30 & 149 & 150 \\
\hline University of Bergen & 891 & 311 & P.M. Ueland & 333 & 189 & 9,797 & 63 & 50 & $\overline{44}$ & 150 \\
\hline University of Bern & 1,666 & 266 & H.U. Gudel & 449 & 109 & 4,840 & 128 & 39 & 85 & 150 \\
\hline University of Birmingham & 4,607 & 97 & J.F. Stoddart & 559 & 74 & 27,990 & 7 & 78 & 5 & 150 \\
\hline University of Bristol & 6,943 & 44 & F.G.A. Stone & 662 & 44 & 2,049 & 232 & 17 & 278 & 150 \\
\hline University of British Columbia & 5,510 & 68 & S.G. Withers & 365 & 157 & 4,451 & 137 & 44 & 62 & 150 \\
\hline University of Calgary & 2,403 & 225 & M. Parvez & 518 & 86 & 5,363 & 114 & 29 & 161 & 150 \\
\hline University of California, Berkley & 13,645 & 6 & G.A. Somorjai & 693 & 39 & 18,065 & 21 & 46 & 55 & 150 \\
\hline University of California, Davis & 5,666 & 62 & M.M. Olmstead & 572 & 71 & 11,329 & 49 & 42 & 68 & 150 \\
\hline University of California, Irvine & 3,315 & 158 & J.W. Ziller & 362 & 161 & 6,696 & 94 & 37 & 95 & 150 \\
\hline University of California, Los Angeles & 7,280 & 41 & K.N. Houk & 657 & 46 & 21,465 & 14 & 56 & 22 & 150 \\
\hline University of California, Riverside & 3,539 & 144 & D.T. Saywer & 238 & 253 & 2,460 & 213 & 5 & 332 & 150 \\
\hline University of California, San Diego & 4,820 & 89 & A.L. Rheingold & 1,473 & 4 & 25,525 & 10 & 52 & 32 & 150 \\
\hline University of California, San Francisco & 1,950 & 253 & P.A. Kollman & 412 & 130 & 17,341 & 24 & 51 & 38 & 150 \\
\hline University of California, Santa Barbara & 4,853 & 88 & T.C. Bruice & 547 & 77 & 7,848 & 83 & 30 & 149 & 150 \\
\hline University of California, Santa Cruz & 1,125 & 297 & A.L. Fink & 207 & 277 & 6,307 & 97 & 51 & 38 & 150 \\
\hline University of Cambridge & 13,410 & 7 & P.R. Raithby & 665 & 41 & 6,305 & 98 & 28 & 181 & 150 \\
\hline University of Canterbury & 1,872 & 259 & P.J. Steel & 273 & 221 & 2,758 & 196 & 23 & 228 & 150 \\
\hline University of Cape Town & 1,108 & 299 & L.R. Nassimbeni & 198 & 283 & 784 & 311 & 14 & 299 & 145 \\
\hline University of Central Florida & 882 & 312 & S.Seal & 236 & 255 & 2,556 & 208 & 31 & 137 & 150 \\
\hline University of Chicago & 5,583 & 65 & S.A. Rice & 575 & 68 & 7,665 & 86 & 26 & 202 & 150 \\
\hline University of Cincinnati & 3,664 & 138 & J.A. Caruso & 278 & 220 & 2,647 & 204 & 31 & 137 & 150 \\
\hline University of Colorado at Boulder & 4,363 & 110 & T.R. Cech & 312 & 201 & 8,896 & 70 & 49 & 48 & 150 \\
\hline University of Connecticut & 2,347 & 230 & S.L. Suib & 390 & 144 & 4,126 & 148 & 36 & 101 & 150 \\
\hline University of Copenhagen & 3,843 & 131 & L.H. Skibsted & 350 & 171 & 3,047 & 181 & 32 & 131 & 150 \\
\hline University of Delaware & 5,042 & 84 & A.L. Rheingold & 1,575 & 3 & 25,528 & 9 & 54 & 26 & 150 \\
\hline University of Dundee & 1,187 & 290 & C.H. Rochester & 257 & 236 & 1,636 & 262 & 12 & 312 & 150 \\
\hline University of Edinburgh & 4,590 & 99 & S. Parsons & 573 & 70 & 8,207 & 78 & 42 & 68 & 150 \\
\hline University of Florida & 8,907 & 28 & A.R. Katritzy & 1,585 & 2 & 17,397 & 23 & 48 & 50 & 150 \\
\hline University of Geneva & 2,317 & 233 & G. Bernardinelli & 335 & 188 & 6,098 & 100 & 37 & 95 & 150 \\
\hline University of Georgia & 4,454 & 107 & H.F Schaefer & 1,098 & 14 & 21,462 & 15 & 46 & 55 & 150 \\
\hline University of Ghent & 3,312 & 160 & N. De Kimpe & 398 & 139 & 2,163 & 226 & 21 & 246 & 150 \\
\hline University of Glasgow & 4,688 & 95 & J.D. Connolly & 224 & 261 & 1,200 & 289 & 150 & 1 & 150 \\
\hline
\end{tabular}




\begin{tabular}{|c|c|c|c|c|c|c|c|c|c|c|}
\hline University of Gothenburg & 39 & 342 & M. Ashton & 56 & 343 & 450 & 328 & 15 & 293 & 121 \\
\hline University of Groningen & 4,009 & 124 & B.L. Feringa & 487 & 98 & 8,559 & 74 & 60 & 14 & 150 \\
\hline University of Helsinki & 3,499 & 147 & M. Leskela & 404 & 137 & 4,377 & 139 & 40 & 80 & 150 \\
\hline University of Hong Kong & 2,439 & 222 & C.M. Che & 630 & 53 & 13,227 & 38 & 55 & 24 & 150 \\
\hline University of Houston & 4,239 & 114 & L. Kevan & 627 & 54 & 5,508 & 111 & 26 & 202 & 150 \\
\hline University of Illinois & 13,068 & 8 & N.J. Leonard & 356 & 165 & 1,833 & 249 & 3 & 336 & 150 \\
\hline University of Illinois, Chicago & 3,959 & 126 & G.A. Cordell & 307 & 204 & 3,260 & 174 & 22 & 238 & 150 \\
\hline University of Indonesia & 69 & 339 & T.A. Ivandini & 22 & 344 & 259 & 339 & 12 & 312 & 50 \\
\hline University of Iowa & 2,896 & 186 & D.J. Burton & 247 & 245 & 1,543 & 269 & 15 & 293 & 140 \\
\hline University of Kansas & 4,030 & 119 & R.T. Borchardt & 473 & 104 & 5,183 & 118 & 30 & 149 & 150 \\
\hline University of Kentucky & 2,474 & 217 & D.A. Butterfield & 385 & 147 & 8,095 & 81 & 61 & 13 & 150 \\
\hline University of Lausanne & 2,051 & 247 & C. Floriani & 349 & 173 & 3,431 & 164 & 30 & 149 & 150 \\
\hline University of Leeds & 5,130 & 78 & B.L. Shaw & 347 & 176 & 815 & 308 & 6 & 328 & 150 \\
\hline University of Leicester & 3,199 & 166 & M.C.R. Symons & 857 & 26 & 3,320 & 171 & 12 & 312 & 150 \\
\hline University of Liverpool & 3,217 & 162 & D.L. Cooper & 245 & 247 & 1,584 & 266 & 17 & 278 & 150 \\
\hline University of Ljubljana & 2,856 & 189 & B. Stanovnik & 284 & 214 & 855 & 305 & 26 & 202 & 150 \\
\hline University of London (Kings College of London) & 21,334 & 2 & M.B. Hursthouse & 1,280 & 7 & 12,992 & 41 & 38 & 92 & 150 \\
\hline University of Manchester & 11,138 & 13 & R.N. Haszeldine & 522 & 85 & 608 & 320 & 0 & 343 & 150 \\
\hline University of Manitoba & 1,529 & 276 & K.G. Standing & 136 & 321 & 2,771 & 194 & 30 & 149 & 150 \\
\hline University of Maryland & 4,085 & 115 & J.C. Fettinger & 234 & 256 & 3,283 & 173 & 30 & 149 & 150 \\
\hline University of Maryland Baltimore County & 2,218 & 237 & J.R. Lakowicz & 533 & 81 & 13,119 & 39 & 53 & 28 & 150 \\
\hline University of Massachusetts & 3,098 & 169 & M.D. Rausch & 319 & 200 & 3,917 & 152 & 24 & 222 & 150 \\
\hline University of Melbourne & 3,926 & 128 & F. Grieser & 268 & 228 & 3,357 & 167 & 24 & 222 & 150 \\
\hline University of Miami & 1,384 & 282 & F.J. Millero & 365 & 157 & 6,487 & 96 & 35 & 110 & 150 \\
\hline University of Michigan & 9,438 & 23 & E.F. Westrum & 310 & 202 & 935 & 301 & 7 & 326 & 150 \\
\hline University of Minnesota & 8,740 & 30 & D.G. Truhlar & 888 & 23 & 27,089 & 8 & 64 & 12 & 150 \\
\hline University of Missouri & 4,882 & 87 & N.P. Rath & 337 & 185 & 2,446 & 215 & 22 & 238 & 150 \\
\hline University of Nebraska & 2,855 & 190 & N.H. Cromwell & 156 & 310 & 367 & 336 & 0 & 343 & 117 \\
\hline University of New Hampshire & 986 & 308 & R.E. Lyle & 133 & 323 & 2,031 & 233 & 25 & 212 & 150 \\
\hline University of New Mexico & 1,569 & 273 & R.T. Paine & 234 & 256 & 3,337 & 170 & 20 & 252 & 150 \\
\hline University of New South Wales & 3,205 & 164 & T.P. Davis & 499 & 92 & 5,580 & 109 & 53 & 28 & 150 \\
\hline University of North Carolina, Chapel Hill & 6,313 & 52 & T.J. Meyer & 490 & 96 & 8,067 & 82 & 36 & 101 & 150 \\
\hline University of North Texas & 1,918 & 254 & W.E. Acree & 439 & 114 & 1,475 & 271 & 26 & 202 & 150 \\
\hline University of Notre Dame & 4,779 & 92 & F.J. Castellino & 382 & 148 & 3,296 & 172 & 29 & 161 & 150 \\
\hline University of Nottingham & 5,735 & 61 & A.J. Blake & 606 & 60 & 10,509 & 56 & 43 & 65 & 150 \\
\hline University of Oklahoma & 2,040 & 248 & R. Frech & 190 & 290 & 1,280 & 284 & 20 & 252 & 131 \\
\hline
\end{tabular}




\begin{tabular}{|c|c|c|c|c|c|c|c|c|c|c|}
\hline University of Oregon & 1,659 & 268 & J.F.W. Keana & 184 & 293 & 1,801 & 253 & 17 & 278 & 150 \\
\hline University of Oslo & 2,539 & 211 & H. Fjellvag & 299 & 206 & 2,448 & 214 & 28 & 181 & 150 \\
\hline University of Otago & 1,124 & 298 & J. Simpson & 179 & 296 & 778 & 312 & 13 & 307 & 150 \\
\hline University of Ottawa & 3,441 & 150 & H. Alper & 415 & 125 & 3,689 & 156 & 28 & 181 & 150 \\
\hline University of Oxford & 9,740 & 21 & R.G. Compton & 917 & 22 & 16,202 & 28 & 51 & 38 & 150 \\
\hline University of Pennsylvania & 5,110 & 80 & R.M. Hochstrasser & 476 & 103 & 5,715 & 107 & 46 & 55 & 150 \\
\hline University of Pittsburgh & 6,025 & 58 & J.T. Yates & 602 & 62 & 16,262 & 27 & 37 & 95 & 150 \\
\hline University of Quebec & 1,078 & 301 & S. Kaliaguine & 323 & 195 & 4,280 & 143 & 35 & 110 & 150 \\
\hline University of Queensland & 2,809 & 192 & C.H.L. Kennard & 283 & 216 & 1,658 & 260 & 18 & 274 & 150 \\
\hline University of Reading & 3,590 & 143 & M.G.B. Drew & 733 & 35 & 7,560 & 89 & 37 & 95 & 150 \\
\hline University of Rochester & 2,791 & 195 & S. Mukamel & 545 & 78 & 4,806 & 129 & 44 & 62 & 150 \\
\hline University of Saskatchewan & 2,189 & 240 & P.G. Mezey & 214 & 269 & 1,186 & 291 & 16 & 287 & 123 \\
\hline University of Science and Technology of China & 5,378 & 72 & Y. Qian & 926 & 21 & 14,357 & 36 & 51 & 38 & 150 \\
\hline University of Sheffield & 4,482 & 105 & H. Adams & 430 & 119 & 3,684 & 157 & 31 & 137 & 150 \\
\hline University of South Carolina & 3,424 & 151 & R.D. Adams & 467 & 106 & 2,132 & 229 & 24 & 222 & 150 \\
\hline University of South Florida & 1,093 & 300 & S.M. Sebti & 229 & 259 & 4,955 & 124 & 50 & 44 & 150 \\
\hline University of Southampton & 5,276 & 76 & M.B. Hursthouse & 1,319 & 6 & 14,634 & 34 & 39 & 85 & 150 \\
\hline University of Southern California & 3,533 & 145 & G.A. Olah & 960 & 19 & 11,774 & 45 & 29 & 161 & 150 \\
\hline University of St Andrews & 3,201 & 165 & C. Glidewell & 645 & 49 & 3,399 & 166 & 22 & 238 & 150 \\
\hline University of Surrey & 2,699 & 200 & J.F. Watts & 234 & 256 & 1,995 & 236 & 21 & 246 & 150 \\
\hline University of Sussex & 4,574 & 102 & P.B. Hitchcock & 1,045 & 15 & 11,086 & 51 & 36 & 101 & 150 \\
\hline University of Sydney & 4,650 & 96 & T.W. Hambley & 363 & 160 & 3,914 & 153 & 27 & 191 & 150 \\
\hline University of Technology, Sydney & 299 & 332 & M.B.Cortie & 138 & 319 & 700 & 316 & 15 & 293 & 118 \\
\hline University of Tennessee Knoxville & 3,038 & 176 & G. Guiochon & 685 & 40 & 10,957 & 52 & 42 & 68 & 150 \\
\hline University of Texas at Austin & 9,788 & 17 & A.J. Bard & 790 & 30 & 24,581 & 11 & 53 & 28 & 150 \\
\hline University of Tokyo & 17,460 & 3 & A. Fujishima & 415 & 125 & 11,336 & 48 & 52 & 32 & 150 \\
\hline University of Toronto & 8,141 & 35 & A.J. Lough & 456 & 108 & 5,170 & 119 & 36 & 101 & 150 \\
\hline University of Tsukuba & 3,178 & 167 & M. Yamamoto & 575 & 68 & 21,360 & 16 & 70 & 8 & 150 \\
\hline University of Twente & 2,454 & 219 & D.N. Reinhoudt & 724 & 36 & 22,809 & 12 & 66 & 11 & 150 \\
\hline University of Utah & 6,797 & 46 & P.J. Stang & 353 & 168 & 7,243 & 91 & 49 & 48 & 150 \\
\hline University of Vermont & 1,198 & 289 & W.E Geiger & 180 & 295 & 2,571 & 206 & 21 & 246 & 150 \\
\hline University of Victoria & 1,070 & 303 & J. Ausio & 166 & 303 & 2,095 & 230 & 24 & 222 & 150 \\
\hline University of Virginia & 4,391 & 109 & L. Andrews & 698 & 38 & 10,877 & 53 & 39 & 85 & 150 \\
\hline University of Warwick & 3,018 & 178 & N.W. Alcock & 343 & 179 & 2,829 & 190 & 27 & 191 & 150 \\
\hline University of Washington & 6,566 & 51 & Y. Xia & 352 & 169 & 19,223 & 19 & 90 & 2 & 150 \\
\hline University of Waterloo & 4,032 & 118 & J. Pawliszyn & 399 & 138 & 5,999 & 102 & 52 & 32 & 150 \\
\hline
\end{tabular}




\begin{tabular}{|c|c|c|c|c|c|c|c|c|c|c|}
\hline University of Western Australia & 2,613 & 206 & A. H. White & 1,245 & 8 & 13,086 & 40 & 38 & 92 & 150 \\
\hline University of Western Ontario & 3,381 & 153 & R.J. Puddephatt & 448 & 111 & 3,534 & 159 & 35 & 110 & 150 \\
\hline University of Wisconsin & 9,416 & 24 & R. West & 516 & 88 & 8,371 & 76 & 31 & 137 & 150 \\
\hline University of Wollongong & 917 & 310 & G.G. Wallace & 508 & 91 & 9,671 & 65 & 40 & 80 & 150 \\
\hline University of York & 2,793 & 194 & J.H. Clark & 282 & 217 & 3,233 & 175 & 31 & 137 & 150 \\
\hline University of Zurich & 2,015 & 249 & A. Linden & 396 & 140 & 2,706 & 198 & 25 & 212 & 150 \\
\hline Univesitas Gadjah Mada & 87 & 338 & N. Yoshioka & 96 & 333 & 732 & 314 & 15 & 293 & 150 \\
\hline Uppsala University & 5,649 & 63 & B. Langstrom & 540 & 80 & 9,566 & 66 & 42 & 68 & 150 \\
\hline Utah State & 934 & 309 & R.W. Sidwell & 241 & 251 & 2,576 & 205 & 28 & 181 & 150 \\
\hline Utrecht University & 6,237 & 55 & A.L. Spek & 997 & 17 & 19,866 & 18 & 52 & 32 & 150 \\
\hline Vanderbilt University & 2,443 & 221 & F.P. Guengerich & 663 & 42 & 32,945 & 3 & 58 & 18 & 150 \\
\hline Victoria University of Wellington & 699 & 321 & N.F. Curtis & 104 & 331 & 628 & 319 & 7 & 326 & 67 \\
\hline Vienna University of Technology & 2,152 & 243 & K. Merelter & 297 & 208 & 2,421 & 216 & 29 & 161 & 150 \\
\hline Virginia Polytechnic Institute & 2,582 & 208 & J.E. McGarth & 584 & 65 & 4,378 & 138 & 29 & 161 & 150 \\
\hline Vrije Universiteit, Brussels & 18 & 345 & M. Besancon & 265 & 230 & 3,141 & 177 & 30 & 149 & 150 \\
\hline VU University Amsterdam & 2,982 & 181 & U.A.T. Brinkman & 509 & 90 & 9,350 & 68 & 41 & 74 & 150 \\
\hline Wageningen University & 2,013 & 251 & A.G.J. Voragen & 361 & 163 & 4,240 & 146 & 33 & 125 & 150 \\
\hline Wake Forest University & 757 & 317 & A.G. King & 156 & 310 & 405 & 332 & 6 & 328 & 27 \\
\hline Waseda University & 2,382 & 227 & E. Tsuchida & 661 & 45 & 7,048 & 93 & 35 & 110 & 150 \\
\hline Washington State University & 2,346 & 232 & R.D. Willett & 269 & 226 & 214 & 341 & 17 & 278 & 150 \\
\hline Washington University in St. Louis & 2,278 & 234 & D.G. Sarantites & 327 & 191 & 1,869 & 243 & 23 & 228 & 150 \\
\hline Wayne State University & 4,317 & 113 & C.F. Poole & 242 & 249 & 2,717 & 197 & 31 & 137 & 143 \\
\hline West Virginia University & 1,153 & 295 & J.L. Peterson & 220 & 264 & 3,718 & 155 & 26 & 202 & 150 \\
\hline Yale University & 5,337 & 73 & K.B. Wiberg & 413 & 128 & 8,352 & 77 & 32 & 131 & 150 \\
\hline Yonsei University & 2,643 & 203 & M. Lee & 136 & 321 & 1,318 & 283 & 25 & 212 & 150 \\
\hline York University & 1,179 & 292 & D.K. Bohme & 263 & 232 & 1,920 & 241 & 21 & 246 & 150 \\
\hline Zhejiang University & 6,910 & 45 & K.F. Cen & 1,175 & 10 & 3,060 & 179 & 19 & 265 & 150 \\
\hline
\end{tabular}




\begin{tabular}{|c|c|c|c|c|c|c|c|c|c|c|}
\hline Materials Data & $\begin{array}{l}\text { Department } \\
\text { Publications }\end{array}$ & Rank & Most Prolific Author & Published & Rank & Cited & Rank & $\begin{array}{c}\text { H- } \\
\text { Index }\end{array}$ & Rank & $\begin{array}{c}\text { \# of } \\
\text { Coauthors }\end{array}$ \\
\hline Aalto University & 3,621 & 73 & L. Niiisto & 268 & 186 & 2,633 & 165 & 30 & 124 & 150 \\
\hline Aarhus University & 1,201 & 223 & F.Besenbacher & 358 & 112 & 6,475 & 62 & 47 & 29 & 150 \\
\hline Arizonia State University & 2,282 & 133 & D.J. Smith & 558 & 44 & 7,513 & 56 & 33 & 93 & 150 \\
\hline Ateneo de Manila University & 8 & 345 & A. Okamoto & 117 & 316 & 580 & 314 & 12 & 307 & 150 \\
\hline Auburn University & 1,759 & 170 & J.W. Fergus & 84 & 330 & 794 & 300 & 13 & 299 & 63 \\
\hline Australian National University & 2,565 & 114 & R.L. Withers & 223 & 229 & 1,552 & 237 & 18 & 245 & 150 \\
\hline Boston College & 360 & 314 & Z.F. Ren & 220 & 231 & 8,085 & 47 & 43 & 35 & 150 \\
\hline Boston University & \begin{tabular}{l|l}
1,077 \\
\end{tabular} & 237 & T.D. Moustakas & 251 & 202 & 3,626 & 115 & 24 & 182 & 150 \\
\hline Brandeis University & 153 & 336 & I.R. Epstein & 322 & 138 & 2,551 & 169 & 25 & 177 & 150 \\
\hline Brigham Young University & 356 & 317 & M.L. Lee & 377 & 102 & 5,085 & 77 & 32 & 101 & 150 \\
\hline Brown University & 1,829 & 165 & A. Wold & 236 & 217 & 2,278 & 189 & 2 & 341 & 150 \\
\hline California Institute of Technology (Calt... & 4,205 & 59 & M.A. Nicolet & 285 & 168 & 1,742 & 219 & 10 & 318 & 150 \\
\hline Cardiff University & 1,412 & 202 & M.B. Hursthouse & 1,322 & 3 & 14,637 & 18 & 39 & 57 & 150 \\
\hline Carnegie Mellon University & 3,661 & 70 & K. Matyjaszewski & 713 & 25 & 37,767 & 5 & 93 & 2 & 150 \\
\hline Case Western Reserve University & 3,749 & 66 & A. Hiltner & 459 & 74 & 3,321 & 128 & 29 & 134 & 150 \\
\hline Chalmers University of Technology & 4,097 & 62 & L. Borjesson & 273 & 183 & 3,028 & 139 & 24 & 182 & 150 \\
\hline Charles University & 1,757 & 171 & V. Sechovsky & 437 & 82 & 1,123 & 264 & 17 & 257 & 150 \\
\hline Chinese University of Hong Kong & 935 & 245 & S.P. Wong & 264 & 188 & 1,146 & 263 & 18 & 245 & 150 \\
\hline Chulalongkorn University & 1,168 & 228 & P. Supaphol & 139 & 301 & 1,204 & 258 & 23 & 195 & 150 \\
\hline City University of Hong Kong & 2,997 & 89 & P.K. Chu & 887 & 16 & 6,609 & 61 & 29 & 134 & 150 \\
\hline City University of New York & 542 & 289 & F.H. Pollak & 345 & 121 & 3,444 & 121 & 20 & 224 & 150 \\
\hline Colorado State University & 738 & 260 & C.E. Patton & 213 & 237 & 829 & 298 & 15 & 287 & 150 \\
\hline Columbia University & 1,820 & 167 & N.J. Turro & 747 & 21 & 16,037 & 16 & 41 & 49 & 150 \\
\hline Cornell University & 4,619 & 48 & C.K.Ober & 338 & 128 & 5,139 & 76 & 36 & 76 & 150 \\
\hline Curtin University of Technology & 490 & 299 & I.M Low & 112 & 318 & 484 & 319 & 10 & 318 & 90 \\
\hline Dalhousie University & 949 & 243 & J.R. Datin & 406 & 91 & 7,651 & 52 & 50 & 25 & 150 \\
\hline Dartmouth College & 735 & 262 & I. Baker & 237 & 216 & 1,206 & 256 & 14 & 291 & 150 \\
\hline Delft University of Technology & 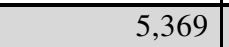 & 39 & J.Schooman & 331 & 132 & 2,822 & 148 & 30 & 124 & 150 \\
\hline Drexel University & 1,966 & 152 & Y. Wei & 276 & 180 & 4,625 & 88 & 36 & 76 & 150 \\
\hline Duke University & 1,182 & 226 & H. Petroski & 160 & 283 & 197 & 335 & 3 & 339 & 16 \\
\hline Durham University & 2,207 & 136 & J.A.K. Howard & 792 & 17 & 10,618 & 29 & 46 & 31 & 150 \\
\hline Ecole Normale Supérieure de Lyon & 349 & 321 & & 212 & 240 & 2,351 & 181 & 29 & 134 & 150 \\
\hline École Normale Supérieure, Paris & 698 & 266 & R. Ferreira & 160 & 283 & 2,638 & 164 & 17 & 257 & 150 \\
\hline École Polytechnique & 1,965 & 153 & J.P. Biolot & 277 & 177 & 3,624 & 116 & 33 & 93 & 150 \\
\hline
\end{tabular}




\begin{tabular}{|c|c|c|c|c|c|c|c|c|c|c|}
\hline Ecole Polytechnique Fédérale de Lausanne & 4,316 & 56 & J.A.E. Manson & 257 & 195 & 1,610 & 231 & 22 & 206 & 150 \\
\hline Eindhoven University of Technology & 3,861 & 65 & E. W. Meijn & 493 & 58 & 11,926 & 26 & 67 & 8 & 150 \\
\hline Emory University & 385 & 311 & E.L. Choikof & 201 & 249 & 3,176 & 134 & 31 & 110 & 150 \\
\hline Erasmus University Rotterdam & 57 & 338 & R. Kanaar & 118 & 315 & 4,388 & 95 & 42 & 41 & 150 \\
\hline ETH Zurich (Swiss Federal Institute of Technology) & 6,194 & 27 & L/J. Gaucker & 307 & 149 & 3,663 & 113 & 33 & 93 & 150 \\
\hline Florida International University & 587 & 281 & A.K. Agarwal & 99 & 326 & 682 & 307 & 18 & 245 & 101 \\
\hline Florida State University & 685 & 269 & I.M. Navon & 129 & 307 & 922 & 289 & 16 & 277 & 150 \\
\hline Freie Universität Berlin & 1,687 & 180 & G. Kaindl & 339 & 127 & 313 & 329 & 22 & 206 & 150 \\
\hline Friedrich Alexander Universität Erlangen Nürnberg & 4,675 & 47 & P. Schmuki & 335 & 131 & 3,322 & 127 & 53 & 18 & 150 \\
\hline Fudan University & 4,307 & 58 & W. Huang & 1,141 & 6 & 13,096 & 23 & 53 & 18 & 150 \\
\hline Georg August Universität Göttingen & 2,208 & 135 & K.P.Lieb & 556 & 45 & 6,702 & 60 & 35 & 84 & 150 \\
\hline George Mason University & 220 & 332 & M.V. Rao & 135 & 302 & 1,820 & 213 & 20 & 224 & 150 \\
\hline George Washington University & 472 & 301 & E. Della Torre & 178 & 271 & 522 & 317 & 10 & 318 & 118 \\
\hline Georgetown University & 331 & 324 & R.G. Weiss & 213 & 237 & 2,466 & 173 & 30 & 124 & 150 \\
\hline Georgia Institute of Technology & 6,441 & 22 & C.P. Wong & 472 & 72 & 2,208 & 194 & 28 & 149 & 150 \\
\hline Georgia State University & 224 & 330 & N. Dietz & 109 & 319 & 327 & 328 & 11 & 313 & 150 \\
\hline Goteborg University & 2,889 & 97 & M. Willander & 477 & 70 & 3,247 & 131 & 23 & 195 & 150 \\
\hline Harvard University & 2,113 & 143 & G.M. Whitesides & 918 & 13 & 75,622 & 1 & 105 & 1 & 150 \\
\hline Hebrew University of Jerusalem & 2,190 & 138 & G. Marom & 195 & 255 & 1,039 & 275 & 15 & 287 & 150 \\
\hline Heidelberg Universität & 1,628 & 183 & G. Huttner & 230 & 225 & 2,468 & 172 & 19 & 235 & 150 \\
\hline Hokkaido University & 6,287 & 24 & T. Kakuchi & 256 & 197 & 883 & 292 & 20 & 224 & 150 \\
\hline Hong Kong Polytechnic University & 4,148 & 61 & H.L.W. Chan & 617 & 33 & 4,551 & 90 & 26 & 166 & 150 \\
\hline Hong Kong University of Science \& Techno... & 3,174 & 85 & B.Z. Tang & 317 & 141 & 2,846 & 147 & 41 & 49 & 150 \\
\hline Humboldt-Universität zu Berlin & 1,598 & 186 & E. Kemnitz & 302 & 153 & 1,393 & 245 & 25 & 177 & 150 \\
\hline Imperial College London & 7,352 & 17 & A. R. Boccaccini & 156 & 287 & 1,052 & 273 & 22 & 206 & 150 \\
\hline Indian Institute of Technology Bombay (I... & 2,353 & 126 & B.P. Kashyap & 121 & 313 & 488 & 318 & 10 & 318 & 94 \\
\hline Indian Institute of Technology Delhi (II... & 3,313 & 81 & V.K. Kothari & 166 & 277 & 223 & 333 & 5 & 337 & 90 \\
\hline Indian Institute of Technology Kanpur (I... & 2,727 & 105 & R. Balasubramamiam & 200 & 250 & 861 & 294 & 17 & 257 & 150 \\
\hline Indiana University Bloomington & 883 & 249 & J.C. Huffman & 780 & 20 & 12,354 & 25 & 33 & 93 & 150 \\
\hline Indiana University Indianapolis & 55 & 340 & M.C. Dinauer & 144 & 298 & 3,880 & 108 & 42 & 41 & 150 \\
\hline Iowa State University & 2,829 & 101 & P.C. Canfield & 404 & 92 & 4,979 & 80 & 43 & 35 & 150 \\
\hline Johns Hopkins University & 2,175 & 140 & S.H. Snyder & 300 & 155 & 14,180 & 20 & 75 & 5 & 150 \\
\hline Kansas State University & 591 & 280 & H.X. Jiang & 310 & 146 & 3,064 & 137 & 36 & 76 & 150 \\
\hline Katholieke Universiteit Leuven & 4,786 & 45 & J. Vleugels & 185 & 267 & 616 & 310 & 16 & 277 & 138 \\
\hline Keio University & 2,385 & 124 & M. Senna & 263 & 190 & 1,548 & 238 & 21 & 218 & 150 \\
\hline
\end{tabular}




\begin{tabular}{|c|c|c|c|c|c|c|c|c|c|c|}
\hline King Fahd University of Petroleum \& Minerals & 1,204 & 222 & B.S. Yilbas & 391 & 99 & 1,093 & 267 & 19 & 235 & 150 \\
\hline King Saud University & 608 & 278 & S.M. Darwish & 61 & 336 & 165 & 337 & 8 & 330 & 49 \\
\hline Kobe University & 2,110 & 145 & M. Okubo & 279 & 175 & 1,669 & 227 & 23 & 195 & 150 \\
\hline Korea Advanced Institute of Science \& Technology & 6,291 & 23 & J.Y. Lee & 16 & 341 & 24 & 342 & 3 & 339 & 88 \\
\hline Korea University & 2,986 & 90 & J. I. Jin & 273 & 183 & 1,864 & 209 & 24 & 182 & 150 \\
\hline Kyoto University & 18,415 & 2 & T. Masuda & 525 & 48 & 15,328 & 17 & 34 & 88 & 150 \\
\hline Kyushu University & 6,752 & 21 & Z. Horita & 313 & 143 & 3,443 & 122 & 53 & 18 & 150 \\
\hline La Trobe University & 331 & 324 & J. Liesegang & 43 & 338 & 881 & 293 & 12 & 307 & 134 \\
\hline Lancaster University & 360 & 314 & C.J. Lambert & 134 & 303 & 1,201 & 259 & 16 & 277 & 145 \\
\hline Leiden University & 1,719 & 176 & J. Reedijk & 1,013 & 8 & 17,105 & 13 & 41 & 49 & 150 \\
\hline Linkoping University & 2,403 & 122 & O. Inganas & 374 & 105 & 7,314 & 57 & 42 & 41 & 150 \\
\hline London School of Economics and Political Science & 9 & 344 & LA Smith & 154 & 290 & 2,418 & 178 & 31 & 110 & 150 \\
\hline Loughborough University & 2,530 & 119 & R.G. Faukner & 140 & 300 & 426 & 324 & 10 & 318 & 150 \\
\hline Louisiana State University & 1,174 & 227 & C.Z. Voyiadjis & 227 & 226 & 1,029 & 276 & 19 & 235 & 109 \\
\hline Ludwig-Maximilians-Universität München & 2,553 & 116 & W. Beck & 300 & 155 & 2,083 & 199 & 17 & 257 & 150 \\
\hline Lund University & 2,604 & 112 & L. Samuelson & 486 & 63 & 5,319 & 74 & 48 & 26 & 150 \\
\hline Maastricht University & 128 & 337 & L.H. Koole & 131 & 305 & 737 & 304 & 17 & 257 & 150 \\
\hline Macquarie University & 442 & 306 & T.L. Tansley & 145 & 297 & 1,570 & 236 & 10 & 318 & 127 \\
\hline Mahidol University & 528 & 291 & C. Sirisinha & 47 & 337 & 219 & 334 & 11 & 313 & 40 \\
\hline Masaryk University & 504 & 297 & V. Holy & 186 & 265 & 1,845 & 211 & 17 & 257 & 150 \\
\hline Massachusetts Institute of Technology & 9,809 & 9 & D. Seyferth & 577 & 40 & 4,515 & 91 & 9 & 327 & 150 \\
\hline McGill University & 4,001 & 63 & J.A. Szpunar & 321 & 139 & 1,151 & 262 & 20 & 224 & 150 \\
\hline McMaster University & 3,657 & 71 & S. Zhu & 236 & 217 & 2,358 & 180 & 30 & 124 & 150 \\
\hline Michigan State University & 2,935 & 93 & M.G. Kanatzidis & 587 & 38 & 9,950 & 33 & 39 & 57 & 150 \\
\hline Michigan Technological University & 1,468 & 193 & G.Subhash & 106 & 320 & 860 & 295 & 19 & 235 & 103 \\
\hline Monash University & 3,206 & 83 & Y. B. Cheng & 250 & 203 & 1,680 & 224 & 22 & 206 & 150 \\
\hline Montana State University & 516 & 295 & V.H. Schimdt & 143 & 299 & 760 & 302 & 15 & 287 & 150 \\
\hline Moscow State University & 7,880 & 14 & A.R. Khokhlov & 414 & 87 & 3,733 & 112 & 37 & 68 & 150 \\
\hline Nagoya University & 10,818 & 7 & O. Takai & 284 & 170 & 2,108 & 198 & 27 & 158 & 150 \\
\hline Nanjing University & 5,634 & 34 & R. Zhang & 330 & 134 & 1,250 & 252 & 18 & 245 & 150 \\
\hline Nanyang Technological University & 6,258 & 25 & S.F. Yoon & 242 & 210 & 1,853 & 210 & 22 & 206 & 150 \\
\hline National Taiwan University & 5,565 & 36 & G.H. Lee & 621 & 32 & 7,846 & 51 & 36 & 76 & 150 \\
\hline National Tsing Hua University & 5,666 & 32 & J.G. Duh & 275 & 181 & 1,421 & 244 & 19 & 235 & 150 \\
\hline National University of Ireland, Galway & 351 & 320 & D. Cunningham & 156 & 287 & 600 & 311 & 10 & 318 & 150 \\
\hline National University of Singapore & 7,722 & 15 & E.T. Kang & 510 & 52 & 8,654 & 40 & 37 & 68 & 150 \\
\hline New Mexico State University & 460 & 304 & J. Ramirez & 289 & 165 & 1,056 & 272 & 17 & 257 & 150 \\
\hline
\end{tabular}




\begin{tabular}{|c|c|c|c|c|c|c|c|c|c|c|}
\hline New York University & 613 & 276 & R.Z. LeGeros & 188 & 262 & 2,768 & 153 & 17 & 257 & 150 \\
\hline Newcastle University & 1,091 & 234 & P.R. Bridden & 354 & 115 & 2,973 & 141 & 33 & 93 & 150 \\
\hline North Carolina State University & 5,969 & 29 & G. Lurovsky & 410 & 88 & 3,254 & 130 & 31 & 110 & 150 \\
\hline Northeastern University & 1,443 & 198 & W.M. Reiff & 200 & 250 & 2,258 & 192 & 13 & 299 & 150 \\
\hline Northwestern University & 5,574 & 35 & T.J. Marks & 792 & 17 & 27,833 & 6 & 66 & 9 & 150 \\
\hline Norwegian University of Science \& Technology & 2,570 & 113 & T. Grande & 154 & 290 & 1,453 & 242 & 18 & 245 & 150 \\
\hline Ohio State University & 4,456 & 53 & B. Bhushan & 702 & 26 & 10,616 & 30 & 37 & 68 & 150 \\
\hline Oklahoma State University & 941 & 244 & W.T. Ford & 366 & 107 & 4,781 & 85 & 26 & 166 & 150 \\
\hline Open University UK & 584 & 282 & F.J. Berry & 277 & 177 & 1,188 & 260 & 17 & 257 & 150 \\
\hline Oregon State University & 1,522 & 192 & A.W. Sleight & 338 & 128 & 6,071 & 65 & 38 & 63 & 150 \\
\hline Osaka University & 15,636 & 4 & Y. Onuki & 785 & 19 & 8,403 & 42 & 45 & 32 & 150 \\
\hline Peking University & 5,516 & 37 & Y.Wang & 341 & 123 & 737 & 304 & 12 & 307 & 150 \\
\hline Pennsylvania State University & 8,548 & 11 & H.R. Allcock & 480 & 67 & 2,751 & 154 & 31 & 110 & 150 \\
\hline Pohang University of Science And Technology & 3,633 & 72 & S. Lee & 254 & 198 & 1,216 & 254 & 18 & 245 & 150 \\
\hline Portland State University & 556 & 286 & G.L. Gard & 188 & 262 & 665 & 309 & 17 & 257 & 150 \\
\hline Princeton University & 3,089 & 87 & S. Wagner & 404 & 92 & 2,433 & 177 & 31 & 110 & 150 \\
\hline Purdue University & 4,678 & 46 & N.A. Peppas & 590 & 37 & 18,997 & 10 & 53 & 18 & 150 \\
\hline Queen's University & 2,036 & 149 & M. Sayer & 206 & 245 & 2,188 & 195 & 17 & 257 & 150 \\
\hline Queen's University of Belfast & 1,379 & 204 & W. Sha & 213 & 237 & 1,599 & 233 & 2 & 341 & 150 \\
\hline Queensland University of Technology & 803 & 257 & R.L. Frost & 602 & 35 & 8,154 & 45 & 40 & 54 & 150 \\
\hline Radboud University, Nijmegen & 1,333 & 208 & J.A. Jansen & 390 & 100 & 4,052 & 106 & 42 & 41 & 150 \\
\hline Rensselaer Polytechnic Institute & 3,484 & 76 & J.V. Crivello & 242 & 210 & 2,035 & 201 & 25 & 177 & 111 \\
\hline Rheinisch Westfalische Technische Hochschule Aach & 6,085 & 28 & E. Lugscheider & 331 & 132 & 1,334 & 248 & 17 & 257 & 150 \\
\hline Rheinische Friedrich Wilhelms Universitat Bonn & 1,287 & 213 & R. Viaden & 147 & 295 & 358 & 325 & 9 & 327 & 150 \\
\hline Rice University & 1,675 & 181 & A.G. Mikos & 352 & 117 & 8,229 & 43 & 60 & 12 & 150 \\
\hline Rochester Institute of Technology & 522 & 293 & R.P. Raffaelle & 120 & 314 & 840 & 296 & 17 & 257 & 150 \\
\hline Royal Institute of Technology, KTH & 5,654 & 33 & A.C. Albertsson & 289 & 165 & 2,729 & 158 & 31 & 110 & 150 \\
\hline Royal Melbourne Institute of Technology & 1,022 & 240 & R.A. Shanks & 176 & 273 & 1,119 & 265 & 18 & 245 & 150 \\
\hline Rutgers & 3,259 & 82 & M. Greenblatt & 300 & 155 & 2,751 & 154 & 26 & 166 & 150 \\
\hline Saint-Petersburg State University & 2,111 & 144 & E.V. Charnaya & 106 & 320 & 196 & 336 & 9 & 327 & 122 \\
\hline San Diego State University & 372 & 313 & E.A. Olevsky & 101 & 324 & 592 & 312 & 18 & 245 & 109 \\
\hline Sapienza University of Rome & 0 & 347 & & 0 & 347 & 0 & 347 & 0 & 347 & 0 \\
\hline Sciences Po Paris & 0 & 347 & & 0 & 347 & 0 & 347 & 0 & 347 & 0 \\
\hline Seoul National University & 7,149 & 18 & H.E.Kim & 257 & 195 & 2,459 & 174 & 29 & 134 & 150 \\
\hline Shanghai Jiao Tong University & 7,616 & 16 & D. Yan & 367 & 106 & 2,982 & 140 & 31 & 110 & 150 \\
\hline Simon Fraser University & 1,043 & 238 & S. holdcroft & 149 & 294 & 2,219 & 193 & 27 & 158 & 150 \\
\hline
\end{tabular}




\begin{tabular}{|c|c|c|c|c|c|c|c|c|c|c|}
\hline Stanford University & 5,083 & 42 & W.D. Nix & 393 & 96 & 7,585 & 53 & 36 & 76 & 150 \\
\hline State University of New York Buffalo & 19 & 343 & W.S. Durfee & 15 & 342 & 122 & 341 & 7 & 333 & 34 \\
\hline Stockholm University & 1,135 & 230 & M.Nygren & 198 & 252 & 1,887 & 208 & 24 & 182 & 150 \\
\hline Stony Brook University & 2,311 & 129 & B.S. Hsiao & 340 & 124 & 4,942 & 81 & 48 & 26 & 150 \\
\hline Syracuse University & 675 & 273 & J. Zubieta & 518 & 50 & 17,598 & 12 & 56 & 15 & 150 \\
\hline Tartu University (University of Tartu) & 656 & 274 & K. Kukli & 129 & 307 & 1,342 & 247 & 28 & 149 & 150 \\
\hline Technical University of Denmark & 2,846 & 99 & S. Morup & 220 & 231 & 2,955 & 142 & 24 & 182 & 150 \\
\hline Technion & 3,714 & 68 & M. Narkis & 269 & 185 & 2,024 & 203 & 23 & 195 & 150 \\
\hline Technische Universität Berlin & 3,599 & 74 & D. Bimberg & 967 & 11 & 18,234 & 11 & 57 & 14 & 150 \\
\hline Technische Universitat Chemnitz & 1,876 & 159 & D.R.T. Zahn & 364 & 109 & 1,762 & 218 & 21 & 218 & 150 \\
\hline Technische Universität Dresden & 4,513 & 51 & P. Offermann & 195 & 255 & 139 & 338 & 6 & 334 & 150 \\
\hline Technische Universität München & 5,493 & 38 & O. Nuyken & 261 & 191 & 2,488 & 171 & 31 & 110 & 150 \\
\hline Tel Aviv University & 1,703 & 178 & R.L. Boxman & 243 & 209 & 936 & 288 & 17 & 257 & 142 \\
\hline Texas A\&M University & 3,933 & 64 & A. Clearfield & 482 & 66 & 5,525 & 69 & 42 & 41 & 150 \\
\hline Texas Tech & 541 & 290 & M. Holtz & 131 & 305 & 1,159 & 261 & 20 & 224 & 150 \\
\hline Tohoku University & 17,515 & 3 & A. Inoue & 1,930 & 1 & 38,085 & 4 & 71 & 7 & 150 \\
\hline Tokyo Institute of Technology & 14,609 & 5 & T. Endo & 1,002 & 10 & 9,558 & 37 & 31 & 110 & 150 \\
\hline Trinity College Dublin & 1,413 & 201 & J.M.D. Coey & 533 & 46 & 12,766 & 24 & 37 & 68 & 150 \\
\hline Tsinghua University & 12,540 & 6 & $\overline{\mathrm{L} . \mathrm{Li}}$ & 516 & 51 & 2,903 & 145 & 23 & 195 & 150 \\
\hline Tufts University & 603 & 279 & A. Vilenkin & 188 & 262 & 3,641 & 114 & 25 & 177 & 67 \\
\hline Universidad Autonoma de Madrid & 2,643 & 110 & J.M. Martinez-Duart & 212 & 240 & 997 & 281 & 16 & 277 & 150 \\
\hline Universidad de Chile & 857 & 253 & R. Quijada & 117 & 316 & 750 & 303 & 18 & 245 & 150 \\
\hline Universidad de Granada & 2,643 & 110 & J.M. Martinez-Duart & 212 & 240 & 997 & 281 & 16 & 277 & 150 \\
\hline Universidad del País Vasco & 2,804 & 102 & I. Mondragon & 245 & 208 & 1,777 & 217 & 24 & 182 & 150 \\
\hline Universidad Nacional Autónoma de México ... & 2,953 & 92 & V.M. Castano & 347 & 120 & 1,291 & 249 & 16 & 277 & 150 \\
\hline Universidad Politecnica de Madrid & 1,543 & 191 & E. Calleja & 206 & 245 & 1,592 & 234 & 24 & 182 & 150 \\
\hline Universidade de São Paulo & 3,727 & 67 & O.N. Oliveira & 328 & 135 & 1,935 & 206 & 27 & 158 & 150 \\
\hline Universidade Estadual de Campinas & 2,083 & 147 & C. Airoldi & 340 & 124 & 1,678 & 225 & 29 & 134 & 150 \\
\hline Università degli Studi di Firenze & 1,569 & 188 & D. Gatteschi & 490 & 60 & 9,603 & 35 & 54 & 16 & 150 \\
\hline Università degli Studi di Padova & 3,555 & 75 & P. Mazzoldi & 304 & 152 & 1,807 & 216 & 27 & 158 & 150 \\
\hline Universita Di Bologna & 2,726 & 106 & L. Angiolini & 106 & 320 & 685 & 306 & 16 & 277 & 111 \\
\hline Universita di Pisa & 1,041 & 239 & D De Rossi & 215 & 234 & 2,272 & 191 & 23 & 195 & 150 \\
\hline Universitat Autonoma de Barcelona & 1,386 & 203 & M.D. Baro & 186 & 265 & 1,712 & 221 & 22 & 206 & 150 \\
\hline Universitat Bielefeld & 546 & 288 & P. Jutzi & 234 & 221 & 2,373 & 179 & 26 & 166 & 150 \\
\hline Universität Bremen & 1,329 & 209 & D.Hommel & 443 & 79 & 3,416 & 123 & 28 & 149 & 150 \\
\hline Universitat d'Alacant & 1,079 & 236 & J.M. Martinez & 164 & 278 & 1,003 & 280 & 17 & 257 & 141 \\
\hline
\end{tabular}




\begin{tabular}{|c|c|c|c|c|c|c|c|c|c|c|}
\hline Universitat de València & 1,559 & 189 & E. Coronado & 337 & 130 & 5,474 & 70 & 44 & 33 & 150 \\
\hline Universität Frankfurt am Main & 1,578 & 187 & H. Baunmann & 129 & 307 & 445 & 321 & 11 & 313 & 150 \\
\hline Universität Freiburg & 2,339 & 127 & R. Mulhaupt & 284 & 170 & 7,915 & 50 & 47 & 29 & 150 \\
\hline Universitat Hamburg & 1,283 & 214 & R. Wiesendanger & 281 & 173 & 2,692 & 161 & 34 & 88 & 150 \\
\hline Universität Karlsruhe & 3,318 & 80 & D. Gerthsen & 246 & 207 & 1,704 & 223 & 27 & 158 & 150 \\
\hline Universitat Leipzig & 1,092 & 233 & J. Karger & 350 & 119 & 2,311 & 187 & 29 & 134 & 150 \\
\hline Universitat Munster (Westfälische Wilhelms-Un & 2,291 & 130 & R. Pottgen & 438 & 81 & 1,485 & 240 & 29 & 134 & 150 \\
\hline Universitat Politecnica de Catalunya & 2,448 & 120 & J.. Gacen & 291 & 162 & 126 & 340 & 5 & 337 & 92 \\
\hline Universität Regensburg & 1,901 & 158 & H. Brunner & 342 & 122 & 2,698 & 160 & 22 & 206 & 150 \\
\hline Universität Stuttgart & 4,395 & 54 & F. Aldinger & 478 & 69 & 4,059 & 105 & 35 & 84 & 150 \\
\hline Universitat Trier & 7 & 346 & M. Stellmes & 12 & 343 & 8 & 346 & 2 & 341 & 63 \\
\hline Universität Tübingen & 1,547 & 190 & E. Lindner & 181 & 268 & 1,424 & 243 & 18 & 245 & 150 \\
\hline Universitat Wien (University of Vienna) & 2,541 & 118 & P. Rogl & 305 & 150 & 2,159 & 197 & 22 & 206 & 150 \\
\hline Universitat Zu Koln & 1,617 & 184 & J. Zittartz & 132 & 304 & 1,058 & 270 & 12 & 307 & 87 \\
\hline Université Catholique de Louvain & 1,639 & 182 & R. Legras & 163 & 279 & 2,939 & 144 & 23 & 195 & 150 \\
\hline Universite de Liege & 1,846 & 163 & R. Jerome & 340 & 124 & 5,320 & 73 & 41 & 49 & 150 \\
\hline Université de Montréal & 1,226 & 219 & M. LeClere & 203 & 247 & 3,875 & 109 & 43 & 35 & 150 \\
\hline Université de Nice Sophia Antipolis & 683 & 270 & A. Cambon & 122 & 312 & 567 & 315 & 13 & 299 & 125 \\
\hline Universite Laval & 2,180 & 139 & R.E. Prud' homme & 232 & 223 & 1,818 & 214 & 18 & 245 & 150 \\
\hline Universite Libre de Bruxelles & 893 & 248 & M. Hou & 92 & 328 & 461 & 320 & 14 & 291 & 133 \\
\hline Université Paris Sorbonne & 575 & 283 & M. Grabisch & 81 & 331 & 671 & 308 & 14 & 291 & 44 \\
\hline Universite Paris-Sud 11 & 5,277 & 41 & D. Jerome & 299 & 158 & 2,560 & 167 & 23 & 195 & 150 \\
\hline Université Pierre et Marie Curie & 5,684 & 31 & C.Sanchez & 305 & 150 & 5,945 & 67 & 44 & 33 & 150 \\
\hline Universiti Malaya (University of Malaya) & 1,310 & 211 & S.W. Ng & 1,108 & 7 & 3,409 & 125 & 16 & 277 & 150 \\
\hline University College Cork & 779 & 258 & M.A. Morris & 105 & 323 & 1,081 & 268 & 21 & 218 & 150 \\
\hline University College Dublin & 697 & 268 & A.R. Manning & 176 & 273 & 439 & 322 & 11 & 313 & 150 \\
\hline University College London & 3,696 & 69 & C.R.A. Catlow & 510 & 52 & 11,374 & 28 & 32 & 101 & 150 \\
\hline University do Porto & 1,358 & 207 & J.B. Sousa & 208 & 244 & 774 & 301 & 14 & 291 & 150 \\
\hline University of Aberdeen & 1,360 & 206 & A.R. West & 290 & 164 & 3,455 & 120 & 28 & 149 & 150 \\
\hline University of Adelaide & 805 & 256 & M.I. Bruce & 407 & 90 & 2,501 & 170 & 26 & 166 & 150 \\
\hline University of Alabama & 2,289 & 132 & J.W Mays & 293 & 161 & 4,006 & 107 & 39 & 57 & 150 \\
\hline University of Alberta & 2,879 & 98 & M.J. Brett & 264 & 188 & 1,467 & 241 & 30 & 124 & 150 \\
\hline University of Amsterdam & 1,922 & 155 & K.H.J. Buschow & 1,148 & 5 & 13,899 & 21 & 20 & 224 & 150 \\
\hline University of Antwerp & 1,825 & 166 & F.M. Peeters & 674 & 27 & 9,761 & 34 & 39 & 57 & 150 \\
\hline University of Arizona & 29,263 & 1 & H.K. Hall & 297 & 160 & 1,606 & 232 & 13 & 299 & 150 \\
\hline University of Athens & 1,267 & 215 & N. Hadjichrisidis & 392 & 98 & 4,588 & 89 & 43 & 35 & 150 \\
\hline
\end{tabular}




\begin{tabular}{|c|c|c|c|c|c|c|c|c|c|c|}
\hline University of Auckland & 1,227 & 217 & W. Gao & 242 & 210 & 1,949 & 205 & 21 & 218 & 150 \\
\hline University of Barcelona & 2,892 & 96 & X. Solans & 495 & 56 & 4,210 & 103 & 30 & 124 & 150 \\
\hline University of Basel & 1,021 & 241 & H.J. Guntherodt & 458 & 75 & 7,158 & 59 & 40 & 54 & 150 \\
\hline University of Bath & 1,786 & 168 & D.P. Almond & 153 & 292 & 1,014 & 278 & 13 & 299 & 150 \\
\hline University of Bergen & 224 & 330 & J. Sletten & 81 & 331 & 1,673 & 226 & 19 & 235 & 113 \\
\hline University of Bern & 399 & 309 & H.U. Gudel & 449 & 76 & 4,840 & 84 & 39 & 57 & 150 \\
\hline University of Birmingham & 4,316 & 56 & I.R. Harris & 316 & 142 & 1,548 & 238 & 19 & 235 & 150 \\
\hline University of Bristol & 3,366 & 79 & A. Keller & 260 & 192 & 4,668 & 86 & 20 & 224 & 150 \\
\hline University of British Columbia & 1,911 & 157 & W.N. Hardy & 252 & 200 & 4,389 & 94 & 34 & 88 & 150 \\
\hline University of Calgary & 524 & 292 & N.G. Shrive & 4 & 346 & 9 & 345 & 1 & 346 & 10 \\
\hline University of California, Berkley & 4,580 & 49 & M.L. Cohen & 648 & 30 & 24,662 & 7 & 43 & 35 & 150 \\
\hline University of California, Davis & 2,290 & 131 & Z.A. Munir & 353 & 116 & 2,783 & 151 & 27 & 158 & 150 \\
\hline University of California, Irvine & 1,220 & 220 & E.J. Lavernia & 493 & 58 & 3,391 & 126 & 32 & 101 & 150 \\
\hline University of California, Los Angeles & 4,191 & 60 & K.L. Wang & 483 & 65 & 4,457 & 93 & 33 & 93 & 150 \\
\hline University of California, Riverside & 1,004 & 242 & Y. Yan & $\mid 161$ & 282 & 2,597 & 166 & 33 & 93 & 150 \\
\hline University of California, San Diego & 2,211 & 134 & M.B. Maple & 663 & 29 & 10,479 & 31 & 32 & 101 & 150 \\
\hline University of California, San Francisco & 360 & 314 & S.B. Prusiner & 233 & 222 & 8,047 & 49 & 73 & 6 & 150 \\
\hline University of California, Santa Barbara & 4,458 & 52 & A.C. Gossard & 490 & 60 & 9,211 & 38 & 31 & 110 & 150 \\
\hline University of California, Santa Cruz & 239 & 329 & A. Shakouri & 214 & 235 & 971 & 283 & 20 & 224 & 150 \\
\hline University of Cambridge & 6,995 & 20 & R.H. Friend & 729 & 23 & 44,986 & 2 & 76 & 4 & 150 \\
\hline University of Canterbury & 338 & 323 & R.J. Blaikie & 101 & 324 & 887 & 291 & 16 & 277 & 114 \\
\hline University of Cape Town & 387 & 310 & D.T. Britton & 76 & 334 & 240 & 331 & 8 & 330 & 111 \\
\hline University of Central Florida & 2,017 & 150 & S.Seal & 236 & 217 & 2,556 & 168 & 31 & 110 & 150 \\
\hline University of Chicago & 548 & 287 & L. Lu & 162 & 280 & 2,713 & 159 & 27 & 158 & 150 \\
\hline University of Cincinnati & 2,732 & 104 & J.E. Mark & 198 & 252 & 1,812 & 215 & 22 & 206 & 150 \\
\hline University of Colorado at Boulder & 1,197 & 224 & C.N. Bowman & 252 & 200 & 2,740 & 156 & 38 & 63 & 150 \\
\hline University of Connecticut & 2,163 & 141 & S.L. Suib & 390 & 100 & 4,126 & 104 & 36 & 76 & 150 \\
\hline University of Copenhagen & 6,244 & 26 & T. Bjornholm & 123 & 311 & 2,019 & 204 & 27 & 158 & 150 \\
\hline University of Delaware & 2,047 & 148 & J.W. Gillespie & 393 & 96 & 4,236 & 100 & 34 & 88 & 150 \\
\hline University of Dundee & 568 & 284 & R.K. Dhir & 155 & 289 & 557 & 316 & 12 & 307 & 109 \\
\hline University of Edinburgh & 727 & 264 & S. Parsons & 573 & 41 & 8,207 & 44 & 42 & 41 & 150 \\
\hline University of Florida & 5,322 & 40 & S.J. Pearton & 1,420 & 2 & 20,761 & 9 & 54 & 16 & 150 \\
\hline University of Geneva & 699 & 265 & R. Flukiger & 288 & 167 & 2,343 & 183 & 25 & 177 & 150 \\
\hline University of Georgia & 881 & 250 & R.B. King & 595 & 36 & 4,374 & 98 & 22 & 206 & 150 \\
\hline University of Ghent & 1,617 & 184 & R. Baets & 250 & 203 & 2,029 & 202 & 24 & 182 & 150 \\
\hline University of Glasgow & 1,837 & 164 & I.C. McNeill & 151 & 293 & 955 & 287 & 6 & 334 & 101 \\
\hline
\end{tabular}




\begin{tabular}{|c|c|c|c|c|c|c|c|c|c|c|}
\hline University of Gothenburg & 39 & 342 & L. Emanualsson & 19 & 340 & 131 & 339 & 6 & 334 & 46 \\
\hline University of Groningen & 1,753 & 172 & J.T.M. De Hosson & 501 & 55 & 3,826 & 110 & 30 & 124 & 150 \\
\hline University of Helsinki & 1,773 & 169 & M. Leskela & 404 & 92 & 4,377 & 97 & 40 & 54 & 150 \\
\hline University of Hong Kong & 1,317 & 210 & A.B. Djurisic & 254 & 198 & 2,276 & 190 & 24 & 182 & 150 \\
\hline University of Houston & 1,459 & 195 & C.W. Chu & 364 & 109 & 4,904 & 83 & 32 & 101 & 150 \\
\hline University of Illinois & 7,126 & 19 & W.M. Kriven & 190 & 259 & 1,285 & 250 & 22 & 206 & 150 \\
\hline University of Illinois, Chicago & 1,299 & 212 & S. Sivananthan & 195 & 255 & 966 & 284 & 17 & 257 & 150 \\
\hline University of Indonesia & 51 & 341 & D. Hartanto & 6 & 345 & 19 & 343 & 2 & 341 & 16 \\
\hline University of Iowa & 503 & 298 & M.E. Flatte & 162 & 280 & 1,712 & 221 & 26 & 166 & 150 \\
\hline University of Kansas & 472 & 301 & T. Van Nguyen & 39 & 339 & 1,009 & 279 & 14 & 291 & 28 \\
\hline University of Kentucky & 1,227 & 217 & H.S. Tzou & 218 & 233 & 1,206 & 256 & 17 & 257 & 86 \\
\hline University of Lausanne & 377 & 312 & R. Roulet & 81 & 331 & 329 & 327 & 8 & 330 & 109 \\
\hline University of Leeds & 2,406 & 121 & I.M. Ward & 671 & 28 & 7,570 & 54 & 24 & 182 & 150 \\
\hline University of Leicester & 930 & 246 & J. Fawcett & 302 & 153 & 2,326 & 185 & 23 & 195 & 150 \\
\hline University of Liverpool & 1,735 & 175 & D.J. Bacon & 236 & 217 & 5,841 & 68 & 30 & 124 & 150 \\
\hline University of Ljubljana & 2,398 & 123 & J. Grum & 124 & 310 & 239 & 332 & 10 & 318 & 55 \\
\hline University of London (Kings College of London) & 7,985 & 13 & I.W. Boyd & 311 & 144 & 2,350 & 182 & 23 & 195 & 150 \\
\hline University of Manchester & 8,152 & 12 & G.E. Thompson & 460 & 73 & 2,692 & 161 & 29 & 134 & 150 \\
\hline University of Manitoba & 1,157 & 229 & M.C. Chaturvedi & 231 & 224 & 1,042 & 274 & 17 & 257 & 150 \\
\hline University of Maryland & 2,560 & 115 & S. Das Sarma & 485 & 64 & 6,119 & 63 & 41 & 49 & 150 \\
\hline University of Maryland Baltimore County & 737 & 261 & J.R. Lakowicz & 533 & 46 & 13,119 & 22 & 53 & 18 & 150 \\
\hline University of Massachusetts & 1,938 & 154 & T.P. Russell & 494 & 57 & 10,209 & 32 & 63 & 11 & 150 \\
\hline University of Melbourne & 1,850 & 162 & D.N. Jamieson & 174 & 275 & 1,098 & 266 & 20 & 224 & 150 \\
\hline University of Miami & 445 & 305 & R.M. Leblanc & 190 & 259 & 1,929 & 207 & 26 & 166 & 150 \\
\hline University of Michigan & 4,922 & 44 & R.C. Ewing & 436 & 83 & 3,151 & 135 & 38 & 63 & 150 \\
\hline University of Minnesota & 2,893 & 95 & W.W. Gerberich & 420 & 84 & 2,886 & 146 & 29 & 134 & 150 \\
\hline University of Missouri & 2,685 & 108 & W.B. Yelon & 318 & 140 & 2,335 & 184 & 19 & 235 & 150 \\
\hline University of Nebraska & 1,433 & 199 & P.A. Dowben & 358 & 112 & 1,841 & 212 & 28 & 149 & 150 \\
\hline University of New Hampshire & 353 & 319 & J.E. Kranowski & 66 & 335 & 591 & 313 & 10 & 318 & 56 \\
\hline University of New Mexico & 1,124 & 231 & S.R.J. Brueck & 309 & 147 & 2,316 & 186 & 28 & 149 & 150 \\
\hline University of New South Wales & 4,385 & 55 & M.A. Green & 403 & 95 & 3,051 & 138 & 28 & 149 & 150 \\
\hline University of North Carolina, Chapel Hill & 1,433 & 199 & T.J. Meyer & 490 & 60 & 8,067 & 48 & 36 & 76 & 150 \\
\hline University of North Texas & 678 & 271 & W. Brostow & 240 & 215 & 921 & 290 & 18 & 245 & 150 \\
\hline University of Notre Dame & 845 & 255 & J.K. Furdyna & 559 & 43 & 8,144 & 46 & 29 & 134 & 150 \\
\hline University of Nottingham & 2,160 & 142 & M. Henini & 631 & 31 & 5,964 & 66 & 31 & 110 & 150 \\
\hline University of Oklahoma & 557 & 285 & D.E. Resasco & 179 & 269 & 2,951 & 143 & 32 & 101 & 150 \\
\hline
\end{tabular}




\begin{tabular}{|c|c|c|c|c|c|c|c|c|c|c|}
\hline University of Oregon & 356 & 317 & D.C. Johnson & 265 & 187 & 4,476 & 92 & 29 & 134 & 150 \\
\hline University of Oslo & 855 & 254 & H. Fjellvag & 299 & 158 & 2,448 & 175 & 28 & 149 & 150 \\
\hline University of Otago & 311 & 326 & J.A. Simpson & 179 & 269 & 834 & 297 & 14 & 291 & 150 \\
\hline University of Ottawa & 744 & 259 & J.C. Sciano & 291 & 162 & 354 & 326 & 22 & 206 & 150 \\
\hline University of Oxford & 4,571 & 50 & R.G. Compton & 917 & 14 & 16,202 & 15 & 51 & 23 & 150 \\
\hline University of Pennsylvania & 2,207 & 136 & J.E. Fischer & 418 & 86 & 9,589 & 36 & 42 & 41 & 150 \\
\hline University of Pittsburgh & 1,368 & 205 & A.C. Balazs & 241 & 213 & 2,816 & 149 & 33 & 93 & 150 \\
\hline University of Quebec & 1,444 & 197 & S. Kaliaguine & 323 & 137 & 4,280 & 99 & 35 & 84 & 150 \\
\hline University of Queensland & 2,002 & 151 & G.Q. $\mathrm{Lu}$ & 309 & 147 & 5,294 & 75 & 43 & 35 & 150 \\
\hline University of Reading & 1,453 & 196 & M.G.B. Drew & 733 & 22 & 7,560 & 55 & 37 & 68 & 150 \\
\hline University of Rochester & 879 & 251 & P.M. Fauchet & 351 & 118 & 5,053 & 78 & 32 & 101 & 150 \\
\hline University of Saskatchewan & 904 & 247 & S.O. Kasap & 225 & 227 & 957 & 286 & 19 & 235 & 150 \\
\hline University of Science and Technology of China & 5,815 & 30 & Y. Qian & 926 & 12 & 14,357 & 19 & 51 & 23 & 150 \\
\hline University of Sheffield & 4,954 & 43 & M. Hopkinson & 522 & 49 & 7,278 & 58 & 32 & 101 & 150 \\
\hline University of South Carolina & 1,744 & 173 & R.E. White & 260 & 192 & 3,179 & 133 & 29 & 134 & 150 \\
\hline University of South Florida & 631 & 275 & A. Kumar & 1,258 & 4 & 8,833 & 39 & 38 & 63 & 150 \\
\hline University of Southampton & 1,870 & 160 & M.T. Weller & 222 & 230 & 1,270 & 251 & 14 & 291 & 150 \\
\hline University of Southern California & 1,705 & 177 & T.G. Langdon & 613 & 34 & 16,813 & 14 & 58 & 13 & 150 \\
\hline University of St Andrews & 868 & 252 & I.D.W. Samuel & 277 & 177 & 3,780 & 111 & 39 & 57 & 150 \\
\hline University of Surrey & 2,787 & 103 & S.R.P. Silva & 327 & 136 & 3,416 & 123 & 32 & 101 & 150 \\
\hline University of Sussex & 678 & 271 & P.D. Townsend & 360 & 111 & 2,733 & 157 & 23 & 195 & 150 \\
\hline University of Sydney & 3,124 & 86 & Y.W. Mai & 419 & 85 & 4,659 & 87 & 30 & 124 & 150 \\
\hline University of Technology, Sydney & 483 & 300 & M.R. Phillips & 157 & 285 & 824 & 299 & 17 & 257 & 150 \\
\hline University of Tennessee Knoxville & 2,092 & 146 & P.K. Liaw & 507 & 54 & 2,308 & 188 & 26 & 166 & 150 \\
\hline University of Texas at Austin & 3,065 & 88 & J.B. Goodenough & 146 & 296 & 5,461 & 71 & 29 & 134 & 106 \\
\hline University of Tokyo & 10,812 & 8 & Y. Tokura & 901 & 15 & 38,181 & 3 & 82 & 3 & 150 \\
\hline University of Toronto & 510 & 296 & M.A. Winnik & 445 & 78 & 5,334 & 72 & 37 & 68 & 150 \\
\hline University of Tsukuba & 2,548 & 117 & Y. Masumoto & 358 & 112 & 3,124 & 136 & 24 & 182 & 150 \\
\hline University of Twente & 2,963 & 91 & D.N. Reinhoudt & 724 & 24 & 22,809 & 8 & 66 & 9 & 150 \\
\hline University of Utah & 2,926 & 94 & Z.V. Vardeny & 376 & 103 & 4,227 & 101 & 37 & 68 & 150 \\
\hline University of Vermont & 421 & 307 & T.B. Flanagan & 250 & 203 & 1,024 & 277 & 13 & 299 & 150 \\
\hline University of Victoria & 207 & 334 & S. Dost & 157 & 285 & 431 & 323 & 13 & 299 & 107 \\
\hline University of Virginia & 1,864 & 161 & H.N.G. Wadley & 281 & 173 & 1,728 & 220 & 26 & 166 & 150 \\
\hline University of Warwick & 1,267 & 215 & C.F. McConville & 203 & 247 & 1,625 & 228 & 21 & 218 & 150 \\
\hline University of Washington & 3,477 & 77 & J.C. Seferis & 285 & 168 & 1,385 & 246 & 12 & 307 & 150 \\
\hline University of Waterloo & 1,738 & 174 & A. Nathan & 311 & 144 & 1,066 & 269 & 17 & 257 & 150 \\
\hline
\end{tabular}




\begin{tabular}{|c|c|c|c|c|c|c|c|c|c|c|}
\hline University of Western Australia & 1,464 & 194 & B.W. Skelton & 1,010 & 9 & 11,519 & 27 & 38 & 63 & 150 \\
\hline University of Western Ontario & 1,916 & 156 & R.J. Puddephatt & 448 & 77 & 3,534 & 118 & 35 & 84 & 150 \\
\hline University of Wisconsin & 2,723 & 107 & Y.A. Chang & 409 & 89 & 2,784 & 150 & 24 & 182 & 150 \\
\hline University of Wollongong & 1,691 & 179 & S.X. Dou & 561 & 42 & 6,118 & 64 & 34 & 88 & 150 \\
\hline University of York & 346 & 322 & J.H. Clark & 282 & 172 & 3,233 & 132 & 31 & 110 & 150 \\
\hline University of Zurich & 418 & 308 & H. Keller & 189 & 261 & 2,659 & 163 & 28 & 149 & 150 \\
\hline Univesitas Gadjah Mada & 56 & 339 & M. Yasin & 11 & 344 & 11 & 344 & 2 & 341 & 30 \\
\hline Uppsala University & 3,183 & 84 & S.Hogmark & 198 & 252 & 2,071 & 200 & 26 & 166 & 150 \\
\hline Utah State & 274 & 328 & M.E. Wright & 93 & 327 & 1,612 & 230 & 15 & 287 & 150 \\
\hline Utrecht University & 2,313 & 128 & G. Blasse & 474 & 71 & 3,510 & 119 & 14 & 291 & 150 \\
\hline Vanderbilt University & 1,192 & 225 & S.T. Pantelides & 376 & 103 & 4,997 & 79 & 36 & 76 & 150 \\
\hline Victoria University of Wellington & 305 & 327 & H.J. Trodahl & 167 & 276 & 1,057 & 271 & 16 & 277 & 150 \\
\hline Vienna University of Technology & 2,367 & 125 & R. Grossinger & 278 & 176 & 1,211 & 255 & 13 & 299 & 150 \\
\hline Virginia Polytechnic Institute & 2,837 & 100 & J.E. McGarth & 584 & 39 & 4,378 & 96 & 29 & 134 & 150 \\
\hline Vrije Universiteit, Brussels & 613 & 276 & H.A.Terryn & 195 & 255 & 961 & 285 & 20 & 224 & 150 \\
\hline VU University Amsterdam & 520 & 294 & R. Griessen & 275 & 181 & 2,446 & 176 & 30 & 124 & 150 \\
\hline Wageningen University & 471 & 303 & M.A. Cohen Stuart & 178 & 271 & 2,770 & 152 & 29 & 134 & 150 \\
\hline Wake Forest University & 218 & 333 & D.L. Carroll & 209 & 243 & 4,926 & 82 & 37 & 68 & 150 \\
\hline Waseda University & 2,666 & 109 & T. Osaka & 479 & 68 & 3,258 & 129 & 31 & 110 & 150 \\
\hline Washington State University & 1,218 & 221 & J.T. Dickerson & 259 & 194 & 1,237 & 253 & 19 & 235 & 150 \\
\hline Washington University in St. Louis & 735 & 262 & K.L. Wooley & 214 & 235 & 4,213 & 102 & 42 & 41 & 150 \\
\hline Wayne State University & 1,114 & 232 & S.K. Putatunda & 85 & 329 & 281 & 330 & 11 & 313 & 68 \\
\hline West Virginia University & 698 & 266 & M.S. Seehra & 225 & 227 & 1,573 & 235 & 20 & 224 & 150 \\
\hline Yale University & 1,082 & 235 & R.H Crabtree & 366 & 107 & 8,595 & 41 & 48 & 26 & 150 \\
\hline Yonsei University & 3,438 & 78 & C.N. Whang & 248 & 206 & 1,623 & 229 & 21 & 218 & 150 \\
\hline York University & 183 & 335 & A.B.P. Lever & 241 & 213 & 3,572 & 117 & 24 & 182 & 150 \\
\hline Zhejiang University & 8,825 & 10 & D. Yang & 441 & 80 & 2,182 & 196 & 26 & 166 & 150 \\
\hline
\end{tabular}




\begin{tabular}{|c|c|c|c|c|c|c|c|c|c|c|}
\hline Immunology and Microbiology Data & $\begin{array}{l}\text { Department } \\
\text { Publications }\end{array}$ & Rank & Most Prolific Author & Published & Rank & Cited & Rank & $\begin{array}{c}\text { H- } \\
\text { Index }\end{array}$ & Rank & $\begin{array}{c}\text { \# of } \\
\text { Coauthors }\end{array}$ \\
\hline Aalto University & 172 & 289 & M. Leisola & 121 & 275 & 1,183 & 269 & 18 & 261 & 144 \\
\hline Aarhus University & 2,141 & 87 & S. Thiel & 146 & 234 & 2,617 & 177 & 36 & 117 & 150 \\
\hline Arizonia State University & 144 & 294 & G.R. Pettit & 570 & 22 & 13,412 & 28 & 35 & 125 & 150 \\
\hline Ateneo de Manila University & 1 & 346 & R. Tan-Palanca & 1 & 345 & 1 & 345 & 1 & 338 & 0 \\
\hline Auburn University & 825 & 194 & B.L. Blagburn & 182 & 196 & 1,796 & 217 & 20 & 239 & 150 \\
\hline Australian National University & 2,418 & 72 & A. Mullbacher & 175 & 200 & 1,942 & 208 & 22 & 215 & 150 \\
\hline Boston College & 112 & 304 & E.R. Kantrowitz & 152 & 228 & 853 & 300 & 16 & 278 & 150 \\
\hline Boston University & 2,725 & 53 & D.T. Felson & 381 & 62 & 15,979 & 22 & 62 & 18 & 150 \\
\hline Brandeis University & 498 & 225 & A. Nisonoff & 146 & 234 & 324 & 325 & 1 & 338 & 115 \\
\hline Brigham Young University & 84 & 317 & P.B. Savage & 131 & 257 & 2,274 & 190 & 31 & 141 & 150 \\
\hline Brown University & 1,081 & 164 & C. Biron & 139 & 247 & 7,271 & 69 & 46 & 55 & 150 \\
\hline California Institute of Technology (Calt... & 1,272 & 149 & J.H. Strass & 130 & 259 & 2,733 & 171 & 19 & 248 & 139 \\
\hline Cardiff University & 2,314 & 74 & A.D. Russell & 262 & 120 & 2,058 & 200 & 26 & 176 & 120 \\
\hline Carnegie Mellon University & 195 & 281 & M.M. Domach & 62 & 321 & 618 & 312 & 12 & 309 & 66 \\
\hline Case Western Reserve University & 2,780 & 52 & M.M. Ledermann & 261 & 122 & 5,911 & 88 & 41 & 82 & 150 \\
\hline Chalmers University of Technology & 177 & 287 & L. Gustafsson & 112 & 283 & 2,037 & 203 & 23 & 206 & 150 \\
\hline Charles University & 744 & 200 & J. Bartunkova & 113 & 281 & 679 & 308 & 18 & 261 & 150 \\
\hline Chinese University of Hong Kong & 182 & 284 & T.B. $\mathrm{Ng}$ & 409 & 52 & 2,912 & 165 & 38 & 104 & 150 \\
\hline Chulalongkorn University & 842 & 192 & S. Tanasupawat & 79 & 307 & 298 & 327 & 12 & 309 & 118 \\
\hline City University of Hong Kong & 54 & 327 & N.F.Y. Tam & 154 & 224 & 1,735 & 220 & 26 & 176 & 150 \\
\hline City University of New York & 141 & 296 & R. Bittman & 249 & 134 & 3,526 & 146 & 27 & 165 & 150 \\
\hline Colorado State University & 842 & 192 & I.M. Orme & 255 & 126 & 5,468 & 98 & 42 & 74 & 150 \\
\hline Columbia University & 3,698 & 31 & H.C. New & 514 & 26 & 4,740 & 112 & 4 & 334 & 150 \\
\hline Cornell University & 6,822 & 9 & J. Laurence & 216 & 160 & 1,288 & 256 & 13 & 302 & 150 \\
\hline Curtin University of Technology & 211 & 279 & W. B. Grubb & 105 & 288 & 1,090 & 278 & 15 & 289 & 130 \\
\hline Dalhousie University & 1,170 & 156 & W.F. Doolittle & 228 & 151 & 5,968 & 86 & 41 & 82 & 150 \\
\hline Dartmouth College & 1,465 & 139 & R.J. Noelle & 192 & 184 & 7,628 & 64 & 46 & 55 & 150 \\
\hline Delft University of Technology & 949 & 174 & J.J. Heijnen & 307 & 96 & 4,837 & 110 & 45 & 57 & 150 \\
\hline Drexel University & 1,095 & 163 & D.M. Murasko & 102 & 289 & 1,173 & 272 & 15 & 289 & 150 \\
\hline Duke University & 4,734 & 20 & B.F. Haynes & 342 & 76 & 7,727 & 62 & 35 & 125 & 150 \\
\hline Durham University & 236 & 271 & S.W. Lindsay & 97 & 292 & 1,592 & 227 & 23 & 206 & 150 \\
\hline Ecole Normale Supérieure de Lyon & 283 & 262 & J.L. Darlix & 219 & 158 & 2,452 & 185 & 33 & 130 & 150 \\
\hline École Normale Supérieure, Paris & 141 & 296 & M. Dreyfus & 61 & 322 & 951 & 289 & 16 & 278 & 78 \\
\hline École Polytechnique & 77 & 321 & S. Blanquet & 188 & 188 & 2,039 & 202 & 22 & 215 & 150 \\
\hline
\end{tabular}




\begin{tabular}{|c|c|c|c|c|c|c|c|c|c|c|}
\hline Ecole Polytechnique Fédérale de Lausanne & 287 & 260 & U. Von Stockar & 150 & 232 & 1,182 & 270 & 20 & 239 & 150 \\
\hline Eindhoven University of Technology & 36 & 331 & EW. Meijer & 493 & 31 & 13,390 & 29 & 71 & 9 & 150 \\
\hline Emory University & 3,840 & 30 & R. Ahmed & 253 & 128 & 10,416 & 37 & 61 & 20 & 150 \\
\hline Erasmus University Rotterdam & 3,311 & 42 & A.D.M E. Osterhaus & 741 & 7 & 23,768 & 13 & 59 & 22 & 150 \\
\hline ETH Zurich (Swiss Federal Institute of Technology) & 2,103 & 90 & K. Wuthrich & 591 & 15 & 39,101 & 7 & 57 & 25 & 150 \\
\hline Florida International University & 172 & 289 & S.L. Smith & 21 & 341 & 168 & 335 & 8 & 327 & 58 \\
\hline Florida State University & 78 & 320 & K.H. Roux & 111 & 284 & 2,295 & 188 & 21 & 227 & 150 \\
\hline Freie Universität Berlin & 1,703 & 116 & H. Hahn & 137 & 249 & 902 & 296 & 15 & 289 & 150 \\
\hline Friedrich Alexander Universität Erlangen Nürnberg & 2,111 & 89 & M. Rollinghoff & 236 & 149 & 5,006 & 107 & 33 & 130 & 150 \\
\hline Fudan University & 742 & 201 & Y.M. Wen & 156 & 221 & 1,317 & 250 & 15 & 289 & 150 \\
\hline Georg August Universität Göttingen & 2,474 & 68 & W. Bruck & 248 & 136 & 6,369 & 76 & 44 & 64 & 150 \\
\hline George Mason University & 37 & 329 & $\mathrm{Y} . \mathrm{Wu}$ & 22 & 340 & 327 & 324 & 10 & 321 & 31 \\
\hline George Washington University & 910 & 184 & J.M. Orenstein & 251 & 131 & 8,493 & 48 & 41 & 82 & 150 \\
\hline Georgetown University & 1,489 & 136 & C.K. Hurley & 188 & 188 & 1,589 & 228 & 22 & 215 & 150 \\
\hline Georgia Institute of Technology & 353 & 251 & F.E. Loffler & 78 & 309 & 956 & 287 & 24 & 195 & 150 \\
\hline Georgia State University & 429 & 240 & D.G. Ahearn & 135 & 252 & 1,161 & 273 & 16 & 278 & 150 \\
\hline Goteborg University & 1,438 & 141 & L.A. Hanson & 418 & 46 & 4,264 & 121 & 27 & 165 & 150 \\
\hline Harvard University & 1,537 & 130 & R. Losick & 250 & 132 & 4,650 & 114 & 48 & 48 & 150 \\
\hline Hebrew University of Jerusalem & 3,397 & 38 & Y. Becker & 245 & 142 & 1,202 & 266 & 10 & 321 & 150 \\
\hline Heidelberg Universität & 2,633 & 60 & G. Opelz & 575 & 19 & 7,802 & 59 & 32 & 135 & 150 \\
\hline Hokkaido University & 3,648 & 32 & H. Kida & 346 & 75 & 3,008 & 162 & 30 & 149 & 150 \\
\hline Hong Kong Polytechnic University & 124 & 301 & H.C. Chua & 117 & 278 & 787 & 304 & 15 & 289 & 150 \\
\hline Hong Kong University of Science \& Techno... & 175 & 288 & P.Y. Qian & 167 & 209 & 1,285 & 258 & 25 & 187 & 150 \\
\hline Humboldt-Universität zu Berlin & 1,017 & 170 & U. Wahn & 483 & 32 & 7,934 & 57 & 54 & 30 & 150 \\
\hline Imperial College London & 6,240 & 10 & M.Feldmann & 462 & 38 & 14,332 & 27 & 53 & 37 & 150 \\
\hline Indian Institute of Technology Bombay (I... & 112 & 304 & P.P.Wangikar & 37 & 334 & 412 & 320 & 11 & 316 & 59 \\
\hline Indian Institute of Technology Delhi (II... & 309 & 256 & M.N. Gupta & 174 & 201 & 1,338 & 246 & 22 & 215 & 101 \\
\hline Indian Institute of Technology Kanpur (I... & 57 & 325 & L.R lyengar & 60 & 323 & 460 & 319 & 8 & 327 & 59 \\
\hline Indiana University Bloomington & 1,228 & 152 & A.L. Koch & 179 & 198 & 1,294 & 253 & 13 & 302 & 70 \\
\hline Indiana University Indianapolis & 1,496 & 135 & K.D. Brandt & 306 & 97 & 5,838 & 90 & 32 & 135 & 150 \\
\hline Iowa State University & 577 & 216 & S.J. Lamont & 158 & 219 & 1,180 & 271 & 18 & 261 & 150 \\
\hline Johns Hopkins University & 9,955 & 3 & D.E. Griffin & 303 & 98 & 5,864 & 89 & 37 & 111 & 150 \\
\hline Kansas State University & 304 & 258 & F. Blecha & 140 & 245 & 1,918 & 209 & 19 & 248 & 150 \\
\hline Katholieke Universiteit Leuven & 2,573 & 64 & E. DeClercq & 1,641 & 1 & 49,331 & 3 & 72 & 7 & 150 \\
\hline Keio University & 1,037 & 166 & T. Takeuchi & 431 & 43 & 3,362 & 154 & 30 & 149 & 150 \\
\hline
\end{tabular}




\begin{tabular}{|c|c|c|c|c|c|c|c|c|c|c|}
\hline King Fahd University of Petroleum \& Minerals & 6 & 343 & A. Aksoy & 25 & 339 & 55 & 342 & 3 & 336 & 33 \\
\hline King Saud University & 595 & 215 & K.A.S. Al-Rasheid & 74 & 313 & 192 & 334 & 9 & 326 & 95 \\
\hline Kobe University & 1,059 & 165 & H. Hotta & 130 & 259 & 1,619 & 224 & 23 & 206 & 150 \\
\hline Korea Advanced Institute of Science \& Technology & 1,025 & 167 & S.T. Lee & 143 & 240 & 1,133 & 275 & 19 & 248 & 150 \\
\hline Korea University & 1,127 & 160 & S.W. Kim & 171 & 204 & 1,411 & 240 & 21 & 227 & 150 \\
\hline Kyoto University & 5,740 & 13 & T. Honjo & 473 & 34 & 12,545 & 33 & 68 & 11 & 150 \\
\hline Kyushu University & 3,373 & 40 & K. Nomoto & 885 & 4 & 15,043 & 25 & 48 & 48 & 150 \\
\hline La Trobe University & 497 & 227 & R.J. Seviour & 143 & 240 & 1,207 & 265 & 23 & 206 & 150 \\
\hline Lancaster University & 14 & 339 & N.J. Fullwood & 77 & 310 & 1,095 & 277 & 21 & 227 & 150 \\
\hline Leiden University & 5,200 & 17 & F.C. Breedveld & 583 & 17 & 24,598 & 11 & 64 & 17 & 150 \\
\hline Linkoping University & 1,156 & 157 & B. Bjorksten & 340 & 79 & 6,948 & 74 & 40 & 90 & 150 \\
\hline London School of Economics and Political Science & 104 & 307 & E. Szyszczak & 12 & 342 & 5 & 343 & 1 & 338 & 3 \\
\hline Loughborough University & 91 & 314 & R.J. Stretton & 63 & 320 & 151 & 337 & 0 & 341 & 57 \\
\hline Louisiana State University & 1,256 & 151 & C. Bouchard & 621 & 12 & 23,796 & 12 & 47 & 53 & 150 \\
\hline Ludwig-Maximilians-Universität München & 3,388 & 39 & A. Bock & 202 & 177 & 2,583 & 178 & 31 & 141 & 150 \\
\hline Lund University & 4,980 & 19 & B. Mattiasson & 593 & 14 & 8,060 & 55 & 31 & 141 & 150 \\
\hline Maastricht University & 1,404 & 142 & D.Van Der Heijde & 329 & 83 & 7,410 & 68 & 55 & 28 & 150 \\
\hline Macquarie University & 424 & 241 & J.M. Whalley & 74 & 313 & 349 & 323 & 14 & 298 & 128 \\
\hline Mahidol University & 2,449 & 69 & N.J. White & 780 & 6 & 27,140 & 10 & 67 & 12 & 150 \\
\hline Masaryk University & 467 & 233 & M. Gelnar & 66 & 319 & 374 & 322 & 15 & 289 & 129 \\
\hline Massachusetts Institute of Technology & 2,724 & 54 & G.C. Walker & 317 & 87 & 4,136 & 126 & 30 & 149 & 150 \\
\hline McGill University & 4,285 & 25 & M.A.Wainerg & 521 & 25 & 9,234 & 40 & 41 & 82 & 150 \\
\hline McMaster University & 2,294 & 76 & D.A. Clark & 397 & 56 & 5,487 & 97 & 37 & 111 & 150 \\
\hline Michigan State University & 3,028 & 48 & J.M. Tiedje & 369 & 69 & 12,332 & 34 & 54 & 30 & 150 \\
\hline Michigan Technological University & 59 & 324 & E.C. Carlson & 10 & 343 & 83 & 341 & 0 & 341 & 13 \\
\hline Monash University & 2,299 & 75 & B. A. Adler & 191 & 186 & 1,595 & 226 & 24 & 195 & 150 \\
\hline Montana State University & 1,111 & 162 & G.A. McPeters & 113 & 281 & 2,014 & 206 & 16 & 278 & 105 \\
\hline Moscow State University & 2,175 & 83 & N.S. Egorov & 365 & 70 & 146 & 338 & 4 & 334 & 150 \\
\hline Nagoya University & 2,583 & 62 & Y. Nishiyama & 267 & 115 & 2,022 & 204 & 26 & 176 & 150 \\
\hline Nanjing University & 230 & 272 & L. Wang & 153 & 226 & 1,055 & 281 & 19 & 248 & 150 \\
\hline Nanyang Technological University & 242 & 269 & J.H.Tay & 246 & 140 & 2,050 & 201 & 31 & 141 & 150 \\
\hline National Taiwan University & 1,862 & 103 & P.R. Hsueh & 417 & 47 & 4,252 & 123 & 36 & 117 & 150 \\
\hline National Tsing Hua University & 309 & 256 & S.C. Wu & 40 & 333 & 309 & 326 & 11 & 316 & 62 \\
\hline National University of Ireland, Galway & 388 & 247 & A.P. Moran & 176 & 199 & 3,667 & 139 & 38 & 104 & 150 \\
\hline National University of Singapore & 1,642 & 120 & J. Kwang & 124 & 270 & 1,365 & 244 & 19 & 248 & 150 \\
\hline New Mexico State University & 216 & 277 & C.B. Jonsson & 56 & 327 & 750 & 307 & 17 & 271 & 146 \\
\hline
\end{tabular}




\begin{tabular}{|c|c|c|c|c|c|c|c|c|c|c|}
\hline New York University & 3,617 & 33 & V. Nussenzweig & 250 & 132 & 3,315 & 155 & 26 & 176 & 150 \\
\hline Newcastle University & 1,640 & 121 & M. Goodfellow & 309 & 93 & 3,386 & 153 & 26 & 176 & 150 \\
\hline North Carolina State University & 2,063 & 92 & T.R. Klaenhammer & 194 & 183 & 3,933 & 129 & 28 & 158 & 150 \\
\hline Northeastern University & 273 & 264 & J.J. Gozzo & 95 & 297 & 211 & 330 & 3 & 336 & 44 \\
\hline Northwestern University & 3,132 & 44 & R. Patterson & 439 & 41 & 2,778 & 170 & 13 & 302 & 150 \\
\hline Norwegian University of Science \& Technology & 550 & 220 & T. Espevik & 196 & 182 & 8,849 & 45 & 42 & 74 & 150 \\
\hline Ohio State University & 4,320 & 24 & L.J. Saif & 262 & 120 & 1,578 & 229 & 25 & 187 & 150 \\
\hline Oklahoma State University & 864 & 189 & K.M. Kocan & 223 & 156 & 1,280 & 259 & 30 & 149 & 150 \\
\hline Open University UK & 97 & 312 & & 0 & 346 & 0 & 346 & 0 & 341 & 0 \\
\hline Oregon State University & 1,705 & 115 & G.F. Rohrmann & 125 & 265 & 1,201 & 267 & 24 & 195 & 114 \\
\hline Osaka University & 5,278 & 16 & S. Akira & 659 & 10 & 68,805 & 1 & 124 & 1 & 150 \\
\hline Peking University & 717 & 204 & H. Zhuang & 99 & 290 & 551 & 315 & 12 & 309 & 150 \\
\hline Pennsylvania State University & 2,644 & 58 & C.R. Bursey & 280 & 105 & 407 & 321 & 12 & 309 & 121 \\
\hline Pohang University of Science And Technology & 333 & 252 & Y.C. Sung & 85 & 303 & 1,821 & 216 & 26 & 176 & 150 \\
\hline Portland State University & 119 & 302 & A.L. Reyensbach & 72 & 316 & 2,269 & 191 & 27 & 165 & 150 \\
\hline Princeton University & 1,005 & 171 & T. Shenk & 225 & 154 & 7,581 & 65 & 43 & 68 & 150 \\
\hline Purdue University & 2,208 & 81 & M.G. Rossmann & 357 & 72 & 6,080 & 85 & 42 & 74 & 150 \\
\hline Queen's University & 922 & 182 & A.J. Daugulis & 152 & 228 & 103 & 340 & 22 & 215 & 140 \\
\hline Queen's University of Belfast & 1,630 & 122 & D.W. Alton & 225 & 154 & 918 & 294 & 18 & 261 & 150 \\
\hline Queensland University of Technology & 322 & 254 & P.Timms & 137 & 249 & 1,339 & 245 & 23 & 206 & 150 \\
\hline Radboud University, Nijmegen & 2,997 & 49 & P.C.L.M. Van Riel & 310 & 92 & 6,345 & 77 & 43 & 68 & 150 \\
\hline Rensselaer Polytechnic Institute & 287 & 260 & J.S. Derdick & 241 & 146 & 4,390 & 118 & 31 & 141 & 150 \\
\hline Rheinisch Westfalische Technische Hochschule Aach & 543 & 222 & G. Hasse & 214 & 164 & 3,569 & 144 & 36 & 117 & 150 \\
\hline Rheinische Friedrich Wilhelms Universitat Bonn & 1,843 & 104 & T. Bieber & 318 & 85 & 5,631 & 93 & 40 & 90 & 150 \\
\hline Rice University & 481 & 229 & G.N. Bennett & 188 & 188 & 1,706 & 222 & 21 & 227 & 150 \\
\hline Rochester Institute of Technology & 8 & 341 & K. Hickman & 10 & 343 & 4 & 344 & 0 & 341 & 5 \\
\hline Royal Institute of Technology, KTH & 370 & 249 & S.O. Enfons & 127 & 262 & 1,289 & 255 & 17 & 271 & 150 \\
\hline Royal Melbourne Institute of Technology & 161 & 292 & P.J. Coloe & 68 & 318 & 595 & 313 & 11 & 316 & 136 \\
\hline Rutgers & 1,870 & 101 & T.J. Montville & 96 & 296 & 1,430 & 237 & 18 & 261 & 109 \\
\hline Saint-Petersburg State University & 190 & 283 & S.I. Fokin & 51 & 328 & 206 & 331 & 11 & 316 & 51 \\
\hline San Diego State University & 299 & 259 & F.L. Rohwer & 76 & 312 & 1,917 & 210 & 34 & 127 & 150 \\
\hline Sapienza University of Rome & 0 & 347 & & 0 & 346 & 0 & 346 & 0 & 341 & 0 \\
\hline Sciences Po Paris & 0 & 347 & & 0 & 346 & 0 & 346 & 0 & 341 & 0 \\
\hline Seoul National University & 3,091 & 45 & J.V. Chai & 275 & 110 & 773 & 306 & 12 & 309 & 150 \\
\hline Shanghai Jiao Tong University & 492 & 228 & Z. Deng & 94 & 299 & 5,762 & 92 & 13 & 302 & 150 \\
\hline Simon Fraser University & 181 & 285 & J.K. Scott & 33 & 335 & 1,917 & 210 & 14 & 298 & 96 \\
\hline
\end{tabular}




\begin{tabular}{|c|c|c|c|c|c|c|c|c|c|c|}
\hline Stanford University & 6,967 & 6 & P. Parham & 417 & 47 & 9,035 & 43 & 54 & 30 & 150 \\
\hline State University of New York Buffalo & 4 & 344 & J.M. Bernstein & 126 & 264 & 1,382 & 243 & 17 & 271 & 150 \\
\hline Stockholm University & 843 & 191 & P.Perlmann & 316 & 89 & 2,335 & 186 & 13 & 302 & 150 \\
\hline Stony Brook University & 1,649 & 119 & E. Wimmer & 253 & 128 & 3,896 & 132 & 32 & 135 & 150 \\
\hline Syracuse University & 331 & 253 & A. Perl & 134 & 254 & 1,703 & 223 & 27 & 165 & 150 \\
\hline Tartu University (University of Tartu) & 362 & 250 & M. Mikelsaar & 69 & 317 & 1,338 & 246 & 19 & 248 & 144 \\
\hline Technical University of Denmark & 2,244 & 79 & J. Nielson & 428 & 45 & 5,208 & 104 & 41 & 82 & 150 \\
\hline Technion & 803 & 195 & E. Toubi & 95 & 297 & 1,420 & 238 & 24 & 195 & 150 \\
\hline Technische Universität Berlin & 431 & 239 & P. Kampter & 239 & 147 & 3,006 & 163 & 27 & 165 & 150 \\
\hline Technische Universitat Chemnitz & 3 & 345 & W. Zimmermann & 139 & 247 & 3,642 & 140 & 21 & 227 & 150 \\
\hline Technische Universität Dresden & 498 & 225 & E.P. Rieber & 140 & 245 & 1,883 & 212 & 23 & 206 & 150 \\
\hline Technische Universität München & 2,169 & 85 & K.H. Schleifer & 370 & 68 & 12,651 & 31 & 40 & 90 & 150 \\
\hline Tel Aviv University & 2,617 & 61 & Y. Shoenfeld & 123 & 272 & 20,283 & 17 & 55 & 28 & 150 \\
\hline Texas A\&M University & 2,491 & 67 & S.C. Ricke & 219 & 158 & 1,124 & 276 & 22 & 215 & 150 \\
\hline Texas Tech & 272 & 265 & D.C. Straus & 125 & 265 & 779 & 305 & 11 & 316 & 135 \\
\hline Tohoku University & 2,244 & 79 & K. Sugamura & 267 & 115 & 5,600 & 94 & 40 & 90 & 150 \\
\hline Tokyo Institute of Technology & 793 & 196 & M. Shoda & 171 & 204 & 1,463 & 236 & 19 & 248 & 150 \\
\hline Trinity College Dublin & 1,181 & 154 & T.S. Foster & 247 & 137 & 3,923 & 130 & 38 & 104 & 150 \\
\hline Tsinghua University & 405 & 243 & L.Du & 85 & 303 & 249 & 328 & 8 & 327 & 150 \\
\hline Tufts University & 2,638 & 59 & R.N.Jones & 1,022 & 3 & 22,801 & 15 & 69 & 10 & 150 \\
\hline Universidad Autonoma de Madrid & 2,034 & 94 & E. Domingo & 277 & 107 & 3,524 & 147 & 41 & 82 & 150 \\
\hline Universidad de Chile & 1,021 & 169 & H. Schenone & 227 & 152 & 526 & 316 & 8 & 327 & 150 \\
\hline Universidad de Granada & 2,034 & 94 & E. Domingo & 277 & 107 & 3,524 & 147 & 41 & 82 & 150 \\
\hline Universidad del País Vasco & 549 & 221 & J.L. Ponton & 183 & 195 & 1,476 & 235 & 21 & 227 & 150 \\
\hline Universidad Nacional Autónoma de México ... & 752 & 198 & E. Scrutto & 97 & 292 & 675 & 309 & 19 & 248 & 150 \\
\hline Universidad Politecnica de Madrid & 230 & 272 & G. Salcedo & 122 & 273 & 1,311 & 252 & 27 & 165 & 150 \\
\hline Universidade de São Paulo & 1,834 & 105 & F.Q. Cunha & 261 & 122 & 4,126 & 127 & 34 & 127 & 150 \\
\hline Universidade Estadual de Campinas & 390 & 246 & E. Antunes & 170 & 206 & 2,181 & 194 & 19 & 248 & 150 \\
\hline Università degli Studi di Firenze & 1,597 & 127 & S. Romagnani & 378 & 66 & 15,708 & 23 & 53 & 37 & 150 \\
\hline Università degli Studi di Padova & 1,655 & 118 & G. Palu & 259 & 125 & 3,701 & 137 & 28 & 158 & 150 \\
\hline Universita Di Bologna & 1,749 & 110 & F. Chiodo & 398 & 54 & 2,781 & 169 & 23 & 206 & 150 \\
\hline Universita di Pisa & 444 & 237 & S. Bombardieri & 285 & 103 & 6,601 & 75 & 28 & 158 & 150 \\
\hline Universitat Autonoma de Barcelona & 1,815 & 107 & J. Barbe & 143 & 240 & 933 & 291 & 19 & 248 & 150 \\
\hline Universitat Bielefeld & 413 & 242 & A. Puhler & 309 & 93 & 7,674 & 63 & 40 & 90 & 150 \\
\hline Universität Bremen & 228 & 275 & B. Reinhold-Hurek & 59 & 326 & 881 & 299 & 21 & 227 & 97 \\
\hline Universitat d'Alacant & 193 & 282 & F. Rodriguez & 120 & 276 & 2,706 & 173 & 33 & 130 & 150 \\
\hline
\end{tabular}




\begin{tabular}{|c|c|c|c|c|c|c|c|c|c|c|}
\hline Universitat de València & 1,266 & 150 & R. Sentandreu & 158 & 219 & 1,227 & 264 & 15 & 289 & 150 \\
\hline Universität Frankfurt am Main & 1,727 & 112 & P. Kraczy & 60 & 323 & 580 & 314 & 21 & 227 & 140 \\
\hline Universität Freiburg & 1,960 & 98 & G. Drews & 198 & 180 & 628 & 311 & 7 & 332 & 150 \\
\hline Universitat Hamburg & 250 & 267 & M. Schachner & 590 & 16 & 22,281 & 16 & 58 & 23 & 150 \\
\hline Universität Karlsruhe & 281 & 263 & M.Zoller & 226 & 153 & 3,016 & 161 & 25 & 187 & 150 \\
\hline Universitat Leipzig & 403 & 244 & F. Emmrich & 222 & 157 & 2,577 & 179 & 21 & 227 & 150 \\
\hline Universitat Munster (Westfälische Wilhelms-Un & 571 & 218 & T.A. Luger & 465 & 37 & 8,426 & 49 & 48 & 48 & 150 \\
\hline Universitat Politecnica de Catalunya & 8 & 341 & J.J. Perez & 137 & 249 & 1,027 & 283 & 16 & 278 & 150 \\
\hline Universität Regensburg & 1,469 & 138 & R.H.Strub & 249 & 134 & 3,595 & 142 & 39 & 100 & 150 \\
\hline Universität Stuttgart & 556 & 219 & K. Pfizenmaier & 181 & 197 & 4,252 & 123 & 28 & 158 & 150 \\
\hline Universitat Trier & 21 & 335 & D.H. Hellhammer & 160 & 216 & 4,945 & 109 & 42 & 74 & 150 \\
\hline Universität Tübingen & 2,582 & 63 & P.G. Kremsner & 245 & 142 & 3,422 & 151 & 34 & 127 & 150 \\
\hline Universitat Wien (University of Vienna) & 2,721 & 55 & D. Kraft & 342 & 76 & 5,367 & 100 & 50 & 41 & 150 \\
\hline Universitat Zu Koln & 1,881 & 100 & W. Doerfler & 267 & 115 & 2,117 & 198 & 20 & 239 & 150 \\
\hline Université Catholique de Louvain & 1,587 & 128 & G.R. Cornellis & 199 & 179 & 3,854 & 133 & 40 & 90 & 150 \\
\hline Universite de Liege & 927 & 181 & P.P. Pastoret & 252 & 130 & 1,721 & 221 & 22 & 215 & 150 \\
\hline Université de Montréal & 1,988 & 96 & R.P. Sekaly & 206 & 172 & 5,599 & 95 & 31 & 141 & 150 \\
\hline Université de Nice Sophia Antipolis & 403 & 244 & R. Christen & 110 & 286 & 2,488 & 182 & 25 & 187 & 150 \\
\hline Universite Laval & 1,693 & 117 & D. Grenier & 152 & 228 & 1,502 & 234 & 20 & 239 & 148 \\
\hline Universite Libre de Bruxelles & 1,611 & 125 & M. Goldman & 396 & 57 & 9,466 & 39 & 45 & 57 & 150 \\
\hline Université Paris Sorbonne & 34 & 332 & N.P. Buu-Hol & 122 & 273 & 104 & 339 & 0 & 341 & 106 \\
\hline Universite Paris-Sud 11 & 1,564 & 129 & J. Van Heijenoort & 144 & 238 & 1,605 & 225 & 26 & 176 & 150 \\
\hline Université Pierre et Marie Curie & 1,522 & 132 & A.P. Moller & 599 & 13 & 19,973 & 18 & 58 & 23 & 150 \\
\hline Universiti Malaya (University of Malaya) & 669 & 208 & S.D. Puthucheary & 125 & 265 & 790 & 303 & 13 & 302 & 150 \\
\hline University College Cork & 921 & 183 & F. Shanahan & 303 & 98 & 7,040 & 71 & 42 & 74 & 150 \\
\hline University College Dublin & 997 & 172 & S. Fanning & 129 & 261 & 1,037 & 282 & 21 & 227 & 150 \\
\hline University College London & 5,768 & 12 & D.A. Isenberg & 661 & 9 & 17,225 & 21 & 48 & 48 & 150 \\
\hline University do Porto & 229 & 274 & F. Carneiro & 164 & 211 & 2,936 & 164 & 29 & 155 & 150 \\
\hline University of Aberdeen & 1,706 & 114 & C.J. Secombes & 261 & 122 & 2,469 & 184 & 36 & 117 & 150 \\
\hline University of Adelaide & 1,754 & 109 & P.A.Manning & 170 & 206 & 1,867 & 213 & 21 & 227 & 150 \\
\hline University of Alabama & 5,433 & 15 & J.R. McGhee & 412 & 50 & 7,788 & 60 & 45 & 57 & 150 \\
\hline University of Alberta & 3,486 & 36 & P.F. Halloran & 295 & 101 & 8,132 & 54 & 43 & 68 & 150 \\
\hline University of Amsterdam & 4,370 & 23 & P.P. Tak & 283 & 104 & 5,296 & 101 & 50 & 41 & 150 \\
\hline University of Antwerp & 883 & 186 & W.J. Stevens & 242 & 144 & 2,224 & 192 & 22 & 215 & 150 \\
\hline University of Arizona & 2,133 & 88 & F.D. Martinez & 264 & 119 & 11,292 & 35 & 54 & 30 & 150 \\
\hline University of Athens & 1,609 & 126 & N.J. Legakis & 190 & 187 & 1,853 & 214 & 24 & 195 & 150 \\
\hline
\end{tabular}




\begin{tabular}{|c|c|c|c|c|c|c|c|c|c|c|}
\hline University of Auckland & 868 & 188 & P.L. Bergquist & 146 & 234 & 1,261 & 261 & 18 & 261 & 150 \\
\hline University of Barcelona & 2,073 & 91 & J.M. Tomas & 155 & 223 & 1,286 & 257 & 23 & 206 & 150 \\
\hline University of Basel & 2,163 & 86 & M. Battegay & 215 & 161 & 4,574 & 115 & 32 & 135 & 150 \\
\hline University of Bath & 169 & 291 & S.G. Ward & 88 & 302 & 2,159 & 195 & 24 & 195 & 122 \\
\hline University of Bergen & 747 & 199 & R. Jonsson & 215 & 161 & 3,635 & 141 & 33 & 130 & 150 \\
\hline University of Bern & 2,559 & 65 & W.J. Pichler & 312 & 91 & 4,254 & 122 & 43 & 68 & 150 \\
\hline University of Birmingham & 4,540 & 22 & A.B. Rickinson & 272 & 112 & 6,962 & 73 & 42 & 74 & 150 \\
\hline University of Bristol & 2,822 & 51 & C.J. Elson & 167 & 209 & 1,524 & 232 & 17 & 271 & 150 \\
\hline University of British Columbia & 1,626 & 123 & R.E.W. Hancock & 380 & 63 & 9,524 & 38 & 60 & 21 & 150 \\
\hline University of Calgary & 715 & 205 & P. Kubes & 246 & 140 & 7,048 & 70 & 47 & 53 & 150 \\
\hline University of California, Berkley & 973 & 173 & D.H. Raulet & 161 & 214 & 6,103 & 84 & 44 & 64 & 150 \\
\hline University of California, Davis & 1,985 & 97 & M.E. Gershwin & 835 & 5 & 15,366 & 24 & 50 & 41 & 150 \\
\hline University of California, Irvine & 886 & 185 & S. Gupta & 376 & 67 & 3,404 & 152 & 27 & 165 & 150 \\
\hline University of California, Los Angeles & 7,756 & 4 & B. Bonavida & 356 & 73 & 3,828 & 136 & 38 & 104 & 150 \\
\hline University of California, Riverside & 1,141 & 159 & I.W. Sherman & 164 & 211 & 953 & 288 & 10 & 321 & 110 \\
\hline University of California, San Diego & 2,182 & 82 & M. Karin & 412 & 50 & 45,578 & 5 & 112 & 3 & 150 \\
\hline University of California, San Francisco & 6,963 & 7 & E.J. Goetzl & 387 & 59 & 6,130 & 82 & 36 & 117 & 150 \\
\hline University of California, Santa Barbara & 63 & 323 & C.E. Samuel & 172 & 203 & 3,524 & 147 & 24 & 195 & 150 \\
\hline University of California, Santa Cruz & 31 & 333 & A.L. Fink & 207 & 171 & 6,307 & 78 & 51 & 39 & 150 \\
\hline University of Cambridge & 1,821 & 106 & J. Trowsdale & 335 & 80 & 9,052 & 42 & 48 & 48 & 150 \\
\hline University of Canterbury & 17 & 336 & M.H.G. Munro & 115 & 280 & 2,292 & 189 & 17 & 271 & 150 \\
\hline University of Cape Town & 481 & 229 & F. Bombacher & 127 & 262 & 4,753 & 111 & 37 & 111 & 150 \\
\hline University of Central Florida & 149 & 293 & D. Chakrabarti & 50 & 329 & 1,085 & 279 & 19 & 248 & 150 \\
\hline University of Chicago & 2,172 & 84 & J.A. Bluestone & 413 & 49 & 14,969 & 26 & 66 & 14 & 150 \\
\hline University of Cincinnati & 2,440 & 70 & G.S. Deepe & 110 & 286 & 903 & 295 & 22 & 215 & 150 \\
\hline University of Colorado at Boulder & 131 & 298 & .R. Watkins & 294 & 102 & 7,458 & 67 & 54 & 30 & 150 \\
\hline University of Connecticut & 945 & 176 & L. Lefrancois & 134 & 254 & 4,401 & 117 & 37 & 111 & 150 \\
\hline University of Copenhagen & 1,866 & 102 & M.H. Claesson & 205 & 174 & 1,328 & 248 & 20 & 239 & 150 \\
\hline University of Delaware & 104 & 307 & J. Burnside & 60 & 323 & 1,274 & 260 & 18 & 261 & 150 \\
\hline University of Dundee & 1,455 & 140 & G.M. Gadd & 200 & 178 & 3,100 & 159 & 27 & 165 & 150 \\
\hline University of Edinburgh & 1,726 & 113 & M. Noval & 205 & 174 & 1,325 & 249 & 20 & 239 & 150 \\
\hline University of Florida & 4,019 & 28 & L.O. Ingram & 211 & 166 & 2,147 & 197 & 25 & 187 & 150 \\
\hline University of Geneva & 1,338 & 146 & S. Izul & 254 & 127 & 2,786 & 168 & 25 & 187 & 150 \\
\hline University of Georgia & 938 & 177 & J. Travis & 238 & 148 & 4,984 & 108 & 32 & 135 & 150 \\
\hline University of Ghent & 1,371 & 145 & C. Bachert & 315 & 90 & 3,253 & 157 & 38 & 104 & 150 \\
\hline University of Glasgow & 4,118 & 26 & G.H. Coombs & 213 & 165 & 3,156 & 158 & 36 & 117 & 150 \\
\hline
\end{tabular}




\begin{tabular}{|c|c|c|c|c|c|c|c|c|c|c|}
\hline University of Gothenburg & 315 & 255 & A. Tarkowski & 318 & 85 & 5,825 & 91 & 38 & 104 & 150 \\
\hline University of Groningen & 3,356 & 41 & C.G.M. Kallenberg & 460 & 39 & 7,002 & 72 & 40 & 90 & 150 \\
\hline University of Helsinki & 3,980 & 29 & P. Hayry & 445 & 40 & 6,272 & 80 & 24 & 195 & 150 \\
\hline University of Hong Kong & 56 & 326 & K.Y. Yuen & 470 & 35 & 8,524 & 47 & 50 & 41 & 150 \\
\hline University of Houston & 41 & 328 & A.M. McDermott & 43 & 332 & 503 & 317 & 12 & 309 & 57 \\
\hline University of Illinois & 3,207 & 43 & A.A. Salyers & 161 & 214 & 1,738 & 219 & 22 & 215 & 150 \\
\hline University of Illinois, Chicago & 2,054 & 93 & S. Dray & 197 & 181 & 194 & 333 & 0 & 341 & 132 \\
\hline University of Indonesia & 142 & 295 & T. Supali & 29 & 337 & 206 & 331 & 10 & 321 & 124 \\
\hline University of Iowa & 1,470 & 137 & G.W. Hunninghake & 309 & 93 & 8,849 & 45 & 44 & 64 & 150 \\
\hline University of Kansas & 602 & 214 & J.S. Hunt & 142 & 243 & 3,083 & 160 & 27 & 165 & 150 \\
\hline University of Kentucky & 949 & 174 & A. Nath & 211 & 166 & 3,563 & 145 & 45 & 57 & 150 \\
\hline University of Lausanne & 1,302 & 147 & J. Tschopp & 334 & 82 & 18,405 & 19 & 85 & 5 & 150 \\
\hline University of Leeds & 575 & 217 & P. Emery & 575 & 19 & 2,312 & 187 & 66 & 14 & 150 \\
\hline University of Leicester & 1,210 & 153 & P.W. Andrew & 169 & 208 & 2,021 & 205 & 28 & 158 & 150 \\
\hline University of Liverpool & 728 & 203 & P.M. Johnson & 162 & 213 & 1,514 & 233 & 17 & 271 & 150 \\
\hline University of Ljubljana & 936 & 178 & F. Strle & 151 & 231 & 1,399 & 241 & 26 & 176 & 150 \\
\hline University of London (Kings College of London) & 18,363 & 1 & S.G.E. Marsh & 580 & 18 & 6,277 & 79 & 33 & 130 & 150 \\
\hline University of Manchester & 12,741 & 2 & W.E.R. Ollier & 379 & 65 & 5,419 & 99 & 39 & 100 & 150 \\
\hline University of Manitoba & 2,292 & 77 & F.A. Plummer & 272 & 112 & 5,944 & 87 & 42 & 74 & 150 \\
\hline University of Maryland & 3,607 & 34 & M.M. Levine & 146 & 234 & 2,480 & 183 & 36 & 117 & 150 \\
\hline University of Maryland Baltimore County & 4,588 & 21 & M/M. Levine & 399 & 53 & 8,222 & 53 & 43 & 68 & 150 \\
\hline University of Massachusetts & 213 & 278 & C.L. Baldwin & 92 & 300 & 799 & 302 & 16 & 278 & 138 \\
\hline University of Melbourne & 3,607 & 34 & R.B. Gasser & 267 & 115 & 1,825 & 215 & 32 & 135 & 150 \\
\hline University of Miami & 525 & 223 & C. Ricordi & 525 & 23 & 12,606 & 32 & 44 & 64 & 150 \\
\hline University of Michigan & 4,038 & 27 & S.L. Kunkel & 204 & 176 & 8,276 & 51 & 62 & 18 & 150 \\
\hline University of Minnesota & 2,251 & 78 & B.R. Blazar & 380 & 63 & 9,201 & 41 & 54 & 30 & 150 \\
\hline University of Missouri & 734 & 202 & H. Braley-Mullen & 125 & 265 & 4,205 & 125 & 23 & 206 & 150 \\
\hline University of Nebraska & 1,404 & 142 & J.L. Van Etten & 185 & 192 & 1,293 & 254 & 26 & 176 & 150 \\
\hline University of New Hampshire & 238 & 270 & F.G. Rodgers & 77 & 310 & 991 & 286 & 16 & 278 & 150 \\
\hline University of New Mexico & 638 & 210 & V. Deretic & 153 & 226 & 3,922 & 131 & 39 & 100 & 150 \\
\hline University of New South Wales & 844 & 190 & D.A. Cooper & 523 & 24 & 23,716 & 14 & 57 & 25 & 150 \\
\hline University of North Carolina, Chapel Hill & 3,474 & 37 & J.P.Y. Ting & 186 & 191 & 4,276 & 120 & 43 & 68 & 150 \\
\hline University of North Texas & 110 & 306 & P.A. Mathew & 49 & 331 & 1,241 & 263 & 18 & 261 & 93 \\
\hline University of Notre Dame & 94 & 313 & F.J. Castellino & 382 & 61 & 3,296 & 156 & 29 & 155 & 150 \\
\hline University of Nottingham & 685 & 207 & D. Wakelin & 215 & 161 & 1,398 & 242 & 16 & 278 & 150 \\
\hline University of Oklahoma & 928 & 180 & J.B. Harley & 209 & 169 & 3,936 & 128 & 31 & 141 & 150 \\
\hline
\end{tabular}




\begin{tabular}{|c|c|c|c|c|c|c|c|c|c|c|}
\hline University of Oregon & 246 & 268 & J.T. Rosenbaum & 300 & 100 & 3,518 & 150 & 27 & 165 & 150 \\
\hline University of Oslo & 1,943 & 99 & P. Brandtzaeg & 495 & 30 & 7,834 & 58 & 40 & 90 & 150 \\
\hline University of Otago & 604 & 212 & J. Crane & 247 & 137 & 4,376 & 119 & 30 & 149 & 150 \\
\hline University of Ottawa & 472 & 232 & S.A. Satter & 125 & 265 & 1,084 & 280 & 16 & 278 & 150 \\
\hline University of Oxford & 2,948 & 50 & S. Gordon & 335 & 80 & 10,973 & 36 & 56 & 27 & 150 \\
\hline University of Pennsylvania & 6,943 & 8 & D.B. Weiner & 349 & 74 & 6,118 & 83 & 45 & 57 & 150 \\
\hline University of Pittsburgh & 2,496 & 66 & T.L. Whiteside & 507 & 28 & 12,806 & 30 & 50 & 41 & 150 \\
\hline University of Quebec & 513 & 224 & D. Grenier & 156 & 221 & 1,419 & 239 & 19 & 248 & 150 \\
\hline University of Queensland & 1,146 & 158 & G.J. Seymour & 276 & 109 & 2,643 & 175 & 25 & 187 & 150 \\
\hline University of Reading & 932 & 179 & M.D. Collins & 141 & 244 & 2,629 & 176 & 28 & 158 & 150 \\
\hline University of Rochester & 1,498 & 134 & R.P. Phipps & 192 & 184 & 3,839 & 135 & 37 & 111 & 150 \\
\hline University of Saskatchewan & 1,524 & 131 & L.A. Babiuk & 206 & 172 & 2,104 & 199 & 31 & 141 & 150 \\
\hline University of Science and Technology of China & 126 & 300 & Z. Tian & 184 & 193 & 1,260 & 262 & 18 & 261 & 150 \\
\hline University of Sheffield & 1,397 & 144 & J.R. Guest & 232 & 150 & 2,895 & 166 & 28 & 158 & 150 \\
\hline University of South Carolina & 603 & 213 & A. L. Huges & 280 & 105 & 6,211 & 81 & 37 & 111 & 150 \\
\hline University of South Florida & 762 & 197 & H. Friedman & 435 & 42 & 2,527 & 180 & 22 & 215 & 150 \\
\hline University of Southampton & 647 & 209 & S.T. Holgate & 1,060 & 2 & 39,705 & 6 & 72 & 7 & 150 \\
\hline University of Southern California & 1,022 & 168 & J. Slots & 274 & 111 & 3,846 & 134 & 29 & 155 & 150 \\
\hline University of St Andrews & 128 & 299 & V.J. Smith & 73 & 315 & 888 & 298 & 15 & 289 & 80 \\
\hline University of Surrey & 79 & 318 & I. Hindmarch & 270 & 114 & 2,506 & 181 & 26 & 176 & 150 \\
\hline University of Sussex & 90 & 315 & P.A. Jeggo & 131 & 257 & 4,705 & 113 & 45 & 57 & 150 \\
\hline University of Sydney & 2,645 & 57 & D.N. Love & 184 & 193 & 1,025 & 284 & 17 & 271 & 150 \\
\hline University of Technology, Sydney & 100 & 310 & R.L. Raison & 79 & 307 & 492 & 318 & 10 & 321 & 128 \\
\hline University of Tennessee Knoxville & 447 & 236 & B.T. Rouse & 341 & 78 & 5,283 & 102 & 36 & 117 & 150 \\
\hline University of Texas at Austin & 218 & 276 & W.A. Kuziel & 124 & 270 & 3,698 & 138 & 40 & 90 & 150 \\
\hline University of Tokyo & 3,070 & 46 & K. Matsushima & 498 & 29 & 18,003 & 20 & 65 & 16 & 150 \\
\hline University of Toronto & 6,081 & 11 & T.W. Mak & 635 & 11 & 47,418 & 4 & 99 & 4 & 150 \\
\hline University of Tsukuba & 465 & 235 & H. Nakauchi & 247 & 137 & 7,788 & 60 & 41 & 82 & 150 \\
\hline University of Twente & 118 & 303 & J. J. H. Rasker & 148 & 233 & 1,984 & 207 & 22 & 215 & 150 \\
\hline University of Utah & 2,440 & 70 & R.A. Dayes & 173 & 202 & 3,595 & 142 & 20 & 239 & 150 \\
\hline University of Vermont & 872 & 187 & R.C. Budd & 83 & 306 & 2,707 & 172 & 24 & 195 & 150 \\
\hline University of Victoria & 104 & 307 & B.F. Koop & 132 & 256 & 4,477 & 116 & 25 & 187 & 150 \\
\hline University of Virginia & 1,293 & 148 & T.A.E. Platts-Mills & 384 & 60 & 8,415 & 50 & 45 & 57 & 150 \\
\hline University of Warwick & 253 & 266 & N.J. Dimmock & 154 & 224 & 933 & 291 & 15 & 289 & 106 \\
\hline University of Washington & 7,505 & 5 & L. Corey & 511 & 27 & 27,474 & 9 & 79 & 6 & 150 \\
\hline University of Waterloo & 85 & 316 & L. Hoffman-Goetz & 135 & 252 & 1,569 & 231 & 21 & 227 & 95 \\
\hline
\end{tabular}




\begin{tabular}{|c|c|c|c|c|c|c|c|c|c|c|}
\hline University of Western Australia & 1,509 & 133 & P.G. Holt & 389 & 58 & 7,989 & 56 & 49 & 46 & 150 \\
\hline University of Western Ontario & 1,737 & 111 & M.A. Valvano & 117 & 278 & 1,792 & 218 & 24 & 195 & 150 \\
\hline University of Wisconsin & 2,373 & 73 & W.W. Busse & 429 & 44 & 5,488 & 96 & 54 & 30 & 150 \\
\hline University of Wollongong & 70 & 322 & M.J. Walker & 317 & 87 & 5,190 & 105 & 38 & 104 & 150 \\
\hline University of York & 198 & 280 & R.A. Wilson & 159 & 218 & 1,315 & 251 & 24 & 195 & 150 \\
\hline University of Zurich & 1,176 & 155 & R.M. Zinkernagel & 573 & 21 & 31,914 & 8 & 67 & 12 & 150 \\
\hline Univesitas Gadjah Mada & 79 & 318 & W. Sosroseno & 50 & 329 & 217 & 329 & 8 & 327 & 63 \\
\hline Uppsala University & 1,625 & 124 & P. Venge & 482 & 33 & 8,957 & 44 & 39 & 100 & 150 \\
\hline Utah State & 99 & 311 & R.W. Sidwell & 242 & 144 & 2,806 & 167 & 30 & 149 & 150 \\
\hline Utrecht University & 5,086 & 18 & J.W.J. Bijlsma & 398 & 54 & 8,262 & 52 & 51 & 39 & 150 \\
\hline Vanderbilt University & 1,119 & 161 & L. Van Kaer & 160 & 216 & 5,094 & 106 & 49 & 46 & 150 \\
\hline Victoria University of Wellington & 37 & 329 & A.C. La Flamme & 30 & 336 & 631 & 310 & 14 & 298 & 69 \\
\hline Vienna University of Technology & 11 & 340 & R. Reihsner & 28 & 338 & 160 & 336 & 7 & 332 & 63 \\
\hline Virginia Polytechnic Institute & 474 & 231 & S.D. Holladay & 111 & 284 & 892 & 297 & 14 & 298 & 150 \\
\hline Vrije Universiteit, Brussels & 15 & 338 & C. Demanet & 91 & 301 & 1,190 & 268 & 18 & 261 & 150 \\
\hline VU University Amsterdam & 3,046 & 47 & B.A.C. Dijkmans & 467 & 36 & 7,555 & 66 & 42 & 74 & 150 \\
\hline Wageningen University & 466 & 234 & H.K. Parmentier & 120 & 276 & 950 & 290 & 16 & 278 & 150 \\
\hline Wake Forest University & 606 & 211 & D.S. Lyles & 97 & 292 & 840 & 301 & 19 & 248 & 113 \\
\hline Waseda University & 16 & 337 & K. Suzuki & 144 & 238 & 1,144 & 274 & 20 & 239 & 150 \\
\hline Washington State University & 701 & 206 & W.C. Davis & 211 & 166 & 2,148 & 196 & 20 & 239 & 150 \\
\hline Washington University in St. Louis & 5,722 & 14 & T. Mohanakumar & 322 & 84 & 2,692 & 174 & 27 & 165 & 150 \\
\hline Wayne State University & 1,804 & 108 & R.H. Swanborg & 99 & 290 & 924 & 293 & 13 & 302 & 71 \\
\hline West Virginia University & 179 & 286 & V. Castranova & 365 & 70 & 5,280 & 103 & 40 & 90 & 150 \\
\hline Yale University & 2,670 & 56 & R.A. Flavell & 734 & 8 & 56,589 & 2 & 113 & 2 & 150 \\
\hline Yonsei University & 434 & 238 & C.S. Hong & 97 & 292 & 992 & 285 & 12 & 309 & 150 \\
\hline York University & 27 & 334 & G.E. Wu & 85 & 303 & 1,574 & 230 & 16 & 278 & 150 \\
\hline Zhejiang University & 380 & 248 & X. Cao & 208 & 170 & 2,220 & 193 & 26 & 176 & 150 \\
\hline
\end{tabular}




\begin{tabular}{|c|c|c|c|c|c|c|c|c|c|c|}
\hline Earth and Planetary Sciences Data & $\begin{array}{l}\text { Department } \\
\text { Publications }\end{array}$ & Rank & Most Prolific Author & Published & Rank & Cited & Rank & $\begin{array}{c}\text { H- } \\
\text { Index }\end{array}$ & Rank & $\begin{array}{c}\text { \# of } \\
\text { Coauthors }\end{array}$ \\
\hline Aalto University & 935 & 173 & M.T. Hallikainen & 313 & 26 & 1,694 & 118 & 19 & 178 & 150 \\
\hline Aarhus University & 1,741 & 123 & A.S. Murray & 206 & 71 & 2,371 & 75 & 38 & 33 & 150 \\
\hline Arizonia State University & 873 & 179 & R. Greeley & 272 & 42 & 2,788 & 65 & 36 & 41 & 150 \\
\hline Ateneo de Manila University & 6 & 341 & R.E.S. Otadoy & 7 & 345 & 10 & 346 & 3 & 339 & 41 \\
\hline Auburn University & 896 & 178 & J.H. Dane & 79 & 253 & 641 & 256 & 9 & 299 & 73 \\
\hline Australian National University & 6,761 & 12 & K.C. Freeman & 243 & 56 & 5,271 & 18 & 49 & 11 & 150 \\
\hline Boston College & 454 & 233 & W.J. Burke & 299 & 29 & 3,489 & 46 & 26 & 100 & 150 \\
\hline Boston University & 2,323 & 86 & M.Mendillo & 122 & 173 & 856 & 219 & 19 & 178 & 150 \\
\hline Brandeis University & 80 & 317 & M. Rosbash & 253 & 52 & 5,621 & 16 & 49 & 11 & 150 \\
\hline Brigham Young University & 85 & 313 & M.J. Dorais & 38 & 325 & 265 & 308 & 8 & 311 & 103 \\
\hline Brown University & 1,766 & 120 & J.W. Head & 383 & 17 & 3,697 & 41 & 44 & 21 & 150 \\
\hline California Institute of Technology (Calt... & 18,103 & 1 & J.H. Seinfeld & 600 & 2 & 19,946 & 2 & 62 & 8 & 150 \\
\hline Cardiff University & 2,417 & 74 & N. Wickramasingh & 288 & 34 & 6,993 & 13 & 34 & 51 & 150 \\
\hline Carnegie Mellon University & 968 & 169 & R.C. Nichol & 208 & 70 & 8,129 & 11 & 65 & 6 & 150 \\
\hline Case Western Reserve University & 624 & 206 & P. Harding & 52 & 305 & 1,910 & 104 & 27 & 88 & 150 \\
\hline Chalmers University of Technology & 1,250 & 148 & M. Olberg & 62 & 288 & 381 & 290 & 14 & 244 & 150 \\
\hline Charles University & 530 & 223 & D. Vokrouhlicky & 108 & 196 & 788 & 239 & 25 & 109 & 150 \\
\hline Chinese University of Hong Kong & 23 & 338 & Q. Zhang & 186 & 92 & 630 & 259 & 14 & 244 & 150 \\
\hline Chulalongkorn University & 240 & 276 & P. Charusiti & 25 & 336 & 83 & 334 & 7 & 321 & 57 \\
\hline City University of Hong Kong & 533 & 221 & J.C.L. Chan & 106 & 203 & 844 & 225 & 19 & 178 & 113 \\
\hline City University of New York & 171 & 291 & H.K. Brueckner & 41 & 320 & 644 & 255 & 13 & 254 & 75 \\
\hline Colorado State University & 305 & 253 & H.J. Stein & 69 & 279 & 837 & 226 & 20 & 161 & 150 \\
\hline Columbia University & 3,085 & 46 & J.P. Halpern & 145 & 135 & 3,021 & 57 & 32 & 58 & 150 \\
\hline Cornell University & 5,473 & 21 & J.Veverka & 260 & 48 & 2,976 & 60 & 38 & 33 & 150 \\
\hline Curtin University of Technology & 1,591 & 133 & S.A. Wilde & 151 & 130 & 1,849 & 109 & 37 & 36 & 150 \\
\hline Dalhousie University & 2,241 & 92 & C. Beaumont & 132 & 155 & 2,306 & 80 & 22 & 140 & 84 \\
\hline Dartmouth College & 2,992 & 51 & J.R. Thorstensen & 101 & 215 & 1,365 & 155 & 23 & 124 & 150 \\
\hline Delft University of Technology & 2,851 & 58 & H.H.G. Savenije & 137 & 147 & 552 & 268 & 13 & 254 & 133 \\
\hline Drexel University & 587 & 209 & R.M. Koerner & 209 & 69 & 455 & 281 & 11 & 277 & 95 \\
\hline Duke University & 1,919 & 107 & O.H. Pilkey & 102 & 213 & 484 & 277 & 8 & 311 & 93 \\
\hline Durham University & 3,545 & 36 & C.S. Frenk & 196 & 83 & 10,130 & 8 & 66 & 4 & 150 \\
\hline Ecole Normale Supérieure de Lyon & 575 & 211 & F. Albarede & 161 & 119 & 3,835 & 40 & 31 & 66 & 150 \\
\hline École Normale Supérieure, Paris & 1,489 & 137 & B. Groffe & 111 & 188 & 1,494 & 140 & 28 & 80 & 150 \\
\hline École Polytechnique & 816 & 184 & B. Giebels & 108 & 196 & 1,259 & 170 & 29 & 78 & 150 \\
\hline
\end{tabular}




\begin{tabular}{|c|c|c|c|c|c|c|c|c|c|c|}
\hline Ecole Polytechnique Fédérale de Lausanne & 744 & 193 & I. Beg & 55 & 296 & 1,311 & 162 & 23 & 124 & 150 \\
\hline Eindhoven University of Technology & 176 & 290 & H. M. Kelder & 94 & 230 & 772 & 241 & 18 & 200 & 150 \\
\hline Emory University & 109 & 307 & D.C. Wallace & 287 & 35 & 12,692 & 3 & 54 & 10 & 150 \\
\hline Erasmus University Rotterdam & 153 & 296 & A.D.M.E. Osterhaus & 741 & 1 & 23,768 & 1 & 59 & 9 & 150 \\
\hline ETH Zurich (Swiss Federal Institute of Technology) & 6,507 & 14 & A.O. Benz & 136 & 148 & 1,505 & 139 & 23 & 124 & 150 \\
\hline Florida International University & 712 & 195 & R. Jaffe & 76 & 264 & 963 & 200 & 20 & 161 & 112 \\
\hline Florida State University & 352 & 248 & W.C. Burnett & 153 & 127 & 1,295 & 163 & 23 & 124 & 150 \\
\hline Freie Universität Berlin & 1,791 & 118 & G. Neukum & 183 & 96 & 2,199 & 85 & 29 & 78 & 150 \\
\hline Friedrich Alexander Universität Erlangen Nürnberg & 1,294 & 145 & B. Seowbari & 109 & 194 & 325 & 301 & 8 & 311 & 79 \\
\hline Fudan University & 286 & 260 & Y.Q. Jin & 192 & 86 & 1,292 & 164 & 11 & 277 & 110 \\
\hline Georg August Universität Göttingen & 2,638 & 69 & J. Hoets & 86 & 241 & 1,160 & 181 & 16 & 218 & 141 \\
\hline George Mason University & 98 & 308 & S.S. Harlan & 30 & 335 & 377 & 292 & 9 & 299 & 54 \\
\hline George Washington University & 445 & 234 & R.H. Lang & 83 & 247 & 383 & 289 & 6 & 324 & 75 \\
\hline Georgetown University & 77 & 319 & T. Beach & 25 & 336 & 212 & 318 & 10 & 287 & 38 \\
\hline Georgia Institute of Technology & 2,304 & 87 & J.C. Powers & 190 & 90 & 3,027 & 56 & 19 & 178 & 150 \\
\hline Georgia State University & 664 & 203 & D.R. Gies & 110 & 191 & 1,152 & 184 & 19 & 178 & 150 \\
\hline Goteborg University & 265 & 267 & B. Schmitz & 85 & 242 & 905 & 207 & 20 & 161 & 130 \\
\hline Harvard University & 3,639 & 35 & D.J. Jacob & 263 & 46 & 6,455 & 15 & 63 & 7 & 150 \\
\hline Hebrew University of Jerusalem & 2,400 & 79 & T. Piran & 191 & 87 & 4,141 & 32 & 41 & 29 & 150 \\
\hline Heidelberg Universität & 1,966 & 104 & U. Platt & 273 & 41 & 2,800 & 64 & 37 & 36 & 150 \\
\hline Hokkaido University & 3,885 & 29 & S. Tsunogai & 108 & 196 & 992 & 198 & 13 & 254 & 127 \\
\hline Hong Kong Polytechnic University & 952 & 171 & J.H. Yin & 134 & 152 & 594 & 262 & 16 & 218 & 150 \\
\hline Hong Kong University of Science \& Techno... & 829 & 182 & C.W.W. Ng & 79 & 253 & 365 & 293 & 11 & 277 & 87 \\
\hline Humboldt-Universität zu Berlin & 857 & 180 & K. Bernlohr & 141 & 140 & 2,122 & 88 & 42 & 27 & 150 \\
\hline Imperial College London & 5,964 & 19 & A. Balogh & 406 & 12 & 2,874 & 61 & 31 & 66 & 150 \\
\hline Indian Institute of Technology Bombay (I... & 665 & 202 & K.V. Subboro & 111 & 188 & 67 & 337 & 16 & 218 & 150 \\
\hline Indian Institute of Technology Delhi (II... & 548 & 217 & V.C. Mohaanty & 104 & 209 & 265 & 308 & 7 & 321 & 120 \\
\hline Indian Institute of Technology Kanpur (I... & 514 & 226 & R.P. Singh & 120 & 178 & 361 & 294 & 10 & 287 & 133 \\
\hline Indiana University Bloomington & 1,937 & 106 & E.M. Ripley & 101 & 215 & 567 & 266 & 15 & 232 & 125 \\
\hline Indiana University Indianapolis & 218 & 282 & G.M. Filippelli & 50 & 308 & 563 & 267 & 15 & 232 & 87 \\
\hline Iowa State University & 114 & 305 & D.A. Brazylinski & 82 & 249 & 1,224 & 173 & 21 & 153 & 141 \\
\hline Johns Hopkins University & 6,550 & 13 & T.M. Heckman & 292 & 31 & 8,628 & 10 & 66 & 4 & 150 \\
\hline Kansas State University & 59 & 330 & R.L. Cullers & 42 & 318 & 716 & 248 & 8 & 311 & 57 \\
\hline Katholieke Universiteit Leuven & 1,688 & 125 & J. Poesen & 297 & 30 & 2,357 & 76 & 32 & 58 & 150 \\
\hline Keio University & 183 & 286 & M. Kato & 53 & 302 & 535 & 271 & 16 & 218 & 31 \\
\hline
\end{tabular}




\begin{tabular}{|c|c|c|c|c|c|c|c|c|c|c|}
\hline King Fahd University of Petroleum \& Minerals & 411 & 242 & M. Sadiq & 45 & 315 & 395 & 286 & 5 & 332 & 26 \\
\hline King Saud University & 556 & 215 & A.M. El-Sheikh & 20 & 339 & 35 & 343 & 0 & 346 & 10 \\
\hline Kobe University & 1,039 & 166 & T. Mukai & 102 & 213 & 595 & 261 & 14 & 244 & 150 \\
\hline Korea Advanced Institute of Science \& Technology & 290 & 258 & K.W. Min & 39 & 321 & 161 & 326 & 6 & 324 & 133 \\
\hline Korea University & 268 & 266 & S.T. Yun & 62 & 288 & 285 & 307 & 11 & 277 & 111 \\
\hline Kyoto University & 6,847 & 11 & S. Fukao & 316 & 25 & 1,490 & 142 & 23 & 124 & 150 \\
\hline Kyushu University & 2,390 & 81 & K. Yumoto & 140 & 141 & 856 & 219 & 15 & 232 & 150 \\
\hline La Trobe University & 916 & 175 & P.L. Dyson & 119 & 179 & 318 & 302 & 10 & 287 & 118 \\
\hline Lancaster University & 1,482 & 138 & L.Wilson & 108 & 196 & 1,271 & 169 & 16 & 218 & 150 \\
\hline Leiden University & 2,592 & 70 & E.F. Van Dishoeck & 280 & 39 & 3,642 & 42 & 47 & 16 & 150 \\
\hline Linkoping University & 245 & 275 & B. Allard & 77 & 257 & 817 & 231 & 14 & 244 & 84 \\
\hline London School of Economics and Political Science & 236 & 278 & LA Smith & 154 & 125 & 2,418 & 73 & 31 & 66 & 150 \\
\hline Loughborough University & 568 & 213 & N. Dixon & 53 & 302 & 344 & 298 & 8 & 311 & 86 \\
\hline Louisiana State University & 252 & 274 & L.H. Chan & 36 & 328 & 678 & 250 & 16 & 218 & 62 \\
\hline Ludwig-Maximilians-Universität München & 2,389 & 82 & J. Egger & 143 & 138 & 899 & 210 & 11 & 277 & 122 \\
\hline Lund University & 2,864 & 57 & S. Bjorck & 118 & 182 & 1,742 & 113 & 23 & 124 & 150 \\
\hline Maastricht University & 123 & 302 & J.W.M. Jagt & 117 & 183 & 341 & 300 & 10 & 287 & 121 \\
\hline Macquarie University & 1,855 & 113 & S.Y. O'Reilly & 218 & 63 & 3,039 & 54 & 38 & 33 & 150 \\
\hline Mahidol University & 74 & 320 & D. Ruffolo & 35 & 329 & 295 & 305 & 12 & 265 & 49 \\
\hline Masaryk University & 411 & 242 & R. Brazdil & 63 & 287 & 507 & 273 & 14 & 244 & 150 \\
\hline Massachusetts Institute of Technology & 8,338 & 6 & W.H.G. Lewin & 166 & 116 & 2,020 & 96 & 32 & 58 & 150 \\
\hline McGill University & 3,406 & 38 & J.A. Finch & 290 & 33 & 1,224 & 173 & 15 & 232 & 150 \\
\hline McMaster University & 2,098 & 95 & H.P. Schwarcz & 256 & 50 & 3,130 & 50 & 24 & 116 & 150 \\
\hline Michigan State University & 1,862 & 112 & T.C. Beer & 239 & 58 & 3,640 & 43 & 47 & 16 & 150 \\
\hline Michigan Technological University & 989 & 167 & W.I. Rose & 128 & 162 & 1,386 & 150 & 19 & 178 & 150 \\
\hline Monash University & 2,407 & 77 & I. Cartwright & 100 & 219 & 917 & 205 & 17 & 209 & 110 \\
\hline Montana State University & 1,044 & 165 & D.W. Longcope & 83 & 247 & 924 & 203 & 24 & 116 & 66 \\
\hline Moscow State University & 6,441 & 15 & E.E. Antonova & 82 & 249 & 101 & 332 & 6 & 324 & 65 \\
\hline Nagoya University & 3,923 & 28 & S. Kobayashi & 154 & 125 & 1,256 & 171 & 25 & 109 & 150 \\
\hline Nanjing University & 3,337 & 42 & Z.G. Dai & 115 & 185 & 1,117 & 186 & 27 & 88 & 98 \\
\hline Nanyang Technological University & 663 & 204 & H. Rahardjo & 87 & 239 & 457 & 280 & 10 & 287 & 61 \\
\hline National Taiwan University & 2,296 & 89 & S.L. Chung & 71 & 274 & 1,358 & 157 & 25 & 109 & 150 \\
\hline National Tsing Hua University & 260 & 269 & D.Y. Chou & 39 & 321 & 182 & 323 & 9 & 299 & 83 \\
\hline National University of Ireland, Galway & 778 & 190 & S.G. Jennings & 91 & 232 & 1,492 & 141 & 18 & 200 & 150 \\
\hline National University of Singapore & 1,112 & 157 & S.C. Liew & 88 & 237 & 304 & 303 & 8 & 311 & 104 \\
\hline New Mexico State University & 1,630 & 131 & W.R. Webber & 130 & 159 & 1,184 & 178 & 15 & 232 & 150 \\
\hline
\end{tabular}




\begin{tabular}{|c|c|c|c|c|c|c|c|c|c|c|}
\hline New York University & 810 & 185 & J. Brinkmannn & 304 & 28 & 10,279 & 7 & 86 & 1 & 150 \\
\hline Newcastle University & 2,396 & 80 & P.L. Younger & 109 & 194 & 589 & 263 & 15 & 232 & 110 \\
\hline North Carolina State University & 2,407 & 77 & S. Ramen & 144 & 136 & 696 & 249 & 12 & 265 & 142 \\
\hline Northeastern University & 292 & 256 & E.L. Miller & 177 & 106 & 1,442 & 144 & 23 & 124 & 150 \\
\hline Northwestern University & 2,335 & 84 & E.A. Okal & 153 & 127 & 1,224 & 173 & 18 & 200 & 134 \\
\hline Norwegian University of Science \& Technology & 1,406 & 140 & B. Ursin & 130 & 159 & 514 & 272 & 14 & 244 & 91 \\
\hline Ohio State University & 4,856 & 24 & A. Gould & 277 & 40 & 2,660 & 70 & 36 & 41 & 150 \\
\hline Oklahoma State University & 574 & 212 & J.C. West & 69 & 279 & 133 & 330 & 9 & 299 & 43 \\
\hline Open University UK & 2,706 & 63 & C.T. Pillinger & 215 & 66 & 1,700 & 117 & 17 & 209 & 150 \\
\hline Oregon State University & 498 & 230 & B.R.T. Simoneit & 350 & 20 & 4,856 & 24 & 43 & 23 & 150 \\
\hline Osaka University & 1,113 & 156 & H. Tsunemi & 263 & 46 & 1,343 & 158 & 22 & 140 & 150 \\
\hline Peking University & 3,397 & 39 & Z.Y. Pu & 74 & 269 & 389 & 288 & 12 & 265 & 150 \\
\hline Pennsylvania State University & 7,152 & 9 & D.P. Schneider & 456 & 8 & 11,932 & 6 & 84 & 2 & 150 \\
\hline Pohang University of Science And Technology & 127 & 301 & K.Lee & 48 & 312 & 1,050 & 190 & 20 & 161 & 103 \\
\hline Portland State University & 441 & 235 & A.G. Fountain & 75 & 266 & 827 & 229 & 18 & 200 & 115 \\
\hline Princeton University & 6,300 & 17 & D.P. Schneder & 456 & 8 & 11,938 & 5 & 84 & 2 & 150 \\
\hline Purdue University & 3,145 & 44 & M.E. Lipschutz & 127 & 163 & 639 & 257 & 10 & 287 & 150 \\
\hline Queen's University & 2,150 & 94 & N.P. James & 139 & 143 & 1,508 & 138 & 19 & 178 & 135 \\
\hline Queen's University of Belfast & 1,876 & 110 & F.P. Keean & 424 & 11 & 1,737 & 115 & 24 & 116 & 150 \\
\hline Queensland University of Technology & 436 & 236 & R.L Frost & 589 & 3 & 8,971 & 9 & 43 & 23 & 150 \\
\hline Radboud University, Nijmegen & 533 & 221 & G. Nelemans & 89 & 236 & 863 & 216 & 20 & 161 & 150 \\
\hline Rensselaer Polytechnic Institute & 1,065 & 163 & E.B. Watson & 136 & 148 & 4,168 & 31 & 26 & 100 & 100 \\
\hline Rheinisch Westfalische Technische Hochschule Aach & 1,229 & 150 & R. Littke & 144 & 136 & 1,287 & 166 & 18 & 200 & 150 \\
\hline Rheinische Friedrich Wilhelms Universitat Bonn & 2,983 & 52 & H.J. Fahr & 172 & 109 & 618 & 260 & 16 & 218 & 150 \\
\hline Rice University & 1,919 & 107 & J. B. Anderson & 110 & 191 & 1,381 & 151 & 20 & 161 & 133 \\
\hline Rochester Institute of Technology & 413 & 241 & D. Merritt & 150 & 132 & 3,961 & 37 & 43 & 23 & 150 \\
\hline Royal Institute of Technology, KTH & 1,157 & 154 & L.E. Sjoberg & 104 & 209 & 265 & 308 & 10 & 287 & 46 \\
\hline Royal Melbourne Institute of Technology & 254 & 272 & A. Sellers-Henderson & 194 & 84 & 2,520 & 72 & 24 & 116 & 150 \\
\hline Rutgers & 2,869 & 56 & J.P. Hughes & 135 & 150 & 2,027 & 93 & 27 & 88 & 150 \\
\hline Saint-Petersburg State University & 2,005 & 103 & M.I. Pudovkin & 103 & 212 & 379 & 291 & 9 & 299 & 141 \\
\hline San Diego State University & 1,236 & 149 & W.C. Oechel & 131 & 158 & 4,987 & 22 & 34 & 51 & 150 \\
\hline Sapienza University of Rome & 0 & 348 & & 0 & 348 & 0 & 347 & 0 & 346 & 0 \\
\hline Sciences Po Paris & 9 & 340 & L. Bruno & 1 & 347 & 0 & 347 & 0 & 346 & 0 \\
\hline Seoul National University & 2,057 & 100 & S.K. Chough & 99 & 220 & 855 & 221 & 14 & 244 & 107 \\
\hline Shanghai Jiao Tong University & 788 & 189 & R. Wang & 377 & 18 & 900 & 208 & 20 & 161 & 150 \\
\hline Simon Fraser University & 963 & 170 & J.J. Claque & 178 & 104 & 1,520 & 137 & 20 & 161 & 150 \\
\hline
\end{tabular}




\begin{tabular}{|c|c|c|c|c|c|c|c|c|c|c|}
\hline Stanford University & 6,949 & 10 & $\overline{\text { J.G. Liou }}$ & 198 & 79 & 2,760 & 67 & 36 & 41 & 150 \\
\hline State University of New York Buffalo & 5 & 343 & M. Brown & 205 & 73 & 4,441 & 28 & 37 & 36 & 150 \\
\hline Stockholm University & 3,016 & 50 & J. Strom & 88 & 237 & 1,169 & 179 & 23 & 124 & 150 \\
\hline Stony Brook University & 2,679 & 66 & D.J. Weidner & 122 & 173 & 1,643 & 126 & 22 & 140 & 150 \\
\hline Syracuse University & 181 & 287 & S.D. Samson & 56 & 294 & 1,155 & 182 & 16 & 218 & 85 \\
\hline Tartu University (University of Tartu) & 676 & 200 & V. Kalm & 54 & 299 & 192 & 320 & 9 & 299 & 96 \\
\hline Technical University of Denmark & 1,272 & 147 & T.H. Christensen & 182 & 98 & 2,785 & 66 & 28 & 80 & 150 \\
\hline Technion & 1,308 & 143 & N.Soker & 167 & 113 & 1,044 & 191 & 21 & 153 & 57 \\
\hline Technische Universität Berlin & 1,388 & 141 & G. Franz & 92 & 231 & 963 & 200 & 17 & 209 & 131 \\
\hline Technische Universitat Chemnitz & 41 & 332 & D. Gerlich & 121 & 177 & 956 & 202 & 15 & 232 & 150 \\
\hline Technische Universität Dresden & 673 & 201 & C.H. Bernhofer & 85 & 242 & 2,806 & 63 & 27 & 88 & 150 \\
\hline Technische Universität München & 1,329 & 142 & H. Knicker & 124 & 169 & 1,381 & 151 & 27 & 88 & 150 \\
\hline Tel Aviv University & 2,196 & 93 & H. Netzer & 133 & 153 & 2,733 & 68 & 35 & 46 & 150 \\
\hline Texas A\&M University & 5,044 & 23 & J.W. Morse & 135 & 150 & 3,032 & 55 & 19 & 178 & 150 \\
\hline Texas Tech & 63 & 328 & Y. Ma & 47 & 313 & 450 & 282 & 9 & 299 & 87 \\
\hline Tohoku University & 3,697 & 32 & Y. Taniguchi & 218 & 63 & 2,323 & 79 & 32 & 58 & 150 \\
\hline Tokyo Institute of Technology & 1,891 & 109 & S. Maruyama & 122 & 173 & 2,333 & 78 & 26 & 100 & 150 \\
\hline Trinity College Dublin & 807 & 186 & V.R. Troll & 42 & 318 & 225 & 316 & 10 & 287 & 77 \\
\hline Tsinghua University & 1,946 & 105 & Y.Q. Lou & 87 & 239 & 298 & 304 & 15 & 232 & 150 \\
\hline Tufts University & 353 & 247 & R.F. Willson & 31 & 333 & 93 & 333 & 4 & 334 & 150 \\
\hline Universidad Autonoma de Madrid & 909 & 176 & C. Eiroa & 71 & 274 & 507 & 273 & 13 & 254 & 150 \\
\hline Universidad de Chile & 1,691 & 124 & G. Garay & 77 & 257 & 1,032 & 194 & 21 & 153 & 150 \\
\hline Universidad de Granada & 909 & 176 & C. Eiroa & 71 & 274 & 507 & 273 & 13 & 254 & 150 \\
\hline Universidad del País Vasco & 819 & 183 & A. Sanchez & 119 & 179 & 637 & 258 & 19 & 178 & 150 \\
\hline Universidad Nacional Autónoma de México ... & 1,639 & 130 & J. Urrutia-Fucugauchi & 203 & 75 & 808 & 234 & 13 & 254 & 150 \\
\hline Universidad Politecnica de Madrid & 556 & 215 & R. Alonso-Sanz & 33 & 332 & 58 & 338 & 9 & 299 & 26 \\
\hline Universidade de São Paulo & 478 & 231 & W. Teixeira & 50 & 308 & 391 & 287 & 11 & 277 & 124 \\
\hline Universidade Estadual de Campinas & 64 & 327 & P.J. Iunes & 69 & 279 & 131 & 331 & 8 & 311 & 104 \\
\hline Università degli Studi di Firenze & 2,536 & 72 & L. Bindi & 98 & 222 & 2,152 & 86 & 36 & 41 & 12 \\
\hline Università degli Studi di Padova & 3,438 & 37 & D. Basitieri & 186 & 92 & 1,598 & 132 & 31 & 66 & 150 \\
\hline Universita Di Bologna & 2,788 & 61 & F.R. Ferraro & 156 & 122 & 1,621 & 128 & 32 & 58 & 150 \\
\hline Universita di Pisa & 435 & 237 & F. Innocenti & 101 & 215 & 1,437 & 146 & 16 & 218 & 150 \\
\hline Universitat Autonoma de Barcelona & 1,090 & 159 & J. Cortina & 111 & 188 & 1,485 & 143 & 32 & 58 & 150 \\
\hline Universitat Bielefeld & 98 & 308 & S.W. Breckle & 50 & 308 & 198 & 319 & 5 & 332 & 58 \\
\hline Universität Bremen & 3,067 & 48 & J.P. Burrows & 396 & 13 & 3,928 & 38 & 43 & 23 & 150 \\
\hline Universitat d'Alacant & 506 & 229 & I. Negueruela & 104 & 209 & 1,054 & 189 & 25 & 109 & 150 \\
\hline
\end{tabular}




\begin{tabular}{|c|c|c|c|c|c|c|c|c|c|c|}
\hline Universitat de València & 1,281 & 146 & V. Caselles & 211 & 67 & 4,244 & 30 & 26 & 100 & 150 \\
\hline Universität Frankfurt am Main & 1,628 & 132 & G.P. Gray & 97 & 226 & 1,630 & 127 & 17 & 209 & 118 \\
\hline Universität Freiburg & 857 & 180 & C. Leibundgut & 74 & 269 & 355 & 296 & 12 & 265 & 86 \\
\hline Universitat Hamburg & 2,925 & 53 & R. Seifert & 45 & 315 & 813 & 232 & 16 & 218 & 134 \\
\hline Universität Karlsruhe & 2,035 & 101 & D. Stuban & 101 & 215 & 1,043 & 192 & 20 & 161 & 150 \\
\hline Universitat Leipzig & 151 & 298 & C. Jacobi & 240 & 57 & 2,579 & 71 & 31 & 66 & 150 \\
\hline Universitat Munster (Westfälische Wilhelms-Un & 559 & 214 & K. Mezger & 125 & 167 & 2,847 & 62 & 32 & 58 & 150 \\
\hline Universitat Politecnica de Catalunya & 114 & 305 & J.A. Canas & 78 & 256 & 580 & 265 & 12 & 265 & 97 \\
\hline Universität Regensburg & 177 & 289 & K. Heine & 39 & 321 & 260 & 311 & 9 & 299 & 39 \\
\hline Universität Stuttgart & 1,070 & 161 & H.J. Massonne & 68 & 282 & 1,089 & 188 & 15 & 232 & 101 \\
\hline Universitat Trier & 256 & 270 & W. Symader & 39 & 321 & 43 & 341 & 3 & 339 & 25 \\
\hline Universität Tübingen & 2,300 & 88 & W. Frisch & 97 & 226 & 1,366 & 154 & 21 & 153 & 150 \\
\hline Universitat Wien (University of Vienna) & 2,412 & 75 & C. Koeberl & 245 & 55 & 1,658 & 125 & 23 & 124 & 150 \\
\hline Universitat Zu Koln & 2,031 & 102 & A. Eckart & 226 & 61 & 2,391 & 74 & 30 & 74 & 150 \\
\hline Université Catholique de Louvain & 1,204 & 152 & H. Grosse & 95 & 229 & 1,155 & 182 & 23 & 124 & 150 \\
\hline Universite de Liege & 2,242 & 91 & G. Rauw & 97 & 226 & 471 & 278 & 17 & 209 & 150 \\
\hline Université de Montréal & 1,645 & 129 & D.A. Yuen & 385 & 14 & 2,290 & 82 & 26 & 100 & 150 \\
\hline Université de Nice Sophia Antipolis & 1,213 & 151 & G.T. Feraud & 99 & 220 & 1,955 & 99 & 25 & 109 & 150 \\
\hline Universite Laval & 2,064 & 99 & F. Habashi & 172 & 109 & 171 & 324 & 2 & 342 & 24 \\
\hline Universite Libre de Bruxelles & 1,088 & 160 & D. Weis & 98 & 222 & 884 & 213 & 22 & 140 & 150 \\
\hline Université Paris Sorbonne & 547 & 218 & P. Claval & 81 & 252 & 69 & 336 & 4 & 334 & 2 \\
\hline Universite Paris-Sud 11 & 2,639 & 68 & P. Cox & 107 & 201 & 2,054 & 91 & 37 & 36 & 150 \\
\hline Université Pierre et Marie Curie & 6,372 & 16 & L. Solivert & 129 & 161 & 2,051 & 92 & 28 & 80 & 150 \\
\hline Universiti Malaya (University of Malaya) & 283 & 261 & F.H. Ali & 24 & 338 & 24 & 344 & 1 & 344 & 21 \\
\hline University College Cork & 509 & 228 & A.J. Wheeler & 15 & 342 & 157 & 327 & 7 & 321 & 35 \\
\hline University College Dublin & 1,178 & 153 & T.C. Weekes & 138 & 145 & 1,675 & 123 & 27 & 88 & 150 \\
\hline University College London & 6,264 & 18 & G.D. Price & 164 & 117 & 2,203 & 84 & 28 & 80 & 150 \\
\hline University do Porto & 27 & 335 & L. Bastos & 16 & 341 & 151 & 328 & 6 & 324 & 44 \\
\hline University of Aberdeen & 1,676 & 127 & J. Parnell & 171 & 112 & 583 & 264 & 13 & 254 & 150 \\
\hline University of Adelaide & 2,524 & 73 & R.A. Vincent & 153 & 127 & 1,709 & 116 & 23 & 124 & 150 \\
\hline University of Alabama & 1,511 & 136 & J.W. Sulentic & 90 & 235 & 825 & 230 & 21 & 153 & 116 \\
\hline University of Alberta & 4,421 & 26 & R.A. Creaser & 113 & 187 & 1,523 & 136 & 22 & 140 & 150 \\
\hline University of Amsterdam & 2,760 & 62 & M. Van Der Klis & 272 & 42 & 3,003 & 59 & 46 & 18 & 150 \\
\hline University of Antwerp & 649 & 205 & L. Vincze & 74 & 269 & 919 & 204 & 19 & 178 & 150 \\
\hline University of Arizona & 10,887 & 3 & G.H. Rieke & 333 & 22 & 5,351 & 17 & 49 & 11 & 150 \\
\hline University of Athens & 1,769 & 119 & H. Mavromichalaki & 85 & 242 & 253 & 313 & 8 & 311 & 109 \\
\hline
\end{tabular}




\begin{tabular}{|c|c|c|c|c|c|c|c|c|c|c|}
\hline University of Auckland & 1,687 & 126 & J.E. Titheridge & 75 & 266 & 350 & 297 & 6 & 324 & 19 \\
\hline University of Barcelona & 2,410 & 76 & J.M. Paredes & 132 & 155 & 873 & 214 & 28 & 80 & 150 \\
\hline University of Basel & 1,066 & 162 & E.K. Grebel & 185 & 94 & 4,825 & 25 & 44 & 21 & 150 \\
\hline University of Bath & 72 & 323 & N.J. Mitchell & 68 & 282 & 421 & 285 & 16 & 218 & 150 \\
\hline University of Bergen & 2,691 & 64 & H. Haftidason & 70 & 278 & 1,379 & 153 & 26 & 100 & 150 \\
\hline University of Bern & 3,082 & 47 & P. Wurz & 198 & 79 & 1,167 & 180 & 20 & 161 & 150 \\
\hline University of Birmingham & 2,826 & 60 & R.M. Harrison & 322 & 24 & 5,067 & 21 & 39 & 30 & 150 \\
\hline University of Bristol & 3,732 & 31 & R.S.P. Sparks & 201 & 76 & 3,497 & 45 & 33 & 55 & 150 \\
\hline University of British Columbia & 693 & 197 & D. Weis & 98 & 222 & 887 & 212 & 22 & 140 & 150 \\
\hline University of Calgary & 373 & 246 & P. Wu & 50 & 308 & 661 & 254 & 16 & 218 & 28 \\
\hline University of California, Berkley & 1,841 & 114 & P.R. Renne & 198 & 79 & 4,072 & 33 & 34 & 51 & 150 \\
\hline University of California, Davis & 460 & 232 & K.L. Verosub & 123 & 171 & 1,526 & 134 & 22 & 140 & 150 \\
\hline University of California, Irvine & 277 & 263 & D.R. Blake & 312 & 27 & 4,064 & 34 & 49 & 11 & 150 \\
\hline University of California, Los Angeles & 7,507 & 8 & C.T. Russell & 558 & 4 & 7,511 & 12 & 34 & 51 & 150 \\
\hline University of California, Riverside & 1,799 & 117 & G.P. Zank & 249 & 54 & 1,601 & 131 & 30 & 74 & 150 \\
\hline University of California, San Diego & 1,800 & 116 & L. Tauxe & 123 & 171 & 1,659 & 124 & 19 & 178 & 150 \\
\hline University of California, San Francisco & 5 & 343 & J.M. Lowenstein & 194 & 84 & 2,118 & 89 & 10 & 287 & 150 \\
\hline University of California, Santa Barbara & 3,684 & 34 & B.R. Hacker & 84 & 245 & 2,063 & 90 & 31 & 66 & 150 \\
\hline University of California, Santa Cruz & 987 & 168 & T. Lay & 179 & 101 & 1,800 & 111 & 22 & 140 & 150 \\
\hline University of Cambridge & 1,591 & 133 & H. Elderfield & 158 & 121 & 3,393 & 47 & 27 & 88 & 150 \\
\hline University of Canterbury & 194 & 285 & U. Ring & 72 & 273 & 799 & 236 & 19 & 178 & 82 \\
\hline University of Cape Town & 2,076 & 98 & C. Harris & 60 & 291 & 552 & 268 & 12 & 265 & 99 \\
\hline University of Central Florida & 542 & 219 & W.L. Jones & 91 & 232 & 167 & 325 & 4 & 334 & 132 \\
\hline University of Chicago & 678 & 199 & R.N. Clayton & 181 & 100 & 4,490 & 27 & 25 & 109 & 150 \\
\hline University of Cincinnati & 1,147 & 155 & L.A. Owen & 106 & 203 & 850 & 223 & 24 & 116 & 150 \\
\hline University of Colorado at Boulder & 10,471 & 4 & J.M. Forbes & 179 & 101 & 1,111 & 187 & 23 & 124 & 150 \\
\hline University of Connecticut & 89 & 311 & T. Torgerson & 60 & 291 & 664 & 253 & 12 & 265 & 85 \\
\hline University of Copenhagen & 709 & 196 & R. Frei & 110 & 191 & 1,330 & 159 & 24 & 116 & 150 \\
\hline University of Delaware & 265 & 267 & G.W. Luther & 179 & 101 & 3,329 & 48 & 33 & 55 & 150 \\
\hline University of Dundee & 758 & 192 & A.P. Cracknell & 172 & 109 & 859 & 217 & 12 & 265 & 115 \\
\hline University of Edinburgh & 919 & 174 & A.H.F. Robertson & 163 & 118 & 1,525 & 135 & 27 & 88 & 150 \\
\hline University of Florida & 3,818 & 30 & J.E.T. Channell & 140 & 141 & 1,904 & 105 & 25 & 109 & 150 \\
\hline University of Geneva & 334 & 249 & M. Mayor & 260 & 48 & 4,254 & 29 & 49 & 11 & 150 \\
\hline University of Georgia & 239 & 277 & R.D. Dallmeyer & 156 & 122 & 1,936 & 101 & 20 & 161 & 150 \\
\hline University of Ghent & 152 & 297 & M. De Batist & 82 & 249 & 806 & 235 & 20 & 161 & 150 \\
\hline University of Glasgow & 2,085 & 97 & J.C. Brown & 167 & 113 & 1,202 & 176 & 19 & 178 & 150 \\
\hline
\end{tabular}




\begin{tabular}{|c|c|c|c|c|c|c|c|c|c|c|}
\hline University of Gothenburg & 4 & 345 & P.S. Eriksson & 191 & 87 & 4,948 & 23 & 31 & 66 & 150 \\
\hline University of Groningen & 62 & 329 & H.A.J. Meijer & 77 & 257 & 851 & 222 & 18 & 200 & 150 \\
\hline University of Helsinki & 3,089 & 45 & K. Kulmala & 286 & 36 & 1,961 & 98 & 36 & 41 & 150 \\
\hline University of Hong Kong & 427 & 240 & M. Sun & 174 & 108 & 1,818 & 110 & 35 & 46 & 150 \\
\hline University of Houston & 235 & 280 & P. Copeland & 31 & 333 & 1,289 & 165 & 9 & 299 & 101 \\
\hline University of Illinois & 5,175 & 22 & Y.H. Chu & 146 & 134 & 1,273 & 168 & 21 & 153 & 150 \\
\hline University of Illinois, Chicago & 789 & 188 & S.L. Forman & 119 & 179 & 1,605 & 130 & 24 & 116 & 150 \\
\hline University of Indonesia & 23 & 338 & M.A. Tatang & 4 & 346 & 151 & 328 & 4 & 334 & 7 \\
\hline University of Iowa & 428 & 238 & D.A. Gurnett & 331 & 23 & 2,134 & 87 & 28 & 80 & 150 \\
\hline University of Kansas & 277 & 263 & T.E. Cravens & 138 & 145 & 1,280 & 167 & 22 & 140 & 150 \\
\hline University of Kentucky & 122 & 303 & J.D. Phillips & 167 & 113 & 1,442 & 144 & 19 & 178 & 146 \\
\hline University of Lausanne & 411 & 242 & T. Adatte & 77 & 257 & 667 & 252 & 19 & 178 & 150 \\
\hline University of Leeds & 85 & 313 & D. Gubbins & 106 & 203 & 1,043 & 192 & 15 & 232 & 90 \\
\hline University of Leicester & 3,687 & 33 & M. Lester & 201 & 76 & 907 & 206 & 22 & 140 & 150 \\
\hline University of Liverpool & 541 & 220 & J.D.A. Piper & 122 & 173 & 551 & 270 & 13 & 254 & 89 \\
\hline University of Ljubljana & 590 & 208 & T. Zwitter & 56 & 294 & 831 & 228 & 19 & 178 & 150 \\
\hline University of London (Kings College of London) & 11,496 & 2 & P.D. Moore & 206 & 71 & 469 & 279 & 6 & 324 & 19 \\
\hline University of Manchester & 4,553 & 25 & A.G Lyne & 254 & 51 & 3,550 & 44 & 42 & 27 & 150 \\
\hline University of Manitoba & 1,755 & 121 & F.C. Hawthorne & 385 & 14 & 4,013 & 35 & 27 & 88 & 150 \\
\hline University of Maryland & 7,544 & 7 & M.R. Kundu & 205 & 73 & 970 & 199 & 17 & 209 & 150 \\
\hline University of Maryland Baltimore County & 2,088 & 96 & O. Reimer & 219 & 62 & 3,963 & 36 & 46 & 18 & 150 \\
\hline University of Massachusetts & 305 & 253 & M.L. Williams & 236 & 59 & 3,851 & 39 & 37 & 36 & 150 \\
\hline University of Melbourne & 2,668 & 67 & C.J.L.wilson & 125 & 167 & 892 & 211 & 22 & 140 & 132 \\
\hline University of Miami & 428 & 238 & F.J. Millero & 365 & 19 & 6,487 & 14 & 35 & 46 & 150 \\
\hline University of Michigan & 1,464 & 139 & A.N. Halliday & 286 & 36 & 5,087 & 19 & 39 & 30 & 150 \\
\hline University of Minnesota & 1,092 & 158 & D.A. Yuen & 384 & 16 & 2,300 & 81 & 26 & 100 & 150 \\
\hline University of Missouri & 287 & 259 & M. Liu & 57 & 293 & 342 & 299 & 12 & 265 & 81 \\
\hline University of Nebraska & 1,666 & 128 & K.G. Hubbard & 114 & 186 & 729 & 245 & 14 & 244 & 150 \\
\hline University of New Hampshire & 2,683 & 65 & C.J. Farrugia & 159 & 120 & 1,141 & 185 & 20 & 161 & 150 \\
\hline University of New Mexico & 765 & 191 & C.K. Shearer & 124 & 169 & 1,008 & 196 & 19 & 178 & 150 \\
\hline University of New South Wales & 171 & 291 & M.H. England & 77 & 257 & 871 & 215 & 17 & 209 & 86 \\
\hline University of North Carolina, Chapel Hill & 1,823 & 115 & A.F. Glazner & 66 & 284 & 778 & 240 & 12 & 265 & 59 \\
\hline University of North Texas & 3 & 347 & P.S. Braterman & 108 & 196 & 810 & 233 & 11 & 277 & 132 \\
\hline University of Notre Dame & 80 & 317 & C.R. Neal & 76 & 264 & 1,692 & 120 & 18 & 200 & 150 \\
\hline University of Nottingham & 84 & 315 & M.J. Leng & 139 & 143 & 1,013 & 195 & 20 & 161 & 150 \\
\hline University of Oklahoma & 3,017 & 49 & R.D. Elmore & 77 & 257 & 358 & 295 & 10 & 287 & 95 \\
\hline
\end{tabular}




\begin{tabular}{|c|c|c|c|c|c|c|c|c|c|c|}
\hline University of Oregon & 320 & 252 & G.J. Retallack & 105 & 207 & 1,315 & 161 & 19 & 178 & 56 \\
\hline University of Oslo & 724 & 194 & J.I. Faleide & 84 & 245 & 732 & 244 & 19 & 178 & 150 \\
\hline University of Otago & 292 & 256 & D. Craw & 191 & 87 & 1,200 & 177 & 20 & 161 & 150 \\
\hline University of Ottawa & 278 & 262 & J. Veizer & 143 & 138 & 3,008 & 58 & 30 & 74 & 150 \\
\hline University of Oxford & 1,298 & 144 & A.N. Halliday & 286 & 36 & 5,087 & 19 & 39 & 30 & 150 \\
\hline University of Pennsylvania & 134 & 300 & B.P. Horton & 79 & 253 & 505 & 276 & 20 & 161 & 150 \\
\hline University of Pittsburgh & 197 & 284 & M.B. Abbott & 37 & 326 & 744 & 243 & 17 & 209 & 75 \\
\hline University of Quebec & 122 & 303 & R. Hebert & 183 & 96 & 2,693 & 69 & 27 & 88 & 150 \\
\hline University of Queensland & 332 & 250 & B.S. Kamber & 91 & 232 & 1,678 & 122 & 27 & 88 & 113 \\
\hline University of Reading & 3,355 & 41 & J.R.L. Allen & 126 & 165 & 1,419 & 148 & 12 & 265 & 49 \\
\hline University of Rochester & 201 & 283 & J.A. Tarduno & 66 & 284 & 727 & 246 & 16 & 218 & 69 \\
\hline University of Saskatchewan & 2,353 & 83 & A.H. Manson & 199 & 78 & 1,234 & 172 & 23 & 124 & 150 \\
\hline University of Science and Technology of China & 1,743 & 122 & Y.F. Zheng & 185 & 94 & 1,428 & 147 & 35 & 46 & 150 \\
\hline University of Sheffield & 3,191 & 43 & D.W. Hughes & 189 & 91 & 848 & 224 & 14 & 244 & 3 \\
\hline University of South Carolina & 1,866 & 111 & I. Lerche & 340 & 21 & 793 & 238 & 11 & 277 & 150 \\
\hline University of South Florida & 231 & 281 & T.M. Quinn & 51 & 307 & 996 & 197 & 18 & 200 & 101 \\
\hline University of Southampton & 514 & 226 & A.P. Roberts & 156 & 122 & 1,889 & 106 & 27 & 88 & 150 \\
\hline University of Southern California & 576 & 210 & T.L. Ku & 127 & 163 & 1,742 & 113 & 15 & 232 & 150 \\
\hline University of St Andrews & 254 & 272 & J. Walden & 37 & 326 & 217 & 317 & 8 & 311 & 60 \\
\hline University of Surrey & 24 & 337 & V. Lappas & 53 & 302 & 48 & 340 & 4 & 334 & 74 \\
\hline University of Sussex & 71 & 324 & M.R. Frogley & 18 & 340 & 257 & 312 & 9 & 299 & 51 \\
\hline University of Sydney & 2,879 & 55 & T.R. Bedding & 116 & 184 & 900 & 208 & 22 & 140 & 150 \\
\hline University of Technology, Sydney & 27 & 335 & G. Caprarelli & 12 & 343 & 78 & 335 & 6 & 324 & 16 \\
\hline University of Tennessee Knoxville & 404 & 245 & L.A. Taylor & 197 & 82 & 1,679 & 121 & 23 & 124 & 150 \\
\hline University of Texas at Austin & 936 & 172 & J.N. Connelly & 52 & 305 & 832 & 227 & 20 & 161 & 82 \\
\hline University of Tokyo & 3,367 & 40 & T. Yamagata & 151 & 130 & 1,916 & 102 & 32 & 58 & 150 \\
\hline University of Toronto & 5,749 & 20 & W.R. Peltier & 251 & 53 & 4,660 & 26 & 31 & 66 & 150 \\
\hline University of Tsukuba & 274 & 265 & T. Tsunogae & 55 & 296 & 230 & 314 & 1 & 344 & 69 \\
\hline University of Twente & 6 & 341 & H. Rogalla & 291 & 32 & 1,953 & 100 & 19 & 178 & 150 \\
\hline University of Utah & 2,548 & 71 & J.D. Miller & 271 & 44 & 1,862 & 108 & 19 & 178 & 150 \\
\hline University of Vermont & 523 & 224 & J.M. Rankin & 65 & 286 & 431 & 283 & 14 & 244 & 41 \\
\hline University of Victoria & 2,335 & 84 & H.W. Dosso & 62 & 288 & 41 & 342 & 3 & 339 & 46 \\
\hline University of Virginia & 162 & 293 & R.E. Johnson & 523 & 5 & 12,195 & 4 & 46 & 18 & 150 \\
\hline University of Warwick & 40 & 333 & R. Dupree & 182 & 98 & 2,027 & 93 & 21 & 153 & 150 \\
\hline University of Washington & 9,400 & 5 & P.V. Hobbs & 34 & 331 & 677 & 251 & 8 & 311 & 72 \\
\hline University of Waterloo & 159 & 295 & P.F. Bernath & 462 & 6 & 3,076 & 51 & 28 & 80 & 150 \\
\hline
\end{tabular}




\begin{tabular}{|c|c|c|c|c|c|c|c|c|c|c|}
\hline University of Western Australia & 2,850 & 59 & D.I. Groves & 217 & 65 & 2,335 & 77 & 24 & 116 & 150 \\
\hline University of Western Ontario & 2,896 & 54 & W.S.Fyfe & 269 & 45 & 2,272 & 83 & 13 & 254 & 150 \\
\hline University of Wisconsin & 807 & 186 & J.W. Valley & 228 & 60 & 3,278 & 49 & 33 & 55 & 150 \\
\hline University of Wollongong & 162 & 293 & C.V. Murray-Wallace & 73 & 272 & 422 & 284 & 13 & 254 & 112 \\
\hline University of York & 84 & 315 & P.F. Bernath & 462 & 6 & 3,076 & 51 & 28 & 80 & 150 \\
\hline University of Zurich & 146 & 299 & S. Ivy-Ochs & 71 & 274 & 857 & 218 & 18 & 200 & 150 \\
\hline Univesitas Gadjah Mada & 70 & 326 & M.A. Marfai & 9 & 344 & 11 & 345 & 2 & 342 & 17 \\
\hline Uppsala University & 516 & 225 & G. Possnert & 178 & 104 & 1,984 & 97 & 23 & 124 & 150 \\
\hline Utah State & 1,531 & 135 & J.W. Shervals & 35 & 329 & 799 & 236 & 9 & 299 & 42 \\
\hline Utrecht University & 4,329 & 27 & J. Oerlemans & 150 & 132 & 1,749 & 112 & 23 & 124 & 150 \\
\hline Vanderbilt University & 73 & 321 & C.F. Miller & 54 & 299 & 1,580 & 133 & 15 & 232 & 88 \\
\hline Victoria University of Wellington & 329 & 251 & M.K. Savage & 55 & 296 & 750 & 242 & 16 & 218 & 82 \\
\hline Vienna University of Technology & 53 & 331 & G. Bloschl & 98 & 222 & 1,365 & 155 & 22 & 140 & 91 \\
\hline Virginia Polytechnic Institute & 236 & 278 & R.J. Bodnar & 105 & 207 & 1,886 & 107 & 12 & 265 & 150 \\
\hline Vrije Universiteit, Brussels & 684 & 198 & F. Dehairs & 126 & 165 & 1,694 & 118 & 26 & 100 & 150 \\
\hline VU University Amsterdam & 2,261 & 90 & P. Nijkamp & 436 & 10 & 1,911 & 103 & 19 & 178 & 150 \\
\hline Wageningen University & 71 & 324 & A Veldkamp & 107 & 201 & 1,401 & 149 & 26 & 100 & 150 \\
\hline Wake Forest University & 4 & 345 & M.B. Bush & 75 & 266 & 1,321 & 160 & 21 & 153 & 150 \\
\hline Waseda University & 73 & 321 & N. Hasebe & 106 & 203 & 183 & 322 & 10 & 287 & 150 \\
\hline Washington State University & 178 & 288 & D. Schulze-Makuch & 77 & 257 & 286 & 306 & 11 & 277 & 150 \\
\hline Washington University in St. Louis & 1,063 & 164 & R.E. Arvidson & 210 & 68 & 2,021 & 95 & 35 & 46 & 150 \\
\hline Wayne State University & 255 & 271 & M. Goodman & 177 & 106 & 3,040 & 53 & 30 & 74 & 150 \\
\hline West Virginia University & 30 & 334 & H. Gunell & 46 & 314 & 188 & 321 & 11 & 277 & 150 \\
\hline Yale University & 620 & 207 & K.K. Turekian & 132 & 155 & 1,608 & 129 & 13 & 254 & 150 \\
\hline Yonsei University & 90 & 310 & S.Y. Park & 43 & 317 & 58 & 338 & 6 & 324 & 54 \\
\hline York University & 296 & 255 & G.G. Shepherd & 133 & 153 & 717 & 247 & 17 & 209 & 150 \\
\hline Zhejiang University & 86 & 312 & H. Chen & 54 & 299 & 230 & 314 & 10 & 287 & 137 \\
\hline
\end{tabular}




\begin{tabular}{|c|c|c|c|c|c|c|c|c|c|c|}
\hline Environmental Science Data & $\begin{array}{l}\text { Department } \\
\text { Publications }\end{array}$ & Rank & Most Prolific Author & Published & Rank & Cited & Rank & $\begin{array}{c}\text { H- } \\
\text { Index }\end{array}$ & Rank & $\begin{array}{c}\text { \# of } \\
\text { Coauthors }\end{array}$ \\
\hline Aalto University & 692 & 229 & D. Varis & 64 & 313 & 433 & 312 & 12 & 301 & 39 \\
\hline Aarhus University & 1,931 & 83 & V. Loeschcke & 226 & 114 & 2,185 & 162 & 31 & 95 & 150 \\
\hline Arizonia State University & 1,166 & 157 & H.J.S. Fernando & 171 & 166 & 1,180 & 231 & 17 & 250 & 150 \\
\hline Ateneo de Manila University & 15 & 347 & R.P Lejano & 24 & 342 & 106 & 335 & 6 & 326 & 31 \\
\hline Auburn University & 1,689 & 107 & B.G. Lockaby & 84 & 293 & 637 & 292 & 14 & 283 & 108 \\
\hline Australian National University & 3,299 & 33 & D.B. Lindenmayer & 276 & 73 & 3,516 & 91 & 36 & 61 & 150 \\
\hline Boston College & 151 & 333 & P. Davidovits & 99 & 268 & 1,643 & 195 & 25 & 157 & 131 \\
\hline Boston University & 1,325 & 142 & I. Valiela & 165 & 178 & 2,966 & 117 & 23 & 178 & 150 \\
\hline Brandeis University & 107 & 338 & M. Rosbash & 253 & 88 & 5,621 & 36 & 49 & 21 & 150 \\
\hline Brigham Young University & 293 & 318 & D.J. Eatbough & 215 & 122 & 1,760 & 192 & 22 & 193 & 150 \\
\hline Brown University & 1,042 & 176 & J.W. Head & 383 & 31 & 3,697 & 80 & 44 & 28 & 150 \\
\hline California Institute of Technology (Calt... & 2,312 & 63 & J.H. Seinfeld & 600 & 9 & 19,946 & 7 & 62 & 7 & 150 \\
\hline Cardiff University & 2,127 & 75 & S.J. Ormerod & 154 & 195 & 2,056 & 173 & 22 & 193 & 150 \\
\hline Carnegie Mellon University & 1,410 & 129 & S.N. Pandis & 151 & 200 & 3,327 & 96 & 37 & 53 & 150 \\
\hline Case Western Reserve University & 643 & 242 & H.S. Rosenkranz & 425 & 26 & 2,256 & 158 & 19 & 224 & 150 \\
\hline Chalmers University of Technology & \begin{tabular}{l|l}
1,048 \\
\end{tabular} & 174 & C. Azar & 46 & 332 & 630 & 293 & 15 & 273 & 42 \\
\hline Charles University & 463 & 282 & M. Stiborova & 164 & 182 & 982 & 247 & 23 & 178 & 150 \\
\hline Chinese University of Hong Kong & 254 & 324 & \begin{tabular}{|l} 
J.C. $\mathrm{Yu}$ \\
\end{tabular} & 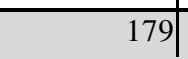 & 154 & 4,353 & 61 & 42 & 34 & 150 \\
\hline Chulalongkorn University & 518 & 270 & P. Pavasant & 54 & 324 & 439 & 311 & 15 & 273 & 61 \\
\hline City University of Hong Kong & 998 & 184 & P.K.S. Lam & 224 & 115 & 3,236 & 100 & 32 & 89 & 150 \\
\hline City University of New York & 300 & 316 & G.M. Friedman & 216 & 120 & 446 & 309 & 9 & 317 & 108 \\
\hline Colorado State University & 5,191 & 10 & J.N. Sofos & 195 & 136 & 1,419 & 209 & 24 & 167 & 150 \\
\hline Columbia University & 1,663 & 109 & E.R. Kandal & 448 & 19 & 17,020 & 8 & 77 & 2 & 150 \\
\hline Cornell University & 5,918 & 7 & T. Eisner & 198 & 133 & 1,634 & 196 & 17 & 250 & 150 \\
\hline Curtin University of Technology & 669 & 234 & B.B. Lamont & 165 & 178 & 2,331 & 148 & 23 & 178 & 150 \\
\hline Dalhousie University & 1,792 & 95 & W.F. Doolittle & 228 & 110 & 5,968 & 32 & 41 & 36 & 150 \\
\hline Dartmouth College & 1,908 & 87 & T. Platt & 141 & 216 & 2,998 & 114 & 20 & 212 & 150 \\
\hline Delft University of Technology & 2,384 & 59 & M.C.M. Van Loosdrech & 341 & 39 & 5,176 & 42 & 50 & 16 & 150 \\
\hline Drexel University & 611 & 248 & C.N. Haas & 157 & 190 & 1,507 & 201 & 18 & 235 & 150 \\
\hline Duke University & 3,370 & 30 & R.J. Lefkowitz & 752 & 5 & 43,621 & 1 & 93 & 1 & 150 \\
\hline Durham University & 1,303 & 145 & B.A. Whitton & 130 & 230 & 1,345 & 221 & 18 & 235 & 147 \\
\hline Ecole Normale Supérieure de Lyon & 72 & 339 & F. Albarede & 161 & 184 & 3,835 & 73 & 31 & 95 & 150 \\
\hline École Normale Supérieure, Paris & 648 & 240 & M. Loreau & 117 & 251 & 3,583 & 87 & 33 & 82 & 150 \\
\hline École Polytechnique & 225 & 328 & R. Vautard & 98 & 271 & 1,314 & 222 & 20 & 212 & 150 \\
\hline
\end{tabular}




\begin{tabular}{|c|c|c|c|c|c|c|c|c|c|c|}
\hline Ecole Polytechnique Fédérale de Lausanne & 938 & 195 & O. Jolliet & 78 & 299 & 721 & 289 & 14 & 283 & 150 \\
\hline Eindhoven University of Technology & 419 & 284 & H. Timmerman & 245 & 96 & 965 & 251 & 15 & 273 & 122 \\
\hline Emory University & 636 & 243 & P.B Ryan & 85 & 292 & 1,106 & 235 & 16 & 263 & 150 \\
\hline Erasmus University Rotterdam & 576 & 259 & A. Burdof & 190 & 139 & 2,018 & 176 & 24 & 167 & 150 \\
\hline ETH Zurich (Swiss Federal Institute of Technology) & 4,173 & 21 & K. Hungerbuhler & 168 & 171 & 946 & 256 & 21 & 202 & 150 \\
\hline Florida International University & 1,126 & 163 & J.W. Fourqurean & 75 & 301 & 1,359 & 217 & 23 & 178 & 137 \\
\hline Florida State University & 539 & 268 & W.C. Burnett & 153 & 197 & 1,295 & 224 & 23 & 178 & 150 \\
\hline Freie Universität Berlin & 1,570 & 118 & D. Neubert & 233 & 106 & 1,201 & 230 & 8 & 322 & 150 \\
\hline Friedrich Alexander Universität Erlangen Nürnberg & 1,183 & 153 & J. Angerer & 360 & 35 & 3,176 & 105 & 37 & 53 & 150 \\
\hline Fudan University & 686 & 231 & J. Chen & 90 & 283 & 1,475 & 205 & 24 & 167 & 150 \\
\hline Georg August Universität Göttingen & 2,820 & 42 & T. Alenius & 48 & 330 & 356 & 316 & 13 & 291 & 69 \\
\hline George Mason University & 256 & 323 & G.W. Mushrush & 166 & 173 & 304 & 321 & 6 & 326 & 103 \\
\hline George Washington University & 477 & 278 & R. Riffat & 16 & 343 & 22 & 342 & 2 & 342 & 23 \\
\hline Georgetown University & 348 & 306 & R.J. Lazarus & 31 & 340 & 10 & 345 & 2 & 342 & 0 \\
\hline Georgia Institute of Technology & 2,233 & 69 & A.G. Russell & 166 & 173 & 1,400 & 212 & 21 & 202 & 150 \\
\hline Georgia State University & 254 & 324 & P.J. Ferraro & 33 & 337 & 444 & 310 & 13 & 291 & 100 \\
\hline Goteborg University & 1,338 & 139 & L. Forlin & 6 & 346 & 10 & 345 & 3 & 340 & 19 \\
\hline Harvard University & 2,967 & 41 & F.A. Bazzaz & 220 & 117 & 7,010 & 26 & 30 & 109 & 150 \\
\hline Hebrew University of Jerusalem & 2,116 & 76 & Y. Hadar & 141 & 216 & 2,005 & 177 & 22 & 193 & 150 \\
\hline Heidelberg Universität & 1,482 & 125 & H. Hollert & 95 & 276 & 370 & 315 & 17 & 250 & 150 \\
\hline Hokkaido University & 2,761 & 44 & Y. Watanabe & 119 & 245 & 1,360 & 216 & 21 & 202 & 150 \\
\hline Hong Kong Polytechnic University & 1,363 & 138 & W. Chu & 156 & 191 & 1,446 & 206 & 24 & 167 & 150 \\
\hline Hong Kong University of Science \& Techno... & 1,180 & 154 & W.X. Wang & 160 & 187 & 1,902 & 184 & 22 & 193 & 150 \\
\hline Humboldt-Universität zu Berlin & 62 & 340 & C. Ionomidou & 89 & 284 & 3,148 & 106 & 32 & 89 & 150 \\
\hline Imperial College London & 4,944 & 12 & J.N .Lester & 288 & 62 & 3,740 & 76 & 24 & 167 & 143 \\
\hline Indian Institute of Technology Bombay (I... & 665 & 235 & R.S. Patil & 69 & 310 & 332 & 318 & 9 & 317 & 71 \\
\hline Indian Institute of Technology Delhi (II... & 1,029 & 180 & V.K. Kofhari & 166 & 173 & 223 & 324 & 5 & 334 & 90 \\
\hline Indian Institute of Technology Kanpur (I... & 516 & 271 & P.S. Vankar & 94 & 279 & 192 & 327 & 6 & 326 & 59 \\
\hline Indiana University Bloomington & 1,958 & 81 & R. A. Hites & 287 & 63 & 5,221 & 41 & 31 & 95 & 150 \\
\hline Indiana University Indianapolis & 144 & 334 & J.E. Klaunig & 185 & 143 & 3,200 & 102 & 26 & 146 & 150 \\
\hline Iowa State University & 1,030 & 179 & R.S. Kanwar & 182 & 149 & 1,172 & 232 & 16 & 263 & 150 \\
\hline Johns Hopkins University & 2,361 & 60 & S.H. Snyder & 300 & 58 & 14,180 & 12 & 75 & 3 & 150 \\
\hline Kansas State University & 654 & 238 & T.G. Nagaraja & 141 & 216 & 1,078 & 242 & 17 & 250 & 150 \\
\hline Katholieke Universiteit Leuven & 1,926 & 84 & M. Hermy & 181 & 151 & 1,763 & 191 & 31 & 95 & 150 \\
\hline Keio University & 342 & 308 & K. Omae & 105 & 263 & 597 & 296 & 13 & 291 & 150 \\
\hline
\end{tabular}




\begin{tabular}{|c|c|c|c|c|c|c|c|c|c|c|}
\hline King Fahd University of Petroleum \& Minerals & 563 & 263 & S. Farooq & 34 & 336 & 194 & 326 & 6 & 326 & 37 \\
\hline King Saud University & 830 & 213 & I.S. Al-Mutaz & 50 & 328 & 125 & 334 & 5 & 334 & 38 \\
\hline Kobe University & 609 & 249 & A. Adachi & 88 & 285 & 826 & 274 & 10 & 315 & 137 \\
\hline Korea Advanced Institute of Science \& Technology & 636 & 243 & S. Park & 86 & 290 & 776 & 281 & 15 & 273 & 127 \\
\hline Korea University & 560 & 265 & S.T. Yun & 62 & 318 & 285 & 322 & 11 & 309 & 111 \\
\hline Kyoto University & 4,538 & 16 & M. Ikeda & 451 & 18 & 2,763 & 124 & 25 & 157 & 150 \\
\hline Kyushu University & 1,704 & 104 & Y. Iwasa & 191 & 138 & 3,183 & 104 & 28 & 127 & 137 \\
\hline La Trobe University & 940 & 194 & A.A. Hofman & 241 & 101 & 2,933 & 119 & 34 & 74 & 150 \\
\hline Lancaster University & 1,882 & 90 & K.C. Jones & 448 & 19 & 6,609 & 29 & 54 & 12 & 150 \\
\hline Leiden University & 1,700 & 105 & L.A. Peletier & 130 & 230 & 1,237 & 229 & 14 & 283 & 122 \\
\hline Linkoping University & 848 & 212 & A. Grimvall & 77 & 300 & 817 & 275 & 14 & 283 & 84 \\
\hline London School of Economics and Political Science & 675 & 232 & E. Neumayer & 101 & 267 & 921 & 259 & 19 & 224 & 17 \\
\hline Loughborough University & 931 & 197 & A.G. Fogg & 231 & 108 & 846 & 270 & 12 & 301 & 150 \\
\hline Louisiana State University & 1,564 & 119 & K.T. Valsaraj & 161 & 184 & 1,074 & 243 & 16 & 263 & 131 \\
\hline Ludwig-Maximilians-Universität München & 1,945 & 82 & J. Heinrich & 330 & 43 & 5,493 & 37 & 47 & 24 & 150 \\
\hline Lund University & 4,739 & 15 & S. Skertving & 228 & 110 & 3,623 & 85 & 29 & 118 & 150 \\
\hline Maastricht University & 416 & 286 & G.M.H. Swaen & 131 & 227 & 1,273 & 227 & 17 & 250 & 150 \\
\hline Macquarie University & 1,238 & 149 & M. Westoby & 175 & 163 & 4,915 & 48 & 37 & 53 & 150 \\
\hline Mahidol University & 376 & 291 & P. Pokethitiyook & 49 & 329 & 508 & 305 & 13 & 291 & 92 \\
\hline Masaryk University & 578 & 257 & I. Holoubek & 111 & 260 & 911 & 261 & 20 & 212 & 150 \\
\hline Massachusetts Institute of Technology & 3,405 & 29 & A. Rich & 337 & 42 & 5,872 & 33 & 32 & 89 & 150 \\
\hline McGill University & 3,121 & 37 & T.R. Moore & 120 & 243 & 2,126 & 165 & 27 & 138 & 150 \\
\hline McMaster University & 1,891 & 89 & C.M.Wood & 436 & 22 & 3,016 & 113 & 37 & 53 & 150 \\
\hline Michigan State University & 4,269 & 19 & J.P. Giesy & 436 & 22 & 7,534 & 22 & 55 & 11 & 150 \\
\hline Michigan Technological University & 1,031 & 177 & K.S. Pregitzer & 165 & 178 & 4,949 & 47 & 46 & 26 & 150 \\
\hline Monash University & 1,822 & 93 & P.S. Lake & 118 & 247 & 1,954 & 181 & 23 & 178 & 148 \\
\hline Montana State University & 1,480 & 126 & R.A. Garrott & 104 & 264 & 853 & 266 & 15 & 273 & 113 \\
\hline Moscow State University & 2,578 & 50 & V.N. Mikhailov & 33 & 337 & 13 & 343 & 2 & 342 & 32 \\
\hline Nagoya University & 1,904 & 88 & Y. Iwaska & 132 & 224 & 837 & 272 & 19 & 224 & 150 \\
\hline Nanjing University & 1,719 & 102 & L. Wang & 153 & 197 & 1,055 & 246 & 19 & 224 & 150 \\
\hline Nanyang Technological University & 870 & 206 & J.H.Tay & 246 & 93 & 2,050 & 175 & 31 & 95 & 150 \\
\hline National Taiwan University & 2,700 & 45 & D.J.Lee & 417 & 27 & 2,345 & 146 & 28 & 127 & 150 \\
\hline National Tsing Hua University & 539 & 268 & R.A. Doong & 66 & 312 & 1,095 & 238 & 23 & 178 & 41 \\
\hline National University of Ireland, Galway & 540 & 267 & S.G. Jennings & 91 & 282 & 1,492 & 203 & 18 & 235 & 150 \\
\hline National University of Singapore & 2,132 & 74 & S.L. Ong & 118 & 247 & 814 & 276 & 16 & 263 & 150 \\
\hline New Mexico State University & 1,381 & 134 & W.G. Whitford & 173 & 164 & 2,575 & 132 & 21 & 202 & 150 \\
\hline
\end{tabular}




\begin{tabular}{|c|c|c|c|c|c|c|c|c|c|c|}
\hline New York University & 1,266 & 146 & G. Stotsky & 179 & 154 & 1,875 & 185 & 22 & 193 & 103 \\
\hline Newcastle University & 2,633 & 49 & S.P. Rushton & 102 & 266 & 1,285 & 226 & 17 & 250 & 150 \\
\hline North Carolina State University & 4,126 & 22 & V. P. Aneja & 145 & 209 & 956 & 253 & 18 & 235 & 150 \\
\hline Northeastern University & 473 & 280 & P. Vouros & 176 & 162 & 2,295 & 152 & 27 & 138 & 150 \\
\hline Northwestern University & 1,179 & 155 & B.E. Rittmann & 273 & 76 & 3,809 & 74 & 24 & 167 & 150 \\
\hline Norwegian University of Science \& Technology & 1,915 & 86 & E. Steinnes & 228 & 110 & 2,126 & 165 & 24 & 167 & 150 \\
\hline Ohio State University & 3,926 & 24 & W.J. Mitsch & 140 & 220 & 1,408 & 211 & 20 & 212 & 150 \\
\hline Oklahoma State University & 1,662 & 110 & D.M. Engle & 122 & 241 & 875 & 265 & 14 & 283 & 125 \\
\hline Open University UK & 986 & 187 & P.J. Smith & 177 & 160 & 38 & 341 & 0 & 347 & 4 \\
\hline Oregon State University & 5,952 & 6 & B.R.T. Simoneit & 350 & 38 & 4,856 & 49 & 43 & 30 & 150 \\
\hline Osaka University & 1,025 & 182 & K. Morimoto & 271 & 77 & 2,247 & 160 & 23 & 178 & 150 \\
\hline Peking University & 1,717 & 103 & S. Tao & 236 & 103 & 1,350 & 218 & 20 & 212 & 150 \\
\hline Pennsylvania State University & 4,513 & 17 & J.M. Bollag & 164 & 182 & 2,458 & 143 & 23 & 178 & 149 \\
\hline Pohang University of Science And Technology & 362 & 296 & W. Choi & 117 & 251 & 6,972 & 27 & 33 & 82 & 125 \\
\hline Portland State University & 563 & 263 & H. Chang & 33 & 337 & 187 & 328 & 12 & 301 & 36 \\
\hline Princeton University & 2,198 & 72 & R.M. May & 371 & 32 & 12,961 & 14 & 27 & 138 & 150 \\
\hline Purdue University & 3,344 & 31 & P.C. Wankat & 199 & 132 & 612 & 294 & 12 & 301 & 112 \\
\hline Queen's University & 1,755 & 98 & J.P. Smol & 300 & 58 & 27,445 & 4 & 30 & 109 & 150 \\
\hline Queen's University of Belfast & 1,506 & 122 & P. Christie & 180 & 153 & 2,515 & 138 & 35 & 68 & 150 \\
\hline Queensland University of Technology & 634 & 245 & L. Morawka & 129 & 233 & 1,085 & 239 & 22 & 193 & 128 \\
\hline Radboud University, Nijmegen & 1,259 & 147 & J.G.M. Roelofs & 141 & 216 & 1,308 & 223 & 24 & 167 & 150 \\
\hline Rensselaer Polytechnic Institute & 702 & 226 & E.R. Altwicker & 88 & 285 & 522 & 304 & 13 & 291 & 54 \\
\hline Rheinisch Westfalische Technische Hochschule Aach & 1,396 & 133 & T. Gries & 227 & 113 & 130 & 333 & 5 & 334 & 150 \\
\hline Rheinische Friedrich Wilhelms Universitat Bonn & 1,755 & 98 & W. Barthlott & 116 & 253 & 2,723 & 125 & 26 & 146 & 150 \\
\hline Rice University & 852 & 211 & D.C. Queller & 125 & 239 & 2,170 & 164 & 25 & 157 & 95 \\
\hline Rochester Institute of Technology & 135 & 336 & A.A. Batabyal & 112 & 258 & 176 & 329 & 8 & 322 & 19 \\
\hline Royal Institute of Technology, KTH & 1,158 & 159 & I. Neretnieks & 156 & 191 & 936 & 257 & 13 & 291 & 79 \\
\hline Royal Melbourne Institute of Technology & 354 & 300 & D.A. Holdway & 73 & 305 & 576 & 298 & 13 & 291 & 73 \\
\hline Rutgers & 3,745 & 26 & J. Burger & 260 & 81 & 2,101 & 169 & 29 & 118 & 150 \\
\hline Saint-Petersburg State University & 468 & 281 & A.D. Nozdrachev & 247 & 92 & 157 & 330 & 6 & 326 & 150 \\
\hline San Diego State University & 1,163 & 158 & W.C. Oechel & 131 & 227 & 4,987 & 46 & 34 & 74 & 150 \\
\hline Sapienza University of Rome & 0 & 348 & & 0 & 348 & 0 & 348 & 0 & 347 & 0 \\
\hline Sciences Po Paris & 16 & 346 & M. Stroper & 46 & 332 & 2,183 & 163 & 11 & 309 & 18 \\
\hline Seoul National University & 1,737 & 101 & K.K. Lee & 129 & 233 & 592 & 297 & 14 & 283 & 150 \\
\hline Shanghai Jiao Tong University & 880 & 203 & W. Wang & 118 & 247 & 754 & 284 & 15 & 273 & 150 \\
\hline Simon Fraser University & 1,680 & 108 & J.H. Borden & 242 & 99 & 1,348 & 220 & 21 & 202 & 150 \\
\hline
\end{tabular}




\begin{tabular}{|c|c|c|c|c|c|c|c|c|c|c|}
\hline Stanford University & 3,891 & 25 & P.R. Ehrlich & 214 & 123 & 3,393 & 94 & 9 & 317 & 150 \\
\hline State University of New York Buffalo & 36 & 345 & S. Kumar & 365 & 33 & 1,806 & 187 & 19 & 224 & 150 \\
\hline Stockholm University & 3,141 & 36 & C. Folke & 122 & 241 & 5,131 & 43 & 35 & 68 & 150 \\
\hline Stony Brook University & 1,556 & 121 & N.S. Fisher & 129 & 233 & 1,791 & 189 & 28 & 127 & 135 \\
\hline Syracuse University & 991 & 186 & C.T. Driscoll & 284 & 67 & 4,518 & 57 & 37 & 53 & 150 \\
\hline Tartu University (University of Tartu) & 891 & 202 & U. Mander & 113 & 257 & 612 & 294 & 16 & 263 & 150 \\
\hline Technical University of Denmark & 2,529 & 52 & T.H. Christensen & 182 & 149 & 2,785 & 123 & 28 & 127 & 150 \\
\hline Technion & 1,373 & 135 & A. Ostfeld & 73 & 305 & 209 & 325 & 8 & 322 & 72 \\
\hline Technische Universität Berlin & 1,365 & 137 & M. Jekel & 149 & 207 & 1,807 & 186 & 26 & 146 & 150 \\
\hline Technische Universitat Chemnitz & 57 & 343 & B. Platzer & 38 & 335 & 53 & 339 & 4 & 337 & 39 \\
\hline Technische Universität Dresden & 1,152 & 160 & P. Offermann & 195 & 136 & 139 & 332 & 6 & 326 & 150 \\
\hline Technische Universität München & 2,224 & 70 & R. Niessner & 353 & 37 & 3,108 & 109 & 30 & 109 & 150 \\
\hline Tel Aviv University & 1,337 & 141 & G. Dagan & 145 & 209 & 1,787 & 190 & 18 & 235 & 76 \\
\hline Texas A\&M University & 5,587 & 9 & K.C. Donnelly & 132 & 224 & 949 & 255 & 15 & 273 & 150 \\
\hline Texas Tech & 607 & 250 & P.K. Dasgupta & 320 & 48 & 2,876 & 121 & 28 & 127 & 150 \\
\hline Tohoku University & 1,693 & 106 & T. Hirose & 98 & 271 & 1,289 & 225 & 23 & 178 & 128 \\
\hline Tokyo Institute of Technology & 921 & 199 & I. Karube & 489 & 14 & 4,685 & 52 & 33 & 82 & 150 \\
\hline Trinity College Dublin & 674 & 233 & M.B. Jones & 74 & 303 & 652 & 291 & 16 & 263 & 150 \\
\hline Tsinghua University & 2,638 & 48 & Y. Qian & 179 & 154 & 852 & 267 & 18 & 235 & 150 \\
\hline Tufts University & 820 & 216 & R.M. Vogel & 123 & 240 & 1,062 & 244 & 15 & 273 & 115 \\
\hline Universidad Autonoma de Madrid & 806 & 217 & F. Suarez & 57 & 322 & 549 & 301 & 11 & 309 & 55 \\
\hline Universidad de Chile & 1,071 & 171 & H.N. Niemeyer & 202 & 131 & 1,248 & 228 & 17 & 250 & 150 \\
\hline Universidad de Granada & 806 & 217 & F. Suarez & 57 & 322 & 549 & 301 & 11 & 309 & 55 \\
\hline Universidad del País Vasco & 972 & 191 & J. Bilbao & 198 & 133 & 955 & 254 & 27 & 138 & 117 \\
\hline Universidad Nacional Autónoma de México ... & 253 & 326 & M. Ramos-Martinez & 58 & 321 & 879 & 264 & 16 & 263 & 128 \\
\hline Universidad Politecnica de Madrid & 632 & 246 & L. Gil & 110 & 261 & 852 & 267 & 19 & 224 & 137 \\
\hline Universidade de São Paulo & 1,119 & 164 & P. Artaxo & 146 & 208 & 2,642 & 129 & 36 & 61 & 150 \\
\hline Universidade Estadual de Campinas & 350 & 303 & N. Duran & 256 & 85 & 2,277 & 154 & 26 & 146 & 150 \\
\hline Università degli Studi di Firenze & 1,338 & 139 & F. Bussotti & 75 & 301 & 569 & 300 & 17 & 250 & 143 \\
\hline Università degli Studi di Padova & 1,613 & 115 & A. Rinaldo & 116 & 253 & 1,801 & 188 & 24 & 167 & 105 \\
\hline Universita Di Bologna & 1,589 & 116 & P. Hrelia & 130 & 230 & 973 & 250 & 18 & 235 & 150 \\
\hline Universita di Pisa & 397 & 289 & L. Migliore & 96 & 274 & 1,421 & 208 & 23 & 178 & 150 \\
\hline Universitat Autonoma de Barcelona & 1,784 & 96 & J. Penuelas & 234 & 105 & 3,961 & 69 & 41 & 36 & 150 \\
\hline Universitat Bielefeld & 376 & 291 & A. Puhler & 309 & 53 & 7,674 & 21 & 40 & 40 & 150 \\
\hline Universität Bremen & 1,101 & 166 & M. Diekmann & 53 & 326 & 772 & 282 & 20 & 212 & 94 \\
\hline Universitat d'Alacant & 594 & 254 & J. Cortina & 53 & 326 & 833 & 273 & 18 & 235 & 65 \\
\hline
\end{tabular}




\begin{tabular}{|c|c|c|c|c|c|c|c|c|c|c|}
\hline Universitat de València & 1,315 & 144 & M.D. Ferrando & 95 & 276 & 785 & 280 & 16 & 263 & 53 \\
\hline Universität Frankfurt am Main & 1,399 & 131 & P. Egler & 8 & 345 & 73 & 337 & 6 & 326 & 24 \\
\hline Universität Freiburg & 1,098 & 167 & C. Leibundgut & 74 & 303 & 355 & 317 & 12 & 301 & 86 \\
\hline Universitat Hamburg & 485 & 275 & R.S.J. Tol & 154 & 195 & 975 & 248 & 20 & 212 & 103 \\
\hline Universität Karlsruhe & 1,614 & 114 & J. Baldyer & 110 & 261 & 740 & 286 & 14 & 283 & 83 \\
\hline Universitat Leipzig & 157 & 331 & O. Herbarth & 136 & 221 & 839 & 271 & 20 & 212 & 150 \\
\hline Universitat Munster (Westfälische Wilhelms-Un & 238 & 327 & A. Steinbuchel & 301 & 57 & 2,998 & 114 & 39 & 45 & 150 \\
\hline Universitat Politecnica de Catalunya & 364 & 295 & J.M. Baldasano & 93 & 280 & 538 & 303 & 17 & 250 & 150 \\
\hline Universität Regensburg & 475 & 279 & J. Heinze & 150 & 203 & 1,160 & 233 & 25 & 157 & 138 \\
\hline Universität Stuttgart & 1,051 & 173 & A. Bardossey & 150 & 203 & 154 & 331 & 15 & 273 & 126 \\
\hline Universitat Trier & 290 & 319 & W. Symader & 39 & 334 & 43 & 340 & 3 & 340 & 25 \\
\hline Universität Tübingen & 1,503 & 123 & P.Grathwohl & 112 & 258 & 1,112 & 234 & 17 & 250 & 150 \\
\hline Universitat Wien (University of Vienna) & 1,919 & 85 & H. Horvath & 118 & 247 & 813 & 277 & 11 & 309 & 150 \\
\hline Universitat Zu Koln & 1,097 & 168 & W. Topp & 63 & 315 & 327 & 319 & 13 & 291 & 47 \\
\hline Université Catholique de Louvain & 1,498 & 124 & J.P. Buchet & 210 & 124 & 3,231 & 101 & 20 & 212 & 150 \\
\hline Universite de Liege & 1,229 & 150 & A. Dassargues & 88 & 285 & 280 & 323 & 9 & 317 & 98 \\
\hline Université de Montréal & 1,434 & 128 & J. Ludden & 97 & 273 & 1,490 & 204 & 18 & 235 & 129 \\
\hline Université de Nice Sophia Antipolis & 487 & 274 & M. Romeo & 70 & 308 & 927 & 258 & 21 & 202 & 122 \\
\hline Universite Laval & 2,290 & 64 & L. Bernatchez & 183 & 146 & 3,648 & 82 & 43 & 30 & 150 \\
\hline Universite Libre de Bruxelles & 861 & 209 & P. Servais & 126 & 236 & 1,648 & 194 & 22 & 193 & 150 \\
\hline Université Paris Sorbonne & 342 & 308 & P. Claval & 81 & 295 & 69 & 338 & 4 & 337 & 2 \\
\hline Universite Paris-Sud 11 & 1,173 & 156 & P.H. Gouyon & 71 & 307 & 1,605 & 198 & 17 & 250 & 135 \\
\hline Université Pierre et Marie Curie & 3,105 & 38 & A.P. Moller & 599 & 10 & 19,973 & 6 & 58 & 9 & 150 \\
\hline Universiti Malaya (University of Malaya) & 482 & 276 & H.H. Masjuki & 104 & 264 & 388 & 313 & 12 & 301 & 88 \\
\hline University College Cork & 733 & 223 & C. Hill & 254 & 86 & 3,190 & 103 & 39 & 45 & 150 \\
\hline University College Dublin & 855 & 210 & E.P. Farrell & 60 & 320 & 383 & 314 & 12 & 301 & 91 \\
\hline University College London & 3,079 & 40 & G. Bruni & 63 & 315 & 326 & 320 & 8 & 322 & 71 \\
\hline University do Porto & 353 & 301 & R.A.R. Boaventura & 64 & 313 & 728 & 288 & 17 & 250 & 73 \\
\hline University of Aberdeen & 2,577 & 51 & J.R.Speakman & 274 & 75 & 3,058 & 111 & 32 & 89 & 150 \\
\hline University of Adelaide & 1,824 & 92 & H.P. Possingham & 216 & 120 & 3,682 & 81 & 37 & 53 & 150 \\
\hline University of Alabama & 1,114 & 165 & J.B. MCClintock & 161 & 184 & 1,386 & 214 & 20 & 212 & 150 \\
\hline University of Alberta & 4,074 & 23 & P.M. Fedorak & 151 & 200 & 1,428 & 207 & 18 & 235 & 118 \\
\hline University of Amsterdam & 2,415 & 57 & M.W. Sabelis & 187 & 142 & 2,324 & 149 & 26 & 146 & 150 \\
\hline University of Antwerp & 1,577 & 117 & R. Blust & 236 & 103 & 2,054 & 174 & 27 & 138 & 150 \\
\hline University of Arizona & 5,630 & 8 & C.P. Gerba & 327 & 44 & 3,573 & 88 & 26 & 146 & 150 \\
\hline University of Athens & 1,046 & 175 & C. Varotsos & 197 & 135 & 756 & 283 & 31 & 95 & 150 \\
\hline
\end{tabular}




\begin{tabular}{|c|c|c|c|c|c|c|c|c|c|c|}
\hline University of Auckland & 1,562 & 120 & L.R. Freguson & 222 & 116 & 2,277 & 154 & 24 & 167 & 150 \\
\hline University of Barcelona & 2,267 & 66 & G. Rauret & 150 & 203 & 2,122 & 167 & 26 & 146 & 150 \\
\hline University of Basel & 1,071 & 171 & C. Korner & 183 & 146 & 4,228 & 63 & 43 & 30 & 150 \\
\hline University of Bath & 141 & 335 & F. Marken & 260 & 81 & 2,553 & 133 & 34 & 74 & 150 \\
\hline University of Bergen & 607 & 250 & H.J.B. Birks & 185 & 143 & 3,467 & 92 & 36 & $\overline{61}$ & 150 \\
\hline University of Bern & 587 & 255 & T.F. Stocker & 150 & 203 & 3,718 & 79 & 39 & 45 & 150 \\
\hline University of Birmingham & 2,447 & 55 & R.M. Harrison & 322 & 46 & 5,067 & 44 & 39 & 45 & 150 \\
\hline University of Bristol & 2,249 & 68 & G. Eglinton & 313 & 51 & 3,723 & 78 & 25 & 157 & 150 \\
\hline University of British Columbia & 2,406 & 58 & W.R. Cullen & 253 & 88 & 3,447 & 93 & 30 & 109 & 150 \\
\hline University of Calgary & 747 & 220 & B. Mayer & 82 & 294 & 1,084 & 240 & 18 & 235 & 150 \\
\hline University of California, Berkley & 614 & 247 & D. Zilberman & 2 & 347 & 1 & 347 & 1 & 346 & 4 \\
\hline University of California, Davis & 8,058 & 3 & B.D. Hammock & 623 & 8 & 11,246 & 15 & 41 & 36 & 150 \\
\hline University of California, Irvine & 824 & 215 & D.R. Blake & 312 & 52 & 4,064 & 66 & 49 & 21 & 150 \\
\hline University of California, Los Angeles & 3,572 & 28 & J.M. Diamond & 184 & 145 & 2,956 & 118 & 22 & 193 & 88 \\
\hline University of California, Riverside & 3,186 & 35 & R. Atkinson & 293 & 61 & 4,476 & 58 & 28 & 127 & 112 \\
\hline University of California, San Diego & 874 & 204 & B.O. Palsson & 319 & 50 & 4,445 & 60 & 50 & 16 & 150 \\
\hline University of California, San Francisco & 258 & 322 & H.I. Maibach & 1,156 & 2 & 15,464 & 10 & 35 & 68 & 150 \\
\hline University of California, Santa Barbara & 1,368 & 136 & O.A. Chadwick & 126 & 236 & 2,700 & 126 & 31 & 95 & 150 \\
\hline University of California, Santa Cruz & 863 & 208 & M. Mangel & 166 & 173 & 3,116 & 108 & 28 & 127 & 150 \\
\hline University of Cambridge & 923 & 198 & A.M. Donald & 257 & 84 & 2,673 & 127 & 30 & 109 & 150 \\
\hline University of Canterbury & 417 & 285 & M.H. Turnbull & 63 & 315 & 903 & 262 & 19 & 224 & 80 \\
\hline University of Cape Town & 2,056 & 79 & T.D. Noakes & 398 & 30 & 4,475 & 59 & 38 & 51 & 150 \\
\hline University of Central Florida & 583 & 256 & N.B. Chang & 54 & 324 & 75 & 336 & 4 & 337 & 65 \\
\hline University of Chicago & 371 & 293 & S.R. Sutton & 246 & 93 & 3,859 & 71 & 31 & 95 & 150 \\
\hline University of Cincinnati & 2,251 & 67 & M.T. Suidan & 251 & 90 & 2,506 & 139 & 26 & 146 & 150 \\
\hline University of Colorado at Boulder & 1,634 & 111 & A.R. Ravishankara & 280 & 69 & 4,655 & 54 & 33 & 82 & 150 \\
\hline University of Connecticut & 867 & 207 & P. Setlow & 322 & 46 & 2,482 & 140 & 34 & 74 & 150 \\
\hline University of Copenhagen & 164 & 330 & S. Loft & 254 & 86 & 4,649 & 55 & 38 & 51 & 150 \\
\hline University of Delaware & 916 & 200 & D.L. Sparks & 276 & 73 & 5,732 & 35 & 39 & 45 & 150 \\
\hline University of Dundee & 910 & 201 & J.A. Raven & 263 & 80 & 3,914 & 70 & 32 & 89 & 150 \\
\hline University of Edinburgh & 985 & 188 & K. Donaldson & 278 & 71 & 5,312 & 39 & 50 & 16 & 150 \\
\hline University of Florida & 6,321 & 5 & K.R. Reddy & 217 & 119 & 3,284 & 98 & 28 & 127 & 150 \\
\hline University of Geneva & 347 & 307 & J. Buffle & 178 & 157 & 2,201 & 161 & 29 & 118 & 150 \\
\hline University of Georgia & 2,199 & 71 & L.R. Beuchat & 356 & 36 & 3,790 & 75 & 34 & 74 & 150 \\
\hline University of Ghent & 3,580 & 27 & W. Verstraete & 323 & 45 & 4,670 & 53 & 40 & 40 & 150 \\
\hline University of Glasgow & 1,854 & 91 & R.W. Furness & 229 & 109 & 2,910 & 120 & 31 & 95 & 150 \\
\hline
\end{tabular}




\begin{tabular}{|c|c|c|c|c|c|c|c|c|c|c|}
\hline University of Gothenburg & 61 & 341 & M. Hagberg & 188 & 141 & 2,524 & 137 & 25 & 157 & 150 \\
\hline University of Groningen & 752 & 219 & H.J. Busscher & 429 & 25 & 4,743 & 50 & 34 & 74 & 150 \\
\hline University of Helsinki & 4,196 & 20 & K. Kulmala & 286 & 64 & 1,961 & 180 & 36 & 61 & 150 \\
\hline University of Hong Kong & 718 & 225 & H.H.P. Fang & 204 & 128 & 2,308 & 151 & 29 & 118 & 150 \\
\hline University of Houston & 285 & 321 & S. Chellam & 61 & 319 & 574 & 299 & 16 & 263 & 47 \\
\hline University of Illinois & 5,071 & 11 & M.R. Berenbaum & 168 & 171 & 2,295 & 152 & 27 & 138 & 150 \\
\hline University of Illinois, Chicago & 1,321 & 143 & J.S. Brown & 132 & 224 & 2,459 & 142 & 26 & 146 & 130 \\
\hline University of Indonesia & 44 & 344 & D.J. Melnick & 68 & 311 & 957 & 252 & 21 & 202 & 98 \\
\hline University of Iowa & 647 & 241 & G.R. Carmicheal & 259 & 83 & 3,606 & 86 & 41 & 36 & 150 \\
\hline University of Kansas & 489 & 273 & A.T. Peterson & 155 & 193 & 2,830 & 122 & 35 & 68 & 150 \\
\hline University of Kentucky & 825 & 214 & L.W. Robertson & 206 & 126 & 1,349 & 219 & 23 & 178 & 150 \\
\hline University of Lausanne & 355 & 299 & D. Haas & 145 & 209 & 2,546 & 136 & 33 & 82 & 150 \\
\hline University of Leeds & 977 & 190 & M.J. Pilling & 296 & 60 & 3,253 & 99 & 28 & 127 & 150 \\
\hline University of Leicester & 1,076 & 170 & P.B. Farmer & 240 & 102 & 2,649 & 128 & 25 & 157 & 150 \\
\hline University of Liverpool & 663 & 236 & P.G. Appleby & 155 & 193 & 2,552 & 134 & 26 & 146 & 150 \\
\hline University of Ljubljana & 938 & 195 & D. Lestan & 48 & 330 & 459 & 308 & 14 & 283 & 45 \\
\hline University of London (Kings College of London) & 8,127 & 2 & P.D. Moore & 206 & 126 & 469 & 306 & 6 & 326 & 19 \\
\hline University of Manchester & 2,796 & 43 & T.W. Choularto. & 133 & 223 & 1,103 & 236 & 17 & 250 & 150 \\
\hline University of Manitoba & 1,750 & 100 & F. Erkes & 80 & 297 & 1,990 & 178 & 22 & 193 & 114 \\
\hline University of Maryland & 4,463 & 18 & R.R. Colwell & 488 & 15 & 8,320 & 20 & 35 & 68 & 150 \\
\hline University of Maryland Baltimore County & 1,221 & 152 & R.R. Colwell & 477 & 17 & 9,220 & 17 & 37 & 53 & 150 \\
\hline University of Massachusetts & 1,096 & 169 & D.R. Lovley & 285 & 66 & 6,590 & 30 & 63 & 5 & 150 \\
\hline University of Melbourne & 2,495 & 53 & M.A. Burgman & 99 & 268 & 1,493 & 202 & 23 & 178 & 150 \\
\hline University of Miami & 699 & 227 & P.J. Walsh & 283 & 68 & 3,989 & 67 & 39 & 45 & 150 \\
\hline University of Michigan & 2,274 & 65 & W.J. Weber & 244 & 97 & 3,646 & 83 & 29 & 118 & 150 \\
\hline University of Minnesota & 2,330 & 61 & P.B. Reich & 286 & 64 & 7,405 & 23 & 50 & 16 & 150 \\
\hline University of Missouri & 1,226 & 151 & G.E. Rottinghaus & 189 & 140 & 1,419 & 209 & 20 & 212 & 150 \\
\hline University of Nebraska & 1,966 & 80 & P.J. Shea & 92 & 281 & 1,060 & 245 & 21 & 202 & 138 \\
\hline University of New Hampshire & 1,623 & 112 & J.D. Aber & 145 & 209 & 8,548 & 19 & 47 & 24 & 150 \\
\hline University of New Mexico & 600 & 253 & J.H. Brown & 166 & 173 & 7,263 & 24 & 40 & 40 & 150 \\
\hline University of New South Wales & 1,029 & 180 & T.D. Waite & 208 & 125 & 2,323 & 150 & 28 & 127 & 150 \\
\hline University of North Carolina, Chapel Hill & 3,201 & 34 & H.W. Paerl & 204 & 128 & 4,284 & 62 & 33 & 82 & 150 \\
\hline University of North Texas & 290 & 319 & P.F. Hudak & 160 & 187 & 794 & 278 & 10 & 315 & 91 \\
\hline University of Notre Dame & 338 & 310 & J.B. Fein & 86 & 290 & 1,079 & 241 & 23 & 178 & 102 \\
\hline University of Nottingham & 566 & 261 & N.Hidal & 126 & 236 & 974 & 249 & 18 & 235 & 128 \\
\hline University of Oklahoma & 728 & 224 & D.A. Sabatini & 144 & 215 & 1,399 & 213 & 21 & 202 & 150 \\
\hline
\end{tabular}




\begin{tabular}{|c|c|c|c|c|c|c|c|c|c|c|}
\hline University of Oregon & 323 & 313 & P.J. Bartlein & 96 & 274 & 3,124 & 107 & 25 & 157 & 150 \\
\hline University of Oslo & 972 & 191 & N.C. Stenseth & 339 & 41 & 4,699 & 51 & 45 & 27 & 150 \\
\hline University of Otago & 607 & 250 & R Poulin & 280 & 69 & 2,275 & 156 & 31 & 95 & 150 \\
\hline University of Ottawa & 658 & 237 & D. Krewski & 309 & 53 & 5,015 & 45 & 31 & 95 & 150 \\
\hline University of Oxford & 1,140 & 161 & R.G. Compton & 917 & 4 & 16,202 & 9 & 51 & 15 & 150 \\
\hline University of Pennsylvania & 407 & 288 & A.B. Fisher & 277 & 72 & 2,995 & 116 & 31 & 95 & 150 \\
\hline University of Pittsburgh & 482 & 276 & V.E. Kagan & 415 & 28 & 5,315 & 38 & 35 & 68 & 150 \\
\hline University of Quebec & 874 & 204 & C. Bouchard & 705 & 6 & 28,823 & 3 & 63 & 5 & 150 \\
\hline University of Queensland & 1,460 & 127 & J.Keller & 145 & 209 & 2,121 & 168 & 31 & 95 & 150 \\
\hline University of Reading & 2,327 & 62 & R.M. Sibly & 119 & 245 & 2,252 & 159 & 18 & 235 & 150 \\
\hline University of Rochester & 301 & 314 & G. Oberdorster & 165 & 178 & 3,859 & 71 & 33 & 82 & 150 \\
\hline University of Saskatchewan & 2,150 & 73 & J.P. Giesy & 320 & 48 & 6,648 & 28 & 50 & 16 & 150 \\
\hline University of Science and Technology of China & 449 & 283 & H.Q. Yu & 116 & 253 & 750 & 285 & 18 & 235 & 150 \\
\hline University of Sheffield & 3,080 & 39 & K.J. Gaston & 442 & 21 & 7,091 & 25 & 54 & 12 & 150 \\
\hline University of South Carolina & 1,776 & 97 & I. Lerche & 340 & 40 & 793 & 279 & 11 & 309 & 150 \\
\hline University of South Florida & 649 & 239 & J.B. Rose & 178 & 157 & 4,202 & 64 & 36 & 61 & 150 \\
\hline University of Southampton & 690 & 230 & C.Cooper & 484 & 16 & 13,232 & 13 & 61 & 8 & 150 \\
\hline University of Southern California & 699 & 227 & C. Sioutas & 171 & 166 & 2,579 & 131 & 34 & 74 & 150 \\
\hline University of St Andrews & 366 & 294 & I.A. Johnston & 246 & 93 & 1,977 & 179 & 25 & 157 & 150 \\
\hline University of Surrey & 412 & 287 & C. Loannides & 244 & 97 & 1,928 & 182 & 18 & 235 & 150 \\
\hline University of Sussex & 358 & 298 & P.B. Hitchcock & 1,045 & 3 & 11,086 & 16 & 36 & 61 & 150 \\
\hline University of Sydney & 2,675 & 47 & R. Shine & 567 & 12 & 14,222 & 11 & 44 & 28 & 150 \\
\hline University of Technology, Sydney & 384 & 290 & S. Vigneswaran & 131 & 227 & 730 & 287 & 16 & 263 & 150 \\
\hline University of Tennessee Knoxville & 1,031 & 177 & G.S. Sayler & 248 & 91 & 3,325 & 97 & 30 & 109 & 150 \\
\hline University of Texas at Austin & 985 & 188 & P.Thomas & 169 & 170 & 2,548 & 135 & 29 & 118 & 150 \\
\hline University of Tokyo & 1,622 & 113 & N. Miyazaki & 134 & 222 & 1,099 & 237 & 19 & 224 & 150 \\
\hline University of Toronto & 4,879 & 13 & D. Mackay & 242 & 99 & 4,634 & 56 & 34 & 74 & 150 \\
\hline University of Tsukuba & 543 & 266 & M. Yamamoto & 575 & 11 & 21,360 & 5 & 70 & 4 & 150 \\
\hline University of Twente & 155 & 332 & K. Seshan & 120 & 243 & 1,585 & 199 & 24 & 167 & 111 \\
\hline University of Utah & 2,098 & 77 & J.R. Ehleringer & 271 & 77 & 5,870 & 34 & 43 & 30 & 150 \\
\hline University of Vermont & 1,258 & 148 & N.J. Gotelli & 88 & 285 & 3,357 & 95 & 27 & 138 & 114 \\
\hline University of Victoria & 508 & 272 & B.W. Glickman & 232 & 107 & 2,343 & 147 & 23 & 178 & 150 \\
\hline University of Virginia & 959 & 193 & S.A. Macko & 220 & 117 & 3,728 & 77 & 29 & 118 & 150 \\
\hline University of Warwick & 299 & 317 & J.C. Murrell & 116 & 253 & 2,350 & 145 & 27 & 138 & 150 \\
\hline University of Washington & 6,354 & 4 & D.P. Lettenmailer & 305 & 56 & 4,072 & 65 & 49 & 21 & 150 \\
\hline University of Waterloo & 1,408 & 130 & J. Pawliszyn & 399 & 29 & 5,999 & 31 & 52 & 14 & 150 \\
\hline
\end{tabular}




\begin{tabular}{|c|c|c|c|c|c|c|c|c|c|c|}
\hline University of Western Australia & 2,068 & 78 & H. Sivapalan & 153 & 197 & 1,700 & 193 & 25 & 157 & 150 \\
\hline University of Western Ontario & 11,605 & 1 & W.S.Fyfe & 269 & 79 & 2,272 & 157 & 13 & 291 & 150 \\
\hline University of Wisconsin & 2,699 & 46 & J.J. Schauer & 145 & 209 & 2,351 & 144 & 32 & 89 & 150 \\
\hline University of Wollongong & 361 & 297 & N.A.S. Taylor & 70 & 308 & 468 & 307 & 9 & 317 & 69 \\
\hline University of York & 577 & 258 & J.P.W. Young & 99 & 268 & 2,064 & 172 & 26 & 146 & 150 \\
\hline University of Zurich & 576 & 259 & B. Schmid & 178 & 157 & 3,988 & 68 & 36 & 61 & 150 \\
\hline Univesitas Gadjah Mada & 59 & 342 & M.A. Marfai & 9 & 344 & 11 & 344 & 2 & 342 & 17 \\
\hline Uppsala University & 1,129 & 162 & L. Hakanson & 173 & 164 & 1,515 & 200 & 15 & 273 & 114 \\
\hline Utah State & 2,443 & 56 & M.M. Caldwell & 151 & 200 & 3,544 & 89 & 30 & 109 & 133 \\
\hline Utrecht University & 3,324 & 32 & J.L.M. Hermens & 171 & 166 & 2,611 & 130 & 30 & 109 & 150 \\
\hline Vanderbilt University & 329 & 311 & F.P. Guengerich & 663 & 7 & 32,945 & 2 & 58 & 9 & 150 \\
\hline Victoria University of Wellington & 193 & 329 & C.H. Daugherty & 81 & 295 & 654 & 290 & 13 & 291 & 95 \\
\hline Vienna University of Technology & 329 & 311 & H. Puxbaum & 170 & 169 & 2,093 & 170 & 29 & 118 & 150 \\
\hline Virginia Polytechnic Institute & 1,399 & 131 & S.T. Oyama & 181 & 151 & 2,477 & 141 & 31 & 95 & 150 \\
\hline Vrije Universiteit, Brussels & 739 & 221 & D.L. Massart & 515 & 13 & 9,064 & 18 & 40 & 40 & 150 \\
\hline VU University Amsterdam & 2,470 & 54 & P. Nijkamp & 436 & 22 & 1,911 & 183 & 19 & 224 & 150 \\
\hline Wageningen University & 4,818 & 14 & G Lettinga & 307 & 55 & 3,521 & 90 & 37 & 53 & 150 \\
\hline Wake Forest University & 301 & 314 & M.R. Silman & 28 & 341 & 852 & 267 & 12 & 301 & 73 \\
\hline Waseda University & 132 & 337 & S.Tsuneda & 159 & 189 & 1,365 & 215 & 20 & 212 & 150 \\
\hline Washington State University & 996 & 185 & D.R. Call & 95 & 276 & 1,630 & 197 & 29 & 118 & 150 \\
\hline Washington University in St. Louis & 349 & 305 & P. Biswas & 203 & 130 & 2,071 & 171 & 28 & 127 & 150 \\
\hline Wayne State University & 734 & 222 & M.Goodman & 177 & 160 & 3,040 & 112 & 30 & 109 & 150 \\
\hline West Virginia University & 564 & 262 & V. Castranova & 365 & 33 & 5,280 & 40 & 40 & 40 & 150 \\
\hline Yale University & 1,003 & 183 & M. Elimelech & 183 & 146 & 3,628 & 84 & 42 & 34 & 130 \\
\hline Yonsei University & 350 & 303 & Y.R. Pyun & 80 & 297 & 892 & 263 & 19 & 224 & 150 \\
\hline York University & 353 & 301 & N.D. Yan & 88 & 285 & 912 & 260 & 21 & 202 & 143 \\
\hline Zhejiang University & 1,793 & 94 & K.F.Cen & 1,175 & 1 & 3,060 & 110 & 19 & 224 & 150 \\
\hline
\end{tabular}




\begin{tabular}{|c|c|c|c|c|c|c|c|c|c|c|}
\hline Agricultural/Biological Science Data & $\begin{array}{l}\text { Department } \\
\text { Publications }\end{array}$ & Rank & Most Prolific Author & Published & Rank & Cited & Rank & $\begin{array}{c}\text { H- } \\
\text { Index }\end{array}$ & Rank & $\begin{array}{c}\text { \# of } \\
\text { Coauthors }\end{array}$ \\
\hline Aalto University & 398 & 240 & P. Linko & 110 & 220 & 848 & 240 & 14 & 263 & 150 \\
\hline Aarhus University & 2,846 & 87 & C. Bendixen & 91 & 259 & 1,517 & 157 & 18 & 207 & 150 \\
\hline Arizonia State University & 269 & 259 & N.B. Grimm & 90 & 262 & 2,196 & 106 & 28 & 82 & 150 \\
\hline Ateneo de Manila University & 17 & 344 & F.M. Dayrit & 17 & 341 & 193 & 324 & 5 & 333 & 30 \\
\hline Auburn University & 4,716 & 49 & C.E. Boyd & 131 & 187 & 749 & 255 & 13 & 272 & 125 \\
\hline Australian National University & 5,224 & 38 & D.B. Lindenmayer & 276 & 62 & 3,516 & 49 & 36 & 35 & 150 \\
\hline Boston College & 112 & 306 & E.R. Kantrowitz & 152 & 154 & 853 & 238 & 16 & 242 & 150 \\
\hline Boston University & 2,161 & 123 & I. Valiela & 165 & 136 & 2,966 & 72 & 23 & 134 & 150 \\
\hline Brandeis University & 363 & 246 & M. Rosbash & 253 & 72 & 5,621 & 26 & 49 & 11 & 150 \\
\hline Brigham Young University & 205 & 273 & R.D. Pope & 26 & 337 & 210 & 322 & 7 & 323 & 13 \\
\hline Brown University & 1,338 & 168 & J.W. Head & 382 & 31 & 3,842 & 47 & 45 & 17 & 150 \\
\hline California Institute of Technology (Calt... & 1,110 & 182 & E.H. Davidson & 314 & 43 & 5,324 & 28 & 47 & 14 & 150 \\
\hline Cardiff University & 2,021 & 130 & S.J. Ormerod & 152 & 154 & 2,327 & 101 & 24 & 123 & 150 \\
\hline Carnegie Mellon University & 386 & 242 & M.G.Morgan & 79 & 280 & 771 & 253 & 11 & 294 & 98 \\
\hline Case Western Reserve University & 1,292 & 169 & M. Jacobs-Lorena & 116 & 210 & 1,187 & 188 & 24 & 123 & 150 \\
\hline Chalmers University of Technology & 502 & 226 & A.S. Sandberg & 96 & 244 & 1,235 & 184 & 18 & 207 & 113 \\
\hline Charles University & 157 & 287 & P. Pysek & 125 & 197 & 1,674 & 143 & 24 & 123 & 144 \\
\hline Chinese University of Hong Kong & 190 & 279 & T.B. Ng & 409 & 23 & 2,912 & 76 & 38 & 28 & 150 \\
\hline Chulalongkorn University & 1,009 & 187 & N. Ruanfrungsi & 87 & 265 & 995 & 222 & 12 & 283 & 150 \\
\hline City University of Hong Kong & 505 & 225 & R.S.S. Wu & 134 & 184 & 1,774 & 134 & 25 & 109 & 150 \\
\hline City University of New York & 93 & 316 & R.E. Stark & 68 & 299 & 789 & 250 & 16 & 242 & 150 \\
\hline Colorado State University & 1,548 & 159 & K. Paustian & 126 & 194 & 3,332 & 54 & 35 & 44 & 150 \\
\hline Columbia University & 2,783 & 88 & S.B. Heymsfield & 494 & 11 & 12,772 & 10 & 59 & 5 & 150 \\
\hline Cornell University & 15,349 & 2 & K.J. Niklas & 163 & 139 & 1,684 & 141 & 23 & 134 & 110 \\
\hline Curtin University of Technology & 664 & 212 & B.B. Lamont & 165 & 136 & 2,331 & 100 & 23 & 134 & 150 \\
\hline Dalhousie University & 2,847 & 86 & H. Whitehead & 144 & 170 & 1,032 & 214 & 22 & 149 & 115 \\
\hline Dartmouth College & 2,271 & 119 & T. Platt & 141 & 177 & 2,998 & 71 & 20 & 172 & 150 \\
\hline Delft University of Technology & 581 & 217 & H.Y. Steensma & 94 & 250 & 1,771 & 135 & 19 & 193 & 150 \\
\hline Drexel University & 701 & 205 & J.R. Spotila & 117 & 209 & 1,143 & 194 & 16 & 242 & 150 \\
\hline Duke University & 5,047 & 41 & R.J. Lefkowitz & 752 & 2 & 43,621 & $\overline{1}$ & 93 & 1 & 150 \\
\hline Durham University & 1,405 & 164 & J.A. Gatehouse & 150 & 157 & 1,929 & 124 & 31 & 60 & 150 \\
\hline Ecole Normale Supérieure de Lyon & 226 & 269 & C. Dumas & 150 & 157 & 2,159 & 109 & 26 & 99 & 150 \\
\hline École Normale Supérieure, Paris & 683 & 210 & R.Lafont & 129 & 189 & 798 & 245 & 16 & 242 & 150 \\
\hline École Polytechnique & 122 & 301 & B. Giebels & 108 & 224 & 1,259 & 180 & 29 & 72 & 150 \\
\hline
\end{tabular}




\begin{tabular}{|c|c|c|c|c|c|c|c|c|c|c|}
\hline Ecole Polytechnique Fédérale de Lausanne & 430 & 234 & E.A.D. Mitchell & 47 & 322 & 248 & 319 & 13 & 272 & 150 \\
\hline Eindhoven University of Technology & 129 & 296 & P.A. LeClercq & 100 & 237 & 478 & 283 & 8 & 311 & 150 \\
\hline Emory University & 1,878 & 140 & F.B.M. De Wael & 127 & 193 & 2,043 & 115 & 28 & 82 & 127 \\
\hline Erasmus University Rotterdam & 681 & 211 & J.H.J. Hoeijmakers & 283 & 57 & 9,390 & 12 & 61 & 4 & 150 \\
\hline ETH Zurich (Swiss Federal Institute of Technology) & 4,248 & 55 & O.Sticher & 318 & 40 & 2,607 & 85 & 20 & 172 & 150 \\
\hline Florida International University & 1,097 & 185 & J. Francisco & 76 & 287 & 1,007 & 218 & 23 & 134 & 150 \\
\hline Florida State University & 158 & 286 & S.K. Sathe & 82 & 277 & 1,149 & 193 & 16 & 242 & 82 \\
\hline Freie Universität Berlin & 2,755 & 89 & H.Kurschner & 102 & 234 & 274 & 315 & 12 & 283 & 150 \\
\hline Friedrich Alexander Universität Erlangen Nürnberg & 1,424 & 163 & D.P. Hader & 315 & 42 & 2,236 & 104 & 30 & 66 & 150 \\
\hline Fudan University & 869 & 194 & K.Tang & 189 & 114 & 659 & 266 & 13 & 272 & 150 \\
\hline Georg August Universität Göttingen & 5,009 & 42 & T. Tscharntke & 161 & 140 & 2,560 & 89 & 38 & 28 & 150 \\
\hline George Mason University & 83 & 320 & L.K. Matukumalli & 27 & 335 & 363 & 303 & 11 & 294 & 150 \\
\hline George Washington University & 788 & 200 & B. Wood & 106 & 228 & 1,125 & 200 & 18 & 207 & 84 \\
\hline Georgetown University & 643 & 214 & J. Mann & 33 & 330 & 442 & 288 & 15 & 257 & 34 \\
\hline Georgia Institute of Technology & 1,209 & 176 & T.W. Snell & 97 & 242 & 1,327 & 176 & 18 & 207 & 89 \\
\hline Georgia State University & 469 & 230 & C.D. Derby & 107 & 227 & 609 & 273 & 20 & 172 & 109 \\
\hline Goteborg University & 376 & 243 & A.S. Sandberg & 96 & 244 & 1,187 & 188 & 18 & 207 & 114 \\
\hline Harvard University & \begin{tabular}{l|l}
4,557 \\
\end{tabular} & 53 & E.O. Wilson & 148 & 161 & 1,930 & 123 & 12 & 283 & 106 \\
\hline Hebrew University of Jerusalem & 5,727 & 29 & D. Sklan & 220 & 94 & 2,168 & 108 & 29 & 72 & 150 \\
\hline Heidelberg Universität & 1,855 & 144 & M. Wink & 308 & 45 & 2,420 & 95 & 23 & 134 & 150 \\
\hline Hokkaido University & 7,750 & 19 & M. Osaki & 146 & 166 & 872 & 235 & 18 & 207 & 150 \\
\hline Hong Kong Polytechnic University & 397 & 241 & C.K. Tse & 300 & 48 & 1,445 & 165 & 23 & 134 & 150 \\
\hline Hong Kong University of Science \& Techno... & 691 & 207 & P.Y. Qian & 167 & 133 & 1,285 & 179 & 25 & 109 & 150 \\
\hline Humboldt-Universität zu Berlin & 371 & 244 & K. Herter & 26 & 337 & 22 & 344 & 0 & 346 & 1 \\
\hline Imperial College London & 4,783 & 47 & H.C. Godfray & 195 & 108 & 3,457 & 50 & 35 & 44 & 150 \\
\hline Indian Institute of Technology Bombay (I... & 245 & 265 & K.V. Venkatesh & 69 & 296 & 369 & 302 & 13 & 272 & 62 \\
\hline Indian Institute of Technology Delhi (II... & 449 & 233 & P. Vasudevan & 145 & 167 & 1,037 & 213 & 16 & 242 & 138 \\
\hline Indian Institute of Technology Kanpur (I... & 261 & 260 & P.S. Vankar & 94 & 250 & 192 & 325 & 6 & 328 & 59 \\
\hline Indiana University Bloomington & 2,616 & 102 & J.D. Palmer & 153 & 153 & 5,017 & 29 & 39 & 25 & 150 \\
\hline Indiana University Indianapolis & 540 & 221 & J.F. Fitzgerald & 215 & 95 & 2,461 & 93 & 22 & 149 & 150 \\
\hline Iowa State University & 2,931 & 82 & R.S. Kanwar & 182 & 119 & 1,172 & 191 & 16 & 242 & 150 \\
\hline Johns Hopkins University & 3,296 & 73 & S.H. Snyder & 300 & 48 & 14,180 & 6 & 75 & 2 & 150 \\
\hline Kansas State University & 2,132 & 125 & K.J. Kramer & 201 & 104 & 1,923 & 125 & 22 & 149 & 150 \\
\hline Katholieke Universiteit Leuven & 4,140 & 56 & E. Decuyere & 402 & 24 & 1,976 & 118 & 23 & 134 & 150 \\
\hline Keio University & 513 & 224 & S. Yamamuri & 325 & 38 & 1,628 & 145 & 20 & 172 & 150 \\
\hline
\end{tabular}




\begin{tabular}{|c|c|c|c|c|c|c|c|c|c|c|}
\hline King Fahd University of Petroleum \& Minerals & 107 & 309 & M. Sadiq & 45 & 324 & 395 & 297 & 5 & 333 & 26 \\
\hline King Saud University & 1,158 & 178 & F.S. El-Ferly & 129 & 189 & 923 & 230 & 13 & 272 & 150 \\
\hline Kobe University & 1,872 & 142 & M. Takeda & 126 & 194 & 683 & 263 & 15 & 257 & 150 \\
\hline Korea Advanced Institute of Science \& Technology & 322 & 251 & S.T. Lee & 143 & 173 & 1,133 & 198 & 19 & 193 & 150 \\
\hline Korea University & 1,160 & 177 & S.T. Lim & 99 & 239 & 724 & 261 & 16 & 242 & 150 \\
\hline Kyoto University & 10,755 & 7 & M. Tanaka & 376 & 32 & 2,358 & 98 & 29 & 72 & 150 \\
\hline Kyushu University & 5,320 & 37 & Y. Iwasa & 191 & 110 & 3,183 & 59 & 28 & 82 & 137 \\
\hline La Trobe University & 1,754 & 148 & A.A. Hofman & 241 & 80 & 2,933 & 74 & 34 & 51 & 150 \\
\hline Lancaster University & 194 & 277 & K.C. Jones & 448 & 15 & 6,609 & 20 & 54 & 7 & 150 \\
\hline Leiden University & 2,712 & 95 & R. Verpoorte & 490 & 12 & 3,198 & 58 & 30 & 66 & 150 \\
\hline Linkoping University & 486 & 228 & P. Milberg & 105 & 229 & 1,234 & 185 & 18 & 207 & 86 \\
\hline London School of Economics and Political Science & 170 & 283 & E. Neumayer & 101 & 236 & 921 & 232 & 19 & 193 & 17 \\
\hline Loughborough University & 476 & 229 & G. Shama & 56 & 312 & 362 & 304 & 11 & 294 & 78 \\
\hline Louisiana State University & 2,602 & 105 & R.L. Parish & 97 & 242 & 109 & 338 & 5 & 333 & 30 \\
\hline Ludwig-Maximilians-Universität München & 4,687 & 50 & H. Wagner & 313 & 44 & 2,903 & 77 & 16 & 242 & 150 \\
\hline Lund University & 5,005 & 43 & S. Bensch & 144 & 170 & 2,550 & 90 & 31 & 60 & 150 \\
\hline Maastricht University & 873 & 193 & W.H.M. Saris & 397 & 28 & 7,413 & 16 & 48 & 12 & 150 \\
\hline Macquarie University & 1,339 & 167 & M. Westoby & 175 & 127 & 4,915 & 32 & 37 & 30 & 150 \\
\hline Mahidol University & 1,239 & 174 & V. Baimai & 86 & 269 & 496 & 280 & 14 & 263 & 150 \\
\hline Masaryk University & 929 & 190 & M. Chytry & 72 & 291 & 530 & 277 & 19 & 193 & 118 \\
\hline Massachusetts Institute of Technology & 96 & 314 & V.R. Young & 421 & 19 & 4,781 & 34 & 26 & 99 & 150 \\
\hline McGill University & 5,387 & 34 & H.H. Ramaswamy & 235 & 86 & 1,473 & 162 & 20 & 172 & 150 \\
\hline McMaster University & 1,897 & 139 & C.M. Wood & 436 & 17 & 3,016 & 69 & 37 & 30 & 150 \\
\hline Michigan State University & 9,253 & 14 & M.G. Nair & 233 & 88 & 3,073 & 64 & 30 & 66 & 150 \\
\hline Michigan Technological University & 882 & 192 & K.S. Pregitzer & 165 & 136 & 4,949 & 31 & 46 & 16 & 150 \\
\hline Monash University & 2,241 & 120 & J. Beardall & 76 & 287 & 1,001 & 219 & 19 & 193 & 150 \\
\hline Montana State University & 2,421 & 109 & G.A. Strobel & 7 & 345 & 12 & 346 & 2 & 344 & 33 \\
\hline Moscow State University & 3,223 & 77 & D.G. Zvyagintsev & 213 & 97 & 272 & 316 & 6 & 328 & 150 \\
\hline Nagoya University & 4,135 & 57 & M. Kimura & 646 & 4 & 13,889 & 7 & 28 & 82 & 150 \\
\hline Nanjing University & 842 & 196 & R.X. Tan & 147 & 163 & 1,528 & 152 & 24 & 123 & 150 \\
\hline Nanyang Technological University & 429 & 237 & Y.K. Ip & 122 & 201 & 426 & 292 & 20 & 172 & 150 \\
\hline National Taiwan University & 3,462 & 71 & W.N. Tzeng & 87 & 265 & 543 & 275 & 16 & 242 & 96 \\
\hline National Tsing Hua University & 255 & 262 & A.S. Chiang & 62 & 306 & 939 & 228 & 17 & 228 & 135 \\
\hline National University of Ireland, Galway & 764 & 201 & M.D. Guiry & 83 & 273 & 432 & 291 & 11 & 294 & 97 \\
\hline National University of Singapore & 2,646 & 98 & P.K.L. Ng & 255 & 71 & 996 & 221 & 14 & 263 & 150 \\
\hline New Mexico State University & 1,803 & 146 & D.M. Hailford & 105 & 229 & 586 & 274 & 10 & 306 & 150 \\
\hline
\end{tabular}




\begin{tabular}{|c|c|c|c|c|c|c|c|c|c|c|}
\hline New York University & 1,465 & 162 & G. Stotsky & 179 & 123 & 1,875 & 127 & 22 & 149 & 103 \\
\hline Newcastle University & 2,953 & 81 & S.A. Edwards & 121 & 204 & 802 & 244 & 19 & 193 & 150 \\
\hline North Carolina State University & 10,073 & 12 & J.W. Wilcut & 141 & 177 & 529 & 278 & 18 & 207 & 143 \\
\hline Northeastern University & 555 & 220 & D.L. Franko & 91 & 259 & 1,557 & 150 & 24 & 123 & 133 \\
\hline Northwestern University & 1,586 & 154 & L.I. Gilbert & 251 & 73 & 1,496 & 160 & 21 & 162 & 150 \\
\hline Norwegian University of Science \& Technology & 1,917 & 137 & E. Roskaft & 111 & 219 & 1,062 & 207 & 21 & 162 & 145 \\
\hline Ohio State University & 8,876 & 15 & R. Lal & 293 & 52 & 3,119 & 62 & 31 & 60 & 150 \\
\hline Oklahoma State University & 3,758 & 66 & W.R. Raun & 116 & 210 & 956 & 227 & 20 & 172 & 150 \\
\hline Open University UK & 569 & 218 & J. W. Silverton & 98 & 240 & 3,125 & 61 & 26 & 99 & 114 \\
\hline Oregon State University & 10,009 & 13 & J.J. Morrell & 156 & 149 & 417 & 294 & 11 & 294 & 133 \\
\hline Osaka University & 1,955 & 133 & R. Tanaka & 231 & 90 & 1,733 & 139 & 23 & 134 & 150 \\
\hline Peking University & 1,467 & 161 & H. Gu & 61 & 308 & 441 & 289 & 12 & 283 & 150 \\
\hline Pennsylvania State University & 7,824 & 18 & C.R. Bursey & 280 & 59 & 407 & 295 & 12 & 283 & 121 \\
\hline Pohang University of Science And Technology & 335 & 249 & G. An & 133 & 186 & 2,032 & 117 & 29 & 72 & 150 \\
\hline Portland State University & 461 & 231 & A.L. Reyensbach & 72 & 291 & 2,269 & 103 & 27 & 90 & 150 \\
\hline Princeton University & 1,873 & 141 & R.M. May & 371 & 33 & 12,961 & 9 & 27 & 90 & 150 \\
\hline Purdue University & 7,925 & 17 & W.P. McCaffertly & 211 & 99 & 374 & 301 & 14 & 263 & 65 \\
\hline Queen's University & 2,281 & 118 & J.P. Smol & 300 & 48 & 27,445 & 3 & 30 & 66 & 150 \\
\hline Queen's University of Belfast & 2,335 & 113 & R.W. Elwood & 141 & 177 & 1,075 & 204 & 20 & 172 & 95 \\
\hline Queensland University of Technology & 567 & 219 & P.B. Mather & 79 & 280 & 611 & 271 & 12 & 283 & 102 \\
\hline Radboud University, Nijmegen & 2,021 & 130 & G. Van Der Velde & 181 & 122 & 1,627 & 146 & 24 & 123 & 150 \\
\hline Rensselaer Polytechnic Institute & 344 & 248 & J.P. Ferris & 161 & 140 & 1,119 & 201 & 17 & 228 & 150 \\
\hline Rheinisch Westfalische Technische Hochschule Aach & 643 & 214 & R. Fischer & 240 & 81 & 3,361 & 52 & 36 & 35 & 150 \\
\hline Rheinische Friedrich Wilhelms Universitat Bonn & 4,093 & 59 & C. Sengonca & 85 & 271 & 255 & 318 & 8 & 311 & 43 \\
\hline Rice University & 650 & 213 & D.C. Queller & 125 & 197 & 2,170 & 107 & 25 & 109 & 95 \\
\hline Rochester Institute of Technology & 85 & 319 & A.A. Batabyal & 112 & 218 & 176 & 327 & 8 & 311 & 19 \\
\hline Royal Institute of Technology, KTH & 588 & 216 & A.K. Borg-Karlson & 83 & 273 & 845 & 241 & 21 & 162 & 127 \\
\hline Royal Melbourne Institute of Technology & 430 & 234 & A. J. Sinclair & 211 & 99 & 2,048 & 114 & 22 & 149 & 150 \\
\hline Rutgers & \begin{tabular}{l|}
5,565 \\
\end{tabular} & 33 & C.T. Ho & 402 & 24 & 5,841 & 25 & 37 & 30 & 150 \\
\hline Saint-Petersburg State University & 804 & 199 & A.D. Nozdrachev & 247 & 75 & 157 & 330 & 6 & 328 & 150 \\
\hline San Diego State University & 1,099 & 184 & J.B. Zedler & 113 & 216 & 1,818 & 130 & 27 & 90 & 100 \\
\hline Sapienza University of Rome & 0 & 348 & & 0 & 348 & 0 & 348 & 0 & 346 & 0 \\
\hline Sciences Po Paris & 4 & 347 & M.C. Smounts & 3 & 347 & 1 & 347 & 1 & 345 & 1 \\
\hline Seoul National University & 2,886 & 83 & I.K. Han & 237 & 85 & 1,013 & 217 & 17 & 228 & 150 \\
\hline Shanghai Jiao Tong University & 914 & 191 & K. Tang & 189 & 114 & 673 & 264 & 13 & 272 & 150 \\
\hline Simon Fraser University & 2,529 & 107 & J.H. Borden & 242 & 79 & 1,348 & 173 & 21 & 162 & 150 \\
\hline
\end{tabular}




\begin{tabular}{|c|c|c|c|c|c|c|c|c|c|c|}
\hline Stanford University & 4,270 & 54 & M.W. Feldman & 279 & 61 & 5,448 & 27 & 35 & 44 & 150 \\
\hline State University of New York Buffalo & 14 & 345 & K.M. Frothingham & 5 & 346 & 64 & 340 & 3 & 339 & 7 \\
\hline Stockholm University & 2,717 & 94 & C. Wiklund & 122 & 201 & 1,794 & 131 & 21 & 162 & 98 \\
\hline Stony Brook University & 2,612 & 104 & W.L. Jungers & 115 & 214 & 1,324 & 177 & 19 & 193 & 137 \\
\hline Syracuse University & 175 & 280 & C.T. Driscoll & 284 & 56 & 4,518 & 36 & 37 & 30 & 150 \\
\hline Tartu University (University of Tartu) & 1,107 & 183 & M. Zobel & 88 & 264 & 1,596 & 148 & 21 & 162 & 150 \\
\hline Technical University of Denmark & 2,653 & 97 & S.R. Jensen & 171 & 128 & 1,222 & 186 & 20 & 172 & 150 \\
\hline Technion & 1,288 & 170 & M.R. Warburg & 96 & 244 & 222 & 321 & 5 & 333 & 50 \\
\hline Technische Universität Berlin & 2,214 & 121 & F. Bohlmann & 548 & 9 & 3,273 & 56 & 0 & 346 & 150 \\
\hline Technische Universitat Chemnitz & 11 & 346 & K.H. Hoffmann & 125 & 197 & 735 & 258 & 15 & 257 & 145 \\
\hline Technische Universität Dresden & 1,251 & 173 & J. Ludwig-Muller & 80 & 279 & 798 & 245 & 22 & 149 & 150 \\
\hline Technische Universität München & 4,055 & 61 & M. Kirchgessner & 475 & 14 & 1,074 & 205 & 12 & 283 & 150 \\
\hline Tel Aviv University & 2,718 & 93 & Y. Loya & 143 & 173 & 1,626 & 147 & 23 & 134 & 150 \\
\hline Texas A\&M University & 10,339 & 9 & S.B. Vinson & 268 & 66 & 1,861 & 128 & 18 & 207 & 150 \\
\hline Texas Tech & 2,298 & 116 & H.T. Nguyen & 147 & 163 & 2,054 & 113 & 31 & 60 & 150 \\
\hline Tohoku University & 4,012 & 62 & H. Ohashi & 161 & 140 & 448 & 287 & 8 & 311 & 128 \\
\hline Tokyo Institute of Technology & 764 & 201 & N. Okada & 177 & 125 & 2,665 & 83 & 36 & 35 & 150 \\
\hline Trinity College Dublin & 1,228 & 175 & M.J. Gibney & 223 & 93 & 2,781 & 78 & 28 & 82 & 150 \\
\hline Tsinghua University & 731 & 204 & B. Liu & 94 & 250 & 777 & 252 & 23 & 134 & 27 \\
\hline Tufts University & 2,288 & 117 & R.M. Russell & 287 & 53 & 4,993 & 30 & 35 & 44 & 150 \\
\hline Universidad Autonoma de Madrid & 1,662 & 150 & F. Lara & 119 & 206 & 279 & 312 & 10 & 306 & 150 \\
\hline Universidad de Chile & 2,318 & 115 & H.N. Niemeyer & 202 & 103 & 1,248 & 181 & 17 & 228 & 150 \\
\hline Universidad de Granada & 1,662 & 150 & F. Lara & 119 & 206 & 279 & 312 & 10 & 306 & 150 \\
\hline Universidad del País Vasco & 1,129 & 181 & J.I. Garcia & 55 & 314 & 542 & 276 & 19 & 193 & 69 \\
\hline Universidad Nacional Autónoma de México ... & 5,715 & 30 & H. Brailovsky & 105 & 229 & 40 & 343 & 3 & 339 & 18 \\
\hline Universidad Politecnica de Madrid & 1,539 & 160 & L. Gil & 110 & 220 & 852 & 239 & 19 & 193 & 137 \\
\hline Universidade de São Paulo & 10,684 & 8 & F.M. Lajolo & 139 & 180 & 798 & 245 & 14 & 263 & 145 \\
\hline Universidade Estadual de Campinas & 248 & 264 & N. Bragagnolo & 37 & 329 & 138 & 336 & 8 & 311 & 42 \\
\hline Università degli Studi di Firenze & 2,636 & 100 & F. Gherardi & 145 & 167 & 790 & 249 & 20 & 172 & 150 \\
\hline Università degli Studi di Padova & 2,963 & 80 & A. Minelli & 110 & 220 & 1,137 & 195 & 16 & 242 & 92 \\
\hline Universita Di Bologna & 3,231 & 76 & L. Alibardi & 156 & 149 & 356 & 306 & 21 & 162 & 56 \\
\hline Universita di Pisa & 355 & 247 & A. Savivozzi & 60 & 309 & 496 & 280 & 12 & 283 & 36 \\
\hline Universitat Autonoma de Barcelona & 2,851 & 85 & J. Penuelas & 234 & 87 & 3,961 & 44 & 41 & 22 & 150 \\
\hline Universitat Bielefeld & 1,081 & 186 & K.J. Dietz & 143 & 173 & 2,406 & 96 & 32 & 55 & 150 \\
\hline Universität Bremen & 1,146 & 179 & V.B. Meyer & 199 & 106 & 786 & 251 & 13 & 272 & 150 \\
\hline Universitat d'Alacant & 696 & 206 & P. Sanchez & 57 & 310 & 473 & 284 & 15 & 257 & 95 \\
\hline
\end{tabular}




\begin{tabular}{|c|c|c|c|c|c|c|c|c|c|c|}
\hline Universitat de València & 2,629 & 101 & J.A. Raga & 134 & 184 & 669 & 265 & 13 & 272 & 150 \\
\hline Universität Frankfurt am Main & 2,023 & 129 & A. Mosandi & 191 & 110 & 875 & 234 & 14 & 263 & 150 \\
\hline Universität Freiburg & 2,640 & 99 & H. Renneberg & 238 & 83 & 2,966 & 72 & 32 & 55 & 150 \\
\hline Universitat Hamburg & 276 & 256 & H. Steinhart & 271 & 64 & 2,353 & 99 & 26 & 99 & 150 \\
\hline Universität Karlsruhe & 687 & 208 & M. Metzler & 168 & 132 & 1,490 & 161 & 21 & 162 & 150 \\
\hline Universitat Leipzig & 72 & 326 & K. Arnold & 167 & 133 & 1,745 & 138 & 26 & 99 & 150 \\
\hline Universitat Munster (Westfälische Wilhelms-Un & 191 & 278 & T. Hofmann & 363 & 34 & 6,164 & 22 & 42 & 21 & 150 \\
\hline Universitat Politecnica de Catalunya & 98 & 312 & L. Candela & 19 & 340 & 51 & 342 & 3 & 339 & 37 \\
\hline Universität Regensburg & 1,137 & 180 & J. Heinze & 150 & 157 & 1,160 & 192 & 25 & 109 & 138 \\
\hline Universität Stuttgart & 428 & 238 & A. Bardossey & 150 & 157 & 154 & 332 & 15 & 257 & 126 \\
\hline Universitat Trier & 250 & 263 & T. Schmitt & 79 & 280 & 509 & 279 & 17 & 228 & 150 \\
\hline Universität Tübingen & 2,697 & 96 & F. Oberwinkler & 193 & 109 & 1,335 & 174 & 19 & 193 & 150 \\
\hline Universitat Wien (University of Vienna) & 4,108 & 58 & G. Buchbauer & 243 & 78 & 1,057 & 208 & 14 & 263 & 150 \\
\hline Universitat Zu Koln & 2,018 & 132 & M. Melkonian & 145 & 167 & 1,531 & 151 & 20 & 172 & 142 \\
\hline Université Catholique de Louvain & 1,857 & 143 & S. Lutts & 68 & 299 & 931 & 229 & 17 & 228 & 98 \\
\hline Universite de Liege & 2,329 & 114 & C. Kevers & 95 & 247 & 726 & 260 & 17 & 228 & 134 \\
\hline Université de Montréal & 2,384 & 110 & A. Barhard & 95 & 247 & 857 & 237 & 17 & 228 & 75 \\
\hline Université de Nice Sophia Antipolis & 685 & 209 & A. Meinesz & 62 & 306 & 714 & 262 & 19 & 193 & 150 \\
\hline Universite Laval & 4,814 & 46 & C. Bouchard & 701 & 3 & 29,931 & 2 & 63 & 3 & 150 \\
\hline Universite Libre de Bruxelles & 1,608 & 153 & J.C. Gregoire & 43 & 327 & 277 & 314 & 8 & 311 & 82 \\
\hline Université Paris Sorbonne & 126 & 297 & T. Pradeu & 9 & 344 & 14 & 345 & 3 & 339 & 1 \\
\hline Universite Paris-Sud 11 & 2,383 & 111 & A. Cave & 239 & 82 & 1,135 & 197 & 16 & 242 & 150 \\
\hline Université Pierre et Marie Curie & 3,777 & 64 & A.P. Moller & 599 & 6 & 19,973 & 4 & 58 & 6 & 150 \\
\hline Universiti Malaya (University of Malaya) & 811 & 198 & S.M. Phang & 55 & 314 & 346 & 308 & 11 & 294 & 114 \\
\hline University College Cork & 2,466 & 108 & A.L. Kelly & 196 & 107 & 2,684 & 82 & 24 & 123 & 150 \\
\hline University College Dublin & 2,613 & 103 & D.W. Sun & 208 & 101 & 1,513 & 158 & 27 & 90 & 147 \\
\hline University College London & 4,071 & 60 & D.U. Pfeiffer & 158 & 148 & 1,443 & 166 & 20 & 172 & 150 \\
\hline University do Porto & 104 & 310 & P.B. Andrade & 152 & 154 & 1,070 & 206 & 25 & 109 & 150 \\
\hline University of Aberdeen & 3,752 & 67 & P.Smith & 94 & 250 & 1,840 & 129 & 27 & 90 & 150 \\
\hline University of Adelaide & 4,605 & 52 & R.D. Graham & 131 & 187 & 1,217 & 187 & 18 & 207 & 150 \\
\hline University of Alabama & 1,924 & 136 & J.B. MCClintock & 161 & 140 & 1,386 & 170 & 20 & 172 & 150 \\
\hline University of Alberta & 6,996 & 20 & L.M. Dosdall & 77 & 285 & 228 & 320 & 11 & 294 & 99 \\
\hline University of Amsterdam & 2,981 & 79 & M.W. Sabelis & 187 & 117 & 2,324 & 102 & 26 & 99 & 150 \\
\hline University of Antwerp & 2,170 & 122 & R. Ceulemans & 212 & 98 & 3,995 & 42 & 35 & 44 & 150 \\
\hline University of Arizona & 6,904 & 22 & D.V. Lightner & 160 & 145 & 1,238 & 183 & 29 & 72 & 150 \\
\hline University of Athens & 1,262 & 171 & B. Galatis & 69 & 296 & 358 & 305 & 12 & 283 & 33 \\
\hline
\end{tabular}




\begin{tabular}{|c|c|c|c|c|c|c|c|c|c|c|}
\hline University of Auckland & 2,590 & 106 & X.D. Chen & 414 & 22 & 1,935 & 122 & 25 & 109 & 150 \\
\hline University of Barcelona & 3,589 & 68 & J.L. Araus & 100 & 237 & 1,032 & 214 & 22 & 149 & 150 \\
\hline University of Basel & 1,566 & 158 & T. Boller & 287 & 53 & 8,226 & 15 & 48 & 12 & 150 \\
\hline University of Bath & 33 & 339 & W. Engstrom & 86 & 269 & 387 & 300 & 8 & 311 & 117 \\
\hline University of Bergen & 2,737 & 92 & V. Torsvik & 45 & 324 & 2,614 & 84 & 23 & 134 & 73 \\
\hline University of Bern & 109 & 308 & J.W. Blum & 263 & 67 & 1,746 & 137 & 26 & 99 & 150 \\
\hline University of Birmingham & 140 & 292 & J.F. Kennedy & 261 & 69 & 1,585 & 149 & 18 & 207 & 150 \\
\hline University of Bristol & 5,326 & 36 & A.I. Houston & 182 & 119 & 3,301 & 55 & 26 & 99 & 114 \\
\hline University of British Columbia & 8,788 & 16 & D.D. Kitts & 144 & 170 & 142 & 335 & 23 & 134 & 131 \\
\hline University of Calgary & 231 & 267 & W.A. Kerr & 69 & 296 & 129 & 337 & 7 & 323 & 46 \\
\hline University of California, Berkley & 1,346 & 166 & J.E. Casida & 586 & 7 & 6,715 & 19 & 29 & 72 & 150 \\
\hline University of California, Davis & 18,452 & 1 & B.D. Hammock & 623 & 5 & 11,246 & 11 & 41 & 22 & 150 \\
\hline University of California, Irvine & 130 & 295 & M.L. Goulden & 78 & 283 & 2,776 & 79 & 28 & 82 & 150 \\
\hline University of California, Los Angeles & 4,727 & 48 & P.S. Nobel & 190 & 112 & 1,458 & 164 & 17 & 228 & 114 \\
\hline University of California, Riverside & 5,863 & 28 & M.S. Mulla & 190 & 112 & 1,039 & 212 & 15 & 257 & 128 \\
\hline University of California, San Diego & 149 & 289 & R.T. Carson & 56 & 312 & 2,584 & 86 & 20 & 172 & 124 \\
\hline University of California, San Francisco & 41 & 337 & E.A. Holly & 166 & 135 & 3,356 & 53 & 36 & 35 & 150 \\
\hline University of California, Santa Barbara & 113 & 305 & D.A. Cleveland & 26 & 337 & 156 & 331 & 8 & 311 & 36 \\
\hline University of California, Santa Cruz & 1,812 & 145 & W. Cheng & 53 & 319 & 1,443 & 166 & 20 & 172 & 74 \\
\hline University of Cambridge & 530 & 222 & C.J.C. Phillips & 137 & 182 & 1,054 & 209 & 18 & 207 & 150 \\
\hline University of Canterbury & 196 & 276 & J.A. Gerrard & 75 & 289 & 493 & 282 & 18 & 207 & 114 \\
\hline University of Cape Town & \begin{tabular}{l|l}
3,471 \\
\end{tabular} & 70 & L. London & 87 & 265 & 390 & 298 & 11 & 294 & 150 \\
\hline University of Central Florida & 457 & 232 & H.W. Daniell & 135 & 183 & 2,923 & 75 & 36 & 35 & 150 \\
\hline University of Chicago & 36 & 338 & C.S. Yuan & 171 & 128 & 2,463 & 92 & 29 & 72 & 150 \\
\hline University of Cincinnati & 1,583 & 155 & G.W. Uetz & 74 & 290 & 1,185 & 190 & 17 & 228 & 54 \\
\hline University of Colorado at Boulder & 226 & 269 & R.K. Monson & 143 & 173 & 3,368 & 51 & 36 & 35 & 150 \\
\hline University of Connecticut & 3,278 & 74 & C. Faustman & 67 & 302 & 611 & 271 & 16 & 242 & 104 \\
\hline University of Copenhagen & 10,240 & 11 & L.H. Skisted & 350 & 36 & 3,047 & 65 & 32 & 55 & 150 \\
\hline University of Delaware & 488 & 227 & W.F. Ritter & 109 & 223 & 403 & 296 & 3 & 339 & 45 \\
\hline University of Dundee & 1,583 & 155 & J.A. Raven & 263 & 67 & 3,914 & 46 & 32 & 55 & 150 \\
\hline University of Edinburgh & 316 & 252 & S. Brotherstone & 78 & 283 & 868 & 236 & 18 & 207 & 96 \\
\hline University of Florida & 15,314 & 3 & W.W. Thatcher & 306 & 47 & 3,621 & 48 & 32 & 55 & 150 \\
\hline University of Geneva & 120 & 303 & A.M. Shelton & 120 & 205 & 1,712 & 140 & 22 & 149 & 150 \\
\hline University of Georgia & 3,239 & 75 & G. Hoogenboom & 161 & 140 & 1,043 & 211 & 17 & 228 & 150 \\
\hline University of Ghent & 6,523 & 26 & P. Sorgeloos & 283 & 57 & 2,042 & 116 & 28 & 82 & 150 \\
\hline University of Glasgow & 4,003 & 63 & G.D. Ruxton & 244 & 77 & 2,157 & 110 & 24 & 123 & 150 \\
\hline
\end{tabular}




\begin{tabular}{|c|c|c|c|c|c|c|c|c|c|c|}
\hline University of Gothenburg & 94 & 315 & L. Lissner & 155 & 151 & 4,417 & 37 & 31 & 60 & 150 \\
\hline University of Groningen & 289 & 253 & J.P. Bakker & 147 & 163 & 2,584 & 86 & 30 & 66 & 150 \\
\hline University of Helsinki & 6,928 & 21 & V. Piironen & 103 & 233 & 1,351 & 172 & 24 & 123 & 150 \\
\hline University of Hong Kong & 169 & 284 & F. Chen & 184 & 118 & 1,473 & 162 & 25 & 109 & 150 \\
\hline University of Houston & 24 & 343 & F.L. Castille & 17 & 341 & 175 & 328 & 4 & 338 & 33 \\
\hline University of Illinois & 10,252 & 10 & D.H. Baker & 401 & 26 & 3,008 & 70 & 22 & 149 & 150 \\
\hline University of Illinois, Chicago & 2,151 & 124 & G.A. Cordell & 307 & 46 & 3,260 & 57 & 22 & 149 & 150 \\
\hline University of Indonesia & 100 & 311 & W. Schultink & 52 & 321 & 729 & 259 & 16 & 242 & 93 \\
\hline University of Iowa & 60 & 331 & S. Ramaswamy & 65 & 304 & 1,948 & 121 & 25 & 109 & 150 \\
\hline University of Kansas & 153 & 288 & K.P. Price & 53 & 319 & 651 & 267 & 14 & 263 & 75 \\
\hline University of Kentucky & 1,576 & 157 & Y.L. Xiong & 122 & 201 & 736 & 257 & 18 & 207 & 135 \\
\hline University of Lausanne & 74 & 324 & K. Hostettmann & 417 & 20 & 4,018 & 41 & 29 & 72 & 150 \\
\hline University of Leeds & 430 & 234 & E. Dickinson & 317 & 41 & 3,145 & 60 & 34 & 51 & 150 \\
\hline University of Leicester & 1,370 & 165 & G.C. Whitelam & 108 & 224 & 1,951 & 120 & 27 & 90 & 150 \\
\hline University of Liverpool & 200 & 274 & R.H. Marrs & 138 & 181 & 993 & 223 & 18 & 207 & 126 \\
\hline University of Ljubljana & 1,936 & 135 & F. Stampar & 83 & 273 & 300 & 310 & 11 & 294 & 51 \\
\hline University of London (Kings College of London) & 12,798 & 4 & P.D. Moore & 206 & 102 & 469 & 285 & 6 & 328 & 19 \\
\hline University of Manchester & 2,750 & 90 & S.G. Oliver & 247 & 75 & 651 & 267 & 39 & 25 & 150 \\
\hline University of Manitoba & 3,767 & 65 & D.S. Jayas & 231 & 90 & 1,102 & 203 & 18 & 207 & 137 \\
\hline University of Maryland & 5,569 & 32 & R.R. Colwell & 488 & 13 & 8,320 & 13 & 35 & 44 & 150 \\
\hline University of Maryland Baltimore County & 1,901 & 138 & T.W. Cronin & 98 & 240 & 1,394 & 169 & 23 & 134 & 112 \\
\hline University of Massachusetts & 981 & 189 & D.J. McClements & 296 & 51 & 2,448 & 94 & 36 & 35 & 150 \\
\hline University of Melbourne & 5,154 & 40 & M.A. Elgar & 148 & 161 & 1,777 & 133 & 23 & 134 & 150 \\
\hline University of Miami & 121 & 302 & D. Letson & 27 & 335 & 159 & 329 & 7 & 323 & 59 \\
\hline University of Michigan & 229 & 268 & I. Perfecto & 71 & 293 & 961 & 226 & 18 & 207 & 95 \\
\hline University of Minnesota & 10,767 & 6 & P.B. Reich & 286 & 55 & 7,405 & 17 & 50 & 10 & 150 \\
\hline University of Missouri & 6,551 & 25 & G.E. Rottinghaus & 189 & 114 & 1,419 & 168 & 20 & 172 & 150 \\
\hline University of Nebraska & 5,610 & 31 & M.A. Hanna & 215 & 95 & 2,479 & 91 & 26 & 99 & 150 \\
\hline University of New Hampshire & 1,941 & 134 & T.D. Kocher & 95 & 247 & 2,769 & 80 & 31 & 60 & 149 \\
\hline University of New Mexico & 120 & 303 & R.P. Berrens & 65 & 304 & 334 & 309 & 12 & 283 & 63 \\
\hline University of New South Wales & 149 & 289 & B.E. Medlyn & 29 & 334 & 809 & 243 & 18 & 207 & 88 \\
\hline University of North Carolina, Chapel Hill & 3,497 & 69 & K.H. Lee & 417 & 20 & 4,846 & 33 & 39 & 25 & 150 \\
\hline University of North Texas & 50 & 335 & P.F. Hudak & 160 & 145 & 794 & 248 & 10 & 306 & 91 \\
\hline University of Notre Dame & 75 & 323 & J.L. Tank & 70 & 294 & 1,044 & 210 & 22 & 149 & 121 \\
\hline University of Nottingham & 817 & 197 & A.J. Taylor & 119 & 206 & 1,128 & 199 & 20 & 172 & 150 \\
\hline University of Oklahoma & 124 & 299 & Y. Luo & 89 & 263 & 1,757 & 136 & 27 & 90 & 150 \\
\hline
\end{tabular}




\begin{tabular}{|c|c|c|c|c|c|c|c|c|c|c|}
\hline University of Oregon & 133 & 293 & R.W. Smiley & 33 & 330 & 268 & 317 & 10 & 306 & 41 \\
\hline University of Oslo & 276 & 256 & N.C. Stenseth & 339 & 37 & 4,699 & 35 & 45 & 17 & 150 \\
\hline University of Otago & 364 & 245 & C.R. Townsend & 116 & 210 & 3,106 & 63 & 25 & 109 & 99 \\
\hline University of Ottawa & 199 & 275 & J.T. Arnason & 225 & 92 & 2,231 & 105 & 22 & 149 & 150 \\
\hline University of Oxford & 327 & 250 & D.W. MacDonald & 383 & 30 & 4,322 & 38 & 35 & 44 & 150 \\
\hline University of Pennsylvania & 69 & 328 & L. McCauley & 55 & 314 & 421 & 293 & 17 & 228 & 96 \\
\hline University of Pittsburgh & 52 & 333 & R. Bentley & 126 & 194 & 1,246 & 182 & 11 & 294 & 78 \\
\hline University of Quebec & 847 & 195 & P. Savoie & 84 & 272 & 185 & 326 & 8 & 311 & 85 \\
\hline University of Queensland & 1,629 & 152 & M.P. Zalucki & 155 & 151 & 998 & 220 & 17 & 228 & 150 \\
\hline University of Reading & 4,673 & 51 & J.B. Harborne & 275 & 63 & 3,046 & 66 & 16 & 242 & 150 \\
\hline University of Rochester & 29 & 341 & D.A. Cory-Slechta & 123 & 200 & 2,093 & 111 & 25 & 109 & 150 \\
\hline University of Saskatchewan & 4,958 & 44 & A. Vandenberg & 93 & 255 & 202 & 323 & 8 & 311 & 97 \\
\hline University of Science and Technology of China & 271 & 258 & Y. Zhang & 321 & 39 & 1,676 & 142 & 19 & 193 & 150 \\
\hline University of Sheffield & 3,178 & 78 & K.J. Gaston & 442 & 16 & 7,091 & 18 & 54 & 7 & 150 \\
\hline University of South Carolina & 1,707 & 149 & A. L. Huges & 280 & 59 & 6,211 & 21 & 37 & 30 & 150 \\
\hline University of South Florida & 97 & 313 & P. Stiling & 93 & 255 & 1,329 & 175 & 21 & 162 & 61 \\
\hline University of Southampton & 210 & 272 & D. Goulson & 129 & 189 & 1,295 & 178 & 24 & 123 & 146 \\
\hline University of Southern California & 57 & 332 & M.C. Yu & 260 & 70 & 8,256 & 14 & 47 & 14 & 150 \\
\hline University of St Andrews & 110 & 307 & N.P. Botting & 77 & 285 & 1,020 & 216 & 17 & 228 & 137 \\
\hline University of Surrey & 167 & 285 & M.N. Clifford & 113 & 216 & 2,067 & 112 & 25 & 109 & 150 \\
\hline University of Sussex & 174 & 281 & I. Scoones & 57 & 310 & 771 & 253 & 11 & 294 & 46 \\
\hline University of Sydney & 6,466 & 27 & R. Shine & 567 & 8 & 14,222 & 5 & 44 & 19 & 150 \\
\hline University of Technology, Sydney & 68 & 329 & D. Eamus & 114 & 215 & 1,521 & 154 & 25 & 109 & 136 \\
\hline University of Tennessee Knoxville & 990 & 188 & A.R. Womac & 70 & 294 & 146 & 334 & 6 & 328 & 104 \\
\hline University of Texas at Austin & 83 & 320 & U.G. Mueller & 81 & 278 & 1,519 & 155 & 22 & 149 & 114 \\
\hline University of Tokyo & 2,859 & 84 & A. Isogai & 388 & 29 & 3,019 & 68 & 28 & 82 & 150 \\
\hline University of Toronto & 6,896 & 23 & N. Mrosovsky & 182 & 119 & 1,972 & 119 & 27 & 90 & 150 \\
\hline University of Tsukuba & 64 & 330 & T. Maekawa & 66 & 303 & 390 & 298 & 12 & 283 & 111 \\
\hline University of Twente & 29 & 341 & A.Y. Hoekstra & 32 & 332 & 150 & 333 & 8 & 311 & 45 \\
\hline University of Utah & 2,365 & 112 & J.R. Ehleringer & 271 & 64 & 5,870 & 24 & 43 & 20 & 150 \\
\hline University of Vermont & 1,798 & 147 & P.S. Kindstedt & 46 & 323 & 437 & 290 & 13 & 272 & 46 \\
\hline University of Victoria & 131 & 294 & G.C. Van Kooten & 94 & 250 & 627 & 270 & 14 & 263 & 88 \\
\hline University of Virginia & 126 & 297 & J.D. Fuentes & 54 & 317 & 1,651 & 144 & 21 & 162 & 150 \\
\hline University of Warwick & 144 & 291 & G.D. Bending & 44 & 326 & 922 & 231 & 20 & 172 & 60 \\
\hline University of Washington & 416 & 239 & D.P. Lettenmaier & 233 & 88 & 4,039 & 40 & 40 & 24 & 150 \\
\hline University of Waterloo & 221 & 271 & J. Pawliszyn & 399 & 27 & 5,999 & 23 & 52 & 9 & 150 \\
\hline
\end{tabular}




\begin{tabular}{|c|c|c|c|c|c|c|c|c|c|c|}
\hline University of Western Australia & 5,155 & 39 & K. Sivasthamparan & 238 & 83 & 1,519 & 155 & 19 & 193 & 150 \\
\hline University of Western Ontario & 2,104 & 126 & N.P.A. Nuner & 128 & 192 & 1,890 & 126 & 26 & 99 & 150 \\
\hline University of Wisconsin & 2,747 & 91 & H.F. Deluca & 841 & 1 & 13,121 & 8 & 36 & 35 & 150 \\
\hline University of Wollongong & 87 & 318 & D.W.T. Griffith & 108 & 224 & 842 & 242 & 18 & 207 & 150 \\
\hline University of York & 279 & 255 & I.A. Graham & 91 & 259 & 1,509 & 159 & 29 & 72 & 150 \\
\hline University of Zurich & 240 & 266 & B. Schmid & 178 & 124 & 3,988 & 43 & 36 & 35 & 150 \\
\hline Univesitas Gadjah Mada & 171 & 282 & T. Jacob & 16 & 343 & 353 & 307 & 7 & 323 & 45 \\
\hline Uppsala University & 522 & 223 & L. Andersson & 200 & 105 & 3,915 & 45 & 33 & 53 & 150 \\
\hline Utah State & 3,301 & 72 & C.M.U. Neale & 87 & 265 & 453 & 286 & 11 & 294 & 146 \\
\hline Utrecht University & 5,342 & 35 & A.C. Beynen & 434 & 18 & 2,759 & 81 & 19 & 193 & 150 \\
\hline Vanderbilt University & 71 & 327 & R.D. Tanner & 93 & 255 & 280 & 311 & 7 & 323 & 147 \\
\hline Victoria University of Wellington & 51 & 334 & M. Zhang & 68 & 299 & 73 & 339 & 5 & 333 & 48 \\
\hline Vienna University of Technology & 73 & 325 & C.P. Kubicek & 250 & 74 & 2,402 & 97 & 29 & 72 & 150 \\
\hline Virginia Polytechnic Institute & 6,698 & 24 & S. Mostaghimi & 116 & 210 & 916 & 233 & 13 & 272 & 150 \\
\hline Vrije Universiteit, Brussels & 754 & 203 & N. Koedam & 102 & 234 & 1,119 & 201 & 25 & 109 & 148 \\
\hline VU University Amsterdam & 2,072 & 127 & H. Schat & 83 & 273 & 1,788 & 132 & 27 & 90 & 27 \\
\hline Wageningen University & 12,684 & 5 & A.G.J. Voragen & 361 & 35 & 4,240 & 39 & 33 & 53 & 150 \\
\hline Wake Forest University & 50 & 335 & T.A. Arcury & 169 & 131 & 1,137 & 195 & 23 & 134 & 150 \\
\hline Waseda University & 32 & 340 & S.Tsuneda & 159 & 147 & 1,365 & 171 & 20 & 172 & 150 \\
\hline Washington State University & 2,071 & 128 & J. Tang & 171 & 128 & 962 & 225 & 25 & 109 & 150 \\
\hline Washington University in St. Louis & 88 & 317 & L.T. Angenent & 38 & 328 & 643 & 269 & 13 & 272 & 70 \\
\hline Wayne State University & 1,253 & 172 & M.Goodman & 177 & 125 & 3,040 & 67 & 30 & 66 & 150 \\
\hline West Virginia University & 282 & 254 & J. Jaczynski & 32 & 332 & 62 & 341 & 8 & 311 & 30 \\
\hline Yale University & 261 & 260 & X. Lee & 54 & 317 & 1,525 & 153 & 20 & 172 & 109 \\
\hline Yonsei University & 124 & 299 & J.K. Hwang & 92 & 258 & 739 & 256 & 18 & 207 & 150 \\
\hline York University & 76 & 322 & J.R. Miller & 105 & 229 & 990 & 224 & 20 & 172 & 150 \\
\hline Zhejiang University & 4,948 & 45 & Y. $\mathrm{He}$ & 540 & 10 & 2,574 & 88 & 24 & 123 & 150 \\
\hline
\end{tabular}




\begin{tabular}{|c|c|c|c|c|c|c|c|c|c|c|}
\hline Mathematics Data & $\begin{array}{l}\text { Department } \\
\text { Publications }\end{array}$ & Rank & Most Prolific Author & Published & Rank & Cited & Rank & $\begin{array}{c}\text { H- } \\
\text { Index }\end{array}$ & Rank & $\begin{array}{c}\text { \# of } \\
\text { Coauthors }\end{array}$ \\
\hline Aalto University & 1,954 & 113 & P.R.J. Ostergard & 110 & 208 & 432 & 231 & 11 & 216 & 62 \\
\hline Aarhus University & 654 & 274 & O.E. Bandroff-Nielsen & 75 & 280 & 904 & 147 & 15 & 152 & 54 \\
\hline Arizonia State University & 1,268 & 178 & Y.C. Lai & 268 & 70 & 3,396 & 37 & 32 & 26 & 150 \\
\hline Ateneo de Manila University & 18 & 344 & J.P.C. Vergara & 5 & 346 & 19 & 343 & 3 & 334 & 3 \\
\hline Auburn University & 1,473 & 160 & C.A. Rodger & 89 & 250 & 187 & 289 & 7 & 286 & 61 \\
\hline Australian National University & 3,116 & 47 & P. Hall & 185 & 118 & 1,805 & 81 & 24 & 72 & 145 \\
\hline Boston College & 365 & 321 & G.J. Kalman & 120 & 196 & 380 & 238 & 12 & 202 & 72 \\
\hline Boston University & 2,425 & 78 & H.E. Stanley & 480 & 13 & 10,348 & 3 & 57 & 2 & 150 \\
\hline Brandeis University & 860 & 242 & C. Blocker & 512 & 10 & 10,281 & 4 & 46 & 4 & 150 \\
\hline Brigham Young University & 475 & 306 & K.L. Kuttler & 46 & 321 & 148 & 305 & 9 & 249 & 24 \\
\hline Brown University & 2,716 & 66 & P.V. Van Hentenryck & 127 & 188 & 774 & 164 & 12 & 202 & 94 \\
\hline California Institute of Technology (Calt... & 3,986 & 28 & R. Kass & 552 & 5 & 6,497 & 12 & 32 & 26 & 150 \\
\hline Cardiff University & 1,114 & 197 & B.M. Brown & 48 & 319 & 134 & 308 & 7 & 286 & 37 \\
\hline Carnegie Mellon University & 4,267 & 23 & A. Frieze & 227 & 90 & 1,754 & 84 & 16 & 138 & 127 \\
\hline Case Western Reserve University & 1,156 & 191 & D. Calvetti & 89 & 250 & 444 & 227 & 14 & 164 & 42 \\
\hline Chalmers University of Technology & 1,651 & 147 & O. Haggstrom & 64 & 295 & 360 & 244 & 13 & 187 & 58 \\
\hline Charles University & 2,511 & 72 & M. Begalli & 311 & 50 & 2,509 & 56 & 28 & 42 & 150 \\
\hline Chinese University of Hong Kong & 1,387 & 169 & J. Wei & 191 & 109 & 689 & 178 & 23 & 77 & 69 \\
\hline Chulalongkorn University & 253 & 329 & P. Chongstitvatana & 46 & 321 & 80 & 325 & 3 & 334 & 49 \\
\hline City University of Hong Kong & 2,886 & 54 & G.Chen & 681 & 1 & 14,794 & 1 & 61 & 1 & 150 \\
\hline City University of New York & 195 & 332 & V.Y. Pan & 149 & 161 & 474 & 222 & 10 & 232 & 63 \\
\hline Colorado State University & 520 & 297 & G.D. Taylor & 42 & 327 & 35 & 336 & 1 & 344 & 29 \\
\hline Columbia University & 3,294 & 42 & H. Wozniakowski & 115 & 201 & 574 & 196 & 14 & 164 & 37 \\
\hline Cornell University & 4,760 & 19 & J.P. Alexander & 399 & 25 & 4,520 & 17 & 35 & 19 & 150 \\
\hline Curtin University of Technology & 574 & 286 & $\mathrm{Y} . \mathrm{Wu}$ & 98 & 228 & 110 & 320 & 5 & 321 & 129 \\
\hline Dalhousie University & 1,223 & 186 & J.M. Borwein & 187 & 116 & 1,234 & 115 & 16 & 138 & 114 \\
\hline \begin{tabular}{|l|} 
Dartmouth College \\
\end{tabular} & 977 & 218 & M. Arkowitz & 25 & 342 & 29 & 341 & 3 & 334 & 8 \\
\hline Delft University of Technology & 2,668 & 69 & H.W.J. Blote & 161 & 138 & 1,925 & 77 & 19 & 108 & 110 \\
\hline Drexel University & 758 & 258 & J. Wimp & 42 & 327 & 132 & 309 & 4 & 327 & 50 \\
\hline Duke University & 2,351 & 87 & P.K. Agarwal & 253 & 76 & 4,245 & 21 & 21 & 91 & 150 \\
\hline Durham University & 1,345 & 171 & W.J. Zakrewski & 173 & 130 & 568 & 198 & 13 & 187 & 88 \\
\hline Ecole Normale Supérieure de Lyon & 961 & 225 & D. Serre & 62 & 301 & 376 & 239 & 11 & 216 & 52 \\
\hline École Normale Supérieure, Paris & 1,710 & 138 & B. Berthame & 109 & 210 & 1,225 & 118 & 22 & 80 & 101 \\
\hline École Polytechnique & 2,744 & 65 & A. Ramani & 167 & 134 & 1,049 & 133 & 15 & 152 & 85 \\
\hline
\end{tabular}




\begin{tabular}{|c|c|c|c|c|c|c|c|c|c|c|}
\hline Ecole Polytechnique Fédérale de Lausanne & 2,452 & 76 & D. DeWerra & 129 & 184 & 533 & 208 & 8 & 269 & 95 \\
\hline Eindhoven University of Technology & 2,945 & 52 & W.M.P. Van Der Aalst & 193 & 107 & 2,506 & 59 & 31 & 30 & 149 \\
\hline Emory University & 972 & 219 & V. Rodl & 212 & 100 & 650 & 187 & 14 & 164 & 116 \\
\hline Erasmus University Rotterdam & 812 & 250 & P.H. Franses & 177 & 128 & 960 & 140 & 18 & 119 & 105 \\
\hline ETH Zurich (Swiss Federal Institute of Technology) & 4,173 & 25 & J. Frohich & 200 & 104 & 2,315 & 62 & 19 & 108 & 150 \\
\hline Florida International University & 788 & 255 & C. Koulamas & 93 & 238 & 677 & 181 & 12 & 202 & 35 \\
\hline Florida State University & 685 & 270 & I.M. Navon & 129 & 184 & 922 & 145 & 16 & 138 & 150 \\
\hline Freie Universität Berlin & 1,620 & 151 & G.Rote & 88 & 252 & 460 & 225 & 9 & 249 & 111 \\
\hline Friedrich Alexander Universität Erlangen Nürnberg & 2,224 & 92 & K. Strambach & 68 & 287 & 78 & 326 & 3 & 334 & 25 \\
\hline Fudan University & 2,682 & 68 & Y. Wei & 180 & 125 & 350 & 245 & 16 & 138 & 124 \\
\hline Georg August Universität Göttingen & 1,637 & 149 & R.Kress & 95 & 233 & 512 & 212 & 14 & 164 & 55 \\
\hline George Mason University & 351 & 325 & R. Lohner & 181 & 122 & 1,351 & 106 & 21 & 91 & 119 \\
\hline George Washington University & 1,003 & 215 & S. Kotz & 235 & 84 & 540 & 206 & 10 & 232 & 54 \\
\hline Georgetown University & 374 & 319 & D.C. Chang & 49 & 317 & 118 & 316 & 7 & 286 & 35 \\
\hline Georgia Institute of Technology & 4,236 & 24 & A. Shaprio & 175 & 129 & 1,701 & 88 & 20 & 99 & 150 \\
\hline Georgia State University & 652 & 275 & Y. Pan & 259 & 74 & 1,192 & 120 & 22 & 80 & 150 \\
\hline Goteborg University & 972 & 219 & O. Haggstrom & 63 & 299 & 338 & 248 & 13 & 187 & 59 \\
\hline Harvard University & 3,835 & 31 & A. Hocker & 377 & 33 & 3,470 & 31 & 29 & 35 & 150 \\
\hline Hebrew University of Jerusalem & 3,681 & 34 & S. Shelah & 521 & 7 & 15 & 344 & 11 & 216 & 150 \\
\hline Heidelberg Universität & 2,089 & 105 & J.W. Gary & 592 & 4 & 8,695 & 10 & 39 & 10 & 150 \\
\hline Hokkaido University & 1,731 & 134 & A. Arai & 59 & 303 & 241 & 271 & 7 & 286 & 8 \\
\hline Hong Kong Polytechnic University & 1,975 & 112 & X.Q. Yang & 163 & 136 & 721 & 174 & 16 & 138 & 94 \\
\hline Hong Kong University of Science \& Techno... & 1,856 & 122 & C.C. Yang & 76 & 274 & 159 & 300 & 6 & 301 & 43 \\
\hline Humboldt-Universität zu Berlin & 2,425 & 78 & W.B. Ebeling & 218 & 96 & 1,154 & 121 & 19 & 108 & 150 \\
\hline Imperial College London & 4,398 & 22 & C. Camagnari & 282 & 61 & 3,334 & 38 & 31 & 30 & 150 \\
\hline Indian Institute of Technology Bombay (I... & 734 & 262 & A.K. pani & 35 & 336 & 72 & 328 & 6 & 301 & 25 \\
\hline Indian Institute of Technology Delhi (II... & 773 & 257 & M.M. Chawla & 80 & 269 & 338 & 248 & 5 & 321 & 30 \\
\hline Indian Institute of Technology Kanpur (I... & 1,150 & 193 & D. Kundu & 107 & 213 & 277 & 265 & 12 & 202 & 48 \\
\hline Indiana University Bloomington & 2,837 & 58 & B. E. Rhoades & 108 & 211 & 370 & 240 & 10 & 232 & 56 \\
\hline Indiana University Indianapolis & 76 & 338 & X.H. Zhou & 148 & 164 & 2,542 & 55 & 29 & 35 & 150 \\
\hline Iowa State University & 1,239 & 185 & J.W. Evans & 338 & 45 & 2,596 & 53 & 27 & 55 & 150 \\
\hline Johns Hopkins University & 3,734 & 32 & A. Hocker & 379 & 32 & 3,492 & 30 & 29 & 35 & 150 \\
\hline Kansas State University & 630 & 279 & A.G. Ramm & 278 & 62 & 321 & 254 & 9 & 249 & 57 \\
\hline Katholieke Universiteit Leuven & 3,365 & 40 & A. Bultheel & 123 & 189 & 406 & 236 & 10 & 232 & 50 \\
\hline Keio University & 1,265 & 180 & M. Maejima & 45 & 323 & 158 & 301 & 7 & 286 & 27 \\
\hline
\end{tabular}




\begin{tabular}{|c|c|c|c|c|c|c|c|c|c|c|}
\hline King Fahd University of Petroleum \& Minerals & 1,093 & 201 & S.A. Messaoudi & 52 & 314 & 125 & 312 & 9 & 249 & 15 \\
\hline King Saud University & 798 & 253 & M.A. Noor & 251 & 77 & 869 & 150 & 21 & 91 & 65 \\
\hline Kobe University & 1,112 & 198 & K. Ohtani & 156 & 143 & 1,237 & 113 & 14 & 164 & 150 \\
\hline Korea Advanced Institute of Science \& Technology & 2,160 & 95 & J.K. Koo & 39 & 331 & 33 & 340 & 4 & 327 & 27 \\
\hline Korea University & 1,642 & 148 & H. Aihari & 322 & 48 & 3,418 & 35 & 40 & 8 & 150 \\
\hline Kyoto University & 5,321 & 13 & T. Ibaraki & 228 & 87 & 1,228 & 117 & 15 & 152 & 149 \\
\hline Kyushu University & 2,170 & 94 & M. Nakao & 101 & 224 & 381 & 237 & 9 & 249 & 59 \\
\hline La Trobe University & 805 & 252 & B.A. Davey & 50 & 316 & 110 & 320 & 6 & 301 & 40 \\
\hline Lancaster University & 492 & 301 & Y. Arnoud & 277 & 63 & 2,704 & 49 & 29 & 35 & 150 \\
\hline Leiden University & 1,720 & 136 & L.A. Peletier & 130 & 183 & 1,237 & 113 & 14 & 164 & 122 \\
\hline Linkoping University & 1,034 & 212 & V. Maz'ya & 90 & 248 & 265 & 267 & 10 & 232 & 48 \\
\hline London School of Economics and Political Scie & 1,053 & 210 & A.C. Atkinson & 60 & 302 & 523 & 210 & 12 & 202 & 98 \\
\hline Loughborough University & 1,152 & 192 & D.J. Evans & 82 & 263 & 9,579 & 7 & 39 & 10 & 150 \\
\hline Louisiana State University & 969 & 222 & J. Oxley & 79 & 272 & 226 & 280 & 9 & 249 & 31 \\
\hline Ludwig-Maximilians-Universität München & 2,050 & 107 & H.P. Kriegel & 171 & 133 & 2,404 & 61 & 20 & 99 & 111 \\
\hline Lund University & 1,443 & 163 & A. Lingas & 88 & 252 & 241 & 271 & 8 & 269 & 60 \\
\hline Maastricht University & 490 & 302 & A. Grigoriev & 29 & 340 & 46 & 334 & 4 & 327 & 23 \\
\hline Macquarie University & 905 & 235 & I.E. Sharlinski & 240 & 82 & 457 & 226 & 14 & 164 & 150 \\
\hline Mahidol University & 160 & 335 & Y. Lenbury & 54 & 311 & 137 & 307 & 6 & 301 & 91 \\
\hline Masaryk University & 664 & 273 & J. Rosicky & 67 & 290 & 120 & 315 & 6 & 301 & 38 \\
\hline Massachusetts Institute of Technology & 7,045 & 3 & A. Hocker & 371 & 36 & 3,288 & 42 & 28 & 42 & 150 \\
\hline McGill University & 3,223 & 43 & L. DeVoroye & 153 & 150 & 732 & 171 & 9 & 249 & 72 \\
\hline McMaster University & 2,100 & 103 & N. Balakrishnan & 367 & 38 & 813 & 157 & 16 & 138 & 150 \\
\hline Michigan State University & 2,870 & 56 & B.Y. Chen & 122 & 190 & 336 & 251 & 12 & 202 & 32 \\
\hline Michigan Technological University & 555 & 290 & V.D. Tonchev & 100 & 226 & 275 & 266 & 9 & 249 & 62 \\
\hline Monash University & 1,480 & 159 & D. Tanier & 153 & 150 & 157 & 302 & 9 & 249 & 110 \\
\hline Montana State University & 365 & 321 & B. Zhu & 64 & 295 & 184 & 291 & 8 & 269 & 80 \\
\hline Moscow State University & 8,467 & 2 & K.D. Ikramov & 143 & 168 & 126 & 310 & 6 & 301 & 31 \\
\hline Nagoya University & 2,372 & 82 & H. Aihara & 310 & 53 & 3,328 & 41 & 39 & 10 & 150 \\
\hline Nanjing University & 2,151 & 98 & Z.W. Sun & 117 & 200 & 154 & 303 & 9 & 249 & 150 \\
\hline Nanyang Technological University & 2,412 & 80 & P.J.Y. Wong & 99 & 227 & 531 & 209 & 15 & 152 & 22 \\
\hline National Taiwan University & 2,352 & 86 & T. Kawasaki & 275 & 65 & 2,101 & 69 & 28 & 42 & 150 \\
\hline National Tsing Hua University & 1,756 & 131 & S.S. Cheng & 111 & 205 & 428 & 232 & 11 & 216 & 75 \\
\hline National University of Ireland, Galway & 913 & 234 & D. O'Regan & 410 & 21 & 1,602 & 95 & 22 & 80 & 143 \\
\hline National University of Singapore & 4,830 & 18 & R.P. Agarwal & 596 & 3 & 3,877 & 24 & 26 & 63 & 150 \\
\hline New Mexico State University & 929 & 231 & F. Harary & 154 & 147 & 928 & 141 & 7 & 286 & 139 \\
\hline
\end{tabular}




\begin{tabular}{|c|c|c|c|c|c|c|c|c|c|c|}
\hline New York University & 3,671 & 35 & M. Sharir & 345 & 44 & 2,106 & 68 & 19 & 108 & 150 \\
\hline Newcastle University & 937 & 230 & K.D. Glazebrook & 86 & 254 & 168 & 298 & 8 & 269 & 150 \\
\hline North Carolina State University & 2,764 & 63 & C.V. Pao & 112 & 202 & 438 & 230 & 13 & 187 & 15 \\
\hline Northeastern University & 1,609 & 153 & G.A. Alves & 385 & 30 & 4,024 & 22 & 38 & 13 & 150 \\
\hline Northwestern University & 3,598 & 38 & T. Belytschko & 473 & 15 & 6,922 & 11 & 48 & 3 & 150 \\
\hline Norwegian University of Science \& Technology & 1,811 & 127 & I. Brevik & 167 & 134 & 873 & 148 & 17 & 129 & 96 \\
\hline Ohio State University & 4,553 & 21 & F. Salvatore & 151 & 155 & 923 & 142 & 19 & 108 & 150 \\
\hline Oklahoma State University & 924 & 233 & G.G. Yen & 150 & 160 & 740 & 169 & 12 & 202 & 55 \\
\hline Open University UK & 1,144 & 194 & M.C. Jones & 110 & 208 & 1,231 & 116 & 15 & 152 & 84 \\
\hline Oregon State University & 849 & 246 & S.U. Randhawa & 65 & 292 & 241 & 271 & 6 & 301 & 56 \\
\hline Osaka University & 3,323 & 41 & T. Kawasaki & 274 & 67 & 2,075 & 71 & 28 & 42 & 150 \\
\hline Peking University & 3,666 & 36 & L.Wang & 403 & 24 & 1,302 & 110 & 22 & 80 & 150 \\
\hline Pennsylvania State University & 4,617 & 20 & G.E. Andrews & 105 & 214 & 605 & 192 & 8 & 269 & 54 \\
\hline Pohang University of Science And Technology & 1,183 & 188 & J.H. Kwak & 104 & 218 & 320 & 255 & 10 & 232 & 125 \\
\hline Portland State University & 387 & 317 & M.A. Perkowski & 151 & 155 & 500 & 214 & 13 & 187 & 144 \\
\hline Princeton University & 6,789 & 5 & F. Salvatore & 151 & 155 & 923 & 142 & 19 & 108 & 150 \\
\hline Purdue University & 4,921 & 17 & W. Gautschi & 86 & 254 & 582 & 194 & 10 & 232 & 28 \\
\hline Queen's University & 1,395 & 167 & P. Ribenboim & 58 & 305 & 149 & 304 & 6 & 301 & 9 \\
\hline Queen's University of Belfast & 686 & 269 & A.W. Wickstead & 40 & 330 & 161 & 299 & 5 & 321 & 25 \\
\hline Queensland University of Technology & 779 & 256 & V.V. Ahn & 144 & 167 & 491 & 218 & 17 & 129 & 108 \\
\hline Radboud University, Nijmegen & 1,284 & 177 & O. Axelsson & 64 & 295 & 417 & 234 & 11 & 216 & 32 \\
\hline Rensselaer Polytechnic Institute & 1,391 & 168 & J. Fish & 104 & 218 & 731 & 172 & 16 & 138 & 72 \\
\hline Rheinisch Westfalische Technische Hochschule Aach & 2,833 & 59 & L. Volkmann & 161 & 138 & 299 & 261 & 11 & 216 & 54 \\
\hline Rheinische Friedrich Wilhelms Universitat Bonn & 2,895 & 53 & S. Albeverio & 394 & 27 & 1,586 & 96 & 22 & 80 & 150 \\
\hline Rice University & 1,660 & 145 & M.Y. Vardi & 235 & 84 & 2,171 & 65 & 16 & 138 & 150 \\
\hline Rochester Institute of Technology & 372 & 320 & A.A. Batabyal & 112 & 202 & 176 & 296 & 8 & 269 & 19 \\
\hline Royal Institute of Technology, KTH & 1,950 & 114 & H. Shahgolian & 42 & 327 & 105 & 322 & 8 & 269 & 29 \\
\hline Royal Melbourne Institute of Technology & 567 & 288 & W. Van Megan & 103 & 223 & 1,896 & 79 & 13 & 187 & 150 \\
\hline Rutgers & 5,492 & 11 & S. Shelah & 466 & 16 & 1,103 & 126 & 12 & 202 & 149 \\
\hline Saint-Petersburg State University & 2,160 & 95 & A.V. Tsiganov & 80 & 269 & 175 & 297 & 8 & 269 & 16 \\
\hline San Diego State University & 536 & 295 & K.J. Lui & 121 & 194 & 637 & 188 & 10 & 232 & 52 \\
\hline Sapienza University of Rome & 0 & 348 & & 0 & 348 & 0 & 347 & 0 & 346 & 0 \\
\hline Sciences Po Paris & 4 & 347 & Y. Algan & 13 & 345 & 35 & 336 & 4 & 327 & 16 \\
\hline Seoul National University & 2,878 & 55 & S. Park & 64 & 295 & 310 & 258 & 10 & 232 & 21 \\
\hline Shanghai Jiao Tong University & 3,379 & 39 & M. Li & 266 & 71 & 216 & 282 & 8 & 269 & 150 \\
\hline Simon Fraser University & 2,104 & 101 & P. Hell & 98 & 228 & 564 & 200 & 12 & 202 & 104 \\
\hline
\end{tabular}




\begin{tabular}{|c|c|c|c|c|c|c|c|c|c|c|}
\hline Stanford University & 6,333 & 7 & F. Salvatore & 151 & 155 & 923 & 142 & 19 & 108 & 150 \\
\hline State University of New York Buffalo & 42 & 342 & V.E. Brimkov & 47 & 320 & 69 & 329 & 6 & 301 & 19 \\
\hline Stockholm University & 872 & 240 & B Shapiro & 34 & 338 & 77 & 327 & 6 & 301 & 26 \\
\hline Stony Brook University & 2,399 & 81 & R. Shrock & 220 & 92 & 2,877 & 45 & 28 & 42 & 150 \\
\hline Syracuse University & 601 & 283 & T. Iwaniec & 43 & 326 & 323 & 253 & 11 & 216 & 26 \\
\hline Tartu University (University of Tartu) & 407 & 315 & E. Oja & 29 & 340 & 69 & 329 & 9 & 249 & 20 \\
\hline Technical University of Denmark & 1,408 & 166 & C. Thomassen & 105 & 214 & 676 & 183 & 8 & 269 & 39 \\
\hline Technion & 5,259 & 14 & A.J. Zaslauski & 137 & 175 & 194 & 286 & 11 & 216 & 17 \\
\hline Technische Universität Berlin & 2,645 & 70 & H. Ehrig & 108 & 211 & 231 & 278 & 10 & 232 & 80 \\
\hline Technische Universitat Chemnitz & 1,079 & 204 & A. Bottcher & 75 & 280 & 185 & 290 & 6 & 301 & 35 \\
\hline Technische Universität Dresden & 1,900 & 117 & J. Ocaritz & 294 & 57 & 1,753 & 85 & 28 & 42 & 150 \\
\hline Technische Universität München & 2,769 & 61 & H. Spohn & 179 & 126 & 2,693 & 51 & 20 & 99 & 118 \\
\hline Tel Aviv University & 5,523 & 10 & N. Alon & 396 & 26 & 3,334 & 38 & 24 & 72 & 150 \\
\hline Texas A\&M University & 4,136 & 26 & R.J. Carrol & 248 & 79 & 3,981 & 23 & 36 & 17 & 150 \\
\hline Texas Tech & 521 & 296 & W.P. Dayawansa & 92 & 245 & 846 & 154 & 8 & 269 & 72 \\
\hline Tohoku University & 2,273 & 88 & T. Nishizeki & 140 & 173 & 565 & 199 & 8 & 269 & 86 \\
\hline Tokyo Institute of Technology & 2,831 & 60 & W. Takahashi & 220 & 92 & 1,060 & 130 & 22 & 80 & 150 \\
\hline Trinity College Dublin & 722 & 264 & W.T. Coffey & 181 & 122 & 619 & 190 & 15 & 152 & 121 \\
\hline Tsinghua University & 5,422 & 12 & X. Yang & 192 & 108 & 1,148 & 122 & 22 & 80 & 150 \\
\hline Tufts University & 735 & 261 & A. Vilenkin & 188 & 115 & 3,641 & 27 & 25 & 66 & 67 \\
\hline Universidad Autonoma de Madrid & 1,819 & 125 & J.L. Vazquez & 134 & 177 & 1,376 & 102 & 15 & 152 & 118 \\
\hline Universidad de Chile & 1,490 & 158 & G. Navarro & 143 & 168 & 1,131 & 123 & 17 & 129 & 150 \\
\hline Universidad de Granada & 1,819 & 125 & J.L. Vazquez & 134 & 177 & 1,376 & 102 & 15 & 152 & 118 \\
\hline Universidad del País Vasco & 1,343 & 172 & M. De la Sen & 405 & 22 & 561 & 202 & 16 & 138 & 71 \\
\hline Universidad Nacional Autónoma de México ... & 1,223 & 186 & F .Luca & 182 & 119 & 182 & 292 & 6 & 301 & 7 \\
\hline Universidad Politecnica de Madrid & 1,692 & 142 & M.L. Menendez & 63 & 299 & 124 & 313 & 6 & 301 & 59 \\
\hline Universidade de São Paulo & 1,455 & 162 & Y. Kohayakawa & 55 & 310 & 199 & 285 & 10 & 232 & 61 \\
\hline Universidade Estadual de Campinas & 870 & 241 & J.M. Martinez & 246 & 80 & 1,660 & 92 & 25 & 66 & 150 \\
\hline Università degli Studi di Firenze & 2,503 & 73 & A. Cianchi & 56 & 308 & 228 & 279 & 11 & 216 & 27 \\
\hline Università degli Studi di Padova & 3,180 & 44 & A. Hocker & 427 & 19 & 5,332 & 13 & 35 & 19 & 150 \\
\hline Universita Di Bologna & 2,765 & 62 & G. Apollinari & 513 & 9 & 11,180 & 2 & 46 & 4 & 150 \\
\hline Universita di Pisa & 999 & 216 & L. Gemingnani & 49 & 317 & 115 & 317 & 8 & 269 & 20 \\
\hline Universitat Autonoma de Barcelona & 2,025 & 110 & J. Llibre & 220 & 92 & 737 & 170 & 14 & 164 & 121 \\
\hline Universitat Bielefeld & 2,367 & 83 & M. Rockner & 156 & 143 & 555 & 205 & 18 & 119 & 61 \\
\hline Universität Bremen & 1,297 & 175 & R. Drechsler & 240 & 82 & 589 & 193 & 13 & 187 & 125 \\
\hline Universitat d'Alacant & 744 & 260 & M.A. Lopez & 65 & 292 & 190 & 287 & 13 & 187 & 51 \\
\hline
\end{tabular}




\begin{tabular}{|c|c|c|c|c|c|c|c|c|c|c|}
\hline Universitat de València & 2,028 & 109 & A. Hocker & 427 & 19 & 5,324 & 14 & 35 & 19 & 150 \\
\hline Universität Frankfurt am Main & 1,894 & 120 & P.E. Kleder & 149 & 161 & 666 & 185 & 13 & 187 & 89 \\
\hline Universität Freiburg & 1,711 & 137 & A. Blumen & 201 & 103 & 2,030 & 74 & 23 & 77 & 125 \\
\hline Universitat Hamburg & 556 & 289 & S. Ghazaryan & 96 & 232 & 1,092 & 127 & 20 & 99 & 150 \\
\hline Universität Karlsruhe & 3,083 & 49 & W.D. Apel & 458 & 17 & 3,464 & 33 & 31 & 30 & 150 \\
\hline Universitat Leipzig & 480 & 303 & P.F. Stadler & 304 & 55 & 3,528 & 29 & 35 & 19 & 150 \\
\hline Universitat Munster (Westfälische Wilhelms-Un & 496 & 299 & X. Jiang & 104 & 218 & 783 & 162 & 12 & 202 & 116 \\
\hline Universitat Politecnica de Catalunya & 3,171 & 45 & R. Quintanilla & 128 & 187 & 293 & 263 & 14 & 164 & 24 \\
\hline Universität Regensburg & 1,054 & 209 & R. Mennicken & 35 & 336 & 114 & 318 & 9 & 249 & 29 \\
\hline Universität Stuttgart & 2,262 & 90 & W.L. Wendland & 95 & 233 & 700 & 176 & 13 & 187 & 77 \\
\hline Universitat Trier & 464 & 308 & H. Fernau & 85 & 257 & 235 & 276 & 9 & 249 & 57 \\
\hline Universität Tübingen & 2,141 & 99 & P. Schmid & 306 & 54 & 3,333 & 40 & 27 & 55 & 150 \\
\hline Universitat Wien (University of Vienna) & 2,462 & 75 & P.F. Stadler & 300 & 56 & 3,862 & 25 & 37 & 15 & 150 \\
\hline Universitat Zu Koln & 2,037 & 108 & D. Stauffer & 358 & 42 & 3,434 & 34 & 25 & 66 & 150 \\
\hline Université Catholique de Louvain & 1,895 & 118 & J. Mawhin & 76 & 274 & 609 & 191 & 9 & 249 & 45 \\
\hline Universite de Liege & 927 & 232 & M. Ausloos & 405 & 22 & 1,947 & 76 & 24 & 72 & 150 \\
\hline Université de Montréal & 2,442 & 77 & P. Winternitz & 210 & 101 & 1,453 & 99 & 18 & 119 & 150 \\
\hline Université de Nice Sophia Antipolis & 1,443 & 163 & D. Sornette & 290 & 58 & 3,397 & 36 & 37 & 15 & 150 \\
\hline Universite Laval & 1,067 & 205 & C. Genest & 65 & 292 & 496 & 216 & 15 & 152 & 73 \\
\hline Universite Libre de Bruxelles & 2,265 & 89 & T. Erneux & 186 & 117 & 1,238 & 112 & 18 & 119 & 150 \\
\hline Université Paris Sorbonne & 575 & 285 & M. Grabisch & 81 & 267 & 671 & 184 & 14 & 164 & 44 \\
\hline Universite Paris-Sud 11 & 4,979 & 16 & O. Favaron & 83 & 260 & 2 & 345 & 10 & 232 & 69 \\
\hline Université Pierre et Marie Curie & 6,509 & 6 & M. Begalli & 143 & 168 & 996 & 136 & 19 & 108 & 150 \\
\hline Universiti Malaya (University of Malaya) & 293 & 328 & M.H. Lim & 22 & 343 & 56 & 332 & 4 & 327 & 6 \\
\hline University College Cork & 629 & 280 & M. Stynes & 59 & 303 & 350 & 245 & 14 & 164 & 36 \\
\hline University College Dublin & 1,097 & 200 & T.J. Laffey & 82 & 263 & 215 & 283 & 5 & 321 & 71 \\
\hline University College London & 2,152 & 97 & F.T. Smith & 154 & 147 & 579 & 195 & 11 & 216 & 87 \\
\hline University do Porto & 205 & 331 & A.J.M. Ferreria & 57 & 307 & 245 & 270 & 13 & 187 & 37 \\
\hline University of Aberdeen & 706 & 266 & G.S. Hall & 94 & 237 & 1,840 & 80 & 27 & 55 & 150 \\
\hline University of Adelaide & 1,253 & 181 & D.B. Leinweber & 182 & 119 & 1,305 & 108 & 28 & 42 & 129 \\
\hline University of Alabama & 1,628 & 150 & J.J. Buckley & 199 & 105 & 1,245 & 111 & 14 & 164 & 39 \\
\hline University of Alberta & 3,646 & 37 & T.B. Moodie & 105 & 214 & 188 & 288 & 7 & 286 & 29 \\
\hline University of Amsterdam & 2,633 & 71 & A. Schrijver & 95 & 233 & 979 & 139 & 11 & 216 & 62 \\
\hline University of Antwerp & 1,111 & 199 & S. Almehed & 289 & 60 & 2,793 & 47 & 27 & 55 & 150 \\
\hline University of Arizona & 3,022 & 50 & M. Shaked & 79 & 272 & 495 & 217 & 14 & 164 & 47 \\
\hline University of Athens & 1,676 & 143 & D.J. Frantzeskakis & 154 & 147 & 857 & 151 & 22 & 80 & 110 \\
\hline
\end{tabular}




\begin{tabular}{|c|c|c|c|c|c|c|c|c|c|c|}
\hline University of Auckland & 1,726 & 135 & J.C. Butcher & 82 & 263 & 307 & 260 & 11 & 216 & 33 \\
\hline University of Barcelona & 2,090 & 104 & D. Nualart & 120 & 196 & 682 & 180 & 14 & 164 & 72 \\
\hline University of Basel & 550 & 291 & E. Baldinger & 53 & 312 & 1 & 346 & 0 & 346 & 40 \\
\hline University of Bath & 606 & 282 & D.A.S. Rees & 112 & 202 & 561 & 202 & 14 & 164 & 59 \\
\hline University of Bergen & 732 & 263 & A. Andrazza & 330 & 46 & 3,261 & 43 & 31 & 30 & 150 \\
\hline University of Bern & 574 & 286 & H. Bunke & 275 & 65 & 1,723 & 87 & 20 & 99 & 150 \\
\hline University of Birmingham & 1,871 & 121 & R. Frey & 266 & 71 & 1,316 & 107 & 24 & 72 & 150 \\
\hline University of Bristol & 2,248 & 91 & C.M. Hawkes & 671 & 2 & 10,000 & 6 & 38 & 13 & 150 \\
\hline University of British Columbia & 1,843 & 124 & M.J. Ward & 69 & 283 & 361 & 243 & 13 & 187 & 108 \\
\hline University of Calgary & 1,266 & 179 & R.S. Dhaliwal & 190 & 111 & 843 & 155 & 7 & 286 & 150 \\
\hline University of California, Berkley & 3,710 & 33 & Y. Peres & 118 & 198 & 754 & 166 & 19 & 108 & 90 \\
\hline University of California, Davis & 1,248 & 182 & A. Hastings & 158 & 142 & 4,303 & 20 & 32 & 26 & 150 \\
\hline University of California, Irvine & 1,056 & 208 & E.S. Titi & 104 & 218 & 984 & 137 & 20 & 99 & 93 \\
\hline University of California, Los Angeles & 5,560 & 8 & A. Hocker & 377 & 33 & 3,470 & 31 & 29 & 35 & 150 \\
\hline University of California, Riverside & 1,786 & 129 & D. Strom & 393 & 28 & 2,037 & 73 & 27 & 55 & 150 \\
\hline University of California, San Diego & 1,749 & 132 & J.B. Remmel & 122 & 190 & 297 & 262 & 7 & 286 & 63 \\
\hline University of California, San Francisco & 50 & 341 & K.A. Dill & 228 & 87 & 8,986 & 9 & 36 & 17 & 150 \\
\hline University of California, Santa Barbara & 1,285 & 176 & A.R. Teel & 270 & 69 & 2,699 & 50 & 25 & 66 & 96 \\
\hline University of California, Santa Cruz & 577 & 284 & H. Widom & 66 & 291 & 779 & 163 & 11 & 216 & 11 \\
\hline University of Cambridge & 2,114 & 100 & B. Bollobas & 226 & 91 & 1,396 & 101 & 15 & 152 & 118 \\
\hline University of Canterbury & 477 & 305 & M. Steel & 122 & 190 & 2,040 & 72 & 21 & 91 & 92 \\
\hline University of Cape Town & 337 & 327 & G.F.R. Ellis & 153 & 150 & 1,550 & 97 & 19 & 108 & 95 \\
\hline University of Central Florida & 1,658 & 146 & K. Vajravelu & 135 & 176 & 726 & 173 & 14 & 164 & 87 \\
\hline University of Chicago & 548 & 293 & $\mathrm{~L} . \mathrm{Yu}$ & 162 & 137 & 2,713 & 48 & 27 & 55 & 150 \\
\hline University of Cincinnati & 1,502 & 157 & I. Narsky & 329 & 47 & 1,995 & 75 & 28 & 42 & 150 \\
\hline University of Colorado at Boulder & 1,245 & 184 & M.J. Ablowitz & 190 & 111 & 2,640 & 52 & 21 & 91 & 108 \\
\hline University of Connecticut & 968 & 224 & M. Neumann & 118 & 198 & 425 & 233 & 9 & 249 & 78 \\
\hline University of Copenhagen & 806 & 251 & S. Hahn & 53 & 312 & 795 & 161 & 11 & 216 & 150 \\
\hline University of Delaware & 675 & 272 & D. Colton & 93 & 238 & 572 & 197 & 16 & 138 & 29 \\
\hline University of Dundee & 549 & 292 & T.N.T. Goodman & 68 & 287 & 316 & 257 & 6 & 301 & 41 \\
\hline University of Edinburgh & 951 & 229 & T.G. Mackay & 129 & 184 & 706 & 175 & 17 & 129 & 70 \\
\hline University of Florida & 3,868 & 30 & P.M. Pardalos & 274 & 67 & 1,639 & 93 & 18 & 119 & 150 \\
\hline University of Geneva & 460 & 310 & E. Hairer & 69 & 283 & 746 & 167 & 12 & 202 & 134 \\
\hline University of Georgia & 996 & 217 & G. Adomian & 172 & 131 & 797 & 160 & 8 & 269 & 23 \\
\hline University of Ghent & 140 & 336 & B. De Baets & 214 & 99 & 1,006 & 135 & 18 & 119 & 150 \\
\hline University of Glasgow & 1,940 & 116 & C. Blocker & 512 & 10 & 10,281 & 4 & 46 & 4 & 150 \\
\hline
\end{tabular}




\begin{tabular}{|c|c|c|c|c|c|c|c|c|c|c|}
\hline University of Gothenburg & 5 & 346 & P.S. Eriksson & 191 & 109 & 4,948 & 15 & 31 & 30 & 150 \\
\hline University of Groningen & 637 & 277 & R.F. Curtain & 131 & 182 & 461 & 224 & 10 & 232 & 43 \\
\hline University of Helsinki & 1,709 & 139 & H. Saarikko & 179 & 126 & 1,195 & 119 & 20 & 99 & 150 \\
\hline University of Hong Kong & 972 & 219 & M.K. Ng & 204 & 102 & 1,070 & 129 & 18 & 119 & 150 \\
\hline University of Houston & 1,459 & 161 & C.W. Chu & 364 & 40 & 4,904 & 16 & 32 & 26 & 150 \\
\hline University of Illinois & 6,980 & 4 & C. Bromberg & 489 & 12 & 4,344 & 19 & 46 & 4 & 150 \\
\hline University of Illinois, Chicago & 2,363 & 85 & C. Knessl & 121 & 194 & 283 & 264 & 7 & 286 & 35 \\
\hline University of Indonesia & 36 & 343 & M. Adriani & 14 & 344 & 20 & 342 & 2 & 342 & 19 \\
\hline University of Iowa & 1,538 & 156 & N.L. Johnson & 152 & 154 & 309 & 259 & 7 & 286 & 38 \\
\hline University of Kansas & 681 & 271 & A.T. Peterson & 155 & 146 & 2,830 & 46 & 35 & 19 & 150 \\
\hline University of Kentucky & 1,115 & 196 & C.S. Man & 68 & 287 & 250 & 269 & 10 & 232 & 61 \\
\hline University of Lausanne & 132 & 337 & H.U. Gerber & 44 & 324 & 369 & 241 & 9 & 249 & 25 \\
\hline University of Leeds & 1,315 & 174 & D.B. Ingham & 393 & 28 & 1,538 & 98 & 18 & 119 & 150 \\
\hline University of Leicester & 895 & 236 & J. Levesley & 39 & 331 & 87 & 324 & 6 & 301 & 31 \\
\hline University of Liverpool & 68 & 340 & M. Begalli & 311 & 50 & 2,508 & 58 & 28 & 42 & 150 \\
\hline University of Ljubljana & 1,980 & 111 & D. Repovs & 145 & 166 & 181 & 293 & 8 & 269 & 73 \\
\hline University of London (Kings College of London) & 8,610 & 1 & A. Hocker & 385 & 30 & 3,581 & 28 & 29 & 35 & 150 \\
\hline University of Manchester & 3,876 & 29 & A. Hocker & 366 & 39 & 3,122 & 44 & 28 & 42 & 150 \\
\hline University of Manitoba & 2,101 & 102 & G. Gratzer & 81 & 267 & 111 & 319 & 6 & 301 & 24 \\
\hline University of Maryland & 5,533 & 9 & D. Strom & 377 & 33 & 1,759 & 83 & 26 & 63 & 150 \\
\hline University of Maryland Baltimore County & 1,180 & 189 & T.I. Seidman & 93 & 238 & 439 & 229 & 7 & 286 & 48 \\
\hline University of Massachusetts & 969 & 222 & P.G. Kevrekidis & 276 & 64 & 1,374 & 105 & 29 & 35 & 150 \\
\hline University of Melbourne & 2,366 & 84 & A.J. Guttmann & 148 & 164 & 755 & 165 & 16 & 138 & 85 \\
\hline University of Miami & 461 & 309 & S. Ruan & 69 & 283 & 984 & 137 & 21 & 91 & 73 \\
\hline University of Michigan & 3,124 & 46 & A.M. Bloch & 140 & 173 & 917 & 146 & 14 & 164 & 68 \\
\hline University of Minnesota & 2,714 & 67 & P.J. Olver & 93 & 238 & 1,666 & 91 & 16 & 138 & 52 \\
\hline University of Missouri & 1,743 & 133 & F. Gesztesy & 82 & 263 & 561 & 202 & 16 & 138 & 45 \\
\hline University of Nebraska & 1,387 & 169 & S. Nadarajah & 441 & 18 & 363 & 242 & 9 & 249 & 54 \\
\hline University of New Hampshire & 361 & 324 & D. Hadwin & 44 & 324 & 126 & 310 & 5 & 321 & 48 \\
\hline University of New Mexico & 691 & 268 & W. Kucharz & 56 & 308 & 63 & 331 & 5 & 321 & 10 \\
\hline University of New South Wales & 1,572 & 154 & I.H. Sloan & 134 & 177 & 661 & 186 & 17 & 129 & 68 \\
\hline University of North Carolina, Chapel Hill & 2,497 & 74 & P.K. Sen & 141 & 172 & 534 & 207 & 9 & 249 & 112 \\
\hline University of North Texas & 850 & 245 & M. Urbanski & 92 & 245 & 335 & 252 & 13 & 187 & 31 \\
\hline University of Notre Dame & 958 & 227 & A.J. Sommese & 76 & 274 & 408 & 235 & 7 & 286 & 42 \\
\hline University of Nottingham & 854 & 244 & J.R. King & 156 & 143 & 1,033 & 134 & 17 & 129 & 122 \\
\hline University of Oklahoma & 635 & 278 & M. Breen & 76 & 274 & 53 & 333 & 3 & 334 & 2 \\
\hline
\end{tabular}




\begin{tabular}{|c|c|c|c|c|c|c|c|c|c|c|}
\hline University of Oregon & 818 & 249 & Y. Xu & 85 & 257 & 210 & 284 & 9 & 249 & 59 \\
\hline University of Oslo & 823 & 248 & L. Bugge & 264 & 73 & 2,466 & 60 & 27 & 55 & 150 \\
\hline University of Otago & 221 & 330 & V.A. Squire & 76 & 274 & 233 & 277 & 10 & 232 & 37 \\
\hline University of Ottawa & 746 & 259 & D. Sankoff & 132 & 180 & 2,150 & 66 & 19 & 108 & 147 \\
\hline University of Oxford & 1,786 & 129 & P.K. Maini & 197 & 106 & 1,692 & 89 & 26 & 63 & 150 \\
\hline University of Pennsylvania & 1,061 & 207 & H.S. Wilf & 76 & 274 & 499 & 215 & 8 & 269 & 48 \\
\hline University of Pittsburgh & 1,084 & 202 & G.B. Ermentrout & 91 & 247 & 2,101 & 69 & 21 & 91 & 74 \\
\hline University of Quebec & 345 & 326 & P.A. Van Rolleghem & 320 & 49 & 2,229 & 64 & 28 & 42 & 150 \\
\hline University of Queensland & 1,038 & 211 & M.D. Gould & 122 & 190 & 512 & 212 & 11 & 216 & 46 \\
\hline University of Reading & 876 & 238 & P. Glaister & 105 & 214 & 265 & 267 & 3 & 334 & 8 \\
\hline University of Rochester & 467 & 307 & C. Mueller & 33 & 339 & 179 & 294 & 6 & 301 & 19 \\
\hline University of Saskatchewan & 874 & 239 & B.S. Lalli & 52 & 314 & 240 & 274 & 2 & 342 & 25 \\
\hline University of Science and Technology of China & 3,116 & 47 & H.Y. Fan & 364 & 40 & 827 & 156 & 22 & 80 & 137 \\
\hline University of Sheffield & 1,612 & 152 & D.W. Hughes & 189 & 113 & 848 & 153 & 14 & 164 & 150 \\
\hline University of South Carolina & 1,676 & 143 & D.H. Wright & 251 & 77 & 1,439 & 100 & 22 & 80 & 150 \\
\hline University of South Florida & 705 & 267 & E.B. Saff & 111 & 205 & 634 & 189 & 9 & 249 & 77 \\
\hline University of Southampton & 857 & 243 & N. Andersson & 83 & 260 & 871 & 149 & 22 & 80 & 46 \\
\hline University of Southern California & 1,338 & 173 & R.M. Guralnick & 101 & 224 & 483 & 220 & 10 & 232 & 85 \\
\hline University of St Andrews & 417 & 312 & E.R. Priest & 218 & 96 & 1,762 & 82 & 23 & 77 & 150 \\
\hline University of Surrey & 414 & 313 & T.J. Bridges & 75 & 280 & 562 & 201 & 15 & 152 & 36 \\
\hline University of Sussex & 389 & 316 & D.E. Edmunds & 69 & 283 & 337 & 250 & 10 & 232 & 46 \\
\hline University of Sydney & 2,212 & 93 & E. N. Dancer & 104 & 218 & 687 & 179 & 14 & 164 & 33 \\
\hline University of Technology, Sydney & 167 & 334 & G. Zhang & 97 & 230 & 138 & 306 & 8 & 269 & 67 \\
\hline University of Tennessee Knoxville & 959 & 226 & D.E. Dodds & 90 & 248 & 178 & 295 & 6 & 301 & 46 \\
\hline University of Texas at Austin & 2,053 & 106 & I. Babuska & 220 & 92 & 4,389 & 18 & 28 & 42 & 150 \\
\hline University of Tokyo & 1,895 & 118 & K. Aihara & 353 & 43 & 1,920 & 78 & 25 & 66 & 150 \\
\hline University of Toronto & 5,060 & 15 & S.G. Whittington & 160 & 140 & 799 & 159 & 16 & 138 & 150 \\
\hline University of Tsukuba & 956 & 228 & H. Nishimura & 38 & 333 & 35 & 336 & 4 & 327 & 2 \\
\hline University of Twente & 843 & 247 & G.J. Woeginger & 255 & 75 & 1,303 & 109 & 17 & 129 & 150 \\
\hline University of Utah & 1,800 & 128 & L. Horvath & 151 & 155 & 742 & 168 & 12 & 202 & 50 \\
\hline University of Vermont & 608 & 281 & A.C.H. Ling & 86 & 254 & 344 & 247 & 13 & 187 & 62 \\
\hline University of Victoria & 1,142 & 195 & H.M. Srivastava & 371 & 36 & 851 & 152 & 17 & 129 & 150 \\
\hline University of Virginia & 1,004 & 214 & I. Lasiecka & 172 & 131 & 677 & 181 & 14 & 164 & 53 \\
\hline University of Warwick & 1,545 & 155 & I. Stewart & 93 & 238 & 487 & 219 & 3 & 334 & 22 \\
\hline University of Washington & 4,090 & 27 & G. Uhlmann & 83 & 260 & 523 & 210 & 14 & 164 & 57 \\
\hline University of Waterloo & 2,869 & 57 & J. Paldus & 182 & 119 & 1,058 & 131 & 25 & 66 & 108 \\
\hline
\end{tabular}




\begin{tabular}{|c|c|c|c|c|c|c|c|c|c|c|}
\hline University of Western Australia & 1,427 & 165 & C.E. Praeger & 153 & 150 & 475 & 221 & 12 & 202 & 101 \\
\hline University of Western Ontario & 1,945 & 115 & P. Yu & 189 & 113 & 1,111 & 124 & 21 & 91 & 150 \\
\hline University of Wisconsin & 2,979 & 51 & R.A. Brualdi & 132 & 180 & 464 & 223 & 3 & 334 & 86 \\
\hline University of Wollongong & 459 & 311 & J.M. Hill & 149 & 161 & 441 & 228 & 12 & 202 & 58 \\
\hline University of York & 546 & 294 & A.M. Arthurs & 93 & 238 & 34 & 339 & 1 & 344 & 31 \\
\hline University of Zurich & 504 & 298 & S. Ghazaryan & 95 & 233 & 1,090 & 128 & 20 & 99 & 150 \\
\hline Univesitas Gadjah Mada & 12 & 345 & D. Rosadi & 4 & 347 & 0 & 347 & 0 & 346 & 1 \\
\hline Uppsala University & 791 & 254 & M. Begalli & 311 & 50 & 2,509 & 56 & 28 & 42 & 150 \\
\hline Utah State & 410 & 314 & Z.Q. Wang & 475 & 14 & 3,807 & 26 & 34 & 24 & 150 \\
\hline Utrecht University & 2,754 & 64 & M.H. Ernst & 159 & 141 & 1,624 & 94 & 18 & 119 & 79 \\
\hline Vanderbilt University & 889 & 237 & M.D. Plummer & 58 & 305 & 219 & 281 & 4 & 327 & 39 \\
\hline Victoria University of Wellington & 363 & 323 & R.G. Downey & 111 & 205 & 38 & 335 & 11 & 216 & 78 \\
\hline Vienna University of Technology & 1,084 & 202 & T. Eiter & 143 & 168 & 1,050 & 132 & 17 & 129 & 109 \\
\hline Virginia Polytechnic Institute & 1,247 & 183 & L.T. Watson & 290 & 58 & 1,667 & 90 & 20 & 99 & 150 \\
\hline Vrije Universiteit, Brussels & 1,062 & 206 & D.L. Massart & 515 & 8 & 9,064 & 8 & 40 & 8 & 150 \\
\hline VU University Amsterdam & 1,705 & 140 & M.A. Kaashoek & 97 & 230 & 318 & 256 & 7 & 286 & 41 \\
\hline Wageningen University & 75 & 339 & J. Grasman & 37 & 335 & 237 & 275 & 6 & 301 & 45 \\
\hline Wake Forest University & 182 & 333 & R.J. Plemmons & 93 & 238 & 694 & 177 & 13 & 187 & 109 \\
\hline Waseda University & 647 & 276 & Y. Muroya & 38 & 333 & 105 & 322 & 7 & 286 & 20 \\
\hline Washington State University & 493 & 300 & A. Saberi & 234 & 86 & 1,109 & 125 & 14 & 164 & 81 \\
\hline Washington University in St. Louis & 722 & 264 & T.J. Tarn & 218 & 96 & 1,375 & 104 & 15 & 152 & 150 \\
\hline Wayne State University & 1,847 & 123 & K.M. Ecklund & 228 & 87 & 1,732 & 86 & 27 & 55 & 150 \\
\hline West Virginia University & 478 & 304 & H.J. Lai & 80 & 269 & 122 & 314 & 6 & 301 & 84 \\
\hline Yale University & 1,178 & 190 & R.R. Coifman & 84 & 259 & 2,304 & 63 & 14 & 164 & 85 \\
\hline Yonsei University & 387 & 317 & H. Aihara & 241 & 81 & 2,122 & 67 & 34 & 24 & 150 \\
\hline York University & 1,017 & 213 & J. Wu & 181 & 122 & 801 & 158 & 18 & 119 & 150 \\
\hline Zhejiang University & 1,697 & 141 & $\mathrm{Y} . \mathrm{He}$ & 540 & 6 & 2,574 & 54 & 24 & 72 & 150 \\
\hline
\end{tabular}




\begin{tabular}{|c|c|c|c|c|c|c|c|c|c|c|}
\hline Computer Science Data & $\begin{array}{l}\text { Department } \\
\text { Publications }\end{array}$ & Rank & Most Prolific Author & Published & Rank & Cited & Rank & $\begin{array}{c}\text { H- } \\
\text { Index }\end{array}$ & Rank & $\begin{array}{c}\text { \# of } \\
\text { Coauthors }\end{array}$ \\
\hline Aalto University & 3,893 & 40 & M.T. Hallikainen & 313 & 83 & 1,694 & 126 & 19 & 140 & 150 \\
\hline Aarhus University & 1,233 & 187 & O. Danvy & 91 & 288 & 305 & 280 & 9 & 269 & 57 \\
\hline Arizonia State University & 625 & 281 & S. Panchanathan & 236 & 149 & 813 & 205 & 14 & 201 & 150 \\
\hline Ateneo de Manila University & 23 & 345 & J.P.C. Vergara & 5 & 345 & 19 & 343 & 3 & 340 & 3 \\
\hline Auburn University & 1,363 & 171 & J.K. Tugnait & 244 & 142 & 1,143 & 170 & 16 & 174 & 38 \\
\hline Australian National University & 1,968 & 114 & R.A. Kennedy & 172 & 194 & 735 & 217 & 13 & 211 & 85 \\
\hline Boston College & 273 & 333 & P. Clote & 47 & 332 & 207 & 302 & 8 & 286 & 38 \\
\hline Boston University & 2,165 & 99 & S. Grossberg & 299 & 95 & 6,313 & 23 & 32 & 50 & 125 \\
\hline Brandeis University & 327 & 326 & J.A. Storer & 62 & 322 & 390 & 260 & 8 & 286 & 28 \\
\hline Brigham Young University & 535 & 296 & D. Henderson & 368 & 50 & 3,013 & 74 & 29 & 72 & 150 \\
\hline Brown University & 2,038 & 106 & R. Tamassia & 136 & 244 & 992 & 184 & 13 & 211 & 150 \\
\hline California Institute of Technology (Calt... & 4,845 & 24 & P.P. Vaidyanathan & 335 & 73 & 2,299 & 103 & 20 & 130 & 74 \\
\hline Cardiff University & 1,418 & 164 & P.L. Rosin & 124 & 255 & 1,144 & 169 & 18 & 150 & 83 \\
\hline Carnegie Mellon University & 9,525 & 4 & T. Kanade & 370 & 49 & 9,377 & 16 & 37 & 29 & 150 \\
\hline Case Western Reserve University & 1,135 & 199 & G. Ozsoyoglu & 82 & 294 & 396 & 258 & 7 & 305 & 75 \\
\hline Chalmers University of Technology & 1,958 & 117 & P.S. Kildal & 311 & 86 & 936 & 187 & 20 & 130 & 150 \\
\hline Charles University & 738 & 261 & B Asman & 373 & 46 & 3,193 & 71 & 28 & 77 & 150 \\
\hline Chinese University of Hong Kong & 2,238 & 92 & M.R. Lyu & 236 & 149 & 858 & 198 & 15 & 192 & 150 \\
\hline Chulalongkorn University & 683 & 269 & C. Lursinap & 102 & 275 & 111 & 329 & 5 & 326 & 117 \\
\hline City University of Hong Kong & 5,014 & 23 & G.Chen & 681 & 6 & 14,794 & 6 & 61 & 5 & 150 \\
\hline City University of New York & 903 & 231 & T. Raphan & 135 & 246 & 1,224 & 161 & 21 & 123 & 105 \\
\hline Colorado State University & 694 & 268 & J.J. Rocca & 356 & 57 & 1,580 & 134 & 27 & 88 & 150 \\
\hline Columbia University & 3,853 & 42 & X. Wang & 800 & 4 & 29,940 & 1 & 57 & 6 & 150 \\
\hline Cornell University & 4,292 & 30 & L.Tong & 286 & 104 & 2,610 & 84 & 25 & 100 & 122 \\
\hline Curtin University of Technology & 1,159 & 195 & E. Chang & 315 & 82 & 295 & 283 & 8 & 286 & 132 \\
\hline Dalhousie University & 1,037 & 215 & C. Watters & 70 & 309 & 146 & 320 & 7 & 305 & 150 \\
\hline \begin{tabular}{|l|} 
Dartmouth College \\
\end{tabular} & 1,310 & 176 & D. Kotz & 83 & 292 & 833 & 202 & 17 & 158 & 91 \\
\hline Delft University of Technology & 4,484 & 27 & S. Vassilliadis & 233 & 153 & 641 & 227 & 12 & 222 & 150 \\
\hline Drexel University & 1,771 & 134 & A.P. Petropulu & 151 & 225 & 572 & 239 & 15 & 192 & 104 \\
\hline Duke University & 2,656 & 72 & P.K. Agarwal & 253 & 137 & 4,245 & 40 & 21 & 123 & 150 \\
\hline Durham University & 751 & 259 & M.Munro & 79 & 296 & 282 & 286 & 8 & 286 & 80 \\
\hline Ecole Normale Supérieure de Lyon & 643 & 274 & Y Robert & 140 & 239 & 524 & 245 & 11 & 242 & 110 \\
\hline École Normale Supérieure, Paris & 782 & 249 & D. Pointcheual & 26 & 340 & 62 & 335 & 5 & 326 & 20 \\
\hline École Polytechnique & 1,051 & 213 & C. Palamidessi & 69 & 312 & 208 & 300 & 9 & 269 & 63 \\
\hline
\end{tabular}




\begin{tabular}{|c|c|c|c|c|c|c|c|c|c|c|}
\hline Ecole Polytechnique Fédérale de Lausanne & 3,859 & 41 & R. Gueerraoui & 176 & 193 & 1,270 & 155 & 17 & 158 & 145 \\
\hline Eindhoven University of Technology & 3,651 & 46 & W.M.P. Van Der Aalst & 193 & 178 & 2,506 & 89 & 31 & 62 & 149 \\
\hline Emory University & 505 & 301 & V. Rodl & 212 & 163 & 650 & 226 & 14 & 201 & 116 \\
\hline Erasmus University Rotterdam & 703 & 267 & V. Kaymak & 72 & 307 & 480 & 250 & 11 & 242 & 77 \\
\hline ETH Zurich (Swiss Federal Institute of Technology) & 4,219 & 33 & L.Van Gool & 17 & 342 & 172 & 312 & 6 & 318 & 51 \\
\hline Florida International University & 1,194 & 188 & T. $\mathrm{Li}$ & 1,201 & 1 & 769 & 212 & 38 & 26 & 150 \\
\hline Florida State University & 869 & 237 & E. Barberis & 259 & 124 & 2,379 & 99 & 32 & 50 & 150 \\
\hline Freie Universität Berlin & 715 & 263 & C. Krauer & 54 & 326 & 59 & 338 & 4 & 335 & 84 \\
\hline Friedrich Alexander Universität Erlangen Nürnberg & 2,758 & 68 & H. Niemannn & 147 & 231 & 918 & 189 & 14 & 201 & 150 \\
\hline Fudan University & 2,520 & 78 & A. Zhou & 170 & 197 & 396 & 258 & 9 & 269 & 150 \\
\hline Georg August Universität Göttingen & 439 & 313 & P. Polozov & 99 & 279 & 216 & 298 & 8 & 286 & 150 \\
\hline George Mason University & 1,188 & 191 & S. Jajodia & 266 & 117 & 2,252 & 104 & 26 & 93 & 150 \\
\hline George Washington University & 1,391 & 167 & D.A. Grier & 77 & 301 & 17 & 344 & 3 & 340 & 2 \\
\hline Georgetown University & 446 & 309 & S.K.Mun & 193 & 178 & 800 & 208 & 11 & 242 & 150 \\
\hline Georgia Institute of Technology & 7,735 & 8 & I.F. Akyildiz & 242 & 145 & 9,875 & 13 & 36 & 33 & 139 \\
\hline Georgia State University & 1,175 & 193 & Y. Pan & 259 & 124 & 1,192 & 164 & 22 & 114 & 150 \\
\hline Goteborg University & 924 & 229 & V.P. Zhdanov & 291 & 100 & 1,912 & 116 & 23 & 110 & 82 \\
\hline Harvard University & 2,206 & 96 & W.M. Davis & 237 & 148 & 3,363 & 65 & 33 & 47 & 150 \\
\hline Hebrew University of Jerusalem & 1,798 & 131 & D. Dolev & 156 & 215 & 1,295 & 153 & 10 & 254 & 146 \\
\hline Heidelberg Universität & 704 & 266 & F. Stephan & 113 & 266 & 256 & 290 & 9 & 269 & 82 \\
\hline Hokkaido University & 1,689 & 139 & Y. Kakazu & 184 & 186 & 156 & 318 & 7 & 305 & 106 \\
\hline Hong Kong Polytechnic University & 4,220 & 32 & D. Zhang & 307 & 88 & 2,993 & 76 & 30 & 68 & 150 \\
\hline Hong Kong University of Science \& Techno... & 1,933 & 120 & Q. Yang & 351 & 63 & 1,493 & 139 & 16 & 174 & 150 \\
\hline Humboldt-Universität zu Berlin & 1,177 & 192 & A. Coja-Oghlan & 50 & 331 & 59 & 338 & 5 & 326 & 31 \\
\hline Imperial College London & 4,082 & 36 & W. Luk & 254 & 136 & 819 & 204 & 15 & 192 & 150 \\
\hline Indian Institute of Technology Bombay (I... & 1,142 & 197 & S. Chaudhuri & 123 & 258 & 756 & 213 & 12 & 222 & 109 \\
\hline Indian Institute of Technology Delhi (II... & 1,527 & 156 & S. Chaudury & 94 & 286 & 316 & 276 & 9 & 269 & 130 \\
\hline Indian Institute of Technology Kanpur (I... & 1,084 & 208 & K.Deb & 137 & 241 & 3,739 & 58 & 21 & 123 & 150 \\
\hline Indiana University Bloomington & 2,092 & 104 & G. Fox & 264 & 121 & 1,437 & 142 & 12 & 222 & 150 \\
\hline Indiana University Indianapolis & 103 & 341 & A.K. Dunker & 152 & 222 & 2,449 & 92 & 41 & 17 & 150 \\
\hline Iowa State University & 1,277 & 180 & D. Strom & 355 & 58 & 1,616 & 131 & 25 & 100 & 150 \\
\hline Johns Hopkins University & 3,107 & 56 & S.H. Snyder & 300 & 92 & 14,180 & 7 & 75 & 1 & 150 \\
\hline Kansas State University & 402 & 318 & E. Barberis & 259 & 124 & 2,381 & 95 & 32 & 50 & 150 \\
\hline Katholieke Universiteit Leuven & 3,829 & 43 & M. Moonen & 271 & 114 & 1,467 & 141 & 20 & 130 & 131 \\
\hline Keio University & 2,417 & 83 & I. Sasase & 350 & 64 & 370 & 266 & 8 & 286 & 150 \\
\hline
\end{tabular}




\begin{tabular}{|c|c|c|c|c|c|c|c|c|c|c|}
\hline King Fahd University of Petroleum \& Minerals & 1,244 & 182 & H.M. Badawi & 133 & 247 & 233 & 296 & 10 & 254 & 66 \\
\hline King Saud University & 709 & 264 & S.A. Alshebeili & 55 & 325 & 62 & 335 & 4 & 335 & 36 \\
\hline Kobe University & 1,082 & 209 & S. Abe & 114 & 265 & 727 & 218 & 11 & 242 & 98 \\
\hline Korea Advanced Institute of Science \& Technology & 5,052 & 22 & D.K. Sung & 209 & 164 & 562 & 241 & 13 & 211 & 15 \\
\hline Korea University & 2,805 & 66 & S.W. Lee & 146 & 233 & 835 & 200 & 16 & 174 & 139 \\
\hline Kyoto University & 5,680 & 17 & M. Tanaka & 376 & 44 & 2,358 & 102 & 29 & 72 & 150 \\
\hline Kyushu University & 2,030 & 108 & K. Sakuri & 154 & 219 & 205 & 304 & 8 & 286 & 150 \\
\hline La Trobe University & 762 & 255 & D. Taniar & 152 & 222 & 157 & 316 & 9 & 269 & 107 \\
\hline Lancaster University & 641 & 275 & M. Abolins & 259 & 124 & 2,192 & 106 & 31 & 62 & 150 \\
\hline Leiden University & 1,240 & 186 & K. De Groot & 294 & 98 & 5,468 & 30 & 40 & 20 & 150 \\
\hline Linkoping University & 1,816 & 130 & F. Gustafsson & 127 & 251 & 1,236 & 159 & 16 & 174 & 94 \\
\hline London School of Economics and Political Science & 460 & 307 & Whitley, E.A. & 23 & 341 & 120 & 325 & 6 & 318 & 19 \\
\hline Loughborough University & 1,604 & 146 & D.J. Evans & 82 & 294 & 9,579 & 15 & 39 & 24 & 150 \\
\hline Louisiana State University & 874 & 236 & M. Basile & 479 & 15 & 4,941 & 34 & 43 & 15 & 150 \\
\hline Ludwig-Maximilians-Universität München & 1,386 & 168 & H.P. Kriegel & 171 & 195 & 2,404 & 94 & 20 & 130 & 111 \\
\hline Lund University & 1,831 & 129 & A. Lingas & 88 & 289 & 241 & 294 & 8 & 286 & 60 \\
\hline Maastricht University & 499 & 302 & W.R.M. Dassen & 125 & 254 & 894 & 191 & 12 & 222 & 150 \\
\hline Macquarie University & 956 & 225 & V. Varadharajan & 150 & 227 & 305 & 280 & 8 & 286 & 89 \\
\hline Mahidol University & 207 & 337 & C. Pornpanomchai & 15 & 343 & 5 & 345 & 2 & 342 & 28 \\
\hline Masaryk University & 492 & 303 & P. Zezula & 52 & 329 & 183 & 309 & 7 & 305 & 32 \\
\hline Massachusetts Institute of Technology & 9,010 & 5 & A.S. Willsky & 363 & 54 & 3,972 & 49 & 28 & 77 & 150 \\
\hline McGill University & 3,206 & 54 & T. Le-Ngoc & 325 & 78 & 586 & 235 & 12 & 222 & 150 \\
\hline McMaster University & 2,036 & 107 & K.M. Wong & 161 & 210 & 1,189 & 165 & 16 & 174 & 111 \\
\hline Michigan State University & 2,482 & 81 & J.B. Hook & 295 & 97 & 742 & 214 & 2 & 342 & 150 \\
\hline Michigan Technological University & 777 & 252 & Z. Tain & 96 & 281 & 1,105 & 179 & 18 & 150 & 98 \\
\hline Monash University & 2,401 & 84 & D. Tanier & 153 & 220 & 157 & 316 & 9 & 269 & 110 \\
\hline Montana State University & 308 & 327 & B. Zhu & 64 & 318 & 184 & 307 & 8 & 286 & 80 \\
\hline Moscow State University & 1,370 & 170 & N. Vereshchagin & 44 & 335 & 92 & 331 & 7 & 305 & 41 \\
\hline Nagoya University & 3,060 & 57 & T. Fukuda & 1,122 & 2 & 5,847 & 26 & 28 & 77 & 150 \\
\hline Nanjing University & 2,401 & 84 & Z.H. Zhou & 213 & 162 & 1,624 & 130 & 24 & 109 & 150 \\
\hline Nanyang Technological University & 7,586 & 9 & E.P. Lim & 141 & 238 & 370 & 266 & 10 & 254 & 150 \\
\hline National Taiwan University & 5,198 & 20 & S.C. Pei & 303 & 91 & 1,571 & 135 & 18 & 150 & 108 \\
\hline National Tsing Hua University & 3,252 & 53 & B.S. Chen & 257 & 134 & 2,512 & 88 & 23 & 110 & 150 \\
\hline National University of Ireland, Galway & 640 & 276 & M. Hauswirth & 73 & 305 & 366 & 268 & 10 & 254 & 100 \\
\hline National University of Singapore & 7,427 & 11 & K.L. Tan & 184 & 186 & 864 & 195 & 17 & 158 & 150 \\
\hline New Mexico State University & 1,025 & 217 & H.T. Nguyen & 218 & 157 & 834 & 201 & 12 & 222 & 150 \\
\hline
\end{tabular}




\begin{tabular}{|c|c|c|c|c|c|c|c|c|c|c|}
\hline New York University & 2,350 & 87 & M. Sharir & 345 & 67 & 2,106 & 111 & 19 & 140 & 150 \\
\hline Newcastle University & 1,437 & 163 & A. Romanovsky & 110 & 267 & 118 & 326 & 9 & 269 & 150 \\
\hline North Carolina State University & 2,785 & 67 & G.N. Rouskas & 109 & 268 & 1,421 & 146 & 20 & 130 & 65 \\
\hline Northeastern University & 1,966 & 116 & F. Lombardi & 244 & 142 & 494 & 249 & 12 & 222 & 143 \\
\hline Northwestern University & 2,956 & 61 & A.K. Katsaggellos & 418 & 36 & 2,936 & 78 & 25 & 100 & 150 \\
\hline Norwegian University of Science \& Technology & 2,226 & 93 & A. Abraham & 313 & 83 & 784 & 210 & 16 & 174 & 150 \\
\hline Ohio State University & 4,344 & 29 & D.K. Panda & 199 & 170 & 574 & 238 & 12 & 222 & 150 \\
\hline Oklahoma State University & 899 & 233 & G.G. Yen & 150 & 227 & 740 & 216 & 12 & 222 & 55 \\
\hline Open University UK & 1,292 & 178 & E. Motta & 115 & 263 & 579 & 237 & 12 & 222 & 90 \\
\hline Oregon State University & 1,241 & 185 & B. Bose & 101 & 276 & 346 & 271 & 8 & 286 & 48 \\
\hline Osaka University & 5,323 & 18 & M. Murata & 471 & 24 & 2,518 & 86 & 21 & 123 & 150 \\
\hline Peking University & 3,721 & 45 & H. Mei & 188 & 181 & 337 & 272 & 11 & 242 & 150 \\
\hline Pennsylvania State University & 4,812 & 25 & M.J. Irwin & 332 & 74 & 1,347 & 150 & 19 & 140 & 150 \\
\hline Pohang University of Science And Technology & 1,724 & 136 & D. Kim & 108 & 269 & 613 & 231 & 12 & 222 & 96 \\
\hline Portland State University & 899 & 233 & X. Song & 167 & 204 & 459 & 252 & 12 & 222 & 150 \\
\hline Princeton University & 4,118 & 35 & N.K. Jha & 282 & 106 & 1,538 & 137 & 22 & 114 & 136 \\
\hline Purdue University & 6,472 & 14 & E. Bertino & 380 & 42 & 1,940 & 115 & 25 & 100 & 150 \\
\hline Queen's University & 2,121 & 102 & S.A. Akl & 167 & 204 & 440 & 253 & 8 & 286 & 76 \\
\hline Queen's University of Belfast & 1,313 & 175 & A. Buridane & 104 & 272 & 226 & 297 & 8 & 286 & 70 \\
\hline Queensland University of Technology & 1,535 & 155 & S. Sridharan & 152 & 222 & 378 & 261 & 10 & 254 & 122 \\
\hline Radboud University, Nijmegen & 1,126 & 200 & B. Jacobs & 69 & 312 & 298 & 282 & 11 & 242 & 58 \\
\hline Rensselaer Polytechnic Institute & 2,614 & 73 & M.S. Shepard & 208 & 167 & 1,165 & 167 & 17 & 158 & 150 \\
\hline Rheinisch Westfalische Technische Hochschule Aach & 3,254 & 52 & H. Ney & 198 & 172 & 1,515 & 138 & 20 & 130 & 150 \\
\hline Rheinische Friedrich Wilhelms Universitat Bonn & 1,296 & 177 & M. Karinski & 96 & 281 & 568 & 240 & 10 & 254 & 80 \\
\hline Rice University & 2,045 & 105 & M.Y. Vardi & 235 & 151 & 2,171 & 107 & 16 & 174 & 150 \\
\hline Rochester Institute of Technology & 1,094 & 207 & M.D. Fairchild & 170 & 197 & 1,138 & 171 & 19 & 140 & 125 \\
\hline Royal Institute of Technology, KTH & 2,730 & 69 & B. Ottersten & 184 & 186 & 1,859 & 122 & 21 & 123 & 103 \\
\hline Royal Melbourne Institute of Technology & 1,118 & 202 & J. Zobel & 95 & 284 & 919 & 188 & 17 & 158 & 60 \\
\hline Rutgers & 4,060 & 37 & M. Parashar & 148 & 230 & 617 & 230 & 14 & 201 & 150 \\
\hline Saint-Petersburg State University & 440 & 311 & I. E. Bocharova & 35 & 339 & 46 & 340 & 5 & 326 & 23 \\
\hline San Diego State University & 551 & 293 & F. Harris & 65 & 316 & 206 & 303 & 8 & 286 & 30 \\
\hline Sapienza University of Rome & 0 & 347 & & 0 & 347 & 0 & 346 & 0 & 346 & 0 \\
\hline Sciences Po Paris & 0 & 347 & & 0 & 347 & 0 & 346 & 0 & 346 & 0 \\
\hline Seoul National University & 4,285 & 31 & S.U. Lee & 218 & 157 & 1,333 & 151 & 14 & 201 & 150 \\
\hline Shanghai Jiao Tong University & 6,580 & 13 & M. Li & 266 & 117 & 216 & 298 & 8 & 286 & 150 \\
\hline Simon Fraser University & 2,381 & 86 & J. Pei & 245 & 141 & 2,845 & 80 & 33 & 47 & 150 \\
\hline
\end{tabular}




\begin{tabular}{|c|c|c|c|c|c|c|c|c|c|c|}
\hline Stanford University & 9,959 & 2 & H. Garcia-Molina & 250 & 139 & 3,771 & 57 & 30 & 68 & 150 \\
\hline State University of New York Buffalo & 32 & 344 & V.E. Brimkov & 47 & 332 & 69 & 333 & 6 & 318 & 19 \\
\hline Stockholm University & 455 & 308 & M. Kajko-mattsson & 64 & 318 & 63 & 334 & 5 & 326 & 90 \\
\hline Stony Brook University & 2,209 & 94 & P.M. Djuric & 171 & 195 & 1,130 & 175 & 17 & 158 & 101 \\
\hline Syracuse University & 708 & 265 & T.K. Sarkar & 501 & 14 & 3,935 & 53 & 20 & 130 & 150 \\
\hline Tartu University (University of Tartu) & 297 & 331 & M. Karelson & 137 & 241 & 2,514 & 87 & 28 & 77 & 150 \\
\hline Technical University of Denmark & 1,976 & 113 & L.K. Hasen & 169 & 201 & 2,072 & 112 & 21 & 123 & 150 \\
\hline Technion & 5,285 & 19 & S.Sharmi & 282 & 106 & 3,260 & 70 & 26 & 93 & 122 \\
\hline Technische Universität Berlin & 2,564 & 75 & H. Boche & 322 & 79 & 859 & 197 & 16 & 174 & 62 \\
\hline Technische Universitat Chemnitz & 591 & 286 & T. Gressner & 288 & 102 & 693 & 222 & 13 & 211 & 150 \\
\hline Technische Universität Dresden & 2,350 & 87 & G.P. Fettweis & 243 & 144 & 1,877 & 118 & 16 & 174 & 150 \\
\hline Technische Universität München & 3,974 & 38 & M. Buss & 216 & 159 & 471 & 251 & 9 & 269 & 150 \\
\hline Tel Aviv University & 4,364 & 28 & M. Sharir & 345 & 67 & 2,111 & 110 & 19 & 140 & 150 \\
\hline Texas A\&M University & 4,150 & 34 & E.R. Dougherty & 376 & 44 & 3,926 & 54 & 32 & 50 & 150 \\
\hline Texas Tech & 333 & 325 & C. Bromberg & 470 & 25 & 4,216 & 41 & 46 & 12 & 150 \\
\hline Tohoku University & 2,888 & 63 & F. Adachi & 365 & 53 & 1,980 & 113 & 23 & 110 & 150 \\
\hline Tokyo Institute of Technology & 4,569 & 26 & K. Hirota & 215 & 160 & 741 & 215 & 13 & 211 & 150 \\
\hline Trinity College Dublin & 1,059 & 212 & V. Cahill & 76 & 302 & 292 & 284 & 8 & 286 & 95 \\
\hline Tsinghua University & 11,261 & 1 & C. Lin & 51 & 330 & 166 & 313 & 7 & 305 & 106 \\
\hline Tufts University & 548 & 294 & K.A. Panetta & 66 & 315 & 95 & 330 & 4 & 335 & 28 \\
\hline Universidad Autonoma de Madrid & 1,113 & 203 & J. Aracil & 126 & 252 & 376 & 262 & 9 & 269 & 150 \\
\hline Universidad de Chile & 1,016 & 219 & G. Navarro & 143 & 236 & 1,131 & 174 & 17 & 158 & 150 \\
\hline Universidad de Granada & 1,113 & 203 & J. Aracil & 126 & 252 & 376 & 262 & 9 & 269 & 150 \\
\hline Universidad del País Vasco & 1,373 & 169 & M. De la Sen & 405 & 38 & 561 & 242 & 16 & 174 & 71 \\
\hline Universidad Nacional Autónoma de México ... & 415 & 315 & S. Rajsbaum & 72 & 307 & 184 & 307 & 9 & 269 & 49 \\
\hline Universidad Politecnica de Madrid & 2,871 & 64 & G. Puebla & 60 & 323 & 113 & 328 & 7 & 305 & 61 \\
\hline Universidade de São Paulo & 1,242 & 184 & C. Traina & 78 & 300 & 144 & 321 & 7 & 305 & 60 \\
\hline Universidade Estadual de Campinas & 769 & 254 & F.J. Von Zuben & 144 & 235 & 900 & 190 & 12 & 222 & 145 \\
\hline Università degli Studi di Firenze & 2,009 & 109 & A. Del Bimbo & 231 & 154 & 1,236 & 159 & 15 & 192 & 136 \\
\hline Università degli Studi di Padova & 2,181 & 98 & M. Zorzi & 281 & 109 & 2,457 & 91 & 21 & 123 & 150 \\
\hline Universita Di Bologna & 3,329 & 50 & L. Benini & 292 & 99 & 2,965 & 77 & 29 & 72 & 150 \\
\hline Universita di Pisa & 1,478 & 159 & A. Hocker & 355 & 58 & 2,896 & 79 & 28 & 77 & 150 \\
\hline Universitat Autonoma de Barcelona & 1,244 & 182 & E. Luque & 156 & 215 & 139 & 322 & 6 & 318 & 110 \\
\hline Universitat Bielefeld & 930 & 228 & H. Ritter & 124 & 255 & 971 & 186 & 16 & 174 & 135 \\
\hline Universität Bremen & 1,563 & 152 & R. Drechsler & 240 & 146 & 589 & 234 & 13 & 211 & 125 \\
\hline Universitat d'Alacant & 972 & 224 & J.D. Trujillo & 104 & 272 & 255 & 291 & 11 & 242 & 58 \\
\hline
\end{tabular}




\begin{tabular}{|c|c|c|c|c|c|c|c|c|c|c|}
\hline Universitat de València & 1,049 & 214 & G. Campos-Valls & 79 & 296 & 620 & 229 & 16 & 174 & 86 \\
\hline Universität Frankfurt am Main & 781 & 250 & R. Mester & 38 & 338 & 192 & 305 & 4 & 335 & 30 \\
\hline Universität Freiburg & 1,417 & 165 & W. Burgard & 161 & 210 & 3,004 & 75 & 28 & 77 & 150 \\
\hline Universitat Hamburg & 470 & 305 & A. De Roeck & 434 & 32 & 5,073 & 32 & 40 & 20 & 150 \\
\hline Universität Karlsruhe & 3,377 & 49 & R. Dillmann & 229 & 156 & 582 & 236 & 12 & 222 & 150 \\
\hline Universitat Leipzig & 546 & 295 & P.F. Stadler & 304 & 90 & 3,528 & 60 & 35 & 39 & 150 \\
\hline Universitat Munster (Westfälische Wilhelms-Un & 386 & 322 & X. Jiang & 104 & 272 & 783 & 211 & 12 & 222 & 116 \\
\hline Universitat Politecnica de Catalunya & 2,115 & 103 & C. Aleman & 268 & 116 & 1,431 & 143 & 22 & 114 & 150 \\
\hline Universität Regensburg & 406 & 316 & E.W. Lang & 156 & 215 & 1,264 & 156 & 17 & 158 & 150 \\
\hline Universität Stuttgart & 1,979 & 112 & T. Ertl & 115 & 263 & 830 & 203 & 17 & 158 & 150 \\
\hline Universitat Trier & 304 & 329 & H. Fernau & 85 & 291 & 235 & 295 & 9 & 269 & 57 \\
\hline Universität Tübingen & 955 & 226 & W.Rosenstiel & 156 & 215 & 279 & 287 & 7 & 305 & 150 \\
\hline Universitat Wien (University of Vienna) & 1,153 & 196 & P.F. Stadler & 300 & 92 & 3,862 & 55 & 37 & 29 & 150 \\
\hline Universitat Zu Koln & 571 & 290 & D. Stauffer & 358 & 56 & 3,434 & 61 & 25 & 100 & 150 \\
\hline Université Catholique de Louvain & 1,700 & 137 & L. Vandendorpe & 235 & 151 & 851 & 199 & 13 & 211 & 150 \\
\hline Universite de Liege & 660 & 270 & G. Leduc & 56 & 324 & 126 & 324 & 6 & 318 & 54 \\
\hline Université de Montréal & 1,692 & 138 & J.W. Gary & 476 & 19 & 4,131 & 43 & 36 & 33 & 150 \\
\hline Université de Nice Sophia Antipolis & 1,107 & 205 & M. Barlaud & 146 & 233 & 2,646 & 82 & 13 & 211 & 97 \\
\hline Universite Laval & 1,271 & 181 & B. Moulin & 96 & 281 & 176 & 310 & 7 & 305 & 77 \\
\hline Universite Libre de Bruxelles & 1,072 & 210 & R. Kiss & 469 & 26 & 3,559 & 59 & 32 & 50 & 150 \\
\hline Université Paris Sorbonne & 400 & 319 & C. Rolland & 79 & 296 & 415 & 255 & 10 & 254 & 80 \\
\hline Universite Paris-Sud 11 & 2,207 & 95 & N. Spyratos & 70 & 309 & 163 & 314 & 5 & 326 & 58 \\
\hline Université Pierre et Marie Curie & 2,604 & 74 & M. Besancon & 336 & 71 & 3,433 & 62 & 30 & 68 & 150 \\
\hline Universiti Malaya (University of Malaya) & 630 & 277 & P. Raveendran & 46 & 334 & 208 & 300 & 7 & 305 & 31 \\
\hline University College Cork & 891 & 235 & B. O'Sullivan & 136 & 244 & 376 & 262 & 12 & 222 & 150 \\
\hline University College Dublin & 1,322 & 174 & B. Smyth & 149 & 229 & 706 & 221 & 15 & 192 & 92 \\
\hline University College London & 2,970 & 60 & A.A. Carter & 479 & 15 & 3,979 & 48 & 34 & 43 & 150 \\
\hline University do Porto & 615 & 283 & A.E. Rodrigues & 327 & 77 & 2,143 & 108 & 27 & 88 & 150 \\
\hline University of Aberdeen & 747 & 260 & B.C. Jones & 92 & 287 & 1,153 & 168 & 22 & 114 & 150 \\
\hline University of Adelaide & 984 & 223 & D. Abbott & 368 & 50 & 1,862 & 120 & 27 & 88 & 150 \\
\hline University of Alabama & 1,625 & 145 & J.J. Buckley & 199 & 170 & 1,245 & 158 & 14 & 201 & 39 \\
\hline University of Alberta & 3,755 & 44 & W. Pedrycz & 509 & 13 & 4,118 & 46 & 27 & 88 & 150 \\
\hline University of Amsterdam & 2,272 & 90 & A.W.M. Smeulders & 160 & 212 & 3,342 & 66 & 19 & 140 & 135 \\
\hline University of Antwerp & 952 & 227 & M. Besancon & 336 & 71 & 3,433 & 62 & 30 & 68 & 150 \\
\hline University of Arizona & 3,586 & 47 & H. Chen & 282 & 106 & 1,873 & 119 & 26 & 93 & 150 \\
\hline University of Athens & 1,563 & 152 & I. Stavrakakis & 133 & 247 & 315 & 277 & 9 & 269 & 98 \\
\hline
\end{tabular}




\begin{tabular}{|c|c|c|c|c|c|c|c|c|c|c|}
\hline University of Auckland & 1,867 & 124 & R. Klette & 121 & 259 & 310 & 279 & 10 & 254 & 96 \\
\hline University of Barcelona & 591 & 286 & P. Radeva & 138 & 240 & 376 & 262 & 11 & 242 & 128 \\
\hline University of Basel & 289 & 332 & W.J. Gehring & 209 & 164 & 6,605 & 22 & 32 & 50 & 150 \\
\hline University of Bath & 1,003 & 220 & D.M. Monro & 70 & 309 & 415 & 255 & 6 & 318 & 63 \\
\hline University of Bergen & 627 & 279 & T. Adye & 343 & 69 & 3,388 & 64 & 29 & 72 & 150 \\
\hline University of Bern & 479 & 304 & H. Bunke & 275 & 111 & 1,723 & 124 & 20 & 130 & 150 \\
\hline University of Birmingham & 1,665 & 143 & J.W. Gary & 476 & 19 & 4,165 & 42 & 36 & 33 & 150 \\
\hline University of Bristol & 1,856 & 127 & D.R. Bull & 258 & 133 & 1,222 & 162 & 16 & 174 & 150 \\
\hline University of British Columbia & 1,946 & 118 & J.W. Gary & 476 & 19 & 4,131 & 43 & 36 & 33 & 150 \\
\hline University of Calgary & 1,498 & 157 & R. Alhajj & 181 & 189 & 271 & 288 & 10 & 254 & 110 \\
\hline University of California, Berkley & 8,211 & 7 & C. $\mathrm{Hu}$ & 622 & 9 & 10,294 & 11 & 41 & 17 & 150 \\
\hline University of California, Davis & 1,470 & 161 & B. Mukherjee & 367 & 52 & 4,935 & 35 & 40 & 20 & 150 \\
\hline University of California, Irvine & 2,245 & 91 & D. Eppstein & 166 & 206 & 1,426 & 145 & 15 & 192 & 99 \\
\hline University of California, Los Angeles & 5,927 & 16 & M. Gerla & 464 & 27 & 4,583 & 37 & 31 & 62 & 150 \\
\hline University of California, Riverside & 1,564 & 151 & B. Bhanu & 204 & 168 & 1,298 & 152 & 18 & 150 & 127 \\
\hline University of California, San Diego & 2,551 & 77 & J.A. McCammon & 451 & 29 & 9,880 & 12 & 47 & 11 & 150 \\
\hline University of California, San Francisco & 584 & 288 & J.M. Bishop & 425 & 35 & 11,011 & 10 & 36 & 33 & 150 \\
\hline University of California, Santa Barbara & 1,593 & 148 & D. Agrawal & 185 & 184 & 879 & 193 & 14 & 201 & 125 \\
\hline University of California, Santa Cruz & 630 & 277 & D. Haussler & 169 & 201 & 18,333 & 5 & 50 & 7 & 150 \\
\hline University of Cambridge & 1,786 & 133 & A.A. Carter & 477 & 17 & 3,969 & 50 & 34 & 43 & 150 \\
\hline University of Canterbury & 444 & 310 & J.G. Chase & 131 & 250 & 321 & 275 & 13 & 211 & 150 \\
\hline University of Cape Town & 251 & 336 & G. Marsden & 40 & 337 & 61 & 337 & 4 & 335 & 67 \\
\hline University of Central Florida & 2,505 & 80 & M.A. Shah & 198 & 172 & 4,033 & 47 & 28 & 77 & 126 \\
\hline University of Chicago & 785 & 248 & A.A. Carter & 477 & 17 & 3,969 & 50 & 34 & 43 & 150 \\
\hline University of Cincinnati & 1,412 & 166 & D.P. Agrawal & 330 & 76 & 1,788 & 123 & 19 & 140 & 150 \\
\hline University of Colorado at Boulder & 1,330 & 173 & A. Ehrenfeucht & 124 & 255 & 1,385 & 148 & 5 & 326 & 64 \\
\hline University of Connecticut & 836 & 244 & B. Javidi & 429 & 34 & 2,124 & 109 & 43 & 15 & 150 \\
\hline University of Copenhagen & 843 & 243 & M. Nielsen & 54 & 326 & 150 & 319 & 5 & 326 & 57 \\
\hline University of Delaware & 809 & 247 & D.W. Prather & 273 & 113 & 1,277 & 154 & 22 & 114 & 150 \\
\hline University of Dundee & 440 & 311 & S.J. McKenna & 43 & 336 & 655 & 225 & 10 & 254 & 53 \\
\hline University of Edinburgh & 165 & 339 & A. Hocker & 264 & 121 & 2,632 & 83 & 27 & 88 & 150 \\
\hline University of Florida & 1,628 & 144 & P.M. Pardalos & 274 & 112 & 1,639 & 129 & 18 & 150 & 150 \\
\hline University of Geneva & 532 & 297 & G. Carlino & 255 & 135 & 2,381 & 95 & 29 & 72 & 150 \\
\hline University of Georgia & 625 & 281 & S.M. Bhandarkar & 98 & 280 & 356 & 269 & 9 & 269 & 81 \\
\hline University of Ghent & 1,160 & 194 & B. De Baets & 214 & 161 & 1,006 & 183 & 18 & 150 & 150 \\
\hline University of Glasgow & 1,967 & 115 & M. Ould-Khaoua & 201 & 169 & 315 & 277 & 11 & 242 & 150 \\
\hline
\end{tabular}




\begin{tabular}{|c|c|c|c|c|c|c|c|c|c|c|}
\hline University of Gothenburg & 17 & 346 & P.S. Eriksson & 191 & 180 & 4,948 & 33 & 31 & 62 & 150 \\
\hline University of Groningen & 563 & 291 & H.J.C. Berendsen & 165 & 207 & 13,694 & 8 & 38 & 26 & 150 \\
\hline University of Helsinki & 1,591 & 149 & E. Ukkonen & 95 & 284 & 1,430 & 144 & 12 & 222 & 150 \\
\hline University of Hong Kong & 3,028 & 58 & F.C.M. Lau & 231 & 154 & 795 & 209 & 16 & 174 & 150 \\
\hline University of Houston & 901 & 232 & L.S. Shieh & 280 & 110 & 594 & 233 & 14 & 201 & 150 \\
\hline University of Illinois & 9,582 & 3 & T.S. Huang & 660 & 8 & 9,148 & 17 & 39 & 24 & 150 \\
\hline University of Illinois, Chicago & 2,696 & 70 & D. Liu & 177 & 191 & 863 & 196 & 16 & 174 & 150 \\
\hline University of Indonesia & 82 & 342 & M. Adriani & 14 & 344 & 20 & 342 & 2 & 342 & 19 \\
\hline University of Iowa & 849 & 242 & G. Wang & 353 & 62 & 1,893 & 117 & 28 & 77 & 150 \\
\hline University of Kansas & 517 & 299 & E. Barberis & 259 & 124 & 2,381 & 95 & 32 & 50 & 150 \\
\hline University of Kentucky & 754 & 258 & M. Truszczynski & 79 & 296 & 332 & 273 & 8 & 286 & 43 \\
\hline University of Lausanne & 176 & 338 & A. Bay & 348 & 66 & 3,833 & 56 & 35 & 39 & 150 \\
\hline University of Leeds & 851 & 241 & A.V. Holden & 196 & 174 & 1,036 & 182 & 16 & 174 & 150 \\
\hline University of Leicester & 835 & 245 & S. Yang & 54 & 326 & 174 & 311 & 10 & 254 & 49 \\
\hline University of Liverpool & 1,017 & 218 & B Asman & 373 & 46 & 3,133 & 72 & 28 & 77 & 150 \\
\hline University of Ljubljana & 1,878 & 123 & A. Leonardis & 74 & 303 & 711 & 219 & 15 & 192 & 56 \\
\hline University of London (Kings College of London) & 8,779 & 6 & E. Izquierdo & 151 & 225 & 263 & 289 & 8 & 286 & 129 \\
\hline University of Manchester & 3,909 & 39 & S. Nadarajah & 441 & 30 & 348 & 270 & 8 & 286 & 54 \\
\hline University of Manitoba & 1,885 & 122 & W. Kisner & 209 & 164 & 290 & 285 & 9 & 269 & 150 \\
\hline University of Maryland & 7,060 & 12 & A. Rosenfeld & 406 & 37 & 4,429 & 38 & 15 & 192 & 150 \\
\hline University of Maryland Baltimore County & 1,910 & 121 & T. Adail & 165 & 207 & 1,117 & 176 & 22 & 114 & 122 \\
\hline University of Massachusetts & 1,569 & 150 & D. Towsley & 392 & 39 & 5,802 & 27 & 37 & 29 & 150 \\
\hline University of Melbourne & 2,680 & 71 & R. Buyya & 153 & 220 & 1,397 & 147 & 18 & 150 & 150 \\
\hline University of Miami & 390 & 321 & M.L. Shyu & 101 & 276 & 254 & 292 & 7 & 305 & 150 \\
\hline University of Michigan & 2,992 & 59 & P. Bhattacharya & 672 & 7 & 6,166 & 24 & 35 & 39 & 150 \\
\hline University of Minnesota & 2,276 & 89 & D.G. Truhlar & 888 & 3 & 27,089 & 3 & 64 & 3 & 150 \\
\hline University of Missouri & 1,675 & 142 & G.K. Venayagamoorthy & 239 & 147 & 522 & 246 & 14 & 201 & 130 \\
\hline University of Nebraska & 1,602 & 147 & J.S. Deogun & 157 & 214 & 514 & 247 & 13 & 211 & 115 \\
\hline University of New Hampshire & 305 & 328 & J.M. Ryan & 74 & 303 & 188 & 306 & 6 & 318 & 150 \\
\hline University of New Mexico & 659 & 271 & S.B. Kim & 288 & 102 & 5,698 & 28 & 33 & 47 & 150 \\
\hline University of New South Wales & 1,685 & 141 & A.B. Yu & 252 & 138 & 1,592 & 133 & 25 & 100 & 150 \\
\hline University of North Carolina, Chapel Hill & 2,152 & 100 & D. Manocha & 196 & 174 & 1,976 & 114 & 22 & 114 & 150 \\
\hline University of North Texas & 470 & 305 & W.E. Acree & 439 & 31 & 1,475 & 140 & 26 & 93 & 150 \\
\hline University of Notre Dame & 605 & 284 & D. Strom & 355 & 58 & 161 & 315 & 25 & 100 & 150 \\
\hline University of Nottingham & 911 & 230 & E.K. Burke & 106 & 271 & 663 & 224 & 17 & 158 & 126 \\
\hline University of Oklahoma & 555 & 292 & M. Abolins & 259 & 124 & 2,196 & 105 & 31 & 62 & 150 \\
\hline
\end{tabular}




\begin{tabular}{|c|c|c|c|c|c|c|c|c|c|c|}
\hline University of Oregon & 366 & 323 & H.R. Band & 286 & 104 & 2,415 & 93 & 25 & 100 & 150 \\
\hline University of Oslo & 626 & 280 & B.Asman & 373 & 46 & 3,133 & 72 & 28 & 77 & 150 \\
\hline University of Otago & 303 & 330 & M. Purvis & 73 & 305 & 117 & 327 & 7 & 305 & 49 \\
\hline University of Ottawa & 1,193 & 189 & I Stojmenovic & 195 & 177 & 1,604 & 132 & 19 & 140 & 150 \\
\hline University of Oxford & 1,946 & 118 & M.S.P. Sansom & 319 & 80 & 4,589 & 36 & 50 & 7 & 150 \\
\hline University of Pennsylvania & 1,843 & 128 & M.L. Klein & 540 & 12 & 24,170 & 4 & 49 & 10 & 150 \\
\hline University of Pittsburgh & 1,490 & 158 & T. Kanade & 266 & 117 & 1,132 & 173 & 17 & 158 & 150 \\
\hline University of Quebec & 532 & 297 & C. Bouchard & 705 & 5 & 28,823 & 2 & 63 & 4 & 150 \\
\hline University of Queensland & 1,107 & 205 & G.J. Milburn & 270 & 115 & 5,538 & 29 & 34 & 43 & 150 \\
\hline University of Reading & 1,001 & 222 & A.M. Andrew & 65 & 316 & 44 & 341 & 2 & 342 & 0 \\
\hline University of Rochester & 756 & 256 & E. Barberis & 259 & 124 & 2,378 & 100 & 32 & 50 & 150 \\
\hline University of Saskatchewan & 1,287 & 179 & C. Gutwin & 100 & 278 & 808 & 207 & 14 & 201 & 109 \\
\hline University of Science and Technology of China & 3,545 & 48 & D.S. Huang & 165 & 207 & 809 & 206 & 18 & 150 & 113 \\
\hline University of Sheffield & 2,555 & 76 & P. Willett & 558 & 11 & 8,862 & 18 & 41 & 17 & 150 \\
\hline University of South Carolina & 1,060 & 211 & M.N. Huhns & 116 & 261 & 878 & 194 & 12 & 222 & 125 \\
\hline University of South Florida & 854 & 240 & A. Kandel & 246 & 140 & 1,248 & 157 & 16 & 174 & 150 \\
\hline University of Southampton & 1,750 & 135 & L. Hanzo & 610 & 10 & 3,339 & 67 & 25 & 100 & 150 \\
\hline University of Southern California & 2,857 & 65 & A. Warshel & 264 & 121 & 7,769 & 19 & 50 & 7 & 150 \\
\hline University of St Andrews & 262 & 335 & D.I. Perrett & 331 & 75 & 7,439 & 20 & 44 & 14 & 150 \\
\hline University of Surrey & 659 & 271 & J. Kittler & 296 & 96 & 5,453 & 31 & 23 & 110 & 150 \\
\hline University of Sussex & 508 & 300 & M.Hennessy & 64 & 318 & 708 & 220 & 10 & 254 & 34 \\
\hline University of Sydney & 2,516 & 79 & H. Yan & 382 & 41 & 1,860 & 121 & 22 & 114 & 150 \\
\hline University of Technology, Sydney & 831 & 246 & T.S. Dillion & 362 & 55 & 609 & 232 & 11 & 242 & 150 \\
\hline University of Tennessee Knoxville & 856 & 239 & J. Dongarra & 306 & 89 & 2,549 & 85 & 22 & 114 & 150 \\
\hline University of Texas at Austin & 2,907 & 62 & P.Stone & 432 & 33 & 9,636 & 14 & 40 & 20 & 150 \\
\hline University of Tokyo & 3,285 & 51 & A.A. Carter & 474 & 23 & 3,950 & 52 & 35 & 39 & 150 \\
\hline University of Toronto & 6,233 & 15 & J. Mylopoulos & 196 & 174 & 1,560 & 136 & 17 & 158 & 150 \\
\hline University of Tsukuba & 1,191 & 190 & R. Tanaka & 187 & 182 & 984 & 185 & 19 & 140 & 150 \\
\hline University of Twente & 2,452 & 82 & J.A.M. Kuipers & 177 & 191 & 1,722 & 125 & 26 & 93 & 133 \\
\hline University of Utah & 2,129 & 101 & E. Cohen & 88 & 289 & 630 & 228 & 10 & 254 & 67 \\
\hline University of Vermont & 592 & 285 & $\mathrm{X} . \mathrm{Wu}$ & 119 & 260 & 1,172 & 166 & 19 & 140 & 118 \\
\hline University of Victoria & 1,993 & 111 & J.W. Gary & 476 & 19 & 4,127 & 45 & 36 & 33 & 150 \\
\hline University of Virginia & 1,003 & 220 & E. Barberis & 259 & 124 & 2,378 & 100 & 32 & 50 & 150 \\
\hline University of Warwick & 780 & 251 & V.B. Golubev & 309 & 87 & 1,647 & 128 & 26 & 93 & 150 \\
\hline University of Washington & 5,118 & 21 & J.N. Hwang & 185 & 184 & 1,201 & 163 & 15 & 192 & 150 \\
\hline University of Waterloo & 3,185 & 55 & R. Boutaba & 170 & 197 & 513 & 248 & 13 & 211 & 130 \\
\hline
\end{tabular}




\begin{tabular}{|c|c|c|c|c|c|c|c|c|c|c|}
\hline University of Western Australia & 1,033 & 216 & A. Datta & 180 & 190 & 541 & 244 & 11 & 242 & $\overline{146}$ \\
\hline University of Western Ontario & 1,994 & 110 & $\mathrm{X} . \mathrm{Wu}$ & 338 & 70 & 3,276 & 69 & 32 & 50 & 150 \\
\hline University of Wisconsin & 1,863 & 126 & A. Hocker & 355 & 58 & 2,844 & 81 & 28 & 77 & 150 \\
\hline University of Wollongong & 755 & 257 & W. Susilo & 137 & 241 & 331 & 274 & 10 & 254 & 97 \\
\hline University of York & 1,448 & 162 & E.R. Hancock & 385 & 40 & 1,111 & 177 & 20 & 130 & 150 \\
\hline University of Zurich & 392 & 320 & E. Barrelet & 187 & 182 & 2,464 & 90 & 32 & 50 & 150 \\
\hline Univesitas Gadjah Mada & 37 & 343 & S. Hartati & 3 & 346 & 0 & 346 & 0 & 346 & 8 \\
\hline Uppsala University & 771 & 253 & O. Botner & 380 & 42 & 3,337 & 68 & 31 & 62 & 150 \\
\hline Utah State & 406 & 316 & H.D. Cheng & 116 & 261 & 1,100 & 180 & 17 & 158 & 119 \\
\hline Utrecht University & 2,197 & 97 & M.A. Viergever & 313 & 83 & 6,626 & 21 & 38 & 26 & 150 \\
\hline Vanderbilt University & 724 & 262 & R.D. Schrimpf & 350 & 64 & 1,377 & 149 & 26 & 93 & 150 \\
\hline Victoria University of Wellington & 350 & 324 & M. Zhang & 68 & 314 & 73 & 332 & 5 & 326 & 48 \\
\hline Vienna University of Technology & 1,795 & 132 & T. Eiter & 143 & 236 & 1,050 & 181 & 17 & 158 & 109 \\
\hline Virginia Polytechnic Institute & 1,688 & 140 & L.T. Watson & 290 & 101 & 1,667 & 127 & 20 & 130 & 150 \\
\hline Vrije Universiteit, Brussels & 1,342 & 172 & J. Cornelis & 170 & 197 & 680 & 223 & 12 & 222 & 150 \\
\hline VU University Amsterdam & 1,865 & 125 & J. Treur & 168 & 203 & 419 & 254 & 11 & 242 & 81 \\
\hline Wageningen University & 265 & 334 & G.B.M. Heuvelinl & 63 & 321 & 885 & 192 & 16 & 174 & 120 \\
\hline Wake Forest University & 123 & 340 & L.E. Wagenknecht & 133 & 247 & 4,352 & 39 & 37 & 29 & 150 \\
\hline Waseda University & 1,119 & 201 & M.J. Kim & 266 & 117 & 1,133 & 172 & 17 & 158 & 150 \\
\hline Washington State University & 584 & 288 & J.G. Delgado-Frias & 108 & 269 & 129 & 323 & 6 & 318 & 88 \\
\hline Washington University in St. Louis & 863 & 238 & D.C. Rao & 453 & 28 & 6,037 & 25 & 46 & 12 & 150 \\
\hline Wayne State University & 1,542 & 154 & C.K. Xu & 159 & 213 & 405 & 257 & 10 & 254 & 150 \\
\hline West Virginia University & 432 & 314 & B. Cukic & 83 & 292 & 246 & 293 & 9 & 269 & 103 \\
\hline Yale University & 1,142 & 197 & M. Gerstein & 316 & 81 & 13,338 & 9 & 66 & 2 & 150 \\
\hline Yonsei University & 1,477 & 160 & S.B. Cho & 147 & 231 & 1,107 & 178 & 17 & 158 & 150 \\
\hline York University & 653 & 273 & E. Barberis & 259 & 124 & 2,381 & 95 & 32 & 50 & 150 \\
\hline Zhejiang University & 7,440 & 10 & Z. Wu & 300 & 92 & 550 & 243 & 12 & 222 & 150 \\
\hline
\end{tabular}




\begin{tabular}{|c|c|c|c|c|c|c|c|c|c|c|}
\hline Chemical Engineering Data & $\begin{array}{l}\text { Department } \\
\text { Publications }\end{array}$ & Rank & Most Prolific Author & Published & Rank & Cited & Rank & $\begin{array}{c}\text { H- } \\
\text { Index }\end{array}$ & Rank & $\begin{array}{c}\text { \# of } \\
\text { Coauthors }\end{array}$ \\
\hline Aalto University & 1,557 & 76 & K. Kotturi & 178 & 205 & 1,850 & 163 & 25 & 142 & 150 \\
\hline Aarhus University & 446 & 245 & F. Besenbacher & 356 & 71 & 6,583 & 25 & 48 & 16 & 150 \\
\hline Arizonia State University & 348 & 268 & J. Wang & 640 & 11 & 21,818 & 3 & 71 & 5 & 150 \\
\hline Ateneo de Manila University & 0 & 346 & & 0 & 344 & 0 & 343 & 0 & 341 & $\overline{0}$ \\
\hline Auburn University & 1,125 & 116 & B.J. Tatarchuk & 205 & 176 & 500 & 302 & 9 & 310 & 126 \\
\hline Australian National University & 874 & 148 & B.W. Ninham & 325 & 85 & 5,779 & 34 & 29 & 90 & 150 \\
\hline Boston College & 133 & 319 & A.H. Hoveyda & 177 & 209 & 5,874 & 32 & 55 & 9 & 150 \\
\hline Boston University & 594 & 202 & H.E Stanley & 480 & 33 & 10,348 & 17 & 57 & 7 & 150 \\
\hline Brandeis University & 112 & 326 & G.A. Petsko & 302 & 101 & 6,292 & 28 & 32 & 66 & 150 \\
\hline Brigham Young University & 347 & 269 & R.M. Izatt & 422 & 44 & 5,873 & 33 & 22 & 171 & 150 \\
\hline Brown University & 807 & 159 & T.J. Webster & 261 & 131 & 2,323 & 130 & 36 & 49 & 150 \\
\hline California Institute of Technology (Calt... & 2,271 & 43 & F.C. Anson & 330 & 82 & 3,880 & 75 & 25 & 142 & 150 \\
\hline Cardiff University & 867 & 150 & G.R. Hutchings & 371 & 66 & 4,574 & 53 & 42 & 30 & 150 \\
\hline Carnegie Mellon University & 1,974 & 55 & I.E. Grossmann & 309 & 95 & 3,183 & 89 & 36 & 49 & 150 \\
\hline Case Western Reserve University & 146 & 317 & D. M. Durand & 385 & 62 & 2,665 & 113 & 27 & 111 & 150 \\
\hline Chalmers University of Technology & 1,842 & 61 & M. Skoglundh & 107 & 298 & 1,301 & 214 & 24 & 152 & 119 \\
\hline Charles University & 82 & 333 & V. Matolin & 162 & 241 & 541 & 295 & 14 & 268 & 134 \\
\hline Chinese University of Hong Kong & 519 & 228 & J.C. Yu & 177 & 209 & 5,076 & 42 & 46 & 21 & 150 \\
\hline Chulalongkorn University & 919 & 144 & P. Praserthdam & 211 & 172 & 852 & 259 & 16 & 251 & 150 \\
\hline City University of Hong Kong & 456 & 242 & P. K. Chu & 887 & 5 & 0 & 343 & 29 & 90 & 150 \\
\hline City University of New York & 191 & 304 & F.H. Pollak & 345 & 77 & 3,444 & 83 & 20 & 195 & 150 \\
\hline Colorado State University & 748 & 172 & S.R. Wickramasinghe & 69 & 324 & 501 & 301 & 11 & 294 & 89 \\
\hline Columbia University & 1,508 & 81 & P. Somasundaran & 385 & 62 & 3,117 & 92 & 23 & 156 & 150 \\
\hline Cornell University & 2,259 & 44 & T. Eisner & 198 & 186 & 1,634 & 181 & 17 & 236 & 150 \\
\hline Curtin University of Technology & 451 & 244 & M.O. Tade & 131 & 273 & 385 & 314 & 11 & 294 & 123 \\
\hline Dalhousie University & 427 & 249 & M.R. Islam & 365 & 69 & 947 & 248 & 13 & 278 & 150 \\
\hline \begin{tabular}{|l|} 
Dartmouth College \\
\end{tabular} & 517 & 229 & L.R. Lynd & 122 & 282 & 1,583 & 187 & 21 & 185 & 150 \\
\hline Delft University of Technology & 3,607 & 14 & J.A. Moulign & 632 & 13 & 1,068 & 238 & 51 & 12 & 150 \\
\hline Drexel University & 1,197 & 110 & B. Farouk & 180 & 203 & 938 & 249 & 13 & 278 & 113 \\
\hline Duke University & 995 & 130 & A. Bejan & 411 & 48 & 3,021 & 96 & 27 & 111 & 150 \\
\hline Durham University & 384 & 262 & M.C. Petty & 299 & 107 & 2,277 & 132 & 21 & 185 & 150 \\
\hline Ecole Normale Supérieure de Lyon & 182 & 307 & C. Pichot & 212 & 170 & 2,351 & 126 & 29 & 90 & 150 \\
\hline École Normale Supérieure, Paris & 344 & 271 & C.Amatore & 325 & 85 & 4,326 & 65 & 30 & 81 & 150 \\
\hline École Polytechnique & 540 & 216 & J.N. Chazalviel & 203 & 178 & 1,475 & 195 & 21 & 185 & 150 \\
\hline
\end{tabular}




\begin{tabular}{|c|c|c|c|c|c|c|c|c|c|c|}
\hline Ecole Polytechnique Fédérale de Lausanne & 1,384 & 95 & A. Renker & 197 & 189 & 1,501 & 194 & 23 & 156 & 150 \\
\hline Eindhoven University of Technology & 2,223 & 47 & R.A. Van Santen & 556 & 23 & 13,845 & 8 & 48 & 16 & 150 \\
\hline Emory University & 406 & 258 & F.M. Menger & 270 & 127 & 4,089 & 70 & 25 & 142 & 150 \\
\hline Erasmus University Rotterdam & 150 & 315 & S.H. Orkin & 222 & 166 & 10,429 & 16 & 73 & 4 & 150 \\
\hline ETH Zurich (Swiss Federal Institute of Technology) & 3,214 & 22 & A. Baiker & 636 & 12 & 16,123 & 6 & 48 & 16 & 150 \\
\hline Florida International University & 454 & 243 & M.A. Ebadian & 200 & 184 & 426 & 308 & 13 & 278 & 107 \\
\hline Florida State University & 209 & 301 & B.R. Locke & 119 & 289 & 1,188 & 223 & 24 & 152 & 109 \\
\hline Freie Universität Berlin & 619 & 197 & J.H. Furhop & 148 & 257 & 2,014 & 153 & 18 & 221 & 150 \\
\hline Friedrich Alexander Universität Erlangen Nürnberg & 2,154 & 50 & F. Durst & 298 & 109 & 3,348 & 85 & 27 & 111 & 150 \\
\hline Fudan University & 1,438 & 86 & Z. Gao & 172 & 219 & 1,657 & 175 & 27 & 111 & 150 \\
\hline Georg August Universität Göttingen & 693 & 183 & M. Burback & 157 & 246 & 1,457 & 199 & 32 & 66 & 150 \\
\hline George Mason University & 186 & 306 & G.W. Mushrush & 164 & 239 & 332 & 320 & 7 & 322 & 105 \\
\hline George Washington University & 205 & 302 & D.E. Ramaker & 155 & 248 & 1,320 & 212 & 22 & 171 & 150 \\
\hline Georgetown University & 257 & 287 & R. De Levie & 124 & 280 & 629 & 282 & 7 & 322 & 56 \\
\hline Georgia Institute of Technology & 3,168 & 24 & E.C. Ashby & 248 & 143 & 1,088 & 235 & 2 & 337 & 128 \\
\hline Georgia State University & 119 & 323 & Y. Pan & 259 & 135 & 1,192 & 222 & 22 & 171 & 150 \\
\hline Goteborg University & 956 & 139 & B. Kasemo & 374 & 65 & 6,704 & 23 & 47 & 19 & 150 \\
\hline Harvard University & 997 & 129 & G.M. Whitesides & 918 & 3 & 75,622 & 1 & 105 & 1 & 150 \\
\hline Hebrew University of Jerusalem & 1,707 & 67 & N. Garti & 225 & 164 & 1,545 & 192 & 28 & 102 & 150 \\
\hline Heidelberg Universität & 792 & 164 & M.L. Zeigler & 96 & 304 & 723 & 273 & 1 & 340 & 150 \\
\hline Hokkaido University & 3,026 & 28 & H. Hattori & 174 & 216 & 2,071 & 152 & 20 & 195 & 150 \\
\hline Hong Kong Polytechnic University & 1,389 & 93 & W.K. Chow & 369 & 67 & 870 & 257 & 14 & 268 & 150 \\
\hline Hong Kong University of Science \& Techno... & 1,309 & 98 & G. Chen & 325 & 85 & 3,655 & 80 & 32 & 66 & 150 \\
\hline Humboldt-Universität zu Berlin & 707 & 179 & E. Kemnitz & 302 & 101 & 1,393 & 208 & 25 & 142 & 150 \\
\hline Imperial College London & 3,859 & 9 & E.N. Pistikopulos & 180 & 203 & 1,621 & 184 & 25 & 142 & 114 \\
\hline Indian Institute of Technology Bombay (I... & 1,093 & 121 & P. Selvam & 121 & 286 & 888 & 256 & 20 & 195 & 133 \\
\hline Indian Institute of Technology Delhi (II... & 1,420 & 91 & V.K. Kothari & 166 & 233 & 223 & 331 & 5 & 331 & 90 \\
\hline Indian Institute of Technology Kanpur (I... & 1,064 & 125 & R.P. Chhabra & 204 & 177 & 708 & 276 & 16 & 251 & 150 \\
\hline Indiana University Bloomington & 524 & 226 & D.G. Peters & 149 & 255 & 793 & 264 & 15 & 260 & 133 \\
\hline Indiana University Indianapolis & 270 & 285 & P.L. Dublin & 170 & 225 & 1,994 & 155 & 27 & 111 & 150 \\
\hline Iowa State University & 760 & 171 & V.V. Tsukruk & 277 & 124 & 2,911 & 100 & 37 & 45 & 150 \\
\hline Johns Hopkins University & 1,616 & 70 & S.H. Snyder & 300 & 106 & 14,180 & 7 & 75 & 3 & 150 \\
\hline Kansas State University & 493 & 237 & L.T. Fan & 411 & 48 & 1,650 & 176 & 12 & 288 & 150 \\
\hline Katholieke Universiteit Leuven & 1,523 & 79 & P.A. Jacobs & 398 & 55 & 6,002 & 30 & 43 & 23 & 150 \\
\hline Keio University & 1,147 & 114 & X. H. Mori & 219 & 167 & 694 & 279 & 14 & 268 & 150 \\
\hline
\end{tabular}




\begin{tabular}{|c|c|c|c|c|c|c|c|c|c|c|}
\hline King Fahd University of Petroleum \& Minerals & 905 & 145 & B.S. Yilbas & 391 & 59 & 1,093 & 232 & 19 & 205 & 150 \\
\hline King Saud University & 525 & 225 & A.E. Abasaeed & 45 & 333 & 230 & 330 & 10 & 303 & 29 \\
\hline Kobe University & 1,292 & 102 & M. Okubo & 279 & 123 & 1,669 & 174 & 23 & 156 & 150 \\
\hline Korea Advanced Institute of Science \& Technology & 2,849 & 30 & H. Lee & 168 & 229 & 1,184 & 225 & 20 & 195 & 150 \\
\hline Korea University & 1,470 & 82 & S.H. Kim & 33 & 338 & 42 & 339 & 3 & 334 & 125 \\
\hline Kyoto University & 7,860 & 2 & T. Kokubo & 433 & 40 & 6,230 & 29 & 47 & 19 & 150 \\
\hline Kyushu University & 3,371 & 20 & I. Mochida & 629 & 14 & 5,397 & 39 & 30 & 81 & 150 \\
\hline La Trobe University & 213 & 300 & B.B. Johnson & 56 & 330 & 902 & 253 & 19 & 205 & 35 \\
\hline Lancaster University & 108 & 328 & P.V.E. McClintock & 321 & 90 & 1,630 & 182 & 22 & 171 & 150 \\
\hline Leiden University & 882 & 147 & V. Ponec & 165 & 235 & 1,851 & 162 & 17 & 236 & 150 \\
\hline Linkoping University & 532 & 220 & B. Liedberg & 151 & 254 & 3,704 & 79 & 26 & 128 & 150 \\
\hline London School of Economics and Political Science & 22 & 342 & LA Smith & 154 & 251 & 2,418 & 121 & 31 & 77 & 150 \\
\hline Loughborough University & 1,250 & 105 & N.A. Hampton & 240 & 147 & 544 & 294 & 0 & 341 & 150 \\
\hline Louisiana State University & 593 & 204 & K.T. Valsaraj & 161 & 243 & 1,074 & 237 & 16 & 251 & 131 \\
\hline Ludwig-Maximilians-Universität München & 988 & 133 & H. Knozinger & 307 & 97 & 3,831 & 77 & 29 & 90 & 150 \\
\hline Lund University & 2,659 & 34 & B. Lindman & 415 & 46 & 5,552 & 38 & 34 & 60 & 150 \\
\hline Maastricht University & 128 & 320 & L.H. Koole & 131 & 273 & 737 & 271 & 17 & 236 & 150 \\
\hline Macquarie University & 254 & 288 & N.W. Cant & 155 & 248 & 1,809 & 166 & 19 & 205 & 111 \\
\hline Mahidol University & 201 & 303 & P. Tangboriboonrat & 39 & 335 & 119 & 336 & 9 & 310 & 45 \\
\hline Masaryk University & 167 & 313 & L. Trnkova & 89 & 311 & 509 & 300 & 22 & 171 & 125 \\
\hline Massachusetts Institute of Technology & 5,169 & 5 & D. Seyferth & 577 & 20 & 4,515 & 57 & 9 & 310 & 150 \\
\hline McGill University & 2,455 & 38 & J.H. Vera & 65 & 327 & 1,445 & 202 & 19 & 205 & 79 \\
\hline McMaster University & 1,120 & 117 & R. Pelton & 235 & 152 & 2,326 & 128 & 26 & 128 & 150 \\
\hline Michigan State University & 1,403 & 92 & L.T. Drzl & 296 & 111 & 2,388 & 124 & 22 & 171 & 150 \\
\hline Michigan Technological University & 539 & 217 & D.R. Shonnard & 81 & 318 & 417 & 311 & 13 & 278 & 109 \\
\hline Monash University & 1,432 & 87 & M. Forsyth & 237 & 150 & 3,187 & 88 & 35 & 54 & 150 \\
\hline Montana State University & 288 & 282 & F.P. McCandless & 51 & 332 & 117 & 337 & 2 & 337 & 37 \\
\hline Moscow State University & 3,197 & 23 & V.V. Lunin & 261 & 131 & 149 & 335 & 21 & 185 & 150 \\
\hline Nagoya University & 3,776 & 11 & T. Kobayshi & 796 & 7 & 39 & 340 & 33 & 63 & 150 \\
\hline Nanjing University & 1,446 & 85 & J.Shen & 227 & 161 & 1,571 & 189 & 23 & 156 & 150 \\
\hline Nanyang Technological University & 1,796 & 64 & K.A.Khor & 303 & 99 & 2,876 & 101 & 31 & 77 & 150 \\
\hline National Taiwan University & 3,153 & 25 & G.H. Lee & 621 & 15 & 7,846 & 22 & 36 & 49 & 150 \\
\hline National Tsing Hua University & 1,659 & 68 & M.L. Wang & 202 & 179 & 347 & 319 & 10 & 303 & 75 \\
\hline National University of Ireland, Galway & 254 & 288 & P. McArdle & 156 & 247 & 600 & 289 & 10 & 303 & 150 \\
\hline National University of Singapore & 3,397 & 18 & T.S. Chung & 354 & 72 & 2,539 & 116 & 32 & 66 & 150 \\
\hline New Mexico State University & 365 & 266 & J. Y. Wang & 613 & 17 & 789 & 266 & 76 & 2 & 150 \\
\hline
\end{tabular}




\begin{tabular}{|c|c|c|c|c|c|c|c|c|c|c|}
\hline New York University & 937 & 142 & R.Z. LeGeros & 188 & 196 & 2,768 & 106 & 17 & 236 & 150 \\
\hline Newcastle University & 1,161 & 113 & J.A. Harrison & 132 & 272 & 860 & 258 & 9 & 310 & 102 \\
\hline North Carolina State University & 2,505 & 36 & A.V. Kuznetsov & 343 & 78 & 2,422 & 120 & 28 & 102 & 150 \\
\hline Northeastern University & 706 & 180 & R.J. Willey & 87 & 312 & 1,122 & 229 & 13 & 278 & 127 \\
\hline Northwestern University & 2,745 & 31 & W.H.M. Sachtler & 330 & 82 & 4,817 & 46 & 36 & 49 & 150 \\
\hline Norwegian University of Science \& Technology & 1,829 & 62 & A. Holmen & 168 & 229 & 1,950 & 157 & 27 & 111 & 150 \\
\hline Ohio State University & 22,667 & 1 & L.S. Fan & 289 & 114 & 2,118 & 145 & 25 & 142 & 150 \\
\hline Oklahoma State University & 609 & 200 & A.J. Ghajar & 101 & 303 & 233 & 328 & 8 & 316 & 67 \\
\hline Open University UK & 105 & 329 & & 0 & 344 & 0 & 343 & 0 & 341 & 111 \\
\hline Oregon State University & 748 & 172 & O. Levenspiel & 93 & 309 & 810 & 263 & 6 & 326 & 56 \\
\hline Osaka University & 3,923 & 8 & I. Komasawa & 172 & 219 & 1,627 & 183 & 27 & 111 & 100 \\
\hline Peking University & 1,467 & 83 & Y. Xie & 173 & 218 & 1,011 & 244 & 19 & 205 & 150 \\
\hline Pennsylvania State University & 3,981 & 7 & M.A. Vannice & 227 & 161 & 4,095 & 69 & 30 & 81 & 131 \\
\hline Pohang University of Science And Technology & 1,239 & 108 & I.B. Lee & 453 & 37 & 3,066 & 94 & 32 & 66 & 150 \\
\hline Portland State University & 178 & 309 & J. McNames & 106 & 300 & 624 & 284 & 14 & 268 & 106 \\
\hline Princeton University & 2,679 & 32 & C.A. Floudas & 232 & 157 & 2,111 & 147 & 29 & 90 & 149 \\
\hline Purdue University & 4,282 & 6 & R. Viskanta & 400 & 52 & 2,964 & 99 & 18 & 221 & 150 \\
\hline Queen's University & 980 & 136 & P.H. Oosthuizen & 241 & 145 & 357 & 316 & 11 & 294 & 92 \\
\hline Queen's University of Belfast & 889 & 146 & C. Hardacre & 196 & 191 & 2,401 & 123 & 30 & 81 & 150 \\
\hline Queensland University of Technology & 421 & 253 & R.L. Frost & 587 & 19 & 8,990 & 21 & 43 & 23 & 150 \\
\hline Radboud University, Nijmegen & 520 & 227 & J.A. Jansen & 390 & 60 & 4,052 & 71 & 42 & 30 & 150 \\
\hline Rensselaer Polytechnic Institute & 1,612 & 71 & G. Belfort & 191 & 192 & 2,525 & 117 & 25 & 142 & 150 \\
\hline Rheinisch Westfalische Technische Hochschule Aach & 2,399 & 40 & W. Marquardt & 235 & 152 & 1,252 & 217 & 21 & 185 & 150 \\
\hline Rheinische Friedrich Wilhelms Universitat Bonn & 613 & 199 & W. Vielstich & 110 & 294 & 1,648 & 177 & 14 & 268 & 99 \\
\hline Rice University & 1,236 & 109 & R. Kobayashi & 142 & 263 & 726 & 272 & 3 & 334 & 114 \\
\hline Rochester Institute of Technology & 295 & 280 & S.G. Kandlikar & 186 & 200 & 1,336 & 211 & 23 & 156 & 101 \\
\hline Royal Institute of Technology, KTH & 2,012 & 53 & P.M. Cleasson & 212 & 170 & 2,810 & 103 & 27 & 111 & 150 \\
\hline Royal Melbourne Institute of Technology & 436 & 248 & S.K. Bhargava & 140 & 265 & 948 & 247 & 17 & 236 & 150 \\
\hline Rutgers & 1,903 & 58 & F.J. Muzzio & 158 & 245 & 1,606 & 185 & 28 & 102 & 147 \\
\hline Saint-Petersburg State University & 953 & 140 & F.M. Kuni & 168 & 229 & 185 & 333 & 8 & 316 & 58 \\
\hline San Diego State University & 162 & 314 & M.A. Ring & 67 & 326 & 293 & 323 & 2 & 337 & 69 \\
\hline Sapienza University of Rome & 0 & 346 & & 0 & 344 & 0 & 343 & 0 & 341 & 0 \\
\hline Sciences Po Paris & 0 & 346 & & 0 & 344 & 0 & 343 & 0 & 341 & 0 \\
\hline Seoul National University & 3,545 & 16 & I.K. Song & 178 & 205 & 612 & 287 & 17 & 236 & 136 \\
\hline Shanghai Jiao Tong University & 2,673 & 33 & R. Wang & 377 & 64 & 900 & 254 & 20 & 195 & 150 \\
\hline Simon Fraser University & 282 & 283 & I.D. Gay & 55 & 331 & 464 & 304 & 6 & 326 & 42 \\
\hline
\end{tabular}




\begin{tabular}{|c|c|c|c|c|c|c|c|c|c|c|}
\hline Stanford University & 3,106 & 27 & C.W. Frank & 288 & 115 & 4,114 & 68 & 35 & 54 & 150 \\
\hline State University of New York Buffalo & 5 & 344 & S. Inamdar & 22 & 340 & 256 & 326 & 12 & 288 & 36 \\
\hline Stockholm University & 339 & 274 & O. Teraski & 242 & 144 & 5,674 & 36 & 42 & 30 & 150 \\
\hline Stony Brook University & 803 & 161 & B. Chu & 392 & 57 & 5,768 & 35 & 41 & 36 & 150 \\
\hline Syracuse University & 407 & 257 & C.T. Driscoll & 284 & 119 & 4,518 & 56 & 37 & 45 & 150 \\
\hline Tartu University (University of Tartu) & 231 & 294 & E. Lust & 137 & 266 & 385 & 314 & 17 & 236 & 80 \\
\hline Technical University of Denmark & 2,225 & 46 & R. Gani & 189 & 194 & 1,028 & 243 & 16 & 251 & 150 \\
\hline Technion & 2,318 & 42 & M. Sheintuch & 201 & 181 & 1,570 & 190 & 18 & 221 & 99 \\
\hline Technische Universität Berlin & 1,846 & 60 & G. Wozny & 187 & 198 & 423 & 309 & 13 & 278 & 150 \\
\hline Technische Universitat Chemnitz & 344 & 271 & R. Holze & 187 & 198 & 1,473 & 198 & 22 & 171 & 150 \\
\hline Technische Universität Dresden & 1,361 & 96 & H.D. Dorfler & 131 & 273 & 235 & 327 & 6 & 326 & 81 \\
\hline Technische Universität München & 2,607 & 35 & J.A. Lerchen & 302 & 101 & 3,616 & 81 & 32 & 66 & 150 \\
\hline Tel Aviv University & 1,861 & 59 & N. Brauner & 130 & 277 & 615 & 286 & 10 & 303 & 150 \\
\hline Texas A\&M University & 3,535 & 17 & J.H. Lunsford & 293 & 113 & 4,470 & 59 & 26 & 128 & 150 \\
\hline Texas Tech & 238 & 291 & G.B. McKenna & 236 & 151 & 2,801 & 104 & 23 & 156 & 150 \\
\hline Tohoku University & 3,600 & 15 & K. Arai & 250 & 141 & 2,160 & 142 & 29 & 90 & 150 \\
\hline Tokyo Institute of Technology & 7,415 & 3 & K.Otsuka & 201 & 181 & 1,640 & 178 & 26 & 128 & 126 \\
\hline Trinity College Dublin & 351 & 267 & D. Weaire & 155 & 248 & 12,226 & 11 & 17 & 236 & 139 \\
\hline Tsinghua University & 6,102 & 4 & Y. Jin & 454 & 36 & 1,536 & 193 & 18 & 221 & 150 \\
\hline Tufts University & 424 & 251 & D.L. Kaplan & 556 & 23 & 10,307 & 18 & 51 & 12 & 150 \\
\hline Universidad Autonoma de Madrid & 676 & 186 & A.J. Arvia & 546 & 25 & 5,034 & 43 & 18 & 221 & 150 \\
\hline Universidad de Chile & 531 & 221 & J.A. Squella & 176 & 212 & 790 & 265 & 18 & 221 & 150 \\
\hline Universidad de Granada & 676 & 186 & A.J. Arvia & 546 & 25 & 5,034 & 43 & 18 & 221 & 150 \\
\hline Universidad del País Vasco & 1,025 & 128 & J. Bilbao & 198 & 186 & 955 & 246 & 27 & 111 & 117 \\
\hline Universidad Nacional Autónoma de México ... & $\mid 515$ & 231 & V.M. Castano & 347 & 76 & 1,291 & 216 & 16 & 251 & 150 \\
\hline Universidad Politecnica de Madrid & 443 & 246 & A. Linan & 110 & 294 & 910 & 252 & 11 & 294 & 94 \\
\hline Universidade de São Paulo & 968 & 137 & M. Zaiat & 109 & 296 & 353 & 317 & 14 & 268 & 111 \\
\hline Universidade Estadual de Campinas & 1,079 & 124 & C. Airoldi & 340 & 80 & 1,678 & 173 & 29 & 90 & 150 \\
\hline Università degli Studi di Firenze & 1,038 & 127 & R. Guidelli & 148 & 257 & 898 & 255 & 18 & 221 & 76 \\
\hline Università degli Studi di Padova & 1,540 & 78 & A. Bertucco & 96 & 304 & 933 & 250 & 19 & 205 & 128 \\
\hline Universita Di Bologna & 2,012 & 53 & F. Trifiro & 197 & 189 & 4,433 & 62 & 22 & 171 & 150 \\
\hline Universita di Pisa & 339 & 274 & E. Chiellini & 226 & 163 & 1,583 & 187 & 20 & 195 & 150 \\
\hline Universitat Autonoma de Barcelona & 785 & 166 & X. Domenech & 96 & 304 & 1,785 & 167 & 22 & 171 & 97 \\
\hline Universitat Bielefeld & 332 & 276 & P. Jutzi & 234 & 155 & 2,373 & 125 & 26 & 128 & 150 \\
\hline Universität Bremen & 657 & 191 & G. Schulz & 161 & 243 & 2,273 & 134 & 25 & 142 & 150 \\
\hline Universitat d'Alacant & 1,042 & 126 & J.M. Feliu & 249 & 142 & 2,218 & 139 & 32 & 66 & 150 \\
\hline
\end{tabular}




\begin{tabular}{|c|c|c|c|c|c|c|c|c|c|c|}
\hline Universitat de València & 805 & 160 & $\overline{\text { J.B. Monton }}$ & 76 & 321 & 718 & 274 & 11 & 294 & 56 \\
\hline Universität Frankfurt am Main & 517 & 229 & M. Bolte & 617 & 16 & 4,536 & 54 & 29 & 90 & 150 \\
\hline Universität Freiburg & 747 & 174 & J. Heinze & 117 & 291 & 2,187 & 141 & 19 & 205 & 150 \\
\hline Universitat Hamburg & 101 & 331 & W. Kaminsky & 183 & 201 & 2,589 & 115 & 27 & 111 & 150 \\
\hline Universität Karlsruhe & 2,172 & 49 & E.V. Schunder & 137 & 266 & 696 & 278 & 9 & 310 & 107 \\
\hline Universitat Leipzig & 290 & 281 & J. Karger & 350 & 75 & 2,311 & 131 & 29 & 90 & 150 \\
\hline Universitat Munster (Westfälische Wilhelms-Un & 115 & 325 & A. Steinbuchel & 301 & 105 & 2,998 & 98 & 39 & 41 & 150 \\
\hline Universitat Politecnica de Catalunya & 526 & 223 & L. Puigjaner & 200 & 184 & 1,153 & 227 & 18 & 221 & 150 \\
\hline Universität Regensburg & 771 & 168 & H. Brunner & 342 & 79 & 2,698 & 108 & 22 & 171 & 150 \\
\hline Universität Stuttgart & 1,827 & 63 & H.Hasse & 125 & 279 & 670 & 280 & 17 & 236 & 139 \\
\hline Universitat Trier & 13 & 343 & K. Fischer & 225 & 164 & 1,457 & 199 & 22 & 171 & 150 \\
\hline Universität Tübingen & 526 & 223 & E. Lidner & 181 & 202 & 1,424 & 205 & 18 & 221 & 150 \\
\hline Universitat Wien (University of Vienna) & 560 & 210 & W. Pauli & 37 & 336 & 2 & 342 & 0 & 341 & 26 \\
\hline Universitat Zu Koln & 475 & 240 & D. Woermann & 135 & 268 & 490 & 303 & 10 & 303 & 131 \\
\hline Université Catholique de Louvain & 1,305 & 100 & B. Delmon & 297 & 110 & 4,441 & 61 & 21 & 185 & 150 \\
\hline Universite de Liege & 615 & 198 & J.P. Pirad & 171 & 222 & 1,049 & 239 & 19 & 205 & 150 \\
\hline Université de Montréal & 699 & 181 & J.D. Wuest & 119 & 289 & 1,764 & 169 & 21 & 185 & 104 \\
\hline Université de Nice Sophia Antipolis & 218 & 299 & E. Dunach & 122 & 282 & 849 & 260 & 17 & 236 & 125 \\
\hline Universite Laval & 1,264 & 104 & S. Kaliaguine & 323 & 88 & 4,526 & 55 & 35 & 54 & 150 \\
\hline Universite Libre de Bruxelles & 657 & 191 & A. DeWit & 57 & 329 & 534 & 296 & 14 & 268 & 61 \\
\hline Université Paris Sorbonne & 32 & 338 & N.P. Buu-Hol & 122 & 282 & 104 & 338 & 0 & 341 & 106 \\
\hline Universite Paris-Sud 11 & 1,093 & 121 & D. Langevin & 198 & 186 & 1,780 & 168 & 30 & 81 & 150 \\
\hline Université Pierre et Marie Curie & 2,429 & 39 & M. Che & 286 & 117 & 3,127 & 91 & 28 & 102 & 150 \\
\hline Universiti Malaya (University of Malaya) & 560 & 210 & M.A. Hashim & 64 & 328 & 444 & 306 & 11 & 294 & 58 \\
\hline University College Cork & 380 & 263 & M.A. Morris & 105 & 301 & 1,081 & 236 & 21 & 185 & 150 \\
\hline University College Dublin & 588 & 208 & A.R. Manning & 176 & 212 & 439 & 307 & 11 & 294 & 150 \\
\hline University College London & 2,027 & 52 & I.W. Boyd & 315 & 92 & 2,250 & 136 & 23 & 156 & 150 \\
\hline University do Porto & 867 & 150 & A.E Rodrigues & 327 & 84 & 2,143 & 143 & 27 & 111 & 150 \\
\hline University of Aberdeen & 544 & 213 & J.N. Low & 429 & 41 & 977 & 245 & 17 & 236 & 150 \\
\hline University of Adelaide & 664 & 189 & M.I. Bruce & 407 & 50 & 2,501 & 118 & 26 & 128 & 150 \\
\hline University of Alabama & 985 & 134 & J.L. Atwood & 571 & 21 & 589 & 290 & 43 & 23 & 150 \\
\hline University of Alberta & 2,463 & 37 & J.H. Masliyah & 399 & 54 & 2,085 & 151 & 25 & 142 & 150 \\
\hline University of Amsterdam & 1,106 & 119 & R. Krishna & 270 & 127 & 3,205 & 87 & 41 & 36 & 150 \\
\hline University of Antwerp & 377 & 265 & E.F. Vansant & 284 & 119 & 2,674 & 112 & 27 & 111 & 150 \\
\hline University of Arizona & 1,168 & 112 & J.E. Pemberton & 131 & 273 & 1,704 & 172 & 20 & 195 & 139 \\
\hline University of Athens & 310 & 278 & N. Hadjichrisidis & 392 & 57 & 4,588 & 52 & 43 & 23 & 150 \\
\hline
\end{tabular}




\begin{tabular}{|c|c|c|c|c|c|c|c|c|c|c|}
\hline University of Auckland & 968 & 137 & D.A. Nield & 134 & 270 & 778 & 267 & 16 & 251 & 24 \\
\hline University of Barcelona & 1,289 & 103 & F. Cunill & 74 & 322 & 450 & 305 & 13 & 278 & 80 \\
\hline University of Basel & 425 & 250 & W.J. Gehring & 209 & 174 & 6,605 & 24 & 32 & 66 & 150 \\
\hline University of Bath & 437 & 247 & J.B. Chaudhuri & 95 & 307 & 751 & 270 & 16 & 251 & 150 \\
\hline University of Bergen & 147 & 316 & J. Sjoblom & 251 & 140 & 1,475 & 195 & 19 & 205 & 150 \\
\hline University of Bern & 2 & 345 & J. Hulliger & 162 & 241 & 1,197 & 221 & 21 & 185 & 150 \\
\hline University of Birmingham & 1,565 & 74 & A.W. Nieow & 280 & 122 & 2,276 & 133 & 27 & 111 & 150 \\
\hline University of Bristol & 1,425 & 89 & J. Eastoe & 165 & 235 & 2,115 & 146 & 30 & 81 & 150 \\
\hline University of British Columbia & 994 & 131 & J.R. Grace & 366 & 68 & 2,619 & 114 & 26 & 128 & 150 \\
\hline University of Calgary & 683 & 185 & W.Y. Syrcek & 149 & 255 & 566 & 293 & 9 & 310 & 143 \\
\hline University of California, Berkley & 1,708 & 66 & J.M. Prausnitz & 532 & 27 & 12,154 & 12 & 30 & 81 & 150 \\
\hline University of California, Davis & 837 & 154 & Z.A. Munir & 353 & 73 & 2,783 & 105 & 27 & 111 & 150 \\
\hline University of California, Irvine & 2,195 & 48 & E.J. Lavernia & 493 & 31 & 3,891 & 74 & 32 & 66 & 150 \\
\hline University of California, Los Angeles & 2,371 & 41 & P.D. Christofides & 239 & 148 & 1,213 & 220 & 33 & 63 & 64 \\
\hline University of California, Riverside & 793 & 163 & F. Zaera & 229 & 159 & 2,350 & 127 & 34 & 60 & 150 \\
\hline University of California, San Diego & 3,379 & 19 & B.O. Palsson & 319 & 91 & 4,445 & 60 & 50 & 15 & 150 \\
\hline University of California, San Francisco & 406 & 258 & & 0 & 344 & 0 & 343 & 0 & 341 & 0 \\
\hline University of California, Santa Barbara & 830 & 157 & U.K. Mishra & 671 & 10 & 12,606 & 10 & 57 & 7 & 150 \\
\hline University of California, Santa Cruz & 554 & 212 & J.Z. Zhang & 143 & 262 & 2,262 & 135 & 26 & 128 & 150 \\
\hline University of Cambridge & 3,147 & 26 & B.F.G. Johnson & 869 & 6 & 5,891 & 31 & 30 & 81 & 150 \\
\hline University of Canterbury & 191 & 304 & K.N. Marsh & 121 & 286 & 1,093 & 232 & 14 & 268 & 150 \\
\hline University of Cape Town & 268 & 286 & C.T. O'Conner & 105 & 301 & 770 & 268 & 15 & 260 & 92 \\
\hline University of Central Florida & 515 & 231 & $\mathrm{Z} . \mathrm{Qu}$ & 213 & 169 & 1,182 & 226 & 15 & 260 & 120 \\
\hline University of Chicago & 543 & 214 & B. Roizman & 191 & 192 & 3,341 & 86 & 43 & 23 & 150 \\
\hline University of Cincinnati & 1,519 & 80 & P.G. Smirniotis & 133 & 271 & 1,759 & 170 & 28 & 102 & 108 \\
\hline University of Colorado at Boulder & 769 & 169 & C.N. Bowman & 252 & 139 & 2,740 & 107 & 38 & 42 & 150 \\
\hline University of Connecticut & 567 & 209 & S.L. Suib & 390 & 60 & 4,126 & 67 & 36 & 49 & 150 \\
\hline University of Copenhagen & 1,309 & 98 & T. Bjornholm & 123 & 281 & 1,820 & 165 & 26 & 128 & 150 \\
\hline University of Delaware & 1,604 & 72 & S.I. Sandler & 261 & 131 & 2,692 & 110 & 23 & 156 & 150 \\
\hline University of Dundee & 315 & 277 & C.H. Rochester & 257 & 138 & 1,636 & 180 & 12 & 288 & 150 \\
\hline University of Edinburgh & 405 & 260 & N.A. Seaton & 8 & 342 & 1,229 & 218 & 20 & 195 & 79 \\
\hline University of Florida & 2,077 & 51 & W. Shyy & 337 & 81 & 2,697 & 109 & 26 & 128 & 150 \\
\hline University of Geneva & 75 & 334 & J. Buffle & 178 & 205 & 2,201 & 140 & 29 & 90 & 150 \\
\hline University of Georgia & 231 & 294 & J.L. Stickney & 178 & 205 & 760 & 269 & 18 & 221 & 127 \\
\hline University of Ghent & 536 & 218 & G.B. Marin & 258 & 136 & 1,829 & 164 & 26 & 128 & 150 \\
\hline University of Glasgow & 773 & 167 & J.H. Dymond & 84 & 317 & 622 & 285 & 10 & 303 & 73 \\
\hline
\end{tabular}




\begin{tabular}{|c|c|c|c|c|c|c|c|c|c|c|}
\hline University of Gothenburg & 26 & 341 & P. Thomsen & 130 & 277 & 2,324 & 129 & 19 & 205 & 150 \\
\hline University of Groningen & 481 & 238 & H.J. Busscher & 429 & 41 & 4,743 & 48 & 34 & 60 & 150 \\
\hline University of Helsinki & 670 & 188 & M. Leskela & 404 & 51 & 4,377 & 64 & 40 & 39 & 150 \\
\hline University of Hong Kong & 690 & 184 & S.F. Chen & 211 & 172 & 1,937 & 159 & 28 & 102 & 150 \\
\hline University of Houston & 713 & 177 & D. Luss & 235 & 152 & 1,096 & 231 & 15 & 260 & 150 \\
\hline University of Illinois & 3,687 & 12 & T.J. Hanratty & 214 & 168 & 1,945 & 158 & 23 & 156 & 132 \\
\hline University of Illinois, Chicago & 1,296 & 101 & D. Poulikakos & 262 & 130 & 2,458 & 119 & 28 & 102 & 150 \\
\hline University of Indonesia & 31 & 340 & T.A. Ivandini & 22 & 340 & 259 & 325 & 12 & 288 & 50 \\
\hline University of Iowa & 989 & 132 & R. Datta & 145 & 260 & 1,371 & 210 & 22 & 171 & 69 \\
\hline University of Kansas & 234 & 292 & B. Subramaniam & 95 & 307 & 927 & 251 & 18 & 221 & 103 \\
\hline University of Kentucky & 499 & 235 & B.H. Davis & 428 & 43 & 2,409 & 122 & 29 & 90 & 150 \\
\hline University of Lausanne & 109 & 327 & R. Roulet & 81 & 318 & 329 & 321 & 8 & 316 & 109 \\
\hline University of Leeds & 862 & 152 & M. Ghadiri & 121 & 286 & 571 & 291 & 18 & 221 & 130 \\
\hline University of Leicester & 380 & 263 & R.D.W. Kemmitt & 142 & 263 & 389 & 313 & 11 & 294 & 124 \\
\hline University of Liverpool & 233 & 293 & P.R. Chalker & 171 & 222 & 1,309 & 213 & 19 & 205 & 150 \\
\hline University of Ljubljana & 733 & 175 & J. Levec & 81 & 318 & 1,449 & 201 & 20 & 195 & 70 \\
\hline University of London (Kings College of London) & 3,831 & 10 & W. Bonfield & 307 & 97 & 3,875 & 76 & 38 & 42 & 150 \\
\hline University of Manchester & 3,225 & 21 & G.E. Thompson & 460 & 34 & 2,692 & 110 & 29 & 90 & 150 \\
\hline University of Manitoba & 645 & 194 & D.S. Jayas & 231 & 158 & 1,102 & 230 & 18 & 221 & 137 \\
\hline University of Maryland & 2,250 & 45 & R. Radermacher & 148 & 257 & 571 & 291 & 8 & 316 & 148 \\
\hline University of Maryland Baltimore County & 530 & 222 & R.C. Gallo & 163 & 240 & 6,517 & 26 & 37 & 45 & 150 \\
\hline University of Massachusetts & 859 & 153 & F.E. Karasz & 484 & 32 & 4,988 & 45 & 26 & 128 & 150 \\
\hline University of Melbourne & 1,561 & 75 & G.W. Stevens & 169 & 228 & 1,042 & 240 & 19 & 205 & 150 \\
\hline University of Miami & 103 & 330 & F.J. Millero & 365 & 69 & 6,487 & 27 & 35 & 54 & 150 \\
\hline University of Michigan & 1,448 & 84 & R.T. Yang & 351 & 74 & 4,817 & 46 & 43 & 23 & 150 \\
\hline University of Minnesota & 1,574 & 73 & J.H. Weaver & 395 & 56 & 3,750 & 78 & 16 & 251 & 150 \\
\hline University of Missouri & 710 & 178 & A.I. Liapis & 107 & 298 & 716 & 275 & 19 & 205 & 73 \\
\hline University of Nebraska & 598 & 201 & Y. Yang & 86 & 314 & 518 & 299 & 16 & 251 & 63 \\
\hline University of New Hampshire & 248 & 290 & P.T. Vasudevan & 35 & 337 & 208 & 332 & 7 & 322 & 21 \\
\hline University of New Mexico & 342 & 273 & M.S. El-Genk & 269 & 129 & 610 & 288 & 12 & 288 & 120 \\
\hline University of New South Wales & 1,117 & 118 & T.P. Davis & 499 & 30 & 5,580 & 37 & 53 & 10 & 150 \\
\hline University of North Carolina, Chapel Hill & 870 & 149 & R.P. Buck & 229 & 159 & 1,974 & 156 & 17 & 236 & 150 \\
\hline University of North Texas & 182 & 307 & W.E. Acree & 439 & 39 & 1,475 & 195 & 26 & 128 & 150 \\
\hline University of Notre Dame & 722 & 176 & A Varma & 27 & 339 & 1,430 & 204 & 17 & 236 & 134 \\
\hline University of Nottingham & 592 & 205 & A.J. Blake & 606 & 18 & 10,509 & 15 & 43 & 23 & 150 \\
\hline University of Oklahoma & 661 & 190 & J.F. Scamehorn & 170 & 225 & 1,299 & 215 & 15 & 260 & 150 \\
\hline
\end{tabular}




\begin{tabular}{|c|c|c|c|c|c|c|c|c|c|c|}
\hline University of Oregon & 168 & 312 & B.W. Matthews & 302 & 101 & 9,260 & 20 & 37 & 45 & 150 \\
\hline University of Oslo & 121 & 322 & B. Nystrom & 122 & 282 & 1,125 & 228 & 22 & 171 & 125 \\
\hline University of Otago & 51 & 336 & T. Rades & 174 & 216 & 1,091 & 234 & 23 & 156 & 150 \\
\hline University of Ottawa & 655 & 193 & T. Matsuura & 443 & 38 & 2,120 & 144 & 25 & 142 & 150 \\
\hline University of Oxford & 499 & 235 & R.G. Compton & 917 & 4 & 16,202 & 5 & 51 & 12 & 150 \\
\hline University of Pennsylvania & 787 & 165 & R.J. Gorte & 274 & 125 & 4,479 & 58 & 42 & 30 & 150 \\
\hline University of Pittsburgh & 809 & 158 & A.C. Balazs & 241 & 145 & 2,816 & 102 & 33 & 63 & 150 \\
\hline University of Quebec & 645 & 194 & S. Kaliaguine & 323 & 88 & 4,280 & 66 & 35 & 54 & 150 \\
\hline University of Queensland & 1,136 & 115 & D.D. Do & 310 & 94 & 2,101 & 148 & 23 & 156 & 109 \\
\hline University of Reading & 645 & 194 & R. Burch & 68 & 325 & 1,639 & 179 & 4 & 332 & 107 \\
\hline University of Rochester & 278 & 284 & S.A. Jenekhe & 260 & 134 & 5,167 & 41 & 45 & 22 & 150 \\
\hline University of Saskatchewan & 1,083 & 123 & A.K. Dalai & 166 & 233 & 1,399 & 206 & 22 & 171 & 150 \\
\hline University of Science and Technology of China & 1,427 & 88 & T. Xu. & 135 & 268 & 531 & 297 & 18 & 221 & 123 \\
\hline University of Sheffield & 1,244 & 107 & D.W. Hughes & 189 & 194 & 848 & 261 & 14 & 268 & 150 \\
\hline University of South Carolina & 696 & 182 & J.A. Ritter & 152 & 253 & 1,585 & 186 & 23 & 156 & 97 \\
\hline University of South Florida & 172 & 310 & V.R. Bhethanabotla & 108 & 297 & 352 & 318 & 10 & 303 & 80 \\
\hline University of Southampton & 1,245 & 106 & D. Pletcher & 299 & 107 & 3,097 & 93 & 19 & 205 & 150 \\
\hline University of Southern California & 541 & 215 & M. Sahimi & 258 & 136 & 2,220 & 138 & 23 & 156 & 150 \\
\hline University of St Andrews & 417 & 256 & C. Glidewell & 683 & 9 & 3,577 & 82 & 23 & 156 & 150 \\
\hline University of Surrey & 424 & 251 & J.F. Watts & 234 & 155 & 1,995 & 154 & 21 & 185 & 150 \\
\hline University of Sussex & 833 & 155 & C. Eaborn & 457 & 35 & 1,567 & 191 & 17 & 236 & 150 \\
\hline University of Sydney & 1,655 & 69 & T.A.G. Langrish & 153 & 252 & 523 & 298 & 14 & 268 & 107 \\
\hline University of Technology, Sydney & 138 & 318 & S. Vigneswaran & 168 & 229 & 842 & 262 & 15 & 260 & 150 \\
\hline University of Tennessee Knoxville & 388 & 261 & G. Guichon & 685 & 8 & 10,957 & 14 & 42 & 30 & 150 \\
\hline University of Texas at Austin & 1,421 & 90 & D.R. Paul & 508 & 28 & 16,217 & 4 & 41 & 36 & 150 \\
\hline University of Tokyo & 1,791 & 65 & A. Fujishima & 415 & 46 & 11,336 & 13 & 52 & 11 & 150 \\
\hline University of Toronto & 2,976 & 29 & A.W. Neumann & 308 & 96 & 3,174 & 90 & 27 & 111 & 150 \\
\hline University of Tsukuba & 297 & 279 & S.F. Chichibu & 206 & 175 & 3,019 & 97 & 32 & 66 & 150 \\
\hline University of Twente & 1,105 & 120 & J.A.M. Kuipers & 177 & 209 & 1,722 & 171 & 26 & 128 & 133 \\
\hline University of Utah & 1,914 & 57 & J.D. Miller & 271 & 126 & 1,865 & 161 & 19 & 205 & 150 \\
\hline University of Vermont & 223 & 297 & A.Campo & 202 & 179 & 658 & 281 & 13 & 278 & 123 \\
\hline University of Victoria & 72 & 335 & D. Sinton & 86 & 314 & 699 & 277 & 17 & 236 & 53 \\
\hline University of Virginia & 479 & 239 & M. Neurock & 175 & 215 & 2,086 & 150 & 30 & 81 & 150 \\
\hline University of Warwick & 535 & 219 & P.R. Unwin & 201 & 181 & 3,975 & 72 & 31 & 77 & 150 \\
\hline University of Washington & 1,966 & 56 & J.C. Berg & 144 & 261 & 1,397 & 207 & 13 & 278 & 95 \\
\hline University of Waterloo & 1,181 & 111 & G.L. Rempel & 239 & 148 & 1,380 & 209 & 15 & 260 & 131 \\
\hline
\end{tabular}




\begin{tabular}{|c|c|c|c|c|c|c|c|c|c|c|}
\hline University of Western Australia & 592 & 205 & A. H. White & 1,245 & 1 & 13,086 & 9 & 38 & 42 & 150 \\
\hline University of Western Ontario & 1,389 & 93 & C.L. Briens & 171 & 222 & 625 & 283 & 12 & 288 & 147 \\
\hline University of Wisconsin & 1,316 & 97 & J.A. Dumesic & 315 & 92 & 4,590 & 51 & 35 & 54 & 150 \\
\hline University of Wollongong & 171 & 311 & G.G. Wallace & 508 & 28 & 9,671 & 19 & 40 & 39 & 150 \\
\hline University of York & 84 & 332 & K. Wilson & 112 & 292 & 1,217 & 219 & 20 & 195 & 150 \\
\hline University of Zurich & 419 & 254 & R. M. Zinkernagel & 571 & 21 & 32,690 & 2 & 70 & 6 & 150 \\
\hline Univesitas Gadjah Mada & 37 & 337 & I. Perdana & 6 & 343 & 19 & 341 & 3 & 334 & 13 \\
\hline Uppsala University & 982 & 135 & M. Almgren & 165 & 235 & 3,944 & 73 & 28 & 102 & 150 \\
\hline Utah State & 221 & 298 & R.E. Spall & 70 & 323 & 233 & 328 & 8 & 316 & 38 \\
\hline Utrecht University & 1,553 & 77 & J.H. Sluyters & 170 & 225 & 1,185 & 224 & 6 & 326 & 83 \\
\hline Vanderbilt University & 763 & 170 & R.D. Tanner & 93 & 309 & 303 & 322 & 7 & 322 & 147 \\
\hline Victoria University of Wellington & 32 & 338 & H.J. Trodahl & 176 & 212 & 1,033 & 241 & 15 & 260 & 150 \\
\hline Vienna University of Technology & 230 & 296 & H. Hofbauer & 87 & 312 & 423 & 309 & 13 & 278 & 104 \\
\hline Virginia Polytechnic Institute & 591 & 207 & G.L. Wilkes & 417 & 45 & 4,413 & 63 & 24 & 152 & 150 \\
\hline Vrije Universiteit, Brussels & 473 & 241 & G.V. Baron & 172 & 219 & 1,445 & 202 & 28 & 102 & 150 \\
\hline VU University Amsterdam & 419 & 254 & F. Bickelhhaupt & 400 & 52 & 4,712 & 49 & 31 & 77 & 150 \\
\hline Wageningen University & 509 & 233 & J. Tramper & 303 & 99 & 3,386 & 84 & 27 & 111 & 150 \\
\hline Wake Forest University & 122 & 321 & A. Atala & 295 & 112 & 5,169 & 40 & 42 & 30 & 150 \\
\hline Waseda University & 946 & 141 & E. KiKuchi & 188 & 196 & 2,099 & 149 & 24 & 152 & 150 \\
\hline Washington State University & 937 & 142 & D.S. Matteson & 165 & 235 & 1,030 & 242 & 11 & 294 & 120 \\
\hline Washington University in St. Louis & 594 & 202 & M.P. Dudukovic & 287 & 116 & 1,896 & 160 & 27 & 111 & 150 \\
\hline Wayne State University & 831 & 156 & K.Y.S. Ng & 86 & 314 & 167 & 334 & 6 & 326 & 82 \\
\hline West Virginia University & 345 & 270 & D.B. Dadyburjor & 112 & 292 & 413 & 312 & 8 & 316 & 84 \\
\hline Yale University & 502 & 234 & C. Horvath & 285 & 118 & 4,708 & 50 & 32 & 66 & 150 \\
\hline Yonsei University & 801 & 162 & H.H. Park & 284 & 119 & 2,231 & 137 & 23 & 156 & 150 \\
\hline York University & 118 & 324 & James G. Laframboise & 42 & 334 & 279 & 324 & 4 & 332 & 43 \\
\hline Zhejiang University & 3,654 & 13 & K.F. Cen & 1,175 & 2 & 3,060 & 95 & 19 & 205 & 150 \\
\hline
\end{tabular}




\begin{tabular}{|c|c|c|c|c|c|c|c|c|c|c|}
\hline Multidisciplinary Data & $\begin{array}{l}\text { Department } \\
\text { Publications }\end{array}$ & Rank & Most Prolific Author & Published & Rank & Cited & Rank & $\begin{array}{c}\text { H- } \\
\text { Index }\end{array}$ & Rank & $\begin{array}{c}\text { \# of } \\
\text { Coauthors }\end{array}$ \\
\hline Aalto University & 81 & 290 & R.Hari & 301 & 54 & 7,650 & 52 & 48 & 45 & 150 \\
\hline Aarhus University & 401 & 111 & H.C. Fogedby & 80 & 231 & 794 & 215 & 10 & 262 & 53 \\
\hline Arizonia State University & 287 & 159 & A. Chattopadhyay & 198 & 117 & 674 & 226 & 18 & 179 & 100 \\
\hline Ateneo de Manila University & 0 & 346 & & 0 & 344 & 0 & 343 & 0 & 324 & 0 \\
\hline Auburn University & 97 & 272 & C.L. Cocke & 251 & 85 & 1,931 & 152 & 27 & 122 & 150 \\
\hline Australian National University & 1,277 & 26 & S.R. Taylor & 160 & 154 & 5,061 & 76 & 10 & 262 & 150 \\
\hline Boston College & 83 & 285 & E.R. Kantrowitz & 152 & 163 & 853 & 209 & 16 & 203 & 150 \\
\hline Boston University & 1,246 & 28 & H.E Stanley & 480 & 22 & 10,348 & 40 & 57 & 32 & 150 \\
\hline Brandeis University & 625 & 67 & M. Roshman & 253 & 82 & 5,621 & 70 & 49 & 42 & 150 \\
\hline Brigham Young University & 90 & 279 & L.L. Howell & 134 & 176 & 549 & 243 & 16 & 203 & 108 \\
\hline Brown University & 941 & 46 & C. Barus & 88 & 222 & 4 & 339 & 0 & 324 & 1 \\
\hline California Institute of Technology (Calt... & 4,183 & 8 & A.H. Zewail & 441 & 28 & 7,471 & 53 & 48 & 45 & 150 \\
\hline Cardiff University & 441 & 98 & M.G. Edmunds & 54 & 275 & 758 & 217 & 16 & 203 & 116 \\
\hline Carnegie Mellon University & 440 & 99 & M.G.Morgan & 79 & 235 & 771 & 216 & 11 & 252 & 98 \\
\hline Case Western Reserve University & 1,094 & 38 & P. Gambetti & 284 & 67 & 6,166 & 66 & 47 & 50 & 150 \\
\hline Chalmers University of Technology & 121 & 247 & O. Orwar & 112 & 201 & 1,668 & 166 & 27 & 122 & 150 \\
\hline Charles University & 99 & 270 & Z. Smahel & 94 & 213 & 299 & 272 & 7 & 292 & 66 \\
\hline Chinese University of Hong Kong & 203 & 199 & M.Y. Wang & 123 & 189 & 553 & 240 & 17 & 188 & 80 \\
\hline Chulalongkorn University & 92 & 278 & P. Charusiri & 25 & 323 & 83 & 317 & 7 & 292 & 57 \\
\hline City University of Hong Kong & 213 & 194 & G.Chen & 681 & 7 & 0 & 343 & 61 & 26 & 150 \\
\hline City University of New York & 127 & 244 & D.B. Weinberg & 9 & 339 & 32 & 328 & 4 & 312 & 15 \\
\hline Colorado State University & 106 & 259 & E. Wohl & 102 & 210 & 942 & 203 & 21 & 158 & 123 \\
\hline Columbia University & 4,060 & 9 & E.R. Kandal & 448 & 27 & 17,020 & 20 & 77 & 10 & 150 \\
\hline Cornell University & 4,318 & 5 & \begin{tabular}{|l|} 
T. Eisner \\
\end{tabular} & 198 & 117 & 1,634 & 169 & 17 & 188 & 150 \\
\hline Curtin University of Technology & 57 & 314 & & 0 & 344 & 0 & 343 & 0 & 324 & 0 \\
\hline Dalhousie University & 429 & 104 & W.F. Doolittle & 228 & 97 & 5,968 & 68 & 41 & 62 & 150 \\
\hline Dartmouth College & 664 & 64 & J.C. Dunlap & 118 & 195 & 3,389 & 112 & 35 & 84 & 150 \\
\hline Delft University of Technology & 222 & 190 & C.Dekker & 164 & 146 & 11,878 & 35 & 50 & 40 & 150 \\
\hline Drexel University & 271 & 167 & D.J. Prockop & 200 & 113 & 8,907 & 44 & 51 & 38 & 150 \\
\hline Duke University & 2,394 & 14 & R.J. Lefkowitz & 752 & 5 & 43,621 & 3 & 93 & 2 & 150 \\
\hline Durham University & 661 & 65 & A.W. Wolfendale & 291 & 63 & 689 & 224 & 14 & 222 & 15 \\
\hline Ecole Normale Supérieure de Lyon & 93 & 276 & F. Albarede & 161 & 153 & 3,835 & 95 & 31 & 104 & 150 \\
\hline École Normale Supérieure, Paris & 259 & 173 & M. Loreau & 117 & 196 & 3,583 & 106 & 33 & 93 & 150 \\
\hline École Polytechnique & 118 & 248 & B. Giebels & 108 & 206 & 1,259 & 187 & 29 & 115 & 150 \\
\hline
\end{tabular}




\begin{tabular}{|c|c|c|c|c|c|c|c|c|c|c|}
\hline Ecole Polytechnique Fédérale de Lausanne & 198 & 205 & M. Gratzel & 663 & 8 & 41,017 & 4 & 79 & 7 & 150 \\
\hline Eindhoven University of Technology & 78 & 291 & E.W. Meijen & 493 & 21 & 11,926 & 34 & 67 & 16 & 150 \\
\hline Emory University & 745 & 55 & R.Ahmed & 253 & 82 & 10,416 & 39 & 61 & 26 & 150 \\
\hline Erasmus University Rotterdam & 224 & 189 & A.D.M.E. Osterhaus & 741 & 6 & 23,768 & 12 & 59 & 30 & 150 \\
\hline ETH Zurich (Swiss Federal Institute of Technology) & 890 & 50 & K.Wuthrich & 591 & 15 & 39,101 & 6 & 57 & 32 & 150 \\
\hline Florida International University & 74 & 295 & B.M. Clement & 46 & 285 & 832 & 213 & 6 & 304 & 83 \\
\hline Florida State University & 87 & 280 & G.H. Doran & 8 & 340 & 79 & 318 & 2 & 317 & 12 \\
\hline Freie Universität Berlin & 330 & 140 & W. Saenger & 239 & 90 & 6,262 & 65 & 35 & 84 & 150 \\
\hline Friedrich Alexander Universität Erlangen Nürnberg & 152 & 229 & H.U. Zeilhofer & 49 & 281 & 1,123 & 193 & 21 & 158 & 150 \\
\hline Fudan University & 412 & 105 & S. Zhao & 136 & 173 & 697 & 223 & 14 & 222 & 150 \\
\hline Georg August Universität Göttingen & 322 & 144 & M. Pfingsten & 65 & 253 & 618 & 231 & 16 & 203 & 104 \\
\hline George Mason University & 75 & 293 & R. Lohner & 181 & 136 & 1,351 & 184 & 21 & 158 & 119 \\
\hline George Washington University & 350 & 134 & C.M. Fraser & 227 & 98 & 24,291 & 11 & 64 & 18 & 150 \\
\hline Georgetown University & 377 & 124 & E. Costa & 659 & 9 & 12,855 & 29 & 35 & 84 & 150 \\
\hline Georgia Institute of Technology & 378 & 121 & M. Landman & 281 & 71 & 8,015 & 48 & 46 & 52 & 150 \\
\hline Georgia State University & 65 & 308 & P.J. Wiita & 87 & 224 & 572 & 237 & 15 & 213 & 84 \\
\hline Goteborg University & 285 & 164 & I. Ekman & 67 & 251 & 617 & 232 & 14 & 222 & 116 \\
\hline Harvard University & 5,197 & 3 & W.M. Davis & 237 & 92 & 3,363 & 113 & 33 & 93 & 150 \\
\hline Hebrew University of Jerusalem & 1,219 & 32 & A. Levitzki & 302 & 53 & 7,958 & 49 & 37 & 73 & 150 \\
\hline Heidelberg Universität & 507 & 86 & P.H. Seeburg & 313 & 49 & 16,754 & 21 & 40 & 63 & 150 \\
\hline Hokkaido University & 435 & 102 & M. Watanabe & 615 & 14 & 13,807 & 25 & 53 & 35 & 150 \\
\hline Hong Kong Polytechnic University & 113 & 251 & C.K. Tse & 300 & 55 & 1,445 & 181 & 23 & 140 & 150 \\
\hline Hong Kong University of Science \& Techno... & 97 & 272 & N.Y. Ip & 177 & 139 & 6,485 & 63 & 22 & 150 & 76 \\
\hline Humboldt-Universität zu Berlin & 212 & 195 & W. Ebeling & 221 & 101 & 1,095 & 196 & 18 & 179 & 150 \\
\hline Imperial College London & 3,000 & 12 & A.G. Gaydon & 83 & 227 & 55 & 323 & 0 & 324 & 105 \\
\hline Indian Institute of Technology Bombay (I... & 107 & 257 & P.D. Sunavala & 35 & 309 & 11 & 336 & 0 & 324 & 16 \\
\hline Indian Institute of Technology Delhi (II... & 166 & 217 & N.K. Gupta & 189 & 127 & 524 & 247 & 12 & 245 & 150 \\
\hline Indian Institute of Technology Kanpur (I... & 154 & 226 & R. Balasubramamian & 200 & 113 & 861 & 208 & 17 & 188 & 150 \\
\hline Indiana University Bloomington & 911 & 49 & F.W. Putnam & 280 & 73 & 3,936 & 91 & 18 & 179 & 150 \\
\hline Indiana University Indianapolis & 210 & 196 & M.C. Dinauer & 144 & 168 & 3,880 & 94 & 42 & 59 & 150 \\
\hline Iowa State University & 156 & 224 & K.M. Bryden & 79 & 235 & 186 & 297 & 8 & 282 & 61 \\
\hline Johns Hopkins University & 4,201 & 7 & S.H. Snyder & 300 & 55 & 14,180 & 24 & 75 & 11 & 150 \\
\hline Kansas State University & 51 & 320 & K.Y. Zhu & 70 & 246 & 491 & 249 & 14 & 222 & 125 \\
\hline Katholieke Universiteit Leuven & 317 & 148 & P. Cameliet & 381 & 33 & 20,026 & 15 & 78 & 9 & 150 \\
\hline Keio University & 202 & 200 & H. Okano & 360 & 39 & 9,185 & 42 & 58 & 31 & 150 \\
\hline
\end{tabular}




\begin{tabular}{|c|c|c|c|c|c|c|c|c|c|c|}
\hline King Fahd University of Petroleum \& Minerals & 210 & 196 & A. Aksoy & 25 & 323 & 55 & 323 & 3 & 313 & 33 \\
\hline King Saud University & 133 & 242 & K.A.S. Al-Rasheid & 74 & 239 & 192 & 295 & 9 & 273 & 95 \\
\hline Kobe University & 185 & 211 & Y. Nishizuka & 187 & 132 & 9,115 & 43 & 11 & 252 & 150 \\
\hline Korea Advanced Institute of Science \& Technology & 74 & 295 & J.O. Lee & 33 & 313 & 2,041 & 146 & 17 & 188 & 146 \\
\hline Korea University & 40 & 328 & K.J. Lee & 162 & 150 & 1,584 & 172 & 17 & 188 & 150 \\
\hline Kyoto University & 1,294 & 25 & T. Honjo & 473 & 23 & 12,545 & 32 & 68 & 15 & 150 \\
\hline Kyushu University & 398 & 114 & T. Miyata & 398 & 31 & 7,421 & 56 & 34 & 91 & 150 \\
\hline La Trobe University & 110 & 255 & J.A. Marshall-Graves & 126 & 185 & 1,964 & 150 & 19 & 170 & 150 \\
\hline Lancaster University & 70 & 300 & S. Condor & 19 & 332 & 140 & 305 & 7 & 292 & 13 \\
\hline Leiden University & 593 & 70 & J.J. VanRood & 422 & 29 & 3,648 & 102 & 22 & 150 & 150 \\
\hline Linkoping University & 86 & 281 & P. Westermark & 89 & 220 & 1,579 & 173 & 17 & 188 & 150 \\
\hline London School of Economics and Political Science & 70 & 300 & C. Badcock & 8 & 340 & 79 & 318 & 3 & 313 & 3 \\
\hline Loughborough University & 96 & 275 & N.A. Halliwell & 114 & 199 & 348 & 264 & 8 & 282 & 79 \\
\hline Louisiana State University & 236 & 182 & M.S. Sothern & 41 & 292 & 471 & 251 & 14 & 222 & 107 \\
\hline Ludwig-Maximilians-Universität München & 583 & 72 & W. Neupert & 355 & 40 & 5,422 & 71 & 55 & 34 & 150 \\
\hline Lund University & 601 & 68 & A. Bjorklund & 472 & 24 & 8,610 & 46 & 51 & 38 & 150 \\
\hline Maastricht University & 70 & 300 & P. Goebel & 134 & 176 & 2,819 & 127 & 37 & 73 & 150 \\
\hline Macquarie University & 185 & 211 & S.Y. O'Reilly & 218 & 103 & 3,039 & 122 & 38 & 68 & 150 \\
\hline Mahidol University & 142 & 235 & W. Gritsanapan & 40 & 295 & 125 & 306 & 7 & 292 & 48 \\
\hline Masaryk University & 30 & 335 & J. Friml & 73 & 243 & 1,995 & 148 & 37 & 73 & 150 \\
\hline Massachusetts Institute of Technology & 5,107 & 4 & A. Rich & 337 & 44 & 5,872 & 69 & 32 & 98 & 150 \\
\hline McGill University & 1,344 & 23 & J.H. Quastel & 116 & 197 & 24 & 332 & 0 & 324 & 80 \\
\hline McMaster University & 402 & 110 & H.P. Schwarcz & 254 & 80 & 3,259 & 116 & 26 & 130 & 150 \\
\hline Michigan State University & 948 & 45 & R.E. Lenski & 160 & 154 & 3,733 & 99 & 38 & 68 & 150 \\
\hline Michigan Technological University & 54 & 319 & W.I. Rose & 128 & 182 & 1,386 & 183 & 19 & 170 & 150 \\
\hline Monash University & 36 & 331 & J.Rossjohn & 162 & 150 & 2,345 & 136 & 36 & 79 & 150 \\
\hline Montana State University & 202 & 200 & J.R. Horner & 48 & 283 & 611 & 233 & 19 & 170 & 78 \\
\hline Moscow State University & 569 & 79 & V.E. Tarasov & 86 & 226 & 209 & 290 & 16 & 203 & 3 \\
\hline Nagoya University & 573 & 76 & K. Matsumoto & 137 & 172 & 7,099 & 58 & 2 & 317 & 150 \\
\hline Nanjing University & 576 & 75 & L. Wang & 153 & 162 & 1,055 & 198 & 19 & 170 & 150 \\
\hline Nanyang Technological University & 83 & 285 & G.W. Ma & 65 & 253 & 290 & 275 & 10 & 262 & 106 \\
\hline National Taiwan University & 146 & 230 & C.H. Wong & 555 & 17 & 20,723 & 14 & 65 & 17 & 150 \\
\hline National Tsing Hua University & 68 & 306 & W.W. Lin & 158 & 156 & 1,477 & 180 & 18 & 179 & 150 \\
\hline National University of Ireland, Galway & 64 & 309 & T. Dillion & 8 & 340 & 31 & 329 & 0 & 324 & 6 \\
\hline National University of Singapore & 245 & 179 & N.S. Sodhi & 93 & 215 & 830 & 214 & 17 & 188 & 15 \\
\hline New Mexico State University & 97 & 272 & B.A. Smith & 102 & 210 & 1,689 & 164 & 13 & 236 & 150 \\
\hline
\end{tabular}




\begin{tabular}{|c|c|c|c|c|c|c|c|c|c|c|}
\hline New York University & 2,035 & 17 & R. Llinas & 294 & 60 & 9,464 & 41 & 30 & 109 & 150 \\
\hline Newcastle University & 572 & 77 & S.K. Runcorn & 81 & 230 & 163 & 299 & 3 & 313 & 82 \\
\hline North Carolina State University & 450 & 97 & C.S. Levings & 53 & 277 & 550 & 242 & 2 & 317 & 60 \\
\hline Northeastern University & 138 & 239 & A.L. Barbasi & 171 & 144 & 18,045 & 18 & 62 & 22 & 150 \\
\hline Northwestern University & 1,582 & 21 & C.A. Mirkin & 352 & 42 & 15,071 & 23 & 73 & 12 & 150 \\
\hline Norwegian University of Science \& Technology & 82 & 289 & E.I. Moser & 65 & 253 & 2,514 & 133 & 30 & 109 & 58 \\
\hline Ohio State University & 1,332 & 24 & R.M. Stulz & 57 & 270 & 1,841 & 154 & 23 & 140 & 54 \\
\hline Oklahoma State University & 123 & 246 & C.A. Yu & 174 & 142 & 1,573 & 174 & 23 & 140 & 150 \\
\hline Open University UK & 369 & 126 & C.T. Pillinger & 215 & 104 & 1,700 & 163 & 17 & 188 & 150 \\
\hline Oregon State University & 821 & 52 & L. Pauling & 251 & 85 & 4,521 & 85 & 0 & 324 & 120 \\
\hline Osaka University & 995 & 44 & T. Kishimoto & 626 & 13 & 44,277 & 2 & 79 & 7 & 150 \\
\hline Peking University & 1,240 & 29 & H. Gu & 61 & 262 & 441 & 255 & 12 & 245 & 150 \\
\hline Pennsylvania State University & 1,693 & 20 & R.Roy & 407 & 30 & 3,422 & 111 & 23 & 140 & 150 \\
\hline Pohang University of Science And Technology & 66 & 307 & K.S. Kim & 790 & 4 & 16,187 & 22 & 60 & 28 & 150 \\
\hline Portland State University & 61 & 312 & A.L. Reyensbach & 72 & 245 & 2,269 & 139 & 27 & 122 & 150 \\
\hline Princeton University & 2,609 & 13 & R.M. May & 371 & 36 & 12,961 & 28 & 27 & 122 & 150 \\
\hline Purdue University & 1,085 & 39 & & 0 & 344 & 0 & 343 & 0 & 324 & 0 \\
\hline Queen's University & 454 & 94 & J.P. Smol & 300 & 55 & 2,745 & 129 & 30 & 109 & 150 \\
\hline Queen's University of Belfast & 323 & 143 & M.J. Benton & 196 & 120 & 2,191 & 140 & 24 & 136 & 150 \\
\hline Queensland University of Technology & 23 & 337 & M. Pantaleon & 15 & 335 & 321 & 268 & 9 & 273 & 34 \\
\hline Radboud University, Nijmegen & 302 & 153 & W.W. DeJong & 194 & 121 & 3,761 & 96 & 35 & 84 & 150 \\
\hline Rensselaer Polytechnic Institute & 222 & 190 & P.M. Ajayan & 364 & 38 & 13,052 & 27 & 62 & 22 & 150 \\
\hline Rheinisch Westfalische Technische Hochschule Aach & 83 & 285 & H. Roskos & 199 & 116 & 1,773 & 158 & 24 & 136 & 150 \\
\hline Rheinische Friedrich Wilhelms Universitat Bonn & 263 & 170 & K. Wilecke & 288 & 66 & 5,294 & 73 & 53 & 35 & 150 \\
\hline Rice University & 496 & 89 & R.E. Smaller & 338 & 43 & 27,011 & 9 & 82 & 4 & 150 \\
\hline Rochester Institute of Technology & 35 & 332 & K. Hickman & 10 & 337 & 4 & 339 & 0 & 324 & 5 \\
\hline Royal Institute of Technology, KTH & 167 & 215 & H. Alfven & 83 & 227 & 288 & 276 & 0 & 324 & 34 \\
\hline Royal Melbourne Institute of Technology & 25 & 336 & A.J. Sinclair & 211 & 108 & 2,048 & 145 & 22 & 150 & 150 \\
\hline Rutgers & 1,190 & 33 & R.H. Ebright & 123 & 189 & 3,273 & 115 & 35 & 84 & 150 \\
\hline Saint-Petersburg State University & 84 & 283 & L.N. Moskvin & 194 & 121 & 187 & 296 & 7 & 292 & 150 \\
\hline San Diego State University & 156 & 224 & J.D. Archibald & 34 & 312 & 327 & 267 & 10 & 262 & 49 \\
\hline Sapienza University of Rome & 0 & 346 & & 0 & 344 & 0 & 343 & 0 & 324 & 0 \\
\hline Sciences Po Paris & 0 & 346 & & 0 & 344 & 0 & 343 & 0 & 324 & 0 \\
\hline Seoul National University & 160 & 220 & B.K. Kaang & 65 & 253 & 1,157 & 191 & 17 & 188 & 150 \\
\hline Shanghai Jiao Tong University & 1,002 & 43 & Z. Huang & 373 & 35 & 925 & 204 & 18 & 179 & 150 \\
\hline Simon Fraser University & 144 & 233 & D.E. Nelson & 74 & 239 & 1,549 & 176 & 6 & 304 & 106 \\
\hline
\end{tabular}




\begin{tabular}{|c|c|c|c|c|c|c|c|c|c|c|}
\hline Stanford University & 6,005 & 2 & I.L. Weissman & 590 & 16 & 40,038 & 5 & 31 & 104 & 150 \\
\hline State University of New York Buffalo & 11 & 342 & D.L. Wiesenthal & 26 & 322 & 152 & 302 & 8 & 282 & 17 \\
\hline Stockholm University & 453 & 96 & G. Von Heijne & 251 & 85 & 19,681 & 16 & 53 & 35 & 150 \\
\hline Stony Brook University & 1,113 & 36 & E. Wimmer & 253 & 82 & 3,896 & 93 & 32 & 98 & 150 \\
\hline Syracuse University & 112 & 252 & A.L. A. Katzenstein & 80 & 231 & 2,603 & 131 & 11 & 252 & 100 \\
\hline Tartu University (University of Tartu) & 43 & 326 & J. Allik & 93 & 215 & 1,429 & 182 & 21 & 158 & 150 \\
\hline Technical University of Denmark & 153 & 227 & E. Mosekilde & 169 & 145 & 1,197 & 190 & 20 & 165 & 150 \\
\hline Technion & 235 & 183 & A. Hershko & 90 & 219 & 4,262 & 88 & 23 & 140 & 101 \\
\hline Technische Universität Berlin & 85 & 282 & A. Zouni & 40 & 295 & 1,744 & 160 & 14 & 222 & 81 \\
\hline Technische Universitat Chemnitz & 8 & 344 & R. Plasil & 35 & 309 & 123 & 307 & 11 & 252 & 72 \\
\hline Technische Universität Dresden & 75 & 293 & P. Schwille & 111 & 202 & 3,703 & 101 & 45 & 55 & 150 \\
\hline Technische Universität München & 390 & 116 & A. Bacher & 382 & 32 & 3,509 & 109 & 38 & 68 & 150 \\
\hline Tel Aviv University & 493 & 91 & J. Klafter & 305 & 51 & 4,700 & 80 & 37 & 73 & 150 \\
\hline Texas A\&M University & 822 & 51 & E.R. Dougherty & 376 & 34 & 3,926 & 92 & 32 & 98 & 150 \\
\hline Texas Tech & 140 & 236 & C.A. Bond & $\mid 58$ & 268 & 704 & 222 & 18 & 179 & 40 \\
\hline Tohoku University & 527 & 83 & E. Htani & 182 & 135 & 1,285 & 186 & 22 & 150 & 150 \\
\hline Tokyo Institute of Technology & 292 & 157 & M. Yoshida & 283 & 69 & 3,635 & 104 & 39 & 65 & 150 \\
\hline Trinity College Dublin & 477 & 93 & J.B. Gatenby & 38 & 302 & 1 & 342 & 0 & 324 & 13 \\
\hline Tsinghua University & 1,268 & 27 & N. Zhao & 138 & 171 & 839 & 211 & 15 & 213 & 150 \\
\hline Tufts University & 748 & 53 & J.M. Coffin & 179 & 138 & 4,350 & 87 & 27 & 122 & 150 \\
\hline Universidad Autonoma de Madrid & 234 & 184 & A. Garcia-Bellido & 80 & 231 & 1,521 & 178 & 17 & 188 & 54 \\
\hline Universidad de Chile & 194 & 208 & J.E. Allende & 132 & 179 & 952 & 202 & 14 & 222 & 150 \\
\hline Universidad de Granada & 234 & 184 & A. Garcia-Bellido & 80 & 231 & 1,521 & 178 & 17 & 188 & 54 \\
\hline Universidad del País Vasco & 55 & 318 & A. Sanchez & 119 & 194 & 637 & 228 & 19 & 170 & 150 \\
\hline Universidad Nacional Autónoma de México ... & 100 & 269 & A. Pardo & 93 & 215 & 2,124 & 143 & 28 & 120 & 150 \\
\hline Universidad Politecnica de Madrid & 62 & 311 & R. Alonso-Sanz & 33 & 313 & 58 & 322 & 9 & 273 & 26 \\
\hline Universidade de São Paulo & 412 & 105 & E.R. Parra & 52 & 279 & 98 & 313 & 7 & 292 & 150 \\
\hline Universidade Estadual de Campinas & 139 & 238 & A. Garcia & 116 & 197 & 447 & 254 & 18 & 179 & 74 \\
\hline Università degli Studi di Firenze & 232 & 187 & I. Bertini & 466 & 25 & 4,681 & 81 & 48 & 45 & 150 \\
\hline Università degli Studi di Padova & 336 & 138 & J.R. Banavar & 258 & 79 & 4,533 & 84 & 32 & 98 & 150 \\
\hline Universita Di Bologna & 225 & 188 & G. Campadelli-Fiume & 109 & 205 & 1,229 & 188 & 24 & 136 & 143 \\
\hline Universita di Pisa & 143 & 234 & G. Petroni & 23 & 325 & 204 & 292 & 9 & 273 & 48 \\
\hline Universitat Autonoma de Barcelona & 145 & 232 & J. Llibre & 220 & 102 & 737 & 220 & 14 & 222 & 121 \\
\hline Universitat Bielefeld & 99 & 270 & M. Drescher & 67 & 251 & 2,030 & 147 & 20 & 165 & 150 \\
\hline Universität Bremen & 133 & 242 & H.O. Peitgen & 38 & 302 & 14 & 335 & 2 & 317 & 150 \\
\hline Universitat d'Alacant & 22 & 338 & A. Contreras & 22 & 328 & 218 & 289 & 9 & 273 & 38 \\
\hline
\end{tabular}




\begin{tabular}{|c|c|c|c|c|c|c|c|c|c|c|}
\hline Universitat de València & 103 & 265 & A. Moya & 184 & 133 & 3,615 & 105 & 31 & 104 & 150 \\
\hline Universität Frankfurt am Main & 280 & 165 & A. Czasch & 54 & 275 & 391 & 259 & 15 & 213 & 150 \\
\hline Universität Freiburg & 374 & 125 & P. Jonas & 74 & 239 & 4,013 & 89 & 29 & 115 & 101 \\
\hline Universitat Hamburg & 69 & 304 & T.M. Kaiser & 27 & 321 & 95 & 315 & 8 & 282 & 28 \\
\hline Universität Karlsruhe & 105 & 261 & G. Keller & 127 & 183 & 1,107 & 195 & 22 & 150 & 134 \\
\hline Universitat Leipzig & 73 & 297 & W. Kiess & 354 & 41 & 5,026 & 77 & 35 & 84 & 150 \\
\hline Universitat Munster (Westfälische Wilhelms-Un & 140 & 236 & H. Jurgens & 295 & 58 & 3,739 & 98 & 30 & 109 & 150 \\
\hline Universitat Politecnica de Catalunya & 51 & 320 & J. Periaux & 83 & 227 & 668 & 227 & 10 & 262 & 80 \\
\hline Universität Regensburg & 199 & 204 & K.O. Stetter & 223 & 100 & 5,256 & 74 & 36 & 79 & 150 \\
\hline Universität Stuttgart & 104 & 264 & M. Schanz & 32 & 316 & 198 & 293 & 8 & 282 & 35 \\
\hline Universitat Trier & 5 & 345 & E.K. Adam & 22 & 328 & 338 & 266 & 10 & 262 & 34 \\
\hline Universität Tübingen & 321 & 145 & F. Lang & 643 & 11 & 17,517 & 19 & 60 & 28 & 150 \\
\hline Universitat Wien (University of Vienna) & 412 & 105 & A. Zeilinger & 292 & 61 & 7,470 & 54 & 49 & 42 & 150 \\
\hline Universitat Zu Koln & 362 & 129 & K. Rajewsky & 202 & 111 & 12,011 & 33 & 72 & 13 & 150 \\
\hline Université Catholique de Louvain & 267 & 169 & A. Goffeau & 232 & 94 & 8,644 & 45 & 38 & 68 & 150 \\
\hline Universite de Liege & 319 & 146 & Z.M. Bacq & 158 & 156 & 59 & 321 & 0 & 324 & 112 \\
\hline Université de Montréal & 353 & 132 & E.L. Schiffrin & 456 & 26 & 8,561 & 47 & 62 & 22 & 150 \\
\hline Université de Nice Sophia Antipolis & 146 & 230 & J.M. Pouyssegur & 323 & 47 & 13,496 & 26 & 63 & 21 & 150 \\
\hline Universite Laval & 195 & 207 & M. Steriade & 243 & 89 & 6,712 & 60 & 46 & 52 & 113 \\
\hline Universite Libre de Bruxelles & 378 & 121 & J.J. Body & 248 & 88 & 3,543 & 108 & 34 & 91 & 150 \\
\hline Université Paris Sorbonne & 56 & 317 & N.P. Buu-Hol & 122 & 191 & 104 & 312 & 0 & 324 & 106 \\
\hline Universite Paris-Sud 11 & 436 & 101 & Y. Langevin & 141 & 170 & 1,319 & 185 & 24 & 136 & 150 \\
\hline Université Pierre et Marie Curie & 577 & 74 & C.J. Allegre & 304 & 52 & 6,367 & 64 & 36 & 79 & 150 \\
\hline Universiti Malaya (University of Malaya) & 260 & 172 & H.H. Masjuki & 104 & 209 & 388 & 260 & 12 & 245 & 88 \\
\hline University College Cork & 103 & 265 & V.A.I. Huvennue & 23 & 325 & 145 & 304 & 10 & 262 & 109 \\
\hline University College Dublin & 286 & 161 & E.J. Conway & 39 & 300 & 11 & 336 & 0 & 324 & 25 \\
\hline University College London & 3,672 & 10 & G. Burnstock & 1,019 & 1 & 32,401 & 8 & 62 & 22 & 150 \\
\hline University do Porto & 70 & 300 & C.A. Conceicao-Anton & 15 & 335 & 96 & 314 & 7 & 292 & 15 \\
\hline University of Aberdeen & 491 & 92 & B.H.Smith & 63 & 260 & 1,017 & 200 & 17 & 188 & 119 \\
\hline University of Adelaide & 532 & 82 & R.K. Morton & 22 & 328 & 50 & 325 & 0 & 324 & 24 \\
\hline University of Alabama & 677 & 61 & M.D. Cooper & 136 & 173 & 3,641 & 103 & 40 & 63 & 150 \\
\hline University of Alberta & 714 & 57 & R.T. Tsuyuki & 181 & 136 & 2,816 & 128 & 27 & 122 & 150 \\
\hline University of Amsterdam & 572 & 77 & J. Van Paradijs & 229 & 96 & 5,024 & 78 & 49 & 42 & 150 \\
\hline University of Antwerp & 73 & 297 & G. Hans & 23 & 325 & 241 & 286 & 8 & 282 & 53 \\
\hline University of Arizona & 1,810 & 19 & D.M. Hunten & 163 & 148 & 1,813 & 156 & 16 & 203 & 150 \\
\hline University of Athens & 105 & 261 & P.A. Varotsos & 158 & 156 & 573 & 236 & 15 & 213 & 59 \\
\hline
\end{tabular}




\begin{tabular}{|c|c|c|c|c|c|c|c|c|c|c|}
\hline University of Auckland & 337 & 137 & M. Horrocks & 69 & 249 & 272 & 278 & 13 & 236 & 98 \\
\hline University of Barcelona & 221 & 192 & E. Salo & 58 & 268 & 620 & 230 & 16 & 203 & 82 \\
\hline University of Basel & 583 & 72 & W.J. Gehring & 209 & 109 & 6,605 & 61 & 32 & 98 & 150 \\
\hline University of Bath & 102 & 268 & C. Eccleston & 110 & 203 & 1,803 & 157 & 29 & 115 & 150 \\
\hline University of Bergen & 219 & 193 & J.S. Skoven & 28 & 320 & 310 & 271 & 9 & 273 & 44 \\
\hline University of Bern & 201 & 202 & S.Szidat & 31 & 318 & 246 & 285 & 11 & 252 & 91 \\
\hline University of Birmingham & 352 & 133 & S. Hariharan & 39 & 300 & 90 & 316 & 6 & 304 & 65 \\
\hline University of Bristol & 1,529 & 22 & G. Eglinton & 313 & 49 & 3,723 & 100 & 25 & 131 & 150 \\
\hline University of British Columbia & 601 & 68 & J. Rootman & 174 & 142 & 1,828 & 155 & 13 & 236 & 150 \\
\hline University of Calgary & 346 & 135 & C.B. Frank & 201 & 112 & 2,288 & 138 & 23 & 140 & 150 \\
\hline University of California, Berkley & 287 & 159 & A.M. Agogino & 124 & 187 & 527 & 246 & 9 & 273 & 132 \\
\hline University of California, Davis & 335 & 139 & S. Harrison & 64 & 258 & 2,488 & 134 & 23 & 140 & 86 \\
\hline University of California, Irvine & 192 & 209 & S. Haldeman & 127 & 183 & 1,137 & 192 & 20 & 165 & 134 \\
\hline University of California, Los Angeles & 4,247 & 6 & J.M. Diamond & 184 & 133 & 2,956 & 125 & 22 & 150 & 88 \\
\hline University of California, Riverside & 674 & 62 & J.K. Zhu & 200 & 113 & 6,821 & 59 & 64 & 18 & 150 \\
\hline University of California, San Diego & 405 & 108 & I. Grant & 369 & 37 & 7,467 & 55 & 42 & 59 & 150 \\
\hline University of California, San Francisco & 645 & 66 & T.E. King & 136 & 173 & 4,581 & 83 & 39 & 65 & 150 \\
\hline University of California, Santa Barbara & 159 & 221 & L. Cosmides & 40 & 295 & 1,641 & 168 & 16 & 203 & 43 \\
\hline University of California, Santa Cruz & 76 & 292 & S.N. Ward & 40 & 295 & 916 & 205 & 15 & 213 & 36 \\
\hline University of Cambridge & 404 & 109 & W.N. Dawes & 89 & 220 & 463 & 252 & 10 & 262 & 72 \\
\hline University of Canterbury & 35 & 332 & J.G. Chase & 131 & 181 & 321 & 268 & 13 & 236 & 150 \\
\hline University of Cape Town & 116 & 249 & T.J. Egan & 60 & 264 & 735 & 221 & 21 & 158 & 101 \\
\hline University of Central Florida & 60 & 313 & D.N. Christodoulides & 275 & 75 & 3,250 & 117 & 43 & 58 & 150 \\
\hline University of Chicago & 378 & 121 & H. Ahsan & 125 & 186 & 2,710 & 130 & 30 & 109 & 150 \\
\hline University of Cincinnati & $\mid 586$ & 71 & J.B. Lingrel & 227 & 98 & 3,222 & 118 & 29 & 115 & 150 \\
\hline University of Colorado at Boulder & 251 & 176 & K. Maute & 60 & 264 & 294 & 273 & 11 & 252 & 46 \\
\hline University of Connecticut & 196 & 206 & M.T. Turvey & 231 & 95 & 2,543 & 132 & 25 & 131 & 146 \\
\hline University of Copenhagen & 312 & 150 & P. Sjoren & 133 & 178 & 1,738 & 162 & 22 & 150 & 150 \\
\hline University of Delaware & 64 & 309 & J.Q. Sun & 124 & 187 & 592 & 234 & 13 & 236 & 70 \\
\hline University of Dundee & 365 & 128 & D.M.J. Lilley & 239 & 90 & 3,757 & 97 & 37 & 73 & 150 \\
\hline University of Edinburgh & 269 & 168 & M.R. Evans & 122 & 191 & 1,991 & 149 & 27 & 122 & 150 \\
\hline University of Florida & 1,068 & 40 & D.L. Dilcher & 106 & 208 & 1,528 & 177 & 17 & 188 & 150 \\
\hline University of Geneva & 362 & 129 & D. Pittet & 282 & 70 & 7,737 & 51 & 47 & 50 & 150 \\
\hline University of Georgia & 187 & 210 & R. Forehand & 284 & 67 & 3,046 & 120 & 25 & 131 & 150 \\
\hline University of Ghent & 327 & 141 & P. Van Cauwenberge & 327 & 46 & 551 & 241 & 36 & 79 & 150 \\
\hline University of Glasgow & 1,135 & 34 & R.W. Pickford & 50 & 280 & 19 & 334 & 0 & 324 & 13 \\
\hline
\end{tabular}




\begin{tabular}{|c|c|c|c|c|c|c|c|c|c|c|}
\hline University of Gothenburg & 14 & 340 & P.S. Eriksson & 191 & 123 & 4,948 & 79 & 31 & 104 & 150 \\
\hline University of Groningen & 454 & 94 & D.J. Van Veldhuisen & 502 & 20 & 10,436 & 38 & 48 & 45 & 150 \\
\hline University of Helsinki & 524 & 84 & K. Alitalo & 292 & 61 & 11,660 & 37 & 89 & 3 & 150 \\
\hline University of Hong Kong & 161 & 219 & C.Y. Jim & 94 & 213 & 359 & 261 & 13 & 236 & 23 \\
\hline University of Houston & 106 & 259 & R. Bannerot & 74 & 239 & 47 & 326 & 1 & 322 & 58 \\
\hline University of Illinois & 2,390 & 15 & G.A. Miller & 73 & 243 & 2 & 341 & 0 & 324 & 0 \\
\hline University of Illinois, Chicago & 748 & 53 & E. Costa & 658 & 10 & 11,773 & 36 & 36 & 79 & 150 \\
\hline University of Indonesia & 19 & 339 & L.I.L. Eng & 4 & 343 & 5 & 338 & 0 & 324 & 1 \\
\hline University of Iowa & 438 & 100 & K.K. Choi & 177 & 139 & 1,065 & 197 & 19 & 170 & 150 \\
\hline University of Kansas & 234 & 184 & S.A. David & 38 & 302 & 225 & 287 & 14 & 222 & 76 \\
\hline University of Kentucky & 289 & 158 & D.K. Moser & 189 & 127 & 2,851 & 126 & 25 & 131 & 150 \\
\hline University of Lausanne & 167 & 215 & P. Romero & 281 & 71 & 7,310 & 57 & 48 & 45 & 150 \\
\hline University of Leeds & 401 & 111 & O.M. Querin & 46 & 285 & 258 & 281 & 13 & 236 & 33 \\
\hline University of Leicester & 556 & 80 & M.C.R. Symons & 857 & 3 & 3,320 & 114 & 12 & 245 & 150 \\
\hline University of Liverpool & 299 & 154 & H.K.F. Van Saene & 214 & 105 & 1,569 & 175 & 22 & 150 & 150 \\
\hline University of Ljubljana & 51 & 320 & J. Mozina & 107 & 207 & 195 & 294 & 8 & 282 & 77 \\
\hline University of London (Kings College of London) & 8,485 & 1 & J.B.S. Haldane & 64 & 258 & 116 & 309 & 1 & 322 & 18 \\
\hline University of Manchester & 1,860 & 18 & A.G. Lyne & 254 & 80 & 3,550 & 107 & 42 & 59 & 150 \\
\hline University of Manitoba & 262 & 171 & V. Smil & 57 & 270 & 679 & 225 & 14 & 222 & 25 \\
\hline University of Maryland & 1,223 & 31 & V. Trimble & 87 & 224 & 251 & 282 & 6 & 304 & 33 \\
\hline University of Maryland Baltimore County & 707 & 59 & R.C. Gallo & 163 & 148 & 6,517 & 62 & 37 & 73 & 150 \\
\hline University of Massachusetts & 108 & 256 & S. Krishnamurty & 45 & 287 & 123 & 307 & 5 & 310 & 42 \\
\hline University of Melbourne & 915 & 48 & D.A. Denton & 295 & 58 & 2,085 & 144 & 19 & 170 & 150 \\
\hline University of Miami & 382 & 120 & D.A. Fishbain & 213 & 106 & 2,186 & 141 & 18 & 179 & 150 \\
\hline University of Michigan & 1,130 & 35 & P.Y. Papalambros & 198 & 117 & 868 & 206 & 20 & 165 & 150 \\
\hline University of Minnesota & 496 & 89 & E.C. Alexander & 41 & 292 & 837 & 212 & 8 & 282 & 73 \\
\hline University of Missouri & 324 & 142 & X. Du & 122 & 191 & 2,141 & 142 & 25 & 131 & 150 \\
\hline University of Nebraska & 295 & 156 & V.N. Gladshev & 150 & 165 & 2,352 & 135 & 39 & 65 & 150 \\
\hline University of New Hampshire & 209 & 198 & P.A. Mayewski & 190 & 125 & 4,583 & 82 & 33 & 93 & 150 \\
\hline University of New Mexico & 158 & 222 & C. Klein & 22 & 328 & 413 & 256 & 5 & 310 & 27 \\
\hline University of New South Wales & 319 & 146 & T. Ray & 63 & 260 & 348 & 264 & 10 & 262 & 48 \\
\hline University of North Carolina, Chapel Hill & 1,226 & 30 & O. Smithies & 273 & 77 & 18,441 & 17 & 46 & 52 & 150 \\
\hline University of North Texas & 45 & 325 & D.J. Cipher & 32 & 316 & 116 & 309 & 7 & 292 & 68 \\
\hline University of Notre Dame & 162 & 218 & J.E. Renaud & 114 & 199 & 562 & 238 & 17 & 188 & 78 \\
\hline University of Nottingham & 242 & 180 & S. Petrovic & 42 & 291 & 270 & 279 & 12 & 245 & 32 \\
\hline University of Oklahoma & 138 & 239 & A.G. Striz & 60 & 264 & 535 & 244 & 6 & 304 & 53 \\
\hline
\end{tabular}




\begin{tabular}{|c|c|c|c|c|c|c|c|c|c|c|}
\hline University of Oregon & 153 & 227 & J.M. Erlandson & 65 & 253 & 1,596 & 170 & 12 & 245 & 119 \\
\hline University of Oslo & 286 & 161 & T.A. Alvegard & 70 & 246 & 1,208 & 189 & 19 & 170 & 150 \\
\hline University of Otago & 504 & 87 & P.A. Silva & 233 & 93 & 7,933 & 50 & 33 & 93 & 150 \\
\hline University of Ottawa & 256 & 174 & G.A. Wells & 542 & 19 & 21,911 & 13 & 70 & 14 & 150 \\
\hline University of Oxford & 391 & 115 & S.J. Ferguson & 278 & 74 & 2,325 & 137 & 29 & 115 & 150 \\
\hline University of Pennsylvania & 711 & 58 & G.K. Ananthasuresh & 98 & 212 & 754 & 219 & 15 & 213 & 70 \\
\hline University of Pittsburgh & 728 & 56 & D.K. Weiner & 61 & 262 & 1,743 & 161 & 18 & 179 & 135 \\
\hline University of Quebec & 169 & 214 & P. Voyer & 40 & 295 & 108 & 311 & 7 & 292 & 69 \\
\hline University of Queensland & 368 & 127 & S. Stewart & 191 & 123 & 3,038 & 123 & 28 & 120 & 150 \\
\hline University of Reading & 670 & 63 & O.V.S. Heath & 37 & 305 & 30 & 330 & 0 & 324 & 11 \\
\hline University of Rochester & 242 & 180 & K.L. Bren & 48 & 283 & 581 & 235 & 15 & 213 & 112 \\
\hline University of Saskatchewan & 247 & 177 & J.W.T. Spinks & 41 & 292 & 20 & 333 & 0 & 324 & 63 \\
\hline University of Science and Technology of China & 499 & 88 & Y. Zhang & 321 & 48 & 1,676 & 165 & 19 & 170 & 150 \\
\hline University of Sheffield & 1,019 & 41 & D.W. Hughes & 189 & 127 & 848 & 210 & 14 & 222 & 150 \\
\hline University of South Carolina & 201 & 202 & J.A. Ritter & 152 & 163 & 1,585 & 171 & 23 & 140 & 97 \\
\hline University of South Florida & 317 & 148 & C.E. Cox & 189 & 127 & 6,138 & 67 & 35 & 84 & 150 \\
\hline University of Southampton & 273 & 166 & A.J. Keane & 144 & 168 & 866 & 207 & 16 & 203 & 108 \\
\hline University of Southern California & 390 & 116 & F.A. Corsetti & 36 & 306 & 313 & 270 & 13 & 236 & 54 \\
\hline University of St Andrews & 57 & 314 & H.T.O. Davies & 328 & 45 & 5,329 & 72 & 44 & 56 & 150 \\
\hline University of Surrey & 69 & 304 & H. Gage & 36 & 306 & 513 & 248 & 12 & 245 & 100 \\
\hline University of Sussex & 42 & 327 & L. Fallowfield & 190 & 125 & 5,249 & 75 & 38 & 68 & 150 \\
\hline University of Sydney & 917 & 47 & V.A. Bailey & 30 & 319 & 45 & 327 & 0 & 324 & 8 \\
\hline University of Technology, Sydney & 51 & 320 & R. Iedema & 56 & 272 & 247 & 283 & 10 & 262 & 86 \\
\hline University of Tennessee Knoxville & 125 & 245 & S.P. Horn & 44 & 290 & 219 & 288 & 9 & 273 & 41 \\
\hline University of Texas at Austin & 246 & 178 & C.C. Seepersad & 33 & 313 & 151 & 303 & 6 & 304 & 51 \\
\hline University of Tokyo & 342 & 136 & Y. Tokura & 901 & 2 & 38,181 & 7 & 82 & 4 & 150 \\
\hline University of Toronto & 2,146 & 16 & T.W. Mak & 630 & 12 & 47,418 & 1 & 99 & 1 & 150 \\
\hline University of Tsukuba & 1,007 & 42 & S.F. Chichibu & 206 & 110 & 3,019 & 124 & 32 & 98 & 150 \\
\hline University of Twente & 83 & 285 & J.J. Rasker & 154 & 161 & 1,876 & 153 & 21 & 158 & 150 \\
\hline University of Utah & 1,108 & 37 & T.E. Cerling & 132 & 179 & 3,503 & 110 & 31 & 104 & 150 \\
\hline University of Vermont & 286 & 161 & D.M. Warsaw & 110 & 203 & 1,964 & 150 & 27 & 122 & 150 \\
\hline University of Victoria & 111 & 253 & A. Suleman & 88 & 222 & 247 & 283 & 8 & 282 & 63 \\
\hline University of Virginia & 310 & 151 & S.M. Burns & 55 & 273 & 398 & 258 & 10 & 262 & 109 \\
\hline University of Warwick & 111 & 253 & J. Dale & 69 & 249 & 755 & 218 & 13 & 236 & 107 \\
\hline University of Washington & 3,668 & 11 & R.D. Palmiter & 291 & 63 & 12,644 & 30 & 50 & 40 & 150 \\
\hline University of Waterloo & 176 & 213 & J. McPhee & 70 & 246 & 275 & 277 & 11 & 252 & 53 \\
\hline
\end{tabular}




\begin{tabular}{|c|c|c|c|c|c|c|c|c|c|c|}
\hline University of Western Australia & 387 & 118 & K. Judd & 53 & 277 & 478 & 250 & 14 & 222 & 29 \\
\hline University of Western Ontario & 433 & 103 & P. Yu & 189 & 127 & 1,111 & 194 & 21 & 158 & 150 \\
\hline University of Wisconsin & 547 & 81 & T.E. Moffitt & 212 & 107 & 12,608 & 31 & 64 & 18 & 150 \\
\hline University of Wollongong & 40 & 328 & S.J. Johnson & 59 & 267 & 634 & 229 & 16 & 203 & 57 \\
\hline University of York & 136 & 241 & M. Lavidor & 45 & 287 & 263 & 280 & 14 & 222 & 43 \\
\hline University of Zurich & 115 & 250 & M.E. Endress & 18 & 333 & 154 & 301 & 9 & 273 & 41 \\
\hline Univesitas Gadjah Mada & 11 & 342 & T. Jacob & 16 & 334 & 353 & 263 & 7 & 292 & 45 \\
\hline Uppsala University & 296 & 155 & K. Ueda & 259 & 78 & 977 & 201 & 23 & 140 & 150 \\
\hline Utah State & 50 & 324 & T. Hauser & 49 & 281 & 181 & 298 & 2 & 317 & 51 \\
\hline Utrecht University & 700 & 60 & J. Oerlemans & 150 & 165 & 1,749 & 159 & 23 & 140 & 150 \\
\hline Vanderbilt University & 255 & 175 & S. Mahadevan & 157 & 159 & 462 & 253 & 15 & 213 & 89 \\
\hline Victoria University of Wellington & 31 & 334 & F Stasolla & 10 & 337 & 26 & 331 & 3 & 313 & 24 \\
\hline Vienna University of Technology & 39 & 330 & H.A. Mang & 157 & 159 & 534 & 245 & 11 & 252 & 104 \\
\hline Virginia Polytechnic Institute & 358 & 131 & L.T. Watson & 290 & 65 & 1,667 & 167 & 20 & 165 & 150 \\
\hline Vrije Universiteit, Brussels & 12 & 341 & M. Meysman & 78 & 237 & 559 & 239 & 14 & 222 & 150 \\
\hline VU University Amsterdam & 307 & 152 & A. Stolk & 75 & 238 & 68 & 320 & 0 & 324 & 28 \\
\hline Wageningen University & 107 & 257 & R. Leesmans & 55 & 273 & 3,218 & 119 & 15 & 213 & 150 \\
\hline Wake Forest University & 157 & 223 & D.W. Kitzman & 164 & 146 & 4,411 & 86 & 33 & 93 & 150 \\
\hline Waseda University & 57 & 314 & Y. Noda & 145 & 167 & 1,022 & 199 & 17 & 188 & 150 \\
\hline Washington State University & 84 & 283 & D.L. Young & 35 & 309 & 208 & 291 & 8 & 282 & 94 \\
\hline Washington University in St. Louis & 400 & 113 & D.H. Gutmann & 274 & 76 & 3,991 & 90 & 44 & 56 & 150 \\
\hline Wayne State University & 383 & 119 & M. Goodman & 177 & 139 & 3,040 & 121 & 30 & 109 & 150 \\
\hline West Virginia University & 105 & 261 & D.J. Jones & 45 & 287 & 292 & 274 & 11 & 252 & 50 \\
\hline Yale University & 515 & 85 & H.M. Krumholz & 547 & 18 & 24,827 & 10 & 81 & 6 & 150 \\
\hline Yonsei University & 93 & 276 & J. Lee & 36 & 306 & 357 & 262 & 7 & 292 & 67 \\
\hline York University & 72 & 299 & W.C. Mahaney & 162 & 150 & 400 & 257 & 11 & 252 & 128 \\
\hline Zhejiang University & 103 & 265 & Y. Zheng & 93 & 215 & 161 & 300 & 7 & 292 & 150 \\
\hline
\end{tabular}




\begin{tabular}{|c|c|c|c|c|c|c|c|c|c|c|}
\hline $\begin{array}{c}\text { Pharmacology/Toxicology/Pharmaceuticals } \\
\text { Data }\end{array}$ & $\begin{array}{l}\text { Department } \\
\text { Publications }\end{array}$ & Rank & Most Prolific Author & Published & Rank & Cited & Rank & $\begin{array}{c}\text { H- } \\
\text { Index }\end{array}$ & Rank & $\begin{array}{c}\text { \# of } \\
\text { Coauthors }\end{array}$ \\
\hline Aalto University & 159 & 301 & A.M.P. Kosinen & 111 & 288 & 1,187 & 248 & 18 & 224 & 121 \\
\hline Aarhus University & 1,668 & 101 & M.J. Mulvany & 275 & 144 & 4,494 & 76 & 26 & 145 & 150 \\
\hline Arizonia State University & 145 & 307 & G.R. Pettit & 570 & 29 & 13,412 & 17 & 35 & 83 & 150 \\
\hline Ateneo de Manila University & 7 & 345 & F.M. Dayrit & 17 & 341 & 193 & 326 & 5 & 321 & 30 \\
\hline Auburn University & 822 & 190 & B.G. Felkey & 82 & 312 & 160 & 331 & 6 & 317 & 26 \\
\hline Australian National University & 1,003 & 171 & L.N. Mander & 168 & 235 & 1,195 & 247 & 15 & 252 & 150 \\
\hline Boston College & 155 & 303 & T.R. Kelly & 84 & 309 & 1,653 & 213 & 12 & 273 & 149 \\
\hline Boston University & 1,774 & 99 & C. Kornetsky & 152 & 248 & 1,273 & 242 & 12 & 273 & 150 \\
\hline Brandeis University & 251 & 278 & B.B. Snider & 250 & 160 & 3,079 & 128 & 27 & 138 & 150 \\
\hline Brigham Young University & 41 & 335 & M.J. Robins & 247 & 166 & 2,643 & 142 & 21 & 189 & 150 \\
\hline Brown University & 1,306 & 136 & E. Mathiowitz & 134 & 270 & 1,915 & 192 & 21 & 189 & 150 \\
\hline California Institute of Technology (Calt... & 405 & 240 & A.H. Zewail & 441 & 48 & 7,471 & 37 & 48 & 20 & 150 \\
\hline Cardiff University & 2,499 & 59 & K.J. Broadley & 186 & 220 & 719 & 282 & 16 & 243 & 117 \\
\hline Carnegie Mellon University & 265 & 273 & C.P Carpenter & 36 & 334 & 132 & 332 & 0 & 340 & 21 \\
\hline Case Western Reserve University & 1,667 & 102 & B.L. Roth & 262 & 151 & 5,710 & 57 & 45 & 30 & 150 \\
\hline Chalmers University of Technology & 178 & 295 & O. Wennerstrom & 80 & 313 & 1,856 & 193 & 9 & 297 & 104 \\
\hline Charles University & 423 & 234 & M. Stiborova & 164 & 239 & 982 & 261 & 23 & 170 & 150 \\
\hline Chinese University of Hong Kong & 1,032 & 167 & T.B. $\mathrm{Ng}$ & 409 & 61 & 2,912 & 134 & 38 & 67 & 150 \\
\hline Chulalongkorn University & 746 & 196 & N. Ruangrungsi & 87 & 304 & 995 & 260 & 12 & 273 & 150 \\
\hline City University of Hong Kong & 242 & 280 & P.K. Lam & 222 & 184 & 3,360 & 114 & 34 & 88 & 150 \\
\hline City University of New York & 451 & 230 & R.J. Bodnar & 249 & 163 & 2,406 & 159 & 25 & 153 & 150 \\
\hline Colorado State University & 269 & 270 & M.E. Andersen & 291 & 126 & 2,524 & 154 & 24 & 160 & 150 \\
\hline Columbia University & 3,064 & 37 & R. Breslow & 374 & 74 & 7,428 & 39 & 32 & 99 & 150 \\
\hline Cornell University & 2,287 & 68 & J. Clardy & 648 & 19 & 12,046 & 21 & 35 & 83 & 150 \\
\hline Curtin University of Technology & 248 & 279 & V.B. Sunderland & 53 & 327 & 211 & 323 & 7 & 311 & 74 \\
\hline Dalhousie University & 1,364 & 129 & J. Sawynok & 131 & 275 & 1,940 & 189 & 22 & 172 & 57 \\
\hline Dartmouth College & 848 & 186 & G.W. Gribble & 253 & 156 & 3,021 & 130 & 33 & 93 & 150 \\
\hline Delft University of Technology & 197 & 290 & R.A. Sheldon & 283 & 136 & 7,536 & 36 & 47 & 24 & 150 \\
\hline Drexel University & 1,154 & 155 & B. Weiss & 244 & 167 & 1,715 & 205 & 17 & 235 & 150 \\
\hline Duke University & 38,888 & 1 & T.A. Slotkin & 504 & 40 & 6,960 & 44 & 43 & 34 & 150 \\
\hline Durham University & 405 & 240 & D. Boulter & 174 & 230 & 1,340 & 238 & 3 & 327 & 150 \\
\hline Ecole Normale Supérieure de Lyon & 45 & 334 & F.L. Cosset & 173 & 231 & 3,437 & 110 & 48 & 20 & 150 \\
\hline École Normale Supérieure, Paris & 330 & 260 & P. Sinay & 242 & 171 & 2,587 & 147 & 27 & 138 & 150 \\
\hline École Polytechnique & 332 & 259 & S.Z. Zard & 236 & 175 & 2,176 & 172 & 28 & 126 & 150 \\
\hline
\end{tabular}




\begin{tabular}{|c|c|c|c|c|c|c|c|c|c|c|}
\hline Ecole Polytechnique Fédérale de Lausanne & 171 & 297 & P. Vogel & 328 & 98 & 1,814 & 199 & 28 & 126 & 150 \\
\hline Eindhoven University of Technology & 117 & 313 & E.W. Meijen & 493 & 41 & 11,926 & 22 & 67 & 6 & 150 \\
\hline Emory University & 2,448 & 62 & S.G. Holtzman & 235 & 177 & 2,022 & 184 & 18 & 224 & 89 \\
\hline Erasmus University Rotterdam & 2,064 & 79 & P.R. Saxena & 379 & 73 & 5,908 & 55 & 31 & 104 & 150 \\
\hline ETH Zurich (Swiss Federal Institute of Technology) & 1,497 & 116 & O. Sticher & 318 & 103 & 2,607 & 145 & 20 & 201 & 150 \\
\hline Florida International University & 197 & 290 & G.M. Rand & 44 & 332 & 123 & 334 & 8 & 306 & 33 \\
\hline Florida State University & 66 & 322 & T.A. Houpt & 64 & 321 & 737 & 279 & 17 & 235 & 93 \\
\hline Freie Universität Berlin & 3,939 & 20 & R.H. Muller & 407 & 62 & 3,523 & 105 & 38 & 67 & 150 \\
\hline Friedrich Alexander Universität Erlangen Nürnberg & 2,022 & 84 & P.C. Konturek & 26 & 336 & 203 & 324 & 8 & 306 & 79 \\
\hline Fudan University & 1,630 & 104 & M.K. Zhong & 104 & 292 & 478 & 293 & 10 & 290 & 150 \\
\hline Georg August Universität Göttingen & 1,955 & 86 & M. Oellerich & 288 & 132 & 3,153 & 124 & 38 & 67 & 150 \\
\hline George Mason University & 41 & 335 & R.F. Smith & 21 & 340 & 129 & 333 & 7 & 311 & 49 \\
\hline George Washington University & 971 & 175 & H.G. Mandel & 90 & 302 & 263 & 320 & 6 & 317 & 100 \\
\hline Georgetown University & 1,806 & 95 & E. Costa & 659 & 18 & 12,855 & 18 & 35 & 83 & 150 \\
\hline Georgia Institute of Technology & 393 & 244 & M.R. Prausnitz & 140 & 258 & 1,698 & 207 & 30 & 109 & 150 \\
\hline Georgia State University & 311 & 264 & D.W. Boykin & 250 & 160 & 1,851 & 194 & 35 & 83 & 150 \\
\hline Goteborg University & 1,165 & 152 & A. Carlsson & 386 & 66 & 5,425 & 59 & 22 & 172 & 150 \\
\hline Harvard University & 1,113 & 159 & E.J. Corey & 938 & 8 & 31,203 & 7 & 48 & 20 & 150 \\
\hline Hebrew University of Jerusalem & 2,575 & 56 & M. Bialer & 193 & 210 & 1,622 & 217 & 22 & 172 & 150 \\
\hline Heidelberg Universität & 3,032 & 39 & W.E. Haeteli & 219 & 187 & 3,220 & 120 & 27 & 138 & 150 \\
\hline Hokkaido University & 4,049 & 19 & J. Kobayashi & 713 & 15 & 2,088 & 178 & 34 & 88 & 150 \\
\hline Hong Kong Polytechnic University & 335 & 258 & A.S.C. Chan & 252 & 157 & 4,268 & 84 & 39 & 59 & 150 \\
\hline Hong Kong University of Science \& Techno... & 421 & 237 & W.M. Dai & 134 & 270 & 2,045 & 181 & 19 & 210 & 150 \\
\hline Humboldt-Universität zu Berlin & 273 & 268 & I. Roots & 309 & 107 & 7,274 & 41 & 46 & 26 & 150 \\
\hline Imperial College London & 2,976 & 40 & J. Caldwell & 227 & 180 & 1,619 & 218 & 17 & 235 & 150 \\
\hline Indian Institute of Technology Bombay (I... & 234 & 282 & S. Kotha & 118 & 283 & 1,542 & 222 & 24 & 160 & 79 \\
\hline Indian Institute of Technology Delhi (II... & 139 & 309 & H.M. Chawla & 79 & 314 & 193 & 326 & 10 & 290 & 69 \\
\hline Indian Institute of Technology Kanpur (I... & 369 & 252 & J. Iqbal & 287 & 133 & 2,289 & 166 & 33 & 93 & 150 \\
\hline Indiana University Bloomington & 1,057 & 166 & R.P. Maickel & 191 & 212 & 427 & 300 & 1 & 335 & 150 \\
\hline Indiana University Indianapolis & 1,794 & 97 & W.J. McBride & 313 & 105 & 3,730 & 102 & 38 & 67 & 150 \\
\hline Iowa State University & 204 & 288 & W.H. Hsu & 342 & 93 & 1,835 & 197 & 16 & 243 & 150 \\
\hline Johns Hopkins University & 4,909 & 9 & R.R. Griffiths & 290 & 129 & 2,915 & 133 & 25 & 153 & 146 \\
\hline Kansas State University & 141 & 308 & T.I. Musch & 154 & 246 & 1,517 & 225 & 22 & 172 & 150 \\
\hline Katholieke Universiteit Leuven & 2,565 & 57 & E. DeClercq & 1,641 & 1 & 49,335 & 1 & 72 & 4 & 150 \\
\hline Keio University & 2,059 & 80 & S. Yamamura & 325 & 99 & 1,628 & 214 & 20 & 201 & 150 \\
\hline
\end{tabular}




\begin{tabular}{|c|c|c|c|c|c|c|c|c|c|c|}
\hline King Fahd University of Petroleum \& Minerals & 87 & 316 & M.I.M. Wazeer & 91 & 298 & 411 & 305 & 9 & 297 & 91 \\
\hline King Saud University & 1,525 & 113 & J.S. Mossa & 113 & 287 & 721 & 281 & 10 & 290 & 147 \\
\hline Kobe University & 1,836 & 92 & T. Sakaeda & 138 & 261 & 1,678 & 211 & 26 & 145 & 150 \\
\hline Korea Advanced Institute of Science \& Technology & 387 & 245 & T.G. Park & 86 & 305 & 776 & 276 & 15 & 252 & 127 \\
\hline Korea University & 577 & 218 & B.Y. Chun & 51 & 328 & 357 & 312 & 11 & 281 & 145 \\
\hline Kyoto University & 10,139 & 3 & M. Hashida & 439 & 50 & 4,136 & 90 & 39 & 59 & 150 \\
\hline Kyushu University & 4,343 & 13 & I. Nishioka & 206 & 200 & 1,928 & 190 & 7 & 311 & 150 \\
\hline La Trobe University & 380 & 249 & G. Singer & 101 & 295 & 427 & 300 & 0 & 340 & 71 \\
\hline Lancaster University & 60 & 326 & H. Huddart & 74 & 316 & 164 & 329 & 6 & 317 & 50 \\
\hline Leiden University & 3,277 & 32 & D.D. Breimer & 443 & 47 & 4,116 & 92 & 22 & 172 & 150 \\
\hline Linkoping University & 896 & 183 & R.G.G. Andersson & 214 & 192 & 1,187 & 248 & 11 & 281 & 150 \\
\hline London School of Economics and Political Science & 147 & 305 & E. Szyszczak & 12 & 342 & 5 & 340 & 1 & 335 & 3 \\
\hline Loughborough University & 366 & 253 & H. Heaney & 123 & 278 & 713 & 283 & 11 & 281 & 107 \\
\hline Louisiana State University & 1,180 & 148 & M.B. Grisham & 287 & 133 & 9,414 & 28 & 43 & 34 & 150 \\
\hline Ludwig-Maximilians-Universität München & 4,167 & 16 & H. Wagner & 313 & 105 & 2,903 & 135 & 16 & 243 & 150 \\
\hline Lund University & 2,763 & 49 & O. Sterner & 291 & 126 & 2,190 & 171 & 10 & 290 & 150 \\
\hline Maastricht University & 1,388 & 127 & H.H.W. Thijssen & 111 & 288 & 723 & 280 & 14 & 258 & 125 \\
\hline Macquarie University & 163 & 299 & J.R. Bassett & 51 & 328 & 270 & 319 & 1 & 335 & 33 \\
\hline Mahidol University & 1,163 & 153 & V. Reutrakul & 122 & 279 & 1,197 & 246 & 16 & 243 & 150 \\
\hline Masaryk University & 268 & 271 & I. Holoubek & 111 & 288 & 911 & 266 & 20 & 201 & 150 \\
\hline Massachusetts Institute of Technology & 1,359 & 131 & R. Langer & 920 & 9 & 48,832 & 2 & 93 & 2 & 150 \\
\hline McGill University & 3,439 & 26 & P.Blier & 301 & 115 & 5,879 & 56 & 42 & 41 & 150 \\
\hline McMaster University & 1,837 & 91 & E.E. Daniel & 536 & 34 & 4,761 & 72 & 19 & 210 & 150 \\
\hline Michigan State University & 2,750 & 50 & J.B. Hook & 295 & 118 & 7,442 & 38 & 2 & 331 & 150 \\
\hline Michigan Technological University & 69 & 320 & D.R. Karnosky & 25 & 337 & 109 & 335 & 4 & 324 & 100 \\
\hline Monash University & 2,594 & 55 & L. Roller & 154 & 246 & 37 & 338 & 3 & 327 & 24 \\
\hline Montana State University & 214 & 286 & G.A. Strobel & 7 & 343 & 12 & 339 & 2 & 331 & 33 \\
\hline Moscow State University & 912 & 181 & I.P. Beletskaya & 183 & 222 & 4,393 & 79 & 28 & 126 & 150 \\
\hline Nagoya University & 3,136 & 34 & T. Nabeshima & 603 & 25 & 10,120 & 26 & 40 & 53 & 150 \\
\hline Nanjing University & 760 & 194 & R.X. Tan & 147 & 252 & 1,528 & 224 & 24 & 160 & 150 \\
\hline Nanyang Technological University & 211 & 287 & T.P. Loh & 182 & 224 & 2,330 & 164 & 36 & 79 & 147 \\
\hline National Taiwan University & 1,513 & 115 & Y.H. Kuo & 295 & 118 & 2,339 & 163 & 24 & 160 & 150 \\
\hline National Tsing Hua University & 383 & 246 & J.R. Hwu & 140 & 258 & 1,079 & 255 & 14 & 258 & 150 \\
\hline National University of Ireland, Galway & 358 & 256 & B.E. Leonard & 381 & 72 & 3,487 & 108 & 33 & 93 & 150 \\
\hline National University of Singapore & 2,059 & 80 & P.W.S. Heng & 116 & 286 & 1,077 & 256 & 14 & 258 & 150 \\
\hline New Mexico State University & 153 & 304 & B.A. Smith & 102 & 294 & 1,689 & 209 & 13 & 268 & 150 \\
\hline
\end{tabular}




\begin{tabular}{|c|c|c|c|c|c|c|c|c|c|c|}
\hline New York University & 2,632 & 54 & S. Gershon & 362 & 82 & 2,238 & 168 & 14 & 258 & 150 \\
\hline Newcastle University & 1,344 & 132 & M.D. Rawlins & 307 & 108 & 3,332 & 115 & 15 & 252 & 150 \\
\hline North Carolina State University & 1,266 & 142 & J.E. Riviere & 281 & 139 & 1,848 & 195 & 20 & 201 & 150 \\
\hline Northeastern University & 1,001 & 172 & V. Torchilin & 176 & 228 & 4,681 & 74 & 37 & 75 & 150 \\
\hline Northwestern University & 1,671 & 100 & T. Narahashi & 360 & 83 & 3,375 & 112 & 24 & 160 & 150 \\
\hline Norwegian University of Science \& Technology & 581 & 217 & O.G. Nilsen & 126 & 277 & 756 & 278 & 10 & 290 & 150 \\
\hline Ohio State University & 4,132 & 18 & M.C. Nahata & 456 & 46 & 2,572 & 149 & 21 & 189 & 150 \\
\hline Oklahoma State University & 639 & 208 & C.L. Ownby & 100 & 296 & 927 & 265 & 16 & 243 & 143 \\
\hline Open University UK & 182 & 293 & J. N. Lley & 91 & 298 & 417 & 304 & 14 & 258 & 137 \\
\hline Oregon State University & 1,573 & 109 & W.H. Gerwick & 200 & 205 & 2,463 & 158 & 30 & 109 & 150 \\
\hline Osaka University & 5,923 & 6 & I. Kitagawa & 295 & 118 & 2,718 & 141 & 18 & 224 & 150 \\
\hline Peking University & 2,355 & 66 & Q Zhang & 265 & 149 & 1,380 & 234 & 22 & 172 & 150 \\
\hline Pennsylvania State University & 1,776 & 98 & E.S. Vesell & 281 & 139 & 1,465 & 229 & 11 & 281 & 150 \\
\hline Pohang University of Science And Technology & 268 & 271 & D.H. Kim & 1,623 & 2 & 12,503 & 19 & 40 & 53 & 150 \\
\hline Portland State University & 82 & 317 & L.I. Crawshaw & 43 & 333 & 283 & 317 & 8 & 306 & 83 \\
\hline Princeton University & 572 & 220 & R.M. May & 369 & 76 & 13,853 & 16 & 28 & 126 & 150 \\
\hline Purdue University & 3,394 & 27 & J.L.McLaughlin & 289 & 130 & 2,638 & 143 & 21 & 189 & 150 \\
\hline Queen's University & 1,337 & 134 & J.F. Brien & 243 & 168 & 1,682 & 210 & 19 & 210 & 150 \\
\hline Queen's University of Belfast & 1,796 & 96 & P.F. D'Arcy & 384 & 69 & 385 & 308 & 1 & 335 & 40 \\
\hline Queensland University of Technology & 147 & 305 & S.F. Zhou & 162 & 240 & 1,529 & 223 & 22 & 172 & 150 \\
\hline Radboud University, Nijmegen & 2,410 & 64 & T.B. Vree & 435 & 51 & 2,010 & 186 & 12 & 273 & 150 \\
\hline Rensselaer Polytechnic Institute & 272 & 269 & L.D. Reid & 100 & 296 & 826 & 271 & 8 & 306 & 138 \\
\hline Rheinisch Westfalische Technische Hochschule Aach & 632 & 210 & D. Enders & 367 & 77 & 5,675 & 58 & 41 & 48 & 150 \\
\hline Rheinische Friedrich Wilhelms Universitat Bonn & 3,073 & 36 & M. Gothert & 255 & 155 & 3,190 & 123 & 26 & 145 & 150 \\
\hline Rice University & 325 & 261 & A.G. Mikos & 345 & 91 & 9,364 & 29 & 65 & 7 & 150 \\
\hline Rochester Institute of Technology & 29 & 339 & T.C. Morrill & 25 & 337 & 60 & 336 & 3 & 327 & 38 \\
\hline Royal Institute of Technology, KTH & 416 & 238 & J. Bergman & 205 & 201 & 1,820 & 198 & 19 & 210 & 150 \\
\hline Royal Melbourne Institute of Technology & 299 & 265 & C.G. Li & 1,417 & 4 & 11,281 & 24 & 39 & 59 & 150 \\
\hline Rutgers & 2,712 & 51 & Y.W. Chien & 215 & 191 & 1,745 & 201 & 16 & 243 & 150 \\
\hline Saint-Petersburg State University & 105 & 315 & M.S. Novikov & 77 & 315 & 178 & 328 & 11 & 281 & 81 \\
\hline San Diego State University & 362 & 255 & E.P. Riley & 189 & 216 & 2,030 & 183 & 31 & 104 & 150 \\
\hline Sapienza University of Rome & 0 & 347 & & 0 & 347 & 0 & 343 & 0 & 340 & 0 \\
\hline Sciences Po Paris & 0 & 347 & & 0 & 347 & 0 & 343 & 0 & 340 & 0 \\
\hline Seoul National University & 3,726 & 22 & M.G. Lee & 216 & 189 & 870 & 269 & 17 & 235 & 150 \\
\hline Shanghai Jiao Tong University & 732 & 199 & W.D. Zhang & 1,555 & 3 & 7,802 & 34 & 39 & 59 & 150 \\
\hline Simon Fraser University & 320 & 263 & A.C. Oehlschlager & 157 & 244 & 1,145 & 251 & 11 & 281 & 150 \\
\hline
\end{tabular}




\begin{tabular}{|c|c|c|c|c|c|c|c|c|c|c|}
\hline Stanford University & 3,332 & 30 & C. Djerassi & 880 & 10 & 4,364 & 81 & 2 & 331 & 150 \\
\hline State University of New York Buffalo & 5 & 346 & S. Kumar & 365 & 80 & 1,806 & 200 & 19 & 210 & 150 \\
\hline Stockholm University & 1,005 & 170 & J.W. DePierre & 183 & 222 & 2,117 & 175 & 14 & 258 & 150 \\
\hline Stony Brook University & 1,084 & 163 & I. Ojima & 261 & 153 & 4,009 & 95 & 29 & 116 & 150 \\
\hline Syracuse University & 373 & 251 & J. Jalife & 219 & 187 & 3,901 & 99 & 39 & 59 & 150 \\
\hline Tartu University (University of Tartu) & 424 & 233 & J. Harro & 132 & 274 & 1,365 & 235 & 21 & 189 & 150 \\
\hline Technical University of Denmark & 588 & 216 & S.R. Jensen & 171 & 233 & 1,222 & 244 & 20 & 201 & 150 \\
\hline Technion & 902 & 182 & M.B.H. Youdim & 520 & 36 & 13,996 & 15 & 52 & 17 & 150 \\
\hline Technische Universität Berlin & 1,363 & 130 & F. Bohlmann & 780 & 13 & 4,938 & 70 & 0 & 340 & 150 \\
\hline Technische Universitat Chemnitz & 14 & 344 & K. Barnert & 57 & 323 & 323 & 313 & 9 & 297 & 84 \\
\hline Technische Universität Dresden & 598 & 213 & W. Kirch & 340 & 94 & 1,837 & 196 & 20 & 201 & 150 \\
\hline Technische Universität München & 1,593 & 107 & A. Bacher & 382 & 70 & 3,509 & 106 & 38 & 67 & 150 \\
\hline Tel Aviv University & 2,099 & 75 & Y. Kashman & 270 & 147 & 4,374 & 80 & 17 & 235 & 150 \\
\hline Texas A\&M University & 2,135 & 71 & D.H.R. Barton & 857 & 11 & 7,372 & 40 & 17 & 235 & 150 \\
\hline Texas Tech & 676 & 206 & J.B. Lombardini & 137 & 266 & 552 & 290 & 9 & 297 & 59 \\
\hline Tohoku University & 6,025 & 4 & N. Taira & 289 & 130 & 1,116 & 252 & 4 & 324 & 138 \\
\hline Tokyo Institute of Technology & 1,555 & 110 & F. Sato & 270 & 147 & 2,213 & 170 & 27 & 138 & 150 \\
\hline Trinity College Dublin & 1,006 & 169 & O.I. Corrgan & 138 & 261 & 1,106 & 254 & 19 & 210 & 120 \\
\hline Tsinghua University & 403 & 242 & D.J. Du & 83 & 311 & 321 & 314 & 11 & 281 & 150 \\
\hline Tufts University & 1,606 & 105 & D.J. Greenblatt & 1,103 & 5 & 17,297 & 11 & 51 & 18 & 150 \\
\hline Universidad Autonoma de Madrid & 1,285 & 138 & J.L. Garcia-Ruano & 205 & 201 & 1,563 & 219 & 22 & 172 & 150 \\
\hline Universidad de Chile & 1,170 & 151 & B.K. Cassels & 162 & 240 & 1,053 & 257 & 16 & 243 & 150 \\
\hline Universidad de Granada & 1,285 & 138 & J.L. Garcia-Ruano & 205 & 201 & 1,563 & 219 & 22 & 172 & 150 \\
\hline Universidad del País Vasco & 724 & 202 & J.L. Pedraz & 138 & 261 & 1,484 & 227 & 24 & 160 & 150 \\
\hline Universidad Nacional Autónoma de México ... & 1,014 & 168 & L.D. Possani & 249 & 163 & 1,927 & 191 & 28 & 126 & 150 \\
\hline Universidad Politecnica de Madrid & 21 & 342 & R. Alonso-Sanz & 33 & 335 & 58 & 337 & 9 & 297 & 26 \\
\hline Universidade de São Paulo & 226 & 283 & F.Q. Cunha & 261 & 153 & 4,126 & 91 & 34 & 88 & 150 \\
\hline Universidade Estadual de Campinas & 677 & 205 & G. De Nucci & 295 & 118 & 3,962 & 97 & 24 & 160 & 150 \\
\hline Università degli Studi di Firenze & 2,813 & 46 & C.T. Supuran & 644 & 21 & 585 & 288 & 59 & 11 & 150 \\
\hline Università degli Studi di Padova & 2,241 & 70 & P. Dorigo & 91 & 298 & 199 & 325 & 6 & 317 & 124 \\
\hline Universita Di Bologna & 2,516 & 58 & A. Tosti & 441 & 48 & 4,248 & 86 & 26 & 145 & 150 \\
\hline Universita di Pisa & 1,062 & 165 & M. Del Tacca & 353 & 88 & 2,519 & 155 & 26 & 145 & 150 \\
\hline Universitat Autonoma de Barcelona & 2,083 & 78 & M. Moreno-Manas & 192 & 211 & 1,958 & 188 & 25 & 153 & 150 \\
\hline Universitat Bielefeld & 156 & 302 & E.V. Dehmlow & 86 & 305 & 371 & 311 & 7 & 311 & 80 \\
\hline Universität Bremen & 289 & 266 & G.V. Roschenthaler & 150 & 251 & 558 & 289 & 13 & 268 & 150 \\
\hline Universitat d'Alacant & 423 & 234 & M.Yus & 432 & 54 & 5,013 & 67 & 44 & 33 & 150 \\
\hline
\end{tabular}




\begin{tabular}{|c|c|c|c|c|c|c|c|c|c|c|}
\hline Universitat de València & 2,085 & 77 & J.L. Rios & 141 & 256 & 2,294 & 165 & 23 & 170 & 150 \\
\hline Universität Frankfurt am Main & 3,714 & 23 & E. Mutschler & 488 & 43 & 3,238 & 119 & 19 & 210 & 150 \\
\hline Universität Freiburg & 1,867 & 88 & H. Prinzbach & 151 & 249 & 788 & 275 & 13 & 268 & 150 \\
\hline Universitat Hamburg & 256 & 276 & M. Schachner & 590 & 26 & 22,218 & 9 & 58 & 12 & 150 \\
\hline Universität Karlsruhe & 377 & 250 & M. Metzler & 168 & 235 & 1,490 & 226 & 21 & 189 & 150 \\
\hline Universitat Leipzig & 459 & 229 & P. Illes & 240 & 173 & 2,527 & 153 & 31 & 104 & 150 \\
\hline Universitat Munster (Westfälische Wilhelms-Un & 517 & 225 & E.J. Speckmann & 263 & 150 & 1,428 & 231 & 19 & 210 & 150 \\
\hline Universitat Politecnica de Catalunya & 29 & 339 & J.J. Perez & 137 & 266 & 1,027 & 258 & 16 & 243 & 150 \\
\hline Universität Regensburg & 1,392 & 125 & G. Franz & 172 & 232 & 1,321 & 239 & 14 & 258 & 150 \\
\hline Universität Stuttgart & 281 & 267 & F. Effenberger & 178 & 226 & 2,992 & 131 & 28 & 126 & 150 \\
\hline Universitat Trier & 53 & 330 & B. Blomeke & 54 & 326 & 688 & 284 & 12 & 273 & 150 \\
\hline Universität Tübingen & 2,861 & 43 & P.C. Schmidt & 224 & 182 & 1,384 & 233 & 18 & 224 & 150 \\
\hline Universitat Wien (University of Vienna) & 3,152 & 33 & A. Bernkop-Schnurch & 211 & 194 & 1,437 & 230 & 37 & 75 & 150 \\
\hline Universitat Zu Koln & 1,434 & 123 & U. Fricke & 121 & 281 & 254 & 321 & 3 & 327 & 63 \\
\hline Université Catholique de Louvain & 2,001 & 85 & T. Godfraind & 262 & 151 & 1,699 & 206 & 12 & 273 & 140 \\
\hline Universite de Liege & 1,372 & 128 & L. Angenot & 166 & 238 & 794 & 273 & 14 & 258 & 150 \\
\hline Université de Montréal & 2,818 & 44 & S. Nattel & 429 & 55 & 7,588 & 35 & 57 & 14 & 150 \\
\hline Université de Nice Sophia Antipolis & 440 & 231 & E. Dunach & 122 & 279 & 849 & 270 & 17 & 235 & 125 \\
\hline Universite Laval & 1,172 & 150 & P.M. Belanger & 85 & 308 & 480 & 292 & 5 & 321 & 72 \\
\hline Universite Libre de Bruxelles & 1,269 & 141 & P. Robberecht & 318 & 103 & 2,862 & 136 & 28 & 126 & 150 \\
\hline Université Paris Sorbonne & 37 & 338 & R. Daudel & 4 & 346 & 0 & 343 & 0 & 340 & 5 \\
\hline Universite Paris-Sud 11 & 2,783 & 48 & P. Couvreur & 350 & 89 & 5,211 & 62 & 43 & 34 & 150 \\
\hline Université Pierre et Marie Curie & 1,305 & 137 & M. Hamon & 190 & 213 & 4,351 & 83 & 41 & 48 & 150 \\
\hline Universiti Malaya (University of Malaya) & 502 & 228 & T.S. Kam & 117 & 284 & 372 & 310 & 19 & 210 & 81 \\
\hline University College Cork & 325 & 261 & F. Shananhan & 303 & 114 & 7,040 & 43 & 42 & 41 & 150 \\
\hline University College Dublin & 594 & 215 & D.M.X. Donnelly & 88 & 303 & 509 & 291 & 7 & 311 & 114 \\
\hline University College London & 3,878 & 21 & G. Burnstock & 1,019 & 6 & 32,401 & 6 & 62 & 8 & 150 \\
\hline University do Porto & 574 & 219 & I. Azevedo & 156 & 245 & 622 & 286 & 12 & 273 & 150 \\
\hline University of Aberdeen & 1,451 & 120 & R. G. Pertwee & 170 & 234 & 5,135 & 65 & 42 & 41 & 150 \\
\hline University of Adelaide & 1,197 & 146 & A.A. Somogyi & 210 & 195 & 2,289 & 166 & 22 & 172 & 150 \\
\hline University of Alabama & 2,112 & 73 & C.T. Curiel & 547 & 30 & 789 & 274 & 70 & 5 & 150 \\
\hline University of Alberta & 3,343 & 29 & A.B.R. Thompson & 465 & 45 & 3,944 & 98 & 28 & 126 & 150 \\
\hline University of Amsterdam & 2,654 & 53 & P.A. Van Zwieten & 520 & 36 & 2,744 & 140 & 17 & 235 & 150 \\
\hline University of Antwerp & 1,249 & 144 & A.G. Herman & 329 & 97 & 4,400 & 78 & 30 & 109 & 150 \\
\hline University of Arizona & 4,152 & 17 & V.J. Hruby & 788 & 12 & 16,959 & 12 & 42 & 41 & 150 \\
\hline University of Athens & 1,826 & 94 & H. Glamarellou & 319 & 102 & 2,605 & 146 & 26 & 145 & 150 \\
\hline
\end{tabular}




\begin{tabular}{|c|c|c|c|c|c|c|c|c|c|c|}
\hline University of Auckland & 1,284 & 140 & W.A. Denny & 490 & 42 & 4,960 & 69 & 38 & 67 & 150 \\
\hline University of Barcelona & 2,445 & 63 & F. Albericio & 356 & 85 & 3,447 & 109 & 29 & 116 & 150 \\
\hline University of Basel & 1,853 & 89 & H. Leuenberger & 145 & 253 & 1,025 & 259 & 18 & 224 & 150 \\
\hline University of Bath & 838 & 189 & B.V.L. Potter & 355 & 87 & 3,191 & 122 & 36 & 79 & 150 \\
\hline University of Bergen & 363 & 254 & P.M. Ueland & 333 & 95 & 9,797 & 27 & 50 & 19 & 150 \\
\hline University of Bern & 3,516 & 25 & W. Thormann & 216 & 189 & 2,482 & 156 & 31 & 104 & 150 \\
\hline University of Birmingham & 1,596 & 106 & G.Y.H. Lip & 1,015 & 7 & 14,863 & 14 & 55 & 15 & 150 \\
\hline University of Bristol & 2,115 & 72 & D.J. Nutt & 625 & 22 & 0 & 343 & 45 & 30 & 150 \\
\hline University of British Columbia & 2,253 & 69 & J.H. McNeill & 470 & 44 & 3,492 & 107 & 29 & 116 & 150 \\
\hline University of Calgary & 1,079 & 164 & M.D. Hollenberg & 401 & 63 & 5,205 & 64 & 43 & 34 & 150 \\
\hline University of California, Berkley & 505 & 227 & J.E. Casida & 586 & 27 & 6,715 & 47 & 29 & 116 & 150 \\
\hline University of California, Davis & 1,481 & 117 & B.D. Hammock & 623 & 23 & 11,246 & 25 & 41 & 48 & 150 \\
\hline University of California, Irvine & 1,106 & 160 & S.P. Duckles & 186 & 220 & 1,673 & 212 & 25 & 153 & 127 \\
\hline University of California, Los Angeles & 4,212 & 15 & A.K. Cho & 179 & 225 & 2,107 & 177 & 18 & 224 & 150 \\
\hline University of California, Riverside & 680 & 204 & F.A. Gunther & 168 & 235 & 164 & 329 & 0 & 340 & 105 \\
\hline University of California, San Diego & 1,530 & 112 & M.Karin & 412 & 60 & 45,578 & 3 & 112 & 1 & 150 \\
\hline University of California, San Francisco & 5,301 & 7 & L.Z. Benet & 427 & 56 & 6,658 & 48 & 40 & 53 & 150 \\
\hline University of California, Santa Barbara & 517 & 225 & T.C. Bruice & 547 & 30 & 7,848 & 33 & 30 & 109 & 150 \\
\hline University of California, Santa Cruz & 54 & 329 & P. Crews & 190 & 213 & 2,586 & 148 & 19 & 210 & 150 \\
\hline University of Cambridge & 1,440 & 122 & T.W. Robbins & 580 & 28 & 39,863 & 4 & 91 & 3 & 150 \\
\hline University of Canterbury & 47 & 333 & R.N. Huges & 71 & 319 & 245 & 322 & 9 & 297 & 30 \\
\hline University of Cape Town & 253 & 277 & L.H. Opie & 536 & 34 & 7,160 & 42 & 30 & 109 & 150 \\
\hline University of Central Florida & 135 & 310 & D.H. Howard & 59 & 322 & 385 & 308 & 8 & 306 & 107 \\
\hline University of Chicago & 1,536 & 111 & M.J. Ratain & 333 & 95 & 6,241 & 53 & 45 & 30 & 150 \\
\hline University of Cincinnati & 2,705 & 52 & W.A. Ritschel & 285 & 135 & 1,358 & 236 & 7 & 311 & 150 \\
\hline University of Colorado at Boulder & 408 & 239 & A.C. Collins & 250 & 160 & 4,353 & 82 & 38 & 67 & 150 \\
\hline University of Connecticut & \begin{tabular}{l|l}
1,148 \\
\end{tabular} & 157 & D.K. Das & 395 & 64 & 6,747 & 46 & 47 & 24 & 150 \\
\hline University of Copenhagen & 1,666 & 103 & A. Schousboe & 415 & 59 & 6,594 & 50 & 35 & 83 & 150 \\
\hline University of Delaware & 62 & 324 & C.R. Plata-Salaman & 138 & 261 & 3,718 & 104 & 32 & 99 & 150 \\
\hline University of Dundee & 1,183 & 147 & B. J. Lipworth & 433 & 53 & 5,365 & 60 & 46 & 26 & 150 \\
\hline University of Edinburgh & 1,342 & 133 & D.J. Webb & 190 & 213 & 4,894 & 71 & 41 & 48 & 150 \\
\hline University of Florida & 4,337 & 14 & H. Derendorf & 305 & 112 & 3,202 & 121 & 33 & 93 & 150 \\
\hline University of Geneva & 731 & 200 & P. Dayer & 283 & 136 & 3,099 & 127 & 27 & 138 & 150 \\
\hline University of Georgia & 800 & 191 & C.K. Chu & 292 & 124 & 3,148 & 125 & 29 & 116 & 150 \\
\hline University of Ghent & 946 & 178 & J.P. Remon & 344 & 92 & 2,236 & 169 & 21 & 189 & 150 \\
\hline University of Glasgow & 2,481 & 61 & J.D. Connolly & 224 & 182 & 1,200 & 245 & 15 & 252 & 150 \\
\hline
\end{tabular}




\begin{tabular}{|c|c|c|c|c|c|c|c|c|c|c|}
\hline University of Gothenburg & 160 & 300 & M. Ashton & 56 & 324 & 450 & 296 & 15 & 252 & 121 \\
\hline University of Groningen & 1,518 & 114 & W.H. Van Gilst & 366 & 79 & 6,296 & 51 & 42 & 41 & 150 \\
\hline University of Helsinki & 2,889 & 42 & P.J. Neuvonen & 200 & 205 & 3,364 & 113 & 42 & 41 & 150 \\
\hline University of Hong Kong & 799 & 192 & B.C.Y. Wong & 307 & 108 & 5,071 & 66 & 43 & 34 & 150 \\
\hline University of Houston & 422 & 236 & M.F. Lokhandwala & 243 & 168 & 964 & 263 & 18 & 224 & 141 \\
\hline University of Illinois & 220 & 284 & G.A. Miller & 73 & 317 & 2 & 341 & 0 & 340 & 0 \\
\hline University of Illinois, Chicago & 4,415 & 12 & G.A. Cordell & 307 & 108 & 3,260 & 117 & 22 & 172 & 150 \\
\hline University of Indonesia & 74 & 319 & Y. Harahap & 5 & 344 & 2 & 341 & 1 & 335 & 9 \\
\hline University of Iowa & 1,392 & 125 & G.F. Gebhart & 356 & 85 & 6,610 & 49 & 40 & 53 & 150 \\
\hline University of Kansas & 3,642 & 24 & C.D. Klaassen & 543 & 32 & 11,309 & 23 & 41 & 48 & 150 \\
\hline University of Kentucky & 1,576 & 108 & D.A. Butterfield & 385 & 67 & 8,095 & 31 & 61 & 9 & 150 \\
\hline University of Lausanne & 348 & 257 & B. Testa & 358 & 84 & 4,222 & 87 & 34 & 88 & 150 \\
\hline University of Leeds & 382 & 247 & C. Peers & 198 & 207 & 2,017 & 185 & 28 & 126 & 150 \\
\hline University of Leicester & 1,106 & 160 & R.A.J. Challiss & 197 & 208 & 3,245 & 118 & 26 & 145 & 150 \\
\hline University of Liverpool & 1,311 & 135 & B.K. Park & 5 & 344 & 0 & 343 & 0 & 340 & 16 \\
\hline University of Ljubljana & 1,449 & 121 & A. Mrhar & 159 & 243 & 406 & 306 & 10 & 290 & 150 \\
\hline University of London (Kings College of London) & 15,915 & 2 & C.D. Marsden & 690 & 16 & 28,554 & 8 & 40 & 53 & 150 \\
\hline University of Manchester & 3,374 & 28 & J.B. Houston & 188 & 217 & 2,060 & 180 & 33 & 93 & 150 \\
\hline University of Manitoba & 1,832 & 93 & W.W. Lautt & 187 & 219 & 1,349 & 237 & 19 & 210 & 90 \\
\hline University of Maryland & 741 & 198 & B.B. Jarvis & 151 & 249 & 1,178 & 250 & 20 & 201 & 150 \\
\hline University of Maryland Baltimore County & 2,914 & 41 & E.X. Albuquerque & 320 & 101 & 4,426 & 77 & 36 & 79 & 150 \\
\hline University of Massachusetts & 200 & 289 & E.J. Calabrese & 385 & 67 & 2,160 & 174 & 32 & 99 & 150 \\
\hline University of Melbourne & 3,039 & 38 & M.J. Rand & 251 & 158 & 1,627 & 215 & 11 & 281 & 145 \\
\hline University of Miami & 744 & 197 & D.C. Mash & 162 & 240 & 3,726 & 103 & 32 & 99 & 150 \\
\hline University of Michigan & 2,814 & 45 & J.H. Woods & 435 & 51 & 3,878 & 100 & 29 & 116 & 150 \\
\hline University of Minnesota & 2,482 & 60 & H.H. Loh & 541 & 33 & 7,877 & 32 & 34 & 88 & 150 \\
\hline University of Missouri & 966 & 176 & A.K. Mitra & 227 & 180 & 1,693 & 208 & 22 & 172 & 150 \\
\hline University of Nebraska & 431 & 232 & R.A. Bevins & 86 & 305 & 809 & 272 & 18 & 224 & 66 \\
\hline University of New Hampshire & 133 & 311 & R.E. Lyle & 133 & 272 & 2,031 & 182 & 25 & 153 & 150 \\
\hline University of New Mexico & 562 & 221 & L.A. Sklar & 242 & 171 & 4,020 & 94 & 30 & 109 & 150 \\
\hline University of New South Wales & 623 & 211 & E.R. Lumbers & 144 & 254 & 902 & 267 & 14 & 258 & 109 \\
\hline University of North Carolina, Chapel Hill & 4,512 & 11 & K.H. Lee & 417 & 58 & 4,752 & 73 & 38 & 67 & 150 \\
\hline University of North Texas & 217 & 285 & J.W. Simpkins & 283 & 136 & 3,838 & 101 & 37 & 75 & 150 \\
\hline University of Notre Dame & 55 & 328 & F.J. Castellino & 382 & 70 & 3,296 & 116 & 29 & 116 & 150 \\
\hline University of Nottingham & 1,266 & 142 & C.A. Marsden & 291 & 126 & 3,387 & 111 & 27 & 138 & 150 \\
\hline University of Oklahoma & 774 & 193 & M.C. Koss & 142 & 255 & 464 & 295 & 9 & 297 & 40 \\
\hline
\end{tabular}




\begin{tabular}{|c|c|c|c|c|c|c|c|c|c|c|}
\hline University of Oregon & 521 & 224 & J.C. Crabbe & 387 & 65 & 4,209 & 88 & 37 & 75 & 150 \\
\hline University of Oslo & 952 & 177 & J.B. Osnes & 133 & 272 & 446 & 297 & 9 & 297 & 147 \\
\hline University of Otago & 725 & 201 & P.F. Smith & 208 & 198 & 1,466 & 228 & 21 & 189 & 114 \\
\hline University of Ottawa & 839 & 188 & R.L. Singhal & 214 & 192 & 588 & 287 & 2 & 331 & 71 \\
\hline University of Oxford & 1,160 & 154 & A.F. Brading & 210 & 195 & 2,079 & 179 & 24 & 160 & 150 \\
\hline University of Pennsylvania & 1,920 & 87 & T.M. Penning & 208 & 198 & 3,032 & 129 & 42 & 41 & 150 \\
\hline University of Pittsburgh & 2,112 & 73 & W.C. De Groat & 427 & 56 & 4,996 & 68 & 43 & 34 & 150 \\
\hline University of Quebec & 549 & 222 & T. Di Paolo & 178 & 226 & 2,571 & 150 & 28 & 126 & 150 \\
\hline University of Queensland & 1,455 & 119 & M.S. Roberts & 325 & 99 & 2,948 & 132 & 29 & 116 & 150 \\
\hline University of Reading & 932 & 179 & M.D. Collins & 141 & 256 & 2,629 & 144 & 28 & 126 & 150 \\
\hline University of Rochester & 1,179 & 149 & M.W. Anders & 292 & 124 & 2,399 & 160 & 22 & 172 & 150 \\
\hline University of Saskatchewan & 1,840 & 90 & K.K. Midha & 294 & 122 & 3,120 & 126 & 18 & 224 & 150 \\
\hline University of Science and Technology of China & 262 & 275 & D.Y. Ruan & 84 & 309 & 284 & 316 & 9 & 297 & 150 \\
\hline University of Sheffield & 1,215 & 145 & G.T. Tucker & 276 & 142 & 4,163 & 89 & 29 & 116 & 150 \\
\hline University of South Carolina & 930 & 180 & J.B. Appel & 109 & 291 & 468 & 294 & 5 & 321 & 97 \\
\hline University of South Florida & 536 & 223 & P.R. Sanberg & 371 & 75 & 5,209 & 63 & 39 & 59 & 150 \\
\hline University of Southampton & 596 & 214 & A.G. Renwick & 228 & 179 & 1,966 & 187 & 22 & 172 & 150 \\
\hline University of Southern California & 1,116 & 158 & R.A. Kloner & 621 & 24 & 17,993 & 10 & 46 & 26 & 150 \\
\hline University of St Andrews & 118 & 312 & G.A. Cottrell & 176 & 228 & 419 & 303 & 10 & 290 & 150 \\
\hline University of Surrey & 639 & 208 & D.F.V. Lewis & 243 & 168 & 2,554 & 151 & 32 & 99 & 150 \\
\hline University of Sussex & 194 & 292 & T. Duka & 104 & 292 & 952 & 264 & 20 & 201 & 135 \\
\hline University of Sydney & 2,807 & 47 & D.M. Jackson & 138 & 261 & 1,276 & 241 & 14 & 258 & 131 \\
\hline University of Technology, Sydney & 53 & 330 & G.M. Nicholson & 47 & 331 & 439 & 299 & 19 & 210 & 102 \\
\hline University of Tennessee Knoxville & 175 & 296 & H.M. Schuller & 117 & 284 & 970 & 262 & 19 & 210 & 149 \\
\hline University of Texas at Austin & 861 & 185 & J.P. Kehrer & 137 & 266 & 2,785 & 138 & 21 & 189 & 150 \\
\hline University of Tokyo & 2,315 & 67 & Y. Sugiyama & 645 & 20 & 15,943 & 13 & 61 & 9 & 150 \\
\hline University of Toronto & 5,929 & 5 & G. Koren & 754 & 14 & 12,085 & 20 & 48 & 20 & 150 \\
\hline University of Tsukuba & 622 & 212 & K. Goto & 280 & 141 & 9,088 & 30 & 33 & 93 & 150 \\
\hline University of Twente & 179 & 294 & J.H.M. Feijen & 349 & 90 & 6,011 & 54 & 39 & 59 & 150 \\
\hline University of Utah & 3,098 & 35 & W.I. Higuchi & 367 & 77 & 2,362 & 161 & 18 & 224 & 150 \\
\hline University of Vermont & 1,090 & 162 & S.T. Higgins & 197 & 208 & 2,824 & 137 & 30 & 109 & 150 \\
\hline University of Victoria & 51 & 332 & E.P. Zehr & 56 & 324 & 657 & 285 & 20 & 201 & 42 \\
\hline University of Virginia & 758 & 195 & J. Linden & 251 & 158 & 4,101 & 93 & 43 & 34 & 150 \\
\hline University of Warwick & 81 & 318 & N.Dale & 139 & 260 & 1,737 & 202 & 21 & 189 & 147 \\
\hline University of Washington & 4,761 & 10 & M.R. Juchau & 220 & 186 & 1,114 & 253 & 11 & 281 & 131 \\
\hline University of Waterloo & 242 & 280 & H.J. Green & 205 & 201 & 2,748 & 139 & 22 & 172 & 150 \\
\hline
\end{tabular}




\begin{tabular}{|c|c|c|c|c|c|c|c|c|c|c|}
\hline University of Western Australia & 1,152 & 156 & K.F. Ilett & 276 & 142 & 2,541 & 152 & 28 & 126 & 150 \\
\hline University of Western Ontario & 1,428 & 124 & M.G. Cherian & 236 & 175 & 1,717 & 204 & 22 & 172 & 150 \\
\hline University of Wisconsin & 1,462 & 118 & R.E. Peterson & 233 & 178 & 4,268 & 84 & 36 & 79 & 150 \\
\hline University of Wollongong & 63 & 323 & C. Deng & 130 & 276 & 389 & 307 & 13 & 268 & 150 \\
\hline University of York & 109 & 314 & G.D. Phillips & 51 & 328 & 876 & 268 & 13 & 268 & 45 \\
\hline University of Zurich & 403 & 242 & J.M. Fritschy & 222 & 184 & 6,293 & 52 & 46 & 26 & 150 \\
\hline Univesitas Gadjah Mada & 59 & 327 & B. Santoso & 23 & 339 & 293 & 315 & 4 & 324 & 142 \\
\hline Uppsala University & 2,052 & 82 & F. Nyberg & 272 & 145 & 2,170 & 173 & 24 & 160 & 150 \\
\hline Utah State & 168 & 298 & R.P. Sharma & 272 & 145 & 1,553 & 221 & 22 & 172 & 150 \\
\hline Utrecht University & 5,033 & 8 & J.H. Beijnen & 505 & 39 & 0 & 343 & 54 & 16 & 150 \\
\hline Vanderbilt University & 2,037 & 83 & F.P. Guengerich & 663 & 17 & 32,945 & 5 & 58 & 12 & 150 \\
\hline Victoria University of Wellington & 39 & 337 & S. Schenk & 72 & 318 & 1,287 & 240 & 16 & 243 & 80 \\
\hline Vienna University of Technology & 16 & 343 & W. Linert & 248 & 165 & 1,625 & 216 & 19 & 210 & 150 \\
\hline Virginia Polytechnic Institute & 382 & 247 & D.M. Denbow & 188 & 217 & 1,255 & 243 & 21 & 189 & 150 \\
\hline Vrije Universiteit, Brussels & 23 & 341 & Y. Vandenplas & 293 & 123 & 2,470 & 157 & 21 & 189 & 150 \\
\hline VU University Amsterdam & 2,365 & 65 & N.P.E. Vermeulen & 297 & 117 & 4,587 & 75 & 29 & 116 & 150 \\
\hline Wageningen University & 263 & 274 & I.M.C.M. Rietjens & 210 & 195 & 2,111 & 176 & 27 & 138 & 150 \\
\hline Wake Forest University & 1,001 & 172 & J.C. Elsenach & 305 & 112 & 3,976 & 96 & 39 & 59 & 150 \\
\hline Waseda University & 69 & 320 & S. Shibata & 306 & 111 & 275 & 318 & 26 & 145 & 150 \\
\hline Washington State University & 655 & 207 & D.E. Baker & 301 & 115 & 443 & 298 & 12 & 273 & $\overline{86}$ \\
\hline Washington University in St. Louis & 878 & 184 & D.F. Covey & 240 & 173 & 2,349 & 162 & 31 & 104 & 150 \\
\hline Wayne State University & 3,291 & 31 & L.H. Lash & 136 & 269 & 1,726 & 203 & 25 & 153 & 150 \\
\hline West Virginia University & 719 & 203 & V. Castranova & 365 & 80 & 5,280 & 61 & 40 & 53 & 150 \\
\hline Yale University & 2,098 & 76 & A. C. Sartorelli & 512 & 38 & 6,818 & 45 & 24 & 160 & 150 \\
\hline Yonsei University & 845 & 187 & J.K. Hwang & 91 & 298 & 766 & 277 & 18 & 224 & 150 \\
\hline York University & 61 & 325 & G. Sweeney & 65 & 320 & 1,403 & 232 & 25 & 153 & 150 \\
\hline Zhejiang University & 989 & 174 & E.Q. Wei & 119 & 282 & 420 & 302 & 15 & 252 & 150 \\
\hline
\end{tabular}




\begin{tabular}{|c|c|c|c|c|c|c|c|c|c|c|}
\hline Neuroscience Data & $\begin{array}{l}\text { Department } \\
\text { Publications }\end{array}$ & Rank & Most Prolific Author & Published & Rank & Cited & Rank & $\begin{array}{c}\text { H- } \\
\text { Index }\end{array}$ & Rank & $\begin{array}{c}\text { \# of } \\
\text { Coauthors }\end{array}$ \\
\hline Aalto University & 798 & 190 & R. Hari & 301 & 94 & 7,650 & 54 & 48 & 44 & 150 \\
\hline Aarhus University & 2,191 & 85 & A. Gjedde & 337 & 73 & 5,144 & 99 & 33 & 132 & 150 \\
\hline Arizonia State University & 462 & 232 & G.E. Stelmach & 177 & 192 & 2,028 & 205 & 23 & 216 & 150 \\
\hline Ateneo de Manila University & 0 & 346 & & 0 & 342 & 0 & 341 & 0 & 340 & 0 \\
\hline Auburn University & 311 & 260 & M.C. Newland & 50 & 326 & 559 & 309 & 12 & 308 & 59 \\
\hline Australian National University & 1,792 & 105 & I.A. Hendry & 143 & 233 & 1,241 & 260 & 13 & 302 & 130 \\
\hline Boston College & 298 & 261 & T.N. Seyfried & 129 & 254 & 1,194 & 266 & 18 & 262 & 150 \\
\hline Boston University & 4,167 & 25 & S. Grossberg & 299 & 96 & 6,313 & 79 & 32 & 140 & 125 \\
\hline Brandeis University & 905 & 175 & E. Marder & 168 & 204 & 2,449 & 186 & 36 & 108 & 135 \\
\hline Brigham Young University & 156 & 298 & R.O. Hopkins & 114 & 267 & 1,699 & 229 & 25 & 196 & 150 \\
\hline Brown University & 2,346 & 79 & M.F. Bear & 125 & 258 & 6,668 & 70 & 46 & 53 & 150 \\
\hline California Institute of Technology (Calt... & 1,768 & 107 & C. Koch & 231 & 145 & 8,574 & 41 & 44 & 62 & 150 \\
\hline Cardiff University & 2,435 & 71 & J.P. Aggeton & 345 & 69 & 4,652 & 111 & 43 & 66 & 150 \\
\hline Carnegie Mellon University & 824 & 185 & M. Behrmann & 105 & 283 & 2,195 & 199 & 27 & 176 & 113 \\
\hline Case Western Reserve University & 3,087 & 47 & G. Perry & 507 & 25 & 964 & 282 & 65 & 9 & 150 \\
\hline Chalmers University of Technology & 69 & 322 & S. Nilsson & 110 & 276 & 1,611 & 235 & 27 & 176 & 150 \\
\hline Charles University & 487 & 227 & E. Sykova & 182 & 188 & 2,245 & 196 & 31 & 148 & 150 \\
\hline Chinese University of Hong Kong & 447 & 235 & D.T. Yew & 252 & 127 & 1,311 & 253 & 19 & 253 & 150 \\
\hline Chulalongkorn University & 170 & 292 & S. Shuangshoti & 144 & 232 & 595 & 306 & 6 & 331 & 107 \\
\hline City University of Hong Kong & 118 & 308 & G.R. Chen & 679 & 6 & 14,752 & 14 & 62 & 14 & 150 \\
\hline City University of New York & 870 & 178 & A. Sclafani & 311 & 87 & 2,184 & 200 & 27 & 176 & 150 \\
\hline Colorado State University & 402 & 245 & F.E. Dudek & 186 & 183 & 3,708 & 137 & 30 & 153 & 150 \\
\hline Columbia University & 8,548 & 7 & Y. Stern & 383 & 54 & 12,582 & 20 & 58 & 21 & 150 \\
\hline Cornell University & 5,554 & 15 & D.J. Reis & 498 & 28 & 8,287 & 45 & 29 & 159 & 150 \\
\hline Curtin University of Technology & 122 & 306 & & 0 & 342 & 0 & 341 & 0 & 340 & 0 \\
\hline Dalhousie University & 2,282 & 81 & H.A. Robertson & 167 & 207 & 3,881 & 130 & 25 & 196 & 150 \\
\hline Dartmouth College & 1,588 & 120 & M.S. Gazzaniga & 230 & 147 & 3,564 & 142 & 29 & 159 & 150 \\
\hline Delft University of Technology & 116 & 309 & A.C. Schuten & 23 & 340 & 95 & 336 & 9 & 319 & 28 \\
\hline Drexel University & 2,041 & 89 & M. Murray & 107 & 280 & 1,645 & 232 & 24 & 202 & 150 \\
\hline Duke University & 5,924 & 14 & T.A. Slotkin & 504 & 27 & 6,960 & 64 & 43 & 66 & 150 \\
\hline Durham University & 534 & 216 & J.M. Findlay & 79 & 306 & 1,851 & 219 & 17 & 271 & 81 \\
\hline Ecole Normale Supérieure de Lyon & 51 & 329 & E. Gilson & 106 & 282 & 2,381 & 192 & 27 & 176 & 150 \\
\hline École Normale Supérieure, Paris & 470 & 229 & A. Triller & 125 & 258 & 3,013 & 162 & 28 & 167 & 150 \\
\hline École Polytechnique & 44 & 332 & & 0 & 342 & 0 & 341 & 0 & 340 & 0 \\
\hline
\end{tabular}




\begin{tabular}{|c|c|c|c|c|c|c|c|c|c|c|}
\hline Ecole Polytechnique Fédérale de Lausanne & 390 & 247 & M. Bierlarie & 344 & 70 & 1,622 & 234 & 22 & 223 & 150 \\
\hline Eindhoven University of Technology & 67 & 324 & W.H. Backes & 86 & 298 & 975 & 280 & 19 & 253 & 150 \\
\hline Emory University & 4,499 & 22 & A.I. Levy & 243 & 132 & 13,025 & 19 & 57 & 24 & 150 \\
\hline Erasmus University Rotterdam & 2,950 & 56 & M.M.B. Bretelar & 341 & 71 & 13,580 & 18 & 71 & 6 & 150 \\
\hline ETH Zurich (Swiss Federal Institute of Technology) & 1,266 & 143 & J.Feldon & 353 & 63 & 4,566 & 114 & 45 & 59 & 150 \\
\hline Florida International University & 170 & 292 & P.K. Stoddard & 41 & 331 & 634 & 304 & 14 & 296 & 56 \\
\hline Florida State University & 512 & 222 & K.J. Berkley & 100 & 288 & 1,915 & 213 & 20 & 244 & 149 \\
\hline Freie Universität Berlin & 1,941 & 95 & R. Menzel & 152 & 225 & 2,597 & 178 & 35 & 115 & 150 \\
\hline Friedrich Alexander Universität Erlangen Nürnberg & 1,877 & 98 & B. Neundofer & 454 & 40 & 3,960 & 126 & 34 & 123 & 150 \\
\hline Fudan University & 913 & 173 & G.C. $\mathrm{Wu}$ & 107 & 280 & 800 & 298 & 16 & 282 & 128 \\
\hline Georg August Universität Göttingen & 2,798 & 59 & W. Paulus & 290 & 102 & 3,813 & 133 & 39 & 89 & 150 \\
\hline George Mason University & 205 & 282 & G.A. Ascoli & 88 & 297 & 494 & 315 & 16 & 282 & 150 \\
\hline George Washington University & 860 & 179 & J.M. Rosenstein & 73 & 312 & 1,131 & 272 & 14 & 296 & 64 \\
\hline Georgetown University & 1,907 & 96 & K. Gale & 138 & 239 & 1,858 & 218 & 14 & 296 & 128 \\
\hline Georgia Institute of Technology & 361 & 248 & A.D. Fisk & 143 & 233 & 903 & 287 & 13 & 302 & 124 \\
\hline Georgia State University & 628 & 206 & H.E. Albers & 119 & 263 & 1,359 & 251 & 17 & 271 & 121 \\
\hline Goteborg University & 1,398 & 135 & K. Blennow & 395 & 51 & 6,896 & 65 & 55 & 27 & 150 \\
\hline Harvard University & 2,321 & 80 & D.L. Schacter & 281 & 109 & 9,351 & 33 & 59 & 19 & 150 \\
\hline Hebrew University of Jerusalem & 2,457 & 70 & M. Devor & 174 & 195 & 3,576 & 141 & 26 & 186 & 150 \\
\hline Heidelberg Universität & 3,313 & 42 & W. Hacke & 477 & 34 & 9,669 & 30 & 64 & 11 & 150 \\
\hline Hokkaido University & 2,404 & 74 & M. Watanabe & 636 & 11 & 40,786 & 2 & 51 & 36 & 150 \\
\hline Hong Kong Polytechnic University & 421 & 241 & P. Cho & 101 & 286 & 572 & 308 & 15 & 291 & 101 \\
\hline Hong Kong University of Science \& Techno... & 252 & 269 & N.Y. Ip & 177 & 192 & 6,485 & 75 & 24 & 202 & 150 \\
\hline Humboldt-Universität zu Berlin & 670 & 205 & U.Dirnagl & 229 & 148 & 7,515 & 56 & 46 & 53 & 150 \\
\hline Imperial College London & 2,614 & 63 & H.F. Bradford & 188 & 180 & 1,714 & 227 & 16 & 282 & 144 \\
\hline Indian Institute of Technology Bombay (I... & 12 & 341 & R. Manchanda & 27 & 337 & 56 & 338 & 5 & 333 & 21 \\
\hline Indian Institute of Technology Delhi (II... & 21 & 339 & G.S. Sekhon & 149 & 227 & 1,151 & 270 & 11 & 313 & 150 \\
\hline Indian Institute of Technology Kanpur (I... & 33 & 334 & R.K. Gupta & 348 & 67 & 1,974 & 210 & 26 & 186 & 150 \\
\hline Indiana University Bloomington & 2,156 & 86 & G.V. Rebec & 157 & 217 & 1,479 & 244 & 20 & 244 & 147 \\
\hline Indiana University Indianapolis & 1,997 & 91 & B. Ghetti & 281 & 109 & 6,068 & 84 & 40 & 82 & 150 \\
\hline Iowa State University & 217 & 276 & D.S. Sakaguchi & 56 & 322 & 897 & 288 & 17 & 271 & 82 \\
\hline Johns Hopkins University & 10,849 & 3 & S.H. Snyder & 300 & 95 & 14,180 & 15 & 75 & 5 & 150 \\
\hline Kansas State University & 105 & 313 & M.L. Weiss & 77 & 307 & 1,154 & 269 & 20 & 244 & 150 \\
\hline Katholieke Universiteit Leuven & 1,624 & 115 & G.A. Orbin & 286 & 105 & 4,273 & 119 & 38 & 96 & 150 \\
\hline Keio University & 1,585 & 121 & Y. Fukuuchi & 231 & 145 & 2,331 & 194 & 25 & 196 & 150 \\
\hline
\end{tabular}




\begin{tabular}{|c|c|c|c|c|c|c|c|c|c|c|}
\hline King Fahd University of Petroleum \& Minerals & 8 & 344 & A. Aksoy & 25 & 338 & 55 & 339 & 3 & 337 & 33 \\
\hline King Saud University & 185 & 287 & A.M. Abu El-Asrar & 108 & 278 & 879 & 291 & 18 & 262 & 136 \\
\hline Kobe University & 1,099 & 161 & N. Saito & 172 & 199 & 2,923 & 165 & 29 & 159 & 150 \\
\hline Korea Advanced Institute of Science \& Technology & 154 & 299 & E. Kim & 154 & 222 & 5,022 & 103 & 38 & 96 & 150 \\
\hline Korea University & 357 & 250 & Y.K. Kim & 236 & 142 & 1,567 & 239 & 24 & 202 & 150 \\
\hline Kyoto University & 6,022 & 13 & H.Shibasaki & 584 & 16 & 10,897 & 24 & 40 & 82 & 150 \\
\hline Kyushu University & 2,880 & 58 & M. Fukui & 517 & 24 & 6,414 & 77 & 28 & 167 & 150 \\
\hline La Trobe University & 675 & 204 & K.T. Ng & 111 & 274 & 1,217 & 264 & 16 & 282 & 94 \\
\hline Lancaster University & 87 & 318 & D. Allsop & 83 & 302 & 1,914 & 214 & 21 & 233 & 150 \\
\hline Leiden University & 2,546 & 66 & R.A.C. Roos & 333 & 75 & 3,581 & 140 & 26 & 186 & 150 \\
\hline Linkoping University & 851 & 181 & A. Blomqvist & 114 & 267 & 2,427 & 189 & 20 & 244 & 120 \\
\hline London School of Economics and Political Scie & 186 & 286 & M.R.J. Knapp & 240 & 138 & 3,887 & 129 & 38 & 96 & 150 \\
\hline Loughborough University & 124 & 305 & J.A. Horne & 111 & 274 & 2,631 & 173 & 20 & 244 & 79 \\
\hline Louisiana State University & 1,209 & 149 & N.G. Bazan & 398 & 50 & 4,960 & 105 & 40 & 82 & 150 \\
\hline Ludwig-Maximilians-Universität München & 4,557 & 21 & H.J. Moller & 792 & 2 & 14,781 & 13 & 53 & 29 & 150 \\
\hline Lund University & 3,780 & 31 & A. Bjorklund & 472 & 35 & 8,610 & 39 & 51 & 36 & 150 \\
\hline Maastricht University & 2,207 & 83 & H.W.M. Steinbusch & 267 & 121 & 3,915 & 128 & 29 & 159 & 150 \\
\hline Macquarie University & 625 & 207 & M. Coltheart & 158 & 216 & 3,544 & 143 & 28 & 167 & 147 \\
\hline Mahidol University & 213 & 279 & P. Govitrapong & 101 & 286 & 827 & 295 & 15 & 291 & 146 \\
\hline Masaryk University & 420 & 242 & I. Rektor & 181 & 189 & 1,125 & 274 & 21 & 233 & 150 \\
\hline Massachusetts Institute of Technology & 3,019 & 54 & R.J. Wurtman & 715 & 3 & 11,570 & 22 & 26 & 186 & 150 \\
\hline McGill University & 8,829 & 6 & F. Andermann & 164 & 208 & 4,584 & 113 & 31 & 148 & 150 \\
\hline McMaster University & 2,152 & 87 & H. Szechtman & 138 & 239 & 1,706 & 228 & 22 & 223 & 150 \\
\hline Michigan State University & 1,699 & 109 & K.E. Moore & 275 & 115 & 1,487 & 243 & 8 & 322 & 115 \\
\hline Michigan Technological University & 32 & 336 & W.S. Helton & 25 & 338 & 94 & 337 & 8 & 322 & 23 \\
\hline Monash University & 2,350 & 78 & J.1. Bradshaw & 296 & 98 & 3,514 & 144 & 30 & 153 & 150 \\
\hline Montana State University & 160 & 296 & C.M. Paden & 41 & 331 & 400 & 318 & 8 & 322 & 74 \\
\hline Moscow State University & 909 & 174 & E.N. Sokolov & 162 & 212 & 401 & 317 & 7 & 328 & 119 \\
\hline Nagoya University & 2,521 & 68 & G. Sobue & 520 & 22 & 8,771 & 36 & 44 & 62 & 150 \\
\hline Nanjing University & 110 & 311 & J.J. Wang & 414 & 46 & 9,592 & 31 & 19 & 253 & 150 \\
\hline Nanyang Technological University & 159 & 297 & C. Quck & 151 & 226 & 742 & 300 & 23 & 216 & 150 \\
\hline National Taiwan University & 921 & 171 & H.G. Hwu & 113 & 270 & 3,295 & 154 & 22 & 223 & 150 \\
\hline National Tsing Hua University & 93 & 315 & Y.C. Chang & 31 & 336 & 180 & 333 & 6 & 331 & 92 \\
\hline National University of Ireland, Galway & 351 & 252 & B.E. Leonard & 381 & 57 & 3,487 & 145 & 33 & 132 & 150 \\
\hline National University of Singapore & 1,325 & 139 & E.A.Lang & 286 & 105 & 2,475 & 182 & 22 & 223 & 150 \\
\hline New Mexico State University & 89 & 317 & & 0 & 342 & 0 & 341 & 0 & 340 & 0 \\
\hline
\end{tabular}




\begin{tabular}{|c|c|c|c|c|c|c|c|c|c|c|}
\hline New York University & 5,491 & 16 & O. Devinsky & 317 & 85 & 6,794 & 66 & 34 & 123 & 150 \\
\hline Newcastle University & 1,670 & 112 & D.M. Turnbull & 353 & 63 & 5,836 & 87 & 50 & 41 & 150 \\
\hline North Carolina State University & 350 & 253 & T.E. LeVere & 40 & 333 & 132 & 334 & 0 & 340 & 24 \\
\hline Northeastern University & 514 & 221 & J.R. Stellar & 52 & 325 & 546 & 311 & 12 & 308 & 79 \\
\hline Northwestern University & 3,878 & 30 & A. Routtenberg & 179 & 191 & 2,579 & 179 & 17 & 271 & 150 \\
\hline Norwegian University of Science \& Technology & 710 & 199 & U. Sonnewald & 155 & 220 & 2,125 & 201 & 29 & 159 & 150 \\
\hline Ohio State University & 3,319 & 40 & J.R. Mendell & 265 & 122 & 5,406 & 95 & 32 & 140 & 150 \\
\hline Oklahoma State University & 120 & 307 & C.W. Stevens & 162 & 212 & 2,619 & 176 & 28 & 167 & 150 \\
\hline Open University UK & 525 & 219 & S.P.R. Rose & 292 & 100 & 132 & 334 & 4 & 335 & 12 \\
\hline Oregon State University & 360 & 249 & F.L. Moore & 93 & 294 & 1,132 & 271 & 19 & 253 & 58 \\
\hline Osaka University & 4,079 & 26 & M. Tohyama & 498 & 28 & 9,683 & 29 & 41 & 76 & 150 \\
\hline Peking University & 1,103 & 160 & J.S. Han & 238 & 140 & 1,736 & 226 & 18 & 262 & 150 \\
\hline Pennsylvania State University & 2,354 & 77 & M.L. Latash & 252 & 127 & 2,009 & 209 & 32 & 140 & 141 \\
\hline Pohang University of Science And Technology & 116 & 309 & K.T. Kim & 121 & 260 & 1,506 & 242 & 21 & 233 & 150 \\
\hline Portland State University & 66 & 327 & L.I. Crawshaw & 43 & 330 & 283 & 325 & 8 & 322 & 83 \\
\hline Princeton University & 1,266 & 143 & B.L. Jacobs & 187 & 182 & 3,844 & 131 & 21 & 233 & 94 \\
\hline Purdue University & 1,538 & 125 & S.A. Bayer & 94 & 293 & 3,293 & 155 & 5 & 333 & 45 \\
\hline Queen's University & 1,807 & 100 & R.J. Beninger & 153 & 224 & 2,023 & 206 & 15 & 291 & 125 \\
\hline Queen's University of Belfast & 680 & 202 & D.J. King & 92 & 295 & 918 & 285 & 13 & 302 & 101 \\
\hline Queensland University of Technology & 343 & 254 & D.A. Atchison & 139 & 237 & 1,071 & 276 & 18 & 262 & 101 \\
\hline Radboud University, Nijmegen & 3,896 & 28 & A.R.Cool & 364 & 60 & 3,118 & 157 & 31 & 148 & 150 \\
\hline Rensselaer Polytechnic Institute & 219 & 275 & L.D. Reid & 100 & 288 & 826 & 296 & 8 & 322 & 138 \\
\hline Rheinisch Westfalische Technische Hochschule Aach & 1,208 & 150 & K. Willmes & 168 & 204 & 2,473 & 183 & 24 & 202 & 150 \\
\hline Rheinische Friedrich Wilhelms Universitat Bonn & 2,574 & 64 & C.E. Elger & 657 & 8 & 15,860 & 11 & 62 & 14 & 150 \\
\hline Rice University & 315 & 258 & R.M. Glantz & 67 & 316 & 190 & 330 & 7 & 328 & 25 \\
\hline Rochester Institute of Technology & 67 & 324 & R.D. Frisina & 617 & 14 & 919 & 284 & 18 & 262 & 96 \\
\hline Royal Institute of Technology, KTH & 168 & 295 & A. Lanser & 75 & 308 & 1,109 & 275 & 17 & 271 & 92 \\
\hline Royal Melbourne Institute of Technology & 68 & 323 & M.J. Rand & 251 & 129 & 1,626 & 233 & 11 & 313 & 145 \\
\hline Rutgers & 2,718 & 61 & G. Buzsaki & 241 & 137 & 8,577 & 40 & 52 & 32 & 150 \\
\hline Saint-Petersburg State University & 335 & 256 & A.S. Batuev & 198 & 169 & 184 & 331 & 4 & 335 & 118 \\
\hline San Diego State University & 525 & 219 & C.L. Murphy & 121 & 260 & 1,660 & 231 & 24 & 202 & 150 \\
\hline Sapienza University of Rome & 0 & 346 & & 0 & 342 & 0 & 341 & 0 & 340 & 0 \\
\hline Sciences Po Paris & 0 & 346 & & 0 & 342 & 0 & 341 & 0 & 340 & 0 \\
\hline Seoul National University & 1,679 & 111 & K. Chu & 91 & 296 & 1,221 & 263 & 24 & 202 & 150 \\
\hline Shanghai Jiao Tong University & 470 & 229 & L. He & 650 & 9 & 8,548 & 42 & 39 & 89 & 150 \\
\hline Simon Fraser University & 601 & 209 & R.E. Misatlberger & 86 & 298 & 1,235 & 262 & 22 & 223 & 89 \\
\hline
\end{tabular}




\begin{tabular}{|c|c|c|c|c|c|c|c|c|c|c|}
\hline Stanford University & 6,700 & 12 & R.M. Sapolsky & 320 & 82 & 1,202 & 265 & 46 & 53 & 150 \\
\hline State University of New York Buffalo & 8 & 344 & M.B. Kristal & 53 & 324 & 227 & 328 & 7 & 328 & 56 \\
\hline Stockholm University & 716 & 198 & T. Bartitai & 327 & 81 & 5,260 & 97 & 40 & 82 & 150 \\
\hline Stony Brook University & 2,434 & 72 & S.M. Sherman & 163 & 210 & 2,202 & 198 & 25 & 196 & 83 \\
\hline Syracuse University & 719 & 197 & S.V. Faraone & 701 & 4 & 31,524 & 6 & 80 & 4 & 150 \\
\hline Tartu University (University of Tartu) & 436 & 237 & J. Harro & 132 & 247 & 1,365 & 248 & 21 & 233 & 150 \\
\hline Technical University of Denmark & 146 & 301 & L.K. hanson & 169 & 203 & 2,072 & 203 & 21 & 233 & 150 \\
\hline Technion & 1,091 & 164 & M.B.H. Youdiam & 520 & 22 & 13,996 & 17 & 52 & 32 & 150 \\
\hline Technische Universität Berlin & 179 & 290 & K. Obermayer & 112 & 272 & 891 & 289 & 18 & 262 & 136 \\
\hline Technische Universitat Chemnitz & 29 & 337 & S. Gauggel & 32 & 335 & 362 & 320 & 12 & 308 & 65 \\
\hline Technische Universität Dresden & 855 & 180 & T.C. Hummel & 332 & 78 & 3,353 & 148 & 42 & 71 & 150 \\
\hline Technische Universität München & 1,486 & 127 & B Conrad & 249 & 130 & 4,256 & 121 & 35 & 115 & 150 \\
\hline Tel Aviv University & 3,048 & 52 & A.D. Korczyn & 622 & 13 & 8,096 & 48 & 36 & 108 & 150 \\
\hline Texas A\&M University & 1,134 & 156 & W.R. Wihelm & 65 & 318 & 287 & 324 & 10 & 317 & 52 \\
\hline Texas Tech & 259 & 267 & D.D. Allen & 74 & 311 & 1,269 & 257 & 20 & 244 & 138 \\
\hline Tohoku University & 3,077 & 49 & Y. Itoyama & 412 & 48 & 5,875 & 86 & 34 & 123 & 150 \\
\hline Tokyo Institute of Technology & 287 & 265 & A.Sato & 318 & 84 & 2,347 & 193 & 18 & 262 & 150 \\
\hline Trinity College Dublin & 1,143 & 154 & R. Anwyl & 135 & 245 & 4,236 & 122 & 32 & 140 & 150 \\
\hline Tsinghua University & 190 & 284 & N.M. Zhao & 136 & 242 & 966 & 281 & 17 & 271 & 150 \\
\hline Tufts University & 1,595 & 118 & R.B. Kanarek & 95 & 292 & 1,562 & 240 & 15 & 291 & 84 \\
\hline Universidad Autonoma de Madrid & 1,449 & 129 & J. Avila & 205 & 164 & 4,438 & 115 & 41 & 76 & 150 \\
\hline Universidad de Chile & 737 & 195 & A. Hernandez & 80 & 305 & 333 & 322 & 11 & 313 & 96 \\
\hline Universidad de Granada & 1,449 & 129 & J. Avila & 205 & 164 & 4,438 & 115 & 41 & 76 & 150 \\
\hline Universidad del País Vasco & 509 & 224 & C. Matute & 108 & 278 & 2,016 & 208 & 27 & 176 & 150 \\
\hline Universidad Nacional Autónoma de México ... & 1,099 & 161 & R. Colin Druker & 163 & 210 & 1,237 & 261 & 17 & 271 & 150 \\
\hline Universidad Politecnica de Madrid & 39 & 333 & M.M. Desco & 130 & 252 & 953 & 283 & 19 & 253 & 150 \\
\hline Universidade de São Paulo & 1,717 & 108 & M.L. Brandao & 164 & 208 & 1,155 & 268 & 25 & 196 & 150 \\
\hline Universidade Estadual de Campinas & 246 & 270 & F. Cendes & 258 & 125 & 3,374 & 147 & 31 & 148 & 150 \\
\hline Università degli Studi di Firenze & 1,899 & 97 & S. Sorbi & 223 & 151 & 6,110 & 82 & 33 & 132 & 150 \\
\hline Università degli Studi di Padova & 2,237 & 82 & C. Angelini & 333 & 75 & 5,135 & 100 & 33 & 132 & 150 \\
\hline Universita Di Bologna & 2,039 & 90 & P. Cortelli & 271 & 117 & 4,257 & 120 & 29 & 159 & 150 \\
\hline Universita di Pisa & 879 & 177 & L. Murri & 298 & 97 & 2,385 & 191 & 25 & 196 & 150 \\
\hline Universitat Autonoma de Barcelona & 1,383 & 137 & A. Armario & 173 & 196 & 2,088 & 202 & 24 & 202 & 115 \\
\hline Universitat Bielefeld & 694 & 200 & H.J. Markowitsch & 243 & 132 & 3,728 & 135 & 31 & 148 & 150 \\
\hline Universität Bremen & 594 & 211 & G. Roth & 104 & 284 & 1,260 & 258 & 20 & 244 & 107 \\
\hline Universitat d'Alacant & 215 & 277 & N. Cuenca & 49 & 327 & 497 & 314 & 15 & 291 & 91 \\
\hline
\end{tabular}




\begin{tabular}{|c|c|c|c|c|c|c|c|c|c|c|}
\hline Universitat de València & 832 & 182 & J.M. Garcia-Verdurgo & $\mid 115$ & 266 & 7,275 & 61 & 40 & 82 & 150 \\
\hline Universität Frankfurt am Main & 2,400 & 75 & H. Braak & 294 & 99 & 8,784 & 35 & 44 & 62 & 150 \\
\hline Universität Freiburg & 2,143 & 88 & M. Frotscher & 271 & 117 & 6,733 & 68 & 43 & 66 & 150 \\
\hline Universitat Hamburg & 553 & 215 & M. Schachner & 590 & 15 & 22,218 & 9 & 58 & 21 & 150 \\
\hline Universität Karlsruhe & 46 & 331 & R. Stietelhager & 81 & 304 & 277 & 326 & 10 & 317 & 86 \\
\hline Universitat Leipzig & 1,040 & 166 & A. Reichenbach & 307 & 89 & 2,573 & 180 & 28 & 167 & 150 \\
\hline Universitat Munster (Westfälische Wilhelms-Un & 888 & 176 & E.J. Speckmann & 263 & 124 & 1,428 & 246 & 19 & 253 & 150 \\
\hline Universitat Politecnica de Catalunya & 29 & 337 & M. Slater & 103 & 285 & 831 & 294 & 20 & 244 & 142 \\
\hline Universität Regensburg & 1,136 & 155 & G. Hajak & 277 & 112 & 2,759 & 170 & 30 & 153 & 150 \\
\hline Universität Stuttgart & 128 & 303 & W. Hauber & 62 & 319 & 741 & 301 & 17 & 271 & 35 \\
\hline Universitat Trier & 231 & 272 & D.H. Hellhammer & 160 & 215 & 4,945 & 106 & 42 & 71 & 150 \\
\hline Universität Tübingen & 3,444 & 35 & N. Birbaumer & 383 & 54 & 7,964 & 51 & 47 & 49 & 150 \\
\hline Universitat Wien (University of Vienna) & 1,806 & 101 & H. Budka & 333 & 75 & 6,107 & 83 & 37 & 102 & 150 \\
\hline Universitat Zu Koln & 1,660 & 113 & J. Klosterkotter & 168 & 204 & 1,570 & 237 & 24 & 202 & 150 \\
\hline Université Catholique de Louvain & 1,188 & 151 & B. Rossion & 97 & 290 & 1,365 & 248 & 28 & 167 & 137 \\
\hline Universite de Liege & 1,260 & 145 & J. Balthazart & 319 & 83 & 2,412 & 190 & 38 & 96 & 150 \\
\hline Université de Montréal & 3,384 & 36 & R.F. Butterworth & 328 & 80 & 2,832 & 168 & 30 & 153 & 150 \\
\hline Université de Nice Sophia Antipolis & 352 & 251 & C.L. Gottesmann & 109 & 277 & 660 & 302 & 14 & 296 & 81 \\
\hline Universite Laval & 1,943 & 94 & M.Steriade & 243 & 132 & 6,712 & 69 & 46 & 53 & 113 \\
\hline Universite Libre de Bruxelles & 1,309 & 141 & S.N. Schiffmann & 126 & 256 & 3,338 & 150 & 26 & 186 & 150 \\
\hline Université Paris Sorbonne & 82 & 321 & M. Cottrell & 33 & 334 & 348 & 321 & 8 & 322 & 46 \\
\hline Universite Paris-Sud 11 & 820 & 187 & S. Laroche & 72 & 313 & 2,052 & 204 & 22 & 223 & 121 \\
\hline Université Pierre et Marie Curie & 1,300 & 142 & J. Mariani & 186 & 183 & 1,959 & 211 & 27 & 176 & 150 \\
\hline Universiti Malaya (University of Malaya) & 135 & 302 & C.T. Tan & 58 & 320 & 580 & 307 & 13 & 302 & 138 \\
\hline University College Cork & 225 & 273 & T.G. Cotter & 183 & 187 & 6,386 & 78 & 36 & 108 & 150 \\
\hline University College Dublin & 509 & 224 & C.M. Regan & 133 & 246 & 1,594 & 236 & 22 & 223 & 150 \\
\hline University College London & 9,547 & 4 & G. Burnstock & 1,019 & 1 & 32,401 & 5 & 62 & 14 & 150 \\
\hline University do Porto & 297 & 262 & M.M. Paula-Barbosa & 146 & 231 & 1,349 & 252 & 17 & 271 & 95 \\
\hline University of Aberdeen & 1,113 & 158 & R.G. Pertwee & 170 & 200 & 5,135 & 100 & 42 & 71 & 150 \\
\hline University of Adelaide & 917 & 172 & T.S. Miles & 126 & 256 & 1,131 & 272 & 17 & 271 & 96 \\
\hline University of Alabama & 3,025 & 53 & E. Faught & 148 & 229 & 4,428 & 117 & 37 & 102 & 150 \\
\hline University of Alberta & 2,892 & 57 & R.B. Stein & 225 & 149 & 3,588 & 139 & 24 & 202 & 150 \\
\hline University of Amsterdam & 3,087 & 47 & M. Joels & 156 & 219 & 3,729 & 134 & 33 & 132 & 150 \\
\hline University of Antwerp & 1,513 & 126 & C. Van Broeeckhoven & 413 & 47 & 9,517 & 32 & 52 & 32 & 150 \\
\hline University of Arizona & 2,792 & 60 & F. Porreca & 432 & 42 & 6,975 & 63 & 53 & 29 & 150 \\
\hline University of Athens & 1,106 & 159 & M. Marklanos & 132 & 247 & 628 & 305 & 12 & 308 & 120 \\
\hline
\end{tabular}




\begin{tabular}{|c|c|c|c|c|c|c|c|c|c|c|}
\hline University of Auckland & 1,601 & 117 & M. Dragunon & 195 & 175 & 7,403 & 60 & 32 & 140 & 150 \\
\hline University of Barcelona & 1,680 & 110 & I. Ferrez & 435 & 41 & 6,607 & 71 & 39 & 89 & 150 \\
\hline University of Basel & 1,799 & 103 & A. Probst & 211 & 160 & 4,703 & 110 & 26 & 186 & 150 \\
\hline University of Bath & 206 & 281 & S. Wonnacott & 142 & 235 & 3,328 & 151 & 35 & 115 & 150 \\
\hline University of Bergen & 528 & 218 & K. Hugdahl & 281 & 109 & 2,934 & 164 & 30 & 153 & 150 \\
\hline University of Bern & 776 & 192 & J.C. Reubi & 359 & 61 & 5,633 & 93 & 45 & 59 & 150 \\
\hline University of Birmingham & 1,259 & 146 & J.H. Fremlin & 154 & 222 & 183 & 332 & 0 & 340 & 110 \\
\hline University of Bristol & 3,017 & 55 & D.J. Nutt & 625 & 12 & 0 & 341 & 45 & 59 & 150 \\
\hline University of British Columbia & 2,432 & 73 & P.L. McGeer & 496 & 30 & 11,609 & 21 & 48 & 44 & 150 \\
\hline University of Calgary & 1,797 & 104 & M.D. Hill & 243 & 132 & 2,964 & 163 & 35 & 115 & 150 \\
\hline University of California, Berkley & 1,611 & 116 & M. D'Esposito & 206 & 163 & 8,137 & 46 & 63 & 12 & 150 \\
\hline University of California, Davis & 1,956 & 93 & E. Carstens & 185 & 185 & 1,525 & 241 & 24 & 202 & 150 \\
\hline University of California, Irvine & 4,614 & 20 & C.W. Cotman & 193 & 176 & 8,771 & 36 & 51 & 36 & 150 \\
\hline University of California, Los Angeles & 11,800 & 2 & A.W. Toga & 471 & 36 & 7,544 & 55 & 57 & 24 & 150 \\
\hline University of California, Riverside & 607 & 208 & G.I. Hatton & 157 & 217 & 1,761 & 223 & 22 & 223 & 87 \\
\hline University of California, San Diego & 5,211 & 18 & E. Masliah & 464 & 38 & 15,534 & 12 & 69 & 7 & 150 \\
\hline University of California, San Francisco & 7,565 & $\overline{9}$ & J.D. Levine & 358 & 62 & 9,687 & 27 & 47 & 49 & 150 \\
\hline University of California, Santa Barbara & 420 & 242 & S.K. Fisher & 132 & 247 & 1,877 & 217 & 23 & 216 & 146 \\
\hline University of California, Santa Cruz & 126 & 304 & A.L. Fink & 207 & 162 & 6,307 & 80 & 51 & 36 & 150 \\
\hline University of Cambridge & 3,247 & 44 & T.W. Robbins & 580 & 18 & 39,863 & 3 & 91 & 2 & 150 \\
\hline University of Canterbury & 100 & 314 & J.C. Dalrymple-Alford & 57 & 321 & 503 & 313 & 11 & 313 & 71 \\
\hline University of Cape Town & 147 & 300 & D.J. Stein & 568 & 19 & 9,685 & 28 & 42 & 71 & 150 \\
\hline University of Central Florida & 205 & 282 & E. Salas & 173 & 196 & 3,027 & 161 & 34 & 123 & 150 \\
\hline University of Chicago & 5,200 & 19 & J.H. Kordower & 234 & 144 & 5,942 & 85 & 43 & 66 & 150 \\
\hline University of Cincinnati & 2,565 & 65 & S.M. Strakowski & 216 & 156 & 5,705 & 89 & 53 & 29 & 150 \\
\hline University of Colorado at Boulder & 823 & 186 & S.F. Maier & 308 & 88 & 7,066 & 62 & 54 & 28 & 150 \\
\hline University of Connecticut & \begin{tabular}{l|l}
1,187 \\
\end{tabular} & 152 & J. D. Salamone & 142 & 235 & 2,602 & 177 & 34 & 123 & 150 \\
\hline University of Copenhagen & 1,434 & 133 & A. Schousboe & 415 & 44 & 6,594 & 72 & 35 & 115 & 150 \\
\hline University of Delaware & 291 & 263 & C.R. Plata-Salaman & 138 & 239 & 3,718 & 136 & 32 & 140 & 150 \\
\hline University of Dundee & 787 & 191 & D.G. Nicholls & 225 & 149 & 5,751 & 88 & 32 & 140 & 150 \\
\hline University of Edinburgh & 1,476 & 128 & J.M. Wardlaw & 282 & 108 & 4,298 & 118 & 39 & 89 & 150 \\
\hline University of Florida & 4,497 & 23 & K.M. Heilman & 488 & 31 & 6,457 & 76 & 29 & 159 & 150 \\
\hline University of Geneva & 1,353 & 138 & D. Bertrand & 583 & 17 & 6,521 & 73 & 49 & 42 & 150 \\
\hline University of Georgia & 336 & 255 & A.V. Terry & 116 & 265 & 1,287 & 254 & 23 & 216 & 150 \\
\hline University of Ghent & 400 & 246 & H. Roeyers & 117 & 264 & 881 & 290 & 19 & 253 & 150 \\
\hline University of Glasgow & 2,399 & 76 & D.I. Graham & 312 & 86 & 7,440 & 57 & 38 & 96 & 150 \\
\hline
\end{tabular}




\begin{tabular}{|c|c|c|c|c|c|c|c|c|c|c|}
\hline University of Gothenburg & 317 & 257 & H. Haberg & 222 & 152 & 4,919 & 107 & 43 & 66 & 150 \\
\hline University of Groningen & 1,439 & 131 & J. Korf & 350 & 66 & 3,113 & 158 & 26 & 186 & 150 \\
\hline University of Helsinki & 3,130 & 45 & P. Naatanen & 337 & 73 & 5,695 & 90 & 52 & 32 & 150 \\
\hline University of Hong Kong & 531 & 217 & K.F. So & 173 & 196 & 1,699 & 229 & 23 & 216 & 150 \\
\hline University of Houston & 460 & 234 & K.A. Alkadhi & 97 & 290 & 373 & 319 & 14 & 296 & 74 \\
\hline University of Illinois & 2,715 & 62 & W.T. Greenough & 180 & 190 & 5,020 & 104 & 37 & 102 & 150 \\
\hline University of Illinois, Chicago & 3,317 & 41 & H.N. Bhargava & 204 & 166 & 978 & 279 & 3 & 337 & 93 \\
\hline University of Indonesia & 20 & 340 & & 0 & 342 & 0 & 341 & 0 & 340 & 0 \\
\hline University of Iowa & 1,848 & 99 & N.C. Andreasen & 431 & 43 & 14,180 & 15 & 58 & 21 & 150 \\
\hline University of Kansas & 812 & 188 & R. Pahwa & 155 & 220 & 3,926 & 127 & 41 & 76 & 150 \\
\hline University of Kentucky & 1,803 & 102 & M.P. Mattson & 678 & 7 & 43,932 & 1 & 100 & 1 & 150 \\
\hline University of Lausanne & 579 & 213 & B.M. Riederer & 131 & 251 & 1,907 & 215 & 23 & 216 & 150 \\
\hline University of Leeds & 509 & 224 & C. Peers & 198 & 169 & 2,017 & 207 & 28 & 167 & 150 \\
\hline University of Leicester & 828 & 184 & R.A.J. Challiss & 197 & 171 & 3,245 & 156 & 26 & 186 & 150 \\
\hline University of Liverpool & 599 & 210 & R.D. Burgoyne & 302 & 93 & 4,825 & 108 & 38 & 96 & 150 \\
\hline University of Ljubljana & 462 & 232 & S. Podnar & 55 & 323 & 217 & 329 & 13 & 302 & 26 \\
\hline University of London (Kings College of London) & 25,837 & 1 & C.D. Marsden & 690 & 5 & 28,554 & 7 & 40 & 82 & 150 \\
\hline University of Manchester & 3,062 & 51 & N.J. Rothwell & 367 & 59 & 7,748 & 53 & 47 & 49 & 150 \\
\hline University of Manitoba & 1,386 & 136 & J.I. Nagy & 197 & 171 & 2,642 & 172 & 28 & 167 & 150 \\
\hline University of Maryland & 1,223 & 147 & W. Hodos & 85 & 301 & 1,047 & 278 & 9 & 319 & 150 \\
\hline University of Maryland Baltimore County & 3,626 & 33 & R. Aschwarch & 244 & 131 & 3,104 & 159 & 28 & 167 & 150 \\
\hline University of Massachusetts & 467 & 231 & J.D. Blaustein & 149 & 227 & 1,957 & 212 & 16 & 282 & 138 \\
\hline University of Melbourne & 4,387 & 24 & S.F. Berkovic & 386 & 53 & 8,485 & 43 & 56 & 26 & 150 \\
\hline University of Miami & 1,315 & 140 & M.D. Ginsberg & 288 & 104 & 6,744 & 67 & 36 & 108 & 150 \\
\hline University of Michigan & 3,096 & 46 & H.Akil & 404 & 49 & 10,261 & 25 & 48 & 44 & 150 \\
\hline University of Minnesota & 2,539 & 67 & H.H. Loh & 541 & 21 & 7,877 & 52 & 34 & 123 & 150 \\
\hline University of Missouri & 730 & 196 & G.Y. Sun & 113 & 270 & 1,361 & 250 & 22 & 223 & 150 \\
\hline University of Nebraska & 315 & 258 & R.A.Bevins & 86 & 298 & 809 & 297 & 18 & 262 & 66 \\
\hline University of New Hampshire & 180 & 289 & R.G. Mair & 66 & 317 & 653 & 303 & 13 & 302 & 60 \\
\hline University of New Mexico & 685 & 201 & C.F.Valenzuela & 75 & 308 & 1,271 & 256 & 24 & 202 & 150 \\
\hline University of New South Wales & 1,121 & 157 & S.C. Gandevia & 352 & 65 & 5,567 & 94 & 40 & 82 & 150 \\
\hline University of North Carolina, Chapel Hill & 3,269 & 43 & J.A. Lieberman & 505 & 26 & 26,638 & 8 & 65 & 9 & 150 \\
\hline University of North Texas & 257 & 268 & J.W. Simpkins & 283 & 107 & 3,838 & 132 & 37 & 102 & 150 \\
\hline University of Notre Dame & 106 & 312 & F.J. Castellino & 382 & 56 & 3,296 & 153 & 29 & 159 & 150 \\
\hline University of Nottingham & 831 & 183 & C.A. Marsden & 291 & 101 & 3,387 & 146 & 27 & 176 & 150 \\
\hline University of Oklahoma & 584 & 212 & R.D. Foreman & 214 & 158 & 1,901 & 216 & 20 & 244 & 150 \\
\hline
\end{tabular}




\begin{tabular}{|c|c|c|c|c|c|c|c|c|c|c|}
\hline University of Oregon & 1,978 & 92 & J.C. Crabbe & 387 & 52 & 4,209 & 123 & 37 & 102 & 150 \\
\hline University of Oslo & 949 & 169 & O.P. Ottersen & 303 & 92 & 7,411 & 59 & 42 & 71 & 150 \\
\hline University of Otago & 775 & 193 & P.F. Smith & 208 & 161 & 1,466 & 245 & 21 & 233 & 114 \\
\hline University of Ottawa & 962 & 167 & Z. Merali & 170 & 200 & 2,884 & 166 & 36 & 108 & 150 \\
\hline University of Oxford & 3,540 & 34 & C. Spence & 235 & 143 & 1,801 & 221 & 36 & 108 & 150 \\
\hline University of Pennsylvania & 3,982 & 27 & J.Q. Trojanowski & 650 & 9 & 39,385 & 4 & 89 & 3 & 150 \\
\hline University of Pittsburgh & 3,689 & 32 & D.A. Lewis & 458 & 39 & 8,064 & 49 & 49 & 42 & 150 \\
\hline University of Quebec & 958 & 168 & M. Steriade & 243 & 132 & 6,504 & 74 & 46 & 53 & 91 \\
\hline University of Queensland & 1,217 & 148 & R.J. Lewis & 214 & 158 & 2,444 & 187 & 33 & 132 & 150 \\
\hline University of Reading & 437 & 236 & E.A. Gaffen & 44 & 329 & 752 & 299 & 12 & 308 & 38 \\
\hline University of Rochester & 1,627 & 114 & H.J. Federoff & 204 & 166 & 4,716 & 109 & 37 & 102 & 150 \\
\hline University of Saskatchewan & 1,078 & 165 & L. Hertz & 268 & 120 & 3,055 & 160 & 23 & 216 & 150 \\
\hline University of Science and Technology of China & 225 & 273 & D.Y. Ruan & 83 & 302 & 310 & 323 & 9 & 319 & 150 \\
\hline University of Sheffield & 1,571 & 122 & P. Redgrave & 127 & 255 & 1,568 & 238 & 21 & 233 & 146 \\
\hline University of South Carolina & 760 & 194 & A.J. Mcdonald & 75 & 308 & 1,778 & 222 & 21 & 233 & 47 \\
\hline University of South Florida & 676 & 203 & P.R. Sanberg & 371 & 58 & 5,209 & 98 & 39 & 89 & 150 \\
\hline University of Southampton & 561 & 214 & V.H. Perry & 277 & 112 & 8,113 & 47 & 41 & 76 & 150 \\
\hline University of Southern California & 1,770 & 106 & M. Baudry & 274 & 116 & 5,640 & 91 & 35 & 115 & 150 \\
\hline University of St Andrews & 429 & 240 & D.I. Perrett & 331 & 79 & 7,439 & 58 & 44 & 62 & 150 \\
\hline University of Surrey & 187 & 285 & J. Arendt & 215 & 157 & 3,309 & 152 & 32 & 140 & 150 \\
\hline University of Sussex & 510 & 223 & P.R. Benjamin & 114 & 267 & 858 & 293 & 18 & 262 & 96 \\
\hline University of Sydney & 3,361 & 38 & E.Gorden & 239 & 139 & 2,622 & 175 & 36 & 108 & 150 \\
\hline University of Technology, Sydney & 33 & 334 & G.M. Nicholson & 47 & 328 & 439 & 316 & 19 & 253 & 102 \\
\hline University of Tennessee Knoxville & 92 & 316 & R. Wetzel & 112 & 272 & 2,814 & 169 & 34 & 123 & 150 \\
\hline University of Texas at Austin & 929 & 170 & T. Schallert & 175 & 194 & 3,346 & 149 & 35 & 115 & 150 \\
\hline University of Tokyo & 2,472 & 69 & K. Mikoshiba & 484 & 32 & 11,458 & 23 & 62 & 14 & 150 \\
\hline University of Toronto & 9,143 & 5 & A.E. Lang & 555 & 20 & 22,018 & 10 & 67 & 8 & 150 \\
\hline University of Tsukuba & 801 & 189 & T. Sakurai & 415 & 44 & 8,334 & 44 & 47 & 49 & 150 \\
\hline University of Twente & 85 & 319 & E. Marani & 192 & 177 & 1,052 & 277 & 14 & 296 & 150 \\
\hline University of Utah & 3,077 & 49 & R.P. Kesner & 222 & 152 & 2,884 & 166 & 34 & 123 & 150 \\
\hline University of Vermont & 1,097 & 163 & R.L. Parsons & 136 & 242 & 913 & 286 & 17 & 271 & 150 \\
\hline University of Victoria & 212 & 280 & N.M. Sherwood & 130 & 252 & 1,743 & 224 & 24 & 202 & 150 \\
\hline University of Virginia & 1,437 & 132 & O. Steward & 219 & 155 & 552 & 310 & 35 & 115 & 150 \\
\hline University of Warwick & 170 & 292 & N.Dale & 139 & 237 & 1,737 & 225 & 21 & 233 & 147 \\
\hline University of Washington & 7,451 & 10 & W.A. Catterall & 197 & 171 & 8,050 & 50 & 63 & 12 & 150 \\
\hline University of Waterloo & 430 & 239 & A.E. Patla & 148 & 229 & 2,523 & 181 & 27 & 176 & 131 \\
\hline
\end{tabular}




\begin{tabular}{|c|c|c|c|c|c|c|c|c|c|c|}
\hline University of Western Australia & 1,549 & 124 & L.D. Beazley & 136 & 242 & 869 & 292 & 16 & 282 & 144 \\
\hline University of Western Ontario & 3,320 & 39 & M. Kavaliens & 270 & 119 & 2,317 & 195 & 24 & 202 & 150 \\
\hline University of Wisconsin & 2,203 & 84 & R.J. Davidson & 256 & 126 & 8,621 & 38 & 51 & 36 & 150 \\
\hline University of Wollongong & 179 & 290 & R.J. Barry & 196 & 174 & 1,418 & 247 & 27 & 176 & 135 \\
\hline University of York & 265 & 266 & A.W. Young & 170 & 200 & 4,609 & 112 & 33 & 132 & 150 \\
\hline University of Zurich & 1,559 & 123 & J.M. Fritschy & 222 & 152 & 6,293 & 81 & 46 & 53 & 150 \\
\hline Univesitas Gadjah Mada & 9 & 343 & G. Partadiredja & 6 & 341 & 15 & 340 & 2 & 339 & 7 \\
\hline Uppsala University & 1,408 & 134 & H.B. Schioth & 185 & 185 & 2,624 & 174 & 39 & 89 & 150 \\
\hline Utah State & 83 & 320 & J.C.S. Breitner & 191 & 178 & 5,635 & 92 & 41 & 76 & 150 \\
\hline Utrecht University & 5,415 & 17 & W.H. Gispen & 469 & 37 & 5,132 & 102 & 30 & 153 & 150 \\
\hline Vanderbilt University & 1,591 & 119 & J.H. Kaas & 346 & 68 & 5,381 & 96 & 34 & 123 & 150 \\
\hline Victoria University of Wellington & 55 & 328 & S. Schenk & 72 & 313 & 1,287 & 254 & 16 & 282 & 80 \\
\hline Vienna University of Technology & 50 & 330 & G. Pfurtscheller & 340 & 72 & 4,159 & 124 & 48 & 44 & 150 \\
\hline Virginia Polytechnic Institute & 181 & 288 & D.M. Denbow & 188 & 180 & 1,255 & 259 & 21 & 233 & 150 \\
\hline Vrije Universiteit, Brussels & 11 & 342 & Y. Michotte & 190 & 179 & 2,225 & 197 & 24 & 202 & 150 \\
\hline VU University Amsterdam & 3,884 & 29 & F. Barkhof & 478 & 33 & 9,733 & 26 & 62 & 14 & 150 \\
\hline Wageningen University & 67 & 324 & V.M. Wiegant & 199 & 168 & 2,435 & 188 & 27 & 176 & 150 \\
\hline Wake Forest University & 1,147 & 153 & J.C. Eisenach & 305 & 91 & 3,976 & 125 & 39 & 89 & 150 \\
\hline Waseda University & 237 & 271 & S. Shibata & 306 & 90 & 275 & 327 & 26 & 186 & 150 \\
\hline Washington State University & 484 & 228 & J.M. Krueger & 265 & 122 & 2,718 & 171 & 33 & 132 & 150 \\
\hline Washington University in St. Louis & 7,038 & 11 & D.M. Holtzman & 277 & 112 & 9,008 & 34 & 59 & 19 & 150 \\
\hline Wayne State University & 3,364 & 37 & J.W. Phillips & 289 & 103 & 2,460 & 185 & 19 & 253 & 117 \\
\hline West Virginia University & 288 & 264 & R.L. Goodman & 162 & 212 & 2,473 & 183 & 16 & 282 & 150 \\
\hline Yale University & 7,980 & 8 & S.G. Waxman & 237 & 141 & 3,705 & 138 & 48 & 44 & 150 \\
\hline Yonsei University & 436 & 237 & K.C. Chung & 69 & 315 & 1,173 & 267 & 22 & 223 & 150 \\
\hline York University & 416 & 244 & J.D. Crawford & 132 & 247 & 1,851 & 219 & 26 & 186 & 150 \\
\hline Zhejiang University & 215 & 277 & Z Chen & 120 & 262 & 545 & 312 & 16 & 282 & 150 \\
\hline
\end{tabular}




\begin{tabular}{|c|c|c|c|c|c|c|c|c|c|c|}
\hline Social Sciences Data & $\begin{array}{l}\text { Department } \\
\text { Publications }\end{array}$ & Rank & Most Prolific Author & Published & Rank & Cited & Rank & $\begin{array}{c}\text { H- } \\
\text { Index }\end{array}$ & Rank & $\begin{array}{c}\text { \# of } \\
\text { Coauthors }\end{array}$ \\
\hline Aalto University & 552 & 251 & R.P. Hamalainen & 98 & 214 & 693 & 205 & 15 & 186 & 61 \\
\hline Aarhus University & 1,249 & 148 & J. Olsen & 479 & 13 & 7,953 & 31 & 42 & 38 & 150 \\
\hline Arizonia State University & 2,341 & 69 & N. Eisenberg & 181 & 119 & 2,995 & 86 & 32 & 66 & 150 \\
\hline Ateneo de Manila University & 65 & 344 & C.J. Montiel & 10 & 345 & 32 & 329 & 3 & 322 & 8 \\
\hline Auburn University & 1,504 & 116 & W. Buskist & 35 & 312 & 113 & 306 & 8 & 274 & 42 \\
\hline Australian National University & 3,583 & 33 & J.C. Caldwell & 92 & 221 & 1,445 & 139 & 13 & 212 & 35 \\
\hline Boston College & 1,475 & 121 & T. O'Hara & 49 & 286 & 566 & 225 & 12 & 223 & 52 \\
\hline Boston University & 3,014 & 44 & H.E. Stanley & 480 & 12 & 10,348 & 21 & 57 & 13 & 150 \\
\hline Brandeis University & 937 & 188 & W.R. Leonard & 154 & 145 & 2,052 & 109 & 19 & 151 & 150 \\
\hline Brigham Young University & 784 & 215 & M.J. Lambert & 134 & 169 & 1,774 & 122 & 25 & 103 & 150 \\
\hline Brown University & 2,324 & 70 & V.N. Mor & 313 & 42 & 7,454 & 36 & 47 & 28 & 150 \\
\hline California Institute of Technology (Calt... & 527 & 254 & A.H. Zewail & 441 & 17 & 7,475 & 35 & 48 & 25 & 150 \\
\hline Cardiff University & 2,443 & 64 & J.P. Aggleton & 171 & 128 & 4,652 & 59 & 43 & 33 & 150 \\
\hline Carnegie Mellon University & 1,891 & 94 & H.A. Simon & 137 & 166 & 4,415 & 63 & 13 & 212 & 92 \\
\hline Case Western Reserve University & 1,800 & 100 & J.W. Mcelharey & 74 & 244 & 39 & 326 & 0 & 336 & 3 \\
\hline Chalmers University of Technology & 425 & 281 & P.S. Kildal & 311 & 46 & 936 & 185 & 20 & 140 & 150 \\
\hline Charles University & 231 & 322 & J. Raboch & 191 & 108 & 252 & 271 & 7 & 283 & 150 \\
\hline Chinese University of Hong Kong & 952 & 186 & D.T.L. Shek & 226 & 85 & 984 & 177 & 20 & 140 & 103 \\
\hline Chulalongkorn University & 245 & 319 & J. Knodel & 97 & 216 & 789 & 201 & 15 & 186 & 76 \\
\hline City University of Hong Kong & 1,493 & 118 & G.R. Chen & 679 & 2 & 14,752 & 10 & 62 & 10 & 150 \\
\hline City University of New York & 250 & 317 & J.T. Parsons & 121 & 186 & 961 & 181 & 20 & 140 & 150 \\
\hline Colorado State University & 698 & 235 & M.D. Slater & 118 & 190 & 1,295 & 148 & 20 & 140 & 150 \\
\hline Columbia University & 6,308 & 7 & E.R. Kandal & 448 & 16 & 17,020 & 8 & 77 & 5 & 150 \\
\hline Cornell University & 4,281 & 23 & T. Eisner & 198 & 104 & 1,634 & 131 & 17 & 170 & 150 \\
\hline Curtin University of Technology & 1,174 & 159 & D.F. Treagust & 85 & 233 & 604 & 219 & 16 & 175 & 86 \\
\hline Dalhousie University & 1,250 & 147 & W.F. Doolittle & 228 & 82 & 5,968 & 46 & 41 & 41 & 150 \\
\hline Dartmouth College & 1,456 & 123 & R.E. Drake & 435 & 20 & 6,146 & 44 & 46 & 31 & 150 \\
\hline Delft University of Technology & 1,441 & 125 & H. Priemus & 111 & 199 & 351 & 249 & 11 & 237 & 52 \\
\hline Drexel University & 1,045 & 177 & H.D. White & 124 & 180 & 1,722 & 127 & 19 & 151 & 127 \\
\hline Duke University & 3,114 & 39 & M.G. Caron & 213 & 93 & 10,944 & 19 & 73 & 7 & 150 \\
\hline Durham University & 2,001 & 89 & R.Hudson & 65 & 261 & 497 & 232 & 12 & 223 & 31 \\
\hline Ecole Normale Supérieure de Lyon & 92 & 337 & P. Jenson & 53 & 278 & 1,232 & 155 & 15 & 186 & 61 \\
\hline École Normale Supérieure, Paris & 260 & 312 & A. Badiou & 23 & 329 & 22 & 335 & 3 & 322 & 5 \\
\hline École Polytechnique & 209 & 325 & B. Giebels & 108 & 203 & 1,259 & 152 & 29 & 81 & 150 \\
\hline
\end{tabular}




\begin{tabular}{|c|c|c|c|c|c|c|c|c|c|c|}
\hline Ecole Polytechnique Fédérale de Lausanne & 334 & 300 & M. Bierlarie & 40 & 304 & 201 & 283 & 9 & 260 & 62 \\
\hline Eindhoven University of Technology & 710 & 232 & H. Timmermanns & 245 & 75 & 965 & 180 & 15 & 186 & 122 \\
\hline Emory University & 2,131 & 80 & R. Hanzlick & 144 & 159 & 645 & 213 & 11 & 237 & 150 \\
\hline Erasmus University Rotterdam & 1,832 & 96 & P.H. Franses & $\mid 177$ & 124 & 960 & 182 & 18 & 162 & 105 \\
\hline ETH Zurich (Swiss Federal Institute of Technology) & 960 & 184 & K.W. Axhausen & 69 & 253 & 539 & 229 & 11 & 237 & 105 \\
\hline Florida International University & 1,367 & 133 & C.P. Koulamas & 93 & 220 & 678 & 208 & 12 & 223 & 35 \\
\hline Florida State University & 3,026 & 42 & T.E. Joiner & 312 & 45 & 3,695 & 71 & 34 & 61 & 150 \\
\hline Freie Universität Berlin & 1,099 & 170 & W. Saenger & 403 & 24 & 7,926 & 32 & 35 & 57 & 150 \\
\hline Friedrich Alexander Universität Erlangen Nürnberg & 661 & 238 & P. Betz & 150 & 152 & 1,241 & 154 & 15 & 186 & 150 \\
\hline Fudan University & 349 & 298 & Y.F. Zhong & 160 & 139 & 1,150 & 163 & 16 & 175 & 150 \\
\hline Georg August Universität Göttingen & 747 & 222 & A. Rothenberger & 238 & 79 & 1,738 & 124 & 25 & 103 & 150 \\
\hline George Mason University & 884 & 203 & T.B. Kashdan & 75 & 242 & 610 & 217 & 15 & 186 & 106 \\
\hline George Washington University & 2,595 & 60 & A. Etzioni & 123 & 181 & 302 & 261 & 9 & 260 & 28 \\
\hline Georgetown University & 2,694 & 53 & L.O. Gostin & 266 & 65 & 2,078 & 105 & 23 & 119 & 150 \\
\hline Georgia Institute of Technology & 1,512 & 115 & A.D. Fisk & 143 & 160 & 903 & 190 & 13 & 212 & 124 \\
\hline Georgia State University & 2,102 & 84 & M.S. Vaugh & 40 & 304 & 94 & 311 & 7 & 283 & 27 \\
\hline Goteborg University & 807 & 213 & C. Gillberg & 362 & 33 & 6,790 & 41 & 42 & 38 & 150 \\
\hline Harvard University & 5,644 & 10 & W.M. Davis & 237 & 80 & 3,363 & 78 & 33 & 65 & 150 \\
\hline Hebrew University of Jerusalem & 3,067 & 41 & P. Tamir & 43 & 296 & 80 & 318 & 3 & 322 & 34 \\
\hline Heidelberg Universität & 828 & 209 & P.H. Seeburg & 313 & 42 & 16,754 & 9 & 40 & 43 & 150 \\
\hline Hokkaido University & 399 & 287 & P. Stapleton & 17 & 338 & 41 & 325 & 5 & 306 & 4 \\
\hline Hong Kong Polytechnic University & 1,687 & 108 & T.C.E. Cheng & 367 & 32 & 2,060 & 108 & 23 & 119 & 150 \\
\hline Hong Kong University of Science \& Techno... & 625 & 244 & H. Yang & 128 & 178 & 948 & 184 & 20 & 140 & 92 \\
\hline Humboldt-Universität zu Berlin & 190 & 328 & O. Prokop & 181 & 119 & 89 & 312 & 0 & 336 & 139 \\
\hline Imperial College London & 1,336 & 137 & R.B. Noland & 81 & 236 & 383 & 245 & 11 & 237 & 58 \\
\hline Indian Institute of Technology Bombay (I... & 173 & 332 & P.D. Sunavala & 35 & 312 & 11 & 344 & 0 & 336 & 16 \\
\hline Indian Institute of Technology Delhi (II... & 242 & 320 & M.S. Sodha & 438 & 18 & 683 & 207 & 9 & 260 & 150 \\
\hline Indian Institute of Technology Kanpur (I... & 147 & 334 & R.P Singh & 117 & 191 & 471 & 233 & 13 & 212 & 129 \\
\hline Indiana University Bloomington & 5,553 & 12 & B. Cronin & 110 & 200 & 586 & 222 & 12 & 223 & 39 \\
\hline Indiana University Indianapolis & 519 & 256 & W.J. McBride & 313 & 42 & 3,730 & 69 & 38 & 46 & 150 \\
\hline Iowa State University & 926 & 193 & F.X. Gibbons & 128 & 178 & 1,923 & 115 & 27 & 87 & 149 \\
\hline Johns Hopkins University & \begin{tabular}{l|l|}
4,903 \\
\end{tabular} & 15 & S.H. Snyder & 300 & 50 & 14,180 & 11 & 75 & 6 & 150 \\
\hline Kansas State University & 447 & 274 & W.R. Schumm & 114 & 195 & 349 & 251 & 9 & 260 & 131 \\
\hline Katholieke Universiteit Leuven & 2,247 & 75 & J. Poesen & 297 & 52 & 2,357 & 98 & 32 & 66 & 150 \\
\hline Keio University & 482 & 262 & S. Ueda & 163 & 134 & 1,062 & 172 & 19 & 151 & 150 \\
\hline
\end{tabular}




\begin{tabular}{|c|c|c|c|c|c|c|c|c|c|c|}
\hline King Fahd University of Petroleum \& Minerals & 295 & 307 & Z. Khurshid & 21 & 331 & 32 & 329 & 2 & 330 & 4 \\
\hline King Saud University & 306 & 303 & M.A. Eben Saleh & 19 & 335 & 21 & 336 & 3 & 322 & 0 \\
\hline Kobe University & 302 & 306 & Y. Nishizuka & 187 & 113 & 9,115 & 25 & 11 & 237 & 150 \\
\hline Korea Advanced Institute of Science \& Technology & 356 & 296 & S.H. Kim & 58 & 271 & 668 & 209 & 14 & 203 & 69 \\
\hline Korea University & 431 & 277 & C.M. Park & 18 & 336 & 65 & 323 & 4 & 312 & 45 \\
\hline Kyoto University & 979 & 181 & R. Kitamura & 107 & 204 & 1,016 & 173 & 17 & 170 & 81 \\
\hline Kyushu University & 322 & 302 & Y. Tochihara & 72 & 250 & 144 & 297 & 6 & 292 & 132 \\
\hline La Trobe University & 1,435 & 126 & J.P. Arnason & 36 & 310 & 17 & 339 & 3 & 322 & 7 \\
\hline Lancaster University & 1,148 & 163 & E.B. Emerson & 123 & 181 & 1,212 & 159 & 23 & 119 & 150 \\
\hline Leiden University & 1,818 & 98 & H.F. Moed & 69 & 253 & 840 & 197 & 16 & 175 & 42 \\
\hline Linkoping University & 932 & 191 & A.W. Jones & 222 & 89 & 1,090 & 170 & 17 & 170 & 150 \\
\hline London School of Economics and Political Scie & 3,722 & 28 & E. Neumayer & 101 & 208 & 921 & 188 & 19 & 151 & 17 \\
\hline Loughborough University & 2,268 & 73 & C. Oppenheim & 145 & 158 & 551 & 226 & 12 & 223 & 113 \\
\hline Louisiana State University & 973 & 183 & J.L. Matson & 286 & 56 & 1,346 & 144 & 27 & 87 & 150 \\
\hline Ludwig-Maximilians-Universität München & 1,319 & 141 & W. Eisenmenger & 261 & 66 & 1,819 & 119 & 21 & 136 & 150 \\
\hline Lund University & 1,756 & 104 & S. Skertving & 228 & 82 & 3,633 & 73 & 29 & 81 & 150 \\
\hline Maastricht University & 1,607 & 113 & C.P.M. Van Der Vleute & 286 & 56 & 2,430 & 95 & 30 & 76 & 150 \\
\hline Macquarie University & 1,406 & 129 & J. Forrest & 50 & 283 & 244 & 276 & 12 & 223 & 17 \\
\hline Mahidol University & 249 & 318 & B. Panijpan & 58 & 271 & 83 & 317 & 3 & 322 & 85 \\
\hline Masaryk University & 195 & 326 & T.Sirovatka & 13 & 343 & 32 & 329 & 5 & 306 & 4 \\
\hline Massachusetts Institute of Technology & 2,687 & 54 & A. Rich & 337 & 40 & 5,872 & 47 & 32 & 66 & 150 \\
\hline McGill University & 2,888 & 47 & Y. Steinert & 66 & 259 & 599 & 220 & 13 & 212 & 83 \\
\hline McMaster University & 2,387 & 66 & G.R. Noramn & 284 & 59 & 5,532 & 51 & 34 & 61 & 150 \\
\hline Michigan State University & 4,505 & 19 & R.E. Lemski & 161 & 137 & 3,733 & 68 & 38 & 46 & 150 \\
\hline Michigan Technological University & 326 & 301 & M. Hindelang & 12 & 344 & 13 & 342 & 2 & 330 & 4 \\
\hline Monash University & 2,861 & 48 & R. Smyth & 121 & 186 & 324 & 256 & 12 & 223 & 56 \\
\hline Montana State University & 641 & 240 & G.R. Notess & 88 & 226 & 76 & 319 & 4 & 312 & 0 \\
\hline Moscow State University & 426 & 280 & V.E. Tarasov & 86 & 231 & 209 & 282 & 16 & 175 & 3 \\
\hline Nagoya University & 448 & 273 & Y. Katsumata & 196 & 105 & 890 & 194 & 11 & 237 & 150 \\
\hline Nanjing University & 497 & 260 & C. Zhu & 57 & 273 & 85 & 313 & 5 & 306 & 134 \\
\hline Nanyang Technological University & 1,470 & 122 & S.Foo & 75 & 242 & 286 & 263 & 9 & 260 & 58 \\
\hline National Taiwan University & 885 & 202 & J.D. Wang & 183 & 118 & 1,385 & 140 & 19 & 151 & 150 \\
\hline National Tsing Hua University & 405 & 285 & S.L. Hwang & 83 & 234 & 176 & 288 & 6 & 292 & 108 \\
\hline National University of Ireland, Galway & 468 & 267 & S. Grimes & 30 & 321 & 111 & 307 & 6 & 292 & 15 \\
\hline National University of Singapore & 2,980 & 45 & B.S.A. Yeoh & 179 & 121 & 597 & 221 & 18 & 162 & 40 \\
\hline New Mexico State University & 890 & 201 & W.G. Stephan & 56 & 275 & 999 & 175 & 16 & 175 & 16 \\
\hline
\end{tabular}




\begin{tabular}{|c|c|c|c|c|c|c|c|c|c|c|}
\hline New York University & 4,402 & 21 & S.J. Brams & 70 & 251 & 310 & 260 & 9 & 260 & 34 \\
\hline Newcastle University & 2,315 & 71 & P. Healey & 73 & 245 & 935 & 186 & 14 & 203 & 33 \\
\hline North Carolina State University & 1,924 & 93 & M.S. Wogalter & 158 & 141 & 456 & 235 & 10 & 249 & 148 \\
\hline Northeastern University & 1,219 & 151 & W.F. Lider & 45 & 293 & 14 & 341 & 0 & 336 & 32 \\
\hline Northwestern University & 3,772 & 27 & W.R. Leonard & 153 & 148 & 2,063 & 107 & 19 & 151 & 150 \\
\hline Norwegian University of Science \& Technology & 1,143 & 165 & T. Rundmo & 42 & 300 & 354 & 248 & 12 & 223 & 28 \\
\hline Ohio State University & 6,154 & 8 & W.S. Maeras & 247 & 73 & 2,073 & 106 & 26 & 96 & 136 \\
\hline Oklahoma State University & 1,056 & 176 & E.J. Eisenbraun & 123 & 181 & 327 & 255 & 2 & 330 & 150 \\
\hline Open University UK & 2,613 & 58 & A. Hammersley & 59 & 270 & 407 & 241 & 13 & 212 & 4 \\
\hline Oregon State University & 1,345 & 135 & L. Pauling & 251 & 70 & 4,521 & 61 & 0 & 336 & 120 \\
\hline Osaka University & 482 & 262 & T. Kishimoto & 626 & 4 & 44,277 & 2 & 79 & 4 & 150 \\
\hline Peking University & 847 & 206 & Z. Cui & 47 & 289 & 172 & 290 & 9 & 260 & 87 \\
\hline Pennsylvania State University & 6,824 & 4 & R. Roy & 407 & 23 & 3,422 & 77 & 23 & 119 & 150 \\
\hline Pohang University of Science And Technology & 169 & 333 & M.K. Chung & 135 & 168 & 1,297 & 147 & 22 & 129 & 150 \\
\hline Portland State University & 1,040 & 178 & P. Backler & 32 & 317 & 154 & 296 & 8 & 274 & 5 \\
\hline Princeton University & 2,813 & 49 & H.N. Alyea & 107 & 204 & 19 & 337 & 0 & 336 & 6 \\
\hline Purdue University & 3,784 & 26 & G. Salvendy & 208 & 98 & 879 & 195 & 15 & 186 & 150 \\
\hline Queen's University & 1,633 & 112 & A. Skaburskis & 35 & 312 & 135 & 301 & 6 & 292 & 12 \\
\hline Queen's University of Belfast & 1,488 & 120 & J. Wainer & 35 & 312 & 115 & 305 & 6 & 292 & 12 \\
\hline Queensland University of Technology & 1,330 & 139 & C.J. McRobbie & 42 & 300 & 282 & 264 & 9 & 260 & 27 \\
\hline Radboud University, Nijmegen & 2,027 & 87 & L. Verhoeven & 69 & 253 & 142 & 300 & 6 & 292 & 80 \\
\hline Rensselaer Polytechnic Institute & 600 & 248 & H.S. Van Klooster & 43 & 296 & 30 & 332 & 0 & 336 & 8 \\
\hline Rheinisch Westfalische Technische Hochschule Aach & 521 & 255 & H. Luczak & 64 & 262 & 192 & 284 & 6 & 292 & 78 \\
\hline Rheinische Friedrich Wilhelms Universitat Bonn & 903 & 200 & B. Madea & 398 & 26 & 1,549 & 135 & 23 & 119 & 150 \\
\hline Rice University & 784 & 215 & R.E. Smaller & 338 & 39 & 27,011 & 5 & 82 & 2 & 150 \\
\hline Rochester Institute of Technology & 431 & 277 & A.A. Batabyal & 112 & 197 & 176 & 288 & 8 & 274 & 19 \\
\hline Royal Institute of Technology, KTH & 598 & 249 & S.O. Hansson & 119 & 188 & 390 & 242 & 10 & 249 & 48 \\
\hline Royal Melbourne Institute of Technology & 730 & 227 & W. Cartwright & 29 & 323 & 60 & 324 & 3 & 322 & 32 \\
\hline Rutgers & \begin{tabular}{l|}
4,979 \\
\end{tabular} & 13 & G. Buzsaki & 241 & 78 & 8,577 & 28 & 52 & 19 & 150 \\
\hline Saint-Petersburg State University & 122 & 335 & L.N. Moskvin & 194 & 106 & 187 & 285 & 7 & 283 & 150 \\
\hline San Diego State University & 2,014 & 88 & D.A. Fisher & 51 & 282 & 390 & 242 & 8 & 274 & 46 \\
\hline Sapienza University of Rome & 0 & 348 & & 0 & 347 & 0 & 347 & 0 & 336 & 0 \\
\hline Sciences Po Paris & 362 & 295 & P.A. Messerlin & 20 & 334 & 85 & 313 & 3 & 322 & 8 \\
\hline Seoul National University & 734 & 226 & Y. Park & 78 & 241 & 216 & 281 & 10 & 249 & 83 \\
\hline Shanghai Jiao Tong University & 425 & 281 & Z. Haung & 373 & 31 & 925 & 187 & 18 & 162 & 150 \\
\hline Simon Fraser University & 1,973 & 90 & R. Hayter & 52 & 280 & 320 & 257 & 10 & 249 & 19 \\
\hline
\end{tabular}




\begin{tabular}{|c|c|c|c|c|c|c|c|c|c|c|}
\hline Stanford University & 5,594 & 11 & I.L. Weissman & 590 & 5 & 40,038 & 3 & 31 & 70 & 150 \\
\hline State University of New York Buffalo & 183 & 330 & W.F. Wieczorek & 44 & 295 & 662 & 210 & 15 & 186 & 57 \\
\hline Stockholm University & 1,533 & 114 & G. Von Heijne & 251 & 70 & 19,681 & 7 & 53 & 18 & 150 \\
\hline Stony Brook University & 1,407 & 127 & W.L. Jungers & 115 & 194 & 1,324 & 145 & 19 & 151 & 137 \\
\hline Syracuse University & 1,163 & 160 & S.V. Faraone & 701 & 1 & 31,524 & 4 & 80 & 3 & 150 \\
\hline Tartu University (University of Tartu) & 482 & 262 & R. Taagepera & 40 & 304 & 181 & 287 & 9 & 260 & 15 \\
\hline Technical University of Denmark & 370 & 293 & E. Mosekilde & 175 & 127 & 1,124 & 166 & 20 & 140 & 150 \\
\hline Technion & 879 & 204 & Y.J. Dori & 37 & 309 & 247 & 274 & 12 & 223 & 40 \\
\hline Technische Universität Berlin & 580 & 250 & D.C. O'Connell & 62 & 263 & 134 & 302 & 6 & 292 & 46 \\
\hline Technische Universitat Chemnitz & 177 & 331 & B. Nauck & 26 & 328 & 100 & 308 & 7 & 283 & 17 \\
\hline Technische Universität Dresden & 614 & 246 & A. Dannehl & 38 & 308 & 18 & 338 & 2 & 330 & 5 \\
\hline Technische Universität München & 498 & 259 & A. Bacher & 382 & 29 & 3,509 & 75 & 38 & 46 & 150 \\
\hline Tel Aviv University & 2,696 & 52 & E. Kobyliansky & 170 & 130 & 710 & 204 & 15 & 186 & 91 \\
\hline Texas A\&M University & 3,668 & 30 & K.J. Meier & 90 & 224 & 693 & 205 & 18 & 162 & 44 \\
\hline Texas Tech & 632 & 242 & J.J. McGlone & 110 & 200 & 1,128 & 165 & 16 & 175 & 148 \\
\hline Tohoku University & 337 & 299 & Y. Dodo & 30 & 321 & 133 & 303 & 8 & 274 & 74 \\
\hline Tokyo Institute of Technology & 354 & 297 & S. Furui & 171 & 128 & 986 & 176 & 9 & 260 & 134 \\
\hline Trinity College Dublin & 955 & 185 & M .Marsh & 33 & 316 & 157 & 295 & 6 & 292 & 17 \\
\hline Tsinghua University & 934 & 189 & N. Zhao & 138 & 165 & 839 & 198 & 15 & 186 & 150 \\
\hline Tufts University & 1,282 & 144 & J.M. Coffin & 179 & 121 & 4,350 & 65 & 27 & 87 & 150 \\
\hline Universidad Autonoma de Madrid & 744 & 223 & S. Okazaki & 31 & 318 & 143 & 298 & 8 & 274 & 17 \\
\hline Universidad de Chile & 631 & 243 & S.R. Jara-Diaz & 53 & 278 & 262 & 268 & 9 & 260 & 35 \\
\hline Universidad de Granada & 744 & 223 & S. Okazaki & 31 & 318 & 143 & 298 & 8 & 274 & 17 \\
\hline Universidad del País Vasco & 765 & 220 & J. Guisola & 23 & 329 & 84 & 315 & 6 & 292 & 37 \\
\hline Universidad Nacional Autónoma de México ... & 268 & 310 & R. Castro & 29 & 323 & 270 & 267 & 10 & 249 & 64 \\
\hline Universidad Politecnica de Madrid & 495 & 261 & & 0 & 347 & 0 & 347 & 0 & 336 & 0 \\
\hline Universidade de São Paulo & 504 & 257 & R. Zucchi & 80 & 240 & 258 & 269 & 13 & 212 & 74 \\
\hline Universidade Estadual de Campinas & 257 & 314 & P. Dalgalarronodo & 62 & 263 & 257 & 270 & 7 & 283 & 88 \\
\hline Università degli Studi di Firenze & 709 & 233 & I. Bertini & 466 & 14 & 4,681 & 58 & 48 & 25 & 150 \\
\hline Università degli Studi di Padova & 912 & 199 & L. Mason & 27 & 327 & 233 & 280 & 12 & 223 & 10 \\
\hline Universita Di Bologna & 924 & 194 & S. Martello & 81 & 236 & 792 & 200 & 13 & 212 & 41 \\
\hline Universita di Pisa & 90 & 338 & G.B. Cassano & 427 & 21 & 4,758 & 57 & 39 & 44 & 150 \\
\hline Universitat Autonoma de Barcelona & 1,204 & 154 & V. Reyes-Garcia & 61 & 268 & 236 & 279 & 14 & 203 & 90 \\
\hline Universitat Bielefeld & 715 & 231 & A. Angleitner & 57 & 273 & 1,381 & 141 & 20 & 140 & 150 \\
\hline Universität Bremen & 763 & 221 & I. Eilks & 16 & 341 & 35 & 328 & 4 & 312 & 19 \\
\hline Universitat d'Alacant & 468 & 267 & J.L. Nicolau & 21 & 331 & 75 & 320 & 5 & 306 & 4 \\
\hline
\end{tabular}




\begin{tabular}{|c|c|c|c|c|c|c|c|c|c|c|}
\hline Universitat de València & 931 & 192 & C. Botella & 104 & 206 & 448 & 236 & 16 & 175 & 150 \\
\hline Universität Frankfurt am Main & 770 & 218 & J. Glucker & 14 & 342 & 170 & 291 & 7 & 283 & 4 \\
\hline Universität Freiburg & 624 & 245 & A. Renkl & 62 & 263 & 635 & 214 & 15 & 186 & 40 \\
\hline Universitat Hamburg & 261 & 311 & R.S.J. Toi & 154 & 145 & 975 & 179 & 20 & 140 & 103 \\
\hline Universität Karlsruhe & 398 & 288 & J. L. Gomez-Barroso & 21 & 331 & 25 & 334 & 4 & 312 & 16 \\
\hline Universitat Leipzig & 210 & 324 & M.C. Angermeyer & 402 & 25 & 4,426 & 62 & 37 & 50 & 150 \\
\hline Universitat Munster (Westfälische Wilhelms-Un & 193 & 327 & K. Berger & 156 & 143 & 3,113 & 81 & 30 & 76 & 150 \\
\hline Universitat Politecnica de Catalunya & 50 & 346 & F. Carreras & 136 & 167 & 569 & 224 & 11 & 237 & 150 \\
\hline Universität Regensburg & 280 & 309 & K.O. Stetter & 223 & 88 & 5,256 & 54 & 36 & 54 & 150 \\
\hline Universität Stuttgart & 364 & 294 & D. Frisch & 42 & 300 & 98 & 309 & 4 & 312 & 48 \\
\hline Universitat Trier & 286 & 308 & L. Montada & 28 & 325 & 273 & 266 & 7 & 283 & 29 \\
\hline Universität Tübingen & 694 & 236 & N.J. Concard & 42 & 300 & 355 & 247 & 11 & 237 & 93 \\
\hline Universitat Wien (University of Vienna) & 1,138 & 167 & S. Kirchengast & 88 & 226 & 607 & 218 & 14 & 203 & 52 \\
\hline Universitat Zu Koln & 918 & 197 & K. Rajewsky & 202 & 102 & 12,011 & 16 & 72 & 8 & 150 \\
\hline Université Catholique de Louvain & 1,190 & 155 & I. Thomas & 52 & 280 & 377 & 246 & 12 & 223 & 150 \\
\hline Universite de Liege & 478 & 265 & P. Pestieau & 119 & 188 & 635 & 214 & 14 & 203 & 63 \\
\hline Université de Montréal & 2,267 & 74 & R.E. Tremblay & 274 & 63 & 3,939 & 66 & 37 & 50 & 150 \\
\hline Université de Nice Sophia Antipolis & 305 & 304 & G. Quatrehomme & 50 & 283 & 246 & 275 & 10 & 249 & 85 \\
\hline Universite Laval & 1,211 & 152 & G. Godin & 153 & 148 & 2,618 & 90 & 17 & 170 & 150 \\
\hline Universite Libre de Bruxelles & 725 & 228 & J.L. Deneubourg & 153 & 148 & 1,564 & 134 & 26 & 96 & 147 \\
\hline Université Paris Sorbonne & 1,824 & 97 & P. Claval & 81 & 236 & 69 & 322 & 4 & 312 & 2 \\
\hline Universite Paris-Sud 11 & 255 & 315 & Y. Langevin & 141 & 163 & 1,319 & 146 & 24 & 108 & 150 \\
\hline Université Pierre et Marie Curie & 303 & 305 & C.J. Allegre & 304 & 48 & 6,367 & 43 & 36 & 54 & 150 \\
\hline Universiti Malaya (University of Malaya) & 378 & 291 & A.N. Zainab & 17 & 338 & 12 & 343 & 2 & 330 & 12 \\
\hline University College Cork & 442 & 276 & I.J. Perry & 130 & 177 & 5,273 & 53 & 24 & 108 & 150 \\
\hline University College Dublin & 1,080 & 173 & E.J. Conway & 39 & 307 & 11 & 344 & 0 & 336 & 25 \\
\hline University College London & 4,473 & 20 & A. Furnham & 575 & 6 & 7,520 & 34 & 30 & 76 & 150 \\
\hline University do Porto & 110 & 336 & H. Barros & 273 & 64 & 1,770 & 123 & 22 & 129 & 150 \\
\hline University of Aberdeen & 1,970 & 91 & L.J. Whalley & 186 & 114 & 2,440 & 93 & 26 & 96 & 150 \\
\hline University of Adelaide & 1,281 & 145 & R.W. Byard & 189 & 109 & 1,202 & 160 & 14 & 203 & 150 \\
\hline University of Alabama & 3,075 & 40 & M.A. Morrisey & 116 & 192 & 1,075 & 171 & 16 & 175 & 74 \\
\hline University of Alberta & 3,118 & 38 & K.S. Courneya & 224 & 87 & 2,395 & 97 & 37 & 50 & 150 \\
\hline University of Amsterdam & 3,609 & 32 & M.H.W. Frings-Dresen & 148 & 157 & 1,260 & 151 & 22 & 129 & 150 \\
\hline University of Antwerp & 816 & 212 & P. Van Damme & 247 & 73 & 3,054 & 83 & 28 & 85 & 150 \\
\hline University of Arizona & 4,298 & 22 & H.Chen & 282 & 61 & 1,873 & 117 & 27 & 87 & 150 \\
\hline University of Athens & 740 & 225 & S. Vosniadou & 28 & 325 & 656 & 212 & 10 & 249 & 19 \\
\hline
\end{tabular}




\begin{tabular}{|c|c|c|c|c|c|c|c|c|c|c|}
\hline University of Auckland & 2,171 & 79 & R.A. Kearns & 99 & 210 & 891 & 192 & 18 & 162 & 106 \\
\hline University of Barcelona & 978 & 182 & A. Costa & 62 & 263 & 537 & 230 & 17 & 170 & 140 \\
\hline University of Basel & 473 & 266 & H. Reisen & 43 & 296 & 73 & 321 & 4 & 312 & 13 \\
\hline University of Bath & 674 & 237 & C. Eccleston & 110 & 200 & 1,803 & 121 & 29 & 81 & 150 \\
\hline University of Bergen & 532 & 253 & B.R. Hanestad & 96 & 217 & 742 & 202 & 16 & 175 & 108 \\
\hline University of Bern & 260 & 312 & M. Egger & 359 & 34 & 13,308 & 13 & 55 & 15 & 150 \\
\hline University of Birmingham & 3,544 & 34 & J.H. Fremlin & 154 & 145 & 183 & 286 & 0 & 336 & 110 \\
\hline University of Bristol & 2,702 & 51 & R. Johnston & 349 & 35 & 1,215 & 158 & 18 & 162 & 97 \\
\hline University of British Columbia & 2,541 & 61 & E. Wood & 236 & 81 & 1,958 & 113 & 34 & 61 & 150 \\
\hline University of Calgary & 1,153 & 161 & S.B. Patten & 209 & 96 & 2,042 & 111 & 27 & 87 & 150 \\
\hline University of California, Berkley & 3,437 & 35 & S.P. Hinshaw & 142 & 161 & 3,657 & 72 & 38 & 46 & 150 \\
\hline University of California, Davis & 1,503 & 117 & P.R. Shaver & 94 & 219 & 3,122 & 80 & 23 & 119 & 129 \\
\hline University of California, Irvine & 1,647 & 111 & B. Grofman & 131 & 174 & 549 & 227 & 11 & 237 & 64 \\
\hline University of California, Los Angeles & 8,606 & 2 & J.M. Diamond & 184 & 116 & 2,956 & 87 & 22 & 129 & 88 \\
\hline University of California, Riverside & 1,352 & 134 & S. Bowler & 48 & 288 & 281 & 265 & 9 & 260 & 33 \\
\hline University of California, San Diego & 1,188 & 156 & M.B. Stein & 347 & 36 & 6,661 & 42 & 47 & 28 & 150 \\
\hline University of California, San Francisco & 1,375 & 131 & C. Harrington & 149 & 155 & 1,103 & 169 & 23 & 119 & 141 \\
\hline University of California, Santa Barbara & 1,375 & 131 & D.M. Mackie & 60 & 269 & 1,191 & 162 & 10 & 249 & 58 \\
\hline University of California, Santa Cruz & 466 & 269 & B. Sinervo & 73 & 245 & 1,603 & 133 & 26 & 96 & 67 \\
\hline University of Cambridge & 1,840 & 95 & S. Baron-Cohen & 226 & 85 & 5,534 & 50 & 49 & 24 & 150 \\
\hline University of Canterbury & 464 & 270 & J. Pearce & 49 & 286 & 238 & 277 & 10 & 249 & 47 \\
\hline University of Cape Town & 769 & 219 & A.J. Flisher & 159 & 140 & 1,373 & 142 & 22 & 129 & 150 \\
\hline University of Central Florida & 1,773 & 102 & M.A. Abdel-Aty & 142 & 161 & 657 & 211 & 15 & 186 & 90 \\
\hline University of Chicago & 4,717 & 17 & C.R. Sunstein & 150 & 152 & 1,220 & 157 & 19 & 151 & 48 \\
\hline University of Cincinnati & 2,361 & 67 & R.E. Oesper & 162 & 136 & 38 & 327 & 0 & 336 & 41 \\
\hline University of Colorado at Boulder & 1,392 & 130 & S.F. Maier & 308 & 47 & 7,066 & 40 & 54 & 16 & 150 \\
\hline University of Connecticut & 1,454 & 124 & H. Tennen & 178 & 123 & 3,917 & 67 & 31 & 70 & 150 \\
\hline University of Copenhagen & 781 & 217 & K. Avlund & 102 & 207 & 918 & 189 & 21 & 136 & 137 \\
\hline University of Delaware & 723 & 229 & J.A. Inciardi & 163 & 134 & 1,816 & 120 & 22 & 129 & 150 \\
\hline University of Dundee & 1,179 & 158 & R.M. Harden & 189 & 109 & 1,951 & 114 & 27 & 87 & 150 \\
\hline University of Edinburgh & 1,492 & 119 & I.J. Deary & 506 & 9 & 11,172 & 18 & 47 & 28 & 150 \\
\hline University of Florida & 4,023 & 24 & K.R. Wiliams & 73 & 245 & 238 & 277 & 7 & 283 & 71 \\
\hline University of Geneva & 397 & 289 & T.V. Perneger & 243 & 76 & 7,443 & 37 & 41 & 41 & 150 \\
\hline University of Georgia & 2,096 & 85 & R. Forehand & 284 & 59 & 3,046 & 84 & 25 & 103 & 150 \\
\hline University of Ghent & 639 & 241 & G. Crombez & 170 & 130 & 2,299 & 99 & 34 & 61 & 150 \\
\hline University of Glasgow & 2,634 & 57 & C. Hough & 47 & 289 & 15 & 340 & 2 & 330 & 0 \\
\hline
\end{tabular}




\begin{tabular}{|c|c|c|c|c|c|c|c|c|c|c|}
\hline University of Gothenburg & 66 & 343 & H. Haberg & 222 & 89 & 4,919 & 56 & 43 & 33 & 150 \\
\hline University of Groningen & 923 & 195 & J. Ormel & 296 & 53 & 7,711 & 33 & 43 & 33 & 150 \\
\hline University of Helsinki & 2,104 & 83 & H. Summala & 73 & 245 & 958 & 183 & 20 & 140 & 67 \\
\hline University of Hong Kong & 995 & 179 & T.H. Lam & 344 & 37 & 3,699 & 70 & 31 & 70 & 150 \\
\hline University of Houston & 849 & 205 & P.J. Norton & 55 & 277 & 611 & 216 & 15 & 186 & 84 \\
\hline University of Illinois & 7,585 & 3 & G.A. Miller & 73 & 245 & 2 & 346 & 0 & 336 & 0 \\
\hline University of Illinois, Chicago & 3,681 & 29 & H.J. Walberg & 86 & 231 & 440 & 237 & 6 & 292 & 93 \\
\hline University of Indonesia & 90 & 338 & C. Podhisita & 18 & 336 & 252 & 271 & 4 & 312 & 36 \\
\hline University of Iowa & 1,340 & 136 & D. Tranel & 211 & 95 & 8,137 & 29 & 43 & 33 & 150 \\
\hline University of Kansas & 1,334 & 138 & C.R. Snyder & 122 & 184 & 1,506 & 136 & 20 & 140 & 149 \\
\hline University of Kentucky & 1,310 & 142 & C. Leukefeld & 209 & 96 & 1,451 & 138 & 21 & 136 & 150 \\
\hline University of Lausanne & 240 & 321 & L. Keller & 186 & 114 & 2,917 & 88 & 36 & 54 & 150 \\
\hline University of Leeds & 1,702 & 106 & M.Conner & 131 & 174 & 2,046 & 110 & 31 & 70 & 150 \\
\hline University of Leicester & 1,696 & 107 & C.C. Williams & 113 & 196 & 330 & 253 & 11 & 237 & 15 \\
\hline University of Liverpool & 933 & 190 & P. Salmon & 151 & 151 & 1,720 & 128 & $25 \mid$ & 103 & 150 \\
\hline University of Ljubljana & 986 & 180 & K. Erjavec & 17 & 338 & 30 & 332 & 4 & 312 & 6 \\
\hline University of London (Kings College of London) & 19,732 & 1 & A. Furnham & 502 & 10 & 6,058 & 45 & 32 & 66 & 150 \\
\hline University of Manchester & 4,944 & 14 & A.G. Lyne & 254 & 69 & 3,550 & 74 & 42 & 38 & 150 \\
\hline University of Manitoba & 1,801 & 99 & N.P. Roos & 122 & 184 & 1,684 & 130 & 13 & 212 & 124 \\
\hline University of Maryland & 4,795 & 16 & V. Trimble & 87 & 229 & 251 & 273 & 6 & 292 & 33 \\
\hline University of Maryland Baltimore County & 1,794 & 101 & M.D. Weist & 87 & 229 & 802 & 199 & 15 & 186 & 145 \\
\hline University of Massachusetts & 1,117 & 168 & G.J. De Vries & 92 & 221 & 2,098 & 104 & 24 & 108 & 124 \\
\hline University of Melbourne & 3,320 & 36 & I. Williamson & 134 & 169 & 330 & 253 & 10 & 249 & 92 \\
\hline University of Miami & 918 & 197 & C.S. Carver & 157 & 142 & 8,589 & 27 & 31 & 70 & 150 \\
\hline University of Michigan & 4,576 & 18 & N. Krause & 168 & 133 & 2,519 & 92 & 22 & 129 & 96 \\
\hline University of Minnesota & 2,891 & 46 & W.G. Lacono & 300 & 50 & 4,628 & 60 & 39 & 44 & 150 \\
\hline University of Missouri & 2,304 & 72 & K.J. Sher & 149 & 155 & 3,099 & 82 & 29 & 81 & 150 \\
\hline University of Nebraska & 2,247 & 75 & D.W. Brooks & 67 & 258 & 121 & 304 & 5 & 306 & 101 \\
\hline University of New Hampshire & 820 & 211 & D. Finkelhor & 140 & 164 & 5,112 & 55 & 26 & 96 & 50 \\
\hline University of New Mexico & 2,037 & 86 & W.R. Miller & 481 & 11 & 9,250 & 24 & 48 & 25 & 150 \\
\hline University of New South Wales & 1,320 & 140 & G. Parker & 417 & 22 & 5,784 & 48 & 30 & 76 & 150 \\
\hline University of North Carolina, Chapel Hill & 5,906 & 9 & G.H. Elder & 99 & 210 & 2,421 & 96 & 24 & 108 & 91 \\
\hline University of North Texas & 1,236 & 149 & B. Hayslip & 99 & 210 & 436 & 238 & 10 & 249 & 124 \\
\hline University of Notre Dame & 603 & 247 & E.M. Cummings & 112 & 197 & 1,738 & 124 & 18 & 162 & 97 \\
\hline University of Nottingham & 1,407 & 127 & M. Wright & 199 & 103 & 1,841 & 118 & 28 & 85 & 150 \\
\hline University of Oklahoma & 831 & 207 & M.D. Mumford & 116 & 192 & 977 & 178 & 20 & 140 & 121 \\
\hline
\end{tabular}




\begin{tabular}{|c|c|c|c|c|c|c|c|c|c|c|}
\hline University of Oregon & 2,105 & 82 & B.W. Matthews & 302 & 49 & 9,262 & 23 & 37 & 50 & 150 \\
\hline University of Oslo & 1,076 & 174 & A.A. Dahl & 188 & 112 & 2,915 & 89 & 27 & 87 & 150 \\
\hline University of Otago & 791 & 214 & D.M. Fergusson & 341 & 38 & 7,992 & 30 & 51 & 21 & 150 \\
\hline University of Ottawa & 823 & 210 & P. Firestone & 62 & 263 & 891 & 192 & 12 & 223 & 100 \\
\hline University of Oxford & 2,776 & 50 & D.W. MacDonald & 383 & 28 & 4,366 & 64 & 35 & 57 & 150 \\
\hline University of Pennsylvania & 2,680 & 55 & E.B. Foa & 260 & 67 & 7,431 & 39 & 43 & 33 & 150 \\
\hline University of Pittsburgh & 1,751 & 105 & E. Frank & 393 & 27 & 10,100 & 22 & 54 & 16 & 150 \\
\hline University of Quebec & 504 & 257 & J.P. Despres & 524 & 7 & 22,828 & 6 & 60 & 11 & 150 \\
\hline University of Queensland & 1,655 & 109 & J.M. Najman & 184 & 116 & 2,194 & 101 & 24 & 108 & 150 \\
\hline University of Reading & 1,651 & 110 & A. Swinbank & 31 & 318 & 96 & 310 & 6 & 292 & 18 \\
\hline University of Rochester & 723 & 229 & R.M. Ryan & 131 & 174 & 5,644 & 49 & 35 & 57 & 127 \\
\hline University of Saskatchewan & 1,112 & 169 & C.K. Leong & 46 & 291 & 158 & 294 & 6 & 292 & 22 \\
\hline University of Science and Technology of China & 254 & 316 & W. Fan & 250 & 72 & 1,628 & 132 & 26 & 96 & 150 \\
\hline University of Sheffield & 3,827 & 25 & D.W. Hughes & 189 & 109 & 848 & 196 & 14 & 203 & 150 \\
\hline University of South Carolina & 2,612 & 59 & R.F. Valois & 98 & 214 & 1,469 & 137 & 18 & 162 & 150 \\
\hline University of South Florida & 2,505 & 62 & J.K. Thompson & 133 & 172 & 2,033 & 112 & 26 & 96 & 150 \\
\hline University of Southampton & 1,144 & 164 & D.J.P. Barker & 457 & 15 & 13,718 & 12 & 65 & 9 & 150 \\
\hline University of Southern California & 1,763 & 103 & S. Sussman & 203 & 100 & 2,147 & 103 & 24 & 108 & 150 \\
\hline University of St Andrews & 373 & 292 & D.I. Perrett & 331 & 41 & 7,439 & 38 & 44 & 32 & 150 \\
\hline University of Surrey & 646 & 239 & S. Arber & 69 & 253 & 1,124 & 166 & 16 & 175 & 68 \\
\hline University of Sussex & 2,395 & 65 & C. Abraham & 70 & 251 & 1,288 & 149 & 19 & 151 & 88 \\
\hline University of Sydney & 3,128 & 37 & D.A. Hensher & 203 & 100 & 1,243 & 153 & 19 & 151 & 128 \\
\hline University of Technology, Sydney & 405 & 285 & S.R. Clegg & 68 & 257 & 408 & 240 & 15 & 186 & 54 \\
\hline University of Tennessee Knoxville & 1,061 & 175 & J.W. Lounsbury & 50 & 283 & 317 & 258 & 9 & 260 & 69 \\
\hline University of Texas at Austin & 2,678 & 56 & C.G. Ellison & 90 & 224 & 1,711 & 129 & 23 & 119 & 119 \\
\hline University of Tokyo & 452 & 272 & M. Ishizuka & 213 & 93 & 459 & 234 & 12 & 223 & 150 \\
\hline University of Toronto & 6,812 & 5 & T.W. Mak & 635 & 3 & 47,418 & 1 & 99 & 1 & 150 \\
\hline University of Tsukuba & 184 & 329 & H. Iso & 192 & 107 & 2,440 & 93 & 24 & 108 & 150 \\
\hline University of Twente & 383 & 290 & A. Nijholt & 95 & 218 & 169 & 293 & 7 & 283 & 102 \\
\hline University of Utah & 2,127 & 81 & T.E. Cerling & 132 & 173 & 3,503 & 76 & 31 & 70 & 150 \\
\hline University of Vermont & 1,229 & 150 & M.F. Giangreco & 36 & 310 & 339 & 252 & 9 & 260 & 21 \\
\hline University of Victoria & 831 & 207 & W.M. Roth & 228 & 82 & 1,109 & 168 & 24 & 108 & 109 \\
\hline University of Virginia & 1,095 & 171 & R.C. Pianta & 150 & 152 & 1,356 & 143 & 25 & 103 & 135 \\
\hline University of Warwick & 1,210 & 153 & S. Joseph & 155 & 144 & 2,188 & 102 & 21 & 136 & 139 \\
\hline University of Washington & 6,659 & 6 & R.D. Palmiter & 291 & 54 & 12,644 & 14 & 50 & 23 & 150 \\
\hline University of Waterloo & 1,187 & 157 & G.T. Fong & 83 & 234 & 1,725 & 126 & 24 & 108 & 147 \\
\hline
\end{tabular}




\begin{tabular}{|c|c|c|c|c|c|c|c|c|c|c|}
\hline University of Western Australia & 1,143 & 165 & P.W. Miller & 81 & 236 & 385 & 244 & 11 & 237 & 24 \\
\hline University of Western Ontario & 2,181 & 77 & L. Vaughan & 43 & 296 & 350 & 250 & 13 & 212 & 25 \\
\hline University of Wisconsin & 3,652 & 31 & R.J. Davidson & 256 & 68 & 8,621 & 26 & 51 & 21 & 150 \\
\hline University of Wollongong & 411 & 283 & P.C.L. Heaven & 100 & 209 & 546 & 228 & 12 & 223 & 77 \\
\hline University of York & 1,090 & 172 & P. Sloper & 88 & 226 & 1,011 & 174 & 15 & 186 & 84 \\
\hline University of Zurich & 447 & 274 & H.C. Steinhausen & 290 & 55 & 2,543 & 91 & 24 & 108 & 150 \\
\hline Univesitas Gadjah Mada & 72 & 342 & E. Indriati & 7 & 346 & 170 & 291 & 5 & 306 & 25 \\
\hline Uppsala University & 702 & 234 & G. Andersson & 176 & 126 & 1,276 & 150 & 27 & 87 & 150 \\
\hline Utah State & 406 & 284 & E.M. Gese & 56 & 275 & 574 & 223 & 14 & 203 & 50 \\
\hline Utrecht University & 3,019 & 43 & T. Schwanen & 46 & 291 & 301 & 262 & 13 & 212 & 19 \\
\hline Vanderbilt University & 1,149 & 162 & J. Garber & 286 & 56 & 10,812 & 20 & 57 & 13 & 150 \\
\hline Victoria University of Wellington & 1,265 & 146 & T.J. Ward & 161 & 137 & 1,192 & 161 & 27 & 87 & 126 \\
\hline Vienna University of Technology & 48 & 347 & G. Feichtinger & 134 & 169 & 417 & 239 & 8 & 274 & 65 \\
\hline Virginia Polytechnic Institute & 948 & 187 & T.H. Ollendick & 208 & 98 & 3,187 & 79 & 24 & 108 & 150 \\
\hline Vrije Universiteit, Brussels & 545 & 252 & J.P. Clarys & 66 & 259 & 529 & 231 & 8 & 274 & 92 \\
\hline VU University Amsterdam & 2,466 & 63 & P. Nijkamp & 436 & 19 & 1,911 & 116 & 19 & 151 & 150 \\
\hline Wageningen University & 461 & 271 & W.A. Van Staveren & 276 & 62 & 5,521 & 52 & 35 & 57 & 150 \\
\hline Wake Forest University & 427 & 279 & T.A. Arcury & 169 & 132 & 1,137 & 164 & 23 & 119 & 150 \\
\hline Waseda University & 82 & 340 & A. Takanishi & 243 & 76 & 903 & 190 & 15 & 186 & 150 \\
\hline Washington State University & 923 & 195 & A.T. Church & 45 & 293 & 730 & 203 & 14 & 203 & 49 \\
\hline Washington University in St. Louis & 2,180 & 78 & J.I. Gordon & 378 & 30 & 12,508 & 15 & 59 & 12 & 150 \\
\hline Wayne State University & 2,356 & 68 & M.Goodman & 177 & 124 & 3,040 & 85 & 30 & 76 & 150 \\
\hline West Virginia University & 59 & 345 & B. Stanton & 222 & 89 & 2,202 & 100 & 23 & 119 & 150 \\
\hline Yale University & 1,959 & 92 & R.A. Rosenheck & 520 & 8 & 11,834 & 17 & 52 & 19 & 150 \\
\hline Yonsei University & 229 & 323 & S.Y. Sohn & 99 & 210 & 311 & 259 & 11 & 237 & 67 \\
\hline York University & 1,293 & 143 & R.J. Burke & 216 & 92 & 1,225 & 156 & 16 & 175 & 150 \\
\hline Zhejiang University & 76 & 341 & J. Gao & 91 & 223 & 84 & 315 & 4 & 312 & 83 \\
\hline
\end{tabular}




\begin{tabular}{|c|c|c|c|c|c|c|c|c|c|c|}
\hline Psychology Data & $\begin{array}{l}\text { Department } \\
\text { Publications }\end{array}$ & Rank & Most Prolific Author & Published & Rank & Cited & Rank & $\begin{array}{c}\text { H- } \\
\text { Index }\end{array}$ & Rank & $\begin{array}{c}\text { \# of } \\
\text { Coauthors }\end{array}$ \\
\hline Aalto University & 147 & 295 & R.Hari & 301 & 56 & 7,650 & 27 & 48 & 23 & 150 \\
\hline Aarhus University & 902 & 149 & R. Zachariae & 74 & 272 & 874 & 242 & 18 & 215 & 145 \\
\hline Arizonia State University & 2,206 & 51 & N. Eisenberg & 181 & 135 & 2,995 & 113 & 32 & 85 & 150 \\
\hline Ateneo de Manila University & 10 & 344 & C.J. Montiel & 10 & 340 & 32 & 334 & 3 & 333 & 8 \\
\hline Auburn University & 1,084 & 118 & G.S. Pettit & 89 & 250 & 3,559 & 89 & 35 & 66 & 99 \\
\hline Australian National University & 839 & 162 & A.F. Jorm & 377 & 31 & 9,730 & 13 & 47 & 27 & 150 \\
\hline Boston College & 920 & 148 & J.R. Mahalik & 49 & 305 & 661 & 262 & 14 & 258 & 55 \\
\hline Boston University & 2,946 & 29 & D.H. Barlow & 172 & 144 & 4,625 & 64 & 35 & 66 & 150 \\
\hline Brandeis University & 598 & 209 & A. Wingfield & 106 & 223 & 1,108 & 219 & 16 & 236 & 113 \\
\hline Brigham Young University & 796 & 173 & E.D. Bigler & 224 & 103 & 2,421 & 144 & 26 & 139 & 150 \\
\hline Brown University & 2,619 & 37 & M.B. Keller & 448 & 16 & 15,203 & 7 & 63 & 10 & 150 \\
\hline California Institute of Technology (Calt... & 214 & 281 & H.A. Lester & 287 & 65 & 7,664 & 25 & 44 & 35 & 150 \\
\hline Cardiff University & 1,923 & 63 & D.M. Jones & 88 & 255 & 844 & 244 & 23 & 172 & 53 \\
\hline Carnegie Mellon University & 1,579 & 88 & J.R. Anderson & 164 & 156 & 4,220 & 70 & 25 & 146 & 120 \\
\hline Case Western Reserve University & 1,710 & 81 & D. Drotar & 249 & 83 & 2,597 & 134 & 27 & 126 & 150 \\
\hline Chalmers University of Technology & 63 & 317 & D. Vasttjall & 14 & 337 & 20 & 340 & 4 & 328 & 23 \\
\hline Charles University & 121 & 302 & P. Bob & 53 & 301 & 98 & 328 & 7 & 310 & 59 \\
\hline Chinese University of Hong Kong & 1,015 & 127 & D.T.L. Shek & 226 & 101 & 984 & 230 & 20 & 193 & 103 \\
\hline Chulalongkorn University & 51 & 324 & S. Shuangshoti & 144 & 181 & 595 & 273 & 6 & 318 & 107 \\
\hline City University of Hong Kong & 369 & 254 & S.T. Cheng & 48 & 306 & 302 & 307 & 11 & 284 & 15 \\
\hline City University of New York & 2,166 & 52 & A. Sclafani & 311 & 54 & 2,184 & 153 & 27 & 126 & 150 \\
\hline Colorado State University & 706 & 188 & J.L. Deffenbacher & 81 & 267 & 841 & 245 & 20 & 193 & 91 \\
\hline Columbia University & 5,163 & 6 & E.R. Kandal & 448 & 16 & 17,020 & 6 & 77 & 2 & 150 \\
\hline Cornell University & 3,222 & 20 & S.J. Ceci & 116 & 205 & 2,977 & 115 & 18 & 215 & 112 \\
\hline Curtin University of Technology & 332 & 258 & J.P. Pick & 51 & 302 & 496 & 283 & 13 & 268 & 57 \\
\hline Dalhousie University & 1,218 & 110 & S.H. Stewart & 162 & 158 & 1,936 & 167 & 32 & 85 & 150 \\
\hline Dartmouth College & 1,122 & 116 & K.T. Muesar & 260 & 80 & 6,110 & 42 & 50 & 21 & 150 \\
\hline Delft University of Technology & 205 & 283 & J.W. De Leeuw & 342 & 42 & 4,603 & 65 & 30 & 101 & 150 \\
\hline Drexel University & 1,198 & 113 & B. Yang & 91 & 246 & 194 & 319 & 7 & 310 & 27 \\
\hline Duke University & 3,608 & 15 & K. Dodge & 211 & 114 & 8,925 & 16 & 54 & 14 & 150 \\
\hline Durham University & 642 & 199 & J.M. Findlay & 79 & 269 & 1,851 & 171 & 17 & 228 & 81 \\
\hline Ecole Normale Supérieure de Lyon & 33 & 335 & & 0 & 345 & 0 & 344 & 0 & 343 & 0 \\
\hline École Normale Supérieure, Paris & 72 & 314 & A.C. Bachoud-Levi & 64 & 286 & 895 & 237 & 19 & 205 & 150 \\
\hline École Polytechnique & 48 & 325 & & 0 & 345 & 0 & 344 & 0 & 343 & 0 \\
\hline
\end{tabular}




\begin{tabular}{|c|c|c|c|c|c|c|c|c|c|c|}
\hline Ecole Polytechnique Fédérale de Lausanne & 79 & 313 & O. Blanke & 91 & 246 & 888 & 239 & 19 & 205 & 116 \\
\hline Eindhoven University of Technology & 218 & 280 & F.G. Kaiser & 39 & 318 & 370 & 298 & 13 & 268 & 76 \\
\hline Emory University & 2,413 & 45 & C.B. Nemeroff & 702 & 3 & 18,480 & 5 & 69 & 5 & 150 \\
\hline Erasmus University Rotterdam & 1,642 & 84 & F.C. Verhulst & 361 & 34 & 4,132 & 74 & 35 & 66 & 150 \\
\hline ETH Zurich (Swiss Federal Institute of Technology) & 264 & 274 & J. Feldon & 344 & 41 & 5,132 & 56 & 48 & 23 & 150 \\
\hline Florida International University & 951 & 140 & W.K. Silverman & 109 & 217 & 2,073 & 159 & 26 & 139 & 125 \\
\hline Florida State University & 1,728 & 78 & T.E. Joiner & 312 & 53 & 3,695 & 85 & 34 & 74 & 150 \\
\hline Freie Universität Berlin & 921 & 146 & R. Schwarzer & 99 & 233 & 994 & 228 & 21 & 183 & 95 \\
\hline Friedrich Alexander Universität Erlangen Nürnberg & 592 & 211 & P. Wuhr & 37 & 319 & 217 & 314 & 11 & 284 & 19 \\
\hline Fudan University & 63 & 317 & L.Y. Lin & 236 & 94 & 665 & 258 & 14 & 258 & 150 \\
\hline Georg August Universität Göttingen & 927 & 145 & A. Rothenberger & 238 & 92 & 1,738 & 176 & 25 & 146 & 150 \\
\hline George Mason University & 660 & 196 & T.B. Kashdan & 75 & 271 & 610 & 269 & 15 & 246 & 106 \\
\hline George Washington University & 972 & 135 & D. Riess & 98 & 235 & 1,441 & 191 & 20 & 193 & 126 \\
\hline Georgetown University & 672 & 192 & N.J. Finkel & 35 & 320 & 173 & 322 & 6 & 318 & 30 \\
\hline Georgia Institute of Technology & 837 & 163 & T.A. Salthouse & 156 & 166 & 3,573 & 88 & 27 & 126 & 80 \\
\hline Georgia State University & 1,446 & 99 & D.A. Washburn & 89 & 250 & 565 & 275 & 13 & 268 & 76 \\
\hline Goteborg University & 672 & 192 & C. Gillberg & 362 & 33 & 6,790 & 36 & 42 & 41 & 150 \\
\hline Harvard University & 2,936 & 30 & D.L. Schacter & 281 & 72 & 9,351 & 14 & 59 & 11 & 150 \\
\hline Hebrew University of Jerusalem & 1,640 & 85 & I. Gati & 63 & 288 & 483 & 285 & 10 & 289 & 41 \\
\hline Heidelberg Universität & 176 & 289 & J. Schroeter & 169 & 150 & 2,243 & 150 & 25 & 146 & 150 \\
\hline Hokkaido University & 351 & 256 & T. Yamagish & 106 & 223 & 1,600 & 183 & 14 & 258 & 150 \\
\hline Hong Kong Polytechnic University & 307 & 265 & H.W.H. Tsang & 61 & 293 & 365 & 299 & 12 & 278 & 76 \\
\hline Hong Kong University of Science \& Techno... & 180 & 286 & R.S. Wyer & 125 & 197 & 1,832 & 172 & 14 & 258 & 135 \\
\hline Humboldt-Universität zu Berlin & 262 & 275 & H. Flot & 214 & 108 & 5,673 & 48 & 41 & 44 & 150 \\
\hline Imperial College London & 670 & 194 & S.A. Montgomery & 286 & 66 & 7,179 & 34 & 31 & 95 & 150 \\
\hline Indian Institute of Technology Bombay (I... & 13 & 342 & P. Rao & 20 & 332 & 87 & 331 & 3 & 333 & 19 \\
\hline Indian Institute of Technology Delhi (II... & 15 & 341 & G.S. Sekhon & 149 & 174 & 1,152 & 216 & 11 & 284 & 150 \\
\hline Indian Institute of Technology Kanpur (I... & 25 & 338 & B. Bhushan & 9 & 341 & 23 & 339 & 3 & 333 & 13 \\
\hline Indiana University Bloomington & 3,016 & 25 & L.B. Smith & 106 & 223 & 1,201 & 208 & 20 & 193 & 59 \\
\hline Indiana University Indianapolis & 634 & 202 & P.H. Lysaker & 155 & 168 & 1,715 & 180 & 29 & 112 & 150 \\
\hline Iowa State University & 1,067 & 121 & F.X. Gibbons & 128 & 195 & 1,923 & 168 & 27 & 126 & 149 \\
\hline Johns Hopkins University & 4,402 & 8 & S.H. Snyder & 300 & 57 & 14,180 & 9 & 75 & 3 & 150 \\
\hline Kansas State University & 466 & 239 & W.R. Schumm & 114 & 207 & 349 & 300 & 9 & 302 & 131 \\
\hline Katholieke Universiteit Leuven & 1,561 & 90 & P. Eelen & 101 & 231 & 1,306 & 200 & 27 & 126 & 76 \\
\hline Keio University & 331 & 259 & $\overline{\text { G. Yagi }}$ & 105 & 226 & 1,252 & 204 & 15 & 246 & 150 \\
\hline
\end{tabular}




\begin{tabular}{|c|c|c|c|c|c|c|c|c|c|c|}
\hline King Fahd University of Petroleum \& Minerals & 29 & 337 & M. Achoui & 8 & 342 & 28 & 336 & 4 & 328 & 12 \\
\hline King Saud University & 37 & 331 & S.A. Al-Shammari & 47 & 309 & 285 & 308 & 6 & 318 & 64 \\
\hline Kobe University & 132 & 297 & K. Maeda & 240 & 89 & 2,765 & 125 & 24 & 158 & 150 \\
\hline Korea Advanced Institute of Science \& Technology & 63 & 317 & C.K. Un & 210 & 115 & 597 & 272 & 3 & 333 & 150 \\
\hline Korea University & 135 & 296 & Y.K. Kim & 236 & 94 & 1,567 & 185 & 24 & 158 & 150 \\
\hline Kyoto University & 726 & 183 & M. Tomonaga & 72 & 275 & 383 & 297 & 13 & 268 & 72 \\
\hline Kyushu University & 443 & 246 & N. Tashiro & 109 & 217 & 1,176 & 213 & 20 & 193 & 150 \\
\hline La Trobe University & 780 & 174 & P. Maruff & 178 & 137 & 2,776 & 123 & 35 & 66 & 150 \\
\hline Lancaster University & 611 & 205 & C. Hatton & 133 & 188 & 1,866 & 170 & 24 & 158 & 150 \\
\hline Leiden University & 2,083 & 53 & P. Spinhoven & 213 & 111 & 3,462 & 95 & 32 & 85 & 150 \\
\hline Linkoping University & 570 & 214 & G. Andersson & 176 & 140 & 1,326 & 199 & 27 & 126 & 150 \\
\hline London School of Economics and Political Scie & 472 & 237 & M.R.J. Knapp & 240 & 89 & 3,887 & 78 & 38 & 53 & 150 \\
\hline Loughborough University & 607 & 206 & D. Cramer & 54 & 300 & 168 & 323 & 7 & 310 & 15 \\
\hline Louisiana State University & 1,300 & 109 & J.L. Matson & 286 & 66 & 1,346 & 197 & 27 & 126 & 150 \\
\hline Ludwig-Maximilians-Universität München & 1,762 & 73 & H.J. Moller & 792 & 1 & 14,781 & 8 & 53 & 17 & 150 \\
\hline Lund University & 942 & 142 & L. Gustafon & 178 & 137 & 2,762 & 126 & 19 & 205 & 150 \\
\hline Maastricht University & 2,241 & 49 & H. Merckelelbach & 346 & 38 & 2,780 & 122 & 33 & 82 & 150 \\
\hline Macquarie University & 1,082 & 119 & R.M. Rapee & 148 & 177 & 3,290 & 101 & 28 & 121 & 150 \\
\hline Mahidol University & 53 & 322 & N.J. White & 772 & 2 & 28,485 & 2 & 68 & 6 & 150 \\
\hline Masaryk University & 71 & 316 & D. Smahel & 11 & 339 & 32 & 334 & 3 & 333 & 8 \\
\hline Massachusetts Institute of Technology & 1,089 & 117 & A. Rich & 337 & 46 & 5,872 & 44 & 32 & 85 & 150 \\
\hline McGill University & 3,354 & 18 & R.O. Pihl & 226 & 101 & 3,514 & 90 & 27 & 126 & 150 \\
\hline McMaster University & 1,831 & 71 & D. Elloitt & 143 & 182 & 833 & 247 & 19 & 205 & 107 \\
\hline Michigan State University & 2,869 & 32 & N. Schmitt & 113 & 210 & 1,812 & 173 & 21 & 183 & 144 \\
\hline Michigan Technological University & 38 & 330 & W.S. Helton & 25 & 330 & 94 & 330 & 8 & 306 & 23 \\
\hline Monash University & 1,348 & 105 & J.L. Bradshaw & 296 & 60 & 3,514 & 90 & 30 & 101 & 150 \\
\hline Montana State University & 207 & 282 & R.A. Block & 30 & 328 & 504 & 281 & 9 & 302 & 27 \\
\hline Moscow State University & 517 & 224 & E.N. Sokolov & 162 & 158 & 401 & 295 & 7 & 310 & 119 \\
\hline Nagoya University & 599 & 208 & T. Hatta & 149 & 174 & 409 & 294 & 7 & 310 & 150 \\
\hline Nanjing University & 11 & 343 & L. Wang & 153 & 170 & 1,055 & 223 & 19 & 205 & 150 \\
\hline Nanyang Technological University & 291 & 268 & R.P. Ang & 51 & 302 & 115 & 326 & 5 & 323 & 57 \\
\hline National Taiwan University & 386 & 251 & H. Hwu & 113 & 210 & 3,295 & 100 & 22 & 177 & 150 \\
\hline National Tsing Hua University & 89 & 309 & H.C. Wang & 85 & 258 & 276 & 311 & 8 & 306 & 70 \\
\hline National University of Ireland, Galway & 275 & 273 & B.E. Leonard & 381 & 29 & 3,487 & 93 & 33 & 82 & 150 \\
\hline National University of Singapore & 636 & 201 & R. Singh & 96 & 236 & 447 & 291 & 15 & 246 & 101 \\
\hline New Mexico State University & 522 & 222 & D. Trafimow & 89 & 250 & 1,046 & 224 & 17 & 228 & 80 \\
\hline
\end{tabular}




\begin{tabular}{|c|c|c|c|c|c|c|c|c|c|c|}
\hline New York University & 3,681 & 13 & B. Reisberg & 170 & 147 & 5,868 & 45 & 27 & 126 & 150 \\
\hline Newcastle University & 744 & 180 & A.H. Young & 214 & 108 & 3,234 & 102 & 32 & 85 & 150 \\
\hline North Carolina State University & 564 & 215 & T.M. Hess & 47 & 309 & 319 & 306 & 10 & 289 & 36 \\
\hline Northeastern University & 752 & 179 & J.A. Hall & 114 & 207 & 4,489 & 66 & 21 & 183 & 134 \\
\hline Northwestern University & 2,553 & 41 & R. Radcliff & 125 & 197 & 3,187 & 103 & 24 & 158 & 63 \\
\hline Norwegian University of Science \& Technology & 537 & 220 & K.G. Gotestam & 161 & 160 & 891 & 238 & 13 & 268 & 116 \\
\hline Ohio State University & 3,079 & 23 & G.G. Berntson & 147 & 179 & 3,813 & 82 & 24 & 158 & 150 \\
\hline Oklahoma State University & 755 & 178 & C.I. Abramson & 69 & 280 & 196 & 318 & 8 & 306 & 118 \\
\hline Open University UK & 546 & 219 & J.R. Crawford & 141 & 184 & 3,339 & 99 & 30 & 101 & 150 \\
\hline Oregon State University & 477 & 234 & F.L. Moore & 93 & 240 & 1,159 & 214 & 20 & 193 & 58 \\
\hline Osaka University & 421 & 247 & M. Takeda & 385 & 27 & 4,081 & 75 & 32 & 85 & 150 \\
\hline Peking University & 331 & 259 & S. Han & 238 & 92 & 1,736 & 178 & 18 & 215 & 150 \\
\hline Pennsylvania State University & 4,160 & 10 & R. Plomin & 452 & 15 & 7,213 & 32 & 48 & 23 & 150 \\
\hline Pohang University of Science And Technology & 22 & 339 & M.K. Chung & 87 & 257 & 534 & 276 & 10 & 289 & 150 \\
\hline Portland State University & 489 & 231 & T.N. Bauer & 34 & 321 & 905 & 235 & 14 & 258 & 150 \\
\hline Princeton University & 1,129 & 115 & P.N. Johnson-Laird & 103 & 229 & 1,039 & 225 & 15 & 246 & 63 \\
\hline Purdue University & 2,702 & 35 & R.W. Proctor & 160 & 163 & 917 & 234 & 18 & 215 & 109 \\
\hline Queen's University & 1,331 & 107 & W.L. Marshall & 132 & 190 & 1,179 & 212 & 17 & 228 & 136 \\
\hline Queen's University of Belfast & 463 & 240 & D.J. King & 92 & 243 & 918 & 233 & 13 & 268 & 101 \\
\hline Queensland University of Technology & 517 & 224 & W. Patton & 45 & 312 & 206 & 316 & 9 & 302 & 20 \\
\hline Radboud University, Nijmegen & 2,330 & 47 & R.C.M.E. Engels & 205 & 120 & 1,187 & 211 & 21 & 183 & 150 \\
\hline Rensselaer Polytechnic Institute & 181 & 285 & D.B. Boles & 47 & 309 & 284 & 309 & 7 & 310 & 27 \\
\hline Rheinisch Westfalische Technische Hochschule Aach & 481 & 232 & K. Willmes & 168 & 151 & 2,473 & 141 & 24 & 158 & 150 \\
\hline Rheinische Friedrich Wilhelms Universitat Bonn & 861 & 155 & W. Maier & 320 & 50 & 5,234 & 54 & 43 & 37 & 150 \\
\hline Rice University & 473 & 236 & R.C. Martin & 44 & 313 & 815 & 249 & 13 & 268 & 55 \\
\hline Rochester Institute of Technology & 164 & 291 & V.J. Samar & 40 & 317 & 336 & 303 & 5 & 323 & 33 \\
\hline Royal Institute of Technology, KTH & 122 & 301 & & 0 & 345 & 0 & 344 & 0 & 343 & 0 \\
\hline Royal Melbourne Institute of Technology & 160 & 292 & A. Hudson & 26 & 329 & 99 & 327 & 5 & 323 & 29 \\
\hline Rutgers & 3,281 & 19 & C. Rovee-Collier & 124 & 199 & 664 & 259 & 17 & 228 & 105 \\
\hline Saint-Petersburg State University & 129 & 298 & A.S. Batuev & 198 & 126 & 184 & 321 & 4 & 328 & 118 \\
\hline San Diego State University & 1,618 & 87 & J.F. Sallis & 319 & 51 & 14,092 & 10 & 64 & 9 & 150 \\
\hline Sapienza University of Rome & 0 & 348 & & 0 & 345 & 0 & 344 & 0 & 343 & 0 \\
\hline Sciences Po Paris & 4 & 347 & B. Bastard & 15 & 334 & 14 & 342 & 1 & 341 & 13 \\
\hline Seoul National University & 321 & 262 & I.K. Lyoo & 81 & 267 & 1,200 & 209 & 21 & 183 & 150 \\
\hline Shanghai Jiao Tong University & 80 & 312 & L.L. He & 399 & 24 & 7,181 & 33 & 39 & 47 & 150 \\
\hline Simon Fraser University & 1,026 & 125 & J. Martin & 67 & 282 & 488 & 284 & 10 & 289 & 41 \\
\hline
\end{tabular}




\begin{tabular}{|c|c|c|c|c|c|c|c|c|c|c|}
\hline Stanford University & 4,704 & 7 & R.H. Moos & 424 & 20 & 6,277 & 40 & 35 & 66 & 150 \\
\hline State University of New York Buffalo & 72 & 314 & W.F. Wieczorek & 44 & 313 & 662 & 261 & 15 & 246 & 57 \\
\hline Stockholm University & 982 & 131 & L.G. Nilsson & 265 & 79 & 4,137 & 73 & 30 & 101 & 150 \\
\hline Stony Brook University & 1,846 & 70 & D.N. Klein & 190 & 131 & 4,191 & 71 & 31 & 95 & 150 \\
\hline Syracuse University & 1,054 & 122 & M.P. Carey & 210 & 115 & 3,471 & 94 & 33 & 82 & 150 \\
\hline Tartu University (University of Tartu) & 288 & 269 & J. Allik & 93 & 240 & 1,429 & 192 & 21 & 183 & 150 \\
\hline Technical University of Denmark & 36 & 333 & R.M.J. Cotterill & 59 & 296 & 750 & 253 & 7 & 310 & 150 \\
\hline Technion & 477 & 234 & Y. Rim & 34 & 321 & 96 & 329 & 0 & 343 & 1 \\
\hline Technische Universität Berlin & 177 & 288 & D.C. O'Connell & 62 & 290 & 134 & 325 & 6 & 318 & 46 \\
\hline Technische Universitat Chemnitz & 124 & 300 & A. Schutz & 31 & 326 & 252 & 312 & 10 & 289 & 150 \\
\hline Technische Universität Dresden & 628 & 203 & H.U. Wittchen & 381 & 29 & 19,949 & 4 & 72 & 4 & 150 \\
\hline Technische Universität München & 391 & 248 & A. Kurz & 292 & 62 & 4,143 & 72 & 31 & 95 & 150 \\
\hline Tel Aviv University & 2,218 & 50 & A. Weizman & 510 & 10 & 6,114 & 41 & 38 & 53 & 150 \\
\hline Texas A\&M University & 1,912 & 64 & C.R. Reynolds & 129 & 194 & 2,017 & 161 & 13 & 268 & 114 \\
\hline Texas Tech & 823 & 169 & R. Cogan & 50 & 304 & 283 & 310 & 6 & 318 & 85 \\
\hline Tohoku University & 382 & 252 & A. Yamadori & 218 & 106 & 1,998 & 163 & 20 & 193 & 150 \\
\hline Tokyo Institute of Technology & 116 & 305 & M. Yoshida & 283 & 69 & 3,635 & 86 & 39 & 47 & 150 \\
\hline Trinity College Dublin & 731 & 181 & M. Gill & 179 & 136 & 3,113 & 106 & 34 & 74 & 150 \\
\hline Tsinghua University & 85 & 310 & G. Salvendy & 212 & 112 & 794 & 251 & 15 & 246 & 150 \\
\hline Tufts University & 1,015 & 127 & P.J. Holcomb & 112 & 212 & 2,134 & 156 & 25 & 146 & 117 \\
\hline Universidad Autonoma de Madrid & 845 & 160 & R. Colom & 82 & 263 & 451 & 289 & 18 & 215 & 110 \\
\hline Universidad de Chile & 277 & 272 & F. Lolas & 103 & 229 & 160 & 324 & 3 & 333 & 65 \\
\hline Universidad de Granada & 845 & 160 & R. Colom & 82 & 263 & 451 & 289 & 18 & 215 & 110 \\
\hline Universidad del País Vasco & 451 & 243 & E. Echeburura & 71 & 277 & 418 & 293 & 13 & 268 & 76 \\
\hline Universidad Nacional Autónoma de México ... & 319 & 263 & F. Ostrosky-Solis & 71 & 277 & 471 & 287 & 10 & 289 & 150 \\
\hline Universidad Politecnica de Madrid & 41 & 328 & A. Lrenzo & 15 & 334 & 24 & 337 & 4 & 328 & 22 \\
\hline Universidade de São Paulo & 369 & 254 & M.L. Brandao & 164 & 156 & 1,155 & 215 & 25 & 146 & 150 \\
\hline Universidade Estadual de Campinas & 52 & 323 & N.J. Botega & 68 & 281 & 345 & 301 & 10 & 289 & 139 \\
\hline Università degli Studi di Firenze & 481 & 232 & C. Faravelli & 114 & 207 & 2,535 & 139 & 18 & 215 & 150 \\
\hline Università degli Studi di Padova & 1,528 & 92 & C. Umilta & 167 & 152 & 2,942 & 117 & 27 & 126 & 150 \\
\hline Universita Di Bologna & 714 & 186 & G.A. Fava & 340 & 45 & 3,092 & 108 & 34 & 74 & 150 \\
\hline Universita di Pisa & 159 & 293 & G. B. Cassano & 427 & 19 & 4,758 & 61 & 39 & 47 & 150 \\
\hline Universitat Autonoma de Barcelona & 550 & 218 & R. Torrubia & 48 & 306 & 512 & 280 & 12 & 278 & 99 \\
\hline Universitat Bielefeld & 682 & 191 & H.J. Markowitsch & 243 & 85 & 3,728 & 84 & 31 & 95 & 150 \\
\hline Universität Bremen & 519 & 223 & F. Petermann & 358 & 35 & 1,595 & 184 & 27 & 126 & 150 \\
\hline Universitat d'Alacant & 103 & 307 & J.M. Garcia & 20 & 332 & 49 & 332 & 5 & 323 & 32 \\
\hline
\end{tabular}




\begin{tabular}{|c|c|c|c|c|c|c|c|c|c|c|}
\hline Universitat de València & 901 & 150 & M.V. Perea & 89 & 250 & 653 & 264 & 23 & 172 & 58 \\
\hline Universität Frankfurt am Main & 821 & 170 & F. Poustka & 142 & 183 & 2,257 & 149 & 26 & 139 & 150 \\
\hline Universität Freiburg & 853 & 158 & A. Renkl & 62 & 290 & 635 & 265 & 15 & 246 & 40 \\
\hline Universitat Hamburg & 279 & 270 & B. Dahme & 112 & 212 & 499 & 282 & 15 & 246 & 150 \\
\hline Universität Karlsruhe & 60 & 320 & D. Fensel & 94 & 238 & 1,344 & 198 & 16 & 236 & 150 \\
\hline Universitat Leipzig & 509 & 226 & M.C. Angermeyer & 402 & 22 & 4,426 & 67 & 37 & 61 & 150 \\
\hline Universitat Munster (Westfälische Wilhelms-Un & 449 & 245 & V. Arolt & 191 & 129 & 2,176 & 155 & 28 & 121 & 150 \\
\hline Universitat Politecnica de Catalunya & 35 & 334 & J. Llabres & 15 & 334 & 41 & 333 & 5 & 323 & 23 \\
\hline Universität Regensburg & 374 & 253 & K. Bauml & 64 & 286 & 445 & 292 & 16 & 236 & 40 \\
\hline Universität Stuttgart & 40 & 329 & M. Schanz & 32 & 325 & 198 & 317 & 8 & 306 & 35 \\
\hline Universitat Trier & 503 & 227 & D.H. Hellhammer & 160 & 163 & 4,945 & 59 & 42 & 41 & 150 \\
\hline Universität Tübingen & 1,018 & 126 & N.Birbaumer & 383 & 28 & 7,964 & 22 & 47 & 27 & 150 \\
\hline Universitat Wien (University of Vienna) & 863 & 154 & M. Voracek & 152 & 171 & 622 & 266 & 19 & 205 & 150 \\
\hline Universitat Zu Koln & 595 & 210 & M. Dopfner & 120 & 203 & 711 & 256 & 18 & 215 & 150 \\
\hline Université Catholique de Louvain & 828 & 165 & X. Seron & 107 & 222 & 1,056 & 222 & 17 & 228 & 150 \\
\hline Universite de Liege & 490 & 230 & M. Van Der Linden & 241 & 87 & 2,991 & 114 & 30 & 101 & 150 \\
\hline Université de Montréal & 1,910 & 65 & R.E. Tremblay & 274 & 74 & 3,939 & 77 & 37 & 61 & 150 \\
\hline Université de Nice Sophia Antipolis & 186 & 284 & C.L. Gottesmann & 109 & 217 & 660 & 263 & 14 & 258 & 81 \\
\hline Universite Laval & 964 & 136 & R. Ladouceur & 203 & 121 & 2,094 & 158 & 30 & 101 & 150 \\
\hline Universite Libre de Bruxelles & 470 & 238 & J. Morais & 126 & 196 & 1,268 & 203 & 18 & 215 & 150 \\
\hline Université Paris Sorbonne & 104 & 306 & J.Y. Jaffray & 56 & 298 & 321 & 305 & 4 & 328 & 74 \\
\hline Universite Paris-Sud 11 & 279 & 270 & M. Denis & 31 & 326 & 583 & 274 & 10 & 289 & 47 \\
\hline Université Pierre et Marie Curie & 250 & 277 & E.G. Hantouche & 95 & 237 & 1,220 & 207 & 21 & 183 & 128 \\
\hline Universiti Malaya (University of Malaya) & 48 & 325 & H.H. Masjuki & 104 & 228 & 388 & 296 & 12 & 278 & 88 \\
\hline University College Cork & 126 & 299 & D. Barnes & 24 & 331 & 187 & 320 & 12 & 278 & 14 \\
\hline University College Dublin & 388 & 250 & M.F. O'Reilly & 198 & 126 & 801 & 250 & 16 & 236 & 150 \\
\hline University College London & 4,329 & 9 & A. Furnham & 575 & 7 & 7,520 & 28 & 30 & 101 & 150 \\
\hline University do Porto & 118 & 303 & F. Neto & 61 & 293 & 328 & 304 & 10 & 289 & 150 \\
\hline University of Aberdeen & 976 & 134 & J.R. Crawford & 131 & 192 & 2,359 & 147 & 24 & 158 & 150 \\
\hline University of Adelaide & 776 & 175 & T. Nettelbeck & 101 & 231 & 473 & 286 & 10 & 289 & 82 \\
\hline University of Alabama & 2,613 & 38 & T.R. Elliot & 166 & 155 & 2,388 & 146 & 25 & 146 & 150 \\
\hline University of Alberta & 2,026 & 57 & K.S. Courneya & 224 & 103 & 2,395 & 145 & 37 & 61 & 150 \\
\hline University of Amsterdam & 2,668 & 36 & P.M.G. Emmelkamp & 177 & 139 & 2,566 & 136 & 25 & 146 & 150 \\
\hline University of Antwerp & 492 & 229 & M. Maes & 372 & 32 & 5,727 & 46 & 46 & 32 & 150 \\
\hline University of Arizona & 2,529 & 42 & J. Greenberg & 120 & 203 & 1,951 & 166 & 30 & 101 & 103 \\
\hline University of Athens & 496 & 228 & C. Stefanis & 33 & 323 & 599 & 271 & 14 & 258 & 84 \\
\hline
\end{tabular}




\begin{tabular}{|c|c|c|c|c|c|c|c|c|c|c|}
\hline University of Auckland & 1,075 & 120 & M.C. Corallis & 2 & 344 & 1 & 343 & 1 & 341 & 4 \\
\hline University of Barcelona & 885 & 152 & E. Vieta & 273 & 75 & 3,019 & 111 & 43 & 37 & 150 \\
\hline University of Basel & 561 & 217 & J. Margraf & 90 & 248 & 1,028 & 226 & 16 & 236 & 100 \\
\hline University of Bath & 309 & 264 & C. Eccleston & 110 & 215 & 1,803 & 174 & 29 & 112 & 150 \\
\hline University of Bergen & 642 & 199 & K. Hugdahl & 281 & 72 & 2,934 & 118 & 30 & 101 & 150 \\
\hline University of Bern & 462 & 241 & R. Von Kanel & 122 & 200 & 888 & 239 & 21 & 183 & 139 \\
\hline University of Birmingham & 1,970 & 61 & G.W. Humphreys & 408 & 21 & 5,362 & 53 & 38 & 53 & 150 \\
\hline University of Bristol & 1,339 & 106 & D.J. Nutt & 625 & 4 & 0 & 344 & 45 & 33 & 150 \\
\hline University of British Columbia & 2,863 & 33 & A.G. Phillips & 231 & 96 & 4,628 & 62 & 32 & 85 & 150 \\
\hline University of Calgary & 996 & 129 & J.J. Eggermont & 210 & 115 & 2,568 & 135 & 32 & 85 & 87 \\
\hline University of California, Berkley & 2,528 & 43 & I. Zucker & 396 & 25 & 3,509 & 92 & 30 & 101 & 150 \\
\hline University of California, Davis & 1,750 & 75 & D.K. Simonton & 89 & 250 & 612 & 268 & 12 & 278 & 10 \\
\hline University of California, Irvine & 1,520 & 94 & J.L. McGaugh & 345 & 40 & 7,879 & 23 & 55 & 13 & 150 \\
\hline University of California, Los Angeles & 7,772 & 2 & P.M. Bentler & 239 & 91 & 10,714 & 12 & 20 & 193 & 137 \\
\hline University of California, Riverside & 947 & 141 & D.C. Funder & 63 & 288 & 1,759 & 175 & 17 & 228 & 37 \\
\hline University of California, San Diego & 2,912 & 31 & M.B. Stein & 347 & 37 & 6,661 & 37 & 47 & 27 & 150 \\
\hline University of California, San Francisco & 1,360 & 104 & S.M. Hall & 161 & 160 & 2,740 & 127 & 26 & 139 & 150 \\
\hline University of California, Santa Barbara & 1,329 & 108 & R.E. Mayer & 60 & 295 & 1,191 & 210 & 10 & 289 & 58 \\
\hline University of California, Santa Cruz & 451 & 243 & B. Bridgeman & 93 & 240 & 1,108 & 219 & 11 & 284 & 91 \\
\hline University of Cambridge & 1,717 & 79 & T.W. Robbins & 580 & 6 & 39,863 & 1 & 91 & 1 & 150 \\
\hline University of Canterbury & 600 & 207 & S. Kemp & 84 & 261 & 345 & 301 & 10 & 289 & 95 \\
\hline University of Cape Town & 298 & 266 & A.J. Flisher & 159 & 165 & 1,373 & 195 & 22 & 177 & 150 \\
\hline University of Central Florida & 825 & 166 & E. Salas & 173 & 143 & 3,027 & 110 & 34 & 74 & 150 \\
\hline University of Chicago & 1,806 & 72 & R.S. Wilson & 283 & 69 & 5,404 & 51 & 45 & 33 & 150 \\
\hline University of Cincinnati & 1,755 & 74 & S.L. McElroy & 314 & 52 & 8,805 & 17 & 65 & $\overline{8}$ & 150 \\
\hline University of Colorado at Boulder & 1,396 & 102 & S.F. Maier & 308 & 55 & 7,066 & 35 & 54 & 14 & 150 \\
\hline University of Connecticut & 1,982 & 60 & M.T. Turvey & 231 & 96 & 2,543 & 137 & 25 & 146 & 146 \\
\hline University of Copenhagen & 331 & 259 & E.L. Mortensen & 134 & 187 & 2,218 & 151 & 20 & 193 & 150 \\
\hline University of Delaware & 929 & 144 & B.P. Ackerman & 85 & 258 & 609 & 270 & 13 & 268 & 38 \\
\hline University of Dundee & 713 & 187 & N.J. Wade & 167 & 152 & 530 & 277 & 11 & 284 & 54 \\
\hline University of Edinburgh & 990 & 130 & I.J. Deary & 506 & 11 & 11,172 & 11 & 47 & 27 & 150 \\
\hline University of Florida & 3,474 & 17 & K.M. Heilman & 488 & 13 & 6,457 & 38 & 29 & 112 & 150 \\
\hline University of Geneva & 722 & 185 & M. Van Der Linden & 244 & 84 & 2,735 & 128 & 28 & 121 & 150 \\
\hline University of Georgia & 1,898 & 66 & R. Forehand & 284 & 68 & 3,046 & 109 & 25 & 146 & 150 \\
\hline University of Ghent & 1,201 & 112 & G. Crombez & 170 & 147 & 2,299 & 148 & 34 & 74 & 150 \\
\hline University of Glasgow & 1,040 & 124 & A.M.Burton & 82 & 263 & 1,229 & 205 & 19 & 205 & 87 \\
\hline
\end{tabular}




\begin{tabular}{|c|c|c|c|c|c|c|c|c|c|c|}
\hline University of Gothenburg & 83 & 311 & K. Blennow & 391 & 26 & 7,494 & 29 & 59 & 11 & 150 \\
\hline University of Groningen & 1,657 & 83 & J. Ormel & 296 & 60 & 7,711 & 24 & 43 & 37 & 150 \\
\hline University of Helsinki & 1,409 & 101 & P. Naatanen & 337 & 46 & 5,695 & 47 & 52 & 18 & 150 \\
\hline University of Hong Kong & 814 & 171 & T.M.C. Lee & 83 & 262 & 882 & 241 & 19 & 205 & 150 \\
\hline University of Houston & 979 & 133 & J.M. Fletcher & 250 & 82 & 6,317 & 39 & 38 & 53 & 150 \\
\hline University of Illinois & 5,272 & 5 & A.F. Kramer & 209 & 118 & 3,985 & 76 & 38 & 53 & 150 \\
\hline University of Illinois, Chicago & 2,570 & 39 & S.E. Ullman & 66 & 284 & 727 & 255 & 25 & 146 & 28 \\
\hline University of Indonesia & 18 & 340 & A. Ariyanto & 6 & 343 & 15 & 341 & 3 & 333 & 7 \\
\hline University of Iowa & 2,347 & 46 & A.K. Johnson & 299 & 59 & 2,690 & 130 & 28 & 121 & 150 \\
\hline University of Kansas & 1,848 & 69 & C.R. Snyder & 122 & 200 & 1,506 & 190 & 20 & 193 & 149 \\
\hline University of Kentucky & 1,453 & 98 & T.R. Zentall & 167 & 152 & 979 & 231 & 18 & 215 & 119 \\
\hline University of Lausanne & 228 & 279 & J. Rossier & 33 & 323 & 207 & 315 & 9 & 302 & 150 \\
\hline University of Leeds & 772 & 176 & J.E. Blundell & 283 & 69 & 4,298 & 69 & 38 & 53 & 150 \\
\hline University of Leicester & 835 & 164 & J. Maltby & 109 & 217 & 521 & 279 & 16 & 236 & 65 \\
\hline University of Liverpool & 724 & 184 & P. Salmon & 151 & 172 & 1,720 & 179 & 25 & 146 & 150 \\
\hline University of Ljubljana & 158 & 294 & M. Zupancic & 14 & 337 & 24 & 337 & 3 & 333 & 11 \\
\hline University of London (Kings College of London) & 14,662 & 1 & A. Furnham & 502 & 12 & 6,058 & 43 & 32 & 85 & 150 \\
\hline University of Manchester & 2,323 & 48 & N. Tarrier & 203 & 121 & 3,853 & 80 & 35 & 66 & 150 \\
\hline University of Manitoba & 1,193 & 114 & B.J. Cox & 200 & 125 & 3,581 & 87 & 36 & 64 & 150 \\
\hline University of Maryland & 3,012 & 26 & N.A. Fox & 182 & 134 & 3,418 & 96 & 29 & 112 & 150 \\
\hline University of Maryland Baltimore County & 1,666 & 82 & M. M. Black & 122 & 200 & 2,661 & 132 & 29 & 112 & 150 \\
\hline University of Massachusetts & 1,382 & 103 & K. Rayner & 212 & 112 & 2,964 & 116 & 29 & 112 & 149 \\
\hline University of Melbourne & 2,017 & 58 & G.D. Barrows & 402 & 22 & 2,770 & 124 & 20 & 193 & 150 \\
\hline University of Miami & 1,471 & 97 & N. Schneiderman & 266 & 78 & 4,316 & 68 & 32 & 85 & 150 \\
\hline University of Michigan & 4,053 & 11 & J.H. Woods & 435 & 18 & 3,878 & 79 & 29 & 112 & 150 \\
\hline University of Minnesota & 3,657 & 14 & W.G. Lacono & 300 & 57 & 4,628 & 62 & 39 & 47 & 150 \\
\hline University of Missouri & 2,997 & 27 & K.J. Sher & 149 & 174 & 3,099 & 107 & 29 & 112 & 150 \\
\hline University of Nebraska & 1,504 & 96 & G.Carlo & 67 & 282 & 823 & 248 & 15 & 246 & 90 \\
\hline University of New Hampshire & 564 & 215 & D. Finkelhor & 140 & 185 & 5,112 & 57 & 26 & 139 & 50 \\
\hline University of New Mexico & 854 & 157 & W.R. Miller & 481 & 14 & 9,250 & 15 & 48 & 23 & 150 \\
\hline University of New South Wales & 1,560 & 91 & R.A. Bryant & 230 & 98 & 3,009 & 112 & 38 & 53 & 150 \\
\hline University of North Carolina, Chapel Hill & 3,761 & 12 & C.M. Bulik & 271 & 77 & 3,771 & 83 & 42 & 41 & 150 \\
\hline University of North Texas & 660 & 196 & R. Rogers & 273 & 75 & 3,343 & 98 & 34 & 74 & 150 \\
\hline University of Notre Dame & 729 & 182 & E.M. Cummings & 112 & 212 & 1,738 & 176 & 18 & 215 & 97 \\
\hline University of Nottingham & 892 & 151 & G. Underwood & 90 & 248 & 621 & 267 & 16 & 236 & 80 \\
\hline University of Oklahoma & 932 & 143 & M.D. Mumford & 116 & 205 & 977 & 232 & 20 & 193 & 121 \\
\hline
\end{tabular}




\begin{tabular}{|c|c|c|c|c|c|c|c|c|c|c|}
\hline University of Oregon & 956 & 139 & T.J. Dishion & 85 & 258 & 2,466 & 142 & 26 & 139 & 84 \\
\hline University of Oslo & 865 & 153 & S. Friis & 148 & 177 & 1,405 & 194 & 22 & 177 & 145 \\
\hline University of Otago & 964 & 136 & D.M. Fergusson & 341 & 44 & 7,992 & 21 & 51 & 19 & 150 \\
\hline University of Ottawa & 959 & 138 & Z. Merali & 170 & 147 & 2,884 & 119 & 36 & 64 & 150 \\
\hline University of Oxford & 2,078 & 54 & E.T. Rolls & 342 & 42 & 8,615 & 19 & 54 & 14 & 150 \\
\hline University of Pennsylvania & 2,986 & 28 & R.E. Gur & 291 & 63 & 8,528 & 20 & 47 & 27 & 150 \\
\hline University of Pittsburgh & 3,600 & 16 & M.E. Thase & 513 & 9 & 20,575 & 3 & 68 & 6 & 150 \\
\hline University of Quebec & 656 & 198 & R. Ladouceur & 201 & 124 & 1,964 & 165 & 30 & 101 & 150 \\
\hline University of Queensland & 1,950 & 62 & T.P.S. Oei & 223 & 105 & 1,510 & 189 & 18 & 215 & 150 \\
\hline University of Reading & 118 & 303 & E.A. Gaffen & 44 & 313 & 752 & 252 & 12 & 278 & 38 \\
\hline University of Rochester & 1,427 & 100 & R.M. Ryan & 131 & 192 & 5,644 & 49 & 35 & 66 & 127 \\
\hline University of Saskatchewan & 661 & 195 & J.I.D. Campbell & 48 & 306 & 526 & 278 & 14 & 258 & 34 \\
\hline University of Science and Technology of China & 32 & 336 & Y. Zhang & 321 & 49 & 1,676 & 181 & 19 & 205 & 150 \\
\hline University of Sheffield & 1,505 & 95 & C. Eiser & 187 & 132 & 2,177 & 154 & 23 & 172 & 150 \\
\hline University of South Carolina & 1,564 & 89 & R.J. Prinz & 62 & 290 & 1,563 & 186 & 14 & 258 & 68 \\
\hline University of South Florida & 1,713 & 80 & J.K. Thompson & 133 & 188 & 2,033 & 160 & 26 & 139 & 150 \\
\hline University of Southampton & 847 & 159 & E.J.S. Sonuga-Barke & 156 & 166 & 2,459 & 143 & 31 & 95 & 150 \\
\hline University of Southern California & 2,028 & 56 & M. Gatz & 171 & 145 & 2,519 & 140 & 29 & 112 & 150 \\
\hline University of St Andrews & 459 & 242 & D.I. Perrett & 331 & 48 & 7,439 & 30 & 44 & 35 & 150 \\
\hline University of Surrey & 592 & 211 & S.E. Hampton & 99 & 233 & 1,965 & 164 & 23 & 172 & 114 \\
\hline University of Sussex & 982 & 131 & M.R. Yeomans & 74 & 272 & 696 & 257 & 18 & 215 & 70 \\
\hline University of Sydney & 1,862 & 67 & R.G. Menzies & 73 & 274 & 732 & 254 & 15 & 246 & 73 \\
\hline University of Technology, Sydney & 96 & 308 & A. Craig & 82 & 263 & 849 & 243 & 17 & 228 & 88 \\
\hline University of Tennessee Knoxville & 921 & 146 & G.M. Burghardt & 94 & 238 & 663 & 260 & 10 & 289 & 99 \\
\hline University of Texas at Austin & 2,528 & 43 & T. Schallert & 175 & 142 & 3,346 & 97 & 35 & 66 & 150 \\
\hline University of Tokyo & 531 & 221 & K. Kasai & 110 & 215 & 1,551 & 187 & 24 & 158 & 150 \\
\hline University of Toronto & 5,484 & 3 & M. Moscovitch & 161 & 160 & 5,039 & 58 & 39 & 47 & 150 \\
\hline University of Tsukuba & 292 & 267 & T. Iwaski & 65 & 285 & 240 & 313 & 7 & 310 & 59 \\
\hline University of Twente & 238 & 278 & E. Taal & 70 & 279 & 835 & 246 & 17 & 228 & 117 \\
\hline University of Utah & 1,854 & 68 & T.W. Smith & 147 & 179 & 2,629 & 133 & 22 & 177 & 150 \\
\hline University of Vermont & 1,213 & 111 & M.J. Zvolensky & 187 & 132 & 1,624 & 182 & 34 & 74 & 150 \\
\hline University of Victoria & 691 & 189 & W.M. Roth & 228 & 100 & 1,109 & 218 & 24 & 158 & 109 \\
\hline University of Virginia & 1,745 & 77 & R.C. Pianta & 150 & 173 & 1,356 & 196 & 25 & 146 & 135 \\
\hline University of Warwick & 622 & 204 & S. Joseph & 155 & 168 & 2,188 & 152 & 21 & 183 & 139 \\
\hline University of Washington & 5,419 & 4 & E.F. Loftus & 171 & 145 & 2,679 & 131 & 21 & 183 & 150 \\
\hline University of Waterloo & 1,527 & 93 & D. Besner & 105 & 226 & 1,007 & 227 & 16 & 236 & 68 \\
\hline
\end{tabular}




\begin{tabular}{|c|c|c|c|c|c|c|c|c|c|c|}
\hline University of Western Australia & 1,054 & 122 & S. Lewandowsky & 59 & 296 & 459 & 288 & 15 & 246 & 38 \\
\hline University of Western Ontario & 2,569 & 40 & J.P. Rushton & 132 & 190 & 1,100 & 221 & 14 & 258 & 82 \\
\hline University of Wisconsin & 3,123 & 22 & R.J. Davidson & 256 & 81 & 8,621 & 18 & 51 & 19 & 150 \\
\hline University of Wollongong & 343 & 257 & R.J. Barry & 196 & 128 & 1,418 & 193 & 27 & 126 & 135 \\
\hline University of York & 861 & 155 & A.W. Ellis & 139 & 186 & 2,114 & 157 & 22 & 177 & 121 \\
\hline University of Zurich & 683 & 190 & H.C. Steinhausen & 290 & 64 & 2,543 & 137 & 24 & 158 & 150 \\
\hline Univesitas Gadjah Mada & 10 & 344 & A. Winkvist & 56 & 298 & 1,121 & 217 & 19 & 205 & 118 \\
\hline Uppsala University & 825 & 166 & G. Andersson & 176 & 140 & 1,276 & 202 & 27 & 126 & 150 \\
\hline Utah State & 389 & 249 & J.C.S. Breitner & 191 & 129 & 5,635 & 50 & 41 & 44 & 150 \\
\hline Utrecht University & 3,079 & 23 & H. Van Engeland & 241 & 87 & 3,850 & 81 & 39 & 47 & 150 \\
\hline Vanderbilt University & 1,995 & 59 & J.H. Kaas & 346 & 38 & 5,381 & 52 & 34 & 74 & 150 \\
\hline Victoria University of Wellington & 37 & 331 & S. Schenk & 72 & 275 & 1,287 & 201 & 16 & 236 & 80 \\
\hline Vienna University of Technology & 47 & 327 & K. Hornik & 88 & 255 & 7,652 & 26 & 22 & 177 & 150 \\
\hline Virginia Polytechnic Institute & 825 & 166 & T.H. Ollendick & 208 & 119 & 3,187 & 103 & 24 & 158 & 150 \\
\hline Vrije Universiteit, Brussels & 6 & 346 & M. Bonduelle & 92 & 243 & 2,013 & 162 & 28 & 121 & 150 \\
\hline VU University Amsterdam & 2,809 & 34 & D.I. Boomsma & 358 & 35 & 4,854 & 60 & 43 & 37 & 150 \\
\hline Wageningen University & 180 & 286 & J.E.R. Frijters & 44 & 313 & 1,903 & 169 & 0 & 343 & 29 \\
\hline Wake Forest University & 571 & 213 & W.J. Rejeski & 108 & 221 & 2,873 & 120 & 31 & 95 & 150 \\
\hline Waseda University & 175 & 290 & A. Takanishi & 243 & 85 & 903 & 236 & 15 & 246 & 150 \\
\hline Washington State University & 803 & 172 & J.W. Wright & 203 & 121 & 2,783 & 121 & 24 & 158 & 150 \\
\hline Washington University in St. Louis & 1,636 & 86 & K.K. Bucholz & 214 & 108 & 5,171 & 55 & 49 & 22 & 150 \\
\hline Wayne State University & 2,029 & 55 & M.A. Lumley & 92 & 243 & 1,521 & 188 & 23 & 172 & 150 \\
\hline West Virginia University & 769 & 177 & G.H. Eifert & 78 & 270 & 988 & 229 & 24 & 158 & 106 \\
\hline Yale University & 3,201 & 21 & C.M. Grilo & 229 & 99 & 3,121 & 105 & 38 & 53 & 150 \\
\hline Yonsei University & 262 & 275 & J.J. Kim & 588 & 5 & 7,322 & 31 & 40 & 46 & 150 \\
\hline York University & 1,749 & 76 & R.J. Burke & 216 & 107 & 1,225 & 206 & 16 & 236 & 150 \\
\hline Zhejiang University & 55 & 321 & W.W. Wang & 525 & 8 & 2,709 & 129 & 24 & 158 & 150 \\
\hline
\end{tabular}




\begin{tabular}{|c|c|c|c|c|c|c|c|c|c|c|}
\hline Health Professions Data & $\begin{array}{l}\text { Department } \\
\text { Publications }\end{array}$ & Rank & Most Prolific Author & Published & Rank & Cited & Rank & $\begin{array}{c}\text { H- } \\
\text { Index }\end{array}$ & Rank & $\begin{array}{c}\text { \# of } \\
\text { Coauthors }\end{array}$ \\
\hline Aalto University & 148 & 201 & R.Hari & 301 & 44 & 7,650 & 20 & 48 & 14 & 150 \\
\hline Aarhus University & 588 & 91 & J.P. Blonde & 177 & 115 & 2,074 & 111 & 28 & 76 & 150 \\
\hline Arizonia State University & 17 & 298 & D.R. Hodge & 94 & 200 & 1,103 & 164 & 19 & 135 & 112 \\
\hline Ateneo de Manila University & 2 & 341 & E. Bagarinao & 19 & 318 & 92 & 302 & 6 & 281 & 31 \\
\hline Auburn University & 336 & 140 & B.G. Felkey & 82 & 220 & 160 & 288 & 6 & 281 & 26 \\
\hline Australian National University & 95 & 229 & S.R. Taylor & 155 & 133 & 5,005 & 37 & 10 & 242 & 150 \\
\hline Boston College & 129 & 209 & S.M. Bruce & 14 & 323 & 12 & 330 & 2 & 319 & 15 \\
\hline Boston University & \begin{tabular}{l|l}
1,846 \\
\end{tabular} & 14 & H.E Stanley & 480 & 19 & 10,348 & 15 & 57 & 10 & 150 \\
\hline Brandeis University & 210 & 171 & M. Rosbash & 253 & 64 & 5,621 & 29 & 49 & 13 & 150 \\
\hline Brigham Young University & 376 & 130 & D.O. Draper & 53 & 266 & 288 & 261 & 11 & 226 & 72 \\
\hline Brown University & 636 & 83 & V. Mor & 313 & 42 & 7,460 & 21 & 47 & 15 & 150 \\
\hline California Institute of Technology (Calt... & 70 & 240 & & 0 & 340 & 0 & 337 & 0 & 329 & 0 \\
\hline Cardiff University & 670 & 73 & S. Hanton & 47 & 278 & 346 & 250 & 17 & 153 & 32 \\
\hline Carnegie Mellon University & 162 & 191 & A.P. Koretsky & 176 & 117 & 3,798 & 58 & 31 & 61 & 150 \\
\hline Case Western Reserve University & 1,185 & 39 & J.L. Duerk & 176 & 117 & 1,982 & 117 & 30 & 70 & 150 \\
\hline Chalmers University of Technology & 66 & 245 & L. Sandsjo & 34 & 295 & 364 & 248 & 10 & 242 & 65 \\
\hline Charles University & 2 & 341 & V. Bencko & 209 & 95 & 932 & 176 & 14 & 185 & 150 \\
\hline Chinese University of Hong Kong & 6 & 327 & D.R. Thompson & 294 & 45 & 3,973 & 52 & 32 & 57 & 150 \\
\hline Chulalongkorn University & 102 & 225 & V. Wiwanitkit & 645 & 10 & 733 & 194 & 9 & 254 & 120 \\
\hline City University of Hong Kong & 107 & 221 & P. K.N. Yu & 87 & 211 & 485 & 229 & 16 & 167 & 51 \\
\hline City University of New York & 16 & 300 & K.M. Nokes & 63 & 252 & 510 & 224 & 11 & 226 & 111 \\
\hline Colorado State University & 280 & 156 & R.F. Reiser & 41 & 288 & 99 & 300 & 5 & 290 & 41 \\
\hline Columbia University & 2,195 & 10 & E.R. Kandal & 448 & 22 & 17,020 & 7 & 77 & 1 & 150 \\
\hline Cornell University & 1,500 & 22 & C.I. Henschke & 245 & 67 & 3,982 & 51 & 34 & 49 & 150 \\
\hline Curtin University of Technology & 337 & 139 & P.B. O'sullivan & 64 & 250 & 769 & 190 & 17 & 153 & 110 \\
\hline Dalhousie University & 460 & $\mid 115$ & W.D. Stanish & 91 & 207 & 1,048 & 168 & 14 & 185 & 150 \\
\hline Dartmouth College & 1,002 & 51 & R.E. Drake & 435 & 23 & 6,146 & 27 & 46 & 16 & 150 \\
\hline Delft University of Technology & 322 & 144 & A.J.J. Bos & 112 & 175 & 654 & 205 & 10 & 242 & 150 \\
\hline Drexel University & 694 & 70 & J.D. Swartz & 109 & 178 & 475 & 232 & 6 & 281 & 128 \\
\hline Duke University & 3,619 & 5 & J.M. Provenzale & 243 & 70 & 5,197 & 33 & 45 & 18 & 150 \\
\hline Durham University & 83 & 234 & & 0 & 340 & 0 & 337 & 0 & 329 & 0 \\
\hline Ecole Normale Supérieure de Lyon & 2 & 341 & T. Nakamura & 88 & 210 & 752 & 192 & 17 & 153 & 150 \\
\hline École Normale Supérieure, Paris & 13 & 309 & V. Croquette & 81 & 222 & 2,220 & 100 & 27 & 81 & 128 \\
\hline École Polytechnique & 17 & 298 & & 0 & 340 & 0 & 337 & 0 & 329 & 0 \\
\hline
\end{tabular}




\begin{tabular}{|c|c|c|c|c|c|c|c|c|c|c|}
\hline Ecole Polytechnique Fédérale de Lausanne & 101 & 228 & M. Unser & 347 & 33 & 4,859 & 38 & 31 & 61 & 150 \\
\hline Eindhoven University of Technology & 113 & 217 & K.Nicolay & 241 & 72 & 4,278 & 45 & 35 & 47 & 150 \\
\hline Emory University & 1,639 & 18 & M.E. Berardino & 180 & 113 & 1,982 & 117 & 2 & 319 & 150 \\
\hline Erasmus University Rotterdam & 1,484 & 26 & E.P. Krennining & 410 & 26 & 6,769 & 23 & 50 & 12 & 150 \\
\hline ETH Zurich (Swiss Federal Institute of Technology) & 339 & 138 & P. Boesiger & 28 & 303 & 5,124 & 34 & 42 & 23 & 150 \\
\hline Florida International University & 128 & 210 & M.A. Cleary & 11 & 326 & 32 & 322 & 3 & 311 & 14 \\
\hline Florida State University & 11 & 315 & C.R. Figley & 60 & 255 & 350 & 249 & 11 & 226 & 49 \\
\hline Freie Universität Berlin & 466 & 112 & R.Felix & 1,036 & 3 & 10,489 & 13 & 41 & 28 & 150 \\
\hline Friedrich Alexander Universität Erlangen Nürnberg & 754 & 67 & R. Sauer & 559 & 14 & 689 & 201 & 39 & 35 & 150 \\
\hline Fudan University & 134 & 205 & W.Q. Huang & 1,100 & 1 & 12,280 & 12 & 52 & 11 & 150 \\
\hline Georg August Universität Göttingen & 546 & 102 & F. Leinsenring & 94 & 200 & 563 & 216 & 11 & 226 & 142 \\
\hline George Mason University & 10 & 316 & P.R. Canelosi & 22 & 314 & 47 & 316 & 4 & 302 & 14 \\
\hline George Washington University & 739 & 68 & B. Fernhall & 142 & 151 & 915 & 179 & 17 & 153 & 150 \\
\hline Georgetown University & 970 & 52 & R.K. Zeman & 146 & 146 & 1,994 & 116 & 10 & 242 & 150 \\
\hline Georgia Institute of Technology & 216 & 168 & N.E. Hertel & 117 & 173 & 258 & 270 & 8 & 263 & 150 \\
\hline Georgia State University & 293 & 151 & R.A. Sevcik & 53 & 266 & 503 & 225 & 10 & 242 & 73 \\
\hline Goteborg University & 6 & 327 & L. Barregard & 97 & 196 & 910 & 181 & 14 & 185 & 150 \\
\hline Harvard University & 464 & 113 & W.M. Davis & 237 & 75 & 3,363 & 71 & 33 & 52 & 150 \\
\hline Hebrew University of Jerusalem & 328 & 142 & N. Katz & 62 & 253 & 535 & 220 & 14 & 185 & 105 \\
\hline Heidelberg Universität & 1,024 & 48 & K. Sartor & 258 & 59 & 3,969 & 53 & 33 & 52 & 150 \\
\hline Hokkaido University & 494 & 109 & N. Tamaki & 481 & 18 & 3,934 & 54 & 31 & 61 & 150 \\
\hline Hong Kong Polytechnic University & 665 & 74 & P. Cho & 101 & 189 & 572 & 214 & 15 & 174 & 101 \\
\hline Hong Kong University of Science \& Techno... & 43 & 266 & K.M. Ko & 91 & 207 & 669 & 204 & 17 & 153 & 119 \\
\hline Humboldt-Universität zu Berlin & 561 & 99 & R. Felix & 1,036 & 3 & 10,446 & 14 & 41 & 28 & 150 \\
\hline Imperial College London & 624 & 86 & G.Z. Yang & 374 & 30 & 2,063 & 113 & 25 & 97 & 150 \\
\hline Indian Institute of Technology Bombay (I... & 18 & 296 & R. Manchanda & 27 & 305 & 56 & 309 & 5 & 290 & 21 \\
\hline Indian Institute of Technology Delhi (II... & 38 & 270 & P. Vasdudevan & 145 & 149 & 1,027 & 169 & 16 & 167 & 138 \\
\hline Indian Institute of Technology Kanpur (I... & 21 & 289 & R.K. Gupta & 349 & 32 & 1,975 & 119 & 26 & 88 & 150 \\
\hline Indiana University Bloomington & 1,146 & 44 & J.S. Skinner & 204 & 100 & 4,334 & 42 & 40 & 30 & 150 \\
\hline Indiana University Indianapolis & 1,216 & 36 & R.B. Gunderman & 207 & 97 & 496 & 228 & 11 & 226 & 150 \\
\hline Iowa State University & 211 & 170 & G.J. Welk & 58 & 257 & 1,456 & 141 & 20 & 122 & 149 \\
\hline Johns Hopkins University & 4,932 & 1 & E.K. Fishman & 398 & 28 & 6,147 & 26 & 44 & 19 & 150 \\
\hline Kansas State University & 243 & 161 & D.C. Poole & 211 & 91 & 3,065 & 78 & 29 & 72 & 150 \\
\hline Katholieke Universiteit Leuven & 674 & 72 & P. Hespel & 108 & 180 & 1,492 & 138 & 20 & 122 & 150 \\
\hline Keio University & 308 & 148 & A. Kubo & 522 & 17 & 4,771 & 39 & 30 & 70 & 150 \\
\hline
\end{tabular}




\begin{tabular}{|c|c|c|c|c|c|c|c|c|c|c|}
\hline King Fahd University of Petroleum \& Minerals & 16 & 300 & A. Aksoy & 25 & 306 & 55 & 310 & 3 & 311 & 33 \\
\hline King Saud University & 95 & 229 & S.A. Al-Shammari & 47 & 278 & 287 & 262 & 6 & 281 & 64 \\
\hline Kobe University & 301 & 149 & K. Sugimura & 235 & 78 & 1,390 & 146 & 21 & 116 & 150 \\
\hline Korea Advanced Institute of Science \& Technology & 73 & 238 & Z.H. Cho & 207 & 97 & 1,334 & 151 & 9 & 254 & 150 \\
\hline Korea University & 107 & 221 & J.A. Choi & 65 & 247 & 618 & 208 & 12 & 211 & 150 \\
\hline Kyoto University & 1,300 & 34 & J. Konishi & 887 & 7 & 13,102 & 10 & 43 & 21 & 150 \\
\hline Kyushu University & 653 & 77 & H. Honda & 557 & 15 & 4,628 & 40 & 28 & 76 & 150 \\
\hline La Trobe University & 508 & 106 & V.J. Robertson & 65 & 247 & 596 & 210 & 13 & 201 & 68 \\
\hline Lancaster University & 142 & 203 & E.B. Emerson & 120 & 171 & 1,370 & 148 & 24 & 100 & 138 \\
\hline Leiden University & 1,137 & 45 & A. De Roos & 372 & 31 & 5,029 & 36 & 42 & 23 & 150 \\
\hline Linkoping University & 809 & 63 & J. Gillquist & 182 & 109 & 3,484 & 66 & 11 & 226 & 113 \\
\hline London School of Economics and Political Scie & 105 & 223 & E.A. Mossialos & 84 & 217 & 578 & 213 & 14 & 185 & 63 \\
\hline Loughborough University & 564 & 98 & C. Williams & 125 & 164 & 1,159 & 162 & 18 & 146 & 150 \\
\hline Louisiana State University & 32 & 275 & P. Synder & 43 & 285 & 437 & 235 & 12 & 211 & 115 \\
\hline Ludwig-Maximilians-Universität München & 1,207 & 37 & M. Reiser & 1,062 & 2 & 19,695 & 4 & 61 & 7 & 150 \\
\hline Lund University & 1,380 & 30 & S. Holtas & 166 & 124 & 2,101 & 109 & 19 & 135 & 150 \\
\hline Maastricht University & 1,100 & 47 & H. Kuipers & 136 & 157 & 2,221 & 99 & 18 & 146 & 150 \\
\hline Macquarie University & 169 & 187 & H. Polland & 54 & 265 & 164 & 286 & 8 & 263 & 54 \\
\hline Mahidol University & 160 & 193 & S. Pongpech & 23 & 311 & 78 & 304 & 4 & 302 & 49 \\
\hline Masaryk University & 34 & 273 & M. Haki & 17 & 321 & 9 & 332 & 1 & 324 & 38 \\
\hline Massachusetts Institute of Technology & 543 & 103 & A. Rich & 337 & 35 & 5,872 & 28 & 32 & 57 & 150 \\
\hline McGill University & 1,877 & 12 & J.H.Bates & 205 & 99 & 2,168 & 104 & 27 & 81 & 150 \\
\hline McMaster University & 1,488 & 24 & O. Bar-Or & 166 & 124 & 2,246 & 98 & 20 & 122 & 150 \\
\hline Michigan State University & 716 & 69 & R.E. Lenski & 160 & 127 & 3,733 & 60 & 38 & 38 & 150 \\
\hline Michigan Technological University & 23 & 285 & W.H. Cooke & 59 & 256 & 868 & 184 & 17 & 153 & 117 \\
\hline Monash University & 508 & 106 & L. Roller & 154 & 134 & 37 & 318 & 3 & 311 & 24 \\
\hline Montana State University & 68 & 242 & T.J. Douglas & 118 & 172 & 2,861 & 83 & 31 & 61 & 150 \\
\hline Moscow State University & 42 & 267 & V.E. Tarasov & 86 & 214 & 209 & 273 & 16 & 167 & 3 \\
\hline Nagoya University & 458 & 117 & T. Ishigak & 234 & 80 & 1,950 & 120 & 23 & 104 & 150 \\
\hline Nanjing University & 30 & 276 & L. Wang & 153 & 139 & 1,055 & 167 & 19 & 135 & 150 \\
\hline Nanyang Technological University & 210 & 171 & E.Y.K. Ng & 146 & 146 & 319 & 256 & 12 & 211 & 145 \\
\hline National Taiwan University & 620 & 88 & F.J. Hsieh & 231 & 82 & 2,070 & 112 & 25 & 97 & 150 \\
\hline National Tsing Hua University & 326 & 143 & K.S. Chuang & 64 & 250 & 291 & 259 & 7 & 275 & 117 \\
\hline National University of Ireland, Galway & 48 & 262 & T. Dillion & 8 & 332 & 31 & 324 & 0 & 329 & 6 \\
\hline National University of Singapore & 272 & 157 & J. Thumboo & 109 & 178 & 895 & 182 & 18 & 146 & 150 \\
\hline New Mexico State University & 74 & 237 & & 0 & 340 & 0 & 337 & 0 & 329 & 0 \\
\hline
\end{tabular}




\begin{tabular}{|c|c|c|c|c|c|c|c|c|c|c|}
\hline New York University & 1,945 & 11 & A.J. Megibow & 154 & 134 & 4,315 & 43 & 19 & 135 & 150 \\
\hline Newcastle University & 295 & 150 & B.J. Dodd & 77 & 229 & 695 & 200 & 13 & 201 & 70 \\
\hline North Carolina State University & 160 & 193 & D.E. Thrall & 172 & 120 & 1,476 & 140 & 20 & 122 & 150 \\
\hline Northeastern University & 283 & 154 & R.W. Schlosser & 40 & 290 & 291 & 259 & 12 & 211 & 41 \\
\hline Northwestern University & 1,802 & 15 & D. Li. & 123 & 168 & 1,572 & 133 & 22 & 110 & 150 \\
\hline Norwegian University of Science \& Technology & 333 & 141 & J. Helgerud & 52 & 269 & 721 & 195 & 16 & 167 & 84 \\
\hline Ohio State University & 1,799 & 16 & D.W. Chakeres & 105 & 183 & 1,389 & 147 & 17 & 153 & 150 \\
\hline Oklahoma State University & 169 & 187 & S.W.S. McKeever & 160 & 127 & 1,229 & 154 & 21 & 116 & 150 \\
\hline Open University UK & 81 & 235 & & 0 & 340 & 0 & 337 & 0 & 329 & 0 \\
\hline Oregon State University & 256 & 158 & B.J. Cardinal & 83 & 218 & 502 & 226 & 14 & 185 & 89 \\
\hline Osaka University & 768 & 66 & H. Nakamura & 420 & 24 & 4,223 & 46 & 34 & 49 & 150 \\
\hline Peking University & 147 & 202 & S.L. Bao & 58 & 257 & 105 & 296 & 5 & 290 & 135 \\
\hline Pennsylvania State University & 1,580 & 20 & K.D. Hopper & 156 & 131 & 2,584 & 88 & 19 & 135 & 150 \\
\hline Pohang University of Science And Technology & 18 & 296 & S. Kim & 129 & 162 & 879 & 183 & 14 & 185 & 150 \\
\hline Portland State University & 161 & 192 & P. Backler & 32 & 297 & 154 & 289 & 8 & 263 & 5 \\
\hline Princeton University & 110 & 219 & U.E. Reinhardt & 182 & 109 & 985 & 172 & 17 & 153 & 150 \\
\hline Purdue University & 694 & 70 & L.B. Leonard & 156 & 131 & 973 & 173 & 16 & 167 & 106 \\
\hline Queen's University & 542 & 104 & M.E Tschkosky & 49 & 275 & 804 & 187 & 19 & 135 & 69 \\
\hline Queen's University of Belfast & 181 & 184 & C.A. Mahoney & 12 & 325 & 54 & 311 & 0 & 329 & 16 \\
\hline Queensland University of Technology & 438 & 123 & D.A. Atchison & 144 & 150 & 964 & 175 & 17 & 153 & 103 \\
\hline Radboud University, Nijmegen & 1,135 & 46 & W.J.G. Oyen & 381 & 29 & 4,145 & 48 & 37 & 41 & 150 \\
\hline Rensselaer Polytechnic Institute & 132 & 207 & X.G. Xu & 48 & 276 & 104 & 297 & 5 & 290 & 66 \\
\hline Rheinisch Westfalische Technische Hochschule Aach & 632 & 85 & R.W. Gunther & 399 & 27 & 3,065 & 78 & 23 & 104 & 150 \\
\hline Rheinische Friedrich Wilhelms Universitat Bonn & 459 & 116 & H.J. Biersack & 344 & 34 & 2,260 & 96 & 20 & 122 & 150 \\
\hline Rice University & 118 & 215 & R.R. Richards-Kortum & 230 & 83 & 3,309 & 74 & 40 & 30 & 150 \\
\hline Rochester Institute of Technology & 102 & 225 & J.P. Hornak & 34 & 295 & 205 & 274 & 4 & 302 & 47 \\
\hline Royal Institute of Technology, KTH & 79 & 236 & J. Sundberg & 138 & 155 & 769 & 190 & 12 & 211 & 138 \\
\hline Royal Melbourne Institute of Technology & 193 & 181 & J.A. Hawley & 174 & 119 & 2,644 & 86 & 34 & 49 & 150 \\
\hline Rutgers & 477 & 111 & D. Mechanic & 200 & 103 & 4,399 & 41 & 29 & 72 & 150 \\
\hline Saint-Petersburg State University & 7 & 323 & L.N. Moskvin & 194 & 105 & 187 & 278 & 7 & 275 & 150 \\
\hline San Diego State University & 464 & 113 & J.F. Sallis & 319 & 41 & 14,092 & 9 & 64 & 2 & 150 \\
\hline Sapienza University of Rome & 0 & 348 & & 0 & 340 & 0 & 337 & 0 & 329 & 0 \\
\hline Sciences Po Paris & 3 & 339 & P. Castrel & 11 & 326 & 53 & 312 & 5 & 290 & 27 \\
\hline Seoul National University & 1,173 & 41 & B.I. Choi & 286 & 46 & 3,040 & 80 & 27 & 81 & 150 \\
\hline Shanghai Jiao Tong University & 172 & 185 & J.H. Wang & 468 & 21 & 2,507 & 92 & 26 & 88 & 150 \\
\hline Simon Fraser University & 200 & 176 & E.W. Banister & 69 & 240 & 615 & 209 & 6 & 281 & 69 \\
\hline
\end{tabular}




\begin{tabular}{|c|c|c|c|c|c|c|c|c|c|c|}
\hline Stanford University & 3,274 & & D.R. Enzmann & 214 & 89 & 3,393 & 69 & 9 & 254 & 150 \\
\hline State University of New York Buffalo & 922 & 56 & K.J. Ottenbacher & 258 & 59 & 3,141 & 75 & 26 & 88 & 150 \\
\hline Stockholm University & 287 & 152 & A. Brahme & 182 & 109 & 1,949 & 121 & 19 & 135 & 150 \\
\hline Stony Brook University & 439 & 122 & E. Wimmer & 253 & 64 & 3,896 & 55 & 32 & 57 & 150 \\
\hline Syracuse University & 15 & 303 & M.P. Carey & 210 & 92 & 3,471 & 67 & 33 & 52 & 150 \\
\hline Tartu University (University of Tartu) & 224 & 166 & T. Jurimae & 102 & 187 & 428 & 240 & 14 & 185 & 81 \\
\hline Technical University of Denmark & 63 & 246 & E. Mosekilde & 169 & 123 & 1,199 & 159 & 20 & 122 & 150 \\
\hline Technion & 347 & 135 & O. Israel & 154 & 134 & 1,854 & 123 & 27 & 81 & 150 \\
\hline Technische Universität Berlin & 68 & 242 & R. Busse & 82 & 220 & 801 & 188 & 12 & 211 & 108 \\
\hline Technische Universitat Chemnitz & 19 & 292 & T. Sterzing & 7 & 333 & 3 & 334 & 1 & 324 & 9 \\
\hline Technische Universität Dresden & 230 & 164 & B. Dorschel & 58 & 257 & 201 & 275 & 13 & 201 & 68 \\
\hline Technische Universität München & 782 & 65 & M. Schwaiger & 560 & 13 & 17,201 & 6 & 61 & 7 & 150 \\
\hline Tel Aviv University & 880 & 59 & G. Navon & 203 & 101 & 1,563 & 134 & 17 & 153 & 150 \\
\hline Texas A\&M University & 655 & 76 & C.H. Shea & 87 & 211 & 567 & 215 & 20 & 122 & 60 \\
\hline Texas Tech & 12 & 314 & A. Green & 19 & 318 & 46 & 317 & 4 & 302 & 45 \\
\hline Tohoku University & 457 & 118 & T. Ido & 10 & 329 & 4 & 333 & 1 & 324 & 49 \\
\hline Tokyo Institute of Technology & 60 & 250 & M. Yoshida & 283 & 47 & 3,635 & 62 & 39 & 35 & 150 \\
\hline Trinity College Dublin & 346 & 136 & W.C. Torreggiani & 210 & 92 & 719 & 196 & 14 & 185 & 150 \\
\hline Tsinghua University & 94 & 231 & J. Bai & 412 & 25 & 1,151 & 163 & 16 & 167 & 150 \\
\hline Tufts University & 585 & 93 & K.I. Kolpan & 24 & 308 & 0 & 337 & 0 & 329 & 1 \\
\hline Universidad Autonoma de Madrid & 151 & 197 & M.G. Nistal & 262 & 55 & 1,641 & 131 & 15 & 174 & 150 \\
\hline Universidad de Chile & 68 & 242 & R. Latorre & 134 & 158 & 3,034 & 82 & 23 & 104 & 150 \\
\hline Universidad de Granada & 151 & 197 & M.G. Nistal & 262 & 55 & 1,641 & 131 & 15 & 174 & 150 \\
\hline Universidad del País Vasco & 72 & 239 & I. Mujika & 48 & 276 & 986 & 171 & 22 & 110 & 82 \\
\hline Universidad Nacional Autónoma de México ... & 28 & 279 & C. Roldan-Henriquez & 22 & 314 & 293 & 258 & 12 & 211 & 124 \\
\hline Universidad Politecnica de Madrid & 102 & 225 & V. Maojo & 57 & 260 & 211 & 272 & 11 & 226 & 111 \\
\hline Universidade de São Paulo & 960 & 54 & G.G. Cerri & 232 & 81 & 971 & 174 & 15 & 174 & 150 \\
\hline Universidade Estadual de Campinas & 236 & 162 & F. Cendes & 282 & 48 & 3,551 & 64 & 33 & 52 & 150 \\
\hline Università degli Studi di Firenze & 366 & 132 & M. Mascalchi & 181 & 112 & 1,819 & 126 & 22 & 110 & 150 \\
\hline Università degli Studi di Padova & 436 & 124 & D. Rubello & 243 & 70 & 2,167 & 105 & 26 & 88 & 150 \\
\hline Universita Di Bologna & 311 & 147 & G. Pilu & 106 & 181 & 1,178 & 160 & 15 & 174 & 150 \\
\hline Universita di Pisa & 1 & 344 & G. Gritti & 76 & 230 & 115 & 295 & 7 & 275 & 147 \\
\hline Universitat Autonoma de Barcelona & 364 & 133 & T. Franquet & 95 & 198 & 1,235 & 153 & 21 & 116 & 150 \\
\hline Universitat Bielefeld & 88 & 232 & M. Brambring & 23 & 311 & 102 & 298 & 3 & 311 & 13 \\
\hline Universität Bremen & 138 & 204 & W. Dreher & 57 & 260 & 562 & 217 & 15 & 174 & 79 \\
\hline Universitat d'Alacant & 49 & 259 & J.A Perez & 6 & 335 & 1 & 336 & 1 & 324 & 20 \\
\hline
\end{tabular}




\begin{tabular}{|c|c|c|c|c|c|c|c|c|c|c|}
\hline Universitat de València & 236 & 162 & F.M. Bonilla & 221 & 87 & 1,489 & 139 & 17 & 153 & 150 \\
\hline Universität Frankfurt am Main & 830 & 61 & T. Vogl & 278 & 49 & 4,005 & 50 & 37 & 41 & 150 \\
\hline Universität Freiburg & 659 & 75 & M. Schumacher & 527 & 16 & 0 & 337 & 40 & 30 & 150 \\
\hline Universitat Hamburg & 228 & 165 & E. Dikomey & 71 & 237 & 705 & 199 & 18 & 146 & 98 \\
\hline Universität Karlsruhe & 45 & 264 & R. Bolte & 10 & 329 & 35 & 319 & 5 & 290 & 26 \\
\hline Universitat Leipzig & 314 & 146 & T.M. Kahn & 236 & 76 & 2,192 & 101 & 22 & 110 & 150 \\
\hline Universitat Munster (Westfälische Wilhelms-Un & 818 & 62 & P.E. Peters & 259 & 58 & 2,190 & 102 & 12 & 211 & 150 \\
\hline Universitat Politecnica de Catalunya & 86 & 233 & M. Ginjaume & 30 & 301 & 174 & 283 & 8 & 263 & 94 \\
\hline Universität Regensburg & 391 & 128 & S. Feuerbach & 239 & 73 & 2,167 & 105 & 27 & 81 & 150 \\
\hline Universität Stuttgart & 37 & 271 & M. Schanz & 32 & 297 & 198 & 276 & 8 & 263 & 35 \\
\hline Universitat Trier & 13 & 309 & G. Krampen & 69 & 240 & 136 & 292 & 5 & 290 & 45 \\
\hline Universität Tübingen & 923 & 55 & C.D. Clausson & 566 & 12 & 8,341 & 18 & 40 & 30 & 150 \\
\hline Universitat Wien (University of Vienna) & 1,003 & 50 & H. Imhof & 262 & 55 & 2,518 & 91 & 26 & 88 & 150 \\
\hline Universitat Zu Koln & 604 & 89 & H. Schicha & 325 & 39 & 3,039 & 81 & 26 & 88 & 150 \\
\hline Université Catholique de Louvain & 352 & 134 & B. Gallez & 128 & 163 & 1,224 & 155 & 23 & 104 & 150 \\
\hline Universite de Liege & 212 & 169 & F. Pirnay & 22 & 314 & 132 & 293 & 5 & 290 & 32 \\
\hline Université de Montréal & 869 & 60 & B. Charlin & 51 & 272 & 279 & 263 & 11 & 226 & 114 \\
\hline Université de Nice Sophia Antipolis & 127 & 211 & P. Iacconi & 85 & 216 & 411 & 241 & 11 & 226 & 107 \\
\hline Universite Laval & 444 & 121 & C. Bouchard & 701 & 9 & 29,931 & 2 & 63 & 4 & 150 \\
\hline Universite Libre de Bruxelles & 571 & 96 & M.J. Struelens & 245 & 67 & 4,008 & 49 & 36 & 44 & 150 \\
\hline Université Paris Sorbonne & 1 & 344 & S. Plane & 4 & 339 & 0 & 337 & 0 & 329 & 5 \\
\hline Universite Paris-Sud 11 & 202 & 174 & & 0 & 340 & 0 & 337 & 0 & 329 & 0 \\
\hline Université Pierre et Marie Curie & 198 & 178 & B. Blondel & 159 & 129 & 1,442 & 143 & 20 & 122 & 150 \\
\hline Universiti Malaya (University of Malaya) & 110 & 219 & B.J.J. Abdullah & 65 & 247 & 259 & 269 & 8 & 263 & 11 \\
\hline University College Cork & 49 & 259 & J. Sweeney & 225 & 85 & 5,217 & 32 & 40 & 30 & 150 \\
\hline University College Dublin & 198 & 178 & E.J. Conway & 39 & 291 & 11 & 331 & 0 & 329 & 25 \\
\hline University College London & 1,604 & 19 & G. Burnstock & 1,019 & 5 & 32,401 & 1 & 62 & 5 & 150 \\
\hline University do Porto & 196 & 180 & J. Mota & 78 & 226 & 429 & 239 & 15 & 174 & 150 \\
\hline University of Aberdeen & 572 & 95 & V. Hundley & 45 & 283 & 379 & 246 & 11 & 226 & 91 \\
\hline University of Adelaide & 186 & 183 & R.K. Morton & 22 & 314 & 50 & 314 & 0 & 329 & 24 \\
\hline University of Alabama & 1,692 & 17 & L.l. Berland & 94 & 200 & 1,394 & 145 & 8 & 263 & 148 \\
\hline University of Alberta & 1,338 & 32 & O. Yonge & 73 & 232 & 264 & 267 & 9 & 254 & 65 \\
\hline University of Amsterdam & 1,153 & 42 & J. Stokeer & 177 & 115 & 2,530 & 90 & 31 & 61 & 150 \\
\hline University of Antwerp & 554 & 101 & R. Remmen & 24 & 308 & 143 & 291 & 6 & 281 & 52 \\
\hline University of Arizona & 1,404 & 29 & T.B. Hunter & 130 & 161 & 525 & 222 & 9 & 254 & 150 \\
\hline University of Athens & 574 & 94 & A. Gouliamos & 138 & 155 & 923 & 178 & 13 & 201 & 150 \\
\hline
\end{tabular}




\begin{tabular}{|c|c|c|c|c|c|c|c|c|c|c|}
\hline University of Auckland & 652 & 78 & J. Cronin & 73 & 232 & 322 & 255 & 12 & 211 & 70 \\
\hline University of Barcelona & 283 & 154 & J. Pavia & 66 & 245 & 433 & 236 & 10 & 242 & 150 \\
\hline University of Basel & 525 & 105 & K. Scheffler & 140 & 153 & 1,829 & 125 & 26 & 88 & 150 \\
\hline University of Bath & 53 & 254 & E. Kuhlmann & 7 & 333 & 21 & 326 & 2 & 319 & 5 \\
\hline University of Bergen & 5 & 330 & B.E. Moen & 140 & 153 & 645 & 206 & 14 & 185 & 150 \\
\hline University of Bern & 393 & 127 & C. Boesch & 125 & 164 & 2,259 & 97 & 28 & 76 & 150 \\
\hline University of Birmingham & 916 & 57 & J.H. Fremlin & 154 & 134 & 183 & 279 & 0 & 329 & 110 \\
\hline University of Bristol & 373 & 131 & D.L. Henshaw & 124 & 166 & 532 & 221 & 9 & 254 & 129 \\
\hline University of British Columbia & 30 & 276 & K. Но & 42 & 287 & 102 & 298 & 5 & 290 & 111 \\
\hline University of Calgary & 20 & 290 & J. Lockyer & 105 & 183 & 718 & 197 & 15 & 174 & 150 \\
\hline University of California, Berkley & 26 & 281 & S.M. Shortell & 258 & 59 & 3,561 & 63 & 26 & 88 & 150 \\
\hline University of California, Davis & 160 & 193 & D.A. Moore & 45 & 283 & 332 & 252 & 9 & 254 & 65 \\
\hline University of California, Irvine & 8 & 322 & J. Shapiro & 102 & 187 & 596 & 210 & 13 & 201 & 86 \\
\hline University of California, Los Angeles & 3,887 & 3 & L.W. Bassett & 245 & 67 & 4,300 & 44 & 22 & 110 & 150 \\
\hline University of California, Riverside & 163 & 190 & J. Blacher & 69 & 240 & 713 & 198 & 17 & 153 & 61 \\
\hline University of California, San Diego & 10 & 316 & R.M. Kaplan & 327 & 38 & 6,283 & 25 & 36 & 44 & 150 \\
\hline University of California, San Francisco & 61 & 249 & K. Grumbach & 151 & 141 & 5,057 & 35 & 29 & 72 & 150 \\
\hline University of California, Santa Barbara & 4 & 335 & D.R. Atkinson & 46 & 281 & 745 & 193 & 12 & 211 & 57 \\
\hline University of California, Santa Cruz & 29 & 278 & & 0 & 340 & 0 & 337 & 0 & 329 & 0 \\
\hline University of Cambridge & 565 & 97 & & 0 & 340 & 0 & 337 & 0 & 329 & 0 \\
\hline University of Canterbury & 132 & 207 & G.T. Gillon & 32 & 297 & 181 & 280 & 8 & 263 & 22 \\
\hline University of Cape Town & 117 & 216 & L. London & 87 & 211 & 390 & 245 & 11 & 226 & 150 \\
\hline University of Central Florida & 189 & 182 & R.F. Zoeller & 43 & 285 & 402 & 243 & 13 & 201 & 127 \\
\hline University of Chicago & 23 & 285 & M.K. Wynia & 92 & 204 & 620 & 207 & 12 & 211 & 136 \\
\hline University of Cincinnati & 1,367 & 31 & E.B. Silberstein & 154 & 134 & 1,012 & 170 & 15 & 174 & 150 \\
\hline University of Colorado at Boulder & 5 & 330 & M.W. Frame & 9 & 331 & 34 & 320 & 3 & 311 & 5 \\
\hline University of Connecticut & 62 & 247 & R.W. Bohannon & 328 & 36 & 3,648 & 61 & 19 & 135 & 150 \\
\hline University of Copenhagen & 125 & 212 & J.M. Traulsen & 35 & 293 & 78 & 304 & 5 & 290 & 21 \\
\hline University of Delaware & 5 & 330 & G.H. Wade & 6 & 335 & 61 & 308 & 3 & 311 & 8 \\
\hline University of Dundee & 286 & 153 & D.M.J. Lilley & 239 & 73 & 3,757 & 59 & 37 & 41 & 150 \\
\hline University of Edinburgh & 149 & 199 & R. Mander & 50 & 273 & 72 & 306 & 4 & 302 & 21 \\
\hline University of Florida & 2,254 & 9 & I.F. Hawkins & 151 & 141 & 1,082 & 166 & 13 & 201 & 150 \\
\hline University of Geneva & 7 & 323 & A. Perrier & 236 & 76 & 2,771 & 84 & 33 & 52 & 150 \\
\hline University of Georgia & 13 & 309 & R.M. Cervero & 28 & 303 & 222 & 271 & 7 & 275 & 32 \\
\hline University of Ghent & 558 & 100 & H.M.A. Thierens & 193 & 106 & 1,932 & 122 & 26 & 88 & 150 \\
\hline University of Glasgow & 485 & 110 & R.W. Pickford & 50 & 273 & 19 & 328 & 0 & 329 & 13 \\
\hline
\end{tabular}




\begin{tabular}{|c|c|c|c|c|c|c|c|c|c|c|}
\hline University of Gothenburg & 154 & 196 & G. Grimby & 266 & 54 & 4,172 & 47 & 22 & 110 & 150 \\
\hline University of Groningen & 7 & 323 & J.W. Groothoff & 214 & 89 & 1,800 & 127 & 25 & 97 & 150 \\
\hline University of Helsinki & 455 & 120 & U.M. Kujala & 95 & 198 & 1,355 & 149 & 20 & 122 & 150 \\
\hline University of Hong Kong & 435 & 125 & P.L. Khong & 101 & 189 & 1,207 & 157 & 20 & 122 & 150 \\
\hline University of Houston & 380 & 129 & J.P.G. Bergmanson & 90 & 209 & 433 & 236 & 11 & 226 & 108 \\
\hline University of Illinois & 1,148 & 43 & G.A. Miller & 73 & 232 & 2 & 335 & 0 & 329 & 0 \\
\hline University of Illinois, Chicago & 1,552 & 21 & M.F. Mafee & 235 & 78 & 2,089 & 110 & 18 & 146 & 150 \\
\hline University of Indonesia & 9 & 319 & A. Gani & 5 & 338 & 32 & 322 & 2 & 319 & 11 \\
\hline University of Iowa & 34 & 273 & F.D. Wolinsky & 179 & 114 & 3,826 & 56 & 27 & 81 & 150 \\
\hline University of Kansas & 20 & 290 & E. Ablah & 46 & 281 & 88 & 303 & 5 & 290 & 88 \\
\hline University of Kentucky & 57 & 253 & C.H. Griffith & 71 & 237 & 483 & 230 & 14 & 185 & 90 \\
\hline University of Lausanne & 5 & 330 & L. Benaroyo & 15 & 322 & 20 & 327 & 3 & 311 & 20 \\
\hline University of Leeds & 19 & 292 & J. Sandars & 83 & 218 & 172 & 284 & 7 & 275 & 61 \\
\hline University of Leicester & 218 & 167 & M.C.R. Symons & 857 & 8 & 3,320 & 73 & 12 & 211 & 150 \\
\hline University of Liverpool & 412 & 126 & D.A. Brodie & 100 & 192 & 1,170 & 161 & 14 & 185 & 121 \\
\hline University of Ljubljana & 250 & 159 & F. Pernus & 81 & 222 & 516 & 223 & 14 & 185 & 53 \\
\hline University of London (Kings College of London) & 4,502 & 2 & K.H. Nicolaides & 892 & 6 & 25,807 & 3 & 64 & 2 & 150 \\
\hline University of Manchester & 1,175 & 40 & A.G. Lyne & 254 & 63 & 3,550 & 65 & 42 & 23 & 150 \\
\hline University of Manitoba & 652 & 78 & N.P. Roos & 122 & 170 & 1,684 & 129 & 13 & 201 & 124 \\
\hline University of Maryland & 586 & 92 & B.F. Hurley & 100 & 192 & 3,085 & 77 & 27 & 81 & 150 \\
\hline University of Maryland Baltimore County & 1,412 & 28 & C.S. White & 146 & 146 & 2,140 & 108 & 23 & 104 & 150 \\
\hline University of Massachusetts & 19 & 292 & R.F. Zoeller & 35 & 293 & 269 & 266 & 11 & 226 & 98 \\
\hline University of Melbourne & 962 & 53 & M. Hargreaves & 133 & 160 & 2,358 & 94 & 28 & 76 & 150 \\
\hline University of Miami & 1,264 & 35 & R.M. Quencer & 153 & 139 & 2,005 & 115 & 10 & 242 & 150 \\
\hline University of Michigan & 59 & 252 & L.D. Gruppen & 92 & 204 & 915 & 179 & 17 & 153 & 150 \\
\hline University of Minnesota & 52 & 255 & J.C. Schommer & 98 & 195 & 473 & 233 & 12 & 211 & 105 \\
\hline University of Missouri & 52 & 255 & K.J. Hagglund & 56 & 263 & 840 & 186 & 11 & 226 & 128 \\
\hline University of Nebraska & 344 & 137 & T.J. Housch & 189 & 107 & 1,204 & 158 & 21 & 116 & 131 \\
\hline University of New Hampshire & 166 & 189 & E.E. Swartz & 23 & 311 & 64 & 307 & 7 & 275 & 32 \\
\hline University of New Mexico & 14 & 305 & S. Kalishman & 24 & 308 & 188 & 277 & 4 & 302 & 87 \\
\hline University of New South Wales & 14 & 305 & J. Braithwaite & 106 & 181 & 590 & 212 & 14 & 185 & 105 \\
\hline University of North Carolina, Chapel Hill & 2,287 & 8 & O. Smithies & 273 & 51 & 18,441 & 5 & 46 & 16 & 150 \\
\hline University of North Texas & 5 & 330 & J.C. Licciardone & 61 & 254 & 273 & 265 & 9 & 254 & 61 \\
\hline University of Notre Dame & 36 & 272 & A.L. Barabasi & 170 & 122 & 15,860 & 8 & 58 & 9 & 150 \\
\hline University of Nottingham & 19 & 292 & P. Bissell & 55 & 264 & 319 & 256 & 11 & 226 & 68 \\
\hline University of Oklahoma & 14 & 305 & H.F. Stein & 80 & 224 & 277 & 264 & 6 & 281 & 54 \\
\hline
\end{tabular}




\begin{tabular}{|c|c|c|c|c|c|c|c|c|c|c|}
\hline University of Oregon & 1,315 & 33 & M.I. Posner & 195 & 104 & 12,847 & 11 & 39 & 35 & 150 \\
\hline University of Oslo & 15 & 303 & I.B. Corless & 73 & 232 & 483 & 230 & 12 & 211 & 150 \\
\hline University of Otago & $\mid 507$ & 108 & S.J. Sullivan & 68 & 243 & 393 & 244 & 10 & 242 & 95 \\
\hline University of Ottawa & 13 & 309 & I.D. Graham & 255 & 62 & 7,359 & 22 & 42 & 23 & 150 \\
\hline University of Oxford & 793 & 64 & S. Neubauer & 272 & 52 & 3,821 & 57 & 38 & 38 & 150 \\
\hline University of Pennsylvania & 41 & 268 & D.R. Hodge & 94 & 200 & 1,102 & 165 & 18 & 146 & 112 \\
\hline University of Pittsburgh & 51 & 258 & R.M. Arnold & 277 & 50 & 3,092 & 76 & 29 & 72 & 150 \\
\hline University of Quebec & 7 & 323 & F. Legara & 70 & 239 & 403 & 242 & 12 & 211 & 150 \\
\hline University of Queensland & 45 & 264 & S. Rodger & 86 & 214 & 324 & 254 & 9 & 254 & 107 \\
\hline University of Reading & 111 & 218 & S.J. Foley & 73 & 232 & 50 & 314 & 0 & 329 & 76 \\
\hline University of Rochester & 22 & 287 & R.M. Epstein & 113 & 174 & 2,471 & 93 & 24 & 100 & 150 \\
\hline University of Saskatchewan & 319 & 145 & P.D. Chilibeck & 78 & 226 & 926 & 177 & 19 & 135 & 111 \\
\hline University of Science and Technology of China & 27 & 280 & Y. Zhang & 321 & 40 & 1,676 & 130 & 19 & 135 & 150 \\
\hline University of Sheffield & 604 & 89 & D.W. Hughes & 189 & 107 & 848 & 185 & 14 & 185 & 150 \\
\hline University of South Carolina & 623 & 87 & R.R. Pate & 210 & 92 & 7,907 & 19 & 43 & 21 & 150 \\
\hline University of South Florida & 24 & 283 & K. Black & 19 & 318 & 116 & 294 & 4 & 302 & 17 \\
\hline University of Southampton & 60 & 250 & S. Payne & 124 & 166 & 1,521 & 136 & 20 & 122 & 150 \\
\hline University of Southern California & 62 & 247 & S. Sussman & 203 & 101 & 2,147 & 107 & 24 & 100 & 150 \\
\hline University of St Andrews & 6 & 327 & H.T.O. Davies & 328 & 36 & 5,329 & 30 & 44 & 19 & 150 \\
\hline University of Surrey & 9 & 319 & P. Smith & 32 & 297 & 162 & 287 & 8 & 263 & 46 \\
\hline University of Sussex & 125 & 212 & A.R. Lehmann & 250 & 66 & 5,248 & 31 & 42 & 23 & 150 \\
\hline University of Sydney & 1,500 & 22 & M. Nslow & 101 & 189 & 346 & 250 & 16 & 167 & 93 \\
\hline University of Technology, Sydney & 133 & 206 & A.J. Coutts & 52 & 269 & 367 & 247 & 10 & 242 & 77 \\
\hline University of Tennessee Knoxville & 457 & 118 & D.R. Bassett & 158 & 130 & 3,407 & 68 & 36 & 44 & 150 \\
\hline University of Texas at Austin & 16 & 300 & R.R. McDaniel & 66 & 245 & 687 & 202 & 18 & 146 & 77 \\
\hline University of Tokyo & 3 & 339 & H. Aiga & 11 & 326 & 33 & 321 & 3 & 311 & 17 \\
\hline University of Toronto & 3,400 & 6 & R.J. Shephard & 644 & 11 & 8,351 & 17 & 31 & 61 & 150 \\
\hline University of Tsukuba & 1 & 344 & E. Yokoyama & 104 & 185 & 263 & 268 & 8 & 263 & 150 \\
\hline University of Twente & 201 & 175 & H.B.K. Boom & 100 & 192 & 538 & 219 & 8 & 263 & 106 \\
\hline University of Utah & 1,854 & 13 & H.R. Harnsberger & 148 & 144 & 1,733 & 128 & 15 & 174 & 150 \\
\hline University of Vermont & 638 & 81 & B.D. Beynnon & 162 & 126 & 3,355 & 72 & 31 & 61 & 150 \\
\hline University of Victoria & 10 & 316 & C. Benoit & 29 & 302 & 94 & 301 & 6 & 281 & 43 \\
\hline University of Virginia & 14 & 305 & P.A. Kulbok & 25 & 306 & 178 & 282 & 6 & 281 & 39 \\
\hline University of Warwick & 125 & 212 & G. Lindsay & 38 & 292 & 166 & 285 & 10 & 242 & 38 \\
\hline University of Washington & 3,667 & 4 & L.A. Mack & 134 & 158 & 2,613 & 87 & 4 & 302 & 150 \\
\hline University of Waterloo & 641 & 80 & R. Hughson & 267 & 53 & 3,373 & 70 & 32 & 57 & 150 \\
\hline
\end{tabular}




\begin{tabular}{|c|c|c|c|c|c|c|c|c|c|c|}
\hline University of Western Australia & 637 & 82 & B. Dawson & 171 & 121 & 1,289 & 152 & 19 & 135 & 150 \\
\hline University of Western Ontario & 1,201 & 38 & B.K. Rutt & 150 & 143 & 2,666 & 85 & 31 & 61 & 150 \\
\hline University of Wisconsin & 69 & 241 & R.H. Laessig & 112 & 175 & 678 & 203 & 10 & 242 & 136 \\
\hline University of Wollongong & 4 & 335 & A. Rosen & 52 & 269 & 561 & 218 & 10 & 242 & 150 \\
\hline University of York & 13 & 309 & S. Brealey & 41 & 288 & 179 & 281 & 8 & 263 & 93 \\
\hline University of Zurich & 4 & 335 & L.M. Bachmann & 123 & 168 & 1,337 & 150 & 20 & 122 & 150 \\
\hline Univesitas Gadjah Mada & 4 & 335 & A. Somanathan & 6 & 335 & 145 & 290 & 5 & 290 & 35 \\
\hline Uppsala University & 883 & 58 & H.K. Ahlstrom & 148 & 144 & 2,049 & 114 & 21 & 116 & 150 \\
\hline Utah State & 149 & 199 & R.B. Gillam & 47 & 278 & 497 & 227 & 15 & 174 & 61 \\
\hline Utrecht University & 1,449 & 27 & M.A. Viergever & 313 & 42 & 6,626 & 24 & 38 & 38 & 150 \\
\hline Vanderbilt University & 9 & 319 & P.I. Buerhaus & 96 & 197 & 1,514 & 137 & 21 & 116 & 74 \\
\hline Victoria University of Wellington & 39 & 269 & J. Sigafoos & 57 & 260 & 53 & 312 & 4 & 302 & 90 \\
\hline Vienna University of Technology & 49 & 259 & K. Unterrainer & 218 & 88 & \begin{tabular}{l|l}
1,404 \\
\end{tabular} & 144 & 24 & 100 & 150 \\
\hline Virginia Polytechnic Institute & 199 & 177 & S.M. Duma & 141 & 152 & 329 & 253 & 13 & 201 & 125 \\
\hline Vrije Universiteit, Brussels & 1 & 344 & Y. Vandenplas & 13 & 324 & 28 & 325 & 2 & 319 & 49 \\
\hline VU University Amsterdam & 1,488 & 24 & F. Barkhof & 478 & 20 & 9,733 & 16 & 62 & 5 & 150 \\
\hline Wageningen University & 52 & 255 & H. Kromhout & 208 & 96 & 2,188 & 103 & 28 & 76 & 150 \\
\hline Wake Forest University & 22 & 287 & M.A. Hall & 229 & 84 & 2,346 & 95 & 31 & 61 & 150 \\
\hline Waseda University & 206 & 173 & T. Fukunaga & 222 & 86 & 2,531 & 89 & 35 & 47 & 150 \\
\hline Washington State University & 171 & 186 & P.D. Gollnick & 67 & 244 & 1,852 & 124 & 0 & 329 & 69 \\
\hline Washington University in St. Louis & 25 & 282 & E.M. Andresen & 80 & 224 & 1,547 & 135 & 20 & 122 & 135 \\
\hline Wayne State University & 1,023 & 49 & J.C. ViVan & 78 & 226 & 16 & 329 & 1 & 324 & 6 \\
\hline West Virginia University & 24 & 283 & R.L. Seip & 76 & 230 & 1,224 & 155 & 14 & 185 & 150 \\
\hline Yale University & 47 & 263 & M.A. Hoge & 53 & 266 & 432 & 238 & 11 & 226 & 150 \\
\hline Yonsei University & 635 & 84 & K.W. Kim & 112 & 175 & 787 & 189 & 17 & 153 & 150 \\
\hline York University & 244 & 160 & D.A. Hood & 92 & 204 & 1,450 & 142 & 23 & 104 & 94 \\
\hline Zhejiang University & 103 & 224 & X. Wang & 104 & 185 & 441 & 234 & 13 & 201 & 150 \\
\hline
\end{tabular}




\begin{tabular}{|c|c|c|c|c|c|c|c|c|c|c|}
\hline Decision Sciences Data & $\begin{array}{l}\text { Department } \\
\text { Publications }\end{array}$ & Rank & Most Prolific Author & Published & Rank & Cited & Rank & $\begin{array}{c}\text { H- } \\
\text { Index }\end{array}$ & Rank & $\begin{array}{c}\text { \# of } \\
\text { Coauthors }\end{array}$ \\
\hline Aalto University & 322 & 159 & R.P. Hamalainen & 98 & 132 & 693 & 136 & 15 & 100 & 61 \\
\hline Aarhus University & 222 & 219 & K.G. Grunert & 65 & 190 & 678 & 140 & 17 & 81 & 87 \\
\hline Arizonia State University & 803 & 38 & D.C. Montgomery & 198 & 55 & 1,709 & 47 & 21 & 45 & 150 \\
\hline Ateneo de Manila University & 0 & 347 & & 0 & 343 & 0 & 341 & 0 & 321 & 0 \\
\hline Auburn University & 372 & 134 & A.E. Smith & 121 & 105 & 1,134 & 84 & 17 & 81 & 96 \\
\hline Australian National University & 374 & 133 & P. Hall & 289 & 27 & 2,165 & 34 & 10 & 178 & 150 \\
\hline Boston College & 112 & 305 & J.L. Ringuest & 42 & 273 & 179 & 263 & 6 & 265 & 20 \\
\hline Boston University & 321 & 160 & H.E. Stanley & 480 & 10 & 10,348 & 17 & 57 & 15 & 150 \\
\hline Brandeis University & 72 & 329 & J.E. Haber & 252 & 40 & 6,952 & 21 & 53 & 17 & 150 \\
\hline Brigham Young University & 136 & 290 & J.V. Hansen & 57 & 219 & 330 & 204 & 9 & 192 & 32 \\
\hline Brown University & 248 & 207 & A. Landy & 99 & 128 & 1,375 & 63 & 16 & 91 & 110 \\
\hline California Institute of Technology (Calt... & 210 & 227 & L.E. Hood & 271 & 34 & 7,259 & 20 & 12 & 148 & 150 \\
\hline Cardiff University & 588 & 71 & S.M. Disney & 58 & 216 & 730 & 131 & 18 & 69 & 42 \\
\hline Carnegie Mellon University & 890 & 31 & E. Balas & 74 & 176 & 1,297 & 68 & 10 & 178 & 53 \\
\hline Case Western Reserve University & 388 & 127 & B. Malakooti & 4 & 339 & 4 & 338 & 1 & 315 & 4 \\
\hline Chalmers University of Technology & 213 & 225 & M. Patriksson & 49 & 241 & 359 & 200 & 11 & 166 & 36 \\
\hline Charles University & 179 & 252 & M. Huskova & 65 & 190 & 137 & 287 & 6 & 265 & 51 \\
\hline Chinese University of Hong Kong & 757 & 44 & D.S. Li & 174 & 70 & 1,055 & 95 & 18 & 69 & 150 \\
\hline Chulalongkorn University & 41 & 336 & P. Charusiri & 25 & 310 & 83 & 308 & 7 & 242 & 57 \\
\hline City University of Hong Kong & 782 & 41 & G.R. Chen & 679 & 5 & 14,882 & 10 & 62 & 9 & 150 \\
\hline City University of New York & 173 & 256 & M.S. Brown & 13 & 333 & 31 & 331 & 2 & 306 & 7 \\
\hline Colorado State University & 284 & 182 & R.A. Davis & 58 & 216 & 585 & 153 & 13 & 132 & 48 \\
\hline Columbia University & 848 & 35 & E.R. Kandal & 448 & 13 & 17,020 & 7 & 77 & 6 & 150 \\
\hline Cornell University & 1,449 & 7 & H.A. Scheraga & 1,020 & 1 & 21,551 & 5 & 47 & 21 & 150 \\
\hline Curtin University of Technology & 160 & 268 & K.L. Teo & 301 & 22 & 1,254 & 72 & 19 & 60 & 150 \\
\hline Dalhousie University & 178 & 254 & Q.M. He & 62 & 205 & 174 & 268 & 9 & 192 & 49 \\
\hline Dartmouth College & 233 & 215 & A.Gunasekaran & 158 & 80 & 1,484 & 57 & 18 & 69 & 118 \\
\hline Delft University of Technology & 401 & 120 & C. Roos & 63 & 201 & 358 & 201 & 11 & 166 & 51 \\
\hline Drexel University & 275 & 186 & M. Igbaria & 65 & 190 & 1,315 & 66 & 17 & 81 & 53 \\
\hline Duke University & 505 & 90 & R.J. Lefkowitz & 752 & 4 & 43,621 & 4 & 93 & 3 & 150 \\
\hline Durham University & 187 & 245 & D. Boulter & 198 & 55 & 1,463 & 58 & 3 & 300 & 150 \\
\hline Ecole Normale Supérieure de Lyon & 40 & 337 & & 0 & 343 & 0 & 341 & 0 & 321 & 0 \\
\hline École Normale Supérieure, Paris & 88 & 321 & F. Baccelli & 109 & 119 & 802 & 123 & 14 & 113 & 86 \\
\hline École Polytechnique & 158 & 271 & P. Bastiste & 54 & 228 & 195 & 252 & 9 & 192 & 57 \\
\hline
\end{tabular}




\begin{tabular}{|c|c|c|c|c|c|c|c|c|c|c|}
\hline Ecole Polytechnique Fédérale de Lausanne & 263 & 194 & D. DeWerra & 129 & 101 & 533 & 165 & 8 & 218 & 95 \\
\hline Eindhoven University of Technology & 585 & 72 & I.J.B.F. Adan & 66 & 187 & 251 & 232 & 9 & 192 & 55 \\
\hline Emory University & 144 & 282 & E. Bendoly & 32 & 297 & 237 & 240 & 11 & 166 & 34 \\
\hline Erasmus University Rotterdam & 652 & 59 & R. Dekker & 82 & 170 & 1,060 & 94 & 18 & 69 & 106 \\
\hline ETH Zurich (Swiss Federal Institute of Technology) & 401 & 120 & J. Nosberger & 102 & 124 & 1,131 & 85 & 22 & 40 & 122 \\
\hline Florida International University & 352 & 142 & C.P. Koulamas & 93 & 142 & 678 & 140 & 12 & 148 & 35 \\
\hline Florida State University & 438 & 108 & A. Kandel & 253 & 38 & 1,408 & 62 & 18 & 69 & 150 \\
\hline Freie Universität Berlin & 191 & 242 & V.A. Erdmann & 23 & 316 & 80 & 309 & 0 & 321 & 40 \\
\hline Friedrich Alexander Universität Erlangen Nürnberg & 217 & 222 & J .Jahn & 28 & 306 & 171 & 273 & 8 & 218 & 19 \\
\hline Fudan University & 271 & 189 & D.L. Zhu & 64 & 198 & 431 & 186 & 9 & 192 & 71 \\
\hline Georg August Universität Göttingen & 145 & 281 & M.M. Kocker & 184 & 65 & 1,247 & 73 & 13 & 132 & 150 \\
\hline George Mason University & 323 & 158 & C.M. Harris & 23 & 316 & 94 & 302 & 2 & 306 & 19 \\
\hline George Washington University & 361 & 139 & S. Kotz & 235 & 47 & 540 & 163 & 10 & 178 & 54 \\
\hline Georgetown University & 167 & 261 & R. Ernst & 16 & 329 & 208 & 248 & 6 & 265 & 14 \\
\hline Georgia Institute of Technology & 1,235 & 13 & G.L. Nemhauser & 110 & 115 & 1,705 & 48 & 19 & 60 & 84 \\
\hline Georgia State University & 248 & 207 & M. Keil & 64 & 198 & 1,171 & 82 & 20 & 49 & 66 \\
\hline Goteborg University & 293 & 177 & K. Alestig & 87 & 151 & 896 & 110 & 11 & 166 & 150 \\
\hline Harvard University & 1,230 & 14 & G.M. Whitesides & 939 & 3 & 75,622 & 1 & 109 & 2 & 150 \\
\hline Hebrew University of Jerusalem & 365 & 138 & G. Mosheviev & 63 & 201 & 450 & 184 & 12 & 148 & 17 \\
\hline Heidelberg Universität & 294 & 176 & R. Wagnefuhr & 18 & 326 & 0 & 341 & 0 & 321 & 4 \\
\hline Hokkaido University & 683 & 55 & J.I. Koyama & 90 & 147 & 188 & 257 & 0 & 321 & 104 \\
\hline Hong Kong Polytechnic University & 931 & 28 & T.C.E. Cheng & 367 & 17 & 2,060 & 36 & 23 & 36 & 150 \\
\hline Hong Kong University of Science \& Techno... & 668 & 57 & H. Yang & 128 & 102 & 948 & 106 & 20 & 49 & 92 \\
\hline Humboldt-Universität zu Berlin & 254 & 202 & R. Werner & 45 & 259 & 346 & 202 & 11 & 166 & 58 \\
\hline Imperial College London & 573 & 76 & B. Rustem & 84 & 166 & 159 & 277 & 9 & 192 & 52 \\
\hline Indian Institute of Technology Bombay (I... & 153 & 275 & P. Vellaisamy & 25 & 310 & 33 & 330 & 4 & 291 & 16 \\
\hline Indian Institute of Technology Delhi (II... & 241 & 210 & S.G. Deshmukh & 97 & 134 & 530 & 166 & 13 & 132 & 95 \\
\hline Indian Institute of Technology Kanpur (I... & 217 & 222 & D. Kundu & 107 & 120 & 277 & 221 & 12 & 148 & 48 \\
\hline Indiana University Bloomington & 590 & 70 & M.L. Puri & 97 & 134 & 879 & 113 & 7 & 242 & 67 \\
\hline Indiana University Indianapolis & 95 & 312 & J. Sarkar & 18 & 326 & 93 & 303 & 8 & 218 & 13 \\
\hline Iowa State University & 756 & 45 & W.Q. Meeker & 86 & 155 & 567 & 157 & 12 & 148 & 75 \\
\hline Johns Hopkins University & 389 & 126 & S.H. Snyder & 300 & 23 & 14,180 & 11 & 75 & 7 & 150 \\
\hline Kansas State University & 343 & 147 & E.S. Lee & 190 & 61 & 1,435 & 60 & 19 & 60 & 150 \\
\hline Katholieke Universiteit Leuven & 642 & 62 & M.J. Goovaerts & 134 & 97 & 360 & 199 & 11 & 166 & 74 \\
\hline Keio University & 304 & 170 & M. Maejima & 50 & 239 & 174 & 268 & 7 & 242 & 30 \\
\hline
\end{tabular}




\begin{tabular}{|c|c|c|c|c|c|c|c|c|c|c|}
\hline King Fahd University of Petroleum \& Minerals & 258 & 198 & M. Ben-Daya & 42 & 273 & 559 & 159 & 14 & 113 & 21 \\
\hline King Saud University & 257 & 199 & M.A. Noor & 251 & 41 & 869 & 115 & 21 & 45 & 65 \\
\hline Kobe University & 308 & 167 & A. Imai & 47 & 250 & 653 & 145 & 16 & 91 & 63 \\
\hline Korea Advanced Institute of Science \& Technology & 731 & 47 & Y.D. Kim & 68 & 186 & 757 & 127 & 14 & 113 & 68 \\
\hline Korea University & 251 & 206 & D.H. Kim & 1 & 342 & 30 & 332 & 0 & 321 & 2 \\
\hline Kyoto University & 464 & 101 & M. Fukushima & 163 & 77 & 1,320 & 65 & 21 & 45 & 150 \\
\hline Kyushu University & 784 & 40 & M. Nishimura & 44 & 268 & 75 & 313 & 0 & 321 & 38 \\
\hline La Trobe University & 106 & 307 & P. Kabaila & 51 & 236 & 73 & 314 & 7 & 242 & 12 \\
\hline Lancaster University & 3 & 343 & G. Johnes & 46 & 253 & 175 & 267 & 6 & 265 & 17 \\
\hline Leiden University & 140 & 286 & A. Hordijk & 63 & 201 & 196 & 250 & 7 & 242 & 36 \\
\hline Linkoping University & 135 & 291 & T. Larsson & 34 & 290 & 276 & 223 & 7 & 242 & 43 \\
\hline London School of Economics and Political Scie & 473 & 98 & Rosenhead, J.V. & 30 & 300 & 260 & 227 & 6 & 265 & 36 \\
\hline Loughborough University & 437 & 110 & J.M. Wilson & 56 & 223 & 268 & 226 & 8 & 218 & 29 \\
\hline Louisiana State University & 517 & 86 & B.R. Sarker & 99 & 128 & 871 & 114 & 18 & 69 & 50 \\
\hline Ludwig-Maximilians-Universität München & 367 & 137 & H.G. Zachau & 189 & 62 & 832 & 121 & 6 & 265 & 150 \\
\hline Lund University & 381 & 130 & S. Axsater & 62 & 205 & 464 & 182 & 12 & 148 & 22 \\
\hline Maastricht University & 252 & 204 & F.C.R. Spieksma & 46 & 253 & 294 & 216 & 8 & 218 & 45 \\
\hline Macquarie University & 133 & 293 & X. Zhou & 45 & 259 & 80 & 309 & 6 & 265 & 25 \\
\hline Mahidol University & 37 & 338 & Y. Lenbury & 54 & 228 & 137 & 287 & 6 & 265 & 91 \\
\hline Masaryk University & 26 & 340 & E. Zazimalova & 29 & 304 & 493 & 174 & 13 & 132 & 138 \\
\hline Massachusetts Institute of Technology & 1,246 & 12 & A. Rich & 337 & 21 & 5,872 & 24 & 32 & 25 & 150 \\
\hline McGill University & 723 & 48 & J.H. Quastel & 144 & 92 & 269 & 225 & 0 & 321 & 85 \\
\hline McMaster University & 657 & 58 & N. Balakrishnan & 367 & 17 & 813 & 122 & 16 & 91 & 150 \\
\hline Michigan State University & 704 & 51 & R. Narasimhan & 72 & 178 & 950 & 104 & 20 & 49 & 52 \\
\hline Michigan Technological University & 82 & 324 & A.P. Godbole & 30 & 300 & 85 & 306 & 5 & 281 & 43 \\
\hline Monash University & 398 & 123 & A.S. Sohal & 121 & 105 & 798 & 124 & 18 & 69 & 103 \\
\hline Montana State University & 75 & 327 & R.J. Boik & 38 & 283 & 375 & 197 & 7 & 242 & 35 \\
\hline Moscow State University & 118 & 301 & V.E. Tarasov & 86 & 155 & 209 & 247 & 16 & 91 & 3 \\
\hline Nagoya University & 164 & 263 & T. Namikawa & 87 & 151 & 569 & 156 & 14 & 113 & 150 \\
\hline Nanjing University & 161 & 267 & L. Wang & 153 & 82 & 1,055 & 95 & 19 & 60 & 150 \\
\hline Nanyang Technological University & 505 & 90 & $\mathrm{Z} . \mathrm{Wu}$ & 53 & 233 & 143 & 283 & 9 & 192 & 46 \\
\hline National Taiwan University & 329 & 155 & J.S. Yao & 46 & 253 & 277 & 221 & 14 & 113 & 34 \\
\hline National Tsing Hua University & 438 & 108 & U.P. Wen & 28 & 306 & 195 & 252 & 5 & 281 & 25 \\
\hline National University of Ireland, Galway & 108 & 306 & D. O'Regan & 410 & 15 & 1,602 & 52 & 22 & 40 & 143 \\
\hline National University of Singapore & 1,180 & 16 & M. Xie & 193 & 60 & 1,238 & 76 & 20 & 49 & 150 \\
\hline New Mexico State University & 140 & 286 & H.T. Nguyen & 218 & 50 & 834 & 120 & 12 & 148 & 150 \\
\hline
\end{tabular}




\begin{tabular}{|c|c|c|c|c|c|c|c|c|c|c|}
\hline New York University & 645 & 60 & S. Seshadri & 46 & 253 & 326 & 207 & 8 & 218 & 40 \\
\hline Newcastle University & 174 & 255 & K.D. Glazewood & 86 & 155 & 168 & 274 & 8 & 218 & 52 \\
\hline North Carolina State University & 637 & 64 & S.C. Fang & 107 & 120 & 547 & 162 & 13 & 132 & 69 \\
\hline Northeastern University & 310 & 165 & S.M. Gupta & 166 & 75 & 939 & 107 & 23 & 36 & 54 \\
\hline Northwestern University & 751 & 46 & W.J. Hopd & 62 & 205 & 791 & 126 & 12 & 148 & 45 \\
\hline Norwegian University of Science \& Technology & 261 & 196 & M. Christiansen & 20 & 323 & 121 & 292 & 8 & 218 & 21 \\
\hline Ohio State University & 1,034 & 23 & N.G. Hall & 60 & 212 & 1,003 & 100 & 16 & 91 & 60 \\
\hline Oklahoma State University & 253 & 203 & H.S. Lau & 85 & 163 & 593 & 152 & 12 & 148 & 26 \\
\hline Open University UK & 196 & 237 & M.C. Jones & 110 & 115 & 1,231 & 77 & 15 & 100 & 84 \\
\hline Oregon State University & 241 & 210 & R. Logendran & 57 & 219 & 363 & 198 & 8 & 218 & 34 \\
\hline Osaka University & 301 & 172 & T. Kishimoto & 626 & 8 & 44,277 & 3 & 79 & 5 & 150 \\
\hline Peking University & 303 & 171 & S.Y. He & 36 & 287 & 87 & 305 & 5 & 281 & 27 \\
\hline Pennsylvania State University & 1,310 & 10 & R.A. Wysk & 150 & 85 & 835 & 119 & 8 & 218 & 148 \\
\hline Pohang University of Science And Technology & 184 & 250 & H. Cho & 123 & 104 & 1,165 & 83 & 13 & 132 & 150 \\
\hline Portland State University & 142 & 284 & T. Daim & 75 & 175 & 155 & 278 & 6 & 265 & 85 \\
\hline Princeton University & 593 & 68 & W.B. Powell & 110 & 115 & 921 & 108 & 17 & 81 & 61 \\
\hline Purdue University & 1,175 & 17 & R. Uzsoy & 101 & 125 & 1,107 & 90 & 19 & 60 & 99 \\
\hline Queen's University & 290 & 179 & Y. Levin & 16 & 329 & 43 & 327 & 4 & 291 & 9 \\
\hline Queen's University of Belfast & 358 & 141 & J.W. Dundee & 464 & 11 & \begin{tabular}{l|l}
1,643 \\
\end{tabular} & 50 & 0 & 321 & 150 \\
\hline Queensland University of Technology & 185 & 248 & E. Kozan & 34 & 290 & 218 & 244 & 9 & 192 & 12 \\
\hline Radboud University, Nijmegen & 166 & 262 & S.H. Tijs & 147 & 88 & 558 & 160 & 10 & 178 & 114 \\
\hline Rensselaer Polytechnic Institute & 399 & 122 & C.J. Malmborg & 88 & 148 & 164 & 275 & 8 & 218 & 42 \\
\hline Rheinisch Westfalische Technische Hochschule Aach & 349 & 145 & H.J. Zimmermann & 46 & 253 & 576 & 154 & 10 & 178 & 53 \\
\hline Rheinische Friedrich Wilhelms Universitat Bonn & 192 & 241 & K. Wilecke & 288 & 28 & 5,294 & 25 & 53 & 17 & 150 \\
\hline Rice University & 283 & 184 & A. Miele & 195 & 58 & 245 & 236 & 8 & 218 & 62 \\
\hline Rochester Institute of Technology & 92 & 316 & A.A. Batatyal & 112 & 112 & 176 & 266 & 8 & 218 & 19 \\
\hline Royal Institute of Technology, KTH & 186 & 247 & & 0 & 343 & 0 & 341 & 0 & 321 & 0 \\
\hline Royal Melbourne Institute of Technology & 89 & 318 & B. Davey & 12 & 334 & 9 & 335 & 2 & 306 & 7 \\
\hline Rutgers & 971 & 24 & E.A. Elsayed & 99 & 128 & 481 & 178 & 9 & 192 & 86 \\
\hline Saint-Petersburg State University & 124 & 297 & V.F. Demyanov & 25 & 310 & 66 & 317 & 4 & 291 & 19 \\
\hline San Diego State University & 143 & 283 & C.W. Chow & 47 & 250 & 466 & 181 & 11 & 166 & 49 \\
\hline Sapienza University of Rome & 0 & 347 & & 0 & 343 & 0 & 341 & 0 & 321 & 0 \\
\hline Sciences Po Paris & 2 & 344 & F. Bidault & 8 & 337 & 64 & 318 & 3 & 300 & 10 \\
\hline Seoul National University & 336 & 152 & S. Lee & 59 & 215 & 124 & 291 & 8 & 218 & 60 \\
\hline Shanghai Jiao Tong University & 466 & 99 & M.O. Han & 147 & 88 & 525 & 169 & 17 & 81 & 88 \\
\hline Simon Fraser University & 228 & 217 & E.V. Choo & 24 & 314 & 308 & 212 & 4 & 291 & 16 \\
\hline
\end{tabular}




\begin{tabular}{|c|c|c|c|c|c|c|c|c|c|c|}
\hline Stanford University & 1,343 & & S.M. Karlin & 243 & 44 & 6,593 & 23 & 32 & 25 & 110 \\
\hline State University of New York Buffalo & 577 & 74 & R. Batta & 93 & 142 & 597 & 151 & 11 & 166 & 91 \\
\hline Stockholm University & 193 & 240 & & 0 & 343 & 0 & 341 & 0 & 321 & 0 \\
\hline Stony Brook University & 324 & 157 & E.A. Feinberg & 47 & 250 & 185 & 259 & 8 & 218 & 30 \\
\hline Syracuse University & 350 & 144 & U.N. Roy & 86 & 155 & 509 & 172 & 13 & 132 & 105 \\
\hline Tartu University (University of Tartu) & 28 & 339 & T. Kollo & 12 & 334 & 40 & 329 & 3 & 300 & 8 \\
\hline Technical University of Denmark & 256 & 200 & E. Mosekilde & 169 & 74 & 1,200 & 79 & 20 & 49 & 150 \\
\hline Technion & 787 & 39 & B. Golany & 65 & 190 & 1,105 & 91 & 12 & 148 & 73 \\
\hline Technische Universität Berlin & 231 & 216 & H.O. Gunther & 40 & 278 & 189 & 256 & 9 & 192 & 3952 \\
\hline Technische Universitat Chemnitz & 123 & 299 & G. Wanka & 56 & 223 & 96 & 301 & 7 & 242 & 14 \\
\hline Technische Universität Dresden & 222 & 219 & G. Scheithauer & 23 & 316 & 177 & 264 & 9 & 192 & 18 \\
\hline Technische Universität München & 330 & 154 & C. Kluppelberg & 57 & 219 & 444 & 185 & 12 & 148 & 52 \\
\hline Tel Aviv University & 758 & 43 & A. Tamir & 88 & 148 & 505 & 173 & 9 & 192 & 59 \\
\hline Texas A\&M University & 964 & 26 & W.E. Wihelm & 65 & 190 & 287 & 219 & 10 & 178 & 52 \\
\hline Texas Tech & 308 & 167 & H.C. Zhang & 88 & 148 & 553 & 161 & 12 & 148 & 100 \\
\hline Tohoku University & 134 & 292 & Z. Yosizawa & 160 & 79 & 254 & 229 & 0 & 321 & 90 \\
\hline Tokyo Institute of Technology & 372 & 134 & M. Kojima & 86 & 155 & 643 & 147 & 16 & 91 & 49 \\
\hline Trinity College Dublin & 147 & 280 & H.H. Dixon & 37 & 285 & 8 & 337 & 0 & 321 & 6 \\
\hline Tsinghua University & 535 & 84 & N. Zhao & 138 & 95 & 839 & 118 & 15 & 100 & 150 \\
\hline Tufts University & 87 & 322 & H.H. Wortis & 85 & 163 & 1,196 & 80 & 15 & 100 & 131 \\
\hline Universidad Autonoma de Madrid & 205 & 230 & A. Cuevas & 45 & 259 & 292 & 217 & 11 & 166 & 69 \\
\hline Universidad de Chile & 196 & 237 & A. Weintraub & 45 & 259 & 251 & 232 & 9 & 192 & 87 \\
\hline Universidad de Granada & 205 & 230 & A. Cuevas & 45 & 259 & 292 & 217 & 11 & 166 & 69 \\
\hline Universidad del País Vasco & 204 & 232 & M. De la Sen & 405 & 16 & 561 & 158 & 16 & 91 & 71 \\
\hline Universidad Nacional Autónoma de México ... & 105 & 308 & L.M. Fridman & 174 & 70 & 642 & 148 & 17 & 81 & 93 \\
\hline Universidad Politecnica de Madrid & 267 & 193 & C. Romero & 131 & 99 & 1,176 & 81 & 21 & 45 & 150 \\
\hline Universidade de São Paulo & 510 & 89 & H. Bolfarine & 85 & 163 & 196 & 250 & 9 & 192 & 63 \\
\hline Universidade Estadual de Campinas & 287 & 181 & J.M. Martinez & 243 & 44 & 1,817 & 43 & 27 & 31 & 150 \\
\hline Università degli Studi di Firenze & 227 & 218 & F. Schoen & 29 & 304 & 177 & 264 & 7 & 242 & 19 \\
\hline Università degli Studi di Padova & 461 & 102 & M. Fischetti & 76 & 172 & 843 & 117 & 15 & 100 & 64 \\
\hline Universita Di Bologna & 338 & 149 & P. Toth & 87 & 151 & 1,294 & 70 & 18 & 69 & 54 \\
\hline Universita di Pisa & 295 & 175 & G. Mastroeni & 23 & 316 & 61 & 320 & 3 & 300 & 21 \\
\hline Universitat Autonoma de Barcelona & 198 & 234 & J. E. Martinez-Legaz & 61 & 208 & 147 & 280 & 7 & 242 & 37 \\
\hline Universitat Bielefeld & 162 & 266 & D. Biskup & 16 & 329 & 236 & 241 & 8 & 218 & 8 \\
\hline Universität Bremen & 142 & 284 & K.D. Thoben & 50 & 239 & 174 & 268 & 5 & 281 & 78 \\
\hline Universitat d'Alacant & 158 & 271 & M.A. Lopez & 65 & 190 & 190 & 255 & 13 & 132 & 51 \\
\hline
\end{tabular}




\begin{tabular}{|c|c|c|c|c|c|c|c|c|c|c|}
\hline Universitat de València & 299 & 174 & R. Marti & \begin{tabular}{|c|}
57 \\
\end{tabular} & 219 & 527 & 167 & 14 & 113 & 51 \\
\hline Universität Frankfurt am Main & 113 & 304 & T. Weitzel & 30 & 300 & 50 & 322 & 4 & 291 & 31 \\
\hline Universität Freiburg & 89 & 318 & L. Ruschendorf & 71 & 181 & 245 & 236 & 7 & 242 & 32 \\
\hline Universitat Hamburg & 333 & 153 & C. Kanzow & 72 & 178 & 711 & 133 & 22 & 40 & 34 \\
\hline Universität Karlsruhe & 390 & 125 & V.D. Hanebeck & 111 & 113 & 233 & 242 & 9 & 192 & 64 \\
\hline Universitat Leipzig & 89 & 318 & S. Gottwald & 49 & 241 & 183 & 260 & 7 & 242 & 20 \\
\hline Universitat Munster (Westfälische Wilhelms-Un & 190 & 243 & H. Maurer & 71 & 181 & 258 & 228 & 11 & 166 & 39 \\
\hline Universitat Politecnica de Catalunya & 49 & 334 & R. Pastor & 45 & 259 & 127 & 290 & 8 & 218 & 39 \\
\hline Universität Regensburg & 99 & 311 & & 0 & 343 & 0 & 341 & 0 & 321 & 0 \\
\hline Universität Stuttgart & 104 & 309 & M. Kohler & 197 & 57 & 949 & 105 & 17 & 81 & 150 \\
\hline Universitat Trier & 139 & 288 & N.V. Thoai & 26 & 308 & 151 & 279 & 7 & 242 & 17 \\
\hline Universität Tübingen & 52 & 333 & F. Lang & 643 & 7 & 17,517 & 6 & 60 & 12 & 150 \\
\hline Universitat Wien (University of Vienna) & 316 & 162 & R.F. Hartl & 101 & 125 & 738 & 130 & 9 & 192 & 67 \\
\hline Universitat Zu Koln & 325 & 156 & K. Rajwsky & 120 & 107 & 9,130 & 18 & 5 & 281 & 150 \\
\hline Université Catholique de Louvain & 402 & 119 & L.A. Wolsey & 94 & 140 & 1,039 & 97 & 14 & 113 & 75 \\
\hline Universite de Liege & 94 & 315 & Y. Crama & 49 & 241 & 608 & 149 & 12 & 148 & 52 \\
\hline Université de Montréal & 713 & 49 & M. Gendreau & 147 & 88 & 2,111 & 35 & 29 & 30 & 130 \\
\hline Université de Nice Sophia Antipolis & 74 & 328 & F. Cuzin & 97 & 134 & 1,296 & 69 & 15 & 100 & 145 \\
\hline Universite Laval & 409 & 116 & J.M. Martel & 48 & 246 & 299 & 213 & 9 & 192 & 39 \\
\hline Universite Libre de Bruxelles & 411 & 115 & M. Labbe & 103 & 123 & 693 & 136 & 15 & 100 & 127 \\
\hline Université Paris Sorbonne & 169 & 259 & M. Hifi & 48 & 246 & 173 & 271 & 10 & 178 & 26 \\
\hline Universite Paris-Sud 11 & 234 & 213 & G. Schehr & 39 & 279 & 92 & 304 & 7 & 242 & 35 \\
\hline Université Pierre et Marie Curie & 597 & 67 & B. Bouchard & 21 & 322 & 79 & 311 & 5 & 281 & 13 \\
\hline Universiti Malaya (University of Malaya) & 114 & 303 & B.B. Zaidan & 19 & 325 & 9 & 335 & 2 & 306 & 28 \\
\hline University College Cork & 78 & 325 & B. Hnich & 41 & 276 & 115 & 294 & 6 & 265 & 37 \\
\hline University College Dublin & 160 & 268 & A. Patel & 69 & 185 & 98 & 300 & 6 & 265 & 61 \\
\hline University College London & 210 & 227 & J.B.S. Haldane & 64 & 198 & 113 & 295 & 1 & 315 & 19 \\
\hline University do Porto & 201 & 233 & J.M.S. Valente & 22 & 320 & 64 & 318 & 5 & 281 & 7 \\
\hline University of Aberdeen & 273 & 187 & J.A. Petty & 35 & 289 & 298 & 214 & 4 & 291 & 24 \\
\hline University of Adelaide & 153 & 275 & R.K. Morton & 22 & 320 & 50 & 322 & 0 & 321 & 24 \\
\hline University of Alabama & 552 & 81 & J.J.Buckley & 199 & 54 & 1,245 & 74 & 14 & 113 & 39 \\
\hline University of Alberta & 591 & 69 & E. Erkut & 48 & 246 & 426 & 187 & 9 & 192 & 52 \\
\hline University of Amsterdam & 449 & 105 & M.J. Goovaerts & 144 & 92 & 382 & 195 & 11 & 166 & 89 \\
\hline University of Antwerp & 269 & 190 & W. Pullaert & 38 & 283 & 120 & 293 & 7 & 242 & 29 \\
\hline University of Arizona & 711 & 50 & H.Chen & 282 & 30 & 1,873 & 42 & 27 & 31 & 150 \\
\hline University of Athens & 234 & 213 & A. Economou & 33 & 294 & 70 & 315 & 5 & 281 & 8 \\
\hline
\end{tabular}




\begin{tabular}{|c|c|c|c|c|c|c|c|c|c|c|}
\hline University of Auckland & 337 & 150 & M. Ehrgott & 53 & 233 & 314 & 211 & 9 & 192 & 57 \\
\hline University of Barcelona & 163 & 264 & D. Nualart & 120 & 107 & 682 & 139 & 14 & 113 & 72 \\
\hline University of Basel & 95 & 312 & T.A. Bickle & 111 & 113 & 1,068 & 93 & 17 & 81 & 150 \\
\hline University of Bath & 77 & 326 & R.H. Green & 26 & 308 & 329 & 205 & 9 & 192 & 12 \\
\hline University of Bergen & 215 & 224 & S.D. Flam & 54 & 228 & 188 & 257 & 6 & 265 & 27 \\
\hline University of Bern & 620 & 65 & H. Bunke & 275 & 32 & 1,723 & 46 & 20 & 49 & 150 \\
\hline University of Birmingham & 211 & 226 & J.H. Fremlin & 154 & 81 & 183 & 260 & 0 & 321 & 110 \\
\hline University of Bristol & 541 & 83 & D.J.D. Nicholas & 205 & 51 & 517 & 170 & 0 & 321 & 134 \\
\hline University of British Columbia & 856 & 33 & M. Queyranne & 51 & 236 & 486 & 177 & 10 & 178 & 64 \\
\hline University of Calgary & 577 & 74 & E.A. Silver & 98 & 132 & 967 & 102 & 7 & 242 & 64 \\
\hline University of California, Berkley & 3,471 & 1 & T.A. Henzinger & 176 & 69 & 2,720 & 31 & 20 & 49 & 145 \\
\hline University of California, Davis & 860 & 32 & H.M. Zhang & 66 & 187 & 451 & 183 & 14 & 113 & 73 \\
\hline University of California, Irvine & 568 & 77 & R.H. Asch & 171 & 72 & 1,971 & 37 & 2 & 306 & 150 \\
\hline University of California, Los Angeles & 1,129 & 20 & C.S. Tang & 60 & 212 & 1,448 & 59 & 14 & 113 & 68 \\
\hline University of California, Riverside & 268 & 191 & S. Schaible & 83 & 169 & 707 & 135 & 13 & 132 & 53 \\
\hline University of California, San Diego & 2,295 & 3 & M. Krstic & 263 & 36 & 1,507 & 56 & 24 & 35 & 105 \\
\hline University of California, San Francisco & 300 & 173 & S.B. Prusiner & 235 & 47 & 8,123 & 19 & 73 & 8 & 150 \\
\hline University of California, Santa Barbara & 1,453 & 6 & A. R. Teel & 270 & 35 & 2,699 & 32 & 25 & 33 & 96 \\
\hline University of California, Santa Cruz & 66 & 331 & H.F. Noller & 178 & 67 & 6,647 & 22 & 34 & 24 & 150 \\
\hline University of Cambridge & 1,186 & 15 & A.R. Fersht & 367 & 17 & 10,551 & 16 & 61 & 11 & 150 \\
\hline University of Canterbury & 185 & 248 & G.R. Wood & 44 & 268 & 173 & 271 & 8 & 218 & 49 \\
\hline University of Cape Town & 194 & 239 & T.J. Steward & 34 & 290 & 489 & 175 & 8 & 218 & 33 \\
\hline University of Central Florida & 404 & 118 & J.R. Schott & 30 & 300 & 131 & 289 & 6 & 265 & 4 \\
\hline University of Chicago & 568 & 77 & G.I. Bell & 294 & 24 & 11,329 & 15 & 48 & 20 & 150 \\
\hline University of Cincinnati & 384 & 129 & J.R. Evans & 44 & 268 & 270 & 224 & 60 & 12 & 31 \\
\hline University of Colorado at Boulder & 449 & 105 & F.W. Glover & 161 & 78 & 1,666 & 49 & 19 & 60 & 133 \\
\hline University of Connecticut & 513 & 87 & P.K. Moon & 42 & 273 & 145 & 281 & 1 & 315 & 8 \\
\hline University of Copenhagen & 424 & 111 & D. Pisinger & 45 & 259 & 665 & 144 & 13 & 132 & 44 \\
\hline University of Delaware & 313 & 164 & W.F.G. Swann & 91 & 146 & 27 & 333 & 0 & 321 & 10 \\
\hline University of Dundee & 70 & 330 & D.M.J. Lilley & 239 & 46 & 3,757 & 27 & 37 & 23 & 150 \\
\hline University of Edinburgh & 2 & 344 & L. Oxley & 76 & 172 & 241 & 238 & 9 & 192 & 32 \\
\hline University of Florida & 1,060 & 22 & P.M. Pardalos & 274 & 33 & 1,639 & 51 & 18 & 69 & 150 \\
\hline University of Geneva & 268 & 191 & S.E. Antonarakis & 245 & 43 & 11,610 & 14 & 54 & 16 & 150 \\
\hline University of Georgia & 580 & 73 & I.V. Basawa & 65 & 190 & 320 & 210 & 7 & 242 & 44 \\
\hline University of Ghent & 557 & 79 & B.D. de Baets & 204 & 52 & 1,205 & 78 & 20 & 49 & 150 \\
\hline University of Glasgow & 553 & 80 & D.M. Titterington & 119 & 109 & 1,327 & 64 & 13 & 132 & 150 \\
\hline
\end{tabular}




\begin{tabular}{|c|c|c|c|c|c|c|c|c|c|c|}
\hline University of Gothenburg & 1 & 346 & V.E. Mooser & 37 & 285 & 393 & 193 & 8 & 218 & 150 \\
\hline University of Groningen & 482 & 96 & G. Sieksma & 46 & 253 & 162 & 276 & 7 & 242 & 36 \\
\hline University of Helsinki & 124 & 297 & K. Alitalo & 292 & 25 & 11,660 & 13 & 89 & 4 & 150 \\
\hline University of Hong Kong & 675 & 56 & K.L. Mak & 146 & 91 & 1,131 & 85 & 20 & 49 & 67 \\
\hline University of Houston & 380 & 131 & G.R. Chen & 679 & 5 & 15,000 & 9 & 62 & 9 & 150 \\
\hline University of Illinois & 1,146 & 19 & S.H. Jacobson & 110 & 115 & 515 & 171 & 13 & 132 & 63 \\
\hline University of Illinois, Chicago & 477 & 97 & W.K. Chen & 92 & 144 & 79 & 311 & 2 & 306 & 66 \\
\hline University of Indonesia & 12 & 342 & D.I.S. Santoso & 2 & 341 & 44 & 326 & 1 & 315 & 9 \\
\hline University of Iowa & 823 & 36 & Y.Ye & 131 & 99 & 1,102 & 92 & 18 & 69 & 94 \\
\hline University of Kansas & 261 & 196 & P.P. Shenoy & 4 & 339 & 0 & 341 & 0 & 321 & 5 \\
\hline University of Kentucky & 417 & 113 & C.W. Holsapple & 96 & 138 & 915 & 109 & 15 & 100 & 63 \\
\hline University of Lausanne & 154 & 274 & H.U. Gerber & 52 & 235 & 487 & 176 & 12 & 148 & 24 \\
\hline University of Leeds & 692 & 54 & A.V. Holden & 195 & 58 & 1,131 & 85 & 16 & 91 & 150 \\
\hline University of Leicester & 290 & 179 & H.E. Street & 79 & 171 & 332 & 203 & 0 & 321 & 70 \\
\hline University of Liverpool & 486 & 95 & C.J.R. Parker & 39 & 279 & 322 & 209 & 6 & 265 & 37 \\
\hline University of Ljubljana & 130 & 294 & D. Matko & 86 & 155 & 254 & 229 & 10 & 178 & 71 \\
\hline University of London (Kings College of London) & 1,926 & 4 & L.J. Audus & 51 & 236 & 139 & 285 & 0 & 321 & 25 \\
\hline University of Manchester & 768 & 42 & A.G. Lyne & 254 & 37 & 3,550 & 29 & 42 & 22 & 150 \\
\hline University of Manitoba & 550 & 82 & A.S.Alfa & 117 & 110 & 573 & 155 & 13 & 132 & 75 \\
\hline University of Maryland & 901 & 29 & S.I. Gass & 61 & 208 & 324 & 208 & 7 & 242 & 36 \\
\hline University of Maryland Baltimore County & 443 & 107 & T.G. Mathew & 125 & 103 & 740 & 129 & 17 & 81 & 150 \\
\hline University of Massachusetts & 42 & 335 & A. Nagurney & 117 & 110 & 526 & 168 & 15 & 100 & 51 \\
\hline University of Melbourne & 452 & 103 & B.D. Craven & 49 & 241 & 212 & 246 & 3 & 300 & 24 \\
\hline University of Miami & 360 & 140 & V.J. Jayaraman & 39 & 279 & 646 & 146 & 14 & 113 & 34 \\
\hline University of Michigan & 1,383 & 8 & R.L. Smith & 60 & 212 & 391 & 194 & 9 & 192 & 43 \\
\hline University of Minnesota & 1,169 & 18 & R.G. Schroeder & 61 & 208 & 1,881 & 41 & 20 & 49 & 60 \\
\hline University of Missouri & 450 & 104 & C.M. Klein & 55 & 226 & 412 & 189 & 10 & 178 & 42 \\
\hline University of Nebraska & 315 & 163 & M.J. Schniederjans & 61 & 208 & 295 & 215 & 7 & 242 & 53 \\
\hline University of New Hampshire & 86 & 323 & D.L. Meeker & 54 & 228 & 1,945 & 38 & 15 & 100 & 93 \\
\hline University of New Mexico & 197 & 236 & J.J. Young & 20 & 323 & 145 & 281 & 7 & 242 & 15 \\
\hline University of New South Wales & 609 & 66 & V. Jeykumar & 84 & 166 & 380 & 196 & 15 & 100 & 40 \\
\hline University of North Carolina, Chapel Hill & 694 & 53 & P.K. Sen & 141 & 94 & 534 & 164 & 9 & 192 & 112 \\
\hline University of North Texas & 126 & 296 & R.J. Pavur & 33 & 294 & 61 & 320 & 4 & 291 & 35 \\
\hline University of Notre Dame & 187 & 245 & A.L. Barabasi & 170 & 73 & 16,008 & 8 & 58 & 14 & 150 \\
\hline University of Nottingham & 639 & 63 & E.K. Burke & 105 & 122 & 792 & 125 & 19 & 60 & 124 \\
\hline University of Oklahoma & 282 & 185 & A.B. Badiru & 65 & 190 & 217 & 245 & 5 & 281 & 47 \\
\hline
\end{tabular}




\begin{tabular}{|c|c|c|c|c|c|c|c|c|c|c|}
\hline University of Oregon & 393 & 124 & G.W. Evans & 49 & 241 & 252 & 231 & 10 & 178 & 24 \\
\hline University of Oslo & 284 & 182 & G. Dahl & 48 & 246 & 204 & 249 & 9 & 192 & 25 \\
\hline University of Otago & 153 & 275 & I.M. Premachandra & 15 & 332 & 70 & 315 & 6 & 265 & 18 \\
\hline University of Ottawa & 377 & 132 & M.G. Tyshenko & 31 & 299 & 2 & 340 & 1 & 315 & 19 \\
\hline University of Oxford & 958 & 27 & G.E. Blackman & 33 & 294 & 42 & 328 & 0 & 321 & 23 \\
\hline University of Pennsylvania & 1,268 & 11 & B. Chance & 452 & 12 & 4,881 & 26 & 32 & 25 & 150 \\
\hline University of Pittsburgh & 822 & 37 & T.L. Saaty & 94 & 140 & 2,411 & 33 & 13 & 132 & 39 \\
\hline University of Quebec & 158 & 271 & F. Legara & 70 & 183 & 403 & 190 & 12 & 148 & 150 \\
\hline University of Queensland & 465 & 100 & D.N.P. Murthy & 136 & 96 & 676 & 143 & 14 & 113 & 79 \\
\hline University of Reading & 95 & 312 & S.J. Foley & 73 & 177 & 50 & 322 & 0 & 321 & 76 \\
\hline University of Rochester & 90 & 317 & A. Seidmann & 76 & 172 & 973 & 101 & 9 & 192 & 58 \\
\hline University of Saskatchewan & 116 & 302 & W.K. Grassmann & 45 & 259 & 248 & 234 & 4 & 291 & 19 \\
\hline University of Science and Technology of China & 368 & 136 & T. Hu & 151 & 83 & 965 & 103 & 15 & 100 & 150 \\
\hline University of Sheffield & 387 & 128 & D.W. Hughes & 189 & 62 & 848 & 116 & 14 & 113 & 150 \\
\hline University of South Carolina & 337 & 150 & M.K. Malhorta & 39 & 279 & 710 & 134 & 14 & 113 & 25 \\
\hline University of South Florida & 321 & 160 & A. Kandel & 253 & 38 & 1,411 & 61 & 18 & 69 & 150 \\
\hline University of Southampton & 703 & 52 & C.N.Potts & 87 & 151 & 1,563 & 55 & 17 & 81 & 85 \\
\hline University of Southern California & 966 & 25 & R.E. Kalaba & 288 & 28 & 473 & 180 & 10 & 178 & 150 \\
\hline University of St Andrews & 148 & 279 & C.Carter & 947 & 2 & 113 & 295 & 8 & 218 & 15 \\
\hline University of Surrey & 121 & 300 & T.J. Bridges & 72 & 178 & 604 & 150 & 15 & 100 & 32 \\
\hline University of Sussex & 255 & 201 & T.J. Flowers & 32 & 297 & 402 & 191 & 2 & 306 & 53 \\
\hline University of Sydney & 293 & 177 & D.A. Hewsher & 203 & 53 & 1,243 & 75 & 19 & 60 & 128 \\
\hline University of Technology, Sydney & 183 & 251 & G.Q. Zhang & 92 & 144 & 182 & 262 & 10 & 178 & 66 \\
\hline University of Tennessee Knoxville & 308 & 167 & M.M. Srinivasan & 36 & 287 & 281 & 220 & 7 & 242 & 25 \\
\hline University of Texas at Austin & 347 & 146 & A.B. Whinston & 280 & 31 & 1,595 & 54 & 23 & 36 & 150 \\
\hline University of Tokyo & 2,565 & 2 & S. Miyachi & 164 & 76 & 1,125 & 89 & 18 & 69 & 150 \\
\hline University of Toronto & 891 & 30 & O. Berman & 150 & 85 & 685 & 138 & 14 & 113 & 70 \\
\hline University of Tsukuba & 504 & 92 & T. Fujii & 24 & 314 & 99 & 299 & 0 & 321 & 25 \\
\hline University of Twente & 519 & 85 & W.M. Albers & 58 & 216 & 230 & 243 & 10 & 178 & 46 \\
\hline University of Utah & 235 & 212 & L. Horvath & 151 & 83 & 741 & 128 & 12 & 148 & 50 \\
\hline University of Vermont & 149 & 278 & B.S. Lee & 34 & 290 & 48 & 325 & 4 & 291 & 54 \\
\hline University of Victoria & 163 & 264 & H.M. Srivastava & 366 & 20 & 1,009 & 99 & 20 & 49 & 150 \\
\hline University of Virginia & 407 & 117 & J.W. Beams & 97 & 134 & 112 & 297 & 0 & 321 & 59 \\
\hline University of Warwick & 159 & 270 & N. Chater & 99 & 128 & 1,129 & 88 & 25 & 33 & 76 \\
\hline University of Washington & 645 & 60 & R.D. Palmiter & 291 & 26 & 12,644 & 12 & 50 & 19 & 150 \\
\hline University of Waterloo & 1,062 & 21 & Y. Gerchak & 86 & 155 & 888 & 112 & 14 & 113 & 49 \\
\hline
\end{tabular}




\begin{tabular}{|c|c|c|c|c|c|c|c|c|c|c|}
\hline University of Western Australia & 272 & 188 & M. McAleer & 181 & 66 & 677 & 142 & 14 & 113 & 113 \\
\hline University of Western Ontario & 512 & 88 & P.W. Yu & 189 & 62 & 1,268 & 71 & 22 & 40 & 150 \\
\hline University of Wisconsin & 1,496 & 5 & O.L. Mansgasarian & 100 & 127 & 1,724 & 45 & 13 & 132 & 33 \\
\hline University of Wollongong & 173 & 256 & J.C.W. Rayner & 54 & 228 & 142 & 284 & 5 & 281 & 18 \\
\hline University of York & 242 & 209 & M.J. Smith & 25 & 310 & 328 & 206 & 2 & 306 & 4 \\
\hline University of Zurich & 352 & 142 & T. Rulicke & 86 & 155 & 3,618 & 28 & 32 & 25 & 150 \\
\hline Univesitas Gadjah Mada & 15 & 341 & Y. Soenarto & 18 & 326 & 104 & 298 & 2 & 306 & 150 \\
\hline Uppsala University & 310 & 165 & A. Gut & 44 & 268 & 195 & 252 & 6 & 265 & 17 \\
\hline Utah State & 179 & 252 & P.S. Kokoszka & 70 & 183 & 481 & 178 & 12 & 148 & 33 \\
\hline Utrecht University & 189 & 244 & J. Oerlemans & 150 & 85 & 1,749 & 44 & 23 & 36 & 150 \\
\hline Vanderbilt University & 262 & 195 & R.W. Blanning & 63 & 201 & 248 & 234 & 8 & 218 & 19 \\
\hline Victoria University of Wellington & 128 & 295 & L.M. Corbett & 11 & 336 & 139 & 285 & 7 & 242 & 16 \\
\hline Vienna University of Technology & 56 & 332 & G. Feichtinger & 134 & 97 & 417 & 188 & 8 & 218 & 65 \\
\hline Virginia Polytechnic Institute & 208 & 229 & H.D. Sherali & 246 & 42 & 1,310 & 67 & 16 & 91 & 146 \\
\hline Vrije Universiteit, Brussels & 198 & 234 & F.A. Plastria & 55 & 226 & 238 & 239 & 9 & 192 & 60 \\
\hline VU University Amsterdam & 419 & 112 & P. Nijkamp & 436 & 14 & 1,911 & 40 & 19 & 60 & 150 \\
\hline Wageningen University & 222 & 219 & J.E.R. Frijters & 44 & 268 & 1,921 & 39 & 0 & 321 & 29 \\
\hline Wake Forest University & 138 & 289 & J.R. Meredith & 56 & 223 & 1,027 & 98 & 8 & 218 & 36 \\
\hline Waseda University & 173 & 256 & M. Gendreau & 222 & 49 & 1,602 & 52 & 22 & 40 & 134 \\
\hline Washington State University & 341 & 148 & M. Jacroux & 45 & 259 & 85 & 306 & 3 & 300 & 14 \\
\hline Washington University in St. Louis & 502 & 93 & P. Kouvelis & 66 & 187 & 891 & 111 & 13 & 132 & 40 \\
\hline Wayne State University & 487 & 94 & M. Goodman & 177 & 68 & 3,040 & 30 & 30 & 29 & 150 \\
\hline West Virginia University & 168 & 260 & R.C. Colwell & 41 & 276 & 4 & 338 & 0 & 321 & 13 \\
\hline Yale University & 851 & 34 & R.A. Flavell & 602 & 9 & 50,757 & 2 & 115 & 1 & 150 \\
\hline Yonsei University & 252 & 204 & S.Y. Sohn & 96 & 138 & 394 & 192 & 12 & 148 & 64 \\
\hline York University & 415 & 114 & W.D. Cook & 84 & 166 & 717 & 132 & 14 & 113 & 40 \\
\hline Zhejiang University & 101 & 310 & J. Chen & 6 & 338 & 26 & 334 & 1 & 315 & 9 \\
\hline
\end{tabular}




\begin{tabular}{|c|c|c|c|c|c|c|c|c|c|c|}
\hline Economics/Econometrics/Finance Data & $\begin{array}{l}\text { Department } \\
\text { Publications }\end{array}$ & Rank & Most Prolific Author & Published & Rank & Cited & Rank & $\begin{array}{c}\text { H- } \\
\text { Index }\end{array}$ & Rank & $\begin{array}{c}\text { \# of } \\
\text { Coauthors }\end{array}$ \\
\hline Aalto University & 127 & 288 & E. Autio & 35 & 255 & 1,113 & 66 & 13 & 103 & 39 \\
\hline Aarhus University & 612 & 90 & T.M. Anderson & 64 & 158 & 208 & 216 & 6 & 253 & 39 \\
\hline Arizonia State University & 587 & 98 & J.C. Brada & 80 & 115 & 304 & 182 & 6 & 253 & 34 \\
\hline Ateneo de Manila University & 7 & 345 & E.L. Beja & 3 & 335 & 4 & 334 & 1 & 331 & 0 \\
\hline Auburn University & 523 & 116 & R.B. Ekelund & 44 & 219 & 150 & 251 & 6 & 253 & 33 \\
\hline Australian National University & 1,287 & 34 & A. Liegh & 50 & 195 & 127 & 269 & 6 & 253 & 21 \\
\hline Boston College & 670 & 77 & E.J. Kane & 66 & 150 & 379 & 157 & 8 & 196 & 23 \\
\hline Boston University & 944 & 55 & H.E Stanley & 480 & 3 & 10,348 & 3 & 57 & 3 & 150 \\
\hline Brandeis University & 235 & 229 & G.H. Jefferson & 33 & 260 & 503 & 126 & 10 & 150 & 33 \\
\hline Brigham Young University & 246 & 222 & C.A. Pope & 72 & 132 & 6,318 & 6 & 23 & 35 & 133 \\
\hline Brown University & 701 & 72 & L. Putterman & 70 & 136 & 533 & 118 & 14 & 88 & 29 \\
\hline California Institute of Technology (Calt... & 519 & 119 & C.R. Plott & 53 & 186 & 806 & 86 & 15 & 79 & 55 \\
\hline Cardiff University & 662 & 79 & D.A. Thomas & 1 & 338 & 1 & 335 & 0 & 336 & 2 \\
\hline Carnegie Mellon University & 932 & 57 & D. Epple & 45 & 215 & 788 & 88 & 11 & 128 & 34 \\
\hline Case Western Reserve University & 6,889 & 1 & B. Carlson & 27 & 283 & 510 & 125 & 10 & 150 & 20 \\
\hline Chalmers University of Technology & 4,623 & 3 & S. Jacobosson & 31 & 270 & 398 & 153 & 10 & 150 & 24 \\
\hline Charles University & 241 & 227 & E. Kocenda & 42 & 232 & 101 & 283 & 7 & 226 & 17 \\
\hline Chinese University of Hong Kong & 627 & 87 & C.C. Chao & 56 & 179 & 167 & 239 & 7 & 226 & 15 \\
\hline Chulalongkorn University & 63 & 316 & P. Limpaphayom & 12 & 324 & 74 & 303 & 6 & 253 & 16 \\
\hline City University of Hong Kong & 549 & 108 & G.R. Chen & 681 & 1 & 14,794 & 1 & 61 & 2 & 150 \\
\hline City University of New York & 603 & 93 & T.G. Bali & 40 & 240 & 144 & 259 & 7 & 226 & 27 \\
\hline Colorado State University & 253 & 219 & J. Loomis & 182 & 31 & 1,265 & 59 & 18 & 56 & 150 \\
\hline Columbia University & 2,192 & 9 & J. Sachs & 31 & 270 & 50 & 312 & 3 & 312 & 96 \\
\hline Cornell University & 1,778 & 18 & T. Mitra & 68 & 145 & 234 & 199 & 7 & 226 & 36 \\
\hline Curtin University of Technology & 203 & 245 & G. Madden & 42 & 232 & 179 & 232 & 9 & 174 & 18 \\
\hline Dalhousie University & 224 & 237 & B. Worm & 50 & 195 & 2,294 & 33 & 25 & 26 & 132 \\
\hline \begin{tabular}{|l|} 
Dartmouth College \\
\end{tabular} & 621 & 88 & J.T. Scott & 43 & 225 & 266 & 191 & 11 & 128 & 22 \\
\hline Delft University of Technology & 146 & 278 & J.W. De Leeuw & 342 & 6 & 4,616 & 12 & 30 & 19 & 150 \\
\hline Drexel University & 299 & 192 & S. Hammoudeh & 32 & 265 & 83 & 298 & 6 & 253 & 26 \\
\hline Duke University & 1,427 & 27 & H. Petroski & 161 & 41 & 183 & 229 & 3 & 312 & 15 \\
\hline Durham University & 313 & 187 & S.C. Parker & 41 & 237 & 247 & 192 & 10 & 150 & 14 \\
\hline Ecole Normale Supérieure de Lyon & 6 & 346 & & 0 & 339 & 0 & 337 & 0 & 336 & 0 \\
\hline École Normale Supérieure, Paris & 108 & 301 & T. Verdier & 48 & 206 & 786 & 89 & 14 & 88 & 34 \\
\hline École Polytechnique & 266 & 210 & E. Strol & 65 & 152 & 358 & 166 & 10 & 150 & 35 \\
\hline
\end{tabular}




\begin{tabular}{|c|c|c|c|c|c|c|c|c|c|c|}
\hline Ecole Polytechnique Fédérale de Lausanne & 53 & 323 & & 20 & 307 & 139 & 260 & 7 & 226 & 18 \\
\hline Eindhoven University of Technology & 245 & 223 & B. Verspagen & 50 & 195 & 576 & 113 & 12 & 114 & 48 \\
\hline Emory University & 553 & 107 & R.J. Cebebula & 129 & 63 & 166 & 240 & 4 & 296 & 40 \\
\hline Erasmus University Rotterdam & 1,631 & 19 & P.H. Franses & 177 & 34 & 960 & 76 & 18 & 56 & 105 \\
\hline ETH Zurich (Swiss Federal Institute of Technology) & 1,545 & 21 & H. Gersbach & 65 & 152 & 153 & 250 & 8 & 196 & 20 \\
\hline Florida International University & 421 & 150 & W.G. Hardin & 32 & 265 & 71 & 304 & 6 & 253 & 27 \\
\hline Florida State University & 462 & 138 & R.G. Holcombe & 69 & 138 & 243 & 194 & 7 & 226 & 26 \\
\hline Freie Universität Berlin & 296 & 195 & K.A. Konrad & 75 & 127 & 461 & 132 & 11 & 128 & 38 \\
\hline Friedrich Alexander Universität Erlangen Nürnberg & 154 & 272 & C. Schnabel & 34 & 258 & 150 & 251 & 8 & 196 & 16 \\
\hline Fudan University & 115 & 295 & & 0 & 339 & 0 & 337 & 0 & 336 & 0 \\
\hline Georg August Universität Göttingen & 262 & 214 & S. Klasen & 38 & 244 & 334 & 171 & 11 & 128 & 34 \\
\hline George Mason University & 3,118 & 6 & K. Button & 112 & 79 & 421 & 142 & 10 & 150 & 58 \\
\hline George Washington University & 637 & 85 & J.M. Logsdon & 89 & 97 & 1,563 & 51 & 21 & 39 & 150 \\
\hline Georgetown University & 649 & 81 & R. Lagunoff & 27 & 283 & 86 & 295 & 6 & 253 & 9 \\
\hline Georgia Institute of Technology & 392 & 155 & R.J. Cebula & 129 & 63 & 166 & 240 & 4 & 296 & 40 \\
\hline Georgia State University & 747 & 70 & J. Alm & 54 & 184 & 466 & 130 & 11 & 128 & 50 \\
\hline Goteborg University & 428 & 146 & T. Garling & 148 & 49 & 1,276 & 58 & 19 & 49 & 150 \\
\hline Harvard University & 4,064 & 5 & A. Shleifer & 81 & 113 & 8,712 & 4 & 43 & 4 & 38 \\
\hline Hebrew University of Jerusalem & 1,118 & 40 & B. Peleg & 68 & 145 & 629 & 109 & 5 & 277 & 37 \\
\hline Heidelberg Universität & 234 & 230 & H. Gersbach & 60 & 168 & 130 & 265 & 7 & 226 & 18 \\
\hline Hokkaido University & 94 & 306 & S. Tabata & 10 & 326 & 47 & 314 & 5 & 277 & 2 \\
\hline Hong Kong Polytechnic University & 454 & 142 & M. Firth & 63 & 161 & 562 & 115 & 14 & 88 & 51 \\
\hline Hong Kong University of Science \& Techno... & 642 & 83 & Y.K. Kwok & 47 & 211 & 103 & 281 & 4 & 296 & 27 \\
\hline Humboldt-Universität zu Berlin & 504 & 125 & W. Guth & 112 & 79 & 1,166 & 63 & 12 & 114 & 89 \\
\hline Imperial College London & 593 & 94 & K. Balcombe & 41 & 237 & 94 & 287 & 5 & 277 & 31 \\
\hline Indian Institute of Technology Bombay (I... & 18 & 340 & V. Kathuria & 19 & 310 & 93 & 289 & 5 & 277 & 10 \\
\hline Indian Institute of Technology Delhi (II... & 37 & 331 & S.G. Deshmukh & 95 & 91 & 686 & 100 & 14 & 88 & 64 \\
\hline Indian Institute of Technology Kanpur (I... & 26 & 337 & & 0 & 339 & 0 & 337 & 0 & 336 & 0 \\
\hline Indiana University Bloomington & 1,308 & 33 & D.B. Audretsch & 124 & 66 & 2,015 & 37 & 19 & 49 & 63 \\
\hline Indiana University Indianapolis & 135 & 285 & P.C. Rangazas & 14 & 322 & 44 & 318 & 4 & 296 & 5 \\
\hline Iowa State University & 657 & 80 & D.A. Hennessy & 83 & 110 & 375 & 159 & 9 & 174 & 32 \\
\hline Johns Hopkins University & 827 & 64 & S.H. Snyder & 300 & 10 & 14,180 & 2 & 75 & 1 & 150 \\
\hline Kansas State University & 317 & 185 & D.L. Weisman & 49 & 204 & 188 & 224 & 9 & 174 & 25 \\
\hline Katholieke Universiteit Leuven & 815 & 66 & M.J. Goovaerts & 134 & 58 & 360 & 165 & 11 & 128 & 74 \\
\hline Keio University & 217 & 241 & M. Yano & 86 & 101 & 234 & 199 & 8 & 196 & 150 \\
\hline
\end{tabular}




\begin{tabular}{|c|c|c|c|c|c|c|c|c|c|c|}
\hline King Fahd University of Petroleum \& Minerals & 76 & 310 & A.M.M. Masih & 38 & 244 & 401 & 152 & 11 & 128 & 13 \\
\hline King Saud University & 43 & 329 & M.A. Hariga & 34 & 258 & 413 & 148 & 11 & 128 & 11 \\
\hline Kobe University & 382 & 160 & S. Hamori & 50 & 195 & 118 & 272 & 5 & 277 & 15 \\
\hline Korea Advanced Institute of Science \& Technology & 144 & 279 & J.C. Kim & 21 & 304 & 47 & 314 & 3 & 312 & 16 \\
\hline Korea University & 284 & 201 & C.J. Kim & 530 & 2 & 0 & 337 & 34 & 11 & 150 \\
\hline Kyoto University & 373 & 165 & K. Nishimura & 248 & 18 & 1,702 & 44 & 21 & 39 & 150 \\
\hline Kyushu University & 28 & 336 & Y. Iwasa & 189 & 29 & 3,456 & 19 & 30 & 19 & 139 \\
\hline La Trobe University & 290 & 197 & I.A. Moosa & 72 & 132 & 225 & 205 & 8 & 196 & 21 \\
\hline Lancaster University & 339 & 175 & G. Johnes & 46 & 212 & 175 & 236 & 6 & 253 & 17 \\
\hline Leiden University & 250 & 221 & W.I.M. Groot & 69 & 138 & 444 & 135 & 9 & 174 & 70 \\
\hline Linkoping University & 88 & 307 & P. Westermark & 266 & 14 & 3,030 & 22 & 25 & 26 & 150 \\
\hline London School of Economics and Political Scie & 2,229 & 8 & O.B. Linton & 78 & 119 & 736 & 94 & 17 & 64 & 99 \\
\hline Loughborough University & 354 & 172 & T.C. Mills & 77 & 123 & 415 & 146 & 9 & 174 & 34 \\
\hline Louisiana State University & 494 & 130 & G.K. Turnbull & 85 & 104 & 339 & 170 & 10 & 150 & 36 \\
\hline Ludwig-Maximilians-Universität München & 636 & 86 & P. Egger & 138 & 56 & 1,584 & 50 & 17 & 64 & 125 \\
\hline Lund University & 523 & 116 & J. Westerlund & 44 & 219 & 201 & 219 & 8 & 196 & 35 \\
\hline Maastricht University & 964 & 51 & H. Peters & 44 & 219 & 124 & 270 & 6 & 253 & 40 \\
\hline Macquarie University & 242 & 226 & J.A .Mathews & 45 & 215 & 556 & 116 & 15 & 79 & 16 \\
\hline Mahidol University & 22 & 338 & & 0 & 339 & 0 & 337 & 0 & 336 & 0 \\
\hline Masaryk University & 43 & 329 & T. Sirovatka & 18 & 314 & 21 & 330 & 2 & 327 & 5 \\
\hline Massachusetts Institute of Technology & 1,982 & 13 & A. Rich & 337 & 7 & 5,872 & 7 & 32 & 14 & 150 \\
\hline McGill University & 562 & 104 & N.Van Long & 80 & 115 & 370 & 161 & 8 & 196 & 41 \\
\hline McMaster University & 588 & 96 & A. Gafri & 319 & 9 & 5,201 & 10 & 35 & 10 & 150 \\
\hline Michigan State University & 1,245 & 35 & P. Schmidt & 62 & 166 & 2,803 & 25 & 9 & 174 & 51 \\
\hline Michigan Technological University & 60 & 318 & M.C. Roberts & 18 & 314 & 37 & 321 & 3 & 312 & 4 \\
\hline Monash University & 839 & 62 & R. Symth & 121 & 67 & 324 & 174 & 12 & 114 & 56 \\
\hline Montana State University & 199 & 249 & W.A. Stock & 106 & 87 & 1,780 & 42 & 21 & 39 & 150 \\
\hline Moscow State University & 52 & 326 & V.E. Tarasov & 86 & 101 & 209 & 214 & 16 & 75 & 3 \\
\hline Nagoya University & 109 & 299 & N. Yamori & 29 & 276 & 104 & 280 & 5 & 277 & 36 \\
\hline Nanjing University & 44 & 327 & L. Wang & 153 & 48 & 1,055 & 68 & 19 & 49 & 150 \\
\hline Nanyang Technological University & 375 & 163 & S.T. Lau & 14 & 322 & 109 & 274 & 5 & 277 & 12 \\
\hline National Taiwan University & 500 & 127 & J.T. Liu & 9 & 328 & 22 & 328 & 3 & 312 & 18 \\
\hline National Tsing Hua University & 130 & 286 & W.W. Lin & 158 & 42 & 1,477 & 53 & 18 & 56 & 150 \\
\hline National University of Ireland, Galway & 109 & 299 & S. Fountas & 35 & 255 & 154 & 247 & 9 & 174 & 22 \\
\hline National University of Singapore & 1,033 & 46 & Y. Sun & 42 & 232 & 108 & 275 & 10 & 150 & 17 \\
\hline New Mexico State University & 147 & 275 & R.T. Peterson & 33 & 260 & 408 & 149 & 8 & 196 & 19 \\
\hline
\end{tabular}




\begin{tabular}{|c|c|c|c|c|c|c|c|c|c|c|}
\hline New York University & 2,086 & 11 & A. Saunders & 68 & 145 & 808 & 85 & 12 & 114 & 65 \\
\hline Newcastle University & 514 & 122 & S.K. Runcorn & 81 & 113 & 163 & 244 & 3 & 312 & 82 \\
\hline North Carolina State University & 566 & 103 & B.K. Goodwin & 61 & 167 & 416 & 144 & 12 & 114 & 40 \\
\hline Northeastern University & 323 & 182 & K.A. Eddeston & 25 & 293 & 281 & 190 & 11 & 128 & 22 \\
\hline Northwestern University & 1,876 & 15 & D.G. Sarri & 93 & 92 & 404 & 150 & 11 & 128 & 29 \\
\hline Norwegian University of Science \& Technology & 255 & 217 & J. Rattso & 38 & 244 & 159 & 246 & 6 & 253 & 18 \\
\hline Ohio State University & 1,441 & 25 & R.M. Stulz & 65 & 152 & 2,217 & 34 & 25 & 26 & 57 \\
\hline Oklahoma State University & 375 & 163 & J.L. Lusk & 69 & 138 & 468 & 129 & 15 & 79 & 65 \\
\hline Open University UK & 171 & 260 & I. Wright & 112 & 79 & 1,034 & 70 & 13 & 103 & 150 \\
\hline Oregon State University & 460 & 139 & R. Fare & 155 & 44 & 1,605 & 48 & 17 & 64 & 111 \\
\hline Osaka University & 427 & 147 & K. Futagami & 24 & 297 & 98 & 284 & 5 & 277 & 14 \\
\hline Peking University & 332 & 177 & J.Y. Lin & 25 & 293 & 135 & 261 & 6 & 253 & 18 \\
\hline Pennsylvania State University & 1,345 & 30 & A. Yavas & 37 & 252 & 146 & 257 & 7 & 226 & 22 \\
\hline Pohang University of Science And Technology & 15 & 341 & Y. Hong & 25 & 293 & 183 & 229 & 7 & 226 & 28 \\
\hline Portland State University & 209 & 243 & M.B. Schimdt & 26 & 288 & 86 & 295 & 7 & 226 & 5 \\
\hline Princeton University & 1,478 & 24 & A.K. Dixt & 45 & 215 & 1,069 & 67 & 17 & 64 & 17 \\
\hline Purdue University & 1,012 & 48 & T.N. Cason & 55 & 182 & 732 & 95 & 12 & 114 & 35 \\
\hline Queen's University & 669 & 78 & R. Boadway & 59 & 171 & 414 & 147 & 10 & 150 & 32 \\
\hline Queen's University of Belfast & 289 & 198 & W.G. Hutchinson & 27 & 283 & 191 & 222 & 10 & 150 & 17 \\
\hline Queensland University of Technology & 199 & 249 & B. Torgler & 37 & 252 & 108 & 275 & 8 & 196 & 17 \\
\hline Radboud University, Nijmegen & 255 & 217 & W.F.C. Verschoor & 27 & 283 & 105 & 279 & 5 & 277 & 20 \\
\hline Rensselaer Polytechnic Institute & 231 & 231 & I. Hasan & 59 & 171 & 333 & 173 & 10 & 150 & 57 \\
\hline Rheinisch Westfalische Technische Hochschule Aach & 73 & 311 & E. Feess & 30 & 274 & 53 & 311 & 5 & 277 & 21 \\
\hline Rheinische Friedrich Wilhelms Universitat Bonn & 836 & 63 & R.Selten & 40 & 240 & 682 & 102 & 11 & 128 & 53 \\
\hline Rice University & 423 & 149 & R. C. Sickles & 50 & 195 & 518 & 123 & 8 & 196 & 53 \\
\hline Rochester Institute of Technology & 97 & 304 & A.A. Batatyal & 112 & 79 & 176 & 234 & 8 & 196 & 19 \\
\hline Royal Institute of Technology, KTH & 140 & 281 & & 0 & 339 & 0 & 337 & 0 & 336 & 0 \\
\hline Royal Melbourne Institute of Technology & 181 & 254 & R.W. Faff & 111 & 83 & 349 & 167 & 10 & 150 & 89 \\
\hline Rutgers & 1,322 & 32 & C.F. Lee & 121 & 67 & 444 & 135 & 11 & 128 & 150 \\
\hline Saint-Petersburg State University & 35 & 333 & H.V. Hovanov & 10 & 326 & 45 & 317 & 2 & 327 & 11 \\
\hline San Diego State University & 319 & 183 & C. Amuedo & 38 & 244 & 203 & 218 & 9 & 174 & 20 \\
\hline Sapienza University of Rome & 0 & 347 & & 0 & 339 & 0 & 337 & 0 & 336 & 0 \\
\hline Sciences Po Paris & 110 & 298 & P.A. Messerlin & 20 & 307 & 85 & 297 & 3 & 312 & 8 \\
\hline Seoul National University & 276 & 206 & Y. Chun & 28 & 281 & 134 & 262 & 4 & 296 & 4 \\
\hline Shanghai Jiao Tong University & 101 & 302 & M.A. Han & 147 & 51 & 523 & 121 & 17 & 64 & 88 \\
\hline Simon Fraser University & 525 & 114 & J. Arifovie & 19 & 310 & 224 & 206 & 7 & 226 & 12 \\
\hline
\end{tabular}




\begin{tabular}{|c|c|c|c|c|c|c|c|c|c|c|}
\hline Stanford University & 2,531 & & P.R. Ehrlich & 265 & 15 & 4,462 & 14 & 30 & 19 & 150 \\
\hline State University of New York Buffalo & 8 & 344 & E.J. Kreig & 6 & 331 & 55 & 310 & 4 & 296 & 1 \\
\hline Stockholm University & 607 & 91 & A. Lindbeck & 38 & 244 & 536 & 117 & 9 & 174 & 10 \\
\hline Stony Brook University & 285 & 200 & P.K. Dubey & 65 & 152 & 612 & 112 & 10 & 150 & 96 \\
\hline Syracuse University & 518 & 120 & J.S. Kelly & 54 & 184 & 129 & 267 & 5 & 277 & 12 \\
\hline Tartu University (University of Tartu) & 59 & 319 & T. Tammaru & 21 & 304 & 79 & 301 & 9 & 174 & 12 \\
\hline Technical University of Denmark & 53 & 323 & E. Mosekilde & 169 & 36 & 1,199 & 61 & 20 & 43 & 150 \\
\hline Technion & 245 & 223 & D. Monderer & 41 & 237 & 618 & 111 & 10 & 150 & 17 \\
\hline Technische Universität Berlin & 147 & 275 & G.G. Wagner & 38 & 244 & 87 & 294 & 6 & 253 & 72 \\
\hline Technische Universitat Chemnitz & 57 & 321 & P. Kochel & 11 & 325 & 59 & 308 & 4 & 296 & 5 \\
\hline Technische Universität Dresden & 147 & 275 & U. Brollo & 56 & 179 & 148 & 255 & 7 & 226 & 33 \\
\hline Technische Universität München & 140 & 281 & C. Kluppelberg & 57 & 175 & 444 & 135 & 12 & 114 & 52 \\
\hline Tel Aviv University & \begin{tabular}{l|l}
1,039 \\
\end{tabular} & 43 & A. Razin & 63 & 161 & 533 & 118 & 9 & 174 & 27 \\
\hline Texas A\&M University & 1,146 & 39 & Q. Li & 82 & 112 & 685 & 101 & 17 & 64 & 50 \\
\hline Texas Tech & 227 & 235 & B.T. Ewing & 87 & 99 & 286 & 187 & 10 & 150 & 48 \\
\hline Tohoku University & 112 & 296 & K. Sasaki & 26 & 288 & 71 & 304 & 4 & 296 & 17 \\
\hline Tokyo Institute of Technology & 116 & 294 & & 0 & 339 & 0 & 337 & 0 & 336 & 0 \\
\hline Trinity College Dublin & 307 & 191 & P.R. Lane & 50 & 195 & 650 & 106 & 13 & 103 & 14 \\
\hline Tsinghua University & 259 & 215 & Q. Li & 181 & 32 & 922 & 77 & 18 & 56 & 150 \\
\hline Tufts University & 363 & 171 & Y.M. Loannides & 43 & 225 & 424 & 140 & 11 & 128 & 21 \\
\hline Universidad Autonoma de Madrid & 167 & 264 & F.J. Vazquez & 15 & 319 & 24 & 325 & 3 & 312 & 17 \\
\hline Universidad de Chile & 230 & 233 & V. Fernandez & 23 & 300 & 48 & 313 & 5 & 277 & 1 \\
\hline Universidad de Granada & 167 & 264 & F.J. Vazquez & 15 & 319 & 24 & 325 & 3 & 312 & 17 \\
\hline Universidad del País Vasco & 310 & 189 & J.C. Barcena-Ruiz & 27 & 283 & 88 & 291 & 7 & 226 & 8 \\
\hline Universidad Nacional Autónoma de México ... & 58 & 320 & M.Cruz & 6 & 331 & 8 & 332 & 2 & 327 & 2 \\
\hline Universidad Politecnica de Madrid & 55 & 322 & A. Garrido & 17 & 316 & 108 & 275 & 7 & 226 & 20 \\
\hline Universidade de São Paulo & 178 & 256 & J. Goldemberg & 87 & 99 & 575 & 114 & 13 & 103 & 98 \\
\hline Universidade Estadual de Campinas & 53 & 323 & S.B. Suslick & 48 & 206 & 57 & 309 & 5 & 277 & 49 \\
\hline Università degli Studi di Firenze & 223 & 239 & A. Cigno & 30 & 274 & 236 & 198 & 8 & 196 & 10 \\
\hline Università degli Studi di Padova & 280 & 204 & G. Bruello & 4 & 333 & 20 & 331 & 1 & 331 & 7 \\
\hline Universita Di Bologna & 517 & 121 & L. Lambertini & 80 & 115 & 310 & 180 & 11 & 128 & 47 \\
\hline Universita di Pisa & 139 & 283 & A. Bonaccorsi & 32 & 265 & 309 & 181 & 10 & 150 & 29 \\
\hline Universitat Autonoma de Barcelona & 568 & 102 & S. Barbera & 33 & 260 & 26 & 324 & 8 & 196 & 28 \\
\hline Universitat Bielefeld & 314 & 186 & A. Greiner & 43 & 225 & 102 & 282 & 6 & 253 & 19 \\
\hline Universität Bremen & 138 & 284 & W. Elsner & 16 & 318 & 28 & 323 & 4 & 296 & 8 \\
\hline Universitat d'Alacant & 384 & 158 & F. Vega & 40 & 240 & 660 & 105 & 13 & 103 & 26 \\
\hline
\end{tabular}




\begin{tabular}{|c|c|c|c|c|c|c|c|c|c|c|}
\hline Universitat de València & 505 & 124 & J. Maudos & 29 & 276 & 314 & 177 & 12 & 114 & 17 \\
\hline Universität Frankfurt am Main & 373 & 165 & R. Inderst & 44 & 219 & 177 & 233 & 7 & 226 & 14 \\
\hline Universität Freiburg & 157 & 271 & T. Gehrig & 19 & 310 & 122 & 271 & 6 & 253 & 15 \\
\hline Universitat Hamburg & 267 & 209 & R.S.J. Toi & 154 & 45 & 975 & 73 & 20 & 43 & 103 \\
\hline Universität Karlsruhe & 207 & 244 & O. Rentz & 139 & 53 & 404 & 150 & 11 & 128 & 142 \\
\hline Universitat Leipzig & 66 & 315 & M.C. Angermeyer & 402 & 5 & 4,426 & 15 & 37 & 6 & 150 \\
\hline Universitat Munster (Westfälische Wilhelms-Un & 111 & 297 & M.T. Bohl & 50 & 195 & 227 & 204 & 8 & 196 & 67 \\
\hline Universitat Politecnica de Catalunya & 72 & 313 & J. Freixas & 36 & 254 & 64 & 307 & 7 & 226 & 19 \\
\hline Universität Regensburg & 123 & 290 & K.O. Stetter & 223 & 24 & 5,256 & 9 & 36 & 8 & 150 \\
\hline Universität Stuttgart & 44 & 327 & O. Renn & 65 & 152 & 966 & 74 & 10 & 150 & 39 \\
\hline Universitat Trier & 36 & 332 & W. Filc & 4 & 333 & 0 & 337 & 0 & 336 & 2 \\
\hline Universität Tübingen & 231 & 231 & J. Baten & 26 & 288 & 95 & 286 & 7 & 226 & 25 \\
\hline Universitat Wien (University of Vienna) & 575 & 101 & E. Kirchler & 69 & 138 & 320 & 175 & 9 & 174 & 113 \\
\hline Universitat Zu Koln & 371 & 167 & C. Fuest & 50 & 195 & 133 & 264 & 7 & 226 & 45 \\
\hline Université Catholique de Louvain & 1,150 & 38 & J.F. Thisse & 139 & 53 & 1,658 & 46 & 19 & 49 & 124 \\
\hline Universite de Liege & 200 & 248 & P. Pestieau & 119 & 69 & 635 & 107 & 14 & 88 & 63 \\
\hline Université de Montréal & 605 & 92 & W. Bosseert & 78 & 119 & 288 & 184 & 7 & 226 & 25 \\
\hline Université de Nice Sophia Antipolis & 158 & 270 & J.L. Gaffard & 25 & 293 & 24 & 325 & 3 & 312 & 17 \\
\hline Universite Laval & 413 & 151 & J.Y. Duclos & 114 & 76 & 1,116 & 65 & 15 & 79 & 150 \\
\hline Universite Libre de Bruxelles & 378 & 162 & V. Ginsburgh & 52 & 191 & 231 & 201 & 8 & 196 & 49 \\
\hline Université Paris Sorbonne & 1,036 & 45 & A. Chateauneuf & 43 & 225 & 386 & 154 & 9 & 174 & 37 \\
\hline Universite Paris-Sud 11 & 69 & 314 & & 0 & 339 & 0 & 337 & 0 & 336 & 0 \\
\hline Université Pierre et Marie Curie & 86 & 308 & A. Chateauneuf & 43 & 225 & 378 & 158 & 9 & 174 & 37 \\
\hline Universiti Malaya (University of Malaya) & 122 & 291 & M.A. Wazed & 15 & 319 & 8 & 332 & 2 & 327 & 11 \\
\hline University College Cork & 73 & 311 & S.A. Tarim & 26 & 288 & 47 & 314 & 4 & 296 & 25 \\
\hline University College Dublin & 409 & 152 & F.P. Barry & 85 & 104 & 2,581 & 28 & 23 & 35 & 150 \\
\hline University College London & 1,037 & 44 & R. Bludell & 78 & 119 & 2,188 & 35 & 20 & 43 & 75 \\
\hline University do Porto & 96 & 305 & J. Gama & 53 & 186 & 154 & 247 & 8 & 196 & 56 \\
\hline University of Aberdeen & 537 & 110 & M. Ryan & 93 & 92 & 1,160 & 64 & 23 & 35 & 130 \\
\hline University of Adelaide & 324 & 181 & K. Anderson & 64 & 158 & 288 & 184 & 10 & 150 & 50 \\
\hline University of Alabama & 614 & 89 & P. Perorino & 46 & 212 & 215 & 211 & 6 & 253 & 11 \\
\hline University of Alberta & 728 & 71 & B. Yeung & 33 & 260 & 847 & 82 & 14 & 88 & 35 \\
\hline University of Amsterdam & 1,433 & 26 & H. Oosterbeek & 43 & 225 & 439 & 138 & 9 & 174 & 22 \\
\hline University of Antwerp & 326 & 178 & P. Beutels & 75 & 127 & 741 & 93 & 17 & 64 & 150 \\
\hline University of Arizona & 822 & 65 & A. Rapoport & 119 & 69 & 781 & 90 & 13 & 103 & 80 \\
\hline University of Athens & 274 & 207 & E. Papapetrou & 23 & 300 & 176 & 234 & 7 & 226 & 2 \\
\hline
\end{tabular}




\begin{tabular}{|c|c|c|c|c|c|c|c|c|c|c|}
\hline University of Auckland & 477 & 137 & P.C.B. Phillips & 154 & 45 & 3,117 & 21 & 18 & 56 & 150 \\
\hline University of Barcelona & 313 & 187 & J. Costa-Font & 57 & 175 & 134 & 262 & 8 & 196 & 43 \\
\hline University of Basel & 224 & 237 & G. Schatz & 222 & 25 & 4,586 & 13 & 26 & 25 & 150 \\
\hline University of Bath & 268 & 208 & J. Hudson & 226 & 23 & 2,327 & 32 & 24 & 31 & 150 \\
\hline University of Bergen & 179 & 255 & S.D. Flam & 67 & 149 & 154 & 247 & 6 & 253 & 31 \\
\hline University of Bern & 167 & 264 & H. Dellas & 48 & 206 & 186 & 225 & 4 & 296 & 24 \\
\hline University of Birmingham & 642 & 83 & J.H. Fremlin & 154 & 45 & 183 & 229 & 0 & 336 & 110 \\
\hline University of Bristol & 530 & 112 & C. Propper & 60 & 168 & 912 & 78 & 16 & 75 & 86 \\
\hline University of British Columbia & 1,117 & 41 & M.B. Devereux & 78 & 119 & 719 & 96 & 14 & 88 & 58 \\
\hline University of Calgary & 427 & 147 & A. Serletis & 110 & 85 & 461 & 132 & 11 & 128 & 47 \\
\hline University of California, Berkley & 2,167 & 10 & D. Zilberman & 2 & 337 & 1 & 335 & 1 & 331 & 4 \\
\hline University of California, Davis & 961 & 52 & S. Rozelle & 131 & 60 & 1,311 & 57 & 25 & 26 & 138 \\
\hline University of California, Irvine & 524 & 115 & A. Glazer & 79 & 118 & 300 & 183 & 7 & 226 & 34 \\
\hline University of California, Los Angeles & 1,910 & 14 & S. Edwards & 63 & 161 & 1,001 & 71 & 14 & 88 & 24 \\
\hline University of California, Riverside & 371 & 167 & J.T. Guo & 26 & 288 & 220 & 208 & 7 & 226 & 14 \\
\hline University of California, San Diego & 671 & 76 & C.W.J. Granger & 84 & 106 & 2,864 & 24 & 18 & 56 & 59 \\
\hline University of California, San Francisco & 177 & 257 & & 0 & 339 & 0 & 337 & 0 & 336 & 0 \\
\hline University of California, Santa Barbara & 438 & 143 & J.K. Sengupta & 113 & 77 & 217 & 210 & 4 & 296 & 19 \\
\hline University of California, Santa Cruz & 265 & 212 & Y.W. Cheung & 60 & 168 & 845 & 83 & 15 & 79 & 24 \\
\hline University of Cambridge & 929 & 58 & P. Dasgupta & 139 & 53 & 1,635 & 47 & 19 & 49 & 150 \\
\hline University of Canterbury & 170 & 262 & L. Oxley & 76 & 125 & 241 & 196 & 9 & 174 & 32 \\
\hline University of Cape Town & 176 & 258 & D. McIntyre & 50 & 195 & 373 & 160 & 13 & 103 & 107 \\
\hline University of Central Florida & 379 & 161 & G.W. Harrison & 68 & 145 & 884 & 80 & 15 & 79 & 51 \\
\hline University of Chicago & 1,782 & 17 & J.J. Heckman & 111 & 83 & 2,603 & 27 & 31 & 16 & 67 \\
\hline University of Cincinnati & 282 & 202 & D. Pal & 32 & 265 & 231 & 201 & 12 & 114 & 27 \\
\hline University of Colorado at Boulder & 545 & 109 & K.E. Maskus & 53 & 186 & 470 & 128 & 11 & 128 & 40 \\
\hline University of Connecticut & 587 & 98 & C.F. Sirmans & 127 & 65 & 701 & 98 & 14 & 88 & 83 \\
\hline University of Copenhagen & 589 & 95 & H. Keiding & 46 & 212 & 166 & 240 & 5 & 277 & 39 \\
\hline University of Delaware & 308 & 190 & W.V. Gehrlein & 92 & 96 & 283 & 188 & 6 & 253 & 19 \\
\hline University of Dundee & 215 & 242 & D.M.J. Lilley & 239 & 19 & 3,757 & 18 & 37 & 6 & 150 \\
\hline University of Edinburgh & 266 & 210 & L. Oxley & 76 & 125 & 241 & 196 & 9 & 174 & 32 \\
\hline University of Florida & 981 & 49 & H. Theil & 75 & 127 & 88 & 291 & 1 & 331 & 34 \\
\hline University of Geneva & 176 & 258 & M. Hoesli & 40 & 240 & 242 & 195 & 10 & 150 & 38 \\
\hline University of Georgia & 685 & 75 & C.A.K. Lovell & 53 & 186 & 1,766 & 43 & 13 & 103 & 52 \\
\hline University of Ghent & 227 & 235 & W. Verbeke & 93 & 92 & 626 & 110 & 17 & 64 & 126 \\
\hline University of Glasgow & 523 & 116 & J.R. Malley & 33 & 260 & 97 & 285 & 6 & 253 & 18 \\
\hline
\end{tabular}




\begin{tabular}{|c|c|c|c|c|c|c|c|c|c|c|}
\hline University of Gothenburg & 0 & 347 & & 0 & 339 & 0 & 337 & 0 & 336 & 0 \\
\hline University of Groningen & 688 & 74 & M.J. Postma & 162 & 40 & 1,180 & 62 & 20 & 43 & 150 \\
\hline University of Helsinki & 482 & 133 & E. Koskela & 73 & 131 & 314 & 177 & 10 & 150 & 22 \\
\hline University of Hong Kong & 21 & 339 & T.W.H. Ng & 20 & 307 & 191 & 222 & 7 & 226 & 8 \\
\hline University of Houston & 437 & 144 & D.H. Papell & 44 & 219 & 763 & 91 & 15 & 79 & 16 \\
\hline University of Illinois & 1,795 & 16 & J.K. Brueckner & 104 & 88 & 1,321 & 56 & 20 & 43 & 37 \\
\hline University of Illinois, Chicago & 583 & 100 & J.F. McDonald & 173 & 35 & 1,857 & 40 & 24 & 31 & 150 \\
\hline University of Indonesia & 35 & 333 & A. Kuncoro & 7 & 330 & 346 & 169 & 4 & 296 & 6 \\
\hline University of Iowa & 479 & 136 & F. Dexter & 253 & 16 & 1,973 & 38 & 31 & 16 & 150 \\
\hline University of Kansas & 292 & 196 & D. Lien & 109 & 86 & 347 & 168 & 11 & 128 & 49 \\
\hline University of Kentucky & 459 & 140 & C.W. Holsapple & 98 & 90 & 812 & 84 & 14 & 88 & 63 \\
\hline University of Lausanne & 229 & 234 & H.U. Gerber & 44 & 219 & 369 & 162 & 9 & 174 & 25 \\
\hline University of Leeds & 319 & 183 & P.J. Buckley & 83 & 110 & 996 & 72 & 18 & 56 & 52 \\
\hline University of Leicester & 481 & 134 & D. Fielding & 52 & 191 & 174 & 237 & 8 & 196 & 13 \\
\hline University of Liverpool & 150 & 274 & T. Walley & 231 & 21 & 2,341 & 31 & 24 & 31 & 150 \\
\hline University of Ljubljana & 192 & 252 & K. Erjavec & 17 & 316 & 30 & 322 & 4 & 296 & 6 \\
\hline University of London (Kings College of London) & 5,699 & 2 & R. Bludell & 77 & 123 & 2,390 & 29 & 21 & 39 & 73 \\
\hline University of Manchester & 1,386 & 29 & C. Kirkpatrick & 55 & 182 & 209 & 214 & 10 & 150 & 32 \\
\hline University of Manitoba & 299 & 192 & V. Smil & 57 & 175 & 679 & 103 & 14 & 88 & 25 \\
\hline University of Maryland & 1,545 & 21 & R.G. Chambers & 116 & 74 & 965 & 75 & 11 & 128 & 56 \\
\hline University of Maryland Baltimore County & 220 & 240 & D. Coates & 38 & 244 & 171 & 238 & 9 & 174 & 13 \\
\hline University of Massachusetts & 354 & 172 & A. Nagurney & 117 & 72 & 526 & 120 & 15 & 79 & 51 \\
\hline University of Melbourne & 953 & 53 & J. Creedy & 84 & 106 & 211 & 213 & 8 & 196 & 33 \\
\hline University of Miami & 256 & 216 & M.T. French & 136 & 57 & 1,330 & 55 & 24 & 31 & 141 \\
\hline University of Michigan & 1,514 & 23 & A.M. Fenrick & 210 & 27 & 4,267 & 16 & 33 & 13 & 150 \\
\hline University of Minnesota & 1,173 & 37 & R. Feldman & 163 & 39 & 1,039 & 69 & 17 & 64 & 150 \\
\hline University of Missouri & 647 & 82 & T. Prato & 56 & 179 & 318 & 176 & 12 & 114 & 48 \\
\hline University of Nebraska & 399 & 154 & W.B. Walstad & 21 & 304 & 117 & 273 & 7 & 226 & 15 \\
\hline University of New Hampshire & 167 & 264 & K.S. Conway & 19 & 310 & 130 & 265 & 8 & 196 & 10 \\
\hline University of New Mexico & 171 & 260 & R.P. Berrens & 65 & 152 & 334 & 171 & 12 & 114 & 63 \\
\hline University of New South Wales & 760 & 68 & M.C. Kemp & 84 & 106 & 245 & 193 & 4 & 296 & 35 \\
\hline University of North Carolina, Chapel Hill & 1,091 & 42 & R. Gray & 86 & 101 & 712 & 97 & 14 & 88 & 80 \\
\hline University of North Texas & 166 & 269 & M. Zafirovski & 43 & 225 & 69 & 306 & 5 & 277 & 1 \\
\hline University of Notre Dame & 368 & 169 & A.K. Dutt & 52 & 191 & 94 & 287 & 3 & 312 & 34 \\
\hline University of Nottingham & 1,033 & 46 & M. Wright & 199 & 28 & 1,841 & 41 & 28 & 23 & 150 \\
\hline University of Oklahoma & 281 & 203 & D. Sutter & 52 & 191 & 147 & 256 & 7 & 226 & 18 \\
\hline
\end{tabular}




\begin{tabular}{|c|c|c|c|c|c|c|c|c|c|c|}
\hline University of Oregon & 12 & 342 & M. Gerrity & 69 & 138 & 1,440 & 54 & 18 & 56 & 150 \\
\hline University of Oslo & 494 & 130 & M. Hoel & 48 & 206 & 523 & 121 & 12 & 114 & 54 \\
\hline University of Otago & 141 & 280 & P. Crampton & 59 & 171 & 283 & 188 & 11 & 128 & 90 \\
\hline University of Ottawa & 201 & 246 & M. Lavoie & 93 & 92 & 745 & 92 & 12 & 114 & 117 \\
\hline University of Oxford & 1,220 & 36 & A Gray & 130 & 62 & 3,375 & 20 & 34 & 11 & 150 \\
\hline University of Pennsylvania & 2,027 & 12 & M.V. Pauly & 271 & 13 & 3,772 & 17 & 25 & 26 & 150 \\
\hline University of Pittsburgh & 488 & 132 & J.R. Lave & 147 & 51 & 2,910 & 23 & 27 & 24 & 150 \\
\hline University of Quebec & 326 & 178 & J.P. Gervais & 29 & 276 & 38 & 320 & 4 & 296 & 23 \\
\hline University of Queensland & 480 & 135 & C. Tisdell & 168 & 38 & 694 & 99 & 13 & 103 & 57 \\
\hline University of Reading & 559 & 105 & C. Brooks & 57 & 175 & 416 & 144 & 13 & 103 & 41 \\
\hline University of Rochester & 801 & 67 & R.W. Jones & 53 & 186 & 213 & 212 & 6 & 253 & 21 \\
\hline University of Saskatchewan & 265 & 212 & M. Altman & 24 & 297 & 88 & 291 & 6 & 253 & 2 \\
\hline University of Science and Technology of China & 34 & 335 & Y. Zhang & 321 & 8 & 1,676 & 45 & 19 & 49 & 150 \\
\hline University of Sheffield & 498 & 128 & D.W. Hughes & 189 & 29 & 848 & 81 & 14 & 88 & 150 \\
\hline University of South Carolina & 588 & 96 & E. Cohn & 28 & 281 & 163 & 244 & 5 & 277 & 16 \\
\hline University of South Florida & 201 & 246 & C. Pantzalis & 23 & 300 & 184 & 227 & 8 & 196 & 21 \\
\hline University of Southampton & 365 & 170 & N.R. Jennings & 218 & 26 & 4,705 & 11 & 36 & 8 & 150 \\
\hline University of Southern California & 876 & 59 & R. Kalaba & 287 & 11 & 422 & 141 & 9 & 174 & 150 \\
\hline University of St Andrews & 237 & 228 & D.G. McMillian & 64 & 158 & 197 & 220 & 8 & 196 & 38 \\
\hline University of Surrey & 188 & 253 & G. Bird & 69 & 138 & 231 & 201 & 10 & 150 & 16 \\
\hline University of Sussex & 333 & 176 & A. Wagstaff & 59 & 171 & 1,513 & 52 & 17 & 64 & 64 \\
\hline University of Sydney & 690 & 73 & A. Frino & 42 & 232 & 150 & 251 & 8 & 196 & 43 \\
\hline University of Technology, Sydney & 253 & 219 & C. Chiarella & 89 & 97 & 288 & 184 & 8 & 196 & 68 \\
\hline University of Tennessee Knoxville & 347 & 174 & R.K. Roberts & 49 & 204 & 128 & 268 & 7 & 226 & 67 \\
\hline University of Texas at Austin & 948 & 54 & A.B. Whinston & 280 & 12 & 1,595 & 49 & 23 & 35 & 150 \\
\hline University of Tokyo & 435 & 145 & Y. Matsuno & 66 & 150 & 81 & 300 & 6 & 253 & 125 \\
\hline University of Toronto & 1,598 & 20 & C. Gourieoux & 63 & 161 & 518 & 123 & 9 & 174 & 40 \\
\hline University of Tsukuba & 278 & 205 & M. Kaneko & 35 & 255 & 220 & 208 & 5 & 277 & 15 \\
\hline University of Twente & 119 & 293 & A.Y. Hoekstra & 32 & 265 & 150 & 251 & 8 & 196 & 45 \\
\hline University of Utah & 390 & 156 & M.R. Capecchi & 169 & 36 & 7,813 & 5 & 40 & 5 & 150 \\
\hline University of Vermont & 4,589 & 4 & R.S. Costanza & 148 & 49 & 5,843 & 8 & 32 & 14 & 150 \\
\hline University of Victoria & 194 & 251 & D.E.A. Giles & 84 & 106 & 426 & 139 & 14 & 88 & 71 \\
\hline University of Virginia & 559 & 105 & C.A. Holt & 72 & 132 & 805 & 87 & 16 & 75 & 62 \\
\hline University of Warwick & 863 & 60 & M.P. Taylor & 249 & 17 & 2,699 & 26 & 30 & 19 & 150 \\
\hline University of Washington & 969 & 50 & S.J. Turnovsky & 117 & 72 & 634 & 108 & 15 & 79 & 59 \\
\hline University of Waterloo & 535 & 111 & P.L. Siklos & 70 & 136 & 383 & 155 & 8 & 196 & 38 \\
\hline University of Western Australia & 496 & 129 & M. McAleer & 181 & 32 & 677 & 104 & 14 & 88 & 113 \\
\hline University of Western Ontario & 752 & 69 & J. Whalley & 113 & 77 & 382 & 156 & 8 & 196 & 68 \\
\hline University of Wisconsin & 1,344 & 31 & J. Buongiorno & 119 & 69 & 458 & 134 & 13 & 103 & 99 \\
\hline University of Wollongong & 121 & 292 & C. Harvie & 31 & 270 & 492 & 127 & 1 & 331 & 29 \\
\hline
\end{tabular}




\begin{tabular}{|c|c|c|c|c|c|c|c|c|c|c|}
\hline Business Management Data & $\begin{array}{l}\text { Department } \\
\text { Publications }\end{array}$ & Rank & Most Prolific Author & Published & Rank & Cited & Rank & $\begin{array}{c}\text { H- } \\
\text { Index }\end{array}$ & Rank & $\begin{array}{c}\text { \# of } \\
\text { Coauthors }\end{array}$ \\
\hline Aalto University & 437 & 127 & J.A. Holmstrom & 47 & 203 & 464 & 167 & 12 & 153 & 55 \\
\hline Aarhus University & 448 & 123 & K.G. Grunert & 65 & 156 & 678 & 131 & 17 & 77 & 87 \\
\hline Arizonia State University & 865 & 44 & W.T. Tsai & 189 & 42 & 585 & 142 & 13 & 133 & 150 \\
\hline Ateneo de Manila University & 4 & 345 & S.M. Colarelli & 15 & 305 & 228 & 225 & 5 & 270 & 21 \\
\hline Auburn University & 706 & 60 & H.J. Rotfeld & 53 & 185 & 91 & 282 & 4 & 290 & 7 \\
\hline Australian National University & 583 & 84 & S.R. Taylor & 155 & 57 & 5,035 & 11 & 10 & 180 & 150 \\
\hline Boston College & 664 & 68 & A.G. Woodside & 138 & 67 & 854 & 106 & 12 & 153 & 111 \\
\hline Boston University & 607 & 78 & H.E Stanley & 480 & 3 & 10,348 & 1 & 57 & 2 & 150 \\
\hline Brandeis University & 76 & 326 & & 0 & 332 & 0 & 331 & 0 & 330 & 0 \\
\hline Brigham Young University & 292 & 191 & J.V. Hansen & 57 & 174 & 299 & 206 & 9 & 200 & 32 \\
\hline Brown University & 139 & 270 & L. Putterman & 71 & 145 & 536 & 149 & 14 & 116 & 30 \\
\hline California Institute of Technology (Calt... & 124 & 280 & D.L. Anderson & 134 & 69 & 4,664 & 13 & 21 & 41 & 103 \\
\hline Cardiff University & 1,162 & 25 & L.C. Harris & 49 & 194 & 521 & 157 & 13 & 133 & 18 \\
\hline Carnegie Mellon University & 1,013 & 33 & D.M. Rousseau & 54 & 181 & 1,240 & 63 & 18 & 64 & 60 \\
\hline Case Western Reserve University & 530 & 97 & P. Gambetti & 284 & 15 & 6,166 & 8 & 47 & 3 & 150 \\
\hline Chalmers University of Technology & 328 & 182 & A. Styhre & 43 & 218 & 86 & 285 & 5 & 270 & 150 \\
\hline Charles University & 179 & 249 & R. Horvath & 22 & 288 & 19 & 318 & 2 & 317 & 14 \\
\hline Chinese University of Hong Kong & 577 & 86 & X. Zhao & 46 & 210 & 349 & 189 & 13 & 133 & 38 \\
\hline Chulalongkorn University & 97 & 305 & M. Techakumphu & 45 & 213 & 74 & 293 & 5 & 270 & 104 \\
\hline City University of Hong Kong & 1,127 & 27 & C.M. Tam & 142 & 65 & 916 & 98 & 18 & 64 & 150 \\
\hline City University of New York & 587 & 83 & T.G. Bali & 40 & 226 & 144 & 257 & 7 & 240 & 27 \\
\hline Colorado State University & 323 & 183 & S.F. Slater & 48 & 200 & 804 & 115 & 16 & 92 & 25 \\
\hline Columbia University & 1,395 & 16 & M.B. Holbrooke & 52 & 188 & 791 & 117 & 10 & 180 & 36 \\
\hline Cornell University & 1,426 & 13 & & 0 & 332 & 0 & 331 & 0 & 330 & 0 \\
\hline Curtin University of Technology & 425 & 136 & I. Phau & 23 & 284 & 92 & 281 & 5 & 270 & 26 \\
\hline Dalhousie University & 140 & 268 & & 0 & 332 & 0 & 331 & 0 & 330 & 0 \\
\hline Dartmouth College & 603 & 79 & A.Gunasekaran & 158 & 53 & 1,484 & 53 & 18 & 64 & 118 \\
\hline Delft University of Technology & 382 & 151 & E.J. Hultink & 36 & 240 & 400 & 176 & 14 & 116 & 26 \\
\hline Drexel University & 517 & 103 & M. Igbaria & 65 & 156 & 1,315 & 58 & 17 & 77 & 53 \\
\hline Duke University & 1,072 & 30 & H. J. Petroski & 160 & 51 & 197 & 237 & 3 & 301 & 16 \\
\hline Durham University & 335 & 179 & T.S. Clark & 37 & 236 & 352 & 187 & 12 & 153 & 35 \\
\hline Ecole Normale Supérieure de Lyon & 7 & 344 & E. Varra & 29 & 265 & 212 & 232 & 11 & 164 & 24 \\
\hline École Normale Supérieure, Paris & 24 & 341 & & 0 & 332 & 0 & 331 & 0 & 330 & 0 \\
\hline École Polytechnique & 88 & 317 & & 0 & 332 & 0 & 331 & 0 & 330 & 0 \\
\hline
\end{tabular}




\begin{tabular}{|c|c|c|c|c|c|c|c|c|c|c|}
\hline Ecole Polytechnique Fédérale de Lausanne & 124 & 280 & M.Gruber & 11 & 322 & 58 & 298 & 5 & 270 & 8 \\
\hline Eindhoven University of Technology & 452 & 121 & G. Duysters & 40 & 226 & 390 & 178 & 15 & 103 & 41 \\
\hline Emory University & 525 & 99 & J.N. Sheth & 44 & 216 & 638 & 136 & 10 & 180 & 43 \\
\hline Erasmus University Rotterdam & 1,247 & 20 & P.H. Franses & 177 & 46 & 960 & 94 & 18 & $\overline{64}$ & 105 \\
\hline ETH Zurich (Swiss Federal Institute of Technology) & 346 & 171 & E. Lichtenthaler & 12 & 320 & 82 & 287 & 7 & 240 & 4 \\
\hline Florida International University & 700 & 61 & C. Viswesvaran & 66 & 154 & 1,991 & 37 & 25 & 25 & 33 \\
\hline Florida State University & 667 & 65 & G.R. Ferris & 124 & 78 & 1,100 & 79 & 22 & 35 & 142 \\
\hline Freie Universität Berlin & 160 & 256 & K.A. Kondrad & 74 & 136 & 529 & 153 & 13 & 133 & 36 \\
\hline Friedrich Alexander Universität Erlangen Nürnberg & 195 & 234 & D. Holtbrugge & 17 & 302 & 28 & 312 & 4 & 290 & 11 \\
\hline Fudan University & 197 & 233 & Y.F. Zhong & 160 & 51 & 1,164 & 71 & 16 & 92 & 150 \\
\hline Georg August Universität Göttingen & 112 & 296 & A Spiller & 32 & 260 & 26 & 314 & 3 & 301 & 59 \\
\hline George Mason University & 399 & 145 & D.A. Menasce & 94 & 110 & 846 & 109 & 15 & 103 & 58 \\
\hline George Washington University & 699 & 62 & E.G. Carayannis & 51 & 190 & 315 & 201 & 11 & 164 & 39 \\
\hline Georgetown University & 512 & 105 & M.R. Czinkota & 33 & 252 & 177 & 250 & $\overline{6}$ & 251 & 20 \\
\hline Georgia Institute of Technology & 781 & 51 & N.K. Mahotra & 79 & 130 & 1,663 & 48 & 15 & 103 & 57 \\
\hline Georgia State University & 1,137 & 26 & W.J. Johnston & 65 & 156 & 757 & 121 & 13 & 133 & 82 \\
\hline Goteborg University & 370 & 157 & A. Styhre & 41 & 225 & 75 & 291 & 5 & 270 & 150 \\
\hline Harvard University & 1,083 & 29 & S.J. Gould & 258 & 24 & 6,974 & 6 & 44 & $\overline{4}$ & 150 \\
\hline Hebrew University of Jerusalem & 567 & 91 & I. Gati & 67 & 151 & 527 & 155 & 11 & 164 & 47 \\
\hline Heidelberg Universität & 78 & 325 & & 0 & 332 & 0 & 331 & 0 & 330 & 0 \\
\hline Hokkaido University & 422 & 138 & M. Onuma & 324 & 12 & 1,160 & 72 & 18 & 64 & 150 \\
\hline Hong Kong Polytechnic University & 1,828 & 6 & R. Law & 101 & 98 & 364 & 182 & 13 & 133 & 75 \\
\hline Hong Kong University of Science \& Techno... & 680 & 64 & K.Y. Tam & 54 & 181 & 1,050 & 84 & 16 & 92 & 51 \\
\hline Humboldt-Universität zu Berlin & 183 & 245 & W. Guth & 112 & 88 & 1,173 & 70 & 13 & 133 & 89 \\
\hline Imperial College London & 551 & 94 & M. Meade & 29 & 265 & 314 & 202 & 8 & 223 & 20 \\
\hline Indian Institute of Technology Bombay (I... & 85 & 318 & J.N. Madal & 63 & 162 & 71 & 296 & 3 & 301 & 22 \\
\hline Indian Institute of Technology Delhi (II... & 369 & 158 & S.G. Deshmukh & 97 & 106 & 530 & 152 & 13 & 133 & 75 \\
\hline Indian Institute of Technology Kanpur (I... & 118 & 290 & P.S. Vankar & 94 & 110 & 192 & 241 & 6 & 251 & 59 \\
\hline Indiana University Bloomington & 1,567 & 7 & C.M. Dalton & 71 & 145 & 75 & 291 & 5 & 270 & 9 \\
\hline Indiana University Indianapolis & 100 & 302 & J.L. Perry & 34 & 249 & 297 & 207 & 10 & 180 & 43 \\
\hline Iowa State University & 421 & 139 & Y. Suzuki & 196 & 38 & 2,083 & 33 & 14 & 116 & 150 \\
\hline Johns Hopkins University & 314 & 186 & S.H. Hanke & 50 & 191 & 95 & 280 & 3 & 301 & 26 \\
\hline Kansas State University & 278 & 195 & C. Sheu & 52 & 188 & 353 & 185 & 10 & 180 & 38 \\
\hline Katholieke Universiteit Leuven & 507 & 106 & M.G. DeKimpe & 40 & 226 & 575 & 144 & 16 & 92 & 47 \\
\hline Keio University & 113 & 294 & K. Asakawa & 14 & 310 & 130 & 265 & 7 & 240 & 7 \\
\hline
\end{tabular}




\begin{tabular}{|c|c|c|c|c|c|c|c|c|c|c|}
\hline King Fahd University of Petroleum \& Minerals & 143 & 266 & M.S. Sohail & 15 & 305 & $\mid 57$ & 299 & 4 & 290 & 19 \\
\hline King Saud University & 82 & 320 & M.A. Al-Mashari & 14 & 310 & 252 & 217 & 7 & 240 & 7 \\
\hline Kobe University & 171 & 251 & H. Kitagawa & 405 & 8 & 2,935 & 24 & 31 & 14 & 150 \\
\hline Korea Advanced Institute of Science \& Technology & 357 & 162 & I. Han & 63 & 162 & 919 & 95 & 18 & 64 & 48 \\
\hline Korea University & 241 & 211 & S.J. Chang & 14 & 310 & 404 & 175 & 10 & 180 & 8 \\
\hline Kyoto University & 204 & 227 & N. Manabe & 96 & 107 & 533 & 150 & 17 & 77 & 150 \\
\hline Kyushu University & 95 & 307 & T. Kusakabe & 104 & 96 & 1,014 & 86 & 17 & 77 & 150 \\
\hline La Trobe University & 285 & 193 & T. Bartrum & 23 & 284 & 35 & 308 & 4 & 290 & 16 \\
\hline Lancaster University & 386 & 150 & M. Pidd & 63 & 162 & 286 & 210 & 9 & 200 & 57 \\
\hline Leiden University & 183 & 245 & K.A. Jehn & 35 & 243 & 196 & 239 & 14 & 116 & 50 \\
\hline Linkoping University & 220 & 223 & J. Soderlund & 18 & 299 & 128 & 267 & 6 & 251 & 9 \\
\hline London School of Economics and Political Scie & 965 & 40 & D.C. Lane & 24 & 280 & 224 & 228 & 10 & 180 & 10 \\
\hline Loughborough University & 800 & 49 & A.R.J. Dainty & 80 & 128 & 248 & 221 & 9 & 200 & 65 \\
\hline Louisiana State University & 527 & 98 & B. Lin & 135 & 68 & 735 & 123 & 15 & 103 & 150 \\
\hline Ludwig-Maximilians-Universität München & 330 & 181 & P.H. Egger & 91 & 115 & 491 & 162 & 14 & 116 & 49 \\
\hline Lund University & 426 & 135 & M. Al Vesson & 36 & 240 & 998 & 87 & 18 & 64 & 15 \\
\hline Maastricht University & 611 & 75 & K. De Ruyter & 74 & 136 & 827 & 113 & 18 & 64 & 41 \\
\hline Macquarie University & 341 & 175 & J. Guthrie & 24 & 280 & 143 & 258 & 7 & 240 & 20 \\
\hline Mahidol University & 51 & 330 & N. Gerdsri & 14 & 310 & 19 & 318 & 3 & 301 & 12 \\
\hline Masaryk University & 18 & 342 & M. Filip & 3 & 330 & 1 & 330 & 1 & 327 & 0 \\
\hline Massachusetts Institute of Technology & 1,330 & 18 & A. Rich & 337 & 11 & 5,872 & 9 & 32 & 13 & 150 \\
\hline McGill University & 523 & 101 & L. Dube & 70 & 147 & 751 & 122 & 16 & 92 & 80 \\
\hline McMaster University & 487 & 111 & N. Bontis & 36 & 240 & 377 & 180 & 7 & 240 & 36 \\
\hline Michigan State University & 1,545 & 8 & R.J. Calantone & 129 & 74 & 2,178 & 32 & 24 & 26 & 127 \\
\hline Michigan Technological University & 81 & 322 & K.I. Pelc & 13 & 317 & 12 & 324 & 2 & 317 & 5 \\
\hline Monash University & 979 & 36 & A.S. Sohal & 121 & 82 & 798 & 116 & 18 & 64 & 103 \\
\hline Montana State University & 122 & 283 & D. Snepenger & 26 & 275 & 225 & 227 & 5 & 270 & 33 \\
\hline Moscow State University & 33 & 339 & V.E. Tarasov & 86 & 122 & 209 & 234 & 16 & 92 & 3 \\
\hline Nagoya University & 89 & 315 & M. Ikeda & 35 & 243 & 340 & 193 & 9 & 200 & 63 \\
\hline Nanjing University & 100 & 302 & L. Wang & 153 & 60 & 1,055 & 83 & 19 & 56 & 150 \\
\hline Nanyang Technological University & 665 & 66 & H.T. Tan & 25 & 277 & 210 & 233 & 8 & 223 & 18 \\
\hline National Taiwan University & 431 & 132 & M.S. Chen & 269 & 20 & 3,055 & 22 & 20 & 44 & 150 \\
\hline National Tsing Hua University & 200 & 229 & S.C. Hung & 26 & 275 & 96 & 279 & 6 & 251 & 30 \\
\hline National University of Ireland, Galway & 124 & 280 & D.G. Collings & 19 & 296 & 61 & 297 & 5 & 270 & 18 \\
\hline National University of Singapore & 1,351 & 17 & T.S.H. Teo & 91 & 115 & 1,113 & 75 & 22 & 35 & 84 \\
\hline New Mexico State University & 315 & 184 & R.T. Peterson & 33 & 252 & 408 & 174 & 8 & 223 & 19 \\
\hline
\end{tabular}




\begin{tabular}{|c|c|c|c|c|c|c|c|c|c|c|}
\hline New York University & 1,463 & 12 & R. Llinas & 294 & 14 & 9,464 & 2 & 30 & 15 & 150 \\
\hline Newcastle University & 378 & 155 & P.M. Taylor & 157 & 55 & 829 & 112 & 15 & 103 & 150 \\
\hline North Carolina State University & 749 & 53 & P.F. Williams & 24 & 280 & 190 & 243 & 6 & 251 & 16 \\
\hline Northeastern University & 603 & 79 & S.M. Puffer & 37 & 236 & 336 & 194 & 12 & 153 & 13 \\
\hline Northwestern University & 1,112 & 28 & D.E. Schultz & 80 & 128 & 140 & 261 & 10 & 180 & 25 \\
\hline Norwegian University of Science \& Technology & 270 & 201 & M. Langseth & 125 & 77 & 986 & 91 & 24 & 26 & 78 \\
\hline Ohio State University & 1,537 & 9 & M.G. Bissell & 133 & 71 & 310 & 205 & 9 & 200 & 123 \\
\hline Oklahoma State University & 590 & 82 & W.G. Kim & 32 & 260 & 172 & 252 & 8 & 223 & 43 \\
\hline Open University UK & 478 & 114 & S. Bell & 29 & 265 & 120 & 268 & 8 & 223 & 9 \\
\hline Oregon State University & 392 & 147 & R. Fare & 155 & 57 & 1,693 & 46 & 17 & 77 & 111 \\
\hline Osaka University & 138 & 272 & & 0 & 332 & 0 & 331 & 0 & 330 & 0 \\
\hline Peking University & 338 & 177 & A.S. Tsui & 33 & 252 & 1,129 & 74 & 17 & 77 & 58 \\
\hline Pennsylvania State University & 1,850 & 4 & R. Roy & 407 & 7 & 3,422 & 18 & 23 & 29 & 150 \\
\hline Pohang University of Science And Technology & 41 & 337 & H.Yu & 25 & 277 & 262 & 214 & 10 & 180 & 35 \\
\hline Portland State University & 454 & 120 & T. Daim & 75 & 135 & 155 & 254 & 6 & 251 & 85 \\
\hline Princeton University & 350 & 168 & R.H. Austin & 158 & 53 & 4,526 & 15 & 38 & 7 & 150 \\
\hline Purdue University & 1,202 & 22 & J.J. McConnell & 39 & 231 & 1,643 & 49 & 13 & 133 & 39 \\
\hline Queen's University & 354 & 163 & J. Barling & 84 & 125 & 1,506 & 51 & 17 & 77 & 77 \\
\hline Queen's University of Belfast & 286 & 192 & P.D. Cousins & 29 & 265 & 480 & 163 & 14 & 116 & 16 \\
\hline Queensland University of Technology & 506 & 108 & M. Skitmore & 67 & 151 & 331 & 196 & 11 & 164 & 67 \\
\hline Radboud University, Nijmegen & 302 & 189 & J. Benders & 39 & 231 & 239 & 223 & 10 & 180 & 34 \\
\hline Rensselaer Polytechnic Institute & 465 & 118 & W.A. Wallace & 262 & 22 & 2,747 & 26 & 19 & 56 & 150 \\
\hline Rheinisch Westfalische Technische Hochschule Aach & 121 & 284 & T. Gries & 227 & 29 & 130 & 265 & 5 & 270 & 150 \\
\hline Rheinische Friedrich Wilhelms Universitat Bonn & 200 & 229 & G. Blickle & 34 & 249 & 120 & 268 & 7 & 240 & 39 \\
\hline Rice University & 408 & 141 & D. Windsor & 29 & 265 & 57 & 299 & 3 & 301 & 2 \\
\hline Rochester Institute of Technology & 177 & 250 & E.H. Fram & 13 & 317 & 17 & 321 & 2 & 317 & 8 \\
\hline Royal Institute of Technology, KTH & 232 & 214 & & 0 & 332 & 0 & 331 & 0 & 330 & 0 \\
\hline Royal Melbourne Institute of Technology & 353 & 165 & J. Zobel & 95 & 109 & 919 & 95 & 17 & 77 & 60 \\
\hline Rutgers & 1,400 & 15 & G.F. Harris & 48 & 200 & 155 & 254 & 6 & 251 & 21 \\
\hline Saint-Petersburg State University & 47 & 335 & C. Romano & 13 & 317 & 2 & 329 & 1 & 327 & 0 \\
\hline San Diego State University & 439 & 126 & C.W. Chow & 47 & 203 & 466 & 165 & 11 & 164 & 49 \\
\hline Sapienza University of Rome & 0 & 348 & & 0 & 332 & 0 & 331 & 0 & 330 & 0 \\
\hline Sciences Po Paris & 36 & 338 & P.A. Messerlin & 20 & 293 & 85 & 286 & 3 & 301 & 8 \\
\hline Seoul National University & 433 & 131 & Y. Park & 78 & 131 & 216 & 230 & 10 & 180 & 83 \\
\hline Shanghai Jiao Tong University & 2,713 & 2 & C. He & 261 & 23 & 289 & 209 & 8 & 223 & 150 \\
\hline Simon Fraser University & 507 & 106 & R.L. Tung & 32 & 260 & 331 & 196 & 11 & 164 & 33 \\
\hline
\end{tabular}




\begin{tabular}{|c|c|c|c|c|c|c|c|c|c|c|}
\hline Stanford University & 1,466 & 11 & & 0 & 332 & 0 & 331 & 0 & 330 & 0 \\
\hline State University of New York Buffalo & 556 & 92 & D. Talukdar & 19 & 296 & 416 & 172 & 9 & 200 & 16 \\
\hline Stockholm University & 298 & 190 & M. Sverke & 35 & 243 & 207 & 235 & 9 & 200 & 40 \\
\hline Stony Brook University & 285 & 193 & P.K. Dubey & 64 & 159 & 616 & 139 & 10 & 180 & 90 \\
\hline Syracuse University & 347 & 170 & K. Crowston & 49 & 194 & 997 & 88 & 12 & 153 & 50 \\
\hline Tartu University (University of Tartu) & 48 & 333 & M. Vadi & 8 & 326 & 49 & 304 & 2 & 317 & 9 \\
\hline Technical University of Denmark & 133 & 275 & E. Mosekilde & 169 & 48 & 1,206 & 67 & 20 & 44 & 150 \\
\hline Technion & 352 & 166 & A. Sholan & 50 & 191 & 336 & 194 & 11 & 164 & 33 \\
\hline Technische Universität Berlin & 201 & 228 & H.G. Gemunder & 20 & 293 & 346 & 191 & 9 & 200 & 20 \\
\hline Technische Universitat Chemnitz & 108 & 298 & U. Gotze & 11 & 322 & 3 & 328 & 1 & 327 & 6 \\
\hline Technische Universität Dresden & 360 & 161 & P. Offermann & 195 & 39 & 139 & 262 & 6 & 251 & 150 \\
\hline Technische Universität München & 138 & 272 & M. Bichler & 40 & 226 & 330 & 198 & 11 & 164 & 41 \\
\hline Tel Aviv University & 610 & 76 & E. I. Meir & 40 & 226 & 244 & 222 & 6 & 251 & 42 \\
\hline Texas A\&M University & 1,537 & 9 & M.A. Hitt & 85 & 123 & 2,665 & 27 & 30 & 15 & 150 \\
\hline Texas Tech & 381 & 152 & B.T. Ewing & 87 & 119 & 286 & 210 & 10 & 180 & 48 \\
\hline Tohoku University & 116 & 291 & K.Hayashi & 151 & 62 & 387 & 179 & 10 & 180 & 150 \\
\hline Tokyo Institute of Technology & 170 & 252 & C. Watanbe & 124 & 78 & 353 & 185 & 9 & 200 & 119 \\
\hline Trinity College Dublin & 160 & 256 & D. Coghlan & 21 & 289 & 227 & 226 & 6 & 251 & 19 \\
\hline Tsinghua University & 591 & 81 & W. Zheng & 235 & 27 & 655 & 135 & 12 & 153 & 150 \\
\hline Tufts University & 140 & 268 & B. Brenner & 15 & 305 & 0 & 331 & 0 & 330 & 0 \\
\hline Universidad Autonoma de Madrid & 188 & 239 & S. Okazaki & 31 & 263 & 143 & 258 & 8 & 223 & 17 \\
\hline Universidad de Chile & 113 & 294 & A. Weintraub & 45 & 213 & 251 & 218 & 9 & 200 & 87 \\
\hline Universidad de Granada & 188 & 239 & S. Okazaki & 31 & 263 & 143 & 258 & 8 & 223 & 17 \\
\hline Universidad del País Vasco & 161 & 255 & I. Heras & 14 & 310 & 146 & 256 & 6 & 251 & 21 \\
\hline Universidad Nacional Autónoma de México ... & 61 & 329 & J.L. Solleiro & 15 & 305 & 19 & 318 & 2 & 317 & 13 \\
\hline Universidad Politecnica de Madrid & 115 & 292 & C.M. Romero & 130 & 73 & 1,262 & 61 & 21 & 41 & 150 \\
\hline Universidade de São Paulo & 185 & 244 & R.M. Faria & 190 & 41 & 896 & 100 & 16 & 92 & 150 \\
\hline Universidade Estadual de Campinas & 91 & 313 & D. Dequench & 18 & 299 & 113 & 272 & 8 & 223 & 0 \\
\hline Università degli Studi di Firenze & 93 & 311 & S. Guercini & 9 & 324 & 13 & 323 & 2 & 317 & 2 \\
\hline Università degli Studi di Padova & 272 & 200 & C. Forza & 35 & 243 & 705 & 125 & 17 & 77 & 15 \\
\hline Universita Di Bologna & 275 & 197 & G. Barbiroli & 49 & 194 & 99 & 277 & 5 & 270 & 27 \\
\hline Universita di Pisa & 95 & 307 & M. Corso & 24 & 280 & 190 & 243 & 8 & 223 & 28 \\
\hline Universitat Autonoma de Barcelona & 188 & 239 & D. Urbano & 21 & 289 & 36 & 307 & 3 & 301 & 31 \\
\hline Universitat Bielefeld & 104 & 301 & A. Muller & 340 & 10 & 5,072 & 10 & 41 & 5 & 150 \\
\hline Universität Bremen & 132 & 276 & B. Scholz-Reiter & 62 & 166 & 101 & 274 & 7 & 240 & 80 \\
\hline Universitat d'Alacant & 227 & 218 & E. Claver & 29 & 265 & 78 & 289 & 7 & 240 & 9 \\
\hline
\end{tabular}




\begin{tabular}{|c|c|c|c|c|c|c|c|c|c|c|}
\hline Universitat de València & 484 & 112 & D.R. Soriano & 365 & 9 & 46 & 305 & 4 & 290 & 21 \\
\hline Universität Frankfurt am Main & 232 & 214 & R. Van Dick & 57 & 174 & 400 & 176 & 13 & 133 & 68 \\
\hline Universität Freiburg & 82 & 320 & T.P. Gehrig & 21 & 289 & 138 & 263 & 6 & 251 & 18 \\
\hline Universitat Hamburg & 84 & 319 & M. Funke & 43 & 218 & 188 & 245 & 8 & 223 & 28 \\
\hline Universität Karlsruhe & 198 & 232 & S.T. Rachev & 123 & 80 & 355 & 184 & 10 & 180 & 114 \\
\hline Universitat Leipzig & 89 & 315 & G.B. Mohr & 17 & 302 & 100 & 275 & 6 & 251 & 15 \\
\hline Universitat Munster (Westfälische Wilhelms-Un & 97 & 305 & G. Vossen & 63 & 162 & 164 & 253 & 6 & 251 & 63 \\
\hline Universitat Politecnica de Catalunya & 332 & 180 & D. Cayuela & 114 & 87 & 73 & 295 & 4 & 290 & 52 \\
\hline Universität Regensburg & 95 & 307 & & 0 & 332 & 0 & 331 & 0 & 330 & 0 \\
\hline Universität Stuttgart & 95 & 307 & F. Leymann & 85 & 123 & 669 & 133 & 13 & 133 & 108 \\
\hline Universitat Trier & 48 & 333 & B. Swoboda & 14 & 310 & 28 & 312 & 3 & 301 & 27 \\
\hline Universität Tübingen & 146 & 262 & M. Pudelko & 14 & 310 & 53 & 303 & 5 & 270 & 10 \\
\hline Universitat Wien (University of Vienna) & 354 & 163 & A. Diamantopoulos & 54 & 181 & 884 & 102 & 15 & 103 & 40 \\
\hline Universitat Zu Koln & 222 & 221 & C. Loebbecke & 33 & 252 & 100 & 275 & 5 & 270 & 31 \\
\hline Université Catholique de Louvain & 243 & 209 & L. Simar & 54 & 181 & 578 & 143 & 16 & 92 & 150 \\
\hline Universite de Liege & 81 & 322 & P. Pestieau & 119 & 83 & 635 & 137 & 14 & 116 & 63 \\
\hline Université de Montréal & 381 & 152 & G. Laporte & 254 & 25 & 3,148 & 21 & 30 & 15 & 150 \\
\hline Université de Nice Sophia Antipolis & 106 & 299 & J.L. Gaffard & 25 & 277 & 24 & 316 & 3 & 301 & 17 \\
\hline Universite Laval & 473 & 116 & N. Amara & 28 & 273 & 341 & 192 & 12 & 153 & 43 \\
\hline Universite Libre de Bruxelles & 132 & 276 & I. Prigogine & 81 & 127 & 779 & 119 & 11 & 164 & 39 \\
\hline Université Paris Sorbonne & 275 & 197 & S. Saussier & 9 & 324 & 39 & 306 & 3 & 301 & 13 \\
\hline Universite Paris-Sud 11 & 51 & 330 & & 0 & 332 & 0 & 331 & 0 & 330 & 0 \\
\hline Université Pierre et Marie Curie & 49 & 332 & & 0 & 332 & 0 & 331 & 0 & 330 & 0 \\
\hline Universiti Malaya (University of Malaya) & 145 & 264 & B.B. Zaidan & 21 & 289 & 11 & 325 & 3 & 301 & 31 \\
\hline University College Cork & 120 & 286 & P. Finnegan & 45 & 213 & 919 & 95 & 16 & 92 & 150 \\
\hline University College Dublin & 311 & 187 & B. Fynes & 20 & 293 & 214 & 231 & 9 & 200 & 21 \\
\hline University College London & 375 & 156 & A. Furnham & 574 & 1 & 7,520 & 5 & 30 & 15 & 150 \\
\hline University do Porto & 62 & 328 & E. Oliveira & 73 & 139 & 98 & 278 & 5 & 270 & 64 \\
\hline University of Aberdeen & 352 & 166 & R. Flin & 96 & 107 & 992 & 90 & 19 & 56 & 107 \\
\hline University of Adelaide & 229 & 216 & P.G. Quester & 47 & 203 & 254 & 216 & 11 & 164 & 42 \\
\hline University of Alabama & 892 & 43 & S.E. Beatty & 37 & 236 & 1,101 & 78 & 15 & 103 & 40 \\
\hline University of Alberta & 806 & 48 & E. Erkut & 48 & 200 & 426 & 171 & 9 & 200 & 52 \\
\hline University of Amsterdam & 727 & 57 & A. Kolk & 42 & 221 & 325 & 200 & 13 & 133 & 21 \\
\hline University of Antwerp & 242 & 210 & P. De Pelsmacker & 35 & 243 & 120 & 268 & 7 & 240 & 29 \\
\hline University of Arizona & 965 & 40 & H. Chen & 282 & 16 & 1,873 & 41 & 27 & 22 & 150 \\
\hline University of Athens & 157 & 258 & F. Tzortzatou-Stathopo & 57 & 174 & 350 & 188 & 11 & 164 & 150 \\
\hline
\end{tabular}




\begin{tabular}{|c|c|c|c|c|c|c|c|c|c|c|}
\hline University of Auckland & 638 & 71 & R.J. Brodie & 33 & 252 & 268 & 213 & 9 & 200 & 32 \\
\hline University of Barcelona & 120 & 286 & J. Costa-Font & 57 & 174 & 134 & 264 & 8 & 223 & 43 \\
\hline University of Basel & 75 & 327 & G. Schatz & 222 & 30 & 4,586 & 14 & 26 & 24 & 150 \\
\hline University of Bath & 427 & 133 & P. Powell & 78 & 131 & 480 & 163 & 12 & 153 & 49 \\
\hline University of Bergen & 139 & 270 & P. Laegreid & 29 & 265 & 115 & 271 & 8 & 223 & 19 \\
\hline University of Bern & 110 & 297 & & 0 & 332 & 0 & 331 & 0 & 330 & 0 \\
\hline University of Birmingham & 633 & 72 & J.H. Fremlin & 154 & 59 & 183 & 247 & 0 & 330 & 110 \\
\hline University of Bristol & 229 & 216 & & 0 & 332 & 0 & 331 & 0 & 330 & 0 \\
\hline University of British Columbia & 519 & 102 & I. Benbasat & 102 & 97 & 2,538 & 28 & 22 & 35 & 77 \\
\hline University of Calgary & 407 & 144 & A. Serletis & 110 & 91 & 461 & 169 & 11 & 164 & 47 \\
\hline University of California, Berkley & 824 & 45 & D.S. Hochbaum & 87 & 119 & 1,342 & 57 & 12 & 153 & 44 \\
\hline University of California, Davis & 195 & 234 & P.L. Mokhtarian & 108 & 94 & 847 & 107 & 23 & 29 & 54 \\
\hline University of California, Irvine & 337 & 178 & K.J. Lin & 119 & 83 & 847 & 107 & 14 & 116 & 120 \\
\hline University of California, Los Angeles & 1,209 & 21 & C.T. Russell & 558 & 2 & 8,108 & 3 & 37 & 8 & 150 \\
\hline University of California, Riverside & 256 & 204 & J.K. Zhu & 200 & 35 & 6,821 & 7 & 64 & 1 & 150 \\
\hline University of California, San Diego & 1,187 & 23 & A. Timmermann & 60 & 170 & 698 & 127 & 17 & 77 & 31 \\
\hline University of California, San Francisco & 98 & 304 & & 0 & 332 & 0 & 331 & 0 & 330 & 0 \\
\hline University of California, Santa Barbara & 808 & 47 & J.Su & 76 & 133 & 549 & 148 & 13 & 133 & 67 \\
\hline University of California, Santa Cruz & 345 & 172 & Y.W. Cheung & 60 & 170 & 845 & 110 & 15 & 103 & 24 \\
\hline University of Cambridge & 568 & 90 & R. Phaal & 61 & 168 & 259 & 215 & 9 & 200 & 72 \\
\hline University of Canterbury & 145 & 264 & L.P. Dana & 37 & 236 & 57 & 299 & 5 & 270 & 21 \\
\hline University of Cape Town & 121 & 284 & M.R. Caira & 183 & 44 & 856 & 105 & 14 & 116 & 150 \\
\hline University of Central Florida & 724 & 58 & E.Salas & 173 & 47 & 3,027 & 23 & 34 & 11 & 150 \\
\hline University of Chicago & 623 & 73 & P.K. Chintagunta & 66 & 154 & 692 & 129 & 19 & 56 & 71 \\
\hline University of Cincinnati & 493 & 110 & F.R. Kardes & 39 & 231 & 1,083 & 80 & 15 & 103 & 107 \\
\hline University of Colorado at Boulder & 408 & 141 & F. Glover & 167 & 50 & 1,738 & 45 & 17 & 77 & 140 \\
\hline University of Connecticut & 537 & 96 & C.F. Sirmans & 127 & 75 & 701 & 126 & 14 & 116 & 83 \\
\hline University of Copenhagen & 115 & 292 & P. Bogetoft & 38 & 235 & 250 & 220 & 10 & 180 & 33 \\
\hline University of Delaware & 274 & 199 & W.V. Gehrlein & 92 & 113 & 283 & 212 & 6 & 251 & 19 \\
\hline University of Dundee & 187 & 243 & D.M.J. Lilley & 239 & 26 & 3,757 & 16 & 37 & 8 & 150 \\
\hline University of Edinburgh & 248 & 207 & Y.H. Chen-Burger & 18 & 299 & 20 & 317 & 3 & 301 & 45 \\
\hline University of Florida & 1,045 & 32 & S.M. Shugan & 47 & 203 & 460 & 170 & 13 & 133 & 18 \\
\hline University of Geneva & 141 & 267 & M.E. Hoesli & 42 & 221 & 291 & 208 & 11 & 164 & 38 \\
\hline University of Georgia & 732 & 55 & R.T. Watson & 74 & 136 & 1,225 & 64 & 18 & 64 & 73 \\
\hline University of Ghent & 218 & 224 & P. Demeester & 466 & 4 & 1,887 & 40 & 21 & 41 & 150 \\
\hline University of Glasgow & 451 & 122 & L.A. Moutinho & 33 & 252 & 105 & 273 & 6 & 251 & 33 \\
\hline
\end{tabular}




\begin{tabular}{|c|c|c|c|c|c|c|c|c|c|c|}
\hline University of Gothenburg & 4 & 345 & M.Z. Axell & 4 & 328 & 192 & 241 & 2 & 317 & 24 \\
\hline University of Groningen & 396 & 146 & M. Wedel & 109 & 93 & 1,496 & 52 & 20 & 44 & 131 \\
\hline University of Helsinki & 234 & 213 & E. Koskela & 72 & 142 & 329 & 199 & 9 & 200 & 22 \\
\hline University of Hong Kong & 437 & 127 & F.T.S. Chan & 194 & 40 & 1,264 & 60 & 19 & 56 & 146 \\
\hline University of Houston & 614 & 74 & D.H. Papell & 44 & 216 & 763 & 120 & 15 & 103 & 16 \\
\hline University of Illinois & 1,846 & 5 & A. Griffin & 56 & 180 & 1,377 & 56 & 14 & 116 & 44 \\
\hline University of Illinois, Chicago & 572 & 87 & R.C. Liden & 49 & 194 & 1,899 & 39 & 20 & 44 & 57 \\
\hline University of Indonesia & 31 & 340 & L. Gani & 4 & 328 & 9 & 326 & 2 & 317 & 1 \\
\hline University of Iowa & 315 & 184 & F.L. Schmidt & 101 & 98 & 3,193 & 20 & 20 & 44 & 75 \\
\hline University of Kansas & 221 & 222 & P.P. Shenoy & 49 & 194 & 361 & 183 & 9 & 200 & 25 \\
\hline University of Kentucky & 390 & 148 & C.W. Holsapple & 98 & 104 & 812 & 114 & 14 & 116 & 63 \\
\hline University of Lausanne & 92 & 312 & Y. Pigneur & 19 & 296 & 29 & 311 & 4 & 290 & 13 \\
\hline University of Leeds & 571 & 88 & P.J. Buckley & 83 & 126 & 996 & 89 & 18 & 64 & $\overline{52}$ \\
\hline University of Leicester & 344 & 173 & A.J.J. Meadows & 70 & 147 & 179 & 249 & 4 & 290 & 65 \\
\hline University of Liverpool & 166 & 254 & M. Woolridge & 153 & 60 & 2,847 & 25 & 22 & 35 & 150 \\
\hline University of Ljubljana & 447 & 124 & M. Nikolic & 61 & 168 & 26 & 314 & 2 & 317 & 36 \\
\hline University of London (Kings College of London) & 3,330 & 1 & J. Birkinshaw & 68 & 150 & 1,202 & 68 & 20 & 44 & 55 \\
\hline University of Manchester & 1,856 & 3 & B.G. Dale & 140 & 66 & 608 & 140 & 14 & 116 & 102 \\
\hline University of Manitoba & 339 & 176 & J. Godard & 23 & 284 & 349 & 189 & 9 & 200 & 2 \\
\hline University of Maryland & 1,425 & 14 & V. Trimble & 87 & 119 & 251 & 218 & 6 & 251 & 33 \\
\hline University of Maryland Baltimore County & 190 & 238 & T.W. Finin & 112 & 88 & 1,775 & 44 & 19 & 56 & 150 \\
\hline University of Massachusetts & 245 & 208 & A. Nagurney & 117 & 85 & 526 & 156 & 15 & 103 & 51 \\
\hline University of Melbourne & 991 & 34 & D. Samson & 47 & 203 & 628 & 138 & 10 & 180 & 47 \\
\hline University of Miami & 417 & 140 & Y. Luo & 89 & 117 & 1,273 & 59 & 23 & 29 & 28 \\
\hline University of Michigan & 1,184 & 24 & R.P. Bagozzi & 94 & 110 & 3,419 & 19 & 23 & 29 & 82 \\
\hline University of Minnesota & 809 & 46 & R.J. Kauffman & 148 & 63 & 1,110 & 76 & 20 & 44 & 123 \\
\hline University of Missouri & 759 & 52 & H.G. Fung & 53 & 185 & 196 & 239 & 9 & 200 & 54 \\
\hline University of Nebraska & 541 & 95 & S.M. Lee & 200 & 35 & 1,199 & 69 & 20 & 44 & 150 \\
\hline University of New Hampshire & 182 & 247 & L. Bstieler & 8 & 326 & 74 & 293 & 4 & 290 & $\overline{4}$ \\
\hline University of New Mexico & 194 & 236 & S.T. Walsh & 58 & 173 & 224 & 228 & 9 & 200 & 70 \\
\hline University of New South Wales & 639 & 70 & B. Bentallah & 101 & 98 & 1,404 & 55 & 15 & 103 & 117 \\
\hline University of North Carolina, Chapel Hill & 973 & 38 & J. B. E.M. Steenkamp & 69 & 149 & 3,617 & 17 & 33 & 12 & 150 \\
\hline University of North Texas & 344 & 173 & V.R. Prybutok & 57 & 174 & 505 & 159 & 12 & 153 & 52 \\
\hline University of Notre Dame & 390 & 148 & S. Devaraj & 23 & 284 & 558 & 147 & 11 & 164 & 20 \\
\hline University of Nottingham & 661 & 69 & M. Wright & 199 & 37 & 1,841 & 42 & 28 & 21 & 150 \\
\hline
\end{tabular}




\begin{tabular}{|c|c|c|c|c|c|c|c|c|c|c|}
\hline University of Oregon & 474 & 115 & L.R. Kahle & 33 & 252 & 515 & 158 & 4 & 290 & 35 \\
\hline University of Oslo & 264 & 202 & F.R. Forsund & 34 & 249 & 498 & 161 & 6 & 251 & 32 \\
\hline University of Otago & 241 & 211 & A.M. Everett & 16 & 304 & 16 & 322 & 3 & 301 & 16 \\
\hline University of Ottawa & 212 & 225 & J.D. Linton & 112 & 88 & 368 & 181 & 12 & 153 & 33 \\
\hline University of Oxford & 570 & 89 & G.L. Clark & 178 & 45 & 671 & 132 & 13 & 133 & 119 \\
\hline University of Pennsylvania & 1,274 & 19 & E.K. Clemons & 105 & 95 & 1,039 & 85 & 9 & 200 & 58 \\
\hline University of Pittsburgh & 473 & 116 & W.R. King & 110 & 91 & 1,075 & 81 & 13 & 133 & 52 \\
\hline University of Quebec & 150 & 261 & S. D'Amours & 47 & 203 & 207 & 235 & 8 & 223 & 41 \\
\hline University of Queensland & 525 & 99 & N.M. Ashkanasy & 72 & 142 & 531 & 151 & 14 & 116 & 61 \\
\hline University of Reading & 464 & 119 & C. Brooks & 57 & 174 & 416 & 172 & 13 & 133 & 41 \\
\hline University of Rochester & 199 & 231 & A. Seidmann & 76 & 133 & 973 & 93 & 9 & 200 & 58 \\
\hline University of Saskatchewan & 252 & 205 & N.T. Sheehan & 15 & 305 & 31 & 310 & 4 & 290 & 7 \\
\hline University of Science and Technology of China & 154 & 259 & L.Y. Liang & 280 & 18 & 1,463 & 54 & 22 & 35 & 150 \\
\hline University of Sheffield & 728 & 56 & D.W. Hughes & 189 & 42 & 875 & 104 & 15 & 103 & 150 \\
\hline University of South Carolina & 976 & 37 & V. Grover & 39 & 231 & 710 & 124 & 14 & 116 & 25 \\
\hline University of South Florida & 379 & 154 & T.D. Allen & 64 & 159 & 1,071 & 82 & 22 & 35 & 86 \\
\hline University of Southampton & 208 & 226 & N.R. Jennings & 218 & 31 & 4,705 & 12 & 36 & 10 & 150 \\
\hline University of Southern California & 735 & 54 & G.J. Tellis & 42 & 221 & 679 & 130 & 17 & 77 & 25 \\
\hline University of St Andrews & 119 & 289 & D.G. McMillian & 64 & 159 & 197 & 237 & 8 & 223 & 38 \\
\hline University of Surrey & 278 & 195 & G. Pavlou & 148 & 63 & 572 & 145 & 13 & 133 & 150 \\
\hline University of Sussex & 146 & 262 & M.Meyer & 126 & 76 & 2,287 & 31 & 29 & 19 & 150 \\
\hline University of Sydney & 665 & 66 & D.A. Hewsher & 203 & 34 & 1,243 & 62 & 19 & 56 & 128 \\
\hline University of Technology, Sydney & 368 & 159 & E Chang & 314 & 13 & 314 & 202 & 8 & 223 & 130 \\
\hline University of Tennessee Knoxville & 435 & 129 & J.T. Mentzer & 43 & 218 & 567 & 146 & 11 & 164 & 54 \\
\hline University of Texas at Austin & 972 & 39 & A.B. Whinston & 280 & 18 & 1,595 & 50 & 23 & 29 & 150 \\
\hline University of Tokyo & 799 & 50 & N. Sasaki & 282 & 16 & 1,834 & 43 & 20 & 44 & 150 \\
\hline University of Toronto & 1,067 & 31 & G.P. Latham & 88 & 118 & 2,032 & 35 & 18 & 64 & 60 \\
\hline University of Tsukuba & 79 & 324 & K. Tsuda & 50 & 191 & 76 & 290 & 3 & 301 & 66 \\
\hline University of Twente & 258 & 203 & M. Reichert & 100 & 101 & 503 & 160 & 10 & 180 & 78 \\
\hline University of Utah & 553 & 93 & M.R. Capecchi & 169 & 48 & 7,813 & 4 & 40 & 6 & 150 \\
\hline University of Vermont & 188 & 239 & J.M. Sinkula & 12 & 320 & 600 & 141 & 6 & 251 & 11 \\
\hline University of Victoria & 136 & 274 & W.M. Roth & 228 & 28 & 1,109 & 77 & 24 & 26 & 109 \\
\hline University of Virginia & 424 & 137 & R.E. Spekman & 33 & 252 & 882 & 103 & 14 & 116 & 25 \\
\hline University of Warwick & 987 & 35 & J. Swan & 53 & 185 & 698 & 127 & 17 & 77 & 17 \\
\hline University of Washington & 949 & 42 & & 0 & 332 & 0 & 331 & 0 & 330 & 0 \\
\hline University of Waterloo & 435 & 129 & K.W. Hipel & 263 & 21 & 831 & 111 & 14 & 116 & 132 \\
\hline
\end{tabular}




\begin{tabular}{|c|c|c|c|c|c|c|c|c|c|c|}
\hline University of Western Australia & 364 & 160 & G.N. Soutor & 46 & 210 & 466 & 165 & 10 & 180 & 52 \\
\hline University of Western Ontario & 683 & 63 & P.W. Beamish & 60 & 170 & 1,151 & 73 & 17 & 77 & 59 \\
\hline University of Wisconsin & 709 & 59 & J.P. Chaves & 92 & 113 & 658 & 134 & 10 & 180 & 61 \\
\hline University of Wollongong & 224 & 219 & S. Dolnicar & 35 & 243 & 87 & 284 & 5 & 270 & 25 \\
\hline University of York & 120 & 286 & K. Hartley & 47 & 203 & 182 & 248 & 7 & 240 & 28 \\
\hline University of Zurich & 106 & 299 & B.S. Frey & 157 & 55 & 2,052 & 34 & 20 & 44 & 111 \\
\hline Univesitas Gadjah Mada & 11 & 343 & M.A. Quaddus & 46 & 210 & 188 & 245 & 8 & 223 & 44 \\
\hline Uppsala University & 151 & 260 & M.O. Karlsson & 208 & 33 & 2,430 & 30 & 27 & 22 & 150 \\
\hline Utah State & 127 & 278 & D. Paper & 29 & 265 & 35 & 308 & 3 & 301 & 16 \\
\hline Utrecht University & 350 & 168 & A.B. Bakker & 99 & 102 & 1,674 & 47 & 29 & 19 & 146 \\
\hline Vanderbilt University & 250 & 206 & P.L. Rousseau & 27 & 274 & 235 & 224 & 9 & 200 & 10 \\
\hline Victoria University of Wellington & 1 & 347 & M.T. Angelillo & 2 & 331 & 7 & 327 & 2 & 317 & 8 \\
\hline Vienna University of Technology & 193 & 237 & G. Feichinger & 134 & 69 & 463 & 168 & 9 & 200 & 61 \\
\hline Virginia Polytechnic Institute & 484 & 112 & M.J. Sirgy & 73 & 139 & 529 & 153 & 13 & 133 & 64 \\
\hline Vrije Universiteit, Brussels & 608 & 77 & P.N. Nijkamp & 436 & 5 & 2,024 & 36 & 20 & 44 & 150 \\
\hline VU University Amsterdam & 578 & 85 & P. Nijkamp & 436 & 5 & 1,911 & 38 & 19 & 56 & 150 \\
\hline Wageningen University & 125 & 279 & R.B.M. Huirne & 131 & 72 & 895 & 101 & 17 & 77 & 137 \\
\hline Wake Forest University & 182 & 247 & J.G. Grzyacz & 72 & 142 & 789 & 118 & 16 & 92 & 95 \\
\hline Waseda University & 46 & 336 & J. Watada & 122 & 81 & 173 & 251 & 5 & 270 & 106 \\
\hline Washington State University & 408 & 141 & J.S. Valacich & 62 & 166 & 908 & 99 & 13 & 133 & 65 \\
\hline Washington University in St. Louis & 311 & 187 & S. Chib & 49 & 194 & 1,208 & 66 & 18 & 64 & 57 \\
\hline Wayne State University & 497 & 109 & A. Reinstein & 42 & 221 & 81 & 288 & 5 & 270 & 28 \\
\hline West Virginia University & 169 & 253 & J.R. Brown & 98 & 104 & 2,498 & 29 & 23 & 29 & 150 \\
\hline Yale University & 90 & 314 & F.J. Fabozzi & 73 & 139 & 91 & 282 & 5 & 270 & 78 \\
\hline Yonsei University & 224 & 219 & S.Y. Sohn & 99 & 102 & 311 & 204 & 11 & 164 & 67 \\
\hline York University & 516 & 104 & R.J. Burke & 216 & 32 & 1,225 & 64 & 16 & 92 & 150 \\
\hline Zhejiang University & 427 & 133 & J.L. Chen & 67 & 151 & 57 & 299 & 5 & 270 & 101 \\
\hline
\end{tabular}




\begin{tabular}{|c|c|c|c|c|c|c|c|c|c|c|}
\hline Nursing Data & $\begin{array}{l}\text { Department } \\
\text { Publications }\end{array}$ & Rank & Most Prolific Author & Published & Rank & Cited & Rank & $\begin{array}{c}\text { H- } \\
\text { Index }\end{array}$ & Rank & $\begin{array}{c}\text { \# of } \\
\text { Coauthors }\end{array}$ \\
\hline Aalto University & 23 & 299 & J. Kujala & 17 & 303 & 68 & 283 & 6 & 254 & 26 \\
\hline Aarhus University & 391 & 102 & F. Olesen & 214 & 78 & 1,757 & 115 & 24 & 95 & 150 \\
\hline Arizonia State University & 266 & 133 & B.M. Melnyk & 107 & 159 & 572 & 197 & 14 & 161 & 132 \\
\hline Ateneo de Manila University & 1 & 343 & E. Bagarinao & 19 & 299 & 92 & 278 & 6 & 254 & 31 \\
\hline Auburn University & 211 & 159 & K.N. Barker & 58 & 234 & 924 & 157 & 12 & 182 & 83 \\
\hline Australian National University & 133 & 200 & & 0 & 313 & 0 & 311 & 0 & 308 & 0 \\
\hline Boston College & 406 & 98 & J.W. Hawkins & 63 & 227 & 144 & 260 & 6 & 254 & 73 \\
\hline Boston University & 1,384 & 16 & A.S. Ash & 141 & 127 & 4,155 & 61 & 37 & 41 & 150 \\
\hline Brandeis University & 203 & 165 & S.S. Wallack & 56 & 239 & 273 & 231 & 7 & 243 & 59 \\
\hline Brigham Young University & 199 & 167 & L.C. Callister & 100 & 167 & 372 & 220 & 13 & 173 & 114 \\
\hline Brown University & 602 & 65 & V. Mor & 313 & 41 & 7,556 & 29 & 48 & 21 & 150 \\
\hline California Institute of Technology (Calt... & 7 & 324 & D. Baltimore & 192 & 88 & 18,947 & 9 & 64 & 11 & 150 \\
\hline Cardiff University & 765 & 45 & P. Burnard & 136 & 130 & 1,213 & 138 & 14 & 161 & 84 \\
\hline Carnegie Mellon University & 63 & 265 & M.G. Morgan & 79 & 195 & 771 & 173 & 11 & 199 & 98 \\
\hline Case Western Reserve University & 1,222 & 24 & D. Neuhauser & 124 & 138 & 623 & 191 & 11 & 199 & 134 \\
\hline Chalmers University of Technology & 15 & 306 & O.Orwar & 112 & 150 & 1,668 & 118 & 27 & 78 & 150 \\
\hline Charles University & 91 & 240 & & 0 & 313 & 0 & 311 & 0 & 308 & 0 \\
\hline Chinese University of Hong Kong & 449 & 80 & D.R. Thompson & 294 & 51 & 3,973 & 65 & 32 & 63 & 150 \\
\hline Chulalongkorn University & 64 & 262 & G.J. Kost & 69 & 206 & 555 & 198 & 15 & 152 & 103 \\
\hline City University of Hong Kong & 33 & 289 & R. Fan & 27 & 292 & 112 & 267 & 7 & 243 & 10 \\
\hline City University of New York & 370 & 105 & S.L. Baumann & 51 & 249 & 96 & 274 & 5 & 266 & 16 \\
\hline Colorado State University & 96 & 235 & P.J. Brennan & 222 & 77 & 4,537 & 54 & 41 & 33 & 150 \\
\hline Columbia University & 1,906 & 9 & E.R. Kandal & 448 & 17 & 17,020 & 12 & 77 & 5 & 150 \\
\hline Cornell University & 1,229 & 22 & R.B. Devereux & 230 & 74 & 8,837 & 24 & 14 & 161 & 150 \\
\hline Curtin University of Technology & 314 & 121 & P. M. Davidson & 231 & 73 & 5,072 & 47 & 17 & 135 & 150 \\
\hline Dalhousie University & 603 & 64 & K.V. Mann & 98 & 169 & 1,101 & 143 & 18 & 128 & 150 \\
\hline Dartmouth College & 714 & 54 & S.C. Beyer & 146 & 124 & 291 & 225 & 8 & 234 & 38 \\
\hline Delft University of Technology & 21 & 301 & & 0 & 313 & 0 & 311 & 0 & 308 & 0 \\
\hline Drexel University & 566 & 72 & H.M. Dreher & 38 & 276 & 41 & 296 & 3 & 289 & 60 \\
\hline Duke University & 1,842 & 10 & E.J. Topol & 1,110 & 2 & 42,490 & 3 & 107 & 1 & 150 \\
\hline Durham University & 106 & 226 & & 0 & 313 & 0 & 311 & 0 & 308 & 0 \\
\hline Ecole Normale Supérieure de Lyon & 2 & 337 & & 0 & 313 & 0 & 311 & 0 & 308 & 0 \\
\hline École Normale Supérieure, Paris & 6 & 327 & & 0 & 313 & 0 & 311 & 0 & 308 & 0 \\
\hline École Polytechnique & 2 & 337 & & 0 & 313 & 0 & 311 & 0 & 308 & 0 \\
\hline Ecole Polytechnique Fédérale de Lausanne & 7 & 324 & & 0 & 313 & 0 & 311 & 0 & 308 & 0 \\
\hline Eindhoven University of Technology & 21 & 301 & R.J.M. Mercx & 17 & 303 & 0 & 311 & 0 & 308 & 5 \\
\hline Emory University & 1,276 & 21 & W.S. Weintraub & 411 & 19 & 11,428 & 18 & 45 & 27 & 150 \\
\hline
\end{tabular}




\begin{tabular}{|c|c|c|c|c|c|c|c|c|c|c|}
\hline Keio University & 103 & 227 & S. Ogawa & 461 & 16 & 9,162 & 22 & 48 & 21 & 150 \\
\hline King Fahd University of Petroleum \& Minerals & 4 & 334 & & 0 & 313 & 0 & 311 & 0 & 308 & 0 \\
\hline King Saud University & 78 & 253 & S.A. Al-Shammari & 47 & 256 & 289 & 226 & 6 & 254 & 64 \\
\hline Kobe University & 51 & 274 & Y. Nishizuka & 187 & 92 & 9,115 & 23 & 11 & 199 & 150 \\
\hline Korea Advanced Institute of Science \& Technology & 4 & 334 & & 0 & 313 & 0 & 311 & 0 & 308 & 0 \\
\hline Korea University & 86 & 245 & Y.J. Park & 57 & 236 & 515 & 203 & 12 & 182 & 150 \\
\hline
\end{tabular}




\begin{tabular}{|c|c|c|c|c|c|c|c|c|c|c|}
\hline New Mexico State University & 91 & 240 & & 0 & 313 & 0 & 311 & 0 & 308 & 0 \\
\hline New York University & 1,023 & 31 & M. Mezey & 103 & 162 & 1,249 & 136 & 15 & 152 & 150 \\
\hline Newcastle University & 505 & 76 & S. Bond & 72 & 198 & 880 & 163 & 16 & 141 & 97 \\
\hline North Carolina State University & 87 & 244 & $\overline{\text { G.S. Davidson }}$ & 21 & 297 & 85 & 281 & 2 & 295 & 21 \\
\hline Northeastern University & 290 & 128 & K.1. Tucker & 20 & 298 & 9 & 306 & 1 & 303 & 69 \\
\hline Northwestern University & 1,103 & 29 & D. Cella & 406 & 21 & 11,603 & 17 & 60 & 12 & 150 \\
\hline Norwegian University of Science \& Technology & 212 & 158 & S. Kaasa & 258 & 61 & 8,770 & 25 & 47 & 24 & 150 \\
\hline Ohio State University & 1,122 & 27 & P.J. Schneider & 101 & 165 & 713 & 181 & 12 & 182 & 133 \\
\hline Oklahoma State University & 94 & 236 & F.N. Owens & 111 & 154 & 1,627 & 119 & 13 & 173 & 146 \\
\hline Open University UK & 129 & 204 & & 0 & 313 & 0 & 311 & 0 & 308 & 0 \\
\hline Oregon State University & 155 & 185 & & 0 & 313 & 0 & 311 & 0 & 308 & 0 \\
\hline Osaka University & 228 & 151 & T. Kishimoto & 626 & 9 & 44,277 & 2 & 79 & 4 & 150 \\
\hline Peking University & 141 & 196 & & 0 & 313 & 0 & 311 & 0 & 308 & 0 \\
\hline Pennsylvania State University & 664 & 56 & R. Roy & 397 & 25 & 3,777 & 69 & 24 & 95 & 150 \\
\hline Pohang University of Science And Technology & 1 & 343 & H.J. Kim & 111 & 154 & 731 & 178 & 12 & 182 & 150 \\
\hline Portland State University & 65 & 261 & & 0 & 313 & 0 & 311 & 0 & 308 & 0 \\
\hline Princeton University & 103 & 227 & U.E. Reinhardt & 182 & 93 & 998 & 151 & 17 & 135 & 150 \\
\hline Purdue University & 411 & 93 & D.R. Black & 112 & 150 & 761 & 174 & 12 & 182 & 150 \\
\hline Queen's University & 342 & 117 & P. Katzmarzyk & 163 & 105 & 3,321 & 74 & 35 & 47 & 150 \\
\hline Queen's University of Belfast & 277 & 130 & S. Porter & 24 & 294 & 224 & 242 & 5 & 266 & 11 \\
\hline Queensland University of Technology & 353 & 110 & M. Courtney & 72 & 198 & 286 & 227 & 11 & 199 & 113 \\
\hline Radboud University, Nijmegen & 514 & 74 & R. Grol & 478 & 15 & 6,402 & 36 & 42 & 31 & 150 \\
\hline Rensselaer Polytechnic Institute & 20 & 303 & R.J. Linhardt & 338 & 36 & 5,590 & 41 & 42 & 31 & 150 \\
\hline Rheinisch Westfalische Technische Hochschule Aach & 99 & 232 & L. Radbruch & 161 & 108 & 1,899 & 110 & 25 & 87 & 150 \\
\hline Rheinische Friedrich Wilhelms Universitat Bonn & 190 & 170 & M. Kersting & 236 & 68 & 883 & 162 & 23 & 99 & 150 \\
\hline Rice University & 45 & 279 & & 0 & 313 & 0 & 311 & 0 & 308 & $\overline{0}$ \\
\hline Rochester Institute of Technology & 1 & 343 & I.A. White & 65 & 222 & 1,062 & 146 & 11 & 199 & 123 \\
\hline Royal Institute of Technology, KTH & 41 & 282 & J.E.F. Sundberg & 133 & 131 & 804 & 168 & 13 & 173 & 136 \\
\hline Royal Melbourne Institute of Technology & 136 & 198 & J.R. Jamison & 43 & 264 & 68 & 283 & 2 & 295 & 17 \\
\hline Rutgers & 752 & 48 & D. Mechanic & 200 & 85 & 4,399 & 57 & 29 & 72 & 150 \\
\hline Saint-Petersburg State University & 2 & 337 & L.N. Moskvin & 194 & 87 & 187 & 253 & 7 & 243 & 150 \\
\hline San Diego State University & 351 & 112 & J.F. Stichler & 69 & 206 & 111 & 269 & 5 & 266 & 31 \\
\hline Sapienza University of Rome & 0 & 346 & & 0 & 313 & 0 & 311 & 0 & 308 & 0 \\
\hline Sciences Po Paris & 0 & 346 & & 0 & 313 & 0 & 311 & 0 & 308 & $\overline{0}$ \\
\hline Seoul National University & 241 & 147 & M.A. Choe & 40 & 270 & 200 & 248 & 7 & 243 & 75 \\
\hline Shanghai Jiao Tong University & 92 & 237 & M.Q. Cai & 68 & 212 & 435 & 213 & 13 & 173 & 107 \\
\hline
\end{tabular}




\begin{tabular}{|c|c|c|c|c|c|c|c|c|c|c|}
\hline Simon Fraser University & 92 & 237 & T.D. Sterling & 124 & 138 & 590 & 194 & 3 & 289 & 69 \\
\hline Stanford University & 1,429 & 14 & S. Falkow & 354 & 32 & 14,118 & 15 & 55 & 16 & 150 \\
\hline State University of New York Buffalo & 6 & 327 & J. Karuza & 48 & 254 & 458 & 210 & 9 & 221 & 92 \\
\hline Stockholm University & 84 & 249 & & 0 & 313 & 0 & 311 & 0 & 308 & $\overline{0}$ \\
\hline Stony Brook University & 381 & 104 & W.J. Lennarz & 297 & 49 & 2,805 & 88 & 27 & 78 & 150 \\
\hline Syracuse University & 84 & 249 & M.P. Carey & 210 & 80 & 3,471 & 72 & 33 & 55 & 150 \\
\hline Tartu University (University of Tartu) & 26 & 294 & R. Kalda & 33 & 281 & 99 & 273 & 6 & 254 & 60 \\
\hline Technical University of Denmark & 47 & 276 & & 0 & 313 & 0 & 311 & 0 & 308 & $\overline{0}$ \\
\hline Technion & 142 & 194 & E. Ben-Arye & 34 & 280 & 151 & 256 & 8 & 234 & 56 \\
\hline Technische Universität Berlin & 53 & 273 & R. Busse & 82 & 192 & 801 & 170 & 12 & 182 & 108 \\
\hline Technische Universitat Chemnitz & 0 & 346 & & 0 & 313 & 0 & 311 & 0 & 308 & 0 \\
\hline Technische Universität Dresden & 75 & 254 & W. Kirch & 340 & 35 & 1,837 & 112 & 20 & 117 & 150 \\
\hline Technische Universität München & 297 & 126 & A. Schoming & 558 & 12 & 20,482 & 7 & 65 & 10 & 150 \\
\hline Tel Aviv University & 439 & 82 & R. Bergman & 44 & 262 & 39 & 299 & 2 & 295 & 42 \\
\hline Texas A\&M University & 345 & 116 & E.R. Dougherty & 365 & 30 & 4,296 & 60 & 35 & 47 & 150 \\
\hline Texas Tech & 176 & 175 & M.L Armstrong & 64 & 224 & 272 & 232 & 11 & 199 & 55 \\
\hline Tohoku University & 135 & 199 & Y. Imai & 364 & 31 & 4,597 & 53 & 43 & 30 & 150 \\
\hline Tokyo Institute of Technology & 8 & 323 & & 0 & 313 & 0 & 311 & 0 & 308 & 0 \\
\hline Trinity College Dublin & 308 & 124 & F. Timmins & 51 & 249 & 148 & 258 & 7 & 243 & 37 \\
\hline Tsinghua University & 10 & 317 & J.S. Bai & 376 & 29 & 861 & 165 & 15 & 152 & 150 \\
\hline Tufts University & 764 & 46 & J.M. Coffin & 179 & 95 & 4,350 & 59 & 27 & 78 & 150 \\
\hline Universidad Autonoma de Madrid & 132 & 201 & F. Rodriguez-Artalejo & 32 & 283 & 102 & 271 & 4 & 279 & 112 \\
\hline Universidad de Chile & 201 & 166 & R. Uauy & 249 & 64 & 5,093 & 46 & 34 & 51 & 150 \\
\hline Universidad de Granada & 132 & 201 & F. Rodriguez-Artalejo & 32 & 283 & 102 & 271 & 4 & 279 & 112 \\
\hline Universidad del País Vasco & 64 & 262 & I. Labayen & 31 & 289 & 174 & 255 & 8 & 234 & 150 \\
\hline Universidad Nacional Autónoma de México ... & 56 & 269 & S. C. Hebert & 233 & 71 & 6,529 & 35 & 52 & 18 & 150 \\
\hline Universidad Politecnica de Madrid & 56 & 269 & M.Gonzalez-Gross & 72 & 198 & 683 & 184 & 16 & 141 & 150 \\
\hline Universidade de São Paulo & 996 & 32 & M.A. Trevizan & 61 & 229 & 44 & 294 & 4 & 279 & 55 \\
\hline Universidade Estadual de Campinas & 113 & 222 & M.H. Lopes & 42 & 265 & 112 & 267 & 4 & 279 & 103 \\
\hline Università degli Studi di Firenze & 155 & 185 & G.F. Gensini & 390 & 26 & 3,917 & 66 & 34 & 51 & 150 \\
\hline Università degli Studi di Padova & 280 & 129 & E. Manzato & 157 & 114 & 871 & 164 & 16 & 141 & 150 \\
\hline Universita Di Bologna & 166 & 178 & G. Marchesini & 280 & 57 & 5,070 & 48 & 33 & 55 & 150 \\
\hline Universita di Pisa & 100 & 230 & S. Del Prato & 49 & 253 & 511 & 204 & 10 & 214 & 150 \\
\hline Universitat Autonoma de Barcelona & 185 & 171 & J. Ybarra & 53 & 245 & 413 & 215 & 12 & 182 & 142 \\
\hline Universitat Bielefeld & 37 & 284 & U. Ravens-Sieberer & 87 & 186 & 1,138 & 140 & 19 & 124 & 150 \\
\hline Universität Bremen & 47 & 276 & W. Ahrens & 42 & 265 & 494 & 206 & 5 & 266 & 150 \\
\hline
\end{tabular}




\begin{tabular}{|c|c|c|c|c|c|c|c|c|c|c|}
\hline Universitat d'Alacant & 71 & 255 & J. Sanz & 39 & 274 & 45 & 293 & 5 & 266 & 47 \\
\hline Universitat de València & 121 & 211 & D. Corella & 56 & 239 & 491 & 207 & 11 & 199 & 150 \\
\hline Universität Frankfurt am Main & 162 & 181 & S. Wicker & 40 & 270 & 53 & 289 & 4 & 279 & 39 \\
\hline Universität Freiburg & 97 & 234 & E.H. Kuner & 202 & 82 & 720 & 180 & 9 & 221 & 150 \\
\hline Universitat Hamburg & 64 & 262 & D.M. Richter & 236 & 68 & 2,903 & 85 & 28 & 74 & 150 \\
\hline Universität Karlsruhe & 9 & 320 & & 0 & 313 & 0 & 311 & 0 & 308 & 0 \\
\hline Universitat Leipzig & 17 & 305 & M.C. Angermeyer & 402 & 24 & 4,426 & 56 & 37 & 41 & 150 \\
\hline Universitat Munster (Westfälische Wilhelms-Un & 170 & 176 & E. Brug & 138 & 129 & 388 & 217 & 7 & 243 & 111 \\
\hline Universitat Politecnica de Catalunya & 12 & 313 & E. Cobo & 36 & 278 & 699 & 183 & 9 & 221 & 147 \\
\hline Universität Regensburg & 114 & 219 & & 0 & 313 & 0 & 311 & 0 & 308 & 0 \\
\hline Universität Stuttgart & 9 & 320 & M. Schanz & 32 & 283 & 198 & 250 & 8 & 234 & 35 \\
\hline Universitat Trier & 5 & 331 & K.M. Pirke & 204 & 81 & 3,170 & 76 & 17 & 135 & 150 \\
\hline Universität Tübingen & 120 & 214 & F. Lang & 643 & 6 & 17,517 & 11 & 60 & 12 & 150 \\
\hline Universitat Wien (University of Vienna) & 247 & 144 & A. N. Laggner & 297 & 49 & 3,069 & 80 & 28 & 74 & 150 \\
\hline Universitat Zu Koln & 215 & 156 & L. Radbruch & 165 & 104 & 2,026 & 105 & 26 & 82 & 150 \\
\hline Université Catholique de Louvain & 111 & 225 & A. Goffeau & 232 & 72 & 8,644 & 26 & 38 & 37 & 150 \\
\hline Universite de Liege & 46 & 278 & Z.M. Bacq & 158 & 112 & 59 & 287 & 0 & 308 & 112 \\
\hline Université de Montréal & 593 & 67 & F. Ducharme & 154 & 117 & 1,506 & 122 & 23 & 99 & 150 \\
\hline Université de Nice Sophia Antipolis & 43 & 281 & A. Iannelli & 64 & 224 & 424 & 214 & 11 & 199 & 150 \\
\hline Universite Laval & 394 & 100 & A. Tremblay & 307 & 43 & 7,110 & 32 & 35 & 47 & 150 \\
\hline Universite Libre de Bruxelles & 166 & 178 & D. Razaui & 68 & 212 & 3,832 & 67 & 15 & 152 & 150 \\
\hline Université Paris Sorbonne & 12 & 313 & S. Cadolle & 17 & 303 & 0 & 311 & 0 & 308 & 0 \\
\hline Universite Paris-Sud 11 & 114 & 219 & B.J. Balkau & 201 & 83 & 7,331 & 31 & 45 & 27 & 45 \\
\hline Université Pierre et Marie Curie & 116 & 218 & J. Belmin & 214 & 78 & 938 & 156 & 16 & 141 & 150 \\
\hline Universiti Malaya (University of Malaya) & 56 & 269 & & 0 & 313 & 0 & 311 & 0 & 308 & 0 \\
\hline University College Cork & 144 & 192 & G. McCarthy & 96 & 174 & 919 & 158 & 16 & 141 & 150 \\
\hline University College Dublin & 231 & 150 & A. Hyde & 40 & 270 & 124 & 265 & 7 & 243 & 43 \\
\hline University College London & 1,361 & 17 & F. Gibson & 69 & 206 & 207 & 246 & 10 & 214 & 117 \\
\hline University do Porto & 13 & 310 & H. Barros & 273 & 59 & 1,770 & 114 & 22 & 105 & 150 \\
\hline University of Aberdeen & 576 & 71 & V. Hundley & 45 & 260 & 379 & 219 & 11 & 199 & 91 \\
\hline University of Adelaide & 383 & 103 & R.K. Morton & 22 & 296 & 50 & 291 & 0 & 308 & 24 \\
\hline University of Alabama & 1,919 & 7 & N.L. Keltner & 70 & 204 & 208 & 245 & 6 & 254 & 60 \\
\hline University of Alberta & 1,593 & 12 & K.S. Courneya & 224 & 75 & 2,395 & 100 & 37 & 41 & 150 \\
\hline University of Amsterdam & 599 & 66 & N.S. Klazinga & 123 & 141 & 1,091 & 145 & 15 & 152 & 150 \\
\hline University of Antwerp & 140 & 197 & P.P. De Deyn & 410 & 20 & 6,824 & 33 & 41 & 33 & 150 \\
\hline University of Arizona & 1,337 & 19 & K.B. Kern & 147 & 123 & 2,920 & 84 & 33 & 55 & 150 \\
\hline
\end{tabular}




\begin{tabular}{|c|c|c|c|c|c|c|c|c|c|c|}
\hline University of Athens & 416 & 90 & C. Stefanadis & 643 & 6 & 8,307 & 27 & 40 & 35 & 150 \\
\hline University of Auckland & 357 & 107 & S. Buetow & 77 & 197 & 817 & 167 & 14 & 161 & 75 \\
\hline University of Barcelona & 257 & 140 & L. Serra-Majem & 112 & 150 & 954 & 155 & 20 & 117 & 150 \\
\hline University of Base & 262 & 136 & S. De Geest & 129 & 136 & 1,359 & 132 & 22 & 105 & 150 \\
\hline University of Bath & 31 & 290 & S.M. Skevington & 68 & 212 & 1,467 & 127 & 16 & 141 & 150 \\
\hline University of Bergen & 123 & 209 & B.R. Hanestad & 96 & 174 & 742 & 177 & 16 & 141 & 108 \\
\hline University of Bern & 35 & 285 & A.E. Stuck & 96 & 174 & 2,328 & 102 & 14 & 161 & 150 \\
\hline University of Birm ngham & 759 & 47 & C. Hicks & 60 & 230 & 349 & 222 & 11 & 199 & 39 \\
\hline University of Bristol & 435 & 87 & G.D. Smith & 666 & 5 & 24,736 & 5 & 69 & 8 & 150 \\
\hline University of British Columbia & 660 & 57 & J.1. Botcorft & 132 & 132 & 1,061 & 147 & 15 & 152 & 150 \\
\hline University of Calgary & 394 & 100 & L.E. Carlson & 67 & 217 & 1,292 & 135 & 24 & 95 & 125 \\
\hline University of California, Berkley & 86 & 245 & J.R. Bloom & 84 & 189 & 2,808 & 87 & 12 & 182 & 116 \\
\hline University of California, Davis & 177 & 173 & R.L. Kraviz & 160 & 110 & 4,363 & 58 & 33 & 55 & 150 \\
\hline University of California, Irvine & 127 & 208 & D.B. Mukame & 97 & 171 & 962 & 154 & 22 & 105 & 106 \\
\hline University of California, Los Angeles & 2,954 & 4 & R.D. Hays & 381 & 28 & 17,781 & 10 & 56 & 15 & 150 \\
\hline University of California, Riverside & 35 & 285 & A.W. Norman & 314 & 40 & 3,115 & 78 & 9 & 221 & 150 \\
\hline University of California, San Diego & 165 & 180 & S. Ancol -Israel & 236 & 68 & 4,007 & 64 & 38 & 37 & 150 \\
\hline University of California, San Francisco & & 11 & C. Miaskowski & 241 & 66 & 3,780 & 68 & 33 & 55 & 150 \\
\hline University of California, Santa Barbara & 29 & 291 & L.C. Wilson & 201 & 83 & 4,789 & 52 & 36 & 45 & 150 \\
\hline University of California, Santa Cruz & 13 & 310 & & 0 & 313 & 0 & 311 & 0 & 308 & 0 \\
\hline University of Cambridge & 66 & 258 & C.Todd & 103 & 162 & 2,246 & 103 & 26 & 82 & 150 \\
\hline University of Canterbury & 5 & 331 & G.M. Shaw & 72 & 198 & 227 & 241 & 12 & 182 & 95 \\
\hline University of Cape Town & 24 & 298 & P. Mayers & 14 & 307 & 55 & 288 & 4 & 279 & 37 \\
\hline University of Central Florida & 354 & 109 & A. Liberman & 68 & 212 & 93 & 275 & 5 & 266 & 64 \\
\hline University of Chicago & 440 & 81 & M.H. Chin & 108 & 157 & 4,505 & 55 & 29 & 72 & 150 \\
\hline University of Cincinnati & 982 & 34 & J. Tseva & 129 & 136 & 2,731 & 91 & 25 & 87 & 150 \\
\hline University of Colorado at Boulder & 58 & 268 & A. Bryan & 47 & 256 & 656 & 187 & 16 & 141 & 56 \\
\hline University of Conneccut & 407 & 96 & C.T. Beck & 101 & 165 & 1,436 & 129 & 20 & 117 & 17 \\
\hline University of Copenhagen & 92 & 237 & K. Avlund & 102 & 164 & 918 & 159 & 21 & 110 & 137 \\
\hline University of Delaware & 142 & 194 & J. Selekman & 40 & 270 & 67 & 285 & 3 & 289 & 20 \\
\hline University of Dundee & 580 & 69 & R.M. Harden & 189 & 90 & 1,951 & 109 & 27 & 78 & 150 \\
\hline University of Edinburgh & 250 & 142 & R. Mander & 50 & 251 & 72 & 282 & 4 & 279 & 21 \\
\hline University of Forida & 1,425 & 15 & C.J. Pepine & 258 & 61 & 9,718 & 20 & 48 & 21 & 150 \\
\hline University of Geneva & 62 & 266 & D. Pittet & 282 & 56 & 7,737 & 28 & 47 & 24 & 150 \\
\hline University of Georgia & 59 & 267 & J.W. Cooper & 89 & 182 & 893 & 161 & 9 & 221 & 74 \\
\hline University of Ghent & 114 & 219 & T. Defloor & 52 & 248 & 352 & 221 & 15 & 152 & 105 \\
\hline
\end{tabular}




\begin{tabular}{|c|c|c|c|c|c|c|c|c|c|c|}
\hline University of Gothenburg & 263 & 134 & E. Danielson & 56 & 239 & 241 & 243 & 9 & 221 & 51 \\
\hline University of Groningen & 118 & 216 & R. Sanderman & 151 & 120 & 2,948 & 82 & 28 & 74 & 150 \\
\hline University of Helsinki & 413 & 91 & H. Sintonen & 118 & 114 & 1,454 & 128 & 21 & 110 & 150 \\
\hline University of Hong Kong & 155 & 185 & T.H. Lam & 344 & 33 & 3,699 & 70 & 31 & 67 & 150 \\
\hline University of Houston & 34 & 288 & S.S. Sansgiry & 59 & 232 & 93 & 275 & 5 & 266 & 67 \\
\hline University of Illinois & 409 & 594 & D. H. Baker & 385 & 27 & 2,967 & 81 & 23 & 99 & 150 \\
\hline University of Illinois, Chicago & 1,919 & 7 & S.S. Epstein & 385 & 27 & 537 & 200 & 6 & 25 & 150 \\
\hline University of Indonesia & & 340 & N. Darmawidjaj & 2 & 311 & 2 & 310 & 1 & 303 & 12 \\
\hline University of Iowa & 879 & 40 & F. Dexter & 253 & 63 & 1,973 & 107 & 31 & 67 & 150 \\
\hline University of Kansas & 469 & 77 & J.D. Pierce & 32 & 283 & 201 & 247 & 6 & 254 & 60 \\
\hline University of Kentucky & 459 & 78 & D.K. Moser & 189 & 90 & 2,85 & 86 & 25 & 87 & 150 \\
\hline University of Lausanne & 18 & 304 & C.J. Bula & 64 & 224 & 1,296 & 134 & 12 & 182 & 133 \\
\hline University of Leeds & 424 & 89 & K. Hurst & 68 & 212 & 142 & 261 & 6 & 25 & 43 \\
\hline University of Leicester & 347 & 113 & R. Baker & 177 & 97 & 2,499 & 96 & 28 & 74 & 150 \\
\hline University of Liverpool & 276 & 131 & P. Salmon & 151 & 120 & 1,720 & 116 & 25 & 87 & 150 \\
\hline University of Ljubljana & 86 & 245 & M. Loc & 56 & 239 & 1.245 & 137 & 15 & 152 & 140 \\
\hline University of London (Kings College of London) & 4,159 & 2 & I.J. Higgingson & 238 & 67 & 3,087 & 79 & 31 & 67 & 150 \\
\hline University of Manchester & 1,345 & 18 & A. Molassoitis & 115 & 14 & 1,129 & 142 & 20 & 117 & 150 \\
\hline University of Manitoba & 737 & 50 & N.P. Roos & 122 & 142 & 1,684 & 117 & 13 & 173 & 124 \\
\hline University of Maryland & 310 & 12 & V. Trimble & 87 & 186 & 251 & 238 & 6 & 254 & 33 \\
\hline University of Maryland Baltimore County & 1,280 & 20 & B. Resnick & 170 & 100 & 1,162 & 139 & 23 & 99 & 150 \\
\hline University of Massachusetts & 242 & 146 & J. Young-Mason & 71 & 203 & 14 & 304 & 2 & 295 & 9 \\
\hline University of Melbourne & 840 & 41 & B. Happel & 180 & 94 & 590 & 194 & 18 & 128 & 64 \\
\hline University of Miami & 262 & 136 & T. Field & 306 & 44 & 4,135 & 62 & 33 & 55 & 150 \\
\hline University of Michigan & 931 & 38 & B.E. Fries & 118 & 144 & 2,551 & 93 & 25 & 87 & 150 \\
\hline University of Minnesota & 745 & 49 & R.L. Kane & 420 & 18 & 6,115 & 38 & 34 & 51 & 150 \\
\hline University of Missouri & 784 & 43 & V.S. Conn & 119 & 143 & 1,10 & 143 & 20 & 117 & 134 \\
\hline University of Nebraska & 178 & 172 & V.N. Gladshev & 150 & 122 & 2,352 & 101 & 39 & 36 & 150 \\
\hline University of New Hampshire & 99 & 232 & S. Fetzer & 46 & 258 & 137 & 263 & 6 & 254 & 64 \\
\hline University of New Mexico & 204 & 148 & P.T. Clements & 59 & 232 & 142 & 261 & 7 & 243 & 67 \\
\hline University of New South Wales & 130 & 20 & H. Brodaty & 16 & 306 & 49 & 29 & 1 & 303 & 31 \\
\hline University of North Carolina, Chapel Hill & 2,126 & 6 & M. Sandelowski & 118 & 144 & 2,776 & 89 & 24 & 95 & 150 \\
\hline University of North Texas & 35 & 285 & B. Haslip & 99 & 168 & 436 & 212 & 10 & 214 & 124 \\
\hline University of Notre Dame & 6 & 327 & T.V. Merluzzi & 24 & 294 & 270 & 233 & 5 & 266 & 28 \\
\hline University of Nottingham & 408 & 95 & D. Kendrick & 97 & 171 & 675 & 186 & 12 & 182 & 150 \\
\hline
\end{tabular}




\begin{tabular}{|c|c|c|c|c|c|c|c|c|c|c|}
\hline University of Oklahoma & 217 & 155 & C. Kenner & 104 & 160 & 148 & 258 & 6 & 254 & 100 \\
\hline University of Oregon & 234 & 149 & Y. Fang & 69 & 206 & 727 & 179 & 15 & 152 & 150 \\
\hline University of Oslo & 304 & 125 & T. Moum & 104 & 160 & 1,613 & 120 & 21 & 110 & 150 \\
\hline University of Otago & 86 & 245 & M. Crowe & 29 & 291 & 129 & 264 & 7 & 243 & 24 \\
\hline University of Ottawa & 337 & 118 & I.D. Graham & 301 & 45 & 9,196 & 21 & 36 & 45 & 150 \\
\hline University of Oxford & 205 & 163 & S. Ziebland & 89 & 182 & 1,997 & 106 & 21 & 110 & 150 \\
\hline University of Pennsylvania & 1,533 & 13 & L.H. Aiken & 154 & 117 & 3,148 & 77 & 31 & 67 & 140 \\
\hline University of Pittsburgh & 1,042 & 30 & N.G. Castle & 167 & 103 & 965 & 153 & 21 & 110 & 135 \\
\hline University of Quebec & 112 & 224 & G. Godin & 155 & 115 & 2,462 & 98 & 17 & 135 & 150 \\
\hline University of Queensland & 225 & 153 & D. Hegney & 72 & 198 & 265 & 236 & 11 & 199 & 101 \\
\hline University of Reading & 160 & 183 & M. Courtenary & 62 & 228 & 199 & 249 & 8 & 234 & 22 \\
\hline University of Rochester & 511 & 75 & G.R. Morrow & 159 & 111 & 2,946 & 83 & 23 & 99 & 150 \\
\hline University of Saskatchewan & 403 & 99 & W. Duggleby & 48 & 254 & 247 & 239 & 9 & 221 & 48 \\
\hline University of Science and Technology of China & 2 & 337 & & 0 & 313 & 0 & 311 & 0 & 308 & $\overrightarrow{0}$ \\
\hline University of Sheffield & 950 & 35 & M. Hayter & 42 & 265 & 92 & 278 & 5 & 266 & 54 \\
\hline University of South Carolina & 646 & 59 & R.F. Valois & 98 & 169 & 1,469 & 125 & 18 & 128 & 150 \\
\hline University of South Florida & 346 & 114 & P.B. Jacobson & 161 & 108 & 3,447 & 73 & 33 & 55 & 150 \\
\hline University of Southampton & 368 & 106 & S. Payne & 124 & 138 & 1,521 & 121 & 20 & 117 & 150 \\
\hline University of Southern California & 206 & 161 & L.S. Schneider & 223 & 76 & 6,732 & 34 & 38 & 37 & 150 \\
\hline University of St Andrews & 26 & 294 & H.T.O. Davies & 328 & 39 & 5,329 & 44 & 44 & 29 & 150 \\
\hline University of Surrey & 219 & 154 & V. Tschudin & 80 & 194 & 40 & 297 & 4 & 279 & 31 \\
\hline University of Sussex & 27 & 293 & L. Fallowfield & 190 & 89 & 5,249 & 45 & 38 & 37 & 150 \\
\hline University of Sydney & 1,107 & 28 & D. Elliot & 46 & 258 & 268 & 234 & 10 & 214 & 74 \\
\hline University of Technology, Sydney & 262 & 136 & C. Duffield & 89 & 182 & 519 & 201 & 12 & 182 & 77 \\
\hline University of Tennessee Knoxville & 249 & 143 & S.P. Thomas & 155 & 115 & 637 & 190 & 14 & 161 & 98 \\
\hline University of Texas at Austin & 582 & 68 & L. Rew & 95 & 177 & 518 & 202 & 11 & 199 & 73 \\
\hline University of Tokyo & 121 & 211 & Y. Ohashi & 406 & 21 & 4,874 & 50 & 32 & 63 & 150 \\
\hline University of Toronto & 2,873 & 5 & T.W. Mak & 632 & 8 & 47,418 & 1 & 101 & 2 & 150 \\
\hline University of Tsukuba & 25 & 297 & Y. Ohashi & 406 & 21 & 4,874 & 50 & 32 & 63 & 150 \\
\hline University of Twente & 14 & 308 & E. Taal & 70 & 204 & 835 & 166 & 17 & 135 & 117 \\
\hline University of Utah & 1,123 & 26 & P.S. Brooke & 89 & 182 & 22 & 302 & 1 & 303 & 1 \\
\hline University of Vermont & 439 & 82 & S.E. Abrams & 45 & 260 & 31 & 300 & 3 & 289 & 12 \\
\hline University of Victoria & 205 & 163 & A.E. Molzahn & 57 & 236 & 229 & 240 & 8 & 234 & 102 \\
\hline University of Virginia & 457 & 79 & M. Gray & 116 & 147 & 331 & 223 & 9 & 221 & 87 \\
\hline University of Warwick & 83 & 251 & J. Dale & 69 & 206 & 755 & 176 & 13 & 173 & 107 \\
\hline University of Washington & 2,975 & 3 & R.D. Palmiter & 291 & 53 & 12,644 & 16 & 50 & 19 & 150 \\
\hline
\end{tabular}




\begin{tabular}{|c|c|c|c|c|c|c|c|c|c|c|}
\hline University of Waterloo & 66 & 258 & J.P. Hirdes & 94 & 179 & 968 & 152 & 13 & 173 & 150 \\
\hline University of Western Australia & 263 & 134 & $\overline{\text { K. Judd }}$ & 53 & 245 & 478 & 209 & 14 & 161 & 29 \\
\hline University of Western Ontario & 622 & 61 & C. Forchuk & 78 & 196 & 277 & 230 & 9 & 221 & 127 \\
\hline University of Wisconsin & 773 & 44 & P.F. Brennan & 94 & 179 & 706 & 182 & 14 & 161 & 145 \\
\hline University of Wollongong & 69 & 257 & A. Shorten & 26 & 293 & 150 & 257 & 8 & 234 & 19 \\
\hline University of York & 215 & 156 & N. Cullum & 115 & 148 & 1,059 & 148 & 18 & 128 & 107 \\
\hline University of Zurich & 245 & 145 & O.M. Hess & 343 & 34 & 6,358 & 37 & 33 & 55 & 150 \\
\hline Univesitas Gadjah Mada & 13 & 310 & M. Julia & 4 & 310 & 6 & 307 & 1 & 303 & 4 \\
\hline Uppsala University & 311 & 122 & P.O. Sjoden & 196 & 86 & 3,182 & 75 & 25 & 87 & 150 \\
\hline Utah State & 49 & 275 & D.R. Black & 112 & 150 & 761 & 174 & 12 & 182 & 150 \\
\hline Utrecht University & 621 & 62 & D.E. Grobbee & 530 & 13 & 21,406 & 6 & 70 & 7 & 150 \\
\hline Vanderbilt University & 407 & 96 & K.A. Wallston & 82 & 192 & 2,546 & 94 & 11 & 199 & 150 \\
\hline Victoria University of Wellington & 56 & 269 & P.J. Wood & 11 & 309 & 5 & 308 & 2 & 295 & 1 \\
\hline Vienna University of Technology & 5 & 331 & & 0 & 313 & 0 & 311 & 0 & 308 & 0 \\
\hline Virginia Polytechnic Institute & 113 & 222 & J.J. Tyson & 170 & 100 & 2,740 & 90 & 26 & 82 & 137 \\
\hline Vrije Universiteit, Brussels & 7 & 324 & Y. Vandenplas & 293 & 52 & 2,470 & 97 & 21 & 110 & 150 \\
\hline VU University Amsterdam & 606 & 63 & L. Deilens & 131 & 133 & 638 & 189 & 16 & 141 & 150 \\
\hline Wageningen University & 15 & 306 & W.A. Van Staveren & 276 & 58 & 5,521 & 43 & 35 & 47 & 150 \\
\hline Wake Forest University & 128 & 205 & T.A. Arcury & 169 & 102 & 1,137 & 141 & 23 & 99 & 150 \\
\hline Waseda University & 38 & 283 & & 0 & 313 & 0 & 311 & 0 & 308 & 0 \\
\hline Washington State University & 146 & 191 & D.E. Baker & 301 & 45 & 443 & 211 & 12 & 182 & 86 \\
\hline Washington University in St. Louis & 208 & 160 & M.H. Kollef & 338 & 36 & 7,546 & 30 & 53 & 17 & 150 \\
\hline Wayne State University & 996 & 32 & M.H. Oermann & 130 & 134 & 647 & 188 & 12 & 182 & 150 \\
\hline West Virginia University & 206 & 161 & J.H. Larrabee & 32 & 283 & 393 & 216 & 9 & 221 & 59 \\
\hline Yale University & 736 & 51 & M. Grey & 108 & 157 & 1,338 & 133 & 19 & 124 & 148 \\
\hline Yonsei University & 122 & 210 & E.G. Oh & 18 & 301 & 40 & 297 & 4 & 279 & 49 \\
\hline York University & 177 & 173 & F.B. Pilkington & 44 & 262 & 93 & 275 & 5 & 266 & 18 \\
\hline Zhejiang University & 10 & 317 & G.Y. Jiang & 19 & 299 & 26 & 301 & 2 & 295 & 50 \\
\hline
\end{tabular}




\begin{tabular}{|c|c|c|c|c|c|c|c|c|c|c|}
\hline Veterinary Data & $\begin{array}{l}\text { Department } \\
\text { Publications }\end{array}$ & Rank & Most Prolific Author & Published & Rank & Cited & Rank & $\begin{array}{c}\text { H- } \\
\text { Index }\end{array}$ & Rank & $\begin{array}{c}\text { \# of } \\
\text { Coauthors }\end{array}$ \\
\hline Aalto University & 2 & 322 & & 0 & 305 & 0 & 304 & 0 & 302 & 0 \\
\hline Aarhus University & 157 & 109 & A. Viidik & 98 & 197 & 711 & 209 & 12 & 221 & 137 \\
\hline Arizonia State University & 18 & 272 & J.P. Collins & 246 & 62 & 2,275 & 100 & 21 & 134 & 150 \\
\hline Ateneo de Manila University & 1 & 332 & R. Tan-Palanca & 1 & 303 & 1 & 303 & 1 & 296 & 0 \\
\hline Auburn University & 1,650 & 19 & B.L. Blagburn & 182 & 108 & 1,796 & 118 & 20 & 145 & 150 \\
\hline Australian National University & 102 & 143 & I.A. McDougall & 154 & 134 & 3,205 & 63 & 23 & 113 & 150 \\
\hline Boston College & 86 & 154 & J.R. Murphy & 176 & 115 & 1,484 & 134 & 17 & 174 & 150 \\
\hline Boston University & 74 & 171 & H.E Stanley & 480 & 11 & 10,348 & 16 & 57 & 8 & 150 \\
\hline Brandeis University & 7 & 307 & C.J. Hall & 286 & 44 & 7,769 & 20 & 57 & 8 & 150 \\
\hline Brigham Young University & 37 & 232 & B.L. Roeder & 31 & 287 & 427 & 241 & 13 & 216 & 88 \\
\hline Brown University & 35 & 237 & A.S. De Groot & 66 & 247 & 705 & 210 & 20 & 145 & 150 \\
\hline California Institute of Technology (Calt... & 11 & 288 & M.I. Simon & 264 & 51 & 11,191 & 13 & 52 & 12 & 150 \\
\hline Cardiff University & 76 & 169 & J. Hemingway & 165 & 128 & 1,896 & 114 & 34 & 58 & 150 \\
\hline Carnegie Mellon University & 6 & 311 & M.G. Morgan & 79 & 224 & 771 & 204 & 11 & 232 & 98 \\
\hline Case Western Reserve University & 53 & 200 & H.J. Kung & 193 & 93 & 3,857 & 48 & 38 & 37 & 150 \\
\hline Chalmers University of Technology & 2 & 322 & & 0 & 305 & 0 & 304 & 0 & 302 & 0 \\
\hline Charles University & 58 & 186 & P. Volf & 90 & 208 & 425 & 242 & 15 & 197 & 150 \\
\hline Chinese University of Hong Kong & 41 & 226 & E.A.S. Nelson & 14 & 299 & 43 & 296 & 1 & 296 & 94 \\
\hline Chulalongkorn University & 339 & 72 & M. Techakumphu & 45 & 270 & 74 & 292 & 5 & 280 & 104 \\
\hline City University of Hong Kong & 1 & 332 & & 0 & 305 & 0 & 304 & 0 & 302 & 0 \\
\hline City University of New York & 8 & 302 & E.D. Kilbourne & 107 & 189 & 817 & 202 & 10 & 241 & 101 \\
\hline Colorado State University & 2,661 & 9 & P.S. Morley & 217 & 75 & 3,007 & 68 & 28 & 82 & 150 \\
\hline Columbia University & 80 & 164 & E.R. Kandal & 448 & 13 & 17,020 & 7 & 77 & 2 & 150 \\
\hline Cornell University & 3,453 & 3 & H.N. Erd & 334 & 33 & 3,572 & 54 & 22 & 122 & 150 \\
\hline Curtin University of Technology & 15 & 280 & J. Jeyaretnam & 2 & 302 & 33 & 297 & 2 & 292 & 2 \\
\hline Dalhousie University & 75 & 170 & M.W.J. Gray & 174 & 117 & 4,923 & 38 & 32 & 63 & 150 \\
\hline Dartmouth College & 0 & 342 & & 0 & 305 & 0 & 304 & 0 & 302 & 0 \\
\hline Delft University of Technology & 17 & 273 & \begin{tabular}{|l} 
J. Rothulize \\
\end{tabular} & 149 & 144 & 926 & 191 & 15 & 197 & 150 \\
\hline Drexel University & 52 & 204 & D.B. Weiner & 346 & 28 & 6,592 & 28 & 46 & 20 & 150 \\
\hline Duke University & 196 & 95 & E.L. Simons & 142 & 153 & 954 & 188 & 16 & 190 & 146 \\
\hline Durham University & 22 & 263 & & 0 & 305 & 0 & 304 & 0 & 302 & 0 \\
\hline Ecole Normale Supérieure de Lyon & 10 & 294 & F.L. Cosset & 173 & 118 & 3,501 & 57 & 48 & 18 & 150 \\
\hline École Normale Supérieure, Paris & 1 & 332 & & 0 & 305 & 0 & 304 & 0 & 302 & 0 \\
\hline École Polytechnique & 1 & 332 & & 0 & 305 & 0 & 304 & 0 & 302 & 0 \\
\hline
\end{tabular}




\begin{tabular}{|c|c|c|c|c|c|c|c|c|c|c|}
\hline Ecole Polytechnique Fédérale de Lausanne & 7 & 307 & & 0 & 305 & 0 & 304 & 0 & 302 & $\overline{0}$ \\
\hline Eindhoven University of Technology & 2 & 322 & R. Huiskes & 240 & 65 & 5,113 & 35 & 42 & 28 & 150 \\
\hline Emory University & 273 & 82 & H.M. McClure & 270 & 48 & 4,107 & 46 & 31 & 66 & 150 \\
\hline Erasmus University Rotterdam & 286 & 79 & A.D.M.E. Osterhaus & 734 & 4 & 23,842 & 1 & 63 & 5 & 150 \\
\hline ETH Zurich (Swiss Federal Institute of Technology) & 19 & 270 & J.W. Blum & 263 & 54 & 1,960 & 112 & 27 & 90 & 150 \\
\hline Florida International University & 4 & 315 & & 0 & 305 & 0 & 304 & 0 & 302 & 0 \\
\hline Florida State University & 7 & 307 & J.E.A. Bertram & 57 & 259 & 763 & 205 & 14 & 210 & 67 \\
\hline Freie Universität Berlin & 1,189 & 38 & L. Brunnberg & 189 & 99 & 317 & 257 & 9 & 252 & 150 \\
\hline Friedrich Alexander Universität Erlangen Nürnberg & 30 & 250 & & 0 & 305 & 0 & 304 & 0 & 302 & 0 \\
\hline Fudan University & 27 & 251 & Y.J. Xie & 262 & 55 & 1,257 & 159 & 17 & 174 & 150 \\
\hline Georg August Universität Göttingen & 355 & 68 & B. Brenig & 184 & 105 & 779 & 203 & 14 & 210 & 150 \\
\hline George Mason University & 11 & 288 & & 0 & 305 & 0 & 304 & 0 & 302 & 0 \\
\hline George Washington University & 43 & 221 & & 0 & 305 & 0 & 304 & 0 & 302 & $\overline{0}$ \\
\hline Georgetown University & 51 & 206 & V.M. Hirsch & 133 & 162 & 3,291 & 61 & 35 & 52 & 150 \\
\hline Georgia Institute of Technology & 40 & 227 & T.L. Maple & 77 & 227 & 298 & 260 & 10 & 241 & 88 \\
\hline Georgia State University & 25 & 256 & D.W. Boykin & 254 & 57 & 1,977 & 110 & 36 & 46 & 150 \\
\hline Goteborg University & 112 & 137 & J. Holmgren & 377 & 22 & 5,141 & 34 & 37 & 38 & 150 \\
\hline Harvard University & 23 & 259 & D.C. Wiley & 193 & 93 & 11,031 & 14 & 46 & 20 & 150 \\
\hline Hebrew University of Jerusalem & 720 & 50 & I. Yeruham & 124 & 172 & 360 & 250 & 8 & 262 & 109 \\
\hline Heidelberg Universität & 87 & 153 & H. Bujard & 120 & 176 & 7,512 & 22 & 32 & 63 & 150 \\
\hline Hokkaido University & 1,236 & 36 & M. Onuma & 333 & 34 & 1,053 & 181 & 17 & 174 & 150 \\
\hline Hong Kong Polytechnic University & 2 & 322 & J.P. Zhang & 1,995 & 1 & 15,145 & 8 & 50 & 14 & 150 \\
\hline Hong Kong University of Science \& Techno... & 6 & 311 & S.Q. Cheng & 44 & 273 & 259 & 263 & 11 & 232 & 87 \\
\hline Humboldt-Universität zu Berlin & 201 & 93 & H. Bergner & 153 & 138 & 154 & 280 & 4 & 285 & 101 \\
\hline Imperial College London & 339 & 72 & G. Dougan & 376 & 23 & 7,965 & 19 & 52 & 12 & 150 \\
\hline Indian Institute of Technology Bombay (I... & 0 & 342 & & 0 & 305 & 0 & 304 & 0 & 302 & 0 \\
\hline Indian Institute of Technology Delhi (II... & 1 & 332 & S.N. Naik & 43 & 274 & 692 & 212 & 9 & 252 & 62 \\
\hline Indian Institute of Technology Kanpur (I... & 1 & 332 & D.C. Rai & 42 & 276 & 469 & 234 & 89 & 1 & 6 \\
\hline Indiana University Bloomington & 45 & 216 & M.D. Pescovitz & 207 & 80 & 4,257 & 43 & 33 & 60 & 150 \\
\hline Indiana University Indianapolis & 42 & 223 & M.E. Bard & 77 & 227 & 2,774 & 76 & 21 & 134 & 150 \\
\hline Iowa State University & 1,441 & 30 & P.G. Halbur & 133 & 162 & 1,875 & 116 & 28 & 82 & 150 \\
\hline Johns Hopkins University & 435 & 62 & S.H. Snyder & 300 & 40 & 14,180 & 9 & 75 & 3 & 150 \\
\hline Kansas State University & 1,533 & 26 & J.A. Pickrell & 96 & 201 & 442 & 238 & 4 & 285 & 126 \\
\hline Katholieke Universiteit Leuven & 252 & 86 & B.M. Goddeeris & 198 & 88 & 1,389 & 141 & 23 & 113 & 150 \\
\hline Keio University & 51 & 206 & T. Iwasaki & 57 & 259 & 334 & 254 & 11 & 232 & 150 \\
\hline
\end{tabular}




\begin{tabular}{|c|c|c|c|c|c|c|c|c|c|c|}
\hline King Fahd University of Petroleum \& Minerals & 1 & 332 & & 0 & 305 & 0 & 304 & 0 & 302 & 0 \\
\hline King Saud University & 148 & 116 & A.A. Al-Qarawi & 60 & 255 & 283 & 261 & 10 & 241 & 54 \\
\hline Kobe University & 151 & 113 & H. Kitagawa & 405 & 18 & 2,935 & 72 & 31 & 66 & 150 \\
\hline Korea Advanced Institute of Science \& Technology & 8 & 302 & O.J. Yoo & 78 & 226 & 1,710 & 122 & 17 & 174 & 150 \\
\hline Korea University & 32 & 244 & D. Cho & 98 & 197 & 1,331 & 151 & 14 & 210 & 150 \\
\hline Kyoto University & 289 & 77 & T. Serikawa & 202 & 83 & 2,089 & 107 & 21 & 134 & 150 \\
\hline Kyushu University & 121 & 131 & M. Furuse & 217 & 75 & 761 & 206 & 20 & 145 & 150 \\
\hline La Trobe University & 48 & 212 & P.H. Hemsworth & 126 & 171 & 1,163 & 165 & 19 & 155 & 112 \\
\hline Lancaster University & 11 & 288 & L.A. Birke & 46 & 268 & 177 & 276 & 5 & 280 & 31 \\
\hline Leiden University & 108 & 139 & T.H.M. Ottenhoff & 347 & 27 & 4,967 & 37 & 41 & 30 & 150 \\
\hline Linkoping University & 47 & 213 & P. Jensen & 95 & 203 & 1,069 & 178 & 20 & 145 & 150 \\
\hline London School of Economics and Political Scie & 1 & 332 & LA Smith & 154 & 134 & 2,418 & 89 & 31 & 66 & 150 \\
\hline Loughborough University & 5 & 313 & B.A. Buffham & 74 & 233 & 214 & 269 & 6 & 277 & 46 \\
\hline Louisiana State University & 1,623 & 20 & T.R. Klei & 154 & 134 & 1,095 & 173 & 16 & 190 & 150 \\
\hline Ludwig-Maximilians-Universität München & 1,566 & 25 & K. Heinritzi & 115 & 182 & 218 & 268 & 8 & 262 & 150 \\
\hline Lund University & 103 & 142 & R. Holmdahl & 388 & 20 & 5,227 & 33 & 41 & 30 & 150 \\
\hline Maastricht University & 62 & 183 & I.D. Wijnberg & 48 & 267 & 114 & 288 & 9 & 252 & 103 \\
\hline Macquarie University & 70 & 180 & J.M. Whalley & 74 & 233 & 349 & 251 & 14 & 210 & 128 \\
\hline Mahidol University & 160 & 106 & P. Kittayapong & 68 & 246 & 688 & 213 & 17 & 174 & 141 \\
\hline Masaryk University & 117 & 135 & D. Horky & 37 & 282 & 93 & 289 & 4 & 285 & 73 \\
\hline Massachusetts Institute of Technology & 137 & 124 & J.G. Fox & 440 & 14 & 6,523 & 29 & 46 & 20 & 150 \\
\hline McGill University & 336 & 74 & X.Q. Zhao & 197 & 89 & 1,612 & 129 & 24 & 107 & 150 \\
\hline McMaster University & 91 & 149 & F.L. Graham & 81 & 221 & 4,187 & 45 & 35 & 52 & 150 \\
\hline Michigan State University & 2,311 & 12 & J.B. Kaneene & 206 & 81 & 21,116 & 3 & 24 & 107 & 150 \\
\hline Michigan Technological University & 3 & 318 & & 0 & 305 & 0 & 304 & 0 & 302 & 0 \\
\hline Monash University & 179 & 100 & B. Adler & 191 & 96 & 1,595 & 131 & 24 & 107 & 150 \\
\hline Montana State University & 159 & 107 & J.P. Dubey & 959 & 2 & 20,441 & 4 & 50 & 14 & 150 \\
\hline Moscow State University & 8 & 302 & V.E. Tarasov & 86 & 211 & 209 & 271 & 16 & 190 & 3 \\
\hline Nagoya University & 139 & 123 & T. Namikawa & 85 & 215 & 636 & 216 & 15 & 197 & 150 \\
\hline Nanjing University & 5 & 313 & L. Wang & 153 & 138 & 1,055 & 179 & 19 & 155 & 150 \\
\hline Nanyang Technological University & 3 & 318 & & 0 & 305 & 0 & 304 & 0 & 302 & 0 \\
\hline National Taiwan University & 288 & 78 & C.H. Wang & 52 & 261 & 172 & 277 & 8 & 262 & 99 \\
\hline National Tsing Hua University & 16 & 278 & W.W. Lin & 158 & 131 & 1,477 & 135 & 18 & 164 & 150 \\
\hline National University of Ireland, Galway & 38 & 229 & P.R. Smith & 61 & 254 & 498 & 229 & 11 & 232 & 80 \\
\hline National University of Singapore & 73 & 174 & J. Kwang & 124 & 172 & 1,365 & 143 & 19 & 155 & 150 \\
\hline New Mexico State University & 125 & 129 & D.M. Hailford & 105 & 190 & 586 & 222 & 10 & 241 & 150 \\
\hline
\end{tabular}




\begin{tabular}{|c|c|c|c|c|c|c|c|c|c|c|}
\hline New York University & 118 & 134 & R.S. Nussenweig & 193 & 93 & 2,666 & 82 & 25 & 102 & 150 \\
\hline Newcastle University & 234 & 87 & P.A. Flecknell & 132 & 165 & 962 & 186 & 15 & 197 & 150 \\
\hline North Carolina State University & 269 & 83 & E.B. Breitschwendt & 243 & 64 & 2,141 & 104 & 33 & 60 & 150 \\
\hline Northeastern University & 17 & 273 & & 0 & 305 & 0 & 304 & 0 & 302 & 0 \\
\hline Northwestern University & 36 & 235 & J.S. Takahashi & 360 & 25 & 3,375 & 59 & 24 & 107 & 150 \\
\hline Norwegian University of Science \& Technology & 21 & 265 & D.B. Chen & 91 & 207 & 1,389 & 141 & 21 & 134 & 150 \\
\hline Ohio State University & 3,052 & 6 & W.W. Muir & 275 & 46 & 1,636 & 127 & 16 & 190 & 150 \\
\hline Oklahoma State University & 1,288 & 34 & A.W. Confer & 167 & 126 & 887 & 198 & 17 & 174 & 150 \\
\hline Open University UK & 20 & 269 & & 0 & 305 & 0 & 304 & 0 & 302 & 0 \\
\hline Oregon State University & 769 & 48 & C.K. Cebra & 76 & 231 & 371 & 249 & 12 & 221 & 100 \\
\hline Osaka University & 108 & 139 & & 0 & 305 & 0 & 304 & 0 & 302 & 0 \\
\hline Peking University & 51 & 206 & Y.X. Zhu & 52 & 261 & 325 & 255 & 12 & 221 & 150 \\
\hline Pennsylvania State University & 575 & 55 & A.J. Heinrichs & 86 & 211 & 675 & 214 & 15 & 197 & 78 \\
\hline Pohang University of Science And Technology & 13 & 283 & Y.C. Sung & 84 & 216 & 1,950 & 113 & 28 & 82 & 150 \\
\hline Portland State University & 2 & 322 & & 0 & 305 & 0 & 304 & 0 & 302 & 0 \\
\hline Princeton University & 14 & 282 & E.C. Cox & 101 & 193 & 2,951 & 70 & 30 & 71 & 150 \\
\hline Purdue University & 1,617 & 21 & L.T. Glickman & 199 & 86 & 2,199 & 102 & 23 & 113 & 150 \\
\hline Queen's University & 46 & 214 & W.P. Aston & 35 & 283 & 70 & 293 & 2 & 292 & 41 \\
\hline Queen's University of Belfast & 653 & 52 & F. McNeilley & 99 & 195 & 1,025 & 183 & 28 & 82 & 150 \\
\hline Queensland University of Technology & 35 & 237 & P. Timms & 137 & 156 & 1,339 & 148 & 23 & 113 & 150 \\
\hline Radboud University, Nijmegen & 142 & 121 & T.B. Vree & 435 & 15 & 2,010 & 109 & 12 & 221 & 150 \\
\hline Rensselaer Polytechnic Institute & 3 & 318 & & 0 & 305 & 0 & 304 & 0 & 302 & 0 \\
\hline Rheinisch Westfalische Technische Hochschule Aach & 17 & 273 & R. Fischer & 240 & 65 & 3,361 & 60 & 36 & 46 & 150 \\
\hline Rheinische Friedrich Wilhelms Universitat Bonn & 163 & 104 & H. Sauerwein & 72 & 238 & 632 & 217 & 12 & 221 & 146 \\
\hline Rice University & 9 & 298 & & 0 & 305 & 0 & 304 & 0 & 302 & 0 \\
\hline Rochester Institute of Technology & 0 & 342 & & 0 & 305 & 0 & 304 & 0 & 302 & 0 \\
\hline Royal Institute of Technology, KTH & 17 & 273 & & 0 & 305 & 0 & 304 & 0 & 302 & 0 \\
\hline Royal Melbourne Institute of Technology & 31 & 248 & G.A. Tannock & 88 & 210 & 301 & 259 & 5 & 280 & 105 \\
\hline Rutgers & 142 & 121 & R.H. Ebright & 123 & 175 & 3,273 & 62 & 35 & 52 & 150 \\
\hline Saint-Petersburg State University & 2 & 322 & L.N. Moskvin & 194 & 92 & 187 & 274 & 7 & 268 & 150 \\
\hline San Diego State University & 16 & 278 & & 0 & 305 & 0 & 304 & 0 & 302 & 0 \\
\hline Sapienza University of Rome & 0 & 342 & & 0 & 305 & 0 & 304 & 0 & 302 & 0 \\
\hline Sciences Po Paris & 0 & 342 & & 0 & 305 & 0 & 304 & 0 & 302 & 0 \\
\hline Seoul National University & 706 & 51 & C. Chae & 149 & 144 & 910 & 193 & 21 & 134 & 150 \\
\hline Shanghai Jiao Tong University & 35 & 237 & J.H. Wang & 522 & 10 & 2,941 & 71 & 26 & 97 & 150 \\
\hline Simon Fraser University & 27 & 251 & D.E. Nelson & 74 & 233 & 1,549 & 133 & 6 & 277 & 106 \\
\hline
\end{tabular}




\begin{tabular}{|c|c|c|c|c|c|c|c|c|c|c|}
\hline Stanford University & 159 & 107 & S. Falkow & 354 & 26 & 14,123 & 10 & 55 & 10 & 150 \\
\hline State University of New York Buffalo & 1 & 332 & D.S. Aga & 52 & 261 & 705 & 210 & 19 & 155 & 61 \\
\hline Stockholm University & 57 & 190 & P.H. Perlmann & 315 & 36 & 2,473 & 86 & 14 & 210 & 150 \\
\hline Stony Brook University & 39 & 228 & V. Citovsky & 104 & 191 & 1,965 & 111 & 35 & 52 & 150 \\
\hline Syracuse University & 23 & 259 & B.N. Singh & 27 & 294 & 229 & 266 & 7 & 268 & 50 \\
\hline Tartu University (University of Tartu) & 26 & 253 & P. Pokk & 25 & 295 & 159 & 278 & 9 & 252 & 23 \\
\hline Technical University of Denmark & 598 & 54 & F.M. Aarestrup & 169 & 124 & 3,068 & 67 & 37 & 38 & 150 \\
\hline Technion & 21 & 265 & B.Z. Levi & 69 & 243 & 2,107 & 106 & 18 & 164 & 150 \\
\hline Technische Universität Berlin & 23 & 259 & E. Kirst & 19 & 297 & 19 & 298 & 3 & 291 & 20 \\
\hline Technische Universitat Chemnitz & 0 & 342 & & 0 & 305 & 0 & 304 & 0 & 302 & 0 \\
\hline Technische Universität Dresden & 10 & 294 & K. Simons & 247 & 60 & 18,155 & 5 & 55 & 10 & 150 \\
\hline Technische Universität München & 448 & 61 & M. Kirchgessner & 475 & 12 & 1,074 & 177 & 12 & 221 & 150 \\
\hline Tel Aviv University & 86 & 154 & J. Klafter & 305 & 39 & 4,700 & 39 & 37 & 38 & 150 \\
\hline Texas A\&M University & 2,840 & 7 & N.D. Cohen & 163 & 129 & 1,420 & 138 & 19 & 155 & 150 \\
\hline Texas Tech & 99 & 146 & J.J. McGlone & 110 & 184 & 1,128 & 169 & 16 & 190 & 148 \\
\hline Tohoku University & 204 & 92 & Y. Nakai & 103 & 192 & 413 & 246 & 10 & 241 & 150 \\
\hline Tokyo Institute of Technology & 7 & 307 & N. Okada & 173 & 118 & 2,934 & 73 & 37 & 38 & 150 \\
\hline Trinity College Dublin & 147 & 120 & P.J. Hartigan & 39 & 279 & 385 & 247 & 7 & 268 & 150 \\
\hline Tsinghua University & 17 & 273 & J.F. Bai & 376 & 23 & 879 & 199 & 15 & 197 & 150 \\
\hline Tufts University & 1,082 & 40 & J.E. Rush & 141 & 155 & 2,404 & 91 & 20 & 145 & 150 \\
\hline Universidad Autonoma de Madrid & 82 & 162 & A.G. Gonzalez & 537 & 8 & 7,432 & 23 & 36 & 46 & 150 \\
\hline Universidad de Chile & 196 & 95 & H. Toro & 45 & 270 & 223 & 267 & 10 & 241 & 89 \\
\hline Universidad de Granada & 82 & 162 & A.G. Gonzalez & 537 & 8 & 7,432 & 23 & 36 & 46 & 150 \\
\hline Universidad del País Vasco & 37 & 232 & J.L.L. Ponton & 183 & 106 & 1,476 & 136 & 21 & 134 & 150 \\
\hline Universidad Nacional Autónoma de México ... & 373 & 67 & C.S. Galina & 72 & 238 & 188 & 273 & 7 & 268 & 150 \\
\hline Universidad Politecnica de Madrid & 84 & 159 & P.G. Rebollar & 31 & 287 & 121 & 283 & 7 & 268 & 59 \\
\hline Universidade de São Paulo & 858 & 47 & S.M. Gennari & 109 & 186 & 667 & 215 & 18 & 164 & 150 \\
\hline Universidade Estadual de Campinas & 115 & 136 & C.W. Arns & 31 & 287 & 118 & 284 & 7 & 268 & 93 \\
\hline Università degli Studi di Firenze & 74 & 171 & P. Bonanni & 109 & 186 & 1,463 & 137 & 23 & 113 & 150 \\
\hline Università degli Studi di Padova & 343 & 70 & I. Andrighetto & 45 & 270 & 250 & 264 & 9 & 252 & 88 \\
\hline Universita Di Bologna & 472 & 60 & A. Diana & 29 & 292 & 45 & 295 & 4 & 285 & 72 \\
\hline Universita di Pisa & 255 & 85 & F. Mancianti & 82 & 220 & 616 & 219 & 12 & 221 & 129 \\
\hline Universitat Autonoma de Barcelona & 1,026 & 42 & J. Segales & 159 & 130 & 1,044 & 182 & 28 & 82 & 150 \\
\hline Universitat Bielefeld & 84 & 159 & & 0 & 305 & 0 & 304 & 0 & 302 & 0 \\
\hline Universität Bremen & 13 & 283 & & 0 & 305 & 0 & 304 & 0 & 302 & 0 \\
\hline Universitat d'Alacant & 9 & 298 & V. Urios & 40 & 277 & 115 & 286 & 9 & 252 & 49 \\
\hline
\end{tabular}




\begin{tabular}{|c|c|c|c|c|c|c|c|c|c|c|}
\hline Universitat de València & 63 & 182 & S. Mas-Coma & 124 & 172 & 897 & 197 & 25 & 102 & 150 \\
\hline Universität Frankfurt am Main & 31 & 248 & K.P. Hunfeld & 63 & 249 & 481 & 233 & 15 & 197 & 150 \\
\hline Universität Freiburg & 25 & 256 & J. Timmer & 145 & 149 & 1,638 & 126 & 26 & 97 & 150 \\
\hline Universitat Hamburg & 25 & 256 & & 0 & 305 & 0 & 304 & 0 & 302 & 0 \\
\hline Universität Karlsruhe & 2 & 322 & H. Tatachewski & 70 & 242 & 489 & 232 & 18 & 164 & 102 \\
\hline Universitat Leipzig & 725 & 49 & H.A. Schoon & 147 & 146 & 530 & 226 & 10 & 241 & 150 \\
\hline Universitat Munster (Westfälische Wilhelms-Un & 19 & 270 & M. Bergmann & 177 & 112 & 2,286 & 98 & 27 & 90 & 150 \\
\hline Universitat Politecnica de Catalunya & 8 & 302 & & 0 & 305 & 0 & 304 & 0 & 302 & 0 \\
\hline Universität Regensburg & 57 & 190 & & 0 & 305 & 0 & 304 & 0 & 302 & 0 \\
\hline Universität Stuttgart & 9 & 298 & M. Schanz & 32 & 284 & 198 & 272 & 8 & 262 & 35 \\
\hline Universitat Trier & 3 & 318 & E. Fuchs & 153 & 138 & 4,070 & 47 & 37 & 38 & 150 \\
\hline Universität Tübingen & 55 & 195 & F. Lang & 643 & 6 & 17,517 & 6 & 60 & 6 & 150 \\
\hline Universitat Wien (University of Vienna) & 545 & 58 & H.E. Konig & 63 & 249 & 84 & 291 & 5 & 280 & 92 \\
\hline Universitat Zu Koln & 35 & 237 & A.H. Radbruch & 238 & 68 & 7,083 & 25 & 43 & 26 & 150 \\
\hline Université Catholique de Louvain & 97 & 148 & A. Massip & 63 & 249 & 851 & 200 & 15 & 197 & 102 \\
\hline Universite de Liege & 1,258 & 35 & P. Lekeux & 268 & 50 & 1,146 & 166 & 18 & 164 & 150 \\
\hline Université de Montréal & 1,145 & 39 & M. Gottschalk & 171 & 122 & 917 & 192 & 21 & 134 & 150 \\
\hline Université de Nice Sophia Antipolis & 13 & 283 & F. Cuzin & 97 & 200 & 1,296 & 154 & 15 & 197 & 145 \\
\hline Universite Laval & 224 & 88 & M.A. Sirard & 173 & 118 & 2,456 & 88 & 30 & 71 & 150 \\
\hline Universite Libre de Bruxelles & 53 & 200 & A. Goldbeter & 146 & 147 & 2,174 & 103 & 22 & 122 & 144 \\
\hline Université Paris Sorbonne & 1 & 332 & & 0 & 305 & 0 & 304 & 0 & 302 & 0 \\
\hline Universite Paris-Sud 11 & 32 & 244 & & 0 & 305 & 0 & 304 & 0 & 302 & 0 \\
\hline Université Pierre et Marie Curie & 54 & 198 & A.P. Moller & 594 & 7 & 21,728 & 2 & 60 & 6 & 150 \\
\hline Universiti Malaya (University of Malaya) & 35 & 237 & P. Agamuthu & 40 & 277 & 86 & 290 & 4 & 285 & 33 \\
\hline University College Cork & 71 & 177 & C. Hill & 254 & 57 & 3,190 & 64 & 39 & 36 & 150 \\
\hline University College Dublin & 989 & 44 & M.P. Boland & 197 & 89 & 3,167 & 65 & 35 & 52 & 150 \\
\hline University College London & 387 & 65 & P.Lees & 221 & 73 & 1,294 & 155 & 20 & 145 & 150 \\
\hline University do Porto & 86 & 154 & F. Gartner & 49 & 266 & 422 & 244 & 11 & 232 & 125 \\
\hline University of Aberdeen & 182 & 99 & C.J. Secombes & 261 & 56 & 2,469 & 87 & 36 & 46 & 150 \\
\hline University of Adelaide & 154 & 111 & R.F. Seamark & 201 & 85 & 2,332 & 95 & 10 & 241 & 150 \\
\hline University of Alabama & 194 & 97 & M.D. Cooper & 136 & 158 & 3,641 & 52 & 40 & 32 & 150 \\
\hline University of Alberta & 341 & 71 & L. Sigler & 69 & 243 & 577 & 224 & 13 & 216 & 150 \\
\hline University of Amsterdam & 88 & 152 & J. Van Paradijs & 229 & 70 & 5,024 & 36 & 49 & 17 & 150 \\
\hline University of Antwerp & 186 & 98 & A. Houvenghel & 133 & 162 & 154 & 280 & 1 & 296 & 47 \\
\hline University of Arizona & 380 & 66 & J.T. Huber & 80 & 222 & 1,054 & 180 & 13 & 216 & 117 \\
\hline University of Athens & 62 & 183 & G.J. Papaevangelou & 143 & 152 & 758 & 207 & 7 & 268 & 150 \\
\hline
\end{tabular}




\begin{tabular}{|c|c|c|c|c|c|c|c|c|c|c|}
\hline University of Auckland & 74 & 171 & B.H. Brier & 151 & 142 & 3,166 & 66 & 26 & 97 & 150 \\
\hline University of Barcelona & 221 & 89 & A. Dominguez & 169 & 124 & 1,116 & 170 & 17 & 174 & 150 \\
\hline University of Basel & 77 & 167 & U. Heininger & 177 & 112 & 1,588 & 132 & 22 & 122 & 150 \\
\hline University of Bath & 10 & 294 & R.H. French-Constant & 172 & 121 & 2,314 & 96 & 30 & 71 & 150 \\
\hline University of Bergen & 268 & 84 & A. Nyland & 79 & 224 & 504 & 228 & 16 & 190 & 130 \\
\hline University of Bern & 1,226 & 37 & J.Frey & 225 & 71 & 2,311 & 97 & 27 & 90 & 150 \\
\hline University of Birmingham & 85 & 157 & & 0 & 305 & 0 & 304 & 0 & 302 & 0 \\
\hline University of Bristol & 1,913 & 17 & T.J. Gruffydd-Jones & 170 & 123 & 1,362 & 144 & 18 & 164 & 150 \\
\hline University of British Columbia & 148 & 116 & D.M. Weary & 134 & 160 & 1,270 & 157 & 23 & 113 & 136 \\
\hline University of Calgary & 149 & 115 & M.E. Olson & 158 & 131 & 2,478 & 85 & 29 & 79 & 150 \\
\hline University of California, Berkley & 534 & 59 & R.S. Lane & 119 & 178 & 1,116 & 170 & 19 & 155 & 150 \\
\hline University of California, Davis & 5,106 & 1 & I.A. Gardner & 244 & 63 & 2,339 & 94 & 25 & 102 & 150 \\
\hline University of California, Irvine & 427 & 63 & E. Head & 14 & 299 & 156 & 279 & 2 & 292 & 37 \\
\hline University of California, Los Angeles & 175 & 101 & & 0 & 305 & 0 & 304 & 0 & 302 & 0 \\
\hline University of California, Riverside & 105 & 141 & B.A. Mullens & 92 & 206 & 444 & 237 & 10 & $\overline{241}$ & 94 \\
\hline University of California, San Diego & 148 & 116 & G.D. Shelton & 134 & 160 & 719 & 208 & 17 & 174 & 150 \\
\hline University of California, San Francisco & 56 & 194 & S.B. Prusiner & 213 & 79 & 7,579 & 21 & 71 & 4 & 150 \\
\hline University of California, Santa Barbara & 11 & 288 & & 0 & 305 & 0 & 304 & 0 & 302 & 0 \\
\hline University of California, Santa Cruz & 8 & 302 & D.P. Costa & 128 & 170 & 1,747 & 120 & 24 & 107 & 150 \\
\hline University of Cambridge & 1,079 & 41 & R.J.M. Franklin & 142 & 153 & 2,355 & 93 & 40 & 32 & 150 \\
\hline University of Canterbury & 55 & 195 & N.J. Gemmell & 77 & 227 & 908 & 194 & 17 & 174 & 150 \\
\hline University of Cape Town & 57 & 190 & A.L. Williamson & 110 & 184 & 1,139 & 167 & 21 & 134 & 150 \\
\hline University of Central Florida & 15 & 280 & H.W. Daniell & 135 & 159 & 2,923 & 74 & 36 & 46 & 150 \\
\hline University of Chicago & 57 & 190 & B.J. Cole & 144 & 150 & 1,267 & 158 & 23 & 113 & 150 \\
\hline University of Cincinnati & 70 & 180 & J.B. Lingrel & 19 & 297 & 115 & 286 & 5 & 280 & 26 \\
\hline University of Colorado at Boulder & 137 & 124 & C. Carey & 39 & 279 & 907 & 195 & 15 & 197 & 75 \\
\hline University of Connecticut & 174 & 102 & S. Frasca & 50 & 265 & 231 & 265 & 9 & 252 & 150 \\
\hline University of Copenhagen & 1,594 & 22 & P. Nansen & 287 & 43 & 1,650 & 125 & 27 & 90 & 150 \\
\hline University of Delaware & 54 & 198 & J. Burnside & 60 & 255 & 1,274 & 156 & 18 & 164 & 150 \\
\hline University of Dundee & 58 & 186 & D.M.J. Lilley & 239 & 67 & 3,757 & 50 & 37 & 38 & 150 \\
\hline University of Edinburgh & 1,686 & 18 & M.E.J. Woolhouse & 191 & 96 & 3,007 & 68 & 31 & 66 & 150 \\
\hline University of Florida & 3,133 & 5 & W.W. Thatcher & 306 & 37 & 3,621 & 53 & 32 & 63 & 150 \\
\hline University of Geneva & 53 & 200 & P.H. Lambert & 273 & 47 & 3,720 & 51 & 22 & 122 & 150 \\
\hline University of Georgia & 2,687 & 8 & J.N. Moore & 185 & 104 & 1,191 & 162 & 14 & 210 & 150 \\
\hline University of Ghent & 1,951 & 16 & F. Haesebrouck & 4 & 301 & 4 & 302 & 1 & 296 & 19 \\
\hline University of Glasgow & 1,585 & 23 & S.W.J. Reid & 154 & 134 & 1,677 & 124 & 26 & 97 & 150 \\
\hline
\end{tabular}




\begin{tabular}{|c|c|c|c|c|c|c|c|c|c|c|}
\hline University of Gothenburg & 23 & 259 & A.M. Svennerholm & 264 & 51 & 2,717 & 79 & 29 & 79 & 150 \\
\hline University of Groningen & 44 & 220 & J.M. Koolhaas & 202 & 83 & 3,522 & 55 & 40 & 32 & 150 \\
\hline University of Helsinki & 611 & 53 & S. Pyorala & 96 & 201 & 940 & 189 & 18 & 164 & 150 \\
\hline University of Hong Kong & 45 & 216 & L.P. Samaranayake & 342 & 31 & 2,254 & 101 & 22 & 122 & 150 \\
\hline University of Houston & 11 & 288 & & 0 & 305 & 0 & 304 & 0 & 302 & 0 \\
\hline University of Illinois & 2,361 & 11 & H.W. Hannah & 337 & 32 & 15 & 299 & 1 & 296 & 1 \\
\hline University of Illinois, Chicago & 122 & 130 & B.T. Bennett & 31 & 287 & 116 & 285 & 2 & 292 & 48 \\
\hline University of Indonesia & 2 & 322 & R.H.H. Nelwan & 28 & 293 & 460 & 235 & 12 & 221 & 150 \\
\hline University of Iowa & 71 & 177 & J.E. Butler & 119 & 178 & 1,015 & 184 & 17 & 174 & 150 \\
\hline University of Kansas & 51 & 206 & Y. Chebloune & 71 & 240 & 335 & 253 & 11 & 232 & 150 \\
\hline University of Kentucky & 553 & 57 & E.T. Lyons & 183 & 106 & 490 & 230 & 11 & 232 & 127 \\
\hline University of Lausanne & 45 & 216 & G. Corradin & 190 & 98 & 2,527 & 83 & 27 & 90 & 150 \\
\hline University of Leeds & 91 & 149 & C.P. Wild & 253 & 59 & 3,386 & 58 & 30 & 71 & 150 \\
\hline University of Leicester & 52 & 204 & A.J. Jefferys & 217 & 75 & 5,330 & 32 & 34 & 58 & 150 \\
\hline University of Liverpool & 1,446 & 29 & S.D. Carter & 269 & 49 & 2,679 & 81 & 30 & 71 & 150 \\
\hline University of Ljubljana & 278 & 81 & M. Ocepek & 32 & 284 & 185 & 275 & 11 & 232 & 111 \\
\hline University of London (Kings College of London) & 3,308 & 4 & P. Lees & 217 & 75 & 1,361 & 145 & 22 & 122 & 150 \\
\hline University of Manchester & 150 & 114 & C.W. Wardlow & 30 & 291 & 7 & 300 & 0 & 302 & 2 \\
\hline University of Manitoba & 216 & 90 & C.M. Nyachoti & 83 & 218 & 582 & 223 & 15 & 197 & 110 \\
\hline University of Maryland & 350 & 69 & R.A. Erdman & 71 & 240 & 1,338 & 149 & 18 & 164 & 117 \\
\hline University of Maryland Baltimore County & 280 & 80 & M.M. Levine & 399 & 19 & 8,222 & 18 & 43 & 26 & 150 \\
\hline University of Massachusetts & 85 & 157 & R.A. Fissore & 86 & 211 & 1,305 & 152 & 28 & 82 & 150 \\
\hline University of Melbourne & 981 & 45 & B.W. Parry & 60 & 255 & 273 & 262 & 4 & 285 & 84 \\
\hline University of Miami & 77 & 167 & J.C. Beier & 204 & 82 & 1,843 & 117 & 21 & 134 & 150 \\
\hline University of Michigan & 80 & 164 & V. Padmanabhnan & 137 & 156 & 1,337 & 150 & 22 & 122 & 150 \\
\hline University of Minnesota & 2,196 & 13 & M.P. Murtaugh & 186 & 103 & 2,385 & 92 & 23 & 113 & 150 \\
\hline University of Missouri & 1,506 & 27 & G.E. Rottinghaus & 189 & 99 & 1,419 & 139 & 20 & 145 & 150 \\
\hline University of Nebraska & 420 & 64 & F.A. Osorio & 74 & 233 & 938 & 190 & 22 & 122 & 150 \\
\hline University of New Hampshire & 58 & 186 & C.G. Schwab & 32 & 284 & 423 & 243 & 10 & 241 & 73 \\
\hline University of New Mexico & 33 & 243 & E.S. Loker & 109 & 186 & 903 & 196 & 18 & 164 & 150 \\
\hline University of New South Wales & 119 & 132 & A.T.J. Lee & 178 & 110 & 5,546 & 31 & 33 & 60 & 150 \\
\hline University of North Carolina, Chapel Hill & 155 & 110 & O. Smithies & 264 & 51 & 13,183 & 11 & 47 & 19 & 150 \\
\hline University of North Texas & 12 & 287 & J.W. Simecka & 63 & 249 & 977 & 185 & 16 & 190 & 124 \\
\hline University of Notre Dame & 26 & 253 & N.J. Besansky & 89 & 209 & 1,237 & 160 & 23 & 113 & 150 \\
\hline University of Nottingham & 197 & 94 & J.M. Behnke & 223 & 72 & 1,410 & 140 & 20 & 145 & 150 \\
\hline University of Oklahoma & 32 & 244 & K.E. Bartels & 83 & 218 & 337 & 252 & 7 & 268 & 150 \\
\hline
\end{tabular}




\begin{tabular}{|c|c|c|c|c|c|c|c|c|c|c|}
\hline University of Oregon & 83 & 161 & S.W. Tolle & 146 & 147 & 1,343 & 147 & 17 & 174 & 143 \\
\hline University of Oslo & 89 & 151 & O. Wiig & 117 & 180 & 1,130 & 168 & 27 & 90 & 150 \\
\hline University of Otago & 126 & 128 & J.F.T. Griffin & 80 & 222 & 515 & 227 & 12 & 221 & 89 \\
\hline University of Ottawa & 55 & 195 & H.L. Davis & 94 & 204 & 4,209 & 44 & 40 & 32 & 150 \\
\hline University of Oxford & 170 & 103 & D.W. MacDonald & 383 & 21 & 4,322 & 42 & 35 & 52 & 150 \\
\hline University of Pennsylvania & 2,645 & 10 & R.L. Brinster & 306 & 37 & 9,252 & 17 & 37 & 38 & 150 \\
\hline University of Pittsburgh & 133 & 126 & E.P. Krenzelok & 276 & 45 & 1,686 & 123 & 17 & 174 & 150 \\
\hline University of Quebec & 42 & 223 & M.A. Sirard & 176 & 115 & 2,408 & 90 & 30 & 71 & 150 \\
\hline University of Queensland & 1,020 & 43 & C.C. Pollitt & 69 & 243 & 415 & 245 & 17 & 174 & 89 \\
\hline University of Reading & 332 & 76 & M.J. Bryant & 52 & 261 & 372 & 248 & 10 & 241 & 69 \\
\hline University of Rochester & 32 & 244 & J.H. Werren & 120 & 176 & 2,286 & 98 & 27 & 90 & 150 \\
\hline University of Saskatchewan & 2,162 & 14 & B.H. Grahn & 144 & 150 & 316 & 258 & 9 & 252 & 119 \\
\hline University of Science and Technology of China & 2 & 322 & & 0 & 305 & 0 & 304 & 0 & 302 & 0 \\
\hline University of Sheffield & 79 & 166 & R. Jennings & 115 & 182 & 561 & 225 & 9 & 252 & 113 \\
\hline University of South Carolina & 37 & 232 & R. Refinetti & 86 & 211 & 490 & 230 & 13 & 216 & 16 \\
\hline University of South Florida & 36 & 235 & D.B. Weiner & 346 & 28 & 6,635 & 27 & 46 & 20 & 150 \\
\hline University of Southampton & 50 & 210 & D. Goodwin & 25 & 295 & 148 & 282 & 9 & 252 & 28 \\
\hline University of Southern California & 38 & 229 & & 0 & 305 & 0 & 304 & 0 & 302 & 0 \\
\hline University of St Andrews & 43 & 221 & H.T.O. Davies & 325 & 35 & 5,932 & 30 & 46 & 20 & 150 \\
\hline University of Surrey & 101 & 144 & R.E. Spier & 177 & 112 & 459 & 236 & 6 & 277 & 57 \\
\hline University of Sussex & 9 & 298 & T.J. Roper & 98 & 197 & 1,088 & 175 & 19 & 155 & 85 \\
\hline University of Sydney & 1,488 & 28 & R. Malik & 199 & 86 & 1,089 & 174 & 20 & 145 & 150 \\
\hline University of Technology, Sydney & 34 & 242 & J.T. Ellis & 100 & 194 & 1,185 & 163 & 21 & 134 & 150 \\
\hline University of Tennessee Knoxville & 1,419 & 32 & T.W. Schultz & 166 & 127 & 1,617 & 128 & 30 & 71 & 150 \\
\hline University of Texas at Austin & 38 & 229 & M.E. Menaker & 195 & 91 & 4,580 & 40 & 25 & 102 & 150 \\
\hline University of Tokyo & 947 & 46 & K. Doi & 773 & 3 & 10,395 & 15 & 37 & 38 & 150 \\
\hline University of Toronto & 211 & 91 & N.M. Mrosovsky & 182 & 108 & 2,074 & 108 & 28 & 82 & 129 \\
\hline University of Tsukuba & 61 & 185 & M. Yamashita & 43 & 274 & 214 & 269 & 8 & 262 & 79 \\
\hline University of Twente & 4 & 315 & & 0 & 305 & 0 & 304 & 0 & 302 & 0 \\
\hline University of Utah & 73 & 174 & T.E. Cerling & 132 & 165 & 3,503 & 56 & 31 & 66 & 150 \\
\hline University of Vermont & 119 & 132 & P.S. Kindstedt & 46 & 268 & 437 & 239 & 13 & 216 & 46 \\
\hline University of Victoria & 13 & 283 & B.F. Koop & 132 & 165 & 4,477 & 41 & 25 & 102 & 150 \\
\hline University of Virginia & 42 & 223 & K.C. Hazen & 77 & 227 & 1,727 & 121 & 17 & 174 & 150 \\
\hline University of Warwick & 130 & 127 & L.E. Green & 129 & 169 & 1,086 & 176 & 20 & 145 & 150 \\
\hline University of Washington & 335 & 75 & R.D. Palmiter & 291 & 42 & 12,644 & 12 & 50 & 14 & 150 \\
\hline University of Waterloo & 22 & 263 & S.M. Smith & 73 & 237 & 624 & 218 & 12 & 221 & 86 \\
\hline
\end{tabular}




\begin{tabular}{|c|c|c|c|c|c|c|c|c|c|c|}
\hline University of Western Australia & 154 & 111 & G.B. Martin & 151 & 142 & 1,608 & 130 & 17 & 174 & 150 \\
\hline University of Western Ontario & 45 & 216 & P.W. Yu & 189 & 99 & 1,298 & 153 & 22 & 122 & 150 \\
\hline University of Wisconsin & 2,090 & 15 & O.J. Ginther & 420 & 17 & 2,513 & 84 & 28 & 82 & 150 \\
\hline University of Wollongong & 10 & 294 & E.J. Steele & 59 & 258 & 322 & 256 & 8 & 262 & 45 \\
\hline University of York & 53 & 200 & P.C.L. White & 84 & 216 & 957 & 187 & 19 & 155 & 140 \\
\hline University of Zurich & 1,576 & 24 & U. Braun & 234 & 69 & 1,352 & 146 & 17 & 174 & 150 \\
\hline Univesitas Gadjah Mada & 26 & 253 & K. Fukuta & 66 & 247 & 431 & 240 & 7 & 268 & 150 \\
\hline Uppsala University & 162 & 105 & J. Hau & 178 & 110 & 601 & 221 & 12 & 221 & 150 \\
\hline Utah State & 148 & 116 & T.D. Bunch & 99 & 195 & 827 & 201 & 11 & 232 & 150 \\
\hline Utrecht University & 3,627 & 2 & A.C. Beynen & 434 & 16 & 2,759 & 77 & 19 & 155 & 150 \\
\hline Vanderbilt University & 21 & 265 & R.C. Gupta & 694 & 5 & 6,648 & 26 & 26 & 97 & 150 \\
\hline Victoria University of Wellington & 2 & 322 & K. Zhang & 1 & 303 & 0 & 304 & 0 & 302 & 4 \\
\hline Vienna University of Technology & 11 & 288 & C.P. Kubicek & 247 & 60 & 2,728 & 78 & 29 & 79 & 150 \\
\hline Virginia Polytechnic Institute & 1,393 & 33 & D.S. Lindsay & 344 & 30 & 2,712 & 80 & 30 & 71 & 150 \\
\hline Vrije Universiteit, Brussels & 50 & 210 & V. Rogiers & 187 & 102 & 1,890 & 115 & 21 & 134 & 150 \\
\hline VU University Amsterdam & 99 & 146 & A. Stolk & 75 & 232 & 68 & 294 & 0 & 302 & 28 \\
\hline Wageningen University & 560 & 56 & W. Takken & 117 & 180 & 1,105 & 172 & 22 & 122 & 150 \\
\hline Wake Forest University & 46 & 214 & J.M. Cline & 94 & 204 & 1,165 & 164 & 22 & 122 & 150 \\
\hline Waseda University & 4 & 315 & & 0 & 305 & 0 & 304 & 0 & 302 & 0 \\
\hline Washington State University & 1,437 & 31 & T.C. McGuire & 296 & 41 & 2,111 & 105 & 24 & 107 & 150 \\
\hline Washington University in St. Louis & 58 & 186 & L.D. Sibley & 152 & 141 & 2,921 & 75 & 45 & 25 & 150 \\
\hline Wayne State University & 71 & 177 & A. Wortinger & 38 & 281 & 5 & 301 & 1 & 296 & 12 \\
\hline West Virginia University & 73 & 174 & E.K. Inskeep & 158 & 131 & 1,234 & 161 & 15 & 197 & 150 \\
\hline Yale University & 112 & 137 & E. Fikrig & 221 & 73 & 3,786 & 49 & 42 & 28 & 150 \\
\hline Yonsei University & 21 & 265 & J.K. Seong & 63 & 249 & 607 & 220 & 15 & 197 & 150 \\
\hline York University & 0 & 342 & & 0 & 305 & 0 & 304 & 0 & 302 & 0 \\
\hline Zhejiang University & 100 & 145 & L. Yu & 131 & 168 & 1,791 & 119 & 22 & 122 & 150 \\
\hline
\end{tabular}




\begin{tabular}{|c|c|c|c|c|c|c|c|c|c|c|}
\hline Arts and Humanities Data & $\begin{array}{l}\text { Department } \\
\text { Publications }\end{array}$ & Rank & Most Prolific Author & Published & Rank & Cited & Rank & $\begin{array}{c}\text { H- } \\
\text { Index }\end{array}$ & Rank & $\begin{array}{c}\text { \# of } \\
\text { Coauthors }\end{array}$ \\
\hline Aalto University & 35 & 232 & O.V. Lounasmaa & 97 & 75 & 2,342 & 45 & 6 & 126 & 150 \\
\hline Aarhus University & 336 & 105 & T.S. Barfod & 20 & 192 & 51 & 183 & 4 & 164 & 39 \\
\hline Arizonia State University & 7 & 270 & H.E. Canary & 7 & 278 & 2 & 274 & 1 & 245 & 5 \\
\hline Ateneo de Manila University & 23 & 243 & A.R.O. Moralina & 3 & 300 & 0 & 299 & 0 & 290 & 3 \\
\hline Auburn University & 206 & 141 & W.O. Hayes & 25 & 176 & 131 & 141 & 4 & 164 & 23 \\
\hline Australian National University & 976 & 23 & M.J.T. Spriggs & 32 & 147 & 336 & 95 & 7 & 112 & 79 \\
\hline Boston College & 406 & 83 & P.S.H. Tang & 10 & 254 & 0 & 299 & 0 & 290 & 0 \\
\hline Boston University & 799 & 36 & H.E Stanley & 480 & 2 & 10,348 & 8 & 57 & 9 & 150 \\
\hline Brandeis University & 312 & 110 & A. Wingfield & 102 & 70 & 1,243 & 64 & 18 & 62 & 100 \\
\hline Brigham Young University & 6 & 276 & R.B. Zabriskie & 13 & 229 & 43 & 189 & 4 & 164 & 19 \\
\hline Brown University & 901 & 27 & R.C. Archibald & 33 & 142 & 2 & 274 & 0 & 290 & 2 \\
\hline California Institute of Technology (Calt... & 168 & 153 & A.H. Zewail & 428 & 4 & 7,875 & 12 & 51 & 10 & 150 \\
\hline Cardiff University & 568 & 59 & C. Norris & 17 & 207 & 1 & 284 & 1 & 245 & 0 \\
\hline Carnegie Mellon University & 4,531 & 2 & H.A. Simon & 137 & 53 & 4,415 & 25 & 13 & 76 & 92 \\
\hline Case Western Reserve University & 209 & 140 & P. Gambetti & 284 & 24 & 6,166 & 16 & 47 & 15 & 150 \\
\hline Chalmers University of Technology & 22 & 245 & R. Bergman & 52 & 105 & 740 & 74 & 18 & 62 & 36 \\
\hline Charles University & 1 & 324 & V. Baca & 24 & 181 & 55 & 179 & 5 & 145 & 61 \\
\hline Chinese University of Hong Kong & 1 & 324 & T. Wong & 133 & 57 & 1,713 & 52 & 17 & 65 & 150 \\
\hline Chulalongkorn University & 24 & 241 & P. Charusiri & 25 & 176 & 83 & 166 & 7 & 112 & 57 \\
\hline City University of Hong Kong & 233 & 134 & J. Flowerdew & 46 & 116 & 274 & 105 & 11 & 91 & 110 \\
\hline City University of New York & 5 & 283 & H. Liu & 50 & 108 & 294 & 102 & 13 & 76 & 131 \\
\hline Colorado State University & 3 & 302 & L. Barnes & 1 & 311 & 4 & 261 & 1 & 245 & 1 \\
\hline Columbia University & 1,288 & 11 & E.R. Kandal & 448 & 3 & 17,020 & 3 & 77 & 2 & 150 \\
\hline Cornell University & 893 & 28 & J. Stratton & 9 & 257 & 6 & 248 & 1 & 245 & 1 \\
\hline Curtin University of Technology & 77 & 199 & J. Stratton & 9 & 257 & 6 & 248 & 1 & 245 & 1 \\
\hline Dalhousie University & 230 & 136 & M.W. Gray & 189 & 38 & 3,732 & 29 & 29 & 31 & 150 \\
\hline \begin{tabular}{|l|} 
Dartmouth College \\
\end{tabular} & 378 & 92 & J.C. Dunlap & 118 & 64 & 3,389 & 32 & 35 & 19 & 150 \\
\hline Delft University of Technology & 109 & 186 & J.W. De Leeuw & 341 & 11 & 4,720 & 22 & 30 & 28 & 150 \\
\hline Drexel University & 60 & 213 & G. Benersky & 19 & 198 & 34 & 198 & 4 & 164 & 9 \\
\hline Duke University & 817 & 31 & & 0 & 318 & 0 & 299 & 0 & 290 & 0 \\
\hline Durham University & 633 & 53 & E.J. Lowe & 33 & 142 & 54 & 180 & 5 & 145 & 1 \\
\hline Ecole Normale Supérieure de Lyon & 31 & 234 & C. Hanni & 46 & 116 & 1,300 & 62 & 18 & 62 & 144 \\
\hline École Normale Supérieure, Paris & 107 & 187 & A. Badiou & 23 & 185 & 22 & 219 & 3 & 189 & 5 \\
\hline École Polytechnique & 64 & 209 & & 0 & 318 & 0 & 299 & 0 & 290 & 0 \\
\hline
\end{tabular}




\begin{tabular}{|c|c|c|c|c|c|c|c|c|c|c|}
\hline Ecole Polytechnique Fédérale de Lausanne & 38 & 228 & O. Blanke & 90 & 80 & 1,170 & 65 & 21 & 52 & 117 \\
\hline Eindhoven University of Technology & 56 & 217 & R.P.J.M. Raven & 26 & 170 & 151 & 134 & 9 & 97 & 37 \\
\hline Emory University & 451 & 75 & & 0 & 318 & 0 & 299 & 0 & 290 & 0 \\
\hline Erasmus University Rotterdam & 206 & 141 & F.A. Muller & 20 & 192 & 37 & 194 & 4 & 164 & 3 \\
\hline ETH Zurich (Swiss Federal Institute of Technology) & 92 & 190 & & 0 & 318 & 0 & 299 & 0 & 290 & 0 \\
\hline Florida International University & 168 & 153 & S. Heine & 7 & 278 & 1 & 284 & 1 & 245 & 1 \\
\hline Florida State University & 665 & 49 & J.Gert & 23 & 185 & 24 & 215 & 2 & 221 & 0 \\
\hline Freie Universität Berlin & 480 & 73 & S. Rosenkranz & 12 & 237 & 16 & 234 & 3 & 189 & 1 \\
\hline Friedrich Alexander Universität Erlangen Nürnberg & 154 & 159 & K.J. Holtgen & 23 & 185 & 2 & 274 & 0 & 290 & 1 \\
\hline Fudan University & 52 & 219 & & 0 & 318 & 0 & 299 & 0 & 290 & 0 \\
\hline Georg August Universität Göttingen & 233 & 134 & K. Hentschel & 18 & 203 & 24 & 215 & 2 & 221 & 6 \\
\hline George Mason University & 4 & 293 & J. Offutt & 47 & 113 & 428 & 91 & 12 & 87 & 42 \\
\hline George Washington University & 286 & 118 & C.M. Fraser & 227 & 35 & 24,291 & 1 & 64 & 6 & 150 \\
\hline Georgetown University & 778 & 38 & D.C. O'Connell & 40 & 123 & 130 & 142 & 7 & 112 & 23 \\
\hline Georgia Institute of Technology & 165 & 156 & J.P. Telotte & 16 & 212 & 6 & 248 & 1 & 245 & 0 \\
\hline Georgia State University & 281 & 120 & D. Belcher & 24 & 181 & 73 & 171 & 5 & 145 & 2 \\
\hline Goteborg University & 1 & 324 & S. Hemlin & 11 & 246 & 32 & 203 & 3 & 189 & 13 \\
\hline Harvard University & 2,135 & 4 & & 0 & 318 & 0 & 299 & 0 & 290 & 0 \\
\hline Hebrew University of Jerusalem & 1,282 & 12 & B. Shannon & 51 & 107 & 324 & 96 & 5 & 145 & 43 \\
\hline Heidelberg Universität & 280 & 121 & H.E. Wiegand & 14 & 224 & 8 & 241 & 2 & 221 & 2 \\
\hline Hokkaido University & 66 & 207 & P. Stapleton & 19 & 198 & 47 & 186 & 6 & 126 & 4 \\
\hline Hong Kong Polytechnic University & 119 & 179 & W. Cheng & 14 & 224 & 72 & 172 & 5 & 145 & 8 \\
\hline Hong Kong University of Science \& Techno... & 38 & 228 & L. Flowerdew & 8 & 267 & 27 & 211 & 3 & 189 & 0 \\
\hline Humboldt-Universität zu Berlin & 357 & 101 & B.J. Schnieder & 23 & 185 & 20 & 221 & 3 & 189 & 1 \\
\hline Imperial College London & 127 & 175 & L. Wilson & 12 & 237 & 36 & 196 & 1 & 245 & 2 \\
\hline Indian Institute of Technology Bombay (I... & 6 & 276 & & 0 & 318 & 0 & 299 & 0 & 290 & 0 \\
\hline Indian Institute of Technology Delhi (II... & 8 & 266 & & 0 & 318 & 0 & 299 & 0 & 290 & 0 \\
\hline Indian Institute of Technology Kanpur (I... & 24 & 241 & G. Neelakantan & 5 & 290 & 1 & 284 & 1 & 245 & 2 \\
\hline Indiana University Bloomington & 1,810 & 6 & A.W. Shipps & 151 & 49 & 0 & 299 & 0 & 290 & 0 \\
\hline Indiana University Indianapolis & 9 & 261 & S. Ochs & 95 & 78 & 311 & 97 & 4 & 164 & 63 \\
\hline Iowa State University & 1 & 324 & E.A. Goeneken & 14 & 224 & 19 & 224 & 1 & 245 & 3 \\
\hline Johns Hopkins University & 748 & 43 & S.H. Snyder & 300 & 16 & 14,180 & 6 & 75 & 4 & 150 \\
\hline Kansas State University & 200 & 145 & G.R. Brown & 32 & 147 & 0 & 299 & 0 & 290 & 1 \\
\hline Katholieke Universiteit Leuven & 775 & 39 & I. Douven & 49 & 109 & 107 & 151 & 78 & 1 & 19 \\
\hline Keio University & 50 & 220 & P. Skeldon & 391 & 6 & 2,071 & 48 & 29 & 31 & 150 \\
\hline
\end{tabular}




\begin{tabular}{|c|c|c|c|c|c|c|c|c|c|c|}
\hline King Fahd University of Petroleum \& Minerals & 10 & 259 & B.S. Yilbas & 391 & 6 & 1,093 & 67 & 19 & 57 & 150 \\
\hline King Saud University & 37 & 230 & R.T. Mortel & 4 & 294 & 3 & 268 & 1 & 245 & 0 \\
\hline Kobe University & 23 & 243 & H. Kishimoto & 12 & 237 & 21 & 220 & 3 & 189 & 0 \\
\hline Korea Advanced Institute of Science \& Technology & 0 & 344 & & 0 & 318 & 0 & 299 & 0 & 290 & 0 \\
\hline Korea University & 68 & 206 & A.E. Kim & 11 & 246 & 32 & 203 & 3 & 189 & 4 \\
\hline Kyoto University & 114 & 184 & & 0 & 318 & 0 & 299 & 0 & 290 & 0 \\
\hline Kyushu University & 25 & 240 & & 0 & 318 & 0 & 299 & 0 & 290 & 0 \\
\hline La Trobe University & 407 & 82 & J.P. Arnason & 36 & 135 & 17 & 233 & 3 & 189 & 7 \\
\hline Lancaster University & 7 & 270 & A. Mackenzie & 13 & 229 & 98 & 156 & 3 & 189 & 25 \\
\hline Leiden University & 506 & 68 & J. McAllister & 26 & 170 & 41 & 190 & 3 & 189 & 1 \\
\hline Linkoping University & 132 & 172 & P. Westermark & 266 & 27 & 3,030 & 37 & 25 & 42 & 150 \\
\hline London School of Economics and Political Scie & 602 & 57 & C.Howson & 35 & 138 & 115 & 149 & 3 & 189 & 5 \\
\hline Loughborough University & 147 & 162 & C. Antaki & 44 & 119 & 290 & 103 & 12 & 87 & 27 \\
\hline Louisiana State University & 5 & 283 & R. Good & 4 & 294 & 48 & 184 & 2 & 221 & 5 \\
\hline Ludwig-Maximilians-Universität München & 498 & 70 & W. Balzer & 53 & 101 & 381 & 94 & 7 & 112 & 115 \\
\hline Lund University & 347 & 103 & W. Rabinowicz & 20 & 192 & 121 & 147 & 6 & 126 & 11 \\
\hline Maastricht University & 92 & 190 & N.O. Schiller & 43 & 121 & 285 & 104 & 13 & 76 & 41 \\
\hline Macquarie University & 365 & 98 & M. Coltheart & 158 & 46 & 3,544 & 30 & 28 & 36 & 147 \\
\hline Mahidol University & 12 & 255 & & 0 & 318 & 0 & 299 & 0 & 290 & 0 \\
\hline Masaryk University & 75 & 201 & J. Raclavsky & 20 & 192 & 20 & 221 & 3 & 189 & 0 \\
\hline Massachusetts Institute of Technology & 651 & 51 & A. Rich & 337 & 12 & 5,872 & 17 & 32 & 24 & 150 \\
\hline McGill University & 813 & 34 & J.H. Quastel & 166 & 44 & 24 & 215 & 0 & 290 & 80 \\
\hline McMaster University & 443 & 77 & & 0 & 318 & 0 & 299 & 0 & 290 & 0 \\
\hline Michigan State University & 825 & 30 & A. Sherbo & 54 & 99 & 3 & 268 & 1 & 245 & 0 \\
\hline Michigan Technological University & 50 & 220 & M.M. Cooper & 6 & 285 & 1 & 284 & 0 & 290 & 0 \\
\hline Monash University & 609 & 56 & L. Humberstone & 26 & 170 & 81 & 167 & 3 & 189 & 5 \\
\hline Montana State University & 116 & 182 & N.C. Carpenter & 9 & 257 & 0 & 299 & 0 & 290 & 0 \\
\hline Moscow State University & 83 & 197 & V.E. Tarasov & 86 & 84 & 209 & 117 & 16 & 71 & 3 \\
\hline Nagoya University & 55 & 218 & & 0 & 318 & 0 & 299 & 0 & 290 & 0 \\
\hline Nanjing University & 66 & 207 & L. Wang & 153 & 47 & 1,055 & 68 & 19 & 57 & 150 \\
\hline Nanyang Technological University & 121 & 178 & A. Whitehead & 12 & 237 & 1 & 284 & 1 & 245 & 0 \\
\hline National Taiwan University & 80 & 198 & & 0 & 318 & 0 & 299 & 0 & 290 & 0 \\
\hline National Tsing Hua University & 49 & 224 & J. Truscott & 12 & 237 & 134 & 138 & 6 & 126 & 3 \\
\hline National University of Ireland, Galway & 137 & 166 & P. Diskin & 9 & 257 & 0 & 299 & 0 & 290 & 0 \\
\hline National University of Singapore & 380 & 91 & L. Wee & 26 & 170 & 33 & 200 & 4 & 164 & 134 \\
\hline New Mexico State University & 144 & 163 & & 0 & 318 & 0 & 299 & 0 & 290 & 0 \\
\hline
\end{tabular}




\begin{tabular}{|c|c|c|c|c|c|c|c|c|c|c|}
\hline New York University & 1,089 & 19 & R. Llinas & 294 & 18 & 9,464 & 10 & 30 & 28 & 150 \\
\hline Newcastle University & 520 & 65 & D.H. Tarling & 116 & 65 & 544 & 84 & 7 & 112 & 127 \\
\hline North Carolina State University & 239 & 131 & S.M. Fitzpatrick & 30 & 157 & 66 & 174 & 7 & 112 & 23 \\
\hline Northeastern University & 176 & 150 & A.L. Barbasi & 11 & 246 & 20 & 221 & 2 & 221 & 28 \\
\hline Northwestern University & 802 & 35 & C.A. Mirkin & 352 & 10 & 15,071 & 4 & 73 & 5 & 150 \\
\hline Norwegian University of Science \& Technology & 136 & 168 & I. Bull & 5 & 290 & $3 \mid$ & 268 & 1 & 245 & 1 \\
\hline Ohio State University & 1,048 & 20 & W.A. Brantley & 152 & 48 & 1,434 & 55 & 13 & 76 & 150 \\
\hline Oklahoma State University & 136 & 168 & S.M. Kennison & 17 & 207 & 154 & 133 & 6 & 126 & 16 \\
\hline Open University UK & 622 & 54 & S.P.R. Rose & 292 & 19 & 132 & 140 & 4 & 164 & 12 \\
\hline Oregon State University & 184 & 148 & D.M. Robinson & 11 & 246 & 1 & 284 & 1 & 245 & 3 \\
\hline Osaka University & 50 & 220 & & 0 & 318 & 0 & 299 & 0 & 290 & 0 \\
\hline Peking University & 204 & 144 & D.H. Shen & 84 & 85 & 542 & 85 & 14 & 75 & 150 \\
\hline Pennsylvania State University & 1,251 & 14 & R. A. Roy & 397 & 5 & 3,891 & 27 & 25 & 42 & 150 \\
\hline Pohang University of Science And Technology & 16 & 248 & G.G. Lee & 66 & 92 & 1,276 & 63 & 13 & 76 & 150 \\
\hline Portland State University & 118 & 181 & V.L. Bulter & 15 & 216 & 182 & 125 & 6 & 126 & 18 \\
\hline Princeton University & 1,313 & 10 & R.M. May & 360 & 9 & 14,341 & 5 & 29 & 31 & 150 \\
\hline Purdue University & 685 & 48 & J.T. Gandour & 104 & 69 & 655 & 78 & 17 & 65 & 80 \\
\hline Queen's University & 361 & 99 & P.C. Dodwell & 61 & 94 & 149 & 136 & 1 & 245 & 43 \\
\hline Queen's University of Belfast & 514 & 67 & M.J. Benton & 187 & 40 & 2,556 & 40 & 26 & 38 & 150 \\
\hline Queensland University of Technology & 71 & 203 & B.E. Hanna & 3 & 300 & 1 & 284 & 1 & 245 & 3 \\
\hline Radboud University, Nijmegen & 565 & 60 & R. Schreuder & 54 & 99 & 608 & 82 & 13 & 76 & 63 \\
\hline Rensselaer Polytechnic Institute & 75 & 201 & & 0 & 318 & 0 & 299 & 0 & 290 & 0 \\
\hline Rheinisch Westfalische Technische Hochschule Aach & 90 & 193 & W. Huber & 187 & 40 & 2,002 & 49 & 21 & 52 & 150 \\
\hline Rheinische Friedrich Wilhelms Universitat Bonn & 181 & 149 & H. Mommsen & 73 & 89 & 195 & 119 & 8 & 105 & 132 \\
\hline Rice University & 374 & 94 & D.C. Queller & 136 & 54 & 2,481 & 42 & 26 & 38 & 146 \\
\hline Rochester Institute of Technology & 70 & 204 & V.V. Raman & 8 & 267 & 2 & 274 & 1 & 245 & 0 \\
\hline Royal Institute of Technology, KTH & 95 & 188 & S.O. Hannsen & 119 & 62 & 390 & 93 & 10 & 95 & 48 \\
\hline Royal Melbourne Institute of Technology & 46 & 226 & J. Smart & 9 & 257 & 6 & 248 & 2 & 221 & 0 \\
\hline Rutgers & 1,103 & 18 & R.H. Ebright & 123 & 61 & 3,273 & 33 & 35 & 19 & 150 \\
\hline Saint-Petersburg State University & 30 & 235 & L.N. Moskvin & 194 & 37 & 187 & 122 & 7 & 112 & 150 \\
\hline San Diego State University & 412 & 80 & A.C. Nichols & 24 & 181 & 18 & 229 & 1 & 245 & 21 \\
\hline Sapienza University of Rome & 0 & 344 & & 0 & 318 & 0 & 299 & 0 & 290 & 0 \\
\hline Sciences Po Paris & 62 & 210 & J.F. Sirinelli & 7 & 278 & 0 & 299 & 0 & 290 & 0 \\
\hline Seoul National University & 93 & 189 & S. Choi & 27 & 167 & 33 & 200 & 3 & 189 & 21 \\
\hline Shanghai Jiao Tong University & 30 & 235 & & 0 & 318 & 0 & 299 & 0 & 290 & 0 \\
\hline Simon Fraser University & 371 & 95 & B. Hayden & 31 & 154 & 308 & 99 & 7 & 112 & 13 \\
\hline
\end{tabular}




\begin{tabular}{|c|c|c|c|c|c|c|c|c|c|c|}
\hline Stanford University & 1,496 & & I.L. Weissman & 316 & 15 & 18,005 & 2 & 77 & 2 & 150 \\
\hline State University of New York Buffalo & 549 & 63 & R. Gasche & 15 & 216 & 7 & 245 & 2 & 221 & 0 \\
\hline Stockholm University & 391 & 87 & P. Needham & 25 & 176 & 60 & 177 & 6 & 126 & 1 \\
\hline Stony Brook University & 450 & 76 & R.A. Levin & 26 & 170 & 4 & 261 & 1 & 245 & 0 \\
\hline Syracuse University & 2 & 313 & H. Synder & 13 & 229 & 190 & 120 & 6 & 126 & 15 \\
\hline Tartu University (University of Tartu) & 119 & 179 & T. Tulviste & 21 & 190 & 41 & 190 & 6 & 126 & 10 \\
\hline Technical University of Denmark & 22 & 245 & R. M.J. Cotterill & 59 & 95 & 772 & 73 & 7 & 112 & 150 \\
\hline Technion & 60 & 213 & M. Ben Chaim & 9 & 257 & 15 & 235 & 3 & 189 & 0 \\
\hline Technische Universität Berlin & 136 & 168 & D.C. O'Connell & 67 & 91 & 134 & 138 & 6 & 126 & 46 \\
\hline Technische Universitat Chemnitz & 29 & 238 & U. Hentschel & 7 & 278 & 2 & 274 & 1 & 245 & 0 \\
\hline Technische Universität Dresden & 87 & 195 & H. Wansing & 39 & 127 & 91 & 161 & 6 & 126 & 8 \\
\hline Technische Universität München & 40 & 227 & & 0 & 318 & 0 & 299 & 0 & 290 & 0 \\
\hline Tel Aviv University & 814 & 33 & D. Ravid & 38 & 131 & 429 & 90 & 8 & 105 & 150 \\
\hline Texas A\&M University & 500 & 69 & & 0 & 318 & 0 & 299 & 0 & 290 & 0 \\
\hline Texas Tech & 3 & 302 & J.A. Wasserman & 3 & 300 & 1 & 284 & 1 & 245 & 4 \\
\hline Tohoku University & 70 & 204 & A.P. Tsai & 322 & 14 & 2,614 & 39 & 31 & 25 & 150 \\
\hline Tokyo Institute of Technology & 29 & 238 & & 0 & 318 & 0 & 299 & 0 & 290 & 0 \\
\hline Trinity College Dublin & 317 & 109 & J.B. Gatenby & 38 & 131 & 1 & 284 & 0 & 290 & 13 \\
\hline Tsinghua University & 130 & 174 & W.M. Zheng & 231 & 32 & 674 & 76 & 12 & 87 & 150 \\
\hline Tufts University & 310 & 112 & J.M. Coffin & 172 & 43 & 4,904 & 20 & 30 & 28 & 150 \\
\hline Universidad Autonoma de Madrid & 415 & 78 & J. Polo & 9 & 257 & 1 & 284 & 1 & 245 & 0 \\
\hline Universidad de Chile & 149 & 161 & R. Latorre & 134 & 56 & 3,034 & 36 & 23 & 47 & 150 \\
\hline Universidad de Granada & 415 & 78 & J. Polo & 9 & 257 & 1 & 284 & 1 & 245 & 0 \\
\hline Universidad del País Vasco & 256 & 129 & J.J. Lanz & 36 & 135 & 136 & 137 & 9 & 97 & 19 \\
\hline Universidad Nacional Autónoma de México ... & 309 & 113 & M. Gomez-Torrente & 13 & 229 & 34 & 198 & 5 & 145 & 0 \\
\hline Universidad Politecnica de Madrid & 48 & 225 & R.E. Chavez-Segura & 34 & 140 & 171 & 128 & 4 & 164 & 71 \\
\hline Universidade de São Paulo & 295 & 117 & A.j.G. Simpson & 275 & 26 & 4,628 & 23 & 33 & 23 & 150 \\
\hline Universidade Estadual de Campinas & 153 & 160 & P.P.A. Funari & 15 & 216 & 28 & 209 & 3 & 189 & 7 \\
\hline Università degli Studi di Firenze & 205 & 143 & E. magnelli & 12 & 237 & 4 & 261 & 1 & 245 & 0 \\
\hline Università degli Studi di Padova & 298 & 115 & C. Semenza & 115 & 66 & 1,001 & 71 & 15 & 72 & 150 \\
\hline Universita Di Bologna & 263 & 127 & G. Pasquino & 19 & 198 & 41 & 190 & 4 & 164 & 3 \\
\hline Universita di Pisa & 162 & 157 & M.P. Colombini & 97 & 75 & 683 & 75 & 17 & 65 & 150 \\
\hline Universitat Autonoma de Barcelona & 376 & 93 & V. Lull & 10 & 254 & 26 & 212 & 3 & 189 & 12 \\
\hline Universitat Bielefeld & 220 & 137 & P. Weingart & 28 & 162 & 269 & 107 & 7 & 112 & 102 \\
\hline Universität Bremen & 116 & 182 & M.P. Ferretti & 8 & 267 & 5 & 255 & 1 & 245 & 4 \\
\hline Universitat d'Alacant & 174 & 152 & A. Del Castillo & 8 & 267 & 4 & 261 & 1 & 245 & 1 \\
\hline
\end{tabular}




\begin{tabular}{|c|c|c|c|c|c|c|c|c|c|c|}
\hline Universitat de València & 282 & 119 & N.V. Perea & 89 & 81 & 654 & 79 & 23 & 47 & 58 \\
\hline Universität Frankfurt am Main & 277 & 122 & W.K. Essler & 16 & 212 & 2 & 274 & 0 & 290 & 7 \\
\hline Universität Freiburg & 239 & 131 & M. Fludernik & 15 & 216 & 38 & 193 & 4 & 164 & 1 \\
\hline Universitat Hamburg & 271 & 125 & T.B. Berg & 230 & 33 & 5,074 & 18 & 40 & 17 & 150 \\
\hline Universität Karlsruhe & 57 & 216 & A.M. Braun & 119 & 62 & 3,065 & 35 & 20 & 55 & 150 \\
\hline Universitat Leipzig & 1 & 324 & K. Alter & 38 & 131 & 472 & 88 & 15 & 72 & 71 \\
\hline Universitat Munster (Westfälische Wilhelms-Un & 1 & 324 & M. Kotter & 2 & 305 & 30 & 207 & 2 & 221 & 2 \\
\hline Universitat Politecnica de Catalunya & 217 & 138 & J. Gacen & 290 & 22 & 123 & 144 & 5 & 145 & 97 \\
\hline Universität Regensburg & 113 & 185 & & 0 & 318 & 0 & 299 & 0 & 290 & 0 \\
\hline Universität Stuttgart & 88 & 194 & M. Schanz & 32 & 147 & 198 & 118 & 8 & 105 & 35 \\
\hline Universitat Trier & 91 & 192 & H. Breuer & 12 & 237 & 3 & 268 & 1 & 245 & 0 \\
\hline Universität Tübingen & 300 & 114 & F. Hoffman & 368 & 8 & 9,887 & 9 & 60 & 7 & 150 \\
\hline Universitat Wien (University of Vienna) & 358 & 100 & A. Zeilinger & 292 & 19 & 7,470 & 13 & 49 & 13 & 150 \\
\hline Universitat $\mathrm{Zu}$ Koln & 369 & 97 & T. Gartner & 56 & 98 & 176 & 127 & 7 & 112 & 27 \\
\hline Université Catholique de Louvain & 466 & 74 & X. Seron & 110 & 68 & 1,129 & 66 & 17 & 65 & 150 \\
\hline Universite de Liege & 140 & 165 & M. Otte & 28 & 162 & 303 & 100 & 9 & 97 & 74 \\
\hline Université de Montréal & 553 & 62 & M. Albert & 11 & 246 & 53 & 181 & 4 & 164 & 7 \\
\hline Université de Nice Sophia Antipolis & 125 & 176 & G.T. Feraud & 99 & 73 & 1,955 & 51 & 25 & 42 & 150 \\
\hline Universite Laval & 297 & 116 & M.Steriade & 243 & 28 & 6,712 & 14 & 46 & 16 & 113 \\
\hline Universite Libre de Bruxelles & 257 & 128 & N. Delvaux & 27 & 167 & 521 & 86 & 6 & 126 & 44 \\
\hline Université Paris Sorbonne & 1,224 & 15 & J. Bessiere & 13 & 229 & 5 & 255 & 2 & 221 & 11 \\
\hline Universite Paris-Sud 11 & 62 & 210 & C. Colliex & 197 & 36 & 4,463 & 24 & 29 & 31 & 150 \\
\hline Université Pierre et Marie Curie & 50 & 220 & C. Bustarret & 2 & 305 & 1 & 284 & 1 & 245 & 1 \\
\hline Universiti Malaya (University of Malaya) & 76 & 200 & M.A. David & 9 & 257 & 8 & 241 & 2 & 221 & 10 \\
\hline University College Cork & 122 & 177 & J. McCarthy & 28 & 162 & 516 & 87 & 9 & 97 & 80 \\
\hline University College Dublin & 400 & 85 & P.J. Lucas & 14 & 224 & 2 & 274 & 0 & 290 & 0 \\
\hline University College London & 2,593 & 3 & E. Bensly & 100 & 72 & 0 & 299 & 0 & 290 & 0 \\
\hline University do Porto & 30 & 235 & A.A.C. Teixeira & 12 & 237 & 8 & 241 & 2 & 221 & 13 \\
\hline University of Aberdeen & 350 & 102 & A. McKie & 81 & 86 & 1,407 & 57 & 21 & 52 & 150 \\
\hline University of Adelaide & 343 & 104 & E. Bensly & 39 & 127 & 0 & 299 & 0 & 290 & 0 \\
\hline University of Alabama & 618 & 55 & E. B. Cooper & 45 & 118 & 182 & 125 & 1 & 245 & 29 \\
\hline University of Alberta & 729 & 44 & P. Brett-MacLean & 11 & 246 & 47 & 186 & 3 & 189 & 23 \\
\hline University of Amsterdam & 816 & 32 & J. Van Paradijs & 229 & 34 & 5,024 & 19 & 49 & 13 & 150 \\
\hline University of Antwerp & 191 & 146 & J. Caen & 3 & 300 & 6 & 248 & 1 & 245 & 11 \\
\hline University of Arizona & 1,026 & 21 & A. Classen & 53 & 101 & 14 & 238 & 2 & 221 & 2 \\
\hline University of Athens & 137 & 166 & S. Psillos & 24 & 181 & 68 & 173 & 5 & 145 & 6 \\
\hline
\end{tabular}




\begin{tabular}{|c|c|c|c|c|c|c|c|c|c|c|}
\hline University of Auckland & 516 & 66 & R. Ellis & 53 & 101 & 237 & 112 & 11 & 91 & 11 \\
\hline University of Barcelona & 411 & 81 & M. Garcia-Carpintero & 16 & 212 & 37 & 194 & 3 & 189 & 1 \\
\hline University of Basel & 176 & 150 & S. Jacomet & 30 & 157 & 189 & 121 & 9 & 97 & 131 \\
\hline University of Bath & 5 & 283 & A. D. Brown & 25 & 176 & 161 & 132 & 8 & 105 & 13 \\
\hline University of Bergen & 4 & 293 & E. Aarseth & 4 & 294 & 7 & 245 & 2 & 221 & 1 \\
\hline University of Bern & 1 & 324 & J. Barth & 141 & 51 & 1,007 & 70 & 12 & 87 & 150 \\
\hline University of Birmingham & 1,272 & 13 & L.R.M. Strachan & 243 & 28 & 0 & 299 & 0 & 290 & 0 \\
\hline University of Bristol & 698 & 47 & R.P. Evershed & 235 & 31 & 2,507 & 41 & 35 & 19 & 150 \\
\hline University of British Columbia & 6 & 276 & I. Meikejohn & 35 & 138 & 4 & 261 & 4 & 164 & 10 \\
\hline University of Calgary & 543 & 64 & K. Nielsen & 48 & 111 & 19 & 224 & 2 & 221 & 0 \\
\hline University of California, Berkley & 16 & 248 & T. Katz-Gerro & 14 & 224 & 84 & 164 & 7 & 112 & 9 \\
\hline University of California, Davis & 770 & 41 & A.B. Damania & 30 & 157 & 107 & 151 & 3 & 189 & 10 \\
\hline University of California, Irvine & 787 & 37 & F.J. Ayala & 278 & 25 & 4,805 & 21 & 31 & 25 & 150 \\
\hline University of California, Los Angeles & 1,726 & 7 & J.M. Diamond & 189 & 38 & 3,272 & 34 & 23 & 47 & 89 \\
\hline University of California, Riverside & 382 & 90 & J.M. Fischer & 33 & 142 & 95 & 157 & 5 & $\overline{145}$ & 5 \\
\hline University of California, San Diego & 4 & 293 & T. Levy & 22 & 189 & 85 & 163 & 6 & 126 & 56 \\
\hline University of California, San Francisco & 2 & 313 & J.R. Merighi & 17 & 207 & 65 & 175 & 4 & 164 & 22 \\
\hline University of California, Santa Barbara & 954 & 26 & A.L. Brueckner & 57 & 96 & 76 & 169 & 4 & 164 & 3 \\
\hline University of California, Santa Cruz & 2 & 313 & E. Zyzik & 7 & 278 & 18 & 229 & 2 & 221 & 3 \\
\hline University of Cambridge & 17 & 247 & K.M. Becvar & 4 & 294 & 2 & 274 & 1 & 245 & 4 \\
\hline University of Canterbury & 2 & 313 & D. Bainbridge & 102 & 70 & 597 & 83 & 13 & 76 & 106 \\
\hline University of Cape Town & 13 & 253 & A. Jerardino & 17 & 207 & 123 & 144 & 5 & 145 & 42 \\
\hline University of Central Florida & 144 & 163 & T. Pugh & 8 & 267 & 5 & 255 & 2 & 221 & 0 \\
\hline University of Chicago & 14 & 252 & M.B. Hansen & 5 & 290 & 28 & 209 & 3 & 189 & 0 \\
\hline University of Cincinnati & 399 & 86 & C. Gauker & 18 & 203 & 35 & 197 & 4 & 164 & 1 \\
\hline University of Colorado at Boulder & 8 & 266 & S.S. Lowe & 2 & 305 & 5 & 255 & 1 & 245 & 0 \\
\hline University of Connecticut & 1 & 324 & R. Shaw & 27 & 167 & 274 & 105 & 7 & 112 & 28 \\
\hline University of Copenhagen & 4 & 293 & L.J. Whalley & 186 & 42 & 2,446 & 43 & 27 & 37 & 150 \\
\hline University of Delaware & 2 & 313 & A.L. Ardis & 1 & 311 & 0 & 299 & 0 & 290 & 0 \\
\hline University of Dundee & 156 & 158 & D.M.J. Lilley & 239 & 30 & 3,757 & 28 & 37 & 18 & 150 \\
\hline University of Edinburgh & 4 & 293 & R. Gertz & 8 & 267 & 29 & 208 & 3 & 189 & 50 \\
\hline University of Florida & 660 & 50 & K.M. Heilman & 488 & 1 & 6,457 & 15 & 29 & 31 & 150 \\
\hline University of Geneva & 1 & 324 & M. Louis-Courvoisier & 40 & 123 & 19 & 224 & 3 & 189 & 5 \\
\hline University of Georgia & 4 & 293 & E.A.S. Pierre & 4 & 294 & 18 & 229 & 2 & 221 & 1 \\
\hline University of Ghent & 5 & 283 & G. Van Hooydonk & 31 & 154 & 250 & 110 & 8 & 105 & 27 \\
\hline University of Glasgow & 752 & 42 & C. Hough & 47 & 113 & 15 & 235 & 2 & 221 & 0 \\
\hline
\end{tabular}




\begin{tabular}{|c|c|c|c|c|c|c|c|c|c|c|}
\hline University of Gothenburg & 3 & 302 & E. Soderpalm & 19 & 198 & 117 & 148 & 7 & 112 & 19 \\
\hline University of Groningen & 7 & 270 & W.A.J. Meijer & 6 & 285 & 3 & 268 & 1 & 245 & 0 \\
\hline University of Helsinki & 3 & 302 & & 0 & 318 & 0 & 299 & 0 & 290 & 0 \\
\hline University of Hong Kong & 332 & 106 & A.H.W. Ngan & 131 & 59 & 805 & 72 & 17 & 65 & 111 \\
\hline University of Houston & 3 & 302 & R. Westerfelhaus & 7 & 278 & 31 & 206 & 3 & 189 & 5 \\
\hline University of Illinois & 1,590 & 8 & S.H. Ambrose & 49 & 109 & 1,312 & 61 & 17 & 65 & 120 \\
\hline University of Illinois, Chicago & 483 & 72 & N.R. Smalheiser & 92 & 79 & 1,635 & 53 & 22 & 51 & 127 \\
\hline University of Indonesia & 6 & 276 & H. Muluk & 2 & 305 & 3 & 268 & 1 & 245 & 11 \\
\hline University of Iowa & 4 & 293 & R.J. Yetman & 8 & 267 & 210 & 115 & 3 & 189 & 8 \\
\hline University of Kansas & 2 & 313 & J. Coulehan & 32 & 147 & 187 & 122 & 6 & 126 & 13 \\
\hline University of Kentucky & 1 & 324 & W. Yan & 1 & 311 & 0 & 299 & 0 & 290 & 2 \\
\hline University of Lausanne & 1 & 324 & M. Louis-Courvoisier & 40 & 123 & 19 & 224 & 3 & 189 & 5 \\
\hline University of Leeds & 9 & 261 & E.F. Halpin & 11 & 246 & 15 & 235 & 2 & 221 & 9 \\
\hline University of Leicester & 493 & 71 & K.A. Pounds & 96 & 77 & 2,351 & 44 & 58 & 8 & 150 \\
\hline University of Liverpool & 5 & 283 & P. Whitten & 74 & 88 & 643 & 80 & 13 & 76 & 103 \\
\hline University of Ljubljana & 253 & 130 & D. Jaksic & 40 & 123 & 10 & 240 & 2 & 221 & 17 \\
\hline University of London (Kings College of London) & 5,108 & 1 & R.A. Weiss & 289 & 23 & 8,808 & 11 & 50 & 11 & 150 \\
\hline University of Manchester & 1,016 & 22 & C.W. Wardlow & 30 & 157 & 7 & 245 & 0 & 290 & 2 \\
\hline University of Manitoba & 327 & 107 & B. Caplan & 13 & 229 & 26 & 212 & 4 & 164 & 4 \\
\hline University of Maryland & 848 & 29 & V. Trimble & 87 & 83 & 251 & 109 & 6 & 126 & 33 \\
\hline University of Maryland Baltimore County & 166 & 155 & & 0 & 318 & 0 & 299 & 0 & 290 & 0 \\
\hline University of Massachusetts & 3 & 302 & T. Roeper & 11 & 246 & 26 & 212 & 3 & 189 & 23 \\
\hline University of Melbourne & 771 & 40 & D.A. Denton & 295 & 17 & 2,085 & 47 & 19 & 57 & 150 \\
\hline University of Miami & 1 & 324 & J.H. Yoepp & 1 & 311 & 8 & 241 & 1 & 245 & 3 \\
\hline University of Michigan & 16 & 248 & L. Schiesari & 10 & 254 & 79 & 168 & 4 & 164 & 17 \\
\hline University of Minnesota & 11 & 257 & M.M. Eaton & 6 & 285 & 18 & 229 & 2 & 221 & 1 \\
\hline University of Missouri & 5 & 283 & K. Welch & 34 & 140 & 261 & 108 & 13 & 76 & 79 \\
\hline University of Nebraska & 370 & 96 & C. Sayward & 36 & 135 & 4 & 261 & 1 & 245 & 4 \\
\hline University of New Hampshire & 132 & 172 & & 0 & 318 & 0 & 299 & 0 & 290 & 0 \\
\hline University of New Mexico & 5 & 283 & D.L. Van Cott & 15 & 216 & 48 & 184 & 5 & 145 & 4 \\
\hline University of New South Wales & 9 & 261 & C.S. Wilson & 44 & 119 & 210 & 115 & 9 & 97 & 34 \\
\hline University of North Carolina, Chapel Hill & 1,132 & 17 & W.G. Lycan & 39 & 127 & 74 & 170 & 3 & 189 & 6 \\
\hline University of North Texas & 2 & 313 & C. Blankson & 18 & 203 & 52 & 182 & 4 & 164 & 22 \\
\hline University of Notre Dame & 4 & 293 & R. Goulding & 2 & 305 & 0 & 299 & 0 & 290 & 0 \\
\hline University of Nottingham & 13 & 253 & A. Booth & 68 & 90 & 1,421 & 56 & 20 & 55 & 61 \\
\hline University of Oklahoma & 2 & 313 & T.S. Murphy & 6 & 285 & 1 & 284 & 1 & 245 & 2 \\
\hline
\end{tabular}




\begin{tabular}{|c|c|c|c|c|c|c|c|c|c|c|}
\hline University of Oregon & 584 & 58 & J.M. Erlandson & 62 & 93 & 673 & 77 & 15 & 72 & 96 \\
\hline University of Oslo & 2 & 313 & O. Eide & 5 & 290 & 2 & 274 & 1 & 245 & 5 \\
\hline University of Otago & 1 & 324 & M.G. Russell & 1 & 311 & 0 & 299 & 0 & 290 & 4 \\
\hline University of Ottawa & 3 & 302 & P. Kanaroglou & 75 & 87 & 643 & 80 & 13 & 76 & 72 \\
\hline University of Oxford & 36 & 231 & P.J. Mitchell & 16 & 212 & 60 & 177 & 4 & 164 & 14 \\
\hline University of Pennsylvania & 7 & 270 & P. Stallybrass & 8 & 267 & 5 & 255 & 1 & 245 & 3 \\
\hline University of Pittsburgh & 7 & 270 & E.M. Rasmussen & 28 & 162 & 214 & 114 & 8 & 105 & 28 \\
\hline University of Quebec & 1 & 324 & R.T. Burnett & 136 & 54 & 4,007 & 26 & 35 & 19 & 150 \\
\hline University of Queensland & 9 & 261 & I. Woodward & 17 & 207 & 84 & 164 & 6 & 126 & 27 \\
\hline University of Reading & 561 & 61 & R. Bradley & 52 & 105 & 162 & 131 & 6 & 126 & 23 \\
\hline University of Rochester & 3 & 302 & E.L. Newport & 31 & 154 & 1,398 & 58 & 13 & 76 & 62 \\
\hline University of Saskatchewan & 214 & 139 & D. Groves & 9 & 257 & 0 & 299 & 0 & 290 & 20 \\
\hline University of Science and Technology of China & 15 & 251 & C.S. Wang & 39 & 127 & 299 & 101 & 11 & 91 & 127 \\
\hline University of Sheffield & 969 & 24 & G.C.M. Smith & 19 & 198 & 0 & 299 & 0 & 290 & 0 \\
\hline University of South Carolina & 402 & 84 & E.T. Long & 13 & 229 & 4 & 261 & 1 & 245 & 0 \\
\hline University of South Florida & 325 & 108 & P. Rogers & 32 & 147 & 6 & 248 & 2 & 221 & 1 \\
\hline University of Southampton & 12 & 255 & A. Pinnock & 3 & 300 & 1 & 284 & 1 & 245 & 1 \\
\hline University of Southern California & 6 & 276 & D.A. Scott & 163 & 45 & 1,323 & 60 & 26 & 38 & 150 \\
\hline University of St Andrews & 1 & 324 & M.Bird & 141 & 51 & 2,116 & 46 & 26 & 38 & 150 \\
\hline University of Surrey & 3 & 302 & M. Blythe & 15 & 216 & 95 & 157 & 5 & 145 & 21 \\
\hline University of Sussex & 8 & 266 & M.L. Murphy & 4 & 294 & 5 & 255 & 2 & 221 & 4 \\
\hline University of Sydney & 1,222 & 16 & R.G. Howarth & 48 & 111 & 2 & 274 & 0 & 290 & 0 \\
\hline University of Technology, Sydney & 6 & 276 & C. Rhodes & 25 & 176 & 164 & 129 & 8 & 105 & 13 \\
\hline University of Tennessee Knoxville & 2 & 313 & S. Das & 33 & 142 & 99 & 155 & 4 & 164 & 19 \\
\hline University of Texas at Austin & 10 & 259 & S. Vaughn & 99 & 73 & 1,050 & 69 & 19 & 57 & 103 \\
\hline University of Tokyo & 185 & 147 & T.D. White & 88 & 82 & 1,443 & 54 & 19 & 57 & 150 \\
\hline University of Toronto & 2,025 & 5 & M. Dennis & 115 & 66 & 1,331 & 59 & 25 & 42 & 150 \\
\hline University of Tsukuba & 60 & 213 & D.R.J. Macer & 47 & 113 & 163 & 130 & 5 & 145 & 41 \\
\hline University of Twente & 1 & 324 & P. Benneworth & 12 & 237 & 89 & 162 & 5 & 145 & 9 \\
\hline University of Utah & 383 & 89 & T.E. Cerling & 132 & 58 & 3,503 & 31 & 31 & 25 & 150 \\
\hline University of Vermont & 276 & 123 & P.A. Prelock & 32 & 147 & 122 & 146 & 5 & 145 & 34 \\
\hline University of Victoria & 5 & 283 & H. Brown & 6 & 285 & 65 & 175 & 4 & 164 & 9 \\
\hline University of Virginia & 7 & 270 & L.B. Smolkin & 8 & 267 & 32 & 203 & 3 & 189 & 9 \\
\hline University of Warwick & 6 & 276 & P. Hancock & 15 & 216 & 47 & 186 & 4 & 164 & 8 \\
\hline University of Washington & 958 & 25 & R.D. Palmiter & 291 & 21 & 12,644 & 7 & 50 & 11 & 150 \\
\hline University of Waterloo & 0 & 344 & & 0 & 318 & 0 & 299 & 0 & 290 & 0 \\
\hline
\end{tabular}




\begin{tabular}{|c|c|c|c|c|c|c|c|c|c|c|}
\hline University of Western Australia & 276 & 123 & M.P. Levine & 26 & 170 & 14 & 238 & 3 & 189 & 3 \\
\hline University of Western Ontario & 719 & 45 & T. Rajan & 20 & 192 & 19 & 224 & 3 & 189 & 3 \\
\hline University of Wisconsin & 5 & 283 & J.S. Russell & 144 & 50 & 435 & 89 & 9 & 97 & 144 \\
\hline University of Wollongong & 1 & 324 & G. Barwell & 1 & 311 & 1 & 284 & 1 & 245 & 0 \\
\hline University of York & 5 & 283 & M. Blythe & 15 & 216 & 95 & 157 & 5 & 145 & 21 \\
\hline University of Zurich & 1 & 324 & P.B. Batles & 128 & 60 & 2,922 & 38 & 25 & 42 & 109 \\
\hline Univesitas Gadjah Mada & 4 & 293 & R.P. Soejono & 7 & 278 & 248 & 111 & 3 & 189 & 33 \\
\hline Uppsala University & 1 & 324 & D. Parker & 32 & 147 & 100 & 154 & 6 & 126 & 27 \\
\hline Utah State & 3 & 302 & G. Kiger & 21 & 190 & 104 & 153 & 6 & 126 & 15 \\
\hline Utrecht University & 651 & 51 & F.A. Muller & 20 & 192 & 33 & 200 & 4 & 164 & 3 \\
\hline Vanderbilt University & 705 & 46 & L.O. Mills & 13 & 229 & 0 & 299 & 0 & 290 & 0 \\
\hline Victoria University of Wellington & 388 & 88 & J. Holmes & 42 & 122 & 408 & 92 & 10 & 95 & 89 \\
\hline Vienna University of Technology & 32 & 233 & P. Weinberger & 326 & 13 & 1,988 & 50 & 23 & 47 & 150 \\
\hline Virginia Polytechnic Institute & 311 & 111 & R.M. Burian & 33 & 142 & 108 & 150 & 5 & 145 & 17 \\
\hline Vrije Universiteit, Brussels & 134 & 171 & Y. Lebrun & 53 & 101 & 151 & 134 & 1 & 245 & 24 \\
\hline VU University Amsterdam & 9 & 261 & F.J. Meijman & 57 & 96 & 92 & 160 & 5 & 145 & 36 \\
\hline Wageningen University & 0 & 344 & & 0 & 318 & 0 & 299 & 0 & 290 & 0 \\
\hline Wake Forest University & 2 & 313 & A. Mitra & 28 & 162 & 184 & 124 & 9 & 97 & 40 \\
\hline Waseda University & 61 & 212 & & 0 & 318 & 0 & 299 & 0 & 290 & 0 \\
\hline Washington State University & 266 & 126 & M.E. Wingate & 38 & 131 & 130 & 142 & 1 & 245 & 4 \\
\hline Washington University in St. Louis & 3 & 302 & D. Walmer & 2 & 305 & 0 & 299 & 0 & 290 & 22 \\
\hline Wayne State University & 0 & 344 & & 0 & 318 & 0 & 299 & 0 & 290 & 0 \\
\hline West Virginia University & 234 & 133 & J.C. McCrosey & 30 & 157 & 310 & 98 & 11 & 91 & 26 \\
\hline Yale University & 8 & 266 & A.L. Mishara & 18 & 203 & 218 & 113 & 5 & 145 & 23 \\
\hline Yonsei University & 86 & 196 & T.P. Murphy & 8 & 267 & 6 & 248 & 2 & 221 & 0 \\
\hline York University & 11 & 257 & D. Zwick & 8 & 267 & 23 & 218 & 4 & 164 & 6 \\
\hline Zhejiang University & 1 & 324 & Z. Cao & 1 & 311 & 0 & 299 & 0 & 290 & 1 \\
\hline
\end{tabular}




\begin{tabular}{|c|c|c|c|c|c|c|c|c|c|c|}
\hline Dentristry Data & $\begin{array}{l}\text { Department } \\
\text { Publications }\end{array}$ & Rank & $\begin{array}{l}\text { Most Prolific } \\
\text { Author }\end{array}$ & Published & Rank & Cited & Rank & $\begin{array}{c}\text { H- } \\
\text { Index }\end{array}$ & Rank & $\begin{array}{c}\text { \# of } \\
\text { Coauthors }\end{array}$ \\
\hline Aalto University & 7 & 267 & M.H.O. Kononen & 95 & 150 & 1,202 & 107 & 14 & 144 & 128 \\
\hline Aarhus University & 1,0 & 23 & P. Sueysson & 221 & 50 & 1,915 & 59 & 34 & 23 & 150 \\
\hline Arizonia State University & 7 & 267 & & 0 & 274 & 0 & 273 & 0 & 272 & 0 \\
\hline Ateneo de Manila University & 5 & 281 & M. Iwaku & 86 & 167 & 937 & 135 & 12 & 164 & 114 \\
\hline Auburn University & 0 & 336 & & 0 & 274 & 0 & 273 & 0 & 272 & 0 \\
\hline Australian National University & 9 & 252 & & 0 & 274 & 0 & 273 & 0 & 272 & 0 \\
\hline Boston College & 1 & 328 & & 0 & 274 & 0 & 273 & 0 & 272 & 0 \\
\hline Boston University & 883 & 36 & T.E. Van Dyke & 232 & 45 & 3,965 & 17 & 29 & 40 & 150 \\
\hline Brandeis University & 3 & 301 & C.J. Miller & 286 & 29 & 7,887 & 6 & 57 & 2 & 150 \\
\hline Brigham Young University & 26 & 195 & G.J. Christensen & 258 & 40 & 861 & 142 & 12 & 164 & 42 \\
\hline Brown University & 37 & 178 & & 0 & 274 & 0 & 273 & 0 & 272 & $\overline{0}$ \\
\hline California Institute of Technology & 1 & 328 & & 0 & 274 & 0 & 273 & 0 & 272 & 0 \\
\hline Cardiff University & 1,0 & 24 & M.E. Addy & 338 & 16 & 2,403 & 46 & 28 & 43 & 150 \\
\hline Carnegie Mellon University & 8 & 260 & M.G. Morgan & 79 & 178 & 771 & 150 & 11 & 173 & 98 \\
\hline Case Western Reserve University & 488 & 65 & N.F. Bissaba & 100 & 143 & 657 & 162 & 10 & 188 & 118 \\
\hline Chalmers University of Technology & 22 & 204 & H. Odelius & 38 & 221 & 253 & 222 & 4 & 244 & 70 \\
\hline Charles University & 34 & 184 & T. Dostalova & 82 & 174 & 282 & 218 & 10 & 188 & 125 \\
\hline Chinese University of Hong Kong & 8 & 260 & K.K.F. Cheng & 146 & 95 & 2,001 & 57 & 25 & 50 & 150 \\
\hline Chulalongkorn University & 200 & 108 & K. Dhanuthai & 32 & 229 & 44 & 261 & 4 & 244 & 82 \\
\hline City University of Hong Kong & 3 & 301 & & 0 & 274 & 0 & 273 & 0 & 272 & 0 \\
\hline City University of New York & 8 & 260 & E.W. Gresik & 62 & 194 & 398 & 200 & 10 & 188 & 58 \\
\hline Colorado State University & 7 & 267 & & 0 & 274 & 0 & 273 & 0 & 272 & 0 \\
\hline Columbia University & 926 & 33 & & 0 & 274 & 0 & 273 & 0 & 272 & 0 \\
\hline Cornell University & 48 & 165 & & 0 & 274 & 0 & 273 & 0 & 272 & 0 \\
\hline Curtin University of Technology & 6 & 273 & & 0 & 274 & 0 & 273 & 0 & 272 & 0 \\
\hline Dalhousie University & 353 & 85 & E.J. Suton & 43 & 217 & $\mid 178$ & 235 & 3 & 256 & 43 \\
\hline Dartmouth College & 3 & 301 & & 0 & 274 & 0 & 273 & 0 & 272 & 0 \\
\hline Delft University of Technology & 0 & 336 & & 0 & 274 & 0 & 273 & 0 & 272 & 0 \\
\hline Drexel University & 72 & 148 & B.H. Hendler & 24 & 243 & 139 & 241 & 4 & 244 & 37 \\
\hline Duke University & 91 & 140 & R.F.D. Kay & 83 & 171 & 1,225 & 103 & 16 & 113 & 128 \\
\hline Durham University & 13 & 236 & & 0 & 274 & 0 & 273 & 0 & 272 & 0 \\
\hline Ecole Normale Supérieure de Lyon & 5 & 281 & H. Magloire & 102 & 141 & 712 & 157 & 14 & 144 & 150 \\
\hline École Normale Supérieure, Paris & 1 & 328 & & 0 & 274 & 0 & 273 & 0 & 272 & 0 \\
\hline
\end{tabular}




\begin{tabular}{|c|c|c|c|c|c|c|c|c|c|c|}
\hline Ecole Polytechnique Fédérale de Lausanne & 7 & 267 & J. Botsis & 80 & 177 & 538 & 174 & 15 & 128 & 86 \\
\hline Eindhoven University of Technology & 3 & 301 & & 0 & 274 & 0 & 273 & 0 & 272 & 0 \\
\hline Emory University & 353 & 85 & C.A. Waldron & 60 & 200 & 964 & 130 & 2 & 264 & 46 \\
\hline Erasmus University Rotterdam & 114 & 133 & E.B. Wolvius & 34 & 224 & 169 & 237 & 8 & 213 & 65 \\
\hline ETH Zurich (Swiss Federal Institute of Technology) & 34 & 184 & & 0 & 274 & 0 & 273 & 0 & 272 & 0 \\
\hline Florida International University & 3 & 301 & & 0 & 274 & 0 & 273 & 0 & 272 & 0 \\
\hline Florida State University & 4 & 291 & & 0 & 274 & 0 & 273 & 0 & 272 & 0 \\
\hline Freie Universität Berlin & 132 & 128 & P.A. Reichart & 290 & 25 & 2,458 & 42 & 24 & 52 & 150 \\
\hline Friedrich Alexander Universität Erlangen Nürnberg & 363 & 82 & F.W. Neukam & 127 & 112 & 1,225 & 103 & 21 & 71 & 150 \\
\hline Fudan University & 9 & 252 & W.Q. Huang & 1,141 & 1 & 13,096 & 1 & 53 & 4 & 150 \\
\hline Georg August Universität Göttingen & 284 & 95 & T. Attin & 168 & 83 & 1,076 & 115 & 23 & 58 & 150 \\
\hline George Mason University & 1 & 328 & J.K. Lunney & 142 & 99 & 1,247 & 101 & 20 & 81 & 150 \\
\hline George Washington University & 44 & 171 & & 0 & 274 & 0 & 273 & 0 & 272 & 0 \\
\hline Georgetown University & 158 & 120 & J.C. Posnick & 138 & 104 & 1,337 & 91 & 9 & 200 & 150 \\
\hline Georgia Institute of Technology & 44 & 171 & B.D. Boyan & 287 & 28 & 5,339 & 11 & 45 & 9 & 150 \\
\hline Georgia State University & 3 & 301 & & 0 & 274 & 0 & 273 & 0 & 272 & 0 \\
\hline Goteborg University & 1,158 & 17 & J. Lindhe & 361 & 11 & 5,023 & 13 & 33 & 29 & 150 \\
\hline Harvard University & 1,232 & 13 & G.S. Shklar & 263 & 36 & 1,278 & 97 & 8 & 213 & 150 \\
\hline Hebrew University of Jerusalem & 1,312 & 11 & B. Peretz & 74 & 182 & 338 & 208 & 10 & 188 & 79 \\
\hline Heidelberg Universität & 284 & 95 & P. Rammelsberg & 75 & 180 & 362 & 203 & 11 & 173 & 108 \\
\hline Hokkaido University & 448 & 69 & H. Sano & 124 & 116 & 2,583 & 38 & 34 & 23 & 150 \\
\hline Hong Kong Polytechnic University & 11 & 247 & M.C.M. Wong & 51 & 213 & 621 & 167 & 16 & 113 & 85 \\
\hline Hong Kong University of Science \& Techno... & 6 & 273 & F.R. Tay & 282 & 30 & 2,927 & 31 & 51 & 6 & 150 \\
\hline Humboldt-Universität zu Berlin & 66 & 153 & P.A. Reichart & 290 & 25 & 2,458 & 42 & 24 & 52 & 150 \\
\hline Imperial College London & 59 & 159 & & 0 & 274 & 0 & 273 & 0 & 272 & 0 \\
\hline Indian Institute of Technology Bombay (I... & 2 & 314 & & 0 & 274 & 0 & 273 & 0 & 272 & 0 \\
\hline Indian Institute of Technology Delhi (II... & 3 & 301 & & 0 & 274 & 0 & 273 & 0 & 272 & 0 \\
\hline Indian Institute of Technology Kanpur (I... & 2 & 314 & & 0 & 274 & 0 & 273 & 0 & 272 & 0 \\
\hline Indiana University Bloomington & 539 & 57 & B. K. Moore & 126 & 114 & 1,630 & 68 & 17 & 104 & 150 \\
\hline Indiana University Indianapolis & 777 & 42 & G.K. Stookey & 245 & 44 & 1,165 & 110 & 17 & 104 & 150 \\
\hline Iowa State University & 4 & 291 & & 0 & 274 & 0 & 273 & 0 & 272 & 0 \\
\hline Johns Hopkins University & 203 & 107 & & 0 & 274 & 0 & 273 & 0 & 272 & 0 \\
\hline Kansas State University & 1 & 328 & & 0 & 274 & 0 & 273 & 0 & 272 & 0 \\
\hline Katholieke Universiteit Leuven & 638 & 51 & M. Quirynem & 207 & 57 & 2,647 & 34 & 28 & 43 & 150 \\
\hline Keio University & 46 & 168 & T. Nakajima & 256 & 42 & 860 & 143 & 12 & 164 & 150 \\
\hline
\end{tabular}




\begin{tabular}{|c|c|c|c|c|c|c|c|c|c|c|}
\hline King Fahd University of Petroleum \& Minerals & 3 & 301 & & 0 & 274 & 0 & 273 & 0 & 272 & 0 \\
\hline King Saud University & 397 & 77 & K. Almas & 57 & 206 & 204 & 231 & 9 & 200 & 79 \\
\hline Kobe University & 34 & 184 & T. Komori & 114 & 125 & 469 & 187 & 1 & 268 & 150 \\
\hline Korea Advanced Institute of Science \& Technology & 0 & 336 & & 0 & 274 & 0 & 273 & 0 & 272 & 0 \\
\hline Korea University & 19 & 211 & Y.K. Lim & 11 & 266 & 14 & 267 & 2 & 264 & 13 \\
\hline Kyoto University & 165 & 119 & T. Lizuka & 86 & 167 & 945 & 134 & 15 & 128 & 150 \\
\hline Kyushu University & 680 & 46 & S. Kanda & 110 & 132 & 1,163 & 111 & 11 & 173 & 150 \\
\hline La Trobe University & 6 & 273 & S.M. Reilly & 38 & 221 & 461 & 189 & 11 & 173 & 83 \\
\hline Lancaster University & 4 & 291 & F.L. Martin & 112 & 126 & 761 & 151 & 18 & 90 & 150 \\
\hline Leiden University & 77 & 145 & C. Lekkas & 21 & 247 & 70 & 252 & 3 & 256 & 18 \\
\hline Linkoping University & 104 & 136 & P. Astrand & 19 & 253 & 286 & 216 & 11 & 173 & 53 \\
\hline London School of Economics and Political Scie & 3 & 301 & & 0 & 274 & 0 & 273 & 0 & 272 & 0 \\
\hline Loughborough University & 10 & 250 & R. Smith & 27 & 239 & 67 & 255 & 5 & 238 & 6 \\
\hline Louisiana State University & 549 & 55 & M.S. Block & 122 & 121 & 1,513 & 74 & 15 & 128 & 121 \\
\hline Ludwig-Maximilians-Universität München & 292 & 94 & R. Hickel & 198 & 61 & 1,702 & 63 & 26 & 49 & 150 \\
\hline Lund University & 672 & 48 & M. Rohlin & 122 & 121 & 870 & 140 & 10 & 188 & 150 \\
\hline Maastricht University & 30 & 192 & P.J.W. Stoelinga & 186 & 72 & 1,021 & 123 & 16 & 113 & 150 \\
\hline Macquarie University & 22 & 204 & P. Petocz & 95 & 150 & 1,359 & 87 & 21 & 71 & 150 \\
\hline Mahidol University & 172 & 117 & R. Srisatjluk & 2 & 271 & 3 & 272 & 1 & 268 & 14 \\
\hline Masaryk University & 19 & 211 & A. Fassmann & 15 & 257 & 118 & 242 & 7 & 222 & 36 \\
\hline Massachusetts Institute of Technology & 48 & 165 & A. Rich & 337 & 17 & 5,872 & 9 & 32 & 32 & 150 \\
\hline McGill University & 329 & 90 & J.S Fiene & 88 & 159 & 1,478 & 78 & 22 & 62 & 150 \\
\hline McMaster University & 56 & 163 & A.T. Merchant & 64 & 192 & 982 & 128 & 16 & 113 & 126 \\
\hline Michigan State University & 25 & 198 & & 0 & 274 & 0 & 273 & 0 & 272 & 0 \\
\hline Michigan Technological University & 2 & 314 & & 0 & 274 & 0 & 273 & 0 & 272 & 0 \\
\hline Monash University & 48 & 165 & D. Figdor & 21 & 247 & 959 & 131 & 9 & 200 & 21 \\
\hline Montana State University & 14 & 230 & K.F. Woodmansey & 13 & 260 & 64 & 256 & 4 & 244 & 5 \\
\hline Moscow State University & 4 & 291 & V.E. Tarasov & 86 & 167 & 209 & 230 & 16 & 113 & 3 \\
\hline Nagoya University & 1,681 & 6 & M. Ueda & 427 & 6 & 2,632 & 36 & 29 & 40 & 150 \\
\hline Nanjing University & 18 & 217 & L. Wang & 153 & 89 & 1,055 & 117 & 19 & 84 & 150 \\
\hline Nanyang Technological University & 15 & 226 & A. Asundi & 301 & 21 & 110 & 245 & 18 & 90 & 150 \\
\hline National Taiwan University & 206 & 105 & C.P. Chaing & 132 & 108 & 1,015 & 124 & 18 & 90 & 150 \\
\hline National Tsing Hua University & 5 & 281 & & 0 & 274 & 0 & 273 & 0 & 272 & 0 \\
\hline National University of Ireland, Galway & 5 & 281 & M.J.T. Fitzgerald & 13 & 260 & 78 & 248 & 2 & 264 & 138 \\
\hline National University of Singapore & 451 & 68 & A.V.J. Yap & 147 & 94 & 1,258 & 99 & 22 & 62 & 150 \\
\hline New Mexico State University & 2 & 314 & & 0 & 274 & 0 & 273 & 0 & 272 & 0 \\
\hline
\end{tabular}




\begin{tabular}{|c|c|c|c|c|c|c|c|c|c|c|}
\hline New York University & 1,298 & 12 & G.R. Goldstein & 138 & 104 & 607 & 169 & 9 & 200 & 119 \\
\hline Newcastle University & 959 & 27 & J.F. McCabe & 197 & 63 & 1,640 & 67 & 18 & 90 & 150 \\
\hline North Carolina State University & 8 & 260 & & 0 & 274 & 0 & 273 & 0 & 272 & 0 \\
\hline Northeastern University & 15 & 226 & & 0 & 274 & 0 & 273 & 0 & 272 & 0 \\
\hline Northwestern University & 425 & 72 & E.H. Greener & 161 & 85 & 864 & 141 & 3 & 256 & 132 \\
\hline Norwegian University of Science \& Technology & 9 & 252 & U. Syversen & 64 & 192 & 1,652 & 65 & 20 & 81 & 150 \\
\hline Ohio State University & 1,174 & 16 & M.C. Nahata & 456 & 4 & 2,572 & 39 & 21 & 71 & 150 \\
\hline Oklahoma State University & 12 & 240 & R.T. Glass & 29 & 236 & 84 & 247 & 5 & 238 & 32 \\
\hline Open University UK & 12 & 240 & & 0 & 274 & 0 & 273 & 0 & 272 & 0 \\
\hline Oregon State University & 13 & 236 & D.O. Kaldenberg & 29 & 236 & 242 & 224 & 7 & 222 & 23 \\
\hline Osaka University & 1,044 & 21 & S. Ebisu & 187 & 71 & 1,958 & 58 & 24 & 52 & 150 \\
\hline Peking University & 311 & 93 & C.F. Cao & 59 & 202 & 243 & 223 & 7 & 222 & 97 \\
\hline Pennsylvania State University & 22 & 204 & P.W. Brown & 67 & 189 & 728 & 155 & 15 & 128 & 50 \\
\hline Pohang University of Science And Technology & 4 & 291 & J.K. Lee & 60 & 200 & 477 & 184 & 12 & 164 & 91 \\
\hline Portland State University & 4 & 291 & & 0 & 274 & 0 & 273 & 0 & 272 & 0 \\
\hline Princeton University & 5 & 281 & W.O. Soboyejo & 195 & 64 & 1,080 & 114 & 17 & 104 & 150 \\
\hline Purdue University & 37 & 178 & M. Analoui & 16 & 256 & 239 & 225 & 8 & 213 & 50 \\
\hline Queen's University & 14 & 230 & K.G. Munhall & 54 & 210 & 814 & 145 & 18 & 90 & 71 \\
\hline Queen's University of Belfast & 369 & 80 & P.J. Lamey & 219 & 52 & 1,443 & 79 & 16 & 113 & 150 \\
\hline Queensland University of Technology & 21 & 208 & Y.M. Xiao & 24 & 243 & 454 & 192 & 12 & 164 & 88 \\
\hline Radboud University, Nijmegen & 1,027 & 25 & A.M. Kuijers-Jagtman & 223 & 49 & 1,153 & 112 & 18 & 90 & 150 \\
\hline Rensselaer Polytechnic Institute & 26 & 195 & & 0 & 274 & 0 & 273 & 0 & 272 & 0 \\
\hline Rheinisch Westfalische Technische Hochschule Aach & 141 & 123 & H. Spiekermann & 32 & 229 & 836 & 144 & 15 & 128 & 67 \\
\hline Rheinische Friedrich Wilhelms Universitat Bonn & 199 & 109 & C. Bourauel & 107 & 134 & 517 & 177 & 14 & 144 & 149 \\
\hline Rice University & 26 & 195 & A. G. Mikos & 340 & 15 & 9,934 & 3 & 67 & 1 & 150 \\
\hline Rochester Institute of Technology & 4 & 291 & K. Hickman & 10 & 268 & 4 & 271 & 0 & 272 & 5 \\
\hline Royal Institute of Technology, KTH & 9 & 252 & T. Arnebrant & 93 & 153 & 957 & 132 & 18 & 90 & 115 \\
\hline Royal Melbourne Institute of Technology & 0 & 336 & & 0 & 274 & 0 & 273 & 0 & 272 & 0 \\
\hline Rutgers & 37 & 178 & R.H. Ebright & 123 & 119 & 3,273 & 24 & 35 & 21 & 150 \\
\hline Saint-Petersburg State University & 1 & 328 & L.N. Moskvin & 194 & 66 & 187 & 234 & 7 & 222 & 150 \\
\hline San Diego State University & 12 & 240 & & 0 & 274 & 0 & 273 & 0 & 272 & 0 \\
\hline Sapienza University of Rome & 0 & 336 & & 0 & 274 & 0 & 273 & 0 & 272 & 0 \\
\hline Sciences Po Paris & 0 & 336 & & 0 & 274 & 0 & 273 & 0 & 272 & 0 \\
\hline Seoul National University & 439 & 71 & Y.K. Lee & 297 & 22 & 1,211 & 105 & 23 & 58 & 150 \\
\hline Shanghai Jiao Tong University & 117 & 130 & F.Q. Zhang & 17 & 255 & 5 & 270 & 1 & 268 & 38 \\
\hline Simon Fraser University & 17 & 221 & M.P. Rosin & 111 & 128 & 1,389 & 84 & 18 & 90 & 150 \\
\hline
\end{tabular}




\begin{tabular}{|c|c|c|c|c|c|c|c|c|c|c|}
\hline Stanford University & 137 & 125 & M.T. Longaker & 453 & 5 & 5,583 & 10 & 48 & 7 & 150 \\
\hline State University of New York Buffalo & 9 & 252 & J. Karuza & 48 & 216 & 458 & 191 & 9 & 200 & 92 \\
\hline Stockholm University & 20 & 209 & M. Bergdahl & 22 & 246 & 347 & 205 & 10 & 188 & 32 \\
\hline Stony Brook University & 546 & 56 & H.B. Waldman & 391 & 8 & 341 & 207 & 9 & 200 & 37 \\
\hline Syracuse University & 14 & 230 & C.M. Davis & 7 & 269 & 19 & 266 & 3 & 256 & 9 \\
\hline Tartu University (University of Tartu) & 19 & 211 & M. Saag & 13 & 260 & 53 & 259 & 4 & 244 & 74 \\
\hline Technical University of Denmark & 12 & 240 & S. Kreiborg & 124 & 116 & 1,398 & 83 & 16 & 113 & 150 \\
\hline Technion & 136 & 126 & M. Peled & 98 & 147 & 780 & 149 & 16 & 113 & 122 \\
\hline Technische Universität Berlin & 5 & 281 & A. Zouni & 40 & 219 & 1,744 & 62 & 14 & 144 & 81 \\
\hline Technische Universitat Chemnitz & 3 & 301 & J.L. Calvo-Guirado & 26 & 241 & 34 & 263 & 4 & 244 & 70 \\
\hline Technische Universität Dresden & 136 & 126 & U. Eckelt & 81 & 175 & 403 & 199 & 12 & 164 & 143 \\
\hline Technische Universität München & 83 & 143 & H.H. Horch & 107 & 134 & 441 & 194 & 11 & 173 & 150 \\
\hline Tel Aviv University & 1,076 & 20 & L. Levin & 81 & 175 & 415 & 196 & 14 & 144 & 82 \\
\hline Texas A\&M University & 37 & 178 & S.H. Safe & 258 & 40 & 9,533 & 4 & 52 & 5 & 150 \\
\hline Texas Tech & 4 & 291 & B.K. Bartee & 13 & 260 & 61 & 257 & 4 & 244 & 12 \\
\hline Tohoku University & 530 & 58 & K. Ooya & 93 & 153 & 672 & 160 & 14 & 144 & 121 \\
\hline Tokyo Institute of Technology & 18 & 217 & N. Okada & 173 & 80 & 2,992 & 28 & 37 & 16 & 150 \\
\hline Trinity College Dublin & 235 & 99 & N. Claffey & 73 & 184 & 708 & 158 & 10 & 188 & 137 \\
\hline Tsinghua University & 12 & 240 & & 0 & 274 & 0 & 273 & 0 & 272 & 0 \\
\hline Tufts University & 932 & 32 & G. Shklar & 263 & 36 & 1,201 & 108 & 7 & 222 & 150 \\
\hline Universidad Autonoma de Madrid & 67 & 151 & M. Sanz & 70 & 186 & 1,030 & 120 & 22 & 62 & 150 \\
\hline Universidad de Chile & 198 & 110 & R. Miralles & 54 & 210 & 323 & 211 & 9 & 200 & 97 \\
\hline Universidad de Granada & 67 & 151 & M. Sanz & 70 & 186 & 1,030 & 120 & 22 & 62 & 150 \\
\hline Universidad del País Vasco & 86 & 142 & J.M. Agurrie & 30 & 234 & 314 & 213 & 11 & 173 & 77 \\
\hline Universidad Nacional Autónoma de México ... & 63 & 156 & C. Montes-Ledesma & 30 & 234 & 154 & 239 & 6 & 235 & 66 \\
\hline Universidad Politecnica de Madrid & 0 & 336 & & 0 & 274 & 0 & 273 & 0 & 272 & 0 \\
\hline Universidade de São Paulo & 2,201 & 2 & J.D. Pecora & 173 & 80 & 636 & 165 & 16 & 113 & 150 \\
\hline Universidade Estadual de Campinas & 112 & 134 & E.A. Sallum & 126 & 114 & 467 & 188 & 15 & 128 & 144 \\
\hline Università degli Studi di Firenze & 328 & 91 & T. Baccetti & 180 & 78 & 976 & 129 & 21 & 71 & 150 \\
\hline Università degli Studi di Padova & 175 & 115 & D. Manfredini & 73 & 184 & 285 & 217 & 12 & 164 & 80 \\
\hline Universita Di Bologna & 383 & 79 & C. Prati & 135 & 107 & 1,256 & 100 & 19 & 84 & 150 \\
\hline Universita di Pisa & 66 & 153 & M. Bosco & 40 & 219 & 168 & 238 & 9 & 200 & 35 \\
\hline Universitat Autonoma de Barcelona & 24 & 200 & & 0 & 274 & 0 & 273 & 0 & 272 & 0 \\
\hline Universitat Bielefeld & 2 & 314 & & 0 & 274 & 0 & 273 & 0 & 272 & 0 \\
\hline Universität Bremen & 8 & 260 & & 0 & 274 & 0 & 273 & 0 & 272 & 0 \\
\hline Universitat d'Alacant & 4 & 291 & & 0 & 274 & 0 & 273 & 0 & 272 & 0 \\
\hline
\end{tabular}




\begin{tabular}{|c|c|c|c|c|c|c|c|c|c|c|}
\hline Universitat de València & 341 & 89 & M.A. Penarrocha & 88 & 159 & 383 & 201 & 9 & 200 & 102 \\
\hline Universität Frankfurt am Main & 186 & 112 & P. Eickholtz & 89 & 157 & 471 & 186 & 16 & 113 & 148 \\
\hline Universität Freiburg & 409 & 74 & J. Strub & 171 & 82 & 1,342 & 89 & 19 & 84 & 150 \\
\hline Universitat Hamburg & 76 & 146 & I. Nergiz & 33 & 226 & 225 & 227 & 7 & 222 & 38 \\
\hline Universität Karlsruhe & 10 & 250 & H.J. Scirdler & 27 & 239 & 68 & 253 & 6 & 235 & 40 \\
\hline Universitat Leipzig & 100 & 137 & M.T. John & 61 & 198 & 324 & 210 & 14 & 144 & 89 \\
\hline Universitat Munster (Westfälische Wilhelms-Un & 139 & 124 & E. Schafer & 62 & 194 & 412 & 197 & 18 & 90 & 62 \\
\hline Universitat Politecnica de Catalunya & 8 & 260 & J.A. Planell & 207 & 57 & 1,873 & 60 & 28 & 43 & 150 \\
\hline Universität Regensburg & 354 & 84 & G. Schmalz & 212 & 54 & 2,124 & 52 & 28 & 43 & 150 \\
\hline Universität Stuttgart & 2 & 314 & M. Schanz & 32 & 229 & 198 & 232 & 8 & 213 & 35 \\
\hline Universitat Trier & 2 & 314 & R. Zougmore & 2 & 271 & 0 & 273 & 0 & 272 & 13 \\
\hline Universität Tübingen & 194 & 111 & R. Weiger & 67 & 189 & 444 & 193 & 10 & 188 & 150 \\
\hline Universitat Wien (University of Vienna) & 262 & 98 & G. Watzek & 14 & 258 & 88 & 246 & 7 & 222 & 28 \\
\hline Universitat $\mathrm{Zu}$ Koln & 223 & 102 & W.J. Finger & 88 & 159 & 983 & 127 & 16 & 113 & 71 \\
\hline Université Catholique de Louvain & 116 & 132 & G. Leloup & 21 & 247 & 344 & 206 & 11 & 173 & 37 \\
\hline Universite de Liege & 45 & 170 & P. Maquet & 151 & 92 & 3,136 & 27 & 34 & 23 & 150 \\
\hline Université de Montréal & 222 & 103 & C. Bedos & 20 & 251 & 40 & 262 & 4 & 244 & 24 \\
\hline Université de Nice Sophia Antipolis & 57 & 162 & M.M. Muller-Bolla & 23 & 245 & 173 & 236 & 8 & 213 & 60 \\
\hline Universite Laval & 177 & 114 & D. Grenier & 152 & 91 & 1,502 & 75 & 20 & 81 & 148 \\
\hline Universite Libre de Bruxelles & 70 & 149 & C. Malevez & 34 & 224 & 411 & 198 & 12 & 164 & 98 \\
\hline Université Paris Sorbonne & 32 & 188 & J.P. Ouhayoun & 55 & 208 & 645 & 164 & 8 & 213 & 103 \\
\hline Universite Paris-Sud 11 & 16 & 224 & & 0 & 274 & 0 & 273 & 0 & 272 & 0 \\
\hline Université Pierre et Marie Curie & 53 & 164 & A. Berdal & 92 & 155 & 633 & 166 & 17 & 104 & 150 \\
\hline Universiti Malaya (University of Malaya) & 204 & 106 & C.H. Siar & 98 & 147 & 478 & 183 & 11 & 173 & 135 \\
\hline University College Cork & 61 & 157 & C.D. Lynch & 50 & 214 & 215 & 229 & 9 & 200 & 80 \\
\hline University College Dublin & 7 & 267 & & 0 & 274 & 0 & 273 & 0 & 272 & 0 \\
\hline University College London & 856 & 38 & A. Sheiham & 270 & 35 & 2,240 & 50 & 30 & 39 & 150 \\
\hline University do Porto & 25 & 198 & H. Clausen & 190 & 67 & 3,662 & 23 & 37 & 16 & 150 \\
\hline University of Aberdeen & 81 & 144 & N.B. Pitts & 190 & 67 & 1,496 & 76 & 24 & 52 & 150 \\
\hline University of Adelaide & 807 & 41 & A.N. Goss & 185 & 73 & 984 & 126 & 16 & 113 & 150 \\
\hline University of Alabama & 1,146 & 18 & D.H. Retief & 179 & 79 & 1,073 & 116 & 3 & 256 & 150 \\
\hline University of Alberta & 365 & 81 & R.V. Rajotte & 316 & 18 & 4,964 & 14 & 33 & 29 & 150 \\
\hline University of Amsterdam & 346 & 88 & J. Hoogstraten & 101 & 142 & 671 & 161 & 17 & 104 & 96 \\
\hline University of Antwerp & 46 & 168 & M. Braem & 66 & 191 & 1,694 & 64 & 9 & 200 & 75 \\
\hline University of Arizona & 32 & 188 & & 0 & 274 & 0 & 273 & 0 & 272 & 0 \\
\hline University of Athens & 672 & 48 & G. Eliades & 99 & 144 & 934 & 136 & 14 & 144 & 100 \\
\hline
\end{tabular}




\begin{tabular}{|c|c|c|c|c|c|c|c|c|c|c|}
\hline University of Auckland & 22 & 204 & M. Horrock & 69 & 188 & 272 & 219 & 13 & 157 & 98 \\
\hline University of Barcelona & 235 & 99 & C. Gay-Escoda & 138 & 104 & 582 & 172 & 11 & 173 & 150 \\
\hline University of Basel & 277 & 97 & N.U. Zitzmann & 61 & 198 & 735 & 154 & 16 & 113 & 82 \\
\hline University of Bath & 12 & 240 & L.D. Hurst & 198 & 61 & 4,181 & 16 & 43 & 10 & 150 \\
\hline University of Bergen & 501 & 62 & O. Haugejorden & 86 & 167 & 524 & 176 & 13 & 157 & 49 \\
\hline University of Bern & 520 & 60 & N.P. Lang & 363 & 10 & 4,837 & 15 & 38 & 14 & 150 \\
\hline University of Birmingham & 875 & 37 & A.D. Walmsley & 159 & 87 & 650 & 163 & 14 & 144 & 150 \\
\hline University of Bristol & 915 & 35 & M. Addy & 342 & 12 & 2,253 & 48 & 27 & 48 & 150 \\
\hline University of British Columbia & 505 & 61 & M.I. MacEntee & 111 & 128 & 811 & 147 & 15 & 128 & 123 \\
\hline University of Calgary & 28 & 194 & A.K.C. Leung & 409 & 7 & 1,797 & 61 & 15 & 128 & 150 \\
\hline University of California, Berkley & 29 & 193 & R.O. Ritchie & 308 & 20 & 3,963 & 18 & 37 & 16 & 150 \\
\hline University of California, Davis & 24 & 200 & C. Selmi & 111 & 128 & 814 & 145 & 22 & 62 & 150 \\
\hline University of California, Irvine & 20 & 209 & L.G. Glance & 55 & 208 & 473 & 185 & 15 & 128 & 57 \\
\hline University of California, Los Angeles & 1,521 & 7 & A.A. Caputo & 190 & 67 & 1,316 & 92 & 13 & 157 & 150 \\
\hline University of California, Riverside & 3 & 301 & & 0 & 274 & 0 & 273 & 0 & 272 & 0 \\
\hline University of California, San Diego & 23 & 203 & R. Yawn & 29 & 236 & 236 & 226 & 7 & 222 & 58 \\
\hline University of California, San Francisco & 1,098 & 19 & D. Fried & 144 & 98 & 782 & 148 & 23 & 58 & 129 \\
\hline University of California, Santa Barbara & 6 & 273 & M.O. Culjat & 33 & 226 & 55 & 258 & 5 & 238 & 60 \\
\hline University of California, Santa Cruz & 2 & 314 & T.G. Bromage & 58 & 204 & 498 & 179 & 7 & 222 & 82 \\
\hline University of Cambridge & 35 & 182 & & 0 & 274 & 0 & 273 & 0 & 272 & 0 \\
\hline University of Canterbury & 4 & 291 & A. Udalski & 209 & 56 & 2,533 & 40 & 40 & 13 & 150 \\
\hline University of Cape Town & 19 & 211 & L.P. Adams & 31 & 233 & 118 & 242 & 3 & 256 & 48 \\
\hline University of Central Florida & 11 & 247 & R. Ruiz & 25 & 242 & 71 & 251 & 4 & 244 & 51 \\
\hline University of Chicago & 76 & 146 & J.A. Toijanic & 33 & 226 & 196 & 233 & 7 & 222 & 68 \\
\hline University of Cincinnati & 70 & 149 & R.D. Marciani & 59 & 202 & 337 & 209 & 9 & 200 & 72 \\
\hline University of Colorado at Boulder & 35 & 182 & C.N. Bowman & 252 & 43 & 2,740 & 33 & 38 & 14 & 150 \\
\hline University of Connecticut & 58 & 160 & C.H. Pameijer & 13 & 260 & 72 & 250 & 5 & 238 & 39 \\
\hline University of Copenhagen & 751 & 43 & E. Asmussen & 195 & 64 & 2,589 & 37 & 21 & 71 & 70 \\
\hline University of Delaware & 5 & 281 & J.R. Freed & 42 & 218 & 111 & 244 & 6 & 235 & 61 \\
\hline University of Dundee & 443 & 70 & N.B. Pitts & 189 & 70 & 1,610 & 70 & 24 & 52 & 150 \\
\hline University of Edinburgh & 117 & 130 & A. Santini & 37 & 223 & 143 & 240 & 7 & 222 & 34 \\
\hline University of Florida & 715 & 44 & K.J. Anusaavice & 149 & 93 & 1,521 & 73 & 18 & 90 & 150 \\
\hline University of Geneva & 352 & 87 & I. Krejci & 153 & 89 & 1,284 & 95 & 16 & 113 & 147 \\
\hline University of Georgia & 13 & 236 & J. Potempa & 199 & 60 & 2,882 & 32 & 32 & 32 & 150 \\
\hline University of Ghent & 166 & 118 & R.J.G. De Moor & 87 & 164 & 493 & 181 & 13 & 157 & 89 \\
\hline University of Glasgow & 948 & 31 & D.F. Kinane & 166 & 84 & 2,247 & 49 & 31 & 36 & 150 \\
\hline
\end{tabular}




\begin{tabular}{|c|c|c|c|c|c|c|c|c|c|c|}
\hline University of Gothenburg & 414 & 73 & T. Berglundh & 128 & 111 & 2,017 & 56 & 31 & 36 & 106 \\
\hline University of Groningen & 838 & 40 & G.M.A. Raghoebar & 185 & 73 & 1,438 & 80 & 24 & 52 & 150 \\
\hline University of Helsinki & 1,001 & 26 & J.H. Meurman & 224 & 48 & 2,167 & 51 & 21 & 71 & 150 \\
\hline University of Hong Kong & 1,036 & 22 & L.P. Samaranayake & 342 & 12 & 2,254 & 47 & 22 & 62 & 150 \\
\hline University of Houston & 5 & 281 & M.C. Advincula & 184 & 75 & 2,090 & 54 & 32 & 32 & 150 \\
\hline University of Illinois & 119 & 129 & D.P. Kuehun & 56 & 207 & 313 & 214 & 9 & 200 & 58 \\
\hline University of Illinois, Chicago & 957 & 28 & J.B. Epstein & 274 & 33 & 3,250 & 25 & 31 & 36 & 150 \\
\hline University of Indonesia & 14 & 230 & C. Lekkas & 21 & 247 & 68 & 253 & 3 & 256 & 18 \\
\hline University of Iowa & 1,365 & 9 & S.M. Levy & 140 & 102 & 1,026 & 122 & 22 & 62 & 134 \\
\hline University of Kansas & 44 & 171 & P. Spencer & 99 & 144 & 1,036 & 118 & 19 & 84 & 106 \\
\hline University of Kentucky & 669 & 50 & C.S. Miller & 92 & 155 & 927 & 137 & 18 & 90 & 150 \\
\hline University of Lausanne & 6 & 273 & C. Madrid & 20 & 251 & 29 & 265 & 3 & 256 & 31 \\
\hline University of Leeds & 218 & 104 & C. Robinson & 341 & 14 & 3,178 & 26 & 35 & 21 & 150 \\
\hline University of Leicester & 18 & 217 & & 0 & 274 & 0 & 273 & 0 & 272 & 0 \\
\hline University of Liverpool & 395 & 78 & S.M. Higham & 88 & 159 & 605 & 170 & 17 & 104 & 73 \\
\hline University of Ljubljana & 112 & 134 & U. Skaleric & 87 & 164 & 492 & 182 & 11 & 173 & 141 \\
\hline University of London (Kings College of London) & 3,508 & 1 & A. Sheiham & 263 & 36 & 2,440 & 44 & 32 & 32 & 150 \\
\hline University of Manchester & 1,332 & 10 & H.V. Worthington & 276 & 31 & 2,104 & 53 & 21 & 71 & 150 \\
\hline University of Manitoba & 464 & 67 & C.M. Dawes & 129 & 109 & 1,185 & 109 & 10 & 188 & 89 \\
\hline University of Maryland & 1,193 & 15 & R.L. Wynn & 146 & 95 & 269 & 221 & 7 & 222 & 73 \\
\hline University of Maryland Baltimore County & 1,199 & 14 & R.L. Wynn & 146 & 95 & 271 & 220 & 7 & 222 & 73 \\
\hline University of Massachusetts & 3 & 301 & L.R. Godfrey & 53 & 212 & 461 & 189 & 15 & 128 & 113 \\
\hline University of Melbourne & 847 & 39 & M.F. Burrow & 142 & 99 & 1,594 & 72 & 23 & 58 & 150 \\
\hline University of Miami & 65 & 155 & A.K. Garg & 78 & 179 & 433 & 195 & 14 & 144 & 71 \\
\hline University of Michigan & 1,807 & 5 & H.L. Wang & 140 & 102 & 1,310 & 93 & 19 & 84 & 150 \\
\hline University of Minnesota & 949 & 30 & N.L. Rhodus & 106 & 137 & 714 & 156 & 15 & 128 & 150 \\
\hline University of Missouri & 521 & 59 & J.D. Eick & 160 & 86 & 1,620 & 69 & 15 & 128 & 150 \\
\hline University of Nebraska & 175 & 115 & R.A. Reinhardt & 94 & 152 & 1,203 & 106 & 13 & 157 & 150 \\
\hline University of New Hampshire & 2 & 314 & R.B. Alley & 184 & 75 & 5,198 & 12 & 34 & 23 & 150 \\
\hline University of New Mexico & 6 & 273 & R.L. Williams & 107 & 134 & 1,380 & 86 & 14 & 144 & 150 \\
\hline University of New South Wales & 16 & 224 & H. Zreiqat & 58 & 204 & 611 & 168 & 18 & 90 & 148 \\
\hline University of North Carolina, Chapel Hill & 1,888 & 4 & E.J. Swift & 231 & 46 & 2,416 & 45 & 22 & 62 & 150 \\
\hline University of North Texas & 2 & 314 & A. Vekua & 19 & 253 & 378 & 202 & 11 & 173 & 42 \\
\hline University of Notre Dame & 0 & 336 & & 0 & 274 & 0 & 273 & 0 & 272 & 0 \\
\hline University of Nottingham & 0 & 336 & & 0 & 274 & 0 & 273 & 0 & 272 & 0 \\
\hline University of Oklahoma & 234 & 101 & R.S. Nanda & 127 & 112 & 1,131 & 113 & 14 & 144 & 129 \\
\hline
\end{tabular}




\begin{tabular}{|c|c|c|c|c|c|c|c|c|c|c|}
\hline University of Oregon & 5 & 281 & A.M.S. Erbaugh & 1 & 273 & 9 & 269 & 1 & 268 & 1 \\
\hline University of Oslo & 677 & 47 & G. Rolla & 261 & 39 & 1,350 & 88 & 10 & 188 & 136 \\
\hline University of Otago & 578 & 53 & W.M. Thomson & 83 & 171 & 954 & 133 & 17 & 104 & 104 \\
\hline University of Ottawa & 18 & 217 & D.S.K. Park & 115 & 124 & 3,861 & 20 & 43 & 10 & 150 \\
\hline University of Oxford & 43 & 176 & & 0 & 274 & 0 & 273 & 0 & 272 & 0 \\
\hline University of Pennsylvania & 683 & 45 & T.P. Croll & 219 & 52 & 527 & 175 & 10 & 188 & 64 \\
\hline University of Pittsburgh & 465 & 66 & P.A. Moore & 212 & 54 & 3,819 & 22 & 34 & 23 & 150 \\
\hline University of Quebec & 90 & 141 & D. Grenier & 156 & 88 & 1,419 & 81 & 19 & 84 & 150 \\
\hline University of Queensland & 495 & 63 & G.J. Seymour & 276 & 31 & 2,643 & 35 & 25 & 50 & 150 \\
\hline University of Reading & 11 & 247 & & 0 & 274 & 0 & 273 & 0 & 272 & 0 \\
\hline University of Rochester & 925 & 34 & R.H. Tallents & 124 & 116 & 1,014 & 125 & 15 & 128 & 150 \\
\hline University of Saskatchewan & 155 & 121 & D.T. Lanigan & 32 & 229 & 294 & 215 & 2 & 264 & 150 \\
\hline University of Science and Technology of China & 1 & 328 & Y.F. Zheng & 183 & 77 & 1,649 & 66 & 37 & 16 & 150 \\
\hline University of Sheffield & 597 & 52 & R. van Noort & 111 & 128 & 1,247 & 101 & 14 & 144 & 150 \\
\hline University of South Carolina & 13 & 236 & & 0 & 274 & 0 & 273 & 0 & 272 & 0 \\
\hline University of South Florida & 14 & 230 & C. Claudio & 11 & 266 & 34 & 263 & 4 & 244 & 20 \\
\hline University of Southampton & 15 & 226 & A.R.S. Collins & 313 & 19 & 8,433 & 5 & 56 & 3 & 150 \\
\hline University of Southern California & 957 & 28 & J. Slots & 274 & 33 & 3,846 & 21 & 29 & 40 & 150 \\
\hline University of St Andrews & 15 & 226 & G.M. Humphris & 105 & 139 & 1,275 & 98 & 22 & 62 & 150 \\
\hline University of Surrey & 6 & 273 & W. Xu & 12 & 265 & 52 & 260 & 5 & 238 & 15 \\
\hline University of Sussex & 2 & 314 & & 0 & 274 & 0 & 273 & 0 & 272 & 0 \\
\hline University of Sydney & 555 & 54 & M.V. Swain & 295 & 23 & 2,969 & 29 & 28 & 43 & 150 \\
\hline University of Technology, Sydney & 9 & 252 & R. Anderson & 4 & 270 & 14 & 267 & 4 & 244 & 2 \\
\hline University of Tennessee Knoxville & 44 & 171 & D. Xie & 129 & 109 & 1,479 & 77 & 18 & 90 & 150 \\
\hline University of Texas at Austin & 14 & 230 & & 0 & 274 & 0 & 273 & 0 & 272 & 0 \\
\hline University of Tokyo & 40 & 177 & H. Kiyono & 384 & 9 & 6,374 & 8 & 48 & 7 & 150 \\
\hline University of Toronto & 1,502 & 8 & D. Locker & 220 & 51 & 2,951 & 30 & 34 & 23 & 150 \\
\hline University of Tsukuba & 17 & 221 & H. Yoshida & 835 & 2 & 7,660 & 7 & 33 & 29 & 150 \\
\hline University of Twente & 9 & 252 & C.A. Van Blitterswijk & 288 & 27 & 3,950 & 19 & 41 & 12 & 150 \\
\hline University of Utah & 100 & 137 & & 0 & 274 & 0 & 273 & 0 & 272 & 0 \\
\hline University of Vermont & 24 & 200 & P.M. Fives-Taylor & 75 & 180 & 1,035 & 119 & 18 & 90 & 85 \\
\hline University of Victoria & 2 & 314 & & 0 & 274 & 0 & 273 & 0 & 272 & 0 \\
\hline University of Virginia & 34 & 184 & & 0 & 274 & 0 & 273 & 0 & 272 & 0 \\
\hline University of Warwick & 9 & 252 & D. Wolke & 14 & 258 & 78 & 248 & 4 & 244 & 49 \\
\hline University of Washington & 2,008 & 3 & P. Milgrom & 206 & 59 & 1,301 & 94 & 17 & 104 & 150 \\
\hline University of Waterloo & 0 & 336 & & 0 & 274 & 0 & 273 & 0 & 272 & 0 \\
\hline
\end{tabular}




\begin{tabular}{|c|c|c|c|c|c|c|c|c|c|c|}
\hline University of Western Australia & 183 & 113 & P.V. Abbott & 62 & 194 & 350 & 204 & 10 & 188 & 61 \\
\hline University of Western Ontario & 407 & 75 & T.D. Daley & 88 & 159 & 747 & 153 & 8 & 213 & 99 \\
\hline University of Wisconsin & 44 & 171 & & 0 & 274 & 0 & 273 & 0 & 272 & 0 \\
\hline University of Wollongong & 1 & 328 & & 0 & 274 & 0 & 273 & 0 & 272 & 0 \\
\hline \begin{tabular}{|l|} 
University of York \\
\end{tabular} & 8 & 260 & F. Song & 99 & 144 & 2,058 & 55 & 21 & 71 & 150 \\
\hline University of Zurich & 495 & 63 & F. Lutz & 227 & 47 & 1,399 & 82 & 15 & 128 & 150 \\
\hline Univesitas Gadjah Mada & 17 & 221 & W. Sosroseno & 50 & 214 & 217 & 228 & 8 & 213 & 63 \\
\hline Uppsala University & 60 & 158 & J.M. Hirsch & 74 & 182 & 1,279 & 96 & 15 & 128 & 150 \\
\hline Utah State & 2 & 314 & & 0 & 274 & 0 & 273 & 0 & 272 & 0 \\
\hline Utrecht University & 357 & 83 & F. Boseman & 62 & 194 & 877 & 139 & 11 & 173 & 47 \\
\hline Vanderbilt University & 31 & 191 & G.A. Weinberg & 89 & 157 & 1,341 & 90 & 16 & 113 & 150 \\
\hline Victoria University of Wellington & 12 & 240 & T.W. Cutress & 106 & 137 & 888 & 138 & 8 & 213 & 89 \\
\hline Vienna University of Technology & 7 & 267 & E. Wintner & 98 & 147 & 494 & 180 & 11 & 173 & 115 \\
\hline Virginia Polytechnic Institute & 19 & 211 & I.J. Good & 87 & 164 & 318 & 212 & 5 & 238 & 30 \\
\hline Vrije Universiteit, Brussels & 2 & 314 & |Y. Vandenplas & 293 & 24 & 2,470 & 41 & 21 & 71 & 150 \\
\hline VU University Amsterdam & 401 & 76 & D.B. Tuinzing & 105 & 139 & 586 & 171 & 12 & 164 & 89 \\
\hline Wageningen University & 0 & 336 & & 0 & 274 & 0 & 273 & 0 & 272 & 0 \\
\hline Wake Forest University & 58 & 160 & R.L. Webber & 119 & 123 & 751 & 152 & 13 & 157 & 150 \\
\hline Waseda University & 6 & 273 & & 0 & 274 & 0 & 273 & 0 & 272 & 0 \\
\hline Washington State University & 5 & 281 & & 0 & 274 & 0 & 273 & 0 & 272 & 0 \\
\hline Washington University in St. Louis & 98 & 139 & C.F. Hildebolt & 141 & 101 & 1,605 & 71 & 21 & 71 & 150 \\
\hline Wayne State University & 0 & 336 & & 0 & 274 & 0 & 273 & 0 & 272 & 0 \\
\hline West Virginia University & 142 & 122 & P. Ngan & 83 & 171 & 705 & 159 & 11 & 173 & 150 \\
\hline Yale University & 19 & 211 & Y.C. Cheng & 519 & 3 & 10,915 & 2 & 37 & 16 & 150 \\
\hline Yonsei University & 328 & 91 & K.N. Kim & 112 & 126 & 512 & 178 & 13 & 157 & 150 \\
\hline York University & 3 & 301 & J. Lexchin & 123 & 119 & 1,382 & 85 & 15 & 128 & 105 \\
\hline Zhejiang University & 32 & 188 & M. Hannig & 110 & 132 & 568 & 173 & 17 & 104 & 150 \\
\hline
\end{tabular}




\begin{tabular}{|c|c|c|c|c|c|c|c|c|c|c|}
\hline Undefined Data & $\begin{array}{l}\text { Department } \\
\text { Publications }\end{array}$ & Rank & Most Prolific Author & Published & Rank & Cited & Rank & $\begin{array}{c}\text { H- } \\
\text { Index }\end{array}$ & Rank & $\begin{array}{c}\text { \# of } \\
\text { Coauthors }\end{array}$ \\
\hline Aalto University & 49 & 220 & & 0 & 310 & 0 & 304 & 0 & 256 & 0 \\
\hline Aarhus University & 304 & 95 & J. Frokiaer & 195 & 70 & 2,278 & 62 & 33 & 31 & 150 \\
\hline Arizonia State University & 5 & 321 & K. Baldwin & 5 & 295 & 79 & 258 & 0 & 256 & 9 \\
\hline Ateneo de Manila University & 0 & 346 & & 0 & 310 & 0 & 304 & 0 & 256 & 0 \\
\hline Auburn University & 87 & 187 & M.C. Jordan & 1 & 305 & 0 & 304 & 0 & 256 & 0 \\
\hline Australian National University & 422 & 68 & T.R. Ophel & 118 & 127 & 383 & 185 & 8 & 168 & 150 \\
\hline Boston College & 115 & 162 & J.A. Vessey & 77 & 171 & 258 & 210 & 7 & 178 & 77 \\
\hline Boston University & 436 & 62 & T.E. Van Dyke & 232 & 52 & 3,965 & 39 & 29 & 42 & 150 \\
\hline Brandeis University & 139 & 151 & & 0 & 310 & 0 & 304 & 0 & 256 & 0 \\
\hline Brigham Young University & 1 & 340 & W.W. Winder & 147 & 98 & 2,413 & 59 & 25 & 52 & 150 \\
\hline Brown University & 648 & 38 & J.S. Buechner & 113 & 134 & 213 & 220 & 3 & 229 & 87 \\
\hline California Institute of Technology (Calt... & 444 & 61 & W.T. Huntress & 96 & 152 & 569 & 160 & 3 & 229 & 138 \\
\hline Cardiff University & 393 & 72 & & 0 & 310 & 0 & 304 & 0 & 256 & 0 \\
\hline Carnegie Mellon University & 381 & 76 & A.H. Meltzer & 63 & 194 & 89 & 256 & 4 & 218 & 11 \\
\hline Case Western Reserve University & 550 & 44 & & 0 & 310 & 0 & 304 & 0 & 256 & 0 \\
\hline Chalmers University of Technology & 115 & 162 & G. Skarnemark & 90 & 158 & 318 & 195 & 10 & 150 & 150 \\
\hline Charles University & 11 & 299 & E.E. St. Lezin & 26 & 257 & 868 & 126 & 12 & 133 & 88 \\
\hline Chinese University of Hong Kong & 16 & 280 & F.L. Chan & 91 & 156 & 1,170 & 105 & 19 & 79 & 150 \\
\hline Chulalongkorn University & 48 & 221 & V. Wiwanitkit & 645 & 5 & 733 & 137 & 9 & 158 & 120 \\
\hline City University of Hong Kong & 7 & 311 & & 0 & 310 & 0 & 304 & 0 & 256 & 0 \\
\hline City University of New York & 7 & 311 & M. Fitting & 43 & 232 & 353 & 188 & 5 & 204 & 2 \\
\hline Colorado State University & 16 & 280 & J.T. Belisle & 103 & 145 & 3,710 & 40 & 34 & 28 & 150 \\
\hline Columbia University & 1,241 & 7 & J.J. Cimino & 196 & 69 & 1,377 & 93 & 19 & 79 & 150 \\
\hline Cornell University & 770 & 25 & H.A. Scheraga & 1,035 & 1 & 5,503 & 26 & 44 & 11 & 150 \\
\hline Curtin University of Technology & 1 & 340 & D. Wynaden & 31 & 248 & 339 & 191 & 8 & 168 & 57 \\
\hline Dalhousie University & 304 & 95 & F. Batlis & 66 & 185 & 283 & 204 & 10 & 150 & 48 \\
\hline Dartmouth College & 296 & 97 & P.B. Bataleden & 103 & 145 & 11,211 & 8 & 18 & 85 & 150 \\
\hline Delft University of Technology & 458 & 59 & S. Emid & 46 & 227 & 145 & 240 & 0 & 256 & 31 \\
\hline Drexel University & 225 & 117 & L.L. Pytlewski & 132 & 112 & 312 & 196 & 0 & 256 & 51 \\
\hline Duke University & 681 & 32 & P. Smith & 146 & 99 & 2,638 & 52 & 25 & 52 & 150 \\
\hline Durham University & 190 & 129 & T.C. Waddington & 160 & 89 & 203 & 225 & 0 & 256 & 98 \\
\hline Ecole Normale Supérieure de Lyon & 9 & 305 & J.T. Quintero & 3 & 300 & 0 & 304 & 0 & 256 & $\overline{0}$ \\
\hline École Normale Supérieure, Paris & 111 & 166 & G.R. Bishop & 24 & 263 & 9 & 291 & 0 & 256 & 14 \\
\hline École Polytechnique & 94 & 182 & L. Behr & 33 & 244 & 857 & 128 & 2 & 237 & 150 \\
\hline
\end{tabular}




\begin{tabular}{|c|c|c|c|c|c|c|c|c|c|c|}
\hline Ecole Polytechnique Fédérale de Lausanne & 79 & 195 & F. Levy & 219 & 58 & 2,423 & 58 & 14 & 113 & 150 \\
\hline Eindhoven University of Technology & 175 & 137 & N.G. De Bruijn & 47 & 222 & 287 & 202 & 0 & 256 & 3 \\
\hline Emory University & 506 & 53 & J. Augustine & 106 & 138 & 512 & 168 & 9 & 158 & 139 \\
\hline Erasmus University Rotterdam & 184 & 133 & A.M. Van Ginnekem & 61 & 198 & 241 & 214 & 8 & 168 & 71 \\
\hline ETH Zurich (Swiss Federal Institute of Technology) & 555 & 43 & R.R. Ernst & 73 & 173 & 4,557 & 35 & 0 & 256 & 75 \\
\hline Florida International University & 37 & 235 & & 0 & 310 & 0 & 304 & 0 & 256 & 0 \\
\hline Florida State University & 5 & 321 & D.L.D. Casper & 89 & 161 & 1,225 & 103 & 9 & 158 & 150 \\
\hline Freie Universität Berlin & 218 & 120 & K. Mobius & 151 & 96 & 1,156 & 107 & 19 & 79 & 150 \\
\hline Friedrich Alexander Universität Erlangen Nürnberg & 230 & 115 & & 0 & 310 & 0 & 304 & 0 & 256 & 0 \\
\hline Fudan University & 907 & 19 & Q.W. Jiang & 104 & 144 & 389 & 183 & 12 & 133 & 150 \\
\hline Georg August Universität Göttingen & 277 & 106 & A. Michler & 10 & 289 & 120 & 249 & 0 & 256 & 7 \\
\hline George Mason University & 4 & 328 & D.M. Berman & 45 & 229 & 3,607 & 41 & 18 & 85 & 150 \\
\hline George Washington University & 256 & 110 & S. Rosenbaum & 118 & 127 & 613 & 153 & 12 & 133 & 150 \\
\hline Georgetown University & 327 & 90 & L.O. Gostin & 266 & 38 & 2,078 & 67 & 23 & 61 & 150 \\
\hline Georgia Institute of Technology & 126 & 157 & E.W. Thomas & 55 & 214 & 82 & 257 & 0 & 256 & 42 \\
\hline Georgia State University & 52 & 214 & C.G. Grindel & 56 & 210 & 222 & 219 & 8 & 168 & 78 \\
\hline Goteborg University & 27 & 250 & M. Kubista & 98 & 149 & 2,231 & 63 & 25 & 52 & 147 \\
\hline Harvard University & 550 & 44 & E.G. Rochow & 97 & 151 & 588 & 156 & 0 & 256 & 62 \\
\hline Hebrew University of Jerusalem & 659 & 35 & A.S. Kertes & 72 & 175 & 432 & 180 & 0 & 256 & 58 \\
\hline Heidelberg Universität & 369 & 77 & R. Haux & 139 & 106 & 548 & 165 & 14 & 113 & 150 \\
\hline Hokkaido University & 762 & 27 & M. Asaka & 510 & 10 & 5,089 & 31 & 35 & 25 & 150 \\
\hline Hong Kong Polytechnic University & 52 & 214 & K.C. Lam & 30 & 252 & 183 & 235 & 5 & 204 & 51 \\
\hline Hong Kong University of Science \& Techno... & 12 & 294 & P. Shi & 113 & 134 & 193 & 231 & 8 & 168 & 80 \\
\hline Humboldt-Universität zu Berlin & 230 & 115 & & 0 & 310 & 0 & 304 & 0 & 256 & 0 \\
\hline Imperial College London & 658 & 36 & & 0 & 310 & 0 & 304 & 0 & 256 & 0 \\
\hline Indian Institute of Technology Bombay (I... & 43 & 227 & R.N. Mukherjee & 71 & 176 & 294 & 200 & 6 & 189 & 60 \\
\hline Indian Institute of Technology Delhi (II... & 105 & 171 & H.P. Garg & 187 & 75 & 467 & 174 & 6 & 189 & 129 \\
\hline Indian Institute of Technology Kanpur (I... & 137 & 153 & S.K. Dogra & 105 & 143 & 445 & 178 & 14 & 113 & 62 \\
\hline Indiana University Bloomington & 504 & 54 & E.S. Duke & 69 & 180 & 580 & 158 & 7 & 178 & 18 \\
\hline Indiana University Indianapolis & 331 & 88 & A.G. Christen & 132 & 112 & 691 & 143 & 6 & 189 & 111 \\
\hline Iowa State University & 24 & 257 & G.T. Leavens & 48 & 221 & 471 & 173 & 11 & 142 & 63 \\
\hline Johns Hopkins University & 1,145 & 9 & S.H. Gottlieb & 32 & 247 & 265 & 209 & 6 & 189 & 44 \\
\hline Kansas State University & 3 & 331 & D.G. Anders & 3 & 300 & 22 & 282 & 0 & 256 & 3 \\
\hline Katholieke Universiteit Leuven & 402 & 70 & G. Willems & 84 & 165 & 882 & 123 & 14 & 113 & 131 \\
\hline Keio University & 602 & 41 & M. Kitajima & 700 & 3 & 1,016 & 116 & 34 & 28 & 150 \\
\hline
\end{tabular}




\begin{tabular}{|c|c|c|c|c|c|c|c|c|c|c|}
\hline King Fahd University of Petroleum \& Minerals & 37 & 235 & F. Abu-Jarad & 56 & 210 & 167 & 238 & 7 & 178 & 53 \\
\hline King Saud University & 115 & 162 & K. Almas & 57 & 207 & 204 & 224 & 9 & 158 & 79 \\
\hline Kobe University & 367 & 78 & M. Okada & 31 & 248 & 66 & 264 & 4 & 218 & 53 \\
\hline Korea Advanced Institute of Science \& Technology & 63 & 207 & S.C. Shim & 233 & 51 & 1,412 & 91 & 23 & 61 & 150 \\
\hline Korea University & 46 & 224 & Y.J. Park & 57 & 207 & 515 & 167 & 12 & 133 & 150 \\
\hline Kyoto University & 1,634 & 3 & K. Nakao & 507 & 11 & 37,338 & 1 & 63 & 1 & 150 \\
\hline Kyushu University & 850 & 22 & S. Ohashi & 68 & 182 & 209 & 222 & 0 & 256 & 64 \\
\hline La Trobe University & 289 & 101 & R.J. MaGee & 130 & 116 & 420 & 181 & 0 & 256 & 85 \\
\hline Lancaster University & 1 & 340 & D.M. Coates & 47 & 222 & 662 & 148 & 14 & 113 & 91 \\
\hline Leiden University & 1,006 & 15 & N.J. Poulis & 146 & 99 & 137 & 241 & 0 & 256 & 109 \\
\hline Linkoping University & 122 & 158 & T. Timpka & 155 & 93 & 602 & 154 & 11 & 142 & 147 \\
\hline London School of Economics and Political Scie & 39 & 231 & & 0 & 310 & 0 & 304 & 0 & 256 & 0 \\
\hline Loughborough University & 116 & 161 & A.H. Norbury & 26 & 257 & 29 & 280 & 0 & 256 & 29 \\
\hline Louisiana State University & 37 & 235 & C. Bouchard & 621 & 6 & 23,796 & 2 & 47 & 9 & 150 \\
\hline Ludwig-Maximilians-Universität München & 382 & 75 & B. Wrackmeyer & 399 & 21 & 1,419 & 90 & 21 & 66 & 150 \\
\hline Lund University & 326 & 91 & S.G. Pierzynowski & 129 & 118 & 512 & 168 & 13 & 124 & 150 \\
\hline Maastricht University & 127 & 156 & A. Hasman & 217 & 59 & 959 & 117 & 14 & 113 & 150 \\
\hline Macquarie University & 50 & 218 & E.T. Linarce & 23 & 264 & 189 & 234 & 2 & 237 & 8 \\
\hline Mahidol University & 23 & 263 & G. Sastravaha & 2 & 303 & 20 & 285 & 2 & 237 & 5 \\
\hline Masaryk University & 23 & 263 & O. Navratil & 5 & 295 & 5 & 297 & 0 & 256 & 1 \\
\hline Massachusetts Institute of Technology & 1,062 & 13 & B.L. Averbach & 103 & 145 & 1,288 & 99 & 0 & 256 & 78 \\
\hline McGill University & 638 & 39 & S.G. Manson & 139 & 106 & 1,731 & 73 & 0 & 256 & 70 \\
\hline McMaster University & 524 & 51 & T.J. Kennett & 116 & 130 & 255 & 211 & 0 & 256 & 59 \\
\hline Michigan State University & 536 & 49 & A.I. Popov & 167 & 84 & 748 & 135 & 1 & 249 & 120 \\
\hline Michigan Technological University & 67 & 204 & & 0 & 310 & 0 & 304 & 0 & 256 & 0 \\
\hline Monash University & 548 & 46 & C. Hassed & 62 & 196 & 191 & 232 & 5 & 204 & 22 \\
\hline Montana State University & 81 & 192 & L.L. Jackson & 95 & 154 & 792 & 131 & 5 & 204 & 145 \\
\hline Moscow State University & 654 & 37 & V.A. Kabonov & 226 & 54 & 564 & 162 & 7 & 178 & 150 \\
\hline Nagoya University & 1,088 & 10 & S. Iwase & 182 & 79 & 1,138 & 110 & 17 & 94 & 150 \\
\hline Nanjing University & 94 & 182 & D.X. Zhu & 31 & 248 & 7 & 292 & 2 & 237 & 94 \\
\hline Nanyang Technological University & 37 & 235 & M.K. Sakharkaar & 52 & 216 & 202 & 228 & 9 & 158 & 74 \\
\hline National Taiwan University & 104 & 173 & I.M. Liu & 7 & 292 & 1 & 301 & 0 & 256 & 2 \\
\hline National Tsing Hua University & 72 & 203 & C.S. $\mathrm{Su}$ & 53 & 215 & 230 & 216 & 6 & 189 & 25 \\
\hline National University of Ireland, Galway & 27 & 250 & M. Dowling & 20 & 271 & 47 & 272 & 4 & 218 & 16 \\
\hline National University of Singapore & 170 & 139 & T.Y. Leong & 16 & 277 & 21 & 283 & 3 & 229 & 21 \\
\hline New Mexico State University & 66 & 205 & & 0 & 310 & 0 & 304 & 0 & 256 & 0 \\
\hline
\end{tabular}




\begin{tabular}{|c|c|c|c|c|c|c|c|c|c|c|}
\hline New York University & 679 & 33 & M. Glanzer & 50 & 217 & 703 & 142 & 6 & 189 & 34 \\
\hline Newcastle University & 264 & 108 & J.F. McCabe & 197 & 68 & 1,640 & 83 & 18 & 85 & 150 \\
\hline North Carolina State University & 243 & 114 & E. Hodgson & 235 & 50 & 1,696 & 78 & 20 & 75 & 150 \\
\hline Northeastern University & 110 & 168 & & 0 & 310 & 0 & 304 & 0 & 256 & 0 \\
\hline Northwestern University & 921 & 18 & B.J. Underwood & 127 & 119 & 713 & 140 & 0 & 256 & 64 \\
\hline Norwegian University of Science \& Technology & 88 & 186 & S. Liaan-Jensen & 164 & 86 & 803 & 130 & 11 & 142 & 150 \\
\hline Ohio State University & 706 & 29 & J.I. Haring & 123 & 124 & 38 & 276 & 0 & 256 & 7 \\
\hline Oklahoma State University & 115 & 162 & J.R. Sauer & 211 & 64 & 2,563 & 56 & 29 & 42 & 150 \\
\hline Open University UK & 89 & 184 & & 0 & 310 & 0 & 304 & 0 & 256 & $\overrightarrow{0}$ \\
\hline Oregon State University & 200 & 124 & R.W. Newburgh & 62 & 196 & 39 & 274 & 0 & 256 & 49 \\
\hline Osaka University & 1,414 & 4 & T. Ogihara & 537 & 9 & 11,681 & 7 & 53 & 5 & 150 \\
\hline Peking University & 1,821 & 2 & C. Cao & 59 & 203 & 213 & 220 & 6 & 189 & 96 \\
\hline Pennsylvania State University & 560 & 42 & J. Heicklen & 179 & 81 & 509 & 170 & 0 & 256 & 94 \\
\hline Pohang University of Science And Technology & 15 & 286 & S. Lee & 254 & 41 & 1,216 & 104 & 18 & 85 & 150 \\
\hline Portland State University & 21 & 268 & & 0 & 310 & 0 & 304 & 0 & 256 & 0 \\
\hline Princeton University & 402 & 70 & A.V. Tobolsky & 116 & 130 & 785 & 133 & 0 & 256 & 96 \\
\hline Purdue University & 511 & 52 & R.G. Cooks & 612 & 7 & 12,767 & 6 & 43 & 14 & 150 \\
\hline Queen's University & 272 & 107 & R.J.C. Brown & 59 & 203 & 118 & 250 & 4 & 218 & 7 \\
\hline Queen's University of Belfast & 191 & 128 & H.G. Heal & 35 & 236 & 38 & 276 & 0 & 256 & 28 \\
\hline Queensland University of Technology & 96 & 180 & H. Edwards & 66 & 185 & 385 & 184 & 12 & 133 & 93 \\
\hline Radboud University, Nijmegen & 536 & 49 & A.J. Plasschaett & 168 & 83 & 507 & 171 & 8 & 168 & 150 \\
\hline Rensselaer Polytechnic Institute & 152 & 145 & G.S. Ansell & 63 & 194 & 177 & 236 & 0 & 256 & 56 \\
\hline Rheinisch Westfalische Technische Hochschule Aach & 222 & 118 & V. Schumpelick & 174 & 82 & 1,357 & 94 & 20 & 75 & 150 \\
\hline Rheinische Friedrich Wilhelms Universitat Bonn & 279 & 105 & H.D. Beckey & 65 & 189 & 74 & 260 & 0 & 256 & 53 \\
\hline Rice University & 292 & 98 & J.L. Margrave & 421 & 19 & 4,735 & 33 & 23 & 61 & 150 \\
\hline Rochester Institute of Technology & 17 & 276 & G.A. Takacs & 31 & 248 & 108 & 253 & 4 & 218 & 58 \\
\hline Royal Institute of Technology, KTH & 186 & 132 & B.O. Jonssen & 14 & 280 & 113 & 251 & 0 & 256 & 12 \\
\hline Royal Melbourne Institute of Technology & 45 & 225 & M.J. Johnson & 50 & 217 & 93 & 255 & 6 & 189 & 19 \\
\hline Rutgers & 428 & 64 & L.L. Pytlewski & 132 & 112 & 310 & 197 & 0 & 256 & 52 \\
\hline Saint-Petersburg State University & 175 & 137 & V.N. Tsvetkov & 217 & 59 & 128 & 247 & 0 & 256 & 150 \\
\hline San Diego State University & 82 & 190 & & 0 & 310 & 0 & 304 & 0 & 256 & 0 \\
\hline Sapienza University of Rome & 0 & 346 & & 0 & 310 & 0 & 304 & 0 & 256 & 0 \\
\hline Sciences Po Paris & 1 & 340 & F. Haegel & 1 & 305 & 0 & 304 & 0 & 256 & 0 \\
\hline Seoul National University & 203 & 122 & Y.S. Vu & 125 & 122 & 736 & 136 & 17 & 94 & 150 \\
\hline Shanghai Jiao Tong University & 103 & 177 & T.G. Zhung & 125 & 122 & 134 & 243 & 5 & 204 & 150 \\
\hline Simon Fraser University & 104 & 173 & C.H.W. Jones & 50 & 217 & 224 & 218 & 3 & 229 & 45 \\
\hline
\end{tabular}




\begin{tabular}{|c|c|c|c|c|c|c|c|c|c|c|}
\hline Stanford University & 1,245 & 6 & M.A. Nusen & 212 & 63 & 1,926 & 71 & 21 & 66 & 150 \\
\hline State University of New York Buffalo & 410 & 69 & & 0 & 310 & 0 & 304 & 0 & 256 & 0 \\
\hline Stockholm University & 152 & 145 & J. Kowalewski & 131 & 115 & 653 & 150 & 17 & 94 & 129 \\
\hline Stony Brook University & 354 & 80 & H.B. Waldman & 391 & 22 & 341 & 189 & 9 & 158 & 37 \\
\hline Syracuse University & 16 & 280 & J M. Chen & 56 & 210 & 710 & 141 & 16 & 103 & 150 \\
\hline Tartu University (University of Tartu) & 29 & 247 & H. Kaarma & 20 & 271 & 54 & 270 & 3 & 229 & 25 \\
\hline Technical University of Denmark & 104 & 173 & L. Gerward & 157 & 92 & 1,114 & 112 & 18 & 85 & 150 \\
\hline Technion & 281 & 104 & A.A. Hirsch & 28 & 253 & 15 & 286 & 0 & 256 & 16 \\
\hline Technische Universität Berlin & 129 & 155 & H. Boersch & 56 & 210 & 121 & 248 & 0 & 256 & 56 \\
\hline Technische Universitat Chemnitz & 12 & 294 & M. Wobst & 3 & 300 & 1 & 301 & 0 & 256 & 1 \\
\hline Technische Universität Dresden & 95 & 181 & & 0 & 310 & 0 & 304 & 0 & 256 & 0 \\
\hline Technische Universität München & 429 & 63 & J.R. Siewert & 503 & 13 & 16,706 & 4 & 35 & 25 & 150 \\
\hline Tel Aviv University & 314 & 93 & G. Navon & 203 & 66 & 1,563 & 86 & 17 & 94 & 150 \\
\hline Texas A\&M University & 358 & 79 & A.E. Martell & 547 & 8 & 8,286 & 10 & 26 & 48 & 150 \\
\hline Texas Tech & 5 & 321 & L.H. Young & 22 & 268 & 671 & 146 & 9 & 158 & 59 \\
\hline Tohoku University & 944 & 17 & T. Kondo & 680 & 4 & 6,369 & 18 & 33 & 31 & 150 \\
\hline Tokyo Institute of Technology & 331 & 88 & M. Sekine & 360 & 25 & 2,786 & 51 & 21 & 66 & 150 \\
\hline Trinity College Dublin & 170 & 139 & S.R. Flint & 44 & 230 & 566 & 161 & 7 & 178 & 100 \\
\hline Tsinghua University & 84 & 188 & M.Y. Ding & 70 & 179 & 283 & 204 & 11 & 142 & 79 \\
\hline Tufts University & 335 & 85 & M.B. Papageogre & 47 & 222 & 147 & 239 & 6 & 189 & 65 \\
\hline Universidad Autonoma de Madrid & 75 & 199 & A.M. Munico & 143 & 102 & 203 & 225 & 0 & 256 & 133 \\
\hline Universidad de Chile & 100 & 179 & S. Bunel & 23 & 264 & 71 & 263 & 4 & 218 & 16 \\
\hline Universidad de Granada & 75 & 199 & A.M. Munico & 143 & 102 & 203 & 225 & 0 & 256 & 133 \\
\hline Universidad del País Vasco & 53 & 212 & & 0 & 310 & 0 & 304 & 0 & 256 & 0 \\
\hline Universidad Nacional Autónoma de México ... & 12 & 294 & I. Lopez Gonzales & 13 & 281 & 196 & 229 & 10 & 150 & 68 \\
\hline Universidad Politecnica de Madrid & 45 & 225 & A. Soler & 66 & 185 & 205 & 223 & 12 & 133 & 13 \\
\hline Universidade de São Paulo & 30 & 245 & W. Marques-Junior & 6 & 294 & 6 & 295 & 0 & 256 & 3 \\
\hline Universidade Estadual de Campinas & 15 & 286 & G. Hessel & 35 & 236 & 134 & 243 & 6 & 189 & 84 \\
\hline Università degli Studi di Firenze & 292 & 98 & & 0 & 310 & 0 & 304 & 0 & 256 & 0 \\
\hline Università degli Studi di Padova & 318 & 92 & & 0 & 310 & 0 & 304 & 0 & 256 & 0 \\
\hline Universita Di Bologna & 333 & 86 & F. Zanetti & 64 & 191 & 375 & 186 & 12 & 133 & 123 \\
\hline Universita di Pisa & 20 & 270 & M. Mosca & 64 & 191 & 1,724 & 74 & 19 & 79 & 150 \\
\hline Universitat Autonoma de Barcelona & 106 & 170 & F. Fernandez & 44 & 230 & 62 & 267 & 5 & 204 & 131 \\
\hline Universitat Bielefeld & 51 & 216 & U. Laaser & 90 & 158 & 1,025 & 115 & 7 & 178 & 150 \\
\hline Universität Bremen & 80 & 193 & & 0 & 310 & 0 & 304 & 0 & 256 & 0 \\
\hline Universitat d'Alacant & 34 & 241 & & 0 & 310 & 0 & 304 & 0 & 256 & 0 \\
\hline
\end{tabular}




\begin{tabular}{|c|c|c|c|c|c|c|c|c|c|c|}
\hline Universitat de València & 84 & 188 & & 0 & 310 & 0 & 304 & 0 & 256 & 0 \\
\hline Universität Frankfurt am Main & 333 & 86 & O. Werz & 89 & 161 & 864 & 127 & 21 & 66 & 150 \\
\hline Universität Freiburg & 292 & 98 & S. Schulz & 162 & 87 & 1,643 & 82 & 21 & 66 & 150 \\
\hline Universitat Hamburg & 14 & 289 & N. Miekle & 8 & 290 & 21 & 283 & 4 & 218 & 40 \\
\hline Universität Karlsruhe & 176 & 135 & & 0 & 310 & 0 & 304 & 0 & 256 & 0 \\
\hline Universitat Leipzig & 7 & 311 & S. Pritz-Hohmeier & 11 & 287 & 64 & 266 & 1 & 249 & 31 \\
\hline Universitat Munster (Westfälische Wilhelms-Un & 18 & 274 & P. Young & 106 & 138 & 5,864 & 22 & 37 & 20 & 150 \\
\hline Universitat Politecnica de Catalunya & 1 & 340 & A.S. Desyatnikov & 91 & 156 & 570 & 159 & 18 & 85 & 109 \\
\hline Universität Regensburg & 136 & 154 & & 0 & 310 & 0 & 304 & 0 & 256 & 0 \\
\hline Universität Stuttgart & 139 & 151 & A. Seeger & 282 & 35 & 1,441 & 89 & 12 & 133 & 150 \\
\hline Universitat Trier & 6 & 318 & S. Mecklenbrauker & 25 & 261 & 110 & 252 & 5 & 204 & 25 \\
\hline Universität Tübingen & 222 & 118 & G. Gaulitz & 206 & 65 & 2,859 & 50 & 29 & 42 & 150 \\
\hline Universitat Wien (University of Vienna) & 245 & 111 & N. Getoff & 194 & 72 & 945 & 118 & 14 & 113 & 148 \\
\hline Universitat Zu Koln & 245 & 111 & W. Kleinow & 33 & 244 & 62 & 267 & 2 & 237 & 28 \\
\hline Université Catholique de Louvain & 190 & 129 & R. Debuyst & 60 & 200 & 303 & 198 & 10 & 150 & 120 \\
\hline Universite de Liege & 764 & 26 & & 0 & 310 & 0 & 304 & 0 & 256 & 0 \\
\hline Université de Montréal & 306 & 94 & M. Barkati & 1 & 305 & 0 & 304 & 0 & 256 & 11 \\
\hline Université de Nice Sophia Antipolis & 34 & 241 & & 0 & 310 & 0 & 304 & 0 & 256 & 0 \\
\hline Universite Laval & 194 & 127 & R.J. Slobodrian & 126 & 121 & 66 & 264 & 2 & 237 & 102 \\
\hline Universite Libre de Bruxelles & 455 & 60 & C. Szpirer & 243 & 46 & 2,606 & 54 & 22 & 64 & 150 \\
\hline Université Paris Sorbonne & 24 & 257 & T. Lefebvre & 34 & 241 & 6 & 295 & 1 & 249 & 1 \\
\hline Universite Paris-Sud 11 & 424 & 67 & F. Tfibel & 42 & 233 & 247 & 213 & 7 & 178 & 88 \\
\hline Université Pierre et Marie Curie & 244 & 113 & D. Aslanian & 19 & 274 & 37 & 278 & 1 & 249 & 34 \\
\hline Universiti Malaya (University of Malaya) & 164 & 141 & L.M. Looi & 138 & 108 & 925 & 122 & 8 & 168 & 150 \\
\hline University College Cork & 57 & 209 & T.G Cotter & 183 & 78 & 6,386 & 17 & 36 & 23 & 150 \\
\hline University College Dublin & 78 & 197 & J.E. Allen & 71 & 176 & 659 & 149 & 13 & 124 & 130 \\
\hline University College London & 851 & 21 & C.P.D. Wheller-Johns & 80 & 168 & 1,136 & 111 & 20 & 75 & 150 \\
\hline University do Porto & 7 & 311 & A. Remppis & 96 & 152 & 1,793 & 72 & 21 & 66 & 150 \\
\hline University of Aberdeen & 289 & 101 & A.D. Dick & 150 & 97 & 1,334 & 96 & 25 & 52 & 150 \\
\hline University of Adelaide & 338 & 82 & C.A. Crowther & 195 & 70 & 2,005 & 69 & 20 & 75 & 150 \\
\hline University of Alabama & 427 & 65 & T. Simpson & 26 & 257 & 131 & 246 & 4 & 218 & 24 \\
\hline University of Alberta & 683 & 31 & P.V. Nguyen & 47 & 222 & 1,702 & 76 & 21 & 66 & 87 \\
\hline University of Amsterdam & 840 & 23 & N.J. Trappeniers & 165 & 85 & 488 & 172 & 0 & 256 & 76 \\
\hline University of Antwerp & 117 & 159 & P.T. Hoff & 13 & 281 & 191 & 232 & 10 & 150 & 33 \\
\hline University of Arizona & 389 & 73 & C. Hammerschlag & 60 & 200 & 3 & 298 & 1 & 249 & 9 \\
\hline University of Athens & 161 & 142 & J. Mantas & 67 & 184 & 268 & 208 & 5 & 204 & 88 \\
\hline
\end{tabular}




\begin{tabular}{|c|c|c|c|c|c|c|c|c|c|c|}
\hline University of Auckland & 338 & 82 & A. Lethaby & 82 & 167 & 676 & 145 & 14 & 113 & 110 \\
\hline University of Barcelona & 176 & 135 & L. Morales & 68 & 182 & 194 & 230 & 5 & 204 & 110 \\
\hline University of Basel & 284 & 103 & J.T. Lambrecht & 73 & 173 & 273 & 207 & 7 & 178 & 105 \\
\hline University of Bath & 5 & 321 & R.M. Tyrrell & 130 & 116 & 3,456 & 45 & 24 & 57 & 150 \\
\hline University of Bergen & 17 & 276 & K. Malterud & 145 & 101 & 1,226 & 102 & 16 & 103 & 108 \\
\hline University of Bern & 25 & 254 & T. Studer & 20 & 271 & 34 & 279 & 4 & 218 & 12 \\
\hline University of Birmingham & 1,078 & 11 & S.A. Durrani & 241 & 47 & 450 & 177 & 6 & 189 & 141 \\
\hline University of Bristol & 466 & 57 & J.R. Sandy & 137 & 110 & 937 & 119 & 19 & 79 & 150 \\
\hline University of British Columbia & 55 & 211 & M.E. Gleave & 229 & 53 & 4,406 & 36 & 44 & 11 & 150 \\
\hline University of Calgary & 30 & 245 & R. Wang & 19 & 274 & 274 & 206 & 13 & 124 & 52 \\
\hline University of California, Berkley & 39 & 231 & G.L. Firestone & 135 & 111 & 2,621 & 53 & 33 & 31 & 150 \\
\hline University of California, Davis & 50 & 218 & C.J. Miller & 279 & 36 & 6,967 & 14 & 52 & 6 & 150 \\
\hline University of California, Irvine & 38 & 233 & A.J. Tenner & 98 & 149 & 2,479 & 57 & 27 & 47 & 150 \\
\hline University of California, Los Angeles & 1,197 & 8 & J.V. Richardson & 33 & 244 & 42 & 273 & 4 & 218 & 5 \\
\hline University of California, Riverside & 142 & 150 & N.T. Keen & 115 & 132 & 3,145 & 48 & 17 & 94 & 150 \\
\hline University of California, San Diego & 66 & 205 & P.A. Insel & 383 & 24 & 5,772 & 23 & 41 & 16 & 150 \\
\hline University of California, San Francisco & 117 & 159 & J.R. Oksenberg & 184 & 77 & 4,645 & 34 & 37 & 20 & 150 \\
\hline University of California, Santa Barbara & 11 & 299 & S. Mysore & 11 & 287 & 7 & 292 & 2 & 237 & 14 \\
\hline University of California, Santa Cruz & 5 & 321 & J.L. Collier & 21 & 269 & 563 & 163 & 6 & 189 & 81 \\
\hline University of Cambridge & 42 & 228 & A. Compston & 236 & 48 & 3,589 & 43 & 33 & 31 & 150 \\
\hline University of Canterbury & 1 & 340 & I.D. Coope & 21 & 269 & 136 & 242 & 5 & 204 & 9 \\
\hline University of Cape Town & 9 & 305 & J.M. Wilmshurst & 41 & 234 & 286 & 203 & 9 & 158 & 116 \\
\hline University of Central Florida & 57 & 209 & & 0 & 310 & 0 & 304 & 0 & 256 & 0 \\
\hline University of Chicago & 76 & 198 & Y.X. Fu & 186 & 76 & 3,607 & 41 & 38 & 19 & 150 \\
\hline University of Cincinnati & 699 & 30 & E. Deutsch & 226 & 54 & 1,659 & 80 & 7 & 178 & 150 \\
\hline University of Colorado at Boulder & 22 & 266 & R.G. Ham & 60 & 200 & 1,043 & 114 & 0 & 256 & 72 \\
\hline University of Connecticut & 26 & 253 & S.E. Pfeiffer & 99 & 148 & 1,939 & 70 & 18 & 85 & 125 \\
\hline University of Copenhagen & 32 & 243 & Y. Ardo & 34 & 241 & 372 & 187 & 13 & 124 & 76 \\
\hline University of Delaware & 7 & 311 & R.D. Joerger & 35 & 236 & 729 & 139 & 8 & 168 & 60 \\
\hline University of Dundee & 199 & 125 & W. McGuire & 250 & 43 & 6,421 & 16 & 26 & 48 & 150 \\
\hline University of Edinburgh & 32 & 243 & E. Laurier & 26 & 257 & 236 & 215 & 11 & 142 & 29 \\
\hline University of Florida & 546 & 47 & R. Baughman & 88 & 163 & 168 & 237 & 5 & 204 & 115 \\
\hline University of Geneva & 25 & 254 & A. Pechere-Bertschi & 46 & 227 & 292 & 201 & 10 & 150 & 73 \\
\hline University of Georgia & 27 & 250 & C.L. Hofacre & 69 & 180 & 587 & 157 & 13 & 124 & 150 \\
\hline University of Ghent & 24 & 257 & F. Haesbrouck & 434 & 18 & 2,863 & 49 & 28 & 45 & 150 \\
\hline University of Glasgow & 542 & 48 & K.H. Lockey & 23 & 264 & 225 & 217 & 0 & 256 & 3 \\
\hline
\end{tabular}




\begin{tabular}{|c|c|c|c|c|c|c|c|c|c|c|}
\hline University of Gothenburg & 12 & 294 & H. Wijk & 18 & 276 & 57 & 269 & 4 & 218 & 26 \\
\hline University of Groningen & 24 & 257 & P. Muller & 12 & 284 & 73 & 262 & 5 & 204 & 23 \\
\hline University of Helsinki & 203 & 122 & E. Spring & 8 & 290 & 2 & 299 & 0 & 256 & 11 \\
\hline University of Hong Kong & 29 & 247 & Y.L. Kwong & 451 & 17 & 5,173 & 30 & 36 & 23 & 150 \\
\hline University of Houston & 4 & 328 & R. Bianchi & 79 & 169 & 1,238 & 101 & 17 & 94 & 150 \\
\hline University of Illinois & 878 & 20 & C.M. Wayman & 310 & 29 & 2,407 & 60 & 6 & 189 & 150 \\
\hline University of Illinois, Chicago & 425 & 66 & B.Z. Rappaport & 12 & 284 & 2 & 299 & 0 & 256 & 18 \\
\hline University of Indonesia & 79 & 195 & I. Alwi & 15 & 278 & 7 & 292 & 2 & 237 & 25 \\
\hline University of Iowa & 53 & 212 & R.G. Strauss & 222 & 57 & 1,722 & 75 & 15 & 108 & 150 \\
\hline University of Kansas & 17 & 276 & S.K. Dey & 324 & 28 & 6,348 & 19 & 52 & 6 & 150 \\
\hline University of Kentucky & 23 & 263 & C. Leroux & 35 & 236 & 461 & 175 & 13 & 124 & 100 \\
\hline University of Lausanne & 12 & 294 & F. Levi & 384 & 23 & 5,709 & 25 & 39 & 18 & 150 \\
\hline University of Leeds & 19 & 273 & C.P. Wild & 253 & 42 & 3,386 & 47 & 30 & 41 & 150 \\
\hline University of Leicester & 190 & 129 & & 0 & 310 & 0 & 304 & 0 & 256 & 0 \\
\hline University of Liverpool & 21 & 268 & E.W. Parry & 28 & 253 & 54 & 270 & 0 & 256 & 5 \\
\hline University of Ljubljana & 153 & 144 & J. Slivink & 15 & 278 & 13 & 289 & 0 & 256 & 16 \\
\hline University of London (Kings College of London) & 2,768 & 1 & A. While & 236 & 48 & 933 & 120 & 15 & 108 & 79 \\
\hline University of Manchester & 1,037 & 14 & H.V. Worthington & 276 & 37 & 2,104 & 66 & 21 & 66 & 150 \\
\hline University of Manitoba & 344 & 81 & A.H. Katz & 66 & 185 & 547 & 166 & 9 & 158 & 100 \\
\hline University of Maryland & 463 & 58 & E.R. Lippincott & 138 & 108 & 615 & 152 & 0 & 256 & 111 \\
\hline University of Maryland Baltimore County & 473 & 55 & & 0 & 310 & 0 & 304 & 0 & 256 & 0 \\
\hline University of Massachusetts & 14 & 289 & B.G. Zorn & 59 & 203 & 321 & 194 & 9 & 158 & 60 \\
\hline University of Melbourne & 830 & 24 & B. Happell & 180 & 80 & 590 & 155 & 18 & 85 & 64 \\
\hline University of Miami & 29 & 247 & M.A. Perez-Pinzon & 84 & 165 & 1,396 & 92 & 24 & 57 & 122 \\
\hline University of Michigan & 111 & 166 & S.J. Weiss & 106 & 138 & 6,835 & 15 & 24 & 57 & 150 \\
\hline University of Minnesota & 101 & 178 & J.R. Johnson & 460 & 16 & 5,391 & 27 & 44 & 11 & 150 \\
\hline University of Missouri & 48 & 221 & H. Zaghouani & 64 & 191 & 792 & 131 & 13 & 124 & 132 \\
\hline University of Nebraska & 150 & 147 & N.J. Rosenburg & 90 & 158 & 872 & 125 & 11 & 142 & 116 \\
\hline University of New Hampshire & 48 & 221 & & 0 & 310 & 0 & 304 & 0 & 256 & 0 \\
\hline University of New Mexico & 25 & 254 & H.W. Kelly & 127 & 119 & 1,502 & 88 & 13 & 124 & 150 \\
\hline University of New South Wales & 16 & 280 & A.R. Lloyd & 191 & 73 & 5,297 & 29 & 31 & 38 & 150 \\
\hline University of North Carolina, Chapel Hill & 740 & 28 & L.I. Gilbert & 249 & 45 & 1,538 & 87 & 22 & 64 & 150 \\
\hline University of North Texas & 3 & 331 & A. Younes & 13 & 281 & 408 & 182 & 6 & 189 & 50 \\
\hline University of Notre Dame & 8 & 309 & P.C. Burns & 263 & 40 & 1,697 & 77 & 32 & 35 & 150 \\
\hline University of Nottingham & 7 & 311 & C.D. Vass & 4 & 297 & 132 & 245 & 3 & 229 & 9 \\
\hline University of Oklahoma & 20 & 270 & F.C. Lai & 114 & 133 & 443 & 179 & 7 & 178 & 50 \\
\hline
\end{tabular}




\begin{tabular}{|c|c|c|c|c|c|c|c|c|c|c|}
\hline University of Oregon & 198 & 126 & J.L. Ferracane & 160 & 89 & 2,193 & 64 & 25 & 52 & 150 \\
\hline University of Oslo & 24 & 257 & P. Brandtzaeg & 495 & 14 & 7,834 & 11 & 40 & 17 & 150 \\
\hline University of Otago & 24 & 257 & C.H. Sissions & 59 & 203 & 326 & 192 & 10 & 150 & 73 \\
\hline University of Ottawa & 20 & 270 & L.P. Renaud & 162 & 87 & 1,593 & 85 & 14 & 113 & 105 \\
\hline University of Oxford & 38 & 233 & P. Klenerman & 201 & 67 & 6,126 & 20 & 47 & 9 & 150 \\
\hline University of Pennsylvania & 105 & 171 & M.I. Greene & 330 & 27 & 4,341 & 37 & 28 & 45 & 150 \\
\hline University of Pittsburgh & 110 & 168 & P.M. Kochanek & 304 & 31 & 5,767 & 24 & 43 & 14 & 150 \\
\hline University of Quebec & 14 & 289 & C. Lodeiros & 65 & 189 & 323 & 193 & 10 & 150 & 120 \\
\hline University of Queensland & 37 & 235 & T.H. Marwick & 409 & 20 & 7,486 & 13 & 49 & 8 & 150 \\
\hline University of Reading & 149 & 148 & M.G.B. Drew & 733 & 2 & 7,560 & 12 & 37 & 20 & 150 \\
\hline University of Rochester & 37 & 235 & B.C. Berk & 266 & 38 & 9,684 & 9 & 55 & 4 & 150 \\
\hline University of Saskatchewan & 177 & 134 & J.A. Weil & 87 & 164 & 732 & 138 & 8 & 168 & 87 \\
\hline University of Science and Technology of China & 82 & 190 & Y. Tabata & 190 & 74 & 549 & 164 & 12 & 133 & 150 \\
\hline University of Sheffield & 632 & 40 & C. Bassett & 34 & 241 & 39 & 274 & 2 & 237 & 25 \\
\hline University of South Carolina & 259 & 109 & P.D. Ellis & 154 & 94 & 1,141 & 109 & 14 & 113 & 150 \\
\hline University of South Florida & 18 & 274 & A.W. Andrews & 2 & 303 & 24 & 281 & 2 & 237 & 6 \\
\hline University of Southampton & 6 & 318 & S. Welchert & 4 & 297 & 75 & 259 & 3 & 229 & 29 \\
\hline University of Southern California & 41 & 229 & M.R. Lieber & 506 & 12 & 22,070 & 3 & 60 & 2 & 150 \\
\hline University of St Andrews & 3 & 331 & J. Dunlop & 214 & 62 & 1,158 & 106 & 16 & 103 & 150 \\
\hline University of Surrey & 11 & 299 & S.M.O. Hourani & 94 & 155 & 1,280 & 100 & 13 & 124 & 82 \\
\hline University of Sussex & 3 & 331 & A. Anstey & 121 & 126 & 1,292 & 98 & 16 & 103 & 150 \\
\hline University of Sydney & 660 & 34 & D.J. Henderson-Smart & 224 & 56 & 1,611 & 84 & 18 & 85 & 150 \\
\hline University of Technology, Sydney & 3 & 331 & R. Braun & 27 & 256 & 15 & 286 & 2 & 237 & 30 \\
\hline University of Tennessee Knoxville & 17 & 276 & M. Shah & 35 & 236 & 772 & 134 & 11 & 142 & 150 \\
\hline University of Texas at Austin & 14 & 289 & K.S. McKinley & 109 & 137 & 811 & 129 & 17 & 94 & 133 \\
\hline University of Tokyo & 51 & 216 & S. Sugano & 289 & 33 & 5,945 & 21 & 34 & 28 & 150 \\
\hline University of Toronto & 1,282 & 5 & A.G. Harrison & 47 & 222 & 341 & 189 & 0 & 256 & 41 \\
\hline University of Tsukuba & 11 & 299 & G.A. Alexandrov & 23 & 264 & 74 & 260 & 5 & 204 & 29 \\
\hline University of Twente & 2 & 336 & J. Greve & 338 & 26 & 5,330 & 28 & 35 & 25 & 150 \\
\hline University of Utah & 467 & 56 & D.M. Grant & 489 & 15 & 4,826 & 32 & 32 & 35 & 150 \\
\hline University of Vermont & 148 & 149 & & 0 & 310 & 0 & 304 & 0 & 256 & 0 \\
\hline University of Victoria & 156 & 143 & & 0 & 310 & 0 & 304 & 0 & 256 & 0 \\
\hline University of Virginia & 75 & 199 & C.L. Slingluff & 118 & 127 & 3,425 & 46 & 31 & 38 & 150 \\
\hline University of Warwick & 4 & 328 & N.J. Dimmock & 154 & 94 & 933 & 120 & 15 & 108 & 106 \\
\hline University of Washington & 1,069 & 12 & L.R. Beach & 57 & 207 & 460 & 176 & 3 & 229 & 60 \\
\hline University of Waterloo & 2 & 336 & V.P. Godambe & 78 & 170 & 96 & 254 & 2 & 237 & 8 \\
\hline
\end{tabular}




\begin{tabular}{|c|c|c|c|c|c|c|c|c|c|c|}
\hline University of Western Australia & 210 & 121 & H.H. Thies & 25 & 261 & 14 & 288 & 0 & 256 & 21 \\
\hline University of Western Ontario & 336 & 84 & A. Paivivo & 74 & 172 & 1,347 & 95 & 6 & 189 & 52 \\
\hline University of Wisconsin & 80 & 193 & R.W. Guillery & 159 & 91 & 2,358 & 61 & 15 & 108 & 95 \\
\hline University of Wollongong & 6 & 318 & X.D. Fang & 49 & 220 & 301 & 199 & 8 & 168 & 47 \\
\hline University of York & 9 & 305 & O. Leyser & 61 & 198 & 2,596 & 55 & 31 & 38 & 105 \\
\hline University of Zurich & 16 & 280 & H. Hengartner & 250 & 43 & 12,962 & 5 & 57 & 3 & 150 \\
\hline Univesitas Gadjah Mada & 8 & 309 & J. Kurnianda & 4 & 297 & 0 & 304 & 0 & 256 & 14 \\
\hline Uppsala University & 15 & 286 & K. Nilsson & 289 & 33 & 4,295 & 38 & 26 & 48 & 150 \\
\hline Utah State & 2 & 336 & L.S. Chou & 12 & 284 & 249 & 212 & 7 & 178 & 30 \\
\hline Utrecht University & 949 & 16 & P.M. Endt & 110 & 136 & 876 & 124 & 5 & 204 & 122 \\
\hline Vanderbilt University & 41 & 229 & A. Pozzi & 71 & 176 & 1,300 & 97 & 21 & 66 & 150 \\
\hline Victoria University of Wellington & 59 & 208 & & 0 & 310 & 0 & 304 & 0 & 256 & 0 \\
\hline Vienna University of Technology & 5 & 321 & T. Eiter & 143 & 102 & 1,050 & 113 & 17 & 94 & 109 \\
\hline Virginia Polytechnic Institute & 10 & 304 & M. Youssef & 7 & 292 & 0 & 304 & 0 & 256 & 13 \\
\hline Vrije Universiteit, Brussels & 89 & 184 & & 0 & 310 & 0 & 304 & 0 & 256 & 0 \\
\hline VU University Amsterdam & 388 & 74 & I. Van der Waal & 309 & 30 & 3,502 & 44 & 26 & 48 & 150 \\
\hline Wageningen University & 16 & 280 & M. Massola & 41 & 234 & 628 & 151 & 16 & 103 & 53 \\
\hline Wake Forest University & 22 & 266 & R.C. Prielpp & 106 & 138 & 1,154 & 108 & 14 & 113 & 150 \\
\hline Waseda University & 2 & 336 & W. Kim & 1 & 305 & 1 & 301 & 1 & 249 & 4 \\
\hline Washington State University & 11 & 299 & T.C. McGuire & 296 & 32 & 2,111 & 65 & 24 & 57 & 150 \\
\hline Washington University in St. Louis & 104 & 173 & J.L. Marsh & 142 & 105 & 1,649 & 81 & 19 & 79 & 150 \\
\hline Wayne State University & 0 & 346 & & 0 & 310 & 0 & 304 & 0 & 256 & 0 \\
\hline West Virginia University & 9 & 305 & J.E. Riggs & 217 & 59 & 1,673 & 79 & 11 & 142 & 150 \\
\hline Yale University & 75 & 199 & L. Manuelidis & 123 & 124 & 2,046 & 68 & 17 & 94 & 95 \\
\hline Yonsei University & 13 & 293 & S. Park & 28 & 253 & 680 & 144 & 32 & 35 & 11 \\
\hline York University & 5 & 321 & D. Ashforth & 1 & 305 & 10 & 290 & 1 & 249 & 1 \\
\hline Zhejiang University & 7 & 311 & J. Zhou & 106 & 138 & 670 & 147 & 15 & 108 & 150 \\
\hline
\end{tabular}


